\title{
Perspectivas económicas de América Latina 2020
}

TRANSFORMACIÓN DIGITAL PARA UNA MEJOR RECONSTRUCCIÓN 



\section{Perspectivas económicas de América Latina 2020}

\section{TRANSFORMACIÓN DIGITAL PARA UNA MEJOR RECONSTRUCCIÓN}


El presente trabajo se publica bajo la responsabilidad del Secretario General de la OCDE. Las opiniones expresadas y los argumentos utilizados en el mismo no reflejan necesariamente el punto de vista oficial de los países miembros de la OCDE, ni del Centro de Desarrollo de la OCDE, ni de las Naciones Unidas, ni de la Corporación Andina de Fomento (CAF) o de la Unión Europea.

Tanto este documento, así como cualquier dato y cualquier mapa que se incluya en él, se entenderán sin perjuicio respecto al estatus o la soberanía de cualquier territorio, a la delimitación de fronteras y límites internacionales, ni al nombre de cualquier territorio, ciudad o área.

Los datos estadísticos para Israel son suministrados por y bajo la responsabilidad de las autoridades israelíes competentes. El uso de estos datos por la OCDE es sin perjuicio del estatuto de los Altos del Golán, Jerusalén Este y los asentamientos israelíes en Cisjordania bajo los términos del derecho internacional.

Nota al pie de página de Turquía

La información del presente documento en relación con "Chipre" se refiere a la parte sur de la Isla. No existe una sola autoridad que represente en conjunto a las comunidades turcochipriota y grecochipriota de la Isla. Turquía reconoce a la República Turca del Norte de Chipre (RTNC). Mientras no haya una solución duradera y equitativa en el marco de las Naciones Unidas, Turquía mantendrá su postura frente al "tema de Chipre".

Nota al pie de página de todos los Estados Miembros de la Unión Europea que pertenecen a la OCDE y de la Unión Europea

Todos los miembros de las Naciones Unidas, con excepción de Turquía, reconocen a la República de Chipre. La información contenida en el presente documento se refiere a la zona sobre la cual el Gobierno de la República de Chipre tiene control efectivo.

Por favor, cite esta publicación de la siguiente manera:

OECD et al. (2020), Perspectivas económicas de América Latina 2020: Transformación digital para una mejor reconstrucción, OECD Publishing, Paris, https://doi.org/10.1787/f2fdced2-es.

ISBN 978-92-64-79884-7 (impresa)

ISBN 978-92-64-63131-1 (pdf)

Perspectivas Económicas de América Latina

ISSN 2072-5191 (impresa)

ISSN 2072-5183 (en línea)

Unión Europea

ISBN 978-92-78-42306-3 (print)

ISBN 978-92-78-42307-0 (PDF)

Catalogue number: OA-02-20-634-ES-C (print); OA-02-20-634-ES-N (PDF)

DOI: $10.2830 / 032342$ (print); 10.2830/071617 (PDF)

Signatura CEPAL: LC/PUB.2020/10

Imágenes: Diseño de la portada realizado por Aida Buendía (Centro de Desarrollo de la OCDE) sobre la base de imágenes de anastasiia ivanova, elenabsl, LuckyStep, Julia Lazebnaya, fongnamforfun, LuckyStep, Remo_Designer, rina Strelnikova, LuckyVector, Lorelyn Medina, ST.art, ArtHead, Lucia Fox, GoodStudio, GoodStudio @ Shutterstock.com.

Las erratas de las publicaciones se encuentran en línea en: www.oecd.org/about/publishing/corrigenda.htm.

(C) OCDE/NACIONES UNIDAS/CAF/UNIÓN EUROPEA 2020

El uso del contenido del presente trabajo, tanto en formato digital como impreso, se rige por los términos y condiciones que se encuentran disponibles en: $h t t p: / / w w w . o e c d . o r g /$ termsandconditions. 


\section{Prefacio}

Las Perspectivas económicas de América Latina analizan cuestiones relativas al desarrollo sostenible e inclusivo en América Latina y el Caribe (ALC). Desde su primera edición en noviembre de 2007, este informe anual compara el desempeño de América Latina y el Caribe con el de otras regiones, analiza los principales retos en materia de desarrollo y plantea recomendaciones, experiencias y buenas prácticas para la elaboración de políticas públicas.

Las Perspectivas económicas de América Latina se benefician de los conocimientos especializados y las contribuciones de los coautores. Desde 2011, este informe se publica de forma conjunta con la Comisión Económica para América Latina y el Caribe (CEPAL) de las Naciones Unidas. En 2013, se incorporó al equipo de autores el Banco de Desarrollo de América Latina (CAF). Y desde 2018, la Comisión Europea pasó a ser uno de sus principales socios.

Esta decimotercera edición de las Perspectivas económicas de América Latina: Transformación digital para una mejor reconstrucción aborda el papel de la transformación digital como herramienta para fomentar el desarrollo en la región, en particular en el contexto de la actual crisis provocada por el coronavirus (Covid-19). El documento hace hincapié en la necesidad de un planteamiento integral, con planes nacionales de desarrollo (PND) que estén en consonancia con las agendas digitales y alianzas internacionales, de vital importancia para aprovechar los beneficios de la transformación digital. También recoge desafíos macroestructurales de esta región en la actual situación de pandemia y, para darles respuesta, insta a la adopción de medidas de alcance tanto nacional como internacional. Esta crisis sin precedentes llega en un momento de grandes aspiraciones y refuerza la necesidad de transformar el modelo de desarrollo de la región. 



\section{Agradecimientos}

Los socios de este informe son la Comisión Económica para América Latina y el Caribe (CEPAL), la CAF-Banco de Desarrollo de América Latina, la Unión Europea (UE) y el Centro de Desarrollo de la Organización para la Cooperación y el Desarrollo Económicos (OCDE). Este informe es el Pilar 1 del Fondo Regional para el Desarrollo en Transición para América Latina y el Caribe de la Unión Europea, una iniciativa liderada por la UE e implementada conjuntamente con la OCDE, el Centro de Desarrollo de la OCDE y la CEPAL.

La contribución del Centro de Desarrollo de la OCDE a este informe ha sido liderada y dirigida por Sebastián Nieto-Parra, jefe de la Unidad para América Latina y el Caribe del Centro de Desarrollo de la OCDE, con el apoyo y la coordinación de René Orozco, economista de esta Unidad, bajo la dirección de Mario Pezzini, director del Centro de Desarrollo de la OCDE, y Federico Bonaglia, director adjunto del Centro de Desarrollo de la OCDE. La contribución de la CEPAL ha estado liderada por Sebastián Rovira, oficial de Asuntos Económicos de la Unidad de Innovación y Nuevas Tecnologías, con el apoyo de Andrés Boeninger y Nunzia Saporito, asistentes de investigación de la Unidad de Innovación y Nuevas Tecnologías, bajo la dirección de Mario Cimoli, secretario ejecutivo adjunto de la CEPAL. La contribución de la CAF-Banco de Desarrollo de América Latina ha estado liderada por Adriana Arreaza, directora de Estudios Macroeconómicos. La contribución de la Comisión Europea (CE) ha estado liderada por Pelayo Roces Fernández, manager de programas en la Dirección de América Latina y el Caribe de la Dirección General de Cooperación Internacional y Desarrollo de la Comisión Europea, bajo la dirección de Jorge de la Caballería, su jefe de Unidad.

El informe se ha beneficiado de la investigación, la redacción y la fructífera colaboración establecida entre varios autores de estas organizaciones, entre los que se incluyen: Adriana Arreaza (CAF), Andrés Boeninger (CEPAL), Nathalie Basto-Aguirre (OCDE), Adriana Caicedo (OCDE), Cristina Cabutto (OCDE), Johan Cañas (CAF), Luis Cecchi (OCDE) Simone Cecchini (CEPAL), Paula Cerutti (OCDE), Mathilde Closset (CEPAL), Rita Da Costa (OCDE), Marin Fouéré (OCDE), Valeria Jordan (CEPAL), Zebulun Kreiter (CEPAL), Nathalia Montoya (OCDE) Sara Piñero Mosquera (OCDE), Georgina Núñez (CEPAL), René Orozco (OCDE), Alejandro Patiño (CEPAL), Esteban Pérez Caldentey (CEPAL), Laura Poveda (CEPAL), Diane Quarless (CEPAL) Pelayo Roces Fernández (CE), Fernando Rojas (CEPAL), Sebastián Rovira (CEPAL), Nunzia Saporito (CEPAL), Daniel Titelman (CEPAL), Juan Nicolás Velandia (OCDE) y Juan Vázquez Zamora (OCDE). Agustina Vierheller (OCDE) ha prestado un apoyo administrativo inestimable durante la elaboración del informe.

Un grupo de expertos y colegas ha participado de forma especialmente activa y solidaria a lo largo del proceso de producción, proporcionando opiniones, aportaciones o gráficos, comentarios y orientación estratégica al informe. Nos gustaría destacar el apoyo proporcionado por Mauricio Agudelo (CAF), Eric Beaume (CE), Elisabet Carlsson (CE), Anthony Caubin (AFD), Andrea Costafreda (OXFAM), Teodora Deaconu (Servicio Europeo de Acción Exterior - SEAE -), Lars-Erik Forsberg (CE), Juan Miguel Gallego (Universidad del Rosario), Daniel Gómez Gaviria (DNP Colombia), Nicolas Grosman (McKinsey Global Institute), Laura Klein (CE), Bruno Leclerc (AFD), Andrea Leone (CE), Marc Litvine (CE), Georgiana Macovei (CE), Lorenzo Pavone (OCDE), Santiago Matallana (Consejo Privado de Competitividad), Roberto de Michele (BID), Carlos Oliveira (CE), Santiago Pinzón (ANDI), Cristina Pombo (BID), Martín Rivero (SEGIB), Laure Rogès (CE), Carlos Santiso (CAF), Carlos Eduardo Sepúlveda (Universidad del Rosario), Carolina Valencia (C4IR), Melanie Vilarasau Slade (OCDE), Jacob Tamm (SEAE), Cristina Xalma (SEGIB), Yumika Yamada (OCDE), Felice Zaccheo (CE) y Felix Zimmermann (OCDE). 
El contenido del informe se ha enriquecido gracias a las constructivas observaciones proporcionadas durante la Reunión de Consulta LEO 2020 que tuvo lugar en París el 17 de junio de 2019 y las Reuniones de Expertos que se celebraron el 31 de octubre de 2019, también en París. Además de los delegados de ALC al Comité Directivo del Centro de Desarrollo de la OCDE en Francia, estamos especialmente agradecidos con los expertos, académicos, representantes del sector privado y funcionarios públicos que nos han aportado su apoyo: Javier Barreiro (AGESIC, Uruguay), David Bradbury (OCDE), Elisabet Carlsson (CE), Pau Castells (GSMA Intelligence), Lucio Castro, (ex BID), Eduardo Chomali (CAF), Chiara Criscuolo (OCDE), Ariel Emirian (Société Générale), David Fraustchy (Telefónica), Lucas Gallitto (GSMA), Lucas Sebastián Gómez, (ex DNP, Colombia), Daniel Gómez Gaviria (DNP Colombia), Héctor Huici (Argentina), Juan Jung (ASIET), Raul Katz (The Columbia Institute for Tele-Information), Gonzalo López Barajas (Telefónica), Reyson Lizardo (República Dominicana), Andrés Mariño (Universidad del Rosario, Colombia), Enrique Maruri (OXFAM), María Isabel Mejía (CAF), Angel Melguizo (AT\&T), Luiz de Mello (OCDE), Natalia Moreno Rigollot (Telefónica), Hugo Ñopo (GRADE, Perú), Eduardo Salido (Telefónica), Claudio Salinas (UE), Carlos Santiso (CAF), Andreas Schleicher (OCDE), Berioska Torres (MINTEL, Ecuador) y João Vasconcelos (OCDE).

Asimismo, un grupo de compañeros de la OCDE ha aportado sus observaciones y análisis, mejorando de forma considerable el informe: José Antonio Ardavin, Jens Arnold, Francesco Avvisati, Séverine Baranger, Laurent Bernat, Sofia Blamey, Lauren Bourke, David Bradbury, Chiara Criscuolo, Silvia Da Rin Pagnetto, John Drummond, Janos Ferencz, Manuela Fitzpatrick, Elizabeth Fordham, Laura Galindo, Paula Garda, Felipe González-Zapata, Robert Grundke, Miyako Ikeda, Daniel Ker, François Keslair, Molly Lesher, Javier López González, Hiroko Matsui, Andrea Minea-Pic, Marco Paccagnella, Kostas Panagiotopoulos, Grace Pérez-Navarro, Karine Perset, Dirk Pilat, Glenda Quintini, Jacob Arturo Rivera Pérez, Elettra Ronchi, Francesca Spinelli, Enes Sunel, Barbara Ubaldi y Benjamin Welby.

Las notas sobre los países se han beneficiado de las aportaciones constructivas, los análisis y las comprobaciones realizadas por las delegaciones de Chile, Colombia y México ante la OCDE, así como por las embajadas en Francia de Argentina, Brasil, Costa Rica, Ecuador, El Salvador, Guatemala, Panamá, Paraguay, Perú, República Dominicana y Uruguay.

El Centro de Desarrollo de la OCDE también desea expresar su sincero agradecimiento a la Agencia Francesa de Desarrollo (AFD), el Departamento Nacional de Planeación (DNP) de Colombia, el Ministerio de Asuntos Exteriores, Unión Europea y Cooperación de España, la Agencia Suiza para el Desarrollo y la Cooperación, Telefónica y la Universidad del Rosario (Colombia) por su apoyo a las Perspectivas Económicas de América Latina.

Por último, nos gustaría dar las gracias a la División de Publicaciones y Comunicaciones del Centro de Desarrollo de la OCDE, en particular a Marika Boiron, Aída Buendía, Mélodie Descours, Delphine Grandrieux, Elizabeth Nash, Irit Perry y Henri-Bernard Solignac-Lecomte, por su gran paciencia y su oportuna labor en la producción de este informe y los materiales relacionados. Los autores también agradecen sinceramente las actividades de edición realizadas por Elizabeth Holbourne, del Centro de Desarrollo de la OCDE, Jessica Hutchings y Jane Marshall; y los servicios de traducción y edición en español prestados por Alejandro Barranco, Julia Gregory, Alexander Summerfield, Liliana Tafur y Esther Waldmeier. 


\section{Índice}

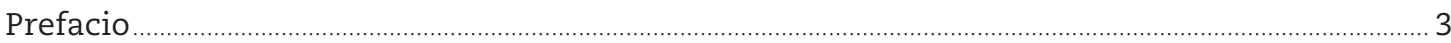

Agradecimientos

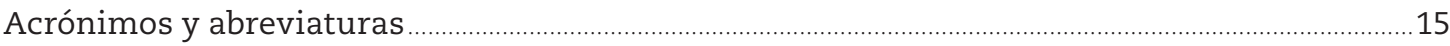

Editorial

Resumen ejecutivo

Resumen: La transformación digital para una recuperación inclusiva y sostenible pos-Covid-19

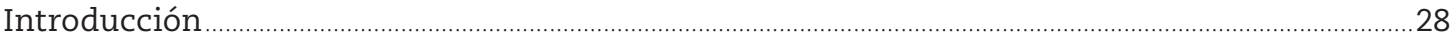

La crisis del coronavirus (Covid-19) ha golpeado a la región en un momento de profundas

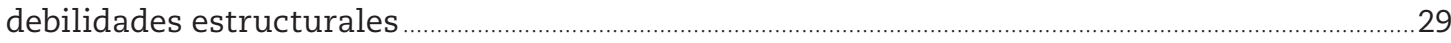

La transformación digital puede impulsar el crecimiento de la productividad ................................31

La transformación digital puede mejorar el bienestar mediante la inclusión social

de las familias, los trabajadores y los estudiantes.................................................................

La transformación digital de las instituciones públicas puede mejorar la gobernanza

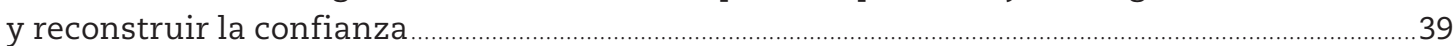

Nuevas alianzas internacionales pueden fomentar el desarrollo en la era digital ........................45

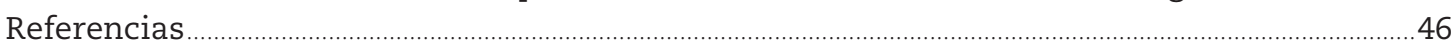

Capítulo 1. Macroperspectiva estructural y el rol de la transformación digital para superar los desafíos en materia de desarrollo

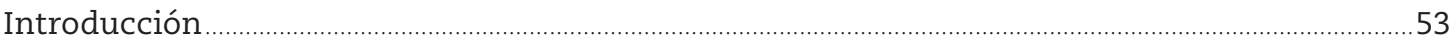

Repercusión externa e interna de la crisis del Covid-19 en el desempeño económico..................55

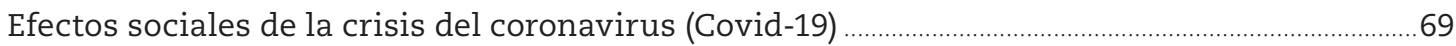

Transformación digital en tiempos de coronavirus (Covid-19) …………………………………......75

Conclusión

Notas $\ldots$

Referencias

Capítulo 2. Promover la productividad y potenciar la transformación digital ……………….............. 89

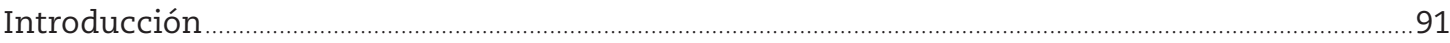

Crisis del Covid-19: Impactos en una estructura productiva y empresarial

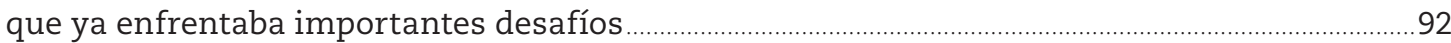

Patrones de productividad y heterogeneidad en América Latina y el Caribe ……………................93

Aumento de la productividad con las tecnologías digitales.........................................................98

Infraestructura de la comunicación, conectividad del transporte y capacidades humanas:

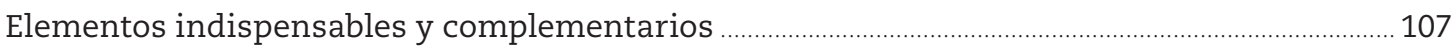

Políticas para promover la transformación digital y aumentar la productividad

en América Latina y el Caribe

La transformación digital poscoronavirus (Covid-19) ………….......................................................... 122

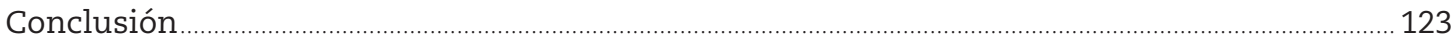

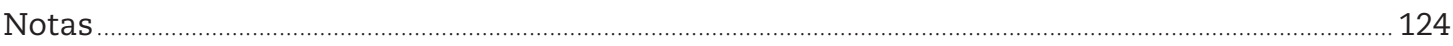

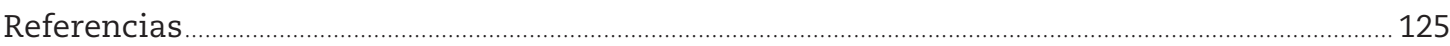

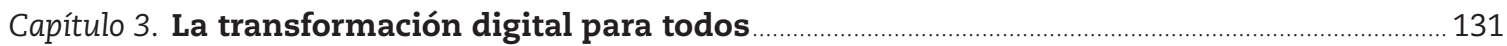

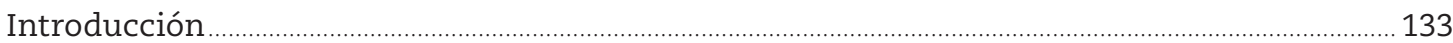

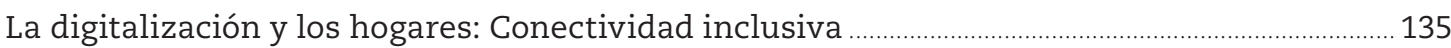


La digitalización y los mercados laborales: El futuro del trabajo y las habilidades ……………... 142

La digitalización y las escuelas: Equidad y calidad en la educación ................................................... 153

La digitalización y el coronavirus (Covid-19): La brecha que se acentúa ...........................................171

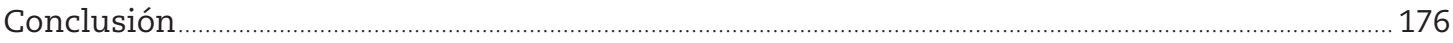

Anexo 3.A1. Datos seleccionados a nivel de país sobre el acceso a Internet y el uso

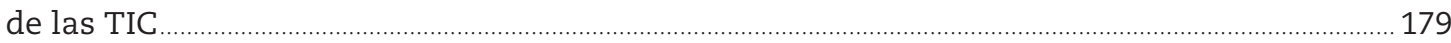

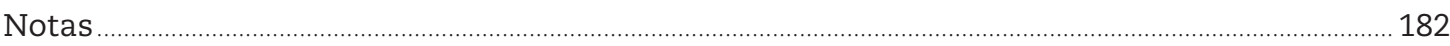

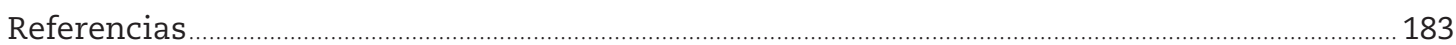

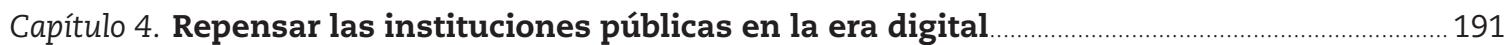

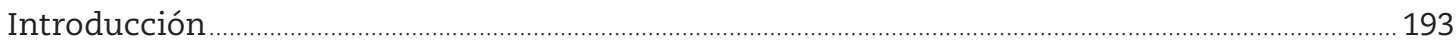

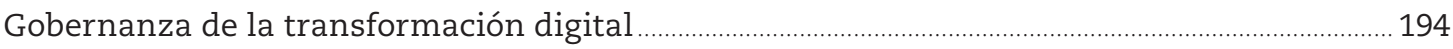

La transformación digital de los gobiernos ..............................................................................................2 205

La agenda digital en las estrategias nacionales de desarrollo .......................................................225

Conclusión .

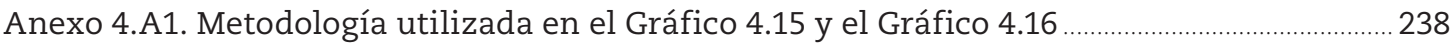

Anexo 4.A2. Características del plan nacional de desarrollo ..................................................... 240

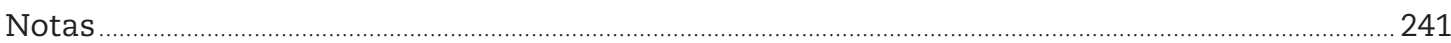

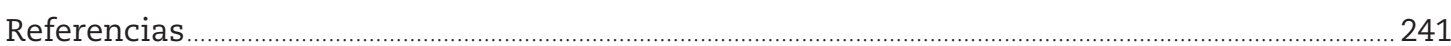

Capítulo 5. El papel de la cooperación internacional en la era digital …......................................... 249

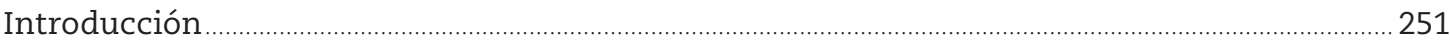

Facilitar el desarrollo de América Latina y el Caribe mediante un modelo renovado

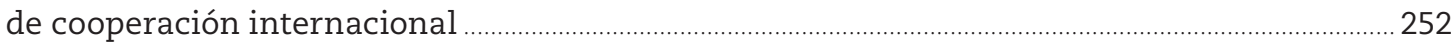

Mejorar las capacidades nacionales mediante la cooperación internacional ...............................25

Aprovechar el potencial digital de América Latina y el Caribe mediante la integración

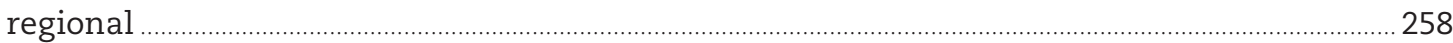

Explorar el potencial de la cooperación regional y las alianzas interregionales .........................266

Afrontar los desafíos mundiales que plantea la digitalización de la economía mediante

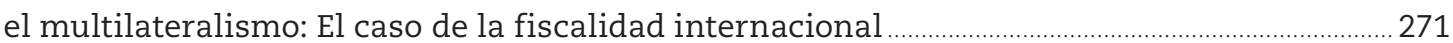

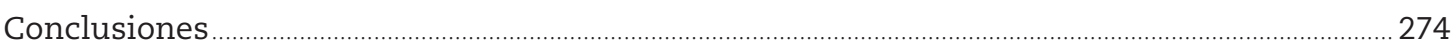

Anexo 5.A1. Ejemplos de cooperación internacional en el ámbito de las TIC para

desarrollar la capacidad de los países de América Latina y el Caribe para superar

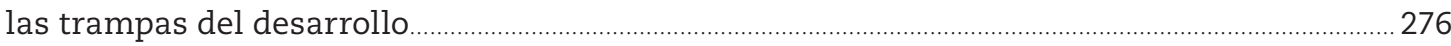

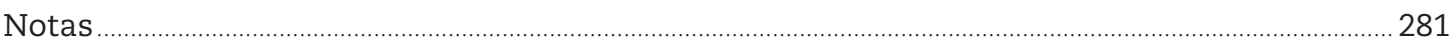

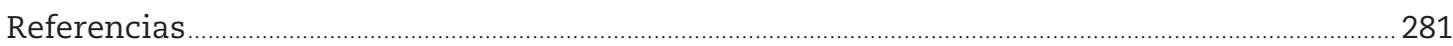

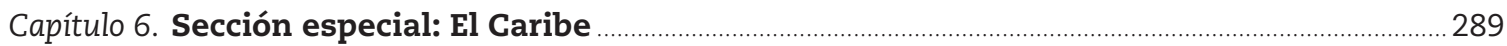

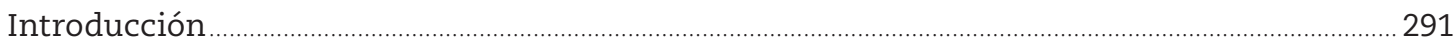

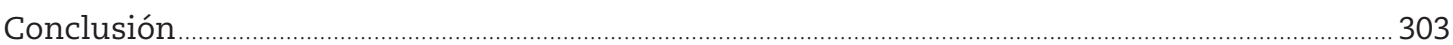

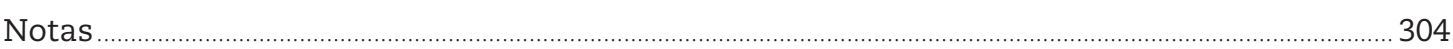

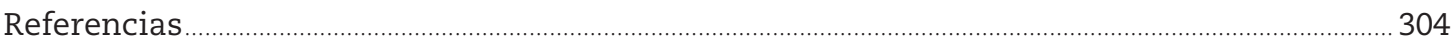

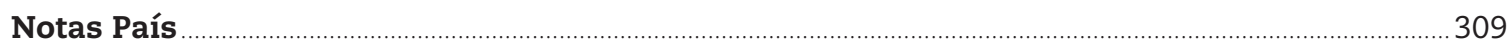

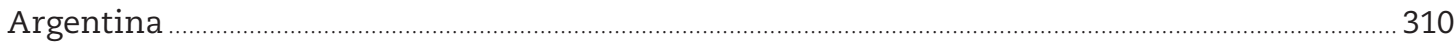

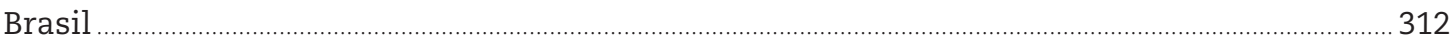

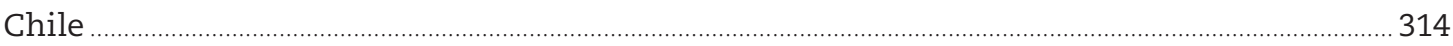

Colombia

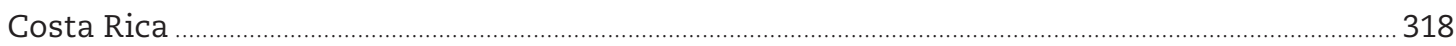

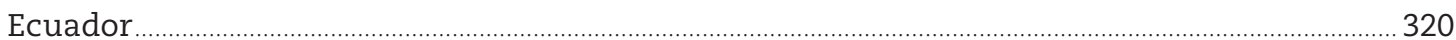




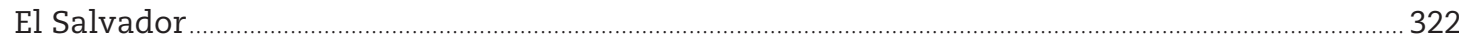

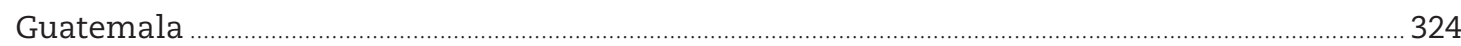

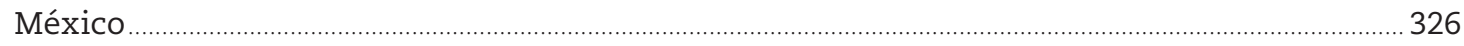

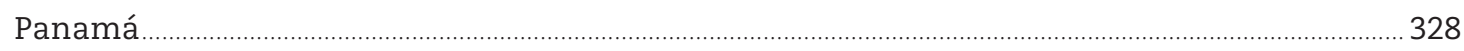

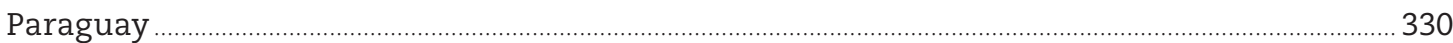

Perú

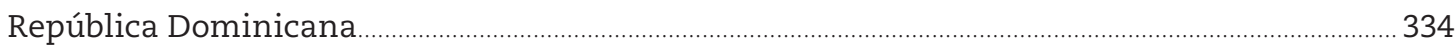

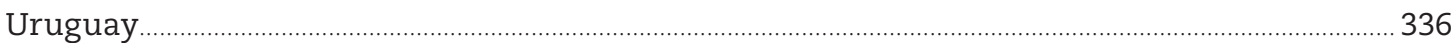

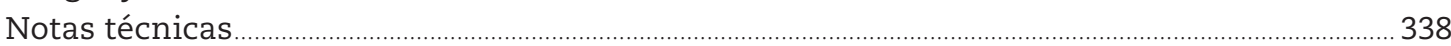

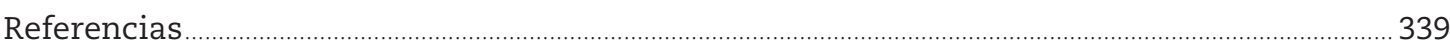

\section{Gráficos}

1. Trabajadores que carecen de una red de seguridad social y empresas que podrían cerrar debido a la crisis del coronavirus (Covid-19) en países seleccionados

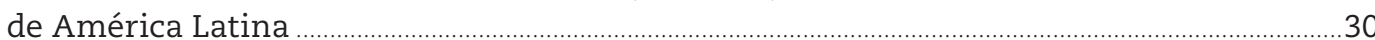

2. Contribución del empleo y la productividad al crecimiento del PIB en países y regiones seleccionados, 2000-19 (porcentajes) ...............................................................................

3. Porcentaje de usuarios de Internet en países seleccionados de América Latina y el Caribe, 2010 y 2018 (o más reciente) …….............................................................................. 33

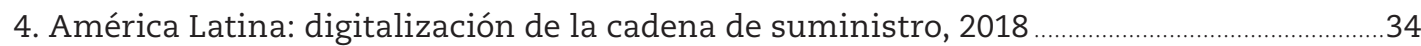

5. Distribución del acceso a Internet y de su uso, junto con el de otros servicios, por decil de ingresos, países seleccionados de América Latina, 2017 o último año disponible..........35

6. Proporción de alumnos matriculados en educación primaria con una computadora conectada a Internet en casa por grupo de ingresos, 2018 o último año disponible.............38

7. Disponibilidad de una plataforma eficaz de apoyo al aprendizaje en línea por nivel socioeconómico de los centros educativos, países seleccionados de América Latina .........38

8. Índice de Desarrollo del Gobierno Electrónico de Naciones Unidas (EGDI) y su evolución

9. Intensidad de los temas vinculados a la digitalización en los planes nacionales de desarrollo, países seleccionados de América Latina y el Caribe, 2019

10. Características institucionales de las agendas digitales nacionales, países seleccionados de América Latina y el Caribe, 2020

1.1. Condiciones financieras, entradas de flujos de capital netas en los mercados

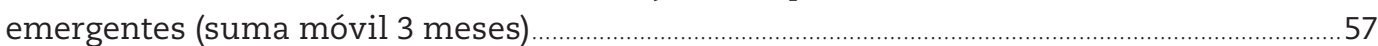

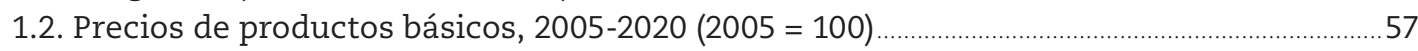

1.3. Tasa de crecimiento anual del PIB y PIB per cápita de América Latina y el Caribe ............59

1.4. Elasticidad de los ingresos por exportaciones e importaciones, regiones seleccionadas.

1.5. Cuentas externas y condiciones financieras, Países de ALC seleccionados ……………........62

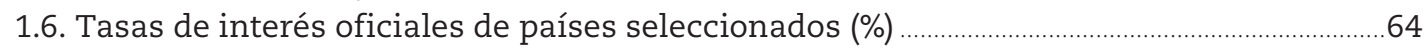

1.7. Coeficiente entre deuda e impuestos (deuda pública bruta) de países de América

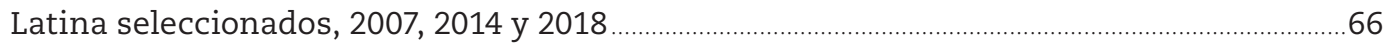

1.8. Deuda pública externa total por acreedor (público y privado) de países seleccionados de América Latina y el Caribe, 2018

1.9. Trabajadores que carecen de una red de medidas de protección y empresas que podrían cerrar debido a la crisis del coronavirus (Covid-19) de países seleccionados de América Latina 
1.10. Evolución de la pobreza y la pobreza extrema en América Latina y el Caribe, por características socioeconómicas, 2002-2019 …........................................................................72

1.11. Desigualdad en países de América Latina seleccionados (índice de Gini), 2002, 2014 y 2018 72

1.12. Indicador de conocimientos avanzados e índice de Gini ................................................75

1.13. Flujos comerciales de bienes y servicios, inversión extranjera directa, otros flujos financieros y capacidad de tráfico internacional de Internet, 1990-2017 (Índice $2003=100$ )

1.14. Distribución de los puntajes del Índice Departamental de Competitividad, el Índice Departamental de Conectividad Tecnológica y el PIB per cápita en Colombia, 2019.

2.1. Productividad laboral de los países de América Latina y el Caribe en relación con el resto del mundo, 1950-2019.

2.2. Contribución del empleo y la productividad al crecimiento del PIB en los países

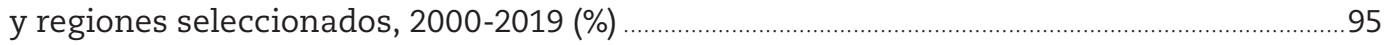

2.3. Valor agregado por la industria manufacturera de mediana y alta tecnología

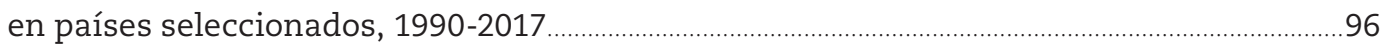

2.4. Coeficiente de variación de productividad sectorial en países seleccionados de América Latina y el Caribe, 1980-2018.

2.5. Brechas de productividad por tamaño de la empresa en comparación con las grandes empresas en países y regiones seleccionados, 2016 ……………………........98

2.6. La transformación digital de la economía ........................................................................................ 102

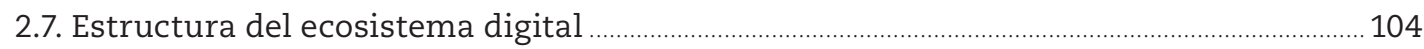

2.8. Tasa de crecimiento del Índice de Desarrollo del Ecosistema Digital en regiones seleccionadas..

2.9. Índice de Desarrollo del Ecosistema Digital en América Latina y el Caribe y la OCDE, 2018 . 106

2.10. Usuarios de Internet en países seleccionados de América Latina y el Caribe, 2010 y 2018 (o más reciente)

2.11. Penetración de banda ancha móvil y fija en países seleccionados de América Latina y el Caribe, 2018 (o más reciente), abonos activos por cada 100 habitantes ............ 109

2.12. Velocidades de descarga de banda ancha fija comparadas con los requisitos de ancho de banda para servicios de Internet en países seleccionados, marzo julio 2020

2.13. Inversión en infraestructuras públicas y privadas como proporción del PIB en regiones en desarrollo seleccionadas, último año disponible

2.14. Oferta y demanda mundial del mercado laboral de competencias en América Latina y el Caribe, 2019

2.15. Cantidad de universidades que ofrecen programas de capacitación en tecnologías digitales en países seleccionados de América Latina, 2016.

2.16. Uso de tecnologías digitales básicas por tamaño de empresa en países seleccionados de América Latina y el Caribe, 2010 y 2017

2.17. Categorías de promoción de tecnologías digitales en las mipymes de países seleccionados de América Latina, en torno a 2019

2.18. América Latina: Digitalización de las cadenas de valor, 2018.

3.1. Distribución del acceso a Internet y de su uso, junto con el de otros servicios, por decil de ingresos, países seleccionados de América Latina, 2017 o último año disponible 
3.2. Usuarios de Internet por quintil de ingresos, países seleccionados de América

Latina, 2017 o último año disponible

3.3. Acceso y uso de las TIC por grupos de edad en América Latina y el Caribe, 2018

o último año disponible

3.4. Proporción de usuarios de Internet urbanos y rurales en América Latina, 2017 .............. 138

3.5. Uso de las TIC por actividad en países seleccionados de América Latina ............................ 140

3.6. Uso de las TIC por género, edad y educación, países seleccionados

de América Latina

3.7. Porcentaje de trabajadores según el riesgo de automatización (análisis de tareas), países seleccionados de la OCDE y de América Latina y el Caribe, 2018 o último año disponible

3.8. Porcentaje de empleos con alto riesgo de automatización (análisis ocupacional), países seleccionados de América Latina, 2018

3.9. Diferencia en el uso de habilidades entre empleos intensivos y no intensivos en tecnología digital en América Latina

3.10. Dominio en la resolución de problemas en entornos con fuerte presencia tecnológica, países seleccionados de la OCDE y de América Latina.

3.11. Uso de las TIC en el trabajo por actividad, países seleccionados de América Latina ..... 149

3.12. Dominio en la resolución de problemas por nivel formativo, países seleccionados de América Latina

3.13. Contribución del dominio de competencias y otros factores a la variación del uso de las competencias en el trabajo, países seleccionados de América Latina y el promedio de la OCDE.

3.14. Tiempo que pasan los estudiantes en Internet en los centros educativos y en el hogar entre semana, países seleccionados de América Latina, 2012 y 2018 ........... 154

3.15. Edad del primer uso de un dispositivo digital según el nivel de competencia en ciencias de PISA, promedios de la OCDE y América Latina y el Caribe, 2018 …............. 156

3.16. Edad del primer uso de un dispositivo digital y resultados de PISA en América Latina y el Caribe, 2018

3.17. Número de estudiantes por computadora y por computadora con conexión a Internet, países seleccionados de América Latina y el Caribe, 2015 y 2018

3.18. Número de estudiantes por computadora y por computadora con conexión a Internet, según las características sociodemográficas, promedios de América Latina y el Caribe y de la OCDE, 2015 y 2018.

3.19. Índice de disponibilidad de TIC en el hogar y en los centros educativos por cuartil(Q) del índice socioeconómico y cultural de PISA, promedios de América Latina y el Caribe y de la OCDE, 2018.

3.20. Índice de disponibilidad de las TIC en el hogar y en los centros educativos, por nivel de competencia en ciencias de PISA, promedios de América Latina y el Caribe y de la OCDE, 2018.

3.21. Usos que los estudiantes hacen de las TIC fuera de la escuela, países seleccionados de América Latina y el Caribe, 2018 o último año disponible.

3.22. Uso de las TIC dentro y fuera de la escuela por categoría sociodemográfica, promedios de América Latina y el Caribe y de la OCDE, 2018

3.23. Uso de las TIC dentro y fuera del centro educativo por nivel socioeconómico y ubicación, promedios de América Latina y el Caribe, 2018.

3.24. Acceso de los estudiantes a las TIC por género, promedios de la OCDE y de América Latina y el Caribe, 2018 
3.25. Uso de las TIC de los estudiantes por género, promedios de la OCDE y de América Latina y el Caribe, 2018

3.26. Habilidades autopercibidas en TIC por género, promedios de la OCDE

y de América Latina y el Caribe, 2018

3.27. Proporción de estudiantes que quieren hacer carrera en ciencias, tecnología, ingeniería y matemáticas a los 30 años, por género, promedios de la OCDE y América Latina y el Caribe, 2018.

3.28. Disponibilidad de una plataforma eficaz de apoyo al aprendizaje en línea por nivel socioeconómico de los centros educativos, países seleccionados de América Latina, 2018

3.29. Proporción de estudiantes matriculados en educación primaria con una computadora en casa por grupo de ingresos, 2018 o último año disponible...... 175

3.A1.1. Distribución del acceso y uso de Internet y otros servicios por decil de ingresos, países seleccionados de América Latina, 2017 o último año disponible.

3.A1.2. Uso de las TIC por actividad, países seleccionados de América Latina.

3.A1.3. Uso de las TIC en el trabajo por actividad, países seleccionados de América Latina ... 182

4.1. Cinco pilares del Índice mundial de ciberseguridad de la Unión Internacional de Telecomunicaciones de Naciones Unidas, 2018.

4.2. Avance hacia un gobierno digital

4.3. Índice de desarrollo del gobierno electrónico de Naciones Unidas, América Latina y el Caribe, 2018

4.4. Índice de desarrollo del gobierno electrónico de Naciones Unidas, por componente, América Latina y el Caribe, 2014, 2016 y 2018

4.5. Confianza en las instituciones y percepción de corrupción, América Latina y el Caribe, 2008-2018

4.6. Percepción de democracia y aprobación del Gobierno, América Latina y el Caribe, 2006-2018.

4.7. Planes de acción en materia de gobierno abierto, países seleccionados de América Latina y el Caribe

4.8. Horas necesarias para realizar un trámite ante la administración pública, países seleccionados de América Latina y el Caribe.

4.9. Trámites ante la administración pública que se pueden iniciar y concluir por Internet, países seleccionados de América Latina y el Caribe

4.10. Las tecnologías digitales y su aplicación en la administración tributaria en ALC ........217

4.11. Índice de e-Participación de la ONU de países seleccionados de ALC y promedio de la OCDE, 2018

4.12. Índice OURdata de la OCDE, países seleccionados de América Latina y el Caribe, 2019

4.13. Popularidad de las búsquedas en Google y aprobación del gobierno en América Latina y el Caribe, 2006-2015

4.14. Índice GovTech de la CAF, países seleccionados de América Latina y el Caribe, 2020 ...... 223

4.15. Intensidad de las dimensiones digitales en los planes nacionales de desarrollo, según el vínculo con las trampas del desarrollo, países seleccionados de América Latina y el Caribe, 2019

4.16. Intensidad de las dimensiones digitales en los planes nacionales de desarrollo, países seleccionados de América Latina y el Caribe, 2019

4.17. Características institucionales de las agendas digitales nacionales, países seleccionados de América Latina y el Caribe, 2020. 
5.1. Iniciativas de cooperación Sur-Sur y triangular que promueven la innovación, por sector

5.2. Áreas de acción de la Agenda Digital para América Latina y el Caribe

6.1. Índice de Desarrollo del Ecosistema Digital, OCDE, América Latina y el Caribe, y el Caribe, 2018

6.2. Usuarios de Internet, países seleccionados del Caribe, 2010-2018 o último año disponible (porcentaje de la población total)

6.3. Penetración de banda ancha fija, países seleccionados del Caribe, 2018 o último año disponible (por cada 100 habitantes)

6.4. Suscripciones activas de banda ancha móvil, países seleccionados del Caribe, 2018 o último año disponible (por cada 100 habitantes)

6.5. Velocidad de descarga de banda ancha fija, países seleccionados y requisitos de ancho de banda de referencia, marzo-julio de 2020

6.6. Características institucionales de las agendas digitales nacionales, países seleccionados del Caribe

6.7. Gobierno electrónico en el Caribe, Índice de desarrollo del gobierno electrónico de las Naciones Unidas, 2018.

6.8. Cinco pilares del Índice mundial de ciberseguridad de la Unión Internacional de Telecomunicaciones de las Naciones Unidas, 2018

\section{Tablas}

2.1. Participación en el PIB y en el empleo, por sector, en los países seleccionados de América Latina y el Caribe, 1981, 2002 y 2018

2.2. Niveles de productividad relativa, por sector, en los países seleccionados de América Latina y el Caribe, 1981, 2002 y 2018

2.3. Posibles soluciones tecnológicas para diversos sectores de Perú.

2.4. Impacto de las complementariedades de la tecnología digital en el aumento de la productividad: Evidencia del mundo desarrollado

2.5. Variables de factores de producción del Índice de Desarrollo del Ecosistema Digital en la OCDE y en América Latina y el Caribe, 2018

2.6. Variables de digitalización de hogares del Índice de Desarrollo del Ecosistema Digital en la OCDE y en América Latina y el Caribe, 2018.

2.7. Variables de infraestructuras del Índice de Desarrollo del Ecosistema Digital en la OCDE y en América Latina y el Caribe, 2018

2.8. Iniciativas de conectividad en países seleccionados de América Latina 110

2.9. Puntuaciones del Índice de Desempeño Logístico (LPI) del Banco Mundial, por región, 2018

2.10. Número de cursos de capacitación en tecnologías digitales avanzadas de corta duración por ámbito temático en países seleccionados de América Latina, 2016.

2.11. Programas de posgrado en tecnologías digitales en países seleccionados de América Latina, 2016.

4.1. Marcos jurídicos de protección de datos, países seleccionados de América Latina y el Caribe, 2019

4.2. Flujos de información transfronterizos: niveles adecuados de protección de datos de países seleccionados de América Latina y el Caribe, 2019

4.3. Estrategias/agendas digitales nacionales, países seleccionados de América Latina y el Caribe 


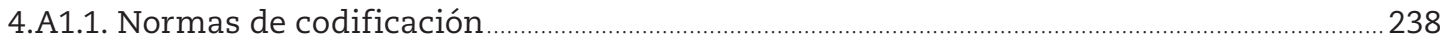

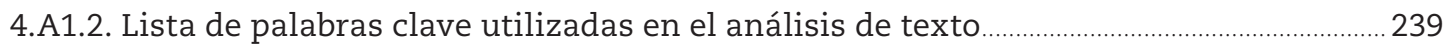

4.A2.1. Características del plan nacional de desarrollo, países seleccionados de América

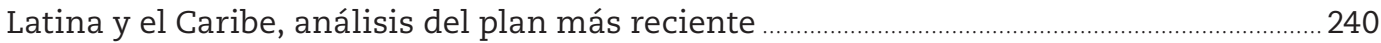

5.1. Facilitar el desarrollo de América Latina y el Caribe mediante una cooperación

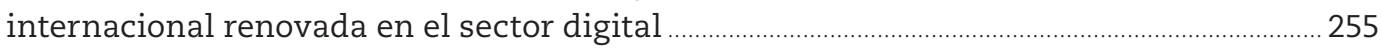

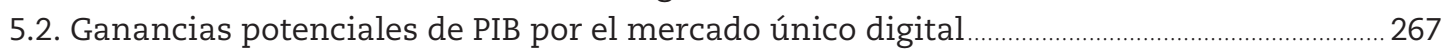

6.1. Estrategias digitales nacionales, países del Caribe seleccionados ........................................... 297

6.2. Índice mundial de ciberseguridad de la Unión Internacional de Telecomunicaciones

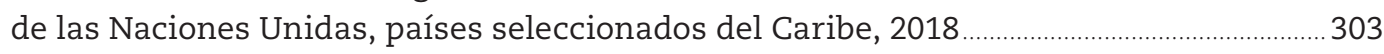

\section{Recuadros}

1.1. Elasticidad de los ingresos por exportaciones e importaciones en América Latina

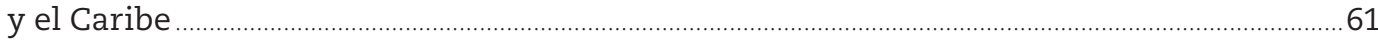

1.2. Carencias regionales en materia de transformación digital: El caso de Colombia …...........78

1.3. Cómo medir la transformación digital: Hoja de ruta para el futuro ............................................... 80

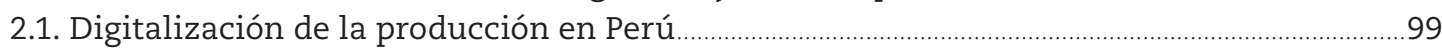

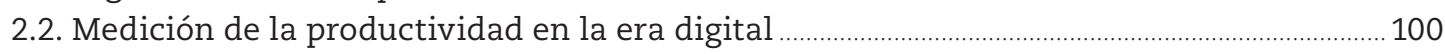

2.3. Principios del G20 para la inversión en infraestructuras de calidad....................................... 113

3.1. Asegurar el acceso a Internet y su uso en América Latina y el Caribe....................................... 139

3.2. Las computadoras en educación ............................................................................................................. 161

4.1. El Observatorio de Políticas de Inteligencia Artificial de la OCDE ............................................ 202

4.2. Medición de la madurez del gobierno digital ............................................................................. 208

4.3. Comunicaciones del gobierno digital: De la difusión a una verdadera participación pública

5.1. Innovación para el desarrollo en Iberoamérica mediante la cooperación Sur-Sur

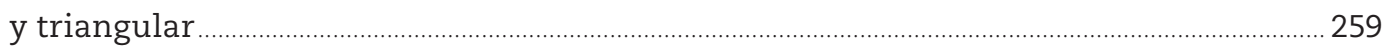




\title{
Acrónimos y abreviaturas
}

\author{
AD Agenda digital \\ ADB Banco Asiático de Desarrollo \\ ALC América Latina y el Caribe \\ AP Alianza del Pacífico \\ APEC Cooperación Económica Asia-Pacífico \\ APP Asociaciones público-privadas \\ BELLA Building the Europe Link with Latin America \\ BEPS Proyecto sobre la erosión de la base imponible y el traslado de beneficios \\ BID Banco Interamericano de Desarrollo \\ C4IR Centro para la Cuarta Revolución Industrial \\ CAF Banco de Desarrollo de América Latina \\ CARICOM La Comunidad del Caribe \\ CE Comisión Europea \\ CEPAL Comisión Económica para América Latina y el Caribe \\ CIAT Centro Interamericano de Administraciones Tributarias \\ CITEL Comisión Interamericana de Telecomunicaciones \\ CIUO Clasificación Internacional Uniforme de Ocupaciones \\ CSS Cooperación Sur-Sur \\ CTA Centro de Tecnologías Ambientales \\ CTIM Ciencias, Tecnología, Ingeniería y Matemáticas \\ EGDI Índice de desarrollo del gobierno electrónico \\ EHR Historia clínica electrónica \\ eLAC Agenda Digital para América Latina y el Caribe \\ EMBI Emerging Markets Bond Index \\ ETER El Registro Europeo de la Educación Superior \\ FEM Foro Económico Mundial \\ FMI Fondo Monetario Internacional \\ HCI Índice de capital humano \\ I+D Investigación y desarrollo \\ IA Inteligencia artificial \\ IED Inversión extranjera directa \\ IIF Institute of International Finance \\ IMT Telecomunicaciones móviles internacionales \\ IoT Internet de las cosas \\ ISEC Índice socioeconómico y cultural \\ IVA Impuesto al valor agregado \\ IXP Punto de intercambio de Internet \\ J-PAL El Abdul Latif Jameel Poverty Action Lab \\ LEO Perspectivas económicas de América Latina \\ MB/s Megabytes por segundo \\ MERCOSUR Mercado Común del Sur \\ MIPYME Micro, pequeñas y medianas empresas \\ MOOC Curso en línea masivo y abierto \\ MS Milisegundos \\ OAS Organización de los Estados Americanos
}


OCDE Organización para la Cooperación y el Desarrollo Económicos

ODS Objetivos de Desarrollo Sostenible

OIT Organización Internacional de Trabajo

OMS Organización Mundial de la Salud

ONG Organizaciones No Gubernamentales

ONU Organización de Naciones Unidas

ORBA Observatorio Regional de Banda Ancha

PCT Tratado de Cooperación en materia de Patentes

PEID Pequeños estados insulares en desarrollo

PIAAC Programa para la Evaluación Internacional de las Competencias de Adultos

PIB Producto interno bruto

PISA Programa para la Evaluación Internacional de Alumnos

PND Planes nacionales de desarrollo

PPA Paridad de poder adquisitivo

PSI Proveedor de servicios de Internet

PYME Pequeñas y medianas empresas

RGPD Reglamento general de protección de datos

SEGIB Secretaría General Iberoamericana

SICA Sistema de la Integración Centroamericana

TIC Tecnología de la información y las comunicaciones

TII Índice de infraestructura de telecomunicaciones

UE Unión Europea

UIT Unión Internacional de Telecomunicaciones

UNCTAD Conferencia de las Naciones Unidas sobre Comercio y Desarrollo

USD Dólar de Estados Unidos

VIX Índice de volatilidad

Wi-Fi Wireless Fidelity 


\section{Editorial}

El informe Perspectivas Económicas de América Latina 2020 aborda la transformación digital como una oportunidad para superar las trampas del desarrollo a las que se enfrenta la región, las cuales se han visto acentuadas durante la pandemia del Covid-19. Esta transformación está afectando las trayectorias del desarrollo en todo el mundo, y en América Latina y el Caribe ofrece oportunidades para acelerar el desarrollo.

El uso adecuado de las nuevas tecnologías ha proporcionado soluciones innovadoras y eficientes para hacer frente a la pandemia y aliviar así las medidas de confinamiento y distanciamiento social al conectar a las personas, las empresas, los mercados y las instituciones. Por otra parte, durante la pandemia hemos comprobado en mayor medida las consecuencias y el costo de la brecha digital. Son muchas las personas que no han podido aprovechar los beneficios de las tecnologías digitales y, por tanto, han quedado excluidas de las soluciones de aprendizaje por medios electrónicos y del teletrabajo.

La Agenda 2030 reconoce que "la difusión de las tecnologías de la información y las comunicaciones y la interconexión mundial tiene grandes posibilidades de acelerar el progreso humano, reducir la brecha digital y desarrollar sociedades del conocimiento". En Perspectivas Económicas de América Latina 2020 sostenemos que la digitalización es un instrumento eficaz para el desarrollo, pero solo si es universal e inclusiva.

El uso generalizado de estas tecnologías puede contribuir a impulsar la productividad, promover la inclusión social y la descarbonización de la economía, apoyando así la respuesta de las instituciones públicas a las crecientes exigencias de los ciudadanos. Sin embargo, la economía digital también entraña importantes riesgos, los cuales son mayores en los países en desarrollo. Si no se canaliza adecuadamente, podría dar lugar a una mayor concentración del mercado, un aumento de las desigualdades, la pérdida de puestos de trabajo y problemas de privacidad y seguridad. En el informe se hace hincapié en que la transformación digital no impulsará automáticamente el desarrollo, sino que requiere de la adopción de una serie de políticas públicas que han de coordinarse en el marco de las estrategias nacionales de desarrollo. Asimismo, se hace un llamado para que, ahora más que nunca, se creen o se refuercen alianzas internacionales que permitan aprovechar los beneficios de la transformación digital.

\section{Se necesitan intervenciones urgentes para respaldar la recuperación socioeconómica}

La crisis del Covid-19 está llevando el crecimiento del PIB a mínimos históricos en toda la región de América Latina y el Caribe, aumentando así la pobreza y la desigualdad. Se han acometido intervenciones en el ámbito de las políticas para preservar las capacidades humanas, productivas y financieras. Sin embargo, las capacidades financieras e institucionales son limitadas y los problemas estructurales - como la elevada informalidad, la baja productividad y la vulnerabilidad socioeconómica - acentúan la necesidad de adoptar medidas enérgicas y eficaces.

Los desafíos creados por esta crisis son numerosos, pero la adopción de sólidas políticas públicas y alianzas, tanto a escala nacional como internacional, puede convertir este complicado escenario en una oportunidad para redefinir el contrato social, dando prioridad al bienestar de las personas. Este proceso participativo debe contribuir a definir e implementar sistemas de protección social más sólidos, una mejor y más accesible atención sanitaria, unas finanzas públicas más sanas y progresivas y unas estrategias productivas más inclusivas y sostenibles. Ahora, más que nunca, la cooperación y la 
coordinación internacionales son cruciales en distintos ámbitos socioeconómicos para preservar la cohesión social, incluida la gestión de la deuda pública externa.

\section{Un llamado a la acción para capitalizar la transformación digital}

La transformación digital puede desempeñar un papel importante para convertir esta crisis en una nueva oportunidad de desarrollo y hacer frente a las trampas del desarrollo de la región. Por ello, en esta publicación se insta a la adopción de una serie de medidas en este sentido.

En primer lugar, la región se caracteriza por el predominio de microempresas y pequeñas empresas que tienen una escasa productividad, que a menudo están desconectadas de sus mercados y que no tienen capacidad para absorber el shock generado por la pandemia. Las herramientas digitales pueden contribuir a impulsar la productividad e incrementar su competitividad, sobre todo en el caso de las empresas que se están quedando atrás. Por tanto, las políticas deben tener por objeto apoyar la adopción de herramientas tecnológicas con ecosistemas digitales integrales, infraestructuras adecuadas y conocimientos digitales apropiados.

En segundo lugar, es necesario abordar las brechas digitales para que los beneficios de la transformación digital lleguen a todos. La adopción de tecnologías digitales centradas en las necesidades de las personas puede aumentar la calidad de vida de los hogares y, por tanto, mejorar el bienestar de las sociedades latinoamericanas al tiempo que se promueve el desarrollo sostenible del medioambiente. Persisten las disparidades de acceso y uso en los distintos territorios, grupos socioeconómicos, de edad o de género, las cuales pueden ampliarse en el contexto de la pandemia. Esta situación puede potenciar la creación de mayores brechas entre ganadores y perdedores, planteando así amenazas adicionales a la estabilidad y la cohesión social.

En tercer lugar, las tecnologías digitales ofrecerán oportunidades y desafíos al mercado laboral. En la región, algunos puestos de trabajo corren un alto riesgo de automatización, mientras que otros experimentarán cambios sustanciales en la forma de realizarlos. Las políticas de fomento de la productividad deben desempeñar un papel importante a la hora de abordar las necesidades del mercado y asegurar así una transición fluida al adoptar los nuevos empleos y dejar atrás los puestos de trabajo obsoletos.

En cuarto lugar, para asegurar que los beneficios de la transformación digital se aprovechen en el hogar y en el trabajo, es necesario impulsar las competencias adecuadas en las primeras etapas de la vida y durante el desarrollo vital de las personas. Entre quienes tienen menos competencias, destaca una mayor proporción de mujeres que no cuenta con experiencia en el ámbito de la informática. No basta con proporcionar a los centros educativos y estudiantes más desfavorecidos un mayor acceso a las Tecnologías de la Información y las Comunicaciones (TIC), sino que también se necesitan programas que desarrollen las aptitudes adecuadas tanto en los estudiantes como en el profesorado.

En quinto lugar, las nuevas tecnologías digitales pueden transformar las instituciones públicas y conseguir que sean más creíbles, eficientes, inclusivas e innovadoras. De este modo, se puede contribuir a restablecer la confianza en los gobiernos simplificando los complejos sistemas burocráticos, prestando servicios públicos más inclusivos-como los servicios de salud a través de Internet o el aprendizaje por medios electrónicos-que lleguen a los sectores más desfavorecidos de la sociedad, dotándolos de una mayor apertura y transparencia, y permitiendo la participación de los ciudadanos en los procesos de toma de decisiones.

Existe una condición importante para que se emprendan las acciones anteriormente mencionadas: a nivel nacional, estas medidas de políticas deben coordinarse en el marco 
de las estrategias nacionales de desarrollo, vinculándolas directamente a las agendas digitales. De esta manera, se aprovecharía el potencial de las políticas digitales para que se conviertan en un factor decisivo en la consecución de un mayor bienestar social.

La crisis del Covid-19 hace que la necesidad de cooperación internacional y de creación de nuevas alianzas en la región sea más importante que nunca. La transformación digital conlleva muchos desafíos que son de carácter transfronterizo y, por tanto, requieren de una mayor cooperación internacional. Entre ellos se incluyen ámbitos como la regulación y las normas, la inversión, el comercio, la seguridad digital o desafíos fiscales derivados de la digitalización de la economía. La creación de alianzas más sólidas también puede promover un intercambio de conocimientos más pertinente y transferencias tecnológicas en distintas dimensiones, contribuyendo así a cerrar la brecha digital. La región ya cuenta con varias plataformas en las que puede basarse, como la Agenda digital para América Latina y el Caribe (eLAC). En este sentido, la transferencia de experiencias de la OCDE y la Unión Europea a la región puede ser de gran utilidad y, por tanto, debe fortalecerse.

La transformación digital no resolverá por sí sola los problemas de desarrollo. Creemos firmemente que, para aprovechar los beneficios de las tecnologías digitales, debemos adoptar una mayor cooperación en las cuestiones más amplias, de manera que podamos emplear estas tecnologías de forma inclusiva, sostenible y socialmente responsable. Los países de América Latina y el Caribe no deben dejar atrás esta oportunidad para adoptar una transformación digital sostenible.

\author{
Alicia Bárcena \\ Secretaria Ejecutiva \\ CEPAL
}

\author{
Luis Carranza \\ Presidente Ejecutivo \\ CAF - Banco de
}

Desarrollo de América Latina

\author{
Angel Gurría \\ Secretario General \\ OCDE \\ Jutta Urpilainen \\ Comisaria Europea \\ para las Alianzas \\ Internacionales
}





\section{Resumen ejecutivo}

El informe Perspectivas económicas de América Latina 2020 aborda el papel de la transformación digital como herramienta para fomentar el desarrollo de la región, en especial en el contexto de la actual crisis del Covid-19, y hace hincapié en la trascendencia de las alianzas internacionales para aprovechar los beneficios de dicha transformación. También presenta los desafíos macro-estructurales, en la situación actual de pandemia, e insta a la adopción de mayores medidas en el plano nacional y en el internacional.

Las tecnologías digitales pueden contribuir a la mejora de la productividad, ayudar a mitigar el cambio climático, fomentar la inclusión y transformar las instituciones públicas, pero solo lo harán si todos los ciudadanos y empresas pueden beneficiarse de una transformación digital promovida mediante un planteamiento centrado en las personas. Este objetivo es muy ambicioso y exige la implementación de una política integral que coordine las estrategias nacionales de desarrollo con las agendas digitales. Ahora, más que nunca, es necesaria la cooperación internacional para materializar plenamente el potencial de la transformación digital en la región.

La pandemia del Covid-19 está incidiendo de diferentes maneras en la transformación digital de los distintos países, con consecuencias socioeconómicas sin precedentes en América Latina y el Caribe (ALC), que agravan una situación ya de por sí compleja, caracterizada por trampas del desarrollo de carácter estructural. La región ha entrado en esta crisis del coronavirus con un bajo crecimiento potencial, escaso margen fiscal y gran descontento social debido a una mayor exigencia de mejores servicios públicos y estándares generales de bienestar más altos en la mayoría de los países. El informe pone de manifiesto las posibilidades que ofrece la transformación digital para dar respuesta a los desafíos que encaran los países de América Latina y el Caribe en este sentido, así como para propiciar una recuperación sostenible de la crisis actual en la región.

\section{Repercusiones socioeconómicas y respuestas de política para hacer frente a la crisis del Covid-19}

Las consecuencias socioeconómicas de la pandemia no tienen precedentes en la región. Pese a existir una gran heterogeneidad entre países, todos ellos están siendo golpeados. En promedio, el crecimiento del PIB se contraerá entre 7\% y 9\% en 2020, y las tasas de pobreza podrían aumentar 4.4 puntos porcentuales en 2020. El impacto social por la pandemia está siendo particularmente difícil para el $40 \%$ de los trabajadores que no tienen acceso a ninguna forma de ayuda ni mecanismo de protección social, pero también para las micro y pequeñas empresas, que carecen de capacidad para amortiguar el golpe. Podrían cerrar 2.7 millones de empresas, en su mayoría microempresas, lo que supondría la pérdida de 8.5 millones de puestos de trabajo.

Coordinar una respuesta global para hacer frente a los efectos de la crisis en América Latina y el Caribe sigue siendo crucial. La región ha adoptado políticas expansivas para proteger a los más vulnerables y preservar las capacidades humanas y productivas. No obstante, las intervenciones se encuentran limitadas por un estrecho margen fiscal y aquellas que se circunscriben exclusivamente al ámbito nacional no bastan. De hecho, se necesitan medidas excepcionales y debidamente coordinadas, de alcance global, para reconstruir la economía y promover la inclusión. En el plano fiscal, este tipo de medidas precisan de una serie de intervenciones, incluyendo la gestión de la deuda pública y la mejora de la transparencia fiscal. El refuerzo de los diálogos en materia de políticas y el intercambio de conocimientos sobre múltiples dimensiones que inciden en el desarrollo inclusivo y sostenible revisten más importancia que nunca. 
Esta secuencia de actuaciones políticas resulta fundamental para lograr una recuperación más sólida y promover el bienestar. A corto plazo, a medida que se eliminen gradualmente las medidas de confinamiento, será fundamental un apoyo económico continuo para estimular el consumo y fortalecer la inclusión, así como iniciativas de inversión para promover la actividad económica. En el mediano plazo, las repercusiones de la crisis deben transformarse en una oportunidad para redefinir el pacto social, convirtiendo el bienestar en un elemento central, dando prioridad a sistemas de protección social más fuertes, unas finanzas públicas más sólidas e inclusivas, así como la necesidad de poner en marcha estrategias productivas inclusivas y sostenibles. Las repercusiones en la economía brindan también una oportunidad para conseguir una recuperación verde.

\section{El papel de la transformación digital para una mejor reconstrucción}

La transformación digital brinda nuevas oportunidades para que la región enfrente la crisis actual y supere sus consecuencias a largo plazo. Las tecnologías digitales han permitido que parte de la población y de las empresas siguiese trabajando o estudiando mientras cumplía las medidas de distanciamiento social. Sin embargo, pese al progreso registrado en la última década, persisten las brechas digitales entre hogares, trabajadores y empresas, de modo que los segmentos más vulnerables se quedan especialmente atrás.

En el futuro, las tecnologías digitales pueden contribuir de manera importante a la recuperación de la región, dando respuesta a sus retos persistentes. Con las políticas adecuadas, las nuevas tecnologías pueden contribuir a la mejora de la calidad del empleo y las competencias, y a la creación de nuevos puestos de trabajo en el mercado formal. Asimismo, las nuevas herramientas digitales pueden resultar decisivas para mejorar las instituciones públicas; si estas adoptan apropiadamente las nuevas tecnologías, podrían ser una fuente de productividad y mayor competitividad. Será fundamental garantizar la existencia de las condiciones subyacentes adecuadas en cuanto a acceso y uso de Internet, así como competencias básicas y digitales para todos, junto con una estrategia digital clara que esté en consonancia con los planes nacionales de desarrollo (PND).

\section{La transformación digital para aumentar la productividad}

Los países de América Latina y el Caribe se han caracterizado por una brecha de productividad elevada y creciente en comparación con las economías desarrolladas. La revolución digital debería ser la fuerza que impulse el aumento de la productividad, en especial en el caso de las micro y pequeñas empresas que se están quedando rezagadas. Estas herramientas digitales están desencadenando innovaciones en los modelos de negocio y los sistemas de producción, la reorganización de los sectores económicos, nuevas dinámicas en el mundo del trabajo, la oferta de bienes y servicios inteligentes y nuevas condiciones de competitividad. Para sacar provecho de la revolución digital, son necesarias dimensiones indispensables y complementarias, como un ecosistema digital integral, infraestructuras adecuadas, entre ellas, la infraestructura de transporte, y competencias digitales generalizadas.

\section{Una transformación digital que mejore el bienestar de todas las familias, los trabajadores y los estudiantes}

La transformación digital influye en la calidad de vida, los mercados de trabajo y la educación. Debido a las medidas de confinamiento de la población, ha quedado patente que muchas actividades pueden realizarse por medios remotos aunque, pese a las considerables mejoras registradas en los últimos años, siguen existiendo carencias entre diferentes grupos socioeconómicos en materia de competencias y también disparidades en cuanto a acceso y uso. En el contexto de la pandemia, estas disparidades pueden 
aumentar, lo que acaba creando ganadores y perdedores. Por ejemplo, menos de la mitad de los latinoamericanos tenían suficiente experiencia en el uso de computadoras y herramientas digitales para tareas profesionales básicas, por lo que en realidad más de la mitad de la población de la región quedó excluida de las actividades a distancia.

En el mercado laboral, las nuevas tecnologías brindan oportunidades, pero también presentan desafíos. Dos de cada diez puestos de trabajo corren un alto riesgo de automatización en varios países de América Latina, mientras que otros cuatro podrían experimentar cambios importantes en las tareas que comportan. Pero también están surgiendo nuevas oportunidades laborales. En el caso de los trabajadores de las industrias en declive, son fundamentales las políticas de apoyo en la transición hacia nuevas oportunidades de trabajo.

Todos los segmentos de la población, y especialmente las mujeres, deben adquirir competencias digitales a una edad temprana y a lo largo de toda la vida. Entre los trabajadores con menores competencias, la proporción de mujeres sin experiencia informática es mayor que la de hombres. No basta con dotar a estudiantes y centros educativos desfavorecidos de un mayor acceso a las Tecnologías de la Información y la Comunicación (TIC), pues también se necesitan programas que permitan a estudiantes y docentes adquirir las competencias adecuadas.

Las actuaciones en materia de políticas deben contribuir a agilizar la transformación digital, garantizando que favorezca la cohesión social y se transforme en un factor de impulso de un mayor bienestar.

\section{Aprovechar la nueva era digital para transformar al Estado}

Las tecnologías digitales pueden ayudar a restaurar la confianza en las instituciones públicas, al hacer que sean más creíbles, eficientes, inclusivas e innovadoras. Los ciudadanos confiarán más en los organismos públicos si estos adoptan políticas de gobierno abierto que promuevan una cultura de transparencia, acceso a la información y control sobre el uso de los fondos públicos por parte de la ciudadanía. Las instituciones pueden aumentar su eficiencia simplificando sistemas burocráticos complejos. La transformación digital de los gobiernos puede favorecer la consecución de servicios públicos más inclusivos, especialmente pertinentes en el contexto del Covid-19, mediante políticas de datos abiertos y servicios de educación o salud por medios electrónicos, además de facilitar la interacción con grupos de interés y la participación ciudadana en la toma de decisiones. La transformación digital será útil para llegar a los segmentos más desfavorecidos de la sociedad. Por último, las herramientas digitales pueden ayudar a las administraciones a usar nuevas fuentes de datos y ser más innovadoras en la forma de abordar las políticas públicas, lo cual mejorará en último término los procesos de formulación de políticas.

En América Latina y el Caribe, los ámbitos de política relacionados con el acceso y uso de tecnologías digitales, infraestructura de comunicaciones y futuro del trabajo se encuentran actualmente más integrados en los planes nacionales de desarrollo que ningún otro campo. La transformación digital abarca una serie de políticas públicas que deben incluirse en los planes nacionales de desarrollo mediante un planteamiento coordinado, con una vinculación directa a agendas digitales. Por último, las nuevas herramientas digitales pueden contribuir a optimizar la formulación, adopción y seguimiento de estas estrategias de desarrollo. 


\section{Cooperación internacional para sacar el máximo partido a la transformación digital}

Puesto que la transformación digital plantea desafíos y oportunidades que transcienden las fronteras nacionales, más aún desde el inicio de la crisis del Covid-19, resulta fundamental que América Latina y el Caribe coordine sus políticas digitales en el plano internacional. La región puede verse favorecida por alianzas internacionales e innovadoras, si estas promueven y facilitan procesos auspiciados en el ámbito nacional y sitúan a los países en pie de igualdad para intercambiar conocimientos sobre políticas de inclusión digital que garanticen competencias digitales para todos. También deberían aprovechar las capacidades existentes y crear otras nuevas que estimulen reformas nacionales e internacionales.

La creación de un mercado digital regional podría ayudar a América Latina y el Caribe a sacar provecho a su potencial digital. Los países de la región han de seguir integrando iniciativas de cooperación regional como eLAC e intercambiar experiencias con otras regiones. América Latina y el Caribe está aprendiendo de las experiencias de otras regiones, en particular del Mercado Único Digital de la UE, cuyo objetivo es incluir a los ciudadanos y sus derechos en la era digital, y reforzar las actividades empresariales.

La cooperación multilateral jamás había sido tan importante. Por ejemplo, las dificultades que plantea la digitalización de la economía en materia fiscal exigen la coordinación internacional de los diferentes países. Así, América Latina y el Caribe puede beneficiarse en gran medida de una mayor cooperación en esta materia, tanto dentro de la propia región como con otras jurisdicciones. La región deberá desempeñar un papel activo en el debate internacional, en pie de igualdad, para alcanzar un consenso y también soluciones mediante una cooperación multilateral eficaz respecto a los temas relacionados con la tributación de la digitalización de la economía. 



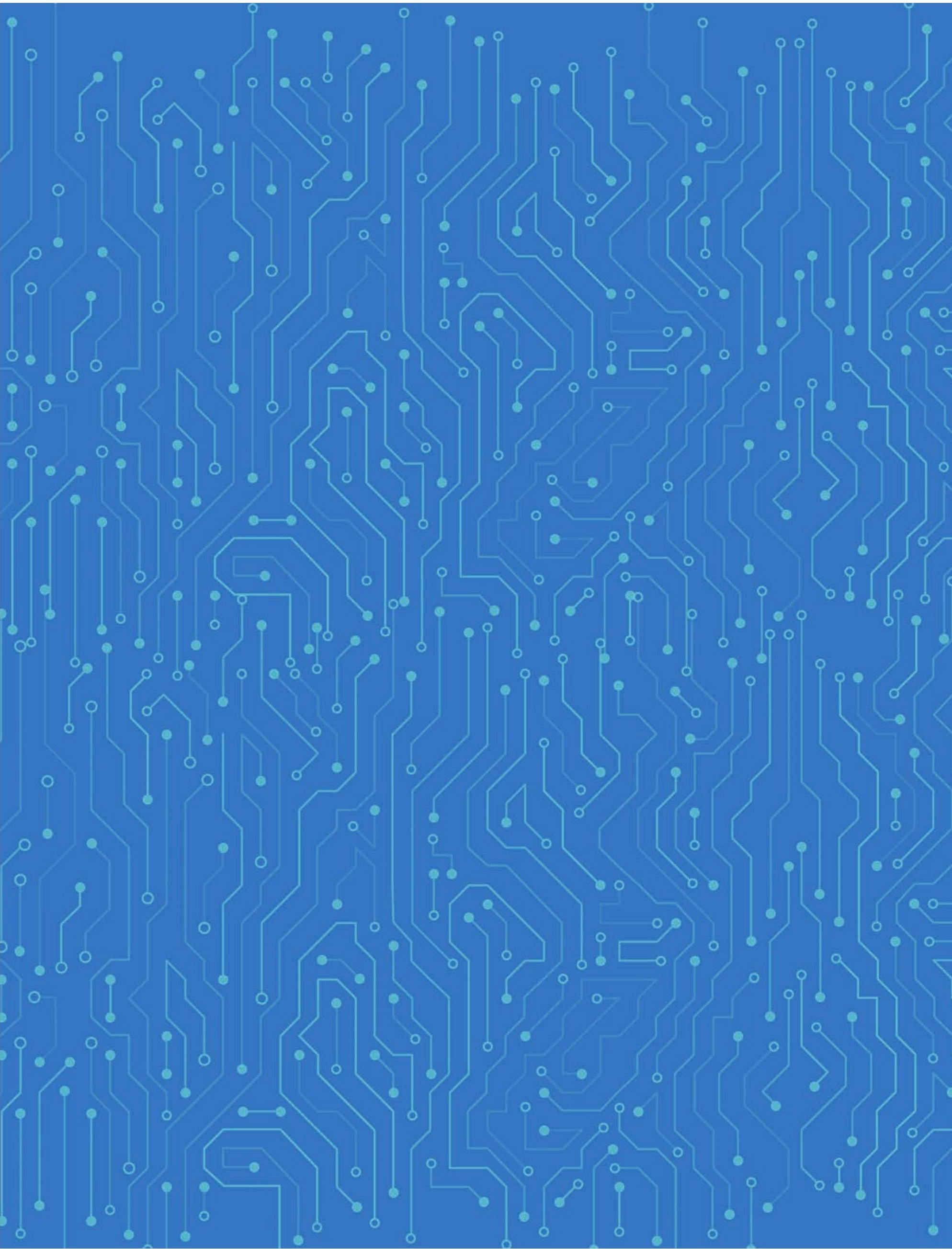




\section{Resumen}

\section{La transformación digital para una recuperación inclusiva y sostenible pos-Covid-19}

El informe Perspectivas económicas de América Latina 2020: Transformación digital para una mejor reconstrucción (LEO 2020, por sus siglas en inglés) analiza y ofrece mensajes en materia de políticas públicas que buscan aprovechar la transformación digital para fomentar un desarrollo inclusivo y sostenible en la región, en particular en el contexto de la actual crisis del coronavirus (Covid-19). En este resumen se ofrece una síntesis de los resultados y mensajes principales de este informe. En primer lugar, la publicación examina las implicaciones socioeconómicas de la crisis del Covid-19 en la región y la forma en que está agravando las vulnerabilidades existentes. Asimismo, pone de manifiesto la trascendencia de la transformación digital para superar las trampas del desarrollo de América Latina y el Caribe (ALC). Posteriormente, analiza el potencial de la transformación digital para: 1) mejorar la diversificación y el crecimiento de la productividad;2) promover la inclusión y el bienestar; y 3) reforzar las instituciones públicas y mejorar la gobernanza. Por último, examina la importancia que reviste reforzar nuevas alianzas internacionales para aprovechar las ventajas de la transformación digital. 


\section{Introducción}

El informe Perspectivas económicas de América Latina 2020: Transformación digital para una mejor reconstrucción analiza y ofrece mensajes en materia de política pública para aprovechar la transformación digital con el fin de fomentar un desarrollo más inclusivo y sostenible en la región, en particular en el contexto de la actual crisis del coronavirus. La región de América Latina y el Caribe atraviesa tiempos difíciles y sin precedentes. La pandemia está afectando profundamente las condiciones socioeconómicas de la región y agravando una situación ya de por sí compleja y de manifiesta debilidad estructural: bajo crecimiento de la productividad, altos niveles de desigualdad e informalidad y servicios públicos e instituciones deficientes con respecto a las aspiraciones de los ciudadanos. La crisis llega en un momento de grandes aspiraciones sociales, lo cual refuerza la necesidad de transformar las bases del modelo de desarrollo de la región, convirtiendo el bienestar de los ciudadanos en su elemento central.

La transformación digital brinda nuevas herramientas y oportunidades para que la región dé respuesta a la crisis actual y supere las dificultades de desarrollo a más largo plazo. La transformación digital conlleva alteraciones que están desencadenando innovaciones en los modelos de negocio y consumo, transformando los sistemas de producción y las cadenas de valor, reorganizando sectores económicos, generando nuevas dinámicas en el mundo del trabajo, creando bienes y servicios inteligentes e introduciendo nuevas condiciones de competitividad (CEPAL, 2016, 2018; OCDE, 2017a, 2017b). Las herramientas digitales también pueden favorecer el acceso a mejores servicios, tales como salud y educación. Por último, pueden resultar cruciales para mejorar el funcionamiento de los Estados, al propiciar instituciones más creíbles, efectivas, inclusivas e innovadoras, que puedan dar respuesta a las exigencias de los ciudadanos y la creciente insatisfacción social.

Los países de América Latina y el Caribe deben acometer importantes inversiones y aplicar políticas ambiciosas para aprovechar al máximo la transformación digital en beneficio de toda la población. La transformación digital dependerá del grado en que previamente se hayan adoptado las Tecnologías de la Información y las Comunicaciones (TIC), como el acceso a banda ancha o el uso de Internet. Para que todas las personas puedan acceder a las nuevas tecnologías, utilizarlas y beneficiarse de ellas, se requiere un trabajo serio, innovador y coordinado de diseño de políticas públicas. La coordinación de políticas públicas pertinentes exige una planificación estratégica, bajo marcos integrales previstos en los Planes Nacionales de Desarrollo (PND) que muestren una clara sintonía con las agendas digitales más específicas.

La crisis del Covid-19 puede haber impulsado el momento para adoptar las reformas necesarias que garanticen los beneficios de la transformación digital a toda la población. Las tecnologías han sido esenciales para mitigar ciertos impactos, por ejemplo, al permitir el teletrabajo y también el comercio electrónico. Sin embargo, también ha quedado más patente la importancia que reviste reducir las brechas digitales entre familias, estudiantes, trabajadores y empresas.

El informe Perspectivas económicas de América Latina 2020: Transformación digital para una mejor reconstrucción examina cómo la transformación digital puede fomentar el desarrollo y promover un mayor bienestar para el conjunto de América Latina y el Caribe. En primer lugar, el informe estudia las implicaciones socioeconómicas de la crisis del Covid-19 en la región y la forma como está agravando las vulnerabilidades existentes, poniendo de manifiesto la trascendencia de la transformación digital para superar las trampas del desarrollo de América Latina y el Caribe (Capítulo 1). A continuación, analiza el potencial de la transformación digital para: 1) mejorar la diversificación y el crecimiento de la 
productividad (Capítulo 2); 2) promover la inclusión y el bienestar (Capítulo 3); y 3) reforzar las instituciones públicas y mejorar la gobernanza (Capítulo 4). Por último, examina la importancia que reviste reforzar nuevas alianzas internacionales para aprovechar las ventajas de la transformación digital mediante la creación de plataformas multilaterales para el intercambio de conocimientos en igualdad de condiciones, el refuerzo de las capacidades de las instituciones nacionales y la promoción de la cooperación en marcos de colaboración que engloben al conjunto de los organismos públicos (Capítulo 5). El informe incluye un análisis específico sobre los países del Caribe (Capítulo 6) y "notas país" para 14 economías de América Latina y el Caribe.

\section{La crisis del coronavirus (Covid-19) ha golpeado a la región en un momento de profundas debilidades estructurales}

El impacto del coronavirus en la economía ha calado hondo y complicará las perspectivas macroeconómicas de América Latina y el Caribe en los próximos años. A partir de 2014, la región ha venido registrando el periodo de crecimiento más bajo desde 1950, con tasas de crecimiento inferiores al promedio de la OCDE y prácticamente sin expansión económica alguna en 2019. Estos datos indican que el potencial de crecimiento ya era escaso. La actual crisis está teniendo consecuencias internas y externas. Las medidas nacionales en materia de salud están repercutiendo de manera importante en la actividad económica y, por ende, en las condiciones sociales. Asimismo, un marcado descenso de la demanda mundial, una reducción considerable de los precios de las materias primas, la volatilidad financiera y otros efectos vinculados a un descenso de la inversión, contracción del turismo y posible descenso de las remesas configuran un escenario complejo. En términos generales, el crecimiento económico de la región descenderá entre 7\% y 9\% en 2020 (CEPAL, 2020a; CAF, 2020a).

La contracción de la actividad provocada por la pandemia está teniendo una enorme repercusión socioeconómica, que afecta a los grupos más vulnerables. Casi un $60 \%$ de los trabajadores de América Latina pertenece al mercado informal. Muchos trabajan por cuenta propia en una economía de subsistencia en la que viven al día y corren el riesgo de volver a caer en la pobreza. Antes de la crisis, cerca del $40 \%$ del total de trabajadores no estaba cubierto por ningún tipo de red de protección social (es decir, no contaba con seguro social alguno ni con ayudas de ningún programa principal de asistencia social) (Gráfico 1., Panel A). Esta situación hace que debido a la crisis actual aumenten los niveles de pobreza y desigualdad, ya estancados desde 2014. Dentro del sector empresarial, la crisis será especialmente difícil para las micro y pequeñas empresas, que no tienen capacidad para amortiguar el golpe: 2.7 millones, en su mayoría microempresas, podrían cerrar, lo que supondría la pérdida de 8.5 millones de puestos de trabajo (Gráfico 1., Panel B).

Los gobiernos han adoptado medidas urgentes e importantes desde el inicio de los confinamientos, para responder a las necesidades de las empresas y los segmentos de la población más vulnerables. Para llegar a hogares y trabajadores del mercado informal, la mayoría de países ha ampliado las transferencias de efectivo incondicionales. Entre las medidas destinadas a apoyar a las empresas están las transferencias directas, garantías de crédito y moratorias al pago de impuestos, servicios públicos o contribuciones a la seguridad social.

No obstante, las intervenciones se ven limitadas por un escaso margen fiscal y las actuaciones en el ámbito nacional no son suficientes. Son necesarias medidas coordinadas a nivel global para reconstruir las economías y promover la inclusión. En el plano fiscal, dichas intervenciones incluyen la gestión de la deuda pública y el incremento de la transparencia en materia de impuestos. Con respecto a la deuda pública, en la región no existe una solución única para su gestión, debido a las diferencias entre países en 
cuanto a condiciones fiscales iniciales, tipo de acreedores internacionales y capacidades financieras para hacer uso de los mercados de capital. Estas divergencias entre los países exigen diferentes acciones de política para responder a la crisis del coronavirus (Covid-19) en el plano nacional y en el internacional.

Gráfico 1. Trabajadores que carecen de una red de seguridad social y empresas que podrían cerrar debido a la crisis del coronavirus (Covid-19) en países seleccionados

Panel A. Trabajadores sin seguridad social ni asistencia de América Latina

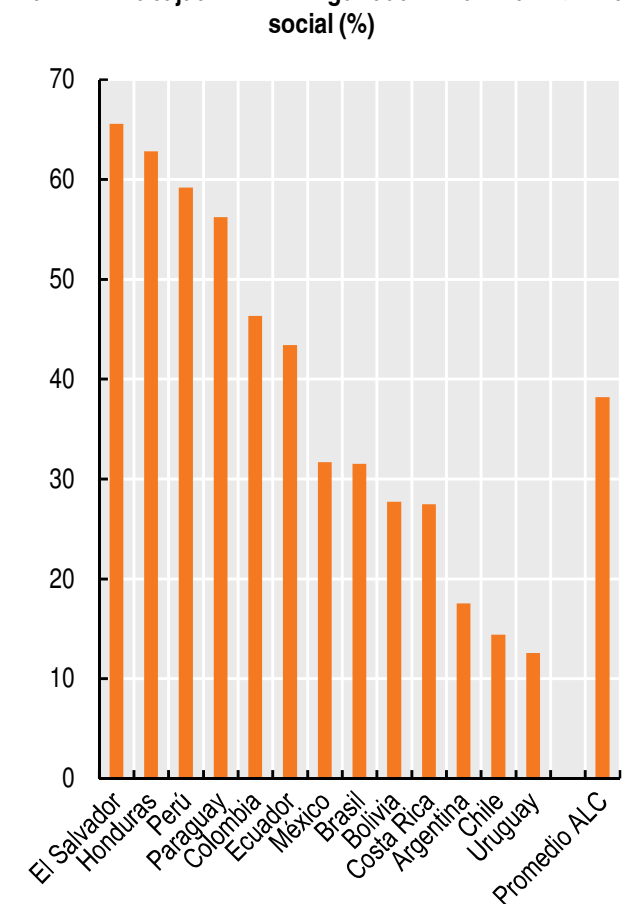

Panel B. Empresas que podrían cerrar por la crisis del coronavirus (Covid-19), por tamaño (\%)

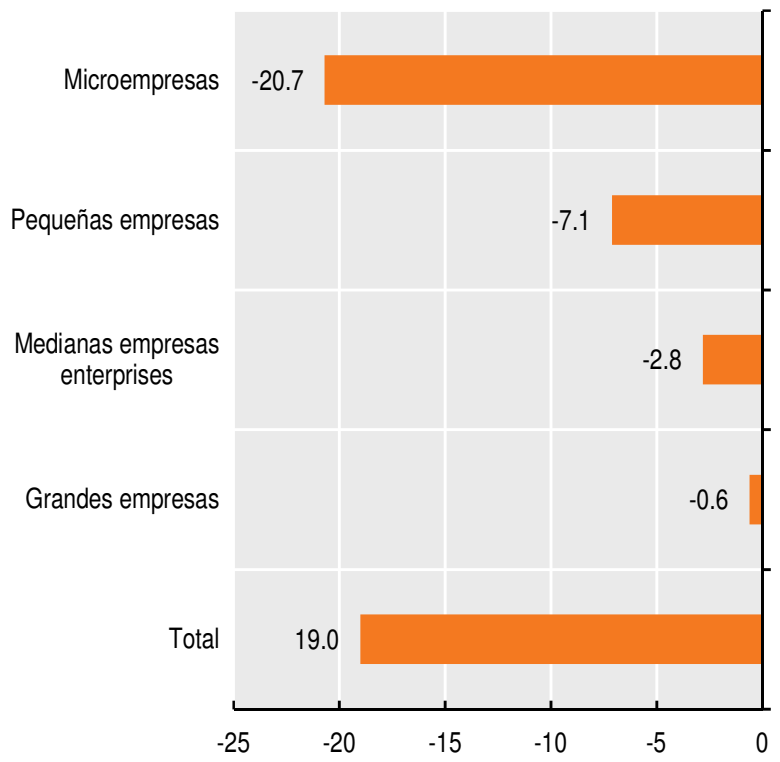

Fuentes: Basto-Aguirre, Nieto-Parra y Vázquez (2020), "Informality in Latin America in the post COVID-19 era: Towards a more formal 'new normal'?", www.lacea.org/vox/?q=blog/informality latam postcovid19; y CEPAL (2020b), "Sectores y empresas frente al COVID-19: emergencia y reactivación", https://repositorio.cepal.org/bitstream/handle/11362/45736/5/ S2000437_en.pdf.

StatLink तiाst https://doi.org/10.1787/888934201629

Más allá de las consecuencias inmediatas de la pandemia, la región debe centrar sus esfuerzos en materia de políticas públicas en superar los desafíos estructurales. Las trampas del desarrollo, que implican una dinámica circular que se perpetúa a sí misma y limita la capacidad de los países para avanzar, son resultado de debilidades persistentes y nuevos desafíos surgidos con el incremento del nivel de ingresos. El informe Perspectivas económicas de América Latina 2019: Desarrollo en transición identificaba cuatro trampas del desarrollo: baja productividad, vulnerabilidad social, debilidad institucional y sostenibilidad ambiental (OCDE et al., 2019). Respecto a esta última, la transformación digital debería contribuir a la consecución de una transición "justa" hacia un crecimiento sostenible con bajas emisiones de carbono que vaya de la mano con el avance de la justicia social.

La transformación digital se ha erigido en una importante tendencia mundial que plantea desafíos y oportunidades y que, si se acompaña de políticas efectivas, puede ayudar a superar las trampas del desarrollo de América Latina y el Caribe. Aunque ya se han puesto en marcha algunas medidas, para aprovechar las oportunidades que se presentan, serán necesarios nuevos planteamientos en materia de políticas y también inversiones complementarias. 
El proyecto Going Digital de la OCDE identifica siete dimensiones de política claves para que la transformación digital favorezca el crecimiento y el bienestar: 1) ampliar el acceso a tecnologías digitales; 2) reforzar su uso efectivo; 3) fomentar la innovación digital; 4) garantizar trabajos de calidad para todos; 5) promover la prosperidad social; 6) reforzar la confianza; y 7) favorecer mercados abiertos (OCDE, 2019a). La adopción de medidas en estos ámbitos ayudará a superar las trampas del desarrollo de América Latina y el Caribe (OCDE, 2019b).

Las actuaciones políticas en pro de la digitalización deben trascender el enfoque sectorial, ya que se trata de un proceso multidimensional que tiene implicaciones en diversos campos. El carácter transfronterizo de algunos de los desafíos y oportunidades que se plantean exige una mayor coordinación internacional. Resulta esencial crear mecanismos de diálogo político en el ámbito regional, promover acuerdos en materias que requieran una coherencia de las regulaciones internacionales y también fomentar la cooperación. Por ello, ha cobrado mayor interés la Agenda Digital para América Latina y el Caribe (eLAC), coordinada por la CEPAL desde el año 2000.

\section{La transformación digital puede impulsar el crecimiento de la productividad}

En las últimas décadas, la región ha registrado una brecha elevada y creciente en materia de productividad con respecto a las economías desarrolladas. La productividad laboral agregada muestra un crecimiento reducido y persistentemente bajo desde 1950. $\mathrm{El}$ aumento de la productividad es el motor principal de un avance económico sostenido, pero el crecimiento del Producto Interno Bruto (PIB) de América Latina y el Caribe se debe mayoritariamente al crecimiento de la fuerza laboral, mientras que la contribución del crecimiento de la productividad es escasa (Gráfico 2).

\section{Gráfico 2. Contribución del empleo y la productividad al crecimiento del PIB en} países y regiones seleccionados, 2000-19 (porcentajes)

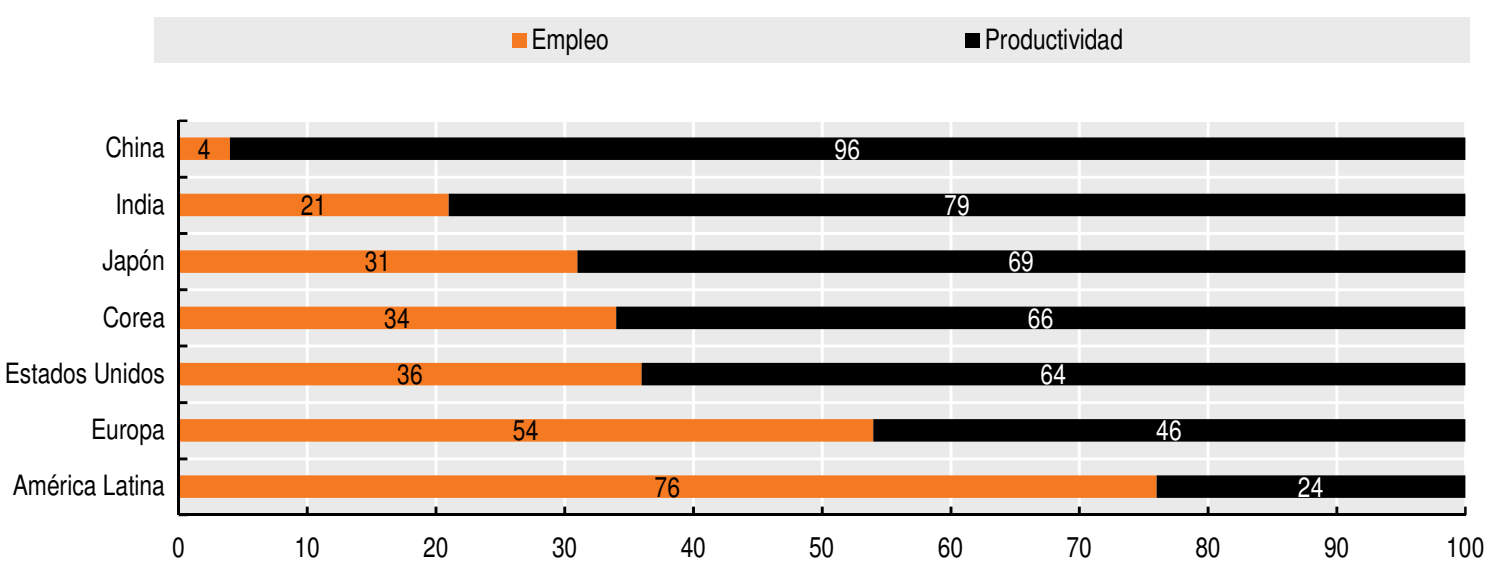

Nota: Promedio simple de los 17 países de América Latina y el Caribe cubiertos por The Conference Board.

Fuente: Cálculos propios a partir de la base de datos Conference Board (2020), Total Economy Database (base de datos), www.conference-board.org/data/economydatabase.

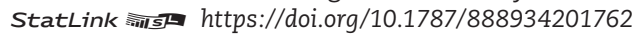

La competitividad de la mayoría de países se basa en gran medida en la abundancia de recursos naturales o mano de obra de escasa cualificación. El resultado es una estructura de producción poco diversificada, con un escaso valor añadido y una especialización en exportaciones que se concentran en bienes de bajo contenido tecnológico. Tal como ocurrió con el auge de los productos básicos, este tipo de estructura puede dar lugar a períodos de rápido crecimiento, pero no favorece el crecimiento sostenido de la productividad. Para 
lograr esto último, se necesita incorporar tecnología y diversificar la producción hacia sectores dinámicos, tanto en relación con la tecnología como en términos de demanda internacional (CEPAL, 2012; OCDE et al., 2019).

\section{Promover la transformación digital de la producción}

América Latina y el Caribe debe aprovechar las herramientas digitales y promover la transformación de la producción para salir de la trampa de la productividad. Algunos países están incorporando políticas para impulsar el desarrollo de tecnologías emergentes, como la robótica avanzada y la inteligencia artificial, para mejorar la productividad. Algunas de las intervenciones en ese sentido son, por ejemplo, el Plan Nacional de Internet de las Cosas de Brasil, el Centro para la Cuarta Revolución Industrial de Colombia, de cuyo funcionamiento se encarga Ruta $\mathrm{N}$ en Medellín, y el Laboratorio de Fabricación Digital de Uruguay. Las dificultades persisten, sobre todo en cuanto a la aplicación de las tecnologías digitales de forma productiva, el fomento de iniciativas de emprendimiento de índole digital y heterogeneidad empresarial. Un amplio porcentaje de las empresas más pequeñas tiene dificultades para adoptar nuevas tecnologías. Por otro lado, pese a la rapidez con que se producen los cambios tecnológicos y las posibilidades de mejorar la eficiencia que ofrecen, el crecimiento de la productividad total a escala global, y también en América Latina y el Caribe, se ha ralentizado en la pasada década, lo que ha provocado una paradoja en materia de productividad (OCDE 2017a, 2017b).

La difusión y el impacto de las tecnologías digitales sobre la productividad en América Latina y el Caribe no son automáticos sino que dependen de elementos indispensables, como el acceso y la difusión adecuados de las tecnologías digitales, un sólido dinamismo empresarial, la participación de las pequeñas y medianas empresas en la transformación digital y una competencia suficiente en la economía digital. Para facilitar la adopción por parte de las empresas, resulta esencial crear un ecosistema digital integral (CAF, 2017). La región de América Latina y el Caribe ha registrado un importante avance en cuanto al uso de Internet. En 2018, el 68\% de la población utilizaba Internet con regularidad, casi el doble de la proporción de 2010, pero por debajo del promedio del 84\% de la OCDE (Gráfico 3). El acceso, la conectividad y la calidad de la conexión siguen siendo desiguales tanto entre los diferentes países como dentro de cada uno de ellos. Además, pese a la mejora sostenida que han experimentado las velocidades de conexión de la región, se mantienen muy por debajo del promedio mundial, lo que limita el tipo de servicios y apps disponibles.

El éxito de las estrategias de transformación digital en el ámbito de la productividad depende de una serie más amplia de intervenciones y sectores, más allá de las propias TIC por sí solas. La conectividad del transporte y el desarrollo de competencias digitales son elementos facilitadores clave en la era digital, en la que la región de América Latina y el Caribe se encuentra rezagada de la OCDE. Las políticas destinadas a promover el desarrollo de competencias digitales deberían encontrarse en sintonía con políticas industriales y tecnológicas de alcance más general, a fin de garantizar que la fuerza de trabajo disponga de las capacidades que precisan sectores prioritarios. La adopción y adaptación de tecnologías digitales abarca una serie de funciones y profesiones, cada una de ellas con diferentes requisitos en cuanto a educación y competencias. Pese al elevado número de programas de grado y posgrado, América Latina y el Caribe es deficitaria en programas de formación de alto nivel (principalmente programas de doctorado), lo cual incide en las actividades de investigación y desarrollo (I+D). Será esencial invertir en competencias adecuadas y reducir la brecha con los países más avanzados tecnológicamente para que América Latina y el Caribe aproveche las tecnologías digitales. Asimismo, la conectividad del transporte resulta fundamental para sacar el máximo partido a la transformación digital. Gracias a las plataformas digitales, el comercio electrónico puede expandir los mercados e incrementar la eficiencia. Mejorar la infraestructura de transporte y la 
logística debería servir para aumentar la competitividad y también la expansión del comercio electrónico.

\section{Gráfico 3. Porcentaje de usuarios de Internet en países seleccionados de América Latina y el Caribe, 2010 y 2018 (o más reciente)}

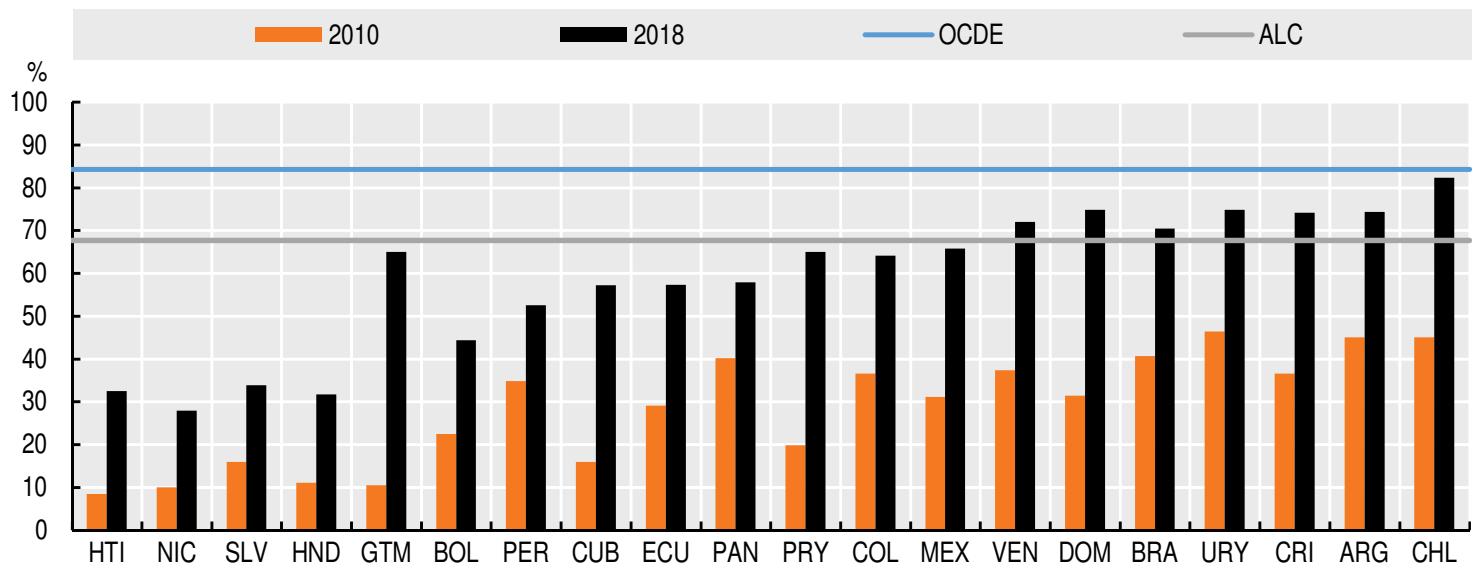

Notas: El indicador puede incluir estimaciones, y la proporción de usuarios de Internet se basa en los resultados de las encuestas nacionales de hogares. Las cifras reflejan la población total o las personas de 5 años o más. Si no se disponía de ninguna de las dos (es decir, la población objetivo refleja un grupo de edad más limitado), se elaboró una estimación de la población total.

Fuente: Elaboración propia a partir de los datos de la UIT (2020), Base de datos de indicadores mundiales de telecomunicaciones y TIC 2020 (base de datos), Unión Internacional de Telecomunicaciones, Ginebra, https://www.itu.int/en/ITU-D/Statistics/Pages/ publications/wtid.aspx (consultada el 21 de agosto de 2020).

StatLink तiाls https://doi.org/10.1787/888934201876

Las tecnologías digitales no son independientes del sector, la estructura organizativa y otros elementos específicos del contexto en el que se encuadran. Las políticas y soluciones tecnológicas deben adaptarse a los distintos sectores y tipos de unidades de producción individuales, en particular a las pequeñas y medianas empresas (pymes), para tener en cuenta las características específicas que influyen en su funcionalidad. En particular, como nos recuerda el Covid-19, en una región con tantas diferencias en materia de productividad según el tamaño de la empresa, la transformación digital brinda oportunidades pero también podría acentuar las disparidades. Si se adoptaran las políticas oportunas, las tecnologías digitales podrían ayudar a cerrar la brecha de productividad existente con respecto a las empresas más grandes. A pesar de los avances logrados en los últimos años, la escasa adopción incluso de tecnologías básicas, especialmente entre las pequeñas empresas, demuestra que aún hay margen para una mayor intervención en el ámbito de las políticas públicas. Por ejemplo, en algunos países de la región, la diferencia de productividad entre pequeñas y grandes empresas que poseen un sitio web propio supera los 30 puntos porcentuales.

La región se ha visto golpeada por la crisis del Covid-19 en un momento en el que el número de empresas que usa medios digitales en sus operaciones rutinarias es relativamente bajo (Gráfico 4). Por lo tanto, la economía posterior a la pandemia se caracterizará por un incremento de la digitalización (CAF, 2020b; CEPAL, 2020b). Las tecnologías digitales serán clave para los nuevos modelos de explotación: las empresas tendrán que adoptar tecnologías para procesar grandes cantidades de información con el fin de mejorar los procesos de decisión, lo cual podría redefinir los modelos de negocio. La industria deberá incorporar un mayor uso de la robótica para mejorar la eficiencia e incrementar también la utilización de herramientas de inteligencia artificial (CAF et al., 2020). La transformación digital también puede incidir en las operaciones de los modelos 
de negocio mediante cambios en la venta y entrega de bienes y servicios o interacciones con proveedores (CEPAL, 2020b).

Gráfico 4. América Latina: digitalización de la cadena de suministro, 2018

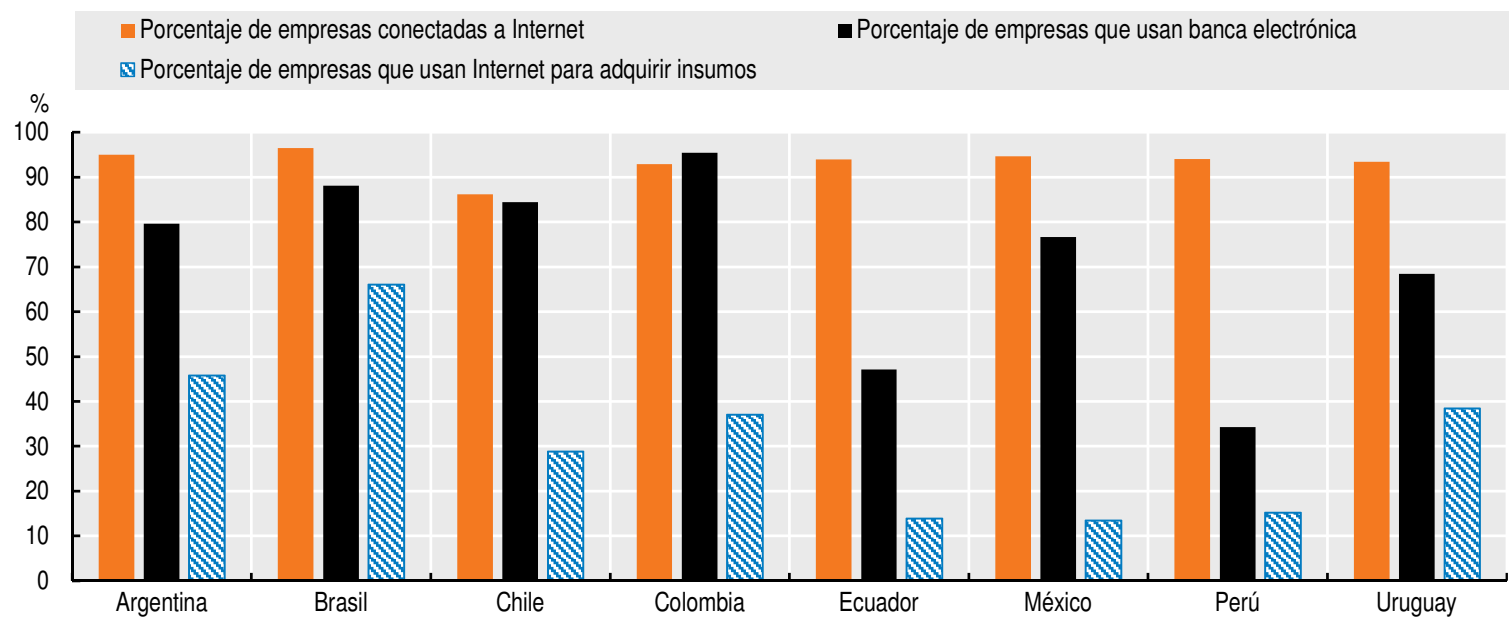

Fuente: CAF (2020b), "El estado de la digitalización de América Latina frente a la pandemia del COVID-19", https://scioteca. caf.com/bitstream/handle/123456789/1540/El_estado_de_la_digitalizacion_de_America_Latina_frente_a_la_pandemia_ del COVID-19.pdf? sequence=1.

StatLink त्नाIs https://doi.org/10.1787/888934201439

La región se encuentra actualmente en una mejor posición para beneficiarse de la transformación digital, principalmente porque se ha extendido el acceso a redes y dispositivos. No obstante, es preciso garantizar la existencia de elementos clave que propicien un ecosistema digital virtuoso, por ejemplo, infraestructuras de calidad, competencias digitales para todos y marcos jurídicos congruentes que estimulen la inversión y la innovación de forma sostenible. La digitalización ofrece importantes posibilidades para promover actividades de I+D, nuevos modelos y ajustes de las cadenas de valor productivas. Experiencias ya vividas en el pasado demuestran que la repercusión que tengan dichas políticas dependerá de la adopción de una visión estratégica, por ejemplo, incluyéndolas en los planes nacionales de desarrollo, garantizando la coordinación entre instituciones y forjando cooperaciones entre entidades públicas y privadas.

\section{La transformación digital puede mejorar el bienestar mediante la inclusión social de las familias, los trabajadores y los estudiantes}

La transformación digital influye en la calidad de vida de los hogares, los trabajos y la educación. Las nuevas tecnologías ofrecen muchas oportunidades para acceder a mejores servicios públicos, mejorar el sistema de salud y educación y crear empleo, además de incorporar al mercado de trabajo a grupos que anteriormente tenían menor representación y tenerlos más en cuenta en las políticas públicas. La transformación digital también puede ayudar a mejorar la calidad del empleo y las competencias, concretamente podrían automatizarse tareas peligrosas o repetitivas. La crisis del coronavirus ha evidenciado que las nuevas tecnologías están permitiendo a ciertos segmentos de la población decidir con mayor libertad dónde y cuándo trabajar, lo cual puede mejorar el balance entre la vida laboral y personal y contribuir a la seguridad y salubridad de los entornos laborales.

La crisis del Covid-19 también pone de manifiesto que la brecha digital de la región es un tema urgente, ya que los trabajadores pobres y vulnerables que no disponen del acceso ni de las competencias para beneficiarse de las herramientas digitales se están quedando atrás. Los que permanezcan al margen de estas nuevas herramientas digitales 
posiblemente se verán más afectados por las consecuencias sanitarias, económicas y sociales de la crisis, lo cual acrecentará las desigualdades socioeconómicas. En concreto, los trabajadores sin acceso a nuevas tecnologías o sin las competencias necesarias serán más vulnerables ante pérdidas económicas y de otro tipo, tanto a corto como a largo plazo; por ejemplo, no podrán teletrabajar ni vender bienes por Internet, y quizá sus hijos tampoco puedan acceder a la educación a distancia para proseguir sus estudios.

\section{Garantizando que los hogares se beneficien de la transformación digital}

Pese a las importantes mejoras en cuanto a acceso a Internet y uso de este medio, persisten las brechas digitales entre hogares por nivel de ingresos, edad y territorio. El acceso a Internet en América Latina y el Caribe sigue estando fuertemente vinculado al nivel de ingresos de los hogares. En promedio, existe una diferencia de casi 40 puntos porcentuales entre el porcentaje de la población total que usa Internet del quintil más rico (75\%) y del más pobre (37\%). En los países de la OCDE, esta diferencia se sitúa en promedio por debajo de los 25 puntos porcentuales. El uso de Internet es considerablemente superior entre las personas de 15 a 34 años (más de un 60\%) que en la población de 65 a 74 años (18\%) y los mayores de 74 años (8\%). El número y la proporción de usuarios urbanos supera las cifras registradas en núcleos rurales (hasta casi cuadruplicarlas en algunos países).

Pese a seguir existiendo una brecha digital en la mayoría de los países, la distribución del acceso a Internet y su uso es mejor que la de los niveles de ingreso, pensiones y algunos servicios públicos (Gráfico 5).

\section{Gráfico 5. Distribución del acceso a Internet y de su uso, junto con el de otros servicios, por decil de ingresos, países seleccionados de América Latina, 2017 o último año disponible}

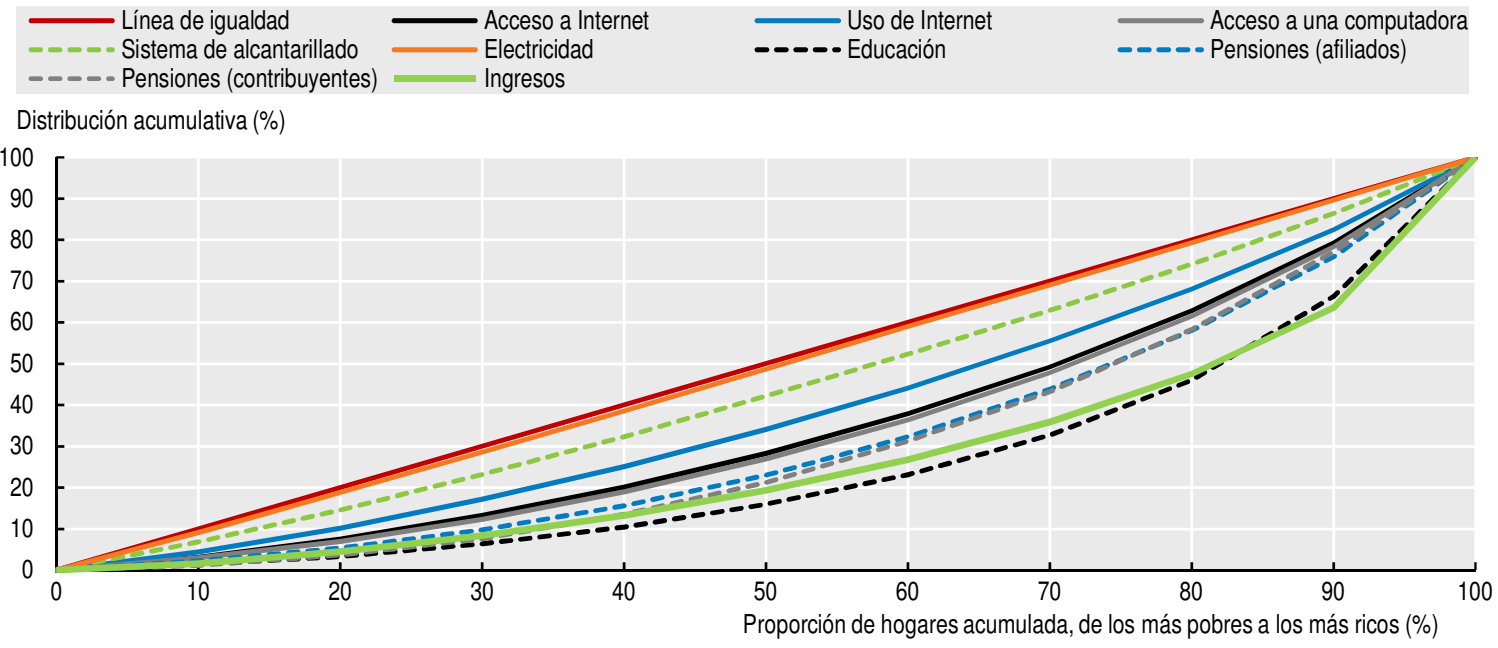

Nota: Promedio simple por decil para países seleccionados de América Latina y el Caribe. Véase la metodología pormenorizada en el Gráfico 3.1.

Fuente: Elaboración propia a partir de ORBA/CEPAL (2019), Banco de Datos de Encuestas de Hogares (base de datos), www.cepal. org/es/observatorio-regional-de-banda-ancha.

StatLink नinst https://doi.org/10.1787/888934202028

\section{Preparándose para el futuro del trabajo y las competencias}

Pocas personas, en particular mujeres, cuentan con las competencias necesarias para beneficiarse de las TIC en su vida cotidiana. La Evaluación de Competencias de Adultos del Programa para la Evaluación Internacional de las Competencias de Adultos (PIAAC, por sus siglas en inglés) de la OCDE ofrece información sobre la frecuencia con 
que las personas realizan tareas relacionadas con las TIC. Menos de la mitad de los latinoamericanos de entre 15 y 65 años que participaron en esta evaluación habían usado una computadora o tenían experiencia suficiente para poder usar computadoras en la realización de tareas profesionales básicas. Las tareas para las que se utilizaba Internet de forma más habitual, al menos una vez a la semana, eran recabar información (73\%) y usar el correo electrónico (69\%). Menos del 10\% de los trabajadores utilizaba las TIC para tareas más avanzadas, como la programación de computadoras. Los individuos con educación terciaria usaban estas herramientas con mayor frecuencia que aquellos con menor educación. Finalmente, los hombres eran más propensos que las mujeres a utilizar las TIC para hacer transacciones o trabajar con hojas de cálculo.

Según las estimaciones del análisis ocupacional de la CEPAL, el 16\% de los empleos de América Latina y el Caribe presentan un alto riesgo de automatización, desde el 5\% en Bolivia hasta el 29\% en Uruguay (CEPAL, 2019). Por otra parte, si se tiene en cuenta la sustitución de tareas dentro de las diferentes ocupaciones, en promedio, un 25\% de los puestos de trabajo de Chile, Ecuador, México y Perú corre un elevado riesgo de automatización, y un 35\% puede experimentar cambios importantes en las tareas realizadas y en la forma de llevarlas a cabo (OCDE, 2019c). Un puesto de trabajo tiene un alto riesgo de automatización si al menos el $70 \%$ de sus tareas son susceptibles de ser automatizadas y correrá el riesgo de sufrir cambios significativos si entre el 50\% y el 70\% de sus tareas pueden automatizarse (Nedelkoska y Quintini, 2018).

Aunque la transformación digital propiciará la desaparición, el cambio o la creación de algunos empleos, muy pocos trabajadores de América Latina y el Caribe dominan o usan herramientas digitales en el trabajo. Solo un tercio de los trabajadores en la región utilizaba las TIC en el trabajo semanalmente, en comparación con Europa, donde más de la mitad lo hacen (OCDE, 2018a).

La gestión de la transición de los trabajadores de los sectores y las regiones en declive hacia nuevas oportunidades de empleo, y el avance hacia sistemas de protección social más amplios e inclusivos siguen constituyendo desafíos fundamentales. El futuro del trabajo dependerá de las decisiones de política pública (OCDE, 2019c). Los sistemas de protección social deberían reinventarse para garantizar una mejor cobertura, que incluya a trabajadores atípicos, como los de la economía bajo demanda (gig), en la que lo habitual es que se ofrezcan contratos temporales o para autónomos, y también contratos de cero horas.

La crisis del coronavirus (Covid-19) pone de manifiesto que las políticas e instituciones deben garantizar que la transformación digital no deje en situación de desventaja a determinados trabajadores. Algunos trabajadores encaran múltiples obstáculos para recibir formación. Los poco cualificados, los que realizan ocupaciones con alto riesgo de automatización o los que han perdido su empleo suelen ser reacios a formarse o incapaces de identificar vías de capacitación pertinentes. Por muy bien informados y motivados que estén, se enfrentan a barreras como la falta de tiempo, dinero o competencias para iniciar una formación específica. Concretamente esa es la situación en la que se encuentran los trabajadores del mercado informal de la región. Por otro lado, los empleadores suelen invertir en la formación de los trabajadores más cualificados, porque prevén un mayor retorno de la inversión.

Las nuevas formas de trabajo de la economía de plataformas (platform economy) pueden brindar oportunidades para la formalización del empleo en América Latina y el Caribe. La digitalización de las operaciones podría reducir los costos y mejorar el seguimiento de las actividades económicas. Para sacar provecho de la situación, las políticas laborales y fiscales tendrán que aplicar los mecanismos adecuados en materia de fiscalidad y protección social. 


\section{Cerrando la brecha digital para una mejor y más inclusiva educación}

El uso de herramientas digitales está ligado a la obtención de mejores resultados académicos. Los alumnos que obtienen mejores puntuaciones en el Programa de la OCDE para la Evaluación Internacional de Alumnos (PISA) habían comenzado a usar dispositivos digitales a una edad más temprana. Si se empezaban a utilizar las TIC antes de los 9 años, se asociaba significativamente a mejores resultados que si se empezaban a usar después de los 12 años. La digitalización en la última década ha influido en la forma como los estudiantes aprenden, hacen los deberes, interactúan con sus compañeros y pasan el tiempo libre. En las escuelas de ALC el uso de Internet entre los estudiantes de 15 años creció más del doble entre 2012 y 2018, y su uso llegó a más de una hora al día de escuela.

Las desigualdades en el uso de las TIC también están relacionadas con el género y la geografía. Los estudiantes de entornos urbanos de América Latina y el Caribe tienen casi un $25 \%$ más de probabilidad de participar en redes sociales y más de un $20 \%$ de usar el chat que sus homólogos de entornos rurales. La diferencia en los países de la OCDE es mínima. Las disparidades en función del género comienzan a temprana edad en los centros educativos e inciden en el futuro desarrollo profesional de los alumnos. Si bien un porcentaje similar de niños (34\%) y niñas (35\%) informaron de que esperaban trabajar en una ocupación relacionada con la ciencia, tendieron a seleccionar diferentes campos, siendo las niñas más propensas a seleccionar profesiones relacionadas con la salud, y los niños más propensos a seleccionar profesiones relacionadas con las TIC, la ciencia y la ingeniería.

Los centros educativos de América Latina y el Caribe fomentan la equidad en cuanto a acceso a las TIC y uso de este tipo de herramientas en países en los que la conectividad de los hogares no es universal. Las cifras de acceso son especialmente bajas en el caso de los alumnos de los hogares más pobres. Por ejemplo, en 2018 menos de un 14\% de los estudiantes pobres en educación primaria tenía una computadora conectada a Internet en casa, en comparación con más de un $80 \%$ de los estudiantes acomodados con el mismo nivel educativo (Gráfico 6). Además, más del 5\% de los alumnos tenía acceso a Internet y otras tecnologías digitales exclusivamente a través de su centro educativo. Por lo tanto, también es necesario ampliar la conexión a Internet en los centros educativos de América Latina y el Caribe. Por ejemplo, alrededor del 95\% de las computadoras de los centros educativos de la OCDE tenían conexión a Internet, en comparación con el 74\% en América Latina y el Caribe.

Solo unas pocas escuelas de América Latina estaban preparadas para el aprendizaje digital antes de la pandemia del coronavirus. Los alumnos de 15 años que asistían a centros de entornos favorecidos de la región tenían más probabilidades de acceder a una plataforma eficaz de apoyo al aprendizaje en línea que los que asisten a centros de entornos desfavorecidos (Gráfico 7). La falta de preparación puede ampliar las diferencias socioeconómicas en materia de educación. En promedio, el 58\% de los jóvenes de 15 años de la región asistían a escuelas cuyos directores consideraban que el cuerpo docente tenía los conocimientos técnicos y pedagógicos necesarios para integrar los dispositivos digitales en la programación. Esto pone de relieve la ingente necesidad de capacitación que tienen por delante los sistemas educativos y las significativas diferencias en términos de capacidad de enseñanza digital de los centros con ventajas socioeconómicas y de los que están en entornos desfavorecidos. 


\section{Gráfico 6. Proporción de alumnos matriculados en educación primaria con una computadora conectada a Internet en casa por grupo de ingresos, 2018 o último año disponible}

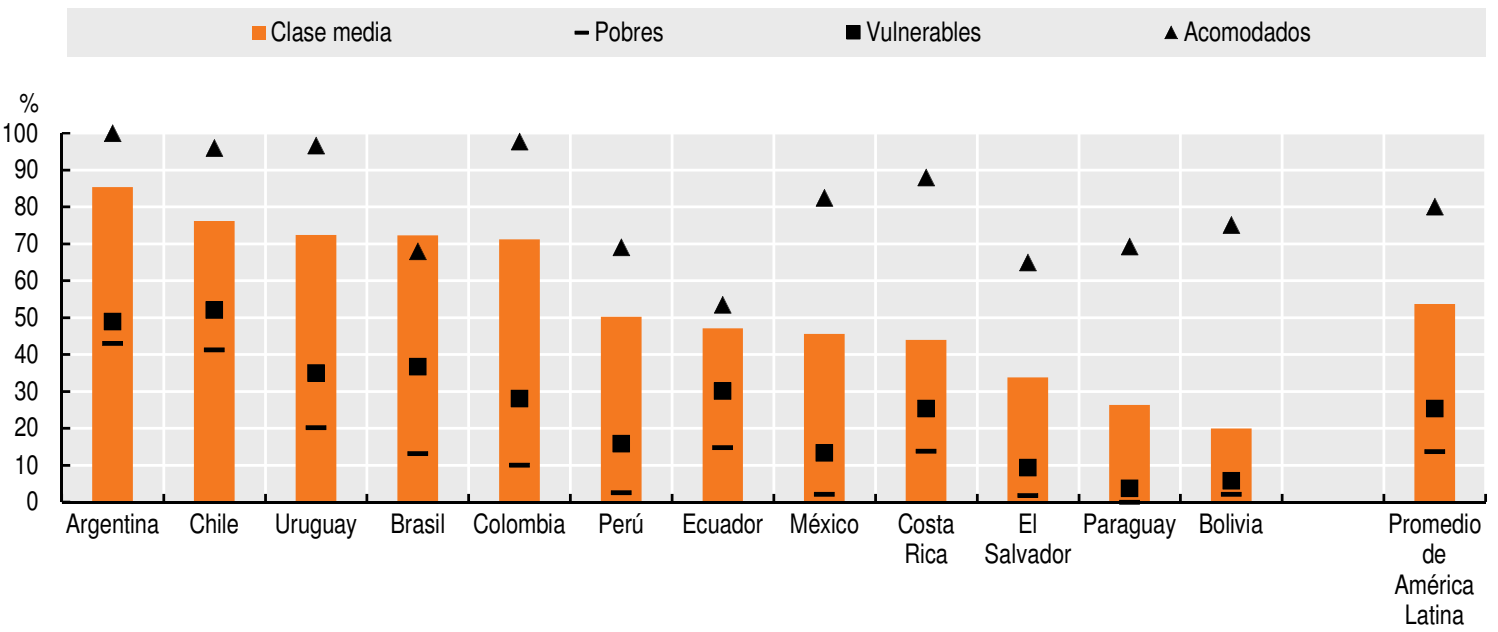

Nota: El promedio regional es un promedio simple. Los pobres son quienes viven con menos de 5.5 USD per cápita al día (PPA 2011). Los vulnerables, quienes viven con entre 5.5 USD y 13 USD per cápita al día (PPA 2011). La clase media está compuesta por quienes viven con entre 13 USD y 70 USD per cápita al día (PPA 2011). Y los acomodados son quienes viven con más de 70 USD per cápita al día (PPA 2011).

Fuente: Basto-Aguirre, Cerutti y Nieto-Parra (2020).

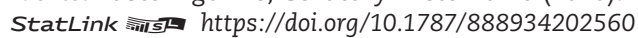

Gráfico 7. Disponibilidad de una plataforma eficaz de apoyo al aprendizaje en línea por nivel socioeconómico de los centros educativos, países seleccionados de América Latina

Porcentaje de alumnos en centros cuyos directores estaban de acuerdo o muy de acuerdo en que tenían una plataforma eficaz de apoyo al aprendizaje en línea, PISA 2018

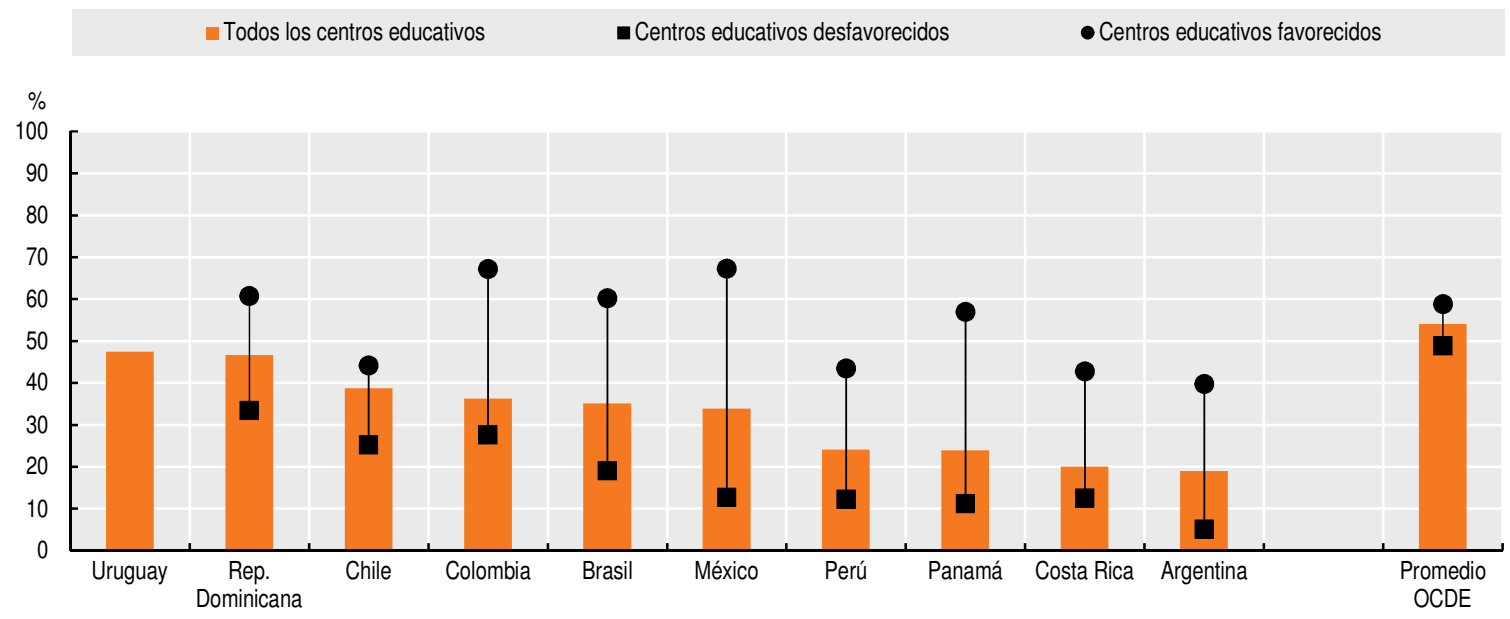

Nota: Los centros educativos de entornos socioeconómicos desfavorecidos (favorecidos) son aquellos en los que la situación socioeconómica promedio de los alumnos se encuentra en el cuartil inferior (superior) del índice socioeconómico y cultural (ISEC) de PISA entre todos los centros educativos del país/ de la economía. Los países/economías están clasificados en orden descendente, según el porcentaje de escuelas con una plataforma de apoyo eficaz al aprendizaje en línea. La diferencia entre escuelas desfavorecidas y favorecidas en Uruguay no es estadísticamente significativa.

Fuente: OCDE (2018b), Base de datos de PISA 2018 (base de datos), www.oecd.org/pisa/data/2018database/.

StatLink inist https://doi.org/10.1787/888934202541 
La crisis del coronavirus (Covid-19) hizo de la transformación digital inclusiva una prioridad máxima, para atenuar los efectos negativos y acelerar la recuperación económica inclusiva. La necesidad de adoptar una transformación digital beneficiosa para todos es una de las principales lecciones extraídas de la crisis, y puede ser una oportunidad para que los países le den el protagonismo que se merece en sus agendas digitales. Para evitar que las desigualdades existentes se acentúen, para que la tecnología beneficie a todos por igual, los países deben ampliar el acceso a esas tecnologías y hacer que las competencias necesarias lleguen a los centros educativos, a los alumnos, a los hogares y a los trabajadores. Las medidas de política pública deben ofrecer una respuesta rápida y articular con eficacia el proceso de transformación digital como factor clave del bienestar social.

\section{La transformación digital de las instituciones públicas puede mejorar la gobernanza y reconstruir la confianza}

El crecimiento de la clase media observado en América Latina y el Caribe desde principios de siglo ha traído consigo un aumento de las aspiraciones sociales, y la pandemia del coronavirus (Covid-19) podría intensificar las exigencias de instituciones públicas más sólidas y servicios públicos de mayor calidad por parte de la ciudadanía. Pese a las mejoras observadas en los últimos años en materia de gobernanza pública, las instituciones no están respondiendo de forma adecuada. En la mayoría de los países de América Latina y el Caribe, la desconfianza y la insatisfacción se están agravando, y el descontento social aumenta, lo que genera una trampa institucional (OCDE et al., 2019). Aún se desconoce en qué medida agravará la pandemia el descontento social y cambiará las aspiraciones de los ciudadanos, pero las instituciones públicas se han visto sometidas a una presión inédita y tendrán que responder a la evolución de las exigencias que plantea la sociedad y las extraordinarias dificultades que esto comporta en materia de políticas.

La transformación digital conlleva nuevos desafíos, pero también importantes oportunidades para reforzar el pacto social, así como para mejorar la respuesta a exigencias públicas que cambian rápidamente. La transformación digital puede contribuir a la mejora de la gobernanza y del funcionamiento de las instituciones públicas, así como a que se avance hacia la consecución de gobiernos digitales en tres sentidos. En primer lugar, son necesarias nuevas normas e instituciones que regulen la transformación digital, entre otros, ámbitos como el de la seguridad digital, la gestión y la protección de datos, así como nuevas cuestiones éticas que deben tenerse en cuenta. En segundo lugar, las tecnologías digitales pueden transformar profundamente las instituciones públicas y conseguir que sean más creíbles, eficientes, inclusivas e innovadoras. En tercer lugar, deben coordinarse las intervenciones encaminadas a digitalizar las economías y las sociedades. Un planteamiento estratégico de la transformación digital implica la formulación de agendas digitales estrechamente ligadas a planes nacionales de desarrollo más amplios.

\section{Adaptar las reglas del juego para gobernar la transformación digital}

La gobernanza de la transformación digital es un tema fundamental de política pública. Son necesarios cambios en las instituciones, las regulaciones y los mercados para garantizar el avance justo y equitativo de la transformación digital. Los gobiernos encaran nuevos desafíos regulatorios, no solo a la hora de gestionar aspectos surgidos con la transformación digital, sino también a la hora de garantizar que sus beneficios lleguen a toda la población (OCDE, 2019b).

Los marcos regulatorios deben adaptarse para dar respuesta a los desafíos en materia de competencia que plantea la mayor convergencia de las redes y los servicios en la economía digital. Un marco regulatorio estable y previsible fomenta la inversión a largo 
plazo en infraestructuras de banda ancha e innovación digital. También se necesitan regulaciones que promuevan la innovación para dar facilidades a nuevos sectores y empresas que hagan un uso intensivo de los medios digitales. Los marcos regulatorios deben contribuir igualmente a la protección de los consumidores. Al formular nuevas normas, deben aclararse las responsabilidades correspondientes, evitando solapamientos y facilitando a las instituciones herramientas específicas que les permitan hacer cumplir sus decisiones.

Resulta esencial contar con medidas suficientes para proteger a sectores vulnerables contra incidentes de seguridad digital. Conforme aumenta la predisposición de personas, administraciones y empresas a usar medios digitales, los incidentes de seguridad serán cada vez más frecuentes y podrían ocasionar perjuicios sociales y económicos. Los riesgos de seguridad pueden causar alteraciones en las operaciones y en servicios esenciales como el suministro de agua y energía o la seguridad y la salud públicas, así como pérdidas económicas directas, litigios, daños a la reputación, pérdida de competitividad, por ejemplo, como consecuencia de la revelación de secretos profesionales, la pérdida de datos personales y la desconfianza por parte de los consumidores (OCDE, 2015). Las organizaciones públicas y privadas deberían tener en cuenta la seguridad digital en sus actividades de gestión de riesgos y no considerarla un riesgo técnico específico al que debe darse una respuesta aislada. Los países de América Latina y el Caribe están avanzando en la formulación de planes estratégicos de seguridad digital a largo plazo. En 2019, 13 países de América Latina poseían una estrategia nacional de seguridad digital (BID/OEA, 2020).

Los datos no solo se han erigido en activos económicos esenciales, sino también en aportaciones fundamentales para una respuesta eficaz en primera línea a la propagación del coronavirus (Covid-19). Se necesita una regulación más estricta en materia de gestión, protección e intercambio transfronterizo de datos. Durante la pandemia, las autoridades de protección de la privacidad han desempeñado una función esencial al aplicar marcos de protección de datos y de la privacidad nuevos o ya existentes para garantizar una gestión de datos fiable, rápida y segura. Los marcos de protección de datos han experimentado importantes avances recientemente y han incidido en los marcos regulatorios de América Latina y el Caribe. La mayoría de países de América Latina y el Caribe tienen marcos de protección de datos, con ciertas características en común. Sus diferencias obedecen principalmente a la fecha de adopción y, en cierta medida, a la influencia de diferentes modelos internacionales. Debería fomentarse la armonización internacional de las normas, con el objetivo de promover un marco que fomente el intercambio de información y también la protección de los derechos de la ciudadanía.

La gobernanza de la transformación digital debe integrar dimensiones éticas y reaccionar a nuevos desafíos. El empleo cada vez mayor de apps de inteligencia artificial plantea preocupaciones relacionadas con los valores humanos, la equidad, la determinación humana, la privacidad, la seguridad y la gestión más responsable, entre otras. Los datos con los que se entrenan los algoritmos pueden ser erróneos, estar sesgados, ser insuficientes o no estar actualizados (Buenadicha Sánchez et al., 2019), lo que pone de relieve la necesidad de avanzar hacia sistemas de inteligencia artificial más sólidos, seguros y transparentes con mecanismos claros de rendición de cuentas (OCDE, 2019d).

Las plataformas de redes sociales han ampliado la capacidad y la rapidez de la desinformación masiva (es decir, la difusión de noticias falsas o fake news). El estar en contacto con este tipo de desinformación guarda una correlación negativa con la confianza en los organismos públicos (OCDE, 2019e). La desinformación tiene otros efectos sociales negativos, por ejemplo, la difusión de noticias falsas sobre el coronavirus (Covid-19) puede alentar comportamientos perjudiciales para la salud pública. 
Transformar los gobiernos: hacia instituciones públicas más creíbles, eficientes, inclusivas e innovadoras

Los países de América Latina y el Caribe se encuentran en distintas etapas de transformación digital de sus gobiernos. El Índice de Desarrollo del Gobierno Electrónico (EGDI) de Naciones Unidas es la medida más completa en materia de desarrollo del gobierno electrónico. Los países de América Latina se dividen en dos grupos. Argentina, Brasil, Chile y Uruguay se sitúan entre los primeros 50 países de los 193 encuestados para la edición de 2018 con resultados ligeramente inferiores al promedio de la OCDE (Gráfico 8, Panel A). Nicaragua (129), Belice (132), Cuba (134) y Haití (263) aparecen entre los que obtienen peores resultados (ONU, 2019). Según la evolución de los subíndices del EGDI, entre 2014 y 2018 (Gráfico 8, Panel B), los mayores desafíos que encaran los países de América Latina y el Caribe están relacionados con las dimensiones de infraestructura de comunicaciones y capital humano.

\section{Gráfico 8. Índice de Desarrollo del Gobierno Electrónico de Naciones Unidas (EGDI) y su evolución}

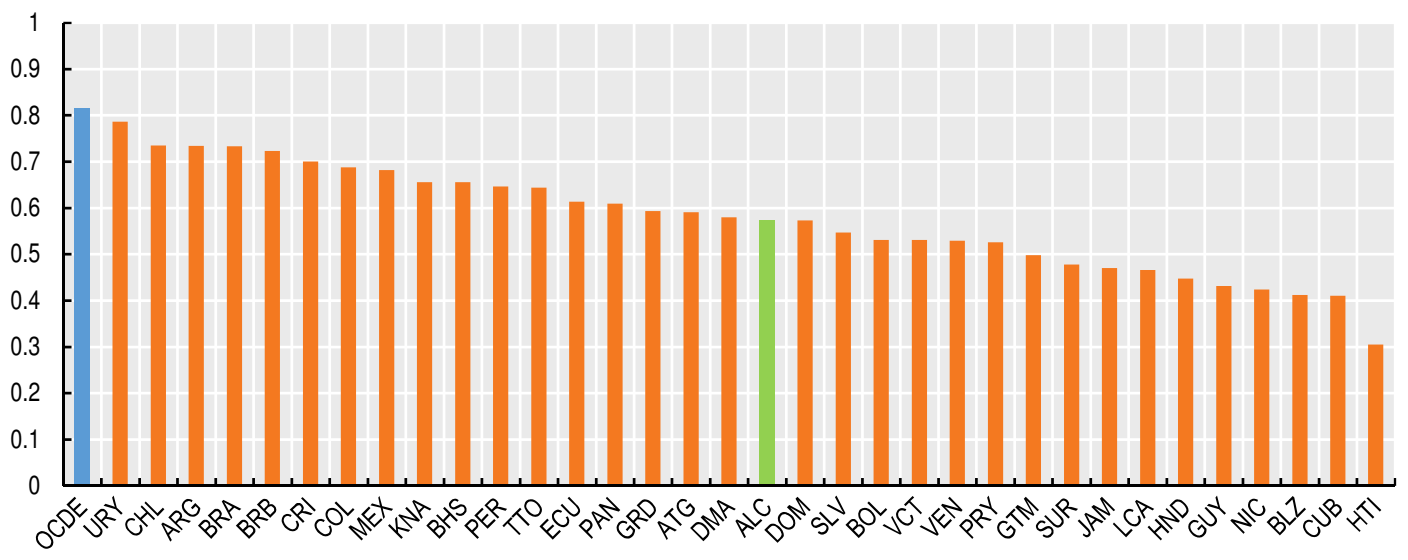

Panel B. Evolución del EGDI por componente en países ALC

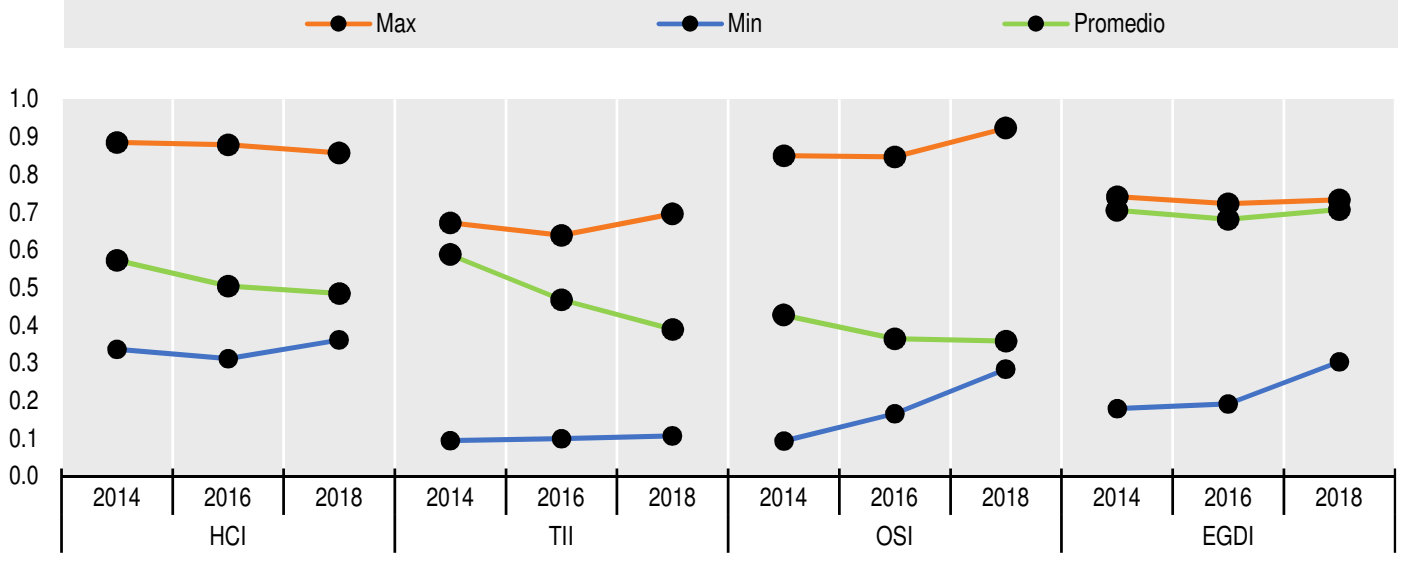

Notas: El Índice de Desarrollo del Gobierno Electrónico (EGDI) de Naciones Unidas es un índice compuesto por el Índice de Servicios en Línea (OSI), el Índice de Infraestructura de Telecomunicaciones (TII) y el Índice de Capital Humano (HCI). Su puntuación se sitúa entre 0 (menos avanzado) y 1 (más avanzado). Promedios simples correspondientes a la OCDE y a América Latina y el Caribe.

Fuente: Elaboración propia a partir de ONU (2019), base de datos e-Government Knowledgebase de Naciones Unidas (base de datos), https://publicadministration.un.org/egovkb/en-us/Data-Center.

StatLink न्ता st https://doi.org/10.1787/888934201458 
Para mejorar la gobernanza, los organismos públicos pueden usar herramientas digitales que los conviertan en instituciones más confiables, eficaces, inclusivas e innovadoras. Las administraciones públicas están inmersas en un proceso de transición de gobiernos electrónicos a gobiernos digitales. El gobierno electrónico usa las TIC, y especialmente Internet, como instrumento para mejorar la administración pública (OCDE, 2014). No obstante, la interacción con los ciudadanos es escasa y persisten las prácticas de gestión jerárquicas. El gobierno digital, sin embargo, se basa en un ecosistema compuesto por agentes de la administración, organizaciones no gubernamentales, empresas, asociaciones y particulares que facilitan la producción de datos, servicios y contenido, y el acceso a estos, mediante interacciones con los organismos públicos. Se prevé que esta transformación en gobiernos digitales aporte mayor transparencia y apertura a las administraciones y las haga más colaborativas, centradas en el usuario y con un planteamiento proactivo que reconozca los datos como activos estratégicos.

Las tecnologías digitales pueden mejorar la fiabilidad de las instituciones públicas y, por lo tanto, aumentar su credibilidad. En 2018, la confianza de la población en el gobierno local había bajado al 26\% desde el 45\% registrado en 2008 (Gallup, 2019). La percepción de corrupción es uno de los principales factores que genera desconfianza en las instituciones públicas: en 2018, el 79\% de la población consideraba que la corrupción era un problema generalizado de sus organismos públicos (Latinobarómetro, 2018) y el 53\% consideraba que la corrupción había aumentado en los 12 meses anteriores (Pring y Vrushi, 2019). La confianza es la piedra angular de la gobernanza pública y resulta fundamental para que las políticas públicas surtan efecto. Sin confianza, los ciudadanos se desvinculan de sus deberes cívicos y encuentran menos incentivos para involucrarse en asuntos políticos o para pagar impuestos. Si se gestiona adecuadamente, la transformación digital puede ayudar a los gobiernos a recuperar la confianza, aprovechando las oportunidades que brindan los datos gubernamentales abiertos y creando una cultura de transparencia, integridad y responsabilidad social.

Las tecnologías digitales ofrecen la posibilidad de poner fin a la malversación de fondos públicos. La plataforma MapaRegalías de Colombia muestra el origen y el destino de los recursos financieros obtenidos con la explotación de los recursos naturales y ha ayudado a identificar numerosas irregularidades (Santiso, 2018). La creación de órganos centrales de compras como centros especializados en adquisiciones y contrataciones, y el desarrollo de soluciones electrónicas para adquisiciones y contrataciones (como ChileCompra y Colombia Compra Eficiente) están transformando las prácticas tradicionales en este ámbito en América Latina y el Caribe. El Observatorio de Gasto Público de Brasil realiza un seguimiento de los datos sobre gasto en adquisiciones y contrataciones, y los contrasta con los de otras bases de datos gubernamentales para identificar situaciones atípicas que, pese a no constatar a priori ninguna irregularidad, justifican que se realice un examen más exhaustivo.

Las redes sociales pueden ser una herramienta muy útil para reforzar la confianza de los ciudadanos. En concreto, en el contexto de una crisis como la del coronavirus (Covid-19), los gobiernos deben cerciorarse de que la comunicación con el grueso de la población sea clara y fiable. Las redes sociales pueden constituir una plataforma importante para informar a los ciudadanos de los riesgos y la evolución de la pandemia, así como de las medidas adoptadas para atajarla. Este canal puede resultar especialmente efectivo en América Latina y el Caribe, debido al uso extendido de dichas plataformas entre la población.

Al aumentar la eficacia de los servicios públicos mediante el uso de nuevas tecnologías, las administraciones pueden mejorar la experiencia de los ciudadanos y recortar los plazos de los trámites y los costos que comporta desplazarse físicamente a las instituciones para realizarlos. El sistema burocrático de América Latina y el Caribe es complejo, ejemplo de 
ello es el promedio de tiempo necesario para realizar un trámite ante la administración pública, como conseguir un certificado de nacimiento, pagar una multa u obtener una licencia. En América Latina y el Caribe, se tarda aproximadamente 5.4 horas en realizar un trámite, aunque las cifras varían mucho en función del país, ya que para la realización de un trámite equivalente se necesitan entre 11 horas o más, en promedio, en Bolivia y menos de 3 horas en Chile (Latinobarómetro, 2017; Roseth, Reyes y Santiso, 2018). El uso de canales digitales para la tramitación de operaciones conlleva un ahorro de tiempo para los ciudadanos, que ya no tendrán que acudir en persona a las instituciones, así como de los costos que esto les acarrea.

La transformación digital de los gobiernos puede favorecer además unos servicios públicos más inclusivos mediante políticas de datos abiertos, más interacciones con las partes interesadas (consultas electrónicas) y la participación ciudadana en procesos de toma de decisiones (toma de decisiones por medios electrónicos). La transformación digital puede ayudar a los gobiernos a prestar servicios públicos más inclusivos, de manera que lleguen a los segmentos de la población más desfavorecidos o a zonas remotas con dificultades de acceso. La educación es un campo en el que las tecnologías digitales pueden ampliar la cobertura de los servicios. El aprendizaje por medios electrónicos ha experimentado una transformación extraordinaria en los últimos años. Asimismo, los servicios de salud electrónicos también ofrecen enormes posibilidades. Las consultas por medios electrónicos durante la pandemia del coronavirus (Covid-19) han tenido una importancia crucial para frenar los contagios y reducir la carga de trabajo de las salas de urgencias.

La transformación digital puede ayudar a los organismos públicos a ser más innovadores en cuanto a formulación, ejecución y evaluación de las políticas públicas y a mejorar el proceso de formulación de políticas, por ejemplo, mediante el uso de macrodatos (big data) o del goutech. La tecnología y la digitalización de sociedades y gobiernos generan cantidades ingentes de datos, que pueden ser activos importantes para fomentar la innovación y crear políticas y servicios públicos mejor fundamentados y orientados. Muchos países están usando datos de proximidad y geolocalización generados por smartphones para cartografiar la distribución geográfica y la evolución del coronavirus (Covid-19) y vigilar el cumplimiento de las medidas de confinamiento. Para aprovechar al máximo la transformación digital, es necesario un cambio dentro de la administración pública, que debe abandonar su concentración en la información para adoptar un planteamiento innovador, basado en datos, que incluya las tecnologías digitales y los datos en la formulación de políticas públicas desde el inicio.

\section{Estrategias de transformación digital en los planes nacionales de desarrollo y las agendas digitales}

La transformación digital abarca una serie de políticas públicas que deben incluirse en el marco de una acción coordinada, como los planes nacionales de desarrollo (PND), con una vinculación directa a las agendas digitales. Para conocer los ámbitos principales en los que se centran los planes nacionales de desarrollo de América Latina y el Caribe, se realizó un ejercicio de extracción de texto (text-mining) con el objetivo de determinar la frecuencia relativa con que aparecían en ellos seis temas sobre digitalización: 1) acceso y uso de las tecnologías digitales e Internet; 2) infraestructura de comunicación; 3) futuro del trabajo (es decir, cambios en materia de políticas relativas al mercado de trabajo debido a las nuevas tecnologías); 4) gobierno digital; 5) economía digital; e 6) integración regional. Surge una combinación de resultados cuantitativos y cualitativos (Gráfico 9).

El acceso a Internet y su uso, la infraestructura de comunicación y el futuro del trabajo son los temas con mayor representación en los planes nacionales de desarrollo 
de América Latina y el Caribe. Un número cada vez más elevado de planes reconoce el acceso a Internet como un servicio doméstico básico, junto con el suministro de agua, electricidad y teléfono. Con respecto al futuro del trabajo, los planes nacionales de desarrollo se centran más en mejorar las competencias que en fomentar nuevas y más flexibles condiciones laborales. La atención prestada al desarrollo de la economía digital sigue siendo escasa, ya que solo se identificó un reducido número de propuestas relativas a la promoción del comercio electrónico, la banca abierta o las empresas de tecnología financiera. La integración regional es importante para el grueso de países, pero la mayoría se centra en la integración energética, fronteriza y comercial. Pocos países contemplan la integración digital regional en sus planes nacionales de desarrollo como parte de su objetivo global de conseguir una economía competitiva e innovadora.

Gráfico 9. Intensidad de los temas vinculados a la digitalización en los planes nacionales de desarrollo, países seleccionados de América Latina y el Caribe, 2019

\begin{tabular}{|l|l|l|l|l|l|l|}
\hline & Acceso y uso & $\begin{array}{c}\text { Infraestructura de } \\
\text { comunicación }\end{array}$ & Futuro del trabajo & Gobierno digital & Economía digital & Integración regional \\
\hline Argentina & & & & & \\
\hline Bolivia & & & & & \\
\hline Brasil & & & & & & \\
\hline Chile & & & & & & \\
\hline Colombia & & & & & & \\
\hline Costa Rica & & & & & & \\
\hline República Dominicana & & & & & & \\
\hline Ecuador & & & & & & \\
\hline El Salvador & & & & & \\
\hline Guatemala & & & & & \\
\hline Honduras & & & & & & \\
\hline México & & & & & & \\
\hline Panamá & & & & & \\
\hline Paraguay & & & & & \\
\hline Perú & & & & & \\
\hline Uruguay
\end{tabular}

Nota: Tabla obtenida mediante la recopilación de palabras clave relativas a cada tema. La intensidad con que se aborda el tema se calculó a partir de la frecuencia relativa. Véase la metodología pormenorizada en el Anexo 4 .A1 del Capítulo 4.

Fuente: Elaboración propia a partir de los planes nacionales de desarrollo más recientes (fin de 2019).

StatLink 젶ㄴ https://doi.org/10.1787/888934202864

Las agendas digitales son otra herramienta clave de política pública para abordar y coordinar la transformación digital a largo plazo. La mayoría de países de América Latina y el Caribe han creado agendas digitales con diferentes características (Gráfico 10), que proponen programas transversales para alcanzar los objetivos en materia de políticas que implica la digitalización de la economía y la sociedad. Las agendas digitales abarcan una amplia serie de políticas, en las que participan no solo los ministerios de TIC sino también instituciones encargadas de las finanzas, la educación, la industria y las administraciones públicas.

La eLAC ha servido como espacio de cooperación entre agendas digitales regionales, donde los gobiernos intercambian experiencias y mejores prácticas y debaten una visión común para usar las tecnologías digitales como herramientas de desarrollo. Este foro ha fijado una serie de metas regionales que sirven para orientar el desarrollo de políticas nacionales. Las agendas digitales de Argentina, Brasil, Colombia, Costa Rica, República Dominicana, Honduras, México, Panamá y Perú establecen de forma explícita la articulación de objetivos de políticas nacionales en consonancia con los recogidos en la eLAC2020. 
Gráfico 10. Características institucionales de las agendas digitales nacionales, países seleccionados de América Latina y el Caribe, 2020

\begin{tabular}{|c|c|c|c|c|c|c|c|}
\hline & $\begin{array}{c}\text { Ministerio de TIC } \\
\text { especializado }\end{array}$ & \begin{tabular}{|c|} 
Objetivos \\
explícitos en la \\
agenda digital
\end{tabular} & $\begin{array}{c}\text { Consulta pública } \\
\text { para la elaboración } \\
\text { de la agenda digital }\end{array}$ & $\begin{array}{l}\text { Comisión o comité de } \\
\text { coordinación } \\
\text { intergubernamental para la } \\
\text { agenda digital }\end{array}$ & $\begin{array}{c}\text { Coordinación de } \\
\text { los numerosos } \\
\text { grupos de interés } \\
\text { para el } \\
\text { seguimiento }\end{array}$ & $\begin{array}{c}\text { Metas } 0 \\
\text { indicadores para } \\
\text { el seguimiento de } \\
\text { la agenda digital }\end{array}$ & $\begin{array}{l}\text { Presupuesto } \\
\text { explícito en la } \\
\text { agenda digital }\end{array}$ \\
\hline \multicolumn{8}{|l|}{ Argentina } \\
\hline \multicolumn{8}{|c|}{ Bolivia } \\
\hline \multicolumn{8}{|l|}{ Brasil } \\
\hline \multicolumn{8}{|l|}{ Chile } \\
\hline \multicolumn{8}{|c|}{ Colombia } \\
\hline \multicolumn{8}{|c|}{ Costa Rica } \\
\hline \multicolumn{8}{|c|}{$\begin{array}{l}\text { República } \\
\text { Dominicana }\end{array}$} \\
\hline \multicolumn{8}{|c|}{ Ecuador } \\
\hline \multicolumn{8}{|l|}{ Honduras } \\
\hline \multicolumn{8}{|c|}{ México } \\
\hline \multicolumn{8}{|l|}{ Panamá } \\
\hline \multicolumn{8}{|c|}{ Paraguay } \\
\hline \multicolumn{8}{|l|}{ Perú } \\
\hline Uruguay & & & & & & & \\
\hline
\end{tabular}

Nota: La intensidad del color indica la intensidad con la que la agenda digital incluye cada característica específica en su configuración institucional.

Fuente: Elaboración propia a partir de las agendas digitales nacionales más recientes (enero de 2020).

StatLink ailst https://doi.org/10.1787/888934202902

\section{Nuevas alianzas internacionales pueden fomentar el desarrollo en la era digital}

Puesto que la digitalización brinda oportunidades y también plantea retos que trascienden fronteras, la cooperación, la coordinación y la formación de nuevas alianzas conforman una dimensión esencial para aprovechar al máximo la transformación digital en el plano local, nacional e internacional.

El informe LEO 2019 estudió y presentó los beneficios de una cooperación internacional reforzada que facilite el desarrollo sostenible. La cooperación en la transformación digital de América Latina y el Caribe, en especial a la luz de la enorme repercusión transversal de las herramientas digitales, podría ayudar a los países a avanzar en su desarrollo y sortear las trampas existentes en este sentido.

La crisis del coronavirus (Covid-19) ha acentuado la importancia de la cooperación internacional y las herramientas digitales. Resulta esencial coordinar políticas en el plano internacional que promuevan una digitalización para todos. Los modelos tradicionales de cooperación internacional no han cumplido las expectativas. Por tanto, un nuevo modelo podría favorecer las estrategias de desarrollo de los países de América Latina y el Caribe. En el sector digital, ya existen ejemplos que indican cuál ha de ser el camino a seguir.

La cooperación internacional puede ayudar a los países de América Latina y el Caribe a crear capacidades digitales nacionales para hacer frente a sus trampas del desarrollo, que suelen estar interrelacionadas. Las iniciativas más eficaces siguen un planteamiento de desarrollo multidimensional, puesto que abordan varios desafíos a la vez. El Programa BELLA y la cooperación científica y tecnológica entre la Unión Europea y Brasil no solo generan capacidades de inclusión social o productivas en América Latina y el Caribe a través de herramientas digitales, sino que además permiten a los países cerrar la brecha entre sus prioridades y las cuestiones internacionales (BELLA, 2019). Iniciativas de 
cooperación triangular, como el Centro de Tecnologías Ambientales de Perú, muestran cómo pueden ayudar las nuevas herramientas a crear capacidades que permitan superar obstáculos en materia de desarrollo (GIZ, 2014).

La integración regional también puede ayudar a materializar el potencial digital de América Latina y el Caribe. Un mercado digital regional podría acelerar el desarrollo, ayudando a los países a mejorar la infraestructura de telecomunicaciones y expandir el comercio, gravemente afectado por la pandemia. No suele haber una armonización de los marcos regulatorios digitales de América Latina y el Caribe, ni de las experiencias en materia de cooperación regional y subregional. Iniciativas de cooperación regional, como la Agenda Digital para América Latina y el Caribe de la CEPAL de 2020 (eLAC2020), podrían resultar útiles para que diferentes grupos de interés y países formulen marcos y niveles de desarrollo digital, intercambien experiencias e inicien diálogos en materia de políticas (CEPAL, 2018). Además de impulsar el desarrollo digital de América Latina y el Caribe, este tipo de iniciativas podrían potenciar la coordinación de las estrategias nacionales con las normas internacionales y promover la participación de la región en plataformas internacionales en pie de igualdad. Resulta fundamental tener en cuenta ejemplos de otras regiones y alianzas interregionales. La estrategia digital de la Unión Europea constituye un ejemplo útil y concreto de cómo crear una plataforma regional integrada y formular una regulación común en materia de innovaciones tecnológicas, que la posiciona al mismo tiempo como un socio clave para la cooperación y refuerza su posición en el sistema multilateral (Comisión Europea, 2019).

La cooperación internacional es esencial para superar los desafíos que trascienden las fronteras, tales como las cuestiones impositivas provocadas por la digitalización de la economía. En igualdad de condiciones, los países de América Latina y el Caribe deberían beneficiarse en gran medida de una mayor cooperación con otras economías. La región de América Latina y el Caribe también tiene un importante papel que desempeñar en el logro de soluciones de consenso mediante una cooperación multilateral eficaz.

\section{Referencias}

Basto-Aguirre, N., S. Nieto-Parra y J. Vázquez-Zamora (2020), "Informality in Latin America in the post COVID-19 era: Towards a more formal 'new normal'?" (blog), Vox Lacea, Bogotá, www.lacea.org/vox/? q=blog/informality latam postcovid19.

BELLA (2019), "BELLA - Building the Europe Link with Latin America" (página web), Consorcio BELLA, Cambridge, http://www.bella-programme.eu/.

BID/OEA (2020), Ciberseguridad: ¿Estamos preparados en América Latina y el Caribe?, Banco Interamericano de Desarrollo y Organización de Estados Americanos, Washington, DC.

Buenadicha Sánchez, C. et al. (2019), La gestión ética de los datos, Banco Interamericano de Desarrollo, Washington, DC, http://dx.doi.org/10.18235/0001623.

CAF (2020a), "Perspectivas económicas para el segundo trimestre", documentos internos, Banco de Desarrollo de América Latina, CAF, Caracas.

CAF (2020b), "El estado de la digitalización de América Latina frente a la pandemia del COVID-19", https://scioteca.caf.com/bitstream/handle/123456789/1540/El_estado_de_la_digitalizacion_de_ America Latina frente a la pandemia del COVID-19.pdf? sequence=1.

CAF (2017), Hacia la transformación digital de América Latina y el Caribe: Observatorio del Ecosistema Digital CAF, Banco de Desarrollo de América Latina, Caracas, https://www.caf.com/app_tic/\#es/ home.

CAF et al. (2020), Las oportunidades de la digitalización en América Latina frente al COVID-19, CAF 2020, ONU CEPAL 2020, https://repositorio.cepal.org/bitstream/handle/11362/45360/4/ OportDigitalizaCovid-19_es.pdf.

CEPAL (2020a), Enfrentar los efectos cada vez mayores del COVID-19 para una reactivación con igualdad: nuevas proyecciones, https://www.cepal.org/en/publications/45784-addressing-growing-impactcovid-19-view-reactivation-equality-new-projections. 
CEPAL (2020b), "Sectores y empresas frente al COVID-19: emergencia y reactivación", Informe especial: COVID-19, n. ${ }^{\circ}$ 4, Comisión Económica para América Latina y el Caribe, Santiago, https://repositorio.cepal.org/bitstream/handle/11362/45736/5/S2000437_en.pdf.

CEPAL (2019), Observatorio Regional de Banda Ancha (base de datos), Comisión Económica para América Latina y el Caribe, Santiago, www.cepal.org/es/observatorio-regional-de-banda-ancha (consultada el 12 de septiembre de 2019).

CEPAL (2018), Agenda Digital para América Latina y el Caribe (eLAC2020), Sexta Conferencia Ministerial sobre la Sociedad de la Información de América Latina y el Caribe, Comisión Económica para América Latina y el Caribe, Cartagena de Indias, https://conferenciaelac.cepal.org/6/sites/ elac2020/files/cmsi.6_digital_agenda-en-23_april.pdf.

CEPAL (2016), Ciencia, tecnología e innovación en la economía digital: la situación de América Latina y el Caribe, Segunda sesión de la Conferencia de Ciencia, Innovación y Tecnologías de la Información y las Comunicaciones de la CEPAL, Naciones Unidas, Santiago, www.cepal.org/ en/publications/40840-science-technology-and-innovation-digital-economy-state-art-latinamerica-and.

CEPAL (2012), Cambio estructural para la igualdad: Una visión integrada del desarrollo, Trigésimo cuarto período de sesiones de la CEPAL, San Salvador, 27-31 de agosto de 2012, https://repositorio.cepal. org/bitstream/handle/11362/3078/1/S2012062_es.pdf.

Comisión Europea (2019), "Configurar el futuro digital de Europa” (página web), Comisión Europea, Bruselas, https://ec.europa.eu/info/strategy/priorities-2019-2024/europe-fit-digital-age/shapingeurope-digital-future_en.

Conference Board (2020), Total Economy Database (base de datos), www.conference-board.org/data/ economydatabase.

Gallup (2019), Gallup World Poll (base de datos), Gallup Inc., Washington, DC, www.gallup.com/ analytics/232838/world-poll.aspx.

GIZ (2014), “Cooperación triangular entre Brasil, Perú y Alemania: Creación de un Centro de Tecnologías Ambientales (CTA) en el Perú" (página web), Deutsche Gesellschaft für Internationale Zusammenarbeit (GIZ), Berlín, www.giz.de/en/worldwide/11836.html.

Latinobarómetro (2018), encuesta Latinobarómetro (base de datos), Latinobarómetro, Providencia, www.latinobarometro.org/lat.jsp.

Latinobarómetro (2017), encuesta Latinobarómetro (base de datos), Latinobarómetro, Providencia, www.latinobarometro.org/lat.jsp.

Nedelkoska, L. y G. Quintini (2018), “Automation, skills use and training”, OECD Social, Employment and Migration Working Papers, n. ${ }^{\circ}$ 202, Publicaciones de la OCDE, París, https://doi.org/10.1787/ 2e2f4eea-en.

OCDE (2020), OECD Secretary-General Tax Report to G20 Finance Ministers and Central Bank Governors - Julio de 2020, Publicaciones de la OCDE, París, www.oecd.org/tax/oecd-secretary-general-taxreport-g20-finance-ministers-july-2020.pdf.

OCDE (2019a), Going Digital: Shaping Policies, Improving Lives, Publicaciones de la OCDE, https://doi. org/10.1787/9789264312012-en.

OCDE (2019b), Perfilando la transformación digital en América Latina: Mayor productividad para una vida mejor, Publicaciones de la OCDE, París, https://doi.org/10.1787/8bb3c9f1-en. Presentado en la Tercera Cumbre Ministerial sobre Productividad del Programa Regional para América Latina y el Caribe, Bogotá-Colombia, 25 de octubre de 2019.

OCDE (2019c), Perspectivas de empleo de la OCDE 2019: El futuro del trabajo, Publicaciones de la OCDE, París, https://doi.org/10.1787/9ee00155-en.

OCDE (2019d), Artificial Intelligence in Society, Publicaciones de la OCDE, París, https://doi.org/10.1787/ eedfee77-en.

OCDE (2019e), How's Life in the Digital Age?: Opportunities and Risks of the Digital Transformation for People's Well-being, Publicaciones de la OCDE, París, https://doi.org/10.1787/9789264311800-en.

OCDE (2018a), Good Jobs for All in a Changing World of Work: The OECD Jobs Strategy, Publicaciones de la OCDE, París, https://doi.org/10.1787/9789264308817-en.

OCDE (2018b), Base de datos de PISA 2018 (base de datos), www.oecd.org/pisa/data/2018database/.

OCDE (2017a), Going Digital: Making the Transformation Work for Growth and Well-Being, Reunión del Consejo de la OCDE a nivel ministerial, 7-9 junio de 2017, Publicaciones de la OCDE, París, www. oecd.org/mcm/documents/C-MIN-2017-4\%20EN.pdf.

OCDE (2017b), Perspectivas de la OCDE sobre la Economía Digital 2017, Publicaciones de la OCDE, París, http://dx.doi.org/10.1787/9789264276284-en. 
OCDE (2015), Digital Security Risk Management for Economic and Social Prosperity: OECD Recommendation and Companion Document, Publicaciones de la OCDE, París, https://doi.org/10.1787/9789264245471en.

OCDE (2014), "Recommendation of the Council on Digital Government Strategies", Publicaciones de la OCDE, París, www.oecd.org/gov/digital-government/Recommendation-digital-governmentstrategies.pdf.

OCDE et al. (2019), Perspectivas económicas de América Latina 2019: Desarrollo en transición, Publicaciones de la OCDE, París, https://doi.org/10.1787/g2g9ff18-en.

ONU (2019), base de datos e-Government Knowledge de Naciones Unidas (base de datos), Departamento de Asuntos Económicos y Sociales de Naciones Unidas, Nueva York, https://publicadministration. un.org/egovkb/en-us/Data-Center.

ORBA/CEPAL (2019), Banco de Datos de Encuestas de Hogares (base de datos), Comisión Económica para América Latina y el Caribe, de las Naciones Unidas, Santiago, www.cepal.org/es/observatorioregional-de-banda-ancha.

Pring, C. y J. Vrushi (2019), Global Corruption Barometer, Latin America and the Caribbean 2019: Citizens' Views and Experiences of Corruption, Transparency International, Berlín, www.transparency.org/ gcb10/latin-america-and-the-caribbean?/news/feature/global corruption barometer gcb latin america_2019\#full-report.

Roseth, B., A. Reyes y C. Santiso (2018), El fin del trámite eterno: Ciudadanos, burocracia y gobierno digital (resumen ejecutivo), Banco Interamericano de Desarrollo, Washington, DC, https://publications. iadb.org/en/wait-no-more-citizens-red-tape-and-digital-government-executive-summary.

Santiso, C. (2018), "El 'big data' al asalto de la corrupción”, BID Gobernarte (blog), Banco Interamericano de Desarrollo, Washington, DC, https://blogs.iadb.org/administracion-publica/ es/el-big-data-al-asalto-de-la-corrupcion/.

UIT (2020), Base de datos de indicadores mundiales de telecomunicaciones y TIC 2020 (base de datos), Unión Internacional de Telecomunicaciones, Ginebra, https://www.itu.int/en/ITU-D/Statistics/ Pages/publications/wtid.aspx (consultada el 21 de agosto de 2020). 



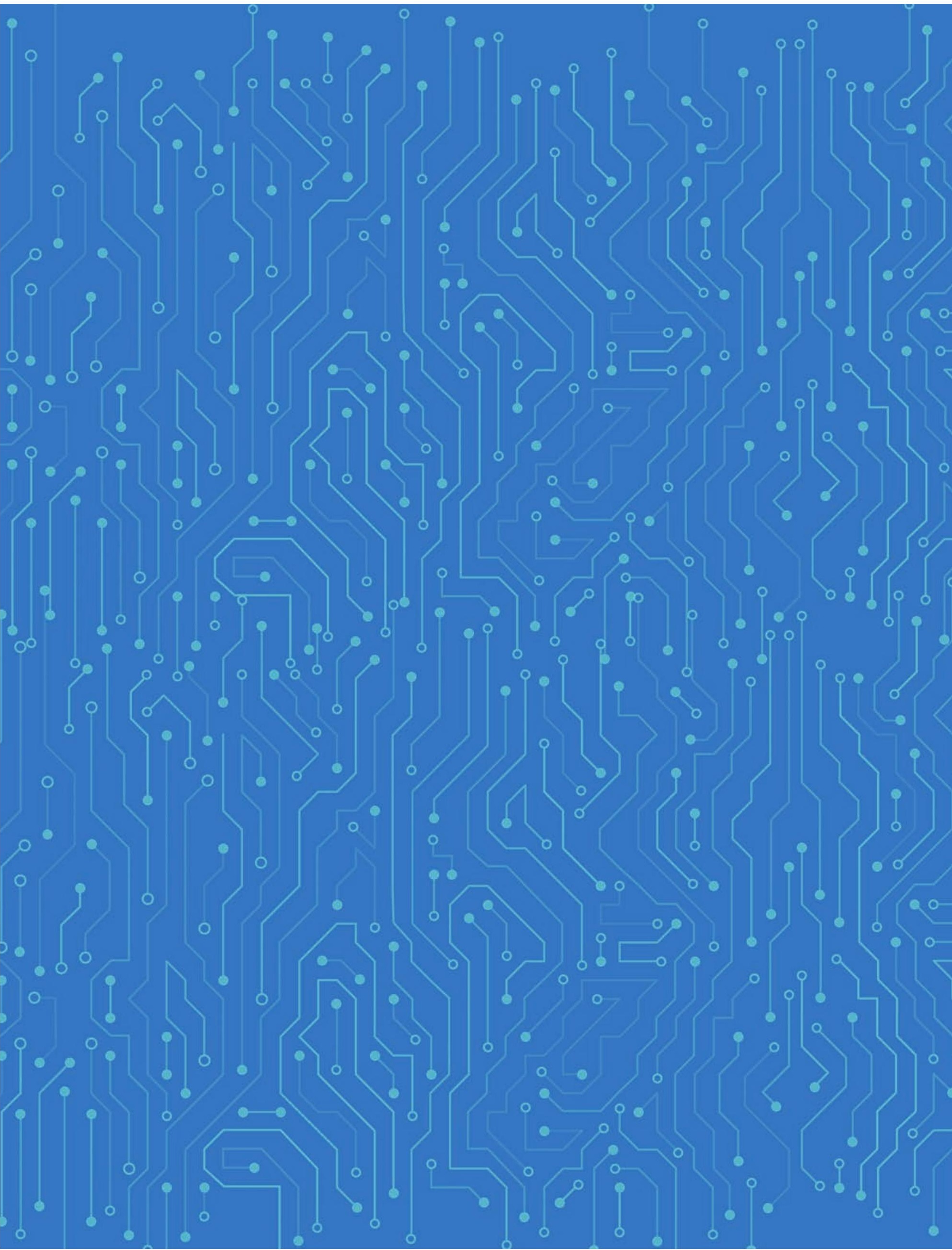




\section{Capítulo 1}

\section{Macroperspectiva estructural y el rol de la transformación digital para superar los desafíos en materia de desarrollo}

La crisis del coronavirus (Covid-19) ha tenido un impacto excepcional, inesperado y exógeno en América Latina y el Caribe, donde la mayoría de los países ya padecían un crecimiento casi nulo. La región se enfrenta a esta crisis con claros desafíos estructurales, como la vulnerabilidad de la clase media, desigualdades permanentes, atrasos en materia de productividad y un espacio fiscal reducido limitando el margen fiscal. Los persistentes obstáculos estructurales reducen las posibilidades de lograr una rápida recuperación. En la región más desigual del mundo, la disminución de la desigualdad en algunos países se ha estancado, y se prevé un aumento de la pobreza y la indigencia debido a la pandemia. Ante tal coyuntura, se han introducido medidas innovadoras y efectivas para contener los daños aunque, para conseguir una recuperación sostenible, serán necesarios más esfuerzos a escala tanto nacional como internacional. Las ventajas que ofrece la transformación digital han quedado patentes durante la crisis, pero solo para algunas empresas y ciudadanos. Si se resuelven adecuadamente las carencias en materia de cobertura, acceso y uso, la transformación digital desempeñará un papel esencial en la recuperación económica, además de ofrecer la posibilidad de superar desafíos persistentes y estimular un desarrollo más sostenible e inclusivo. 


\section{ALC enfrenta la crisis de Covid-19 con un bajo crecimiento de productividad, una clase media vulnerable, un aumento de la pobreza y desigualdades persistentes}

Las consecuencias sociales de la crisis no son iguales para todos y afectan principalmente a los grupos más vulnerables
En 2020, es probable que la pobreza extrema aumente en 4.5 puntos porcentuales, lo que significa un aumento de

\section{5 millones de} latinoamericanos

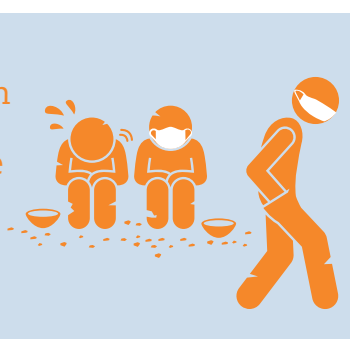

Llegando a un total de

96.2 millones de personas en condición de pobreza extrema

El lento crecimiento de los últimos años y la fuerte caída de las proyecciones de crecimiento del PIB limitan la posibilidad de una rápida recuperación

ALC enfrenta una crisis económica sin precedentes

Crecimiento promedio del PIB en ALC

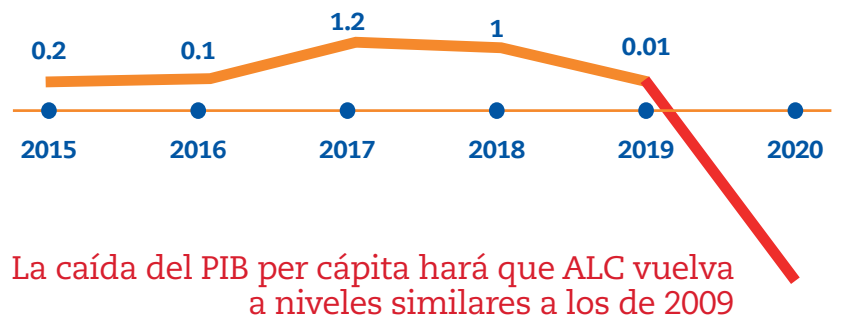
a niveles similares a los de 2009

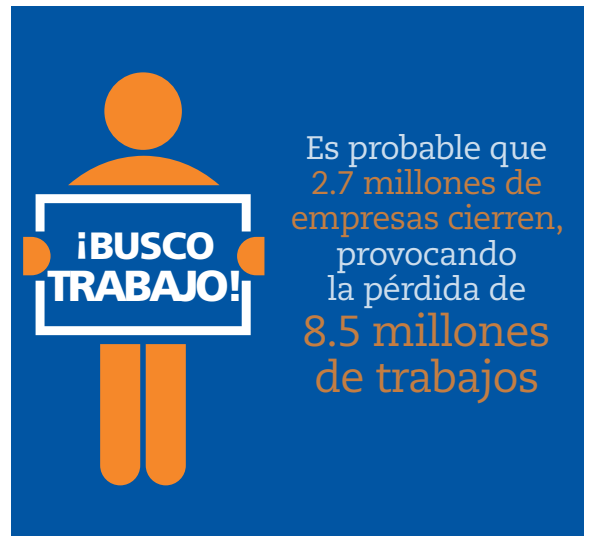

La crisis del Covid-19 está acentuando las trampas del desarrollo estructural que impiden un crecimiento más inclusivo y sostenible

La transformación digital puede ayudar a evitar estas trampas: mejorar la productividad, promover la inclusión, fortalecer las instituciones y trazar un camino de desarrollo sostenible.

\section{La} transformación digital es una tendencia clave a nivel mundial 


\section{Introducción}

La región de América Latina y el Caribe (ALC) atraviesa tiempos difíciles, de calado histórico, ya que el mundo se enfrenta a la peor recesión del siglo en tiempos de paz (OCDE, 2020a; FMI, 2020). La pandemia no solo ha costado la vida a una gran cantidad de latinoamericanos, sino que ha incidido de forma considerable en las condiciones socioeconómicas de la región, con medidas de confinamiento en el hogar para contener la propagación del virus que provocaron una caída inmediata de la actividad económica, añadidas a un contexto externo desfavorable, caracterizado por fuertes descensos de la demanda mundial, el comercio internacional, el turismo, el precio de los productos básicos y un repunte de la volatilidad financiera. Con una caída del crecimiento económico entre el 7\% y 9\% prevista para 2020 (CEPAL, 2020a; CAF, 2020a), ALC es la región de los mercados emergentes y las economías en desarrollo que registrará la mayor contracción (FMI, 2020). ALC entró en la crisis tras una oleada de protestas en algunos países, auspiciadas por un profundo descontento social. Esto se debió en parte a un mal desempeño económico, que dificultó avances en el progreso social. Entre 2014 y 2019, esta región experimentó el periodo expansivo más precario que se ha registrado desde 1950, con tasas de crecimiento inferiores al promedio de la Organización para la Cooperación y el Desarrollo Económicos (OCDE) y sin mostrar prácticamente expansión económica alguna en 2019. Estos datos indican que el potencial de crecimiento ya era limitado en gran parte de los países de América Latina y el Caribe.

La mayoría de los países de esta región ha respondido a las consecuencias socioeconómicos provocados por la crisis del coronavirus (Covid-19) con medidas monetarias y fiscales de apoyo desde el inicio de los confinamientos. La política fiscal reviste una importancia crucial para mitigar los efectos económicos y sociales negativos, y seguirá desempeñando un papel decisivo en la recuperación. La capacidad de los países para reaccionar a la pandemia con medidas de política fiscal dependerá de su margen fiscal y del acceso del que dispongan a los mercados internacionales. Las actuaciones encaminadas a mitigar los efectos de la pandemia se han concentrado principalmente en aplicar medidas anticíclicas para apoyar a hogares y empresas vulnerables. Algunos bancos centrales han relajado las condiciones monetarias mediante rebajas de las tasas de interés y la adopción de medidas de liquidez, incluso medidas monetarias no habituales, con la finalidad de impulsar la demanda interna y estimular la actividad empresarial. Las autoridades de control también flexibilizaron la regulación prudencial para que los requisitos regulatorios vinculantes no obstaculizaran la concesión de créditos en el contexto de la crisis.

Debido al marcado descenso del crecimiento económico, las perspectivas de progreso socioeconómico han empeorado, al haberse estancando la disminución de la pobreza y la desigualdad, con algunos países que incluso podrían registrar retrocesos en ese sentido en 2020. En el caso de que el PIB se contraiga un 9\% en 2020, la pobreza en América Latina y el Caribe podría aumentar 6 puntos porcentuales (en 45.4 millones de personas), respecto al año anterior, de modo que afectaría a un total de 230.9 millones de personas (un $37.3 \%$ de la población de ALC). La pobreza extrema podría aumentar 4.5 puntos porcentuales (en 28.5 millones de personas), de manera que afectaría a un total de 96.2 millones de personas (CEPAL, 2020a). Asimismo, tras un marcado descenso de la desigualdad durante la época de auge de las materias primas, desde 2014 esta permanece estancada, en una región que es la más desigual del mundo (OCDE et al., 2019). La desigualdad es una característica histórica y estructural de las sociedades de América Latina y el Caribe, que se ha venido manteniendo y repitiendo a lo largo de los años. Sin duda, esta característica constituye un obstáculo para la erradicación de la pobreza, la consecución de un desarrollo sostenible y la protección de los derechos de las personas, así como para alcanzar un modelo de desarrollo más sostenible. La crisis actual podría agravar la 
elevada y pertinaz desigualdad de la región. Son necesarias medidas urgentes en materia de políticas, en varios frentes, para erradicar las causas principales de este problema y abordar los factores que contribuyen al mismo (CEPAL, 2018a; OCDE et al., 2019).

El avance socioeconómico tras la crisis del coronavirus (Covid-19) también será endeble, ya que esta situación está agravando los desafíos estructurales de la región. El escaso potencial de crecimiento, el estancamiento de la productividad en niveles bajos, la vulnerabilidad de la clase media y las desigualdades persistentes son solo algunas muestras de las dificultades estructurales que obstaculizan un desarrollo más inclusivo y sostenible, así como la convergencia con economías más avanzadas. Las Perspectivas económicas de América Latina 2019 (LEO) identificaban cuatro trampas del desarrollo: la baja productividad, la vulnerabilidad social, la institucional y la ambiental (OCDE et al., 2019). Las protestas masivas que tuvieron lugar en 2019 en algunos países pusieron de manifiesto la urgencia de recuperar la confianza de los ciudadanos y reconstruir el pacto social.

La crisis actual puede constituir una oportunidad para conseguir un consenso entre la ciudadanía respecto a importantes reformas pendientes. Tales reformas han de tener en cuenta el modo en que la pandemia está agravando las trampas del desarrollo ya existentes (OCDE et al., 2019). Así pues, entre los elementos que deben considerarse están la necesidad de mejorar la calidad y la cobertura universal de los servicios de salud, y la protección social, reforzar los mecanismos previos de respuesta a crisis (por ejemplo, instrumentos automáticos de estabilización) y aplicar reformas fiscales tanto en materia de ingresos como de gastos, además de estrategias de desarrollo claras para impulsar la productividad, promover la formalización del empleo y reducir la dependencia de los combustibles fósiles, y la transición a un modelo de desarrollo con bajas emisiones de carbonos.

La transformación digital puede ser crucial para abordar la crisis sanitaria, mitigar sus consecuencias socioeconómicas y promover una recuperación que propicie un desarrollo más sostenible e inclusivo. El término 'transformación digital' alude a los efectos de la digitalización en la economía y la sociedad. La revolución digital comporta cambios que están promoviendo innovaciones en los modelos de negocio y consumo, transformando los sistemas de producción y las cadenas de valor, reorganizando sectores económicos, generando nuevas dinámicas en el mundo del trabajo, creando bienes y servicios inteligentes e introduciendo nuevas condiciones en el ámbito de la competitividad. Todos estos cambios inciden en la vida de los ciudadanos, en su forma de aprender, trabajar, consumir o interactuar, tanto entre ellos como con los organismos públicos. Esta revolución es resultado de la adopción combinada de tecnologías, por ejemplo redes de banda ancha, dispositivos inteligentes, computación en la nube, Internet de las Cosas, el blockchain, análisis de macrodatos, inteligencia artificial, robótica, la fabricación aditiva (impresión en 3D) y la realidad virtual y aumentada. La disponibilidad de dichas tecnologías propicia la aparición y aportación de nuevas soluciones en el plano económico, social, institucional y ambiental. Estos nuevos medios ya están ayudando a mitigar los efectos de la pandemia, ya sea permitiendo, en cierta medida, la continuidad empresarial, el teletrabajo y la educación desde el hogar, o realizando un seguimiento del cumplimiento de las cuarentenas por parte de los ciudadanos. No obstante, estas oportunidades no se materializan de forma automática. En muchos países de América Latina y el Caribe, la pobreza, las desigualdades y la precariedad, así como los mercados de trabajo informal, dificultan el acceso a estas soluciones digitales y, por ende, su uso.

El ritmo de cambio auspiciado por el carácter exponencial de los avances tecnológicos, la enorme utilidad de las tecnologías digitales en todos los sectores e industrias y su amplia capacidad para transformar de forma integral sistemas de producción, gestión y gobernanza brinda oportunidades, pero también añade complejidad e incertidumbre a la dinámica de desarrollo (CEPAL, 2018b; OCDE, 2019a, 2019b). 
Para garantizar que las políticas puedan sacar provecho de las ventajas que ofrece la transformación digital y, al mismo tiempo, superen los desafíos que se presentan, los responsables políticos de América Latina y el Caribe deben adoptar una actitud más proactiva respecto a la digitalización y reforzar su interacción con ciudadanos, empresas, sindicatos y académicos para adaptar las políticas al nuevo contexto en que vivimos. Los responsables de políticas deben construir un entorno propicio para la innovación y la adopción de tecnologías digitales (Andrews, Nicoletti y Timiliotis, 2018). El uso de nuevas tecnologías puede generar una polarización entre las empresas productivas y las menos productivas, concentrar el poder de mercado y obstaculizar la competencia y la entrada de nuevas empresas, cambiar la estructura del mercado de trabajo e incrementar potencialmente las desigualdades existentes, lo que agravaría la brecha digital en hogares, centros educativos y lugares de trabajo. Todas estas circunstancias, unidas a la precariedad laboral y las deficiencias de cobertura de los sistemas de protección social, pueden acentuar la vulnerabilidad de ciertos sectores sociales. Tales dificultades ya existían antes del surgimiento del Covid-19, pero la pandemia -y las medidas implantadas para contenerla- le han conferido un carácter más apremiante.

En este capítulo se presenta, en primer lugar, el contexto externo al que se enfrenta América Latina y el Caribe en la actual crisis del coronavirus (Covid-19). En segundo lugar, se señala el impacto económico en la región y las respuestas políticas necesarias en el plano nacional e internacional. En tercer lugar, se indica que la crisis afecta de manera asimétrica a ciudadanos y empresas, y se insiste en particular en que los más perjudicados son los grupos más vulnerables. El último apartado identifica la forma en que la transformación digital puede ayudar a superar los desafíos estructurales que encara esta región.

\section{Repercusión externa e interna de la crisis del Covid-19 en el desempeño económico}

\section{Un contexto internacional complicado}

Debido al coronavirus (Covid-19) y a las medidas de contención vinculadas a la crisis sanitaria, en 2020 la actividad económica se contrajo drásticamente en todo el mundo. La pandemia ha obligado a los gobiernos a centrar sus esfuerzos en las medidas de salud como principal ámbito de preocupación. El confinamiento y las medidas de aislamiento han provocado el cierre temporal y, en ocasiones, permanente de negocios, además de restricciones a la movilidad general y los desplazamientos, turbulencias en los mercados financieros, una erosión de la confianza y agudización de la incertidumbre, con el añadido de que la reducción de los ingresos por el aumento del desempleo mermó enormemente la demanda (OCDE, 2020a). En un entorno que cambia rápidamente, es difícil cuantificar la magnitud del impacto de las medidas en el crecimiento del producto interno bruto (PIB). No obstante, resulta obvio que supondrán fuertes contracciones históricas de la producción, el gasto de los hogares, la inversión empresarial y el comercio internacional. Según indican las últimas previsiones, el crecimiento anual del PIB de la economía mundial en 2020 se situará entre el -4.5\% y el -5.0\% (FMI 2020; OCDE, 2020a). Sin la implementación de políticas públicas rápidas y eficaces introducidas en todas las economías, la contracción de la producción habría sido sustancialmente mayor (OCDE, 2020a).

El brote del coronavirus (Covid-19) ha venido a agravar la compleja situación económica, financiera, comercial y tecnológica que se ha venido registrando en los últimos años. En 2019, se frenó el ritmo de crecimiento de economías tanto avanzadas como emergentes. El descenso de la demanda y el aumento de las tensiones comerciales debilitaron el comercio internacional, lo que acentuó la incertidumbre sobre las perspectivas económicas y minó la confianza empresarial y, por ende, la inversión. 
En 2020, la desaceleración de los flujos de comercio es cada vez mayor. El comercio mundial se derrumbó, disminuyendo en más del 15\% en la primera mitad de 2020 (OCDE, 2020a). Las medidas de confinamiento provocaron un desplome de la demanda y la alteración de las cadenas de valor mundiales. Los trastornos en la producción registrados en países que participan en las cadenas de valor mundiales serán un factor crucial en el deterioro del comercio de productos intermedios, que se verá agravado por un debilitamiento generalizado de la demanda de productos de inversión y consumo, a consecuencia del confinamiento y la crisis económica (CEPAL, 2020b).

A pesar de la heterogeneidad entre países, el crecimiento de Estados Unidos, Europa y la República Popular de China (en lo sucesivo, "China"), socios esenciales de América Latina y el Caribe, se verán afectados antes de repuntar en 2021. El brote del coronavirus (Covid-19) frenará la expansión económica de Estados Unidos y provocará un notable crecimiento económico negativo en 2020. El PIB de Estados Unidos se contrajo el 32.9\% en el primer trimestre, en términos anualizados (BEA, 2020). Si bien no existe certeza sobre cómo evolucionará la pandemia, se prevé que el PIB disminuya el -3.8\% este año, con un repunte del $4 \%$ en 2021. Las respuestas de carácter monetario y fiscal adoptadas de forma masiva han aliviado a hogares y empresas de Estados Unidos, pero será necesario un apoyo continuo, por medio de políticas, para impulsar la recuperación económica y evitar que las elevadas cifras de desempleo se prolonguen en el tiempo (OCDE, 2020a). Los confinamientos de las economías europeas también provocarán una importante recesión. La caída podría situarse cerca del $-7.9 \%$ en 2020 , con cifras de desempleo de dos dígitos y un fuerte aumento de la deuda pública. Se mantendrán políticas fiscales y monetarias propicias para impulsar una ulterior recuperación económica, que se calcula será de en torno al 5.1\% en 2021. En China, el PIB se desacelerará al 1.8\% en 2020. La pandemia provocó un aumento del ahorro preventivo y erosionó la confianza del consumidor. En 2021, se espera que la economía crezca un $8 \%$ anual (OCDE, 2020a).

\section{Volatilidad financiera en mercados emergentes}

Aunque la pandemia ha tenido un impacto excepcional, inesperado y exógeno en la economía mundial, los mercados internacionales de capital siguen gozando de abundante liquidez, lo cual diferencia esta crisis de otras crisis mundiales anteriores. Tras la súbita interrupción de la actividad en marzo de 2020 y salidas de capital de los mercados emergentes que marcaron máximos históricos (IIF, 2020), ha aumentado la liquidez mundial y también el atractivo de los mercados emergentes, gracias a la política monetaria expansiva de la Reserva Federal. Las entradas de capital netas han regresado a los mercados emergentes. En concreto, en abril de 2020 los mercados emergentes volvieron a registrar flujos de deuda pese a no haberse recuperado por completo todavía. En agosto de 2020, el conjunto de las economías emergentes acumulaban salidas de capital netas próximas a los 25000 millones de dólares. El grueso de dichos movimientos correspondió a China, mientras que el resto de economías emergentes registró entradas netas, aunque por debajo de los niveles acumulados durante el mismo periodo del año anterior (Gráfico 1.1).

Pese a la abundante liquidez internacional y las políticas expansivas registradas en el área de la OCDE para dar respuesta a la crisis, la incertidumbre provocada por la caída del comercio y el deterioro de las perspectivas económicas ha impulsado la volatilidad en los mercados financieros, con un aumento de la aversión al riesgo y un empeoramiento de las condiciones financieras internacionales. Estos factores provocaron un aumento de la demanda de activos seguros (por ejemplo, las tasas de rentabilidad de los títulos valores estadounidenses registraron mínimos históricos), un descenso de la demanda de activos financieros de América Latina y el Caribe y considerables depreciaciones de la divisa en algunos países (CEPAL, 2020c; OCDE, 2020b). 
Gráfico 1.1. Condiciones financieras, entradas de flujos de capital netas en los mercados emergentes (suma móvil 3 meses)

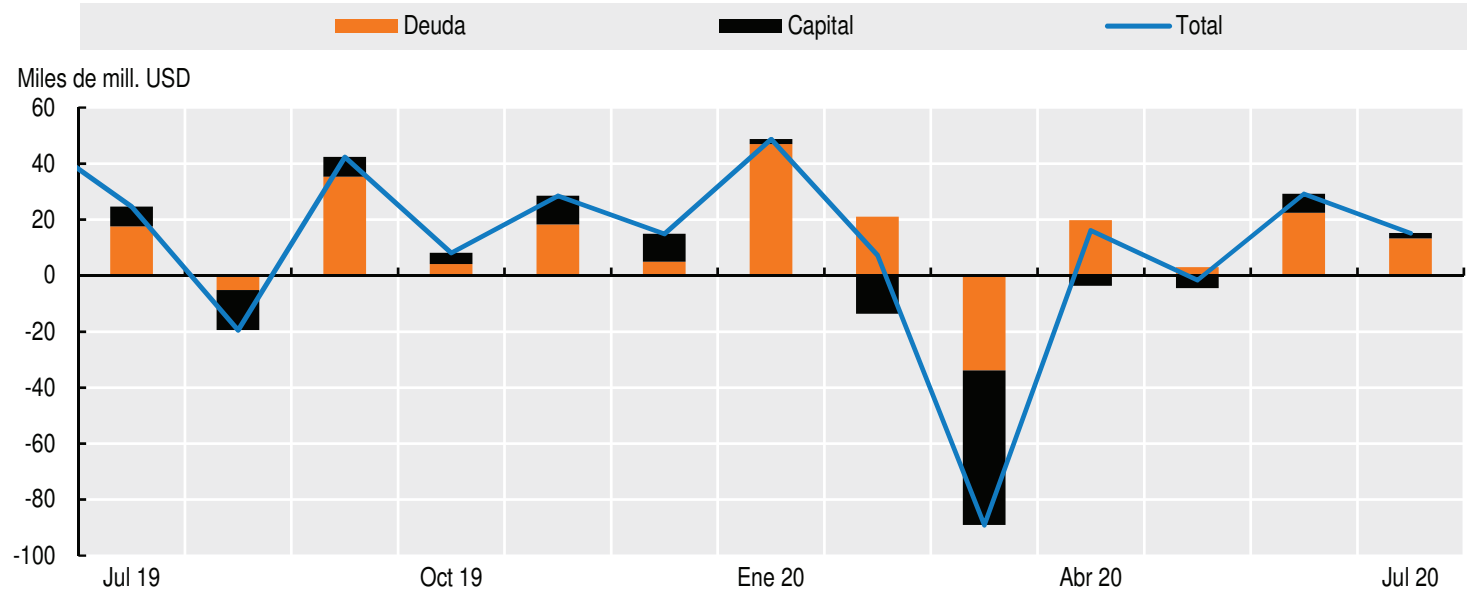

Fuentes: Basado en flujos de capital, IIF (agosto de 2020) y Bloomberg.

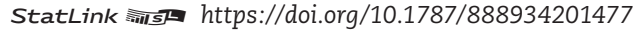

\section{Fuerte descenso de los precios de los productos básicos}

La crisis sanitaria provocó un fuerte descenso del precio de los productos básicos (Gráfico 1.2) que perjudica considerablemente los niveles de ingresos de varias economías de América Latina y el Caribe. La contracción de la demanda mundial, en particular la procedente de China, Europa y Estados Unidos, tiene una importancia crucial en la dinámica de precios de los productos básicos. Una crisis geopolítica del mercado del petróleo provocó una bajada de precios del $24 \%$ en menos de una semana, a principios de marzo de 2020 (CEPAL, 2020c), una situación que se vio agravada por las limitaciones físicas a la acumulación de inventario, en particular en Estados Unidos.

Gráfico 1.2. Precios de productos básicos, 2005-2020 (2005 = 100)

Panel A. Petróleo

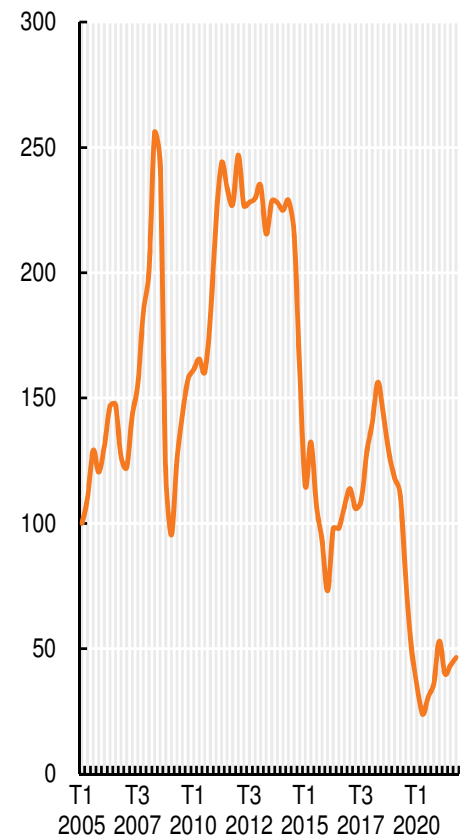

Panel B. Materias primas

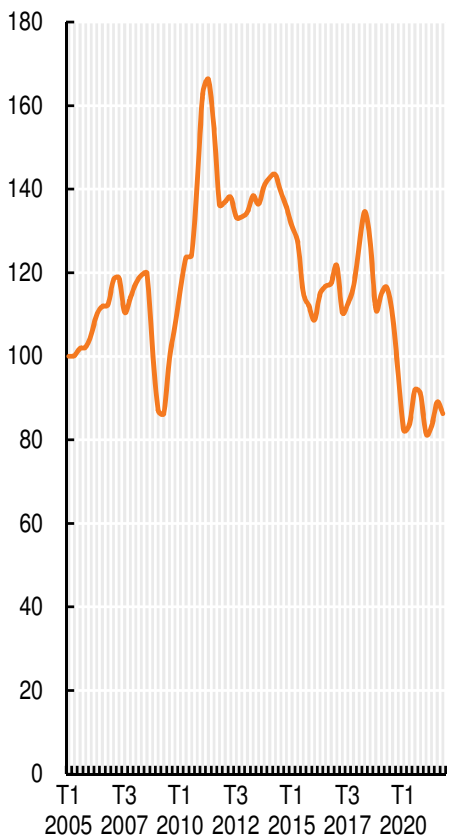

Panel C. Metales

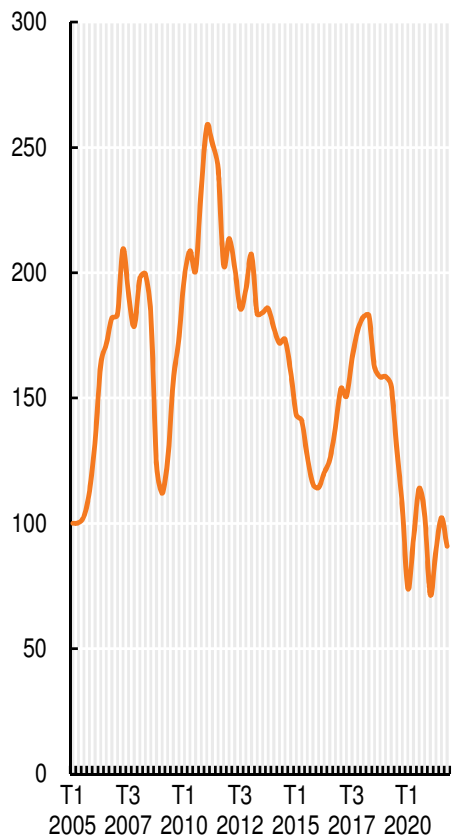

Fuente: Datos de Bloomberg. Cálculos propios a partir de un modelo GVAR. 
El precio de los metales comunes experimentó una notable caída en 2020 debido a la contracción de la producción industrial. En el caso de los productos agrícolas, también bajaron considerablemente los precios de la soja, el azúcar y el café (OCDE, 2020a). Según las previsiones, los precios se mantendrán en niveles relativamente bajos durante los próximos dos años.

\section{Desempeño decepcionante en América Latina y el Caribe}

La pandemia de coronavirus (Covid-19) tendrá consecuencias socioeconómicas de carácter general y permanente en América Latina y el Caribe, puesto que ha venido a agravar la compleja situación en la que ya se encontraba esta región. La recuperación de las economías latinoamericanas tras la recesión, entre 2015 y 2016, resultó muy endeble. Entre 2014 y 2019, ALC experimentó el periodo de crecimiento más precario que se ha registrado desde la década los años cincuenta, ya que de manera constante alcanzó tasas de crecimiento inferiores al promedio de la OCDE. En 2018, el aumento de la actividad se ralentizó y, en 2019, siguió desplomándose. Ese último año, debido a la heterogeneidad de esta región, la combinación de un entorno externo menos favorable y perturbaciones negativas idiosincráticas en varios países provocó un crecimiento promedio próximo al $0 \%$. La pandemia está provocando actualmente convulsiones tanto externas como internas que acentúan la vulnerabilidad y los desafíos estructurales pendientes de resolver de esta región.

La repercusión de esta crisis en la actividad económica y las condiciones sociales está siendo especialmente grave para ALC, debido a la ausencia de estabilizadores automáticos, como el seguro de desempleo, en la mayor parte de los países que la conforman (OCDE, 2020b). Puesto que la mayoría de las empresas financia sus inversiones principalmente con utilidades retenidas, la formación de capital bruto se ha visto inevitablemente perjudicada. Los efectos multiplicadores registrados en distintos sectores y en la economía en general serán importantes y se verán acentuados por la incertidumbre respecto a la duración de la pandemia. Varias organizaciones internacionales calculan que el crecimiento anual del PIB en 2020 se situará entre el -7\% y el -9\% en América Latina y el Caribe (CAF, 2020a; CEPAL, 2020a; FMI, 2020). Estos datos suponen un descenso histórico del crecimiento económico de la región (Gráfico 1.3, Panel A). La mayoría de los países de ALC registrará un crecimiento negativo en 2020 (CAF, 2020a; CEPAL, 2020a; OCDE, 2020a). La magnitud de la contracción económica variará considerablemente de unos países a otros y dependerá de varios factores, entre ellos, el alcance y la duración de los confinamientos, el calado y la eficacia de las medidas complementarias adoptadas, tanto dentro como fuera de la región, durante los periodos de confinamiento y después de estos, la composición sectorial de la economía, el grado de apertura a la economía mundial y el desempeño de la economía mundial tras la crisis (OCDE, 2020b).

En 2020, se estima que el PIB per cápita promedio de la región vuelva a situarse en los niveles de 2009 (Gráfico 1.3, Panel B). La confianza de los inversores y de los consumidores se mantendrá baja mientras no se controle la pandemia. Esta circunstancia no solo supondrá una obstáculo para la inversión y la demanda agregada a corto plazo, sino que limitará aún más el crecimiento potencial a mediano plazo, al reducir la acumulación de capital. Por otra parte, la lentitud en la recuperación del empleo podría engrosar los niveles de trabajo informal y de pobreza, y poner en riesgo la acumulación del capital humano (ver la siguiente sección sobre los efectos sociales de la crisis del coronavirus [Covid-19]). Por último, si no se introducen reformas que promuevan la formalización del empleo, fomenten la competencia y faciliten la reasignación de recursos, el aumento de la productividad se estancará. Los daños a la producción podrían adquirir un carácter permanente, lo que podría dar lugar a otra década perdida en cuanto a mejora de los ingresos per cápita. 


\section{Gráfico 1.3. Tasa de crecimiento anual del PIB y PIB per cápita de América Latina y el Caribe}

Panel A.

Crecimiento del PIB en América Latina

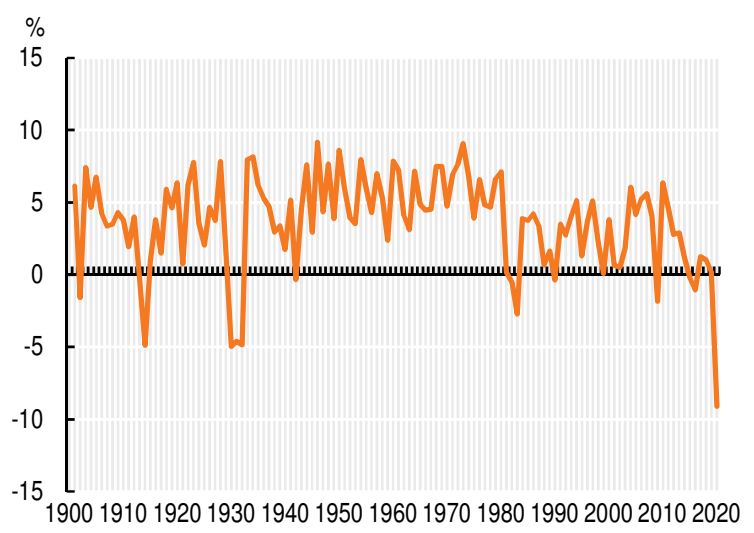

Panel B. PIB per cápita, precios constantes

2011 mil USD a precios internacionales

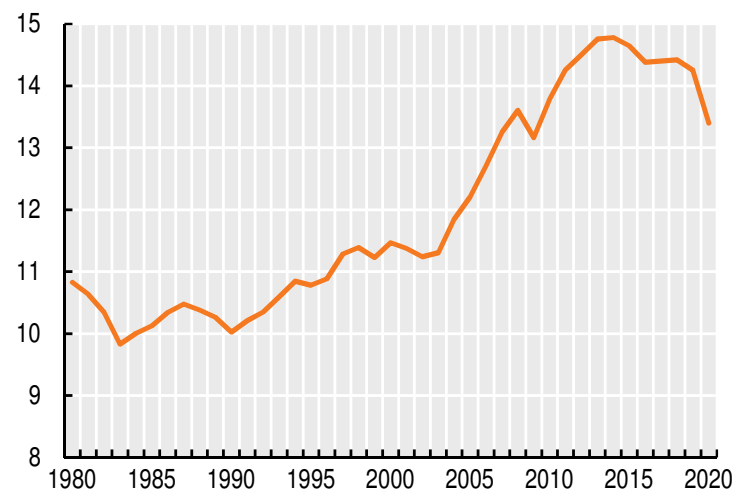

Fuente: Cálculos propios a partir de CEPAL (2020a), "Enfrentar los efectos cada vez mayores del COVID-19 para una reactivación con igualdad: Nuevas proyecciones", Informe especial COVID-19 n. ${ }^{\circ}$ 5; CAF (2020a), "Economic Perspective for the Second Quarter"; y FMI (2020), "Una crisis como ninguna otra, una recuperación incierta”, Actualización de las perspectivas de la economía mundial, junio.

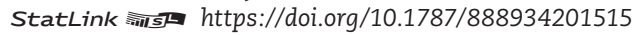

\section{El coronavirus (Covid-19) y sus canales de transmisión socioeconómicos}

Además de la repercusión directa que el coronavirus (Covid-19) tiene en la salud, en América Latina y el Caribe, su impacto socioeconómico se está propagando -y seguirá propagándose- - a través de una serie de canales de transmisión.

En primer lugar, las medidas de confinamiento producen una caída inmediata de la actividad económica de gran calado. Las medidas adoptadas en el ámbito de la salud comportan una ralentización significativa y, en algunos casos, una interrupción total de la producción y distribución de bienes y servicios. Al recomendar a los trabajadores que no vayan a trabajar, el consiguiente aumento del desempleo y descenso de las horas de trabajo, acompañado de una caída del gasto salarial y los ingresos, provoca una reducción de la demanda agregada de bienes y servicios, así como de los beneficios empresariales. La estructura de producción imperante, la envergadura del mercado de trabajo informal, las limitaciones en materia de infraestructura y las carencias en cuanto a competencias digitales reducen la proporción de trabajadores que podrían trabajar desde su hogar. Por ello, un importante porcentaje del PIB y del empleo de América Latina y el Caribe se ha visto afectado por las medidas de confinamiento ${ }^{1}$. Ante la contracción del consumo, la incertidumbre y el aumento de la deuda, las empresas también están reduciendo sus inversiones.

En segundo lugar, las medidas de contención, las restricciones al cruce de fronteras y la "ansiedad social" afectan a sectores clave, como el turismo y los viajes internacionales. La incidencia es especialmente elevada en países en los que el turismo constituye un importante motor económico, como es el caso de las economías caribeñas. En estos países, los servicios de turismo representaban el 13.9\% del PIB y el 15.2\% del empleo total en 2019 (ver el Capítulo 6), y podrían registrar un descenso próximo al 25\% (CEPAL, 2020c). En los primeros cuatro meses de 2020, las llegadas de turistas internacionales descendieron un $39 \%$ en el Caribe, un 35\% en América Central y un 35\% en América del Sur respecto al año anterior (CEPAL, 2020c). Otros sectores como el comercio minorista, el comercio mayorista y las industrias manufactureras también se están viendo gravemente afectados. 
En tercer lugar, la desaceleración mundial (OCDE, 2020a) y la alteración de las cadenas de valor globales y regionales generan un fuerte descenso de las exportaciones de ALC y podrían deteriorar la producción interna en los sectores más vulnerables a las perturbaciones de las cadenas globales de valor.

En cuarto lugar, la bajada de precios de los productos básicos, la ralentización económica y la respuesta fiscal afectan a los balances fiscal y comercial de los países de esta región.

En quinto lugar, el aumento de volatilidad de los mercados financieros genera gran incertidumbre sobre la deuda de América Latina y el Caribe, lo que afecta a la solvencia de grandes empresas que están en contacto con mercados de productos básicos o que carecen de otra forma de cobertura frente a las fluctuaciones monetarias. Parte de esta tendencia se ha invertido desde el mes de abril, tras la aplicación de políticas expansivas en los mercados desarrollados y una fuerte reducción de las tasas de interés. No obstante, el costo del crédito sigue siendo elevado para algunos países y empresas, debido a las primas de riesgo.

En contraste con estos efectos negativos, la adopción de tecnologías digitales y la expansión del uso de Internet han sido fundamentales para mantener una cierta continuidad de las actividades empresariales, el empleo o la educación desde el hogar, aunque la brecha digital (en especial la falta de acceso a Internet de banda ancha de alta velocidad y las carencias en materia de competencias digitales) ha impedido que tales beneficios lleguen a toda la población. Las tecnologías digitales revisten una importancia crucial en el contexto de la pandemia actual.

\section{Fuerte revés en las cuentas externas}

El marcado descenso de la actividad económica mundial y regional registrado en 2020 tendrá consecuencias en las cuentas externas de ALC. Los déficits en los saldos de cuenta corriente se redujeron ligeramente en 2019, después de la desaceleración del comercio internacional y la corrección de los precios de los productos básicos. Con pocas excepciones, los déficits de cuenta corriente se financiaron con inversión extranjera directa (IED) (Gráfico 1.5. Panel A).

El impacto global de la crisis en la cuenta externa dependerá del comportamiento combinado de varios componentes y de la elasticidad de los ingresos por exportaciones e importaciones (Recuadro 1.1). Pese a que la marcada reducción de las importaciones debería aliviar la balanza comercial, la contracción de la demanda mundial y los precios de los productos básicos podría perjudicar las economías de ALC con mayor orientación al exterior y dependientes de los ingresos por productos básicos. De igual manera, las economías con un gran peso del sector turístico, por ejemplo las del Caribe, deberían notar un efecto negativo en el componente de servicios de la balanza comercial. Las primeras previsiones indican que, en 2020, la caída de las importaciones será más importante que la de las exportaciones en esta región, lo que provocará una ligera mejora del saldo por cuenta corriente (CEPAL, 2020b). Si bien el balance de transferencias de la cuenta corriente se deteriorará, por el menor número de remesas, la cuenta de ingresos podría mejorar gracias a un descenso de la repatriación de beneficios. 


\section{Recuadro 1.1. Elasticidad de los ingresos por exportaciones e importaciones en América Latina y el Caribe}

Los países de América Latina y el Caribe tienen que cambiar sus modelos de inserción en la economía mundial para lograr mayores tasas de crecimiento del PIB sin sufrir desequilibrios externos. La relación entre las elasticidades de los ingresos por exportaciones e importaciones permite calcular el límite máximo de crecimiento con equilibrio externo. Por ejemplo, en el caso de América del Sur, la relación entre la elasticidad de los ingresos por exportaciones e importaciones se acerca al 0.8, lo cual implica que, si el PIB mundial aumentase hasta el $2 \%$ en los próximos años, América del Sur podría crecer un 1.4\% sin incurrir en un aumento de la deuda externa (Gráfico 1.4. Panel A) (Abeles y Cherkasky, 2020). El cociente de México es de 1.2, lo que establece un límite máximo de restricción externa del $2.2 \%$. Estos valores son mucho más bajos que los calculados para las economías asiáticas, próximos al $4 \%$, debido a que poseen un margen de crecimiento mucho más elevado sin alcanzar la restricción externa. Las elasticidades de las importaciones son similares entre las diferentes regiones, por lo que son las elasticidades de exportaciones mínimas las que definen el menor límite máximo de crecimiento con equilibrio externo en América Latina y el Caribe, con una tendencia al descenso de la elasticidad de los ingresos por exportaciones (Gráfico 1.4, Panel B).

Las exportaciones de esta región muestran una escasa diversificación y, por lo tanto, son mucho menos sensibles al aumento de la demanda mundial que otras regiones, que han registrado tasas de crecimiento del PIB mucho más elevadas y sostenidas durante varias décadas. Los países con un mayor contenido de exportaciones industriales y, en especial, aquellas que poseen un elevado contenido tecnológico, suelen presentar mayores elasticidades de las exportaciones que los países que exportan materias primas. Las elasticidades de las exportaciones han tendido a empeorar en los últimos años, a un ritmo superior al crecimiento del producto mundial. A excepción de Paraguay, en la última década, dada la coyuntura de ascenso de los precios de los productos básicos internacionales, las elasticidades de las exportaciones descendieron con respecto a la década anterior.

\section{Gráfico 1.4. Elasticidad de los ingresos por exportaciones e importaciones, regiones seleccionadas}

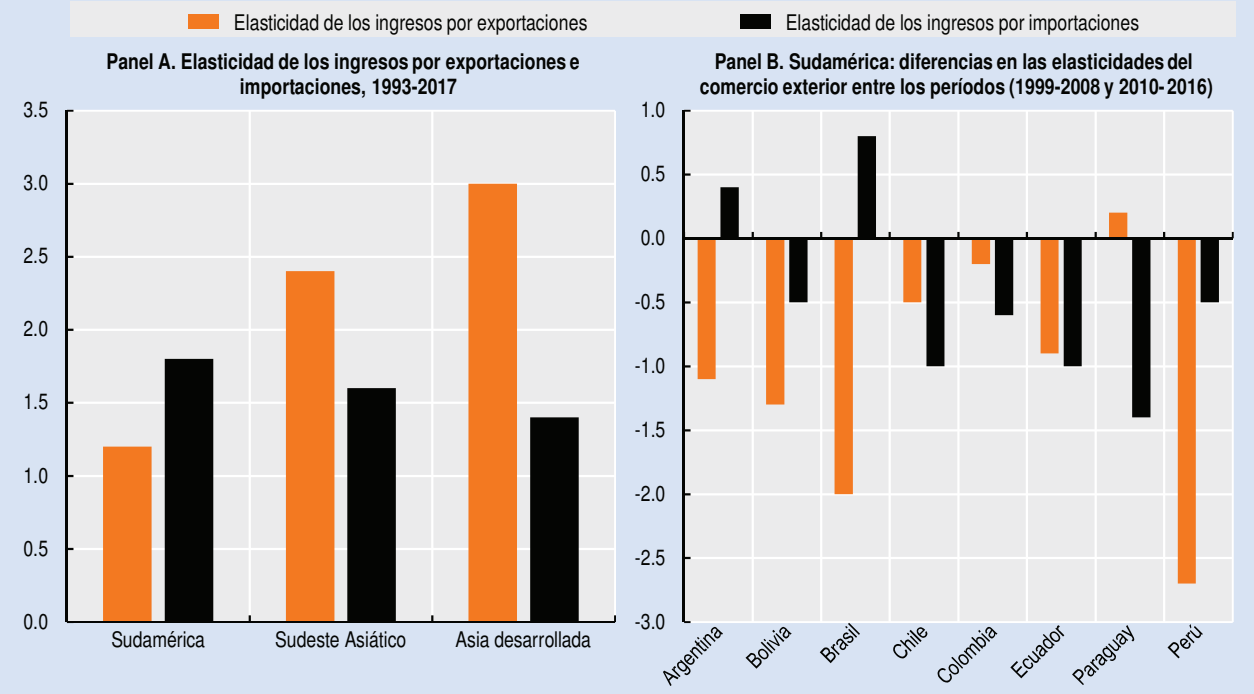

Fuente: Abeles y Cherkasky, (2020), "Revisiting Balance of Payments Constrained Growth 70 years after ECALC's Manifesto, the Case of South America", Revista de Economia Contemporânea, 24(1), y CEPALSTAT (base de datos), https://estadisticas.cepal.org/cepalstat/WEB_CEPALSTAT/estadisticasIndicadores.asp?idioma=i. StatLink न्ता stle https://doi.org/10.1787/888934201534 
La fuerte caída de la demanda mundial está afectando a los precios y a los volúmenes de las exportaciones, pues la bajada de precios de los productos básicos provoca un deterioro en las condiciones comerciales de muchos países de la región. El valor de las exportaciones de la región podría caer hasta un 23\%, con una bajada de precios del 11\% y un descenso de volumen del $12 \%$, debido básicamente a una mayor contracción de la demanda mundial (CEPAL, 2020b). En concreto, a principios de abril de 2020, los precios del petróleo habían bajado un $60 \%$ desde principios de año y los precios del cobre, el hierro, el azúcar y el café, por su parte, también registraron descensos notables. Si bien el desplome de los precios del petróleo puede suponer un alivio para las economías caribeñas y centroamericanas importadoras de crudo, también afecta a las cuentas fiscales y externas de varios países sudamericanos y otras economías de la región, como México y Trinidad y Tobago. La caída de los precios de los metales también está perjudicando a estos países. Así, Chile y Perú, por ejemplo, se están viendo afectados por el descenso de los precios del cobre.

\section{Gráfico 1.5. Cuentas externas y condiciones financieras, Países de ALC seleccionados}

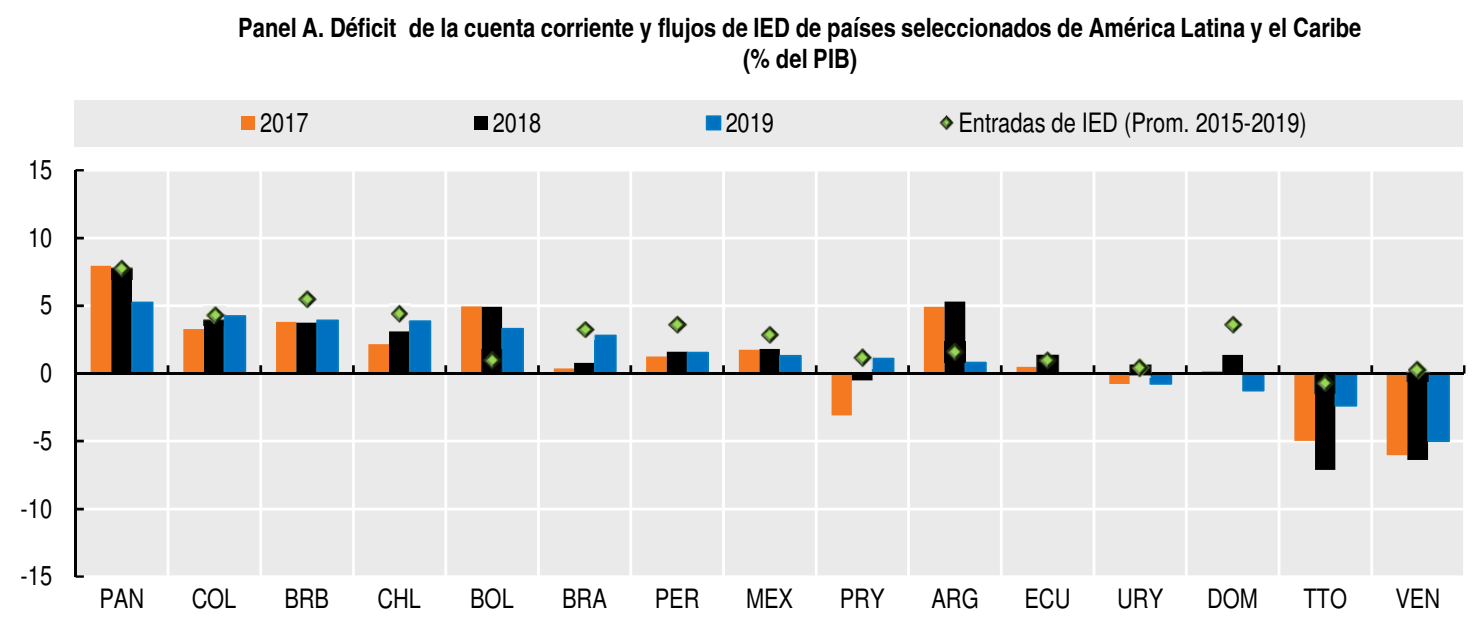

Panel B. Emerging Markets Bond Index (EMBI) del ALC e índice CBOE de volatilidad (VIX)

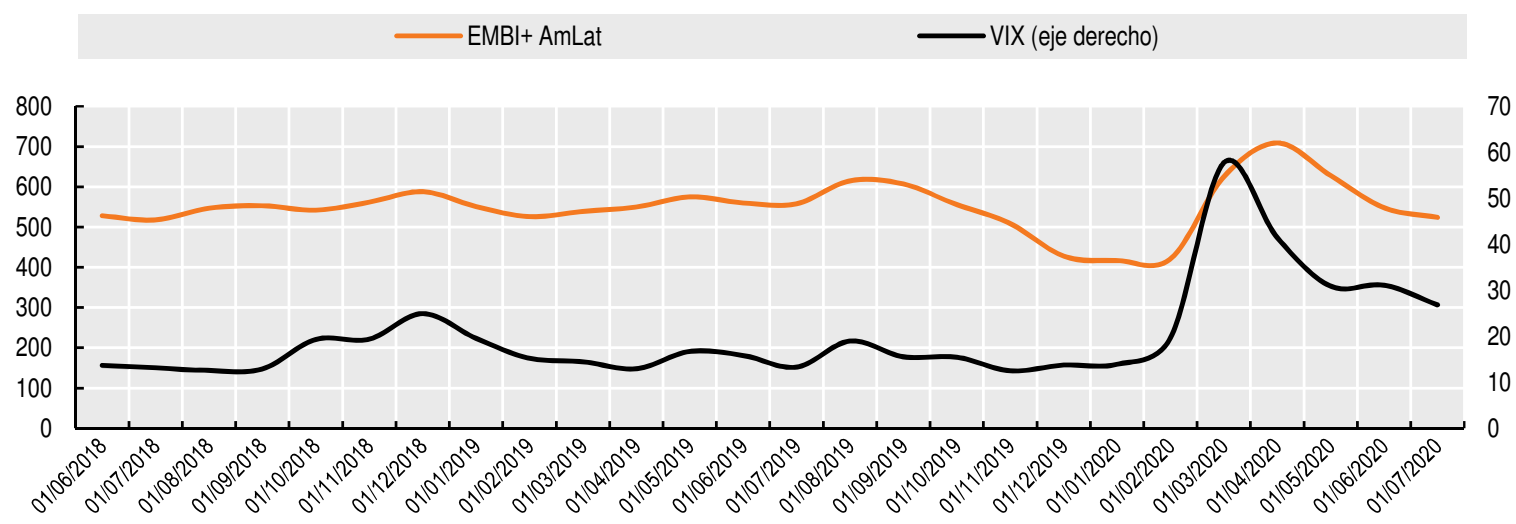

Fuentes: A partir de datos oficiales, FMI y Bloomberg.

StatLink त्नाता https://doi.org/10.1787/888934201553

La inversión extranjera directa se reducirá drásticamente, con lo que disminuirá la calidad del financiamiento del déficit por cuenta corriente y se restringirán las mejoras en la productividad. En el plano mundial, se prevé que la IED disminuya entre un 30\% y un $40 \%$. El descenso será mayor en las economías a las que la pandemia ha golpeado con más fuerza (UNCTAD, 2020). La fuerte caída de las remesas (Banco Mundial, 2020a) debilitará 
aún más los saldos por cuenta corriente y las consecuencias podrían ser más notables en América Central y México. Según algunos cálculos prudentes, las remesas procedentes de Estados Unidos descenderán como mínimo un 3\% en 2020 (Inter-American Dialogue, 2020). Esta cifra podría ser aún más baja debido a que las restricciones impuestas al cruce de fronteras detendrán bruscamente los flujos migratorios, como el traslado de temporales a Estados Unidos.

La desaceleración de la actividad económica en los principales socios comerciales de América Latina y el Caribe, sobre todo en China y Estados Unidos, es un factor importante que está afectando a las perspectivas de esta región. China se ha convertido en el principal socio comercial de muchas economías sudamericanas (OCDE/CAF/CEPAL, 2015). Este país no es solo un gran importador de materias primas sino también un inversionista directo y un proveedor de crédito para las economías de América Latina y el Caribe, principalmente Argentina, Brasil, Ecuador y Venezuela (Inter-American Dialogue, 2020). La contracción de Estados Unidos afectará sobre todo a México, América Central, Colombia y el Caribe.

Entre febrero y mayo de 2020, América Latina y el Caribe experimentó cuantiosas salidas de capitales (en particular de inversión de cartera), que sobrepasaron los niveles alcanzados en el periodo posterior a la crisis financiera de 2008 (BID 2020; IIF, 2020). Si bien los diferenciales del Emerging Markets Bond Index (EMBI) de ALC se mantienen por debajo de los registrados en la crisis financiera de 2008, sí se sitúan por encima de los observados en los últimos cinco años (Nieto-Parra y Orozco, 2020). La evolución del diferencial de bonos soberanos en algunos países de la región, en particular en los que atraviesan problemas de solvencia, ha guardado una gran correlación con las condiciones de volatilidad de los mercados internacionales. Por ejemplo, de forma similar a la expectativa de volatilidad de los mercados internacionales que mide el índice de volatilidad (VIX) de la Chicago Board Options Exchange (CBOE), el EMBI de América Latina y el Caribe experimentó subidas considerables en marzo de 2020 y posteriormente retrocedió (Gráfico 1.5, Panel B).

Desde abril de 2020, administraciones y empresas de esta región (por ejemplo, de Chile, Colombia, Guatemala, México, Paraguay, Perú y Uruguay) han podido emitir deuda en mercados internacionales a costos relativamente bajos, aunque persisten las variaciones entre los diferentes países, también entre aquellos que poseen la calificación de grado de inversión. Del mismo modo, en lo concerniente a los mercados de divisas, las depreciaciones han sido dispares, incluso entre dichos países. En comparación con los promedios observados entre 2015 y 2019, entre enero y mayo de 2020, la tasa de cambio promedio de Perú descendió un 4\%, en Colombia y México, cerca de un 15\% y, en Brasil, en torno a un $33 \%$. Las fuertes depreciaciones monetarias constituirán otro motivo de preocupación para las administraciones y empresas ampliamente endeudadas en moneda extranjera que no hayan cubierto su deuda en divisas (OCDE, 2020b).

\section{Política monetaria y condiciones financieras para responder a la crisis}

Los bancos centrales han desempeñado un activo papel en la respuesta a la crisis del coronavirus (Covid-19). La mayoría de los bancos centrales de la región comenzó a relajar las condiciones monetarias al inicio de las medidas de confinamiento (Gráfico 1.6). Las actuaciones en materia monetaria resultaron muy oportunas, y más de diez países redujeron la tasa de interés oficial e intervinieron el mercado de divisas. Algunos inyectaron liquidez en dólares mediante líneas swap y compraron títulos valores públicos o privados. En particular, los bancos centrales de Brasil, Chile, Colombia y, en cierta medida, Perú adquirieron títulos de deuda pública y privada en mercados financieros nacionales. Las regulaciones en materia de crédito también se flexibilizaron para que los bancos comerciales pudiesen renegociar préstamos con hogares y empresas sin que eso afectase a su calificación crediticia. 
Gráfico 1.6. Tasas de interés oficiales de países seleccionados (\%)

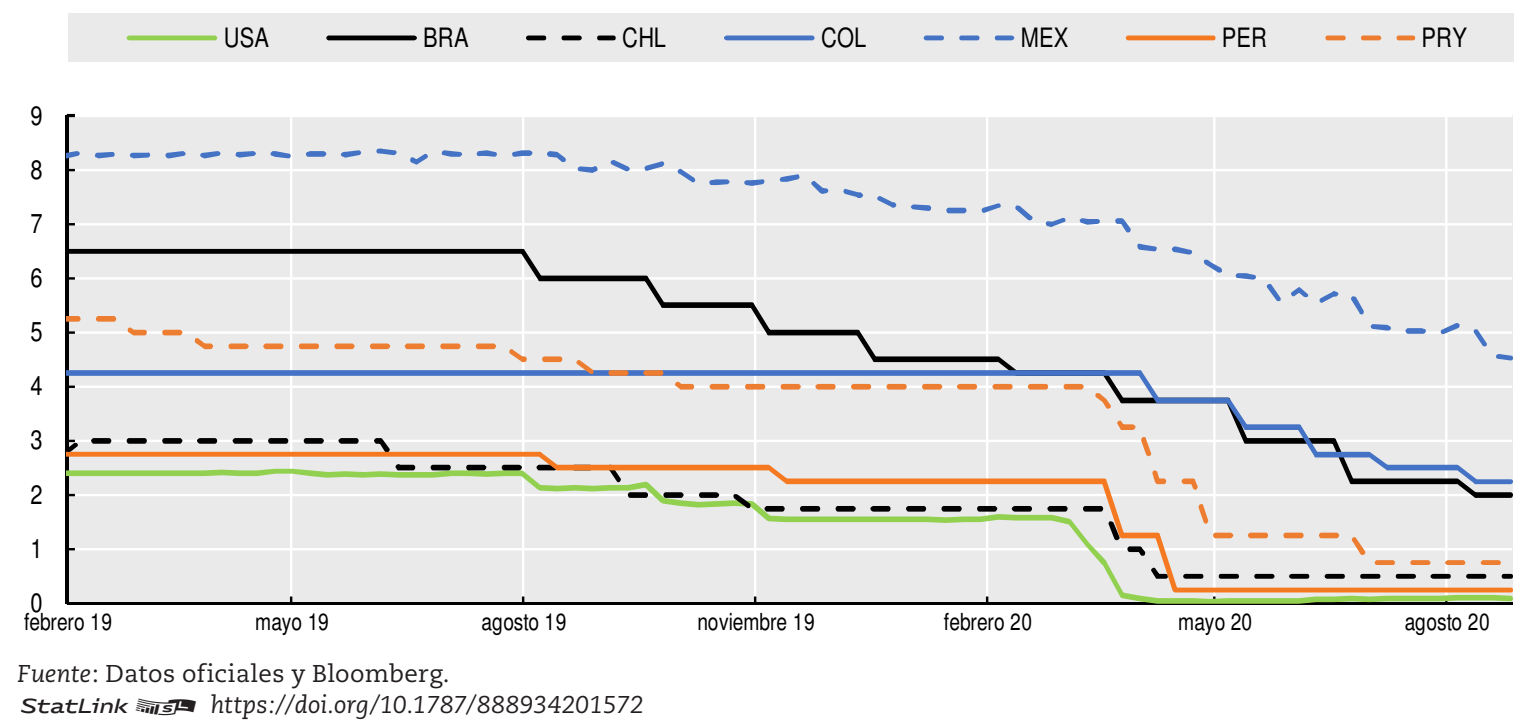

Debido al considerable descenso de la demanda interna, la inflación sigue contenida en la mayoría de los países latinoamericanos. Pese a la disparidad entre ellos, se pueden prever subidas de precios moderadas a corto plazo, por la depreciación de la moneda y los problemas en el ámbito de la oferta. No obstante, habida cuenta de que no existen presiones importantes sobre los precios y la holgura de algunas economías es considerable, los bancos centrales de América Latina han seguido rebajando las tasas de interés para hacer que la actividad remonte. La incertidumbre económica sobre la duración de la crisis del coronavirus (Covid-19), y, por lo tanto, de las medidas de confinamiento en esta región, afectará a las condiciones monetarias.

Antes de la crisis, los sistemas financieros nacionales estaban relativamente bien preparados para hacer frente a su impacto económico, pues presentaban ratios de liquidez y solvencia elevados. Con todo, se prevé un aumento de la demanda de liquidez, porque empresas y hogares podrían solicitar más créditos o usar líneas existentes para mitigar los nocivos efectos de las medidas de confinamiento en la actividad económica. La pronta intervención de los bancos centrales ha reducido enormemente los riesgos de falta de liquidez en los sistemas financieros. También podrían aumentar los préstamos fallidos, en especial después de que hayan vencido los préstamos renegociados. Existen indicios de que los bancos se comportan de manera procíclica en época de crisis y pueden restringir el crédito para proteger sus balances, pero los países de la región ya han adoptado medidas para prevenir un empeoramiento drástico de la situación. Más de 15 países han impuesto moratorias para la amortización de préstamos, abierto líneas preferentes para facilitar crédito o recursos líquidos a pequeñas y medianas empresas (pymes) y reducido los requisitos en materia de liquidez y reservas para favorecer el crédito (Nuguer y Powell, 2020).

\section{Política fiscal para mitigar la crisis e impulsar la recuperación}

La política fiscal tiene especial importancia para mitigar los efectos económicos y sociales de la pandemia, y seguirá jugando un importante papel en la recuperación. En una coyuntura regional caracterizada por sistemas de seguro por desempleo precarios o inexistentes, altos niveles de informalidad y baja recaudación fiscal, los estabilizadores automáticos resultan insuficientes (Espino y González Rozada, 2012), por lo que resulta todavía más apremiante introducir medidas fiscales discrecionales para dar respuesta a la crisis. 
La mayoría de las economías de América Latina y el Caribe han adoptado medidas fiscales (OCDE, 2020c). Más de 20 países han implantado transferencias a hogares y abierto líneas de crédito para empresas. Más de 15 países han introducido además rebajas o aplazamientos en el pago de los impuestos laborales y las contribuciones a la seguridad social, así como moratorias para la amortización de deudas y compensaciones salariales para los trabajadores. Las intervenciones dirigidas a mitigar los efectos de la crisis del coronavirus (Covid-19) deberían concebirse como medidas temporales, para no poner en peligro la futura estabilidad fiscal (CEPAL, 2020c; Izquierdo y Ardanaz, 2020).

En promedio, la ayuda fiscal de algunos países de la región ha sido modesta, si la comparamos con la envergadura de la crisis y con economías avanzadas y otras economías emergentes. El apoyo fiscal varía de manera considerable entre los diferentes países y, en algunas economías, como Brasil, Chile y Perú, ha sido relativamente elevado. No obstante, el valor último de dichas medidas sigue sin conocerse, habida cuenta que se desconoce cómo se ejecutarán finalmente estos anuncios, la posibilidad de que la duración o cobertura de las medidas temporales se prolongue o se anuncien nuevas actuaciones en los próximos meses. Por otra parte, la informalidad y el acceso limitado a cuentas bancarias complican la logística, orientación y eficacia de las transferencias a empresas y hogares vulnerables. No obstante, algunos países han implantado políticas innovadoras en este sentido (ver la sección posterior sobre los efectos sociales de la crisis del coronavirus [Covid-19]).

Las políticas macroeconómicas aprobadas para dar respuesta a la crisis del Covid-19, incluidas las de índole fiscal, deberían distinguir entre objetivos e instrumentos a corto y mediano plazo. En el corto plazo se situarían las políticas destinadas a paliar los efectos inmediatos de la crisis. El mediano plazo, por su parte, sería un contexto de aplanamiento de la curva de contagios y progresivo levantamiento de las medidas de confinamiento. Resulta fundamental coordinar las políticas en materia de regulación monetaria, fiscal y cuentas de capital tanto a corto como a mediano y largo plazo.

La política fiscal a corto plazo debería reforzar los sistemas de salud, aportar liquidez a las empresas para mantener el empleo y ayudarles a sobrevivir, así como amortiguar las pérdidas de ingresos de los hogares, en particular las de los más vulnerables. Algunos países con altos niveles de informalidad o redes de seguridad social poco desarrolladas han recurrido a la implantación de programas de transferencias sociales o a la ampliación de los ya existentes, así como a garantías para facilitar préstamos a pymes.

A mediano plazo, estas transferencias y garantías deberán dar paso a un mayor gasto de capital e inversión en educación y competencias, como factores clave para promover y sostener las labores de recuperación. Tras la emergencia sanitaria, la política fiscal debería aumentar la demanda y centrarse, al mismo tiempo, en invertir en infraestructura y capital humano para impulsar la productividad a mediano plazo. El gasto público de capital deberá tener un mayor efecto multiplicador en la economía y ofrecer una expectativa de rentabilidad para captar inversión del sector privado, en especial si tal objetivo se persigue en estrecha coordinación con políticas que posibiliten la formalización y la reasignación a empresas más productivas. No todas las medidas fiscales son iguales, y los gobiernos deberían tratar de formular paquetes de estímulo que posibiliten amplios multiplicadores económicos de forma razonablemente rápida, además de conducir la economía hacia un desarrollo con bajas emisiones de carbonos (Hepburn et al., 2020). ${ }^{2}$

La capacidad de los países de América Latina y el Caribe para responder a la pandemia mediante la política fiscal dependerá de su posición fiscal inicial y de su acceso a mercados internacionales. Antes de la crisis, si bien existía gran disparidad entre los diferentes países, el margen fiscal de la mayoría ya era limitado y muchas economías estaban introduciendo ajustes en este ámbito. Los déficits fiscales siguen siendo la norma en la mayoría de los países de la región. Pese a presentar un alto nivel de heterogeneidad, los 
ingresos tributarios siguen siendo escasos, ya que equivalen a cerca del $23.1 \%$ del PIB, más de 10 puntos porcentuales por debajo del promedio de la OCDE (OCDE et al., 2020). Además, la política fiscal no ha sido suficientemente eficaz en lo que se refiere a reducir la desigualdad y la informalidad, y a promover el emprendimiento. Los ingresos tributarios relativamente bajos generan además la necesidad de mejorar la estructura, orientación y ejecución del gasto público (Izquierdo, Pessino y Vuletin, 2018; OCDE et al., 2019).

Desde 2014, los niveles de deuda han ido en aumento en casi todos los países. Los coeficientes entre la deuda pública y los impuestos, un indicador representativo de la capacidad financiera nacional para pagar la deuda, se incrementaron en la mayoría de los países. De este modo, su posición para encarar la crisis del coronavirus (Covid-19) era peor que en 2007, antes de la crisis financiera de 2008 (Gráfico 1.7). En el futuro, las medidas tributarias para hacer frente a la crisis y a la consiguiente desaceleración económica podrían causar estragos en los ingresos fiscales. Ante la reducción cada vez mayor del margen fiscal y el incremento de ingresos necesario para dar respuesta a los heterogéneos desafíos que encaran los países de América Latina y el Caribe, debería priorizarse la coordinación mundial de la gestión de la deuda pública.

\section{Gráfico 1.7. Coeficiente entre deuda e impuestos (deuda pública bruta) de países de América Latina seleccionados, 2007, 2014 y 2018}

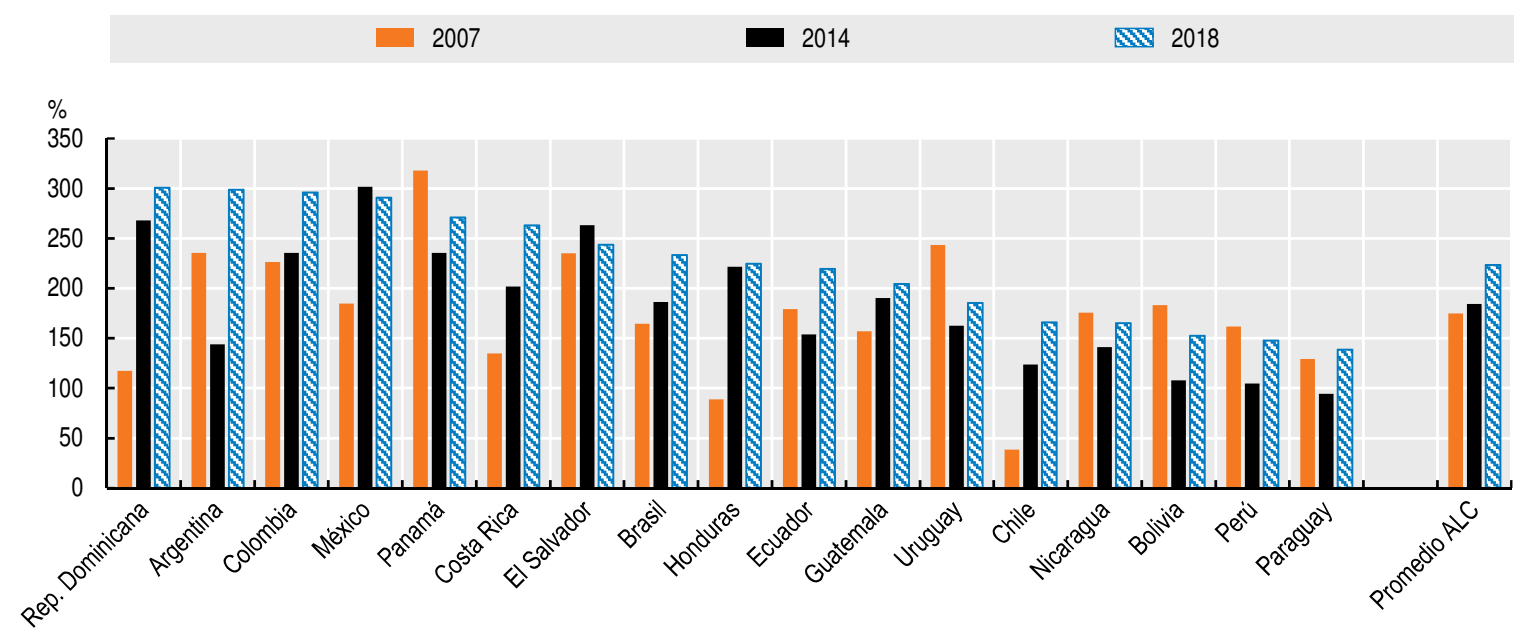

Fuentes: Datos oficiales (2019) y OCDE et al. (2020), Estadísticas Tributarias de América Latina y el Caribe 2020.

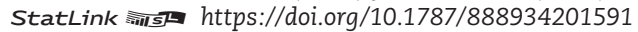

\section{Coordinación mundial de la gestión de la deuda pública}

Las necesidades fiscales generadas por la pandemia exigen que la deuda se gestione de manera coordinada a escala mundial. La inacción de emisores o acreedores puede derivar en impagos de deuda y, por lo tanto, generar problemas en este sentido, lo que agravaría una situación ya de por sí complicada. En la región, no existe una solución única a la gestión de la deuda, ya que las condiciones fiscales iniciales de las que parten los distintos países, el tipo de acreedores extranjeros que tienen y su capacidad económica para recurrir a los mercados de capital son diferentes.

La situación financiera de algunos países ya era complicada antes de la pandemia. En países como Argentina y Ecuador, antes de la crisis ya se habían iniciado negociaciones internacionales sobre las obligaciones de pago de la deuda pública pendientes, y Ecuador logró la mayoría necesaria para reestructurar la deuda con acreedores privados en agosto de 2020. Los actores de los mercados de capital ya habían puesto precio al costo de reestructuración antes de la crisis (Nieto-Parra y Orozco, 2020). Del mismo modo, 
Argentina llegó a un acuerdo para reestructurar casi la totalidad de su deuda pública externa el 31 de agosto de 2020. Los países caribeños están muy endeudados y podrían tener dificultades para acceder a créditos. En 2018, tres de los 25 países más endeudados del mundo (según los niveles de deuda pública bruta en relación con el PIB) eran caribeños: Antigua y Barbuda, Barbados y Jamaica (FMI, 2019; OCDE et al., 2019).

La manera de conseguir recursos en esta región es diferente según el país del que se trate. Algunos países de América Central (como Guatemala, Honduras, Nicaragua), economías caribeñas (como Haití, San Vicente y las Granadinas, Dominica) y algunas economías sudamericanas (como Bolivia y Ecuador) han emitido deuda tradicionalmente a través de acreedores bilaterales o bancos multilaterales. México y la mayoría de economías sudamericanas, por su parte, han tenido habitualmente acceso a los mercados de capital para conseguir fondos (Gráfico 1.8), y alrededor de la mitad de su deuda se encuentra denominada en moneda nacional. Brasil emite la mayor parte de su deuda en moneda nacional. Cuando el grueso principal de la emisión de deuda se realiza en la moneda nacional, en caso de depreciaciones importantes de la divisa, los riesgos de sostenibilidad son menores.

En los próximos dos años se prevé un aumento de los coeficientes de la deuda pública. Mientras las tasas de interés se mantengan por debajo de las tasas de crecimiento, los coeficientes de deuda deberían estabilizarse a mediano plazo, pero en niveles más elevados. La deuda debería recuperar finalmente niveles más sostenibles y debería recobrarse el margen fiscal. No obstante, para que el crecimiento y el progreso social no se estanquen, este proceso debería ser gradual. Debido a la abundante liquidez existente los mercados de capital internacionales parecen más dispuestos a admitir coeficientes de deuda superiores $\mathrm{y}$, por lo tanto, se mantiene el acceso a flujos de capital. No obstante, las condiciones financieras para aprovechar los recursos del mercado de capitales varían de unos países a otros y los precios fluctúan considerablemente en función de la sostenibilidad de la deuda de cada país. Además, las condiciones podrían cambiar rápidamente a mediano plazo si se normaliza la política monetaria de las economías avanzadas.

\section{Gráfico 1.8. Deuda pública externa total por acreedor (público y privado) de países seleccionados de América Latina y el Caribe, 2018}

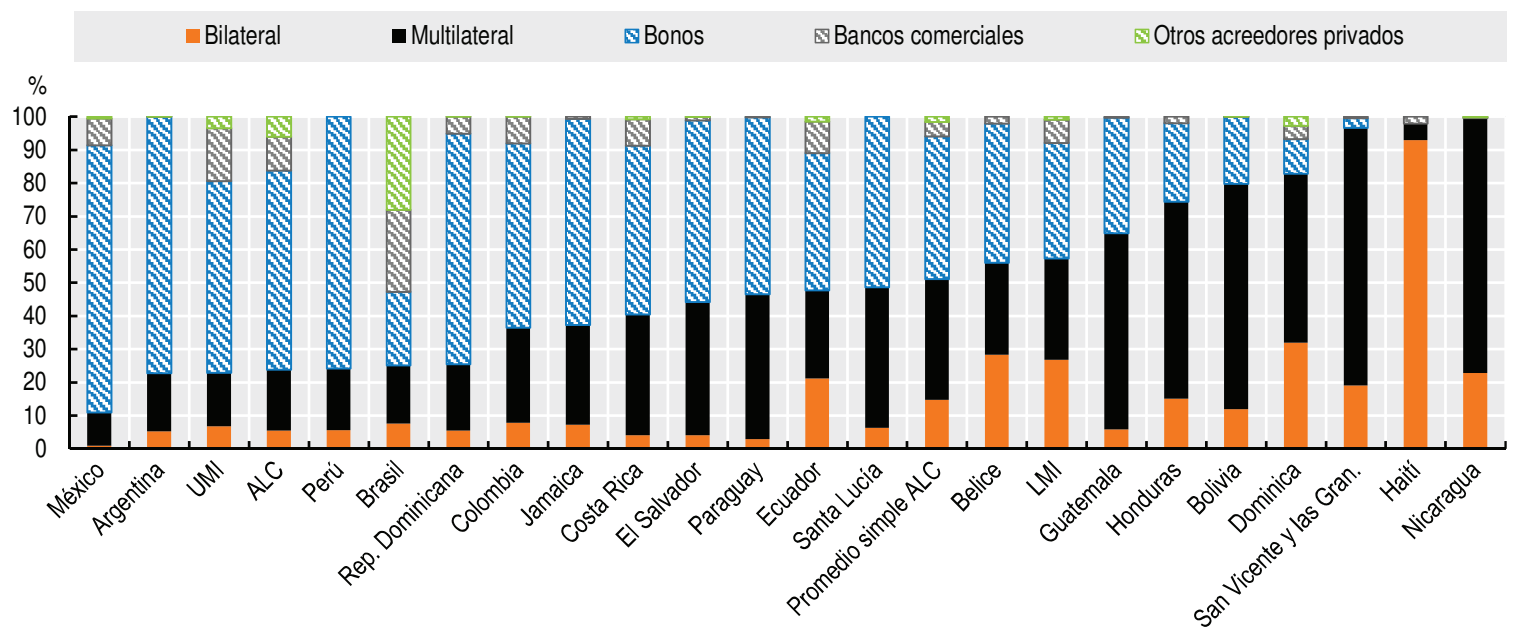

Notas: En el promedio simple de ALC se ponderan por igual todos los países según la distribución de los titulares de crédito. ALC tiene en cuenta la cantidad emitida por cada país de la región. LMI y UMI se refieren a todos los países de ingresos medios bajos e ingresos medios altos del mundo.

Fuente: Cálculos del Centro de Desarrollo de la OCDE a partir de Banco Mundial (2020b), International Debt Statistics (base de datos), https://data.worldbank.org/products/ids (consulta de mayo de 2020).

StatLink तiाst https://doi.org/10.1787/888934201610 
Las enormes divergencias existentes en los niveles de deuda pública y las condiciones financieras de los diferentes países de América Latina y el Caribe resaltan las distintas actuaciones políticas, que pueden ser cruciales para responder a la crisis del coronavirus (Covid-19) en función de cada caso:

- Se necesita una acción coordinada de los tenedores de deuda y los actores del mercado de capitales para reestructurar la deuda emitida por países que ya atravesaban dificultades financieras. Dicha actuación resulta fundamental para reducir al mínimo el riesgo reputacional (es decir, el futuro acceso a los mercados de capital) y brindar a los países cierto margen fiscal para poder responder a la crisis. Para facilitar la renegociación con los titulares de deuda, podrían emplearse cláusulas de acción colectiva.

- También puede resultar útil la experiencia adquirida en el pasado con mecanismos de reestructuración y alivio de la deuda y, en particular, el hecho de que acreedores y deudores deberían asumir conjuntamente la carga que supone la deuda. Las iniciativas de reestructuración o alivio de la deuda deberían estar lideradas por los acreedores públicos e implicar posteriormente a acreedores privados (Bolton et al., 2020). Los gobiernos deberían centrarse en lograr una estrategia de comunicación efectiva sobre las políticas económicas y en los objetivos en cuanto a logros previstos con la reestructuración o el alivio de la deuda. Es esencial que se intercambien información y datos prácticos con los acreedores. Por último, los gobiernos deberían incluir en el acuerdo las cláusulas de contingencia pertinentes.

- La ayuda oficial debería dar prioridad a las economías con un acceso escaso o nulo a los mercados de capital.

- Los países que ya gozan de una sostenibilidad fiscal deben mantener el acceso a los mercados de capital con primas de bajo riesgo que les permitan obtener los recursos necesarios para responder a la crisis aprovechando su abundante liquidez.

- Otro grupo de países podría tener acceso a los mercados de capital, pero incurrir en un elevado costo de la deuda, por un deterioro en la interpretación que los partícipes del mercado hacen de la sostenibilidad de la deuda, por ejemplo respecto a rebajas actuales o potenciales de las calificaciones crediticias o bajas previsiones sobre crecimiento e ingresos públicos futuros. Existen varias opciones en materia de políticas, entre ellas, moratorias o interrupciones del pago de la deuda, distintas modalidades de alivio de la deuda, crear un vehículo especial para financiar la crisis o pagar la deuda, y hacer un mayor uso de los Derechos Especiales de Giro, pero todas ellas requieren de una cooperación internacional que implique a bancos multilaterales, países desarrollados o acreedores privados (Nieto-Parra y Orozco, 2020; Bolton et al., 2020).

La historia nos brinda ejemplos de los que podemos aprender para superar los desafíos actuales en materia de finanzas públicas, entre ellos, el desenlace del largo proceso que atravesó esta región en 1980 para resolver la crisis de deuda. La cooperación y el apoyo en materia de políticas entre los distintos países (por ejemplo, con la conversión de préstamos bancarios en bonos [Plan Brady]), a principios de la década de los noventa, resultaron cruciales para reducir los costos socioeconómicos. La participación de acreedores privados contribuyó a disminuir la incertidumbre respecto al acceso a los mercados de capital y permitió a las economías acceder a los mercados financieros y recibir en préstamo otros recursos (Eichengreen, 2020). Para no incurrir en costos socioeconómicos elevados, resulta esencial que la respuesta política sea rápida (Flores Zendejas, 2020).

\section{Mayor productividad para impulsar el crecimiento}

El escaso aumento de la productividad ha constituido durante largo tiempo un lastre para el crecimiento potencial. Uno de los desafíos más importantes que encaran los 
países de América Latina y el Caribe son sus bajos niveles de productividad (ver el Capítulo 2). Los países de esta región basan en gran medida su competitividad en las ventajas de los recursos naturales o en la abundancia de mano de obra poco cualificada. Este tipo de ventaja comparativa puede propiciar periodos de rápido crecimiento, por ejemplo en épocas de auge de las materias primas, pero no favorece la convergencia con países avanzados a largo plazo.

El tipo de competitividad necesaria para lograr un crecimiento económico sostenido se basa en la incorporación de tecnología y en la diversificación de la producción hacia sectores dinámicos, tanto en lo que respecta a la tecnología como a la demanda internacional (CEPAL, 2012) (ver el Capítulo 2). La importancia que reviste la tecnología queda evidenciada por su capacidad para responder a las crisis. Los países con una infraestructura de comunicaciones más avanzada y más adelantados en cuanto a adopción de tecnologías digitales gozan de una mejor posición para preservar determinadas actividades económicas y salvar puestos de trabajo en la región. No obstante, en muchos países siguen existiendo importantes carencias en cuanto a asimilación de tecnologías y medios digitales (CAF, 2020b).

A mediano plazo, el gasto de capital público puede revestir gran importancia para impulsar iniciativas de recuperación e impulsar un crecimiento de la productividad. En las circunstancias previstas, los gastos de capital han de tener necesariamente un elevado efecto multiplicador sobre el empleo y fomentar la productividad. Pueden actuar como vehículo de captación de inversión procedente del sector privado, en especial si tal objetivo se persigue en estrecha coordinación con la transformación de la producción y con mejoras en las políticas del sector privado y el clima empresarial. De hecho, este tipo de coordinación entre la inversión pública y la transformación productiva (por ejemplo, mediante políticas de contratación pública) puede maximizar los efectos multiplicadores de la primera.

Las consecuencias de una larga oleada de contagios, restricciones a la movilidad y moderadas ayudas por medio de políticas en la mayoría de países de América Latina y el Caribe bien podrían incluir la destrucción de capital (por ejemplo, el cierre de empresas) y un elevado nivel de desempleo y empleo informal. Las intervenciones en materia de políticas deberían enfocarse en facilitar la movilidad y la reasignación eficiente de recursos a empresas y sectores más productivos. Existe margen para promover la competencia, la innovación y el emprendimiento, para simplificar los sistemas tributarios a fin de propiciar la expansión empresarial y la formalización del empleo, y lograr una política fiscal más progresiva, así como para mejorar las capacidades estatales necesarias para ofrecer mejores bienes y servicios a los ciudadanos y restaurar la confianza en las administraciones públicas (OCDE et al., 2019). Los gobiernos más eficientes y mejor financiados contarán con más medios para hacer frente a las dificultades que conlleva promover un crecimiento sostenible y desarrollar sistemas adecuados de redes de seguridad y protección social.

\section{Efectos sociales de la crisis del coronavirus (Covid-19)}

La lucha contra la pobreza y la desigualdad, y la consecución de sociedades más justas e inclusivas con mayores niveles de bienestar para toda la población, tal como estipula la Agenda de Desarrollo Sostenible 2030 de Naciones Unidas, es un objetivo prioritario de las agendas políticas de América Latina y el Caribe. Pese a que en las últimas décadas los países han logrado importantes progresos en cuanto a reducción de la pobreza y la desigualdad, siguen existiendo importantes desafíos y déficits estructurales por resolver que están siendo acentuados por la crisis actual.

La desigualdad existente en ALC es resultado de una matriz compleja de factores determinantes y tiene como causas primordiales la estructura económica y la 
configuración institucional de la región. La clase o grupo de ingresos es uno de los ejes estructurales de la desigualdad social, junto con el género, la edad (ciclo de vida), la procedencia étnica, la raza y el territorio. La condición socioeconómica individual refleja y explica muchas de las dimensiones en las que se manifiesta la desigualdad: empleo y trabajo, acceso a ingresos y recursos productivos, educación, salud, servicios básicos, vivienda, alimentos, seguridad, protección social, oportunidades para vivir sin violencia, tecnología y participación, entre otros (CEPAL, 2018a, 2016).

Las sociedades de América Latina y el Caribe se caracterizan por una desigualdad estructural que se ha venido manteniendo y reproduciendo incluso en periodos de prosperidad y expansión económica. Esta desigualdad constituye un obstáculo infranqueable para erradicar la pobreza, lograr un crecimiento sostenible y garantizar los derechos de las personas. Unos niveles elevados de desigualdad en cuanto a ingresos pueden perjudicar el crecimiento económico y generar inestabilidad política (Milanović, 2020). La desigualdad se basa en una estructura económica que se concentra en un reducido número de sectores y se enmarca en un contexto complejo, en el que las desigualdades socioeconómicas se mezclan con otras de género, territoriales, étnicas, raciales y generacionales (CEPAL, 2016).

Las consecuencias sociales de la crisis del coronavirus son asimétricas y afectan principalmente a los grupos más vulnerables, lo que agrava la ya de por sí complicada situación social de la región (ver en el Capítulo 3 la trascendencia de la transformación digital para estos grupos).

Por lo que se refiere a la estructura de producción, la recesión económica afectará principalmente a trabajadores de sectores como el turismo, el comercio y el transporte, en especial a micro, pequeñas y medianas empresas y a trabajadores por cuenta propia, la mayoría de los cuales se sitúa en el mercado de trabajo informal. La crisis será especialmente difícil para las micro y pequeñas empresas, que no tienen capacidad para amortiguar el golpe. Cerca de 2.7 millones de empresas (o el 19\% de todas las empresas), en su mayoría microempresas, podrían cerrar (Gráfico 1.9, Panel A), lo que supondría la pérdida de 8.5 millones de puestos de trabajo y afectaría a la forma que tienen muchos hogares de ganarse un sustento, ya que sus ingresos familiares dependen de dichos puestos de trabajo (CEPAL, 2020d).

Brindar ayuda a las empresas no es tarea fácil, ya que muchas pertenecen a la economía informal y suelen quedar fuera del ámbito de aplicación de los programas destinados al sector productivo. Las transferencias directas, las garantías de crédito y las moratorias al pago de impuestos, servicios públicos o contribuciones a la seguridad social suelen comportar unos requisitos de formalización. Además, puesto que las ayudas destinadas a actividades de carácter informal van dirigidas principalmente a empleados por cuenta propia, las pymes informales quedan al margen de dichos sistemas. Algunos países están animando a las empresas a integrarse en la economía formal, al menos en cierto modo, puesto que al registrarse, tienen derecho a percibir ayudas (Basto-Aguirre, Nieto-Parra y Vázquez-Zamora, 2020).

El impacto de la crisis del coronavirus (Covid-19) en los ingresos está empeorando las condiciones sociales de América Latina y el Caribe, en particular las de los segmentos más vulnerables. El daño provocado por la pandemia afecta de forma desproporcionada a los hogares más pobres y vulnerables económicamente, en una región en la que el $25 \%$ de la población es pobre, y el $37 \%$ es vulnerable y podría caer en la pobreza. La mayoría de los trabajadores de estos grupos de ingresos ha caído en la trampa de la vulnerabilidad social, es decir, en puestos de trabajo informales que limitan su acceso a sistemas de protección social (como los servicios de salud), un seguro por desempleo, una estabilidad en cuanto a ingresos y el ahorro como red de seguridad. 
En promedio, cerca del 60\% de los trabajadores de la región se consideran informales, con especial incidencia entre los grupos socioeconómicos más desfavorecidos (OCDE, 2020b). En torno al 58\% de los trabajadores del mercado informal vive en situación de vulnerabilidad económica (5.5 USD - 13.0 USD al día) o de pobreza (menos de 5.5 USD al día).

Los programas de asistencia social de la región llegan a un porcentaje importante de hogares pobres, pero muchos continúan en situación de riesgo. Cerca del $40 \%$ de los trabajadores carece de protección alguna de redes de seguridad social (Gráfico 1.9, Panel B), una cifra que se eleva al $65 \%$ en los trabajadores del mercado informal (Basto-Aguirre, Nieto-Parra y Vázquez-Zamora, 2020). Estos trabajadores a duras penas pueden asumir el incremento de los gastos de salud o la pérdida de ingresos que han provocado las medidas de cuarentena. Para frenar el avance de la pobreza, son necesarias nuevas formas de protección social que lleguen a los grupos vulnerables durante esta crisis o la concesión de una renta básica de urgencia, para que ningún ciudadano viva por debajo del umbral de la pobreza nacional (CEPAL, 2019).

\section{Gráfico 1.9. Trabajadores que carecen de una red de medidas de protección y empresas que podrían cerrar debido a la crisis del coronavirus (Covid-19) de países seleccionados de América Latina}
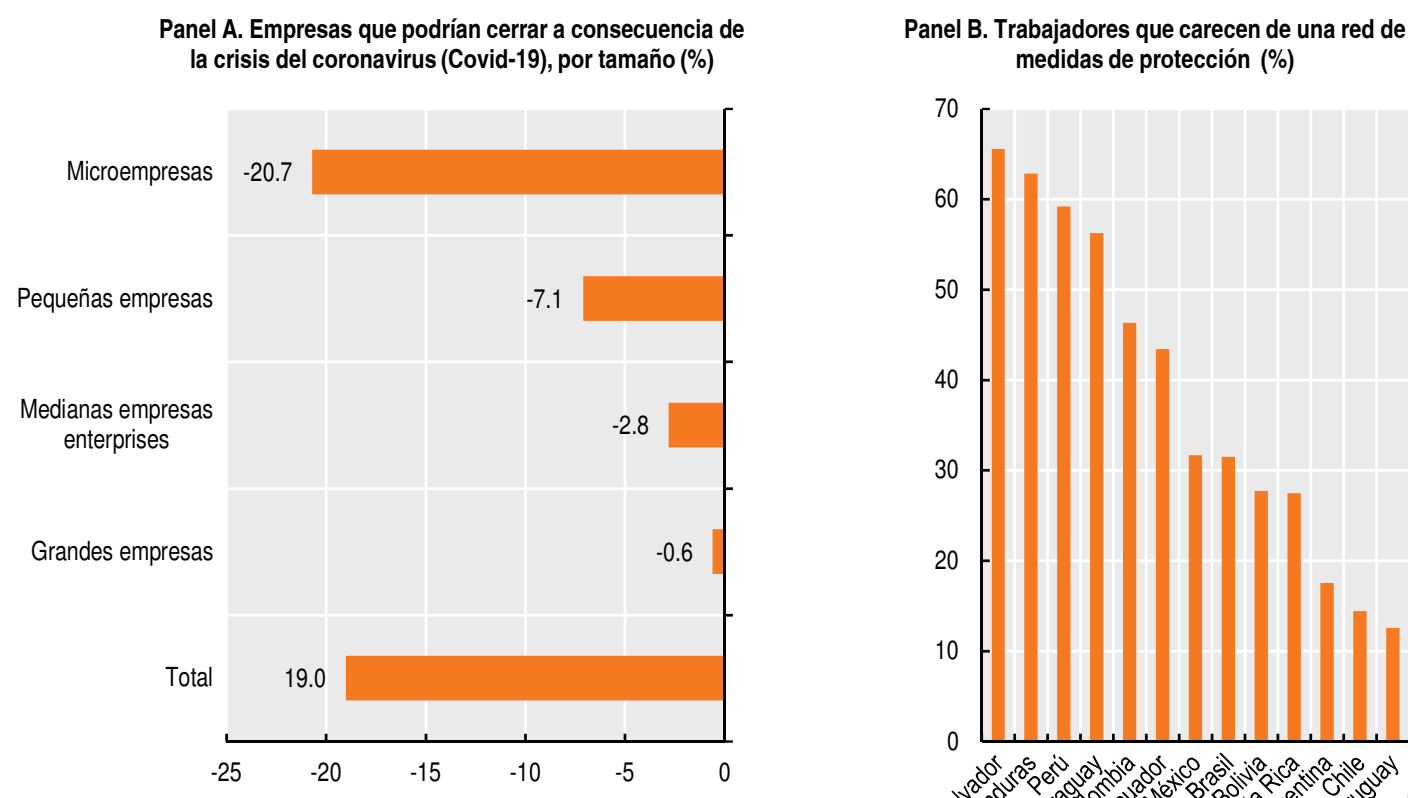
medidas de protección (\%)

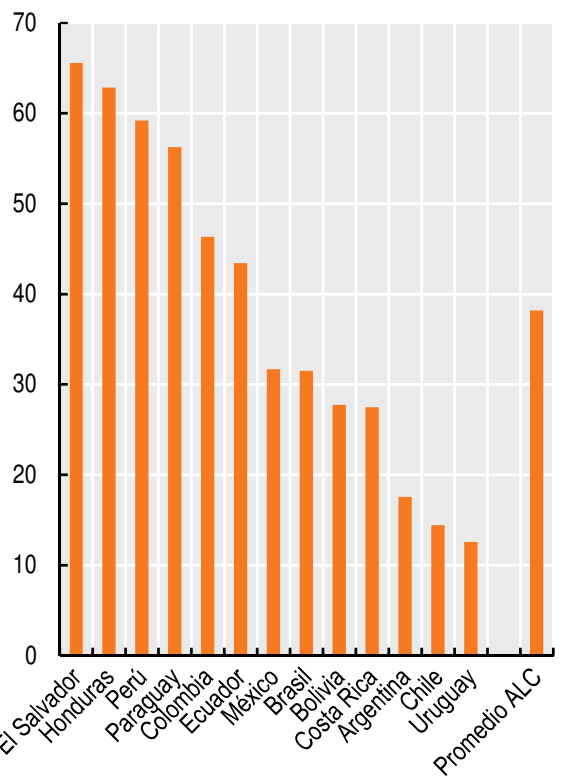

Fuente: CEPAL (2020d), “Sectores y empresas frente al COVID-19: Emergencia y reactivación”, Informe especial: COVID-19, n. 4 y Basto-Aguirre, Nieto-Parra y Vázquez-Zamora (2020), Informality in Latin America in the post COVID-19 era: Towards a more formal "new normal"?", Vox Lacea.

StatLink 젶ㄴ https://doi.org/10.1787/888934201629

Los gobiernos han puesto un empeño importante en llegar a hogares y trabajadores del mercado informal ampliando las transferencias de efectivo incondicionales. El Ingreso Familiar de Emergencia de Argentina está destinado explícitamente a hogares cuya subsistencia dependa de actividades informales, empleos por cuenta propia o trabajo doméstico. En Brasil, los trabajadores del mercado informal y los desempleados que ganan menos de la mitad del salario mínimo y no están cubiertos por prestaciones sociales, a excepción de Bolsa Família, recibieron una nueva prestación temporal. En Chile, el Ingreso Familiar de Emergencia se facilita a trabajadores del mercado informal y hogares vulnerables. En Colombia, el Ingreso Solidario tiene por objeto llegar a tres millones de 
hogares vulnerables cuya economía depende del mercado informal o de una actividad por cuenta propia y sin el amparo de ninguna prestación social. La República Dominicana puso en marcha los programas Quédate en Casa y Pa' Ti. Ecuador amplió la cobertura de su Bono de Protección Familiar a hogares dependientes de la economía informal que no recibían otras transferencias sociales. Perú también amplió el Bono Familiar Universal durante la crisis para llegar a 2.3 millones de hogares sin una actividad laboral vinculada a la economía formal (OCDE, 2020b). Pese a que la crisis del coronavirus (Covid-19) supone un desafío importante para la región, también constituye una oportunidad para replantear los sistemas de protección social y avanzar hacia regímenes más inclusivos (Basto-Aguirre, Nieto-Parra y Vázquez-Zamora, 2020).

\section{La dimensión de la pobreza}

Entre 2002 y 2014, esta región consiguió importantes avances en cuanto a reducción de la tasa de pobreza (del $45.4 \%$ al $27.2 \%$ ) y la tasa de pobreza extrema (del $12.2 \%$ al $7.8 \%$ ). El fin del periodo de bonanza de las exportaciones de productos básicos y la consiguiente ralentización económica invirtieron la tendencia observada a partir de 2015, y el número y la tasa de personas pobres comenzó a aumentar de nuevo. En 2019, el número de personas en situación de pobreza y pobreza extrema alcanzó los 191 millones y los 72 millones, o el 30.8\% y el 11.5\% de la población de América Latina y el Caribe, respectivamente (Gráfico 1.10, Panel A) (CEPAL, 2019). La caída del precio de los productos básicos se vio agravada por la reducción del margen fiscal y por políticas de ajuste que afectaron la cobertura y continuidad de políticas de inclusión laboral, social y lucha contra la pobreza (Abramo, Cecchini y Morales, 2019). Los indicadores del mercado de trabajo empeoraron, ya que el desempleo aumentó y se frenó la tendencia a una mayor formalización del empleo. El incremento de la pobreza varía según el país de ALC, y el impacto es mayor entre quienes viven en núcleos rurales, mujeres y niños (y pueblos indígenas y afrodescendientes) (Gráfico 1.10, Panel B).

Gráfico 1.10. Evolución de la pobreza y la pobreza extrema en América Latina y el Caribe, por características socioeconómicas, 2002-2019

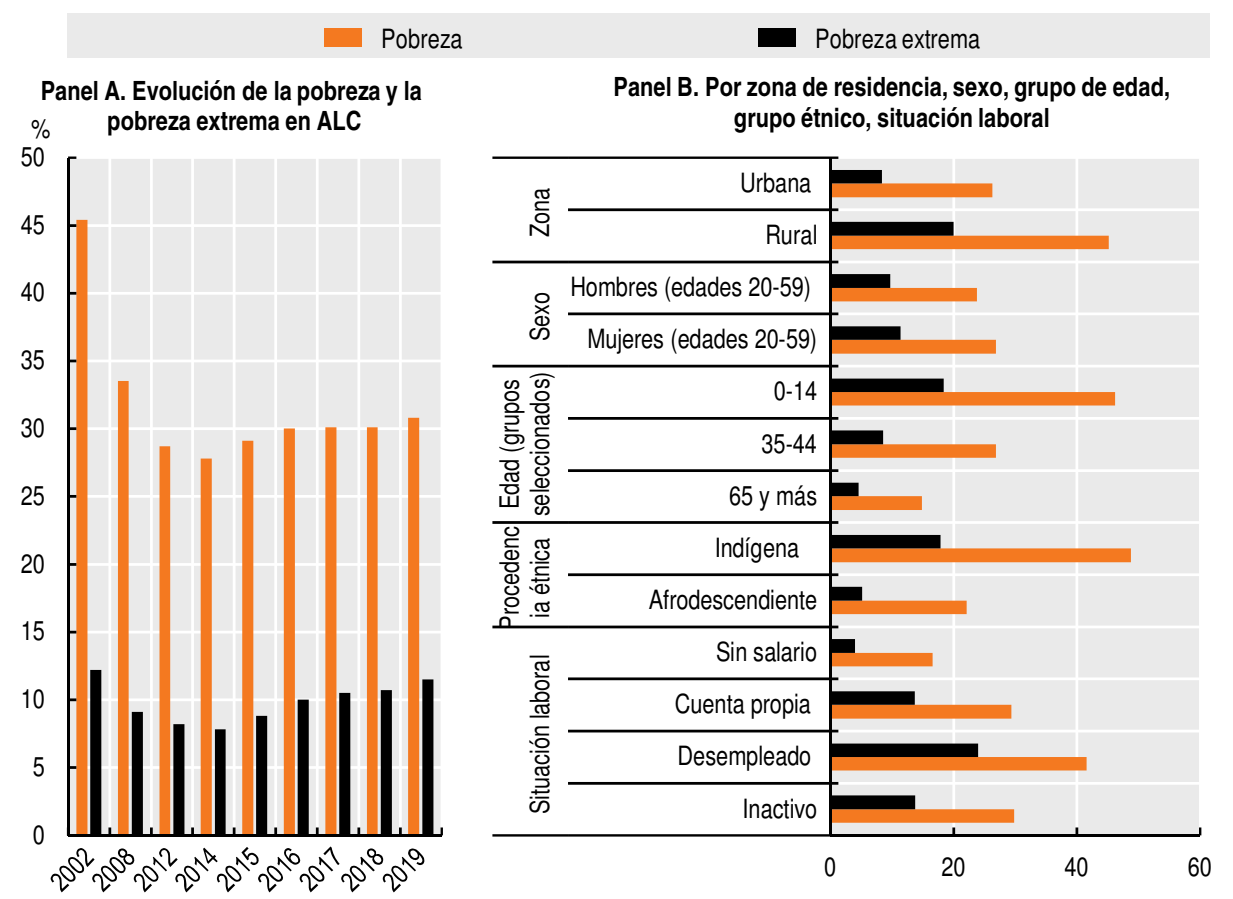

Fuente: Elaboración propia a partir de información de CEPAL (2019), Panorama social de América Latina.

StatLink intsta https://doi.org/10.1787/888934201648 
Si no se da una respuesta contundente a la pandemia, podrían aumentar tanto la pobreza como la pobreza extrema. El número de personas pobres podría incrementarse en 45.4 millones, de modo que la cifra total se situaría en 230.9 millones (el 37.3\% de la población de ALC). La pobreza extrema podría aumentar un 4.5\%, en 28.5 millones de personas, de manera que afectaría a 96.2 millones de personas en total (CEPAL, 2020a).

\section{La dimensión de la desigualdad}

Pese a los importantes avances registrados en los últimos 15 años, la región de América Latina y el Caribe sigue aquejada de un gran nivel de desigualdad. Esta es la región más desigual del mundo, con un índice de Gini promedio que supera al de Europa prácticamente en un tercio. El índice de Gini promedio de ALC descendió del 0.54 en 2002 al 0.47 en 2014, y al 0.46 en 2018 - un descenso del 13.6\% en 16 años o del $0.9 \%$ anual, en promedio-. Durante este periodo se fue ralentizando el ritmo de descenso, ya que el promedio entre 2014 y 2018 fue del 0.6\% anual, frente al 1\% anual registrado entre 2002 y 2014. Sin embargo, estos promedios ocultan patrones dispares entre los diferentes países de ALC, en términos tanto de desigualdad como de intensidad, y también en relación con la dirección de los cambios registrados a lo largo de estos periodos. En 2018, Argentina, El Salvador y Uruguay presentaron los niveles más bajos (por debajo de 0.40), mientras que Brasil y Colombia obtuvieron niveles superiores a 0.52 (CEPAL, 2019) (Gráfico 1.11).

\section{Gráfico 1.11. Desigualdad en países de América Latina seleccionados (índice de Gini), 2002, 2014 y 2018}

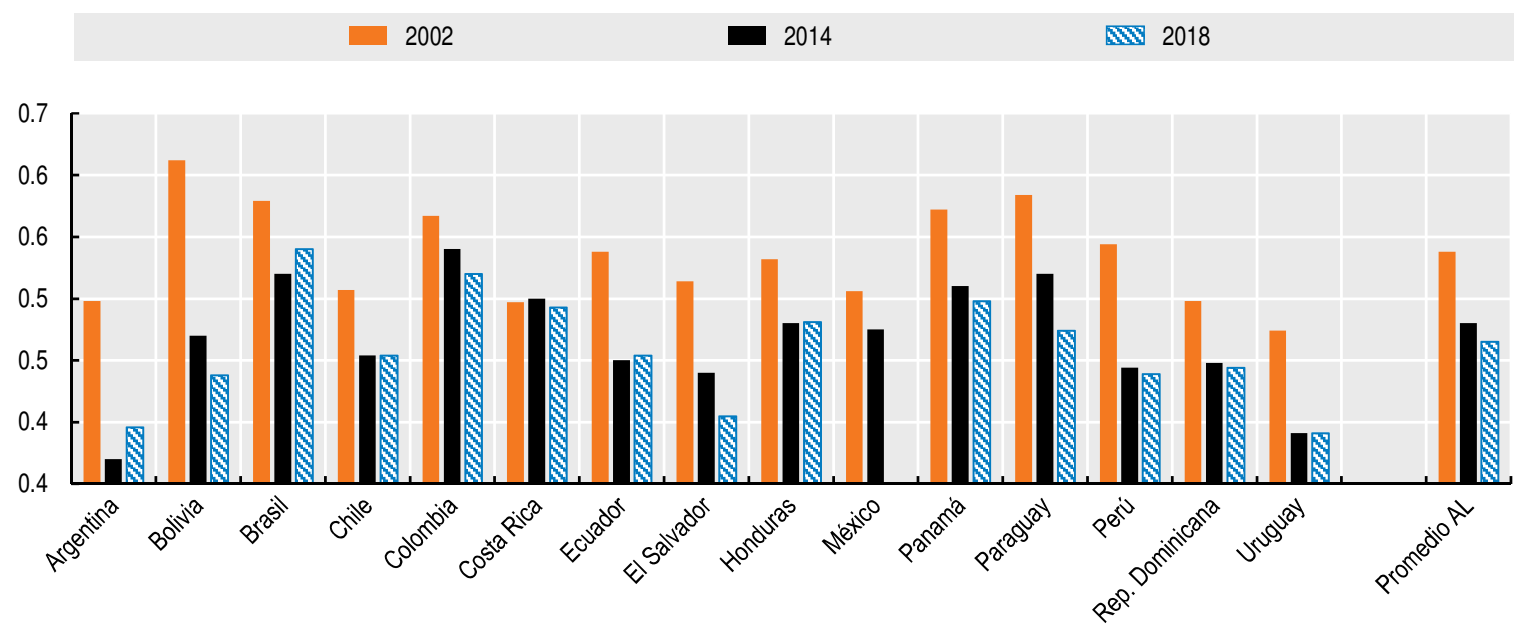

Fuente: CEPAL (2019), Panorama social de América Latina.

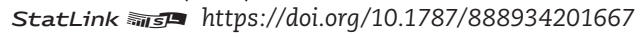

La crisis del coronavirus (Covid-19) acentuará las desigualdades ya existentes debido a su mayor influencia en los segmentos más vulnerables de la población. En este sentido, la brecha digital existente en esta región se ha convertido en una preocupación aún mayor, ya que puede intensificar las desigualdades. Para mitigar las consecuencias de los confinamientos, se han creado soluciones digitales. Sin embargo, el 32\% de la población de América Latina y el Caribe carece de acceso a Internet, una herramienta que ha demostrado ser esencial para frenar el impacto de la pandemia (CAF, 2020b). Buen ejemplo de ello sería la educación, ya que ni todos los estudiantes ni todos los centros educativos están dotados de los mismos equipamientos ni tienen acceso a las herramientas pedagógicas y los equipos necesarios para poder impartir clases por medios remotos. Los alumnos de entornos más desfavorecidos o de centros educativos situados en zonas menos aventajadas son los más afectados por el cierre de los centros en cuanto a resultados académicos, un 
fenómeno que podría tener profundas secuelas (OCDE, 2020b) (ver el Capítulo 3). De hecho, las consecuencias en materia de desigualdad pueden prolongarse más allá de la crisis, como demuestra la experiencia en educación. Así, el aumento de las tasas de abandono escolar y el empeoramiento de los resultados académicos podrían acarrear profundas secuelas en cuanto a formación de capital humano, oportunidades laborales y futuros ingresos (OCDE, 2020b) (ver el Capítulo 3). Además, las niñas corren mayor riesgo de no regresar a los centros educativos cuando vuelvan a abrir, lo que ampliaría las brechas de género y mermaría el empoderamiento de la mujer. ${ }^{3}$

\section{Desafíos socioeconómicos y estructura productiva}

La pobreza, las desigualdades y las vulnerabilidades sociales guardan una importante relación con la estructura productiva y la inserción de los países en la economía del conocimiento. Así lo demuestra el análisis de la relación entre la desigualdad y el indicador de conocimientos avanzados, una medida representativa de la estructura productiva. Este indicador combina el nivel de especialización de un país en producción y exportación de productos de alta tecnología con actividades de investigación y desarrollo (I+D), teniendo en cuenta las capacidades productivas y tecnológicas y la generación y divulgación de conocimientos (Rovira, próxima publicación). Al comparar este indicador con un índice de desigualdad de ingresos (índice de Gini), se identifican cuatro grupos posibles con respecto al promedio mundial.

América Latina se sitúa en el grupo que presenta mayores desigualdades y escasa adopción de la tecnología, aunque existen diferencias entre los distintos países que conforman esta región. Los países del primer grupo (cuadrante A, Gráfico 1.12) obtienen un valor elevado en el indicador de conocimientos avanzados (economías que exportan productos de alta tecnología e incorporan actividades de I+D como elemento principal en sus estrategias de desarrollo) y registran una baja desigualdad en cuanto a ingresos. Los del segundo grupo (cuadrante B) no muestran un grado muy elevado de sofisticación, pero sus niveles de desigualdad en cuanto a ingresos son bajos gracias al sistema de bienestar social. Los del tercer grupo (cuadrante $C$ ) presentan estructuras de producción diversificadas y una economía basada en el conocimiento, pero la desigualdad en cuanto a ingresos es alta. Los que se sitúan en el cuarto grupo (cuadrante D) registran una gran desigualdad en cuanto a ingresos y una escasa capacidad para crear tecnologías e incorporarlas en su estructura productiva. Algunos países africanos, Turquía, Tailandia y todos los países de América Latina forman parte de este cuadrante, aunque con grandes divergencias entre ellos. Los países con inferiores niveles relativos de desigualdad en cuanto a ingresos, como Argentina y Uruguay, contrastan con otros como Brasil, Colombia y Honduras.

La crisis del coronavirus (Covid-19) constituye una oportunidad para introducir reformas estructurales pendientes en la región y sentar las bases de un nuevo pacto social. La pandemia llega en un momento de creciente descontento de los ciudadanos con las administraciones públicas - como pusieron de manifiesto las protestas registradas a finales de 2019- y de demandas no satisfechas en relación con servicios públicos de mejor calidad y mayores niveles de bienestar (OCDE et al., 2020). Si bien la crisis podría acentuar el descontento de la ciudadanía, también podría impulsar la reformulación del pacto social, dar respuesta a vulnerabilidades estructurales - las trampas del desarrollo de la productividad, la vulnerabilidad social, institucional y ambiental de esta regióny responder así al incremento de las demandas sociales. Al configurar un nuevo pacto social, resulta esencial que todas las partes implicadas, incluida la sociedad civil, los responsables de políticas, la comunidad intelectual, los trabajadores y el sector privado, mantengan un diálogo encaminado a lograr un consenso, abordar problemas existentes y garantizar la sostenibilidad del acuerdo. 


\section{Gráfico 1.12. Indicador de conocimientos avanzados e índice de Gini}

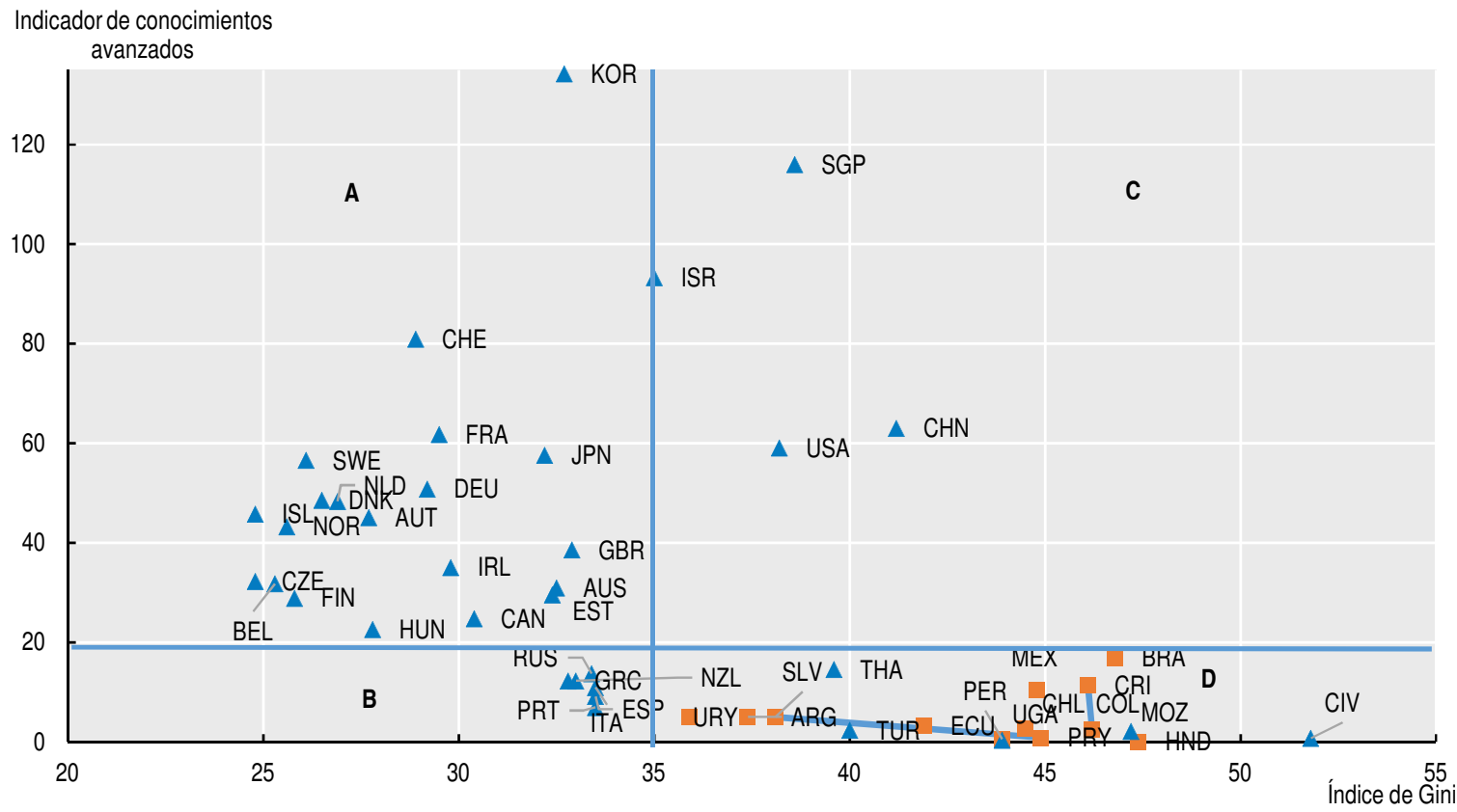

Nota: El coeficiente de Gini utiliza los ingresos después de impuestos y transferencias. Para calcular el indicador de "conocimientos avanzados" se multiplican los promedios (2014-2017) de las variables relativas a i) exportaciones de alta tecnología, como porcentaje de las exportaciones de manufacturas, y ii) el gasto en I+D, como porcentaje del PIB. Para calcular el promedio de la variable de gasto en I+D como porcentaje del PIB, en el caso de la India, Mozambique, Nueva Zelanda y Senegal, solo se tuvo en cuenta el año 2015 por causas de disponibilidad de la información. En el caso de México, se tomaron los datos de 2014, 2015 y 2016 y, en el caso de Costa de Marfil, el año 2016. Para calcular el promedio de la variable de exportaciones de alta tecnología como porcentaje de las exportaciones del sector manufacturero, en el caso de Mozambique, solo se tomaron los datos de 2014, 2016 y 2017.

Fuente: Rovira (próxima publicación), Deconstruyendo el proceso de desarrollo de ALC: entre la heterogeneidad productiva, la escasa complejidad tecnológica y la concentración del ingreso.

StatLink न्माIs] https://doi.org/10.1787/888934201686

Este proceso debería tener en cuenta varias dimensiones. En primer lugar, el refuerzo de los sistemas de protección social podría revestir una importancia crucial en futuras políticas públicas. En segundo lugar, serán necesarios más recursos para generar resiliencia y financiar un desarrollo inclusivo, por ejemplo, mediante la aplicación de reformas, con sistemas tributarios progresivos y un gasto público más eficiente. En tercer lugar, unas estrategias de desarrollo sostenible eficaces deberían promover una coordinación efectiva destinada a impulsar la formalización del empleo, el aumento de la productividad y la transición hacia modelos de desarrollo más inclusivos y con bajas emisiones de carbonos. Es necesaria la participación de un amplio número de actores a lo largo del proceso de formulación de políticas, a fin de tener en cuenta diferentes puntos de vista y conocimientos. Por ese motivo, la cooperación internacional y regional también constituirá una fuente importante de conocimiento, financiamiento y medidas coordinadas tanto en la respuesta inmediata a la crisis como en la consecución de apoyo para futuras reformas y una recuperación sostenible en la región (OCDE et al., 2020).

\section{Transformación digital en tiempos de coronavirus (Covid-19)}

El coronavirus (Covid-19) y los esfuerzos destinados a contenerlo han corroborado la importancia creciente de las nuevas tecnologías y la digitalización de la sociedad y la economía. El aumento exponencial del tráfico por Internet, la creciente relevancia 
del teletrabajo y de las teleconferencias, así como el mantenimiento de las cadenas globales de valor para el suministro y la distribución son solo algunos indicadores de dicha aceleración (CAF, 2020b). La tecnología ha devenido en un elemento especialmente útil para ayudar a frenar la pandemia, con algunas economías usando herramientas digitales para comunicar resultados de pruebas y hacer un seguimiento del cumplimiento de las cuarentenas por parte de los ciudadanos (Kim, 2020) (ver el Capítulo 4). Las tecnologías digitales han permitido que partes de la población siguiesen trabajando o estudiando desde el hogar durante la cuarentena, además de poder acceder a información actualizada, servicios públicos y programas educativos mientras cumplían las medidas de distanciamiento social (ver el Capítulo 3).

Las plataformas digitales, Internet y el comercio electrónico han ayudado a algunos sectores a mantener parcialmente su actividad. Así, han facilitado las transacciones comerciales (Amazon, Mercado Libre, Rappi), los servicios financieros (Ant Financial, Avant, Mercado Pago, Nubank), los servicios de comunicación y las redes sociales (Facebook, Skype, WhatsApp, Zoom), los servicios de turismo y alojamiento (TakeOff, Booking, Airbnb), el desarrollo de apps (Apple iOS, Google Android) y la búsqueda de empleo (Laborum, LinkedIn, Workana, Freelancer). Las tecnologías digitales pueden contribuir de manera importante a la recuperación de la región, al tiempo que se aborda el persistente desafío que plantea la baja productividad. Además, pueden estimular nuevas conexiones entre oferta y demanda, facilitar operaciones comerciales y de búsqueda de empleo, así como crear o modernizar industrias, por ejemplo en el sector agropecuario (Aggrotech), bancario y financiero (Fintech) o de automoción (Autotech) (ver el Capítulo 2). El análisis de macrodatos capturados por medio de pagos digitales está permitiendo que los órganos públicos puedan hacer un seguimiento de la recuperación, y facilitando el estudio de la eficacia de las políticas de forma más inmediata.

Las distintas consecuencias de las medidas de contención en los diferentes sectores y grupos socioeconómicos son un claro recordatorio de los motivos por los que cerrar las brechas digitales, promover la inclusión y conseguir que las tecnologías beneficien a toda la población deberían erigirse en objetivos principales de las políticas. Solo los trabajadores, estudiantes, ciudadanos y consumidores con la infraestructura y las competencias apropiadas pueden aprovechar las ventajas de las herramientas tecnológicas para seguir trabajando, estudiando y accediendo a bienes y servicios. Son necesarias más intervenciones urgentes en esta región destinadas a desplegar infraestructura de la comunicación (CAF, 2020b), mejorar los marcos regulatorios y ampliar el acceso a Internet y los servicios digitales. En paralelo, los sistemas de educación y formación deben estar mejor preparados para dotar a los alumnos de competencias digitales (OCDE, 2020d) y competencias transversales (BID, 2019), ya que son necesarias para que las personas puedan sacar partido de la transformación digital y adaptarse a los cambios en las circunstancias a lo largo de su vida. Por ejemplo, las disparidades en función del género comienzan a temprana edad en los centros educativos e inciden en el futuro desarrollo profesional del alumnado. Tanto en los países de ALC como en los de la OCDE, los niños tienen cuatro puntos porcentuales más probabilidades de comenzar a utilizar dispositivos digitales antes de los 4 años y cinco puntos porcentuales más de comenzar entre los 4 y los 6 años (ver el Capítulo 3). Es necesaria una mayor cooperación internacional para coordinar e intensificar esos trabajos (ver el Capítulo 5).

\section{La transformación digital como elemento catalizador de desarrollo inclusivo y sostenible}

Un escaso crecimiento económico, una clase media vulnerable y desigualdades persistentes son síntomas de las cuatro trampas del desarrollo de la región. Las trampas se identifican por su dinámica circular, que se perpetúa a sí misma, limita las capacidades 
de los países para lograr un crecimiento más inclusivo y sostenible. Estas trampas son resultado de debilidades persistentes y nuevos desafíos surgidos con el incremento del nivel de ingresos (OCDE et al., 2019). La transformación digital ofrece nuevas herramientas y oportunidades, pero también plantea desafíos. Si se adaptan correctamente, las herramientas digitales pueden ayudar a esta región a encarar la crisis actual y las dificultades estructurales que presenta. El progreso tecnológico se ha acelerado y se están registrando cambios de gran calado que están transformando radicalmente las economías y las sociedades.

La transformación digital se encuentra aún en una fase incipiente en América Latina y el Caribe, y todavía está por ver cuál será la repercusión principal de los cambios que comporta. La inteligencia artificial, los macrodatos, el blockchain, el Internet de las Cosas, los drones, la impresión en 3D, la potencia computacional, la computación en la nube y las redes $5 \mathrm{G}$ son ejemplos destacados de la denominada cuarta revolución industrial o próxima revolución de la producción (OCDE, 2017a, 2017b). La agilidad de la digitalización queda demostrada por el rápido crecimiento de la capacidad de ancho de banda internacional ${ }^{4}$ desde 2007, pese a la volatilidad de los mercados internacionales y la crisis económica mundial. Los flujos de datos internacionales se multiplicaron por 130 entre 2002 у 2017, mientras que los flujos financieros y comerciales tan solo se triplicaron. Destacan tres fases: la primera, de crecimiento, comprendida entre 2000 y 2010, marca el inicio de la transformación digital y los flujos de datos relacionados; la segunda, entre 2010 y 2015, muestra una aceleración de estos flujos, debido principalmente al avance de las redes de banda ancha; la tercera, a partir de 2015, muestra una mayor aceleración de los flujos de datos, provocada por una adopción combinada de tecnologías digitales (Gráfico 1.13).

Gráfico 1.13. Flujos comerciales de bienes y servicios, inversión extranjera directa, otros flujos financieros y capacidad de tráfico internacional de Internet, 1990-2017 (Índice $2003=100$ )

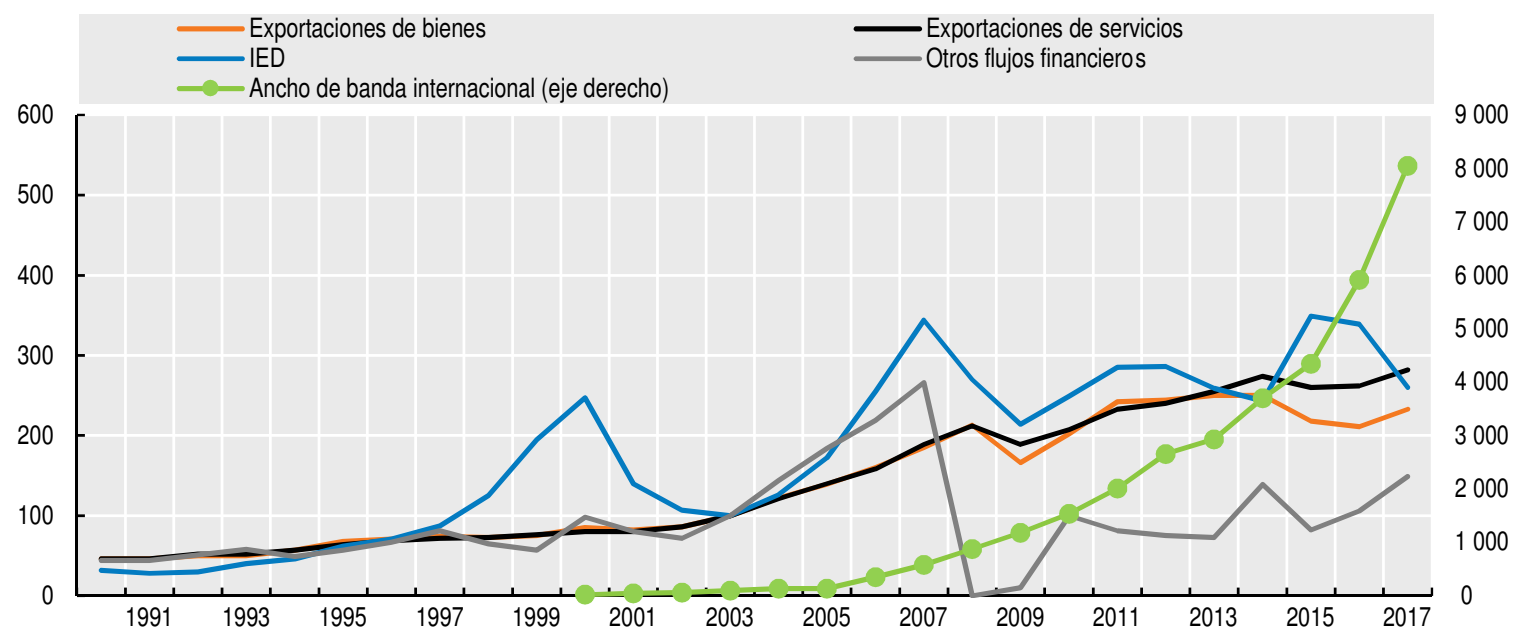

Fuente: CEPAL (2018b), Estado de la banda ancha en América Latina y el Caribe 2017. StatLink intsta https://doi.org/10.1787/888934201705

La transformación digital puede ayudar a erradicar las trampas del desarrollo de esta región. Así, puede promover una sociedad más inclusiva y productiva (ver los Capítulos 2 y 3), ayudar a diversificar las economías de América Latina y el Caribe (OCDE, próxima publicación), contribuir a la mejora de la gobernanza, ampliar el acceso a servicios públicos (ver el Capítulo 4), incrementar la colaboración y creación de contenido por parte de la población, y permitir que esta se beneficie de acceso a los mercados mundiales y de una mayor diversidad y una gama más amplia de productos. Los Objetivos de Desarrollo 
Sostenible (ODS) de Naciones Unidas identifican el acceso a las tecnologías de la información y las comunicaciones (TIC) y el acceso universal y asequible a Internet como un objetivo clave (meta 9c). Las herramientas digitales pueden favorecer la consecución de un gran número de ODS (OCDE et al., 2019).

Los responsables políticos de América Latina y el Caribe deben adoptar una actitud más proactiva respecto a la digitalización e intensificar su interacción con ciudadanos, empresas y trabajadores para adaptar las políticas al nuevo contexto en que vivimos. Pese a las iniciativas en curso, siguen existiendo obstáculos importantes (OCDE, 2020e) y, para aprovechar las oportunidades, también serán necesarios nuevos planteamientos políticos que tengan en cuenta cómo incide la transformación en todos los aspectos de la economía y la sociedad, de maneras complejas e interconectadas, que cuestionen las políticas existentes en muchas materias y trasciendan los ámbitos a los que se circunscriben las políticas sectoriales. Será esencial contar con una mayor colaboración y cooperación tanto en el plano nacional (que incluya a los diferentes niveles de la administración) como internacional, y replantear la formulación y aplicación de las políticas. El proyecto Going Digital de la OCDE identifica siete ámbitos clave para que la transformación digital favorezca el crecimiento y el bienestar: 1) ampliar el acceso a tecnologías digitales; 2) reforzar su uso efectivo; 3) fomentar la innovación digital; 4) garantizar trabajos de calidad para todos; 5) promover una sociedad digital inclusiva; 6) reforzar la confianza; y 7) favorecer mercados abiertos (OCDE, 2019a). La adopción de medidas en estos ámbitos puede dotar a las instituciones públicas de América Latina y el Caribe de un marco propicio para superar las trampas del desarrollo de esta región.

Si la digitalización va a ser un motor del desarrollo sostenible, la formulación y aplicación de estrategias de transformación digital debería ser congruente con una estrategia nacional de desarrollo sostenible y armonizarse con esta. En ese sentido, cabe destacar que la transformación digital puede ayudar a superar disparidades espaciales y avanzar hacia un modelo de desarrollo con bajas emisiones de carbono. Tampoco debería pasarse por alto la dimensión regional (subnacional), pues debe abordarse la considerable heterogeneidad de la transformación digital entre las diferentes áreas que conforman

\section{Recuadro 1.2. Carencias regionales en materia de transformación digital: El caso de Colombia}

Durante los últimos siete años, el Consejo Privado de Competitividad y la Universidad del Rosario han elaborado y publicado el Índice Departamental de Competitividad (IDC), un diagnóstico multidimensional del desarrollo económico de las regiones de Colombia que se basa en la metodología del Índice de Competitividad Global del Foro Económico Mundial (FEM).

El IDC se construye a partir de 104 indicadores sólidos - que no corresponden a resultados de encuestas de opinión-, agrupados en 13 pilares y cuatro factores de competitividad. El resultado final obtenido es la asignación de un puntaje normalizado de entre 0 y 10 a cada uno de los 32 departamentos de Colombia y Bogotá.

Este indicador se ha venido utilizando como herramienta de diagnóstico y seguimiento de los planes locales de desarrollo. En 2017, el indicador fue reconocido por el FEM por su capacidad para medir el desempeño local en materia de competencia, y ha generado un gran número de foros de debate en todo el país como dato clave para analizar las políticas públicas de las regiones (Consejo Privado de Competitividad/Universidad del Rosario, 2016; FEM, 2017). 


\section{Recuadro 1.2. Carencias regionales en materia de transformación digital: El caso de Colombia (cont.)}

En 2019, el IDC hizo hincapié en la importancia de la transformación digital al incluir un pilar sobre adopción de TIC. De ese modo, se sentaron las bases para la elaboración del Índice Departamental de Conectividad Tecnológica (IDCT), que se inspiró en el pilar sobre adopción de las TIC del Índice de Competitividad Global y en el marco conceptual del índice Going Digital de la OCDE. El IDCT evalúa el desempeño de los departamentos en cinco ámbitos: 1) dotación pública de TIC; 2) infraestructura de TIC en los territorios; 3) acceso de los hogares; 4) emprendimiento en TIC; y 5) formación de capital humano.

El IDCT revela brechas importantes en el ámbito de la inserción y la adopción masiva de las TIC a nivel regional, pues existe una diferencia entre departamentos de 5,6 puntos en la clasificación del IDC y de 8.0 puntos en el IDCT. La clasificación del IDCT coincide, en parte, con los ingresos per cápita de los departamentos (Gráfico 1.14).

\section{Gráfico 1.14. Distribución de los puntajes del Índice Departamental de Competitividad, el Índice Departamental de Conectividad Tecnológica y el PIB per cápita en Colombia, 2019
$\triangle I D C$
- IDCT
- PIB per cápita normal

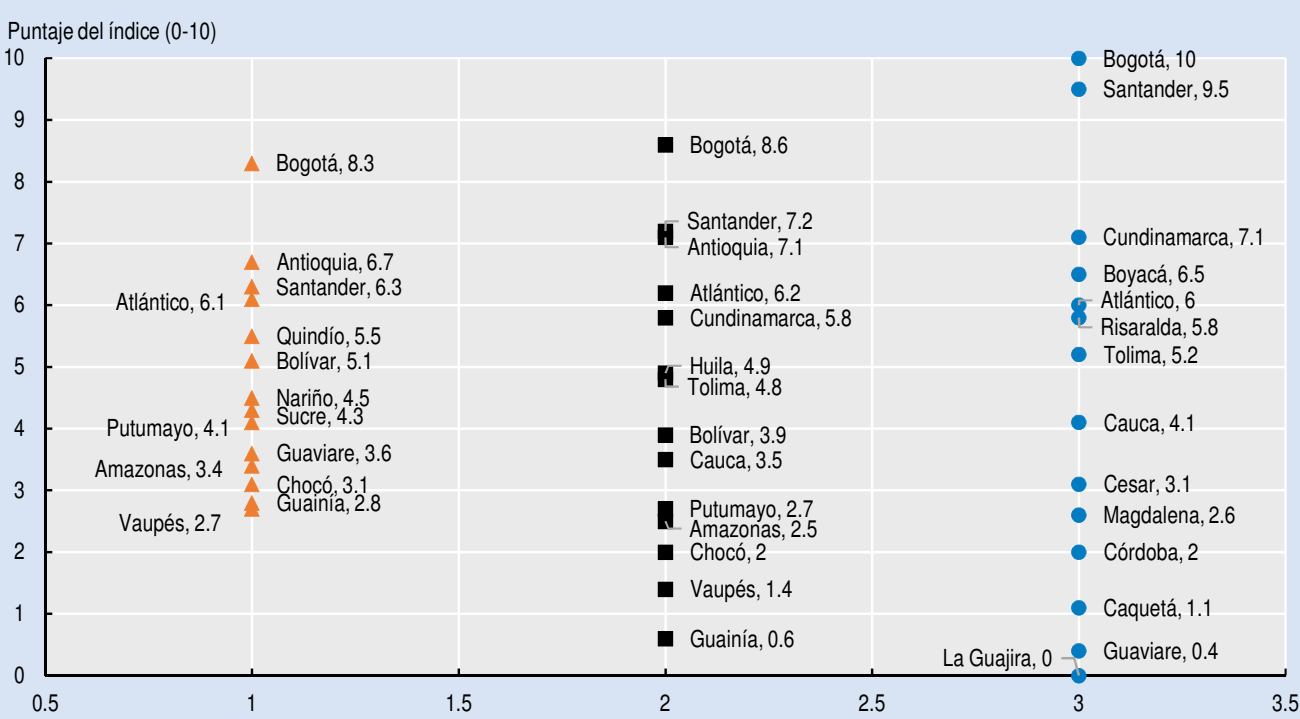

Notas: El PIB per cápita no incluye las actividades minero energéticas. Para la normalización, se utilizó una transformación de máximos y mínimos que asigna un valor de entre 0 y 10.

Indicador $=(($ valor del departamento - valor mínimo del indicador $) /($ valor máximo del indicador - valor mínimo del indicador) $) * 10$

Fuente: Consejo Privado de Competitividad (2019).

StatLink त्मा5 https://doi.org/10.1787/888934201724

El primer paso es esclarecer las enormes disparidades que existen en Colombia en materia de transformación digital y estos índices deberían tomarse como base de las actuaciones en materia de políticas públicas. Por ejemplo, habida cuenta de que las diferencias más pronunciadas en materia de transformación digital se encuentran en departamentos con amplios núcleos rurales, se podría recurrir a asociaciones público-privadas con el fin de obtener la infraestructura de la comunicación necesaria para la conectividad regional, de modo que dicha responsabilidad no recayese íntegramente en el sector público (Consejo Privado de Competitividad, 2019). 
cada país, con el objetivo de impulsar la productividad, la competitividad y la inclusión en coordinación con políticas nacionales (Recuadro 1.2).

Como consecuencia de la desmaterialización de la economía, la transformación digital puede ayudar a conseguir una transición "justa" hacia un crecimiento sostenible con una baja emisión de carbonos, mediante la producción de energías limpias (por ejemplo, la electrificación de la industria, el transporte y el consumo de los hogares; la regeneración de sumideros de carbono naturales) y una mayor eficiencia en el uso de los recursos (por ejemplo, reduciendo residuos, minimizando el nivel de producción de carbonos de la construcción) (BID /DDPLAC, 2019). En todo caso, el suministro de bienes digitales y la prestación de servicios por medios digitales reduce la necesidad de trasladarse físicamente a otro lugar, con lo que disminuyen las emisiones. Del mismo modo, ambos procesos pueden aumentar la eficiencia de la producción y el consumo de energía. La transformación digital y la transición a una economía con bajas emisiones de carbonos pueden repercutir de manera positiva e importante en la inclusión social y cívica. Además, pueden generar beneficios en materia de salud y ayudar a crear trabajos de calidad. La transición a una economía con bajas emisiones de carbonos debe ser justa, en el sentido de que el empeño por proteger el planeta debe conjugarse con una justicia social. El elevado consumo energético de los medios digitales también comporta riesgos, como procesos de producción contaminantes y, en el caso de los dispositivos de hardware, importantes residuos electrónicos. En 2017, la tecnología digital y el almacenamiento de datos generados representaron casi el $7 \%$ del consumo eléctrico mundial. Habida cuenta de que la mayor parte de ciudadanos y dispositivos se conectan a Internet, se prevé un incremento de esta cifra que supondrá una mayor presión sobre el entorno (Greenpeace, 2017).

La medición reviste una importancia crucial para la formulación y evaluación de las políticas, y para velar por una mayor efectividad y una gestión más responsable, necesarias para restaurar la confianza entre ciudadanos y administraciones públicas. No obstante, las herramientas y métricas que existen en la actualidad no logran abarcar el alcance de la transformación digital y sus posibles consecuencias (Recuadro 1.3) (OCDE, 2019c). A corto plazo, debería darse prioridad a mejorar la capacidad, para realizar comparaciones de carácter internacional de los indicadores actuales y flexibilizar los sistemas estadísticos con el objeto de introducir nuevos conceptos relativos a la transformación digital. A más largo plazo, la comunidad estadística tendrá que inventar métodos nuevos e interdisciplinares para recopilar datos y aprovechar la información recabada por tecnologías digitales. Las alianzas con el sector privado revestirán especial

\section{Recuadro 1.3. Cómo medir la transformación digital: Hoja de ruta para el futuro}

La OCDE ha enunciado nueve medidas que deberían mejorar la capacidad de los países para hacer un seguimiento y una medición de la transformación digital y sus consecuencias. Las cuatro primeras tienen por objeto facilitar a las administraciones públicas mejores datos e indicadores que les permitan superar los obstáculos encontrados. Las cinco restantes se centran en ámbitos que requieren atención prioritaria. El objetivo es avanzar en el programa de medición y preparar indicadores clave relativos a las dimensiones del marco de políticas integradas de la OCDE Going Digital, así como indicadores complementarios que briden información más pormenorizada y con más matices (OCDE, 2019c).

Primera medida. Dar visibilidad a la economía digital en las estadísticas económicas.

Segunda medida. Conocer las repercusiones de la transformación digital en la economía. 


\section{Recuadro 1.3. Cómo medir la transformación digital: Hoja de ruta para el futuro (cont.)}

Tercera medida. Fomentar la medición de los efectos de la transformación digital en los objetivos sociales y el bienestar de las personas.

Cuarta medida. Formular métodos nuevos e interdisciplinares para la recopilación de datos.

Quinta medida. Hacer un seguimiento de las tecnologías en las que se sustenta la transformación digital, en particular del Internet de las Cosas, la inteligencia artificial y el blockchain.

Sexta medida. Mejorar la medición de datos y flujos de datos.

Séptima medida. Definir y medir las necesidades en materia de competencias para la transformación digital.

Octava medida. Medir la confianza en los entornos en línea.

Novena medida. Establecer un marco de evaluación del impacto para los gobiernos digitales.

importancia para la introducción de perspectivas y datos novedosos en el proceso de formulación de políticas encaminadas a alcanzar estos objetivos (OCDE, 2019c).

La ambiciosa transformación que prevé la Agenda de Desarrollo Sostenible 2030 de Naciones Unidas comporta un cambio en el paradigma de desarrollo, que debe gestarse teniendo en cuenta la nueva era industrial auspiciada por la revolución digital. La transformación digital provoca cambios en los modelos de producción y consumo que pueden ofrecer oportunidades, pero también conllevan riesgos para el medioambiente. La respuesta a la crisis del coronavirus (Covid-19) brinda una oportunidad para solventar ambos problemas de manera simultánea, ya que las políticas de recuperación deberían orientar los estímulos económicos a crear un modelo de desarrollo basado en la sostenibilidad ambiental (OCDE, 2020b).

\section{Conclusión}

La región de América Latina y el Caribe se vio golpeada por la crisis del coronavirus (Covid-19) en un momento caracterizado por la existencia de trampas del desarrollo y profundo descontento social, manifestado en la oleada de protestas masivas que tuvieron lugar a finales de 2019. Además, la región atravesaba el periodo con el peor dato de crecimiento registrado desde 1950. Por lo tanto, la crisis ha acentuado problemas estructurales de gran calado en los países de esta región.

Las medidas de contención provocaron una caída drástica e inmediata de la actividad económica, al tiempo que los confinamientos globales generaron un contexto externo poco favorable, con un marcado descenso de la demanda mundial, el comercio, el turismo y los precios de los productos básicos, y un aumento de la volatilidad financiera, como demuestran los máximos históricos de salidas de capital que se observaron en el primer trimestre de 2020 y las depreciaciones de las divisas.

El pronunciado descenso del crecimiento económico ha debilitado los pronósticos de avance socioeconómico en América Latina y el Caribe. Las consecuencias sociales de la crisis han sido asimétricas y afectan principalmente a los grupos más vulnerables. Un gran número de empresas, en su mayoría microempresas, podría cerrar, lo que comportaría pérdidas de empleo considerables y afectaría a los ingresos de los hogares. 
El impacto en materia de ingresos se sentirá en mayor medida en los hogares más pobres y económicamente vulnerables, y se prevén importantes aumentos en los niveles de pobreza y pobreza extrema. La mayoría de los trabajadores que integran estos grupos de ingresos con más riesgo se encuentran inmersos en la trampa de la vulnerabilidad social, a saber, puestos de trabajo informales que limitan su acceso a los sistemas de protección social, el seguro por desempleo, una estabilidad en cuanto a ingresos y el ahorro como red de seguridad. Los trabajadores del mercado informal son también especialmente vulnerables a los problemas sanitarios provocados por la pandemia y carecen de las condiciones laborales necesarias para mitigar los riesgos para su salud que ha generado.

La mayoría de los países ha respondido con medidas fiscales y monetarias oportunas encaminadas a atenuar las consecuencias socioeconómicas de la crisis. Algunos bancos centrales han relajado las condiciones monetarias mediante rebajas de las tasas de interés y la adopción de medidas de liquidez, con el fin de favorecer el aumento de la demanda interna y estimular la actividad empresarial. La política fiscal ha desempeñado un importante papel a corto plazo y será esencial para la recuperación, así como para superar las dificultades estructurales, por ejemplo el tenue crecimiento de la productividad, a mediano plazo. La capacidad de los países para implementar una política fiscal dependerá de la posición fiscal inicial y de su acceso a los mercados internacionales. Habida cuenta del escaso margen y los dispares desafíos existentes, resulta prioritario lograr una coordinación internacional de las políticas macroeconómicas y la gestión de la deuda pública.

Las tecnologías digitales han sido esenciales para luchar contra la pandemia y sus consecuencias socioeconómicas, ya que han ayudado a mantener la continuidad empresarial y han permitido que parte de la población teletrabajara y siguiera con su educación por medios remotos. No obstante, pocos países de ALC cuentan con la infraestructura y las competencias necesarias para beneficiarse plenamente de estas tecnologías. La pandemia confirma el elevado potencial de la transformación digital, pero destaca la apremiante necesidad que supone cerrar la brecha digital.

La utilidad de las tecnologías digitales durante la pandemia es un ejemplo de la importancia que reviste la transformación digital para superar los problemas estructurales de ALC, y las trampas del desarrollo identificadas en las Perspectivas Económicas de América Latina 2019. Dichas trampas son en sí mismas resultado de carencias estructurales históricas que acrecientan las dificultades de desarrollo. En este sentido, con el avance de los países en sus respectivas sendas de desarrollo, ciertas deficiencias estructurales en dimensiones clave de desarrollo, como son la productividad, la inclusión social y la pobreza, han generado una dinámica defectuosa que ha desembocado en una situación de bloqueo. La pandemia ha revelado que los problemas estructurales que encara esta región restringen el desarrollo y la adopción de soluciones y tecnologías digitales. El escaso porcentaje de población que ha podido acceder a soluciones digitales, como el teletrabajo, y el reducido número de empresas que hicieron frente a la crisis del coronavirus con medios digitales deberían ser una llamada de atención.

La revolución digital plantea múltiples oportunidades, que pueden ayudar a la región a superar sus deficiencias estructurales. Una correcta adopción de nuevas tecnologías puede propiciar la aparición de nuevos motores de crecimiento, y favorecer el aumento de la productividad y la diversificación (ver el Capítulo 2). Las herramientas digitales pueden incrementar el bienestar gracias a la creación de nuevos empleos, la mejora del capital humano y el fomento de una mejor conciliación de la vida laboral y personal (ver el Capítulo 3). Además, pueden reforzar la gobernanza pública, al favorecer la consecución de instituciones más creíbles, efectivas, inclusivas e innovadoras y dotarles de más instrumentos para dar respuesta a las exigencias de los ciudadanos y atajar la creciente 
insatisfacción social (ver el Capítulo 4). Asimismo, pueden contribuir a la consecución de una transición justa hacia un crecimiento verde y sostenible, y un modelo de desarrollo con bajas emisiones de carbono gracias a la desmaterialización de la economía. Muchos desafíos planteados por la transformación digital transcienden fronteras, por lo que se requieren actuaciones y alianzas de desarrollo de alcance internacional. América Latina y el Caribe puede aprender de las experiencias vividas en otros países con el objetivo de hacer un mejor uso de las tecnologías y garantizar que la transformación digital beneficie a toda la población (ver el Capítulo 5).

\section{Notas}

1. La Organización Internacional del Trabajo calcula que el $23 \%$ de los trabajadores de América Latina ocupa puestos de trabajo que podrían desempeñarse desde el hogar, frente al $30 \%$ en Norteamérica y Europa, el 12\% en Asia-Pacífico y el 7\% en África (OIT, 2020).

2. Hepburn et al. (2020) encuesta a varios responsables ejecutivos y otros expertos económicos de países del G20 sobre el rendimiento relativo de 25 paquetes fiscales "tipo" principales para la recuperación fiscal, que abarcan cuatro dimensiones: ritmo de implantación, multiplicador económico, potencial de impacto climático y conveniencia global. Identifican cinco políticas con grandes posibilidades respecto a los indicadores multiplicador económico e impacto climático: infraestructura física limpia, ajustes en la eficiencia de las construcciones, inversión en educación y formación, inversión en riqueza natural y actividades de I+D limpias.

3. Burzynska y Contreras (2020) señalan dos motivos principales por los que es más factible que las niñas no regresen a los centros educativos: un mayor riesgo de que sean sometidas a explotación sexual, se queden embarazadas o contraigan matrimonio (forzoso) durante los confinamientos; y un aumento desproporcionado del trabajo doméstico no remunerado que provoca que las niñas dediquen más tiempo a ayudar en el hogar que a estudiar.

4. El ancho de banda internacional es la cantidad máxima de transmisión de datos desde un país al resto del mundo.

\section{Referencias}

Abeles, M. y M. Cherkasky (2020), "Revisiting balance of payments constrained growth 70 years after ECALC's Manifesto, the case of South America", Revista de Economia Contemporânea, 24(1), Río de Janeiro, https://doi.org/10.1590/198055272417.

Abramo, L., S. Cecchini y B. Morales (2019), Programas sociales, superación de la pobreza e inclusión laboral: Aprendizajes desde América Latina y el Caribe, Comisión Económica para América Latina y el Caribe, Santiago, https://repositorio.cepal.org/bitstream/handle/11362/44622/1/S1900004 en.pdf.

Andrews, D., G. Nicoletti y C. Timiliotis (2018), "Digital technology diffusion: A matter of capabilities, incentives or both?", Documentos de trabajo del Departamento de Asuntos Económicos de la OCDE, n. 1476, OCDE, París, https://doi.org/10.1787/7c542c16-en.

Banco Mundial (2020a), "El Banco Mundial prevé la mayor caída de remesas de la historia reciente", https://www.worldbank.org/en/news/press-release/2020/04/22/world-bank-predicts-sharpestdecline-of-remittances-in-recent-history\#: :text=Remittances\%20flows\%20into\%20Latin\%20 America,to\%20\%2496\%20billion\%20in\%202019.\&text=In\%202020\%2C\%20remittance \%20 flows $\% 20$ to,the\%20first\%20quarter\%20of\%202020.

Banco Mundial (2020b), International Debt Statistics, Banco Mundial, Washington, D. C., https://data. worldbank.org/products/ids (consulta de mayo de 2020).

Basto-Aguirre, N., S. Nieto-Parra y J. Vázquez-Zamora (2020), Informality in Latin America in the post COVID-19 era: Towards a more formal "new normal"?, Vox Lacea, http://vox.lacea.org/?q=blog/ informality_latam_postcovid19.

BEA (2020), Gross Domestic Product, 2nd Quarter 2020 (Advance Estimate) and Annual Update, U.S. Bureau of Economic Analysis (BEA), https://www.bea.gov/news/2020/gross-domestic-product-2ndquarter-2020-advance-estimate-and-annual-update.

BID (2020), "How exposed is Latin America to the trade effects of COVID-19?", Banco Interamericano de Desarrollo, Washington, D. C., https://blogs.iadb.org/integration-trade/en/latin-americatrade-effects-covid-19/. 
BID (2019), Habilidades del siglo 21: Desarrollo de habilidades transversales en América Latina y el Caribe, Banco Interamericano de Desarrollo, Washington, D. C., http://dx.doi.org/10.18235/0001574.

BID y DDPLAC (2019), Getting to Net-Zero Emissions: Lessons from Latin America and the Caribbean, Banco Interamericano de Desarrollo, Washington, D. C., https://www.iddri.org/en/publications-andevents/report/getting-net-zero-emissions-lessons-latin-america-and-caribbean.

Bolton, P. et al. (2020), "Born out of necessity: A debt standstill for COVID-19”, Policy Insight n. ${ }^{\circ} 103$, 27 de abril, Center for Economic Policy Research, Duke Law School Public Law \& Legal Theory Series n. ${ }^{\circ}$ 2020-23, disponible en SSRN: https://ssrn.com/abstract=3586785.

Burzynska K. y G. Contreras (2020), "Gendered effects of school closures during the COVID-19 pandemic", The Lancet, Vol. 395(10242) p. 1968. 27 junio-3 julio, 10.1016/S0140-6736(20)31377-5.

CAF (2020a), "Perspectivas Económicas para el segundo trimestre", documentos internos.

CAF (2020b), "El estado de la digitalización de América Latina frente a la pandemia del COVID-19", Observatorio CAF del Ecosistema Digital, abril.

CEPAL (2020a), "Enfrentar los efectos cada vez mayores del COVID-19 para una reactivación con igualdad: nuevas proyecciones", Informe especial: COVID-19, n. ${ }^{\circ}$ 5, Comisión Económica para América Latina y el Caribe, Santiago, https://www.cepal.org/en/publications/45784-addressinggrowing-impact-covid-19-view-reactivation-equality-new-projections.

CEPAL (2020b), "Los efectos del COVID-19 en el comercio internacional y la logística", Informe Especial COVID-19 n. 6, Comisión Económica para América Latina y el Caribe, Santiago, https://www.cepal.org/en/publications/45878-effects-coronavirus-disease-covid-19-pandemicinternational-trade-and-logistics.

CEPAL (2020c), "América Latina y el Caribe ante la pandemia del COVID-19: efectos económicos y sociales", Informe Especial COVID-19 n.1, Comisión Económica para América Latina y el Caribe, Santiago, https://repositorio.cepal.org/bitstream/handle/11362/45351/S2000263 en. pdf? sequence $=1$ \&is Allowed $=\mathrm{y}$.

CEPAL (2020d), "Sectores y empresas frente al COVID-19: emergencia y reactivación", Informe especial: COVID-19 n. ${ }^{\circ}$, Comisión Económica para América Latina y el Caribe, Santiago, https://www.cepal.org/en/publications/45736-sectors-and-businesses-facing-covid-19emergency-and-reactivation.

CEPAL (2019), Panorama social de América Latina, Comisión Económica para América Latina y el Caribe, Santiago, https://repositorio.cepal.org/bitstream/handle/11362/44969/5/S1901133 es.pdf.

CEPAL (2018a), La ineficiencia de la desigualdad, Comisión Económica para América Latina y el Caribe, Santiago, https://www.cepal.org/en/publications/43443-inefficiency-inequality\#: :text=It\%20 analyses\%20and\%20measures\%20the,\%2D\%20or\%20thnicity\%2Dbased\%20discrimination.

CEPAL (2018b), Estado de la banda ancha en América Latina y el Caribe 2017, Comisión Económica para América Latina y el Caribe, Santiago, https://www.cepal.org/en/publications/43670-statebroadband-latin-america-and-caribbean-2017.

CEPAL (2016), La matriz de la desigualdad social en América Latina (LC/G.2690(MDS.1/2)), Comisión Económica para América Latina y el Caribe, Santiago, octubre, https://repositorio.cepal.org/ handle/11362/40710.

CEPAL (2012), Los países de renta media: Un nuevo enfoque basado en brechas estructurales, LC/G.2532/ Rev.1, Comisión Económica para América Latina y el Caribe, Santiago, https://repositorio.cepal. org/bitstream/handle/11362/13536/1/S2012864_en.pdf.

Consejo Privado de Competitividad (2019), Informe Nacional de Competitividad 2019-2020, Consejo Privado de Competitividad, Bogotá, D. C.

Consejo Privado de Competitividad/Universidad del Rosario (2016), Índice Departamental de Competitividad, Consejo Privado de Competitividad, Bogotá D. C.

Espino, E. and M. González Rozada (2012), "Automatic Stabilization and Fiscal Policy: Some Quantitative Implications for Latin America and the Caribbean", IDB Working Paper Series No. IDB-WP-367 I.

Eichengreen, B. (2020), "Managing the coming global debt crisis", Project Syndicate, https://www. project-syndicate.org/commentary/managiing-coming-global-debt-crisis-by-barry-eichengreen2020-05?a la=english\&a $d=5$ ebbc22031305e26b0b72bda\&a $m=\& a \quad a=c l i c k \& a \quad s=\& a \quad p=\% 2 F$ columnist\%2Fbarry-eichengreen\&a_li=managiing-coming-global-debt-crisis-by-barry-eichengreen2020-05\&a_pa=columnist-commentaries\&a_ps=\&a ms=\&a r=\&barrier=accesspaylog.

FEM (2017), The Global Competitiveness Report 2017, Foro Económico Mundial, Ginebra.

Flores Zendejas, J. (2020), "What can Latin America learn from historic debt crises to face the COVID-19 crisis today?", OECD Development Matters, https://oecd-development-matters.org/2020/05/25/ what-can-latin-america-learn-from-historic-debt-crises-to-face-the-covid-19-crisis-today/. 
FMI (2020), "Una crisis como ninguna otra, una recuperación incierta", Actualización de las perspectivas de la economía mundial, junio, Fondo Monetario Internacional, https://www.imf.org/ en/Publications/WEO/Issues/2020/06/24/WEOUpdateJune2020.

FMI (2019), Base de datos de las Perspectivas de la Economía Mundial, octubre, https://www.imf.org/ external/pubs/ft/weo/2019/02/weodata/index.aspx.

Greenpeace (2017), Clicking Clean: Who is winning the race to build a green internet?, https://www. greenpeace.org/international/publication/6826/clicking-clean-2017/.

Hepburn, C. et al. (2020), "Will COVID-19 fiscal recovery packages accelerate or retard progress on climate change?", Oxford Review of Economic Policy, https://doi.org/10.1093/oxrep/graa015.

IIF (2020), COVID-19 Capital Flow Exodus from EM, Institute of International Finance, Washington, D. C., https://www.iif.com/COVID-19.

Inter-American Dialogue (2020), China-Latin America Finance Database, https://www.thedialogue. org/map_list/.

Izquierdo, A. y M. Ardanaz (2020), "Fiscal policy in the time of coronavirus: Constraints and policy options for Latin American and Caribbean countries", Banco Interamericano de Desarrollo, Washington D. C., https://blogs.iadb.org/ideas-matter/en/fiscal-policy-in-the-time-of-coronavirusconstraints-and-policy-options-for-latin-american-and-caribbean-countries/.

Izquierdo, A., C. Pessino y G. Vuletin (eds.) (2018), Mejor gasto para mejores vidas: Cómo América Latina y el Caribe puede hacer más con menos, Desarrollo en las Américas, Banco Interamericano de Desarrollo, Washington, D. C. y Palgrave Macmillan, Nueva York.

Kim, M. (2020), "South Korea is watching quarantined citizens with a smartphone app", MIT Technology Review, https://www.technologyreview.com/s/615329/coronavirus-south-koreasmartphone-app-quarantine/.

Milanović, B. (2020), “Por qué importa la desigualdad?”, Letras Libres, https://www.letraslibres. com/espana-mexico/economia/por-que-importa-la-desigualdad.

Nieto-Parra, S. y R. Orozco (2020), "Public debt and COVID-19. Paying for the crisis in Latin America and the Caribbean", Le Grand Continent, https://legrandcontinent.eu/fr/2020/07/22/public-debtand-covid-19-paying-for-the-crisis-in-latin-america-and-the-caribbean/.

Nuguer, V. y A. Powell (2020), "Políticas para combatir la pandemia", Informe macroeconómico de América Latina y el Caribe 2020, Banco Interamericano de Desarrollo, Washington, D. C., http://dx.doi.org/10.18235/0002284.

OCDE (próxima publicación), Estudios Económicos de la OCDE: Chile 2020, Publicaciones de la OCDE, París.

OCDE (2020a), Perspectivas económicas provisionales de la OCDE, septiembre de 2020, Publicaciones de la OCDE, Paris, https:// doi.org/10.1787/34ffc900-en.

OCDE (2020b), COVID-19 in Latin America and the Caribbean: Regional Socio-Economic Implications and Policy Priorities, Publicaciones de la OCDE, París, http://www.oecd.org/coronavirus/policy-responses/ covid-19-in-latin-america-and-the-caribbean-regional-socio-economic-implications-andpolicy-priorities-93a64fde/.

OCDE (2020c), “Afrontar el coronavirus (COVID-19): Unidos en un esfuerzo global”, OECD Country Policy Tracker, https://www.oecd.org/coronavirus/country-policy-tracker/.

OCDE (2020d), OECD Employment Outlook 2020: Worker Security and the COVID-19 Crisis, Publicaciones de la OCDE, París, https://doi.org/10.1787/1686c758-en.

OCDE (2020e), Estudios Económicos de la OCDE: Costa Rica 2020, Publicaciones de la OCDE, París, https://doi.org/10.1787/2e0fea6c-en.

OCDE (2019a), Going Digital: Shaping Policies, Improving Lives, Publicaciones de la OCDE, París, https:// doi.org/10.1787/9789264312012-en.

OCDE (2019b), Perfilando la transformación digital en América Latina. Mayor productividad para una vida mejor, Publicaciones de la OCDE, París, https://doi.org/10.1787/8bb3c9f1-en.

OCDE (2019c), Cómo medir la transformación digital. Hoja de ruta para el futuro, Publicaciones de la OCDE, París, https://doi.org/10.1787/9789264311992-en.

OCDE (2017a), Going Digital: Making the Transformation Work for Growth and Well-Being, Reunión del Consejo de la OCDE a nivel ministerial, París, https://www.oecd.org/mcm/documents/C-MIN-2017-4\%20 EN.pdf.

OCDE (2017b), Perspectivas de la OCDE sobre la Economía Digital 2017, Publicaciones de la OCDE, París, http://dx.doi.org/10.1787/9789264276284-en.

OCDE et al. (2020), Estadísticas tributarias en América Latina y el Caribe 2020, Publicaciones de la OCDE, París, https://doi.org/10.1787/68739b9b-en-es. 
OCDE et al. (2019), Perspectivas económicas de América Latina 2019: Desarrollo en transición, Publicaciones de la OCDE, París, https://doi.org/10.1787/g2g9ff18-en.

OCDE/CAF/CEPAL (2015), Perspectivas económicas de América Latina 2016: Hacia una nueva asociación con China, Publicaciones de la OCDE, París, https://doi.org/10.1787/9789264246218-en.

OIT (2020), "Working from Home: Estimating the worldwide potential, International Labour Organization", Resumen de políticas, https://www.ilo.org/wcmsp5/groups/public/---ed protect/ ---protrav/---travail/documents/briefingnote/wcms 743447.pdf.

Rovira, S. (próxima publicación), Deconstruyendo el proceso de desarrollo de ALC: entre la heterogeneidad productiva, la escasa complejidad tecnológica y la concentración del ingreso.

UNCTAD (2020), Impact of the Coronavirus Outbreak on Global FDI, https://unctad.org/en/ PublicationsLibrary/diae_gitm34_coronavirus_8march2020.pdf. 



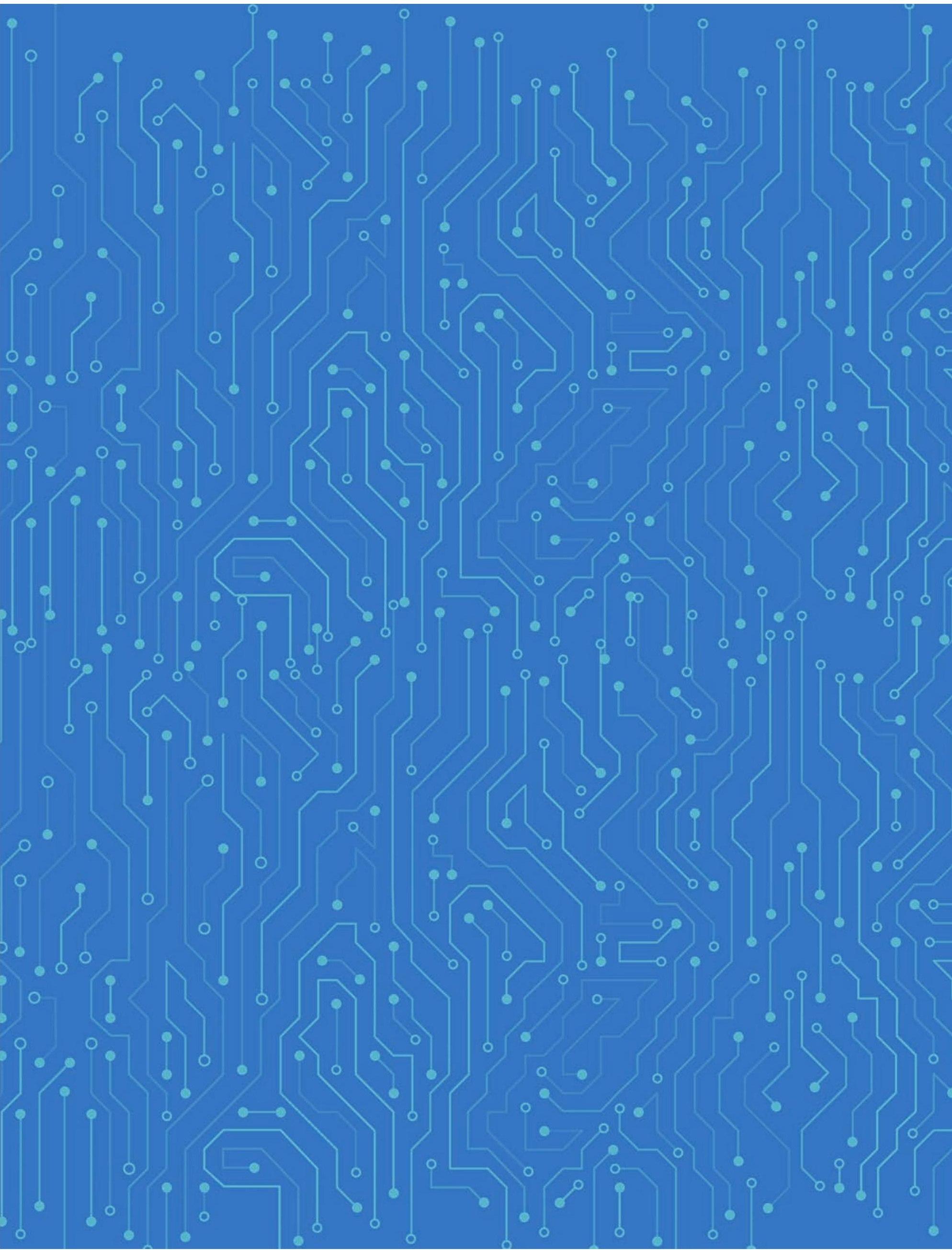




\section{Capítulo 2}

\section{Promover la productividad y potenciar la transformación digital}

Desde la década de los años cincuenta, la productividad ha ido cayendo en América Latina y el Caribe (ALC) en comparación con los países de la OCDE. Esta creciente brecha se debe a una estructura productiva basada en los recursos naturales y en la abundancia de mano de obra poco calificada, lo que se traduce en un bajo valor agregado. Las grandes diferencias de productividad existentes dentro de los sectores y empresas ponen de manifiesto una estructura productiva heterogénea. Estas dificultades estructurales podrían verse amplificadas por la crisis del Covid-19. La transformación digital podría ayudar a los países a hacer frente a la pandemia mejorando la productividad y la eficiencia y diversificando la matriz productiva. Sin embargo, su impacto neto dependerá de las políticas que se adopten y del desarrollo de factores indispensables y complementarios, como las infraestructuras de las comunicaciones, la conectividad del transporte y las competencias y capacidades digitales. 


\section{La revolución digital puede impulsar el crecimiento de la productividad}

La estructura productiva y la heterogeneidad estructural de los países de ALC explican la creciente brecha de productividad

La productividad laboral de ALC ha disminuido durante las últimas décadas en comparación con el resto del mundo

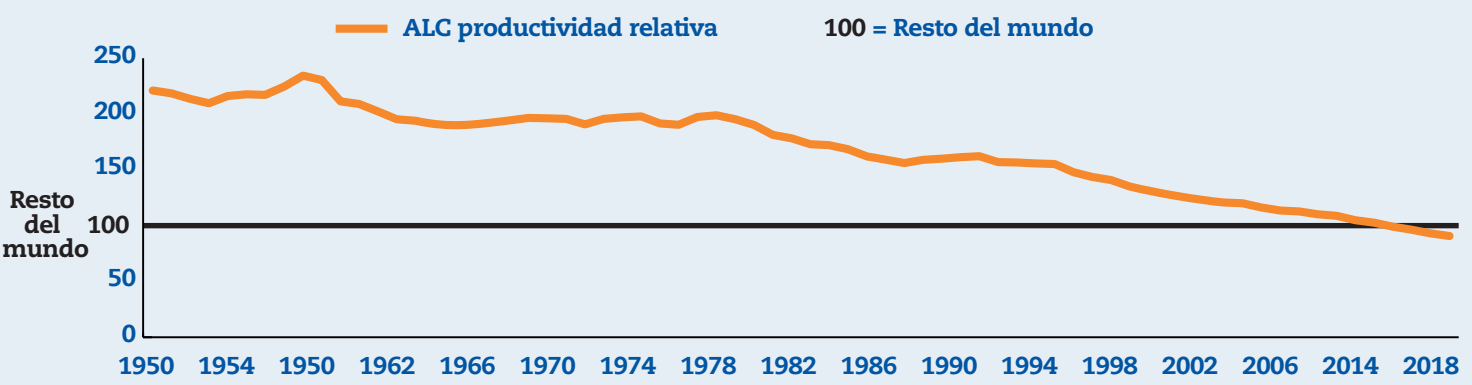

Para aprovechar la revolución digital se necesitan elementos indispensables tales como un ecosistema digital holístico y una infraestructura confiable

La proporción de personas en ALC que utilizan Internet

casi se ha duplicado desde 2010

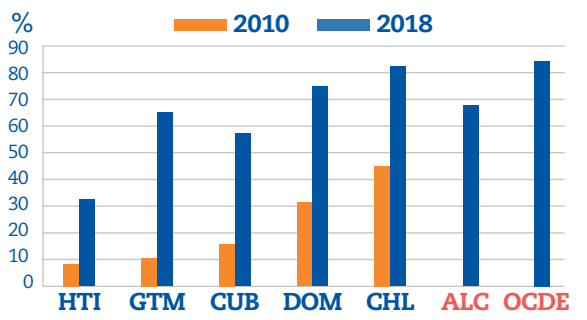

La baja adopción de tecnologías básicas, especialmente entre las pequeñas empresas, sigue siendo un problema en algunos países

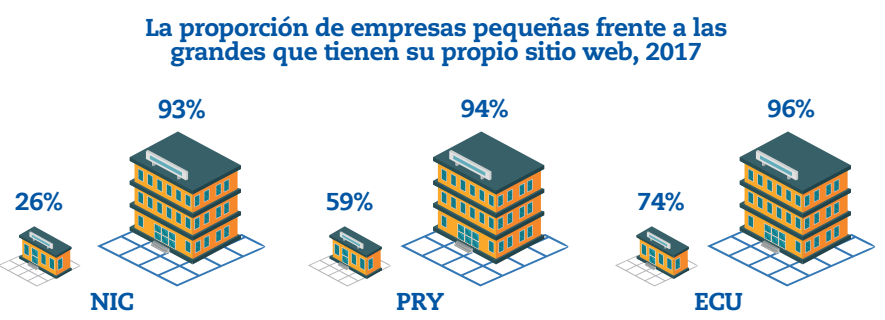

Para las empresas de ALC, una transformación digital exitosa depende de varios elementos complementarios que incluyen:
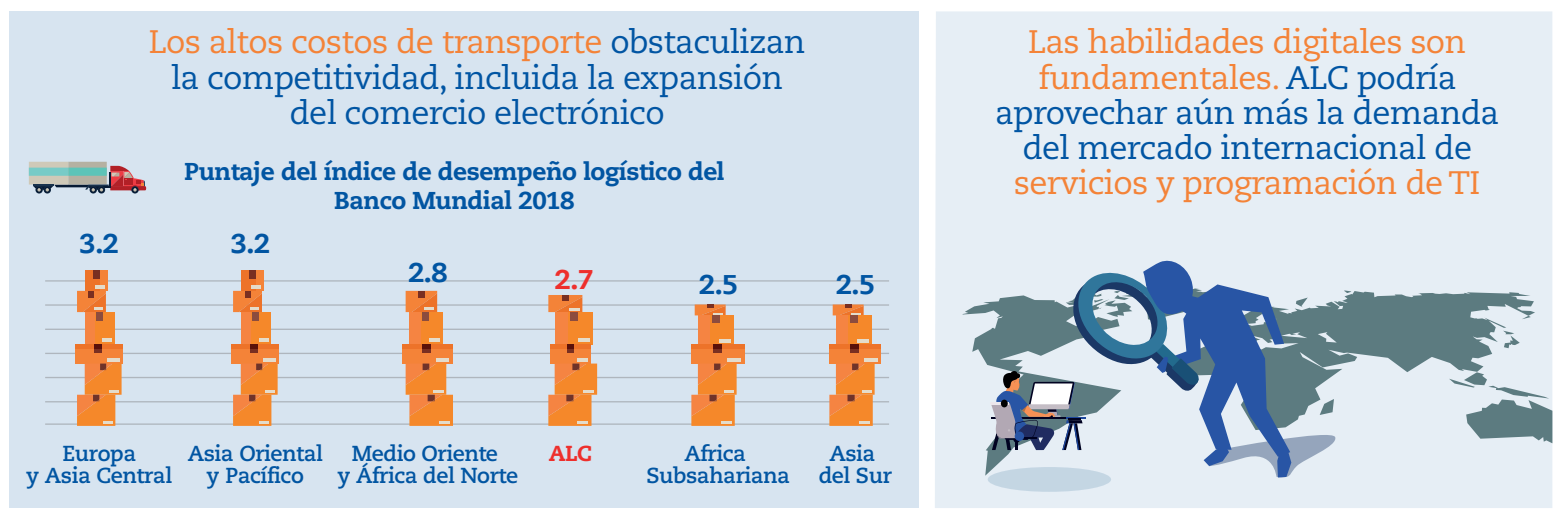


\section{Introducción}

El aumento de la productividad es uno de los retos más pertinentes a los que se enfrenta América Latina y el Caribe (OCDE et al., 2019). La competitividad de la región se basa en gran medida en las ventajas de los recursos naturales y en la abundancia de la mano de obra poco cualificada. Este tipo de ventaja comparativa puede dar lugar a períodos de rápido crecimiento del producto interno bruto (PIB) (por ejemplo, durante periodos de auge de las materias primas), pero no favorece el crecimiento sostenido de la productividad. El tipo de competitividad necesario para lograr la convergencia de la productividad a largo plazo con los países avanzados depende de la incorporación de tecnología y la diversificación de la estructura productiva hacia sectores más dinámicos, tanto en lo que respecta a la tecnología como a la demanda internacional (CEPAL, 2014).

El aumento de la productividad va de la mano de la acumulación de capacidades en los ámbitos más avanzados de la tecnología digital. A medida que se aceleran los avances tecnológicos, existe un menor margen para la competencia con base en ventajas comparativas estáticas, como la abundancia de recursos naturales y la mano de obra poco cualificada. El desarrollo económico requiere la reasignación de recursos hacia la innovación y los sectores intensivos en conocimientos, y la diversificación hacia sectores y actividades que tengan una demanda interna y externa en rápido crecimiento.

La revolución digital entraña grandes disrupciones que podrían promover la diversificación productiva y el crecimiento sostenible de la productividad en la región. Estas alteraciones digitales están desencadenando innovaciones en los modelos de negocio y los sistemas de producción, la reorganización de los sectores económicos, nuevas dinámicas en el mundo del trabajo, la oferta de bienes y servicios inteligentes y nuevas condiciones de competitividad. Estas alteraciones implican diversas tecnologías que, desde hace unos años, son cada vez más numerosas, asequibles y potentes. Las posibilidades de conseguir un cambio estructural progresivo e inclusivo se han incrementado de forma paulatina, pero no uniforme, en los distintos países y sectores. El aprovechamiento de las oportunidades de la revolución digital depende cada vez más de la forma en que las economías, los sectores productivos, las instituciones y las sociedades se posicionan para absorber y adaptar las nuevas tecnologías.

La digitalización afecta a todos los sectores y agrega valor a lo largo de las cadenas de producción, pero la magnitud del cambio depende del estado de factores indispensables y complementarios. La transformación digital afecta a los distintos sectores en grados y con velocidades diferentes (OCDE, 2019a). La adopción de las tecnologías digitales por parte de las empresas más pequeñas de América Latina y el Caribe muestra un potencial significativo, a la vista de la heterogeneidad estructural de la región (CEPAL, 2013). Las tecnologías digitales también promueven la integración en las cadenas productivas al facilitar la interacción en la oferta y la distribución. Asimismo, dichas tecnologías pueden promover la inserción comercial de las empresas al reducir las asimetrías de información y los costos (por ejemplo, de logística y transporte). Sin embargo, no existe una relación directa entre la incorporación de las tecnologías de la información y las comunicaciones (TIC) y el aumento de la productividad. La magnitud del efecto positivo depende de factores indispensables y complementarios, como el acceso y la difusión adecuados de las tecnologías digitales, un sólido dinamismo empresarial, la participación de las pequeñas y medianas empresas (pymes) en la transformación digital, una capacitación y conectividad del transporte adecuadas y un nivel suficiente de competencia en la economía digital. De igual modo, las especificidades del ecosistema en el que actúan los agentes productivos, las características de las tecnologías, la idiosincrasia de las empresas y la capacidad para crear sistemas de innovación eficientes también permiten aprovechar plenamente las tecnologías (CEPAL, 2010; CEPAL, 2013). 
Las tecnologías e infraestructuras digitales han sido más importantes que nunca durante la crisis del coronavirus (Covid-19). Las infraestructuras de telecomunicaciones, el acceso a Internet y los servicios de las TIC han sido claves para apoyar la vida económica y social. Por ejemplo, en los países de la OCDE, algunos operadores obtuvieron hasta un $60 \%$ de aumento en el tráfico de Internet en comparación con antes de la crisis (OCDE, 2020a). La crisis acelerará los cambios estructurales que se han venido produciendo durante la última década. El aumento de la digitalización será una característica de la economía posterior a la pandemia (CEPAL, 2020a). Dado que las cuarentenas han aumentado la virtualización de las relaciones económicas y sociales, puede que el teletrabajo prevalezca en más sectores y regiones, lo que provocaría un avance aún más rápido de la digitalización. Las empresas tecnológicamente más avanzadas, en particular determinadas mipymes (microempresas y pymes), aumentarán su ventaja. Las prolongadas cuarentenas a las que se han visto obligados muchos trabajadores fomentan la inversión en automatización y robótica y el aumento del uso de herramientas de inteligencia artificial (CAF et al., 2020).

Este capítulo comienza analizando brevemente el impacto del Covid-19 en la estructura productiva. Posteriormente se identifican las causas de la persistente y creciente brecha de productividad entre América Latina y el Caribe y los países de la OCDE. Se investiga cómo las tecnologías digitales podrían promover el crecimiento de la productividad, haciendo hincapié en el papel del ecosistema digital. En el tercer apartado se destaca la importancia de las infraestructuras de la comunicación, la conectividad del transporte y las competencias y capacidades digitales como elementos complementarios e indispensables para sacar el mayor provecho de la transformación digital. La cuarta sección explora las políticas que promueven la transformación digital y el aumento de la productividad en la región. La quinta sección estudia el rol de la transformación digital en ALC en el contexto posterior a la pandemia. Finalmente, el capítulo concluye con recomendaciones de política.

\section{Crisis del Covid-19: Impactos en una estructura productiva y empresarial que ya enfrentaba importantes desafíos}

La pandemia del coronavirus (Covid-19) ha generado la mayor crisis de los últimos 100 años en América Latina y el Caribe (ver el Capítulo 1). Ha puesto al descubierto las debilidades históricas de un sistema de producción caracterizado por una estructura productiva heterogénea tanto entre sectores y empresas, como dentro de ellos.

La crisis económica causada por el coronavirus (Covid-19) en la región afecta tanto a la oferta como a la demanda. En lo que respecta a la oferta, los efectos sectoriales han sido transversales pero heterogéneos. Las restricciones sociales han llevado a la suspensión parcial o total de las actividades productivas, afectando principalmente a los sectores cuya actividad depende de la proximidad física. Los sectores definidos como esenciales han experimentado un efecto moderado. El impacto de la crisis es mucho mayor para las mipymes, en las que se han producido graves pérdidas de empleo (CEPAL, 2020b). Debido a la interdependencia de las cadenas de valor mundiales, la interrupción de algunas actividades productivas ha provocado problemas en el suministro de insumos, tanto nacionales como importados, lo que ha creado dificultades para que las empresas sigan operando.

En lo que respecta a la demanda, la reducción de los ingresos de los consumidores y la incertidumbre sobre los escenarios futuros han provocado un descenso de los patrones de consumo y cambios en los mismos. La mayoría de los grupos vulnerables se han visto afectados por esta crisis, en particular los trabajadores del sector informal que han sufrido una repentina reducción de sus ingresos. La disminución de la actividad económica y otros aspectos de la situación internacional han reducido la demanda 
externa. La disminución de los precios de las materias primas ha afectado en particular las economías de América del Sur y algunas economías seleccionadas, entre ellas México y Trinidad y Tobago (OCDE, 2020b).

Las empresas han registrado fuertes caídas en sus ingresos y han experimentado dificultades en la continuidad de sus actividades, lo que puede degradar considerablemente el tejido productivo regional. La falta de productividad y la heterogeneidad que caracterizan la estructura productiva han amplificado el impacto del Covid-19. La pandemia hace más evidentes las debilidades y exacerba los desafíos económicos, sociales y ambientales. En el ámbito productivo, la situación intensifica la urgencia de mitigar la destrucción de capacidades, sin olvidar la necesidad de aumentar la productividad de manera sostenible, generar cadenas productivas y promover la innovación y la transformación digital.

La reactivación económica debe suponer cambios importantes en las empresas y en la organización de la cadena productiva. La pandemia ha obligado a las empresas a adoptar cambios en las condiciones de seguridad y en las relaciones entre trabajadores, proveedores y clientes. El distanciamiento social ha acelerado la transformación digital y ha promovido la adopción de procesos que buscan aumentar la productividad y la eficiencia. En un entorno de rápidos cambios y gran incertidumbre, muchas empresas se han visto obligadas a innovar, reevaluar sus operaciones y cambiar sus modelos de negocio (CEPAL, 2020b).

Las medidas adoptadas por los países de América Latina y el Caribe para hacer frente a la emergencia sanitaria han dado lugar a que las empresas hagan un mayor uso de las tecnologías digitales ${ }^{1}$ en sus interacciones con consumidores, proveedores y empleados, así como en la organización de los procesos de gestión interna. Muchos de estos cambios se mantendrán después de la pandemia, sobre todo en lo que respecta al comportamiento de los consumidores. Las tecnologías digitales serán fundamentales para los nuevos modelos de funcionamiento en tres aspectos. En primer lugar, figurarán en las operaciones de promoción, venta y entrega de bienes y servicios, y en las interacciones con los proveedores. En segundo lugar, las empresas tendrán que incorporar capacidades para adquirir y procesar grandes cantidades de información (big data) para los procesos de decisión (por ejemplo, monitoreo y adaptación a los cambios en la demanda, pero también para redefinir las cadenas de suministro). En tercer lugar, en la industria, cabe esperar una mayor incorporación de dispositivos conectados digitalmente en los procesos de producción y un mayor uso de la robótica para aumentar la eficiencia, sobre todo teniendo en cuenta que la seguridad sanitaria puede requerir menos trabajadores en algunas fases de la producción.

El coronavirus (Covid-19) ha puesto de manifiesto deficiencias estructurales en el sistema productivo de ALC. Para hacer frente a estas deficiencias, las empresas deben tratar de conseguir una mayor eficiencia y productividad, teniendo en cuenta una serie de elementos clave: cómo se redefinen los modelos de negocio y se organizan las cadenas de valor; orientación hacia productos de mayor valor agregado; cambios en el consumo de energía; una mayor interacción entre las empresas (eficiencia colectiva); y la incorporación de nuevas tecnologías y la promoción de la transformación digital (CEPAL, 2020b).

\section{Patrones de productividad y heterogeneidad en América Latina y el Caribe}

La dinámica de la productividad es uno de los aspectos más problemáticos del desempeño económico de América Latina y el Caribe (OCDE et al., 2019; CEPAL, 2018a; CEPAL, 2014; CEPAL, 2010). La región muestra una brecha de productividad elevada y creciente con respecto a las economías desarrolladas. El retraso del PIB per cápita se debe principalmente a la baja productividad laboral. El aumento de la productividad en 
el trabajo permite una inserción más favorable en la economía mundial al tiempo que aumenta la renta disponible, lo que promueve tanto la demanda interna como la externa.

\section{La persistente brecha de productividad}

La productividad laboral agregada de América Latina y el Caribe muestra un crecimiento reducido y poco persistente a partir de 1950. La productividad de la región ha disminuido en comparación con el resto del mundo desde los años sesenta (Gráfico 2.1).

El crecimiento del PIB en América Latina y el Caribe se debe principalmente al crecimiento de la población activa, con escasa contribución del crecimiento de la productividad (Gráfico 2.2). En este sentido, existe un crecimiento por absorción de empleo vinculado al aumento de la demanda agregada, unido a un bajo o nulo progreso técnico e innovación. Esto contrasta con las economías de rápido crecimiento, como la República Popular China (en adelante "China"), India o Corea, donde la productividad es un importante motor del crecimiento del PIB.

La evolución de la estructura de empleo de la región explica en gran medida el bajo crecimiento de la productividad. La estructura sectorial del empleo en ALC a partir de 1980 muestra tres grandes cambios: disminución del peso de la agricultura, descenso del peso de la industria manufacturera y aumento de la participación del comercio (mayorista y minorista). Esta combinación dio lugar a una migración del campo a la ciudad que no produjo un crecimiento de la productividad. La disminución de la mano de obra en el sector agrícola impidió un mayor deterioro de su nivel de productividad. No obstante, la mano de obra que llegaba a las ciudades no conseguía obtener empleos de calidad debido al fenómeno simultáneo de la desindustrialización prematura desde la década de los ochenta. El sector comercial sirvió de vía para el empleo de emergencia, en gran parte informal y predominantemente de mipymes (sobre todo microempresas que ofrecían empleos de baja productividad). Esto se refleja en el aumento de la participación de las mipymes en el empleo total, que pasó del 14.3\% en 1981 al 25.3\% en 2018 (Tabla 2.1).

\section{Gráfico 2.1. Productividad laboral de los países de América Latina y el Caribe en relación con el resto del mundo, 1950-2019}

Proporción de la productividad laboral del resto del mundo

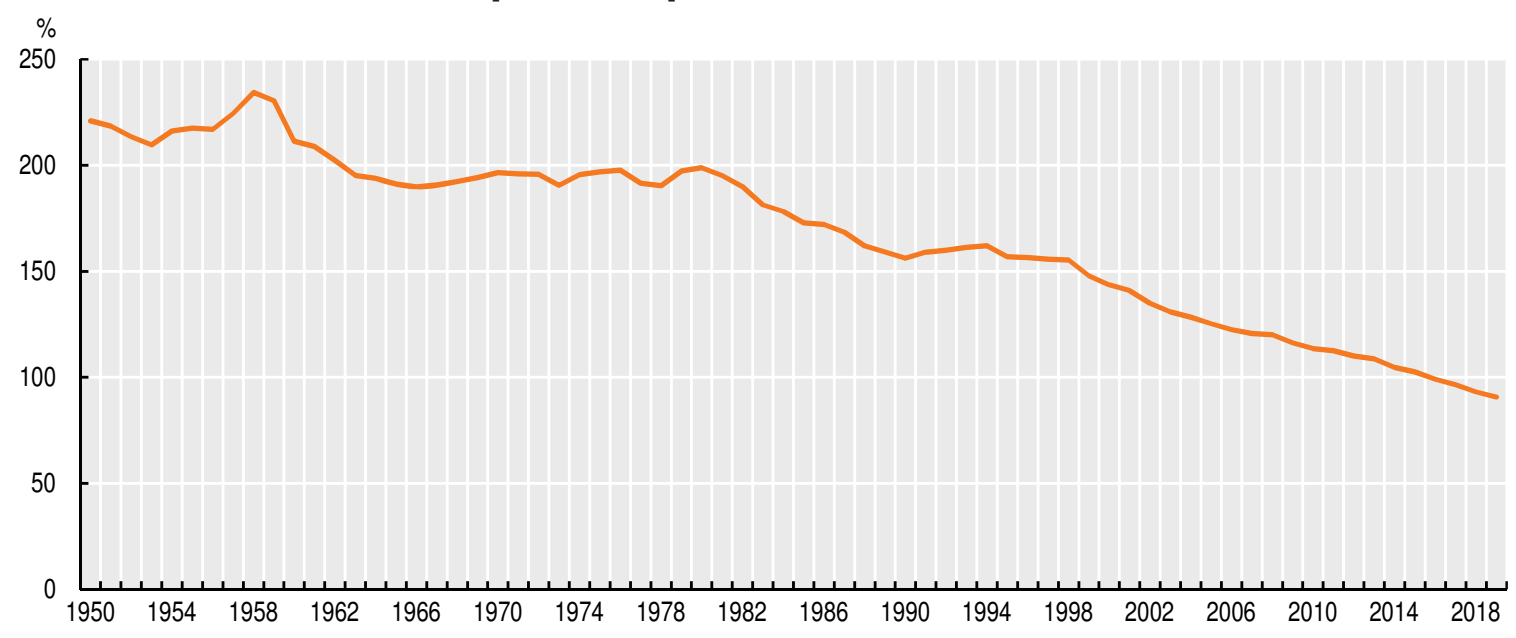

Nota: Promedio simple de los 17 países de América Latina y el Caribe cubiertos por The Conference Board. La productividad laboral se mide como la productividad laboral por persona empleada en dólares de 2018.

Fuente: Estimaciones propias basadas en The Conference Board (2020), Total Economy Database (base de datos), www. conference-board.org/data/economydatabase.

StatLink -intst https://doi.org/10.1787/888934201743 


\section{Gráfico 2.2. Contribución del empleo y la productividad al crecimiento del PIB en los países y regiones seleccionados, 2000-2019 (\%)}

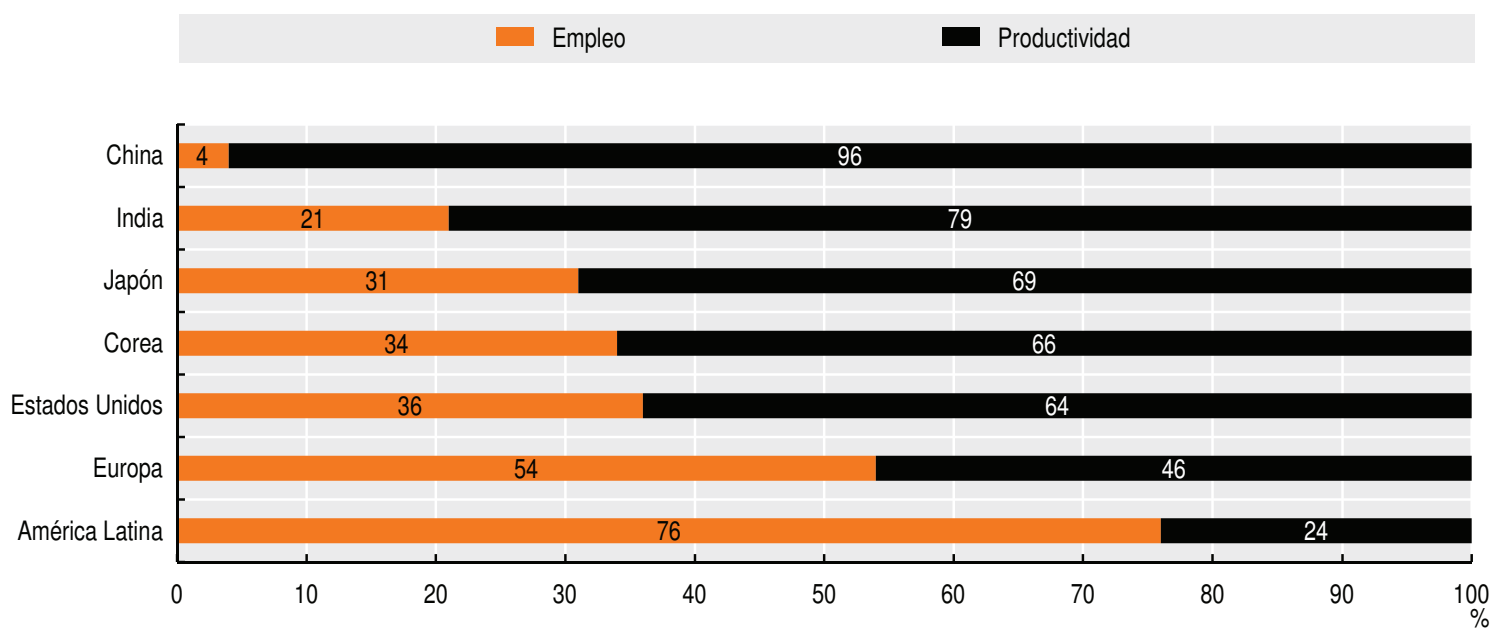

Nota: Promedio simple de los 17 países de América Latina y el Caribe cubiertos por The Conference Board.

Fuente: Estimaciones propias en base a Conference Board (2020), Total Economy Database (base de datos), www.conferenceboard.org/data/economydatabase.

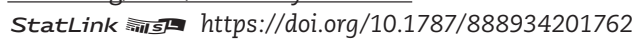

Tabla 2.1. Participación en el PIB y en el empleo, por sector, en los países seleccionados de América Latina y el Caribe, 1981, 2002 y 2018

\begin{tabular}{lcccccc}
\hline & \multicolumn{3}{c}{$\begin{array}{c}\text { Valor agregado } \\
\text { (\%) }\end{array}$} & \multicolumn{3}{c}{$\begin{array}{c}\text { Empleo } \\
\text { (\%) }\end{array}$} \\
& 1981 & 2002 & 2018 & 1981 & 2002 & 2018 \\
\hline Agricultura & 5.2 & 5.6 & 5.5 & 23.3 & 20.2 & 14.6 \\
\hline Minería & 6.9 & 8.0 & 5.2 & 1.0 & 0.5 & 0.6 \\
\hline Fabricación & 18.9 & 16.7 & 13.6 & 16.2 & 14.2 & 12.2 \\
\hline Electricidad & 1.6 & 2.6 & 2.5 & 0.9 & 0.5 & 0.5 \\
\hline Construcción & 10.2 & 6.6 & 7.1 & 7.1 & 6 & 7.7 \\
\hline Comercio mayorista y minorista & 15.4 & 13.7 & 14.5 & 14.3 & 23.3 & 25.3 \\
\hline Transporte y comunicaciones & 4.3 & 6.7 & 9.6 & 4.7 & 5.1 & 6.4 \\
\hline Servicios financieros y empresariales & 15.2 & 16 & 18.6 & 5.6 & 5.5 & 7.7 \\
\hline Servicios para la comunidad & 22.3 & 24.3 & 23.3 & 27 & 24.7 & 25 \\
\hline Total & 100 & 100 & 100 & 100 & 100 & 100 \\
\hline
\end{tabular}

Nota: Los países seleccionados de América Latina y el Caribe son Argentina, Bolivia, Brasil, Chile, Colombia, Costa Rica, Cuba, República Dominicana, Ecuador, El Salvador, Guatemala, Honduras, México, Panamá, Paraguay, Perú, Uruguay y Venezuela.

Fuentes: CEPAL (2020c), Bases de datos y publicaciones estadísticas (base de datos), https://estadisticas.cepal.org/ cepalstat/WEB CEPALSTAT/buscador.asp?idioma=i\&string busqueda=; OIT (2020), Estadísticas y bases de datos (base de datos), www.ilo.org/global/statistics-and-databases/lang--en/index.htm.

\section{Estructura productiva}

La estructura productiva y la heterogeneidad estructural de los países de América Latina y el Caribe explican la creciente brecha de productividad. La mayoría de los países de la región han desarrollado actividades productivas que utilizan mano de obra poco cualificada y operan con escasas conexiones con el resto de la economía. Estas actividades no generan beneficios tecnológicos ni capacidades locales, y tampoco se benefician de ellos. Las cadenas productivas dinámicas son casos aislados que no afectan al entorno económico general. 
ALC tiene una estructura productiva poco diversificada, lo cual se traduce en un bajo valor agregado. Las exportaciones en las que se han especializado estos países se concentran en bienes de bajo contenido tecnológico. Esto se correlaciona con el valor agregado relativamente más bajo que genera el sector manufacturero y, en particular, las industrias de mediana y alta tecnología, un elemento especialmente relevante a medida que el progreso tecnológico crece en importancia (Gráfico 2.3). La escasa diversificación de la estructura productiva de la región y la gran heterogeneidad de la productividad entre las empresas pueden hacer de la digitalización una mayor fuente de polarización, lo que aumenta los diferenciales de productividad dentro de los países. El desarrollo de mayores cadenas productivas y tecnológicas requiere de políticas que faciliten y promuevan la incorporación de tecnologías por parte de las empresas en todos los sectores.

Los efectos de la estructura productiva en la productividad laboral promedio tienen su origen en la heterogeneidad estructural (definida como la amplia variación de la productividad laboral entre los sectores y dentro de ellos). La variación en la región es lo suficientemente marcada como para segmentar el sistema productivo y el mercado laboral. Las condiciones tecnológicas y de remuneración son fuertemente asimétricas entre los distintos segmentos (Cimoli y Porcile, 2013).

Dos indicadores ponen de manifiesto la heterogeneidad estructural de la productividad en las economías de América Latina y el Caribe. El indicador intersectorial ha mostrado una alta heterogeneidad en los últimos años, en comparación con las décadas anteriores (Tabla 2.2): por ejemplo, entre la minería y el comercio mayorista y minorista ésta aumentó entre 1981 y 2018. La heterogeneidad intrasectorial (unidades de producción dentro de un sector) se suele medir en función del coeficiente de variación del nivel de productividad de los sectores. Utilizando la desviación estándar sobre el promedio de la productividad sectorial, se estima que la heterogeneidad estructural interna aumentó en casi un 20\% durante el período: en particular, aumentó en un 50\% entre 1981 y 1998 debido a los movimientos de la productividad en los sectores de la minería y los hidrocarburos, y posteriormente disminuyó un 35\% hasta 2018 (Gráfico 2.4). Los indicadores intersectoriales e intrasectoriales son complementarios y ambos contribuyen a comprender el aumento de la mayor heterogeneidad.

\section{Gráfico 2.3. Valor agregado por la industria manufacturera de mediana y alta tecnología} en países seleccionados, 1990-2017

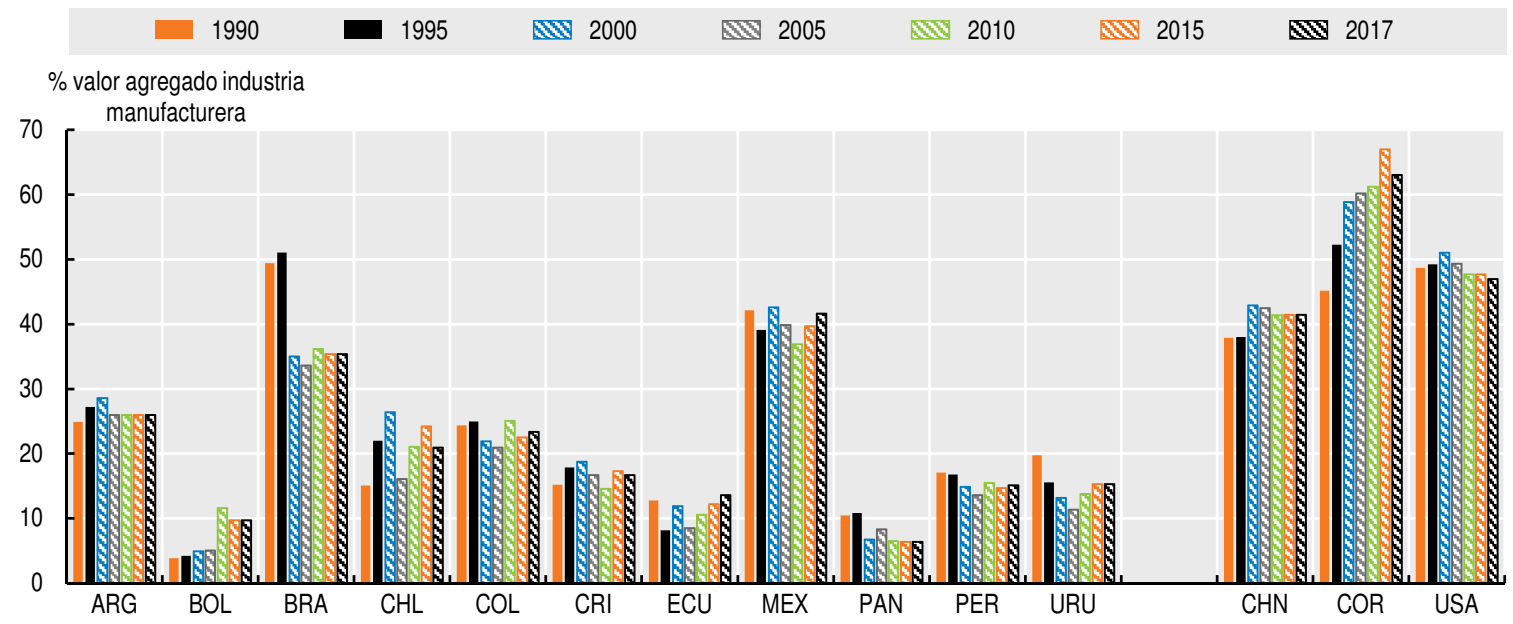

Fuente: UNIDO (2019), Estadísticas de la UNIDO (base de datos), www.unido.org/researchers/statistical-databases. StatLink 尚Ista https://doi.org/10.1787/888934201781 
Tabla 2.2. Niveles de productividad relativa, por sector, en los países seleccionados de América Latina y el Caribe, 1981, 2002 y 2018

\begin{tabular}{lccc}
\hline & $\mathbf{1 9 8 1}$ & $\mathbf{2 0 0 2}$ & $\mathbf{2 0 1 8}$ \\
\hline Agricultura & 20 & 25 & 34 \\
Minería & 606 & 1322 & 846 \\
Fabricación & 105 & 105 & 100 \\
Electricidad & 165 & 448 & 409 \\
Construcción & 131 & 99 & 84 \\
Comercio mayorista y minorista & 98 & 53 & 51 \\
\hline Transporte y comunicaciones & 84 & 119 & 135 \\
Servicios empresariales & 247 & 259 & 218 \\
Servicios para la comunidad & 75 & 89 & 84 \\
\hline
\end{tabular}

Nota: Los países seleccionados de América Latina y el Caribe son Argentina, Bolivia, Brasil, Chile, Colombia, Costa Rica, Cuba, República Dominicana, Ecuador, El Salvador, Guatemala, Honduras, México, Panamá, Paraguay, Perú, Uruguay y Venezuela. Base 100 = sector manufacturero 2018.

Fuentes: Elaboración propia a partir de datos oficiales de los países; CEPAL, (2020c), Bases de datos y publicaciones estadísticas (base de datos), https://estadisticas.cepal.org/cepalstat/WEB_CEPALSTAT/buscador. asp?idioma=i\&string busqueda=; OIT, (2020), Estadísticas y bases de datos (base de datos), www.ilo.org/global/ statistics-and-databases/lang--en/index.htm.

También se observa heterogeneidad estructural en la productividad por tamaño de empresa. La productividad de las micro, pequeñas y medianas empresas en 2016 fue del $6 \%, 23 \%$ y $46 \%$ de la de las grandes empresas en América Latina, respectivamente —niveles que prácticamente no han variado desde 2009 (Gráfico 2.5) - Estos valores contrastan con los diferenciales observados en la Unión Europea para las micro (42\%), pequeñas (58\%) y medianas (76\%) empresas. Los diferenciales son más pronunciados cuando se compara la productividad de las empresas en países seleccionados. Las diferencias de productividad en las pequeñas empresas son más de 18 veces mayores que las observadas en los países europeos. En Brasil, la productividad de las microempresas representa el $4 \%$ de la existente en las grandes empresas, en comparación con el 74\% en Francia.

La heterogeneidad de la productividad es importante para identificar los posibles efectos de la digitalización. En una región en la que las disparidades de productividad se manifiestan entre los sectores económicos y segmentos de producción y también dentro de ellos, y en la que los niveles de productividad de los trabajadores varían ampliamente (asociados a los niveles de educación), la digitalización trae consigo una oportunidad pero también un riesgo de reforzar las disparidades existentes.

\section{Gráfico 2.4. Coeficiente de variación de productividad sectorial en países seleccionados de América Latina y el Caribe, 1980-2018}

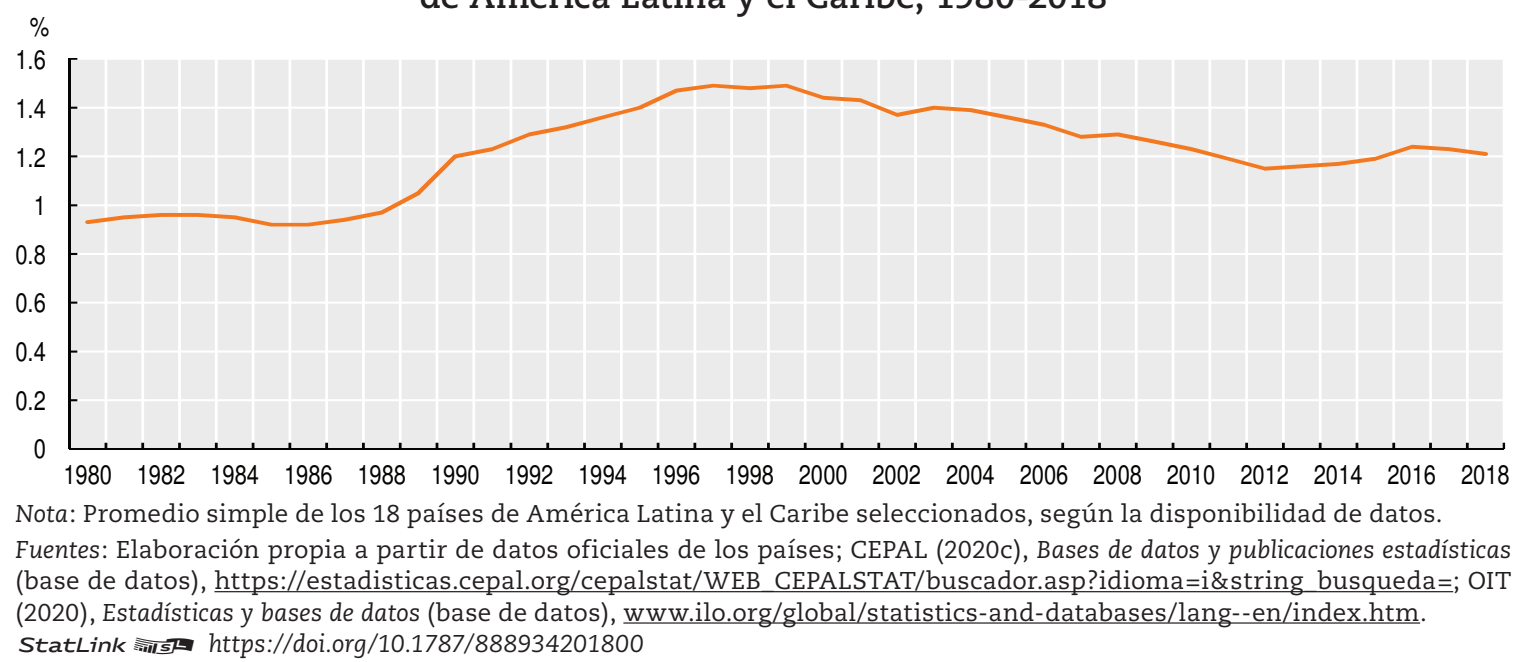


Gráfico 2.5. Brechas de productividad por tamaño de la empresa en comparación con las grandes empresas en países y regiones seleccionados, 2016

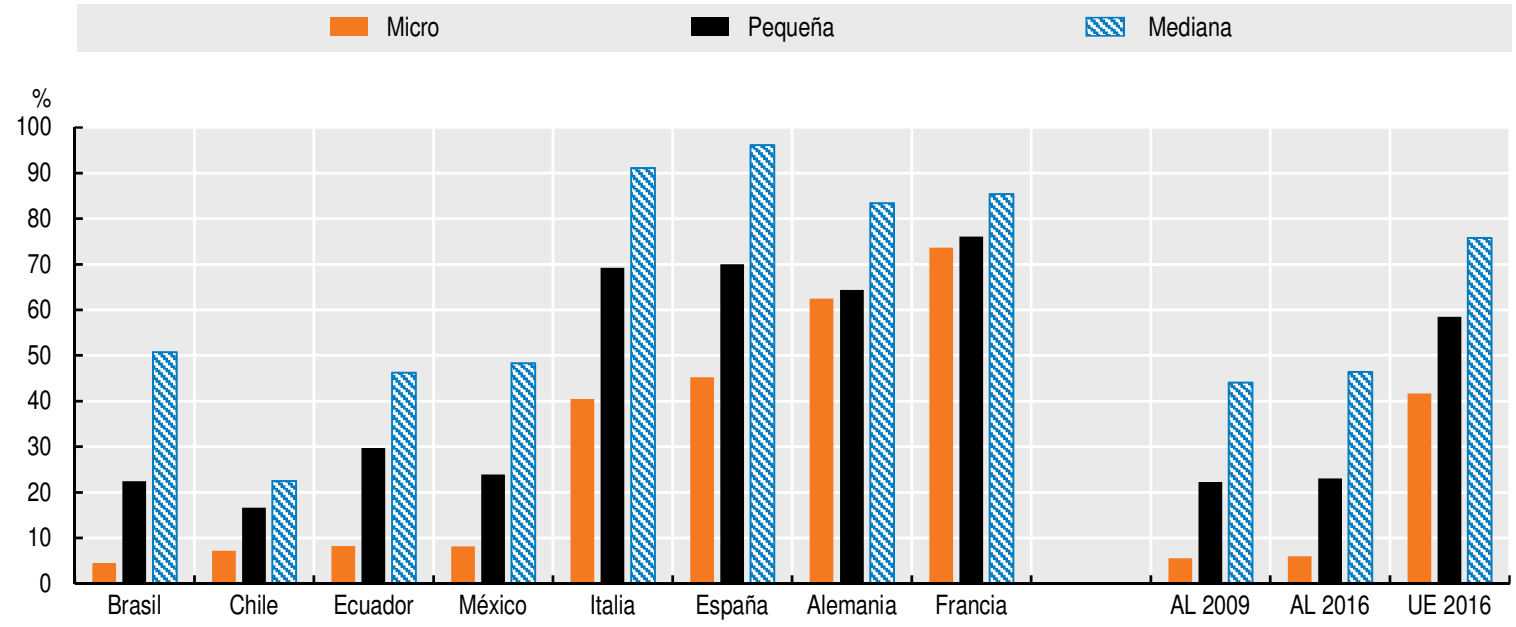

Fuente: CEPAL (2020b), "Sectores y empresas frente a Covid-19: Emergencia y reactivación”, Informe especial: Covid-19, Comisión Económica para América Latina y el Caribe, Santiago, https://repositorio.cepal.org/bitstream/handle/11362/45736/5/ S2000437_en.pdf.

StatLink त्ञाता https://doi.org/10.1787/888934201819

La heterogeneidad estructural es una consideración clave en el diseño de políticas que equilibren el crecimiento económico con la igualdad. La heterogeneidad estructural influye con fuerza en la distribución desigual de los ingresos en la región. El sector de baja productividad, que tiene un gran peso, emplea en su mayoría a trabajadores de bajo nivel educativo y prácticamente no ofrece ninguna cobertura de seguridad social (CEPAL, 2010; CEPAL, 2014; OCDE et al., 2019).

\section{Aumento de la productividad con las tecnologías digitales}

\section{Tecnologías digitales y aumento de la productividad: Una relación compleja}

El crecimiento de la productividad es el principal motor del crecimiento económico sostenido (Solow, 1988). ${ }^{2}$ Desde la primera revolución industrial, las nuevas tecnologías han mejorado la productividad (Dosi, 1984) y pueden contribuir a cerrar la brecha en los países de América Latina y el Caribe (CEPAL, 2016). En la cúspide de la cuarta revolución industrial, existe un debate cada vez mayor sobre el potencial de las tecnologías digitales para fomentar la productividad en los países desarrollados y en transición. El debate tradicional está polarizado, con "tecnooptimistas" que predicen un impacto positivo (Brynjolfsson, McAfee y Spence, 2014) y "tecnopesimistas" que cuestionan el impacto incremental en la productividad y el crecimiento (Gordon, 2012).

Las dinámicas de la innovación y la tecnología no son independientes de las estructuras industriales, las relaciones laborales y la distribución de los ingresos (ver en el Capítulo 3 los efectos sociales de la transformación digital). Por el contrario, estas dinámicas están arraigadas en economías políticas complejas y, por tanto, en gran medida son específicas del contexto (ver el Recuadro 2.1 para un caso específico en la región). En última instancia, los efectos de las tecnologías digitales en la productividad serán el resultado de un acceso y una difusión adecuados de las tecnologías digitales, un dinamismo empresarial sólido, la participación de las pymes en la transformación digital, unas competencias adecuadas y un entorno suficientemente competitivo en la economía digital (OCDE, 2019a). Estos aspectos han sido discutidos en el marco de la 
Tercera Reunión Ministerial del Programa Regional de la OCDE para América Latina y el Caribe sobre Productividad (Bogotá-Colombia, octubre de 2019). Por último, las políticas deben adaptar los marcos digitales e incluir factores sociales y económicos.

La disponibilidad de datos y las hipótesis teóricas y empíricas hacen que resulte difícil desenmarañar los vínculos existentes entre la tecnología y la productividad. La complejidad puede que explique la existencia de resultados empíricos contradictorios (Recuadro 2.2). Las tecnologías digitales son complementarias de otros factores: las características estructurales de las empresas, el sector y el país. Los estudios entre países sugieren que la adopción de las tecnologías digitales por parte de las empresas varía mucho entre los distintos países y también dentro de ellos (Hagsten et al., 2012), en función de las capacidades e incentivos de las empresas (Andrews, Nicoletti y Timiliotis, 2018). Los estudios a nivel de empresa y sector muestran que la capacidad de las empresas y la sofisticación del sector son importantes para acelerar los beneficios de las nuevas tecnologías.

\section{Recuadro 2.1. Digitalización de la producción en Perú}

La Comisión Económica para América Latina y el Caribe de Naciones Unidas, en coordinación con el Banco de Desarrollo de América Latina, está desarrollando un proyecto piloto centrado en la digitalización de los procesos de producción. En dicho proyecto se ha identificado una cadena de producción que tiene un impacto significativo en la economía de Perú.

El departamento de Ica es un contribuyente clave al PIB nacional, y sus exportaciones representan el 7.4\% del total nacional. Las principales exportaciones agrícolas son los espárragos, el aguacate, el maíz amarillo duro y la mandarina. En el proyecto se evaluó en primer lugar la conectividad digital de la región y el potencial de las soluciones digitales para abordar los principales problemas identificados en las cadenas de valor.

Los resultados de los análisis de la industria de exportación agrícola condujeron a la identificación de posibles soluciones tecnológicas para diversos sectores y cadenas de valor (Tabla 2.3). En el caso de la cadena de valor de la pesca, estos resultados incluyeron sistemas de rastreo de sensores de captura con identificación por radiofrecuencia, visualizaciones de bancos y del fondo marino, sistemas de geolocalización para flotas, digitalización de las relaciones proveedor-cliente y gestión de inventarios, y automatización de subastas de productos. En lo que respecta a la cadena de valor de la energía eléctrica, se incluían sistemas de vigilancia a distancia y sensores atmosféricos, gestión automática de reservas de energía, mantenimiento predictivo de activos, identificación mediante sensores de fugas en la fase de distribución y vigilancia automática de rutas de transporte mediante drones.

Tabla 2.3. Posibles soluciones tecnológicas para diversos sectores de Perú

\begin{tabular}{ll}
\hline Soluciones tecnológicas y producción & Logística y exportaciones \\
\hline Sistemas de irrigación inteligentes & Control de la cadena de frío \\
\hline Monitoreo de tierras & Sistema de seguimiento y trazabilidad de productos \\
Herramientas de recolección inteligentes & Sistema eficiente de gestión de inventarios \\
\hline Teledetección geográfica & Optimización de logística y herramientas de gestión \\
Control de plagas inteligente & \\
\hline \multicolumn{1}{c}{ Facilitadores tecnológicos incluyen: IoT, Big Data, Servicios en la nube, Análisis de datos, Drones } \\
\hline
\end{tabular}

Nota: IoT $=$ Internet de las Cosas.

Source: Elaboración propia en base a información oficial.

El ejercicio demostró que, para lograr un mayor impacto, las políticas relacionadas con la digitalización de la producción deben tener en cuenta las características distintivas de cada sector. A pesar de los elementos facilitadores comunes, como las infraestructuras y las competencias digitales, cada sector requiere soluciones a medida. 


\section{Recuadro 2.2. Medición de la productividad en la era digital}

La productividad laboral se mide habitualmente como el PIB por hora trabajada. El crecimiento de la productividad suele medir la eficiencia de los procesos productivos en términos de la relación insumo/producto: asciende cuando el producto aumenta más que el insumo. La medición de la productividad en la era digital y, por tanto, de los aumentos de productividad resultantes de la adopción de tecnología plantea problemas de medición.

1. Es posible que los precios y la calidad no estén plenamente identificados, lo que implica una medición imprecisa del crecimiento del producto en el PIB. El precio, el volumen y la calidad son fundamentales para la medición de la productividad. Desentrañar su relación es especialmente difícil en la era digital. En los mercados eficientes, los precios reflejan alguna dimensión de la calidad valorada por los consumidores (Stiglitz, Sen y Fitoussi, 2009). La relación entre la calidad y el precio de los productos y servicios digitales puede ser contradictoria; por ejemplo, la calidad de los productos digitales ha aumentado, pero los precios han bajado en la última década. Algunos productos, como las apps o los servicios digitales, son gratuitos y no encajan en las mediciones del PIB. No obstante, los consumidores pagan a través de sus datos personales y su exposición a la publicidad. Debido a la complejidad existente para desenmarañar los efectos del precio y la calidad, la creciente digitalización puede aumentar la medición deficiente de la productividad.

2. Los productos digitales tienen efectos compensatorios con respecto a las medidas de productividad multifactorial (MFP por sus siglas en inglés). La productividad multifactorial mide el producto generado por el efecto combinado del trabajo y el capital. Los productos digitales son a la vez insumos y productos y, por tanto, contribuyen a ambos lados de la relación de la productividad multifactorial, lo que lleva a subestimar su contribución como insumo y a sobreestimar la medición de la productividad multifactorial.

3. La globalización y el comercio internacional dificultan las mediciones de insumos y productos. Las estadísticas de producción a nivel agregado pueden ocultar problemas de medición en la información que se presenta sobre el producto. Puede ser el caso de la producción efectuada por países desarrollados en el extranjero, de la que se informan en el país productor y no en el país propietario, lo cual afecta negativamente a la medición de la productividad de este último. El comercio transfronterizo también podría afectar a la medición del capital, sobre todo al subestimar la contribución de activos del conocimiento, lo que daría lugar a sobreestimaciones de la productividad multifactorial.

Los aumentos de productividad están fuertemente correlacionados con el rendimiento y las capacidades de las empresas, y las nuevas tecnologías podrían ampliar la dispersión de la productividad entre los países y también dentro de ellos. Una nueva corriente de investigación encuentra un vínculo positivo entre la difusión a nivel sectorial de las tecnologías digitales y el crecimiento de la productividad (Tabla 2.4). Los resultados son más sólidos en el caso de las empresas de alta productividad. Las empresas más cercanas a la frontera tienen más probabilidades de adoptar nuevas tecnologías debido a la existencia de importantes complementariedades entre las nuevas tecnologías y otras inversiones que aumentan la productividad. El uso eficiente de las tecnologías digitales está relacionado con las capacidades de las empresas, la sofisticación tecnológica, las competencias de gestión y las aptitudes de los trabajadores. Las empresas de alta productividad en sectores de uso intensivo en tecnología también tienen más probabilidades de adoptar nuevas tecnologías y experimentar aumentos de productividad (Berlingieri, Blanchenay y Criscuolo, 2017; Gal et al., 2019; Sorbe, 2019; OCDE, 2019b). 
Tabla 2.4. Impacto de las complementariedades de la tecnología digital en el aumento de la productividad: Evidencia del mundo desarrollado

\begin{tabular}{|c|c|c|}
\hline $\begin{array}{l}\text { Variable } \\
\text { complementaria }\end{array}$ & $\begin{array}{l}\text { Enfoque del } \\
\text { análisis }\end{array}$ & Resultados \\
\hline \multirow{5}{*}{$\begin{array}{l}\text { Innovación } \\
\text { e inversión } \\
\text { tecnológica }\end{array}$} & \multirow[t]{5}{*}{ OCDE } & La inversión en I+D y tecnología acelera los beneficios de las tecnologías digitales. \\
\hline & & $\begin{array}{l}\text { 1. Los efectos indirectos del conocimiento a nivel sectorial y de país amplían el impacto } \\
\text { de las TIC en la productividad (Corrado, Haskel y Jona-Lasinio, 2017). }\end{array}$ \\
\hline & & $\begin{array}{l}\text { 2. Las actividades de innovación e I+D pueden contribuir al aumento de la productividad a } \\
\text { nivel agregado y, si se combinan con las tecnologías digitales, pueden aumentar los beneficios } \\
\text { dentro de las empresas (Bartelsman, Leeuwen y Polder, 2017). }\end{array}$ \\
\hline & & $\begin{array}{l}\text { 3. La inversión en las TIC es un canal importante para impulsar el aumento de la } \\
\text { productividad (Cette, Lopez y Mairesse, 2017). }\end{array}$ \\
\hline & & $\begin{array}{l}\text { 4. La I+D, las TIC y las capacidades de las organizaciones son complementarias, } \\
\text { y las inversiones conjuntas potencian el aumento de la productividad (Mohnen, Polder y Van } \\
\text { Leeuwen, 2018). }\end{array}$ \\
\hline \multirow[t]{3}{*}{$\begin{array}{l}\text { Competencias y } \\
\text { capital humano }\end{array}$} & \multirow[t]{3}{*}{ Unión Europea } & $\begin{array}{l}\text { El aumento de las competencias digitales podría fortalecer el vínculo entre la adopción } \\
\text { de la tecnología digital y la productividad. }\end{array}$ \\
\hline & & $\begin{array}{l}\text { 1. La escasez de competencias técnicas a nivel de sector reduce el vínculo entre la adopción } \\
\text { de la tecnología y el rendimiento de la productividad (Gal et al., 2019). }\end{array}$ \\
\hline & & $\begin{array}{l}\text { 2. La inversión en la mejora de competencias es fundamental para facilitar la adopción } \\
\text { eficiente de la tecnología. La escasez de competencias es un factor principal de la falta } \\
\text { de aumento de la productividad en las empresas rezagadas (Andrews, Nicoletti y Timiliotis, } \\
\text { 2018). }\end{array}$ \\
\hline \multirow[t]{5}{*}{$\begin{array}{l}\text { Sofisticación } \\
\text { sectorial }\end{array}$} & \multirow[t]{5}{*}{ OCDE } & $\begin{array}{l}\text { Los aumentos de productividad varían en función del sector, con mayores beneficios para } \\
\text { la industria manufacturera. }\end{array}$ \\
\hline & & $\begin{array}{l}\text { 1. La adopción de tecnología varía en función del sector y de las características estructurales } \\
\text { de cada uno de ellos, como la sofisticación tecnológica y el capital humano (Andrews, Nicoletti } \\
\text { y Timiliotis, 2018). }\end{array}$ \\
\hline & & $\begin{array}{l}\text { 2. Los aumentos de productividad son mayores en los sectores con actividades } \\
\text { estandarizadas y rutinarias (Chevalier y Luciani, 2018). }\end{array}$ \\
\hline & & $\begin{array}{l}\text { 3. La digitalización genera mayores niveles de productividad en la industria manufacturera } \\
\text { (Dhyne et al., 2018; Gal et al., 2019). }\end{array}$ \\
\hline & & $\begin{array}{l}\text { 4. La proximidad - dentro del sector o en las cadenas de valor mundiales - con otras } \\
\text { empresas digitalizadas puede generar efectos indirectos positivos y aumentar la adopción } \\
\text { de la tecnología y los beneficios de la productividad (Andrews, Nicoletti y Timiliotis, 2018). }\end{array}$ \\
\hline \multirow[t]{4}{*}{$\begin{array}{l}\text { Capacidades de las } \\
\text { organizaciones }\end{array}$} & \multirow{4}{*}{$\begin{array}{l}\text { Industria } \\
\text { manufacturera } \\
\text { de Estados } \\
\text { Unidos, OCDE }\end{array}$} & $\begin{array}{l}\text { Las capacidades de las organizaciones y las competencias de gestión pueden ampliar } \\
\text { los aumentos de productividad. }\end{array}$ \\
\hline & & $\begin{array}{l}\text { 1. La adopción de tecnología se asocia con un mayor aumento de la productividad si es } \\
\text { sistémica y se asocia con incentivos más amplios, pero genera pocos o ningún beneficio } \\
\text { cuando se adopta de forma aislada (Aral, Brunjolfsson y Wu, 2012). }\end{array}$ \\
\hline & & $\begin{array}{l}\text { 2. La dispersión de la inversión en TI por empleado explica el 8\% de la dispersión de la } \\
\text { productividad; la calidad de la gestión explica hasta el 17\% (Bloom, Sadun y Van Reenen, } \\
\text { 2017). }\end{array}$ \\
\hline & & $\begin{array}{l}\text { 3. Las capacidades de la organización son complementarias a las inversiones en TIC e I+D } \\
\text { (Mohnen, Polder y van Leeuwen, 2018). }\end{array}$ \\
\hline \multirow[t]{2}{*}{$\begin{array}{l}\text { Infraestructuras de } \\
\text { calidad }\end{array}$} & \multirow[t]{2}{*}{ Reino Unido } & $\begin{array}{l}\text { Las infraestructuras de calidad son fundamentales para garantizar un uso eficiente de las } \\
\text { tecnologías digitales, si bien no tienen un efecto directo en la productividad. }\end{array}$ \\
\hline & & $\begin{array}{l}\text { 1. Las infraestructuras digitales son un factor determinante para la adopción y uso de las } \\
\text { tecnologías digitales. El acceso a la banda ancha de calidad está vinculado a las inversiones } \\
\text { complementarias en TIC. No existe un vínculo claro con el rendimiento de las empresas } \\
\text { (De Stefano, 2018). }\end{array}$ \\
\hline
\end{tabular}

Notas: $\mathrm{TI}=$ tecnología de la información. TIC = tecnología de la información y las comunicaciones. I+D = investigación y desarrollo.

\section{La economía digitalizada: Cambiar la estructura productiva}

La revolución digital está dando lugar a una cuarta revolución industrial, que está generando una economía digitalizada. El contexto actual no es simplemente un mundo globalizado e hiperconectado desde un punto de vista económico y social; es un contexto en el que los esquemas de organización, producción y gobernanza de la economía 
tradicional coexisten y se fusionan con las innovaciones de la economía digital en cuanto a modelos de negocio, producción, organización empresarial y gobernanza (Gráfico 2.6). La pandemia ha acelerado este fenómeno. Las esferas tradicional y digital se integran e interactúan, dando lugar a ecosistemas más complejos, que están experimentando una rápida transformación organizativa, institucional y regulatoria en consonancia con la revolución digital (CEPAL, 2018a).

La primera fase de la revolución digital condujo al desarrollo de la economía digital: los modelos de negocio se centraron en el suministro de bienes y servicios digitales (Bukht y Heeks, 2017). El valor de los bienes y servicios cambió radicalmente. Las cámaras digitales redefinieron la fotografía, la lectura electrónica redefinió los medios impresos, la retransmisión en continuo (streaming) redefinió la música, la economía colaborativa redefinió el transporte y la industria hotelera, por mencionar algunos de los primeros sectores afectados por los efectos disruptivos de la digitalización.

\section{Gráfico 2.6. La transformación digital de la economía}

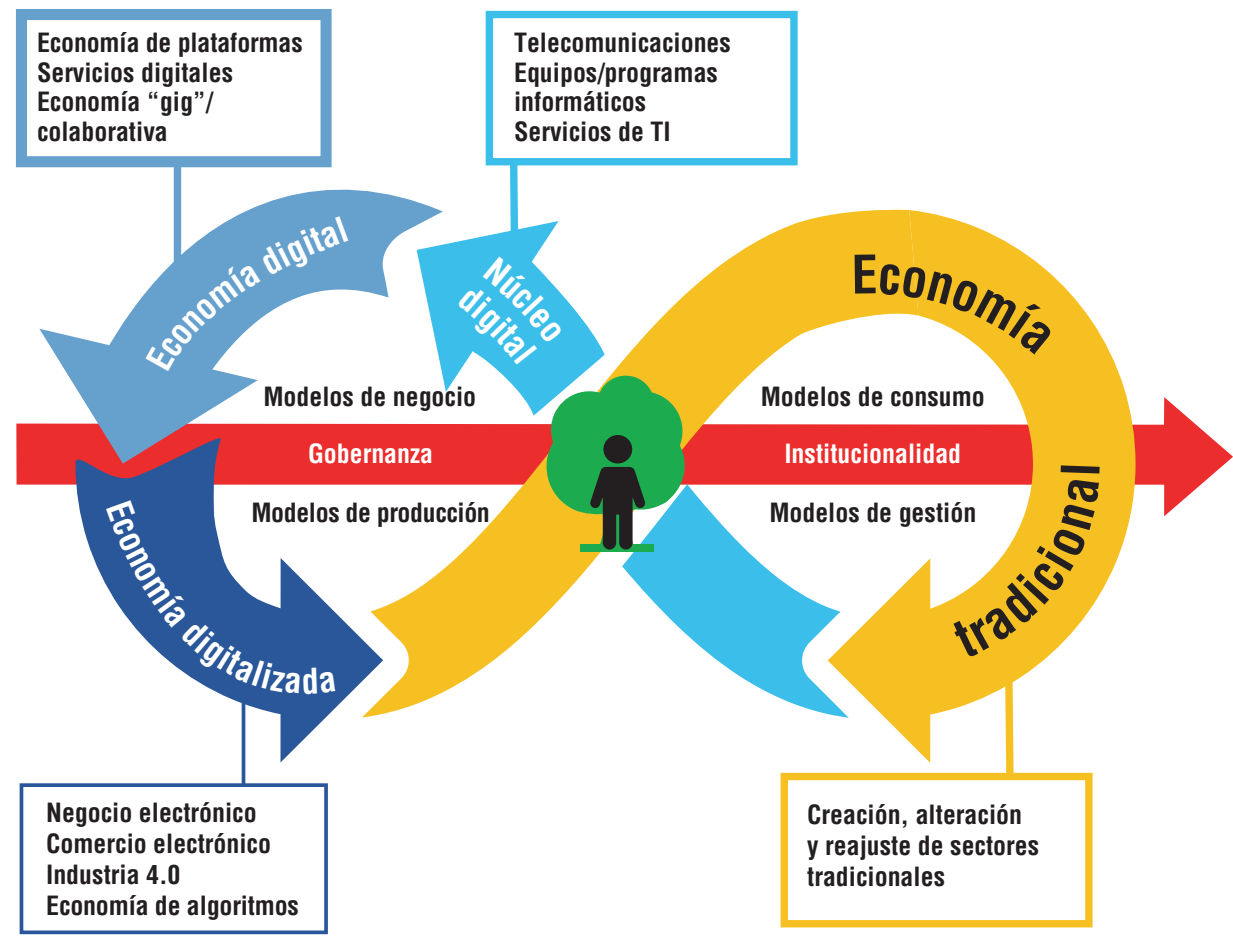

Fuente: Elaboración propia.

Las plataformas digitales realizan importantes contribuciones a la economía al crear nuevas conexiones entre la oferta y la demanda en diversos mercados, reduciendo los costos de transacción y de intermediación, generando aumentos de eficiencia en el uso de activos y abriendo nuevos mercados y oportunidades de negocio, incluido para para las mipymes (OCDE, 2019c). Los nuevos modelos de negocio operan en plataformas digitales en múltiples sectores en América Latina y el Caribe. Facilitan las transacciones comerciales (Amazon, Alibaba, Mercado Libre), los servicios financieros (Ant Financial, Avant, Mercado Pago, Nubank), los servicios de comunicación y las redes sociales (Facebook, Skype, WhatsApp), los servicios de turismo y alojamiento (TakeOff, Booking, Airbnb), el desarrollo de apps (Apple iOS, Google Android) y la búsqueda de empleo (Laborum, LinkedIn, Workana, Freelancer). Sin embargo, en parte debido a la estructura 
productiva y social de ALC, la pandemia del Covid-19 ha demostrado una adopción desigual de estas plataformas en la población, lo que puede acentuar la exclusión digital en función del estatus económico, edad y ubicación. Estas soluciones requieren factores complementarios, como altas velocidades de conexión y competencias digitales. La ausencia de estos factores compromete el uso de plataformas digitales más sofisticadas, como ha sido el caso durante la crisis.

Los negocios digitales han evolucionado para incorporar la explotación de los datos generados e intercambiados en las plataformas. Al tiempo que ofrecen servicios y bienes digitales con unos menores costos de intermediación y de transacción, también han ampliado sus modelos de negocio. Los datos procesados y analizados con herramientas inteligentes permiten mejorar la toma de decisiones y optimizar la propuesta de valor mediante una mayor agilidad en las operaciones, la segmentación del mercado y la personalización. Esto conlleva la necesidad de regular y considerar las cuestiones éticas de la recopilación y el uso de datos. Otro reto es la protección de las personas contra el riesgo de robo de datos y uso indebido de los mismos (ver el Capítulo 4).

La adopción generalizada de las tecnologías digitales en todos los sectores dio paso a la segunda fase de la revolución digital: la economía digitalizada. Se caracteriza por el uso de información y conocimientos digitalizados como factor de producción, motor de productividad y herramienta de optimización para los modelos de negocio. La digitalización va más allá de la optimización de la producción y la gestión; se mejora el rendimiento mediante la reconfiguración de productos y servicios, modelos de negocio y producción basada en la adopción de la inteligencia digital. La digitalización está impulsando la transformación de sectores tradicionales, creando otros nuevos, como el autotech, el agritech y el fintech, entre otros (CEPAL, 2020d).

Los algoritmos revolucionaron la competencia, presentando la posibilidad de colusión, cárteles, segmentación, etc., y crearon mecanismos públicos y privados capaces de cambiar y regular mercados, por ejemplo, a través de la detección algorítmica de fraudes. Sin embargo, dado el gran volumen de datos generados por la transformación digital en América Latina y el Caribe y el valor que dichos datos tiene para las empresas extranjeras; las estrategias de fusión y adquisición y la concentración de los mercados de las grandes tecnologías (big tech) pueden amenazar la competitividad de la región (OCDE, 2017).

La creación de un ecosistema digital sostenible depende de que exista una competencia leal en los mercados. La transformación digital sostenible requiere marcos regulatorios adecuados con instituciones sólidas (por ejemplo, que aseguren la competencia, la ciberseguridad y la privacidad). El coronavirus (Covid-19) ha acelerado las transformaciones digitales, lo que a su vez ha agilizado el desarrollo de nuevos marcos jurídicos e institucionales.

La digitalización tiene el potencial de aumentar la productividad y lograr un desarrollo sostenible, pero su impacto neto dependerá de las políticas que se adopten y del ecosistema digital. Incluso en las economías más avanzadas de la OCDE, la difusión de las tecnologías digitales está lejos de ser completa. ${ }^{3}$ La digitalización cambia los modelos de consumo y producción, generando aumentos de productividad y bienestar entre los consumidores que pueden combinarse con objetivos de sostenibilidad ambiental para beneficiar a toda la sociedad. Sin embargo, el desarrollo y la adopción de la digitalización que no se rige por principios de inclusión y sostenibilidad puede reforzar la exclusión social y la discriminación y las prácticas de explotación y producción insostenibles (CEPAL, 2020d). El efecto neto de la digitalización con respecto al desarrollo sostenible dependerá de una evaluación minuciosa de la situación y de la adopción de políticas para encauzar adecuadamente la digitalización (ver el Capítulo 4), y del desarrollo de ecosistemas digitales que permitan el pleno aprovechamiento de los beneficios de la transformación. 


\section{Desarrollo del ecosistema digital en América Latina y el Caribe}

El ecosistema digital desempeña un papel importante a la hora de acelerar los beneficios de las tecnologías digitales, lo que tiene importantes consecuencias para las empresas, sectores y países rezagados. Ofrece importantes oportunidades para el diseño de políticas, especialmente en los países de América Latina y el Caribe. Dada la estructura y la sofisticación tecnológica del sector productivo de la región, no basta con facilitar la adopción de la tecnología. Es necesario desarrollar todos los elementos del ecosistema digital - infraestructuras, capacidades humanas y entorno empresarial - para promover la inversión, la innovación y la iniciativa empresarial.

El Índice de Desarrollo del Ecosistema Digital ${ }^{4}$ se basa en ocho pilares compuestos por múltiples componentes: infraestructuras, conectividad, digitalización de los hogares, digitalización de la producción, intensidad de la competencia, sectores digitales, factores de producción y marcos regulatorios (CAF, 2017; CAF et al., 2020). El concepto de ecosistema capta la interrelación sistémica de los pilares (Gráfico 2.7). Por ejemplo, la infraestructura digital es esencial para el acceso de los hogares y la utilización por parte de las empresas de los contenidos y servicios digitales, y permite a los operadores de la cadena de valor (por ejemplo, proveedores de apps y contenidos) conectarse y presentar una propuesta de valor al mercado (Katz, 2015).

\section{Gráfico 2.7. Estructura del ecosistema digital}

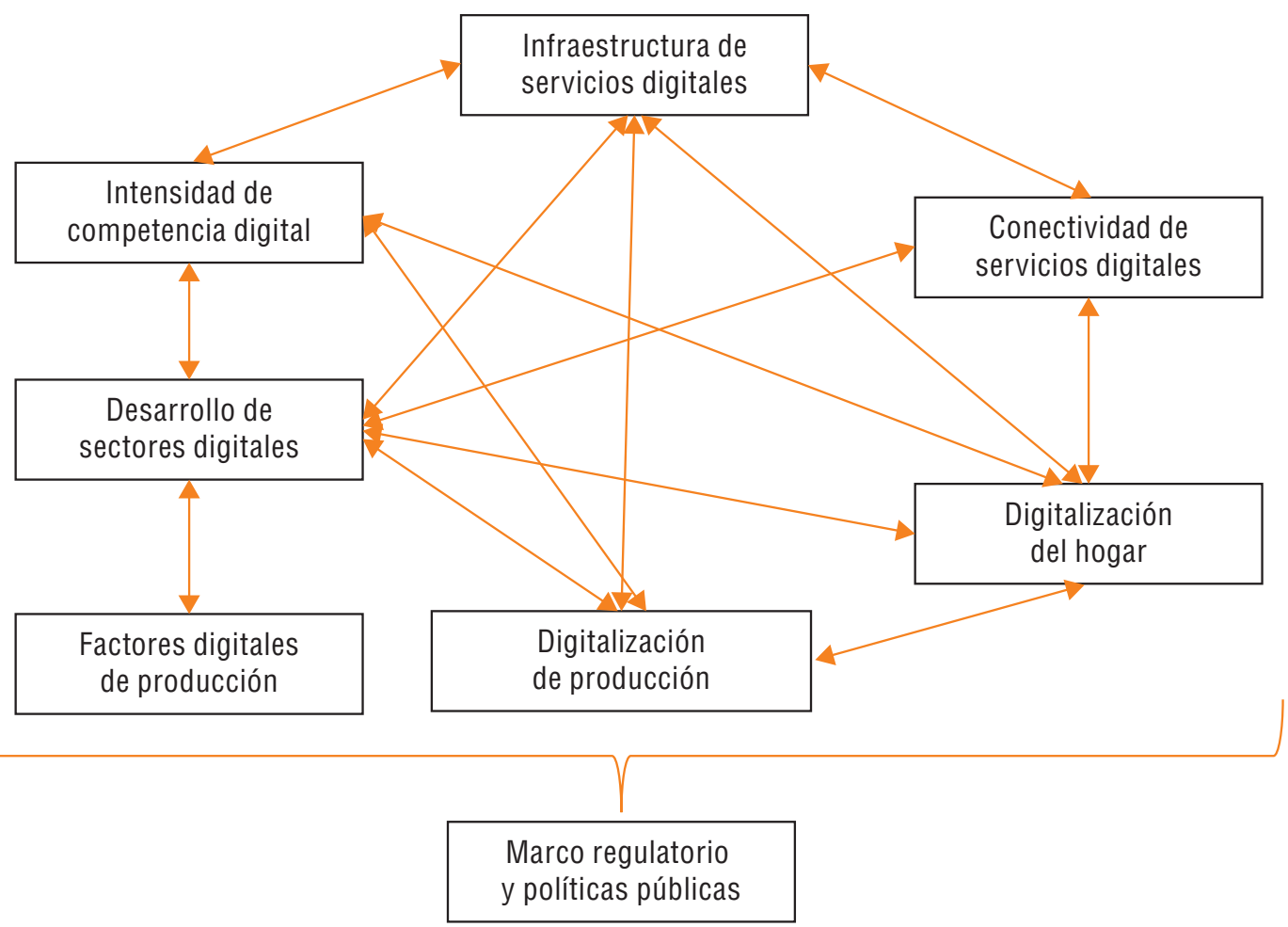

Fuente: CAF (2017), Hacia la transformación digital de América Latina y el Caribe: El Observatorio CAF del Ecosistema Digital, Banco de Desarrollo de América Latina, Caracas, https://www.caf.com/app tic/\#es/home, y https://scioteca.caf.com/bitstream/ handle/123456789/1052/METODOLOGIA\%20DE\%20IDED.pdf?sequence=1\&isAllowed=y; Katz y Callorda (2018), "Acelerando el desarrollo del ecosistema digital latinoamericano y sus implicaciones para la política de banda ancha", https://doi. org/10.1016/j.telpol.2017.11.002.

Si bien el índice comparte indicadores con el conjunto de herramientas Going Digital Toolkit de la OCDE, como la penetración de la banda ancha móvil y fija, los usuarios de 
Internet, el índice de desarrollo del gobierno electrónico de Naciones Unidas y el gasto en I+D en relación con el PIB, los marcos tienen propósitos diferentes pero complementarios (OCDE, 2019d). El conjunto de herramientas del Going Digital Toolkit está estructurado en torno a las siete dimensiones del marco integrado de políticas Going Digital, que abarca todas las áreas de políticas para contribuir a la adopción de un enfoque con alcance a toda la economía y a toda la sociedad que permita materializar promesas de la transformación digital en beneficio de todos (OCDE, 2019d). El Índice de Desarrollo del Ecosistema Digital se basa en un modelo econométrico que mide el impacto de la digitalización en el desarrollo económico mediante la evaluación del progreso de América Latina y el Caribe con respecto a las economías de la OCDE (CAF, 2017; CAF et al., 2020; Katz y Callorda, 2018). Incluye las condiciones para el desarrollo del ecosistema y aspectos relacionados, como el grado de competencia (indicadores de asequibilidad), marcos regulatorios (por ejemplo, características y atribuciones del regulador) y el papel de la digitalización en los procesos de producción (por ejemplo, empleados y acceso a la transformación digital).

A pesar de los importantes avances de los últimos 15 años, el ecosistema digital de América Latina y el Caribe se encuentra en un nivel de desarrollo intermedio (valor del índice 48.7 en una escala de 0 a 100), en comparación con África (34.2), Asia-Pacífico (42.1), Oriente Medio y África del Norte (55.4), la OCDE (66.8), Europa Occidental (67.6) y América del Norte (75.4) (Gráfico 2.8).

La tasa de crecimiento anual del índice es menor en América Latina y el Caribe que en otras regiones. Los países de la región pertenecen a un grupo del mundo emergente que experimenta una moderada tasa de crecimiento anual de la digitalización. El índice de América Latina y el Caribe creció a una tasa anual compuesta del 6.1\% entre 2004 y 2018, la tercera más baja entre las regiones emergentes después de Oriente Medio y África del Norte.

\section{Gráfico 2.8. Tasa de crecimiento del Índice de Desarrollo del Ecosistema Digital en regiones seleccionadas}

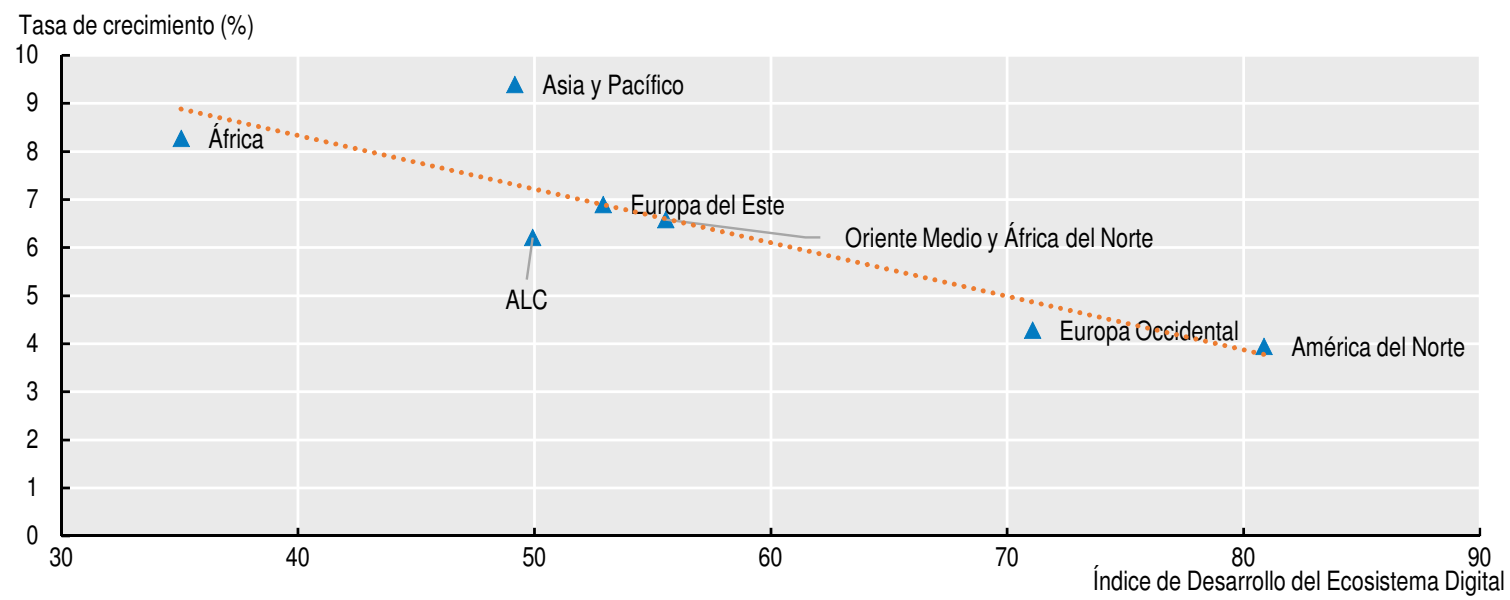

Fuente: CAF et al. (2020), Las oportunidades de la digitalización en América Latina frente al Covid-19, CAF 2020, ONU CEPAL 2020, https://repositorio.cepal.org/bitstream/handle/11362/45360/4/OportDigitalizaCovid-19 es.pdf. StatLink नinsts https://doi.org/10.1787/888934201838

Las diferencias entre los países de América Latina y el Caribe y los de la OCDE se mantienen en los ocho pilares multicomponentes de este índice. Los pilares menos desarrollados en la región son la infraestructura, los factores productivos (capital humano, inversión en I+D y capacidad de innovación) y el desarrollo limitado de las industrias digitales (Gráfico 2.9). 
Los factores de producción y digitalización de los hogares muestran las dos mayores diferencias con respecto a las economías de la OCDE. Los factores de producción están rezagados en todas las variables (Tabla 2.5). Las diferencias en las variables de digitalización en los hogares son heterogéneas: la penetración de las redes sociales y el uso de datos móviles son relativamente similares (ver el Capítulo 1 sobre el análisis Going Digital para países de América Latina y el Caribe), mientras que el uso del comercio electrónico y el vídeo a la carta/de libre transmisión difieren enormemente (Tabla 2.6). También son dignas de mención las diferencias existentes entre ALC y la OCDE en los pilares de infraestructuras y conectividad (Tabla 2.7).

\section{Gráfico 2.9. Índice de Desarrollo del Ecosistema Digital en América Latina y el Caribe y la OCDE, 2018}

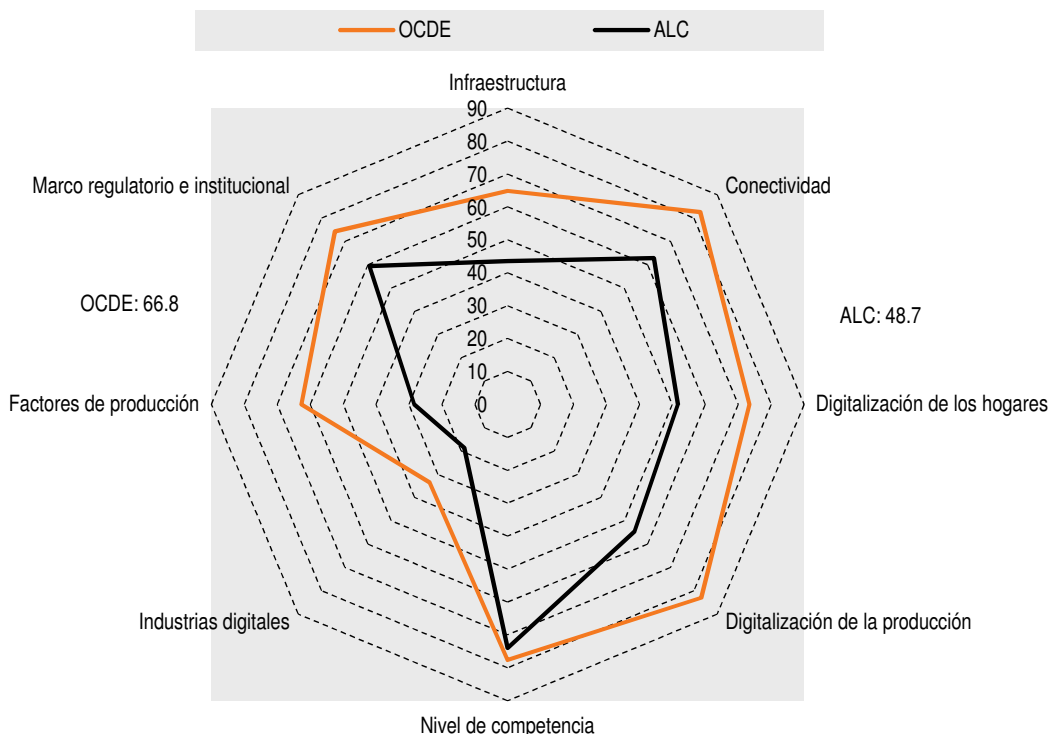

Fuentes: CAF (2017), Hacia la transformación digital de América Latina y el Caribe: El Observatorio CAF del Ecosistema Digital; CEPAL (2019a), Observatorio Regional de Planificación para el Desarrollo de América Latina y el Caribe (base de datos), https:// observatorioplanificacion.cepal.org/en/opengov.

StatLink तiाst https://doi.org/10.1787/888934201857

Tabla 2.5. Variables de factores de producción del Índice de Desarrollo del Ecosistema Digital en la OCDE y en América Latina y el Caribe, 2018

\begin{tabular}{llcc}
\hline Componente & \multicolumn{1}{c}{ Variable } & OCDE & ALC \\
\hline Capital humano & Expectativa de años de educación (años) & 16.4 & 14.4 \\
& Matriculación en la educación terciaria (\% bruto) & 73.7 & 50.3 \\
\multirow{2}{*}{ Tecnología educativa } & Centros educativos con acceso a Internet (\% de centros) & 81.7 & 55.9 \\
& Relación estudiante/computadora & 6.8 & 41.9 \\
\multirow{2}{*}{ Innovación } & Patentes de la USPTO concedidas por cada 1 000 000 habitantes & 211.4 & 1.2 \\
& Ingresos por uso de propiedad intelectual (PPP per cápita en USD a precios corrientes) & 268.6 & 31.3 \\
\hline \multirow{2}{*}{ Inversión en innovación } & Gasto público y privado en I+D (\% del PIB) & 2.2 & 0.7 \\
\hline
\end{tabular}

Notas: Los valores son promedios ponderados por la población. PIB $=$ producto interno bruto. PPP $=$ paridad de poder adquisitivo. I+D = investigación y desarrollo. USPTO = Oficina de Patentes y Marcas Registradas de Estados Unidos.

Fuentes: Banco Mundial (2020), Indicadores de Desarrollo Mundial; USPTO (2020), Oficina de Patentes y Marcas Registradas de Estados Unidos; Banco Mundial/UNESCO (2020), Indicadores de Educación (base de datos), https:// data.worldbank.org/topic/education. 
Tabla 2.6. Variables de digitalización de hogares del Índice de Desarrollo del Ecosistema Digital en la OCDE y en América Latina y el Caribe, 2018

\begin{tabular}{lcc}
\hline & OCDE & ALC \\
\hline Usuarios de Internet (\% de la población) & 84.3 & 67.7 \\
Redes sociales (\% de la población) & 61.5 & 59.0 \\
ARPU de datos móviles como porcentaje del ARPU total & 57.2 & 54.8 \\
Índice de desarrollo de gobierno electrónico de Naciones Unidas & 0.82 & 0.65 \\
Comercio electrónico como porcentaje de ventas minoristas & 9.6 & 4.8 \\
Penetración VOD/OTT (hogares) & 40.8 & $4.9^{\star}$ \\
\hline
\end{tabular}

* Incluye Argentina, Brasil, Chile, Colombia, México y Venezuela.

Notas: Los valores son promedios ponderados por la población. ARPU = promedio de ingresos por usuario. VOD/ OTT = vídeo a la carta/de libre transmisión.

Fuentes: Euromonitor (2020), www.euromonitor.com/; GSMA Intelligence (2020), "Definitive Data and Analysis for the Mobile Industry" (webpage), www.gsmaintelligence.com/; UIT (2020), Indicadores del sector mundial de las TIC y de las telecomunicaciones. Base de datos 2020, www.itu.int/en/ITU-D/Statistics/Pages/publications/wtid.aspx; Naciones Unidas (2019), UN e-Government Knowledge Database (base de datos); PNUD (2019), Datos de Desarrollo Humano (19902018) (base de datos), http://hdr.undp.org/en/data.

Tabla 2.7. Variables de infraestructuras del Índice de Desarrollo del Ecosistema Digital en la OCDE y en América Latina y el Caribe, 2018

\begin{tabular}{lcc}
\hline & OCDE & ALC \\
\hline Conexiones de fibra óptica como porcentaje del total de conexiones de banda ancha fija & 20.8 & 7.4 \\
\hline Ancho de banda internacional por usuario de Internet (bit/s) & 121389.1 & 55819.4 \\
Cobertura de población de redes 3G (\% de población) & 98.8 & 94.6 \\
Cobertura de población de redes 4G (\% de población) & 96.4 & 86 \\
IXP por cada 1000 000 personas & 0.21 & 0.12 \\
\hline
\end{tabular}

Notas: Los valores por grupo de países son promedios ponderados por la población. IXP = Punto de intercambio de Internet. PPP = paridad de poder adquisitivo. $\mathrm{MB} / \mathrm{s}=$ Megabytes por segundo.

Fuentes: Estimación propia a partir de GSMA Intelligence (2020), "Definitive Data and Analysis for the Mobile Industry" (sitio web), www.gsmaintelligence.com/; Packet Clearing House (2020), Packet Clearing House Data (database), https://web.archive.org/web/20060413225415/ www.pch.net/resources/data/; UIT (2020), Indicadores del sector mundial de las TIC y de las telecomunicaciones. Base de datos 2020, Unión Internacional de Telecomunicaciones, Ginebra, www.itu.int/en/ITU-D/Statistics/Pages/publications/wtid.aspx (consultado el 21 de agosto de 2020).

\section{Infraestructura de la comunicación, conectividad del transporte y capacidades humanas: Elementos indispensables y complementarios}

La digitalización afecta a todos los sectores y agrega valor a la cadena de producción, si bien la magnitud del cambio dependerá de factores indispensables y complementarios. La transformación digital, al igual que otros cambios tecnológicos, no se refiere únicamente a la difusión de la tecnología, sino también a las inversiones complementarias que las empresas deben realizar en materia de competencias, cambios organizacionales, innovación en procesos, nuevos sistemas y nuevos modelos de negocio (Haskel y Westlake, 2017).

\section{Conectividad y desarrollo de la infraestructura de la comunicación}

La conectividad ha evolucionado en los últimos años, en particular la banda ancha, que en un principio estaba disponible exclusivamente a través de las redes fijas, pero fue rápidamente superada por la tecnología móvil (OCDE, 2019a). En promedio, la proporción de usuarios de Internet ha mejorado en los países de América Latina y el Caribe y, a pesar de la diferencia entre ambas regiones, la brecha digital con respecto a la zona de la OCDE se ha reducido. En particular, en 2018, el 68\% de la población usó Internet regularmente, casi el doble de la proporción en 2010, aunque por debajo del promedio de la OCDE del $84 \%$ (Gráfico 2.10). 
La banda ancha móvil activa ha evolucionado de forma considerable en las últimas décadas. En 2018, la cantidad de suscripciones activas a la banda ancha móvil era más de cinco veces superior a la de la banda ancha fija (Gráfico 2.11), con una cobertura promedio de casi el $74 \%$ de la población. ${ }^{5}$ El crecimiento de las suscripciones activas de conectividad móvil es desigual entre los países, superando el 85\% de la población en Brasil, Chile, Costa Rica y Uruguay en 2018, frente a casi el 30\% en Haití y Honduras. Las diferencias existentes entre América Latina y el Caribe y la OCDE se han mantenido relativamente constantes en torno a los 30 puntos porcentuales, en promedio.

A pesar de la mejora sostenida que se ha venido produciendo, las velocidades de conexión están muy por debajo del promedio mundial, lo que limita el tipo de servicios y apps disponibles (Gráfico 2.12). Este aspecto ha sido clave durante la pandemia del coronavirus (Covid-19) ya que la baja velocidad de conexión impide el uso de apps simultáneas: los usuarios de la mayoría de los países de América Latina y el Caribe tuvieron que elegir entre el teletrabajo, la formación a distancia y el entretenimiento.

Gráfico 2.10. Usuarios de Internet en países seleccionados de América Latina y el Caribe, 2010 y 2018 (o más reciente)

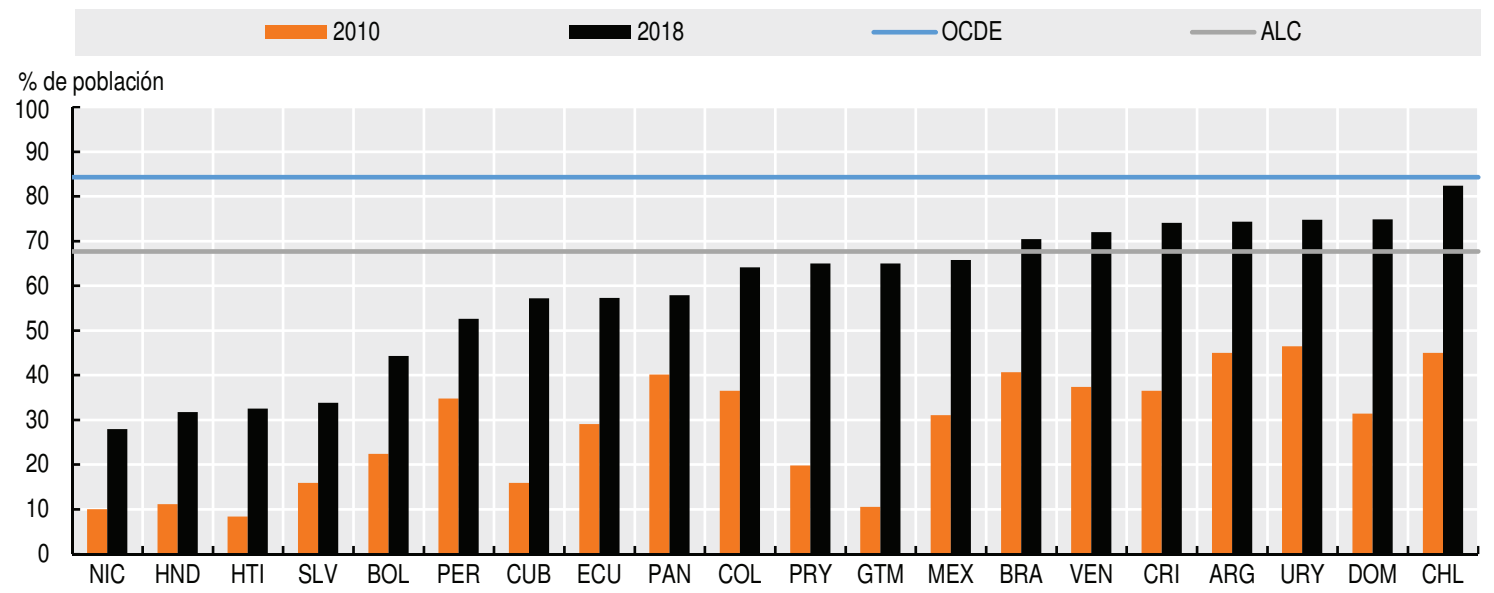

Notas: El indicador puede incluir estimaciones y la proporción de usuarios de Internet se basa en los resultados de las encuestas nacionales de hogares. Las cifras reflejan la población total o las personas de 5 años o más. Si no se dispone de ninguna de las dos (es decir, la población objetivo refleja un grupo de edad más limitado), se elabora una estimación de población total. Fuente: Estimación propia a partir de UIT (2020), Indicadores del sector mundial de las TIC y de las telecomunicaciones. Base de datos 2020, Unión Internacional de Telecomunicaciones, Ginebra, www.itu.int/en/ITU-D/Statistics/Pages/publications/wtid.aspx (consultado el 21 de agosto de 2020).

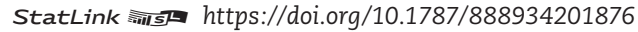


Gráfico 2.11. Penetración de banda ancha móvil y fija en países seleccionados de América Latina y el Caribe, 2018 (o más reciente), abonos activos por cada 100 habitantes

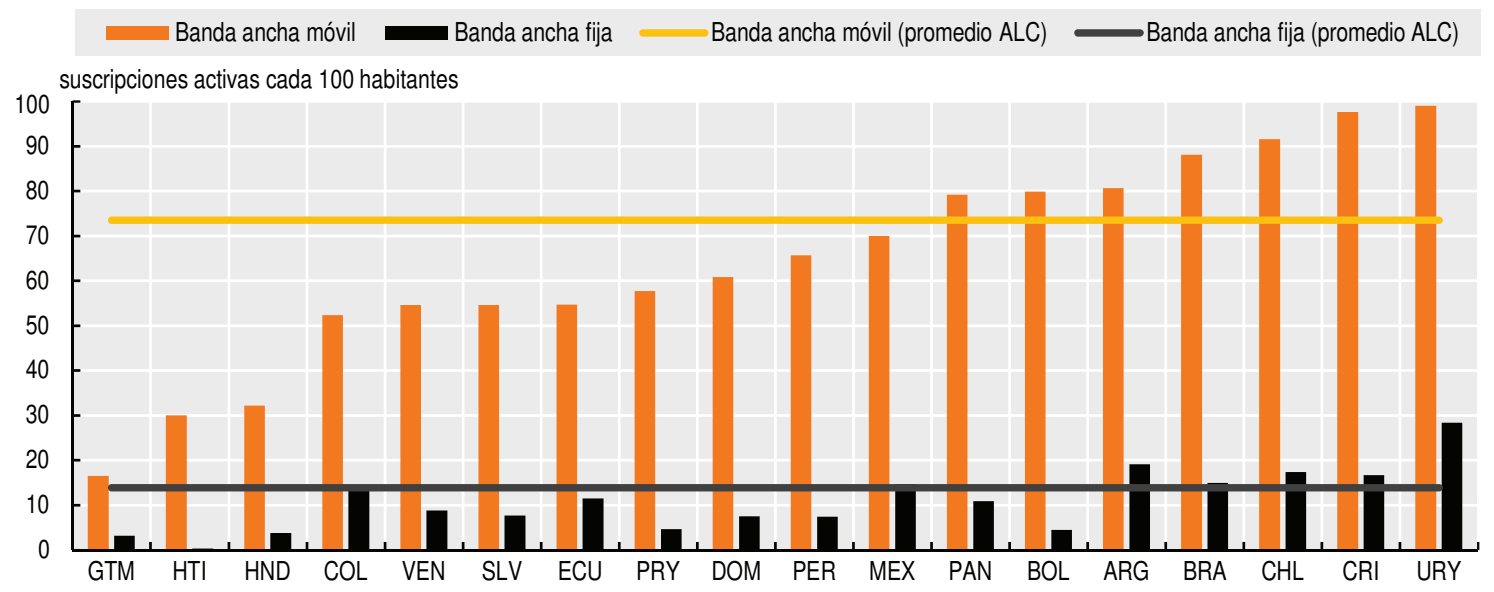

Nota: Por abonos activos de banda ancha móvil se entiende la suma de los abonos de banda ancha móvil estándar y de banda ancha móvil dedicada al Internet público. Abarcan los abonados reales (no potenciales), aunque estos últimos puedan tener terminales de banda ancha.

Fuente: Estimación propia a partir de UIT (2020), Indicadores del sector mundial de las TIC y de las telecomunicaciones. Base de datos 2020, Unión Internacional de Telecomunicaciones, Ginebra, www.itu.int/en/ITU-D/Statistics/Pages/publications/wtid.aspx (consultado el 21 de agosto de 2020).

StatLink त्तilst https://doi.org/10.1787/888934201895

Gráfico 2.12. Velocidades de descarga de banda ancha fija comparadas con los requisitos de ancho de banda para servicios de Internet en países seleccionados, marzo - julio 2020

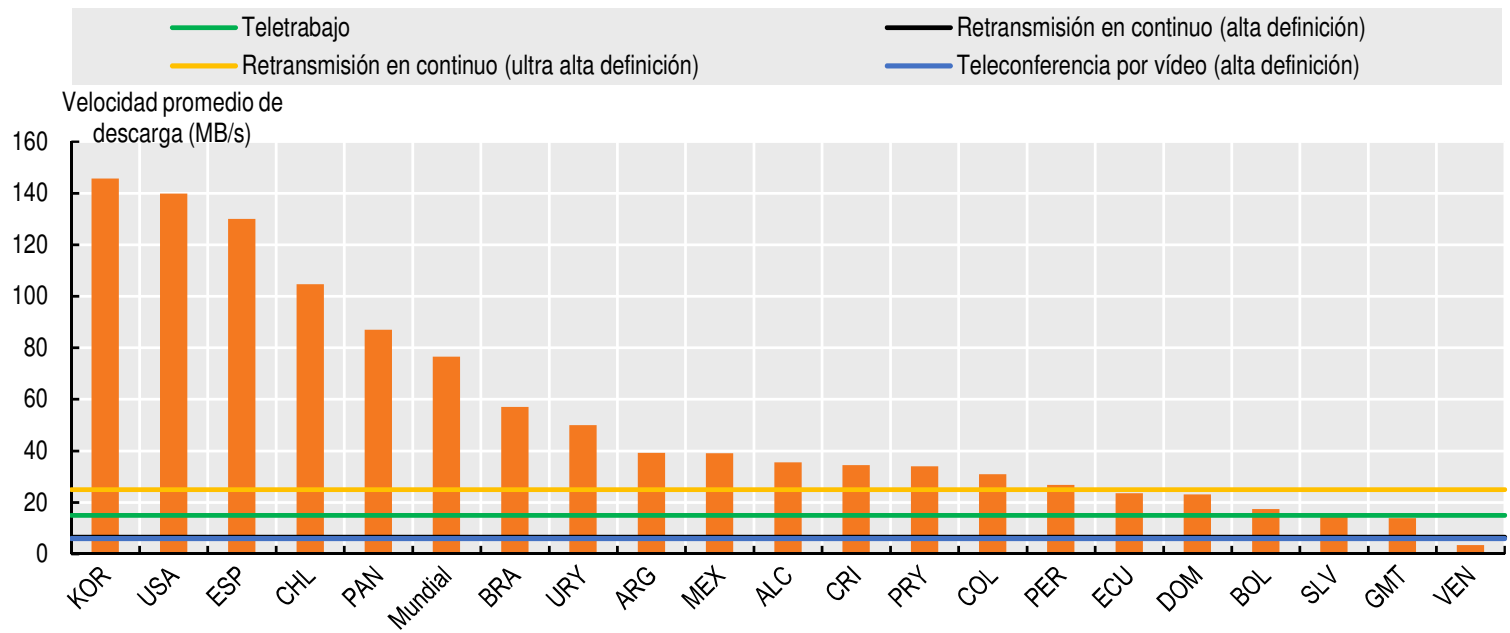

Nota: $\mathrm{HD}$ = Alta definición. MB/s = Megabytes por segundo. El indicador refleja la velocidad de la banda ancha por cable que se puede alcanzar "onnet". No representa plenamente la experiencia general de Internet y solo ofrece una visión parcial de la velocidad de Internet. No obstante, proporciona un útil indicador parcial disponible tanto para los países de la OCDE como para los que no pertenecen a ella (OCDE, 2019e). Los datos de velocidad de descarga de banda ancha fija son un promedio mensual de marzo a julio de 2020.

Fuente: Observatorio Regional de Banda Ancha (ORBA) de la CEPAL, basado en datos de la Comisión Federal de Comunicaciones y el Índice de Prueba de Velocidad Global de Ookla.

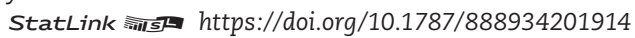

Dado que la mayoría de los contenidos a los que se accede en América Latina y el Caribe se generan fuera de la región (sobre todo en Estados Unidos), las infraestructuras de conectividad internacional son muy importantes. El desarrollo de redes de distribución de contenidos ${ }^{6} \mathrm{y}$ de puntos de intercambio de Internet son fundamentales para mejorar la eficiencia de las redes. Los puntos de intercambio de Internet permiten a los proveedores 
de servicios de Internet intercambiar tráfico entre sus redes a nivel local. El desarrollo de los puntos de intercambio reduce tanto los costos de transmisión, al no tener que intercambiar tráfico en puntos distantes, como la latencia, un parámetro esencial en la calidad de los servicios que requiere integridad en la transmisión. Los puntos de intercambio de Internet también desempeñan un papel importante al facilitar la entrada de los proveedores de servicios de Internet, que pueden lograr su interconexión doméstica en el país a través de otros proveedores.

Los puntos de intercambio de Internet también reducen la dependencia de los proveedores ascendentes (es decir, de proveedores de conexiones internacionales), aumentan la eficiencia y proporcionan rutas alternativas para el tráfico, asegurando así la fiabilidad y estabilidad de la calidad de la red. Facilitan el tráfico local o regional y favorecen el alojamiento de contenido en el país (por ejemplo, mediante la instalación de redes de distribución de contenidos), y tienen un efecto positivo en la masificación del acceso a Internet al reducir los costos, principalmente cuando surge contenido local abundante. Cuando no existe una interconexión de los proveedores de servicios de Internet grandes y pequeños a través de puntos de intercambio de Internet que permitan el acceso nacional a apps y contenidos desarrollados localmente en condiciones no discriminatorias, es razonable incentivar este tipo de conexiones, ya sea aplicando la legislación sobre la competencia o imponiendo la interconexión local de Internet entre todos los proveedores de servicios de Internet del país mediante la regulación, según la modalidad más conveniente.

El acceso y la calidad de la conexión siguen siendo desiguales entre los países de América Latina y el Caribe y dentro de ellos. Existen varias iniciativas para mejorar la conectividad, sobre todo en la banda ancha, junto con iniciativas específicas para facilitar el despliegue de infraestructuras (Tabla 2.8).

Tabla 2.8. Iniciativas de conectividad en países seleccionados de América Latina

\begin{tabular}{|c|c|c|c|c|c|c|}
\hline & \multicolumn{3}{|c|}{ Objetivos de conectividad } & \multirow{2}{*}{$\begin{array}{l}\text { Fondo de Servicio } \\
\text { Universal (año) }\end{array}$} & \multirow{2}{*}{$\begin{array}{l}\text { Agenda digital } \\
\text { nacional }\end{array}$} & \multirow{2}{*}{$\begin{array}{l}\text { Plan nacional de banda } \\
\text { ancha }\end{array}$} \\
\hline & Velocidad & Cobertura & Año & & & \\
\hline \multirow[t]{2}{*}{ Argentina } & $20 \mathrm{MB} / \mathrm{s}$ & 2 millones de & & Sí & Sí & Sí \\
\hline & & nuevas conexiones & disponible & $(2000)$ & Agenda Digital 2030 & Plan Nacional de Conectividad \\
\hline \multirow[t]{2}{*}{ Brasil } & No hay & 2.471 ciudades & No & Sí & Sí & Sí \\
\hline & objetivo & & disponible & (2000) & $\begin{array}{l}\text { Estrategia para la } \\
\text { transformación digital }\end{array}$ & Internet para todos \\
\hline \multirow[t]{2}{*}{ Chile } & $10 \mathrm{MB} / \mathrm{s}$ & $90 \%$ de hogares & 2020 & Sí & Sí & Sí \\
\hline & & (20\% fibra) & & (1994) & Agenda Digital 2020 & Agenda Digital 2020 \\
\hline \multirow[t]{3}{*}{ Colombia } & $25 \mathrm{MB} / \mathrm{s}$ & $70 \%$ de hogares con & 2022 & Sí & Sí & Sí \\
\hline & $4 \mathrm{MB} / \mathrm{s}$ de & acceso a Internet & & (1976) & Plan Nacional de & Plan Nacional de Desarrollo \\
\hline & $\begin{array}{l}\text { promedio } \\
\text { para } 2019\end{array}$ & $\begin{array}{l}50 \% \text { de hogares con } \\
\text { banda ancha }\end{array}$ & & & $\begin{array}{l}\text { Desarrollo 2018-2022; } \\
\text { Agenda } 2030\end{array}$ & $2018-2022$ \\
\hline \multirow[t]{2}{*}{ México } & No hay & $100 \%$ de población & 2024 & No & Sí & Sí \\
\hline & objetivo & & & & $\begin{array}{l}\text { Plan Nacional de } \\
\text { Desarrollo } 2024\end{array}$ & Internet para todos \\
\hline
\end{tabular}

Fuente: CEPAL (2019b), "Observatorio Regional de Banda Ancha" (sitio web), www.cepal.org/es/observatorioregional-de-banda-ancha según Cullen International (2019), "Cullen International" (sitio web), www.culleninternational.com/.

\section{Infraestructura 5G para la digitalización de los procesos de producción}

A diferencia de las generaciones anteriores, se espera que la quinta generación de redes inalámbricas (la denominada 5G) transforme radicalmente el papel de las tecnologías en la sociedad y las empresas. La 5G permite una nueva era de Internet aplicable a todos los ámbitos a través de conexiones masivas, velocidades de transmisión más rápidas, menor latencia y menor consumo energético. La 5G representa la evolución de las generaciones 
anteriores (2G, 3G y 4G). Su objetivo es proporcionar una velocidad de descarga de $20 \mathrm{~GB} / \mathrm{s}$, una velocidad de subida de $10 \mathrm{~GB} / \mathrm{s}$ y una latencia de $1 \mathrm{~ms}$, es decir, una velocidad de descarga 200 veces más rápida, una velocidad de subida 100 veces más rápida y una décima parte de la latencia en comparación con las redes LTE actuales (4G) (OCDE, 2019f). Se prevé que la $5 \mathrm{G}$ dé lugar a nuevos usos, como ciudades y agricultura inteligentes, una logística más eficiente, la transformación de los servicios de salud y educación y la renovación de los organismos de seguridad. También se prevé que revolucione el sector industrial y dé lugar a nuevos modelos de negocio mediante la integración de tecnologías como la inteligencia artificial y la realidad virtual y aumentada.

Se estima que un tercio de los posibles usos de la 5G se produzcan en la industria manufacturera, si bien puede fomentar el crecimiento en todos los sectores. Con la 3G y la 4G, los nuevos modelos de negocio, como el comercio electrónico, cambiaron profundamente los sectores de consumo, incluidos el comercio minorista y los medios de comunicación (O'Halloran, 2019). Las características distintivas de la 5G implican que permita seguir innovando y revolucionando los procesos empresariales y de producción en todos los sectores. Puede apoyar el desarrollo y la introducción de nuevas apps, mejorar la eficiencia de las empresas, permitir los servicios de Internet de las Cosas y promover nuevas formas de competencia (OCDE, 2019f). La conectividad de alta velocidad ofrecida por la 5G puede fortalecer los servicios de empresa a consumidor y de empresa a empresa y hacerlos más sensibles a las preferencias. Su baja latencia permite el control remoto en tiempo real de las máquinas a escala y a distancia. El control remoto en tiempo real también podría revolucionar el sector de la logística con flotas autónomas y vehículos de control remoto. La alta densidad de conexión permite múltiples dispositivos sin congestión de la red, haciendo posible la instalación de sensores en las máquinas de las fábricas y la adopción de decisiones inteligentes que se basen en datos en tiempo real de máquinas interconectadas, la denominada Internet industrial de las cosas (WEF, 2020).

La automatización de algunos procesos de producción repetitivos permitiría a los trabajadores centrarse en actividades de mayor valor agregado, a condición de que recibieran formación complementaria (ver el apartado sobre el desarrollo de las capacidades humanas y el Capítulo 3). El aumento de la eficacia operativa de las fábricas podría generar beneficios económicos. La 5G también podría tener beneficios ambientales al ayudar a las industrias a gestionar su huella de carbono con datos en tiempo real y redes inteligentes (WEF, 2020).

En 2018, la 4G se convirtió en la tecnología móvil más utilizada en todo el mundo. Con 3.400 millones de conexiones ( $43 \%$ del total) ${ }^{7}$ se espera que la $4 \mathrm{G}$ se consolide como la tecnología móvil dominante, alcanzando casi el 60\% del total para el año 2025 (GSMA, 2019a). Las redes 5G se están convirtiendo en una realidad comercial. Tras su lanzamiento en Estados Unidos y Corea del Sur en abril de 2019, se espera que otros países implanten la $5 G$ en los próximos años (OCDE, 2019f).

La tecnología 5G estará operativa a medio y largo plazo en América Latina y el Caribe. La primera fase de la disponibilidad comercial de los dispositivos $5 \mathrm{G}$ se inició a finales de 2019, si bien la mayoría de los lanzamientos se esperan para fines de 2020 o 2021. El grado de preparación para la 5G depende de múltiples factores y varía sobre todo porque los mercados regionales se encuentran en diversas fases de madurez.

\section{Conectividad del transporte: Logística e infraestructuras de transporte}

Cuando las sociedades están bien conectadas, las personas consiguen una mayor productividad, un mejor acceso al empleo, a la educación básica y a los servicios de salud, interacciones sociales más fluidas y un mayor empoderamiento a través de la innovación y el uso de la tecnología. Las nuevas tecnologías del transporte han permitido el ahorro 
de tiempo, mayor seguridad y un menor impacto ambiental de la movilidad (ITF, 2019). Una infraestructura física y digital bien desarrollada reduce los costos de transacción, mitiga los obstáculos de la distancia y el tiempo, facilita el flujo de bienes, información y personas, y ayuda a que los mercados se integren en las cadenas de valor mundiales. Las infraestructuras ineficientes e inadecuadas obstaculizan la integración social, el crecimiento y la prosperidad.

La conectividad del transporte es fundamental para aprovechar al máximo la transformación digital. Gracias a las plataformas digitales, el comercio electrónico puede ampliar los mercados y mejorar la eficiencia. El rápido crecimiento del comercio electrónico podría llevar a aumentos en los volúmenes de carga de entre el $2 \%$ y el $11 \%$, dependiendo del modo de transporte (ITF, 2019). En ese contexto, una conectividad de transporte deficiente debería ser una barrera para el desarrollo del comercio electrónico de bienes físicos en la mayoría de los países en desarrollo (Rodríguez, 2018). Infraestructuras de transporte que funcionan bien, incluyendo carreteras, puertos, aeropuertos, ferrocarriles, así como procesos logísticos eficientes, tales como los servicios de entrega postal y de aduanas, ayudan a garantizar el cumplimiento efectivo de los pedidos (Rodríguez, 2018). A la inversa, una infraestructura y una logística de transporte inadecuadas dificultan que las empresas se comprometan de manera eficiente en el comercio electrónico a nivel local, regional e internacional. Esto es particularmente evidente para las pymes, que por ejemplo dependen en gran medida de los servicios logísticos externos.

A pesar de su nivel de ingresos, América Latina y el Caribe no cuenta con unas infraestructuras adecuadas. Más del $60 \%$ de las carreteras de la región están sin pavimentar, en comparación con el $46 \%$ en los países emergentes de Asia y el $17 \%$ en Europa. Dos tercios de las aguas residuales no están tratadas, mientras que el deficiente saneamiento y la falta de acceso a agua potable provocan una elevada tasa de mortalidad en niños menores de 5 años, según la Organización Mundial de la Salud. Los niveles de interrupciones y cortes de electricidad se sitúan entre los más altos del mundo, afectando el uso adecuado de las nuevas tecnologías. El gasto en infraestructuras en relación con el PIB es inferior al de cualquier otra región, excepto el África subsahariana (Gráfico 2.13).

\section{Gráfico 2.13. Inversión en infraestructuras públicas y privadas como proporción del PIB en regiones en desarrollo seleccionadas, último año disponible}

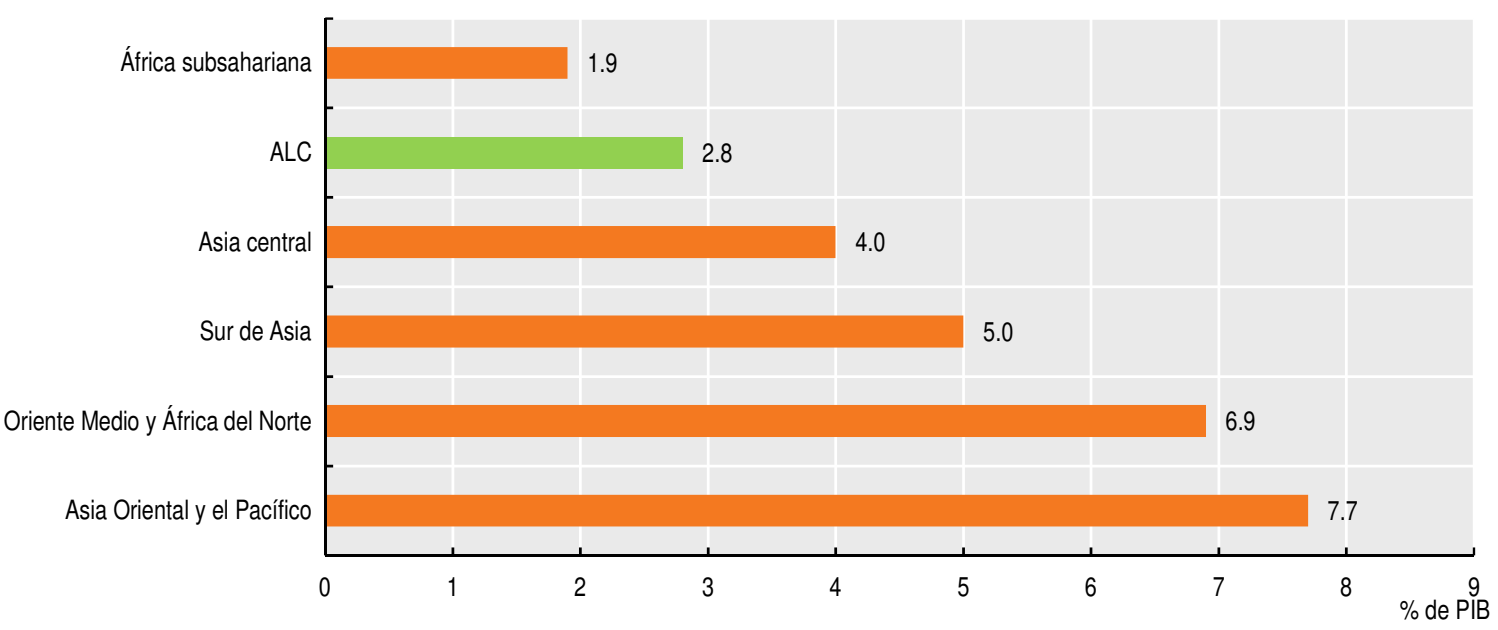

Fuentes: ADB (2017), Informe Anual del ADB 2017, http://dx.doi.org/10.22617/FLS189307; Banco Internacional de Reconstrucción y Fomento/Banco Mundial (2017), Rethinking Infrastructure in Latin America and the Caribbean: Spending Better to Achieve More, http://documents.worldbank.org/curated/en/676711491563967405/pdf/114110-REVISED-Rethinking-Infrastructure-LowRes.pdf según Infralatam (2020), Datos de Inversión en Infraestructura Económica (base de datos), http://infralatam.info; estimaciones propias.

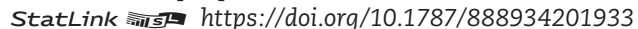




\section{Infraestructuras de transporte insuficientes en América Latina y el Caribe}

Para aprovechar al máximo la transformación digital, es esencial promover una conectividad de transporte adecuada. La infraestructura de transporte es un ingrediente clave para favorecer la conectividad de las personas y las mercancías. En América Latina, el costo total del transporte, la inversión y el mantenimiento de una carretera no mantenida es entre tres y siete veces más alto que el costo de una carretera que sí dispone de un mantenimiento adecuado (OCDE/CAF/UN CEPAL, 2018). Las ineficiencias operativas debido al mal estado de las redes viales y ferroviarias obstaculizan el desarrollo empresarial. Es necesario contar con una infraestructura de calidad para conseguir un desarrollo sostenible e inclusivo (Cuadro 2.3). Además, la adopción de un enfoque multimodal que deje de centrarse en las carreteras (por ejemplo, el desarrollo de ferrocarriles, puertos y vías navegables) es fundamental para promover una adecuada infraestructura de transporte sostenible.

Los fallos de diseño existentes en los contratos de concesión han generado unos costos fiscales excesivos (OCDE/CAF/CEPAL, 2018). La debilidad de la regulación y la falta de marcos institucionales suelen provocar retrasos importantes con el consiguiente aumento de los costos.

Es importante que los precios en el transporte sean asequibles para asegurar un acceso y un uso público equitativos e inclusivos. Se necesitan marcos regulatorios que aseguren la asequibilidad para promover un uso equitativo del transporte público. Para ello, deben considerarse modalidades de pago innovadoras que tengan en cuenta determinados tramos de ingresos, sobre todo a los que se encuentran en la parte inferior de la distribución. En lo que respecta a las empresas, la relación entre los costos de transporte y las tarifas en la región ha sido tradicionalmente más alta que en los países de la OCDE (OCDE, 2016).

Algunos países de la región han mejorado los marcos reglamentarios e institucionales para las asociaciones público-privadas. Por ejemplo, en los últimos cinco años, Colombia, Honduras y Perú han logrado una participación privada más eficaz en infraestructura mediante la mejora de las regulaciones (OCDE/CAF/CEPAL, 2018).

Recuadro 2.3. Principios del G20 para la inversión en infraestructuras de calidad

En junio de 2019, los líderes del G20 aprobaron en Japón los Principios para la inversión en infraestructuras de calidad $(G 20,2019)$. Estos principios tratan de potenciar los efectos indirectos de las infraestructuras para el desarrollo sostenible e inclusivo, asegurando la accesibilidad, asequibilidad e inclusión, al tiempo que fomentan la igualdad de género, la no discriminación, los derechos humanos y las normas laborales, los derechos de los pueblos indígenas, la acción por el clima, la creación de empleo, el alivio de la pobreza, la mitigación de los efectos de los reasentamientos forzosos, la transparencia de las instituciones y la lucha contra la corrupción.

Principio 1: Maximizar los efectos positivos de las infraestructuras para lograr un crecimiento y desarrollo sostenibles

Principio 2: Aumentar la eficiencia económica en vista del costo del ciclo de vida Principio 3: Integrar las consideraciones ambientales en las inversiones en infraestructuras Principio 4: Fomentar la resiliencia frente a las catástrofes naturales y otros riesgos Principio 5: Integrar las consideraciones sociales en las inversiones en infraestructuras Principio 6: Fortalecer la gobernanza de las infraestructuras 
Recuadro 2.3. Principios del G20 para la inversión en infraestructuras de calidad (cont.)

Estos principios voluntarios y no vinculantes pueden proporcionar una orientación estratégica hacia las inversiones en infraestructuras de calidad en las economías en desarrollo y emergentes. Para promover su aplicación, el Centro de Desarrollo de la OCDE trabaja con miembros e instituciones asociadas para proporcionar foros igualitarios que reúnen a las economías en desarrollo y emergentes y a los países de la OCDE para intercambiar experiencias y lecciones aprendidas. Gracias a su composición única (está integrado por 30 economías ajenas a la OCDE y 27 países de la OCDE), el diálogo establecido por el Centro de Desarrollo en materia de políticas puede ayudar a identificar cuestiones concretas de desarrollo de infraestructuras, cultivar una comprensión común de las necesidades y desafíos más apremiantes y promover mejores soluciones en materia de políticas mediante el intercambio de conocimientos y experiencias.

Sin embargo, la mayoría de los países de la región tienen margen para mejorar en varias esferas en relación con las concesiones de carreteras. La explotación de los beneficios de las concesiones requiere una mayor capacidad de evaluar, licitar y gestionar los contratos. Además, mejores procedimientos de contabilidad fiscal en la región podrían mejorar la selección de los contratistas. Esto impediría el uso de asociaciones público-privadas únicamente para preservar el espacio fiscal (OCDE et al., 2019).

\section{Los elevados costos logísticos y los beneficios de la digitalización}

Los elevados costos logísticos que existen en América Latina y el Caribe obstaculizan la competitividad, incluida la expansión del comercio electrónico. La puntuación del Índice de Desempeño Logístico (LPI por sus siglas en inglés) del Banco Mundial en 2018 fue de 2.7: por debajo de Europa y Asia Central (3.2), Asia Oriental y el Pacífico (3.2) y Oriente Medio y África del Norte (2.8), pero por encima de las regiones en desarrollo del África subsahariana (2.5) y Sur de Asia (2.5) (Tabla 2.9). Los principales impedimentos de la región son la calidad de las infraestructuras, la eficiencia de los procesos de autorización, incluidas las aduanas, y el costo y la calidad de los servicios logísticos.

Las tecnologías digitales pueden simplificar los procedimientos administrativos y acelerar los envíos transfronterizos. Las ventanillas únicas electrónicas permiten a los comerciantes presentar electrónicamente los requisitos regulatorios de importación y exportación. Al no ser necesario el envío de copias impresas a los distintos órganos se aumenta la transparencia, se agiliza la autorización de las transacciones internacionales y mejoran las estadísticas comerciales. Países como Argentina, Chile, Colombia, Costa Rica, México y Perú han adoptado sistemas de ventanillas únicas. Algunos países han puesto en marcha medidas para potenciar la interoperabilidad compartiendo certificados fitosanitarios (junio de 2016) y certificados de origen (finales de 2017) (Opertti, 2019). De este modo, se podrían conseguir las condiciones necesarias para integrar controles fronterizos mediante de un sistema de ventanilla única que funcione a través de soluciones en la nube, como el Internet de las Cosas, haciendo que el comercio sea más fluido y que se reduzcan los costos de logística (Martincus, 2016). 
Tabla 2.9. Puntuaciones del Índice de Desempeño Logístico (LPI) del Banco Mundial, por región, 2018

\begin{tabular}{lccccccc}
\hline Región & $\begin{array}{c}\text { Puntuación } \\
\text { del LPI }\end{array}$ & Aduanas & $\begin{array}{c}\text { Infra- } \\
\text { estructuras }\end{array}$ & $\begin{array}{c}\text { Envíos } \\
\text { internacionales }\end{array}$ & $\begin{array}{c}\text { Competencia } \\
\text { logística }\end{array}$ & $\begin{array}{c}\text { Seguimiento } \\
\text { y localización }\end{array}$ & $\begin{array}{c}\text { Puntualidad } \\
\text { de envíos }\end{array}$ \\
\hline Europa y Asia Central & 3.2 & 3.0 & 3.1 & 3.1 & 3.2 & 3.3 & 3.7 \\
Asia Oriental y el Pacífico & 3.2 & 3.0 & 3.0 & 3.0 & 3.1 & 3.2 & 3.5 \\
Oriente Medio y África del Norte & 2.8 & 2.5 & 2.7 & 2.7 & 2.7 & 2.8 & 3.2 \\
América Latina y el Caribe & 2.7 & 2.5 & 2.5 & 2.7 & 2.6 & 2.7 & 3.0 \\
Sur de Asia & 2.5 & 2.3 & 2.3 & 2.5 & 2.5 & 2.6 & 2.9 \\
\hline África subsahariana & 2.5 & 2.3 & 2.2 & 2.5 & 2.4 & 2.5 & 2.8 \\
\hline
\end{tabular}

Notas: El LPI es el promedio ponderado de las puntuaciones en seis dimensiones: 1) eficiencia de procesos de autorización por parte de los organismos de control de fronteras, incluidas aduanas (rapidez, sencillez y previsibilidad de trámites); 2) calidad de infraestructuras relacionadas con el comercio y el transporte (puertos, ferrocarriles, carreteras, tecnología de la información); 3) facilidad para organizar envíos a precios competitivos; 4) competencia y calidad de los servicios logísticos (operadores de transporte, agentes de aduanas); 5) capacidad para rastrear y localizar envíos; 6) puntualidad de envíos para llegar a su destino con arreglo a la entrega prevista o programada.

Fuente: Banco Mundial (2018), Índice de Desempeño Logístico del Banco Mundial 2018 (base de datos), https://lpi. worldbank.org/international/scorecard/radar/254/C/DEU/2018/R/EAP/2018/R/ECA/2018/R/LAC/2018/R/ MNA/2018/R/SAS/2018/R/SSA/2018? featured $=17$.

La digitalización puede hacer que el sector de la logística sea más eficiente en cuanto a recursos, y más ágil y sensible a las necesidades de los clientes. Los nuevos modelos de negocio, incluido el comercio electrónico, están contribuyendo a la creciente demanda de servicios logísticos. Las industrias que tienen vínculos estrechos con la logística, como el comercio minorista, han experimentado grandes transformaciones gracias a las tecnologías digitales. El sector de la logística ha sido más lento (Bauer, Dichter y Rothko, 2018; WEF, 2016), a pesar de los beneficios existentes. Las plataformas digitales no solo ayudan a las empresas a conectar con los consumidores, sino que también pueden ajustar mejor la demanda de envíos con las capacidades logísticas, por ejemplo, mediante servicios de reservas por Internet de extremo a extremo. Estas plataformas podrían ser especialmente útiles para la internacionalización de las pymes, que a menudo no tienen la misma experiencia que las grandes empresas en la organización de envíos internacionales. Además, el Internet de las Cosas - una red compuesta por dispositivos inteligentes, sensores y la nube, junto con técnicas avanzadas de análisis de datos- permite el análisis en tiempo real de los datos de la cadena de suministro. Los conocimientos pueden utilizarse para optimizar la toma de decisiones y detectar y reaccionar rápidamente ante los problemas. Además de la reducción de los costos de explotación, la mejora del análisis de datos aporta beneficios ambientales. La optimización de la red puede reducir el número de camiones en la carretera, disminuyendo así las emisiones y los residuos. Las plataformas digitales pueden respaldar el uso de espacios compartidos en almacenes y en capacidades de transporte, aumentando así los niveles de utilización y reduciendo las emisiones (WEF, 2016).

Aunque el coronavirus (Covid-19) ha acelerado el uso de las plataformas de comercio electrónico y ha alentado a las empresas a aplicar modelos de negocio ajustados a la disminución de la demanda debido a las restricciones, no deben subestimarse los obstáculos al comercio electrónico existentes en la región. Entre ellos, los altos costos de envío, el temor al uso indebido de información confidencial y sensible, y la baja adopción de las tecnologías por parte de las mipymes exigen la adopción de un enfoque sistémico y de políticas, que varíe según el país, para impulsar el comercio electrónico. 


\section{Desarrollo de capacidades humanas para la digitalización en América Latina y el Caribe}

Desarrollar las capacidades humanas y adaptarse al nuevo contexto digital es necesario para aprovechar al máximo las nuevas tecnologías. Los datos de la Unión Europea indican que los aumentos de productividad derivados de la adopción de la tecnología digital en las empresas tienden a ser menores cuando existe una escasez de competencias. Las políticas de apoyo a la adopción de tecnologías deben complementarse con la creación de las condiciones que permitan a las empresas más rezagadas ponerse al día, por ejemplo, mediante la promoción de un mejor acceso a competencias, en particular en materia de formación en TIC para trabajadores poco cualificados (Gal et al., 2019; Andrews, Nicoletti y Timiliotis, 2018).

Los factores de producción representan la mayor brecha en el desarrollo del ecosistema digital entre los países de América Latina y el Caribe y la OCDE. La formación en competencias digitales es un elemento fundamental. Invertir en competencias adecuadas y reducir la brecha en la región con respecto a los países de la frontera tecnológica será esencial para que ALC aproveche las tecnologías digitales y no se quede atrás por los cambios fundamentales que alteran el entorno industrial.

En América Latina y el Caribe, la brecha existente entre la oferta y la demanda de competencias es considerable. En el ámbito de los servicios relacionados con las TI y la programación, la demanda mundial del mercado laboral supera considerablemente la oferta de profesionales en la región. Sin embargo, ocurre lo contrario en otros ámbitos como la arquitectura, el diseño de medios de comunicación y los servicios de redacción y traducción (Gráfico 2.14). El desajuste observado indica la necesidad de aumentar la capacitación en esferas relacionadas con la economía digital para aprovechar las crecientes oportunidades.

\section{Gráfico 2.14. Oferta y demanda mundial del mercado laboral de competencias en América Latina y el Caribe, 2019}

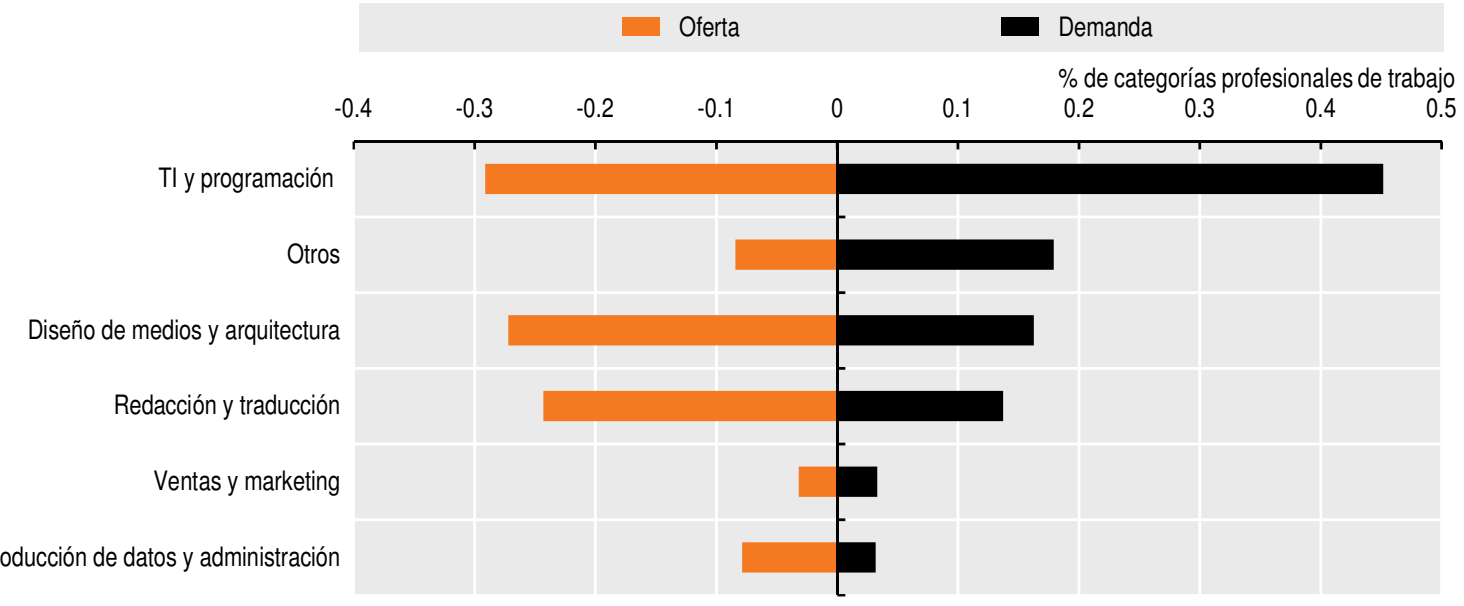

Notas: Otros se refiere a: Trabajos locales y servicios; transporte de carga y transporte; ingeniería y manufactura; y contabilidad empresarial, recursos humanos y jurídicos. Según Freelancer y Workana, dos plataformas laborales digitales. Freelancer tiene un mayor alcance mundial; Workana se centra en América Latina. En estas plataformas, los profesionales ofrecen competencias específicas y los clientes buscan ayuda para proyectos concretos. Ambas plataformas ofrecen a los profesionales la oportunidad de publicar su perfil y a los empleadores la posibilidad de publicar oportunidades de trabajo.

Fuente: CEPAL (2020e), Análisis de la huella digital en América Latina y el Caribe, https://repositorio.cepal.org/handle/11362/45484.

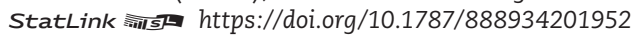


Para hacer frente a las carencias existentes en el ámbito de las capacidades humanas, es importante considerar tanto las necesidades de la estructura productiva como su trayectoria de desarrollo prevista o deseada. La escasa formación de los investigadores que participan en la creación de nuevos productos y servicios afecta a la capacidad para desarrollar nuevas tecnologías y sectores, mientras que la falta de capacidades humanas para asimilar nuevas tecnologías dificulta la adopción de factores de producción que puedan mejorar la productividad.

Las necesidades de competencias y educación para cada una de estas funciones son diferentes. Los investigadores que participan en el desarrollo de las tecnologías digitales suelen tener una maestría y a menudo un doctorado. Los profesionales que incorporan las tecnologías digitales a los procesos productivos suelen poseer un certificado de estudios de grado o de maestría, aunque también pueden estar cualificados mediante una titulación más breve (por ejemplo, de formación profesional o un certificado). Cada profesión conlleva competencias muy diferentes. Entre las competencias que se requieren para asimilar tecnologías maduras figuran la formación en áreas básicas de informática de gestión y las competencias que se requieren para incorporar tecnologías avanzadas a la cadena de producción, que incluyen la capacitación en áreas como la inteligencia artificial y la robótica.

Las TIC amplían las oportunidades de educación continua. Los denominados MOOC (cursos gratuitos a gran escala y abiertos a todo el mundo) y las plataformas de formación abierta ofrecen una capacitación asequible y flexible en todas las etapas de la vida así como contenido adaptado a las necesidades personales o laborales. Estas tecnologías pueden impulsar la productividad y ayudar a los trabajadores formales e informales con tiempo o recursos limitados a acumular capital humano y competencias. Los trabajadores podrían beneficiarse de alternativas a la educación y formación tradicionales (OCDE et al., 2019).

En las dos últimas décadas, la región de América Latina y el Caribe ha desarrollado una generosa oferta de programas de capacitación en tecnologías digitales. Más de 1600 universidades de Argentina, Brasil, Chile, Colombia, México, Perú y Uruguay el 52\% del total de universidades de los siete países- ofrecen más de 6.390 programas de grado y posgrado de este tipo (Katz y Callorda, 2018). Entre los países seleccionados, Argentina es el país que tiene más universidades de este tipo (66\%) (Gráfico 2.15).

\section{Gráfico 2.15. Cantidad de universidades que ofrecen programas de capacitación en tecnologías digitales en países seleccionados de América Latina, 2016}

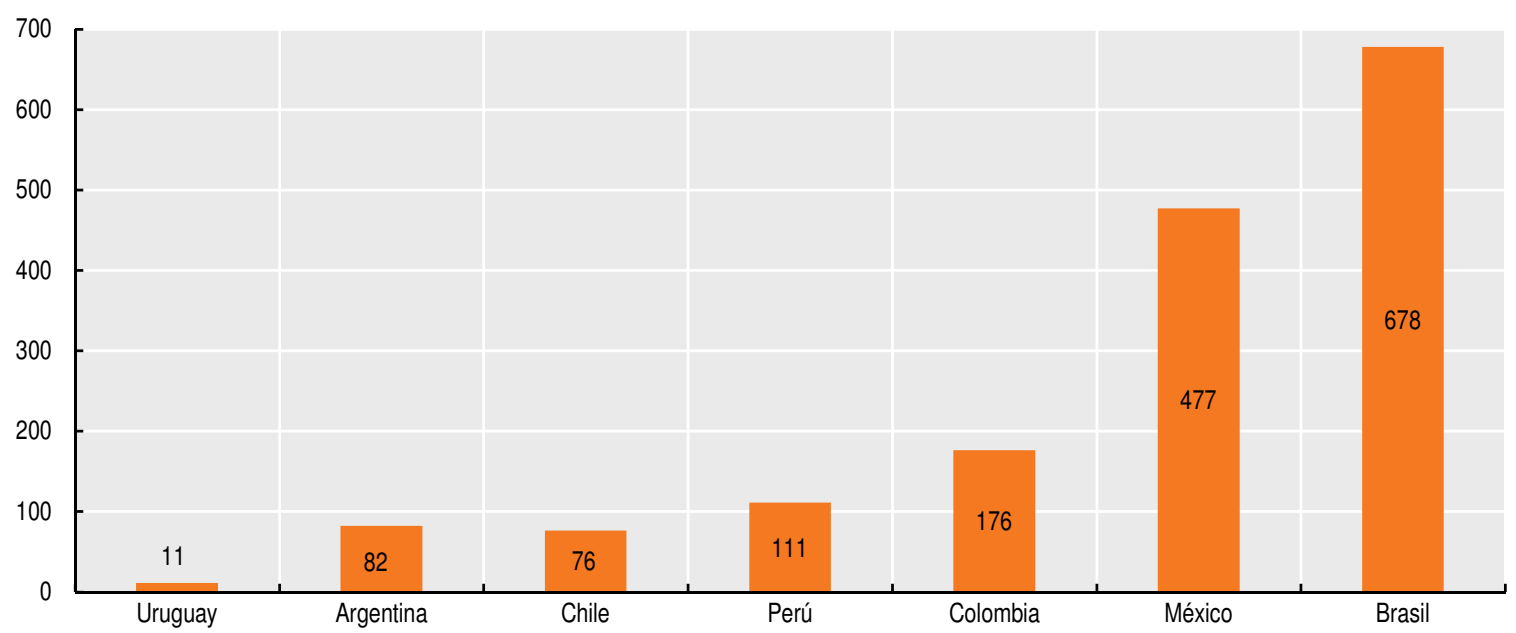

Fuente: CEPAL (2018b), Datos, algoritmos y políticas: La redefinición del mundo digital, https://repositorio.cepal.org/bitstream/ handle/11362/43515/7/S1800052 en.pdf.

StatLink तinlst https://doi.org/10.1787/888934201971 
La oferta de cursos de corta duración es aún más sólida: más de 7938 en los siete países. La mayoría incluyen cursos relacionados con robótica y control, inteligencia artificial y aprendizaje automático, y macrodatos (Big Data) y analítica (Tabla 2.10).

Tabla 2.10. Número de cursos de capacitación en tecnologías digitales avanzadas de corta duración por ámbito temático en países seleccionados de América Latina, 2016

\begin{tabular}{lcccc}
\hline & Robótica y control & IA/aprendizaje automático & Macrodatos/análisis & Total \\
\hline Argentina & 196 & 216 & 201 & 613 \\
Brasil & 1032 & 1218 & 891 & 3141 \\
Chile & 194 & 89 & 84 & 367 \\
Colombia & 441 & 208 & 178 & 827 \\
México & 907 & 944 & 644 & 2495 \\
Perú & 183 & 111 & 100 & 394 \\
Uruguay & 36 & 29 & 36 & 101 \\
Total & 2989 & 2815 & 2134 & 7938 \\
\hline
\end{tabular}

Nota: IA = inteligencia artificial.

Fuente: CEPAL (2018b), Datos, algoritmos y políticas: La redefinición del mundo digital, https://repositorio.cepal.org/ bitstream/handle/11362/43515/7/S1800052 en.pdf.

La oferta de posgrado, especialmente los doctorados, es limitada. Existen 294 programas de doctorado en tecnologías digitales en los siete países, y solo 130 programas de doctorado ofrecidos por las 20 universidades de mejores resultados (Tabla 2.11). Esta relativa escasez dificulta el desarrollo de competencias digitales específicas y la investigación básica y aplicada de alto nivel, lo que plantea un importante desafío para los países que están en transición hacia economías basadas en el conocimiento que requieren que los ciudadanos innoven, se adapten y aprovechen las competencias avanzadas del capital humano.

Tabla 2.11. Programas de posgrado en tecnologías digitales en países seleccionados de América Latina, 2016

\begin{tabular}{lccc}
\hline & Maestría & Doctorado & Total \\
\hline Argentina & 37 & 35 & 72 \\
Brasil & 72 & 152 & 224 \\
Chile & 36 & 10 & 46 \\
Colombia & 68 & 13 & 81 \\
México & 187 & 67 & 254 \\
Perú & 49 & 14 & 63 \\
Uruguay & 11 & 3 & 14 \\
Total & 460 & 294 & 753 \\
\hline
\end{tabular}

Fuente: CEPAL (2018b), Datos, algoritmos y políticas: La redefinición del mundo digital, https://repositorio.cepal.org/ bitstream/handle/11362/43515/7/S1800052 en.pdf.

\section{Políticas para promover la transformación digital y aumentar la productividad en América Latina y el Caribe}

Las políticas adoptadas en América Latina y el Caribe para promover la transformación digital del sector industrial y estimular la productividad muestran resultados desiguales. La falta de visión estratégica y de coordinación de los distintos grupos de interés suele generar iniciativas escasamente coherentes entre sí. Sin embargo, no se debe subestimar el potencial de la revolución digital, sobre todo en el caso de las mipymes, dado su importante papel en la economía formal de América Latina y el Caribe. Las mipymes representan el $99.5 \%$ de las empresas y el $61.2 \%$ del empleo, pero solo aportan el $24.6 \%$ 
de la producción de la región (Correa, Leiva y Stumpo, 2018). Si se adoptaran las políticas adecuadas, las tecnologías digitales podrían ayudar a cerrar la brecha de productividad existente con respecto a las empresas más grandes. A pesar de los avances logrados en los últimos años, la escasa adopción incluso de tecnologías básicas, especialmente entre las pequeñas empresas, demuestra que aún hay margen para una mayor intervención en el ámbito de las políticas. Por ejemplo, en algunos países de la región la brecha entre las pequeñas y grandes empresas que poseen su propio sitio web es superior a 30 puntos porcentuales (Gráfico 2.16).

América Latina y el Caribe todavía tienen que alinear los esfuerzos adoptados desde la esfera pública y privada para desarrollar los sectores digitales. Las principales razones de ello son el escaso entendimiento existente sobre la importancia del sector privado; la falta de coordinación dentro de las administraciones públicas; la escasa transparencia y confianza en las relaciones público-privadas; y la falta de coordinación entre los distintos grupos de interés y en la canalización de los esfuerzos del sector privado (ver el Capítulo 4 sobre el papel de los planes nacionales de desarrollo y las agendas digitales en la transformación digital) (Katz, 2015).

Algunos países han empezado recientemente a incorporar estas políticas en sus agendas digitales para impulsar la adopción y el desarrollo de tecnologías emergentes, como la robótica avanzada, los sensores, la IA, el blockchain y el Internet de las Cosas, con el fin de mejorar la industria (ver el Capítulo 4). La agenda digital de Uruguay creó el Laboratorio de Fabricación Digital, un organismo de fabricación digital centrado en sectores industriales prioritarios. Del mismo modo, el laboratorio del Parque Tecnológico Industrial de Cerro facilita la capacitación, invención y producción de prototipos a pequeña escala y da acceso a herramientas para la fabricación digital de última generación. Los objetivos de la estrategia E-Digital de Brasil incluyen la aplicación del plan nacional relativo al Internet de las Cosas y las plataformas de pruebas de este ámbito en las cadenas de valor de cuatro sectores clave: salud, agricultura, industria y ciudades inteligentes. El plan de TIC de Colombia promueve proyectos orientados al uso del Internet de las Cosas, la IA y la tecnología blockchain en los procesos de transformación de las empresas digitales. El Centro para la Cuarta Revolución Industrial de Colombia, dirigido por la entidad Ruta N en Medellín, se creó para lograr este objetivo.

En la última década, la región ha avanzado en las políticas de productividad para mipymes. Muchos países han adoptado marcos jurídicos para apoyar a estas empresas; sin embargo, más allá de las instituciones históricas de Chile (SERCOTEC, INDAP, CORFO) y Brasil (SEBRAE), las instituciones de fomento y asistencia a las mipymes con autonomía operativa y financiera siguen siendo la excepción. INNPULSA en Colombia y el CONAMYPE en El Salvador han cobrado relevancia en los últimos años; el papel desempeñado por INADEM en México todavía puede mejorar. La falta de una estrategia común entre las instituciones, la fragmentación de las intervenciones y el limitado alcance y presupuesto siguen siendo las principales limitaciones de las políticas de productividad de las mipymes en América Latina y el Caribe. La falta de un seguimiento y una evaluación sistemáticos de las iniciativas impide aprender de las experiencias anteriores (Correa, Leiva y Stumpo, 2018). 


\section{Gráfico 2.16. Uso de tecnologías digitales básicas por tamaño de empresa en países seleccionados de América Latina y el Caribe, 2010 y 2017}

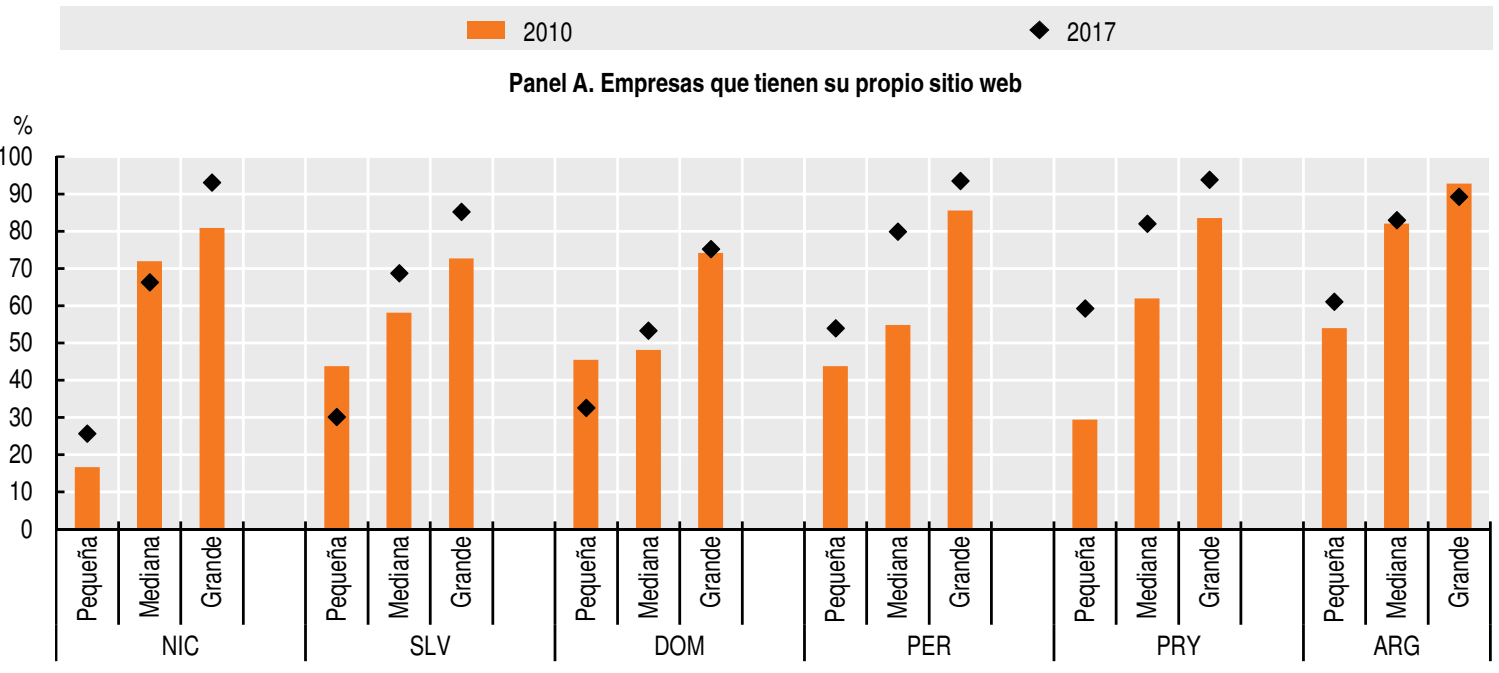

Panel B. Empresas que utilizan el correo electrónico para interactuar con clientes / proveedores

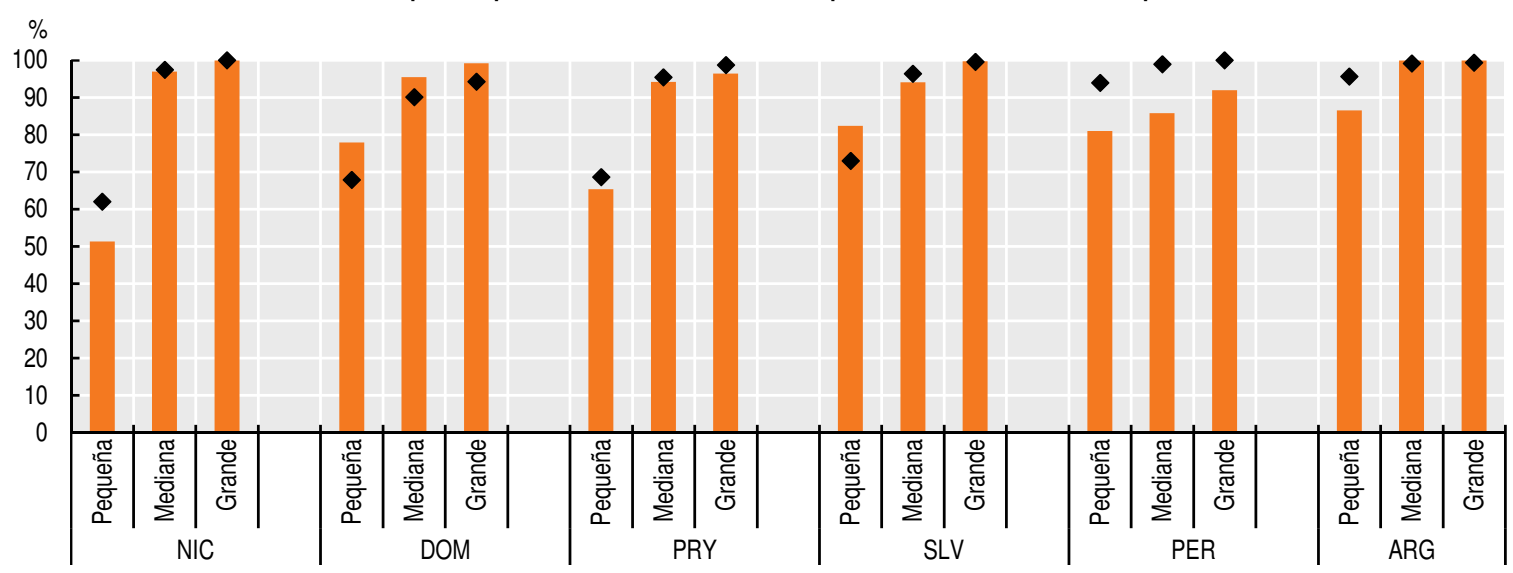

Fuentes: Elaboración propia a partir de Banco Mundial (2020b), Enterprise Surveys (base de datos), www.enterprisesurveys. org/; Correa, Leiva and Stumpo (2018), "Avances y desafíos de las políticas de fomento a las mipymes", Mipymes en América Latina: Un frágil desempeño y nuevos desafíos para las políticas de fomento, https://repositorio.cepal.org/bitstream/ handle/11362/44148/1/S1800707 es.pdf.

StatLink न्ताISt https://doi.org/10.1787/888934201990

Muchos países de América Latina y el Caribe han fomentado la adopción de tecnologías digitales por parte de las mipymes en la última década, sobre todo para estimular la iniciativa empresarial. Sin embargo, no siempre ha habido una conexión clara con las estrategias nacionales en el ámbito de la transformación productiva. El análisis de 11 categorías de iniciativas, en una escala de complejidad creciente - que va desde la creación de un ecosistema propicio para la adopción de las tecnologías digitales hasta la transformación de las capacidades tecnológicas y estratégicas de las empresas - muestra que la mayoría de las iniciativas aún no se han implantado o están en fase de implantación (Gráfico 2.17). Una lectura vertical muestra la variación en la distribución de estos programas, que se centran en mayor medida en los elementos facilitadores y en las políticas de desarrollo de capacidades (parte superior del mapa) y en menor medida en herramientas más complejas para cambiar la estructura productiva (parte inferior). 
Varios países han creado plataformas y portales por Internet específicos para mipymes. Entre ellos figuran Escritorio Empresa en Chile, Ventana Única Pyme en Costa Rica, Portal Mi Empresa en El Salvador y Red de Apoyo al Emprendedor en México, que también cuentan con oficinas físicas. Asimismo, son habituales las iniciativas de concienciación y de alfabetización digital mediante campañas de sensibilización y la asistencia técnica ofrecida por organismos especializados: los Centros de Transformación Digital Empresarial en Colombia y la red de Infocentros Comunitarios en el Ecuador, por ejemplo, ofrecen capacitación gratuita en el ámbito de las competencias digitales. Muchos países cuentan con iniciativas dirigidas a facilitar el acceso a las tecnologías digitales y su adopción. Iniciativas como Transformación Digital PyMEs en Argentina, Espacio Pyme en Chile y Kit Digital en Perú ofrecen capacitación digital, asistencia técnica, programas informáticos y apps para gestionar los cambios relacionados con la transformación digital de las empresas. Asimismo, Costa Rica ofrece asistencia financiera para la adopción de tecnologías digitales a través del fondo de innovación PROPYME, mientras que el Fondo Nacional Emprendedor del INADEM presta un servicio similar en México. El SEBRAETEC de Brasil es un programa del SEBRAE que ofrece asistencia que va desde la capacitación digital hasta el asesoramiento a empresas (Heredia, 2020).

Sigue habiendo grandes oportunidades para promover la investigación y el desarrollo, los nuevos modelos de negocio y los ajustes en la cadena de producción (Gráfico 2.17). Los incentivos para el sector de las TIC son escasos, aunque el Fondo Fiduciario de Fomento de la Industria del Software en Argentina y el Programa para el Desarrollo de la Industria del Software en México apoyan a las pymes del sector de las TIC, entre otras actividades. Es necesario adoptar medidas adicionales para apoyar y promover la investigación y la innovación en la tecnología industrial. Entre los ejemplos existentes se encuentran el FONTAR en Argentina, un fondo para la innovación en tecnología, y la EMBRAPII de Brasil, una institución que promueve la investigación y el desarrollo para la industria con el objetivo de compartir el riesgo en la fase precompetitiva de la innovación (Heredia, 2020). El desafío para América Latina y el Caribe es ir más allá de las políticas que fomentan la adopción de las tecnologías digitales en el sector industrial y prestar una asistencia efectiva para la transformación completa de los procesos de producción y la creación de nuevos modelos de negocio apoyados en las nuevas tecnologías (Heredia, 2020).

Las políticas industriales para la era digital son esenciales para alentar a la economía a avanzar hacia actividades de mayor valor agregado. La transformación digital del sector industrial en América Latina y el Caribe está lejos de haberse completado. La política industrial para la economía digital debe fortalecer primero la industria local de la TI. Los nuevos sectores tecnológicos pueden contribuir al desarrollo tecnológico mediante la transferencia y difusión de tecnologías, la generación de recursos humanos cualificados y la exportación de servicios. Aunque algunos países, entre ellos Argentina, Brasil, Chile, Colombia, México y Uruguay, han promovido con éxito la industria de las TI, todavía hay deficiencias en la difusión del uso de los productos TI y su aplicación en actividades empresariales, en particular entre las pymes (CEPAL, 2018b).

Las políticas industriales deben adoptar una visión estratégica y formar parte tanto de planes de desarrollo más amplios como de planes sectoriales productivos y tecnológicos. La colaboración entre los sectores productivos y de investigación (centros públicos de investigación, universidades, institutos tecnológicos) es fundamental para conseguir una estructura institucional de investigación estrechamente vinculada a la innovación y el desarrollo empresarial (Casalet, 2018). La creación de un ecosistema digital virtuoso es esencial para que las empresas, los gobiernos y los ciudadanos se beneficien de la transformación digital. 
Gráfico 2.17. Categorías de promoción de tecnologías digitales en las mipymes de países seleccionados de América Latina, en torno a 2019

\begin{tabular}{|l|l|l|l|l|l|l|l|l|l|}
\hline \multicolumn{1}{|c|}{ Categoría } & ARG & BRA & CHI & COL & CRI & ECU & SLV & MEX & PER \\
\hline Simplificación de procedimientos (gobierno digital) & & & & & & & & & \\
\hline Concienciación y alfabetización digital & & & & & & & & & \\
\hline Acceso a tecnología digital & & & & & & & & & \\
\hline Capacitación & & & & & & & & & \\
\hline Asistencia técnica o financiera & & & & & & & & & \\
\hline Desarrollo de nuevas oportunidades de negocio & & & & & & & & & \\
\hline Incentivos para sectores de las TIC & & & & & & & & & \\
\hline Apoyo a la creación de empresas digitales & & & & & & & & & \\
\hline Investigación e innovación tecnológica & & & & & & & & & \\
\hline Integración digital de cadenas de producción o proveedores & & & & & & & & & \\
\hline Apoyo al desarrollo de nuevos modelos de negocio & & & & & & & & & \\
\hline
\end{tabular}

Notas: La intensidad del color indica el grado de aplicación de la política; el color blanco indica que la categoría no fue implementada. TIC = tecnología de la información y las comunicaciones.

Fuente: Heredia (2020), Políticas de fomento para la incorporación de las tecnologías digitales en las micro, pequeñas y medianas empresas de América Latina: Revisión de experiencias y oportunidades, https://repositorio.cepal.org/bitstream/handle/11362/45096/1/ S1900987 es.pdf.

La adopción de la tecnología digital se verá facilitada por una asignación eficiente de los recursos, ya que los incentivos de una empresa para experimentar con tecnologías digitales inciertas o arriesgadas vendrán determinados por su percepción de que podrá ampliar rápidamente sus operaciones en caso de éxito y reducir e incluso abandonar el mercado a bajo costo en caso de fracaso (Andrews y Criscuolo, 2013). Desde esta perspectiva, las políticas que fomenten el dinamismo empresarial y la reasignación eficiente de recursos cobran una importancia aún mayor a la hora de potenciar la transformación digital en las empresas. Se trata de un desafío importante en muchos países, en el contexto de la caída del dinamismo empresarial (Criscuolo, Menon y Gal, 2014) y del aumento de la asignación deficiente de recursos (Adalet McGowan, Andrews y Mil, 2017; Berlingieri, Blanchenay y Criscuolo, 2017) de la última década.

\section{La transformación digital poscoronavirus (Covid-19)}

Para la mayoría de las economías de América Latina y el Caribe la recuperación será más lenta y gradual de lo previsto. A pesar de los programas públicos, se prevé una importante pérdida de empresas y empleos. Cuanto mayor sea el número, mayor será la pérdida de capacidades acumuladas en las empresas, la dispersión de conocimientos y experiencias y la ruptura de las relaciones de confianza entre los agentes económicos. Se necesitarán incentivos adicionales a los existentes antes del coronavirus (Covid-19) para que las empresas privadas, y también el Estado, realicen las inversiones necesarias para diversificar la estructura económica, asegurar un crecimiento continuo y estable y evitar retrocesos. La transformación digital será fundamental para que las empresas avancen hacia una mayor eficiencia y productividad. Las tecnologías digitales serán clave para los nuevos modelos de explotación: las empresas tendrán que adoptar tecnologías para procesar grandes cantidades de información con el fin de mejorar los procesos de decisión, lo cual podría redefinir los modelos de negocio. La industria deberá incorporar un mayor uso de la robótica para aumentar la eficiencia. La transformación digital 
también puede afectar las operaciones de los modelos de negocio mediante cambios en la venta y la entrega de bienes y servicios o interacciones con proveedores (CEPAL, 2020b).

Gráfico 2.18. América Latina: Digitalización de las cadenas de valor, 2018

$$
\text { Conectadas a internet Utilizan banca electrónica Utilizan internet para adquirir insumos }
$$

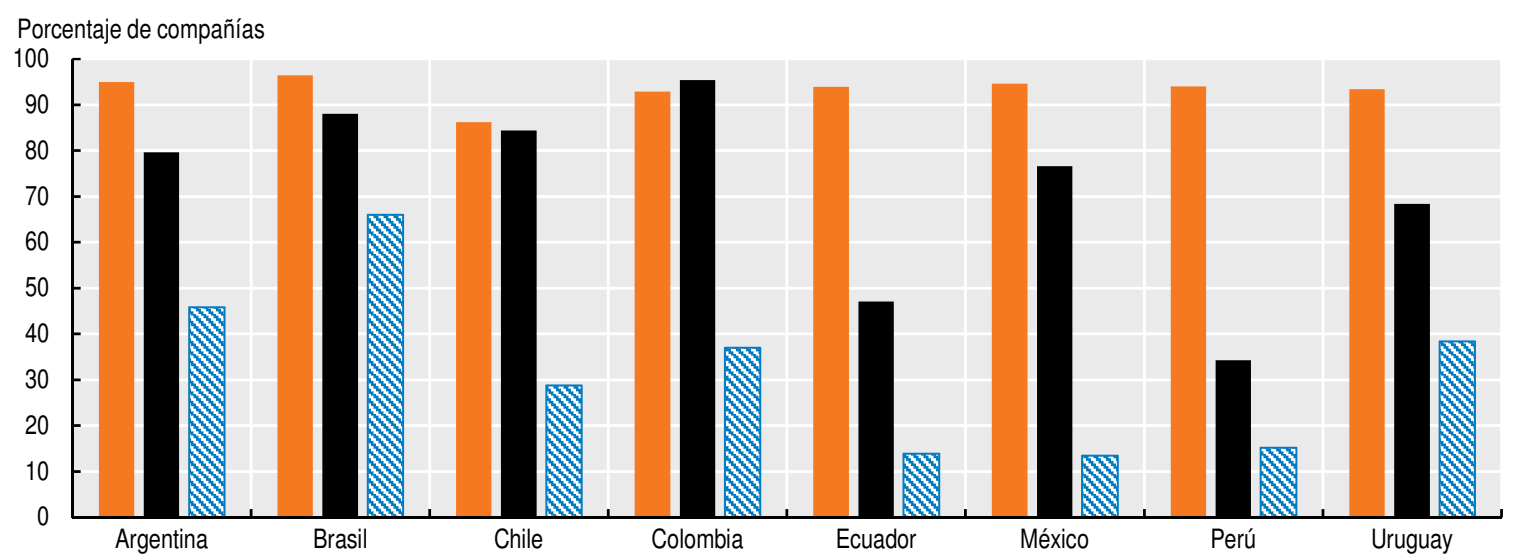

Fuente: CAF (2020), El estado de la digitalización de América Latina frente a la pandemia del Covid-19, https://scioteca.caf.com/ bitstream/handle/123456789/1540/El estado de la digitalizacion de America Latina frente a la pandemia del COVID-19.pdf?sequence=1.

StatLink त्ताड़ https://doi.org/10.1787/888934202009

Es de esperar que el mundo no vuelva al mismo contexto que existía antes de la pandemia. Aunque la crisis parece poner de manifiesto la fragilidad del multilateralismo, la globalización no dará marcha atrás: habrá una demanda por mayor integración regional. La economía mundial podría regionalizarse en torno a tres polos: Europa, América del Norte y Asia Oriental. Dados los desafíos estructurales existentes en América Latina y el Caribe, este escenario requeriría avanzar hacia una mayor integración productiva, comercial y tecnológica. El futuro de la región en la nueva geografía económica implica cadenas de valor regionales que la hagan menos dependiente de las manufacturas importadas y mejoren la estructura productiva hacia bienes más sofisticados. Las políticas industriales y tecnológicas deben fortalecer las capacidades productivas y la generación de nuevos sectores estratégicos. Esto aportaría una mayor resiliencia a las redes regionales de producción que se enfrentan al desafío de la diversificación de proveedores (tanto en términos de países como de empresas) que favorece las ubicaciones más cercanas a los mercados de consumo final (nearshoring) o la reubicación de procesos tecnológicos y productivos estratégicos (reshoring).

La emergencia sanitaria ha hecho que resulte esencial y más importante que nunca reflexionar sobre la estructura productiva y los mecanismos de integración regional. Ambos deben formar parte de la misma estrategia. Existe la oportunidad de recordar los beneficios de la integración regional y retomar las acciones en pos de una gobernanza internacional inclusiva y sostenible basada en la Agenda de Desarrollo Sostenible de las Naciones Unidas para 2030.

\section{Conclusión}

En este capítulo se han analizado las causas subyacentes de la baja productividad de América Latina y el Caribe, y se ha evaluado el potencial de las tecnologías digitales para aumentar la productividad y facilitar el avance de la región hacia una estructura productiva de mayor valor agregado, con una menor heterogeneidad estructural. 
Las tecnologías digitales no son independientes del sector, la estructura organizacional ni de otros aspectos específicos del contexto en el que operan. El impacto de las tecnologías digitales no es determinista y depende de múltiples factores. Las políticas y soluciones tecnológicas deben adaptarse a los distintos sectores y tipos de unidades de producción, incluyendo a las pymes, para abordar las características específicas que influyen en su funcionalidad. A pesar de la necesidad de adoptar intervenciones específicas para cada contexto, es esencial realizar inversiones complementarias comunes para aprovechar los beneficios de la integración de las tecnologías digitales en los procesos productivos.

El éxito de las estrategias de transformación digital en el ámbito de la productividad industrial depende de una gama amplia de intervenciones y sectores, más allá de las propias TIC. Las infraestructuras de la comunicación, la conectividad del transporte y las competencias son elementos facilitadores clave en la era digital en las que ALC se encuentra a la zaga de la OCDE. Los responsables de las políticas disponen de numerosos modelos de financiamiento y de negocio para acometer inversiones en infraestructuras. La adopción de mecanismos adecuados dependerá del país y del contexto tecnológico. Los responsables de las políticas deben evitar el riesgo de que la adopción de las tecnologías digitales agrave las desigualdades. Es necesario ampliar el acceso a las infraestructuras y a las competencias a través de políticas específicas y adaptadas al contexto para asegurar que todas las personas y empresas se beneficien de las nuevas tecnologías y evitar que se amplíe, con sus impactos distributivos, la heterogeneidad estructural de los sectores y las empresas.

\section{Notas}

1. Las tecnologías digitales incluyen teléfonos inteligentes, potencia de cálculo, Internet de las Cosas, redes 5G, computación en nube, inteligencia artificial y blockchain.

2. En el debate económico iniciado con Solow, los aumentos de productividad se consideran medidas de cambio tecnológico, y son parte del producto que no se explica a través de la adopción de insumos y por tanto se relaciona con el progreso tecnológico (Solow, 1957).

3. Las investigaciones de la OCDE muestran que hay posibilidades de aumentar la productividad en la era digital gracias a la adopción de políticas favorables para las empresas (OCDE, 2019g).

4. Un índice compuesto ofrece una útil visión general de los resultados obtenidos por los distintos países. No obstante, la utilización de la agregación de múltiples indicadores en un índice compuesto no está exenta de problemas, ya que un buen desempeño en un indicador puede ocultar un mal desempeño en otro indicador (OCDE et al., 2019).

5. Las proporciones de usuarios de Internet se basan en los resultados de las encuestas nacionales de hogares para la población total de personas de 5 años o más. Las suscripciones activas a la banda ancha móvil se refieren a la suma de las suscripciones estándar a la banda ancha móvil y los abonos a la banda ancha móvil dedicada a la Internet pública.

6. Las redes de distribución de contenido sirven como agregadores de contenido, sistemas para la distribución del tráfico directamente a la red de terminación, y los proveedores de insumos para mejorar la calidad, como el almacenamiento de datos cerca del usuario final. Estas redes son útiles para los proveedores de servicios en línea, como la BBC, Google, Netflix y Hulu, que buscan mejorar la experiencia de sus clientes. Una entrega más directa, menos bucles intermedios y el almacenamiento local reducen la latencia y mejoran la calidad del servicio (OCDE, 2013).

7. No incluye conexiones de Internet de las Cosas. 


\section{Referencias}

Adalet McGowan, M., D. Andrews y V. Mil (2017), Insolvency Regimes, Zombie Firms and Capital Reallocation, Publicaciones de la OCDE, París, http://www.OCDE.org/officialdocuments/public displaydocumentpdf/?cote=ECO/WKP(2017)31\&docLanguage=En .

ADB (2017), ADB Annual Report 2017, Asian Development Bank, Manila, http://dx.doi.org/10.22617/ FLS189307.

Andrews, D. y C. Criscuolo (2013), "Knowledge-based capital, innovation and resource allocation", OECD Economics Department Working Papers, N..$^{\circ}$ 1046, Publicaciones de la OCDE, París, http://www.OCDE.org/officialdocuments/publicdisplaydocumentpdf/?cote=ECO/ WKP(2013)38\&docLanguage $=$ En.

Andrews, D., G. Nicoletti y C. Timiliotis (2018), "Digital technology diffusion: A matter of capabilities, incentives or both?", OECD Economics Department Working Papers, N. ${ }^{\circ}$ 1476, Publicaciones de la OCDE, París, https://doi.org/10.1787/7c542c16-en.

Aral, S., E. Brynjolfsson y L. Wu (2012), "Three-way complementarities: Performance pay, human resource analytics, and information technology", Management Science, Institute for Operations Research and the Management Sciences, Catonsville, MD, pp. 913-931, http://hdl.handle. net/1721.1/74643.

Banco Internacional de Reconstrucción y Fomento /Banco Mundial (2017), Rethinking Infrastructure in Latin America and the Caribbean: Spending Better to Achieve More, Banco Internacional de Reconstrucción y Fomento/Grupo Banco Mundial, Washington, DC, http://documents.worldbank. org/curated/en/676711491563967405/pdf/114110-REVISED-RethinkingInfrastructure-Low-Res.pdf.

Banco Mundial (2020a), World Bank World Development Indicators (base de datos), World Bank Group, Washington, DC, https://databank.worldbank.org/source/world-development-indicators (consultada el 12 de mayo de 2020).

Banco Mundial (2020b), Enterprise Surveys (base de datos), World Bank Group, Washington, DC, http://www.enterprisesurveys.org/ (consultada el 4 de marzo de 2020).

Banco Mundial (2018), World Bank Global Logistic Performance Index 2018 (base de datos), World Bank Group, Washington, DC, https://lpi.worldbank.org/international/scorecard/radar/254/C/ DEU/2018/R/EAP/2018/R/ECA/2018/R/LAC/2018/R/MNA/2018/R/SAS/2018/R/SSA/2018? featured=17 (consultada el 18 de febrero de 2020).

Banco Mundial/UNESCO (2020), Education Indicators (base de datos), World Bank Group, Washington, DC, https://data.worldbank.org/topic/education.

Bartelsman, E., G. Leeuwen y M. Polder (2016), "CDM using a cross-country micro moments database", Economics of Innovation and New Technology, Vol. 26, N. ${ }^{\circ} 1-2$, pp. 168-182, Taylor \& Francis Online, https://doi.org/10.1080/10438599.2016.1202517.

Bauer, F., A. Dichter y M. Rothko (2018), "Travel and logistics: Data drives the race for customers", Travel, Transport and Logistics, McKinsey \& Company, http://www.mckinsey.com/industries/ travel-transport-and-logistics/our-insights/travel-and-logistics-data-drives-the-race-forcustomers (consultada el 21 de abril de 2020).

Berlingieri, G., P. Blanchenay y C. Criscuolo (2017), "The great divergence(s)", OECD Science, Technology and Industry Policy Papers, N. ${ }^{\circ}$ 39, Publicaciones de la OCDE, París, https://doi. org/10.1787/953f3853-en.

Bloom, N., R. Sadun y J. Van Reenen (2017), “Management as a technology?”, Working Paper 16-133, Harvard Business School, http://www.hbs.edu/faculty/Publication\%20Files/16-133_64fd57c15f76-415a-9567-f1c0d310aff3.pdf.

Brynjolfsson, E., A. McAfee y M. Spence (2014), "New world order: Labor, capital, and ideas in the power law economy", Foreign Affairs, Vol. 93, n. ${ }^{\circ} 4$, pp. 44-53, http://www.jstor.org/ stable/24483556? seg=1.

Bukht, R. y R. Heeks (2017), "Defining, conceptualising and measuring the digital economy", Working Paper Series, n. ${ }^{\circ}$ 68, Centre for Development Informatics Global Development Institute, Manchester, http://hummedia.manchester.ac.uk/institutes/gdi/publications/workingpapers/ di/di wp68.pdf.

CAF (2020), El estado de la digitalización de América Latina frente a la pandemia del COVID-19, Development Bank of Latin America, Caracas, http://scioteca.caf.com/handle/123456789/1540.

CAF (2017), Towards the digital transformation of Latin America and the Caribbean: The CAF Observatory of the Digital Ecosystem, Development Bank of Latin America, Caracas, https://www.caf.com/ app_tic/\#es/home. 
CAF et al. (2020), Las oportunidades de la digitalización en América Latina frente al COVID-19, CAF 2020, UN CEPAL 2020, https://repositorio.cepal.org/bitstream/handle/11362/45360/4/ OportDigitalizaCovid-19_es.pdf.

Casalet, M. (2018), "La digitalización industrial: Un camino hacia la gobernanza colaborativa", Estudios de Casos, Economic Commission for Latin America and the Caribbean, Santiago, https://repositorio.cepal.org/bitstream/handle/11362/44266/1/S1800941 es.pdf.

CEPAL (2020a), "América Latina y el Caribe ante la pandemia del COVID-19: Efectos económicos y sociales", Informe Especial COVID-19, N. ${ }^{\circ} 1$, Economic Commission for Latin America and the Caribbean, Santiago, https://repositorio.cepal.org/bitstream/handle/11362/45337/4/S20000264 es.pdf.

CEPAL (2020b), "Sectores y empresas frente al COVID-19: emergencia y reactivación", Special Report: COVID-19, Comisión Económica para América Latina y el Caribe, Santiago, https://repositorio.cepal.org/bitstream/handle/11362/45736/5/S2000437 en.pdf.

CEPAL (2020c), Databases and Statistical Publications (base de datos), Comisión Económica para América Latina y el Caribe, Santiago, https://estadisticas.cepal.org/cepalstat/WEB_CEPALSTAT/ buscador.asp?idioma=i\&string busqueda= (consultada el 2 de junio de 2020).

CEPAL (2020d), Análisis de la huella digital en América Latina y el Caribe, Comisión Económica para América Latina y el Caribe, Santiago, https://repositorio.cepal.org/bitstream/handle/11362/ 45484/1/S1901128_en.pdf.

CEPAL (2019a), Regional Observatory on Planning for Development in Latin America and the Caribbean (base de datos), https://observatorioplanificacion.cepal.org/en/opengov.

CEPAL (2019b), "Observatorio Regional de Banda Ancha” (página web), Comisión Económica para América Latina y el Caribe, Santiago, http://www.cepal.org/es/observatorio-regional-de-bandaancha.

CEPAL (2018a), La Ineficiencia de la Desigualdad 2018: Trigésimo Séptimo Periodo de Sesiones de la Cepal, Comisión Económica para América Latina y el Caribe, Santiago, https://repositorio.cepal.org/ bitstream/handle/11362/43566/4/S1800302 es.pdf.

CEPAL (2018b), Datos, algoritmos y políticas: la redefinición del mundo digital, Comisión Económica para América Latina y el Caribe, Santiago, https://repositorio.cepal.org/bitstream/handle/11362/ 43515/7/S1800052_en.pdf.

CEPAL (2016), "Ciencia, tecnología e innovación en la economía digital: la situación de América Latina y el Caribe", Second Conference on Science, Innovation and Information Technology, Comisión Económica para América Latina y el Caribe, Santiago, https://repositorio.cepal.org/ bitstream/handle/11362/40840/1/S1600832.

CEPAL (2014), Cambio Estructural para la Igualdad: Una Visión Integrada del Desarrollo, Comisión Económica para América Latina y el Caribe, Santiago, http://dx.doi.org/LC/G.2604.

CEPAL (2013), The Digital Economy for Structural Change and Equality, Comisión Económica para América Latina y el Caribe, Santiago, https://repositorio.cepal.org/bitstream/handle/ 11362/35954/S2013350_en.pdf.

CEPAL (2010), La Hora de la Igualdad: Brechas por Cerrar, Caminos por Abrir, Comisión Económica para América Latina y el Caribe, Santiago, https://repositorio.cepal.org/bitstream/handle/11362/ 13309/S2010986 es.pdf.

Cette, G., J. Lopez y J. Mairesse (2017), “Upstream product market regulations, ICT, R\&D and productivity", The Review of Income and Wealth, International Association for Research in Income and Wealth, pp. 68-69, http://dx.doi.org/10.1111/roiw.12252.

Chevalier, C. y A. Luciani (2018), "Computerization, labor productivity and employment: Impacts across industries vary with technological level”, Série des documents de travail, Institut National de la Statistique et des Études Économiques, París, http://www.insee.fr/en/statistiques/3557555.

Cimoli, M. y G. Porcile (2013), "Tecnología, heterogeneidad y crecimiento: Una caja de herramientas estructuralistas", Serie Desarrollo Productivo, n. 194 , Comisión Económica para América Latina y el Caribe, Santiago, https://repositorio.cepal.org/bitstram/handle/11362/4592/1/S2013731 es.pdf.

Comisión Federal de Comunicaciones (2020), Data - Reports and Research (base de datos), Federal Communications Commission, Washington, DC, http://www.fcc.gov/reports-research/data (consultada el 23 de junio de 2020).

Conference Board (2020), "Total Economy Database (base de datos)", The Conference Board, http://www.conference-board.org/data/economydatabase (consultada el 4 de abril de 2020).

Corrado, C., J. Haskel y C. Jona-Lasinio (2017), "Knowledge spillovers, ICT and productivity growth", Oxford Bulletin of Economics and Statistics, The Department of Economics, University of Oxford and John Wiley \& Sons Ltd., Oxford, pp. 592-618, https://doi.org/10.1111/obes.12171. 
Correa, F., V. Leiva y G. Stumpo (2018), "Mipymes y heterogeneidad estructural en América Latina”, Mipymes en América Latina: Un frágil desempeño y nuevos desafíos para las políticas de fomento, Comisión Económica para América Latina y el Caribe, Santiago, https://repositorio.cepal.org/ bitstream/handle/11362/44148/1/S1800707 es.pdf.

Criscuolo, C., C. Menon y P. Gal (2014), "The dynamics of employment growth: New evidence from 18 countries", OECD Science, Technology and Industry Policy Papers, n. ${ }^{14}$, Publicaciones de la OCDE, París, https://doi.org/10.1787/5jz417hj6hg6-en.

Cullen International (2019), "Cullen International” (página web), https://www.cullen-international. com/.

De Stefano, V. (2018), "Negotiating the algorithm: Automation, artificial intelligence and labour protection", Employment Working Paper, n. ${ }^{\circ}$ 246, International Labour Office, Ginebra, https://www.ilo.org/wcmsp5/groups/public/---ed_emp/---emp_policy/documents/publication/ wcms 634157.pdf.

Dhyne, E. et al. (2018), "IT and productivity: A firm level analysis", NBB Working Paper, National Bank of Belgium, Bruselas, http://hdl.handle.net/10419/207726.

Dosi, G. (1984), Technical change and industrial transformation: The theory and an application to the semiconductor industry, Palgrave Macmillan UK, Londres, http://www.palgrave.com/gp/ book/9780333363430.

EUROMONITOR (2020), Euromonitor International, https://www.euromonitor.com/.

G20 (2019), "G20 Finance Ministers welcome the Quality Infrastructure Investment Database” (página web), Global Infrastructure Hub, Sydney, https://www.gihub.org/news/g20-welcomequality-infrastructure-investment-database/ (consultada el 14 de abril de 2020).

Gal, P. et al. (2019), "Digitalisation and productivity: In search of the holy grail - Firm-level empirical evidence from EU countries", OECD Economics Department Working Papers, n. ${ }^{\circ} 1533$, Publicaciones de la OCDE, París, https://doi.org/10.1787/5080f4b6-en.

Gordon, R. (2012), "Is U.S. economic growth over? Faltering innovation confronts the six headwinds", NBER Working Paper, n. ${ }^{\circ}$ 18315, National Bureau of Economic Research, Cambridge, MA, http://www.nber.org/papers/w18315.

GSMA (2019), The Mobile Economy 2019, GSM Association, London, http://www.gsma.com/r/ mobileeconomy/3/.

GSMA Intelligence (2020), "Definitive data and analysis for the mobile industry" (página web), https://www.gsmaintelligence.com/ (consultada el 5 de mayo de 2020).

Hagsten, E. et al. (2012), "Final report of the ESSnet on linking of microdata to analyse ICT impact", Eurostat Grant Agreement 50701.2010.001-2010.578, Eurostat, Bruselas, https://ec.europa.eu/ eurostat/documents/341889/725524/2010-2012-ICT-IMPACT-2012-Final-report.pdf/90cf5094334a4ff1-8f60-047c2d650c60.

Haskel, J. y S. Westlake (2017), "Capitalism without capital: The rise of the intangible economy", Princeton University Press, Princeton, NJ, https://press.princeton.edu/books/ hardcover/9780691175034/capitalism-without-capital.

Heredia, A. (2020), "Políticas de fomento para la incorporación de las tecnologías digitales en las micro, pequeñas y medianas empresas de América Latina: Revisión de experiencias y oportunidades", Comisión Económica para América Latina y el Caribe, https://repositorio.cepal.org/ bitstream/handle/11362/45096/1/S1900987_es.pdf.

Infralatam (2020), Datos de Inversión en Infraestructura Económica (base de datos), Infralatam, Santiago, http://infralatam.info/.

ITF (2019), ITF Transport Outlook 2019, Publicaciones de la OCDE, París, https://doi.org/10.1787/ transp outlook-en-2019-en.

Katz, R. (2015), The role of National Development Plans and Digital Agendas in the Digital Transformation, Fundación Telefónica, http://scioteca.caf.com/handle/123456789/768.

Katz, R. y F. Callorda (2018), "Accelerating the development of Latin American digital ecosystem and implications for broadband", Telecommunications Policy, Elsevier Ltd., Amsterdam, pp. 661-681, http://dx.doi.org/10.1016/j.telpol.2017.11.002.

Martincus, C. (2016), Out of the Border Labyrinth; An assessment of trade facilitation initiatives in Latin America and the Caribbean, Inter-American Development Bank, https://publications.iadb.org/ publications/english/document/Out-of-the-Border-Labyrinth-An-Assessment-of-TradeFacilitation-Initiatives-in-Latin-America-and-the-Caribbean.pdf.

Mohnen, P., M. Polder y G. van Leeuwen (2018), “ICT, R\&D and organizational innovation: Exploring complementarities in investment and production", NBER Working Paper, n. ${ }^{\circ} 25044$, http://www. nber.org/papers/w25044. 
Naciones Unidas (2019), UN E-Government Knowledgebase (UNeGouKB), Departamento de Asuntos Económicos y Sociales, Naciones Unidas, Nueva York, https://publicadministration.un.org/ egovkb.

O’Halloran, D. (2019), “What you need to know about 5G” (página web), Foro Económico Mundial, Cologny, Suiza, http://www.weforum.org/agenda/2019/12/what-you-need-to-know-about-5g/ (consultada el 21 de abril de 2020).

OCDE (2020a), "Keeping the Internet up and running in times of crisis", OECD Policy Responses to Coronavirus (COVID-19), http://www.OECD.org/coronavirus/policy-responses/keeping-the internet-up-and-running-in-times-of-crisis-4017c4c9/.

OCDE (2020b), COVID-19 in Latin America and the Caribbean: Regional socio-economic implications and policy priorities, http://www.OECD.org/coronavirus/policy-responses/covid-19-in-latin-americaand-the-caribbean-regional-socio-economic-implications-and-policy-priorities-93a64fde/.

OCDE (2019a), Shaping the Digital Transformation in Latin America: Strengthening productivity, improving lives, Publicaciones de la OCDE, París, https://doi.org/10.1787/8bb3c9f1-en, presented at the Third LAC Regional Programme Ministerial Meeting on Productivity, Bogotá-Colombia, 25 de octubre de 2019.

OCDE (2019b), Going Digital: Shaping Policies, Improving Lives, OECD Publishing, https://doi. org/10.1787/9789264312012-en.

OCDE (2019c), An Introduction to Online Platforms and Their Role in the Digital Transformation, Publicaciones de la OCDE, París, https://doi.org/10.1787/53e5f593-en.

OCDE (2019d), "Productivity growth in the Digital Age", OECD Going Digital Policy Note, Publicaciones de la OCDE, París, http://www.OCDE.org/going-digital/productivity-growth-inthe-digital-age.pdf.

OCDE (2019e), "Speed", in Measuring the Digital Transformation: A roadmap for the future, Publicaciones de la OCDE, París, https://doi.org/10.1787/094fe0ca-en.

OCDE (2019f), “The road to 5G networks: Experience to date and future developments”, OECD Digital Economy Papers, n. ${ }^{\circ}$ 284, Publicaciones de la OCDE, París, https://doi.org/10.1787/2f880843-en.

OCDE (2019g), "Productivity Growth in the Digital Age”, OECD Going Digital Policy Note, Publicaciones de la OCDE, París, http://www.OCDE.org/going-digital/productivity-growth-in-the-digital-age. pdf.

OCDE (2017), Algorithms and Collusion: Competition Policy in the Digital Age, www.OECD.org/competition/ algorithms-collusion-competition-policy-in-the-digital-age.htm.

OCDE (2016), Multi-dimensional Review of Peru: Volume 2. In-depth Analysis and Recommendations, OECD Development Pathways, Publicaciones de la OCDE, París, http://dx.doi.org/10.1787/ 9789264264670-en.

OCDE (2013), "Internet traffic exchange: Market developments and policy challenges", http://dx.doi.org/10.1787/5k918gpt130q-en.

OCDE et al. (2019), Perspectivas económicas de América Latina 2019: Desarrollo en transición, Publicaciones de la OCDE, París, https://doi.org/10.1787/g2g9ff18-en.

OCDE/CAF/UN CEPAL (2018), Perspectivas económicas de América Latina 2018: Repensando las instituciones para el desarrollo, Publicaciones de la OCDE, París, https://dx.doi.org/10.1787/leo-2018-en.

OIT (2020), Statistics and Databases (base de datos), Organización Internacional del Trabajo, Ginebra, http://www.ilo.org/global/statistics-and-databases/lang--en/index.htm (consultada el 10 de marzo de 2020).

Opertti, F. (2019), "Latin America struggles with trade logistics. Here's what we can do.", IDB Blog on Integration and Trade Sector, Inter-American Development Bank, Washington, DC, https://blogs.iadb.org/integration-trade/en/latin-america-trade-logistics/ (consultada el 21 de abril de 2020).

Packet Clearing House (2020), Packet Clearing House (base de datos), Packet Clearing House, San Francisco, https://web.archive.org/web/20060413225415/www.pch.net/resources/data/.

PNUD (2019), Human Development Data (1990-2018) (base de datos), Programa de las Naciones Unidas para el Desarrollo, Nueva York, http://hdr.undp.org/en/data.

Rodríguez, L (2018), "The role of transport and logistics in promoting e-commerce in developing countries", UNCTAD Transport and Trade Facilitation Newsletter, n. ${ }^{\circ} 77$, https://unctad.org/en/pages/ newsdetails.aspx? OriginalVersionID=1705.

Solow, R. (1988), "Growth theory and after", American Economic Review, Vol. 78, n. ${ }^{\circ}$ 3, pp. 307-17, https://EconPapers.repec.org/RePEc:aea:aecrev:v:78:y:1988:i:3:p:307-17. 
Solow, R. (1957), "Technical change and the aggregate production function", The Review of Economics and Statistics, Massachusetts Institute of Technology Press, Cambridge, MA, pp. 312-320, http://www.jstor.org/stable/1926047.

Sorbe, S. (2019), "Digital dividend: Policies to harness the productivity potential of digital technologies", OECD Economic Policy Papers, n. ${ }^{\circ}$ 26, Publicaciones de la OCDE, París, https://doi.org/ $10.1787 / 273176 \mathrm{bc}-\mathrm{en}$.

Stiglitz, J., A. Sen y J. Fitoussi (2009), Report by the Commission on the Measurement of Economic Performance and Social Progress, Commission on the Measurement of Economic Performance and Social Progress, http://citeseerx.ist.psu.edu/viewdoc/download?doi=10.1.1.215.58\&rep=rep1\& type $=$ pdf.

UIT (2020), World Telecommunication/ICT Indicators Database 2020 (base de datos), Unión Internacional de Telecomunicaciones, Ginebra, https://www.itu.int/en/ITU-D/Statistics/Pages/publications/ wtid.aspx (consultada el 21 de agosto de 2020).

UNIDO (2019), UNIDO Statistical Databases (base de datos), United Nations Industrial Development Organization, http://www.unido.org/researchers/statistical-databases (consultada el 1 de marzo de 2020).

USPTO (2020), “United States Patent and Trademark Office” (página web), United States Patent and Trademark Office, Alexandria, VA, http://www.uspto.gov/ (consultada el 9 de junio de 2020).

WEF (2020), "The impact of 5G: Creating new value across industries and societies", World Economic Forum White Paper, Foro Económico Mundial, Cologny, Suiza, http://www3.weforum.org/docs/ WEF_The_Impact_of_5G_Report.pdf.

WEF (2016), “Digital Transformation of Industries: Logistics”, World Economic Forum White Paper, Foro Económico Mundial, Cologny, Suiza, http://reports.weforum.org/digital-transformation/wpcontent/blogs.dir/94/mp/files/pages/files/wef-dti-logisticswhitepaper-final-january-2016.pdf. 


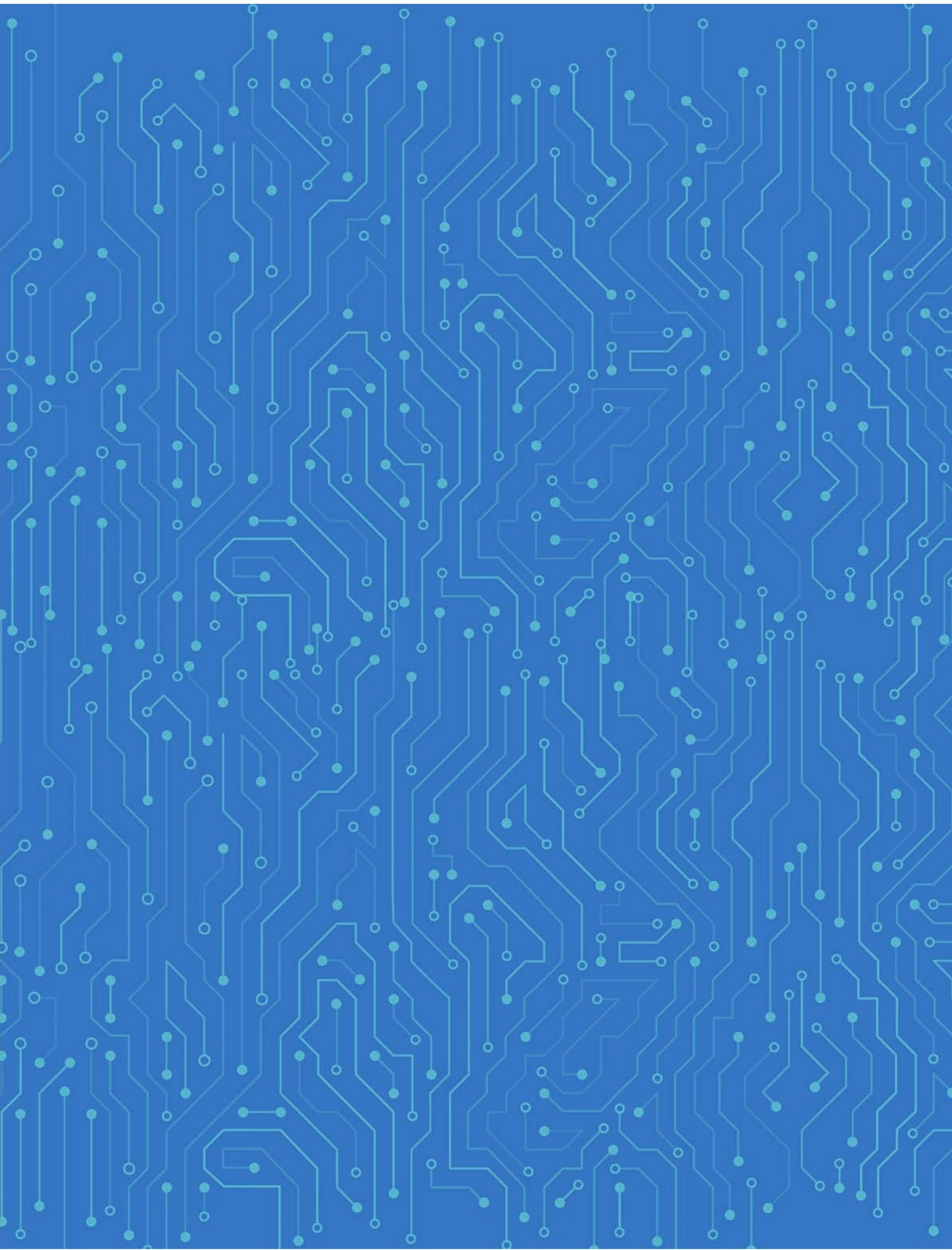




\section{Capítulo 3}

\section{La transformación digital para todos}

El acceso y uso de herramientas digitales en América Latina y el Caribe puede tener un fuerte impacto en la inclusión. Las herramientas digitales, como Internet, presentan una distribución menos desigual que los ingresos y otros servicios públicos. A pesar de una significativa reducción de las desigualdades socioeconómicas, de género, de edad y geográficas, las políticas públicas deben centrarse en cerrar las brechas que aún persisten. En este capítulo se describen los avances y las tendencias en torno al acceso a Internet y su uso en el hogar, el trabajo y los centros educativos. Se presentan asimismo los efectos potenciales de la transformación digital en el futuro del trabajo y se evalúan las habilidades digitales de la fuerza de trabajo actual. También se analiza el papel de los centros educativos en la era de la digitalización y el fomento de la inclusión digital. Por último, en el contexto de la crisis del coronavirus (Covid-19), se constata que la brecha digital de la región la hace vulnerable y, de no aplicar las políticas adecuadas, las desigualdades podrían acrecentarse. En este contexto, la inclusión digital debe entenderse necesaria para garantizar el bienestar social. 


\section{Las políticas de ALC son fundamentales para aprovechar al máximo la transformación digital, fomentar la inclusión y mejorar el bienestar}

El acceso y el uso de Internet están estrechamente relacionados con el ingreso y ubicación del hogar
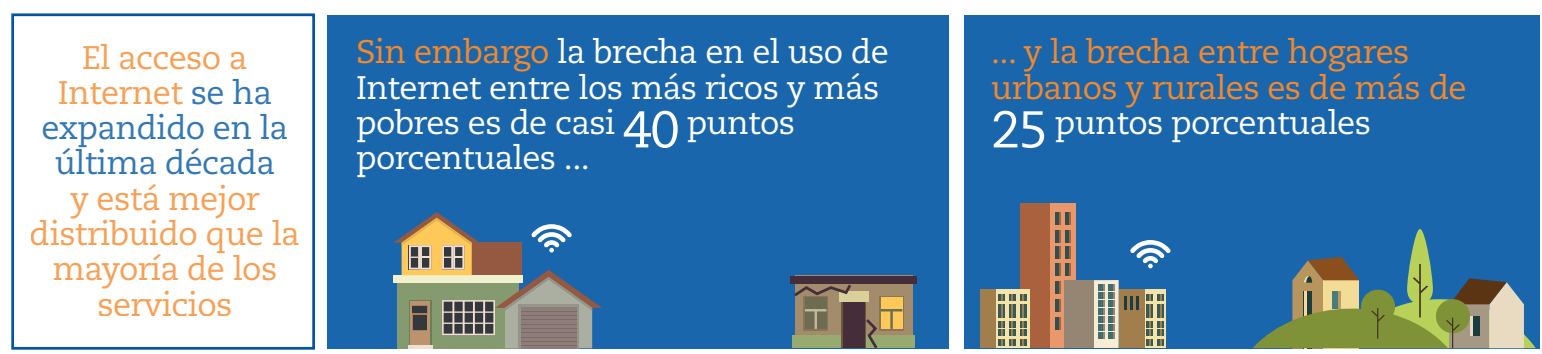

Las políticas no deben centrarse solo en la pérdida de puestos de trabajo, sino también en la creación y transformación de estos
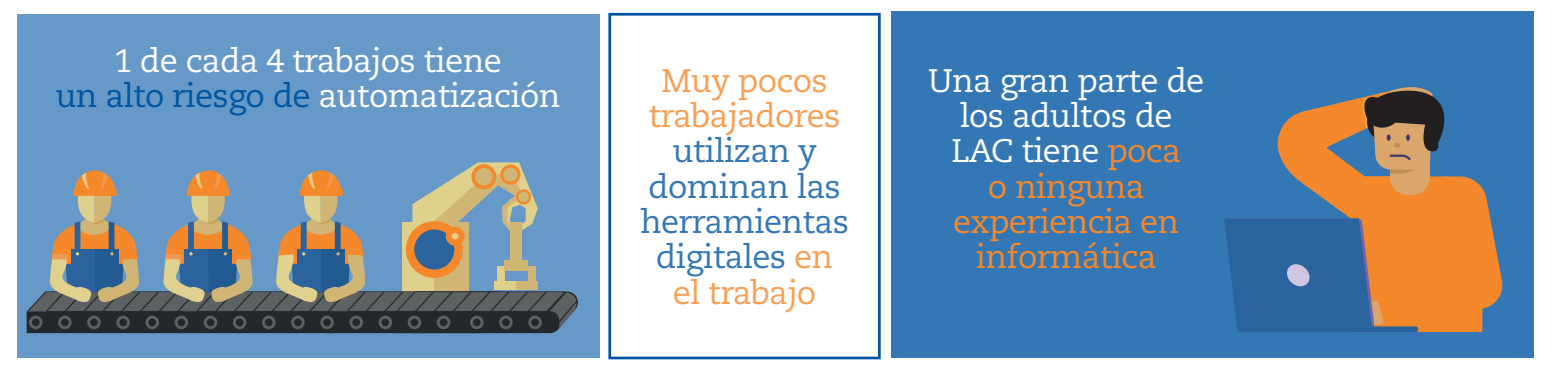

La crisis del Covid-19 resaltó el papel en la equidad que tienen las TIC en la educación
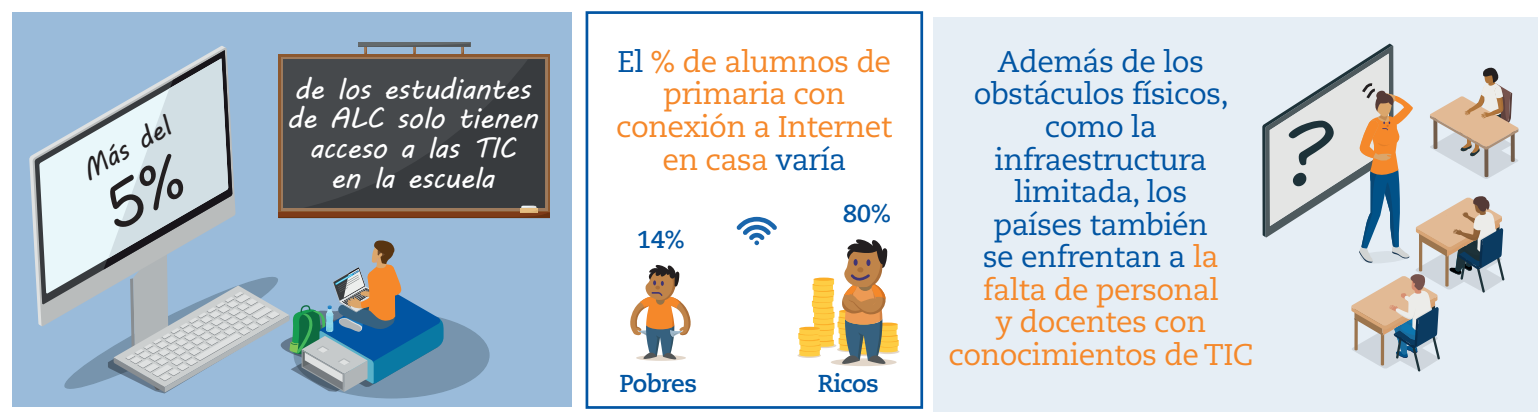

El género es un factor discriminatorio en muchos aspectos de la transformación digital

\begin{tabular}{|c|}
\hline Persisten \\
grandes \\
diferencias de \\
género en la \\
inclinación de los \\
estudiantes \\
hacía carreras \\
relacionadas con \\
la ciencia
\end{tabular}
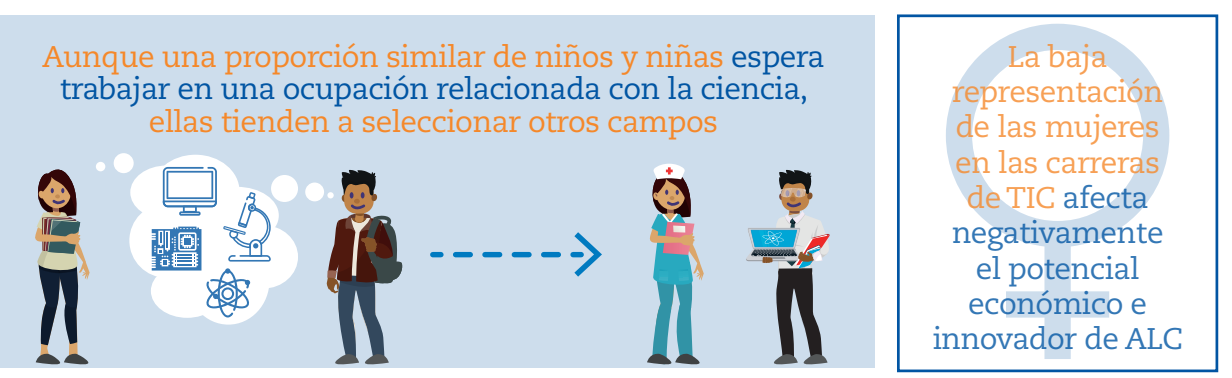


\section{Introducción}

En América Latina y el Caribe hay más personas conectadas a Internet que nunca, pero sigue habiendo carencias y estas pueden continuar surgiendo. La brecha digital o la brecha de oportunidades de personas, hogares, empresas y zonas geográficas para acceder a las tecnologías de la información y la comunicación (TIC) se ha contraído en varios países de la región. Sin embargo, el alcance y la velocidad de la digitalización varían ostensiblemente según el país, el sector, las personas y las zonas geográficas.

El progreso tecnológico puede mejorar el bienestar y eliminar barreras sociales; no obstante, también puede incrementar las desigualdades por ingresos, género, edad y territorio. La digitalización solo beneficiará plenamente a los individuos, las sociedades y las economías si las políticas públicas logran hacer llegar sus beneficios a todos los hogares, los centros educativos y las empresas. En el contexto de la crisis del coronavirus (Covid-19), no tener acceso a la infraestructura de las comunicaciones y a las habilidades necesarias para usarla, puede aumentar las disparidades, lo que acaba creando ganadores y perdedores. Las acciones de política deben contribuir a acelerar la transformación digital para lograr la inclusión social. En respuesta a la pandemia del coronavirus (Covid-19) y para asegurar la recuperación económica, las políticas deben articular mejores herramientas digitales, pues son un factor decisivo para el progreso del bienestar social.

La digitalización brinda oportunidades de inclusión social, preservando e impulsando el progreso de las dos últimas décadas. Las nuevas tecnologías pueden mejorar el acceso a los servicios públicos, la salud y la educación, así como la transparencia de los organismos públicos y la creación de empleo. Además, pueden hacer que grupos subrepresentados se incorporen a las políticas públicas, como es el caso de las mujeres, las personas con discapacidad, los inmigrantes y la población indígena, y pueden crear nuevas formas de trabajo y facilitar la incorporación al mercado laboral.

Gracias a su capacidad para mejorar las habilidades, los servicios y los puestos de trabajo, la digitalización puede mitigar la trampa de la vulnerabilidad social de América Latina y el Caribe. La trayectoria laboral de la región es inestable. El predominio de los empleos informales de baja calidad, así como la elevada rotación en empleos precarios hacen que muchos trabajadores sean vulnerables a choques a nivel personal, de hogar o incluso a nivel macroeconómico (OCDE et al., 2019). La digitalización puede automatizar tareas peligrosas o repetitivas, y puede hacer que los entornos de trabajo sean más seguros y saludables. También permite elegir más libremente cuándo y dónde trabajar, mejorando el balance entre la vida laboral y personal. Por otro lado, maximizar las nuevas tecnologías puede contribuir a que las empresas informales transiten al sector formal. Contribuyendo a superar algunos obstáculos tradicionales a la participación en el mercado laboral, las nuevas tecnologías pueden facilitar la integración de grupos subrepresentados. La digitalización también ofrece vías más económicas y sencillas para ahorrar e invertir en capital humano y en la actividad empresarial. Todo ello impulsa la productividad laboral, refuerza la calidad del empleo y contribuye a la estabilidad de ingresos, por lo que puede transformar el círculo vicioso, de baja productividad, escasez de capital humano e inestabilidad de ingresos en que está atrapada el $40 \%$ de la población de América Latina y el Caribe, en un círculo virtuoso de inclusión social y crecimiento sostenible.

Al mismo tiempo, las nuevas tecnologías también pueden ampliar las desigualdades y reforzar la trampa de la vulnerabilidad social (OCDE et al., 2019). La digitalización ha incrementado la automatización y algunas tareas han sido sustituidas por la tecnología. Entre estas tareas, se encuentran los trabajos rutinarios, como las tareas administrativas, financieras, de asistencia jurídica y presentación de informes, por lo que trabajadores poco cualificados y mujeres trabajadoras se han visto afectados. El aumento de los macrodatos (big data), la inteligencia artificial y la potencia computacional está automatizando 
progresivamente tareas no rutinarias (OCDE, 2019a), por lo que la población deberá estar preparada para hacer frente a esta nueva realidad. La dificultad para acceder a las TIC, darles un uso efectivo, y la falta de habilidades básicas, técnicas y digitales puede dificultar que los grupos vulnerables se beneficien de las oportunidades y ventajas de la digitalización. Según las políticas públicas que se apliquen, las herramientas digitales fomentarán la inclusión o ampliarán las desigualdades. La tecnología cambia con rapidez y la capacidad de adaptación es fundamental. Más allá de los conocimientos básicos sobre dispositivos digitales e Internet, es preciso familiarizarse con el pensamiento computacional, ser capaz de entender y resolver problemas mediante las TIC, y de seleccionar e interpretar la información producida por herramientas digitales.

Para aprovechar las oportunidades de la digitalización, es fundamental empezar a utilizar la tecnología digital apropiadamente y de manera temprana, junto con un aprendizaje permanente para desarrollar las habilidades necesarias para interactuar con las tecnologías y aprovechar al máximo sus oportunidades. La preparación de los países de ALC dependerá de si se abordan las brechas de acceso, uso y dominio de las nuevas tecnologías en hogares, centros educativos y lugares de trabajo. Conforme los países van ampliando los servicios, las herramientas y la infraestructura de las comunicaciones, la formación adquiere un claro protagonismo durante todo el ciclo de vida, para que se pueda acceder a las habilidades básicas, técnicas y digitales, y para que no se perpetúen las desigualdades socioeconómicas del mercado laboral.

La tecnología digital permite superar ciertos obstáculos tradicionales para incorporarse al mercado laboral y puede reducir costos, tanto para los empleadores como para los empleados. Sin embargo, las nuevas formas de trabajo - teletrabajo, economía de plataformas, entre otras- plantean nuevos desafíos con respecto a la protección social. Si los sistemas no logran absorber y adecuar la regulación a estas nuevas formas de trabajo, se pueden producir pérdidas en el bienestar.

La crisis del coronavirus (Covid-19) pone de manifiesto que la brecha digital es un tema urgente, ya que los trabajadores pobres y vulnerables que no disponen de la infraestructura ni de las habilidades para beneficiarse de las herramientas digitales se están quedando atrás. Estas herramientas han permitido que algunos sectores y empresas continuar funcionando, al menos de forma parcial y cumpliendo con las medidas de distanciamiento social. Por ejemplo, en respuesta a las medidas de confinamiento, la transformación digital ha permitido que trabajadores, estudiantes, empresas y hogares puedan acceder al teletrabajo, al aprendizaje en línea a distancia, a plataformas y al comercio electrónico, así como a otros servicios públicos y privados. Sin embargo, la brecha digital ha impedido que la mayoría de la población pobre y vulnerable se beneficie de estas oportunidades. Los que queden al margen de estas herramientas posiblemente se verán más afectados por las consecuencias económicas y sociales de la crisis, y las desigualdades socioeconómicas se acrecentarán.

Los efectos de la pandemia en el mercado de trabajo, las personas y los hogares siguen siendo inciertos, pero es evidente que la capacidad de las personas para adaptarse a esta situación es desigual. La clase acomodada y la clase media tienen mayores probabilidades de tener conexión a Internet e integrar las tecnologías digitales en su día a día laboral, formativo y familiar. La clase más pobre y vulnerable, en cambio, probablemente tendrá un acceso escaso o nulo a la tecnología digital o a las habilidades necesarias, lo que dificultará que puedan acceder a los bienes y servicios públicos y privados. Los trabajadores sin acceso a la tecnología y sin las habilidades necesarias serán más propensos a sufrir pérdidas económicas y de otro tipo, tanto a corto como a largo plazo; por ejemplo, no podrán teletrabajar ni vender bienes por Internet, y quizá sus hijos tampoco puedan acceder a la educación a distancia para continuar con sus estudios. 
Es preciso ejecutar diversas acciones para promover una recuperación económica en la que todos se beneficien de las oportunidades de la transformación digital. En particular, hay que consolidar el proceso de expansión del acceso y el uso de las tecnologías digitales y la infraestructura de las comunicaciones, fortaleciendo al mismo tiempo las habilidades digitales, cognitivas y no cognitivas. Para que todas las personas puedan acceder a las nuevas tecnologías, utilizarlas y beneficiarse de ellas, se requiere un trabajo serio y coordinado de diseño de políticas públicas (ver el Capítulo 4). Un buen paquete de políticas, por un lado, debe promover la digitalización para aumentar la productividad y el bienestar y, por otro lado, debe amortiguar sus posibles potenciales impactos negativos (OCDE, 2019b).

En este capítulo se describen los avances del acceso y el uso de Internet en los hogares según zonas geográficas, nivel socioeconómico, género y edad. Posteriormente, el capítulo se enfoca en la digitalización y los mercados laborales; se presentan sus efectos potenciales en el futuro del trabajo en la región y las habilidades digitales de la fuerza de trabajo actual. Se comparan las tendencias de acceso a Internet en los centros educativos y el papel de estos en el fomento de la inclusión digital y en la formación de futuros trabajadores mejor preparados para la digitalización. Se constata asimismo que el coronavirus (Covid-19) ha puesto en evidencia la brecha digital. En todas las secciones se tiene en cuenta el género como una consideración clave. El capítulo concluye con las implicaciones de todo ello en materia de política pública.

\section{La digitalización y los hogares: Conectividad inclusiva}

Los países de América Latina y el Caribe han experimentado, en el siglo XXI, un crecimiento significativo del acceso a Internet. En 2018, el 68\% de la población utilizó Internet, casi el doble que en 2010 (ver el Capítulo 2). Esta expansión redujo la brecha en el número de usuarios conectados y que utilizan Internet entre América Latina y el Caribe y los países de la Organización para la Cooperación y el Desarrollo Económico (OCDE) (84\% en 2018). Sin embargo, siguen existiendo grandes brechas en múltiples dimensiones.

Como se ha hecho evidente con la crisis sanitaria, la brecha digital puede ampliar las desigualdades. Los hogares con acceso a infraestructuras de las comunicaciones y a una conexión a Internet de calidad son más resilientes y pueden adaptarse más fácilmente a las nuevas formas de trabajar y a las actividades cotidianas. El acceso a las TIC y a Internet y su utilización eficaz son ahora básicos para la inclusión en el mercado laboral, la participación en la educación a distancia y el acceso a los bienes públicos y privados, al tiempo que reducen el contacto y, por consiguiente, la probabilidad de infección. Es probable que los hogares con menos recursos tecnológicos se vean más afectados por la crisis. En esta sección se analizan los avances en el acceso a Internet, a las TIC y su uso en la región, por grupos socioeconómicos y zonas geográficas. La infraestructura y las habilidades TIC son complementarias para el bienestar social. En esta sección se presenta una visión general de la preparación de los hogares de América Latina y el Caribe para hacer frente a los desafíos de la transformación digital en el contexto de la crisis del coronavirus (Covid-19).

\section{Si bien la brecha digital aún persiste, el acceso y el uso de Internet están distribuidos más equitativamente que los ingresos, la educación secundaria y las pensiones}

En comparación con la expansión de otros servicios, la de Internet ha generado una distribución más equitativa de las oportunidades en ALC (Gráfico 3.1). El acceso a Internet y su uso también están menos concentrados que los ingresos y las pensiones. Sin embargo, están distribuidos de forma más desigual que el acceso al alcantarillado y a la electricidad.

A nivel regional agregado, el uso de Internet es menos desigual que el acceso. Las personas pueden usar Internet fuera de casa a diario: en el trabajo, la escuela, en casa de amigos o familiares, en ciertos espacios públicos urbanos o en cibercafés. La conectividad de los teléfonos celulares también está aumentando, lo que contribuye a cerrar la brecha. 
La mayoría de los países —incluidos Bolivia, Honduras, Paraguay y Perú—siguen pautas similares; tanto el acceso a Internet y a las computadoras como su uso se distribuyen más equitativamente que el acceso a la educación secundaria y las pensiones (Gráfico 3.A1.1). En Chile y Uruguay, la distribución del uso de Internet es similar a la distribución del acceso a los servicios públicos básicos, como el alcantarillado y la electricidad. En Colombia, Ecuador y México, el acceso a Internet y a las computadoras es más igualitario que el acceso a la educación, pero más desigual que el acceso a los servicios públicos básicos. En los países con fuertes desigualdades en el acceso a los servicios básicos, como El Salvador y Honduras, el acceso a las TIC también es desigual.

Las políticas públicas deben tener en cuenta la transformación digital, con actuaciones que mitiguen la brecha digital proporcionando: 1) la infraestructura necesaria para ampliar el acceso; 2) el apoyo para adquirir habilidades digitales, y 3) el acceso de los grupos tradicionalmente excluidos.

\section{Gráfico 3.1. Distribución del acceso a Internet y de su uso, junto con el de otros servicios, por decil de ingresos, países seleccionados de América Latina, 2017 o último año disponible}

$\begin{array}{lll}\text { Línea de igualdad } & \text { Acceso a Internet } & \text { Uso de Internet }\end{array}$ Acceso a computadora

Distribución acumulativa (\%)

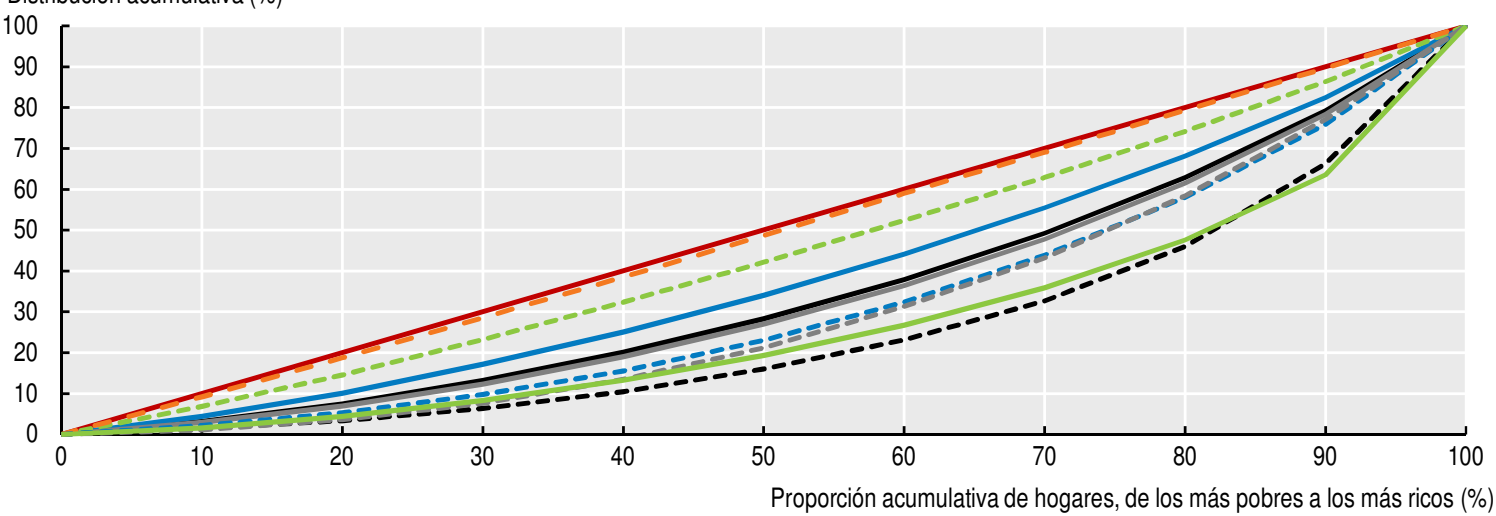

Notas: Promedio simple por decil para países seleccionados de América Latina y el Caribe. Eje X = decil de ingresos. Eje Y = porcentaje acumulativo de personas con acceso a Internet y a computadora en el hogar; porcentaje acumulativo de personas que declaran haber usado Internet en los 3 o 12 meses anteriores, según la pregunta de la encuesta de hogares; porcentaje acumulativo de personas en un hogar con alcantarillado o electricidad; y porcentaje acumulativo de personas de 20 años o más con al menos educación secundaria. Cálculos a partir de las encuestas de hogares de 2017 o el último año disponible: 2016 para Bolivia, Honduras y México. La edad en que se empieza a usar Internet varía según el país: en El Salvador y Paraguay, a partir de los 10 años; en Bolivia, Chile, Ecuador y Honduras, a partir de los 5 años; en Perú y Uruguay, a partir de los 6 años. Por período anterior de uso de Internet, según los datos de la encuesta, se entienden los tres meses anteriores en el caso de Bolivia, Honduras, Paraguay y Uruguay, y los 12 meses anteriores en el caso de Chile, Ecuador y El Salvador. Otras variables incluyen todas las edades. Brasil, Chile, Costa Rica, Ecuador, El Salvador, Paraguay y Uruguay incluyen los datos móviles en el acceso a Internet. Bolivia, Colombia, México y Perú no especifican si se incluyen los datos móviles en ese indicador. Bolivia, Brasil, Chile, Costa Rica, Ecuador, Paraguay y Uruguay incluyen computadoras portátiles y tabletas en el acceso a computadora. Colombia, El Salvador, México y Perú no especifican si se incluyen las computadoras portátiles o las tabletas en ese indicador. Fuente: Elaboración propia a partir de ORBA/CEPAL (2019), Banco de Datos de Encuestas de Hogares (base de datos), http://www. cepal.org/es/observatorio-regional-de-banda-ancha. StatLink 刑Ist https://doi.org/10.1787/888934202028

$\mathrm{El}$ acceso a Internet y su uso en América Latina y el Caribe sigue estando fuertemente vinculado al nivel de ingresos de los hogares. En promedio, la brecha en el uso de Internet entre los hogares de los quintiles más ricosy los más pobres es de casi 40 puntos porcentuales (Gráfico 3.2). La mayoría de los países se sitúan en la línea del promedio de ALC. La brecha es mayor en Honduras (58 puntos porcentuales) y Perú (60 puntos porcentuales), y menor en Chile (22 puntos porcentuales) y Uruguay (17 puntos porcentuales). 


\section{Gráfico 3.2. Usuarios de Internet por quintil de ingresos, países seleccionados de América Latina, 2017 o último año disponible}

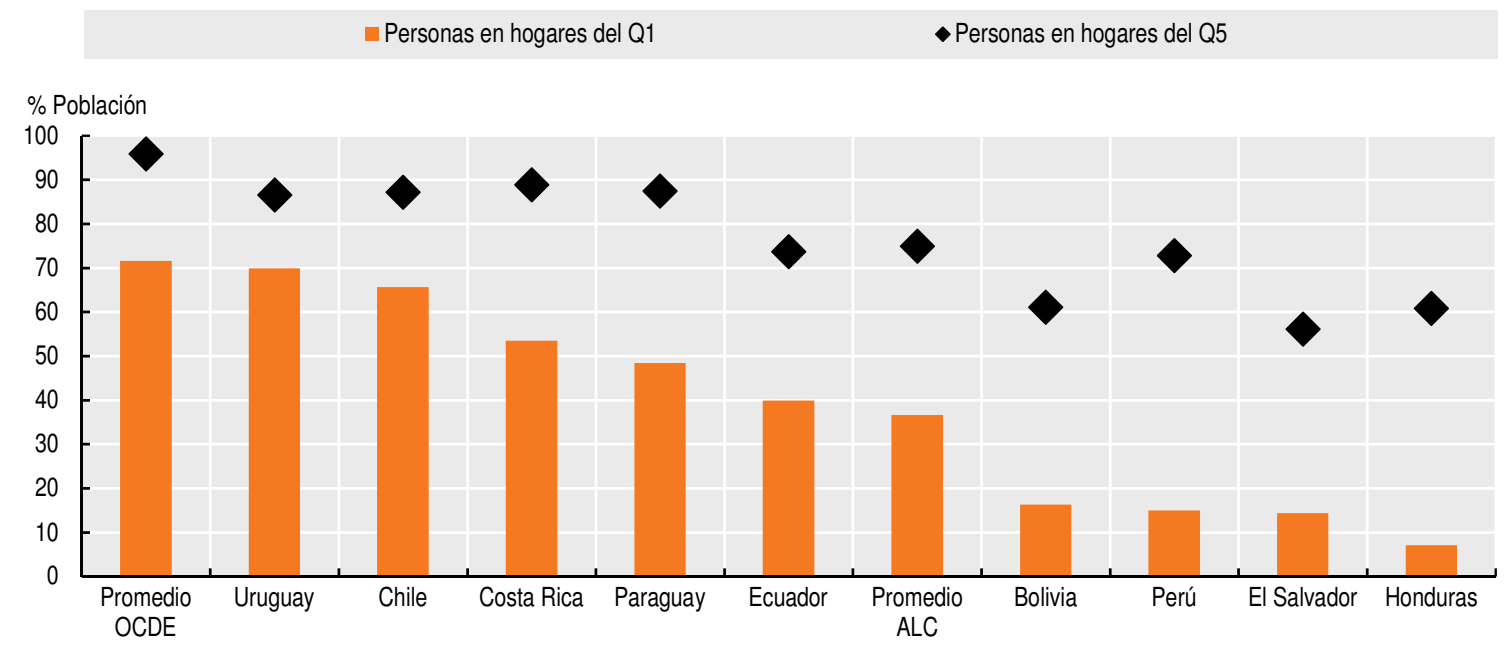

Notas: La edad de inicio del uso de Internet varía según el país: en El Salvador y Paraguay, a partir de los 10 años; en Bolivia, Chile, Ecuador y Honduras, a partir de los 5 años, y en Perú y Uruguay, a partir de los 6 años. El período anterior de uso de Internet, según los datos de la encuesta, se refiere a los tres meses anteriores en el caso de Bolivia, Honduras, Paraguay, Uruguay y la OCDE, y a los 12 meses anteriores en el caso de Chile, Ecuador y El Salvador. Los datos de Bolivia son de 2016. El promedio ALC es un promedio simple por quintil para los países disponibles. La muestra de la OCDE presenta datos para el primer y el cuarto cuartil, correspondientes a individuos de 16 años o mas.

Fuente: Elaboración propia a partir de ORBA/CEPAL (2019), Banco de Datos de Encuestas de Hogares (base de datos), https://www. cepal.org/es/observatorio-regional-de-banda-ancha.

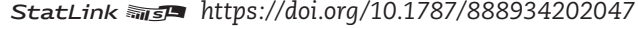

\section{Las brechas de conectividad y uso de TIC deben reducirse}

Los grupos de edad más avanzada no están aprovechando las oportunidades de la conectividad. El uso de computadoras e Internet es significativamente mayor entre la población más joven (15-34 años) (Gráfico 3.3). El acceso a Internet es más homogéneo entre los diferentes grupos, pero las personas mayores (65 años o más) siguen quedando rezagadas. Los adultos y las personas de edad avanzada podrían sacar más partido a Internet para acceder a bienes y servicios públicos y privados de forma más habitual y eficiente. Las políticas públicas para fomentar la competencia digital de los adultos son fundamentales para el desarrollo y la inclusión.

Abordar la amplia brecha digital entre las zonas urbanas y rurales de los países de América Latina y el Caribe, tanto a nivel nacional como local, es de particular importancia. En los países analizados, los usuarios urbanos de Internet superaban a los rurales, tanto en cifras absolutas como en proporción, y en algunos países llegaba incluso a cuadruplicarse (Gráfico 3.4). En la mayoría de los países de la OCDE, la reducción de la brecha entre las zonas urbanas y las zonas rurales se debe a políticas públicas que fijan objetivos nacionales en materia de disponibilidad de banda ancha (OCDE, 2018a). Para los países de ALC, la reducción de la brecha digital en las zonas rurales es un desafío, debido a la ubicación estratégica de las redes troncales, cerca de las grandes ciudades, densamente pobladas (OCDE, 2018a). Las estrategias claras para conectar las zonas menos pobladas y hacer que Internet llegue a todos los ciudadanos deberían ser una prioridad de las agendas y estrategias digitales (AD) nacionales (ver el Capítulo 4). La transformación digital requiere primero de una infraestructura básica y reducir las brechas de los servicios básicos entre las zonas rurales y las urbanas (ver el Recuadro 3.1). El acceso a la electricidad y a las carreteras o a los sistemas de transporte fluvial necesarios para la infraestructura de alta velocidad sigue creando dificultades en algunos países de ALC. 


\section{Gráfico 3.3. Acceso y uso de las TIC por grupos de edad en América Latina y el Caribe, 2018 o último año disponible}

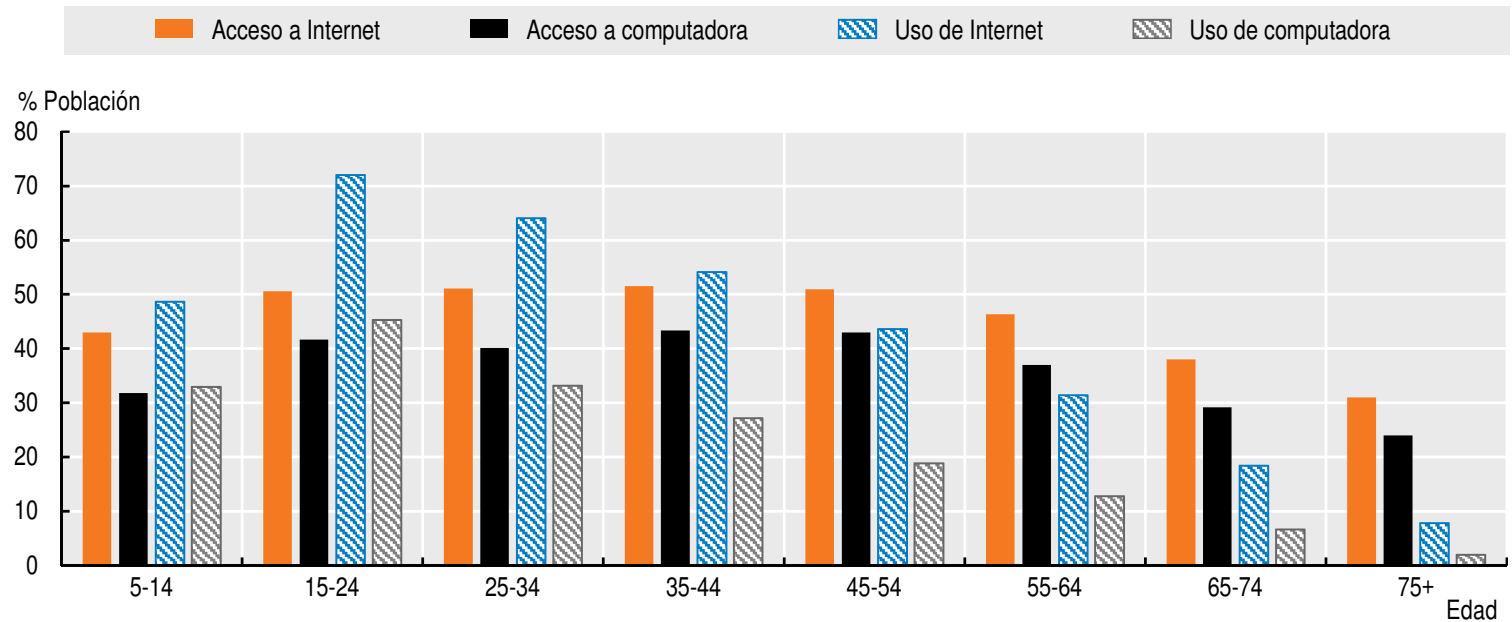

Notas: Las variables de acceso se refieren a la población que vive en un hogar con conexión a Internet y en un hogar que posee una computadora. El acceso a Internet incluye a Argentina, Bolivia, Chile, Colombia, Costa Rica, El Salvador, México y Perú. El acceso a computadora incluye a Argentina, Bolivia, Chile, Colombia, Costa Rica, El Salvador, Honduras, México y Perú. La inclusión de las conexiones fijas o móviles varían en las encuestas de hogares. El uso de Internet se refiere al porcentaje de personas que informan usar Internet al menos una vez a la semana. Debido a las distintas definiciones de uso, los promedios pueden diferir de otras cifras. El uso de Internet incluye a Argentina, Bolivia, Chile, Colombia, Costa Rica, El Salvador, Honduras y Perú. El uso de la computadora se refiere al porcentaje de personas que informan usarla al menos una vez a la semana. El uso de computadoras incluye a Bolivia y Colombia. Chile no tiene datos disponibles sobre Internet y acceso a computadoras para personas menores de 15 años en esta encuesta de hogares.

Fuente: Elaboración propia a partir de las encuestas de hogares de 2018 o en el último año disponible: Encuesta Permanente de Hogares (2018) (Argentina), Encuesta de Hogares (2018) (Bolivia), Encuesta de Caracterización Socioeconómica Nacional (2017) (Chile), Encuesta Nacional de Calidad de Vida (2017) (Colombia), Encuesta de Hogares de Propósitos Múltiples (2017) (El Salvador), Encuesta Permanente de Hogares de Propósitos Múltiples (2014) (Honduras), Encuesta Nacional de los Hogares (2018) (México), Encuesta Permanente de Hogares (2018) (Paraguay) y Encuesta Nacional de Hogares (2018) (Perú).

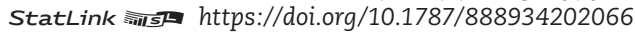

\section{Gráfico 3.4. Proporción de usuarios de Internet urbanos y rurales en América Latina, 2017}

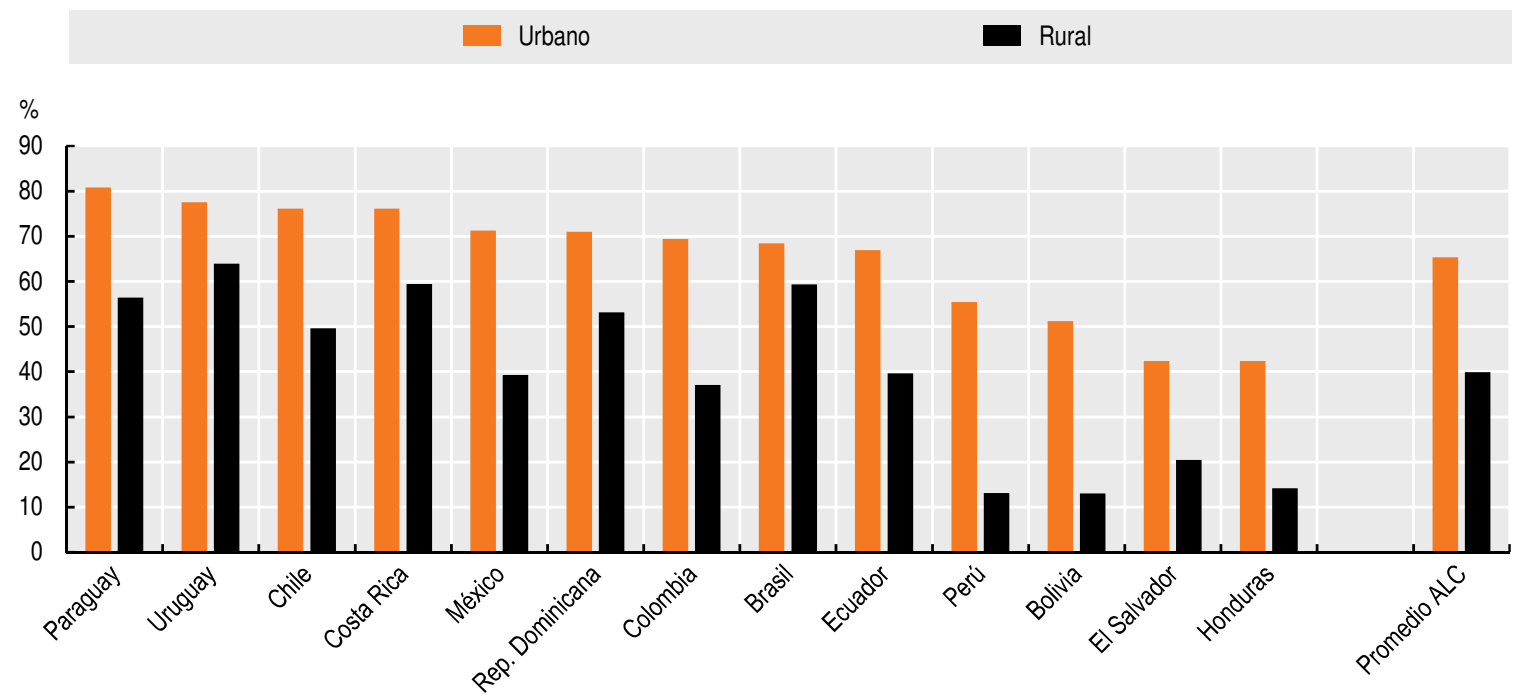

Fuente: Elaboración propia a partir de ORBA/CEPAL (2019), Banco de Datos de Encuestas de Hogares (base de datos), www. cepal.org/es/observatorio-regional-de-banda-ancha; UIT (2019), Base de datos de indicadores mundiales de telecomunicaciones/ TIC (base de datos), www.itu.int/pub/D-IND-WTID.OL-2019.

StatLink न्ताst https://doi.org/10.1787/888934202085 


\section{Recuadro 3.1. Asegurar el acceso a Internet y su uso en América Latina y el Caribe}

Las estrategias para aumentar el acceso a Internet y su uso en poblaciones desfavorecidas se centran en los obstáculos para la demanda o la oferta. En cuanto a la demanda, los latinoamericanos experimentan dificultades para acceder a Internet, sobre todo por el costo de los dispositivos de TIC y las tarifas de los proveedores. La desigualdad de ingresos intensifica las barreras a la asequibilidad, ya que la renta de los hogares de bajos ingresos suele estar muy por debajo del promedio (OCDE/BID, 2016). En cuanto a la oferta, entre otros obstáculos, la limitada infraestructura de telecomunicaciones, la carga fiscal, las ineficiencias en la prestación de servicios, las distorsiones de los precios por la falta de competencia y una reglamentación adecuada limitan el acceso de los servicios TIC a una parte importante de la población (West, 2015).

Las iniciativas referentes a la oferta, que han aumentado la asequibilidad de Internet incluyen una mayor competencia, estrategias eficaces de expansión de la banda ancha, una asignación eficiente del espectro y modelos de consumo colaborativo de la infraestructura (A4AI, 2019). El programa Internet para Todos, en Perú, se propone hacer llegar los datos móviles $4 \mathrm{G}$ a 6 millones de personas en más de 30000 zonas rurales para finales de 2021. La asociación entre Telefónica, Facebook, BID Invest y Corporación Andina de Fomento (CAF) permite a las operadoras utilizar la infraestructura de las comunicaciones para ampliar la cobertura en las zonas rurales. Telefónica dispone de 3130 torres en todo Perú e Internet para Todos se propone instalar 866 torres más para 2021. Este programa también constituye una posibilidad de crecimiento para Telefónica, ya que puede probar otros modelos de negocio y tecnologías en nuevas ubicaciones y, potencialmente, ampliar la base de clientes en nuevos mercados (MAEUEC, 2020). El objetivo a largo plazo es replicar el enfoque en otros países de América Latina y el Caribe, donde unos 100 millones de personas todavía no tienen acceso a Internet (BID, 2020).

El programa Redes Comunitarias también está ganando terreno en la región. En el marco del plan digital ecuatoriano, el programa Ecuador Conectado pretende llevar redes comunitarias a 127000 hogares, lo que permitirá acceder a Internet a un precio reducido (MINTEL, 2019). El gobierno colombiano está ampliando las zonas de acceso comunitario para aumentar la conectividad rural: el objetivo es conectar 1000 zonas rurales e instalar redes con capacidad para prestar servicio al menos a diez usuarios simultáneamente a una velocidad mínima de $9 \mathrm{MB} / \mathrm{s}$ (MinTIC, 2019). Del mismo modo, el programa Conectar lo no conectado apoya la implementación de redes comunitarias en Argentina, Ecuador y México; proporcionando capacitación en TIC, asegurando la sostenibilidad de las redes, y promoviendo la creación de mejores marcos regulatorios (APC, 2020).

En cuanto a la demanda, los sistemas de transferencia (por ejemplo, los programas de transferencias monetarias condicionadas) podrían mitigar la barrera del costo, pero en realidad son los beneficiarios los que deciden cómo gastarse el dinero que reciben (pueden gastarlo en otros bienes y servicios). Los subsidios directos para Internet, en cambio, canalizan los recursos para aumentar el uso de Internet de ciertos grupos y pueden distribuirse mediante un sistema de vales o con transferencias directas a los operadores, o mediante precios más bajos, por lo que efectivamente los beneficiarios dispondrían de más ingresos (OCDE/BID, 2016). Este tipo de programa también permite dirigirse a segmentos más vulnerables de la población, como los ancianos, las mujeres y la población rural. En Colombia, el programa Vive Digital tiene por objeto aumentar el acceso a Internet de los dos estratos más pobres de la población (hay seis estratos); entre otras cosas, mediante ayudas a la adquisición de dispositivos y servicios de Internet, así como de computadoras y contenidos pedagógicos digitales para las escuelas públicas rurales. En Costa Rica, el programa Hogares Conectados se propone ayudar a las personas vulnerables de los quintiles 1 , 2 y 3 para que tengan acceso a las TIC con computadoras subvencionadas y para que determinados hogares tengan acceso a Internet (OCDE/BID, 2016). 


\section{Pocas personas tienen las habilidades para usar efectivamente las TIC} en el día a día

El número de usuarios de Internet ${ }^{1}$ crece a medida que más hogares, empresas y espacios públicos se conectan a la red. El 68\% de la población de ALC usa Internet de forma regular (al menos una vez en los tres meses anteriores), casi el doble de la proporción en 2010, pero aún por debajo del promedio de la OCDE de 84\% (ver Capítulo 2).

Para aprovechar al máximo las TIC, la gente debe utilizarlas para obtener información, resolver problemas, interactuar con otras personas y acceder a bienes y servicios. La Evaluación de Habilidades de Adultos, en el marco del Programa para la Evaluación Internacional de Competencias de Adultos (PIAAC) de la OCDE, analiza las habilidades para procesar información clave -competencia lectora, competencia matemática y resolución de problemas-, y reúne información y datos sobre cómo los adultos utilizan sus habilidades en el hogar, el trabajo y en la sociedad.

Las brechas en el uso de las TIC son importantes. Menos de la mitad de los latinoamericanos han usado una computadora o tienen habilidades para usar computadoras para tareas profesionales básicas. En promedio, el 50\% de los adultos entre 16 y 65 años de los países de ALC encuestados (Chile, Ecuador, México y Perú) habían utilizado una computadora o tenían conocimientos básicos de informática, según la sección basada en computadoras de PIAAC. Los datos oscilan entre el $42 \%$ de México y el 67\% de Chile (OCDE, 2019c).

Las actividades cotidianas más comunes entre los que tenían conocimientos informáticos eran buscar información en Internet (73\%) y usar el correo electrónico (69\%), seguidos de las comunicaciones a tiempo real, como videoconferencias o chats (Gráfico 3.5). Solo el 8\% usaba computadoras para programar. El uso de la computadora y de Internet varía según el país. En México, el 15\% utiliza las TIC para hacer transacciones al menos una vez por semana, frente al 30\% de Chile (Gráfico 3.A1.2).

\section{Gráfico 3.5. Uso de las TIC por actividad en países seleccionados de América Latina}

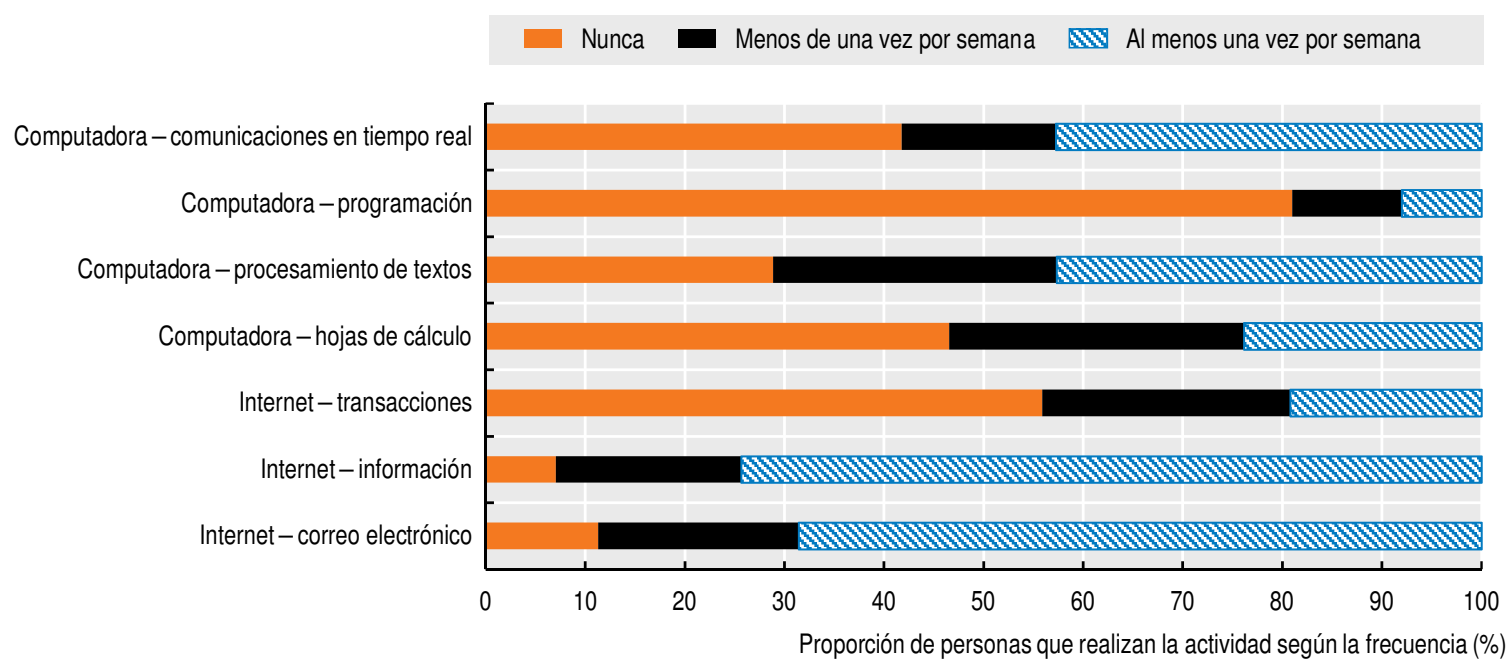

Nota: El promedio de América Latina es un promedio simple que incluye a Chile, Ecuador, México y Perú. Chile participó en la segunda ronda de la Evaluación Internacional de las Competencias de los Adultos (PIAAC), y el resto de los países, en la tercera ronda.

Fuente: Elaboración propia a partir de OCDE/PIAAC (2018), Evaluación Internacional de las Competencias de los Adultos (PIAAC) (base de datos), www.oecd.org/skills/piaac/data/.

StatLink : 
Hay poca variación entre los encuestados en cuanto al uso de herramientas digitales básicas, como el correo electrónico y el chat. El género, la edad y la educación afectan el uso de herramientas más complejas (Gráfico 3.6). Los hombres son más propensos que las mujeres a utilizar las TIC para hacer transacciones o trabajar con hojas de cálculo. Las personas con educación superior utilizan esos instrumentos con más frecuencia que las personas con menos estudios, mientras que estas últimas tienen una probabilidad ligeramente superior de participar en comunicaciones a tiempo real. Las personas de mediana edad y mayores hacen transacciones en la red con mayor frecuencia que las más jóvenes, mientras que estas últimas trabajan con hojas de cálculo de forma mucho más habitual.

\section{Gráfico 3.6. Uso de las TIC por género, edad y educación, países seleccionados de América Latina}

Proporción de personas que usan TIC al menos una vez por semana

Panel A. Comportamiento en transacciones en línea

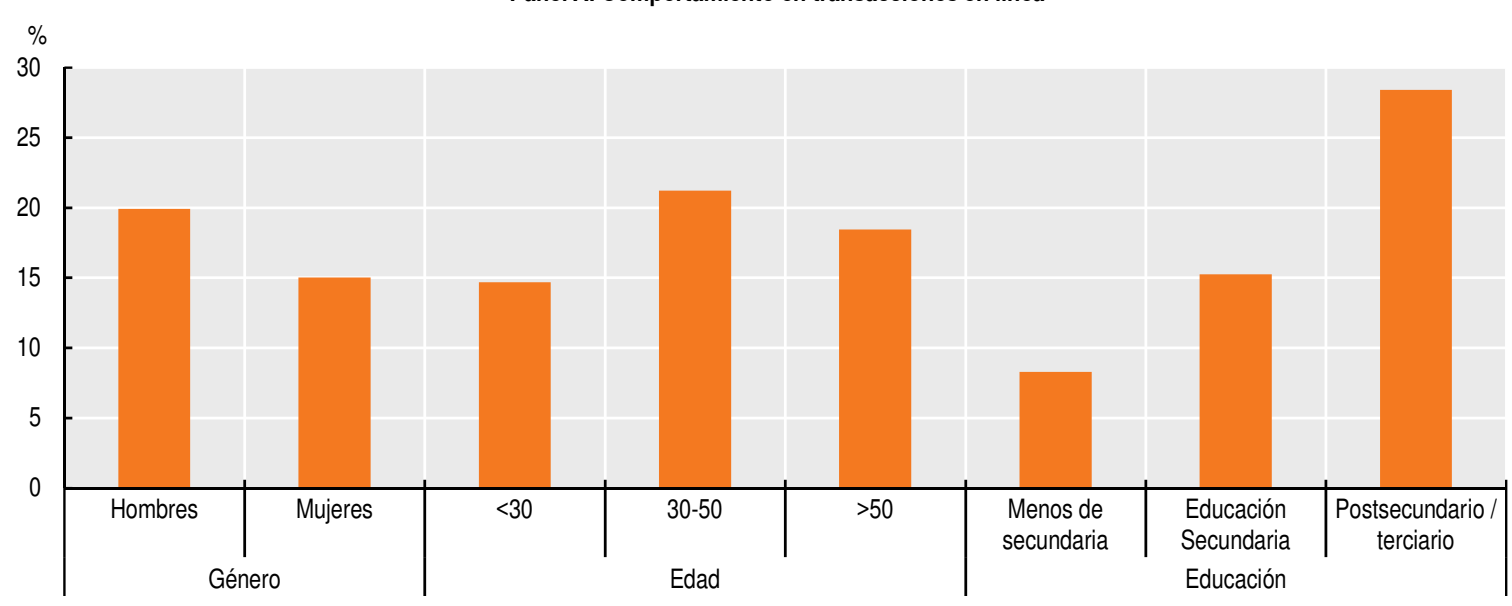

Panel B. Trabajo con hojas de cálculo

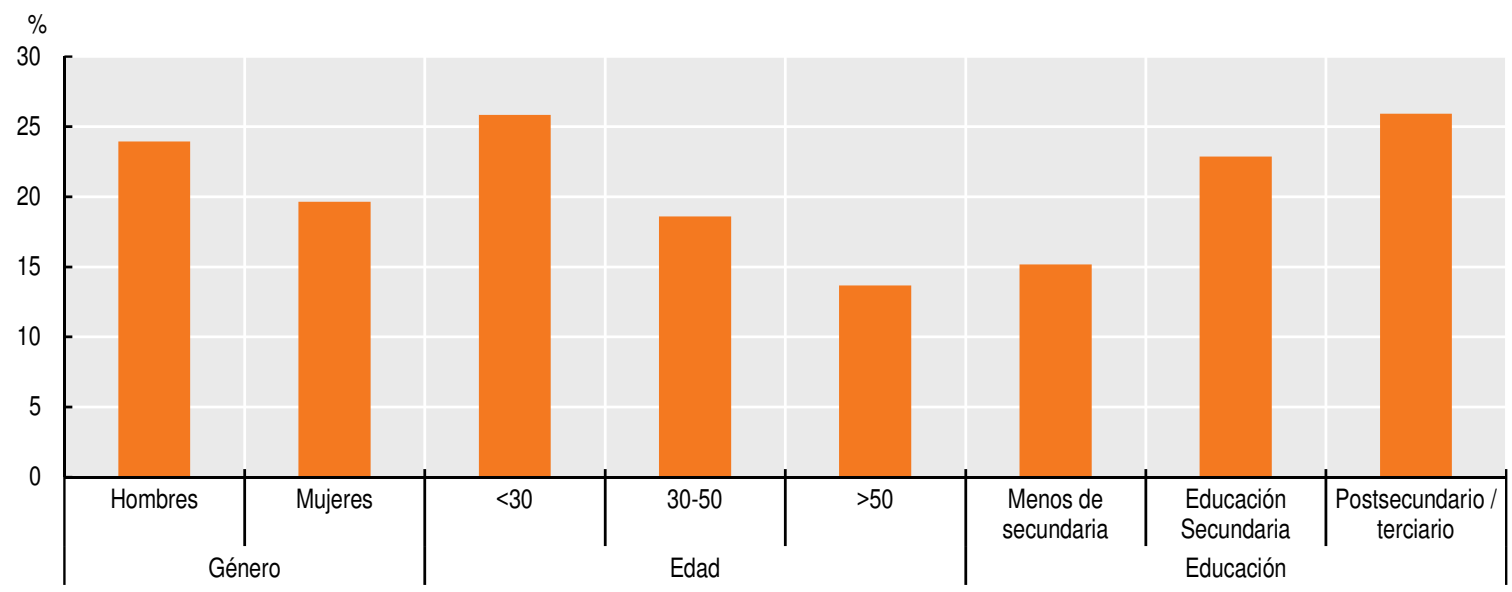

Nota: El promedio de América Latina es un promedio simple que incluye a Chile, Ecuador, México y Perú. Datos brindados por los encuestados tras descartar a las personas sin conocimientos de TIC o que no utilizan las TIC en su día a día. Chile participó en la segunda ronda de la Evaluación Internacional de Competencias de Adultos (PIAAC), y el resto de los países de América Latina y el Caribe, en la tercera ronda.

Fuente: Elaboración propia a partir de OCDE/PIAAC (2018), Evaluación de Competencias de Adultos (base de datos), www.oecd. org/skills/piaac/data/.

StatLink त्नाजा https://doi.org/10.1787/888934202123 


\section{La digitalización y los mercados laborales: El futuro del trabajo y las habilidades}

Las nuevas tecnologías de producción, los nuevos modelos de organización y la evolución de las preferencias de los trabajadores generan nuevas maneras de trabajar que demandan nuevas habilidades. Las tecnologías digitales aplicadas a la producción han contribuido a la automatización, la reestructuración de las operaciones y los procesos, así como al desarrollo y a la aplicación de soluciones tecnológicas. Algunos trabajos están siendo reemplazados, pero otros se modernizan y otros se crean. A muchos les preocupa que se destruyan puestos de trabajo, que se precarice el empleo, que los trabajadores pierdan capacidad de negociación y que las brechas en habilidades digitales se acentúen con la edad de los trabajadores. La mayoría de los puestos de trabajo cambiarán a medida que la economía avance en su proceso de digitalización.

Con la crisis económica generada por la pandemia, la destrucción de empleo puede ser enorme. El desempleo en América Latina y el Caribe podría aumentar hasta el 13.5\% a finales de 2020 (CEPAL, 2020a). Para apoyar a los trabajadores y las empresas, los gobiernos han aplicado políticas, entre estas, esquemas para la retención de empleos y subsidios dirigidos a la sustitución de ingresos. Estas acciones no deben dejar a nadie atrás. La crisis brinda la oportunidad de replantear programas de apoyo a trabajadores, especialmente a los jóvenes y a otros grupos tradicionalmente vulnerables, tanto en lo que respecta a las oportunidades de formación y capacitación, como a la experiencia de incorporación al mercado de trabajo, para evitar que haya una generación de jóvenes cuyas carreras se vean permanentemente afectadas por las perturbaciones del mercado laboral (OCDE, 2020a). Con las cuarentenas, el teletrabajo y otras formas de trabajo no estándar se han vuelto algo habitual. Sin embargo, estos cambios solo benefician a una porción de la fuerza de trabajo cuyas labores pueden desarrollarse de manera remota y que a su vez están asociadas a un mayor nivel de entrenamiento y con salarios más altos (CEPAL, 2020b), potencialmente amplificando las inequidades ya existentes. Por eso, fomentar el acceso a la infraestructura de las comunicaciones y, más importante aún, fomentar el desarrollo de habilidades digitales es esencial para que los trabajadores se puedan adaptar a las nuevas condiciones del mercado de trabajo.

Esta sección se basa en las conclusiones y principales mensajes de política pública de las Perspectivas de empleo de la OCDE 2019: El futuro del trabajo y de la publicación Skills Matter: Additional Results from the Survey of Adult Skills (OCDE, 2019a, 2019c). En las siguientes páginas se analiza el riesgo de automatización, el uso de las habilidades digitales en el trabajo, los determinantes clave y la razón por la cual la competencia digital es importante para los trabajadores y las economías. Se trabaja a partir de los datos de la Evaluación Internacional de las Competencias de los Adultos (PIAAC) (Survey of Adult Skills), que pone a prueba la capacidad de resolver problemas en entornos con fuerte presencia tecnológica utilizando herramientas de TIC, como el correo electrónico, las hojas de cálculo, el procesamiento de texto e Internet. Cuatro países de América Latina participaron en los estudios del programa PIAAC: Chile en la segunda ronda (2015), y Ecuador, México y Perú en la tercera ronda (2018). Los promedios de ALC son un promedio simple de los resultados de los cuatro países.

\section{Con la digitalización, habrá empleos que desaparecerán, otros cambiarán y otros se crearán}

A pesar de la ansiedad generalizada ante la potencial destrucción de empleo a causa del cambio tecnológico y la globalización, parece poco probable que se produzca una fuerte 
caída de las cifras de empleo. Hay tareas que aparecen, desaparecen y evolucionan, lo cual genera cambios estructurales en el mercado laboral y en la demanda de competencias. Sin embargo, el empleo crece y nada parece indicar que no habrá trabajo en un futuro próximo (OCDE, 2019a).

Se han desarrollado dos metodologías para estimar el impacto de la digitalización en los niveles de empleo. En primer lugar, el análisis ocupacional calcula la proporción de trabajadores en ocupaciones que podrían ser realizadas por computadoras, algoritmos y robots. Frey y Osborne (2017) clasificaron una muestra de ocupaciones estadounidenses como automatizables o no automatizables. A partir de un conjunto estandarizado de características para cada ocupación, utilizaron un algoritmo de aprendizaje automatizado para generar una "probabilidad de computarización" de ocupaciones, lo cual genera una predicción única por ocupación. Los resultados, por tanto, asumen que todos los trabajadores de una ocupación se enfrentan al mismo riesgo de reemplazo por la digitalización.

En segunda instancia, el análisis de tareas tiene en cuenta la considerable variación en la composición de las tareas dentro de ocupaciones con el mismo título. En lugar de asumir el reemplazo de ocupaciones enteras por computadoras, algoritmos y robots, se considera el reemplazo de determinadas tareas dentro de las ocupaciones. Arntz, Gregory y Zierahn (2016), y Nedelkoska y Quintini (2018) utilizaron los mismos resultados que Frey y Osborne (2017) para calcular el efecto de la automatización en cada tarea y estimar la probabilidad de automatización de cada ocupación en función de la proporción de tareas repetitivas y rutinarias que podrían ser reemplazadas. Las estimaciones tienen en cuenta que la misma ocupación puede ser más o menos susceptible de automatización en diferentes puestos de trabajo. La metodología aplicada depende de la disponibilidad de información y el análisis de tareas requiere un nivel de detalle mucho más alto.

En los países de América Latina y el Caribe, en torno al 25\% de los puestos de trabajo corren un alto riesgo de automatización, según las estimaciones del análisis de tareas de la OCDE para Chile, Ecuador, México y Perú. Las estimaciones se sitúan desde el $21 \%$ en Chile hasta el $28 \%$ en Perú. Además, el $35 \%$ de los empleos en esos países puede sufrir cambios sustanciales en las tareas realizadas y en la forma en que se llevan a cabo (OCDE, 2019a). Un puesto de trabajo tiene un alto riesgo de automatización si al menos el $70 \%$ de sus tareas son susceptibles de ser automatizadas y correrá el riesgo de sufrir cambios significativos si entre el $50 \%$ y el $70 \%$ de sus tareas pueden automatizarse (Nedelkoska y Quintini, 2018). En comparación, para los países de la OCDE, se estima que la automatización podría sustituir al 14\% de los empleos. La potencial automatización de los trabajos no significa que las máquinas vayan a sustituir a los trabajadores en un futuro próximo; la automatización puede no siempre ser eficaz en función de los costos o puede no ser deseable; puede plantear problemas jurídicos y éticos, y verse afectada por preferencias de los trabajadores y decisiones de política (OCDE, 2019a).

Las estimaciones para los países de la OCDE (incluidos Chile y México) y otros socios, como Ecuador y Perú, se calcularon utilizando el análisis de tareas y los datos de la Evaluación de Competencias de Adultos sobre una lista exhaustiva de tareas que las personas realizan en sus ocupaciones (Nedelkoska y Quintini, 2018) (Gráfico 3.7). Mediante el uso de datos individuales, las estimaciones dan cuenta de la variación de las tareas realizadas dentro de una misma ocupación. Las tareas descritas por los encuestados pueden ser un mejor indicador de la realidad que las descripciones profesionales. 
Gráfico 3.7. Porcentaje de trabajadores según el riesgo de automatización (análisis de tareas), países seleccionados de la OCDE y de América Latina y el Caribe, 2018 o último año disponible

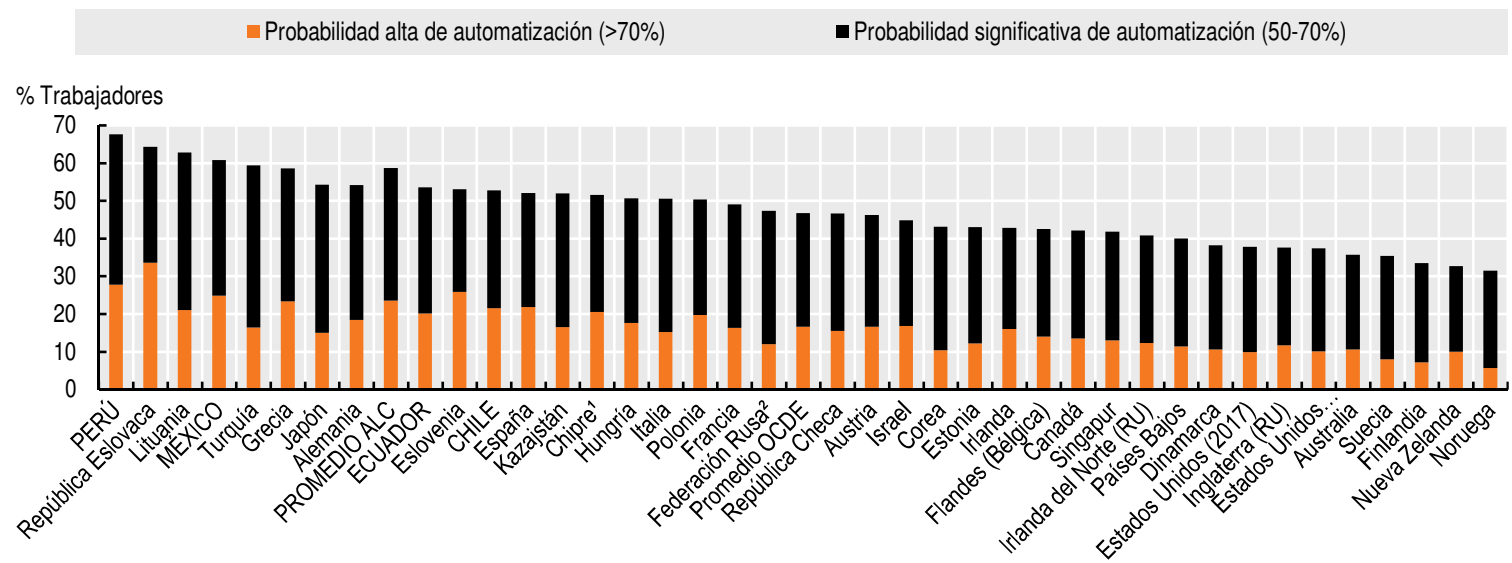

Notas: Las ocupaciones corren un alto riesgo de automatización si su probabilidad de ser automatizadas es de al menos el $70 \%$. Correrán el riesgo de sufrir cambios significativos si entre el 50\% y el 70\% de sus tareas pueden automatizarse. Estas estimaciones se basan en datos de Nedelkoska y Quintini (2018). Los valores para los países de la OCDE son promedios simples.

1. Nota para Turquía: La información del presente documento en relación con Chipre se refiere a la parte sur de la Isla. No existe una sola autoridad que represente en conjunto a las comunidades turcochipriota y grecochipriota de la Isla. Turquía reconoce a la República Turca del Norte de Chipre (RTNC). Mientras no haya una solución duradera y equitativa en el marco de las Naciones Unidas, Turquía mantendrá su postura frente al "tema de Chipre".

Nota elaborada por todos los Estados miembros de la Unión Europea que también lo son de la OCDE, y por la Unión Europea: Todos los miembros de las Naciones Unidas, con excepción de Turquía, reconocen a la República de Chipre. La información contenida en el presente documento se refiere a la zona sobre la cual el Gobierno de la República de Chipre tiene control efectivo

2. La muestra de la Federación Rusa no incluye la población de la zona de Moscú. Puede encontrarse información detallada sobre los datos de la Federación Rusa en el Informe técnico de la Evaluación de las Competencias de los Adultos (Technical Report of the Survey of Adult Skills, Third Edition) (OCDE, 2019d).

Fuente: OCDE (2019c), Skills Matter: Additional Results from the Survey of Adult Skills, OECD Skills Studies; OCDE/PIAAC (2018), Evaluación Internacional de las Competencias de los Adultos (PIAAC) (base de datos), www.oecd.org/skills/piaac/data/.

StatLink inाs] https://doi.org/10.1787/888934202142

Las estimaciones del análisis ocupacional de la CEPAL indican que el $16 \%$ de los empleos en América Latina y el Caribe presentan un alto riesgo de automatización, desde el $5 \%$ en Bolivia hasta el 29\% en Uruguay (CEPAL, 2019) (Gráfico 3.8). Otro 16\% de los empleos puede experimentar cambios sustanciales (ocupaciones con riesgo intermedio de automatización). Estas estimaciones se calcularon utilizando una metodología de análisis ocupacional ajustada siguiendo a Weller, Gontero y Campbell (2019) y datos de encuestas de población activa. La metodología de análisis ocupacional de Frey y Osborne (2017) se basa en el mercado laboral estadounidense. Los mercados laborales de ALC difieren significativamente en al menos dos aspectos: segmentación del mercado y rezago en la implementación de tecnología (Katz, 2017, 2018).

En promedio, los resultados indican una probabilidad similar de sustitución tecnológica de ocupaciones típicamente ocupadas por hombres y mujeres, con algunas variaciones entre países (Bustelo et al., 2020; CEPAL, 2019). 
Gráfico 3.8. Porcentaje de empleos con alto riesgo de automatización (análisis ocupacional), países seleccionados de América Latina, 2018

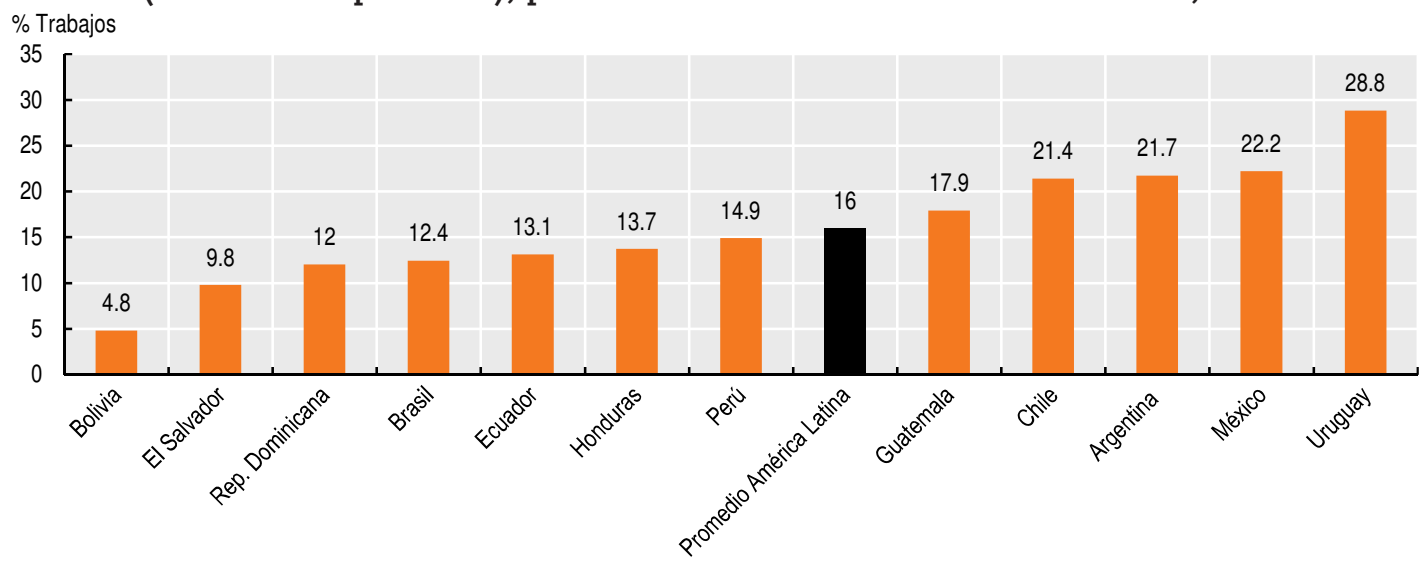

Fuente: Weller, Gontero y Campbell (2019), "Cambio tecnológico y empleo: Una perspectiva latinoamericana. Riesgos de la sustitución tecnológica del trabajo humano y desafíos de la generación de nuevos puestos de trabajo”, www.cepal.org/es/ publicaciones/44637-cambio-tecnologico-empleo-perspectiva-latinoamericana-riesgos-la-sustitucion.

StatLink तiाs https://doi.org/10.1787/888934202161

\section{La digitalización está cambiando los trabajos, las tareas y la demanda de habilidades}

El cambio en las profesiones hace que evolucionen, a su vez, las habilidades demandadas (Amaral et al., 2018). Los datos de contrataciones recientes de LinkedIn para Argentina, Australia, Brasil, Chile, Estados Unidos, Francia, India, México, Reino Unido y Sudáfrica muestran que las habilidades digitales y tecnológicas avanzadas se encuentran entre las de más rápido crecimiento: las categorías de habilidades relacionadas con la tecnología se sitúan entre las dos de mayor crecimiento en todos los países, excepto en Brasil. También presentan alta demanda las habilidades relacionadas con el almacenamiento de datos, el ciclo de vida del desarrollo de programas informáticos, la gestión de redes sociales, la interacción de las personas con las computadoras, y el desarrollo de aplicaciones móviles. El cambio en las profesiones también parece estar impulsando un aumento de categorías como el marketing, la publicidad, el diseño gráfico y el marketing digital, que se superpone a la categoría de la tecnología.

En cambio, la demanda de habilidades para la gestión de proyectos, la dirección de empresas, la gestión de recursos humanos y la gestión de cuentas está disminuyendo. Las tareas de apoyo administrativo y de compras se encuentran entre las categorías que más demanda están perdiendo. Dado que se trata de habilidades centradas en las personas, aunque los empleos que las requieren puedan ir a la baja, su valor puede aumentar si se combinan con aptitudes técnicas (Amaral et al., 2018).

Los adultos que trabajan en entornos de uso intensivo de tecnología digital hacen tareas distintas de los que trabajan en entornos no intensivos en tecnología digital. Para esta sección, los trabajadores del mismo grupo de ocupaciones (CIUO-08, 1 dígito [Clasificación Internacional Uniforme de Ocupaciones 2008]) se dividen según la exposición de sus empleos al entorno digital. Los trabajadores con empleos intensivos en tecnología digital se definen como aquellos que obtienen una puntuación superior a la mediana en el índice de uso de habilidades TIC en el trabajo. ${ }^{2}$ Los trabajadores con empleos no intensivos en tecnología digital se definen como aquellos que presentan cifras inferiores a la mediana de todos los países de América Latina.

Las personas con trabajos intensivos en tecnología digital movilizan habilidades que van más allá de las requeridas para el uso de dispositivos digitales y TIC. En particular, requieren un mayor uso de las habilidades de comprensión lectora y expresión escrita (la mayoría de las ocupaciones); y habilidades matemáticas (especialmente para operadores de plantas y máquinas y ensambladores, artesanos y oficios afines, legisladores y administradores) (Gráfico 3.9). 


\section{Gráfico 3.9. Diferencia en el uso de habilidades entre empleos intensivos y no intensivos en tecnología digital en América Latina}

Efecto de una variable dicotómica de trabajar en una ocupación intensiva en tecnologías digitales sobre índices estandarizados de uso de habilidades, controlando por años de educación (las barras se muestran

cuando la diferencia es significativa al $5 \%$ )
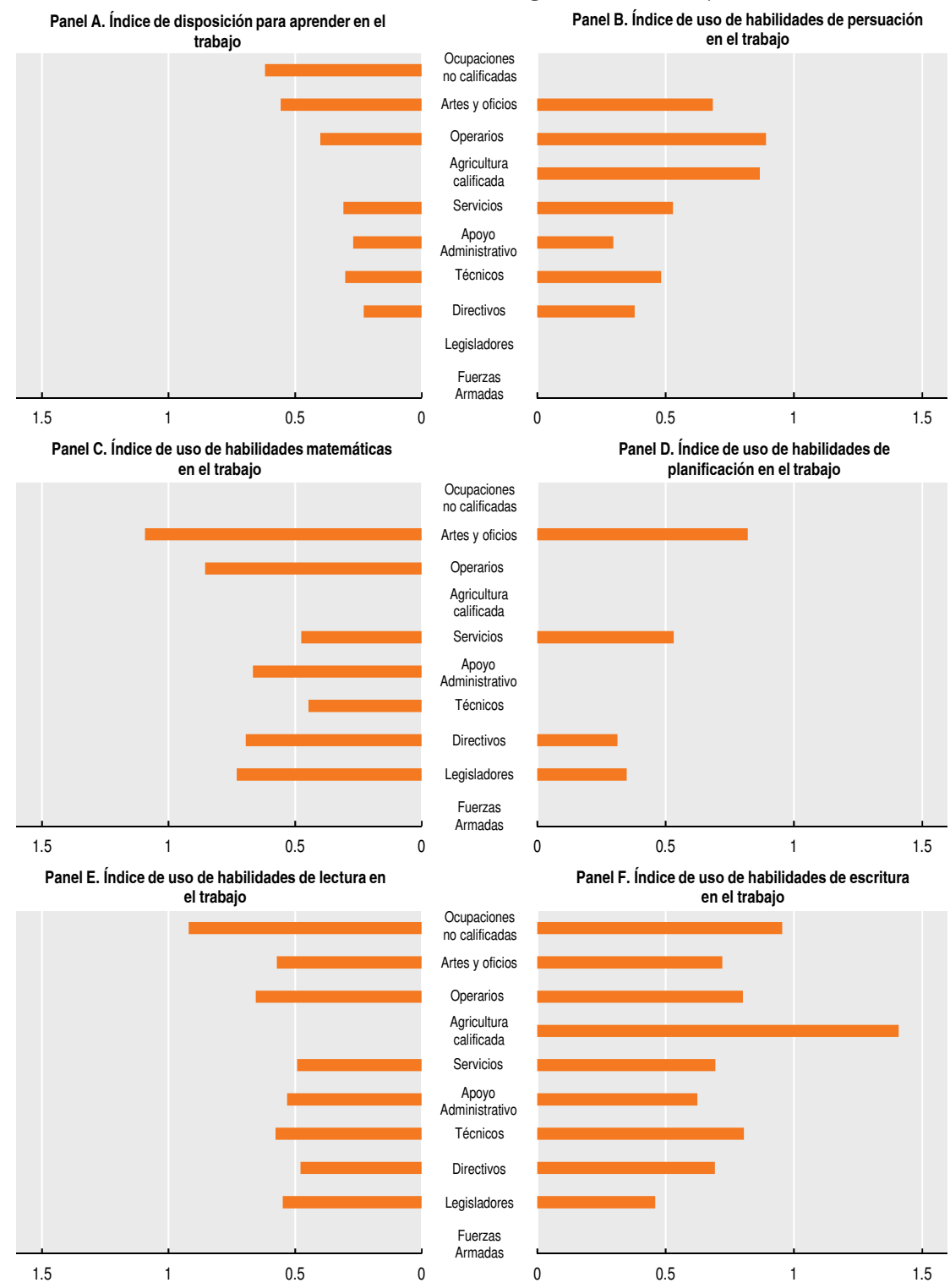

Notas: Las cifras muestran los coeficientes estimados de trabajar en una ocupación intensiva en tecnologías digitales en diferentes índices de uso de habilidades derivados de las rondas 2 y 3 de la Evaluación Internacional de las Competencias de los Adultos (PIAAC) (los coeficientes solo se muestran cuando son significativos al 5\%). Cuanto más alto sea el valor, mayor será la diferencia en el uso de las habilidades dentro de la misma ocupación. Tener una ocupación con uso intensivo de tecnología digital se mide por una variable dicotómica igual a 1 si el índice de uso de habilidades TIC en el trabajo es mayor o igual a la mediana del índice en los cuatro países de América Latina y el Caribe participantes: Chile, Ecuador, México y Perú. La variable dependiente corresponde a los valores estandarizados de los índices de uso de las habilidades utilizando la mediana y la desviación estándar para el conjunto de los países de ALC participantes. En este sentido, los coeficientes miden el cambio, en desviaciones estándar de la media, en los índices de uso de habilidades en el trabajo para una persona en una ocupación intensiva en tecnologías digitales en comparación con una persona en una ocupación no intensiva en tecnologías digitales. Se estiman regresiones separadas para cada ocupación según la clasificación CIUO-08, 1 dígito. Las regresiones se calculan mediante la metodología de mínimos cuadrados ordinarios estándar y se controlan por años de educación y efectos fijos por país.

Fuente: Elaboración propia a partir de OCDE/PIAAC (2018), Evaluación Internacional de las Competencias de los Adultos (base de datos), www.oecd.org/skills/piaac/data/.

StatLink ailst https://doi.org/10.1787/888934202180 
Para minimizar riesgos y maximizar los beneficios de los cambios en el mercado laboral, es esencial contar con políticas eficaces de formación permanente en competencias básicas y habilidades técnicas para estudiantes y trabajadores. Si se identifica y se comprende cuáles son las ocupaciones y las necesidades de habilidades en auge y en declive de los países, se contribuirá a fundamentar las decisiones de política pública relativas a la capacitación, la orientación profesional y la priorización de los recursos (Amaral et al., 2018). En un contexto cambiante de la demanda por habilidades, las habilidades básicas y la capacidad de aprender y de actualizarse son fundamentales para las buenas políticas públicas en materia de adquisición de habilidades. El aprendizaje de adultos puede contribuir a que no se pierdan habilidades y a que los trabajadores no se queden atrás, así como a facilitar la transición de empleos y sectores que van perdiendo peso hacia otros en expansión. Los sistemas de formación profesional también deben adaptarse a la rápida evolución de la demanda de habilidades (OCDE, 2020a).

Los trabajadores de entornos desfavorecidos suelen enfrentarse a múltiples barreras de capacitación. Los trabajadores poco cualificados, los trabajadores de ocupaciones con alto riesgo de automatización y los trabajadores que han perdido su empleo suelen ser reacios a formarse o incapaces de identificar actividades de aprendizaje pertinentes. Aun cuando están informados y motivados, a veces se enfrentan a barreras como la falta de tiempo, dinero o habilidades para iniciar una formación específica. Por otro lado, los empleadores suelen invertir en la formación de los trabajadores más cualificados, porque prevén un mayor retorno de la inversión.

\section{En América Latina, pocos trabajadores usan o saben usar herramientas digitales en el trabajo}

En los entornos en que se usa intensivamente la tecnología, aplicar las habilidades digitales en el trabajo es tan importante para los resultados económicos individuales y agregados como el uso de las habilidades generales. Los países seguirán enfrentándose a importantes cambios en el mercado de trabajo que tendrán repercusiones en la demanda de habilidades. Los dispositivos digitales, la conectividad, los programas informáticos y los datos están cambiando profundamente las tareas de los puestos de trabajo, así como la organización de la producción y de las empresas.

Las habilidades digitales y las habilidades de solución de problemas en entornos intensivos en tecnologías son cada vez más importantes para que las personas participen en los mercados laborales, la educación y la vida social. El Programa para la Evaluación Internacional de las Competencias de los Adultos (PIAAC) evalúa las habilidades informáticas básicas de los trabajadores, así como sus competencias en la resolución de problemas en entornos con fuerte presencia tecnológica, tanto en el trabajo como fuera de él. Cabe señalar que este programa no tiene en cuenta a los trabajadores del mercado informal. Dada la fuerte presencia del trabajo informal en los países de América Latina y el Caribe, algunas de las cifras de esta sección basadas en los datos del PIAAC podrían estar sesgados si los trabajadores del mercado informal utilizan las TIC de manera diferente a los trabajadores formales.

Las habilidades en la resolución de problemas en entornos con fuerte presencia tecnológica, como la utilización de tecnología digital, las herramientas de comunicación y las redes para adquirir y evaluar información, comunicarse con terceras personas y hacer tareas prácticas en un nivel de competencia de 1 a 5 (PIAAC Expert Group in Problem Solving in Technology-Rich Environments, 2009). Si el dominio se sitúa por debajo del nivel 1 significa que solo se usan aplicaciones conocidas para resolver problemas que implican pocos pasos y criterios explícitos, como la clasificación de correos electrónicos en carpetas creadas previamente (Gráfico 3.10). 


\section{Gráfico 3.10. Dominio en la resolución de problemas en entornos con fuerte presencia tecnológica, países seleccionados de la OCDE y de América Latina}

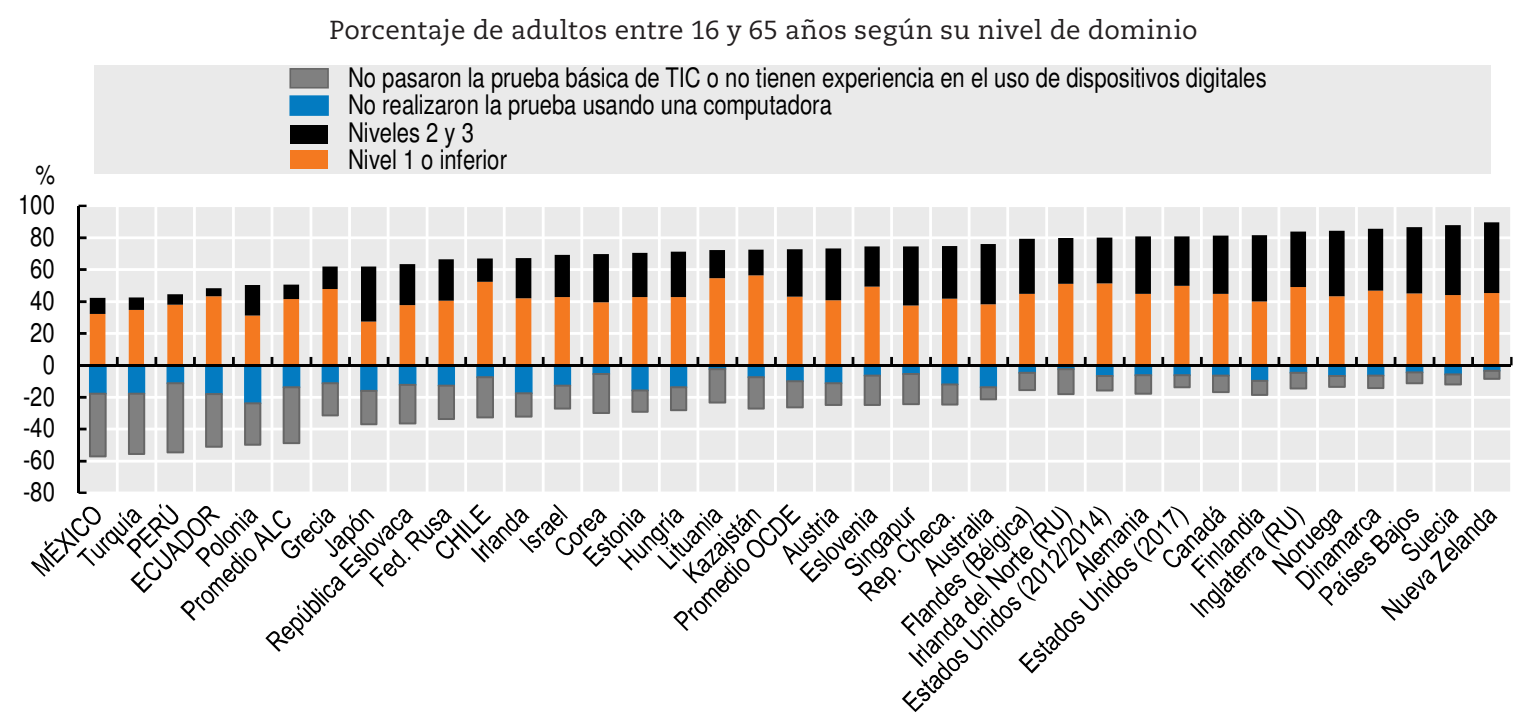

Notas: La categoría "faltante" comprende a los adultos que no pueden proporcionar suficiente información de antecedentes para valorar su competencia debido a barreras lingüísticas o a un problema de aprendizaje o psicológico (por ejemplo, no han respondido por un problema de comprensión lectora) y los que no pueden completar la evaluación debido a problemas técnicos. Los países y las economías se clasificaron en orden descendente según los porcentajes combinados de adultos que se situaron en los niveles 2 y 3.

Fuente: OCDE (2015a); OCDE/PIAAC (2018), Evaluación Internacional de las Competencias de los Adultos (base de datos), www.oecd. org/skills/piaac/data/.

StatLink तiाIs https://doi.org/10.1787/888934202199

Una gran parte de los adultos latinoamericanos tienen muy poca experiencia informática o no tienen ninguna, desde el $43.6 \%$ en Perú hasta el $25.2 \%$ en Chile. La proporción de adultos sin conocimientos básicos de TIC o experiencia informática refleja el nivel de desarrollo económico y de penetración de las TIC en estos países (OCDE, 2019c). Aparte de los adultos que no cumplían los requisitos mínimos para realizar la prueba de resolución de problemas, una gran proporción de adultos optó por no participar en la prueba informática, a pesar de que tenían experiencia en el uso de computadoras (el $7.5 \%$ en Chile, el $10.0 \%$ en la OCDE, el $11.1 \%$ en Perú, el $17.8 \%$ en México y el $18.1 \%$ en Ecuador).

Pocos adultos en América Latina y el Caribe tienen conocimientos intermedios y altos del uso de computadoras y habilidades de resolución de problemas en entornos con fuerte presencia tecnológica. La proporción de adultos en los niveles 2 y 3 es muy inferior al promedio de la OCDE (29.7\%): 5.2\% en Ecuador, 6.6\% en Perú, $10.2 \%$ en México y $14.6 \%$ en Chile.

Un tercio de los trabajadores de América Latina y el Caribe utilizan computadoras, smartphones $\mathrm{u}$ otras herramientas TIC en el trabajo una vez por semana o más, en comparación con más de la mitad de los trabajadores europeos (OCDE, 2018b). Las habilidades utilizadas en el trabajo son las que se observan en el puesto de trabajo dentro de un determinado campo de habilidades (OCDE, 2016b). Alrededor del 30\% de los que hicieron la prueba informática no utilizaban habilidades de resolución de problemas para solucionar problemas complejos en el trabajo (OCDE, 2019g). 
El uso de computadoras, Internet, correo electrónico y programas informáticos presenta una gran variación. Más del $25 \%$ de los trabajadores de América Latina y el Caribe utilizaban regularmente las TIC para tareas sencillas, como el correo electrónico o la búsqueda de información relacionada con el trabajo. Menos del 10\% utilizaba las TIC para tareas más avanzadas, como la programación y las comunicaciones en tiempo real (Gráfico 3.11).

\section{Gráfico 3.11. Uso de las TIC en el trabajo por actividad, países seleccionados de América Latina}

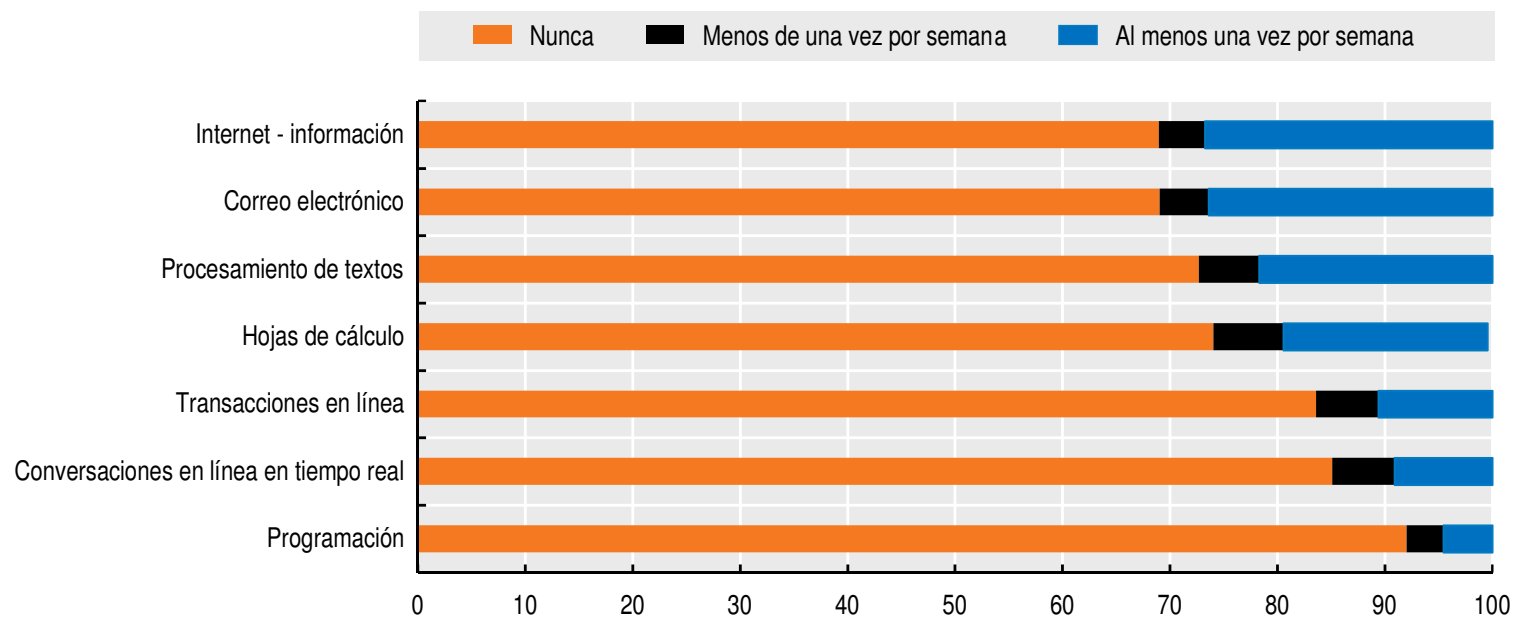

Nota: "Nunca" incluye a los trabajadores que nunca han usado una computadora o que no usan las TIC en el trabajo. Chile participó en la segunda ronda de la Evaluación Internacional de las Competencias de los Adultos (PIAAC), y el resto de los países de América Latina y el Caribe (México, Perú y Ecuador), en la tercera ronda.

Fuente: Elaboración propia a partir de OCDE/PIAAC (2018), Evaluación Internacional de Competencias de Adultos (base de datos), www.oecd.org/skills/piaac/data/.

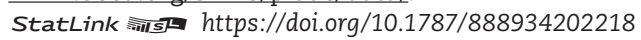

Los factores socioeconómicos son determinantes para el uso de las habilidades de TIC en América Latina. Una gran parte de los adultos sin la secundaria superior carecían de la competencia básica necesaria para la prueba de resolución de problemas de la Evaluación Internacional de las Competencias de los Adultos; por ejemplo, no sabían usar un mouse (OCDE, 2019c). En promedio, el $42 \%$ de los adultos con bajo nivel educativo en los países de la OCDE no tenían experiencia informática o no superaron la prueba básica de TIC, en comparación con el $66 \%$ en Chile, el $69 \%$ en México y Ecuador y el $86 \%$ en Perú. Menos del $2 \%$ de los adultos de estos cuatro países latinoamericanos obtuvieron una puntuación de nivel 2 o 3 en el uso de las TIC, en comparación con el 7\% de los países de la OCDE. Alrededor del $20 \%$ de los latinoamericanos con educación superior obtuvieron una puntuación de nivel 2 o superior, en promedio: 30\% en Chile, $26 \%$ en México, $14 \%$ en Perú y 12\% en Ecuador (Gráfico 3.12). Mejorar el acceso y la calidad de la educación infantil, primaria y secundaria es fundamental para fortalecer la competencia digital de la población activa de América Latina y el Caribe, así como la formación permanente y la superación de los obstáculos a la formación, dado que muchos abandonan los estudios sin haber adquirido las habilidades necesarias. 


\section{Gráfico 3.12. Dominio en la resolución de problemas por nivel formativo, países seleccionados de América Latina}

Porcentaje de adultos con bajo y alto nivel educativo que obtienen una puntuación de nivel 2 o 3 en la resolución de problemas en entornos con fuerte presencia tecnológica o que no tienen experiencia informática (adultos entre 25 y 65 años)

No pasan la prueba básica de TIC 0
no tienen experiencia informática Nivel 2

Panel A. Menos de educación secundaria superior
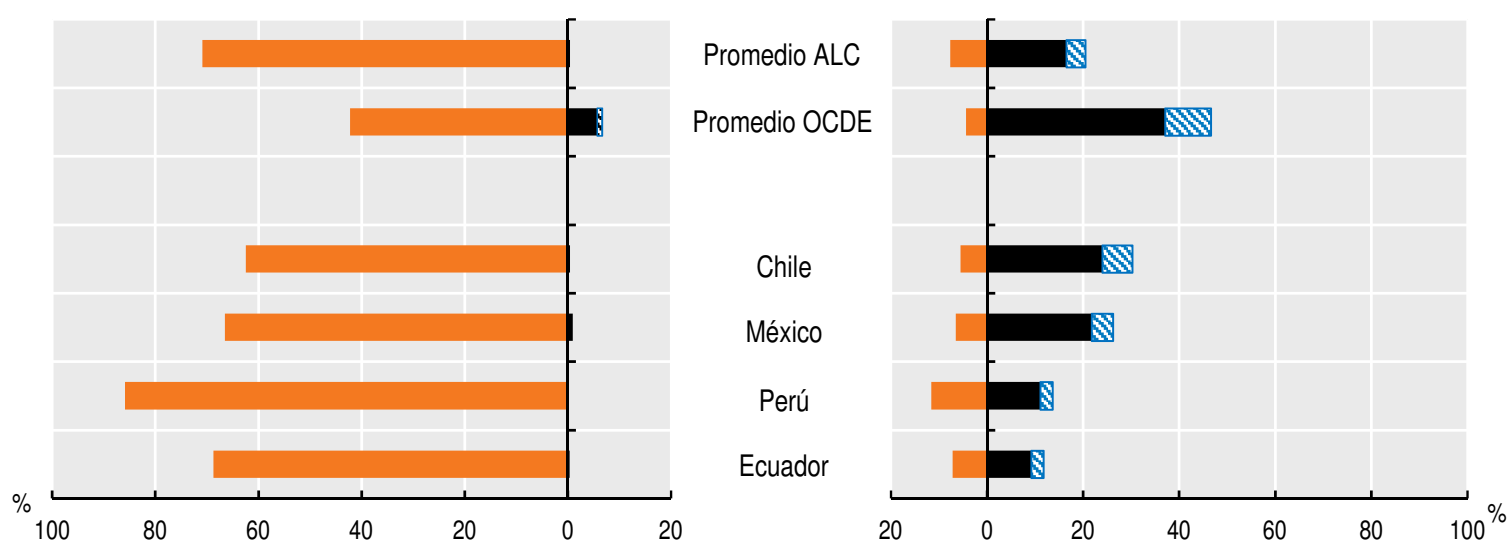

Notas: Los adultos se dividen en una de las siguientes categorías, excluyentes entre sí: no hicieron la prueba informática; no tenían experiencia informática; no pasaron la prueba básica de TIC; por debajo del nivel 1, en el nivel 1, en el nivel 2 y en el nivel 3 (escala de resolución de problemas en entornos con fuerte presencia tecnológica). Para acceder a los resultados detallados de cada categoría, ver OCDE (2019c). Los países y las economías se clasifican en orden descendente según los porcentajes combinados de adultos con educación terciaria con una puntuación de nivel 2 o 3. Chile participó en la segunda ronda de la Evaluación Internacional de Competencias de Adultos (PIAAC), y el resto de los países de América Latina y el Caribe (México, Perú y Ecuador), en la tercera ronda.

Fuente: Elaboración propia a partir de OCDE/PIAAC (2018), Evaluación Internacional de Competencias de Adultos (base de datos), www.oecd.org/skills/piaac/data/.

StatLink त्ञातs https://doi.org/10.1787/888934202237

La brecha de género no es tan amplia en este caso. En todos los países de la OCDE, los hombres tenían una pequeña ventaja en los niveles 2 o 3: el 32\% de los hombres frente al $28 \%$ de las mujeres. Las brechas eran similares o ligeramente menores en los países de América Latina y el Caribe. Sin embargo, en la parte inferior de la distribución de competencias, en todos los países, la proporción de mujeres que no tenían experiencia en informática o que no superaron la prueba básica de TIC era mayor que la de hombres: el $26 \%$ frente al 24\% en Chile, el 35\% frente al 31\% en Ecuador, el $41 \%$ frente al 38\% en México y el $47 \%$ frente al 41\% en Perú.

El dominio de estas habilidades explica apenas una pequeña parte del uso de competencias en el trabajo en América Latina y el Caribe (del 1\% al 6\%), y afecta principalmente al sector, la profesión, el tamaño de las empresas y las prácticas laborales de alto rendimiento (Gráfico 3.13). Las habilidades que utilizan los trabajadores dependen tanto de cómo despliegan sus conocimientos en el trabajo - que a su vez puede depender de los incentivos y la propia iniciativa- como de las competencias requeridas para el puesto. Algunos trabajadores pueden tener más habilidades de las necesarias y no aprovecharlas; otros pueden no ser suficientemente competentes, pero mantienen el puesto, al menos a corto plazo, a pesar de sus resultados inadecuados (OCDE, 2016b). Así pues, es probable que la relación entre el dominio de las competencias y su uso efectivo en el trabajo dependa de cómo se distribuyen los trabajadores en ocupaciones, sectores y empresas (OCDE, 2016c). 


\section{Gráfico 3.13. Contribución del dominio de competencias y otros factores a la variación del uso de las competencias en el trabajo, países seleccionados de América Latina y el promedio de la OCDE}

Porcentaje de la variación del uso competencias en el trabajo explicada por cada factor

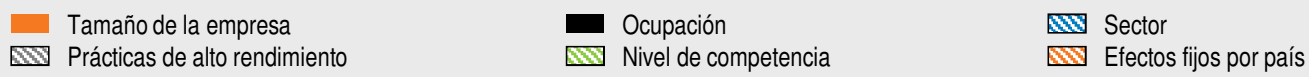

Panel A. Habilidades TIC

Panel B. Habilidades de resolución de problemas
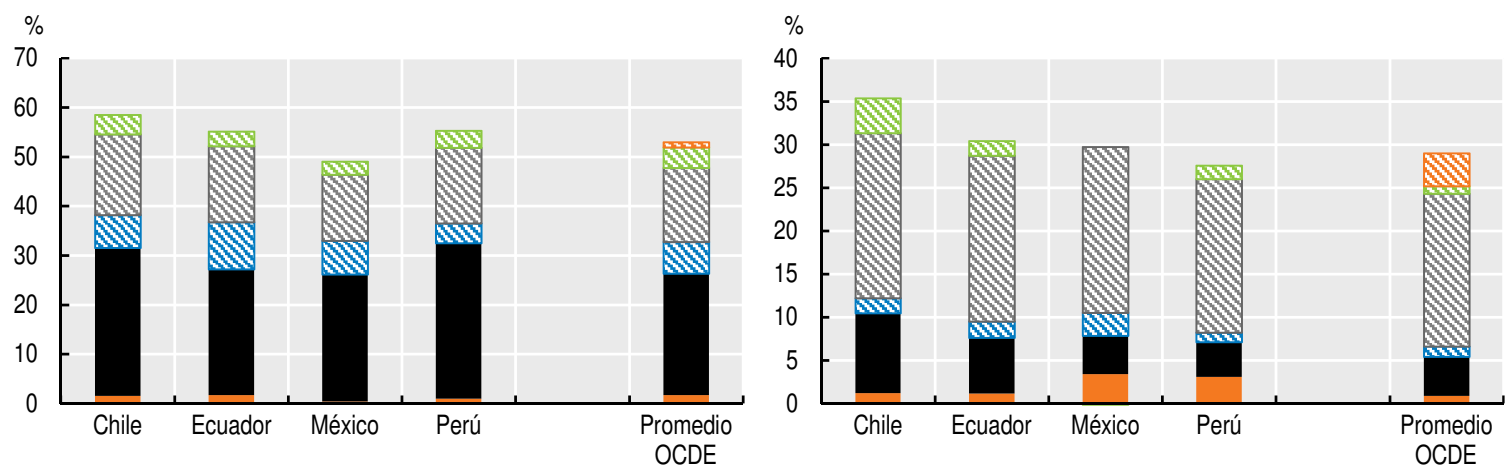

Notas: El promedio de la OCDE corresponde a la regresión de los países agrupados de la OCDE, incluidos los efectos fijos por país. Las competencias de comprensión lectora, expresión escrita, capacidad de cálculo y TIC van de 0 a 1. El índice de competencias de resolución de problemas en el trabajo se calcula promediando la frecuencia con la que los trabajadores resuelven problemas simples y complejos, y oscila entre 0 y 4 . Las prácticas de alto rendimiento incluyen las siguientes variables: elegir y cambiar la secuencia de tareas, el ritmo de trabajo y cómo hacer el trabajo; organizar el tiempo y planificar actividades; cooperar con otras personas; instruir, enseñar o formar a otras personas; compartir información con los compañeros de trabajo; recibir primas, asistir a cursos de formación y tener un horario de trabajo flexible. Para la resolución de problemas, nivel de competencia = habilidad en la resolución de problemas en entornos con fuerte presencia tecnológica; por consiguiente, el análisis excluye a los países que no evalúan este ámbito de la competencia. Chile participó en la segunda ronda de la Evaluación Internacional de Competencias de Adultos (PIAAC), y el resto de los países de América Latina y el Caribe (México, Perú y Ecuador), en la tercera ronda.

Fuente: OCDE (2019c), Skills Matter: Additional Results from the Survey of Adult Skills, https://doi.org/10.1787/1f029d8f-en.

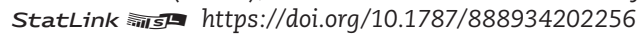

Las características de las ocupaciones y las empresas, medidas por la aplicación de las prácticas de alto rendimiento, son importantes para predecir el uso de las competencias digitales y de resolución de problemas en el trabajo en América Latina y el Caribe. Las ocupaciones explican entre el 25\% (Ecuador) y el 31\% (Perú) de la variación del uso de las habilidades TIC en el trabajo. Las prácticas de alto rendimiento explican entre el $17 \%$ (Perú) y el 19\% (Ecuador) de la variación en el uso de las competencias de resolución de problemas en entornos con fuerte presencia tecnológica.

El uso de las habilidades digitales varía mucho según la ocupación. Los directivos, profesionales, técnicos y el personal administrativo utilizan con relativa frecuencia la competencia en TIC. En cambio, los trabajadores del ámbito de servicios y ventas, agricultura, silvicultura y pesca, operarios y artesanos de artes mecánicas y de otros oficios, operadores de instalaciones y máquinas y montadores, y los trabajos no cualificados la utilizan mucho menos (OCDE, 2016b).

\section{Las políticas públicas pueden fomentar la inclusión en los mercados laborales de América Latina y el Caribe}

En la mayoría de los países de América Latina y el Caribe los mercados laborales están parcialmente polarizados. La proporción del empleo y los salarios ha aumentado sustancialmente para los trabajos de alta cualificación y para algunos de baja cualificación, especialmente en el sector de los servicios, y ha disminuido para los trabajos de cualificación intermedia (Azuara Herrera et al., 2019). El trabajo manual 
en ocupaciones muy automatizables, como es el caso de los operarios de maquinaria y reparación de equipos, ha disminuido considerablemente, y los aumentos salariales en otras ocupaciones automatizables han disminuido. Sin embargo, estos cambios son menores que los observados en otras regiones y en la OCDE.

El mercado laboral más cualificado no ha absorbido el volumen de profesionales con alta cualificación que se incorporaron a la fuerza de trabajo entre 2000 y 2015. Esto contrasta con los países más desarrollados, donde la incorporación de nuevas tecnologías ha impulsado la demanda y los salarios de los profesionales más formados. Además, en contraste con la OCDE, las profesiones relacionadas con el conocimiento han experimentado un menor incremento salarial que las profesiones manuales (Azuara Herrera et al., 2019).

El personal de limpieza y los trabajos de especialistas financieros fueron los que más crecieron en América Latina y el Caribe entre 2000 y 2015. Los empleos de vendedor, especialista en informática y matemáticas, preparador de alimentos, técnico sanitario, abogado, piloto y controlador de tráfico aéreo, trabajador de la construcción y personal administrativo también crecieron, según las encuestas de hogares de Bolivia, Brasil, Chile, Costa Rica, República Dominicana, Ecuador, Jamaica, México y Paraguay. Los trabajos de directivo, operario de maquinaria, cuidador, técnico de mantenimiento y reparación de maquinaria, conductor, técnico en ciencias físicas, especialista en educación, técnico en biología, artista, atleta y guardia de seguridad fueron los que más disminuyeron durante el período (Azuara Herrera et al., 2019).

La digitalización y el rápido avance de las TIC han acelerado las dinámicas de "el ganador se lo lleva todo", lo que podría contribuir a aumentar la desigualdad salarial en ALC. Las TIC han facilitado que vendedores y compradores se encuentren, a pesar de la distancia geográfica. También han facilitado la aparición de mercados mundiales en varios sectores de servicios tradicionales, como la venta al por menor y el transporte, así como en los servicios de TIC, cuyo costo marginal de ampliación es prácticamente inexistente (OCDE, 2018c). En algunos de estos sectores, especialmente en los servicios de TIC, la venta al por menor y el transporte, las externalidades de red que favorecen a un actor dominante han cobrado importancia. En consonancia con la idea de que "el ganador se lo lleva casi todo", los datos sugieren que la integración comercial y la digitalización han contribuido a las diferencias salariales entre las empresas que tienen más éxito y el resto (Berlingieri, Blanchenay y Criscuolo, 2017).

La digitalización plantea ciertos temores sobre la calidad del trabajo. Si bien la diversidad de los contratos laborales puede aportar flexibilidad a muchos trabajadores y empresas, persisten las dificultades para garantizar la calidad de los contratos que se salen de lo estándar. Las disparidades del mercado laboral podrían aumentar si las medidas de política pública no hacen una distribución más equitativa de los costos del ajuste estructural en el mundo del trabajo (OCDE, 2019a).

Muchas economías de la OCDE y economías emergentes han experimentado un crecimiento de las formas de empleo que se salen de lo estándar, lo que ha planteado diversos problemas. Las nuevas formas de trabajo son el resultado de los cambios en las preferencias de los trabajadores, la innovación en los modelos empresariales y en la organización del trabajo, los avances tecnológicos y las opciones políticas. Un ejemplo es la economía bajo demanda (gig economy), en la que los trabajadores prestan servicios a través de plataformas en línea, pero otras formas de trabajo que se salen de lo habitual - como los contratos de guardia (on-call) o de cero horas (zero-hours), por prestación de servicios y el trabajo por cuenta propia- también han ganado terreno en muchos países. Estas modalidades de trabajo más flexibles suelen surgir como respuesta a ciertas necesidades, tanto de los empleadores como de los trabajadores, pero a estos les 
pueden ocasionar una pérdida de bienestar, a falta de políticas que garanticen derechos y protecciones adecuados. Esta es una preocupación importante en los países en que proliferan las formas de trabajo no estándar y en que las empresas dependen cada vez más de redes de contratistas y subcontratistas para desempeñar numerosas funciones, en lugar de contar con una fuerza de trabajo permanente. Esto da lugar al concepto de empresas fisuradas (fissured workplace) (OCDE, 2019a).

En los países con una gran presencia del trabajo informal, la economía por demanda través de plataformas podría ofrecer una vía hacia la regularización. Podría reducir los costos y mejorar el seguimiento de las actividades económicas gracias a que queda constancia de las transacciones digitales. Sin embargo, para sacar provecho de la situación, las economías emergentes tendrán que aplicar los mecanismos adecuados en materia fiscal y de protección social.

A medida que se producen estas transformaciones, surgen desafíos para gestionar la transición de los trabajadores de los sectores y las regiones en declive hacia nuevas oportunidades de empleo, y avanzar hacia la protección social universal. El mensaje clave de las Perspectivas de empleo de la OCDE 2019 es que el futuro del trabajo dependerá en gran medida de las decisiones de política pública (OCDE, 2019a). Con las políticas correctas y las instituciones adecuadas, se podrán aprovechar las oportunidades que brindarán la digitalización, la globalización y la longevidad, de manera que se logren mitigar los riesgos (OCDE, 2019a).

Las políticas públicas para construir un mundo laboral más gratificante e inclusivo requerirán recursos financieros adecuados, en particular para fortalecer el aprendizaje de los adultos y la protección social. Dadas las limitaciones de las finanzas públicas, sin embargo, habrá que dar con una nueva forma de obtener los recursos necesarios. Al mismo tiempo, ciertas opciones de política pública apenas implican un gasto público y pueden aumentar los ingresos fiscales.

\section{La digitalización y las escuelas: Equidad y calidad en la educación}

La digitalización aporta ventajas y oportunidades a quienes tienen las habilidades necesarias, pero también puede ampliar las desigualdades y la vulnerabilidad de quienes no están bien preparados. La adquisición de habilidades, la distribución de conocimientos y las oportunidades de formación son cruciales para mejorar el bienestar de los ciudadanos en la era digital. Para promover una recuperación inclusiva, es fundamental que no aumente la brecha de educación durante la pandemia. Por tanto, aumentar la competencia digital en los centros educativos es algo crucial, insistiendo en el fortalecimiento de la competencia digital de los profesores, las familias y los estudiantes (ver la sección "La digitalización y el Covid-19").

Las nuevas tecnologías pueden contribuir a reducir la brecha de habilidades entre América Latina y el Caribe y la OCDE; es más, pueden promover la adquisición de habilidades básicas en los grupos tradicionalmente marginados. El uso de las tecnologías en los centros académicos podría ser una respuesta a esos obstáculos, sobre todo si tenemos en cuenta que, en caso de entornos desfavorables (por ejemplo, con desventaja socioeconómica), es más eficaz abordar el efecto de las habilidades en las primeras etapas de la vida (Cunha, Heckman y Schennach, 2010). Al mismo tiempo, los sistemas educativos deben enseñar a los jóvenes las habilidades que utilizarán en un futuro con una presencia de la tecnología digital cada vez mayor.

Las nuevas tecnologías permiten aplicar prácticas docentes innovadoras, cursos personalizados y a distancia, y también permiten hacer observaciones a los estudiantes sobre su trabajo, al igual que fomentan el interés y la participación de los estudiantes 
gracias a las nuevas modalidades de aprendizaje, como la gamificación. La conectividad abre la puerta a los centros de estudio para acceder a nuevos recursos y materiales de aprendizaje; por consiguiente, la transformación digital puede proporcionar un apoyo más para el desarrollo de habilidades fundamentales cognitivas, no cognitivas y digitales, lo que puede preparar a los estudiantes a vivir y a prosperar en el mundo digital.

En esta sección se analiza el papel de los centros educativos para preparar a las generaciones futuras para la era digital y para promover la inclusión digital. Se reflexiona sobre si dichos centros están bien equipados para fomentar habilidades digitales sólidas, cómo usan los estudiantes de 15 años las herramientas de TIC y cómo adquieren habilidades digitales, además de analizar qué que estudiantes son los más beneficiados. Los datos de base son los del Programa para la Evaluación Internacional de Estudiantes de la OCDE (PISA). Unos 600000 estudiantes hicieron las pruebas PISA 2018, una muestra representativa de los aproximadamente 32 millones de jóvenes de 15 años escolarizados en 79 países. Esta sección presenta los resultados de los diez países latinoamericanos que participaron en PISA 2018 (Argentina, Brasil, Chile, Colombia, Costa Rica, República Dominicana, México, Panamá, Perú y Uruguay), aunque Argentina, Colombia y Perú no utilizaron el cuestionario de familiaridad con las TIC, que es opcional. ${ }^{3}$

\section{Los estudiantes acceden a las TIC a edades cada vez más tempranas}

La rápida digitalización de la última década ha influido en la forma en que los estudiantes aprenden, hacen los deberes, interactúan con sus compañeros y se entretienen en su tiempo libre. El acceso a Internet y su uso adquieren un importante protagonismo. Para los estudiantes de 15 años de América Latina y el Caribe, el uso de Internet en los centros educativos se duplicó entre 2012 y 2018, y llegó a más de una hora en un día escolar típico. Fuera de la escuela, el tiempo en línea va en aumento. Entre semana se sitúa, en promedio, entre casi 1.4 horas y 3 horas al día (Gráfico 3.14), y los fines de semana, casi 3.5 horas, en consonancia con el promedio de la OCDE.

\section{Gráfico 3.14. Tiempo que pasan los estudiantes en Internet en los centros educativos y en el hogar entre semana, países seleccionados de América Latina, 2012 y 2018}
En la escuela 2018
En el hogar 2018
- En la escuela 2012
An el hogar 2012

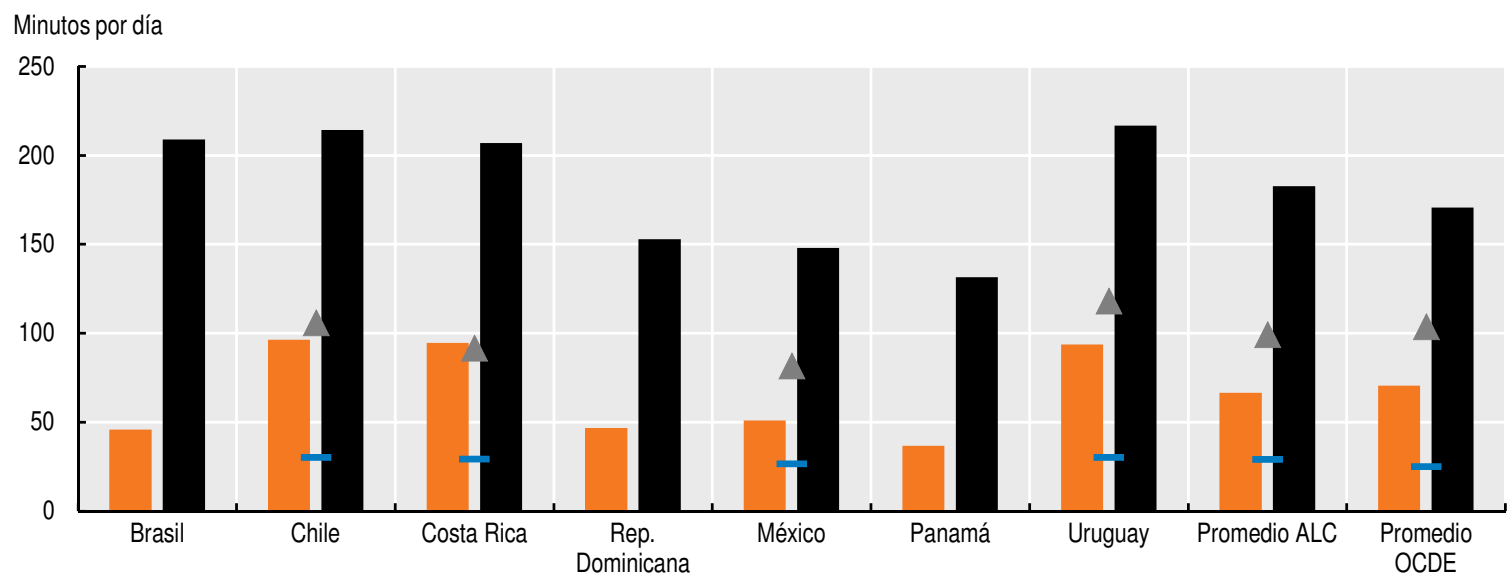

Notas: Las respuestas fueron: nada, 1-30 minutos, 31-60 minutos, 1-2 horas, 2-4 horas, 4-6 horas y más de 6 horas. Las respuestas se convirtieron al menor número de minutos del intervalo: 0, 1, 31, 61, 121, 241 o 361. Por ello, las cifras corresponden a los límites inferiores del tiempo promedio que se pasa en Internet por día. Los promedios de la OCDE y de América Latina y el Caribe son promedios simples que utilizan los datos disponibles para cada año.

Fuente: OCDE (2018d), Base de datos de PISA 2018 (base de datos), www.oecd.org/pisa/data/2018database/.

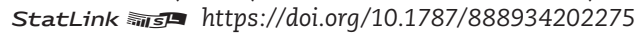


Los estudiantes de América Latina y el Caribe usan Internet a edades cada vez más tempranas. En 2015, en los cinco países de ALC que disponen de información de PISA sobre las TIC, tanto en 2015 como en 2018 (Brasil, Chile, Costa Rica, México, Perú, República Dominicana y Uruguay), el 61\% de los estudiantes de 15 años accedieron por primera vez a un dispositivo digital antes de los 10 años, cifra que se eleva al 62\% en 2018. En 2018, más del $20 \%$ accedió a un dispositivo digital antes de los 6 años y el $7 \%$ antes de los 3 años. Es probable que esta tendencia se mantenga (OCDE, 2016d, 2016e).

En los países de ALC la variación en el promedio de edad de iniciación digital es muy amplia. En 2015, el 73\% de los estudiantes de 15 años en Chile había interactuado con dispositivos digitales, en comparación con el 41\% en Perú. En 2018, en Chile y Uruguay, casi el 75\% de los estudiantes de 15 años habían comenzado a usar dispositivos digitales antes de los 10 años, y en México y República Dominicana, ese porcentaje era de poco más del 50\%. En República Dominicana y Panamá, entre el 3\% y el 5\% nunca habían utilizado un dispositivo digital (OCDE, 2018d).

En la OCDE, en promedio, las personas empiezan a usar Internet a una edad más temprana. En 2015, en los países de la OCDE que disponen de datos de PISA, el 73\% de los estudiantes de 15 años accedieron por primera vez a Internet antes de los 10 años, y el 34\%, antes de los 6 (OCDE, 2017a), con pequeñas variaciones para 2018. Menos del 1\% de los estudiantes de 15 años de los países de la OCDE nunca había usado un dispositivo digital, frente a más del $2 \%$ en América Latina y el Caribe.

El acceso a las TIC y el desarrollo de la competencia digital están vinculados a la adquisición de habilidades básicas. Al considerar la edad de la primera exposición a los dispositivos digitales y el rendimiento escolar, en promedio, los estudiantes con niveles de competencia más altos en PISA (es decir, los niveles 5 y 6 en ciencias) habían empezado a utilizar dispositivos digitales a una edad más temprana (Gráfico 3.15). Los estudiantes del nivel 2, que es el básico para las ciencias, son capaces de utilizar los conocimientos y procedimientos aprendidos en ciencias básicas para identificar una explicación científica adecuada, interpretar datos e identificar la cuestión tratada en un diseño experimental simple. En el nivel 2, los estudiantes demuestran conocimientos y aptitudes científicas suficientes para participar activamente en situaciones cotidianas relacionadas con la ciencia y la tecnología. Al final de la educación obligatoria, todos los estudiantes deben haber alcanzado el nivel 2 (OCDE, 2015b, 2016e). Una gran proporción de los que no lo alcanzan nunca habían utilizado tecnologías o las habían comenzado a utilizar a partir de los 10 años. La proporción es mayor en los países de América Latina y el Caribe, lo que refleja la brecha digital.

La exposición temprana a los dispositivos digitales se relaciona con un mejor desempeño en PISA: si se empiezan a utilizar las TIC antes de los 9 años, se asocia significativamente a mejores resultados que si se empiezan a usar después de los 12 años. En cambio, comenzar antes de los 3 años tiene un efecto menos beneficioso sobre el rendimiento que si se empieza entre los 3 y los 6 años; por tanto, comenzar a tan corta edad no tiene una correlación significativa con el rendimiento escolar (Gráfico 3.16). No está claro si la tecnología es lo que justifica esa correlación entre el uso de las TIC y los resultados de PISA. Los estudiantes más motivados para estudiar y rendir más también pueden estar más motivados por utilizar las TIC en los primeros años de vida. Los estudiantes que utilizan las TIC a una edad más temprana pueden tener padres que los estimulen más y fomenten nuevas experiencias, incluido el uso de las TIC, que pueden apoyar el desarrollo de habilidades y un mejor desempeño. Es posible, pues, que el simple hecho de proporcionar TIC no mejore los resultados de inmediato, por lo que las políticas coordinadas de TIC y educación se hacen necesarias. 


\section{Gráfico 3.15. Edad del primer uso de un dispositivo digital según el nivel de competencia en ciencias de PISA, promedios de la OCDE y América Latina y el Caribe, 2018}

Proporción de estudiantes en cada categoría de edad para el primer uso de dispositivos digitales por nivel de competencia en ciencias

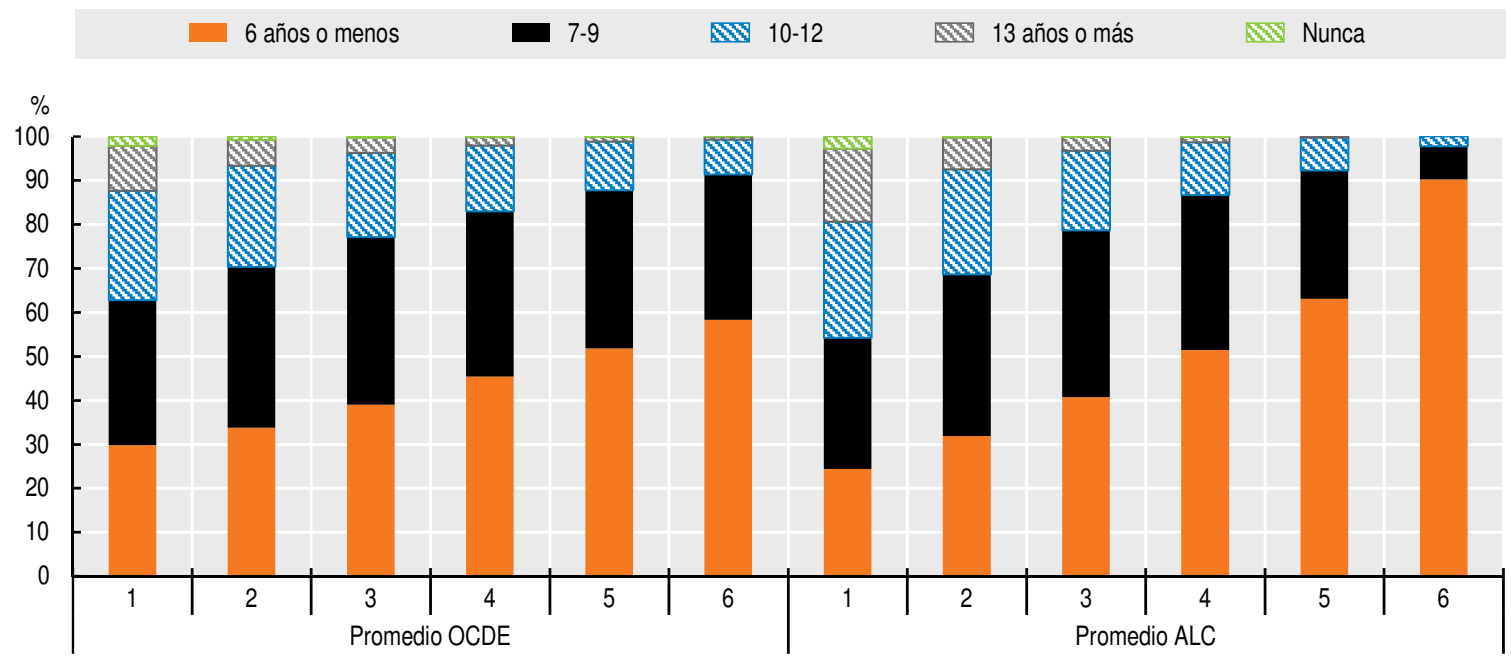

Nota: La diferencia entre América Latina y el Caribe y la OCDE (excluyendo a México, Colombia y Chile) en la proporción de estudiantes que utilizaron un dispositivo digital por primera vez a partir de los 9 años es significativa.

Fuente: Elaboración propia a partir de OCDE (2018d), PISA 2018 (base de datos), www.oecd.org/pisa/data/2018database/. StatLink तilst https://doi.org/10.1787/888934202294

\section{Gráfico 3.16. Edad del primer uso de un dispositivo digital y resultados de PISA en América Latina y el Caribe, 2018}
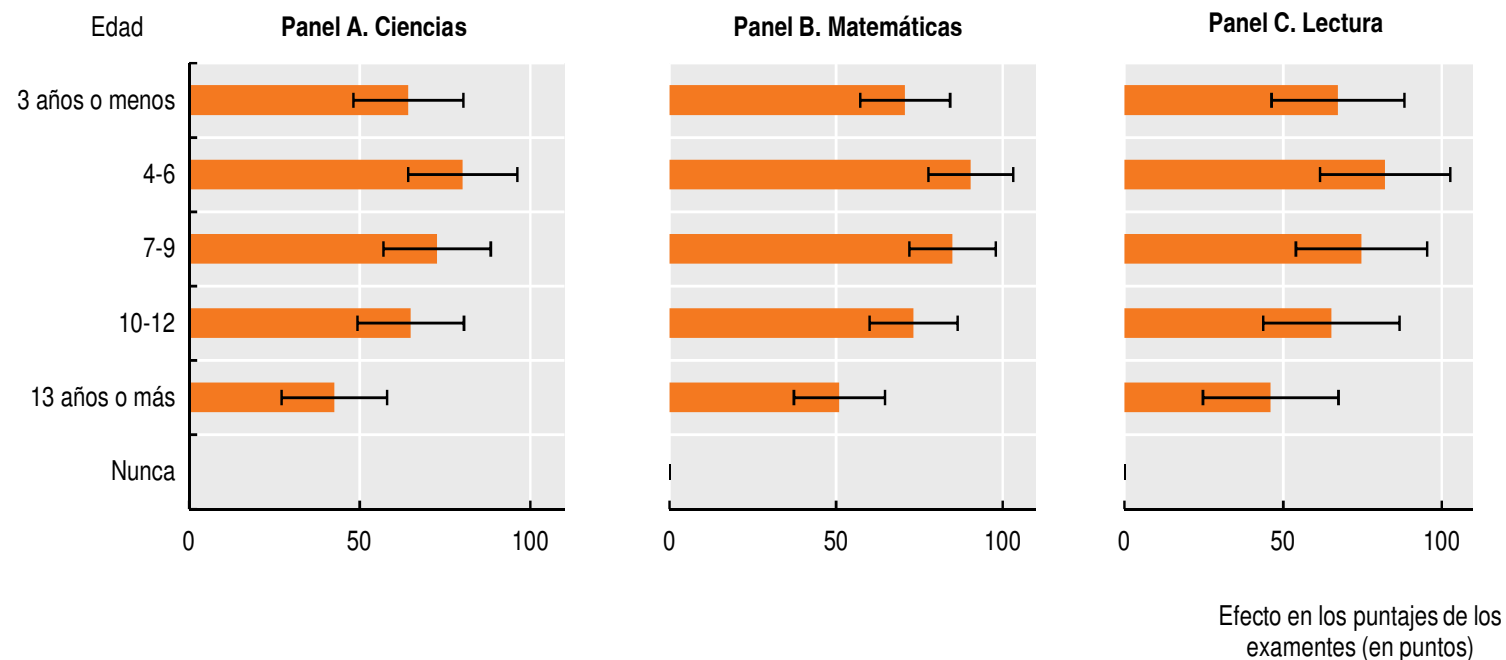

Notas: Efectos estimados de la edad del primer uso de un dispositivo digital, por franjas de edad, en relación con la categoría "Nunca ha utilizado un dispositivo digital", en los resultados de ciencias, matemáticas y lectura. Las barras muestran los coeficientes a partir de una regresión que estima el efecto de la edad a la que se accede por primera vez a un dispositivo digital en los resultados de PISA. Los controles de la regresión incluyen los datos de PISA sobre el nivel socioeconómico de los estudiantes, la edad, el sexo, la condición de inmigrante, una variable dicotómica para los que estudian en un centro privado y una variable para los que viven en zonas rurales. Los efectos fijos por país se incluyen en la regresión. Las barras de error corresponden a un error estándar de 1.96 y, por tanto, representan un intervalo de confianza del 95\%. La muestra incluye a todos los países de América Latina y el Caribe que participaron en PISA 2018 con los datos disponibles.

Fuente: Elaboración propia a partir de OCDE (2018d), PISA 2018 (base de datos), www.oecd.org/pisa/data/2018database/.

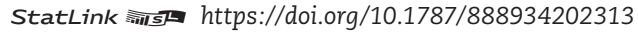




\section{Los centros educativos contribuyen a un acceso equitativo a las TIC en ALC}

En los países en que la conectividad de los hogares no es universal, los espacios públicos y las instituciones, como los centros educativos, facilitan el acceso a Internet (Unesco, 2017). Más del 5\% de los estudiantes de América Latina y el Caribe solo pueden acceder a las TIC cuando están en la escuela. En esta sección se utiliza el cuestionario para centros educativos de PISA 2018, que responden los directores o el equipo directivo, para analizar el acceso de los estudiantes de 15 años a las computadoras, las TIC e Internet en los centros educativos.

Aunque en los centros académicos de ALC cada vez es más habitual que se tenga acceso a herramientas digitales, sigue existiendo una brecha con respecto a la OCDE. En promedio, en los centros latinoamericanos, dos o más estudiantes comparten computadora, cuando en la OCDE se dispone de una computadora por estudiante. El acceso a Internet también es esencial para adquirir las habilidades digitales pertinentes. Alrededor del $95 \%$ de las computadoras de los centros educativos de la OCDE tienen conexión a Internet, en comparación con el 74\% en América Latina y el Caribe (Gráfico 3.17).

\section{Gráfico 3.17. Número de estudiantes por computadora y por computadora con conexión a Internet, países seleccionados de América Latina y el Caribe, 2015 y 2018}

\section{Por computadora 2018 Por computadora con Internet 2018 - Por computadora 2015 - Por computadora con Internet 2015}

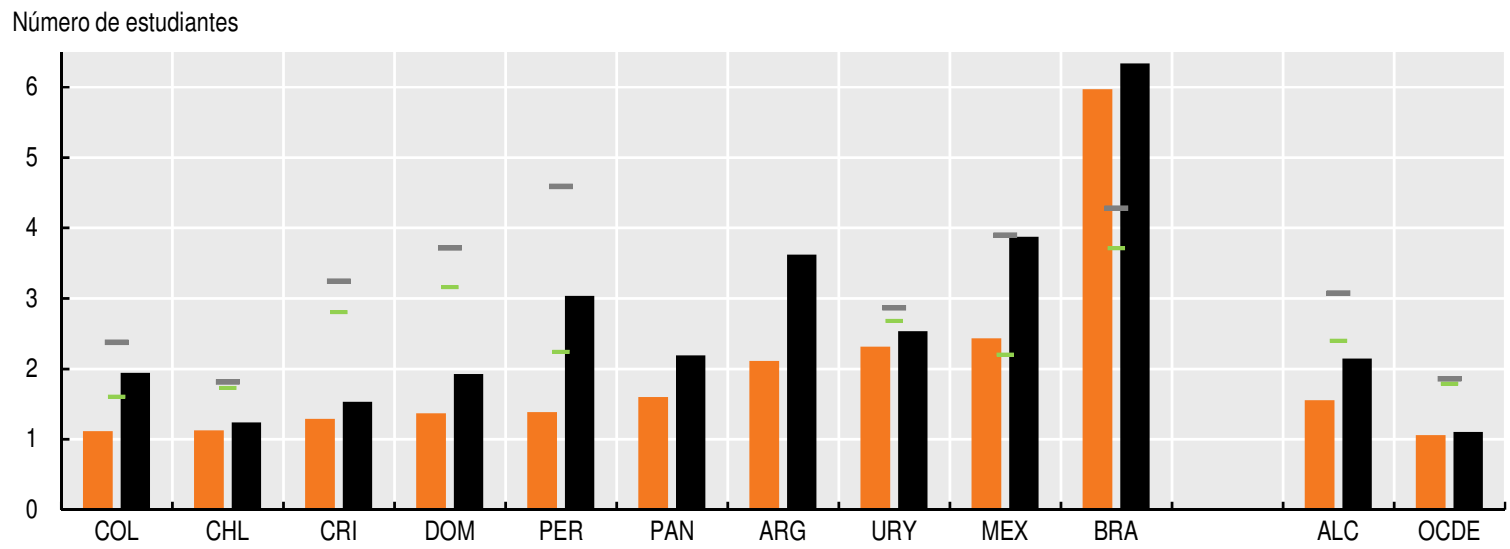

Fuente: Elaboración propia a partir de OCDE (2018d), Base de datos de PISA 2018 (base de datos), www.oecd.org/pisa/ data/2018database/.

StatLink तils https://doi.org/10.1787/888934202332

Si se tiene computadora, pero no Internet o personal capacitado, es difícil que las TIC se usen adecuadamente como una herramienta para desarrollar competencias de base y habilidades digitales. Los países de América Latina y el Caribe no solo se enfrentan a barreras físicas - limitaciones de infraestructura, programas y equipos informáticos, calidad de la conexión a Internet, entre otras-, sino que también deben franquear otro tipo de barreras; en particular, la falta de personal y de docentes con conocimientos de TIC (OCDE, 2019g), algo clave para ofrecer una educación de calidad. Para mejorar la calidad de la educación y el desarrollo de las habilidades, la tecnología no basta: el acceso es una condición necesaria, pero no es suficiente. Se necesita un enfoque de educación más amplio. Los estudios sugieren que el efecto de las TIC en el desempeño de los estudiantes depende de la forma en que la tecnología complementa o sustituye la práctica docente (Recuadro 3.2).

El acceso a las computadoras en los centros educativos varía entre los países de América Latina y el Caribe y dentro de cada país. En Chile y Colombia, los centros proporcionan 
casi una computadora por estudiante, como en la mayoría de los países de la OCDE. En cuanto a la conexión a Internet, en Chile casi todos tienen, pero en Colombia, menos de dos tercios. En Brasil, hay más de cinco estudiantes por computadora con conexión a Internet.

Se constatan importantes diferencias en el acceso y la conectividad dentro de los países de ALC, en varios aspectos. En las aldeas o poblaciones más pequeñas, hay una computadora con conexión a Internet por cada tres estudiantes, en comparación con los dos estudiantes de las grandes ciudades. En el cuartil inferior del índice socioeconómico y cultural (ESCS) de PISA, tres estudiantes comparten computadora con conexión a Internet, en comparación con dos o menos del cuartil superior. En las escuelas públicas hay tres estudiantes en promedio por computadora con conexión a Internet, frente a casi uno por estudiante en los centros privados (Gráfico 3.18).

\section{Gráfico 3.18. Número de estudiantes por computadora y por computadora con conexión a Internet, según las características sociodemográficas, promedios de América Latina y el Caribe y de la OCDE, 2015 y 2018}

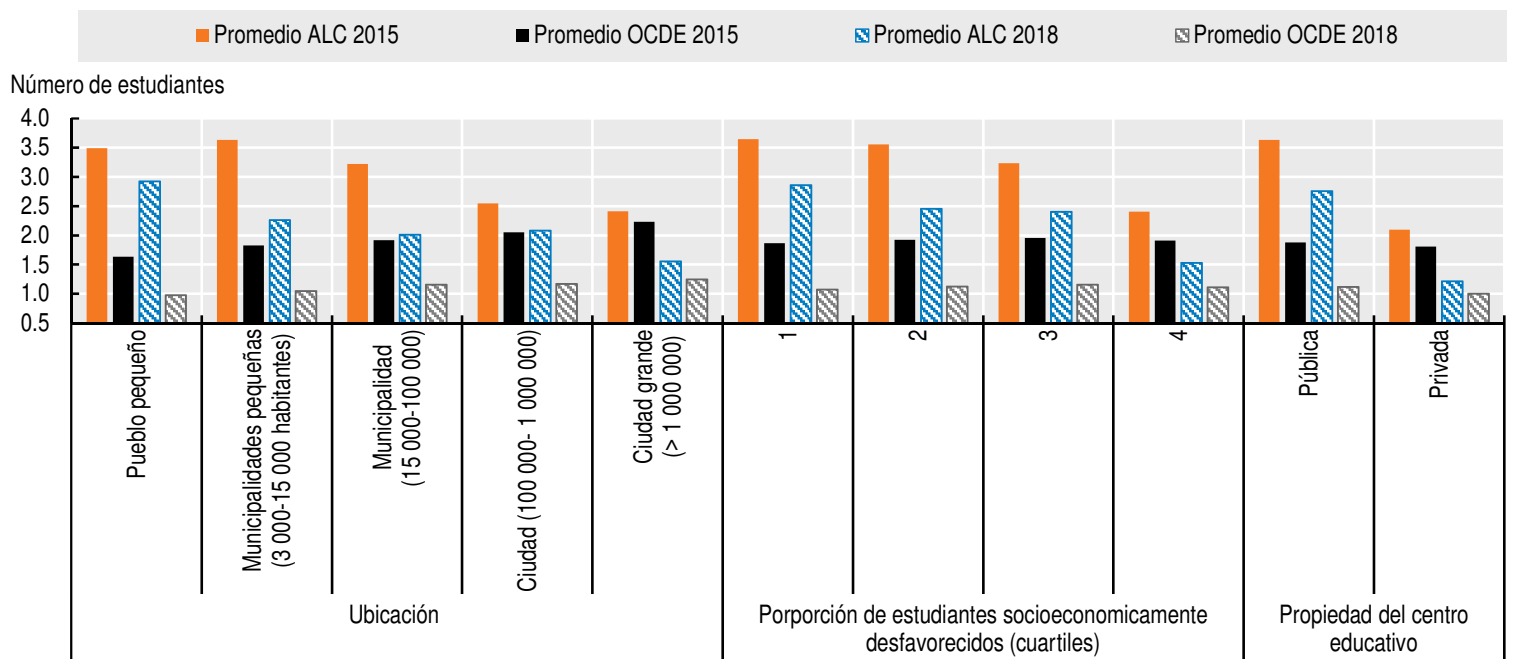

Fuente: Elaboración propia a partir de OCDE (2018d), Base de datos de PISA 2018 (base de datos), www.oecd.org/pisa/ data/2018database/ y OCDE (2015c), Base de datos de PISA 2015 (base de datos), www.oecd.org/pisa/data/2015database/. StatLink न्तilst https://doi.org/10.1787/888934202351

Al proporcionar acceso a las computadoras y a Internet, los centros educativos ayudan a cerrar la brecha entre los estudiantes que tienen acceso a las TIC en el hogar y los que no lo tienen (OCDE/BID, 2016). PISA obtiene los índices de disponibilidad de TIC en los centros educativos y el hogar. ${ }^{4}$ Estos indicadores calculan la disponibilidad combinada de diversos instrumentos digitales, incluidas las computadoras, una conexión a Internet y los smartphones, en una escala de 0 (sin acceso a ningún instrumento digital) a 10 (con acceso a todos los instrumentos enumerados; 11, en caso de la disponibilidad de TIC en el hogar). La desigualdad en la disponibilidad de las TIC entre los estudiantes con un entorno socioeconómico favorable y desfavorable es mayor en el hogar que en la escuela. En América Latina y el Caribe, el índice de disponibilidad de TIC en el hogar es un $50 \%$ (un $40 \%$ en la OCDE) más alto para los estudiantes del cuarto cuartil del índice socioeconómico y cultural (ESCS) de PISA que para los estudiantes del primer cuartil. El índice de disponibilidad de TIC en los centros educativos es un $42 \%$ ( $18 \%$ en la OCDE) más elevado para los estudiantes del cuarto cuartil (Gráfico 3.19). Los centros educativos contribuyen a reducir la brecha digital en el acceso a las TIC. Es pertinente y necesario ampliar la infraestructura de comunicaciones en las escuelas de ALC. 
La equidad en la asignación de recursos es importante para garantizar la igualdad de oportunidades en materia de educación y está relacionada con el desempeño del sistema educativo en general. Los países de alto rendimiento suelen asignar los recursos, incluidas las computadoras y las herramientas digitales, de manera más equitativa, con independencia de los perfiles socioeconómicos de los centros educativos. Un mejor acceso a las TIC en el ámbito escolar puede compensar el escaso acceso de los hogares rurales o de los entornos socioeconómicos desfavorecidos (OCDE, 2015d).

En los países de la región, con demasiada frecuencia, la escasez de recursos educativos, como las TIC, hace que su distribución sea desigual entre las escuelas de entornos desfavorecidos y favorecidos. Los directores de la mayoría de estos centros educativos informan que los recursos con los que cuentan son inadecuados. Costa Rica, México y Perú suelen destinar sus escasos recursos a los centros de entornos favorecidos. La falta o la insuficiencia de recursos dificultan el aprendizaje en muchos centros, en particular en los desaventajados desde el punto de vista socioeconómico. En contraste, los directores de escuelas en Finlandia informan que asignan los recursos de forma similar, independientemente de la situación socioeconómica de los centros educativos (OCDE, 2016d).

\section{Gráfico 3.19. Índice de disponibilidad de TIC en el hogar y en los centros educativos por cuartil(Q) del índice socioeconómico y cultural de PISA, promedios de América Latina y el Caribe y de la OCDE, 2018}

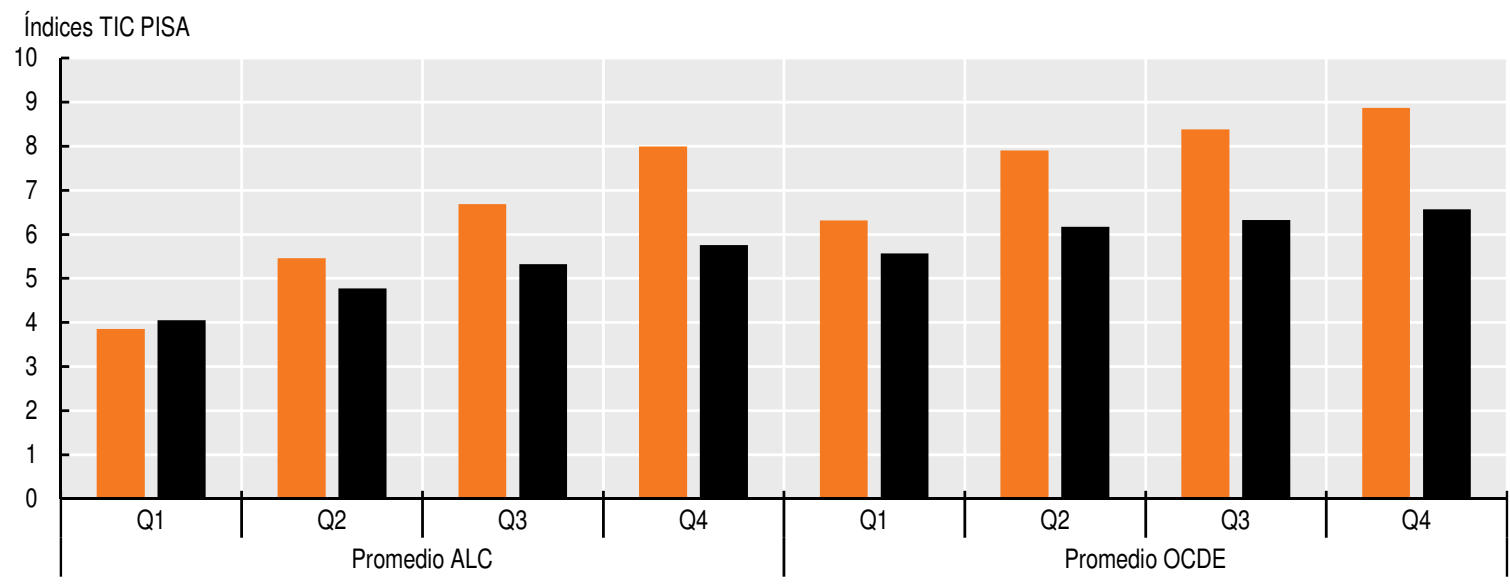

Notas: El cuestionario de familiaridad con las TIC de PISA pregunta sobre la disponibilidad de TIC en el hogar y en los centros educativos y sobre su uso para diversos fines. ICTHOME es un índice basado en la suma de la disponibilidad de todos los artículos listados en IC001. IC009 pregunta sobre la disponibilidad de TIC en los centros educativos. La variable derivada respectiva ICTSCHOOL es un índice basado en la suma de la disponibilidad de todos los artículos enumerados. En ICTHOME e ICTSCHOOL, la diferencia entre el cuarto y el primer cuartil es significativa en América Latina y el Caribe; en cambio, en la OCDE no es significativa. En promedio, tanto el ICTHOME como el ICTSCHOOL son significativamente diferentes entre la OCDE y ALC. El promedio de ambos índices para cada nivel es significativo.

Fuente: Elaboración propia a partir de OCDE (2018d), Base de datos de PISA 2018 (base de datos), www.oecd.org/pisa/ data/2018database/.

StatLink तinst https://doi.org/10.1787/888934202370

Es importante mejorar el acceso a las TIC en el hogar y en las escuelas de América Latina y el Caribe, ya que tiene una correlación positiva con el rendimiento académico. La mayoría de los estudiantes que se sitúan en los dos niveles superiores de la prueba de ciencias de PISA tenían acceso a las TIC en el hogar, como lo evidencia un mayor resultado del índice de disponibilidad TIC en el hogar, en comparación con aquellos que resultaron 
en los niveles más bajos (Gráfico 3.20). El acceso a las TIC en el hogar podría ayudar a los estudiantes a obtener mejores resultados o el mejor rendimiento podría derivarse asimismo de un mejor rendimiento de los estudiantes que demandan más TIC. Es probable que la disponibilidad de las TIC esté correlacionada con el mayor nivel de ingresos, entre otros indicadores de desarrollo. En los centros educativos todos los estudiantes tienen una disponibilidad de TIC similar, tanto en los países de América Latina y el Caribe como en los de la OCDE, independientemente de su nivel de competencia.

Proporcionar computadoras y TIC a las escuelas y a los estudiantes de entornos desfavorecidos no basta para mejorar el rendimiento (Recuadro 3.2). Las herramientas digitales deben utilizarse para mejorar el aprendizaje, sin distracciones (OCDE, 2016c). El desarrollo de habilidades digitales es clave para aprovechar al máximo la transformación digital. El acceso a los dispositivos digitales debe complementarse con programas de desarrollo de competencias TIC de los estudiantes y el cuerpo docente. Los centros educativos de América Latina y el Caribe han ampliado los currículos para incluir las habilidades digitales; sin embargo, la variación entre escuelas es grande, lo que aumenta las disparidades. Los centros educativos con más computadoras conectadas a Internet tienen mayor probabilidad de ofrecer actividades para desarrollar la competencia informática o de TIC, lo que refuerza la brecha en el acceso a las TIC y su uso en centros educativos entre los estudiantes de ALC. Además, aunque los centros cuenten con buena proporción de computadoras conectadas a Internet, son escasos los programas para fomentar el uso de dispositivos digitales en el aula y en el aprendizaje de determinadas materias.

\section{Gráfico 3.20. Índice de disponibilidad de las TIC en el hogar y en los centros educativos, por nivel de competencia en ciencias de PISA, promedios de América Latina y el Caribe y de la OCDE, 2018}

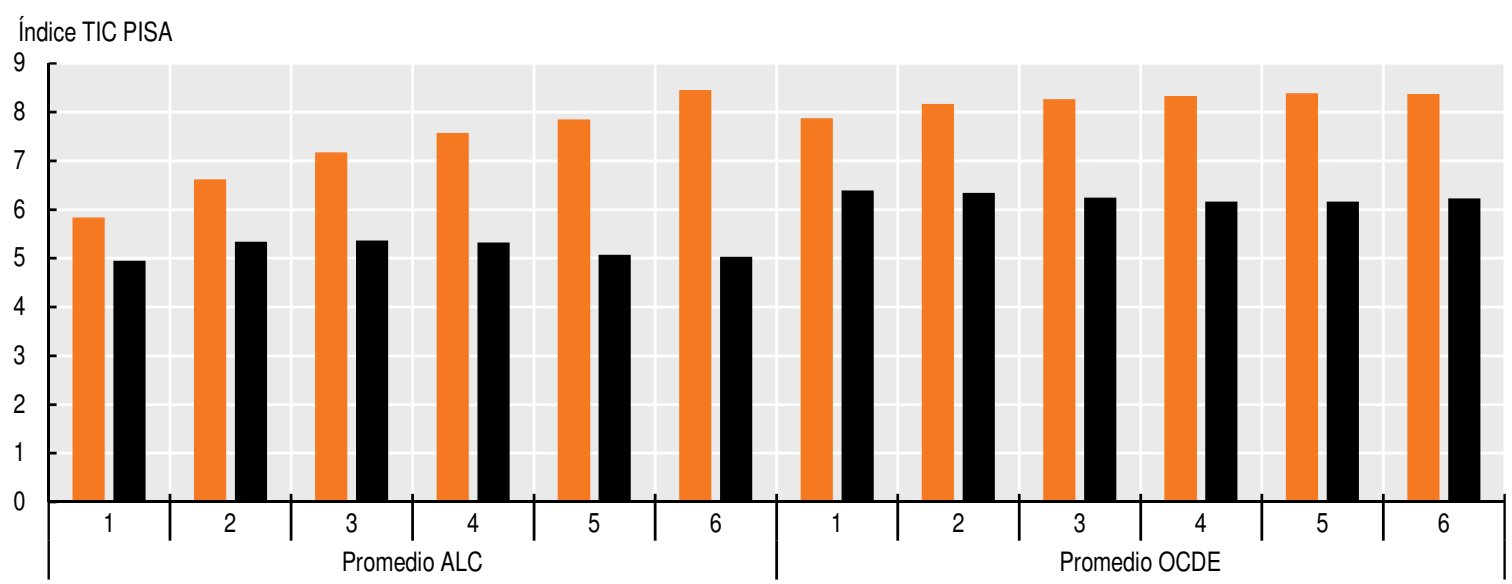

Notas: El cuestionario de familiaridad con las TIC de PISA pregunta sobre la disponibilidad de TIC en el hogar y su uso para diversos fines. ICTHOME es un índice basado en la suma de la disponibilidad de todos los artículos listados en IC001. IC009 pregunta sobre la disponibilidad de TIC en los centros educativos. La variable derivada respectiva ICTSCHOOL es un índice basado en la suma de la disponibilidad de todos los artículos enumerados. Para América Latina y el Caribe y la OCDE, la diferencia en ICTHOME es significativa entre los niveles 1 y 6 , mientras que para ICTSCHOOL la diferencia no es significativa. En promedio, tanto el ICTHOME como el ICTSCHOOL son significativamente diferentes entre la OCDE y ALC. El promedio de ambos índices para cada nivel es significativo.

Fuente: Elaboración propia a partir de OCDE (2018d), Base de datos de PISA 2018 (base de datos), www.oecd.org/pisa/ data/2018database/.

StatLink तilst https://doi.org/10.1787/888934202389 
Hasta ahora, las políticas para impulsar los beneficios de la digitalización han priorizado el aumento del acceso y la conectividad con respecto a la calidad de la experiencia en el uso (Bulman y Fairlie, 2016). La falta de pedagogía digital, probablemente afecta los posibles efectos positivos del acceso a las TIC en los resultados de aprendizaje. En los países de la región donde se proporciona una computadora con conexión a Internet por estudiante hay una proporción similar de centros educativos con actividades extracurriculares para desarrollar habilidades TIC o programas específicos para utilizar las TIC en la docencia y el aprendizaje. Estar preparado para la transformación digital implica ir más allá del acceso a Internet y de su uso; los sistemas educativos deben adaptar el contenido pedagógico y los servicios prestados a las necesidades que los estudiantes tendrán en un futuro cada vez más digital.

La mayoría de las administraciones regionales tienen recursos limitados. Deben evaluar qué programas poner en práctica y adaptar las políticas públicas para mejorar sustancialmente la calidad de la educación. Los datos sobre el efecto de los programas que proporcionan herramientas (computadoras, programas informáticos, conectividad) y habilidades digitales son fundamentales para determinar qué es lo más beneficioso para el aprendizaje (Escueta et al., 2017; J-PAL Evidence Review, 2019; Malamud et al., 2018).

\section{Recuadro 3.2. Las computadoras en educación}

Las TIC se han convertido en una parte fundamental del proceso de aprendizaje, dentro y fuera del aula. Los gobiernos de América Latina y el Caribe han hecho grandes inversiones para introducir las TIC en sus sistemas educativos durante las dos últimas décadas, pero el impacto del acceso y el uso en el desempeño y los resultados de los estudiantes no ha sido el esperado.

\section{Lecciones aprendidas del proyecto Una Computadora por Niño}

El proyecto Una Computadora por Niño (Una Laptop por Niño) en América Latina y el Caribe, que distribuye a gran escala computadoras portátiles a los estudiantes para que las usen en los centros educativos y en el hogar, ha sido clave en el debate de cómo inciden las computadoras en el aprendizaje. Los resultados del programa son heterogéneos: la incertidumbre sobre su eficacia y su impacto persiste.

Uruguay fue uno de los pocos países que aplicó el programa a escala nacional. No se detectó efecto alguno en las notas de matemáticas y comprensión lectora en los dos primeros años (Melo, Machado y Miranda, 2014), posiblemente debido a la falta de formación obligatoria de los docentes y a que las computadoras se usaron principalmente en las aulas para buscar información en Internet.

Perú invirtió más de 200 millones de dólares para distribuir 900000 computadoras. Los conocimientos informáticos mejoraron, pero la competencia lectora y la matemática no. Se observó que el programa no incluía la conexión a Internet y que se aplicó principalmente en zonas rurales, donde ni los docentes ni las familias tenían los conocimientos necesarios para ayudar a los niños a utilizar la tecnología digital. En cambio, en Lima se aplicó un programa experimental que proporcionó computadoras portátiles, acceso a Internet de alta velocidad y ocho sesiones de capacitación para niños sobre cómo acceder a sitios web de educación y buscar información en sitios como Wikipedia; ese programa sí aumentó el acceso a las computadoras y su uso en el hogar, y sus usuarios mejoraron los resultados en un test de aptitud con una desviación típica de 0.8 (Beuermann et al., 2015).

Lecciones aprendidas del uso de la computadora en los centros educativos

Proporcionar dispositivos digitales no asegura un mejor rendimiento (Bulman y Fairlie, 2016; Escueta et al., 2017; OCDE, 2020b). En el informe PISA 2012 los datos mostraron que los estudiantes que utilizaban computadoras de forma limitada en sus centros educativos obtenían mejores 


\section{Recuadro 3.2. Las computadoras en educación (cont.)}

resultados en competencia lectora que los estudiantes que no las usaban en absoluto; sin embargo, los estudiantes que las usaban por encima del promedio de la OCDE obtuvieron resultados significativamente peores (OCDE, 2015d). Así pues, el uso inadecuado de las computadoras puede tener efectos nocivos o puede no tener efecto alguno en los resultados académicos.

Otros estudios demuestran que el impacto del aprendizaje asistido por computadora (por ejemplo, con programas informáticos educativos) depende de si se utiliza como elemento sustitutivo o complementario de la enseñanza tradicional. Su efecto también dependerá de la calidad del método de enseñanza que la instrucción asistida por computadora está reemplazando o complementando. El uso del aprendizaje asistido por computadora es más eficaz para mejorar los resultados en los países en desarrollo cuando sustituye a la enseñanza de menor calidad o compensa la falta de profesores (Banerjee et al., 2007; OCDE, 2020b).

Hay formas de mejorar los resultados del uso de las TIC. Una parte significativa de la investigación sugiere que el aprendizaje guiado por el profesor - con un programa informático bien diseñado que se utilice en el centro educativo y que amplíe los contenidos trabajados en clase- es una de las formas más eficaces de ayudar a los niños y niñas a desarrollar habilidades (BID, 2011).

Se ha demostrado que, sin la supervisión de un adulto, un niño con una computadora pasará más tiempo haciendo tareas que no le ayudarán en sus resultados que haciendo deberes o estudiando. Si se interviene para que los niños tengan más acceso a las TIC, deben ponerse en práctica mecanismos para garantizar un uso adecuado; por ejemplo, computadoras que lleven instalados programas informáticos educativos interactivos y aplicaciones que se abran automáticamente para estimular su uso (BID, 2011).

Ofrecer formación informática una o dos horas por semana también tiene efectos positivos en las oportunidades de aprendizaje y empleo. Puede ser una inversión más barata para la región y produce beneficios relativamente altos, en particular para los países con recursos limitados: la creación y el mantenimiento de un laboratorio de informática en el centro educativo cuesta unos 23 dólares por estudiante, en comparación con los 217 dólares por estudiante de los programas para repartirle una computadora a cada niño (BID, 2011).

El cuerpo docente debe tener las habilidades tecnológicas adecuadas para transmitir los conocimientos (Paniagua e Istance, 2018; Peterson et al., 2018). Según la Evaluación de Competencias de Adultos, la proporción de docentes de los países de la OCDE con poca capacidad de resolución de problemas en entornos con fuerte presencia tecnológica oscilaba entre menos del $5 \%$ en Australia y el 20\% o más en Chile y Turquía (OCDE, 2019g, 2016e).

Se puede recurrir a los cursos en línea abiertos y gratuitos (MOOC) para mejorar las habilidades o como herramienta pedagógica. Algunas universidades de Estados Unidos han colaborado con las plataformas de tipo MOOC para ofrecer cursos preparatorios para estudiantes de secundaria con nivel más avanzado (Advanced Placement). Los estudiantes que siguen los $\mathrm{MOOC}$ en vez de estudiar con material estándar suelen lograr resultados de aprendizaje ligeramente superiores. Muchos de los participantes de los MOOC son docentes (Seaton et al., 2014). Además de aumentar el índice de computadoras por estudiante, invertir en dispositivos digitales dedicados a los profesores y a su formación suele traducirse en mejores resultados de los estudiantes (Denoël et al., 2017). La calidad de las herramientas, su coordinación con otras prácticas de enseñanza y la formación del profesorado es fundamental. 


\section{Los centros educativos contribuyen a la equidad en el uso de las TIC en América Latina y el Caribe}

Contar con las competencias y la formación adecuadas puede proteger contra la brecha digital y mitigar otro tipo de brechas. La inclusión digital requiere algo más que un mejor acceso a las herramientas e infraestructuras de las comunicaciones; requiere contar con numerosas habilidades cognitivas, metacognitivas y digitales para aprovechar esa tecnología. La forma en que las personas utilizan Internet y las tecnologías digitales determina los beneficios que obtienen. A medida que se reduce la brecha de acceso a las TIC, las diferencias en cómo se utilizan y qué resultados se obtienen ganan importancia, especialmente en educación.

La brecha digital suele estar relacionada con el modo en que las personas con diferentes perfiles sociodemográficos utilizan Internet y las TIC y, por tanto, se crean diferencias en las oportunidades de esa transformación digital. La exclusión digital es compuesta y secuencial; el mecanismo de ampliación de la exclusión digital sugiere que Internet magnifica las desigualdades existentes fuera de Internet (Van Deursen et al., 2017). La digitalización puede ampliar las diferencias si los estudiantes de zonas rurales, de entornos socioeconómicos desfavorecidos o con bajo rendimiento académico tienen menos contacto con contenidos de educación digital, utilizan Internet para estudiar, pero de forma inadecuada, o utilizan Internet sobre todo para el ocio (OCDE, 2019g).

Fuera del ámbito académico, los estudiantes de América Latina y el Caribe suelen utilizar las TIC para participar en redes sociales, chatear y buscar información (Gráfico 3.21). Dos de cada tres participan en redes sociales y chatean todos los días o casi todos los días (al menos tres veces por semana), en comparación con tres de cada cuatro en los países de la OCDE. De forma similar al promedio de la OCDE, uno de cada tres estudiantes en ALC usa regularmente Internet para buscar información práctica.

Gráfico 3.21. Usos que los estudiantes hacen de las TIC fuera de la escuela, países seleccionados de América Latina y el Caribe, 2018 o último año disponible

Proporción de estudiantes que utilizan las TIC fuera de la escuela para una actividad, todos los días o casi todos los días (al menos tres veces por semana)

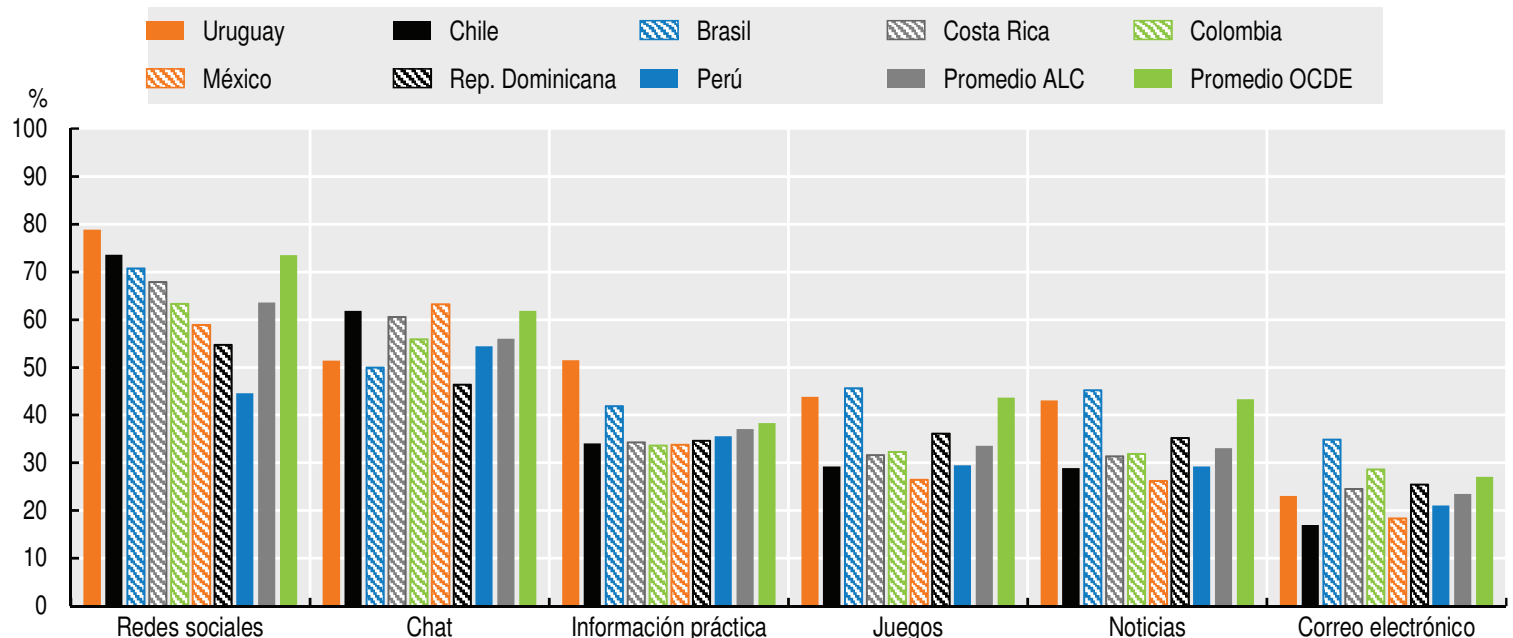

Notas: Los porcentajes son significativos para cada país/región. No se ven diferencias significativas entre la OCDE y América Latina y el Caribe con respecto a la proporción de estudiantes que utilizan dispositivos digitales para cada actividad. Los datos de Colombia y Perú corresponden a PISA 2015, por la disponibilidad técnica de datos en el momento de la elaboración de este informe.

Fuente: Elaboración propia a partir de OCDE (2018d), Base de datos de PISA 2018 (base de datos),www.oecd.org/pisa/ data/2018database/ y OCDE (2015c), Base de datos de PISA 2015 (base de datos), www.oecd.org/pisa/data/2015database/. StatLink ainsta https://doi.org/10.1787/888934202408 
Los factores que determinan las desigualdades con respecto al acceso a la tecnología digital - género, origen socioeconómico, situación de la fuerza de trabajo, geografía o habilidades - también determinan las desigualdades en el uso (Demoussis y Giannakopoulos, 2006; Dewan y Riggins, 2005; Dimaggio y Hargittai, 2003; Fairlie, 2004; Robinson, Hargittai y Hsieh, 2013). La proporción de latinoamericanos con bajo nivel educativo que no tiene conectividad ha disminuido en la última década. Según los estudios realizados, las personas con un nivel educativo bajo usan Internet para el ocio, más que para el aprendizaje, lo que contrasta con los hábitos de las personas con un nivel educativo más alto (Van Deursen y Van Dijk, 2014; OCDE, 2019d).

El nivel socioeconómico y las habilidades se relacionan con el uso que hacen de las TIC los estudiantes fuera de los centros educativos en América Latina y el Caribe. En los países de la OCDE, los estudiantes de entornos socioeconómicos desfavorecidos participan en las redes sociales y chatean casi tanto como los de entornos favorecidos, pero los resultados difieren en los indicadores de obtención de información práctica y envío de correos electrónicos. En los países de la región, todos los usos difieren entre los dos grupos (Gráfico 3.22). Los estudiantes que obtienen mejores resultados suelen utilizar las TIC con mayor frecuencia que los que obtienen peores resultados. Esto es así tanto en la OCDE como en América Latina y el Caribe, pero la diferencia es más acusada en ALC, lo que indica una mayor brecha digital en la frecuencia de uso según el tipo de competencias.

Las desigualdades en el uso de las TIC también están relacionadas con el género y la geografía. Si bien se detectan pequeñas diferencias, los niños y las niñas de los países de América Latina y el Caribe y de la OCDE utilizan los dispositivos digitales de manera diferente (ver la sección siguiente). Además, aunque existen diferencias marginales de uso entre los estudiantes de entornos rurales y urbanos en los países de la OCDE, en América Latina y el Caribe los estudiantes urbanos participan en las redes sociales casi 30 puntos porcentuales más y usan el chat 20 puntos porcentuales más que los estudiantes rurales.

Los centros educativos también contribuyen a cerrar la brecha digital en los países de América Latina y el Caribe en lo que respecta al uso de Internet. En todas las categorías, las diferencias en el uso de Internet entre estudiantes de distintos orígenes socioeconómicos fueron menores dentro de los centros escolares que fuera, aunque las diferencias seguían siendo importantes.

Los centros educativos desempeñan un papel sustancial para reducir la brecha digital que conformará las habilidades futuras (Gráfico 3.23). Sin embargo, persisten grandes diferencias entre los centros escolares de América Latina y el Caribe, y los responsables de las políticas públicas deben abordarlas. Los estudiantes con un entorno socioeconómico favorable tienen entre 5 y 10 puntos porcentuales más de probabilidades de chatear y navegar por Internet en el centro educativo para tareas académicas que aquellos con un entorno económico desfavorecido (Gráfico 3.23, Panel B). Esto probablemente está relacionado con el acceso a Internet en los centros educativos, pero también podría deberse a que los estudiantes tengan y utilicen teléfonos celulares en horario escolar. También es más probable que practiquen y utilicen las TIC para desarrollar habilidades digitales (ejercicios y práctica). En América Latina y el Caribe, los chicos son más propensos que las chicas a usar Internet en las escuelas para el correo electrónico, los deberes y para práctica y ejercicios. Las desigualdades territoriales agravan las desigualdades socioeconómicas y de género en el uso de los dispositivos digitales, tanto en el hogar como en los centros escolares. Los estudiantes de entornos rurales desfavorecidos tienen menos probabilidad de usar TIC que los de entornos urbanos favorecidos. 


\section{Gráfico 3.22. Uso de las TIC dentro y fuera de la escuela por categoría sociodemográfica, promedios de América Latina y el Caribe y de la OCDE, 2018}

Proporción de estudiantes que utilizan las TIC dentro y fuera de la escuela para una actividad al menos tres veces por semana

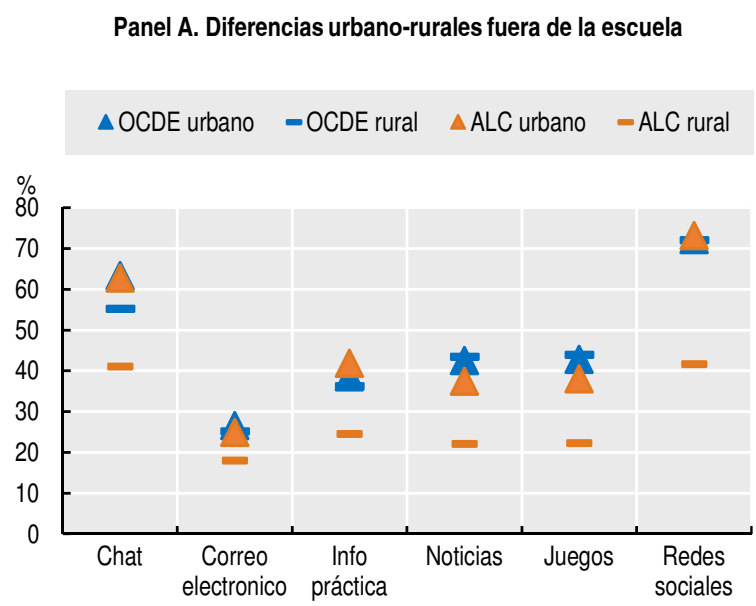

Panel C. Diferencias urbano-rurales en la escuela

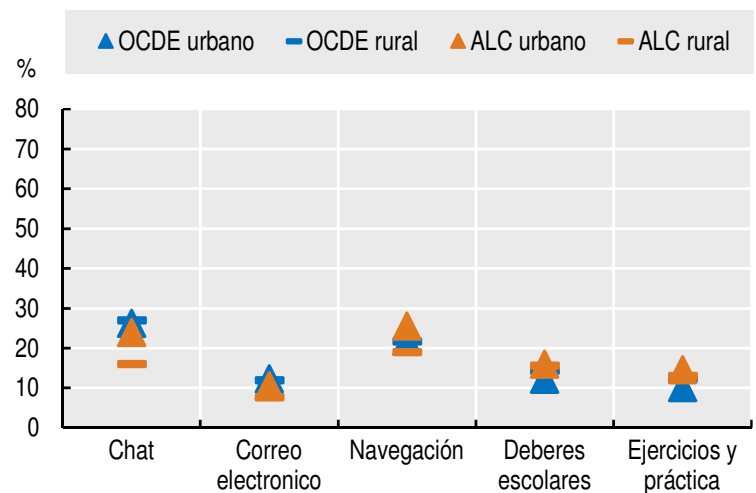

Panel B. Diferencias socioeconómicas fuera de la escuela

$\triangle$ OCDE favorecido OCDE desfavorecido
$\triangle$ ALC favorecido

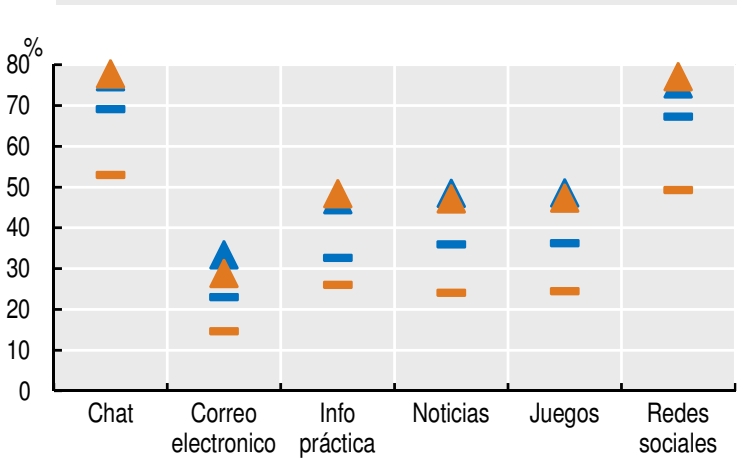

Panel D. Diferencias socioeconómicas en la escuela

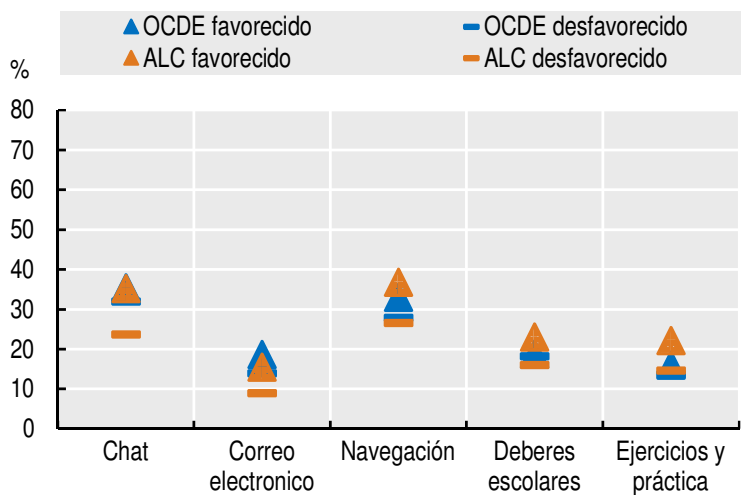

Notas: La proporción se ha calculado como promedio de los países de la OCDE y de América Latina y el Caribe que participaron en el cuestionario de familiaridad con las TIC de PISA. Se considera que los estudiantes pertenecen a entornos socioeconómicos desfavorecidos si sus valores en el índice socioeconómico y cultural de PISA están en el 25\% más bajo de su país o economía. Los estudiantes rurales son aquellos cuya escuela se encuentra en "una aldea, caserío o núcleo rural con menos de 3.000 habitantes"; los estudiantes urbanos son aquellos cuya escuela se encuentra en una ciudad de más de 100.000 habitantes. "Navegar" se entiende como "navegar por Internet para hacer tareas escolares" y "descargar, cargar contenidos o navegar el sitio web de la escuela (por ejemplo, la intranet)". "Ejercicios y práctica" se refiere a "practicar y hacer ejercicios, como se hace para aprender idiomas o matemáticas". "Deberes" se refiere a "hacer los deberes en una computadora del centro educativo" y "utilizar las computadoras del centro para el trabajo en grupo y la comunicación con otros estudiantes".

Fuente: Elaboración propia a partir de OCDE (2018d), Base de datos de PISA 2018 (base de datos), www.oecd.org/pisa/ data/2018database/.

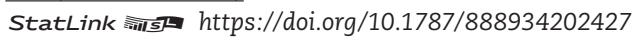




\section{Gráfico 3.23. Uso de las TIC dentro y fuera del centro educativo por nivel socioeconómico y ubicación, promedios de América Latina y el Caribe, 2018}

Proporción de estudiantes que utilizan las TIC dentro y fuera de la escuela para una actividad al menos tres veces por semana

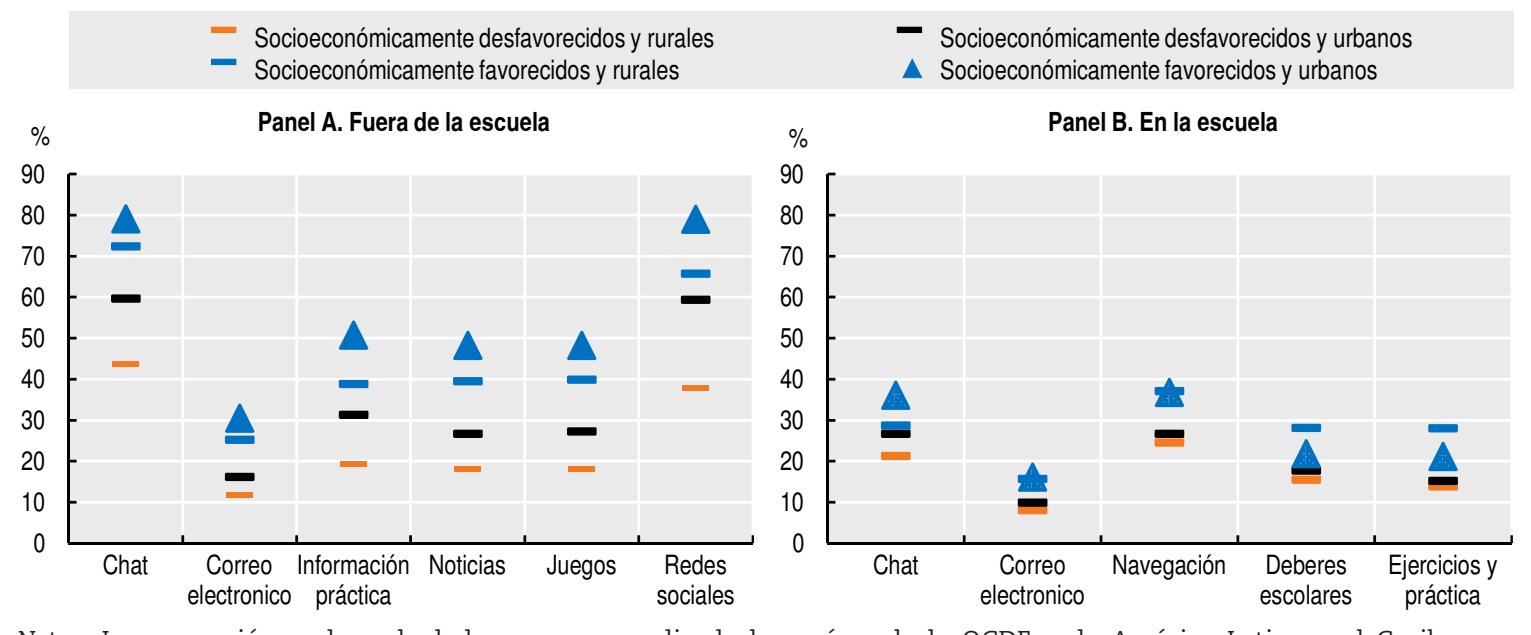

Notas: La proporción se ha calculado como promedio de los países de la OCDE y de América Latina y el Caribe que participaron en el cuestionario de familiaridad con las TIC de PISA. Se considera que los estudiantes pertenecen a entornos socioeconómicos desfavorecidos si sus valores en el índice socioeconómico y cultural de PISA están en el 25\% más bajo de su país o economía. Los estudiantes rurales son aquellos cuya escuela se encuentra en "una aldea, caserío o núcleo rural con menos de 3000 habitantes"; los estudiantes urbanos son aquellos cuya escuela se encuentra en una ciudad de más de 100000 habitantes. Navegar se entiende como "navegar por Internet para hacer tareas escolares" y " descargar, cargar contenidos o navegar el sitio web de la escuela (por ejemplo, la intranet)". "Ejercicios y práctica" se refiere a "practicar y hacer ejercicios, como se hace para aprender idiomas o matemáticas". "Deberes" se refiere a "hacer los deberes en una computadora del centro educativo" y "utilizar las computadoras del centro para el trabajo en grupo y la comunicación con otros estudiantes".

Fuente: Elaboración propia a partir de OCDE (2018d), Base de datos de PISA 2018 (base de datos), www.oecd.org/pisa/ data/2018database/.

StatLink -iाst https://doi.org/10.1787/888934202446

La forma en que la brecha socioeconómica y la de entorno urbano o rural afecta al uso de las TIC se agrava cuando se combinan. Fuera de los centros académicos, las diferencias se registran entre los estudiantes rurales de entornos desfavorecidos y los estudiantes urbanos de entornos favorecidos. Los estudiantes de entornos favorecidos, urbanos o rurales, tienen más probabilidades de utilizar las TIC en la escuela, en comparación con sus compañeros de entornos desfavorecidos, pero las diferencias no son significativas.

\section{Las diferencias de género en el acceso a las tecnologías y en su uso empiezan temprano en la vida}

El género es una dimensión crítica en muchos aspectos de la transformación digital, especialmente en el mercado laboral, el desarrollo de competencias, la participación política y el ciberacoso (ver el Capítulo 4). La perspectiva de género es pertinente para elaborar políticas públicas inclusivas y no discriminatorias que promuevan los derechos económicos y sociales de la mujer, pongan fin a los estereotipos de género y cierren la brecha digital de género.

En el acceso a la tecnología las diferencias de género empiezan temprano en la vida. Tanto en los países de América Latina y el Caribe como en los de la OCDE, los niños tienen 4 puntos porcentuales más de probabilidades que las niñas de comenzar a utilizar dispositivos digitales antes de los 4 años y 5 puntos porcentuales más de comenzar entre los 
4 y los 6 años. Las niñas son aproximadamente 5 puntos porcentuales más propensas que los niños a usar un dispositivo digital por primera vez entre los 10 y los 12 años. Teniendo en cuenta que la exposición temprana tiene una correlación positiva y significativa con mejores resultados en las pruebas PISA, como se ha dicho anteriormente, las niñas están en desventaja desde los primeros años de vida.

\section{Gráfico 3.24. Acceso de los estudiantes a las TIC por género, promedios de la OCDE y de América Latina y el Caribe, 2018}

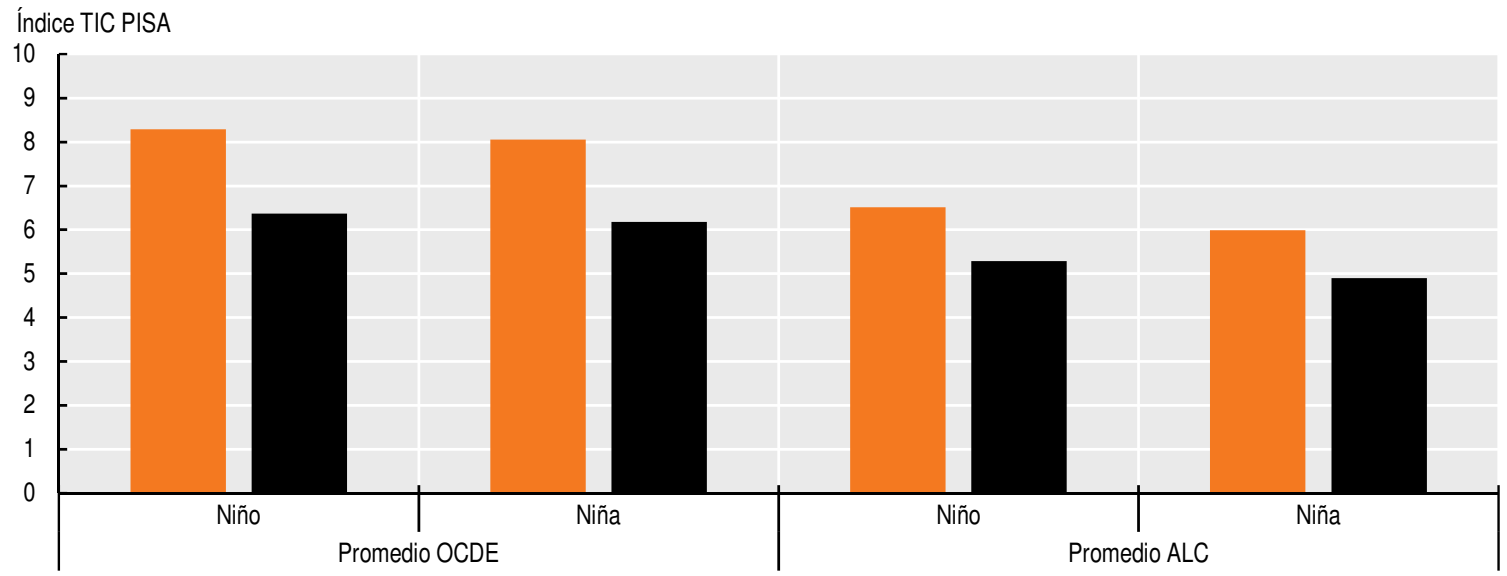

Notas: La diferencia entre niños y niñas es significativa, un 10\% en la OCDE y América Latina y el Caribe para ambos índices. La diferencia entre la OCDE y América Latina y el Caribe es significativa para ambos índices cuando se refiere a niños o a niñas.

Fuente: Elaboración propia a partir de OCDE (2018d), Base de datos de PISA 2018, www.oecd.org/pisa/data/2018database/. StatLink (न्नाs https://doi.org/10.1787/888934202465

Los niños también tienen más acceso a las TIC que las niñas. La brecha de género del acceso es mayor para los estudiantes de América Latina y el Caribe que para el de la OCDE. La diferencia entre niños y niñas en la OCDE y en ALC es significativa para los índices que miden el acceso a las TIC dentro y fuera de los centros educativos. Las niñas de 15 años siguen estando comparativamente menos expuestas a las TIC y, por lo tanto, desarrollan menos habilidades digitales (Gráfico 3.24).

Las diferencias de género son evidentes en el uso de las TIC. La base de datos de PISA obtiene índices basados en las respuestas a la frecuencia con que se utilizan los dispositivos digitales: 1) fuera de los centros educativos para actividades de ocio; 2) fuera de los centros educativos para deberes, y 3 ) en los centros educativos para cualquier tipo de actividad, incluidos correo electrónico, juegos, redes sociales, deberes y publicación de trabajos en el sitio web de la escuela. En promedio, los niños suelen utilizar más las TIC fuera de la escuela para actividades de ocio, tanto en la OCDE como en América Latina y el Caribe. Las diferencias son menos pronunciadas en lo que respecta al uso de las TIC fuera de la escuela para deberes, ya que niños y niñas muestran un uso similar de las TIC para los deberes (Gráfico 3.25). 


\title{
Gráfico 3.25. Uso de las TIC de los estudiantes por género, promedios de la OCDE y de América Latina y el Caribe, 2018
}

\author{
Los índices se transforman a una métrica internacional con un promedio de la OCDE de 0 \\ y una desviación estándar de la OCDE de 1
}
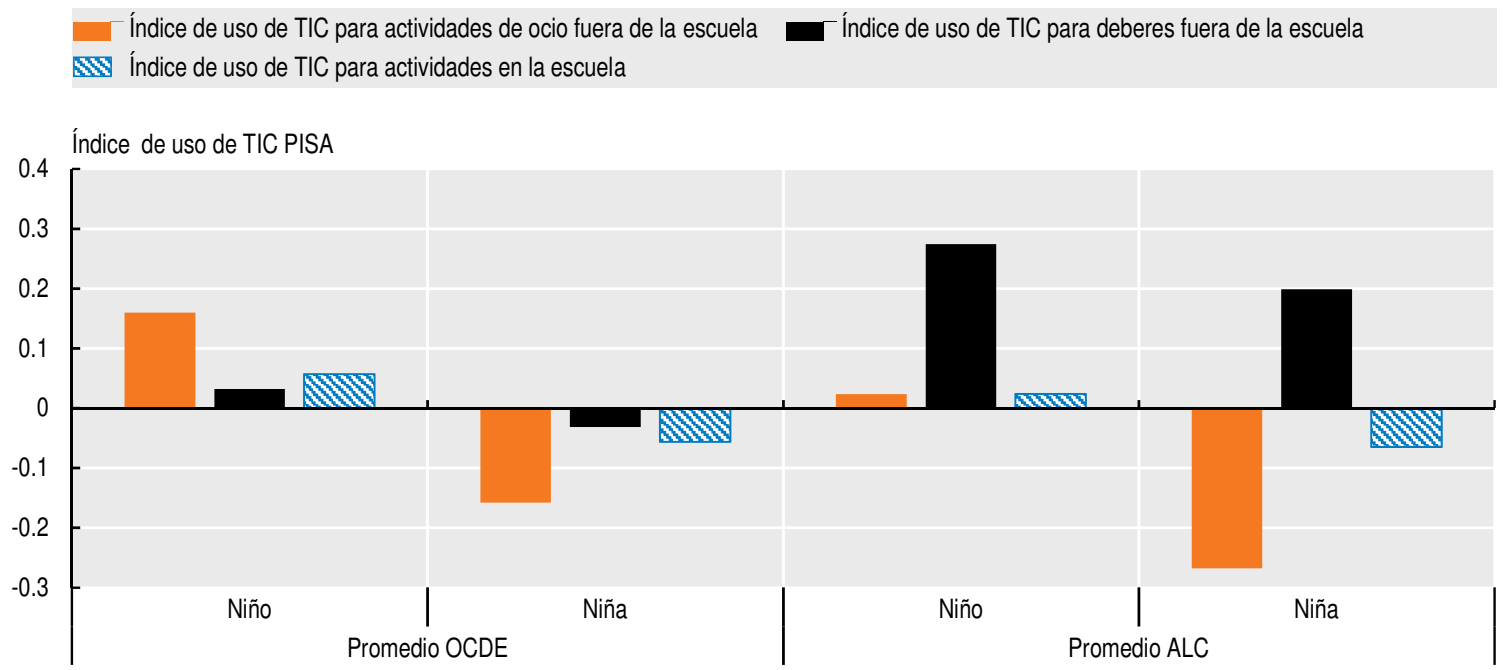

Notas: La diferencia entre niños y niñas es significativa en la OCDE y América Latina y el Caribe solo para el índice ENTUSE (actividades de ocio fuera de la escuela). La diferencia entre la OCDE y América Latina y el Caribe, al referirse a los niños y al comparar las niñas en los dos grupos geográficos, solo es significativa para el índice de deberes fuera de la escuela (HOMESCH) al referirse a las niñas. Tres preguntas del cuestionario de familiaridad con las TIC se refieren a la frecuencia con que los dispositivos digitales se utilizan fuera de la escuela para actividades de ocio (IC008), fuera de la escuela para deberes (IC010) y en la escuela para actividades (IC011). Las posibles respuestas son "nunca o casi nunca", "una o dos veces al mes", "una o dos veces a la semana", "casi todos los días" y "todos los días". Los respectivos índices —ENTUSE (actividades de ocio fuera de la escuela), HOMESCH (deberes fuera de la escuela) y USESCH (uso de las TIC en la escuela)- se escalan utilizando la metodología de la teoría de respuesta al ítem (TRI) (OCDE, 2017b). Se usa la verosimilitud ponderada (WLE), (Warm, 1989) para las respuestas de los participantes individuales y se transforman en parámetros internacionales con un promedio OCDE de 0 y una desviación típica OCDE de 1 (OCDE, 2017b). Los índices de TIC utilizan la metodología de escala de TRI, con el modelo general de escala de clasificación que estima la probabilidad de seleccionar una frecuencia de uso para cada uno de los elementos que forman parte de cada uno de los tres escenarios: fuera de la escuela para actividades de ocio (IC008), fuera de la escuela para deberes (IC010) y en la escuela para actividades (IC011). Los parámetros internacionales de ítems y personas se obtienen en un único análisis a partir de los datos de todas las personas de todos los países. Para cada escala, solo se incluyen las personas con un mínimo de tres respuestas válidas. Los datos de los estudiantes se ponderan a partir de la ponderación final de los estudiantes, y todos los países contribuyen por igual a la estimación. Después de este proceso, la verosimilitud ponderada se utiliza para los resultados individuales de los participantes, donde 0 sugiere una baja frecuencia de uso y valores cercanos a 5 sugieren una alta frecuencia. Por último, PISA deriva una variable que facilita la comparación, y las puntuaciones se transforman en parámetros internacionales con un promedio de la OCDE de 0 y una desviación estándar de la OCDE de 1. Para información detallada sobre la creación de los índices, ver OCDE (2017b).

Fuente: Elaboración propia a partir de OCDE (2018d), Base de datos de PISA 2018 (base de datos), www.oecd.org/pisa/ data/2018database/.

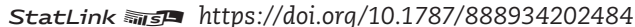

En América Latina y el Caribe, las niñas tienen un peor concepto de sus habilidades en materia de las TIC, menos autonomía para usarlas y no hablan de esas tecnologías en sus interacciones sociales con la misma frecuencia que los niños (Gráfico 3.26). PISA 2015 tiene cuatro variables para medir y comparar este tema: el interés de los estudiantes por las TIC, la competencia percibida en el uso de las TIC, la autonomía percibida en el uso de las TIC, y el grado en que se habla de las TIC en la interacción social diaria. Los estudiantes respondieron con una escala de "totalmente en desacuerdo" a "totalmente de acuerdo" a las declaraciones de autoevaluación en diversas situaciones en relación con esas variables. Dado que las niñas no usan tanto las TIC y no muestran tanta confianza al utilizarlas, se sitúan en desventaja con respecto a los niños, y es probable que eso les disuada de hacer carrera en el ámbito digital o en profesiones relacionadas con las TIC. 


\section{Gráfico 3.26. Habilidades autopercibidas en TIC por género, promedios de la OCDE y de América Latina y el Caribe, 2018}

Índices de percepción de TIC (interés, competencia, autonomía, tema de interacción social). Los índices se transforman en una métrica internacional con un promedio de la OCDE de 0 y una desviación estándar de la OCDE de 1

Interés por las TIC

Autonomía percibida en el uso de las TIC
Competencia percibida en el uso de las TIC

Grado en que las TIC se perciben como tema de interacción social

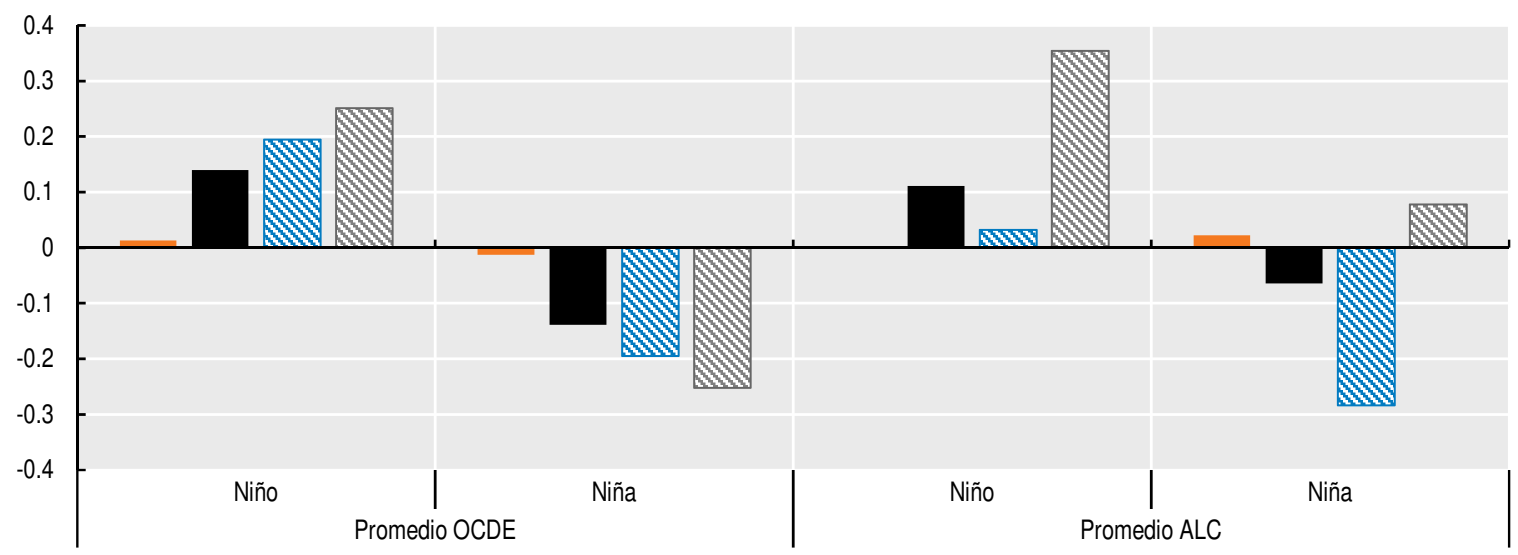

Notas: La diferencia entre niños y niñas es significativa, con un 10\% en la OCDE para los cuatro índices y en América Latina y el Caribe para la competencia percibida en TIC, la autonomía percibida sobre el uso de TIC y las TIC como tema de interacción social. La diferencia entre la OCDE y América Latina y el Caribe es significativa para la autonomía percibida sobre el uso de TIC y para las TIC como tema de interacción social cuando se refiere a los niños y para TIC como tema de interacción social cuando se refiere a las niñas. PISA 2015 incluyó cuatro nuevas preguntas en el cuestionario de familiaridad con las TIC que abordan el interés por las TIC de los estudiantes (IC013, INTICT), la competencia percibida en el uso de las TIC (IC014, COMPICT), la autonomía percibida en el uso de las TIC (IC015, AUTICT) y el grado en que las TIC son un tema en la interacción social (IC016, SOIAICT). Todas las preguntas utilizan una escala de respuesta de Likert de cuatro puntos, que va desde "muy en desacuerdo" a "muy de acuerdo". Se usa la verosimilitud ponderada (WLE) (Warm, 1989) para las respuestas de los participantes individuales y se transforman en parámetros internacionales con un promedio OCDE de 0 y una desviación típica OCDE de 1 (OCDE, 2017b). Los índices de percepción de las TIC utilizan la metodología de escala de la teoría de la respuesta al ítem (TRI), con el modelo general de escala de clasificación que estima la probabilidad de seleccionar una de las cuatro posibles respuestas que expresan el grado de acuerdo con cada afirmación relacionada con el interés de los estudiantes, la autonomía percibida, la competencia percibida y las TIC como tema de interacción social para cada uno de los ítems que forman parte de las cuatro variables. Los parámetros internacionales de ítems y personas se obtienen en un único análisis basado en los datos de todas las personas de todos los países. Los datos de los estudiantes se ponderan a partir de la ponderación final de los estudiantes, y todos los países contribuyen por igual a la estimación. Tras este proceso, la verosimilitud ponderada se utiliza para los resultados individuales de los participantes, donde 0 sugiere un fuerte desacuerdo y los valores cercanos a 4 sugieren un acuerdo considerable. Por último, PISA deriva una variable que facilita la comparación, y las puntuaciones se transforman en parámetros internacionales con un promedio de la OCDE de 0 y una desviación estándar de la OCDE de 1. Para información detallada sobre la creación de los índices, ver OCDE (2017b). Fuente: Elaboración propia a partir de OCDE (2018d), Base de datos de PISA 2018 (base de datos), www.oecd.org/pisa/ data/2018database/.

StatLink न्ताsta https://doi.org/10.1787/888934202503

Las diferencias de género afectan a las opciones futuras y al desarrollo profesional. Los estereotipos de género pueden disuadir a las chicas de hacer una carrera de ciencias. Los centros educativos pueden corregir esos estereotipos y ayudar a todos los estudiantes a tener perspectivas más amplias; por ejemplo, se puede brindar más información sobre las opciones profesionales o de carrera. Los empleadores y los educadores en ámbitos científicos percibidos como masculinos o femeninos pueden ayudar a eliminar los estereotipos subrayando las relaciones entre las disciplinas (OCDE, 2018e, 2016e, 2015b).

En América Latina y el Caribe persisten grandes diferencias de género en la disposición de los estudiantes hacia las carreras relacionadas con la ciencia. Aunque la proporción que decía querer trabajar en una ocupación científica era similar para ambos sexos (34\% de los niños y $35 \%$ de las niñas), al final solían seleccionar ámbitos diferentes (Gráfico 3.27). Las chicas, más que los chicos, solían optar por profesiones relacionadas con la salud; 
los chicos, más que las chicas, optaban por profesiones relacionadas con las TIC, la ciencia o la ingeniería. Dado que los profesionales de las TIC tienen una gran demanda, esta segmentación profesional basada en el género supone una amenaza para ALC. La infrarrepresentación de mujeres en las carreras de TIC puede afectar negativamente al potencial innovador y económico de América Latina y el Caribe, ya que los inventos que surgen de equipos mixtos están mejor valorados social y económicamente, y es menos probable que reproduzcan los sesgos de género en la propia tecnología (Instituto Europeo para la Igualdad de Género, EIGE, 2018; OCDE, 2018e). La baja participación en las carreras de TIC también hace que las mujeres sean más propensas a pasar de largo ante los beneficios económicos del floreciente sector de la tecnología (EIGE, 2018).

\section{Gráfico 3.27. Proporción de estudiantes que quieren hacer carrera en ciencias, tecnología, ingeniería y matemáticas a los 30 años, por género, promedios de la OCDE y América Latina y el Caribe, 2018}

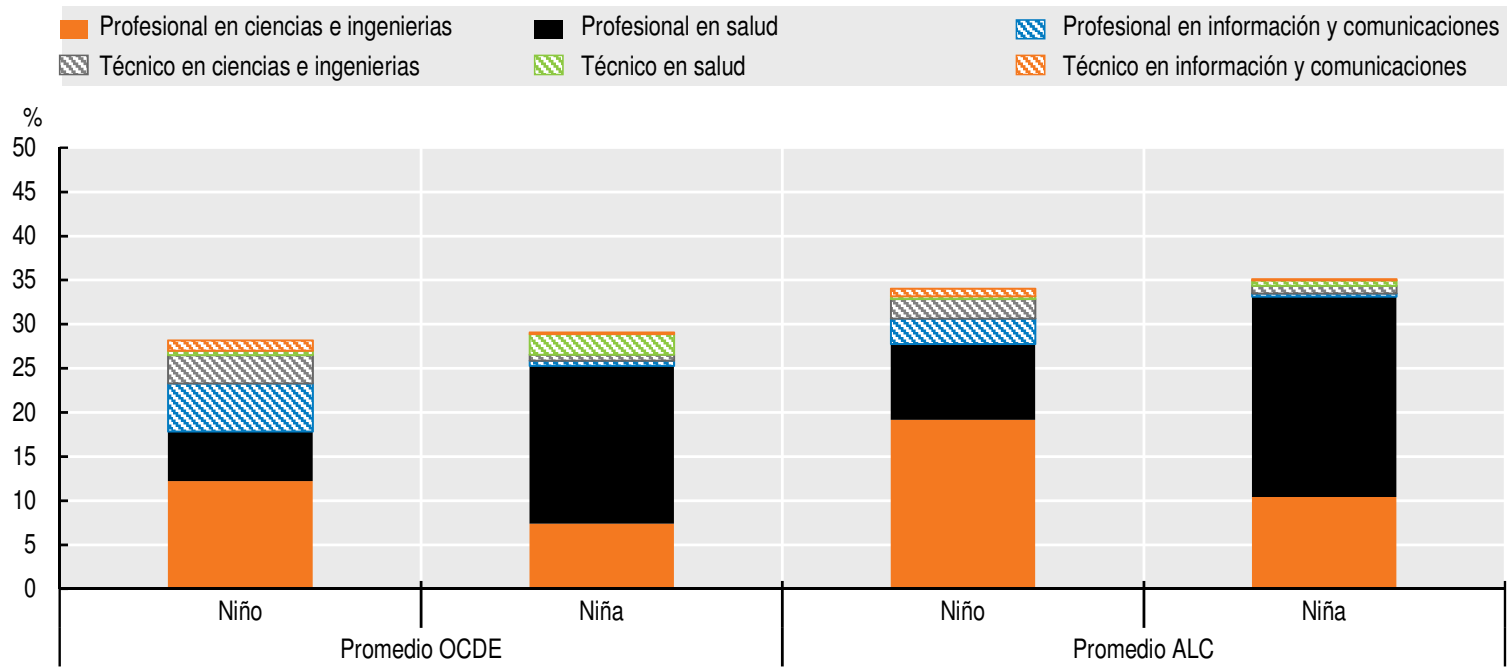

Notas: La diferencia entre géneros es significativa al 10\% en la OCDE para las profesiones relacionadas con la salud, la tecnología de la información y las comunicaciones, técnicos de la salud y técnicos de la información y las comunicaciones. La diferencia por sexos es significativa en América Latina y el Caribe para todas las profesiones, excepto en el caso de los técnicos de salud. La diferencia entre América Latina y el Caribe y la OCDE es significativa al 10\% para los profesionales de la salud cuando se refiere a chicos y, en el caso de las chicas, no es significativa para ninguna ocupación. Según la Resolución sobre la actualización de la Clasificación Internacional Uniforme de Ocupaciones, la carrera relacionada con ciencias incluye a los profesionales de las ciencias y de la ingeniería; profesionales de la salud; profesionales de tecnología de la información y las comunicaciones; técnicos de ciencia e ingeniería y otros profesionales; técnicos de salud y otros profesionales; y técnicos y profesionales de nivel medio en tecnología de la información y las comunicaciones.

Fuente: Elaboración propia a partir de OCDE (2018d), Base de datos de PISA 2018, www.oecd.org/pisa/data/2018database/. StatLink 게내 https://doi.org/10.1787/888934202522

La brecha digital por género tiene múltiples causas; entre ellas, la dificultad de acceso, el menor grado de estudios terminados, el nivel de conocimientos técnicos y tecnológicos, y las normas sociales. Las intervenciones a través de políticas públicas deben mejorar el acceso y las habilidades, pero también deben abordar los sesgos estructurales a largo plazo (OCDE, 2018a). Es preciso que las políticas públicas impulsen la competencia digital de las mujeres y su confianza en lo referente a sus habilidades digitales para que puedan prosperar y participar en igualdad de condiciones en la transformación digital. Las políticas públicas también deben combatir la norma social que contribuye a la brecha digital basada en el género. Por ejemplo, se pueden hacer campañas que transmitan las competencias de la mujer para las profesiones relacionadas con la ciencia, la tecnología, la ingeniería y las matemáticas (STEM) y las TIC; promover modelos de liderazgo femenino, y fomentar el trabajo en equipo de género mixto, especialmente en STEM (OCDE, 2018a). 
Si las mujeres participan más activamente en el mundo digital —por ejemplo, a través de campañas por Internet para sensibilizar sobre la desigualdad de género o la participación en los procesos de formulación de políticas, entre otros-podrán aprovechar los beneficios de las tecnologías digitales (ver el Capítulo 4).

\section{La digitalización y el coronavirus (Covid-19): La brecha que se acentúa}

La crisis del coronavirus (Covid-19) ha puesto sobre la mesa la importancia de la transformación digital, que es la que ha permitido que la actividad de empresas, trabajadores, estudiantes y ciudadanos pudiera tener una cierta continuidad. Con la ampliación de las posibilidades de teletrabajo, los mercados laborales podrían ser más inclusivos, más accesibles para las personas con discapacidad y otros grupos tradicionalmente excluidos. Sin embargo, a la luz de las respuestas de política pública, la brecha digital ahora preocupa más: solo una parte de los trabajadores, estudiantes y consumidores cuenta con las herramientas y las habilidades digitales para beneficiarse de sus ventajas.

Si no se adoptan medidas públicas sólidas, la crisis puede ampliar las disparidades socioeconómicas y geográficas en América Latina y el Caribe. No tener acceso a los servicios públicos básicos o a una vivienda de calidad dificulta el cumplimiento de las medidas de distanciamiento social en hogares pobres y vulnerables. Alrededor del $21 \%$ de la población de ALC vive en barrios marginales, asentamientos informales o viviendas inadecuadas, con más de tres personas por habitación y difícil acceso a servicios básicos como el agua potable (Oxfam, 2020). Estas condiciones dificultan el cumplimiento de las medidas básicas de salud y seguridad, como lavarse las manos y aislar a las personas con síntomas de la enfermedad. Además, el acceso limitado a Internet y la falta de espacios adecuados dificultan el aprendizaje electrónico y el teletrabajo.

La disminución de la actividad económica tendrá repercusiones negativas para el mercado laboral, con un aumento del desempleo de 5.4 puntos porcentuales (CEPAL, 2020a), y para la calidad del empleo, en una región con casi 58\% de informalidad (OCDE, 2020c). Posiblemente, los trabajadores pobres se verán afectados de forma desproporcionada, se ampliarán las desigualdades y se estima que la tasa de pobreza aumentará 7.1 puntos porcentuales en 2020, con un 37.3\% de la población afectada (CEPAL, 2020a).

También es probable que el cierre de empresas —especialmente las que implican interacción personal-y las medidas de cuarentena tengan unos efectos desproporcionados en los trabajadores más pobres (que viven con menos de 5.5 USD per cápita al día, PPA 2011) y a los trabajadores vulnerables (que viven con 5.5-13 USD per cápita al día, PPA 2011). Los trabajadores vulnerables suelen ser informales, tienen empleos de baja calidad, con escasa protección social, y sus ingresos son más inestables (OCDE et al., 2019), lo que les hace más propensos cuando enfrentan choques económicos negativos en los hogares o a nivel macroeconómico. La destrucción de empleos a escala mundial será enorme. La región de América Latina y el Caribe se enfrenta a la posible pérdida de 17 millones de puestos de trabajo en el sector estructurado y a un posible aumento de la presencia de la economía informal hasta el 62\% (Altamirano Montoya, Azuara Herrera y González, 2020).

Las desigualdades derivadas de la pandemia se manifiestan ante todo en la capacidad de trabajar desde casa (Birdsall y Lustig, 2020). De hecho, el porcentaje de trabajos que pueden migrar al teletrabajo se relaciona positivamente con el nivel de PIB per cápita (Dingel y Neiman, 2020) y con menores niveles de informalidad. La composición sectorial del mercado laboral, así como el acceso limitado a las TIC y las capacidades digitales insuficientes de algunos trabajadores afectan la posibilidad de teletrabajo (CEPAL, 2020b). 
La mayoría de los trabajadores pobres y vulnerables de América Latina y el Caribe trabajan con tareas manuales y en sectores bastante más afectados por la crisis del coronavirus (Covid-19) como el comercio minorista, los restaurantes, los hoteles, los servicios, la industria manufacturera, el transporte y la construcción. El $42 \%$ de los trabajadores del sector servicios y el $62 \%$ de comercio y ventas al por menor, restaurantes y hoteles son informales (Altamirano Montoya, Azuara Herrera y González, 2020). Los trabajadores de estos sectores tienen las probabilidades más bajas de poder teletrabajar, desde menos del $5 \%$ en los hoteles y restaurantes hasta alrededor del 15\% para el comercio mayorista y minorista (CEPAL, 2020b). Debido a las características de sus trabajos, informales y de baja calidad, estos trabajadores están más expuestos a las infecciones y tienen un menor acceso a una atención sanitaria de calidad. Por ello, el riesgo de volver a caer en la pobreza es considerable. Además, a estos trabajadores se les hace más difícil cumplir con las medidas de confinamiento, puesto que para obtener ingresos dependen de la interacción social, y la mayoría tiene ahorros limitados, lo que no les permite afrontar un periodo prolongado de inactividad (CEPAL/OIT, 2020). Apoyar a los más vulnerables, a los que viven en la pobreza y a los trabajadores del mercado informal será decisivo para contrarrestar las desigualdades creadas por el coronavirus (Covid-19) (OCDE, 2020c).

A pesar de los avances de América Latina y el Caribe en el acceso a la infraestructura de las TIC, los trabajadores pobres y vulnerables quedan especialmente excluidos de sus beneficios. Aunque pudieran trabajar a distancia, en promedio, aproximadamente solo un $15 \%$ de los trabajadores pobres y un $25 \%$ de los trabajadores vulnerables de América Latina y el Caribe tienen acceso a una computadora con conexión a Internet para trabajar desde casa. Por el contrario, el 50\% de los trabajadores de clase media (que viven con 13-70 USD per cápita al día, PPA 2011) y el 81\% de los trabajadores más acomodados (que viven con más de 70 USD per cápita al día, PPA 2011) disponen de las TIC necesarias. Además, como se ha visto, muy pocos trabajadores tienen una buena competencia digital, incluidos los conocimientos informáticos y la capacidad de resolver problemas en entornos con fuerte presencia tecnológica (Gráfico 3.11).

El aumento de la conectividad y la oferta de programas de capacitación pueden ayudar a los trabajadores a adaptarse más rápidamente al teletrabajo, pero también es necesario abordar las dificultades de quienes no pueden trabajar a distancia. La recuperación económica debería ir de la mano de políticas públicas que prioricen la salud y la seguridad en el lugar de trabajo. Las condiciones del lugar de trabajo, el distanciamiento social en las instalaciones y los desplazamientos deben tenerse en cuenta al diseñar los protocolos de vuelta al trabajo (CEPAL/OIT, 2020).

Las mujeres trabajadoras están más expuestas a las dificultades materiales asociadas a las consecuencias económicas de la pandemia. En general, las mujeres tienen una mayor probabilidad que los hombres de ser vulnerables ante cualquier pérdida de ingresos provocada por una crisis. Los ingresos y el patrimonio de las mujeres son, en promedio, más bajos que los de los hombres, y su tasa de pobreza es más elevada. Las mujeres también pueden experimentar más dificultad para encontrar trabajo y, en caso de despido, les es más difícil conseguir ingresos porque es más habitual que tenga terceros a cargo. Alrededor del 10\% de las mujeres que trabajan en la región son empleadas del hogar, con tareas de cuidado y limpieza, y la mayoría no tienen contrato formal (Oxfam, 2020). Además, los sectores con sobrerrepresentación femenina — viajes, turismo, servicios de alojamiento, alimentación y bebidas, y venta al por menor, entre otros- han sido los más afectados por la crisis. Por otro lado, si bien el teletrabajo reduce algunos efectos económicos inmediatos de las medidas de distanciamiento social, solo una pequeña parte de las trabajadoras de esos sectores pueden acogerse a ello, y algunas deben hacer frente a más responsabilidades y costos por cuidados, debido al cierre de escuelas y porque deben hacerse cargo de familiares vulnerables (OCDE, 2020d). 
La crisis sanitaria está cambiando el mundo laboral y puede tener efectos duraderos en el futuro del mercado de trabajo. El papel de la transformación digital se hará más evidente en el día a día si persisten los cambios para hacer frente a la pandemia. El teletrabajo, el aprendizaje a distancia y otras estrategias observadas durante el confinamiento señalan la necesidad de fortalecer la infraestructura de las comunicaciones y las habilidades digitales; ayudar a los empleadores, empleados y estudiantes universitarios a prepararse mejor; y aumentar la resiliencia de los sistemas (OCDE, 2020e). Las administraciones públicas deben apoyar a las empresas, especialmente a las pequeñas y medianas, a los trabajadores por cuenta propia y a los empleados, para que adquieran rápidamente las habilidades para el teletrabajo y el comercio electrónico rápidamente, y también deben elaborar políticas públicas que se adecuen a estos cambios (OCDE, 2020f).

Los efectos negativos de la crisis dependerán asimismo de la rapidez con que la sociedad y los gobiernos se adapten a las nuevas formas de trabajo, como los empleos de las economías bajo demanda y de plataformas (gig and platform economies), los contratos de cero horas y a tiempo parcial, y el teletrabajo. Los sectores más afectados por la crisis emplean a una gran proporción de trabajadores atípicos (trabajadores a tiempo parcial, independientes y con contrato a plazo fijo). Muchos tienen un menor acceso a la protección social y a las prestaciones de salud, y tienen más probabilidades de perder su trabajo (OCDE, 2020g). Las medidas de política pública deben fijar las condiciones para que las empresas actúen de forma adecuada y para evitar efectos distributivos no deseados a largo plazo. Urge contar con un mercado laboral más flexible que absorba nuevas formas de trabajo, con sistemas de seguridad social y disposiciones en materia de salud y seguridad en el trabajo.

Las políticas públicas deberían sensibilizar a los consumidores con respecto a la compra de bienes y servicios, y al acceso a los servicios públicos en línea. El acceso a los servicios públicos, de salud y bancarios por medio de las tecnologías digitales puede ser más eficiente y, además, permite respetar el distanciamiento social. La disponibilidad de servicios, la asequibilidad y la competencia digital limitan la adopción de las tecnologías digitales y el uso del Internet en muchos países. La falta de sensibilización y de conocimientos sobre las TIC afecta sobre todo a los hogares rurales y a los adultos mayores (Galperin, 2017); es decir, a aquellos especialmente vulnerables al virus y que más se beneficiarían de hacer las actividades diarias a distancia.

La pandemia puede asimismo ampliar las desigualdades en educación. Con el cierre de los centros educativos en casi todos los países de América Latina y el Caribe, el aprendizaje en línea es fundamental (Unicef, 2020). En cuestión de días, los directores y el equipo docente pasaron a coordinar las clases virtuales y de radiodifusión, preparar material de aprendizaje a distancia y reorganizar el funcionamiento de los sistemas de alimentación escolar (Basto-Aguirre, Cerutti y Nieto-Parra, 2020). A pesar de esos esfuerzos, los sistemas educativos de América Latina y el Caribe tienen una capacidad limitada para impartir enseñanza a distancia de calidad: no todos los hogares cuentan con la tecnología necesaria; no todas las familias están preparadas para asumir las tareas de enseñanza, al tiempo que tratan de trabajar o de encontrar trabajo. La suspensión de las clases presenciales puede afectar en mayor medida a los estudiantes de países de bajos ingresos y de entornos socioeconómicos desfavorecidos. El cierre de las escuelas pone límites al aprendizaje y puede traducirse en pérdidas de ingresos y productividad laboral (Psacharopoulos et al., 2020). El alcance de los efectos en la acumulación de capital humano y los futuros ingresos dependerá de la respuesta de los gobiernos.

Solo unas pocas escuelas de América Latina estaban preparadas para el aprendizaje digital antes de la pandemia. Los estudiantes de 15 años que asisten a centros de entornos favorecidos de la región tienen más probabilidades de acceder a una plataforma eficaz de 
apoyo al aprendizaje en línea que los que asisten a centros de entornos desfavorecidos (Gráfico 3.28). De esta forma, la falta de preparación puede ampliar las diferencias socioeconómicas en materia de educación.

Además, las herramientas tecnológicas son útiles solo si se sabe usarlas. En promedio, el $58 \%$ de los jóvenes de 15 años de la región asistían a escuelas cuyos directores consideraban que el cuerpo docente tenía los conocimientos técnicos y pedagógicos necesarios para integrar los dispositivos digitales en la programación. Esto pone de relieve la urgente necesidad de capacitación que tienen por delante los sistemas educativos. Son significativas las diferencias en términos de capacidad de enseñanza digital de los centros con ventajas socioeconómicas y de los que están en entornos socioeconómicamente desfavorecidos. En Colombia, tres de cada cuatro centros educativos de entornos favorecidos declaraban estar preparados, en comparación con menos de la mitad de los centros de entornos desfavorecidos. Por tanto, los centros educativos pueden ampliar, en lugar de reducir, la desventaja relativa de los estudiantes (OCDE, 2020h). Casi la mitad de los países de ALC proporcionaron orientación o capacitación sobre la participación con estudiantes de forma remota. Uno de cada tres centros proporcionó orientaciones sobre las comunicaciones, pero no sobre enseñanza a distancia; solo el $18 \%$ de los centros proporcionó ambas (Vargas, 2020).

\section{Gráfico 3.28. Disponibilidad de una plataforma eficaz de apoyo al aprendizaje en línea por nivel socioeconómico de los centros educativos, países seleccionados de América Latina, 2018}

Porcentaje de estudiantes en centros educativos cuyos directores estaban de acuerdo o muy de acuerdo en que tenían una plataforma eficaz de apoyo al aprendizaje en línea, PISA 2018

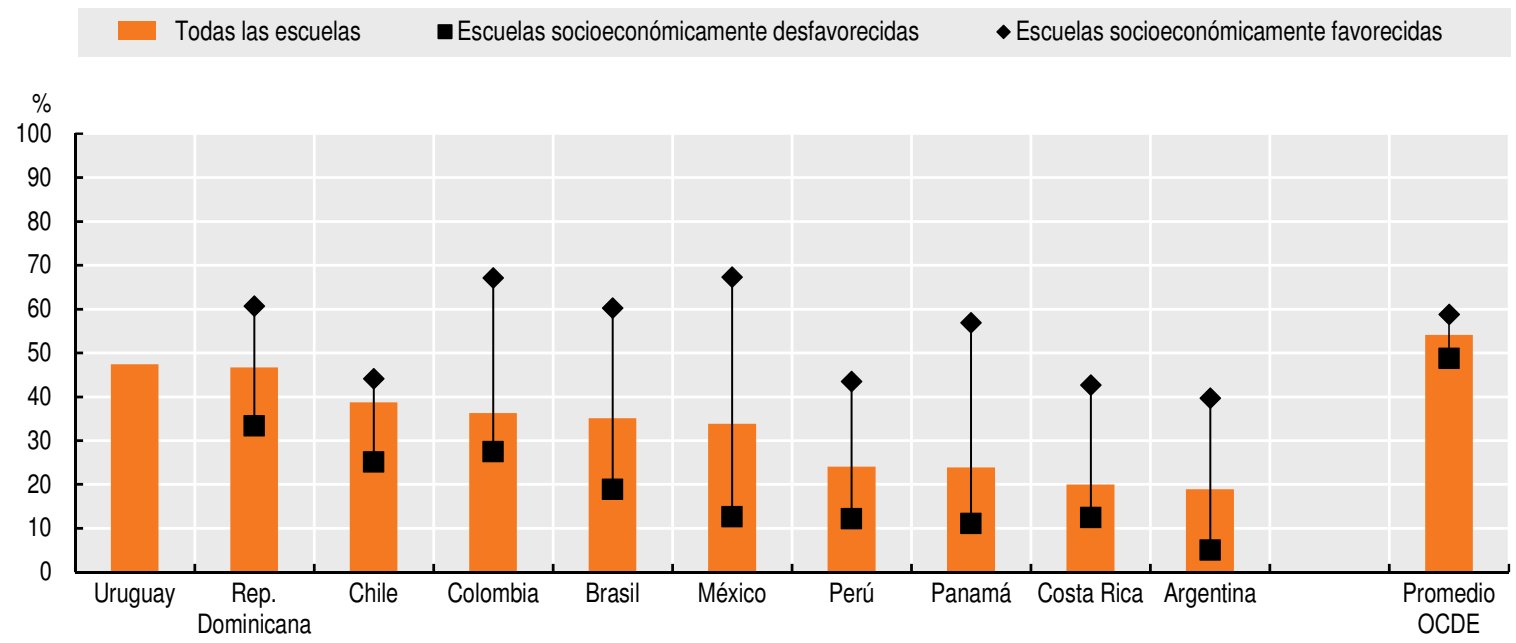

Nota: Los centros educativos de entornos socioeconómicos desfavorecidos (favorecidos) son aquellos en los que la situación socioeconómica promedio de los estudiantes se encuentra en el cuartil inferior (superior) del ISEC de PISA entre todos los centros educativos del país / de la economía. Los países/economías están clasificados en orden descendente, según el porcentaje de escuelas con una plataforma de apoyo eficaz al aprendizaje en línea. La diferencia entre escuelas desfavorecidas y favorecidas en Uruguay no es estadísticamente significativa.

Fuente: OCDE (2018d), Base de datos de PISA 2018 (base de datos), www.oecd.org/pisa/data/2018database/.

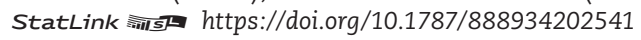

El nivel de preparación de los hogares también es pertinente. Al igual que con el teletrabajo, estudiar a distancia se hace difícil o imposible para los estudiantes de hogares vulnerables y pobres. La computadora y el acceso a Internet en el hogar son requisitos para el aprendizaje en línea. Alrededor del 34\% de los estudiantes de educación primaria; el $41 \%$ de secundaria y el $68 \%$ de educación superior tienen acceso a una computadora con conexión a Internet. Las cifras de acceso son especialmente bajas para los estudiantes 
de los hogares más pobres. Por ejemplo, menos del $14 \%$ de los estudiantes pobres de educación primaria tienen una computadora conectada a Internet en casa, en comparación con más del $80 \%$ de estudiantes pudientes con el mismo nivel educativo (Gráfico 3.29) (Basto-Aguirre, Cerutti y Nieto-Parra, 2020). Tener acceso a un lugar para estudiar también puede influir en los resultados de la educación a distancia. En países como México, uno de cada cuatro estudiantes carece de un espacio tranquilo para estudiar en casa; para la región, el promedio supera uno de cada cinco estudiantes sin espacio propio para el estudio (OCDE, 2020h).

Gráfico 3.29. Proporción de estudiantes matriculados en educación primaria con una computadora en casa por grupo de ingresos, 2018 o último año disponible

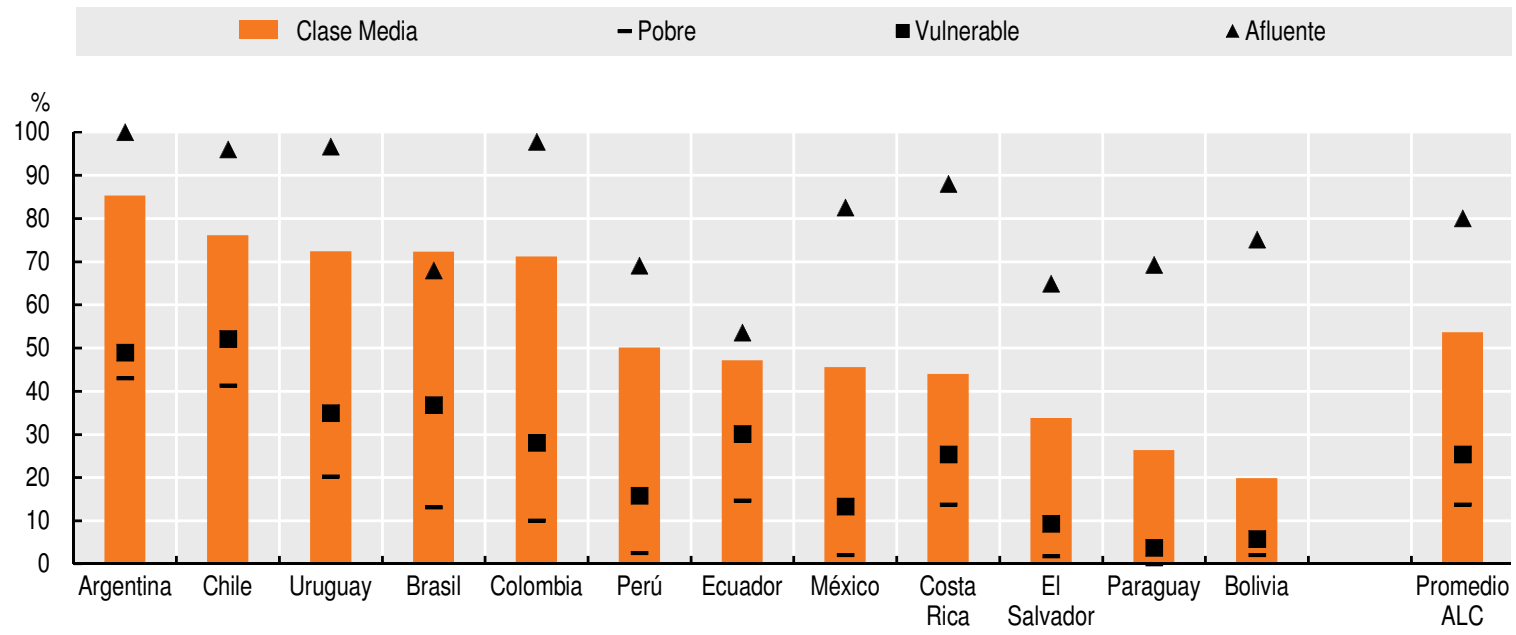

Nota: El promedio regional es un promedio simple. Son pobres quienes viven con menos de 5.5 USD per cápita al día (PPP 2011). Vulnerables, aquellos que viven con 5 a 13 USD diarios per cápita (PPP 2011). Clase media, aquellos que viven con 13 a 70 USD diarios per cápita (PPP 2011). Y los afluentes son aquellos que viven con más de 70 USD diarios per cápita (PPP 2011). Fuente: Basto-Aguirre, Cerutti and Nieto-Parra (2020).

StatLink तilst https://doi.org/10.1787/888934202560

Las diferencias de aprendizaje entre los estudiantes de entornos favorecidos y de entornos desfavorecidos eran amplias antes de la pandemia. En Brasil y Uruguay, los estudiantes de 15 años en entornos favorecidos llevaba cuatro años de ventaja en ciencias al de entornos más desfavorecidos (OCDE, 2018d). Los estudiantes de entornos desfavorecidos suelen experimentar una mayor pérdida de aprendizaje si no van a la escuela (Alexander, Entwisle y Olson, 2001; Quinn et al., 2016) y, en promedio, con independencia de las asignaturas y los cursos, pierden unos tres meses más de aprendizaje que los estudiantes de ingresos medios (Busso y Camacho Muñoz, 2020; Cooper et al., 1996; Evans y Yuan, 2018). En particular, en comparación con sus compañeros de entornos favorecidos, los estudiantes de entornos desfavorecidos tienden a perder conocimientos de matemáticas y lectura. El acceso a los materiales de aprendizaje y escolares en el hogar explica en parte esta diferencia. El coronavirus (Covid-19) puede ampliar estos resultados, pues los centros educativos, las familias y los estudiantes de entornos favorecidos están mejor equipados, formados y posicionados para mitigar los efectos del cierre de escuelas. Aunque los efectos de la pandemia en educación todavía no se pueden cuantificar, los estudiantes de entornos favorecidos, que suelen estar entre los que logran mejores resultados, podrían seguir aprendiendo casi como si los centros estuvieran abiertos, mientras que los estudiantes de entornos desfavorecidos, que suelen estar entre los de peor rendimiento, podrían quedar más rezagados (Iqbal et al., 2020). 
Para superar tanto el cierre de los centros escolares como la falta de conectividad, y evitar la ampliación de las desigualdades educativas durante la pandemia, los sistemas de educación latinoamericanos aprovecharon su experiencia con la llegada a zonas remotas y la difusión de contenidos educativos a través de los medios de comunicación. Para reducir las desigualdades no basta con garantizar que todos los estudiantes tengan acceso a la infraestructura de las comunicaciones. Las inversiones también debe abordar la formación de profesores para que introduzcan dispositivos digitales en su práctica docente, y fortalecer las habilidades cognitivas y digitales para que los estudiantes aprovechen al máximo la transformación digital. La crisis del coronavirus (Covid-19) podría brindar una oportunidad para ofrecer propuestas políticas que aceleren la transformación de los sistemas educativos, con efectos positivos a largo plazo que contribuyan a cerrar la brecha socioeconómica en cuanto a calidad de la educación y habilidades. Al mismo tiempo, para que no se amplíe la brecha, los sistemas están incorporando otros canales, como la radio y la televisión, en combinación con plataformas en línea, redes sociales y materiales impresos tradicionales para apoyar a los estudiantes y a las familias que carecen de la infraestructura de las comunicaciones necesaria (Basto-Aguirre, Cerutti y Nieto-Parra, 2020).

Aumentar la conectividad, la infraestructura para el aprendizaje y las alternativas para la prestación de servicios educativos a las zonas remotas es fundamental para mitigar los efectos negativos. Además de abordar la apremiante necesidad de ofrecer formación a distancia, las administraciones deben elaborar estrategias para un regreso a las aulas exitoso (OCDE, 2020i).

La crisis del coronavirus (Covid-19) ha demostrado que el acceso a Internet y a las TIC, así como su uso, son necesidades básicas para la igualdad de oportunidades. La tecnología digital permite que los trabajadores puedan acceder a ingresos sostenidos; los estudiantes, a un aprendizaje de alta calidad, y los consumidores, a los servicios básicos. Para evitar que las desigualdades se agudicen, los países no solo deben proporcionar acceso a las TIC, instalaciones, equipos y contenidos digitales, sino que también deben velar por que trabajadores, estudiantes y consumidores tengan las competencias básicas, cognitivas y digitales para beneficiarse en igualdad de condiciones.

\section{Conclusión}

La digitalización está transformando la forma de trabajar, consumir, comunicarse y aprender, y el modo en que las familias, la sociedad y las empresas funcionan. Las nuevas tecnologías brindan numerosas oportunidades para la inclusión social, política y económica. Para sacar el máximo beneficio de este nuevo contexto, las personas deben ser resilientes y adaptarse a las nuevas exigencias del mundo digital en el hogar, el trabajo y los centros educativos. Los gobiernos, el sector privado y la ciudadanía deberían colaborar para integrar a las personas en la sociedad con instrumentos digitales que mejoren los servicios, la información y el empleo.

En América Latina y el Caribe, hay más gente que nunca conectada a Internet, pero hay brechas que persisten y pueden surgir unas nuevas. El acceso a Internet y su uso se han vuelto más equitativos en comparación con otros servicios públicos como la educación secundaria o las pensiones. Aun así, menos de cuatro de cada diez hogares con ingresos mensuales per cápita en el quintil inferior no usan Internet, lo que contrasta con casi ocho de cada diez en el quintil superior. Si nos fijamos en cómo se usa Internet según el nivel educativo, la brecha se hace evidente; la inclusión socioeconómica depende tanto del acceso como de las habilidades digitales.

En el mercado laboral, las nuevas tecnologías brindan oportunidades, pero también presentan desafíos. Basados en las estimaciones que usan la metodología de 
automatización de ocupaciones, dos de cada diez puestos de trabajo corren un alto riesgo de automatización en los países de América Latina y el Caribe. Además, teniendo en cuenta la sustitución de tareas dentro de las ocupaciones, en promedio, el 25\% de los empleos en Chile, Ecuador, México y Perú están en alto riesgo de automatización, y el $35 \%$ puede experimentar cambios sustanciales en las tareas y en cómo se llevan a cabo. Las políticas para apoyar la transición de los trabajadores de industrias en declive hacia nuevos trabajos y avanzar hacia la protección social universal son fundamentales. La protección social debe reformarse para proteger a los trabajadores y promover la inclusión en un mundo laboral cambiante, incluyendo la garantía de un tratamiento más neutral de las diversas formas de trabajo para prevenir el arbitraje entre ellos, ampliar el alcance de los sistemas de protección social existentes a nuevas formas de trabajo y el aumento de la portabilidad de los derechos y prestaciones entre los programas de seguridad social destinado a distintos grupos del mercado laboral (OCDE, 2019b).

Los países pueden facilitar la transformación digital y mejorar la vida de la ciudadanía fomentando la infraestructura y las habilidades necesarias para aprovechar las oportunidades de la digitalización. La accesibilidad y la calidad de los datos móviles y de la conexión a Internet siguen siendo una cuestión importante en muchos países de América Latina y el Caribe. Sin embargo, la mejora de la conectividad es solo el primer paso para aprovechar al máximo las tecnologías y oportunidades digitales (OCDE, 2019c). Hasta ahora, las políticas para impulsar los beneficios de la digitalización han prestado mayor atención a aumentar el acceso y la conectividad que a la calidad de la experiencia o el uso. Los gobiernos, mediante su intervención en el mercado laboral y las políticas educativas, deben identificar y abordar las brechas en materia de competencias básicas y habilidades digitales que pueden ampliar la brecha digital. Deben, asimismo, elaborar estrategias integrales en relación con las habilidades, en coherencia con sus estrategias productivas, incluyendo la etapa de la educación infantil y la formación continua para que las habilidades cognitivas, metacognitivas, técnicas y digitales lleguen a todos.

Para lograr la transición hacia un mundo de trabajo digital y prosperar, no solo se necesitan habilidades digitales, sino también otras competencias, incluidas habilidades cognitivas y socioemocionales (OCDE, 2019a). Los países de América Latina que han participado en la Evaluación Internacional de Competencias de Adultos (PIAAC) y en PISA van rezagados en habilidades digitales y habilidades básicas, y acceso a herramientas digitales, por lo que se infiere que una gran parte de la población tal vez no tenga las competencias necesarias para hacer frente a la transformación digital y beneficiarse de ella. En el caso de los trabajadores cuyos puestos de trabajo se están reconfigurando a causa de la transformación digital, los recursos digitales amplían sus oportunidades de formarse y desarrollar nuevas habilidades de forma flexible (OCDE, 2020b).

Si se quiere cerrar brechas, es fundamental trabajar las habilidades digitales a una edad temprana y a lo largo del ciclo de vida. Hay una mayor proporción de mujeres que de hombres, con menores no tiene experiencia informatica y también hay diferencias entre la población de mayor nivel económico y más educación, y la población más vulnerable y con menos formación académica. En todos los niveles de educación y formación, las nuevas tecnologías ofrecen oportunidades de aprendizaje. Las nuevas tecnologías en el ámbito de la educación pueden apoyar el desarrollo de las habilidades del siglo XXI. El cuerpo docente desempeña un papel fundamental para que la transformación digital sea inclusiva, puede integrar las tecnologías digitales en el aula y velar por que las TIC tengan un efecto positivo en el aprendizaje. Esto exige una alta capacitación de los profesores, amplia y apropiada. No basta con que los centros educativos y los estudiantes de entornos desfavorecidos tengan más acceso a las TIC; hay que ofrecer programas para que se trabajen las habilidades necesarias. 
Durante las crisis, suelen ampliarse las desigualdades. En América Latina y el Caribe, las medidas para contener el coronavirus (Covid-19 han evidenciado las brechas digitales entre empresas, individuos y países, entre los que asimilan la tecnología y los que se quedan atrás. Durante la pandemia, la transformación digital ha sido esencial para continuar las actividades cotidianas y preservar puestos de trabajo. Las tecnologías digitales han desempeñado un papel importante para mitigar el impacto de los ingresos de los hogares, los trabajadores y las empresas con un nivel socioeconómico privilegiado. Las familias, los trabajadores y los estudiantes con acceso a Internet y a las TIC siguieron haciendo su vida casi como de costumbre, manteniendo su nivel de ingresos y aprendiendo. No obstante, los que quedaron desconectados de la digitalización quedaron aún más rezagados. Menos de la mitad de los latinoamericanos tenía suficiente experiencia en el uso de computadoras y herramientas digitales para tareas profesionales básicas, por lo que muchos quedaron excluidos de las actividades a distancia. La lucha contra la brecha digital puede producir empleos mejores y más productivos, fomentar la inclusión y el acceso a los servicios públicos y crear sociedades más preparadas para hacer frente a las crisis que acompañan a una economía cada vez más globalizada.

La crisis del coronavirus (Covid-19) hizo de la transformación digital inclusiva una máxima prioridad, para atenuar los efectos negativos y acelerar la recuperación económica inclusiva. La necesidad de adoptar una transformación digital beneficiosa para todos es una de las principales lecciones extraídas de la crisis, y puede ser una oportunidad para que los países le den el protagonismo que se merece en sus agendas digitales (ver el Capítulo 4).

Las sociedades que aspiran a la igualdad de oportunidades deben permitir que todos alcancen su pleno potencial. La tecnología digital promete grandes avances en esa dirección. Sin embargo, para evitar que las desigualdades heredadas se amplifiquen, para que la tecnología beneficie a todos por igual, los países deben ampliar el acceso a esas tecnologías y hacer que las habilidades necesarias lleguen a los centros educativos, a los estudiantes, a los hogares y a los trabajadores. Las medidas de política pública deben ofrecer una respuesta rápida y articular con eficacia el proceso de transformación digital como factor clave del bienestar social. 


\section{Anexo 3.A1. Datos seleccionados a nivel de país sobre el acceso a Internet} y el uso de las TIC

Gráfico 3.A1.1. Distribución del acceso y uso de Internet y otros servicios por decil de ingresos, países seleccionados de América Latina, 2017 o último año disponible
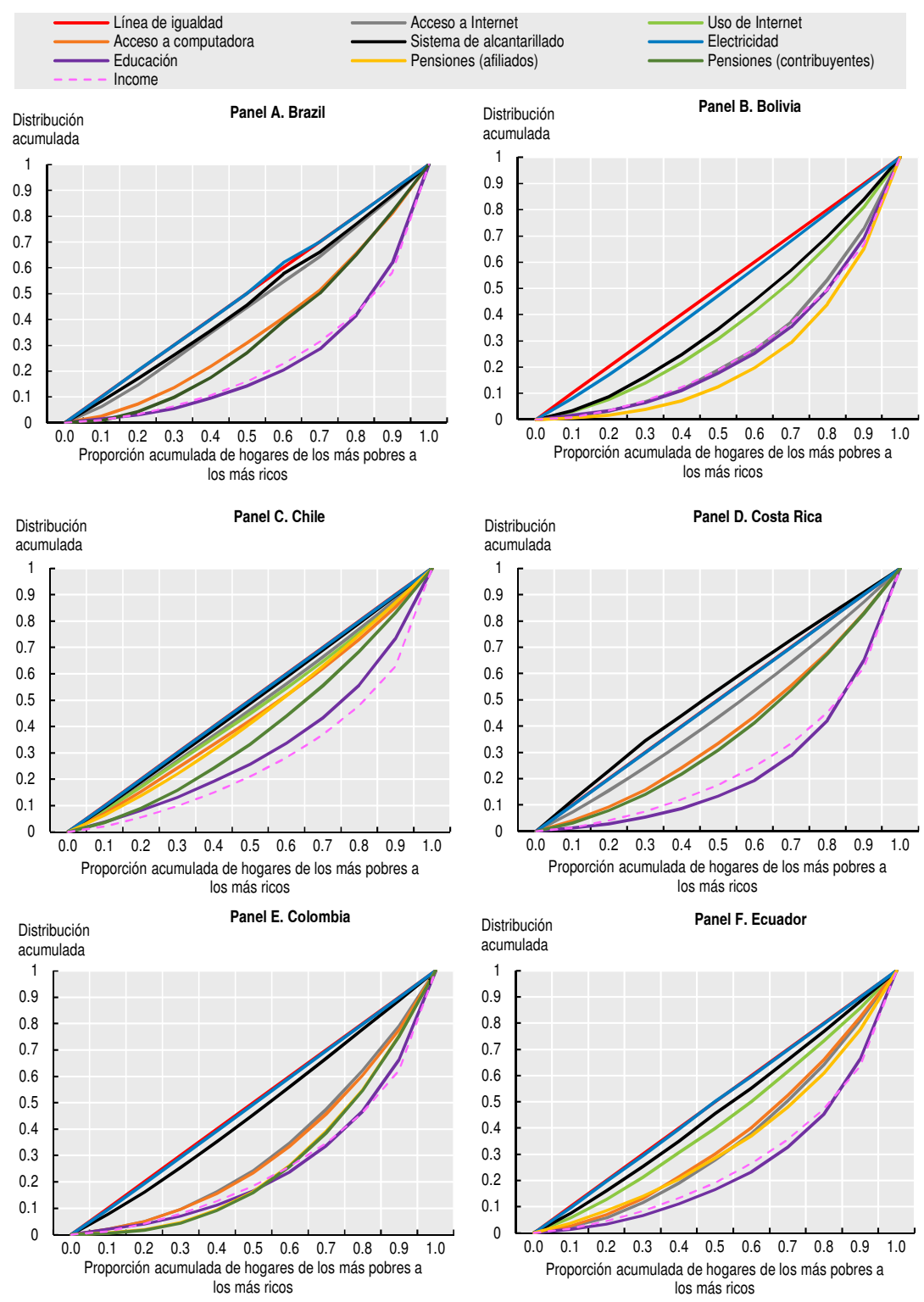
Gráfico 3.A1.1. Distribución del acceso y uso de Internet y otros servicios por decil de ingresos, países seleccionados de América Latina, 2017 o último año disponible (cont.)

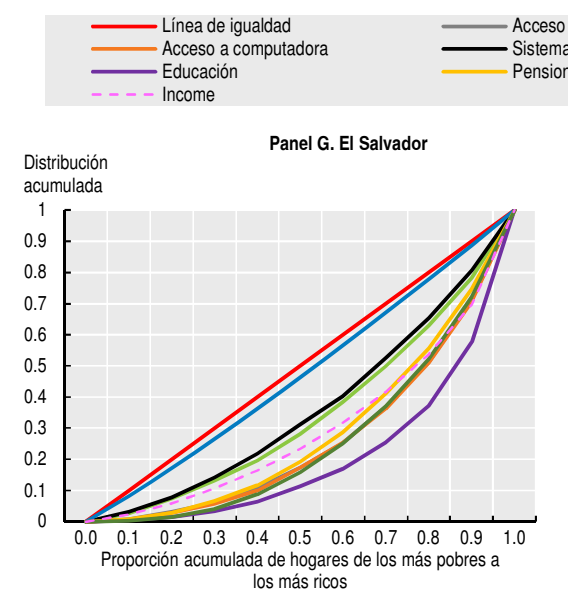

los más ricos
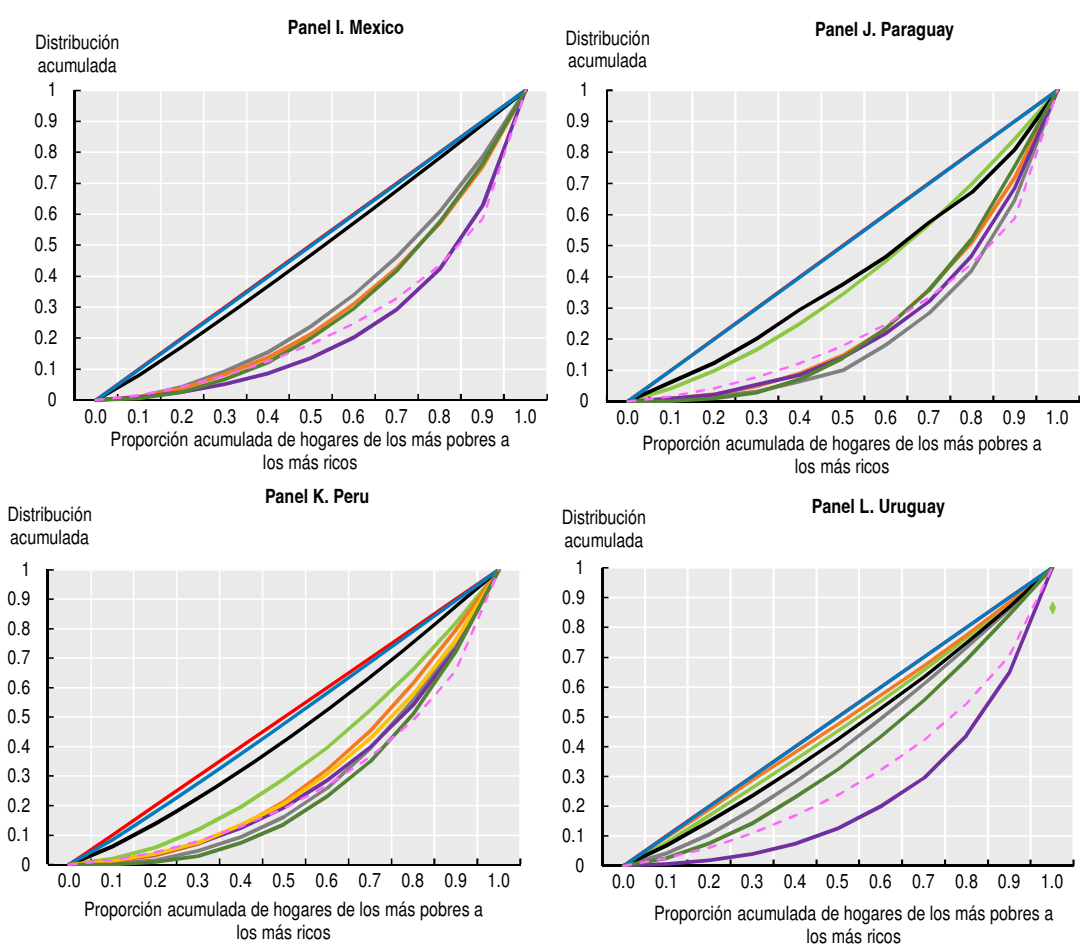

Notas: Promedio simple por decil para países seleccionados de América Latina y el Caribe. Eje $\mathrm{X}=$ decil de ingresos. Eje $\mathrm{Y}=$ porcentaje acumulativo de personas con acceso a Internet y a la computadora en el hogar; porcentaje acumulativo de personas que declaran haber usado Internet en los 3 o 12 meses anteriores, según la pregunta de la encuesta de hogares; porcentaje acumulativo de personas en un hogar con alcantarillado o electricidad, y porcentaje acumulativo de personas de 20 años o más con al menos educación secundaria. Cálculos a partir de las encuestas de hogares de 2017 o el último año disponible: 2016 para Bolivia, Honduras y México. La edad en que se empieza a usar Internet varía según el país: en El Salvador y Paraguay, a partir de los 10 años; en Bolivia, Chile, Ecuador y Honduras, a partir de los 5 años, y en Perú y Uruguay, a partir de los 6 años. Por período anterior de uso de Internet, según los datos de la encuesta, se entienden los tres meses anteriores en el caso de Bolivia, Honduras, Paraguay y Uruguay, y los 12 meses anteriores en el caso de Chile, Ecuador y El Salvador. Otras variables incluyen todas las edades. Brasil, Chile, Costa Rica, Ecuador, El Salvador, Paraguay y Uruguay incluyen los datos móviles en el acceso a Internet. Bolivia, Colombia, México y Perú no especifican si se incluyen los datos móviles. Bolivia, Brasil, Chile, Costa Rica, Ecuador, Paraguay y Uruguay incluyen computadoras portátiles y tabletas en el acceso a computadora. Colombia, El Salvador, México y Perú no especifican si se incluyen las computadoras portátiles o las tabletas.

Fuente: Elaboración propia a partir de ORBA/CEPAL (2019), Banco de Datos de Encuestas de Hogares (base de datos), www.cepal. org/es/observatorio-regional-de-banda-ancha.

StatLink तinst https://doi.org/10.1787/888934202579 


\section{Gráfico 3.A1.2. Uso de las TIC por actividad, países seleccionados de América Latina}

Proporción de personas que realizan la actividad según la frecuencia (\%)

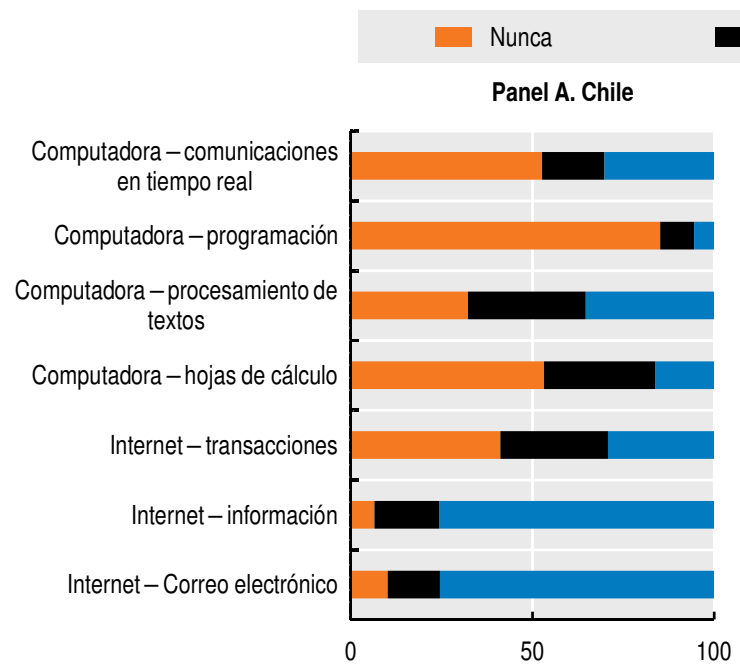

Menos de una vez por semana $\quad \square$ Al menos una vez por semana

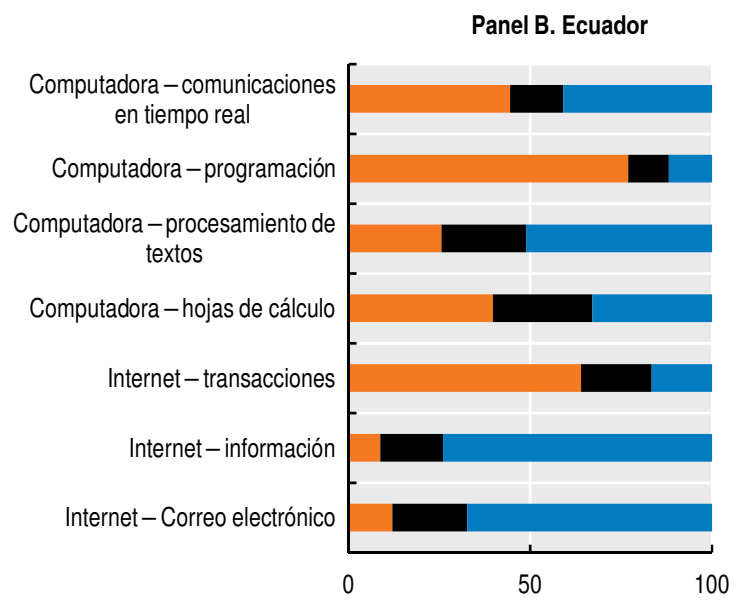

Panel C. México
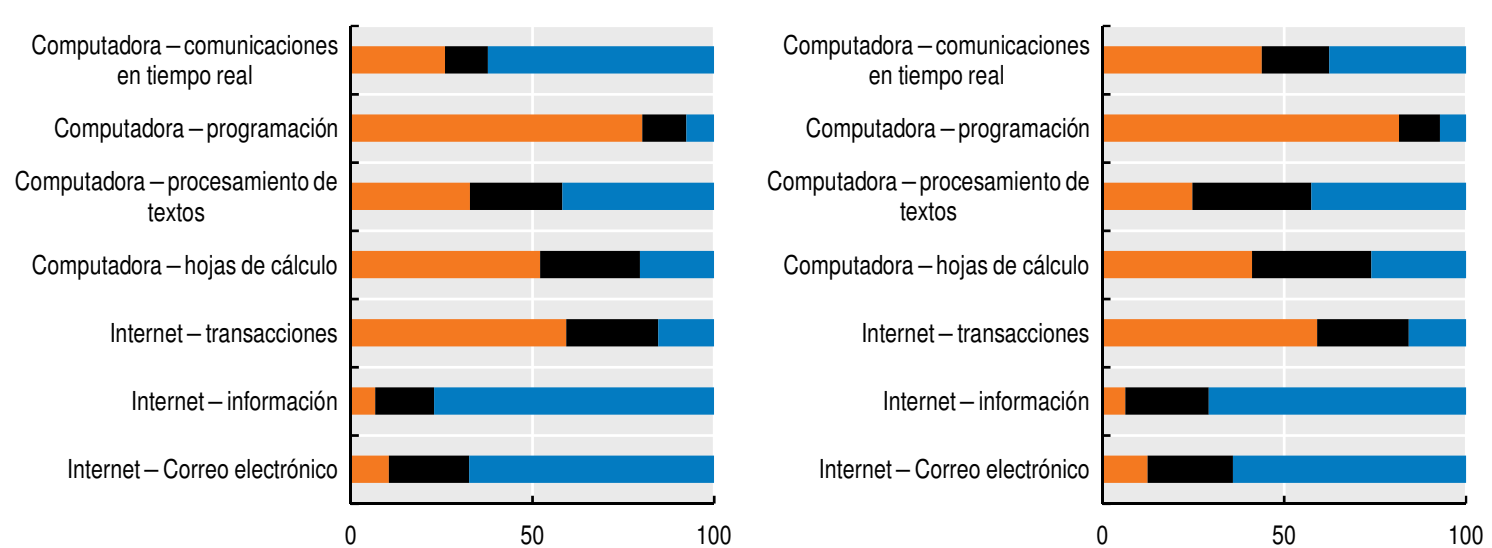

Nota: El promedio de América Latina es un promedio simple que incluye a Chile, Ecuador, México y Perú. Chile participó en la segunda ronda de la Evaluación Internacional de Competencias de Adultos (PIAAC), y el resto de los países de América Latina y el Caribe (México, Perú y Ecuador), en la tercera ronda.

Fuente: Elaboración propia a partir de OCDE/PIAAC (2018), Evaluación Internacional de Habilidades de Adultos (base de datos), www.oecd.org/skills/piaac/data/.

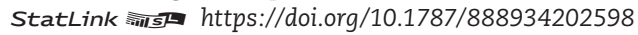




\section{Gráfico 3.A1.3. Uso de las TIC en el trabajo por actividad, países seleccionados de América Latina}

Proporción de personas que realizan la actividad según la frecuencia (\%)

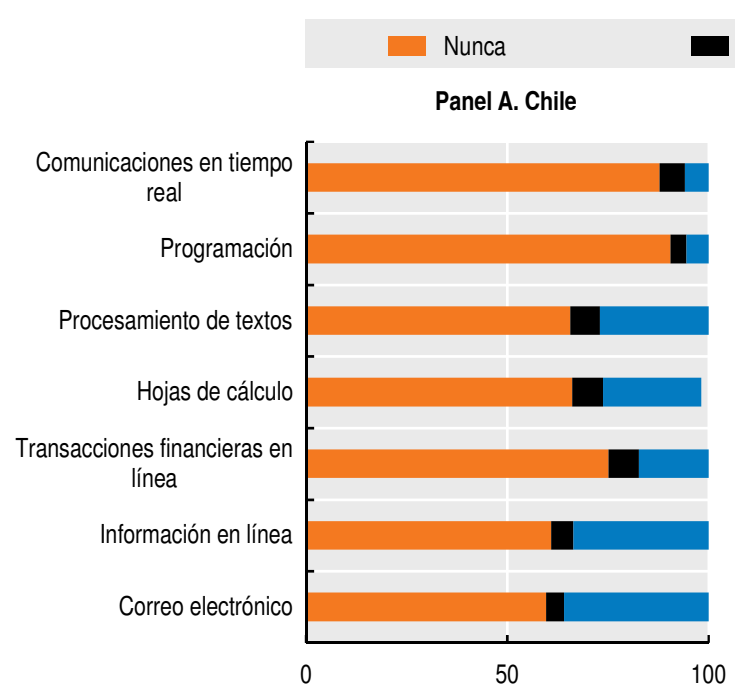

Menos de una vez por semana

Al menos una vez por semana

Panel A. Chile

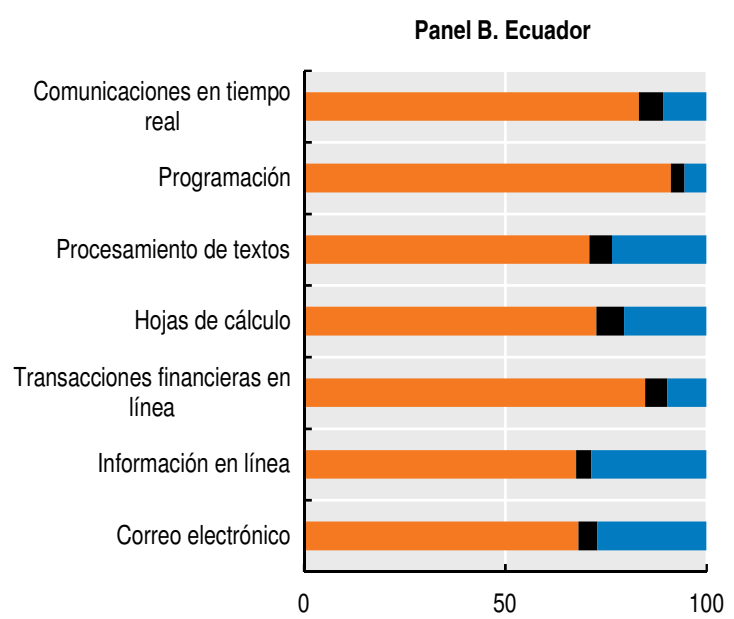

Panel C. México
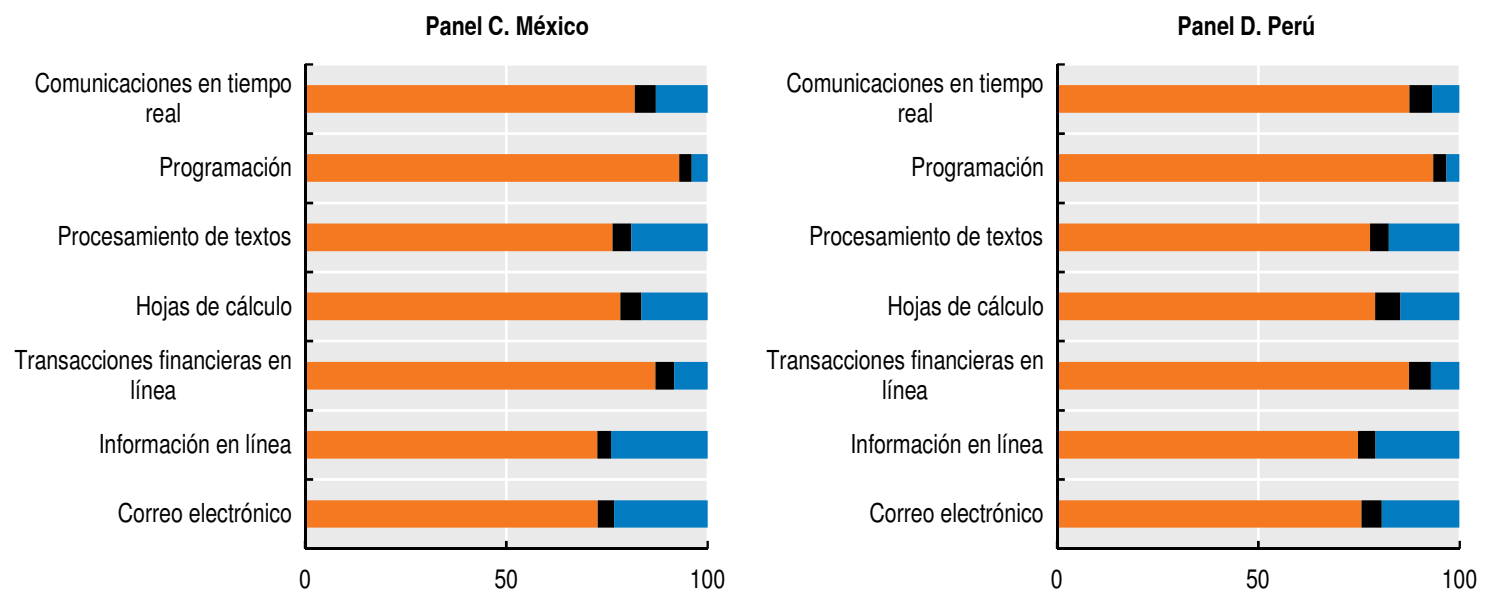

Nota: "Nunca" incluye a los trabajadores que nunca han usado una computadora o que no usan las TIC en el trabajo. Chile participó en la segunda ronda de la Evaluación Internacional de Competencias de Adultos (PIAAC), y el resto de los países de América Latina y el Caribe (México, Perú y Ecuador), en la tercera ronda.

Fuente: Elaboración propia a partir de OCDE/PIAAC (2018), Evaluación Internacional de Competencias de Adultos (base de datos), www.oecd.org/skills/piaac/data/.

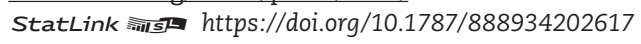

\section{Notas}

1. Los usuarios de Internet se calculan sobre la base de estimaciones y datos de encuestas correspondientes a la proporción de personas que utilizan internet. El número debe reflejar la población total del país de al menos 5 años o más cuando sea posible.

2. El índice de uso de habilidades TIC en el trabajo es una variable derivada de PIAAC. En el cuestionario de antecedentes recopila información sobre las actividades relacionadas con la competencia lectora y matemática de los encuestados, el uso de las TIC en el trabajo y en la vida cotidiana, y las competencias genéricas requeridas en el trabajo. El índice trata de resumir la frecuencia con la que se realizan determinadas actividades laborales. Se pregunta a los encuestados sobre su uso de las TIC (correo electrónico, Internet, hojas de cálculo, procesamiento de textos, programación, transacciones en línea, comunicaciones en línea, como llamadas grupales o chats) y se les pide que indiquen la frecuencia con que hacen cada actividad en una escala de "nunca" a "todos los días". El índice se reajusta mediante el modelo 
de escala de clasificación general (generalised partial credit model). Ver The Survey of Adult Skills: Reader's Companion (OCDE, 2019e). Esta información se recopila mediante el cuestionario de antecedentes de la Evaluación de Competencias de Adultos (Survey of Adult Skills), donde se pregunta sobre las habilidades lectora, matemática, las habilidades TIC y otras competencias en el trabajo y en la vida cotidiana. Las preguntas relativas a las actividades relacionadas con las TIC (uso de computadoras, correo electrónico, Internet para información, Internet para transacciones, hojas de cálculo, procesamiento de textos, programación de computadoras, Internet para comunicaciones en tiempo real) tratan de medir el nivel general de uso de las habilidades TIC en términos de frecuencia y complejidad. Los índices de uso de otras competencias incluyen la capacidad matemática, la expresión escrita, la comprensión lectora, la planificación y la capacidad de persuasión. La característica principal de los ítems es el orden tras las posibles respuestas: las alternativas consecutivas indican una mayor frecuencia de una tarea detallada en un elemento determinado, que va de 0 (nunca) a 4 (a diario). El Programa para la Evaluación Internacional de las Competencias de Adultos (PIAAC) utiliza un modelo general de escala de clasificación, un modelo de teoría de respuesta al ítem (TRI), que resulta en una escala unidimensional continua que explica la covarianza entre las respuestas al ítem: las personas con un nivel más alto en la escala derivada tienen mayor probabilidad de realizar esa tarea con frecuencia. Las personas que declaran no haber hecho nunca ninguna de las tareas de la escala de la TRI quedan descartadas. Los ítems utilizados para el cálculo de las escalas relacionadas con el uso de las competencias TIC en el trabajo y en el hogar solo se plantean a las personas que informan haber utilizado anteriormente una computadora. Los índices derivados de la TRI son variables continuas, que deben interpretarse como representativas del nivel de utilización de las habilidades subyacentes y que, para facilitar la comparación, se han normalizado para tener una media igual a 2 y una desviación típica igual a 1 en toda la muestra conjunta de encuestados de todos los países/economías (debidamente ponderada). Esto da como resultado unos índices para los cuales al menos el $90 \%$ de las observaciones se encuentran entre 0 y 4; los valores cercanos a 0 sugieren una baja frecuencia de uso y los valores cercanos a 4 sugieren una alta frecuencia. Para más información sobre la creación de los índices, ver OCDE (2019d, 2019e).

3. En este capítulo se utilizan datos de los centros educativos, de los estudiantes y de los cuestionarios opcionales de familiaridad con las TIC de los informes PISA de 2012, 2015 y 2018. De los diez países latinoamericanos que participaron en PISA 2018, Argentina, Colombia y Perú no utilizaron el cuestionario de familiaridad con las TIC. Ver OCDE (2017b, 2016d, 2016e). Salvo indicación contraria, el promedio de América Latina y el Caribe incluye a todos los países que participaron en cada ronda de PISA, y omite a los que no tienen datos disponibles para las variables TIC.

4. Los índices de disponibilidad de TIC son variables derivadas del cuestionario de familiaridad con las TIC de PISA (OCDE, 2017b). Se basan en la suma de las tecnologías disponibles en el hogar y en la escuela. En el hogar, se incluye lo siguiente: computadora de escritorio, computadora portátil o notebook, tableta, conexión a Internet, consola de videojuegos, teléfono celular, smartphone, reproductor de música portátil, impresora, memoria USB y lector de libros electrónicos. En el centro educativo, se incluye lo siguiente: computadora de escritorio, computadora portátil o notebook, tableta, computadora escolar conectada a Internet, conexión inalámbrica a Internet, espacio de almacenamiento de datos del centro, memoria USB, lector de libros electrónicos, proyector de datos y pizarra electrónica.

\section{Referencias}

A4AI (2019), Affordability Report: Americas 2019, Alliance for Affordable Internet, Washington, DC, https://a4ai.org/affordability-report/report/2019/.

Alexander, K., D. Entwisle y L. Olson (2001), "Schools, achievement, and inequality: A seasonal perspective", Educational Evaluation and Policy Analysis, vol. 23, n. ${ }^{\circ}$ 2, American Educational Research Association, Washington, DC, pp. 171-191, disponible en www.jstor.org/stable/3594128? seq=1.

Altamirano Montoya, A., O. Azuara Herrera, S. González (2020), ¿Cómo Impactará la COVID-19 al empleo?: Posibles escenarios para América Latina y el Caribe, Banco Interamericano de Desarrollo, Washington, DC, http://dx.doi.org/10.18235/0002301.

Amaral, N. et al. (2018), "How far can your skills take you: Understanding skill demand changes due to occupational shifts and the transferability of workers across occupations", Labour Markets and Social Technical Note, IDB-TN-01501, IDB Labour Markets and Social Security Division, Banco Interamericano de Desarrollo, Washington, DC, http://dx.doi.org/10.18235/0001291.

APC (2020), "Conectar lo no conectado: apoyo a las redes comunitarias y otras iniciativas de conectividad con base en la comunidad", Asociación para el Progreso de las Comunicaciones, Melville, ZA, www.apc.org/es/project/conectar-lo-no-conectado-apoyo-las-redes-comunitarias -y-otras-iniciativas-de-conectividad. 
Arntz, M., T. Gregory y U. Zierahn (2016), "The risk of automation for jobs in OECD Countries", OECD Social, Employment and Migration Working Papers, n. ${ }^{\circ}$ 189, Publicaciones de la OCDE, París, https://doi.org/10.1787/1815199X.

Azuara Herrera, O. et al. (2019), The future of work in Latin America and the Caribbean: What are the most in-demand occupations and emerging skills in the region?, Banco Interamericano de Desarrollo, Washington, DC, http://dx.doi.org/10.18235/0001677.

Banerjee, A. et al. (2007), "Remedying education: Evidence from two randomized experiments in India", The Quarterly Journal of Economics, vol. 122, n. ${ }^{\circ}$, Oxford University Press, Oxford, pp. 1235-1264, http://dx.doi.org/10.1162/qjec.122.3.1235.

Basto-Aguirre, N., P. Cerutti y S. Nieto-Parra (2020), "COVID-19 can widen educational gaps in Latin America: Some lessons for urgent policy action” (blog), Vox Lacea, Bogotá, https://vox.lacea. org/? q=blog/covid19 widen educational gaps.

Berlingieri, G., P. Blanchenay y C. Criscuolo (2017), “The great divergence(s)”, OECD Science, Technology and Industry Policy Papers, n. ${ }^{\circ}$ 39, Publicaciones de la OCDE, París, https://doi.org/10.1787/ 953f3853-en.

Beuermann, D. W. et al. (2015), "One Laptop per Child at home: Short-term impacts from a randomized experiment in Peru”, American Economic Journal: Applied Economics, vol. 7, n. ${ }^{\circ}$ 2, American Economic Association, Nashville, pp. 53-80, http://dx.doi.org/10.1257/app.20130267.

Birdsall, N. y N. Lustig (2020), "The new inequalities and people-to-people social protection", Center for Global Development, Washington, DC, www.cgdev.org/blog/new-inequalities-andpeople-people-social-protection.

Bulman, G. y R. Fairlie (2016), “Chapter 5 - Technology and education: Computers, software, and the Internet", en Handbook of the Economics of Education, vol. 5, Elsevier B.V., Ámsterdam, pp. 239-280, http://dx.doi.org/10.1016/B978-0-444-63459-7.00005-1.

Busso, M. y J. Camacho Munoz (2020), "Pandemia y desigualdad: ¿cuánto capital humano se pierde cuando los colegios cierran?", BID Mejorando vidas, Banco Interamericano de Desarrollo, Washington, DC, https://blogs.iadb.org/ideas-matter/en/pandemic-and-inequality-how-muchhuman-capital-is-lost-when-schools-close/.

Bustelo, M. et al. (2020), "Automation in Latin America: Are women at higher risk of losing their jobs?", IDB Working Paper Series; 1137. http://dx.doi.org/10.18235/0002566.

Cooper, H. et al. (1996), "The effects of summer vacation on achievement test scores: A narrative and meta-analytic review", Review of Educational Research, vol. 66, n. ${ }^{\circ}$, American Educational Research Association, Washington, DC, pp. 227-268, disponible en www.jstor.org/stable/1170523.

Cunha, F., J. Heckman y S. Schennach (2010), "Estimating the technology of cognitive and noncognitive skill formation”, Econometrica, vol. 78, n. ${ }^{\circ}$ 3, Wiley Online Library, pp. 883-931, http://dx.doi.org/10.3982/ECTA6551.

Demoussis, M. y N. Giannakopoulos (2006), "Facets of the digital divide in Europe: Determination and extent of Internet use", Economics of Innovation and New Technology, vol. 15, n. 3 , Taylor \& Francis Online, pp. 235-246, http://dx.doi.org/10.1080/10438590500216016.

Denoël, E. et al. (2017), "Drivers of student performance: Insights from Europe", McKinsey \& Company, Nueva York, www.mckinsey.com/industries/social-sector/our-insights/drivers-ofstudent-performance-insights-from-europe.

Dewan, S. y F. Riggins (2005), “The digital divide: Current and future research directions”, Journal of the Association for Information Systems, vol. 6, n. ${ }^{\circ} 12$, Association for Information Systems, Atlanta, pp. 298-337, https://pdfs.semanticscholar.org/d6c1/18d8c0461b350e9925103db435776714781d. pdf (consultada el 17 de octubre de 2018).

Dingel, J. and B. Neiman (2020), "How many jobs can be done at home?", Journal of Public Economics, Vol 189, 2020, 104235, ISSN 0047-2727, https://doi.org/10.1016/j.jpubeco.2020.104235.

CEPAL (2019), Observatorio Regional de Banda Ancha (base de datos), a partir del Banco de Datos de Encuestas de Hogares ORBA/CEPAL (base de datos); la muestra de hogares con acceso a Internet incluye Bolivia (2016), Chile (2017), Colombia (2017), Costa Rica (2017), Ecuador (2017), Paraguay (2017), Uruguay (2017), El Salvador (2017), Brasil (2017) y Perú (2017), Comisión Económica para América Latina y el Caribe, Santiago, www.cepal.org/es/observatorio-regional-de-banda-ancha (consultada el 12 de septiembre de 2019).

CEPAL (2020a), "Addressing the growing impact of COVID-19 with a view to reactivation with equality: New projections", Comisión Económica para América Latina y el Caribe, Santiago, www.cepal.org/en/publications/45784-addressing-growing-impact-covid-19-viewreactivation-equality-new-projections.

CEPAL (2020b), "Universalizing access to digital technologies to address the consequences of COVID-19”, Special Report COVID-19, n. ${ }^{\circ}$, Comisión Económica para América Latina y el Caribe, Santiago, https://repositorio.cepal.org/handle/11362/45939. 
CEPAL/OIT (2020), "El trabajo en tiempos de pandemia: Desafíos frente a la enfermedad por coronavirus (COVID-19)", Coyuntura Laboral en América Latina y el Caribe, n. 22 (LC/TS.2020/46), Comisión Económica para América Latina y el Caribe / Organización Internacional del Trabajo, Santiago, www.cepal.org/en/publications/45582-employment-situation-latin-americaand-caribbean-work-times-pandemic-challenges.

EIGE (2018), Gender Equality and Digitalisation in the European Union, factsheet, European Institute for Gender Equality, Vilnius, https://eige.europa.eu/publications/gender-equality-and-digitalisationeuropean-union.

Escueta, M. et al. (2017), "Education technology: An evidence-based review", NBER Working Paper, n. ${ }^{\circ}$ 23744, National Bureau of Economic Research, Cambridge, www.nber.org/papers/w23744.

Evans, D. y F. Yuan (2018), "Equivalent years of schooling: A metric to communicate learning gains in concrete terms", World Bank Policy Research Working Paper, n. ${ }^{\circ}$ WPS 8752, Grupo Banco Mundial, Washington, DC, http://documents.worldbank.org/curated/en/123371550594320297/EquivalentYears-of-Schooling-A-Metric-to-Communicate-Learning-Gains-in-Concrete-Terms.

Fairlie, R. (2004), "Race and the digital divide”, Contributions to Economic Analysis \& Policy, vol. 3, n. ${ }^{\circ} 1$, Berkeley Electronic Press, Berkeley, pp. 1-40, https://econpapers.repec.org/article/bpjbejeap/v 3acontributions.3_3ay_3a2004_3ai_3a1_3an_3a15.htm (consultada el 17 de octubre de 2018).

Frey, C. y M. Osborne (2017), "The future of employment: How susceptible are jobs to computerisation?", Technological Forecasting and Social Change, vol. 114, Elsevier Inc., Ámsterdam, pp. 254-280, http://dx.doi.org/10.1016/j.techfore.2016.08.019.

Galperin, H. (2017), "Why are half of Latin Americans not online? A four-country study of reasons for Internet non-adoption", International Journal of Communication, vol. 11, University of Southern California Annenberg Press, Los Ángeles, pp. 3332-3354, https://ijoc.org/index.php/ijoc/article/ view/6287.

Hargittai, E. y Y. Hsieh (2013), Digital Inequality, Oxford University Press, Oxford, http://dx.doi. org/10.1093/oxfordhb/9780199589074.013.0007.

BID (2020), Internet Para Todos: Helping Latin America to Log On, Technologies, Banco Interamericano de Desarrollo, Washington, DC, www.iadb.org/en/improvinglives/internet-para-todos-helpinglatin-america-log.

BID (2011), Conexiones del desarrollo: Impacto de las nuevas tecnologías de la información, Banco Interamericano de Desarrollo, Washington, DC, https://publications.iadb.org/en/publication/ 16270/development-connections-unveiling-impact-new-information-technologies-summary.

Iqbal, S. A. et al. (2020), "Se debe evitar aplanar la curva de la educación - Posibles escenarios de pérdida en los aprendizajes durante el cierre de escuelas" (blog), Grupo Banco Mundial, Washington, DC, https://blogs.worldbank.org/education/we-should-avoid-flattening-curveeducation-possible-scenarios-learning-loss-during-school (consultada el 16 de abril de 2020).

UIT (2019), Base de Datos de Indicadores Mundiales de las Telecomunicaciones (base de datos), Unión Internacional de Telecomunicaciones, Ginebra, www.itu.int/pub/D-IND-WTID.OL-2019.

J-PAL Evidence Review (2019), “Will technology transform education for the better?”, J-PAL Evidence Review, Abdul Latif Jameel Poverty Action Lab, Cambridge, www.povertyactionlab.org/sites/ default/files/2020-03/education-technology-evidence-review.pdf.

Katz, R. (2018), Capital Humano para la Transformación Digital en América Latina, Serie Desarrollo Productivo, Comisión Económica para América Latina y el Caribe, Santiago, www.cepal.org/es/ publicaciones/43529-capital-humano-la-transformacion-digital-america-latina.

Katz, R. (2017), "Social and economic impact of digital transformation on the economy”, Documento de debate presentado en el GSR-17 de la Unión Internacional de Telecomunicaciones, Nassau, www.itu.int/en/ITU-D/Conferences/GSR/Documents/GSR2017/Soc Eco impact Digital transformation finalGSR.pdf.

MAEUEC (2020), Contribución de las empresas españolas al desarrollo sostenible en Iberoamérica, Ministerio de Asuntos Exteriores, Unión Europea y Cooperación de España, Madrid, www.espanha-brasil. org/img/documentos/2020 05 DOC\%20CONTRIBUCION\%20EMPRESAS\%20final.pdf.

Malamud, O. et al. (2018), "Do children benefit from internet access? Experimental evidence from Peru", NBER Working Paper, n. ${ }^{\circ}$ 25312, National Bureau of Economic Research, Cambridge, http://dx.doi.org/10.3386/w25312.

Melo, G., A. Machado y A. Miranda (2014), "The impact of a One Laptop per Child Program on learning: Evidence from Uruguay", Discussion Paper, n. ${ }^{\circ} 8489$, Centro de Investigación y Docencia Económicas / Institute of Labor Economics, México / Bonn, http://ftp.iza.org/dp8489.pdf.

MINTEL (2019), Ecuador Digital, Ministerio de las Telecomunicaciones y de la Sociedad de la Información de Ecuador, Quito, www.telecomunicaciones.gob.ec/wp-content/uploads/2019/05/ PPT-Estrategia-Ecuador-Digital.pdf. 
MinTIC (2019), "MinTIC anuncia inicio de nuevo proyecto que conectará 1.000 zonas rurales en el país", Ministerio de Tecnologías de la Información y las Comunicaciones de Colombia, Bogotá, www.mintic.gov.co/portal/inicio/Sala-de-Prensa/Noticias/101504:MinTICanuncia-inicio-de-nuevo-proyecto-que-conectara-1-000-zonas-rurales-en-el-pais.

Nedelkoska, L. y G. Quintini (2018), "Automation, skills use and training", OECD Social, Employment and Migration Working Papers, n. ${ }^{\circ}$ 202, Publicaciones de la OCDE, París, https://doi. org $/ 10.1787 / 2 \mathrm{e} 2 \mathrm{f} 4 \mathrm{eea}-\mathrm{en}$.

OCDE (2020a), OECD Employment Outlook 2020: Worker Security and the COVID-19 Crisis, Publicaciones de la OCDE, París, https://doi.org/10.1787/1686c758-en.

OCDE (2020b), Making the Most of Technology for Learning and Training in Latin America, OECD Skills Studies, Publicaciones de la OCDE, París, https://doi.org/10.1787/ce2b1a62-en.

OCDE (2020c), COVID-19 in Latin America and the Caribbean: Regional Socio-economic Implications and Policy Priorities, Publicaciones de la OCDE, París, www.oecd.org/coronavirus/policy-responses/ covid-19-in-latin-america-and-the-caribbean-regional-socio-economic-implications-andpolicy-priorities-93a64fdel.

OCDE (2020d), Women at the Core of the Fight Against COVID-19, Publicaciones de la OCDE, París, www. oecd.org/coronavirus/policy-responses/women-at-the-core-of-the-fight-against-covid-19-crisis/.

OCDE (2020e), COVID-19: Protecting People and Societies, Publicaciones de la OCDE, París, www.oecd. org/coronavirus/policy-responses/covid-19-protecting-people-and-societies-e5c9de1a/.

OCDE (2020f), Supporting People and Companies to deal with the COVID-19 Virus: Options for an Immediate Employment and Social-Policy Response, Publicaciones de la OCDE, París, www.oecd. org/coronavirus/policy-responses/supporting-people-and-companies-to-deal-with-thecovid-19-virus-options-for-an-immediate-employment-and-social-policy-response-d33dffe6/.

OCDE (2020g), Distributional Risks Associated with Non-standard Work: Stylised Facts and Policy Considerations, Publicaciones de la OCDE, París, www.oecd.org/coronavirus/policy-responses/ distributional-risks-associated-with-non-standard-work-stylised-facts-and-policyconsiderations-68fa7d61/.

OCDE (2020h), Learning Remotely When Schools Close: How Well Are Students and Schools Prepared? Insights from PISA, Publicaciones de la OCDE, París, https://read.oecd-ilibrary.org/view/?ref=127_127063iiwm328658\&title=Learning-remotely-when-schools-close.

OCDE (2020i), A Framework to Guide an Education Response to the COVID-19 Pandemic of 2020, Publicaciones de la OCDE, París, https://read.oecd-ilibrary.org/view/?ref=126_126988-t63lxosohs\& title=A-framework-to-guide-an-education-response-to-the-Covid-19-Pandemic-of-2020.

OCDE (2019a), Perspectivas de empleo de la OCDE 2019: El futuro del trabajo, Publicaciones de la OCDE, París, https://doi.org/10.1787/9ee00155-en.

OCDE (2019b), How's Life in the Digital Age?: Opportunities and Risks of the Digital Transformation for People's Well-being, Publicaciones de la OCDE, París, https://doi.org/10.1787/9789264311800-en.

OCDE (2019c), Skills Matter: Additional Results from the Survey of Adult Skills, OECD Skills Studies, Publicaciones de la OCDE, París, https://doi.org/10.1787/1f029d8f-en.

OCDE (2019d), Technical Report of the Survey of Adult Skills (PIAAC), Third Edition, Publicaciones de la OCDE, París, www.oecd.org/skills/piaac/publications/PIAAC_Technical_Report_2019.pdf.

OCDE (2019e), The Survey of Adult Skills: Reader's Companion, Third Edition, OECD Skills Studies, Publicaciones de la OCDE, París, https://doi.org/10.1787/f70238c7-en.

OCDE (2019f), OECD Skills Outlook 2019: Thriving in a Digital World, Publicaciones de la OCDE, París, https://doi.org/10.1787/df80bc12-en.

OCDE (2019g), Survey of Adult Skills (PIAAC) (sitio web), Publicaciones de la OCDE, París, www.oecd. org/skills/piaac/.

OCDE (2018a), "Bridging the rural digital divide”, OECD Digital Economy Papers, n. ${ }^{\circ}$ 265, Publicaciones de la OCDE, París, https://dx.doi.org/10.1787/852bd3b9-en.

OCDE (2018b), Good Jobs for All in a Changing World of Work: The OECD Jobs Strategy, Publicaciones de la OCDE, París, https://doi.org/10.1787/9789264308817-en.

OCDE (2018c), Perspectivas de empleo de la OCDE 2018, Publicaciones de la OCDE, París, http://dx.doi. org/10.1787/empl_outlook-2018-en.

OCDE (2018d), Base de datos de PISA 2018 (base de datos), Publicaciones de la OCDE, París, www. oecd.org/pisa/data/2018database/.

OCDE (2018e), Bridging the Digital Gender Divide: Include, Upskill, Innovate, Publicaciones de la OCDE, París, www.oecd.org/internet/bridging-the-digital-gender-divide.pdf.

OCDE (2017a), PISA 2015 Results (Volume III): Students' Well-Being, PISA, Publicaciones de la OCDE, París, https://dx.doi.org/10.1787/9789264273856-en. 
OCDE (2017b), PISA 2015 Technical Report, Publicaciones de la OCDE, París, www.oecd.org/pisa/ data/2015-technical-report/.

OCDE (2016a), Declaración de la Reunión Ministerial de Economía Digital de la OCDE: Innovación, crecimiento y prosperidad social, Publicaciones de la OCDE, París, www.oecd.org/internet/Digital-EconomyMinisterial-Declaration-2016.pdf.

OCDE (2016b), Perspectivas de empleo de la OCDE 2016, Publicaciones de la OCDE, París, https://doi. org/10.1787/empl_outlook-2016-en.

OCDE (2016c), Skills Matter: Further Results from the Survey of Adult Skills, OECD Skills Studies, Publicaciones de la OCDE, París, https://dx.doi.org/10.1787/9789264258051-en.

OCDE (2016d), PISA 2015 Results (Volume II): Policies and Practices for Successful Schools, PISA, Publicaciones de la OCDE, París, http://dx.doi.org/10.1787/9789264267510-en

OCDE (2016e), PISA 2015 Results (Volume I): Excellence and Equity in Education, PISA, Publicaciones de la OCDE, París, http://dx.doi.org/10.1787/9789264266490-en.

OCDE (2015a), Evaluación de Competencias de Adultos (PIAAC 2015): selección completa de indicadores (base de datos), Publicaciones de la OCDE, París, www.oecd.org/skills/piaac/.

OCDE (2015b), Panorama de la educación 2015: Indicadores de la OCDE, Publicaciones de la OCDE, París, http://dx.doi.org/10.1787/eag-2015-en.

OCDE (2015c), Base de datos de PISA 2015 (base de datos), Publicaciones de la OCDE, París, www.oecd. org/pisa/data/2015database/.

OCDE (2015d), “How Computers are related to students' performance”, en Students, Computers and Learning: Making the Connection, Publicaciones de la OCDE, París, https://doi. org/10.1787/9789264239555-en.

OCDE et al. (2019), Perspectivas económicas de América Latina 2019. Desarrollo en transición, OCDE/CAF/ CEPAL/UE, Publicaciones de la OCDE, París, https://doi.org/10.1787/g2g9ff18-en.

OCDE/BID (2016), Políticas de banda ancha para América Latina y el Caribe: Un manual para la economía digital, Publicaciones de la OCDE, París, https://dx.doi.org/10.1787/9789264251823.

OCDE/PIAAC (2018), Evaluación Internacional de Competencias de Adultos (base de datos), Publicaciones de la OCDE, París, www.oecd.org/skills/piaac/data/.

ORBA/CEPAL (2019), Banco de Datos de Encuestas de Hogares (base de datos), Comisión Económica para América Latina y el Caribe, de las Naciones Unidas, Santiago, www.cepal.org/es/observatorioregional-de-banda-ancha.

Oxfam (2020), "El COVID-19 no discrimina, las desigualdades sí", Oxfam Briefing, Oxfam internacional, https://oi-files-d8-prod.s3.eu-west-2.amazonaws.com/s3fs-public/2020-03/Covid \%2019\%20en\%20LAC_nota\%20informativa_F_0.pdf.

Paniagua, A. y D. Istance (2018), Teachers as Designers of Learning Environments: The Importance of Innovative Pedagogies, Centre for Educational Research and Innovation, Publicaciones de la OCDE, París, https://doi.org/10.1787/9789264085374-en.

Peterson, A. et al. (2018), "Understanding innovative pedagogies: Key themes to analyse new approaches to teaching and learning", OECD Education Working Papers, n. ${ }^{\circ} 172$, Publicaciones de la OCDE, París, https://dx.doi.org/10.1787/9f843a6e-en.

PIAAC Expert Group in Problem Solving in Technology-Rich Environments (2009), "PIAAC problem solving in technology-rich Environments: A conceptual framework", OECD Education Working Papers, n. ${ }^{\circ}$ 36, Publicaciones de la OCDE, París, https://doi.org/10.1787/220262483674.

Psacharopoulos, G. et al. (2020), "Lost wages: The COVID-19 cost of school closures," Policy Research Working Paper Series, n. 9246, Grupo Banco Mundial, Washington, DC, disponible en https:// papers.ssrn.com/sol3/papers.cfm?abstract id=3601422.

Quinn, D. et al. (2016), "Seasonal dynamics of academic achievement inequality by socioeconomic status and race/ethnicity: Updating and extending past research with new national data", Educational Researcher, vol. 45, n. ${ }^{\circ}$ 8, SAGE Publishing, Thousand Oaks, CA, pp. 443-453, https://doi.org/10.3102/0013189X16677965.

Robinson, J., P. Dimaggio y E. Hargittai (2003), "New social survey perspectives on the digital divide", IT \& Society, vol. 1, Northwestern University, Evanston, IL, pp. 1-22, www.scholars. northwestern.edu/en/publications/new-social-survey-perspectives-on-the-digital-divide.

Seaton, D. et al. (2014), “Teacher enrolment in MIT MOOCs: Are we educating educators?", SSRN Electronic Journal, Elsevier, Ámsterdam, http://dx.doi.org/10.2139/ssrn.2515385.

Unesco (2017), "Sociedad digital: brechas y retos para la inclusión digital en América Latina y el Caribe", Unesco Policy Papers, Unesco Office Montevideo and Regional Bureau for Science in Latin America and the Caribbean, Montevideo, https://unesdoc.unesco.org/ark:/48223/pf0000262860 eng?posInSet=1\&queryId=12146cc0-ecca-4b00-bf19-2d26b45d9af0. 
Unicef (2020), "COVID-19: Más del 95 por ciento de niños y niñas está fuera de las escuelas de América Latina y el Caribe", Unicef América Latina y el Caribe, Panamá, www.unicef.org/pressreleases/covid-19-more-95-cent-children-are-out-school-latin-america-and-caribbean.

Van Deursen, A. y J. van Dijk (2014), "The digital divide shifts to differences in usage", New Media \& Society, vol. 16, n. ${ }^{\circ}$ 3, SAGE Publishing, Thousand Oaks, CA, pp. 507-526, http://dx.doi. org/10.1177/1461444813487959.

Van Deursen, A. et al. (2017), "The compoundness and sequentiality of digital inequality", International Journal of Communication, vol. 11(2017), University of Southern California Annenberg Press, Los Ángeles, pp. 452-473, https://ijoc.org/index.php/ijoc/article/view/5739/1911.

Vargas, E. (2020), School Closures, Government Responses, and Learning Inequality around the World during COVID-19, The Brookings Institution, Washington, DC, www.brookings.edu/research/schoolclosures-government-responses-and-learning-inequality-around-the-world-during-covid19/?preview id=799315.

Warm, T. A. (1989), "Weighted likelihood estimation of ability in item response theory", Psychometrika, vol. 54, SpringerLink, pp. 427-450, https://doi.org/10.1007/BF02294627.

Weller J., S. Gontero y S. Campbell (2019), "Cambio tecnológico y empleo: Una perspectiva latinoamericana. Riesgos de la sustitución tecnológica del trabajo humano y desafíos de la generación de nuevos puestos de trabajo", Serie Macroeconomía del Desarrollo, n. 201 (LC/ TS.2019/37), Comisión Económica para América Latina y el Caribe, de las Naciones Unidas, Santiago, www.cepal.org/es/publicaciones/44637-cambio-tecnologico-empleo-perspectivalatinoamericana-riesgos-la-sustitucion.

West, D. (2015), Digital Divide: Improving Internet Access in the Developing World, Center for Technology Innovation at Brookings, Washington, DC, www.brookings.edu/wp-content/uploads/2016/06/ West_Internet-Access.pdf. 



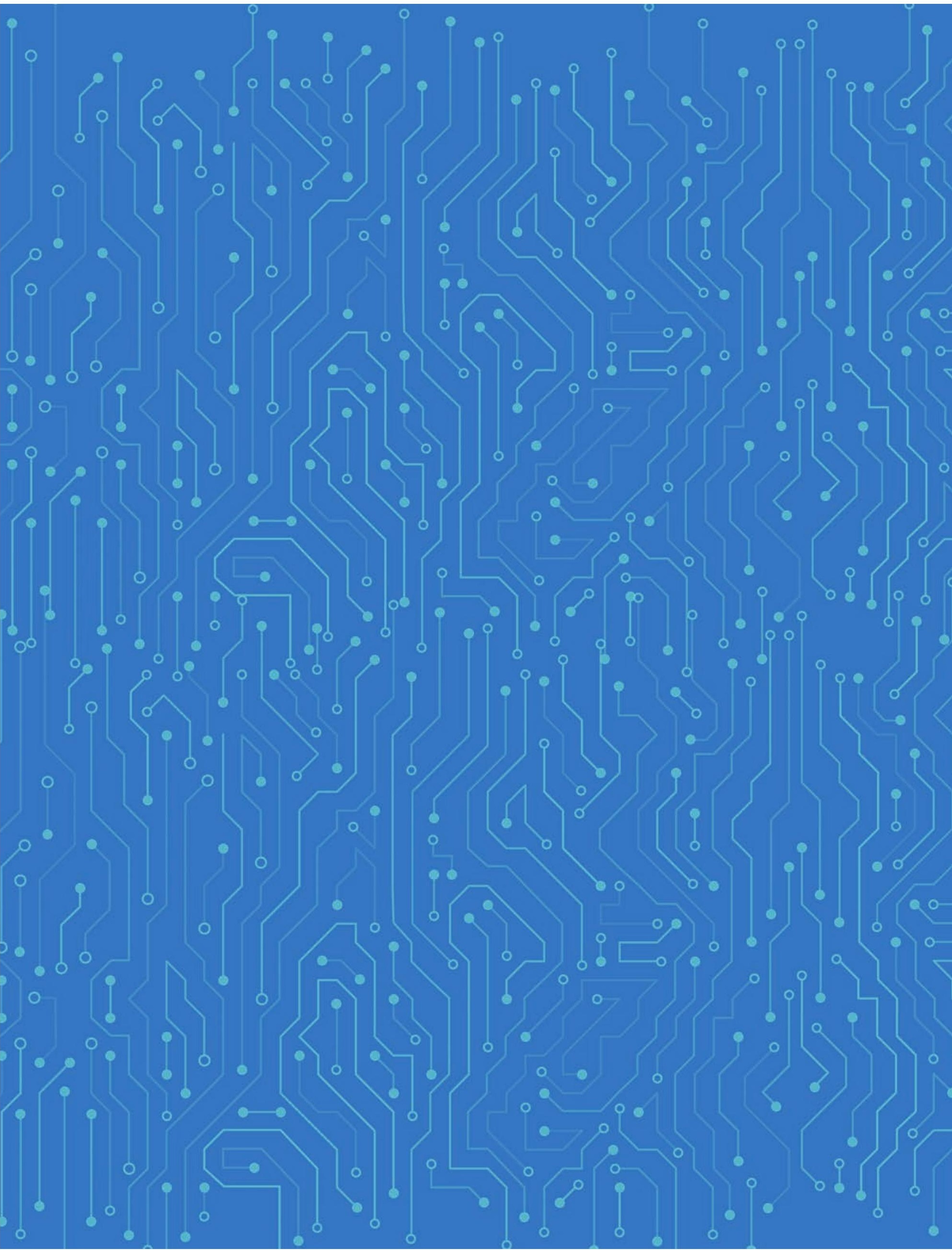




\section{Capítulo 4}

\section{Repensar las instituciones públicas en la era digital}

El incremento de la desconfianza en las instituciones públicas y de la insatisfacción con los servicios públicos en América Latina y el Caribe indica un debilitamiento del pacto social, que podría deteriorarse aún más por el impacto del coronavirus (Covid-19). La transformación digital constituye una oportunidad única para mejorar el funcionamiento y la calidad de los servicios públicos. Si bien deben tenerse en cuenta riesgos institucionales que están surgiendo, avanzar hacia gobiernos digitales puede ayudar a las instituciones públicas a ser más creíbles, más eficaces, más inclusivas y más innovadoras. La transformación digital incide en un amplio rango de políticas públicas, por lo que debe formar parte de un marco integral como el que representan las estrategias nacionales de desarrollo, que permita aprovecharla al máximo y garantizar la coherencia en su avance. Vincular las estrategias digitales con los planes nacionales de desarrollo resulta crucial para armonizar la labor de digitalización con objetivos de desarrollo más amplios a largo plazo. 


\section{Las tecnologías digitales pueden transformar las instituciones públicas y ayudarlas a enfrentar sus principales desafíos}

La transición hacia gobiernos digitales puede ayudar a las instituciones públicas a ser más creíbles, inclusivas, eficientes e innovadoras

El gobierno abierto
puede hacer que las
instituciones
públicas sean más
creíbles al mejorar
la transparencia,
el acceso a la
información y
la participación
ciudadana

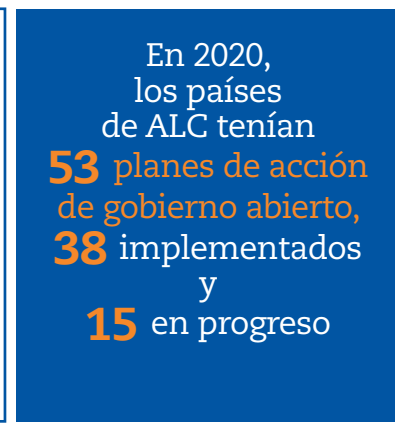

Las tecnologías digitales, como el aprendizaje en línea y la telemedicina, pueden apoyar servicios públicos más inclusivos y la participación de los ciudadanos en el proceso de toma de decisiones

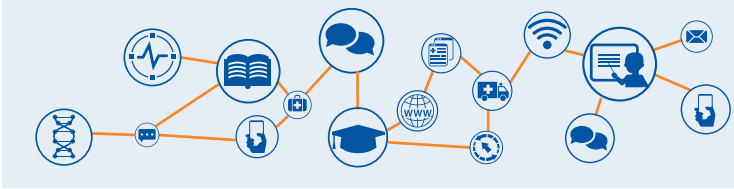

La automatización de servicios puede hacer que las instituciones sean más eficientes

Se necesitan, en promedio, 5.4 horas para completar una transacción pública en ALC, con grandes diferencias entre países:

Desde menos de 3 horas en Chile

a más de 11 en Bolivia
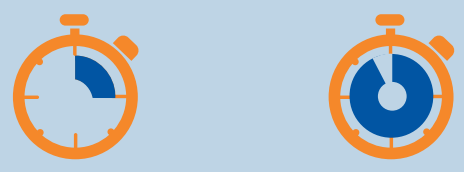

Las herramientas digitales pueden apoyar enfoques innovadores de políticas públicas, utilizando nuevas fuentes de datos, mejorando así el proceso de formulación de políticas

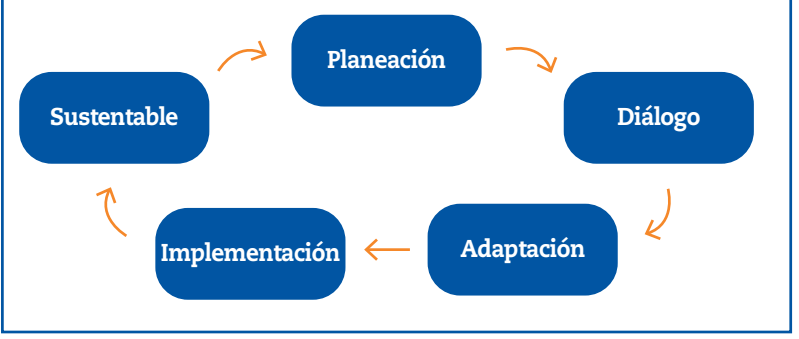

Para aprovechar todo su potencial, la transformación digital debe abordarse de manera integral dentro de las estrategias de desarrollo de ALC

\begin{tabular}{|c|} 
La seguridad digital, \\
la regulación de \\
la privacidad y \\
la gestión segura \\
y transparente \\
de los datos son \\
importantes para \\
garantizar la \\
confianza del \\
público en las \\
tecnologías \\
digitales
\end{tabular}

Los planes nacionales de desarrollo (PND) y las agendas digitales son herramientas estratégicas clave para planificar y coordinar la transformación digital

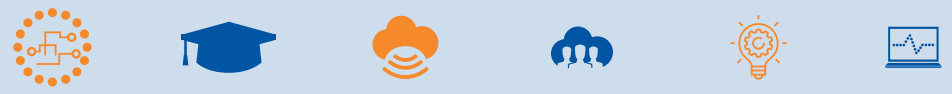

Entre los 16 PND analizados, la mayoría incluye políticas para ampliar

el acceso y uso de tecnologías digitales, así como para aumentar la inversión en infraestructura de comunicaciones. Las políticas para abordar el futuro del trabajo también están ganando relevancia en los PND 


\section{Introducción}

La expansión de la clase media observada en América Latina y el Caribe (ALC) desde principios de siglo ha ido acompañada de un incremento de las aspiraciones sociales. La pandemia del coronavirus (Covid-19) podría intensificar las exigencias de instituciones públicas más sólidas y servicios públicos de mayor calidad por parte de la ciudadanía. Pese a las mejoras observadas en los últimos años en materia de gobernanza pública, las instituciones no están respondiendo a ese aumento de las aspiraciones. En la mayoría de los países de ALC, la desconfianza y la insatisfacción se están agravando, y aumenta el descontento social. Por ese motivo, desciende el valor que los ciudadanos confieren al cumplimiento de obligaciones sociales como pagar impuestos, tal como demuestran los bajos niveles de moral fiscal. Este fenómeno incide, a su vez, en la obtención de los recursos tributarios necesarios para financiar mejores servicios públicos y responder a las demandas sociales (OCDE, 2019a). Así, en ALC asistimos a la aparición de un círculo vicioso que puede interpretarse como una "trampa institucional" provocada por una dinámica circular que se autorrefuerza y pone límites a la capacidad para alcanzar un mayor desarrollo (OCDE et al., 2019). Aún se desconoce en qué medida agravará la pandemia del coronavirus (Covid-19) el descontento social y cambiará las aspiraciones de los ciudadanos, pero las instituciones públicas se han visto sometidas a una presión inédita y tendrán que encontrar formas de responder a la evolución de las exigencias que plantea la sociedad y a las extraordinarias dificultades que esto comporta en materia de políticas.

En este contexto, la transformación digital conlleva nuevos desafíos, pero también importantes oportunidades para reforzar el pacto social entre ciudadanía y Estado, así como para mejorar la respuesta a exigencias públicas que están cambiando rápidamente.

En primer lugar, la transformación digital ha supuesto un aumento de las expectativas de los ciudadanos digitales respecto a la calidad de los servicios públicos y la integridad, transparencia y capacidad de respuesta de las instituciones públicas. El crecimiento exponencial de los smartphones y la transmisión diaria de macrodatos (big data) está cambiando la forma de vida de los latinoamericanos, en especial en núcleos urbanos. La clase media, cada vez más numerosa, y los jóvenes son segmentos de población que dominan el uso de los medios digitales y tienen fuertes demandas sociales (Santiso, 2017). El acceso a servicios digitales con gran facilidad intensifica las exigencias de los ciudadanos respecto al sector público, con el consiguiente desafío que esto representa para las instituciones. Si los organismos públicos no formulan e implementan políticas públicas apropiadas y no satisfacen dichas expectativas, la brecha entre ciudadanía e instituciones públicas podría ampliarse.

En segundo lugar, el avance tecnológico exige respuestas políticas innovadoras para superar nuevos obstáculos en materia de regulación. Regular la transformación digital con el objetivo de atenuar los efectos perjudiciales que comporta y promover sus ventajas en beneficio de toda la población constituye un elemento esencial de la agenda política. La regulación es una herramienta crucial para preservar la confianza pública en el contexto de la transformación digital y cada vez cobran mayor importancia nuevos dominios en materia de políticas como la seguridad digital, la privacidad, protección y gobernanza de los datos, así como las cuestiones éticas.

En tercer lugar, las nuevas tecnologías y la analítica de datos pueden transformar los gobiernos. Para responder a los nuevos desafíos y aprovechar las nuevas oportunidades que se presentan, las instituciones públicas deben reinventarse. Los gobiernos de ALC tienen la posibilidad de ser más creíbles, eficaces, inclusivos e innovadores aprovechando las nuevas posibilidades que les ofrecen los avances tecnológicos. De este modo se 
restablecería la confianza en las instituciones públicas y mejoraría la calidad y cobertura de los servicios públicos.

En cuarto lugar, para aprovechar al máximo la transformación digital, se necesita una estrategia ambiciosa y coordinada. Los gobiernos de ALC han de incorporar la transformación digital de forma generalizada en los planes nacionales de desarrollo (PND) y las estrategias/agendas digitales (AD). Las tecnologías digitales forman además parte de la solución. Las herramientas digitales (por ejemplo, las teleconferencias y las consultas por Internet) facilitan la participación de diferentes grupos de interés en la formulación de las estrategias nacionales de desarrollo, para sentar las bases de un nuevo pacto social verdaderamente inclusivo.

En quinto lugar, la economía digital constituye una extensión de la economía material. Los cambios radicales que ha propiciado la tecnología en los modelos de producción y consumo exigen marcos regulatorios y de formulación de políticas destinados a generar las condiciones adecuadas para que administraciones, consumidores, productores y ciudadanos consigan nuevas capacidades, generen valor y se conviertan en partícipes importantes de la economía digital (CEPAL, 2016).

La crisis del coronavirus (Covid-19) confiere un carácter más urgente a la transformación digital de los gobiernos y la convierte en una prioridad máxima de los planes nacionales de desarrollo. El cierre de las administraciones públicas en algunos momentos de la pandemia dejó clara la importancia que reviste contar con servicios digitales integrales y sistemas compatibles entre sí. Habida cuenta de que los datos se han convertido en activos esenciales, en especial en el ámbito de la salud pública, también cobran mayor importancia las políticas en materia de protección de datos y seguridad digital.

Las tres secciones del presente capítulo analizan los desafíos y las oportunidades que comporta la transformación digital para las instituciones públicas y plantea vías encaminadas a reinventar y adaptar los marcos institucionales para la era digital. La primera sección, "Gobernanza de la transformación digital", describe los desafíos y las oportunidades principales que plantea la transformación digital en materia de confianza pública, entre otros una adecuada seguridad digital, protección de datos y gobernanza, y nuevas cuestiones éticas que deben tenerse en cuenta. La segunda, "La transformación digital de los gobiernos", analiza cómo pueden contribuir las tecnologías digitales a la consecución de Estados más creíbles, eficaces, inclusivos e innovadores. La última sección, "La agenda digital en las estrategias nacionales de desarrollo", estudia cómo han incluido los países de ALC la transformación digital en los planes nacionales de desarrollo y las agendas digitales, además de cómo estos PND y DA hacen frente a las trampas del desarrollo de la región.

\section{Gobernanza de la transformación digital}

Las profundas transformaciones generadas por los avances tecnológicos ponen en cuestión la idoneidad del marco institucional a nivel nacional e internacional. Se presentan nuevos riesgos y oportunidades que exigen una adaptación de las reglas del juego, a fin de convertir la transformación digital en un motor de progreso y mayor bienestar para toda la población. En esta sección se abordan aspectos regulatorios que determinan la transformación digital y cuestiones que inciden en la confianza de los ciudadanos en las tecnologías digitales, como son la seguridad digital, la protección de datos y la gobernanza, así como aspectos de índole ética, por ejemplo con respecto a la inteligencia artificial, la desinformación y la difusión de noticias falsas. También se analiza lo que puede definirse como la evolución de los derechos humanos en la era digital, es decir "derechos digitales" como el derecho de protección de los datos personales, transparencia, información sobre 
inteligencia artificial y no participación (OCDE, 2019b). En la siguiente sección, se analizan otros derechos digitales, como la comunicación con las administraciones públicas por medios digitales, la aplicación del principio de "una sola vez", los datos abiertos y la prestación proactiva de servicios.

\section{Los marcos regulatorios deben promover una transformación digital justa y equitativa}

Los gobiernos enfrentan nuevos desafíos regulatorios a la hora de garantizar que toda la población pueda aprovechar las oportunidades y ventajas que ofrece la transformación digital (OCDE, 2019c). Los marcos regulatorios deben conciliar la promoción de la transformación digital con la protección de un acceso seguro y asequible a las tecnologías digitales. Existen cinco medidas que pueden contribuir al logro de tal objetivo.

En primer lugar, los marcos regulatorios deben promover la competencia y la inversión derivadas de una mayor convergencia de las redes y los servicios en la economía digital (por ejemplo, la prestación eficiente de servicios digitales en las diferentes redes). La competencia es clave para fomentar la innovación y permitir que todos los consumidores se beneficien de ella a precios competitivos. Son necesarios organismos independientes para hacer frente a problemas de dominio del mercado o imponer regulaciones de nivel mayorista cuando sea necesario, a fin de reducir los obstáculos que encuentran los nuevos operadores (OCDE, 2019c). Algunas reformas de ALC, tal como la reforma del sector de telecomunicaciones de México de 2013, ponen de relieve la importancia de una competencia activa, marcos regulatorios sólidos, y apoyo a la inversión, en particular en zonas remotas y núcleos rurales (OCDE, 2017a; OCDE, 2019c). Para que el público confíe en la integridad de las decisiones en materia de regulación, resulta fundamental que exista una autoridad regulatoria independiente (OCDE, 2019d, 2014a).

En segundo lugar, un marco regulatorio estable y previsible fomenta la inversión a largo plazo en infraestructuras de comunicación e innovación digital. En un sector en el que la rentabilidad de la inversión suele observarse décadas más tarde, garantizar estabilidad regulatoria, transparencia y seguridad jurídica ayuda a las empresas a formular planes de negocio y, en última instancia, facilita la inversión (OCDE, 2012). La solidez de las instituciones aumenta la confianza de los inversores y fomenta la inversión en infraestructura de comunicación.

En tercer lugar, el marco regulatorio debe contribuir a la protección de los consumidores, en especial en las operaciones por Internet en las que se facilitan datos personales. La ausencia de una protección adecuada puede frenar el comercio electrónico y la adopción del uso de nuevos productos. Promover el acceso a datos y la portabilidad de estos, así como la resolución de problemas relacionados con la propiedad de la información, debería constituir una prioridad de la regulación, garantizando que la acumulación de datos de interesados no genere obstáculos a la entrada de nuevos operadores que frenen la innovación y menoscaben la competencia (OCDE, 2019c).

En cuarto lugar, las regulaciones que promueven la innovación propician el crecimiento de nuevos sectores y empresas que hacen un uso intensivo de los medios digitales. La innovación digital suele producirse fuera de los marcos existentes. Por lo tanto, la regulación debería ser flexible y alcanzar los objetivos legítimos que le corresponden sin desincentivar la innovación ni desaprovechar los beneficios de la transformación digital. Los "sandboxes regulatorios" constituyen una respuesta de política que ofrece flexibilidad, ya que facilitan un espacio controlado en el que probar la regulación, normalmente con la finalidad de facilitar la experimentación y la realización de pruebas (OCDE, 2019c). La estrategia de inteligencia artificial y transformación digital de Colombia propuso 
"entornos de prueba (tipo sandbox) regulatorios" (República de Colombia, 2019). Fomentar y materializar iniciativas de innovación exige regulaciones neutrales desde el punto de vista tecnológico que garanticen una competencia leal entre las tecnologías en desarrollo (OCDE, 2003).

En quinto lugar, al crear nuevas normas, deben aclararse las responsabilidades de los diferentes interlocutores, evitando solapamientos y facilitando a las instituciones herramientas que les permitan aplicar sus decisiones. Debería existir una separación clara entre la formulación de las políticas y el marco regulatorio. Resulta esencial que se implementen marcos de medición sistemáticos para realizar un seguimiento del crecimiento de los servicios digitales y de banda ancha, a fin de aportar información para las decisiones en materia de políticas y regulación. Debería fomentarse la participación de los grupos de interés y el análisis por parte de homólogos y terceros independientes para identificar posibles mejoras del marco regulatorio. Un ejemplo de esta metodología serían las revisiones entre pares de los mercados de telecomunicaciones de Colombia (OCDE, 2014b) y México por parte de la Organización para la Cooperación y el Desarrollo Económicos (OCDE, 2012; OCDE, 2017a).

En el ámbito internacional, es necesario actualizar las normas multilaterales de comercio y tributación digital. La digitalización de la economía plantea nuevos desafíos de carácter fiscal. En el seno de la OCDE se mantiene una negociación de alcance mundial destinada a lograr un acuerdo internacional para que aquellas empresas multinacionales con un nivel de actividad importante en lugares donde no necesariamente están presentes físicamente - una característica habitual de las empresas digitales- puedan tributar en dichas jurisdicciones (ver el Capítulo 5). Los flujos de datos transfronterizos constituyen otro ámbito de especial relevancia. Los datos determinan la transformación digital y las relaciones comerciales. Los gobiernos tratan de regular cada vez más las transferencias de datos transfronterizas, con miras a proteger la privacidad cuando se almacenan o tratan datos en el extranjero o a exigir que los datos se almacenen en territorio nacional (OCDE, 2019c).

Dentro del ámbito regional, en muchos casos los marcos regulatorios de ALC siguen funcionando de manera aislada. Deberían promoverse acuerdos de cooperación regional, intercambios de experiencias en materia de regulación, un despliegue de infraestructuras regionales, flujos de datos transfronterizos y la reducción del costo de los servicios de itinerancia y conectividad internacional (OCDE, 2019c) (ver el Capítulo 5).

\section{La seguridad digital es clave para que toda la población se beneficie de la transformación digital}

Los incidentes de seguridad digital pueden provocar perjuicios sociales y económicos si no se gestionan correctamente. Pueden causar alteraciones en las operaciones y en servicios públicos esenciales, así como pérdidas económicas directas, litigios, daños a la reputación, pérdida de competitividad (por ejemplo, a consecuencia de la revelación de secretos profesionales), vulneración de la privacidad y desconfianza por parte de los consumidores (OCDE, 2015a). ${ }^{1}$

Durante la crisis del coronavirus (Covid-19) se han acentuado los riesgos de seguridad digital. Los ciberdelincuentes aprovechan el hecho de que, en períodos de gran nerviosismo, aumentan las probabilidades de que particulares y empresas caigan con mayor facilidad en sus trampas o paguen los rescates exigidos, en especial cuando no aplican buenas prácticas en materia de seguridad digital o ven alterado el funcionamiento de su organización. Este incremento de los riesgos refuerza la necesidad de contar con medidas suficientes para proteger sectores vulnerables contra incidentes de seguridad digital. Ante la existencia de sectores de servicios esenciales e infraestructuras críticas, 
tanto de carácter público como privado, que dependen cada vez más de los medios digitales, resultan cada vez más necesarias estrategias nacionales globales e integrales en materia de seguridad digital, formuladas mediante consultas a todos los grupos de interés.

Algunos ejemplos recientes ponen de relieve la importancia que revisten los incidentes de seguridad digital desde una perspectiva socioeconómica. El ataque a la seguridad digital perpetrado en 2017 mediante el virus NotPetya, que afectó a varios países y empresas mundiales, provocó la interrupción temporal de la producción, las operaciones comerciales y la investigación de la gran empresa farmacéutica Merck. En noviembre de 2019, un ataque mediante ransomware obligó a Pemex (la petrolera mexicana de propiedad estatal) a desconectar sus computadoras en todo México, pues le exigían un rescate de cinco millones de dólares para poner fin a tal situación. Pese a que este suceso solo habría afectado al sistema de pagos según las informaciones disponibles, podría haber puesto en peligro la seguridad energética de todo el país (Barrera y Satter, 2019). Estos ejemplos demuestran que el riesgo de seguridad digital debe considerarse un problema económico y social, y no una cuestión de seguridad nacional o un problema técnico determinado exclusivamente.

La mayoría de los países de América Latina y el Caribe avanzan hacia la consecución de una visión estratégica a largo plazo en materia de seguridad digital (OCDE/BID, 2016). En 2019, 13 países de la región poseían una estrategia nacional de seguridad digital (BID/OAS, 2020), aunque las políticas reflejaban un escaso conocimiento de las dimensiones económica y social de la seguridad digital y solían centrarse en aspectos técnicos o delictivos o en la seguridad nacional. Asimismo, mostraban un reducido grado de coordinación con los grupos de interés de los diferentes sectores empresariales y las administraciones públicas. Esta labor de coordinación es un aspecto importante de la transformación digital, puesto que servicios esenciales del sector financiero, energético y de transporte son ofrecidos cada vez con más frecuencia por start-ups que facilitan sistemas de pago innovadores, o se subcontratan a pequeñas y medianas empresas (pymes) en cadenas de valor de servicios esenciales. La cooperación y el diálogo entre los diferentes grupos de interés cobran mayor importancia si cabe a la hora de garantizar una gestión adecuada de los riesgos de seguridad digital de todos los sectores y agentes, incluidas las pymes (OCDE, 2019c).

En ALC, se ha trabajado de manera intensiva en las cuestiones jurídicas relacionadas con la seguridad digital, pero permanecen desatendidas otras dimensiones fundamentales. Según el Índice mundial de ciberseguridad (UIT, 2019), que mide cinco dimensiones (aspectos legales, técnicos, organizativos, capacidades y cooperación internacional), ALC es la región menos comprometida con la seguridad digital después de África. Este índice combina 25 indicadores en uno y su valor oscila entre 0 (ninguna iniciativa en materia de ciberseguridad) y 1 . Solo en Uruguay la ciberseguridad es relativamente elevada, ya que obtiene una puntuación de 0.68 que lo sitúa en el puesto 51 de 175 países. El resto de la región obtiene una puntuación mediana o baja. Los avances más apreciables se han producido en el ámbito de la legislación: 30 países cuentan con leyes sobre ciberdelincuencia y normas en materia de ciberseguridad, y 10 con reglas para frenar el envío de correo electrónico no deseado (spam). Las iniciativas regionales se han centrado además en la formulación de estrategias de seguridad digital, pero dejan de lado otras dimensiones (Gráfico 4.1). 
Gráfico 4.1. Cinco pilares del Índice mundial de ciberseguridad de la Unión Internacional de Telecomunicaciones de Naciones Unidas, 2018

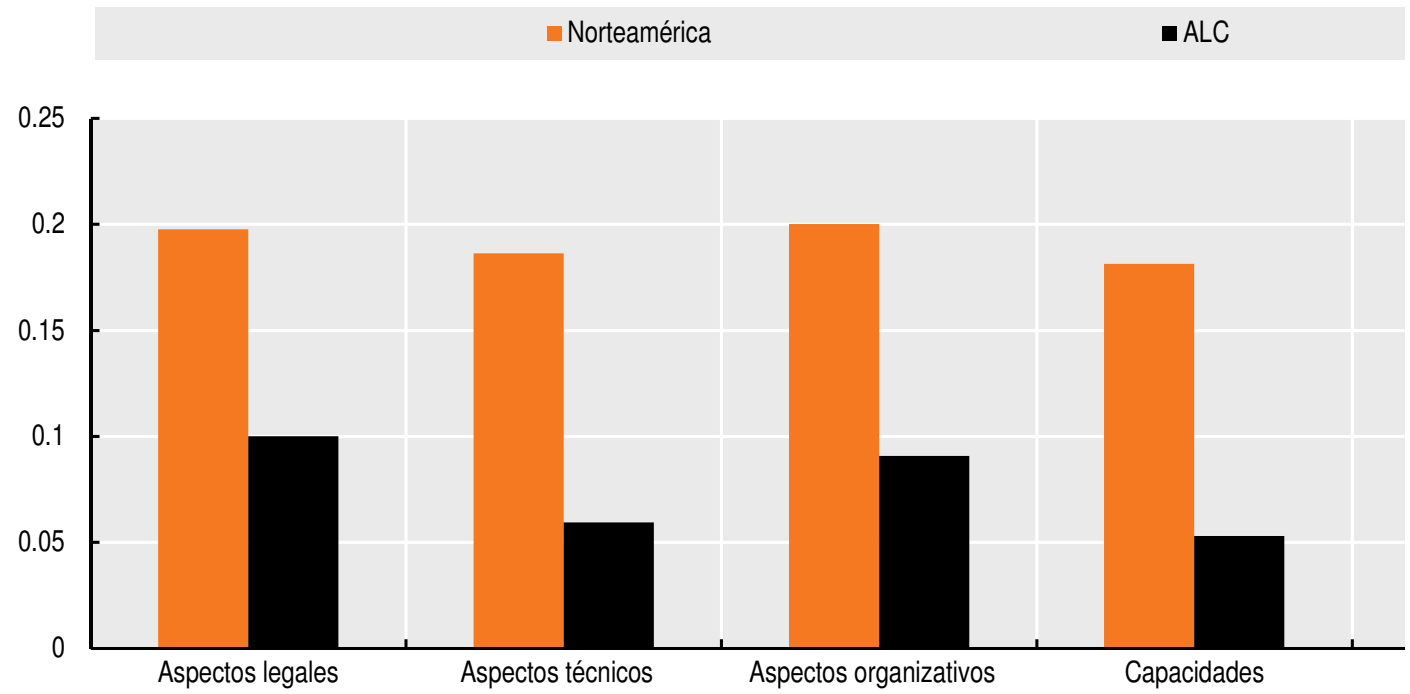

Notas: ALC es un promedio simple de 31 países de la región, excepto Haití y Dominica. Norteamérica es un promedio simple de Estados Unidos y Canadá.

Fuente: UIT (2019), Índice mundial de ciberseguridad (base de datos), www.itu.int/en/ITU-D/Cybersecurity/Pages/globalcybersecurity-index.aspx.

StatLink -insts https://doi.org/10.1787/888934202636

Los datos son activos cada vez más importantes: privacidad, gobernanza y valor

La economía digital se caracteriza por un número cada vez mayor de entidades que recaba ingentes cantidades de datos personales, por ejemplo, minoristas que venden a través de Internet, plataformas digitales, proveedores de servicios financieros y administraciones públicas. Este entorno en el que se manejan enormes cantidades de datos, unido a la aparición de herramientas de análisis más sofisticadas, ofrece la posibilidad de inferir información sensible. Un mal uso de esta información podría menoscabar la privacidad de las personas, por ejemplo, su autonomía, igualdad y libertad de expresión (Buenadicha Sánchez et al., 2019; OCDE, 2016a).

Durante la emergencia sanitaria, muchos gobiernos han recurrido a las tecnologías digitales y la analítica para recabar, tratar y compartir datos con la finalidad de ofrecer respuestas eficaces a la propagación del virus en primera línea (por ejemplo, rastreo de contactos, datos biométricos y geolocalización de datos por medio de apps para móviles). Estas tecnologías pueden ser útiles, ya que ofrecen información esencial para mejorar la eficacia de las políticas. Sin embargo, si no se controlan, también pueden utilizarse para recabar e intercambiar datos personales de forma exhaustiva, realizar una vigilancia masiva, restringir las libertades individuales y poner en riesgo la gobernanza democrática. Pocos países de ALC cuentan con marcos que favorezcan estas medidas extraordinarias de forma rápida, segura, fiable, escalable y conforme a la normativa existente en materia de privacidad y protección de datos. Las autoridades de protección de datos desempeñan una función esencial en la aplicación de marcos de protección de datos y privacidad ya existentes o nuevos. Por ejemplo, la autoridad responsable de la protección de datos de Argentina, la Agencia de Acceso a la Información Pública, publicó unas directrices generales sobre la aplicación de las leyes de protección de los datos y la privacidad durante la crisis, destinadas tanto a responsables como a encargados del tratamiento de datos. Las medidas adoptadas deberían ser proporcionales y su vigencia debería limitarse a la duración de la situación de emergencia (OCDE 2020a, 2020b). 
También resulta esencial incorporar reflexiones de carácter ético sobre la gestión y el uso de los datos en las regulaciones y los códigos de conducta. La gestión ética de los datos abarca los siguientes aspectos: 1) respeto por los datos y la privacidad de particulares y empresas; 2) respeto del derecho al anonimato; 3) necesidad de solicitar un consentimiento informado para recabar datos (comunicar la finalidad y verificar que se consienta el uso de los datos para tal finalidad); y 4) la necesidad general de actuar con transparencia (Brito, 2017; Buenadicha Sánchez et al., 2019; Hand, 2018; Mittelstadt y Floridi, 2016). Las Directrices de la OCDE sobre protección de la privacidad y flujos transfronterizos de datos personales, actualizadas en 2013, siguen representando el consenso internacional sobre directrices generales relativas a la recopilación y gestión de información personal (OCDE, 2013a).

La regulación en materia de protección de datos ha evolucionado de manera importante recientemente, lo que ha suscitado grandes cambios en ALC. El Reglamento General de Protección de Datos (RGPD) de la Unión Europea (UE) ha tenido una gran repercusión en los marcos regulatorios de la región. En dicho instrumento se establece una estricta normativa para regular la digitalización de la economía que se aplica a toda entidad que recabe, controle, trate o utilice datos personales de interesados de la UE, independientemente del lugar en el que se encuentre físicamente la organización (ver el Capítulo 5). En agosto de 2018, Brasil aprobó la Lei Geral de Proteção de Dados, una nueva ley general de protección de datos que entrará en vigor en 2021. En Chile, están debatiendo actualmente un nuevo marco legislativo. Argentina y Uruguay han actualizado recientemente la legislación para cumplir el RGPD.

En Estados Unidos, las normas sobre protección de datos dan prioridad a la seguridad de los datos y la privacidad, y algunas normas del marco estadounidense se aplican también a entidades situadas fuera del territorio de este país que gestionen datos personales de ciudadanos estadounidenses. El Marco de Privacidad del Foro de Cooperación Económica Asia Pacífico, que se centra en evitar obstáculos a los flujos de información comercial en América Latina y el Caribe, constituye otro documento de referencia importante, que ha influido en la formulación de los marcos de protección de datos de México, Colombia y Perú (Lehuedé, 2019).

El avance de los marcos regulatorios de protección de datos en ALC ha sido dispar, pues aunque la mayoría de países de la región tiene uno implantado, sus características comunes varían considerablemente (Tabla 4.1). La mayoría de las diferencias se deben a la fecha de adopción y, en cierta medida, a la influencia de los diferentes marcos regulatorios mencionados anteriormente. Además, la falta de coordinación de las normas nacionales adoptadas constituye uno de los principales obstáculos para la transferencia de datos personales entre jurisdicciones. La red de permisos, consentimientos y restricciones resultante podría incidir en la actividad económica. Por lo tanto, deberían promoverse iniciativas internacionales de armonización en este sentido, con un alcance regional (Lehuedé, 2019). Por ejemplo, el documento publicado por la Comisión Europea en 2020 titulado "Configurar el futuro digital de Europa" contempla la creación de un mercado común de datos (Comisión Europea, 2020).

Los modelos de regulación también influyen en la fijación de los niveles de protección adecuados que rigen las autorizaciones de transferencias internacionales de datos personales. La Comisión Europea ${ }^{2}$ determina si un país no perteneciente a la UE ofrece un nivel adecuado de protección de datos. En la actualidad, en ALC, Argentina y Uruguay ofrecen un "nivel adecuado de protección de datos" para la transferencia transfronteriza de datos (Tabla 4.2). En dichos casos, se permiten las transferencias de datos personales a encargados del tratamiento, y tanto responsables como encargados del tratamiento de datos asumen conjuntamente las obligaciones que correspondan por violaciones de la seguridad (Comisión Europea, 2019a). 
Tabla 4.1. Marcos jurídicos de protección de datos, países seleccionados de América Latina y el Caribe, 2019

\begin{tabular}{|c|c|c|c|c|c|c|c|}
\hline & Argentina & Brasil $^{*}$ & Chile $^{*}$ & Colombia & México & Perú & Uruguay \\
\hline $\begin{array}{l}\text { Definiciones de datos personales y } \\
\text { datos personales sensibles }\end{array}$ & $\checkmark$ & $\begin{array}{c}\text { Solo } \\
\text { personales }\end{array}$ & $\checkmark$ & $\checkmark$ & $\checkmark$ & $\checkmark$ & $\checkmark$ \\
\hline Extraterritorialidad & $\checkmark$ & $\checkmark$ & $x$ & $\checkmark$ & $\checkmark$ & $x$ & $\checkmark$ \\
\hline Requisitos de consentimiento & $\checkmark$ & $\checkmark$ & $\checkmark$ & $\checkmark$ & $\checkmark$ & $\checkmark$ & $\checkmark$ \\
\hline Derechos de las personas & $\checkmark$ & $\checkmark$ & $\checkmark$ & $\checkmark$ & $\checkmark$ & $\checkmark$ & $\checkmark$ \\
\hline $\begin{array}{l}\text { Restricciones sobre transferencias } \\
\text { internacionales de datos }\end{array}$ & $\checkmark$ & $x$ & $x$ & $\checkmark$ & $x$ & $x$ & $\checkmark$ \\
\hline $\begin{array}{l}\text { Restricciones sobre transferencias } \\
\text { de datos impuestas a encargados del } \\
\text { tratamiento }\end{array}$ & $\checkmark$ & $\checkmark$ & $\checkmark$ & $\checkmark$ & $\checkmark$ & $\checkmark$ & $\checkmark$ \\
\hline Sanciones & $\checkmark$ & $\checkmark$ & $\checkmark$ & $\checkmark$ & $\checkmark$ & $\checkmark$ & $\checkmark$ \\
\hline $\begin{array}{l}\text { Notificación obligatoria de violaciones } \\
\text { de la seguridad a la autoridad o los } \\
\text { interesados }\end{array}$ & $x$ & $x$ & $x$ & $\begin{array}{c}\text { A la } \\
\text { autoridad }\end{array}$ & $\checkmark$ & $x$ & $\checkmark$ \\
\hline Autoridad de protección de datos & $\checkmark$ & $x$ & $x$ & $\checkmark$ & $\checkmark$ & $\checkmark$ & $\checkmark$ \\
\hline
\end{tabular}

* Brasil adoptó estas medidas en virtud de una nueva ley que entrará en vigor en 2021. Chile incluyó parte de estas medidas en el proyecto de ley debatido por el Congreso en 2020.

Nota: Los siguientes se consideran derechos de las personas: información, acceso, rectificación, supresión, destrucción y habeas data.

Fuente: Lehuedé (2019), "Corporate governance and data protection in Latin America and the Caribbean", http://hdl.handle.net/11362/44629.

Tabla 4.2. Flujos de información transfronterizos: niveles adecuados de protección de datos de países seleccionados de América Latina y el Caribe, 2019

\begin{tabular}{lccccccc}
\hline $\begin{array}{l}\text { De: } \\
\text { A: }\end{array}$ & Argentina & Brasil & Chile & Colombia & México & Perú & Uruguay \\
\hline Argentina & - & $\checkmark$ & $\checkmark$ & $\checkmark$ & $\checkmark$ & $\checkmark$ & $\checkmark$ \\
\hline Brasil & $x$ & - & $\checkmark$ & $x$ & $\checkmark$ & $\checkmark$ & $x$ \\
Chile & $x$ & $\checkmark$ & - & $x$ & $\checkmark$ & $\checkmark$ & $x$ \\
Colombia & $x$ & $\checkmark$ & $\checkmark$ & - & $\checkmark$ & $\checkmark$ & $x$ \\
México & $x$ & $\checkmark$ & $\checkmark$ & $\checkmark$ & - & $\checkmark$ & $x$ \\
Perú & $x$ & $\checkmark$ & $\checkmark$ & $\checkmark$ & $\checkmark$ & - & $x$ \\
Uruguay & $\checkmark$ & $\checkmark$ & $\checkmark$ & $\checkmark$ & $\checkmark$ & $\checkmark$ & - \\
\hline
\end{tabular}

Nota: Las autorizaciones de transferencias internacionales de datos personales se rigen por unos niveles de protección adecuados.

Fuente: Lehuedé (2019), "Corporate governance and data protection in Latin America and the Caribbean", http:// hdl.handle.net/11362/44629.

La investigación actualmente se nutre cada vez más de datos más precisos y detallados, lo cual exige reforzar las precauciones en materia de protección y privacidad. Los nuevos formatos de datos, en particular de datos personales procedentes de información facilitada en el marco de operaciones comerciales y uso de Internet, sistemas de rastreo y datos del Internet de las Cosas e información gubernamental pueden revolucionar la labor investigadora y brindar nueva información económica y social. No obstante, también plantean nuevos dilemas éticos y conllevan la responsabilidad de garantizar que el público pueda confiar en su uso correcto para fines de investigación (Metcalf y Crawford, 2016; Mittelstadt y Floridi, 2016). En 2013, la OCDE recomendó elaborar un código de conducta marco sobre el uso de nuevos formatos de datos personales para fines de investigación. Esta recomendación hacía hincapié en la necesidad de conciliar el valor social de la investigación con la protección del bienestar y los derechos de las personas, entre ellos el derecho a la privacidad (OCDE, 2016a). La Unión Europea exige a organizaciones y universidades que solicitan financiamiento público para investigación 
y desarrollo ( $\mathrm{I}+\mathrm{D})$ en el marco del programa Horizonte 2020 que aborden 11 cuestiones éticas y faciliten explicaciones y garantías de seguimiento en relación con los proyectos más sensibles (Comisión Europea, 2019b; Buenadicha Sánchez et al., 2019). México cuenta con una lista de verificación para ayudar a los científicos a garantizar protocolos éticos y también posee una "Guía nacional para la integración y el funcionamiento de los comités de ética en investigación".

Definir la responsabilidad y la propiedad en materia de datos es una cuestión crítica y compleja. Pese a que la protección de los derechos de propiedad intelectual puede incentivar la inversión en I+D, también podría restringir el acceso a datos obtenidos a partir de investigaciones financiadas con fondos públicos. Aunque plantea dificultades, desentrañar los tipos de datos puede resultar útil a efectos regulatorios.

Se estima que el acceso a datos y el intercambio de estos generan beneficios sociales y económicos por valor de entre un $0.1 \%$ y un $1.5 \%$ del producto interno bruto (PIB), en el caso de datos del sector público, y entre un $1 \%$ y un $2.5 \%$ del PIB (hasta un $4 \%$ según algunos estudios) si se incluyen los datos del sector privado. La magnitud estimada de estos efectos depende del alcance y grado de apertura de los datos (OCDE, 2019e). Cada vez son más habituales los modelos empresariales que se basan principalmente en el uso de datos personales (OCDE, 2013b). Habida cuenta de que los datos se han convertido en los factores de producción fundamentales de la economía digital y, por lo tanto, constituyen activos competitivos, la regulación debería velar por que no se utilicen ni mantengan de forma que coarten la competencia y que los agentes económicos puedan acceder a ellos de manera equitativa.

\section{La transformación digital plantea nuevos dilemas éticos}

\section{La inteligencia artificial ha de ser justa, segura y transparente}

Con la adopción de aplicaciones de inteligencia artificial en todo el mundo, su uso puede plantear cuestiones y dilemas en materia de valores humanos, equidad, determinación humana, privacidad, seguridad y gestión más responsable, entre otros, que ponen de relieve la necesidad de avanzar hacia sistemas de inteligencia artificial más sólidos, seguros y transparentes con mecanismos claros de rendición de cuentas (OCDE, 2019f). Las consideraciones de índole ética deberían reconocer la posibilidad de que se registren sesgos discriminatorios en el funcionamiento de las tecnologías modernas. Este aspecto cobra especial relevancia si se tiene en cuenta el creciente uso de la inteligencia artificial y el aprendizaje automático en la toma de decisiones de las instituciones públicas, por ejemplo, para la prestación de servicios públicos. Los datos pueden incluir imperfecciones provocadas por decisiones erróneas de quienes los recaban. Además, pueden ser insuficientes o estar errados, sesgados o desactualizados (Buenadicha Sánchez et al., 2019). Así, por ejemplo, los algoritmos utilizados para establecer correspondencias entre ofertas y demandas de empleo pueden reproducir desigualdades y prejuicios históricos por razón del color de la piel o del sexo. Un experimento concluyó que los Servicios de Google Ad tendían a mostrar las ofertas de empleo con una alta remuneración a más hombres que mujeres. Puede haber ocurrido que el algoritmo encargado de mostrar esas ofertas al público se haya entrenado con datos en los que las mujeres realizasen trabajos peor remunerados (Datta, Tschantz y Datta, 2015). La falta de diversidad registrada en el sector tecnológico podría perpetuar estos sesgos. Según informaciones de Linkedin y el Foro Económico Mundial, solo el 22\% de los profesionales del sector de inteligencia artificial son mujeres (PNUD, 2019).

Resulta esencial que haya transparencia respecto al uso de sistemas de inteligencia artificial y a su funcionamiento. En este sentido, la regulación ha experimentado 
recientemente ciertos avances, ya que varios países se han acogido a la normativa internacional. El RGPD incluye el derecho a oponerse a la creación de perfiles automatizados, lo que permite a los interesados solicitar que se les excluya de procesos que comporten la toma de decisiones por métodos automatizados. También contempla el derecho a recibir una explicación, es decir, las personas afectadas por una decisión adoptada mediante algoritmos tienen derecho a que se les informe de la lógica aplicada, así como de la importancia y consecuencias de esta en dicha persona. Los países de la OCDE adoptaron la Recomendación del Consejo de la OCDE sobre Inteligencia Artificial (Principios de la OCDE sobre Inteligencia Artificial) en mayo de 2019, destinada a promover una inteligencia artificial que respete los derechos humanos y los valores democráticos (OCDE, 2019f). Estos principios complementan las normas actuales de la OCDE en materia de privacidad, gestión de riesgos de seguridad digital y conducta empresarial responsable. En ALC, dichos principios han sido adoptados por Argentina, Brasil, Chile, Colombia, Costa Rica, México y Perú. La OCDE puso también en funcionamiento un Observatorio de Políticas de Inteligencia Artificial en febrero de 2020 (Recuadro 4.1).

\section{Recuadro 4.1. El Observatorio de Políticas de Inteligencia Artificial de la OCDE}

El Observatorio de Políticas de Inteligencia Artificial de la OCDE tiene por objeto ayudar a los países a fomentar, promover y supervisar el desarrollo responsable de sistemas de inteligencia artificial fidedignos en beneficio de la sociedad. Tomando como base los Principios de la OCDE sobre Inteligencia Artificial, el Observatorio combina recursos de los diferentes países de la OCDE con los de socios de todos los grupos de interés, a fin de facilitar el diálogo y brindar un análisis multidisciplinar de políticas sobre inteligencia artificial basado en pruebas empíricas.

El Observatorio facilita recursos sobre temas de políticas públicas, iniciativas, tendencias y datos en materia de inteligencia artificial, así como orientaciones prácticas para la aplicación de los principios. Tanto los países como otros grupos de interés comparten y actualizan una base de datos de políticas e iniciativas de inteligencia artificial en tiempo real, que incluye políticas de inteligencia artificial de siete países de ALC, lo cual permite efectuar comparaciones interactivas de los principales elementos. La base de datos es el punto central del que los gobiernos extraen pruebas empíricas orientadas a la formulación de políticas y su debate, así como directrices en la materia, respaldadas por fuertes alianzas con un amplio número de agentes externos (OCDE, 2020c).

Aparte de favorecer la transparencia, las políticas que promueven sistemas de inteligencia artificial fidedignos son, entre otras, aquellas que fomentan la inversión en labores de I+D centradas en inteligencia artificial responsable, propician un ecosistema digital en el que no se pone en peligro la privacidad debido a un mayor acceso a los datos, permiten que las pymes prosperen, favorecen la competencia, al tiempo que protegen la propiedad intelectual, y dotan a las personas de las aptitudes necesarias para favorecer transiciones conforme evoluciona el mercado laboral (OCDE, 2019f). Además de contribuir a la aplicación de los Principios de la OCDE sobre Inteligencia Artificial, el grupo de expertos en inteligencia artificial de la OCDE, un grupo multidisciplinar formado por miembros de varios grupos de interés, brinda información para la creación de un repositorio de iniciativas de diferentes organismos públicos e interlocutores no gubernamentales, como por ejemplo normas privadas, programas voluntarios, directrices profesionales o códigos de conducta, mejores prácticas, principios, asociaciones público-privadas y programas de certificación. 
Más de 20 países disponen ya de estrategias nacionales sobre inteligencia artificial y ALC está registrando también avances. México se colocó entre los diez países pioneros y fue el primero de ALC en formular una estrategia de inteligencia artificial en 2018. La Política Nacional sobre Transformación Digital e Inteligencia Artificial creada por Colombia en 2019 asume el compromiso de crear un mercado de inteligencia artificial, dando prioridad a innovaciones que propicien el surgimiento de dicho mercado, así como al marco ético y al grado de experimentación. En Brasil, se prevé que las consultas públicas a través de Internet aporten datos para formular una estrategia brasileña en materia de inteligencia artificial destinada a maximizar los beneficios para el país. Argentina está elaborando un plan nacional para fomentar el desarrollo de la inteligencia artificial, en consonancia con los principios jurídicos y éticos consagrados en la Agenda Digital Argentina 2030 y como uno de los desafíos nacionales de la Estrategia Argentina Innovadora 2030. El Ministerio de Ciencia, Tecnología, Conocimiento e Innovación de Chile cuenta con un programa de trabajo para poner en marcha un Plan de Acción y una Estrategia de Inteligencia Artificial en 2020. Algunas de sus prioridades son alcanzar un consenso en materia de ética, normativa, ciberseguridad y regulación (OCDE, 2020d). Uruguay va camino de aprobar el borrador definitivo de la Estrategia Nacional de Inteligencia Artificial para el Gobierno Digital tras la realización de una consulta pública por Internet entre los meses de abril y junio de 2019 (Agesic, 2019).

\section{Los riesgos de la desinformación masiva: Las noticias falsas}

Las tecnologías digitales determinan la vida cotidiana actual pues facilitan la comunicación, el acceso y el intercambio de información política y social. El abandono de los canales de información tradicionales (entre ellos, periódicos, radio y televisión) en favor de los digitales (por ejemplo, redes sociales, sitios web y apps de mensajería privada) incrementa el riesgo de desinformación y las denominadas noticias falsas (fake news). La capacidad crítica de la ciudadanía se puede ver especialmente mermada en épocas de pánico o nerviosismo (como la crisis del Covid-19 o períodos electorales), por lo que es más probable que sea más complejo discernir entre contenidos fiables y sensacionalistas. Pese a que todavía se desconoce la repercusión que tiene la desinformación en los resultados de procesos democráticos, parece existir una correlación negativa entre el grado de exposición a esta y la confianza en el Gobierno (OCDE, 2019g). A medida que los canales digitales adquieren relevancia en los diferentes países de ALC, los responsables de las políticas deberían tratar de frenar la proliferación de noticias falsas y capacitar a los ciudadanos para que valoren con mentalidad crítica la información que encuentren.

Las nuevas tecnologías plantean desafíos esenciales debido a la mayor facilidad y rapidez con que pueden difundirse noticias falsas. Las tecnologías digitales permiten realizar análisis de datos complejos que pueden utilizarse para configurar la información y orientarla a grupos socioeconómicos o zonas geográficas con la finalidad de influir en su manera de pensar. La repercusión que esto puede tener, por ejemplo, en procesos electorales plantea numerosas dudas de carácter ético. Del mismo modo, la difusión de información falsa sobre el coronavirus (Covid-19) puede resultar perjudicial para la salud pública. Las plataformas digitales facilitan la creación de redes sociales homogéneas que actúan como cámaras de resonancia o burbujas que filtran la información, de modo que se aísla a los usuarios de opiniones contrarias. Así, permiten que las noticias falsas lleguen a las grandes audiencias y fomentan la polarización social (Lazer et al., 2018; Marwick y Lewis, 2017; Tucker et al., 2018; Wardle y Derakhshan, 2017).

Las noticias falsas pueden utilizarse para desacreditar a las autoridades y también ser empleadas por los poderes públicos para mantener el status quo o por grupos de interés para modificar la opinión pública. Las plataformas digitales, aparte de facilitar la divulgación de noticias sesgadas o falsas por medio de una clasificación algorítmica, permiten hacer 
campaña política y también publicidad basándose en técnicas de microtargeting y creación de perfiles psicográficos que obtienen datos de los usuarios recabados en redes sociales (Neudert y Marchal, 2019). La analítica de macrodatos añade un nuevo nivel al fenómeno de las noticias falsas, ya que permite orientar los mensajes políticos en función de los deseos y las necesidades de cada persona, tal como demostró el sonado caso de Cambridge Analytica.

Por otra parte, escándalos recientes relativos al alcance masivo y la repercusión de noticias falsas han hecho que los ciudadanos cuestionen la fiabilidad de la información que circula por redes sociales. En 2019, un 53\% de la población de ALC consideraba que de manera frecuente o muy frecuente se difundía información falsa para influir en los procesos electorales (Pring y Vrushi, 2019). Tres de cada cuatro así lo creían en Brasil, donde la confianza en las noticias en general descendió 11 puntos porcentuales en 2019 respecto al año anterior (Reuters Institute for the Study of Journalism, 2019).

Las escasas pruebas empíricas disponibles indican que la repercusión de las noticias falsas en la opinión pública es importante, al menos en lo que se refiere al número de personas a las que llegan. Durante el mes anterior a las elecciones celebradas en Estados Unidos en 2016, los estadounidenses estuvieron en contacto con entre una y tres noticias falsas (Allcott y Gentzkow, 2017). De igual manera, a partir de la investigación de cerca de 126000 tuiteos durante el período de 2006 a 2017, los datos falsos se difundían con una rapidez considerablemente superior, de manera más amplia y también más detallada que los ciertos, y los efectos de las noticias falsas de índole política eran más acusados que los de noticias falsas sobre terrorismo, catástrofes naturales, ciencia, leyendas urbanas o información económica (Vosoughi, Roy y Aral, 2018). Los estudios suelen centrarse en analizar el número de personas que han compartido noticias falsas o interactuado con ellas, porque calcular cuántas se han visto afectadas es más difícil y el resultado podría ser considerablemente superior (Lazer et al., 2018).

Los responsables de políticas tienen la obligación de garantizar que los ciudadanos dispongan de acceso a información veraz y fiable (OCDE, 2017b). Resulta esencial emprender acciones encaminadas a frenar la difusión de noticias falsas para aumentar la confianza en las instituciones públicas, en especial en ALC. En la región, la confianza que los ciudadanos depositan en las redes sociales como canal de noticias supera el promedio mundial, pese a haberse reducido en todos los países consultados, salvo Argentina: en 2019, el máximo grado de confianza en las noticias de redes sociales se registró en México (39\% de los encuestados), seguido de Chile (32\%), Argentina (32\%) y Brasil (31\%), frente al promedio mundial del $23 \%$. Las redes sociales son el medio para acceder a noticias por Internet preferido por un $42 \%$ de los encuestados en Chile, seguidas de los buscadores (21\%) y los sitios web o apps de noticias directamente (19\%). En Brasil, se observan tendencias similares (Reuters Institute for the Study of Journalism, 2019). ${ }^{3}$

La regulación y la adquisición de conocimientos básicos sobre el uso de los medios de comunicación son las dos intervenciones utilizadas principalmente para hacer frente a este problema. La regulación de los medios de comunicación consiste en introducir cambios estructurales para prevenir que lleguen a los usuarios contenidos falsos. Las plataformas ya han adoptado medidas en este sentido. WhatsApp limitó el reenvío simultáneo de mensajes a cinco chats para frenar los envíos masivos. Facebook modificó su algoritmo y, junto con Twitter, ahora publica un informe de transparencia sobre el número de actividades malintencionadas observadas en la plataforma. Twitter comunicó que, entre los meses de enero y junio de 2019, verificó entre 14 y 20 millones de cuentas al mes sospechosas de haber incurrido en actividades malintencionadas o no deseadas (Twitter, 2019).

El abandono de plataformas de redes sociales, como Facebook, en favor de apps de mensajería privada, como WhatsApp y Facebook Messenger, para acceder a noticias por 
Internet podría menoscabar la lucha contra las noticias falsas. Un 53\% de los brasileños consultados manifestó haber utilizado WhatsApp para acceder a noticias ${ }^{4}$ y un $58 \%$ de los usuarios de WhatsApp de Brasil declaró utilizar grupos para interactuar con personas que no conocían. ${ }^{5}$ Las cifras correspondientes a Reino Unido fueron un $9 \%$ y un $12 \%$ respectivamente y en Australia, un 6\% y un 27\% (Reuters Institute for the Study of Journalism, 2019).

La adquisición de conocimientos básicos sobre el uso de los medios de comunicación constituye una intervención complementaria para dotar a las personas de competencias y herramientas adecuadas que les permitan evaluar las noticias a las que tienen acceso, incluso mediante iniciativas de verificación de noticias y comprobación de los hechos (Lazer et al., 2018). En ALC, se ha disparado el número de iniciativas de este tipo, en algunos casos gracias a la realización de actividades periodísticas previas a las elecciones, como es el caso de Chequeado y Reverso en Argentina, Agencia Lupa y Comprova en Brasil, Colombiacheck, Ecuador Chequea, VerificadoMX en México y Verificado.uy en Uruguay. Los gobiernos han fomentado otras iniciativas de formación sobre medios de comunicación, como Gobierno Aclara en Costa Rica y\#VerdadElecciones2019 en Colombia. Más recientemente, han surgido iniciativas para combatir la desinformación sobre la crisis del coronavirus (Covid-19). En Colombia, el Centro de Información de Naciones Unidas formó asociaciones estratégicas con emisoras de radio locales y agencias nuevas para realizar un seguimiento de las noticias falsas. También dirige la emisora de radio Voces Unidas, que responde a preguntas o dudas sobre el virus en español y en las lenguas indígenas (ONU, 2020a).

Al no circunscribirse a un ámbito territorial determinado, las noticias falsas y su alcance mundial ponen de manifiesto la necesidad de plantear redes de cooperación en el plano regional y en el internacional, intercambiar mejores prácticas sobre cómo frenar la desinformación y organizar respuestas coordinadas. El sistema de alerta rápida, creado como parte del Plan de Acción contra la desinformación de la UE, constituye un ejemplo de cooperación internacional (Comisión Europea, 2019c). Dicho Plan de Acción, elaborado antes de las elecciones al Parlamento Europeo de 2019, fue una iniciativa integral para hacer frente a las noticias falsas en el plano estatal. Su propósito es mejorar la detección y el análisis de la desinformación y paliar la exposición a esta, reforzar la cooperación de las respuestas conjuntas a las amenazas mediante un sistema específico de alerta rápida, potenciar la colaboración con plataformas de Internet y con la industria para atajar la desinformación, y sensibilizar y mejorar la resiliencia social (Comisión Europea, 2018). La Unión Europea elaboró también el Código de Prácticas sobre Desinformación, un conjunto de normas voluntarias y de autorregulación para combatir la desinformación firmado por plataformas, redes sociales de primer orden y el sector publicitario.

\section{La transformación digital de los gobiernos}

\section{La transición de gobiernos electrónicos a gobiernos digitales en América Latina y el Caribe: Situación actual}

La incorporación de tecnologías digitales a la transformación de las instituciones públicas evoluciona rápidamente. En esta evolución pueden identificarse tres etapas principales (Gráfico 4.2). El gobierno analógico se basaba en procedimientos analógicos. El gobierno electrónico consiste en el empleo por parte de las entidades públicas de las tecnologías de la información y las comunicaciones (TIC), y especialmente de Internet, como instrumento para mejorar la administración pública (OCDE, 2014c). El gobierno electrónico facilita mayor contenido e información a través de Internet, pero existe una escasa interacción con los ciudadanos y persisten las prácticas de gestión jerárquicas. 


\section{Gráfico 4.2. Avance hacia un gobierno digital}

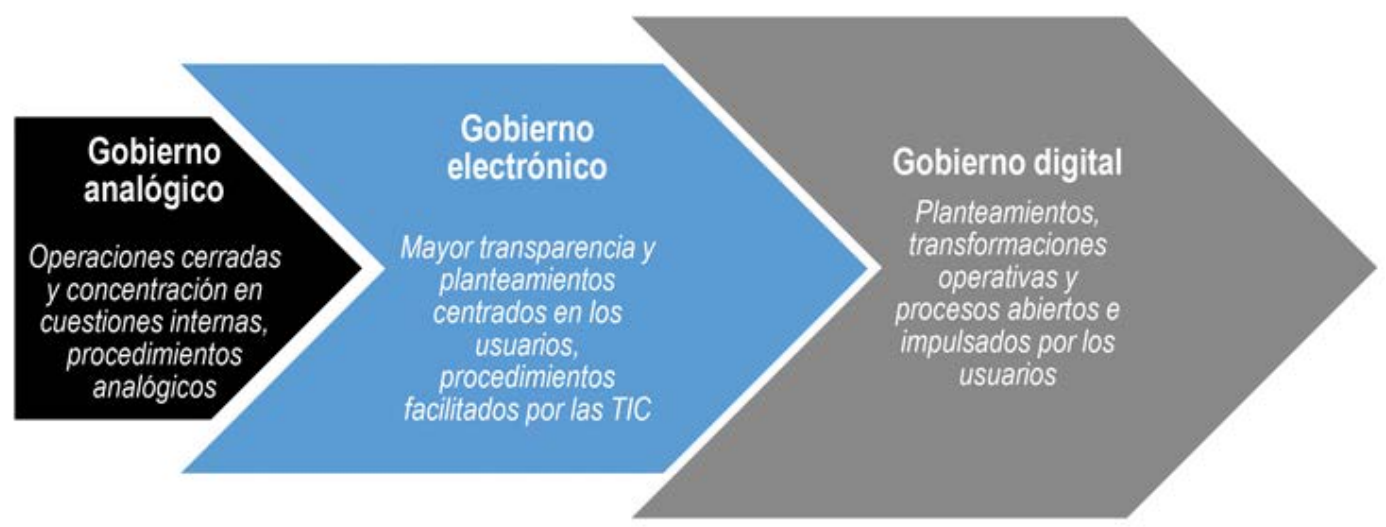

Fuente: OCDE (2014c), Recommendation of the Council on Digital Government Strategies, www.oecd.org/gov/digitalgovernment/Recommendation-digital-government-strategies.pdf.

El gobierno digital se define como el uso de las tecnologías digitales, a modo de componente integrado en las estrategias de modernización de las administraciones, con la finalidad de generar valor público. Se basa en un ecosistema de gobierno digital compuesto por actores socioeconómicos del país que facilitan la producción de datos, servicios y contenido, y el acceso a estos, mediante interacciones con los organismos públicos (OCDE, 2014c). El avance hacia la transformación digital del gobierno comporta un cambio radical en la concepción del sector público con respecto a la participación, la formulación de políticas, la prestación de servicios públicos y la colaboración. El Marco de Gobierno Digital de la OCDE señala que el gobierno digital presenta seis dimensiones: digital en su diseño, enfocado en el ciudadano, el gobierno como plataforma, apertura por defecto, impulsado por datos y proactivo. Mientras que el gobierno electrónico se centraba en la tecnología, el gobierno digital se basa en la introducción de una mentalidad digital en la práctica de la administración pública, que se centre en las necesidades, reestructurando y redefiniendo servicios y procesos. La tecnología es un elemento facilitador contextual, insertado en la actividad constante de mejora del gobierno, y no el impulsor de la transformación (digital en su diseño) (OCDE, 2019h).

Las nuevas tecnologías han cambiado las expectativas en cuanto a la interacción con los organismos públicos. Las tecnologías digitales le permiten a la población nuevas formas de participación, lo que supone un giro desde planteamientos centrados en la ciudadanía, en los que el gobierno es quien prevé las necesidades de ciudadanos y empresas, hacia otros directamente impulsados por la ciudadanía, en los que tanto ciudadanos como empresas identifican sus necesidades y responden a ellas en colaboración con la administración (OCDE, 2014c). En este tipo de administraciones públicas (enfocadas en los ciudadanos), el gobierno deja de ser un proveedor de servicios para convertirse en una plataforma en la que se genera conjuntamente valor público (el gobierno como plataforma) gracias a la divulgación de datos en formato abierto (apertura por defecto) (OCDE, 2019h).

El aprovechamiento de todas las posibilidades que ofrecen las nuevas tecnologías digitales y los datos durante la formulación, ejecución y seguimiento de políticas y servicios públicos puede transformar las administraciones públicas. Un sector público verdaderamente impulsado por los datos debería: 1) reconocer que estos constituyen un activo estratégico esencial, definir su valor y medir su impacto; 2) mostrar un empeño activo por eliminar obstáculos a la gestión, el intercambio y la reutilización de los datos; 3) aplicar los datos a la transformación de la formulación, ejecución y seguimiento de 
políticas y servicios públicos; 4) apreciar las iniciativas destinadas a publicar datos de manera abierta y el uso de datos tanto entre organizaciones del sector público como dentro de estas; y 5) entender los derechos de los ciudadanos en materia de datos, en cuanto a comportamiento ético, transparencia respecto al uso, y protección de la privacidad y la seguridad de los datos (OCDE, 2019b). A su vez, el tratamiento automático de los datos permite a los gobiernos prever y responder rápidamente a necesidades o cuestiones públicas que vayan surgiendo en lugar de reaccionar a ellas (proactivo) (OCDE, 2019h).

Los países de ALC se encuentran en distintas etapas de transformación digital de sus gobiernos. El Índice de desarrollo del gobierno electrónico (EGDI) de Naciones Unidas, pese a no reflejar todas las dimensiones de un gobierno totalmente digital, constituye una de las medidas en materia de desarrollo del gobierno electrónico más utilizadas internacionalmente para comparar los avances de los países en este sentido. El índice se basa en medidas de servicios prestados a través de Internet, infraestructura de telecomunicaciones y capital humano. En ALC, Argentina, Brasil, Chile y Uruguay se situaron entre los primeros 50 países de los 193 encuestados para la elaboración del EGDI 2018, ${ }^{6}$ con resultados ligeramente inferiores al promedio de la OCDE. Belice, Cuba, Haití y Nicaragua se situaron entre los países con peores resultados de ALC (ONU, 2019). Los análisis pormenorizados de los países sobre el avance de la transformación digital de los gobiernos de ALC pueden encontrarse en la serie de Estudios sobre Gobierno Digital de la OCDE relativos a Argentina, Brasil, Chile, Colombia, México, Panamá y Perú.

\section{Gráfico 4.3. Índice de desarrollo del gobierno electrónico de Naciones Unidas, América Latina y el Caribe, 2018}

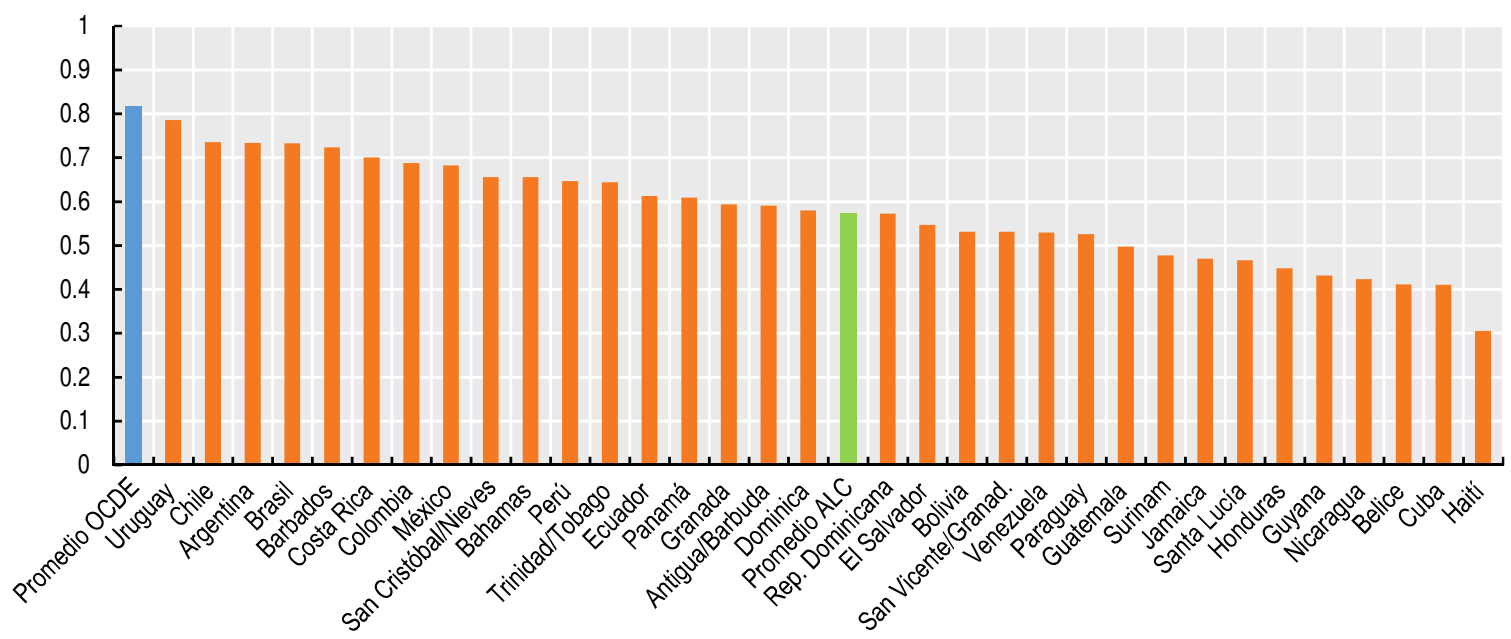

Notas: El Índice de desarrollo del gobierno electrónico (EGDI) de Naciones Unidas es un índice compuesto por el Índice de servicios en línea (OSI), el Índice de infraestructura de telecomunicaciones (TII) y el Índice de capital humano (HCI). El índice OSI valora el alcance y la calidad de los servicios públicos prestados a través de Internet que figuran en la página web nacional del país; el TII mide el desarrollo de la infraestructura de telecomunicaciones; el HCI, por su parte, refleja, la situación del país en materia de capital humano. Su puntuación se sitúa entre 0 (menos avanzado) y 1 (más avanzado). Promedios simples correspondientes a la OCDE y a América Latina y el Caribe.

Fuente: ONU (2019), UN e-Government Knowledge Database (base de datos), https://publicadministration.un.org/egovkb/en-us/ Data-Center.

StatLink तillst https://doi.org/10.1787/888934202655

Según la evolución de los subíndices del EGDI entre 2014 y 2018, los mayores desafíos que encaran los países de ALC están relacionados con las dimensiones de infraestructura de telecomunicaciones y capital humano. Durante ese periodo, la dimensión de servicios por Internet registró un avance moderado (Gráfico 4.4). Esta evolución pone de manifiesto la dificultad que comporta modificar variables estructurales, como el capital humano y la infraestructura. La formulación y aplicación de estrategias de gobierno electrónico 
ha constituido un factor determinante para el avance de la prestación de servicios por Internet en los países de ALC.

\section{Gráfico 4.4. Índice de desarrollo del gobierno electrónico de Naciones Unidas, por componente, América Latina y el Caribe, 2014, 2016 y 2018}

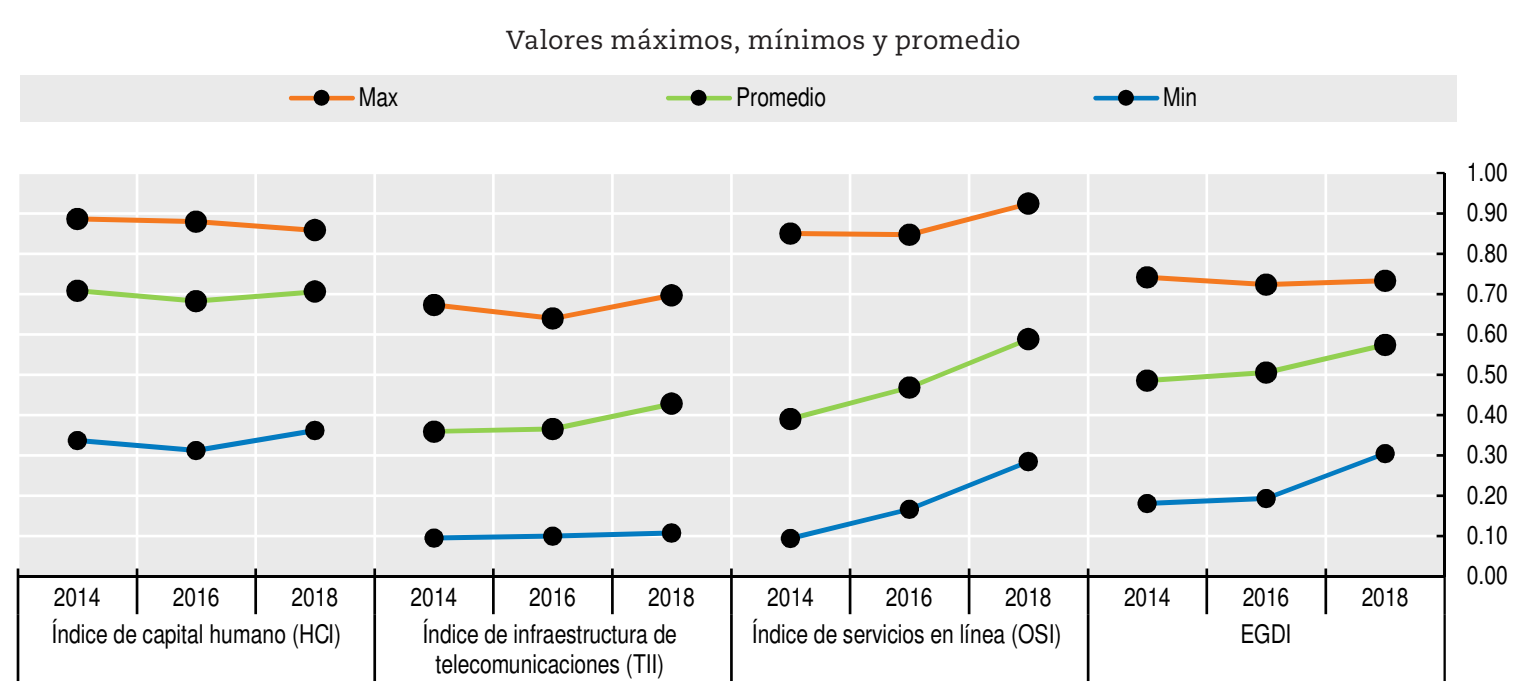

Notas: Promedios simples utilizados. América Latina y el Caribe incluye Antigua/Barbuda, Argentina, Bahamas, Belice, Bolivia, Brasil, Barbados, Costa Rica, Colombia, Chile, Cuba, Dominica, República Dominicana, Ecuador, El Salvador, Granada, Guatemala, Guyana, Haití, Honduras, Jamaica, México, Nicaragua, San Cristóbal/Nieves, Panamá, Paraguay, Perú, San Vicente/Granad., Surinam, Santa Lucía, Trinidad/Tobago, Uruguay y Venezuela.

Fuente: Elaboración propia a partir de ONU (2019), UN e-Government Knowledge Database (base de datos), https:// publicadministration.un.org/egovkb/en-us/Data-Center.

StatLink तints https://doi.org/10.1787/888934202674

En los sistemas estadísticos, todavía no se ha producido el cambio de gobiernos electrónicos a gobiernos digitales. En la actualidad, no existe ninguna medida del gobierno digital capaz de reflejar todas sus dimensiones. Varios indicadores dispersos muestran que Chile, México y Uruguay avanzan rápidamente en la prestación de servicios de la administración pública por Internet (Gráfico 4.9) y Colombia está haciendo progresos en materia de políticas de datos gubernamentales abiertos (OGD) (Gráfico 4.12). No obstante, ninguna de estas medidas ofrece una imagen completa de la situación de las administraciones públicas en cuanto a transformación digital. La OCDE está formulando actualmente una nueva generación de indicadores de gobierno digital (Recuadro 4.2).

\section{Recuadro 4.2. Medición de la madurez del gobierno digital}

La mayoría de las medidas internacionales siguen centrándose en el uso de tecnologías por parte de los organismos públicos para promover la digitalización de los procesos, procedimientos y servicios existentes (gobierno electrónico), y no en las características que confieren a un gobierno un carácter plenamente digital. La OCDE ha creado un conjunto de indicadores que engloban las seis dimensiones de un gobierno digital (digital en su diseño, enfocado en el ciudadano, el gobierno como plataforma, apertura por defecto, impulsado por los datos y proactivo) y pueden utilizarse como índice de madurez, lo que permite a las administraciones públicas determinar cuánto han avanzado en cada dimensión. 


\section{Recuadro 4.2. Medición de la madurez del gobierno digital (cont.)}

Este proyecto constituye un primer intento de medir la transformación digital del sector público y es el resultado de una colaboración entre la Unidad de Gobierno Digital de la Dirección de Gobernanza Pública de la OCDE y el Grupo de Trabajo de Altos Funcionarios en Gobierno Digital (E-Leaders) de la OCDE. Esta iniciativa se basa en el marco teórico de la Recomendación del Consejo sobre Estrategias de Gobierno Digital de 2014 y las consiguientes revisiones entre pares. El índice no solo proporcionará un punto de referencia entre los diferentes países sino que además les permitirá realizar un seguimiento de las iniciativas que emprendan para aplicar la Recomendación (OCDE, 2019i).

\section{Avanzar hacia instituciones públicas más creíbles, eficientes, inclusivas e innovadoras}

La transformación digital representa una oportunidad única para lograr una profunda transformación de las instituciones públicas y adaptarlas a las aspiraciones crecientes de la sociedad. En un mundo que cambia rápidamente, los procesos de desarrollo exigen unas instituciones públicas ágiles, que estén preparadas para hacer frente a los desafíos que surjan y aprovechar nuevas oportunidades. El contexto latinoamericano se ha caracterizado por una ampliación de la brecha entre ciudadanía e instituciones, lo que ha generado una trampa institucional que deriva en un círculo vicioso de desconfianza, menor predisposición a pagar impuestos y, en consecuencia, un déficit de recursos para financiar servicios públicos de buena calidad y satisfacer las demandas de la ciudadanía (OCDE et al., 2019). En esta sección se analizan las oportunidades que ofrece la transformación digital para avanzar hacia instituciones públicas más creíbles, eficaces, inclusivas e innovadoras en ALC.

Pese a no ser el tema principal de esta sección, el desarrollo de infraestructuras y la inversión en competencias digitales de los servidores públicos constituyen dos requisitos previos esenciales para garantizar una adecuada transformación digital de los gobiernos. El desarrollo de las infraestructuras debe eliminar la brecha digital, de modo que todos los ciudadanos gocen por igual de acceso a servicios públicos por Internet e interactúen con la administración y también entre sí por medios digitales. Las competencias digitales y la adquisición de conocimientos básicos en dicha materia son esenciales en la administración pública, para aprovechar al máximo las tecnologías digitales y responder a nuevos desafíos (ver el Capítulo 3). Aparte de las competencias de los usuarios en materia de tecnologías digitales (por ejemplo, correo electrónico, procesador de textos, hojas de cálculo, apps de flujo de trabajo) y competencias digitales tanto de índole técnica como social en las profesiones del sector público (entre ellas, la de analista de datos), cada vez es más necesario contar con unos conocimientos complementarios en materia digital para desempeñar funciones públicas que han registrado una profunda transformación debido a la digitalización (por ejemplo, planificación, gestión de servicios a los ciudadanos, comunicaciones gubernamentales, cobro de impuestos) (OCDE, 2019j). La gestión digital y las competencias directivas también son necesarias para reconocer las oportunidades, los beneficios y los riesgos que conlleva el uso de tecnologías digitales en el sector público (OCDE, 2017c).

\section{Hacia instituciones públicas más creíbles}

En los últimos años, en ALC ha descendido la confianza en las instituciones públicas y democráticas. En 2018, la confianza de la población en el Gobierno nacional descendió 
del $45 \%$ registrado en 2008 a un $26 \%$, en el Congreso del $32 \%$ al 21\%, en el sistema judicial del $28 \%$ al 24\% y en los partidos políticos del 21\% al 13\% (Gráfico 4.5). La percepción de democracia también se ha deteriorado considerablemente (Gráfico 4.6).

Un factor principal determinante de la falta de confianza en las instituciones públicas es la sensación generalizada de corrupción. En 2018, un 79\% de la población de ALC consideraba que la corrupción era un mal muy extendido en la administración pública (Gráfico 4.5). Cerca de un 53\% opinaba que la corrupción había aumentado entre finales de 2018 y finales de 2019 (Pring y Vrushi, 2019). Este hecho intensifica la sensación del público de que las élites económicas y políticas ejercen una fuerte influencia en las decisiones de política pública en su propio beneficio, y de hecho casi un 79\% tenía la convicción de que el país era gobernado por unos pocos con la intención de lucrarse (Gráfico 4.6).

\section{Gráfico 4.5. Confianza en las instituciones y percepción de corrupción, América Latina y el Caribe, 2008-2018}

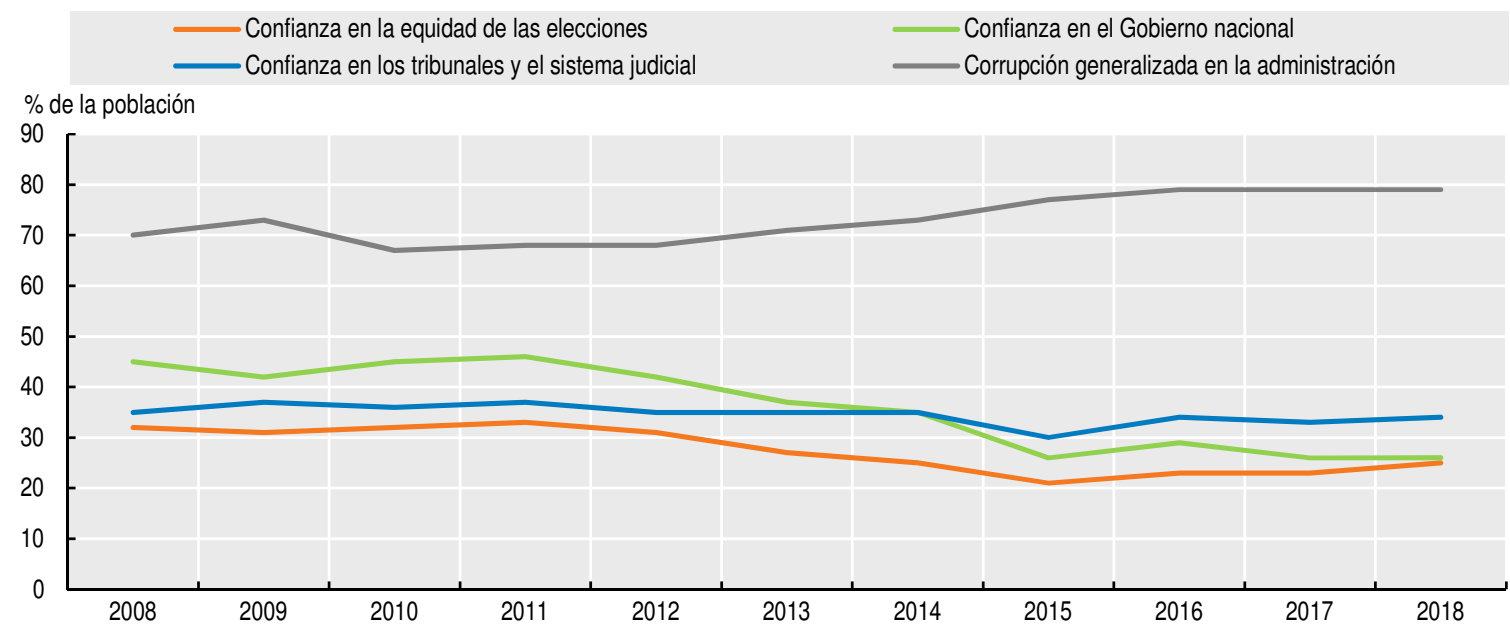

Nota: Promedio ponderado.

Fuente: Elaboración propia a partir de Gallup (2019), Gallup World Poll (base de datos), www.gallup.com/analytics/232838/ world-poll.aspx y Latinobarómetro (2018), Encuesta Latinobarómetro (base de datos), www.latinobarometro.org/lat.jsp.

StatLink न्ना15la https://doi.org/10.1787/888934202693

La confianza es la piedra angular de la gobernanza pública y resulta fundamental para que las políticas públicas surtan efecto. Muchas de ellas dependen de la cooperación y el cumplimiento de los ciudadanos y muchas otras asumen un determinado comportamiento del público que las convertirá en medidas efectivas (OCDE/CAF/CEPAL, 2018).

El gobierno abierto, como paradigma de la gestión pública, puede contribuir a la superación de estos desafíos, al hacer hincapié en la importancia que revisten la transparencia, el acceso a la información, la colaboración y la participación ciudadana (Naser, Ramírez-Alujas y Rosales, 2017). Los países de ALC han demostrado su compromiso con el gobierno abierto (Gráfico 4.7), ya que en enero de 2020 esta región contaba con 53 planes de acción -38 de ellos ya implantados y 15 en curso-. A dichos planes se sumaban además 1116 compromisos de actuación, lo que refleja la importancia de la apertura en materia de innovación como una modalidad de colaboración con los ciudadanos para crear soluciones conjuntamente. 


\section{Gráfico 4.6. Percepción de democracia y aprobación del Gobierno, América Latina y el Caribe, 2006-2018}

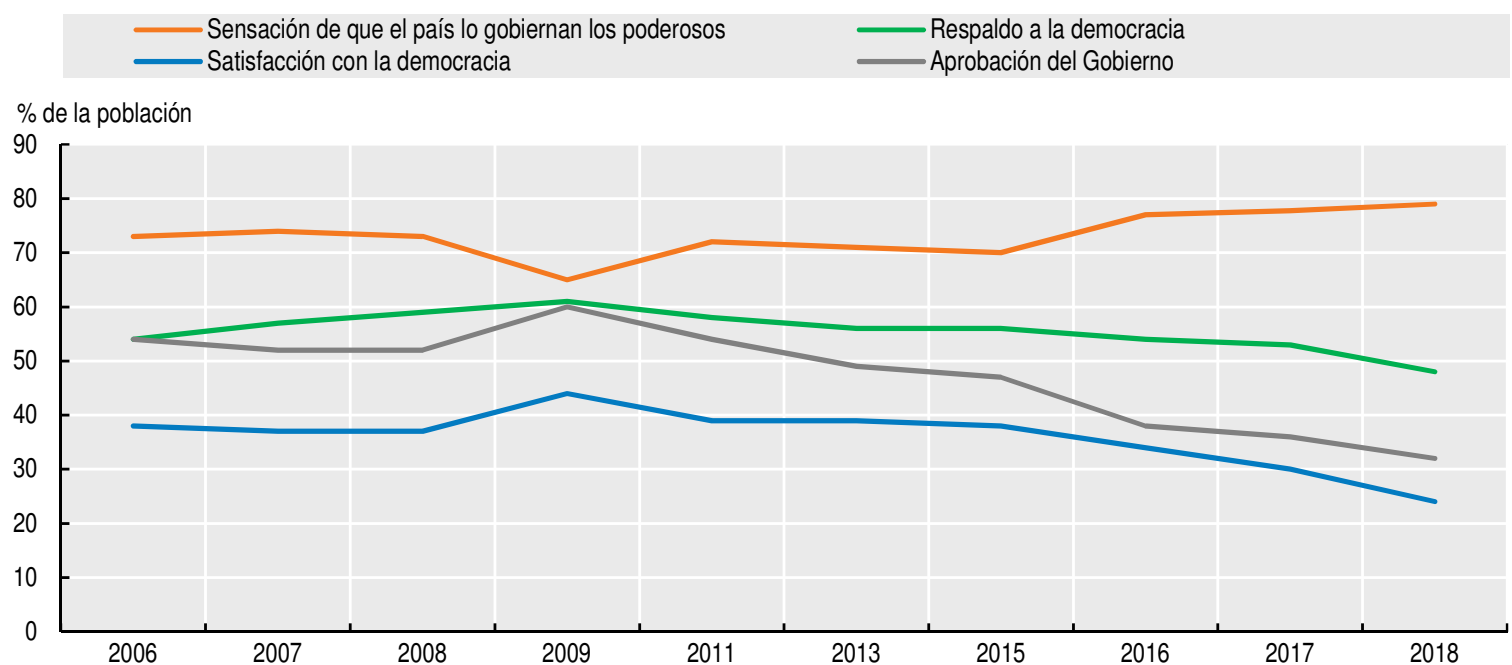

Nota: Promedio simple.

Fuente: Elaboración propia a partir del Latinobarómetro (2018), Encuesta Latinobarómetro (base de datos), www.latinobarometro. org/lat.jsp.

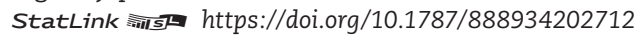

\section{Gráfico 4.7. Planes de acción en materia de gobierno abierto, países seleccionados de América Latina y el Caribe}

\begin{tabular}{|c|c|c|c|c|c|c|c|c|c|c|}
\hline & \multicolumn{5}{|c|}{$\begin{array}{l}\text { Integración en la Open Government Partnership } \\
\text { Tercer Plan }\end{array}$} & \multicolumn{2}{|c|}{$\begin{array}{l}\text { Primer Plan } \\
\text { Cuarto Plan }\end{array}$} & \multicolumn{2}{|c|}{ Segundo Plan } & \multirow[b]{2}{*}{2020} \\
\hline & 2011 & 2012 & 2013 & 2014 & 2015 & 2016 & 2017 & 2018 & 2019 & \\
\hline México & - & & & & & & & & & \\
\hline Brasil & - & & & & & & & & & \\
\hline Chile & - & & & & & & & & & \\
\hline El Salvador & $\bullet$ & & & & & & & & & \\
\hline Guatemala & $\bullet$ & & & & & & & & & \\
\hline Honduras & - & & & & & & & & & \\
\hline Rep. Dominicana & $\bullet$ & & & & & & & & & \\
\hline Uruguay & - & & & & & & & & & \\
\hline Paraguay & $\bullet$ & & & & & & & & & \\
\hline Perú & $\bullet$ & & & & & & & & & \\
\hline Colombia & $\bullet$ & & & & & & & & & \\
\hline Costa Rica & & - & & & & & & & & \\
\hline Argentina & & $\bullet$ & & & & & & & & \\
\hline Panamá & & 0 & & & & & & & & \\
\hline Trinidad y Tobago & & & $\bullet$ & & & & & & & \\
\hline Ecuador & & & & & & & & - & & \\
\hline Jamaica & & & & & & - & Sin Plan de Acción & & & \\
\hline
\end{tabular}

Fuente: CEPAL (2020), Observatorio Regional de Planificación para el Desarrollo de América Latina y el Caribe, https://observatorio planificacion.cepal.org/en/opengov.

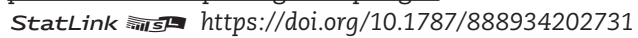

El acceso a la información constituye un aspecto fundamental del gobierno abierto y disponer de los datos gubernamentales es una evolución natural de la publicación proactiva de información pública. Por lo tanto, los datos se han convertido en un componente esencial de los planes de gobierno abierto. El incremento del nivel de disponibilidad de datos crea nuevas vías para aumentar la fiabilidad de las instituciones públicas. Las estrategias 
de datos gubernamentales disponibles ofrecen enormes posibilidades para mejorar la gobernanza democrática, ya que propician una filosofía de transparencia, una gestión más responsable y el acceso a información pública. Los datos gubernamentales abiertos brindan grandes cantidades de información a la ciudadanía, la sociedad civil y las organizaciones internacionales, que de este modo pueden desempeñar una función de control y actuar como entes de vigilancia y denuncia de casos de corrupción o malversación. El hecho de disponer de datos sobre finanzas públicas y presupuestos resultó esencial para destapar escándalos de corrupción a gran escala dentro de la región, como el de los Papeles de Panamá o la red de corrupción Odebrecht (Santiso y Roseth, 2017).

Las tecnologías digitales pueden propiciar mejoras en ámbitos especialmente propensos a registrar prácticas corruptas, como la contratación pública, las inversiones en infraestructuras y las transferencias de las autoridades nacionales a las subnacionales. Pese a existir todavía margen de mejora, ALC ha registrado avances en este sentido. MapaInversiones es una iniciativa del Banco Interamericano de Desarrollo (BID) destinada a ayudar a los países a crear plataformas digitales para la visualización de datos. Su objetivo principal es mejorar la transparencia y la eficiencia de la inversión pública. Los ciudadanos pueden emplear las plataformas para ejercer un control social sobre el uso de los fondos públicos, el sector privado puede recurrir a ellas para fijar prioridades de inversión y los responsables de políticas para dar mayor empuje a la planificación, la formulación y la aplicación de políticas públicas (Kahn, Baron y Vieyra, 2018). Colombia, Costa Rica, República Dominicana, Jamaica, Paraguay y Perú han puesto en funcionamiento plataformas de ese tipo. En Colombia, la plataforma MapaRegalías, que muestra el origen y el destino de los recursos financieros obtenidos con la explotación de los recursos naturales, ha ayudado a identificar numerosas irregularidades (Santiso, 2018). Desde su puesta en funcionamiento, la eficiencia en la aplicación de proyectos financiados con regalías aumentó en promedio un 8\% (Lauletta et al., 2019).

La creación de órganos centrales de compras como centros especializados en adquisiciones y contrataciones públicas, y el desarrollo de soluciones electrónicas para adquisiciones y contrataciones están transformando las prácticas tradicionales en este ámbito en ALC. ChileCompra y Colombia Compra Eficiente son, por ejemplo, dos plataformas electrónicas para adquisiciones y contrataciones que facilitan información sobre contratos públicos de forma transparente. Además de mejorar la transparencia de la gestión pública, los datos generados por las plataformas electrónicas de adquisiciones y contrataciones pueden reutilizarse para fines de lucha contra la corrupción mediante técnicas de aprendizaje automático y macrodatos. El sistema OCÉANO, creado por la Contraloría General de Colombia, contrasta información del sistema electrónico de adquisiciones y contrataciones, administrado por Colombia Compra Eficiente, con el registro social y empresarial para detectar redes de corrupción (Cetina, 2020). El Observatorio de Gasto Público de Brasil realiza un seguimiento de los datos de gasto en adquisiciones y contrataciones y los contrasta con los de otras bases de datos gubernamentales para identificar situaciones atípicas que, pese a no constatar a priori ninguna irregularidad, justifican la realización de un examen más exhaustivo. Esta plataforma detectó un fraude en el mayor programa de bienestar social de Brasil, Bolsa Família.

El blockchain es otra tecnología emergente que puede potenciar la integridad de las instituciones públicas y prevenir que se incurra en prácticas de corrupción. El blockchain facilita las labores de contabilización de activos, transferencia de valor y rastreo de operaciones de forma descentralizada, lo que garantiza la transparencia, integridad y trazabilidad de los datos. De este modo, se elimina la necesidad de intermediarios, se reduce la burocracia y también disminuye el riesgo de que se tomen decisiones arbitrarias. 
Las redes sociales y los medios audiovisuales en línea pueden ayudar a generar confianza en la gestión de crisis. Tal como se ha visto durante la pandemia del coronavirus (Covid-19), si los gobiernos emiten mensajes contradictorios, al público le resulta más difícil entender la gravedad de los riesgos y saber qué deben hacer al respecto. La desinformación y las noticias falsas pueden acentuar esta tendencia y generar pánico y confusión (De la Garza, 2020). Las administraciones deben asegurarse de que existan canales de información claros y fiables para la mayor parte de la población. Las redes sociales pueden constituir una plataforma importante para informar a los ciudadanos de los riesgos y la evolución de episodios de crisis, así como de las medidas adoptadas para atajarla. Algunos ejemplos de este tipo de actuaciones son las campañas digitales de concienciación y la publicación de informes diarios en las cuentas oficiales de los gobiernos en redes sociales. En ALC, este canal puede resultar especialmente efectivo debido al uso extendido de dichas plataformas entre la población. Las iniciativas de verificación de noticias también pueden ayudar a frenar la difusión de noticias falsas (ver la sección "Los riesgos de la desinformación masiva"). La ONU ha puesto en marcha la plataforma Verified, cuyo objetivo es aumentar el volumen y alcance de la información fiable y precisa sobre la crisis del Covid-19 (ONU, 2020b).

Las redes sociales y los buscadores también pueden ayudar a las administraciones a gestionar mejor las crisis, dando prioridad a información oficial y que provenga de fuentes autorizadas (Donovan, 2020; OCDE, 2020e). Los algoritmos de redes sociales suelen promocionar el contenido más atractivo, por lo que podrían potenciar la difusión de noticias falsas de corte sensacionalista. Sin embargo, durante la pandemia, las plataformas digitales incluyeron enlaces a las páginas web de los gobiernos con información acerca del coronavirus (Covid-19) en los resultados principales de las búsquedas sobre este tema. Google ajustó su algoritmo para que los primeros resultados de las búsquedas ofreciesen una visión panorámica del brote, información sobre los síntomas, consejos preventivos y enlaces a páginas web de gobiernos nacionales y la Organización Mundial de la Salud (OMS). Otras iniciativas han incluido la cooperación con verificadores de hechos y autoridades sanitarias para identificar y eliminar la desinformación, ofreciendo espacios publicitarios gratuitos a las autoridades para diseminar información crítica en torno a la pandemia (OCDE, 2020e).

Las tecnologías digitales también plantean nuevos desafíos en materia de confianza en las instituciones. La creciente interconexión propiciada por los avances tecnológicos puede dar lugar a nuevos paradigmas de progreso social. Las generaciones más jóvenes, al resultarles más sencillo efectuar una comparación con el progreso de países más avanzados, podrían aumentar sus exigencias a las instituciones públicas y frustrarse si estas incumplen sus expectativas (Nieto-Parra, Pezzini y Vázquez, 2019). El acceso generalizado a información también puede acentuar la fragilidad de la confianza en las instituciones públicas en la medida en que se utilice Internet para difundir propaganda y noticias falsas que desinformen a los ciudadanos. Combatir la difusión de este tipo de noticias es una labor compleja, aunque están surgiendo iniciativas destinadas a contrarrestar su significativa repercusión en la confianza pública (ver la sección "Gobierno de la transformación digital"). Internet puede incidir además en las actitudes políticas y, en determinadas circunstancias, mermar la confianza del público en el Gobierno (Guriev, Melnikov y Zhuravskaya, 2019).

\section{Hacia instituciones públicas más eficientes}

En un contexto en el que los gobiernos enfrentan importantes limitaciones en cuanto a gasto público y se esfuerzan por satisfacer las expectativas crecientes de la población, las tecnologías digitales pueden ayudar a incrementar la eficiencia de los servicios públicos, al reducir los plazos de tramitación de operaciones y también los costos administrativos. 
Un buen ejemplo de la compleja burocracia que existe en ALC es el promedio de tiempo necesario para realizar un trámite ante la administración pública, por ejemplo, conseguir un certificado de nacimiento, pagar una multa u obtener una licencia. En ALC, dicho promedio es de 5.4 horas, aunque las cifras varían mucho en función del país, ya que oscilan entre más de 11 horas en Bolivia y menos de 3 horas en Chile (Gráfico 4.8). Un elevado porcentaje de trámites exige tres interacciones o más con funcionarios públicos, lo que eleva enormemente los costos para la ciudadanía, pues debe invertir tiempo y dinero en sus gestiones con la administración, pero también para los gobiernos, que deben invertir recursos económicos en atender presencialmente a los ciudadanos, revisar la documentación y responder a consultas. Las herramientas digitales pueden ayudar a reducir esta carga. Por ejemplo, el distrito londinense de Barking and Dagenham redujo los plazos de tramitación en 30 días y ahorró 617000 libras al año con la digitalización de las solicitudes de prestaciones sociales (Local Government Association, 2014).

\section{Gráfico 4.8. Horas necesarias para realizar un trámite ante la administración pública, países seleccionados de América Latina y el Caribe}

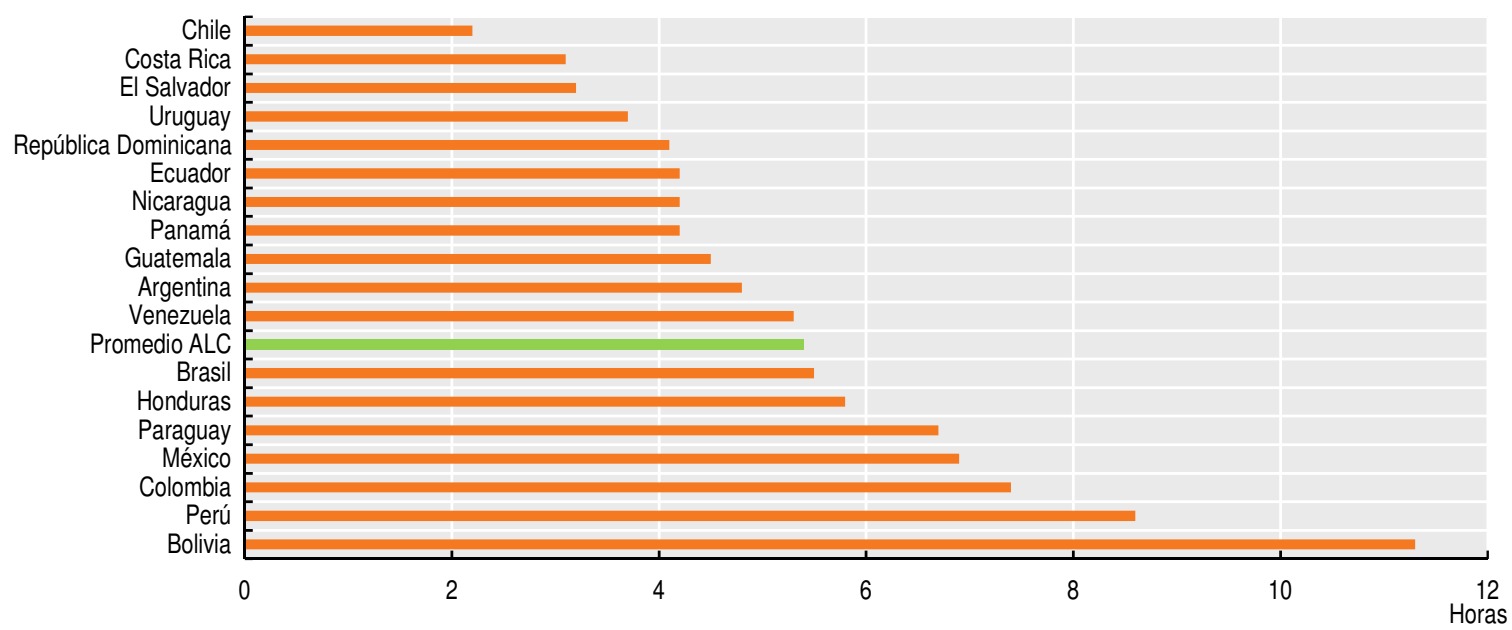

Fuente: Roseth, Reyes y Santiso (2018), El fin del trámite eterno: ciudadanos, burocracia y gobierno digital, https://publications.iadb. org/publications/english/document/Wait-No-More-Citizens-Red-Tape-and-Digital-Government.pdf; cálculos basados en el Latinobarómetro (2017), Encuesta Latinobarómetro (base de datos), www.latinobarometro.org/lat.jsp.

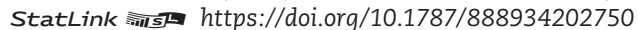

Los plazos de tramitación y los costos administrativos podrían reducirse con la simplificación de los trámites burocráticos y la automatización por medio de tecnologías. La creación de un canal digital para la tramitación de operaciones conlleva un ahorro de tiempo para los ciudadanos, que ya no tendrán que acudir en persona a las instituciones, así como del costo que esto les acarrea. La implantación de sistemas automatizados que interactúen entre sí en los organismos públicos reduciría y simplificaría aún más los pasos necesarios para efectuar un trámite, una transformación que depende de la coordinación interinstitucional entre los diferentes organismos. La Recomendación del Consejo de la OCDE sobre Estrategias de Gobierno Digital reivindica que se ha de dotar a la institución oficialmente responsable de coordinar el gobierno digital de un mecanismo adecuado para armonizar las opciones estratégicas generales de inversión en tecnologías digitales (OCDE, 2014c).

Las reformas administrativas de los países de ALC se centran principalmente en la posibilidad de simplificar o eliminar regulaciones ${ }^{7}$. Por ejemplo, República Dominicana puso en marcha RD+ Simple, un sitio web para denunciar regulaciones o procesos administrativos que resulten demasiado gravosos. Argentina también ha creado un 
sitio web similar. No obstante, solo la mitad entre diez países encuestados (Argentina, Colombia, Costa Rica, México y Perú) había acometido un proceso de simplificación administrativa en el ámbito regional y municipal, y los progresos registrados desde el período comprendido entre 2015 y 2016 han sido escasos (OCDE, 2020f).

Con respecto a la automatización, el uso de trámites digitales en ALC es dispar, aunque en la mayoría de los países constituye una práctica poco habitual, por lo general debido a que: 1) no se puede acceder a los trámites por Internet; 2) el público carece de acceso a las operaciones por Internet (por ejemplo, por no disponer de servicio de banda ancha o de una tarjeta de identificación o de pago); y 3) la experiencia de la ciudadanía con trámites disponibles a los que sí tienen acceso no es satisfactoria (Roseth, Reyes y Santiso, 2018). México y Chile son los únicos países de ALC en los que más de la mitad de los trámites con la administración pública se pueden iniciar y concluir a través de Internet (Gráfico 4.9). Una transformación digital inclusiva no debería olvidar el canal físico de prestación de servicios, puesto que en muchos países de ALC sigue revistiendo gran importancia, sobre todo para los ciudadanos de edad más avanzada y menos hábiles con las tecnologías digitales, así como para quienes carecen de acceso a Internet.

\section{Gráfico 4.9. Trámites ante la administración pública que se pueden iniciar y concluir por Internet, países seleccionados de América Latina y el Caribe}

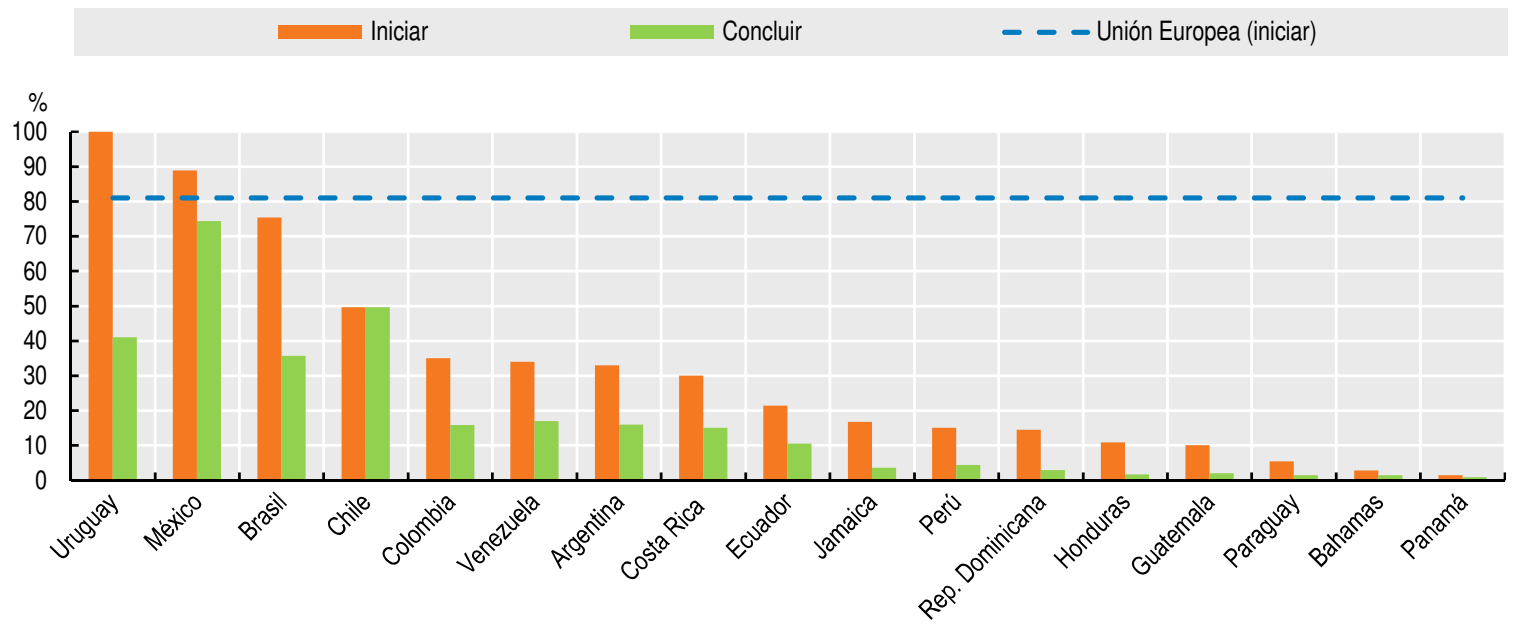

Notas: "Iniciar" indica el porcentaje de trámites con la administración pública que se pueden iniciar a través de Internet. "Concluir" indica el número de trámites con la administración pública que se pueden realizar y concluir a través de Internet. Los gráficos se basan en la definición del término "servicio de tramitación" de cada autoridad nacional. Los cálculos relativos a México solo tienen en cuenta los servicios de tramitación (2.708 servicios) y no el número total de registros del Catálogo Nacional de Transacciones y Servicios, que incluye trámites ante la administración e información oficial.

Fuente: Roseth, Reyes y Santiso (2018), El fin del trámite eterno: Ciudadanos, burocracia y gobierno digital, https://publications. iadb.org/publications/english/document/Wait-No-More-Citizens-Red-Tape-and-Digital-Government.pdf. StatLink नins ht https://doi.org/10.1787/888934202769

En el proceso de transformación de los servicios administrativos, el diseño es fundamental, en particular para: 1) conocer el recorrido que realizan los ciudadanos desde que intentan resolver un problema por primera vez hasta que lo solucionan definitivamente (proceso integral desde el inicio hasta el final de la prestación, en lugar de partes aisladas de la organización); 2) afrontar las experiencias de atención presencial al ciudadano y los consiguientes procesos auxiliares (del exterior al interior y viceversa) como un proceso continuo en lugar de dos modelos separados; y 3) propiciar una coherencia en el acceso y la experiencia tanto entre los diferentes canales (omnicanal) como dentro de ellos, en lugar de adoptar soluciones diferentes para canales distintos (multicanal) (OCDE, próxima publicación). 
El proyecto de seis años que se inició en 2012 con el objetivo de transformar el sistema de justicia de Panamá constituye un ejemplo de diseño e implementación de servicios eficaz. La colaboración entre la Autoridad Nacional para la Innovación Gubernamental y varios grupos involucrados se centró en cuestiones digitales y también en problemas de las infraestructuras físicas, así como en interacciones analógicas, de manera que se abordó la experiencia de forma integral. Como resultado, ya no se emplea papel y el sistema de justicia ha reducido la inversión de tiempo en un 96\% (OCDE, 2019j). La transformación digital de la Procuraduría General de la Nación (PGN) de Colombia representa otra iniciativa prometedora. Por medio de un proyecto de archivo digital, se prevé que todos los casos de la PGN estén plenamente operativos en todas las oficinas de esta entidad mediante el uso de: 1) flujos de trabajo optimizados que facilitan la interacción directa entre funcionarios y ciudadanos por medio de canales digitales; 2) procesamiento de documentos digitales, gestión de contenidos y servicios a los usuarios; y 3) acceso a información de sistemas heredados. No obstante, pese a algunas excepciones notables, el sistema de justicia sigue siendo uno de los sectores menos digitalizados de la administración pública en ALC.

Además de la simplificación, el diseño de los servicios y la automatización para conseguir gobiernos más eficientes, resulta esencial que las diferentes administraciones públicas adopten sistemas que puedan interactuar entre sí. La integración de sistemas de datos de diferentes órganos gubernamentales exige una importante labor de digitalización de bases de datos que compartan identificadores y estándares de comunicación de información. El cotejo automático de datos fiscales, patrimoniales, sociales y laborales podría incrementar la eficacia de las labores de orientación de las transferencias sociales y detección de casos de evasión de impuestos (Izquierdo, Pessino y Vuletin, 2018). Por ejemplo, el Sistema de Información de la Red de Seguridad Social de Irak, al integrar información sobre beneficiarios de diferentes programas, permitió al Ministerio de Trabajo y Asuntos Sociales identificar a familias que percibían diferentes prestaciones a las que no tenían derecho. Su exclusión de los programas generó un ahorro de 18 millones de dólares en el presupuesto del sistema correspondiente solo a Bagdad. Estonia y la República de Corea son los países más avanzados en cuanto a integración de sistemas, mientras que en ALC el Sistema de Identificación Nacional Tributario y Social de Argentina (SINTyS), el Sistema Integrado de Información Social de Chile (SIIS) y el Cadastro Único de Brasil han alcanzado un grado de eficiencia notable (Barca y Chirchir, 2014).

La Historia Clínica Electrónica Nacional (EHR) de Uruguay también presenta un tipo de integración similar. Aunque los proveedores gestionan sus propios sistemas de EHR, la aplicación de estándares en materia de datos compartidos permite utilizar la información indistintamente en todos ellos. Los pacientes pueden recibir, a través de una única plataforma, una atención personalizada en el sistema de salud en cualquier punto del país, porque los distintos proveedores tienen acceso a sus historias, que incluyen visitas médicas, resultados de exámenes y consultas ambulatorias (Bastias-Butler y Ulrich, 2019).

La transformación digital de la administración tributaria puede incidir positivamente en la eficiencia de los procesos y la prestación de servicios (OCDE, 2019k). Las tecnologías digitales ofrecen nuevas formas de recabar, almacenar, gestionar y analizar información fiscal. La presentación del impuesto sobre la renta es uno de los servicios de la administración disponibles a través de Internet más extendidos en todo el mundo (ONU, 2019). América Latina es pionera en facturación electrónica, un sistema con el que las operaciones comerciales se registran y se trasladan automáticamente a las autoridades tributarias usando medios electrónicos. La facturación electrónica ayuda a combatir la evasión de impuestos, al suministrar información en tiempo real y facilitar la consulta de las diferentes declaraciones fiscales (Barreix y Zambrano, 2018; Bellon et al., 2019). Chile fue el primer país en adoptar este sistema en 2003, seguido de Argentina, Brasil, Ecuador, México, Perú, Uruguay y otros países de ALC. Ecuador ha ido introduciendo 
paulatinamente la facturación electrónica desde 2013. En 2016, los contribuyentes que emitían facturas electrónicas declararon un $24 \%$ más de ventas gravables que aquellos no incluidos en ese programa, frente a un 17\% de diferencia en 2016 (Ramírez Álvarez, Oliva y Andino, 2018). Otras tecnologías digitales como el Internet de las Cosas, la computación en la nube, la analítica de macrodatos, la inteligencia artificial y blockchain, ofrecen nuevas oportunidades para aumentar la eficiencia de la administración tributaria (Gráfico 4.10).

Gráfico 4.10. Las tecnologías digitales y su aplicación en la administración tributaria en ALC
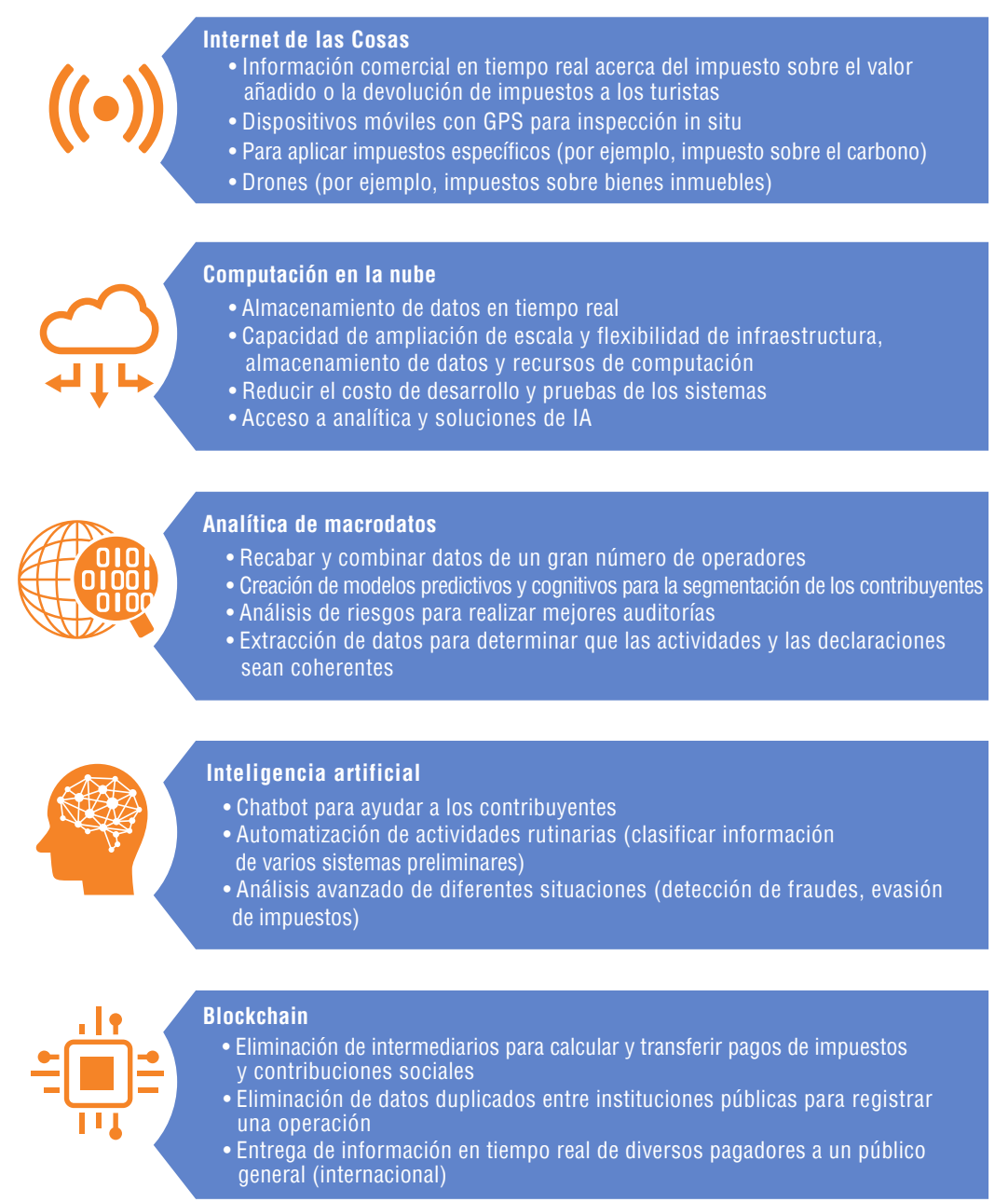

Fuente: Elaboración propia a partir de CEPAL (2018), Datos, algoritmos y políticas: La redefinición del mundo digital (LC/CMSI.6/4), https://repositorio.cepal.org/bitstream/handle/11362/43477/7/S1800053 es.pdf.

\section{Hacia instituciones públicas más inclusivas}

La transformación digital puede incrementar el carácter inclusivo de las instituciones públicas al facilitar la interacción con los interesados (consultas electrónicas) y la participación ciudadana en la toma de decisiones (toma de decisiones electrónica). Las plataformas digitales pueden constituir un medio de costo reducido para que los gobiernos interactúen con ciudadanos durante la formulación, seguimiento y aplicación de políticas. La transformación digital puede ayudar a las administraciones a prestar servicios públicos más inclusivos, de manera que las instituciones públicas resulten más accesibles y se centren más en la ciudadanía. El uso de tecnologías digitales permite a los 
gobiernos formular políticas mejor orientadas y transformar en eje central de dicha labor la experiencia de la ciudadanía.

Según el Índice de e-Participación de la ONU de 2018, que incluye medidas relativas al intercambio de información, las consultas y la toma de decisiones por medios electrónicos, el desempeño de Brasil, Colombia, México y Uruguay se situó por encima del promedio de la OCDE, mientras que otros países se encontraban bastante más rezagados en esta materia (Gráfico 4.11).

\section{Gráfico 4.11. Índice de e-Participación de la ONU de países seleccionados de ALC y promedio de la OCDE, 2018}

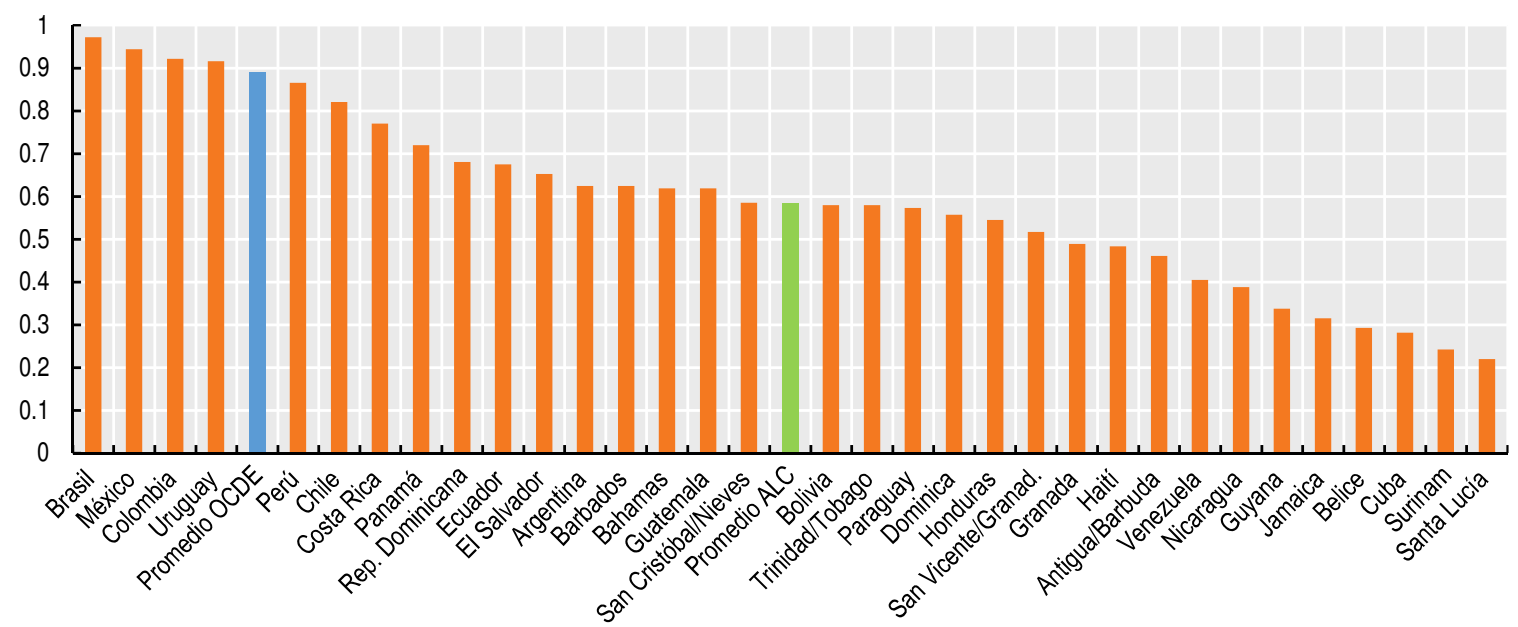

Notas: El Índice de e-Participación de la ONU se centra en el uso de servicios a través de Internet por parte de las instituciones para facilitar información pública (intercambio de información por medios electrónicos), interactuar con grupos de interés (consulta electrónica) y para que ciudadanos y grupos de interés participen en la toma de decisiones (toma de decisiones por medios electrónicos). El objetivo de esta medida es ofrecer datos pormenorizados sobre el uso de instrumentos a través de Internet por parte de los países para promover interacciones con los ciudadanos y de los ciudadanos con la administración en beneficio de todos. La puntuación del índice se sitúa entre 0 (menos participativo) y 1 (más participativo).

Fuente: ONU (2019), UN e-Government Knowledge Database (base de datos), https://publicadministration.un.org/egovkb/en-us/ Data-Center.

StatLink तinst https://doi.org/10.1787/888934202788

Las tecnologías digitales están propiciando el surgimiento de canales innovadores para que la ciudadanía participe en diferentes etapas del proceso de formulación de políticas. En 2018, la ciudad de Montevideo creó la plataforma Montevideo Decide con la finalidad de fomentar y facilitar la participación ciudadana en cuestiones públicas mediante debates, propuestas y presupuestos participativos. Una de las características más innovadoras es un espacio para que los ciudadanos realicen propuestas a la ciudad y determinen las opciones más respaldadas, y posteriormente la ciudad se compromete a ponerlas en práctica. El sistema Vota Inteligente de Chile era una plataforma abierta y participativa similar, destinada a transmitir propuestas a los candidatos a las elecciones de 2017. La app Promise Tracker de Brasil permite que los ciudadanos supervisen el cumplimiento de los compromisos que han asumido las autoridades y promueve espacios de diálogo entre estas y la ciudadanía para buscar soluciones comunes a problemas acuciantes. Los ciudadanos también pueden incrementar su participación en los procesos legislativos a través de CrowdLaw, que emplea la tecnología con la finalidad de aprovechar los conocimientos, la creatividad y la experiencia de los ciudadanos para mejorar el proceso legislativo. La comunicación resulta esencial para que las políticas públicas funcionen. Las tecnologías digitales ofrecen muchas oportunidades para lograr una verdadera participación pública y reforzar la repercusión de las comunicaciones efectuadas por los gobiernos (Recuadro 4.3). 
Recuadro 4.3. Comunicaciones del gobierno digital:

De la difusión a una verdadera participación pública

Las comunicaciones constituyen una herramienta indispensable para que las instituciones públicas generen confianza, promuevan la moral fiscal y fomenten la participación pública. La digitalización plantea oportunidades sin precedentes en materia de comunicaciones gubernamentales.

Las redes sociales ofrecen una forma de llegar a millones de ciudadanos que resulta relativamente asequible desde el punto de vista económico. Las administraciones pueden conseguir respaldo para políticas y demostrar los avances usando formatos atractivos a través de Internet (entre otros, video, narrativa digital, visualizaciones de datos), promover cambios en el comportamiento y animar a los ciudadanos a unirse a iniciativas nacionales y locales para conseguir un desarrollo sostenible.

Las instituciones más innovadoras no consideran que los medios digitales sean un nuevo canal de difusión sino un proceso multicanal, al crear plataformas que permiten a la ciudadanía orientar el debate y comunicar sus propios mensajes.

La digitalización también brinda a los gobiernos una preciada fuente de información. Gracias a la analítica de datos y las consultas por Internet, pueden prever mejor qué cuestiones serán objeto de debate público, identificar las audiencias potenciales, crear mensajes más atractivos y efectivos (OCDE, 2020g).

La transformación digital de los gobiernos también puede promover servicios públicos inclusivos al dirigirse a segmentos de la sociedad desfavorecidos y situados en lugares remotos que tienen dificultades para acceder a los servicios. Así, por ejemplo, las tecnologías digitales han ampliado la cobertura del sistema de educación pública. Entre otros avances, en los últimos años las alternativas de aprendizaje por medios electrónicos han experimentado una transformación extraordinaria. Los cursos abiertos que se imparten a gran escala a través de Internet pueden democratizar la educación, al ampliar el acceso y ofrecer a muchas personas la oportunidad de cursar una formación flexible, mejor adaptada a las necesidades del mercado laboral (OCDE, 2015b). Los sistemas de prestación de servicios de salud por medios electrónicos, tales como las consultas remotas, los portales web y los dispositivos portátiles ofrecen a los profesionales de la salud nuevas opciones para atender casos no urgentes cuando se les solicita y dar cobertura a un mayor número de pacientes por menos dinero. Estas modalidades digitales pueden permitir reorientar los servicios de salud hacia la prevención y el diagnóstico precoz (Pombo, Gupta y Stankovic, 2018). Perú había realizado 6800 mamografías telemáticas y diagnosticado 39 casos de cáncer de mama en zonas en las que no contaban con ningún radiólogo un año y medio después de haber implantado el servicio por Internet (Ministerio de Salud de Perú, 2018).

Estas soluciones digitales han tenido una importancia vital durante la crisis del coronavirus (Covid-19). En algunos casos, los centros educativos adaptaron el contenido y pasaron a emplear medios digitales para garantizar la continuidad de la formación (ver el Capítulo 3). Los médicos atendieron consultas por medios electrónicos para evitar la aglomeración de pacientes en las salas de urgencias y la propagación del virus. Los acontecimientos recientes han sentado las bases para la aparición de un mercado de servicios de salud por medios electrónicos que podría trascender las fronteras nacionales (Blyde, 2020), de manera similar a lo ocurrido con el aprendizaje electrónico. Los escasos obstáculos que presenta ALC en cuanto a idioma y cultura podrían dar lugar a importantes economías de escala para los proveedores de servicios de salud y aprendizaje por medios electrónicos. No obstante, de no realizarse inversiones complementarias para garantizar 
un acceso igualitario a competencias e infraestructuras de comunicación, dichos servicios podrían beneficiar únicamente a un reducido porcentaje de la población, lo que agravaría las desigualdades existentes en la región (Basto-Aguirre, Cerutti y Nieto-Parra, 2020).

\section{Hacia instituciones públicas más innovadoras}

La transformación digital puede contribuir a una mayor innovación por parte de los gobiernos en todas las etapas de formulación de políticas y, por ende, a un aumento de la calidad de las políticas públicas. Las tecnologías digitales, combinadas con datos, pueden constituir factores de impulso de la innovación en la administración pública, al favorecer servicios y políticas públicas mejor orientadas y documentadas.

La tecnología y la digitalización de sociedades y gobiernos generan cantidades ingentes de datos. Disponer de datos suficientemente detallados en el momento oportuno brinda la oportunidad de decidir a partir de pruebas empíricas, con el respaldo de las tecnologías digitales a lo largo del ciclo de formulación de políticas. Para aprovechar estas oportunidades, es necesario un cambio en la administración pública, que debe abandonar la perspectiva centrada en la información en favor de un planteamiento innovador, basado en los datos, que integre las tecnologías digitales y los datos en la formulación, implantación y evaluación de las políticas.

Las tecnologías digitales y los datos facilitan de diversas maneras la adopción de esta nueva perspectiva. Permiten realizar un seguimiento de fenómenos que cambian con gran rapidez o cuyos datos no se habían podido registrar en el pasado, por ejemplo, en relación con la contaminación, la actividad económica o brotes de enfermedades. La mejora en la disponibilidad de los datos, su intercambio y su visualización ayuda a los responsables de políticas a adaptar y diferenciar la formulación de estas en función de la zona geográfica, el entorno político o el grupo socioeconómico (Huichalaf, 2017). Las técnicas econométricas avanzadas y los macrodatos respaldados por información más detallada permiten una mayor experimentación y evaluación en materia de políticas públicas. Por último, las herramientas digitales facilitan la recopilación de datos en tiempo real entre entidades tanto públicas como privadas, lo que permite a los gobiernos predecir tendencias o riesgos emergentes y responder a ellos de manera proactiva (OCDE, 2019k). La pandemia del coronavirus (Covid-19) ha demostrado cómo emplear las tecnologías digitales y los datos para innovar en la formulación de políticas. La plataforma Country Policy Tracker de la OCDE para el seguimiento de las políticas de los países es un instrumento visual creado para seguir y comparar las medidas adoptadas en relación con el coronavirus (Covid-19) (OCDE, 2020h). La República de Corea fue uno de los primeros países en utilizar una app para smartphones para entregar los resultados de los test del Covid-19, supervisar el cumplimiento de las cuarentenas y cartografiar la distribución geográfica y la evolución de los contagios (Kim, 2020). Otros países han usado una herramienta de rastreo de los contactos, como Go.Data, desarrollada por la OMS y los socios de la Red Mundial de Alerta y Respuesta ante Brotes Epidémicos para recabar datos sobre casos y contactos y visualizar la transmisión de la enfermedad (OMS, 2020).

La formulación de políticas innovadoras se puede promover facilitando datos abiertos, pero propiciando también su uso y reutilización. Las políticas de datos gubernamentales abiertos deben complementarse con iniciativas destinadas a que se puedan reutilizar los datos, de manera que sea posible introducirlos en los ciclos de formulación de políticas de las administraciones públicas y ayudar a empresas y particulares a tomar decisiones mejor documentadas (Van Ooijen, Ubaldi y Welby, 2019). El Índice OURdata (Open, Useful and Re-usable data) de la OCDE y el BID de 2019 medía el compromiso de los gobiernos con las políticas de datos gubernamentales abiertos, mediante una puntuación de entre 0 (mínima) y 1 (máxima). Los países de ALC obtuvieron una puntuación de 0.43 en 2019, frente a un promedio de la OCDE de 0.60. En ALC, la situación en materia de datos gubernamentales 
abiertos es muy dispar: Colombia (0.88), México (0.71) y Brasil (0.63) son los más avanzados, mientras que los países del Caribe, como las Bahamas (0.04) y Dominica (0.00), todavía no aplican políticas de datos gubernamentales abiertos (Gráfico 4.12).

ElPilar 1 delÍndice OURdata, sobrela disponibilidad delos datos, mideel grado depromoción de los datos gubernamentales abiertos por parte de administraciones centrales o federales, y muestra que, a excepción de Brasil, Colombia y México, la región de ALC presenta resultados inferiores a los de la OCDE; 10 de los 16 países de ALC encuestados imponen oficialmente una serie de obligaciones para garantizar la publicación de datos sobre transparencia. ALC muestra mejores resultados con respecto a la accesibilidad de los datos (Pilar 2), que mide el modo en que se publican los datos gubernamentales abiertos: 13 de 16 países, incluidos Costa Rica, República Dominicana y Guatemala, facilitan la totalidad o la mayor parte de los datos codificados en lenguaje de computadora en sus portales centrales y 12, entre ellos Argentina, Brasil y Chile, facilitan la totalidad y la mayoría de los metadatos asociados. Salvo en Brasil, Colombia y México, el avance en cuanto a promoción de la reutilización de los datos por parte de los organismos públicos (Pilar 3) es más lento en la mayoría de los países de ALC. Los países podrían mejorar en particular el seguimiento de la repercusión que tiene el uso de datos gubernamentales abiertos, ya que la puntuación promedio de ALC en esta subcategoría es de 0.07, frente al 0.14 de la OCDE (Gráfico 4.12) (OCDE, 2020f).

\section{Gráfico 4.12. Índice OURdata de la OCDE, países seleccionados de América Latina y el Caribe, 2019}

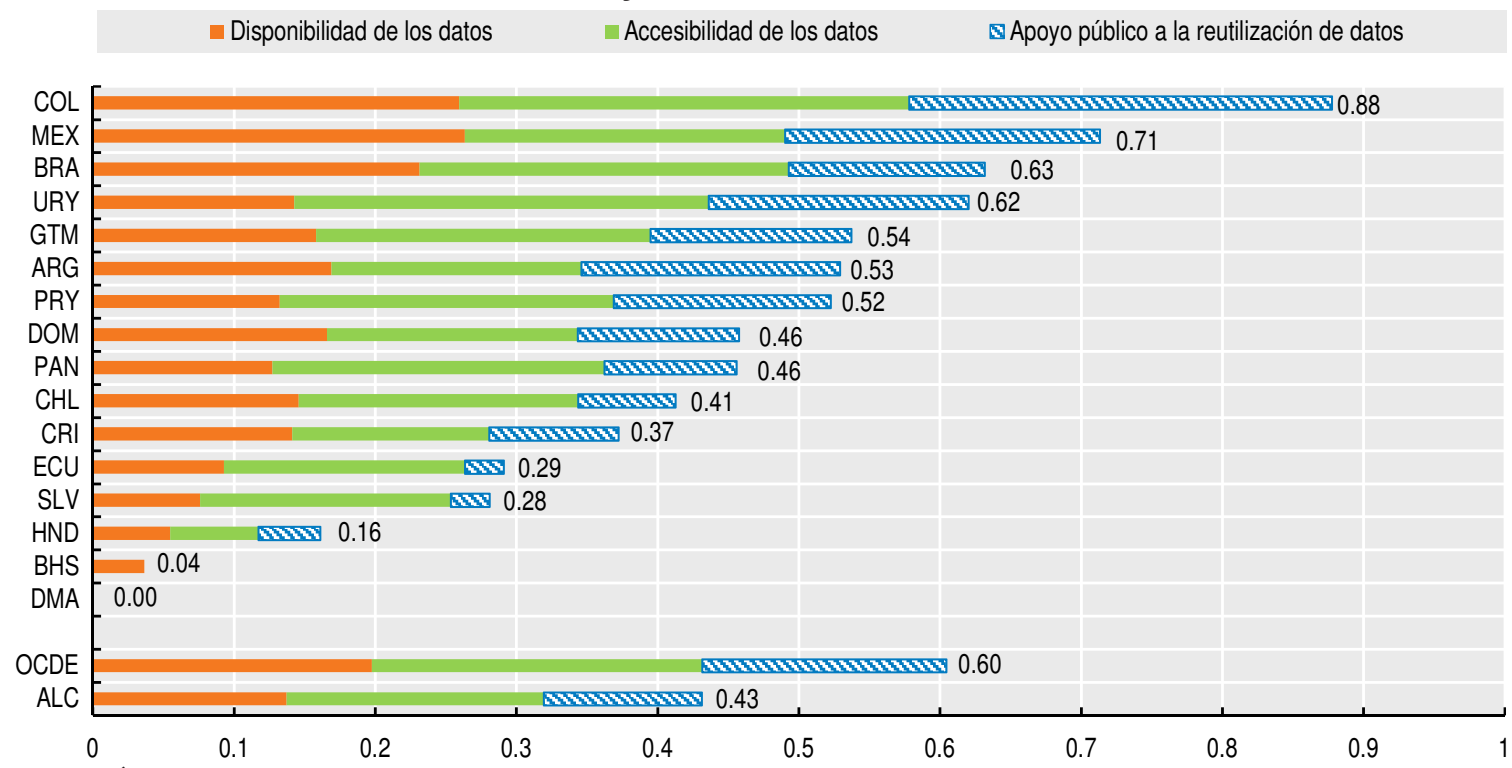

Notas: El Índice OURdata de la OCDE sobre datos gubernamentales abiertos evalúa la labor realizada por las administraciones públicas para implantar datos abiertos de acuerdo a tres criterios: disponibilidad de datos en el portal nacional, accesibilidad a los datos del portal nacional y apoyo público a la reutilización de los datos de forma innovadora por la administración y participación de los grupos de interés. Las puntuaciones de este índice compuesto oscilan entre 0 (mínima) y 1 (máxima). La puntuación de cada indicador se halla mediante un promedio simple no ponderado de cada subindicador. El índice no mide la repercusión de los datos gubernamentales abiertos en los resultados socioeconómicos, sino más bien el trabajo que realizan los organismos públicos para propiciar las condiciones adecuadas que permitan y estimulen su reutilización. El índice se basa en la metodología analítica de la OCDE descrita por Lafortune y Ubaldi (2018), que esquematiza también los principios de la Carta Internacional sobre Datos Abiertos. Los datos relativos a Argentina, Chile, Colombia y México se recabaron mediante la Encuesta de Datos Abiertos de Organismos Públicos (Open Government Data Survey) de la OCDE de 2018. Honduras creó un portal central de datos gubernamentales abiertos a mediados de 2019, después de la realización de la encuesta. En Brasil, desde julio de 2019, la oficina de la Contraloría General se ha encargado de las políticas en materia de datos gubernamentales abiertos y, por lo tanto, se han producido cambios en su aplicación.

Fuente: OCDE (2020f), Panorama de las administraciones públicas: América Latina y el Caribe 2020, https://doi.org/10.1787/13130fbb-en.

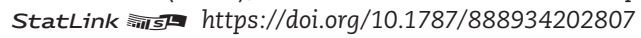


Los gobiernos innovadores deben analizar la posibilidad de que entidades públicas y privadas colaboren en el intercambio de datos con el objetivo de orientar las políticas públicas. Los buscadores de Internet pueden brindar una información inestimable que complementa los datos institucionales y socioeconómicos tradicionales. Frente a las encuestas tradicionales a los ciudadanos o indicadores macroeconómicos como la tasa de crecimiento del PIB, inflación o desempleo, la información generada por las búsquedas en Internet puede aportar datos fácilmente disponibles, anónimos y muy frecuentes para la formulación de políticas públicas. Por ejemplo, la frecuencia con que se buscan en Google Trends términos relacionados con la corrupción en los organismos públicos, reclamos a servicios públicos e inseguridad influye de manera negativa y estadísticamente significativa en los niveles de aprobación de los gobiernos de la región, una vez que se elimina el efecto que pueden tener en esta relación otras variables macroeconómicas tradicionales (Montoya et al., 2020) (Gráfico 4.13). Muchos ejemplos demuestran que la colaboración entre entes públicos y privados para abordar cuestiones políticas es posible (Socías, 2017). Durante la pandemia del Covid-19 y la crisis del ébola de 2014, se utilizaron datos de teléfonos móviles para identificar geográficamente los movimientos de la población regional y las zonas que presentaban mayor riesgo de sufrir un brote, y así decidir dónde concentrar las medidas de prevención y servicios de salud (OCDE, 2019l). Este mismo tipo de datos se puede utilizar para rastrear las migraciones (Frias-Martinez et al., 2019; Isaacman, Frias-Martinez y Frias-Martinez, 2018) o determinar territorialmente los niveles de pobreza, como se ha hecho en Guatemala (Benjamins et al., 2017; Hernández et al., 2017). El BID utilizó datos de tráfico de Waze para medir la influencia de un puente de Buenos Aires en la congestión del tráfico (Yañez-Pagans y Sánchez, 2019).

\section{Gráfico 4.13. Popularidad de las búsquedas en Google y aprobación del gobierno en América Latina y el Caribe, 2006-2015}

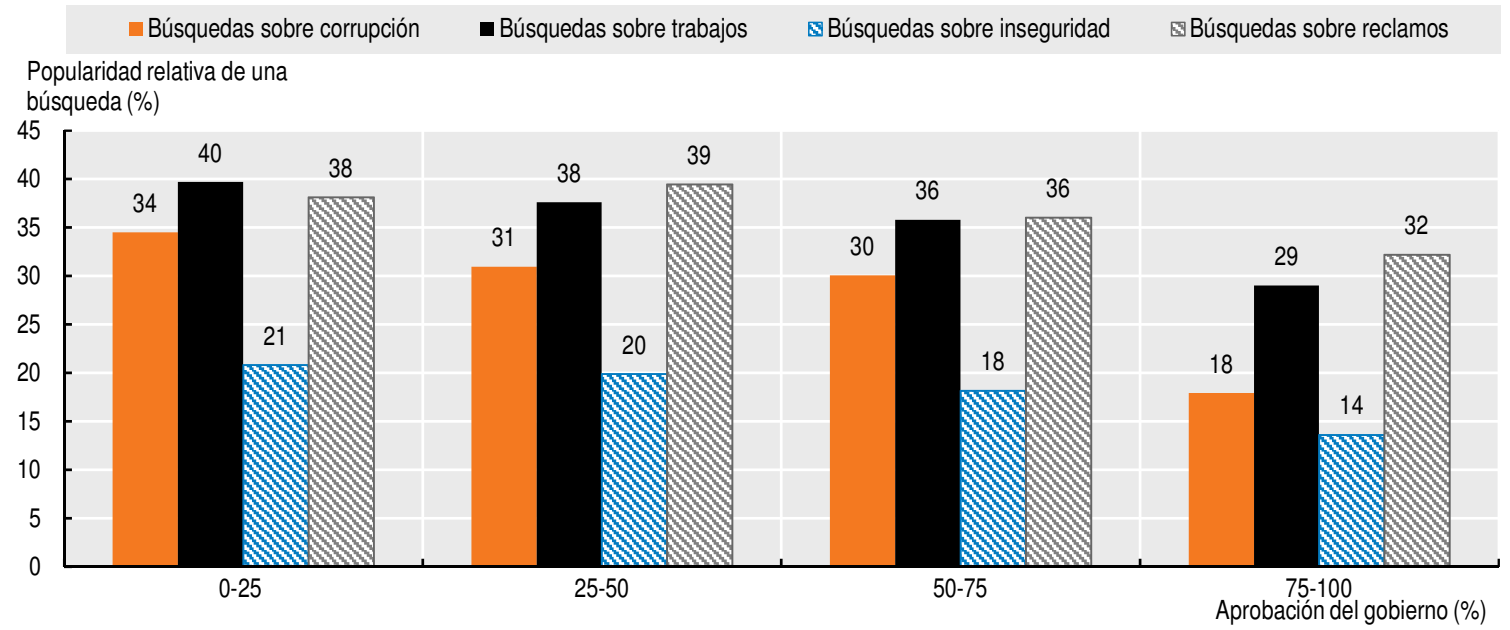

Nota: Basado en un promedio simple de 18 países de América Latina y el Caribe.

Fuente: Montoya et al. (2020), "Using Google data to understand governments' approval in Latin America", https://doi. org/10.1787/89ed5e8f-en.

StatLink - जils https://doi.org/10.1787/888934202826

Para fomentar la innovación en el sector público, resulta esencial invertir en la formación de los funcionarios públicos, por ejemplo en competencias técnicas, así como en una serie de competencias cognitivas y conductuales de índole más relacional, como son el pensamiento creativo y la comunicación. El personal de primera línea y los responsables intermedios pueden desempeñar un importante papel a la hora de llevar adelante ideas y desarrollarlas en cada etapa del proceso si se sienten respaldados y motivados. Por lo tanto, 
la gestión de las personas constituye un importante factor de impulso para mantener la innovación en el sector público, así como un área fundamental en la que los países deberían centrar sus esfuerzos para incrementar las posibilidades de innovación. En 2014, Chile creó el Laboratorio de Gobierno, una institución multidisciplinar para catalizar la innovación del sector público centrada en los ciudadanos, con especial interés en ampliar las capacidades de innovación y respaldar proyectos innovadores en las instituciones públicas. Su prometedor programa Experimenta defiende un planteamiento de aprendizaje práctico y contribuye a que los funcionarios públicos afronten desafíos institucionales concretos aplicando un método basado en la colaboración y centrado en los ciudadanos (OCDE, 2017d).

Los gobiernos deberían adoptar una postura más decidida en favor de la innovación, por ejemplo, apoyando iniciativas innovadoras fuera del sector público. Parte de esta estrategia debería consistir en ayudas al sector goutech (pymes y start-ups dedicadas al desarrollo de soluciones tecnológicas digitales para las administraciones públicas). Pese a que el mercado de las soluciones tecnológicas para la administración pública, que genera cerca de 400000 millones de USD al año en todo el mundo, está dominado por las grandes empresas, en ALC también han surgido emprendedores creativos (Santiso, 2019).

La madurez de los ecosistemas goutech en los diferentes países de esta región es dispar. El Índice GovTech de la Corporación Andina de Fomento (CAF) de 2020 constituye el primer intento de medición del desarrollo de ecosistemas goutech de la región. Sus tres pilares evalúan el sector de las start-ups, las políticas gubernamentales encaminadas a promover el ecosistema goutech y la calidad y eficiencia de los sistemas de adquisiciones y contrataciones. El pilar relativo a las start-ups es el que registra la puntuación más baja en toda la región. El motivo es el déficit de capital de riesgo disponible que se necesita para el financiamiento de start-ups y proyectos de incremento de escala. Portugal y España registran una madurez promedio superior a la de sus homólogos en América Latina (Gráfico 4.14).

\section{Gráfico 4.14. Índice GovTech de la CAF, países seleccionados de América Latina y el Caribe, 2020}

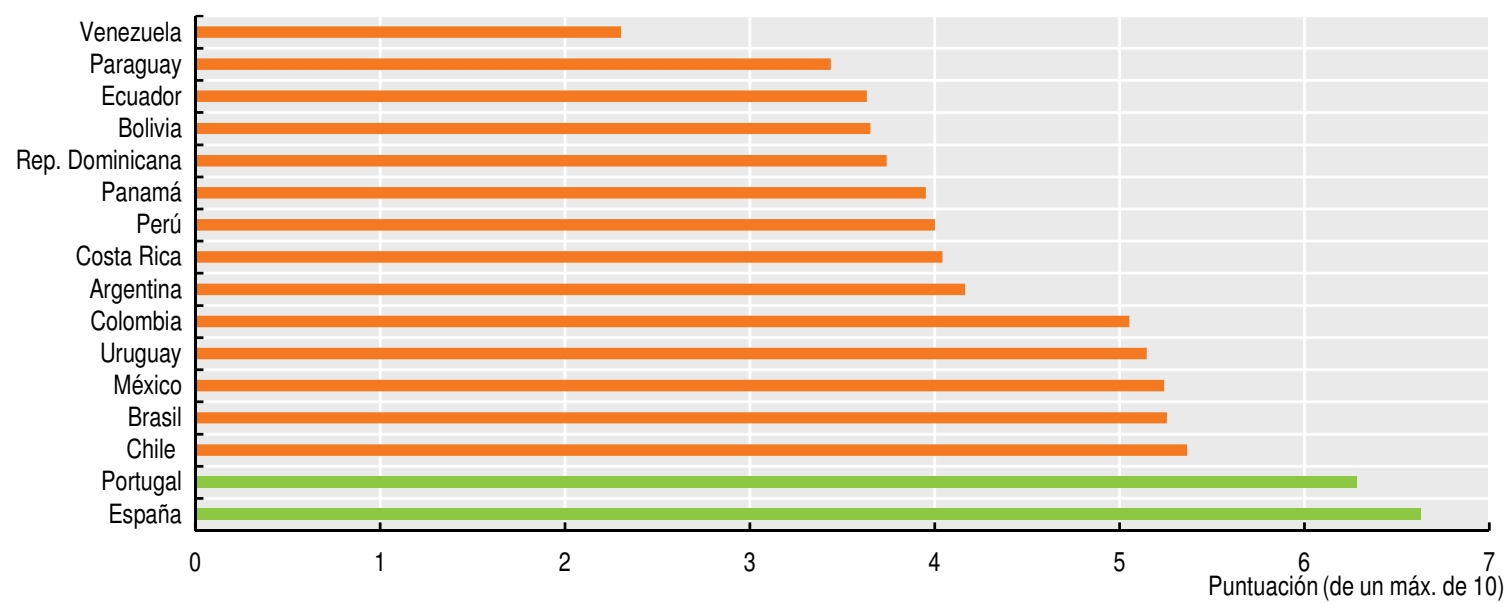

Notas: El Índice GovTech de la CAF de 2020 mide la madurez de los ecosistemas goutech a partir de 28 indicadores relativos a siete dimensiones que juntas conforman sus tres pilares igualmente ponderados: sector de las start-ups, políticas gubernamentales y sistemas de adquisiciones y contrataciones. Su puntuación oscila entre 0 (menos desarrollado) y 10 (más desarrollado).

Fuente: Zapata et al. (2020), The GovTech Index 2020: Unlocking the Potential of GouTech Ecosystems in Latin America, Spain and Portugal, http://scioteca.caf.com/handle/123456789/1580.

StatLink ains https://doi.org/10.1787/888934202845 
Entre las iniciativas de éxito en materia de goutech emprendidas en ALC está Visor Urbano, una plataforma para gestionar a través de Internet los trámites relacionados con la obtención de licencias de negocios y permisos de construcción del Gobierno de Guadalajara (México), que ha contribuido a la lucha contra la corrupción, ha respaldado la formulación de políticas basadas en datos empíricos y ha ahorrado tiempo y dinero a la ciudadanía (Zapata y Gerbasi, 2019a).

MuniDigital®, una plataforma centrada en mejorar la gestión de los servicios municipales mediante la recopilación de datos accesibles actualizados, se utiliza actualmente en 40 municipios e instituciones de 10 provincias argentinas. El ahorro materializado por el gobierno y los ciudadanos se atribuyó, entre otras causas, a una mayor eficiencia administrativa y la disminución de los costos relacionados con el mantenimiento de infraestructuras y el transporte público, que ayudaron a reducir los costos ambientales (Zapata y Gerbasi, 2019b).

La colaboración entre las administraciones públicas y el sector goutech plantea una serie de obstáculos que deben superarse. Los contratos fijos, a largo plazo, con empresas tecnológicas obstaculizan la contratación de operadores recién llegados al mercado por parte de las administraciones públicas. El proceso de contratación pública es además largo y complejo, por lo que la búsqueda de la solución más barata y la duración del proceso de toma de decisiones puede derivar en la contratación de empresas con un perfil competitivo, pero no innovador (Ortiz, 2018). Los marcos regulatorios deberían centrarse en reducir las barreras de entrada para start-ups innovadoras. La iniciativa Compra Pública para la Innovación de Colombia aplica un criterio de innovación en los procesos de adquisiciones y contrataciones con el objetivo de buscar soluciones alternativas que satisfagan las necesidades públicas. Brasil y Chile también están flexibilizando sus normas de contratación pública (Santiso, 2019). Para innovar, se necesita un financiamiento inicial y también a largo plazo (Mazzucato y MacFarlane, 2018). El hecho de que las empresas que atienden al sector público necesiten plazos más amplios para alcanzar la madurez empresarial obstaculiza la obtención de capital de riesgo para el financiamiento. El sector público podría desempeñar una función esencial en la generación de fondos destinados a respaldar a este tipo de start-ups emergentes. Dinamarca, Israel, Lituania, Polonia, Portugal y Reino Unido ya han adoptado medidas en este sentido. México está probando también esta metodología por medio de Reto México.

Las tecnologías digitales y los nuevos formatos de datos ofrecen nuevas oportunidades en todos los ámbitos de la administración, entre ellos, las ciudades, algo especialmente pertinente en una región sumamente urbanizada. La incorporación de tecnologías digitales puede transformar la prestación de servicios públicos y la calidad de vida (ciudades inteligentes). Las interacciones periódicas de los ciudadanos con la administración pública local (por ejemplo, realizar trámites en oficinas del gobierno local, ejercer el voto en cada circunscripción electoral o utilizar el transporte público) influyen en la impresión que estos tienen de las instituciones públicas, por lo que la inversión en tecnologías digitales en el ámbito local resulta esencial para mejorar su grado de bienestar y satisfacción con los organismos públicos.

Instituciones públicas y ciudades pueden beneficiarse de la transformación digital en cuanto a confianza, eficiencia, inclusión e innovación. La innovación impulsada por los datos puede incrementar la eficiencia y promover la integración de sistemas urbanos. Por ejemplo, se pueden conectar los vehículos eléctricos y los electrodomésticos a redes de suministro inteligentes para gestionar de manera más eficiente la oferta y demanda de energía. La tecnología cívica puede fomentar la participación ciudadana al facilitar el acceso a la información y brindar espacios para expresar opiniones, realizar consultas públicas o votar a través de Internet. Asimismo, la innovación digital en el ámbito local 
suele comportar costos inferiores y exigir un menor gasto de capital, de modo que empresas más pequeñas pueden competir con las entidades dominantes, ya asentadas, en un ecosistema disruptivo (OCDE, 2019l). El Valle de Pinhão, el ecosistema de innovación de Curitiba, en Brasil, da cabida a un gran número de entidades, entre ellas universidades, aceleradoras, incubadoras, fondos de inversión, start-ups, movimientos culturales y creativos, y la sociedad civil.

Es importante medir el uso de tecnologías en las ciudades y su repercusión en la mejora de la ciudadanía para orientar la inversión en TIC y aumentar la eficacia de las políticas públicas. En Colombia, la clasificación de las ciudades como ciudades inteligentes se realiza atendiendo tres criterios: infraestructura de TIC, contexto socioeconómico, institucional y ambiental, y relación entre TIC y progreso en diferentes dimensiones de bienestar. Los municipios de Armenia, distrito capital de Bogotá, Envigado, Pereira y Medellín fueron los que obtuvieron mejores resultados (Gallego et al., próxima publicación).

\section{La agenda digital en las estrategias nacionales de desarrollo}

La transformación digital, junto con las posibilidades de desarrollo que comporta, ofrece nuevas oportunidades y plantea diversos desafíos que deberían integrarse en la planificación del desarrollo. En capítulos anteriores y en las secciones "Gobernanza de la transformación digital" y "La transformación digital de los gobiernos" se destacan las oportunidades y los desafíos vinculados a la era digital. Para afrontar eficazmente estos cambios, deben coordinarse las actuaciones políticas y debe adoptarse una perspectiva de largo plazo.

América Latina y el Caribe enfrentan una serie de desafíos cada vez más importantes que impiden que la región avance hacia la siguiente etapa de su proceso de desarrollo. Las trampas del desarrollo descritas en las Perspectivas económicas de América Latina 2019: Desarrollo en transición hacen referencia a la escasa productividad, la vulnerabilidad social, las debilidades institucionales y los riesgos ambientales intrínsecos al actual modelo de desarrollo (OCDE et al., 2019). Estas trampas subrayan la importancia que reviste planificar el desarrollo si se quiere avanzar en una idea clara y coherente de progreso para esta región. El descenso de los niveles de confianza en las instituciones destaca en particular la necesidad de un nuevo pacto social que debe ser resultado de un proceso en el que participen todos los grupos sociales y en el que tengan representación tanto ciudadanos como empresas. Las tecnologías digitales pueden facilitar la formulación de estrategias de desarrollo inclusivas mediante la apertura de canales innovadores para que participen los diferentes interlocutores (por ejemplo, teleconferencias, consultas por Internet).

Los planes nacionales de desarrollo constituyen un instrumento de gran utilidad para aprovechar las oportunidades que ofrece la transformación digital y superar los desafíos persistentes. Los planes nacionales de desarrollo bien diseñados abordan problemas cada vez más complejos e interconectados con una visión coherente y a largo plazo. También pueden ayudar a superar los desafíos del desarrollo de manera integral, haciendo partícipes al conjunto de las instituciones públicas de todos los ámbitos (nacional, regional, municipal). La eficacia de los planes nacionales de desarrollo puede medirse con arreglo a seis dimensiones: 1) indicadores y objetivos claros para definir prioridades, asignar recursos financieros y monitorear e identificar brechas pendientes; 2) un marco jurídico sólido que dote al plan de autoridad; 3) un vínculo con el presupuesto nacional, que permita valorar a lo largo del tiempo la viabilidad de cada política; 4) inclusión de una dimensión subnacional y participación pública en la formulación del plan, que le confiera mayor legitimidad; 5) un organismo especializado responsable de la formulación de 
cuestiones relativas a los planes nacionales de desarrollo en términos de compromiso y con conocimientos especializados; y 6) seguimiento y evaluación, que son fundamentales para valorar la implementación y posibilitar el aprendizaje, la determinación de prioridades y la mejora de las políticas a lo largo del tiempo.

La planificación del desarrollo en los países de ALC ha experimentado importantes mejoras (Chimhowu, Hulme y Munro, 2019). No obstante, la era digital exige la integración de la transformación digital como un pilar esencial y transversal de los planes nacionales de desarrollo y la formulación de programas específicos en materia de digitalización. La crisis del Covid-19 ha puesto de relieve la importancia que reviste el avance de la transformación digital. En concreto, ha revelado la persistente brecha digital, manifiesta en la distribución desigual de acceso y uso de Internet y competencias digitales entre los distintos segmentos de población de ALC, que puede agravar las desigualdades existentes (OCDE, 2020i). Integrar las agendas digitales en los planes nacionales de desarrollo debería ser una prioridad.

En esta sección se analiza la incorporación de la transformación digital a los planes nacionales de desarrollo de ALC, examinando la importancia relativa de una serie de temas digitales y la relación que guardan las tecnologías digitales con las cuatro trampas del desarrollo. A continuación se efectúa un repaso de las agendas digitales y se identifican elementos esenciales para que sean exitosas.

\section{Incorporación de la transformación digital a los planes nacionales de desarrollo}

La atención que se les dedica a políticas relacionadas con cuestiones digitales en los planes nacionales de desarrollo de ALC es dispar. En la mayoría de los casos, se podría realizar una integración más completa de la transformación digital. Lo más habitual es que tal integración se vincule con elementos relacionados con los aumentos de la productividad y no tanto con cuestiones sociales, institucionales y ambientales (Gráfico 4.15). Estos resultados se han obtenido a partir de un análisis de extracción de textos, que identificó y clasificó los planes nacionales de desarrollo de 16 países latinoamericanos, calculando la frecuencia de palabras clave relacionadas con cuestiones digitales y analizando su vinculación con las cuatro trampas del desarrollo o con un conjunto de temas pertinentes para la transformación digital nacional (puede consultarse la metodología pormenorizada en el Anexo 4.A1 y una relación de los planes nacionales de desarrollo analizados en el Anexo 4.A2). La infraestructura de comunicación, el acceso y uso de Internet y el tema del futuro del trabajo son aspectos destacados, mientras que la presencia de aquellos relacionados con la economía o el gobierno digital es relativamente inferior (Gráfico 4.16).

Relación entre la transformación digital y las cuatros trampas del desarrollo en los planes nacionales de desarrollo de América Latina y el Caribe

Los planes nacionales de desarrollo de ALC incorporan de manera dispar cuestiones relacionadas con aspectos digitales. La presencia de la digitalización es relativamente superior en los planes nacionales de desarrollo de Chile, Colombia, Perú y Uruguay (Gráfico 4.15). El plan nacional de desarrollo de Chile define la revolución digital y los cambios necesarios en la estructura económica, social e institucional como un compromiso principal del Gobierno. El plan nacional de desarrollo de Colombia dedica un pilar, o Pacto, a la transformación digital: el "Pacto por la Transformación Digital de Colombia". El plan nacional de desarrollo de Perú incluye un capítulo dedicado a la adquisición de competencias en materia de innovación, y la adopción y transferencia de mejoras tecnológicas. El plan nacional de desarrollo de Uruguay señala la revolución tecnológica como una tendencia mundial principal y la importancia estratégica de las TIC para la transformación productiva de la economía. 
Los planes nacionales de desarrollo de ALC se centran en mayor medida en políticas digitales vinculadas con la trampa de la productividad. En particular, el interés por invertir en infraestructuras de comunicación es generalizado y se refleja ampliamente el desafío que supone desplegar la red por banda ancha en todo el país, incluso en zonas remotas y núcleos rurales. Solo algunos planes nacionales de desarrollo mencionan las posibilidades que brinda, por ejemplo, el sector fintech para facilitar un financiamiento más inclusivo a las pymes. Colombia se centra en la adaptación del marco regulatorio a las tecnologías financieras emergentes, en consonancia con los principios que promueve la Alianza del Pacífico. El objetivo de Perú, por su parte, es aplicar una propuesta legislativa sobre la regulación de los servicios financieros para 2021 y crear una plataforma regulatoria del sector fintech para 2025. Honduras hace hincapié en el desarrollo de servicios financieros digitales para mejorar la inclusión financiera. Uruguay aborda el importante tema de la automatización y robotización de los procesos de producción y el uso de los macrodatos para incrementar la productividad agroalimentaria y mejorar la trazabilidad de los productos.

\section{Gráfico 4.15. Intensidad de las dimensiones digitales en los planes nacionales de desarrollo, según el vínculo con las trampas del desarrollo, países seleccionados de América Latina y el Caribe, 2019}

\begin{tabular}{|l|l|l|l|l|l|}
\hline & Total & $\begin{array}{c}\text { Trampa de la } \\
\text { productividad }\end{array}$ & Trampa institucional & $\begin{array}{c}\text { Trampa de la } \\
\text { vulnerabilidad social }\end{array}$ & Trampa ambiental \\
\hline Argentina & & & & & \\
\hline Bolivia & & & & & \\
\hline Brasil & & & & & \\
\hline Chile & & & & & \\
\hline Colombia & & & & & \\
\hline Costa Rica & & & & & \\
\hline Rep. Dominicana & & & & & \\
\hline Ecuador & & & & & \\
\hline El Salvador & & & & & \\
\hline Guatemala & & & & & \\
\hline Honduras & & & & & \\
\hline México & & & & & \\
\hline Panamá & & & & & \\
\hline Paraguay & & & & & \\
\hline Perú & & & & & \\
\hline Uruguay & & & & & \\
\hline
\end{tabular}

Notas: Un color más oscuro indica una mayor intensidad de la transformación digital. Para configurar la tabla, se vinculó cada política de los planes nacionales de desarrollo con una trampa del desarrollo y, posteriormente, se calculó la frecuencia relativa de las palabras "computacional", "digital", "digitalización", "electrónico", "informática", "inteligente", "Internet", "online", "tecnología", "tecnológico", "virtual” y todos sus derivados con respecto a cada trampa. Los análisis relativos al plan nacional de Brasil se realizaron en portugués y los de todos los demás planes, en español. Véase la metodología pormenorizada en el Anexo 4.A1.

Fuente: Elaboración propia a partir de los planes nacionales de desarrollo más recientes (fin de 2019).

StatLink ailst https://doi.org/10.1787/888934202864

La conexión entre la transformación digital y la trampa de la vulnerabilidad social recibe una atención relativamente inferior en los planes nacionales de desarrollo, y se concentra principalmente en el ámbito del fortalecimiento de las competencias en ciencias y tecnologías de la información en las escuelas. La digitalización de los servicios de educación y salud, por ejemplo, mediante el aprendizaje a distancia o los servicios de salud por medios electrónicos, constituyen alternativas que por lo general todavía no se han explorado. Algunos planes nacionales de desarrollo incluyen marcos de políticas destinados a mejorar la conectividad en las escuelas e impulsar la inclusión. El Plan de Gobierno de Chile para el período 2018-2022 propone una academia virtual, Conectados con el Futuro, que ofrece clases gratuitas de ciencia y tecnología a todos los ciudadanos. República Dominicana, Paraguay y Perú promueven políticas similares. El plan nacional 
de desarrollo de Colombia incluye propuestas para crear una plataforma digital con recomendaciones sobre la educación infantil dirigida a las familias. Los planes nacionales de desarrollo abarcan también propuestas para dotar a los centros educativos de conexión a Internet y computadoras, en la línea de la iniciativa Niñez y Juventud del Futuro: una Niña, un Niño, una Computadora de El Salvador. El plan nacional de desarrollo de Uruguay tiene por objeto facilitar y democratizar el acceso a las nuevas tecnologías, con la finalidad de garantizar que todos los ciudadanos se beneficien de servicios de salud a través de Internet.

En cuanto a la relación de la transformación digital con la trampa institucional, la mayoría de los planes nacionales de desarrollo reconocen la importancia de adoptar herramientas digitales para modernizar la administración pública (gobierno electrónico), aunque las propuestas son dispares respecto a la reorganización del sector público con la finalidad de integrar ideas estratégicas sobre tecnologías digitales desde su diseño (gobierno digital). Los planes nacionales de desarrollo de Argentina, Chile, Colombia y Perú presentan las recomendaciones más avanzadas para modernizar la administración. Argentina propone una "boleta única electrónica" para incrementar la transparencia de los procesos electorales, la digitalización de las aduanas (algo que también ha propuesto Perú) y el plan País Digital para promover el uso de Internet por parte de las administraciones provinciales y municipales. Brasil y Colombia tienen intención de introducir plataformas digitales encaminadas a mejorar las interacciones entre la administración, la ciudadanía y la comunidad empresarial. Chile pretende mejorar la gestión policial con sistemas seguros de información electrónica y apps móviles para emergencias y delitos. Colombia y Perú planean introducir un modelo de justicia digital en el que la mayoría de las actuaciones judiciales puedan realizarse mediante procedimientos electrónicos.

La conexión entre la transformación digital y la trampa ambiental observada en los planes resulta menos notoria. Brasil propone utilizar tecnologías para la detección remota de prácticas de deforestación, uso del suelo e incendios forestales, así como para la difusión de información. Costa Rica propone instalar medidores inteligentes en el sistema eléctrico nacional como parte de su plan nacional de descarbonización y crear una plataforma digital para agilizar la tramitación de permisos, procesos y operaciones de carácter ambiental. Uruguay planea impulsar el I+D sobre tecnologías relacionadas con el control, seguimiento y gestión ambiental. Los países deberían adoptar nuevas tecnologías digitales para controlar la contaminación y la conservación de especies. Los avances en el tratamiento de imágenes, si se utilizan en combinación con el aprendizaje automático, pueden resultar útiles para la política de conservación, al permitir rastrear las poblaciones de animales salvajes y llevar un seguimiento de la pérdida de biodiversidad (OCDE, 2019l). Para preparar el primer censo de cebra de Grévy en Kenia se utilizaron este tipo de métodos (Berger-Wolf et al., 2016).

Principales temas relacionados con cuestiones digitales que aparecen en los diferentes planes nacionales de desarrollo

La transformación digital es relevante para muchos ámbitos de la política pública. Para determinar los principales temas digitales que se incluyen en los planes nacionales de desarrollo de ALC, se realizó un ejercicio de extracción de texto con el objetivo de calcular la frecuencia con que aparecen estos elementos de política: acceso y uso de Internet y de tecnologías digitales; infraestructura de comunicación; economía digital; gobierno digital; integración regional; y el futuro del trabajo (puede consultarse la metodología pormenorizada en el Anexo 4.A1 y una relación de los planes nacionales de desarrollo analizados en el Anexo 4.A2).

En términos generales, la transformación digital aparece mencionada en una amplia variedad de áreas de la política pública en los planes nacionales de desarrollo. Los países no se centran en una única cuestión, aunque pueden hacer hincapié en algún aspecto concreto. Por ejemplo, Paraguay considera prioritaria la integración regional, mientras Perú y Uruguay prestan especial atención al futuro del trabajo (Gráfico 4.16). 
Gráfico 4.16. Intensidad de las dimensiones digitales en los planes nacionales de desarrollo, países seleccionados de América Latina y el Caribe, 2019

\begin{tabular}{|c|c|c|c|c|c|c|}
\hline & Acceso y uso & $\begin{array}{l}\text { Infraestructura de } \\
\text { comunicación }\end{array}$ & Futuro del trabajo & Gobierno digital & Economía digital & $\begin{array}{c}\text { Integración } \\
\text { regional }\end{array}$ \\
\hline \multicolumn{7}{|l|}{ Argentina } \\
\hline \multicolumn{7}{|l|}{ Bolivia } \\
\hline \multicolumn{7}{|l|}{ Brasil } \\
\hline \multicolumn{7}{|l|}{ Chile } \\
\hline \multicolumn{7}{|l|}{ Colombia } \\
\hline \multicolumn{7}{|c|}{ Costa Rica } \\
\hline \multicolumn{7}{|c|}{ Rep. Dominicana } \\
\hline \multicolumn{7}{|l|}{ Ecuador } \\
\hline \multicolumn{7}{|c|}{ El Salvador } \\
\hline \multicolumn{7}{|c|}{ Guatemala } \\
\hline \multicolumn{7}{|l|}{ Honduras } \\
\hline \multicolumn{7}{|l|}{ México } \\
\hline \multicolumn{7}{|l|}{ Panamá } \\
\hline \multicolumn{7}{|l|}{ Paraguay } \\
\hline \multicolumn{7}{|l|}{ Perú } \\
\hline Uruguay & & & & & & \\
\hline
\end{tabular}

Nota: Tabla obtenida mediante la recopilación de una relación de palabras clave relativas a cada tema. La intensidad con que se aborda el tema se calculó a partir de la frecuencia relativa. Véase la metodología pormenorizada en el Anexo 4.A1. Fuente: Elaboración propia a partir de los planes nacionales de desarrollo más recientes (fin de 2019).

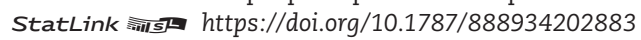

La mayoría de los planes nacionales de desarrollo recogen la ampliación del acceso y el uso de tecnologías digitales como medida para cerrar la brecha digital y garantizar una cobertura universal de Internet. En la mayoría, se sitúa el acceso a Internet entre los servicios básicos de los hogares, junto con el suministro de agua, electricidad y teléfono. Algunos países, como Brasil, Chile y Colombia, proponen puntos de acceso wifi de alcance nacional para garantizar la inclusión digital de toda la ciudadanía.

Las políticas que buscan ampliar la infraestructura de comunicación son fundamentales para una transformación digital inclusiva. La mayoría de los países cuenta con programas destinados a garantizar la banda ancha universal, aunque las prioridades fijadas dependen de lo avanzado que se encuentre el desarrollo de la infraestructura de comunicación en el país. Aquellos que presentan bajos niveles de acceso a Internet, como es el caso de Honduras, se centran en ampliar la cobertura de red y el número de abonados. Sin embargo, el objetivo que se marcan los países con ingresos más altos, como Colombia y Costa Rica, es mejorar la infraestructura actual y migrar a redes 4G y 5G, el segundo en los próximos años. Uruguay planea reforzar la conectividad del Internet de las Cosas, ya que el país presenta un desarrollo relativamente adecuado de la banda ancha fija y móvil.

Por lo que respecta a la influencia de la digitalización en los mercados de trabajo y la adaptación a un nuevo entorno laboral, los países hacen más hincapié en potenciar las competencias que en fomentar otros sistemas de trabajo más flexibles o transformar las instituciones del mercado laboral. El plan de Uruguay adopta una perspectiva de género sobre los riesgos de la automatización y el posible incremento de la desigualdad salarial. Destaca la importancia de poner fin a la segregación de la educación y fomentar la participación de la mujer en estudios de índole científica y tecnológica. También procura garantizar el derecho a la formación permanente y la seguridad y protección social universal de todos los trabajadores, con la finalidad de mitigar cambios en el futuro del trabajo. El teletrabajo recibe, en términos relativos, menos atención, a excepción de las propuestas del plan de Chile para mejorar la conciliación de la vida laboral y personal, del plan de Colombia para promover la igualdad laboral y favorecer la participación de la mujer en el mercado de trabajo, y del plan de Perú para aprobar una nueva ley sobre teletrabajo para 2021. 
Los planes recogen de manera generalizada propuestas relativas a la aplicación de tecnologías digitales para acelerar procesos internos de la administración pública y adoptar políticas de datos abiertos. No obstante, salvo Argentina, Brasil, Chile, Colombia, México y Uruguay, ningún otro país menciona la ampliación complementaria de la regulación en materia de seguridad digital. Aumenta cada vez más la creación de ventanillas únicas digitales para realizar trámites ante la administración. La Ventanilla Única Digital y Presencial de Argentina propone unificar todos los canales de acceso a servicios sociales y envío de transferencias. Chile sin Papeleo 2025 y Chile Atiende Online son iniciativas importantes destinadas a conseguir capacidad suficiente para que todos los procedimientos con las administraciones públicas se realicen a través de Internet para 2025. Colombia tiene una meta similar para 2030. Perú implementará la Ventanilla Única Digital Minero Energética, un instrumento destinado a gestionar permisos y autorizaciones para inversionistas del sector minero y energético de aquí a 2021.

La atención prestada al desarrollo de la economía digital sigue siendo escasa, al encontrarse solo un reducido número de propuestas relativas a la promoción del comercio electrónico, la banca abierta o las empresas de tecnología financiera. La iniciativa Pymes Digitales de Chile promueve el acceso a la conectividad y ofrece formación a través de plataformas digitales. Chile creará además una hoja de ruta para la participación de las empresas en el comercio electrónico, la masificación de los pagos y la certificación de origen electrónico en el marco de los compromisos asumidos en la Alianza del Pacífico. Colombia, aparte de promover el comercio electrónico, planea un programa de fabricación avanzada para desarrollar tecnologías vinculadas a la industria 4.0, entre ellas, Internet de las Cosas industrial, macrodatos, inteligencia artificial, robótica, impresión en 3D, nanotecnología y realidad virtual y aumentada. Panamá tiene el objetivo de implementar un sistema de pagos por Internet como parte de su ley de gobierno electrónico (Panamá en Línea). Uruguay está analizando la posibilidad de aumentar las exportaciones de carne mediante el comercio electrónico y también el papel del sector creativo en el avance de la economía digital.

La integración regional es importante para el grueso de países consultados, pero la mayoría se centra en la integración energética, fronteriza y comercial. Pocos países incluyen la integración digital como parte de sus objetivos más amplios de conseguir una economía competitiva e innovadora.

El modo en que aparecen reflejados los aspectos digitales en los planes nacionales de desarrollo señala carencias y oportunidades para seguir beneficiándose de la transformación digital. No obstante, los resultados del análisis de los planes nacionales de desarrollo han de interpretarse con cautela. La ausencia de una temática puede indicar que no constituye una prioridad máxima, que se trata por medio de políticas ya existentes o que ya se ha alcanzado dicho objetivo. Por ejemplo, Uruguay no menciona el gobierno digital, pero tal omisión puede obedecer a los avances registrados hasta la fecha en ese ámbito y a la existencia de una agenda digital y un plan de gobierno digital.

\section{Estrategias/agendas digitales nacionales: Medidas integrales para aprovechar las ventajas de las nuevas tecnologías}

Desde mediados de la década de los noventa, los gobiernos de ALC han dedicado cada vez más esfuerzos y recursos a desarrollar agendas digitales o estrategias TIC, lo que ha generado una serie de iniciativas y políticas de carácter integral en esta materia. Brasil, Chile y Colombia se situaron entre los países pioneros, con la formulación de ambiciosas estrategias TIC. Varios países, entre ellos Chile, Colombia y Uruguay, han consolidado desde entonces políticas e instituciones y creado agendas digitales de tercera o cuarta generación (CEPAL, 2016). La mayoría de los países de ALC posee actualmente una agenda digital (Tabla 4.3). 
Tabla 4.3. Estrategias/agendas digitales nacionales, países seleccionados de América Latina y el Caribe

\begin{tabular}{|c|c|c|c|}
\hline & $\begin{array}{l}\text { Estrategia/agenda } \\
\text { digital }\end{array}$ & Objetivos & Institución \\
\hline Argentina & Agenda Digital 2030 & $\begin{array}{l}\text { Educación digital, infraestructura, conectividad, } \\
\text { creación de un marco jurídico relativo al tratamiento } \\
\text { de datos, gobierno eficiente, ciberseguridad, } \\
\text { desarrollo económico y proactividad en la } \\
\text { transformación digital a escala internacional }\end{array}$ & $\begin{array}{l}\text { Unidad Ejecutora Especial Temporal } \\
\text { "Unidad Agenda Digital Argentina", } \\
\text { bajo la órbita de la Secretaría de } \\
\text { Modernización del Gobierno }\end{array}$ \\
\hline Bolivia & Agenda Digital 2025 & $\begin{array}{l}\text { Biodiversidad y tecnología, economía del } \\
\text { conocimiento y digital, comunicación y artes digitales, } \\
\text { gobierno abierto, tecnología para la vida, género e } \\
\text { inclusión, y seguridad e infraestructura }\end{array}$ & $\begin{array}{l}\text { Agencia de Gobierno Electrónico } \\
\text { y Tecnologías de Información y } \\
\text { Comunicación, bajo la supervisión } \\
\text { del Ministerio de la Presidencia }\end{array}$ \\
\hline Brasil & $\begin{array}{l}\text { Estratégia Brasileira } \\
\text { para a Transformação } \\
\text { Digital (E-Digital) } \\
\text { (2018) }\end{array}$ & $\begin{array}{l}\text { Por eje temático: 1) elementos facilitadores } \\
\text { (infraestructura y acceso a TIC, comunicación, I+D e } \\
\text { innovación, confianza en el entorno digital, educación } \\
\text { digital y dimensión internacional) y 2) transformación } \\
\text { digital de la economía, los ciudadanos y el gobierno }\end{array}$ & $\begin{array}{l}\text { Ministerio de Ciencia, Tecnología, } \\
\text { Innovación y Comunicaciones }\end{array}$ \\
\hline Chile & $\begin{array}{l}\text { Chile Digital para } \\
\text { Tod@s Agenda Digital } \\
2020\end{array}$ & $\begin{array}{l}\text { Derechos en materia de desarrollo digital, conectividad } \\
\text { digital, gobierno digital, economía digital y } \\
\text { competencias digitales }\end{array}$ & $\begin{array}{l}\text { Presidencia de la República con } \\
\text { asesoramiento del Comité de } \\
\text { Ministros para el Desarrollo Digital }\end{array}$ \\
\hline Colombia & $\begin{array}{l}\text { Plan TIC 2018-2022 } \\
\text { El Futuro Digital es de } \\
\text { Todos }\end{array}$ & $\begin{array}{l}\text { Entorno TIC, inclusión social digital, empoderamiento } \\
\text { de los ciudadanos y los hogares en un entorno digital, } \\
\text { y transformaciones digitales sectoriales. }\end{array}$ & $\begin{array}{l}\text { Ministerio de Tecnologías de la } \\
\text { Información y las Comunicaciones }\end{array}$ \\
\hline Costa Rica & $\begin{array}{l}\text { Estrategia de } \\
\text { Transformación Digital } \\
\text { del Bicentenario } \\
2018-2022\end{array}$ & $\begin{array}{l}\text { Transformación digital de las instituciones públicas } \\
\text { y la sociedad con especial orientación a personas, } \\
\text { transparencia, eficiencia, productividad, buena } \\
\text { gobernanza y liderazgo mundial }\end{array}$ & $\begin{array}{l}\text { Ministerio de Ciencia, Tecnología y } \\
\text { Telecomunicaciones }\end{array}$ \\
\hline $\begin{array}{l}\text { República } \\
\text { Dominicana }\end{array}$ & $\begin{array}{l}\text { Agenda Digital } \\
\text { 2016-2020 de la } \\
\text { República Dominicana }\end{array}$ & $\begin{array}{l}\text { Infraestructura y acceso, gobierno electrónico y } \\
\text { servicios digitales, desarrollo de competencias, } \\
\text { desarrollo productivo e innovación y entorno } \\
\text { favorable. }\end{array}$ & $\begin{array}{l}\text { Comisión Nacional para la Sociedad } \\
\text { de la Información y el Conocimiento, } \\
\text { presidida por el Instituto Dominicano } \\
\text { de las Telecomunicaciones }\end{array}$ \\
\hline Ecuador & Política Ecuador Digital & $\begin{array}{l}\text { Conectividad, eficiencia y seguridad de la información, } \\
\text { e innovación y competitividad. }\end{array}$ & Ministerio de Telecomunicaciones \\
\hline Guatemala & $\begin{array}{l}\text { Agenda Nación Digital } \\
\text { 2016-2032 }\end{array}$ & $\begin{array}{l}\text { Educación, salud, seguridad, desarrollo y } \\
\text { transparencia }\end{array}$ & $x$ \\
\hline Honduras & $\begin{array}{l}\text { Agenda Digital } \\
\text { Honduras 2014-2018 }\end{array}$ & $\begin{array}{l}\text { Conectividad digital con equidad, estrategias de } \\
\text { gobierno digital, capital humano y TIC, y creación } \\
\text { de un marco legislativo e institucional para las TIC }\end{array}$ & $\begin{array}{l}\text { Secretaría Técnica de Planificación y } \\
\text { Cooperación Externa }\end{array}$ \\
\hline México & $\begin{array}{l}\text { Estrategia Digital } \\
\text { Nacional 2013-2018 }\end{array}$ & $\begin{array}{l}\text { Transformación del gobierno, economía digital, } \\
\text { educación de calidad, sistema de salud universal y } \\
\text { efectivo, y seguridad pública }\end{array}$ & $\begin{array}{l}\text { Presidencia de la República, } \\
\text { Coordinador de Estrategia Digital } \\
\text { Nacional }\end{array}$ \\
\hline Panamá & $\begin{array}{l}\text { El Camino a un } \\
\text { Ciudadano Digital } \\
\text { Agenda Digital } 2020\end{array}$ & $\begin{array}{l}\text { Equidad e inclusión social, consolidación democrática, } \\
\text { transformación del Estado, desarrollo de infraestructu- } \\
\text { ras, desarrollo económico basado en el conocimiento, } \\
\text { educación a través de las TIC, generación de } \\
\text { conocimientos, investigación, desarrollo e innovación, } \\
\text { y acción en el plano territorial e internacional }\end{array}$ & $\begin{array}{l}\text { Autoridad Nacional para la } \\
\text { Innovación Gubernamental }\end{array}$ \\
\hline Paraguay & Agenda Digital & $\begin{array}{l}\text { Conectividad, gobierno digital, economía digital y } \\
\text { consolidación institucional, y ciberseguridad }\end{array}$ & $\begin{array}{l}\text { Ministerio de Tecnologías de la } \\
\text { Información y Comunicación }\end{array}$ \\
\hline Perú & $\begin{array}{l}\text { Agenda Digital al } \\
\text { Bicentenario } 2021\end{array}$ & $\begin{array}{l}\text { Integridad, competitividad, vínculo con los } \\
\text { ciudadanos, confianza, innovación }\end{array}$ & $\begin{array}{l}\text { Comisión Multisectorial para el } \\
\text { Seguimiento y Evaluación del Plan } \\
\text { de Desarrollo de la Sociedad de la } \\
\text { Información, bajo la dirección de la } \\
\text { Presidencia del Consejo de Ministros }\end{array}$ \\
\hline Uruguay & $\begin{array}{l}\text { Transformación con } \\
\text { equidad Agenda Digital } \\
2020\end{array}$ & $\begin{array}{l}\text { Adquisición de competencias digitales para la } \\
\text { inclusión, innovación para el bienestar social, } \\
\text { inversión en infraestructuras, economía digital, } \\
\text { gestión inteligente de información ambiental y } \\
\text { emergencias, y ydministración inteligente y conectada }\end{array}$ & $\begin{array}{l}\text { Agencia de Gobierno Electrónico y } \\
\text { Sociedad de la Información y del } \\
\text { Conocimiento, subordinada a la } \\
\text { Presidencia de la República }\end{array}$ \\
\hline
\end{tabular}

Nota: $\mathrm{x}=$ no aplica.

Fuente: Elaboración propia a partir de las fuentes Katz (2009), El papel de las TIC en el desarrollo: Propuesta de América Latina a los retos económicos actuales; OCDE/BID (2016), Políticas de banda ancha para América Latina y el Caribe: Un manual para la economía digital, https://doi.org/10.1787/9789264251823-en y agendas digitales de países ALC. 
Diversos países, entre ellos Argentina, Brasil, Ecuador, Panamá y Paraguay, aprobaron sus agendas digitales durante el período 2018-2019. Tras un largo proceso de consulta a más de 30 instituciones públicas, Brasil aprobó la Estratégia Brasileira para a Transformação Digital (E-Digital) (Estrategia Brasileña de Transformación Digital) en 2018. Ecuador adoptó la política Ecuador Digital en 2019 y actualmente está preparando su nueva agenda digital. Paraguay aprobó recientemente una ambiciosa agenda digital, además de crear un Ministerio de Tecnologías de la Información y las Comunicaciones en 2018.

Chile, Colombia, Costa Rica, República Dominicana y Panamá cuentan con marcos políticos permanentes sobre cuestiones digitales, mientras que otros países de ALC, como México, todavía tienen que actualizar sus marcos legislativos, en parte debido a los cambios políticos registrados en la región.

Las agendas digitales son transversales a diferentes sectores y abordan diversos objetivos de política relacionados con la transformación digital de las economías y las sociedades. La mayoría de las agendas digitales de ALC incluyen o priorizan objetivos relacionados con la infraestructura y el acceso a las TIC, la instalación de redes de banda ancha, la adquisición de competencias digitales, el marco jurídico, el gobierno digital, las TIC en centros educativos y políticas que incrementen la productividad destinadas principalmente a la adopción de tecnologías digitales por parte de las pymes, la promoción del sector de tecnologías de la información, el comercio electrónico y el emprendimiento digital. Las políticas de atención sanitaria por medios electrónicos y, en concreto, las políticas de carácter ambiental no se mencionan con tanta frecuencia. Un número cada vez mayor de agendas digitales señala la importancia de la cooperación internacional como componente estratégico de sus agendas políticas (ver el Capítulo 5). Esta sección se centra en las agendas digitales, aunque muchos países de ALC poseen estrategias de gobierno digital independientes relativas a la transformación digital de las instituciones públicas. Brasil, por ejemplo, posee la Agenda Digital E-Digital y la Estrategia de Gobierno Digital (2020-2022) (OCDE, 2018).

Las agendas digitales de los países de ALC abarcan una amplia serie de políticas, incluyendo no solo a los ministerios de TIC sino también a otras instituciones públicas como las encargadas de las finanzas, la educación, la industria y la administración pública (Gráfico 4.17). La coordinación eficaz entre organismos públicos resulta esencial para la aplicación de una agenda digital coherente. Los responsables de políticas pueden interpretar erróneamente que la gobernanza de datos es responsabilidad exclusiva de los departamentos de TIC, pero un marco integral de gobernanza de datos debe garantizar una adecuada gestión de estos a lo largo de todo su ciclo de vida, es decir, en los diferentes departamentos (OCDE, 2019b). La transformación digital exige políticas y prácticas que aborden los problemas de manera integral y coherente en los distintos sectores en que surjan (OCDE, 2019n, 2019o; Quintanilla, 2017). La respuesta al cambio tecnológico exige un cierto grado de disrupción institucional, en otras palabras, una transformación de la organización tradicional del gobierno con respecto a las políticas digitales.

En las diferentes agendas digitales de ALC se observan ejemplos de coordinación interinstitucional, pero son pocos los países que han consolidado mecanismos de este tipo. El Consejo Asesor Honorario para la Sociedad de la Información de Uruguay se reúne periódicamente para evaluar la aplicación de la agenda digital.

La transformación digital no solo es promovida por los gobiernos sino también por las empresas, las personas y otros grupos de interés no gubernamentales. Para velar por unas estrategias inclusivas y útiles para todos, es importante incluir a todas las instancias del gobierno y todos los grupos de interés. Un diálogo entre múltiples interlocutores puede ayudar a identificar obstáculos, intercambiar mejores prácticas y generar oportunidades de autorregulación, fijación de normas a instancia de los interesados y formación de asociaciones público-privadas. Las tecnologías digitales facilitan cada vez más este tipo 
de interacciones, por ejemplo a través de consultas web (OCDE, 2019o). Los países de ALC admiten la importancia que reviste la participación de los diferentes grupos de interés en la elaboración de las agendas digitales, aunque pocos cuentan con una configuración institucional que procure la coordinación con el sector privado y la sociedad civil para su aplicación y seguimiento.

Para conseguir resultados adecuados con las agendas digitales, es necesario definir responsabilidades claras y competencias suficientes para su aplicación. Un órgano de alto nivel que se encargue de dirigir la estrategia puede resultar especialmente útil para coordinar una transformación digital sin problemas (OCDE, 2019i, 2019n). Los métodos planteados para gestionar las agendas digitales varían de un país a otro, tanto en la OCDE como en ALC. Los países de la OCDE siguen dos modelos. El primero se caracteriza por un liderazgo de alto nivel y la centralización de la responsabilidad de coordinación estratégica en un plano superior al ministerial, por ejemplo, a nivel del jefe de Estado u otra figura de igual importancia. Este sería el caso de la República Eslovaca, donde el primer ministro posee amplias competencias en materia digital, como la formulación de la estrategia, que se ejecuta a través de una oficina de coordinación exclusiva. En otros países, como Estonia, Corea y Luxemburgo, además de Chile y Perú en ALC, el primer ministro (o la Presidencia) se encarga de determinadas funciones, como la coordinación estratégica, pero los ministerios también pueden tener gran relevancia, por ejemplo, en contribuir a la formulación y diseño de la estrategia (OCDE, 20190).

El segundo planteamiento asigna la responsabilidad de coordinar la agenda digital a un ministerio. En varios países de la OCDE como Bélgica, Japón, Polonia, Portugal y Eslovenia, el ministerio responsable se dedica de manera exclusiva a los asuntos digitales. En algunos países de ALC, como Brasil, Colombia, Costa Rica, Ecuador y Paraguay, son los ministerios responsables en materia de TIC o Ciencia y Tecnología los que se encargan de las agendas digitales. En Bolivia, Panamá y Uruguay, entre otros países, la supervisión de las agendas digitales corre a cargo de un órgano especial bajo el control de la Presidencia de la República (Gráfico 4.17).

Es importante contar con un marco de supervisión efectivo para el seguimiento de la aplicación y la evaluación de las agendas digitales. Dichas actividades deberían permitir el aprendizaje, la fijación de prioridades y la mejora de las políticas a lo largo del tiempo (OCDE, 2019n). Muchos gobiernos de la OCDE han fijado metas que se pueden medir en plazos determinados. En promedio, el seguimiento de estas medidas se inició en 2013. Algunos países supervisan la implantación por medio de un índice supranacional, como el Índice de economía y sociedad digital de la UE. Otros, como Alemania y México, crearon sus propios índices de digitalización agregados (OCDE, 2017e). El conjunto de herramientas Going Digital Toolkit de la OCDE ayuda a los países a evaluar su situación en cuanto a desarrollo digital y formular estrategias políticas, así como métodos de respuesta. La publicación Cómo medir la transformación digital: Hoja de ruta para el futuro señala otros indicadores y un futuro programa de medición (OCDE, 2019i).

Pese a que es importante realizar un seguimiento de indicadores de desempeño esenciales para valorar el avance de programas determinados, también es necesario realizar un seguimiento integral del avance de la agenda digital en general. Esto último resulta especialmente útil para las autoridades nacionales cuando la consecución de un objetivo político depende de que se haya alcanzado otra meta (OCDE/BID, 2016). Varios países de ALC han comenzado a incluir indicadores de seguimiento para supervisar la aplicación de la agenda digital. La estrategia de Brasil establece indicadores de seguimiento de cada objetivo basados en datos estadísticos del Centro Regional de Estudios para el Desarrollo de la Sociedad de la Información, la principal fuente de datos estadísticos del país en materia de TIC. 
Gráfico 4.17. Características institucionales de las agendas digitales nacionales, países seleccionados de América Latina y el Caribe, 2020

\begin{tabular}{|c|c|c|c|c|c|c|c|}
\hline & $\begin{array}{c}\text { Ministerio } \\
\text { de TIC } \\
\text { especializado }\end{array}$ & $\begin{array}{l}\text { Objetivos } \\
\text { explícitos en la } \\
\text { agenda digital }\end{array}$ & $\begin{array}{c}\text { Consulta } \\
\text { pública para } \\
\text { la elaboración } \\
\text { de la agenda } \\
\text { digital }\end{array}$ & $\begin{array}{c}\text { Comisión o } \\
\text { comité de } \\
\text { coordinación } \\
\text { interguberna- } \\
\text { mental para la } \\
\text { agenda digital }\end{array}$ & $\begin{array}{l}\text { Coordinación } \\
\text { de los múltiples } \\
\text { grupos de } \\
\text { interés para el } \\
\text { seguimiento } \\
\text { de la agenda } \\
\text { digital }\end{array}$ & $\begin{array}{c}\text { Metas } 0 \\
\text { indicadores para } \\
\text { el seguimiento } \\
\text { de la agenda } \\
\text { digital }\end{array}$ & $\begin{array}{l}\text { Presupuesto } \\
\text { explícito en la } \\
\text { agenda digital }\end{array}$ \\
\hline \multicolumn{8}{|c|}{ Argentina } \\
\hline \multicolumn{8}{|c|}{ Bolivia } \\
\hline \multicolumn{8}{|l|}{ Brasil } \\
\hline \multicolumn{8}{|c|}{ Colombia } \\
\hline \multicolumn{8}{|c|}{ Chile } \\
\hline \multicolumn{8}{|c|}{ Costa Rica } \\
\hline \multicolumn{8}{|c|}{ México } \\
\hline \multicolumn{8}{|c|}{ Rep. Dominicana } \\
\hline \multicolumn{8}{|c|}{ Ecuador } \\
\hline \multicolumn{8}{|c|}{ Honduras } \\
\hline \multicolumn{8}{|c|}{ Panamá } \\
\hline \multicolumn{8}{|c|}{ Paraguay } \\
\hline \multicolumn{8}{|l|}{ Perú } \\
\hline Uruguay & & & & & & & \\
\hline
\end{tabular}

Nota: La intensidad del color indica la intensidad con la que presenta la agenda digital cada característica específica en su configuración institucional.

Fuente: Elaboración propia a partir de las agendas digitales nacionales más recientes (enero de 2020). StatLink ailst https://doi.org/10.1787/888934202902

Es importante que las agendas digitales estén alineadas con los planes nacionales de desarrollo, el documento de planificación principal de los países. Los planes nacionales de desarrollo establecen estrategias de desarrollo y pueden articularse en varios planes regionales y sectoriales, tales como las agendas digitales. Resulta esencial que se armonicen los objetivos de los diferentes planes públicos para coordinar la formulación de políticas. Por ejemplo, la Agenda Digital Panamá 4.0 tuvo en cuenta los objetivos principales del Plan de Gobierno 2014-2019, el Plan Estratégico de Gobierno, el Plan Nacional de Competitividad y los objetivos de la Agenda Digital regional (eLAC2020) bajo la coordinación de la Comisión Económica para América Latina y el Caribe.

Las agendas digitales deberían establecerse con un marco temporal a mediano plazo de entre cinco y diez años (Katz, 2009). Aunque muchas agendas digitales de ALC tienen su origen en objetivos principales de los planes nacionales de desarrollo y se armonizan con estos, tal armonización suele plantear problemas porque el marco temporal de las agendas digitales coincide normalmente con el mandato presidencial (Mattar y Cuervo, 2017), de modo que la continuidad de la estrategia se ve amenazada con cada cambio de gobierno. Pese a que un plan a corto plazo resulta útil para coordinar medidas inmediatas, se necesita una estrategia a más largo plazo para invertir en proyectos tales como infraestructura TIC, con plazos de vencimiento más amplios y resultados que solo pueden valorarse a mediano y largo plazo.

\section{Conclusión}

La pandemia del coronavirus (Covid-19) ha planteado desafíos inéditos para las instituciones públicas, que enfrentan nuevos dilemas de política pública en un contexto en que la ciudadanía es cada vez más exigente y en que han aumentado la desconfianza, la insatisfacción y el descontento social. La crisis podría acentuar las demandas por 
instituciones públicas más fuertes y servicios públicos de mayor calidad. La transformación digital ofrece vías para superar estos desafíos, aunque no será tarea sencilla.

Las profundas transformaciones propiciadas por el avance tecnológico cuestionan la idoneidad del marco institucional actual, tanto en el plano nacional como en el internacional. Están apareciendo nuevos riesgos y oportunidades, y las reglas del juego deben adaptarse para convertir la transformación digital en un motor de mayor bienestar para toda la población. La transformación digital ofrece una oportunidad para que las instituciones públicas se adapten a las aspiraciones crecientes de la sociedad, en algunos casos relacionadas con nuevos "derechos digitales". En América Latina y el Caribe se ha incrementado la brecha entre ciudadanos e instituciones, dando lugar a una trampa institucional, un círculo vicioso de escasa confianza, baja disposición a pagar impuestos $y$, en consecuencia, un déficit de recursos para financiar servicios públicos de calidad y satisfacer las demandas de la ciudadanía (OCDE et al., 2019).

En la era digital hay tres dimensiones de las instituciones públicas que deben repensarse. La primera es la gobernanza de la transformación digital. Están surgiendo nuevos desafíos en materia de regulación. Las normativas deben velar por un avance justo y equitativo de la transformación digital promoviendo una competencia justa, así como la inversión e innovación digital, y protegiendo a ciudadanos y consumidores. Para ello, es preciso contar con un regulador independiente y un marco regulatorio estable y predecible que fomente la inversión a largo plazo. La seguridad digital es uno de los desafíos más importantes. Sin embargo, después de África, ALC es la región que muestra el menor compromiso en este sentido, según el Índice mundial de ciberseguridad. No obstante, se han registrado avances ya que, en 2019, 13 países contaban con una estrategia de seguridad digital. La protección de datos es otra cuestión esencial que merece un marco político renovado. El RGPD representa un modelo para muchos países de ALC.

La transformación digital acarrea nuevos dilemas éticos. El empleo cada vez mayor de la inteligencia artificial y el aprendizaje automático en la toma de decisiones de las instituciones públicas puede plantear cuestiones y desafíos relacionados con los valores humanos, la equidad, la determinación humana, la privacidad, la seguridad y la rendición de cuentas, entre otros. Las regulaciones para responder a estas cuestiones han avanzado en los últimos años. Los Principios de la OCDE sobre Inteligencia Artificial de 2019 promueven una inteligencia artificial innovadora y confiable, que respete los derechos humanos y los valores democráticos. Argentina, Brasil, Chile, Colombia, Costa Rica, México y Perú han adoptado estos principios. Los riesgos de la desinformación masiva (noticias falsas) representan otra dificultad fundamental. En ALC, el 53\% de la población consideraba que de manera frecuente o muy frecuente se difundía información falsa para influir en las elecciones. Para superar este problema se están empleando dos tipos de actuaciones principales: la regulación de los medios, consistente en cambios estructurales destinados a prevenir la exposición a noticias falsas, y la formación con respecto a los medios, consistente en dotar a las personas de herramientas necesarias para evaluar las noticias que encuentren, por ejemplo mediante iniciativas de comprobación de datos y verificación de noticias.

La segunda dimensión es la transformación digital de las administraciones públicas. Los gobiernos están incorporando tecnologías, y han progresado en pasar de administraciones públicas analógicas a electrónicas, para posteriormente avanzar paulatinamente hacia servicios públicos totalmente digitales. El Marco de Gobierno Digital de la OCDE destaca seis dimensiones de un gobierno digital: digital por diseño; promovido por los usuarios; el gobierno como plataforma; abierto por defecto; impulsado por datos; y proactivo. Los organismos públicos no solo están obligados a adoptar nuevas tecnologías sino también a reinventar su manera de utilizarlas, con la finalidad de integrar su uso 
en la modernización del sector público desde el primer momento. Los países de ALC se encuentran en distintas etapas de transformación digital de sus gobiernos. El EGDI, pese a constituir una medida insuficiente que no capta las dimensiones más generales de los gobiernos digitales, mostraba en 2018 que Argentina, Brasil, Chile y Uruguay se situaban entre los primeros 50 países de los 193 estudiados, con un desempeño ligeramente inferior al promedio de la OCDE. Belice, Cuba, Haití y Nicaragua, por su parte, se situaron entre los países con peores resultados de ALC.

Las tecnologías digitales ofrecen la oportunidad de transformar la gobernanza pública y avanzar hacia instituciones públicas más creíbles, eficientes, inclusivas e innovadoras. Con políticas nuevas como los datos gubernamentales abiertos, que favorecen una filosofía de transparencia, gestión más responsable y acceso a información pública, los gobiernos se erigen en entidades dignas de una mayor confianza. Los países de ALC han demostrado su compromiso con los datos gubernamentales abiertos, ya que en enero de 2020, esta región contaba con 53 planes de acción en esta materia. Las tecnologías digitales pueden propiciar mejoras en ámbitos especialmente propensos a registrar prácticas corruptas, como la contratación pública, las inversiones en infraestructuras y las transferencias de las autoridades nacionales a las subnacionales. La creación de órganos centrales de compras, el desarrollo de soluciones de adquisiciones y contrataciones por medios electrónicos y el uso del blockchain son todas iniciativas muy prometedoras.

Los gobiernos de ALC pueden adquirir mayor efectividad si utilizan tecnologías digitales para reducir los amplios plazos de tramitación y los costos administrativos. La simplificación de la burocracia y la automatización, la creación de sistemas automatizados que permitan interactuar a las diferentes instituciones gubernamentales y la transformación digital de la administración tributaria (mejorando la recopilación, el almacenamiento, la gestión y el análisis de la información fiscal) puede reducir los costos y aumentar los ingresos públicos. La transformación digital de la judicatura sigue siendo enormemente necesaria, aunque es un aspecto pendiente en la agenda de la mayoría de países de ALC.

La transformación digital puede incrementar el carácter inclusivo de las instituciones públicas al facilitar las interacciones con diversos grupos sociales y la participación ciudadana en la toma de decisiones. Existen canales innovadores para que la ciudadanía participe en diversas etapas del proceso de formulación de políticas. Por ejemplo, una plataforma para que los ciudadanos supervisen el cumplimiento por parte de las autoridades de los compromisos asumidos o espacios para el diálogo entre ciudadanos y autoridades, destinados a crear soluciones a desafíos políticos conjuntamente. Al hacer de la formulación de políticas un proceso más inclusivo, las tecnologías digitales pueden sentar las bases de un pacto social más participativo. Las herramientas digitales también pueden contribuir a que los servicios públicos (por ejemplo, aprendizaje y servicios de salud por medios electrónicos y a distancia) sean más inclusivos, al ampliar su cobertura para llegar a segmentos remotos o más desfavorecidos de la sociedad.

Las tecnologías digitales pueden ayudar a los gobiernos a ser más innovadores en todas las etapas de formulación de políticas. La disponibilidad de cantidades ingentes de datos permite realizar un seguimiento de fenómenos que cambian con gran rapidez o sobre los que anteriormente no había capacidad para realizar registros. También puede ayudar a los responsables de políticas a adaptar y diferenciar la formulación de políticas en función de la zona geográfica, el entorno político o el grupo socioeconómico. Las técnicas econométricas avanzadas y los macrodatos respaldados por información más detallada permiten una mayor experimentación y evaluación en materia de políticas. Los gobiernos innovadores deberían analizar la posibilidad de que entidades públicas y privadas colaboren en el intercambio de datos con el objetivo de orientar las políticas públicas, 
cooperando, por ejemplo, con empresas del segmento goutech (pymes y start-ups dedicadas a desarrollar soluciones de tecnología digital para las administraciones públicas).

La tercera dimensión es la agenda digital en los planes nacionales de desarrollo. El empeño por transformar y adaptar la gobernanza pública a la era digital debe coordinarse con una perspectiva estratégica a largo plazo. Los planes nacionales de desarrollo y, particularmente las agendas digitales, resultan esenciales. La incorporación de aspectos digitales varía en los diferentes planes nacionales de desarrollo de ALC. Lo más habitual es que en estos PND aparezcan fundamentalmente aspectos relacionados con los incrementos de la productividad y no tanto con cuestiones sociales, institucionales y ambientales. La infraestructura de comunicación, el acceso y uso de Internet y el futuro del trabajo son temas destacados en los PND, mientras que la presencia de la economía digital, del gobierno digital y de la integración regional es relativamente inferior. La mayoría de los países de ALC posee además una agenda digital. Es importante que las agendas digitales se armonicen con los PND. También resulta esencial que las agendas digitales incluyan a todas las instancias de la administración pública e interactúen con todos los grupos sociales no pertenecientes a este ámbito. Así, la coordinación institucional y el diálogo con los múltiples grupos reviste una importancia vital para lograr una transformación digital adecuada, pero también para avanzar hacia un pacto social más inclusivo. Para conseguir resultados adecuados con las agendas digitales, es necesario definir responsabilidades claras y competencias suficientes para su aplicación, además de contar con un marco de supervisión efectivo para el seguimiento de su aplicación y para su evaluación. 


\section{Anexo 4.A1. Metodología utilizada en el Gráfico 4.15 y el Gráfico 4.16}

En el caso del Gráfico 4.15, se valoró cada plan nacional de desarrollo mediante el programa informático de análisis de datos cualitativos NVivo y se codificó de acuerdo con las cuatro trampas del desarrollo. Las normas de codificación aplicadas fueron las siguientes:

Tabla 4.A1.1. Normas de codificación

\begin{tabular}{|c|c|c|}
\hline CÓDIGO & DESCRIPCIÓN & EJEMPLOS \\
\hline \multirow[t]{2}{*}{$\begin{array}{l}\text { Trampa } \\
\text { ambiental }\end{array}$} & \multirow[t]{2}{*}{$\begin{array}{l}\text { Incluye temas relacionados con el } \\
\text { medioambiente y la mitigación y } \\
\text { adaptación al cambio climático }\end{array}$} & $\begin{array}{l}\text { - "Formulación de una Política Nacional en materia de Uso Sostenible de la } \\
\text { Madera, que incluye un plan para sustituir la madera por energía procedente de } \\
\text { fuentes menos contaminantes, una mejor regulación del mercado maderero...". }\end{array}$ \\
\hline & & $\begin{array}{l}\text { - "Promoción de la educación, sensibilización y concienciación ambiental, así } \\
\text { como del acceso a información sobre medioambiente". }\end{array}$ \\
\hline \multirow[t]{2}{*}{$\begin{array}{l}\text { Trampa } \\
\text { institucional }\end{array}$} & \multirow{2}{*}{$\begin{array}{l}\text { Incluye reformas relacionadas con el } \\
\text { fortalecimiento de las instituciones, } \\
\text { lo que comprende la modernización } \\
\text { de los servicios públicos, la } \\
\text { seguridad ciudadana, la justicia y la } \\
\text { cooperación internacional }\end{array}$} & $\begin{array}{l}\text { - "El Gobierno nacional en coordinación con la Oficina del Fiscal General } \\
\text { desmantelará organizaciones delictivas, además de realizar investigaciones para } \\
\text { acabar con prácticas de blanqueo de capitales, a fin de desarticular las redes } \\
\text { económicas y la cadena de valor de actividades ilícitas". }\end{array}$ \\
\hline & & $\begin{array}{l}\text { • "Las entidades públicas territoriales (prefecturas y municipios) consolidarán } \\
\text { su proceso de transformación digital para aprovechar las posibilidades que } \\
\text { ofrece el Decreto } 1008 \text { de } 2018 \text { en materia de gobierno digital". }\end{array}$ \\
\hline \multirow[t]{2}{*}{$\begin{array}{l}\text { Trampa de la } \\
\text { vulnerabilidad } \\
\text { social }\end{array}$} & \multirow[t]{2}{*}{$\begin{array}{l}\text { Incluye desarrollo social y humano, } \\
\text { inclusión y cohesión social, equidad, } \\
\text { calidad de la educación y acceso a } \\
\text { los servicios básicos. }\end{array}$} & $\begin{array}{l}\text { - "Ampliar el alcance de la Estrategia de la Plataforma de Gestión 'para Una Vida } \\
\text { Mejor', de modo que trascienda el papel que desempeña en la mitigación de la } \\
\text { pobreza y cumpla una función más amplia que incluya una estrategia destinada } \\
\text { a salir de ella". }\end{array}$ \\
\hline & & $\begin{array}{l}\text { - "Aumentar el número de hogares con servicio de electricidad, en especial en } \\
\text { núcleos rurales". }\end{array}$ \\
\hline \multirow{3}{*}{$\begin{array}{l}\text { Trampa de la } \\
\text { productividad }\end{array}$} & \multirow{3}{*}{$\begin{array}{l}\text { Incluye estabilidad } \\
\text { macroeconómica, crecimiento } \\
\text { y empleo, desarrollo de } \\
\text { infraestructura e inversiones en } \\
\text { ciencia y tecnología. }\end{array}$} & • “Duplicar la tasa de crecimiento con respecto al gobierno actual”. \\
\hline & & $\begin{array}{l}\text { - "Converger paulatinamente hacia un equilibrio entre ingresos y gastos } \\
\text { estructurales a lo largo de los próximos seis a ocho años, con la finalidad de } \\
\text { estabilizar y posteriormente reducir la cuantía de la deuda pública con respecto } \\
\text { al PIB". }\end{array}$ \\
\hline & & • "Mejorar la competitividad de las pymes rurales". \\
\hline
\end{tabular}

Fuente: Elaboración propia.

Después de esto, se calculó la frecuencia de la palabra más repetida en la agenda digital. Se determinó la frecuencia con que aparecían las palabras "computacional", "digital", “digitalización”, "electrónico", “informático", "inteligente”, "Internet”, “online”, "tecnología", "tecnológico", "virtual” y sus derivados (por ejemplo, "digital", "digitales", "digitalizar") con respecto a cada trampa. Por último, se tomó el ratio de dicha frecuencia respecto a la frecuencia de la palabra más repetida para obtener las frecuencias relativas del Gráfico 4.15.

Con respecto al Gráfico 4.16, se analizó cada plan nacional de desarrollo con NVivo. Se asoció una lista de palabras clave con los diversos temas y se calcularon las frecuencias relativas. 
Tabla 4.A1.2. Lista de palabras clave utilizadas en el análisis de texto

\begin{tabular}{|c|c|}
\hline TEMA & PALABRAS CLAVE \\
\hline Acceso y uso & $\begin{array}{l}\text { Acceso a tecnología, acceso a Internet, cobertura de Internet, cobertura web, conexión a Internet, penetración de } \\
\text { Internet, penetración de la tecnología, uso de Internet, uso de tecnología, conectividad, brecha digital }\end{array}$ \\
\hline $\begin{array}{l}\text { Infraestructura } \\
\text { digital }\end{array}$ & $\begin{array}{l}\text { Analógico, antena, electrificación, alámbrico, inalámbrico, microondas, móvil, router, satélite, telecomunicaciones, } \\
\text { telefonía, televisión, transmisión, } 2 \mathrm{G}, 3 \mathrm{G}, 4 \mathrm{G}, 5 \mathrm{G} \text {, alta definición, alta velocidad, ancho de banda, fibra óptica, GPRS, } \\
\text { hardware, infraestructura TIC, datos móviles, MB/s, MHz, wifi }\end{array}$ \\
\hline $\begin{array}{l}\text { Gobierno } \\
\text { digital }\end{array}$ & $\begin{array}{l}\text { Administración electrónica, administración digital, ciberseguridad, ciudad inteligente, adquisiciones y contrataciones } \\
\text { electrónicas, datos abiertos, Estado/gobierno abierto, factura electrónica, gobierno-e; educación por medios } \\
\text { electrónicos, salud por medios electrónicos, gobierno-m, gobierno electrónico, gobierno digital, gobierno online, } \\
\text { gobierno móvil, privacidad de la información, seguridad de la información, seguridad digital }\end{array}$ \\
\hline $\begin{array}{l}\text { Economía } \\
\text { digital }\end{array}$ & $\begin{array}{l}\text { Incubación, incubadora, macrodatos, blockchain, comercio electrónico, comercio digital, comercio por Internet, } \\
\text { comercio-e, pago electrónico, fintech, inteligencia artificial, Internet de las Cosas, industria 4.0, mercado audiovisual, } \\
\text { empresa online, banca abierta, pago online, pago digital, pagar por Internet, plataforma digital, productividad digital, } \\
\text { competencia digital, transferencia tecnológica, servicios digitales, servicios a través de Internet, start-up }\end{array}$ \\
\hline $\begin{array}{l}\text { Futuro del } \\
\text { trabajo }\end{array}$ & $\begin{array}{l}\text { Academia virtual, educación en medios digitales, aprendizaje continuo, automatización, capital digital, competencias } \\
\text { tecnológicas, competencias digitales, conocimientos digitales, co-working, clase digital, formación digital, educación } \\
\text { sobre tecnología, formación digital, innovación tecnológica, I+D, talento digital, teletrabajo, transformación digital, } \\
\text { trabajo digital, trabajo a distancia }\end{array}$ \\
\hline $\begin{array}{l}\text { Integración } \\
\text { regional }\end{array}$ & $\begin{array}{l}\text { Tratado bilateral, tratado de integración, tratado comercial, tratado subregional, tratado plurilateral, arancel común, } \\
\text { comercio bilateral, cooperación internacional, integración fronteriza, integración latinoamericana, integración macro } \\
\text { regional, integración mundial, integración de los países, integración regional, libre circulación/tránsito, libre comercio, } \\
\text { Asociación de Estados del Caribe, Asociación Latinoamericana de Integración, Alianza Bolivariana para los Pueblos } \\
\text { de Nuestra América, Alianza del Pacífico, Comunidad de Estados Latinoamericanos y Caribeños, Comunidad Andina, } \\
\text { Sistema Andino de Integración, Mercado Común Centroamericano, Mercado Común del Sur, Organización de los } \\
\text { Estados Americanos, Organización del Tratado de Cooperación Amazónica, Proyecto de Integración y Desarrollo } \\
\text { de Mesoamérica, Proyecto Mesoamérica, Sistema Económico Latinoamericano y del Caribe, Unión de Naciones } \\
\text { Suramericanas }\end{array}$ \\
\hline
\end{tabular}




\section{Anexo 4.A2. Características del plan nacional de desarrollo}

\section{Tabla 4.A2.1. Características del plan nacional de desarrollo, países seleccionados de América Latina y el Caribe, análisis del plan más reciente}

\begin{tabular}{|c|c|c|c|c|c|}
\hline & Último PND analizado & $\begin{array}{l}\text { Marco } \\
\text { regulatorio }\end{array}$ & Presupuesto & Participación & Autoridad de planificación \\
\hline Argentina & $\begin{array}{l}\text { Objetivos de Gobierno de } \\
\text { Argentina 2015-2019 }\end{array}$ & & & & $\begin{array}{l}\text { Ministerio del Interior, Obras } \\
\text { Públicas y Vivienda (MIOPV) } \\
\text { de la Argentina }\end{array}$ \\
\hline Bolivia & $\begin{array}{l}\text { Plan de Desarrollo Económico y } \\
\text { Social en el marco del } \\
\text { Desarrollo Integral para Vivir Bien } \\
2016-2020\end{array}$ & $\checkmark$ & & $\checkmark$ & $\begin{array}{l}\text { Ministerio de Planificación del } \\
\text { Desarrollo (MPD) de Bolivia }\end{array}$ \\
\hline Brasil & $\begin{array}{l}\text { Plano Plurianual (PPA) "Desenvol- } \\
\text { vimento, produtividade e inclusão } \\
\text { social" 2016-19 }\end{array}$ & $\checkmark$ & $\checkmark$ & $\checkmark$ & $\begin{array}{l}\text { Ministério do Planejamento, } \\
\text { Desenvolvimento e Gestão de } \\
\text { Brasil }\end{array}$ \\
\hline Chile & $\begin{array}{l}\text { Plan de Gobierno "Construyamos } \\
\text { tiempos mejores para Chile" } \\
2018-22\end{array}$ & & & & $\begin{array}{l}\text { Presidencia de la República de } \\
\text { Chile }\end{array}$ \\
\hline Colombia & $\begin{array}{l}\text { Plan Nacional de Desarrollo } \\
\text { "Pacto por Colombia, Pacto por la } \\
\text { equidad" 2018-22 }\end{array}$ & $\checkmark$ & & $\checkmark$ & $\begin{array}{l}\text { Departamento Nacional de } \\
\text { Planeación (DNP) de Colombia }\end{array}$ \\
\hline Costa Rica & $\begin{array}{l}\text { Plan Nacional de Desarrollo y de } \\
\text { Inversion Publica 2019-22 }\end{array}$ & $\checkmark$ & $\checkmark$ & $\checkmark$ & $\begin{array}{l}\text { Ministerio de Planificación y } \\
\text { Política Económica (MIDEPLAN) } \\
\text { de Costa Rica }\end{array}$ \\
\hline $\begin{array}{l}\text { Rep. } \\
\text { Dominicana }\end{array}$ & $\begin{array}{l}\text { Estrategia Nacional de Desarrollo } \\
\text { "Un viaje de transformación hacia } \\
\text { un país mejor" 2010-30 }\end{array}$ & $\checkmark$ & & $\checkmark$ & $\begin{array}{l}\text { Ministerio de Economía, } \\
\text { Planificación y Desarrollo } \\
\text { (MEPyD) de República } \\
\text { Dominicana }\end{array}$ \\
\hline Ecuador & $\begin{array}{l}\text { Plan Nacional de Desarrollo "Toda } \\
\text { una Vida" 2017-21 }\end{array}$ & $\checkmark$ & $\checkmark$ & $\checkmark$ & $\begin{array}{l}\text { Secretaría Nacional de } \\
\text { Planificación y Desarrollo } \\
\text { (SENPLADES) de Ecuador }\end{array}$ \\
\hline El Salvador & $\begin{array}{l}\text { "El Salvador: productivo, educado } \\
\text { y seguro" 2014-19 }\end{array}$ & & $\checkmark$ & & $\begin{array}{l}\text { Secretaría Técnica y de } \\
\text { Planificación (SETEPLAN) de El } \\
\text { Salvador }\end{array}$ \\
\hline Guatemala & $\begin{array}{l}\text { Plan Nacional de Desarrollo: } \\
\text { K'atun Nuestra Guatemala } 2032\end{array}$ & $\checkmark$ & $\checkmark$ & $\checkmark$ & $\begin{array}{l}\text { Secretaría de Planificación y de } \\
\text { Programación de la Presidencia } \\
\text { (SEGEPLAN) de Guatemala }\end{array}$ \\
\hline Honduras & $\begin{array}{l}\text { Plan Estrategico de Gobierno } \\
\text { 2018-22 }\end{array}$ & $\checkmark$ & & $\checkmark$ & $\begin{array}{l}\text { Secretaría de Coordinación } \\
\text { General de Gobierno de Honduras }\end{array}$ \\
\hline México & $\begin{array}{l}\text { Plan Nacional de Desarrollo de } \\
\text { México 2019-24 }\end{array}$ & & & & $\begin{array}{l}\text { Presidencia de los Estados Unidos } \\
\text { Mexicanos }\end{array}$ \\
\hline Panamá & $\begin{array}{l}\text { Plan Estratégico de Gobierno } \\
\text { 2015-19 }\end{array}$ & & & & $\begin{array}{l}\text { Ministerio de Economía y Finanzas } \\
\text { (MEF) de Panamá }\end{array}$ \\
\hline Paraguay & $\begin{array}{l}\text { Plan Nacional de Desarrollo } \\
\text { "Paraguay 2030" }\end{array}$ & $\checkmark$ & & & $\begin{array}{l}\text { Secretaría Técnica de Planificación } \\
\text { del Desarrollo Económico y Social } \\
\text { (STP) del Paraguay }\end{array}$ \\
\hline Perú & $\begin{array}{l}\text { Plan Nacional de Competitividad y } \\
\text { Productividad 2019-30 }\end{array}$ & $\checkmark$ & & $\checkmark$ & $\begin{array}{l}\text { Centro Nacional de Planeamiento } \\
\text { Estratégico (CEPLAN) de Perú }\end{array}$ \\
\hline Uruguay & $\begin{array}{l}\text { Estrategia Nacional de Desarrollo } \\
\text { Uruguay } 2050\end{array}$ & $\checkmark$ & $\checkmark$ & $\checkmark$ & $\begin{array}{l}\text { Oficina de Planeamiento y } \\
\text { Presupuesto (OPP) de Uruguay }\end{array}$ \\
\hline
\end{tabular}

Notas: Cuando se encontraba disponible más de un documento de planificación, se dio prioridad a los planes de gobierno o los planes nacionales de desarrollo por encima de la "visión país" y los planes a largo plazo, por motivos de coherencia. En Argentina, la Presidencia se encarga de formular el Plan de Gobierno, cuyos objetivos se incluirán en el Plan Estratégico Territorial creado por el Ministerio del Interior. En Ecuador, la Secretaría Técnica de Planificación "Planifica Ecuador" sustituyó recientemente a SENPLADES como autoridad de planificación principal. En Perú, el Consejo Nacional de Competitividad y Formalización del Ministerio de Economía y Finanzas formuló el Plan Nacional de Competitividad y Productividad 2019-2030, aunque la autoridad de planificación principal es el Centro Nacional de Planeamiento Estratégico. Obsérvese también que Panamá publicó un nuevo Plan Estratégico de Gobierno 2019-2024 en diciembre de 2019, pero el análisis se basa en el plan anterior.

Fuente: Elaboración propia a partir de información de CEPAL (2020). 


\section{Notas}

1. Este tipo de riesgos se denominan riesgos de "seguridad digital", en línea con la Recomendación y documento complementario de la OCDE sobre Seguridad Digital y Gestión de riesgos para la prosperidad económica y social, que prefiere este término a "ciberseguridad" para evitar la especificidad de "ciber" (OCDE, 2015a).

2. Basado en el artículo 45 del Reglamento UE 2016/679.

3. La encuesta preguntó: “¿Cuál de estas fue la forma PRINCIPAL en la que encontró noticias en la última semana?".

4. La encuesta preguntó: “¿Cuál de los siguientes medios, si alguno, ha utilizado para las noticias en la última semana?". La proporción de personas que utilizan WhatsApp para acceder a noticias fue del 39\% en Argentina, 40\% en Chile y 41\% en México, en comparación con un promedio mundial del $19 \%$.

5. La encuesta preguntó: "WhatsApp te permite configurar grupos, unirte y participar en ellos, donde puedes discutir noticias o temas relacionados con personas de ideas afines. ¿Cuál, si alguno, de los siguientes ha utilizado en el último mes en WhatsApp?".

6. La información se basa en la encuesta de la OCDE / BID sobre políticas regulatorias y gobernanza. Los países de ALC encuestados en 2015-2016 fueron Brasil, Chile, Colombia, Costa Rica, Ecuador, México y Perú. La encuesta de 2019 actualizó esos países e incluyó a Argentina, República Dominicana y El Salvador. Las respuestas fueron proporcionadas por funcionarios gubernamentales y reflejan la situación al 31 de marzo de 2019.

\section{Referencias}

Agesic (2019), "Está abierta una nueva etapa de la consulta pública sobre Inteligencia Artificial para el Gobierno Digital”, Noticias, República Oriental del Uruguay, Montevideo, www.gub.uy/ agencia-gobierno-electronico-sociedad-informacion-conocimiento/comunicacion/noticias/ consulta-publica-inteligencia-artificial-para-el-gobierno-digital.

Allcott, H. y M. Gentzkow (2017), "Social media and fake news in the 2016 election", Journal of Economic Perspectives, Vol. 31, n. ${ }^{\circ}$ 2, American Economic Association, Pittsburgh, pp. 211-236, www.aeaweb.org/articles?id=10.1257/jep.31.2.211.

Barca, V. y R. Chirchir (2014), "Single registries and integrated MISs: De-mystifying data and information management concepts", Social Protection and Growth: Research Synthesis, Department of Social Affairs and Trade, Gobierno de Australia, Canberra, www.opml.co.uk/files/2018-05/ barca-chirchir-2014-data-information-management-social-protection.pdf?noredirect=1.

Barreix, A. y R. Zambrano (2018), Factura Electrónica en América Latina, Banco Interamericano de Desarrollo y CIAT, Washington, DC, http://dx.doi.org/10.18235/0001038.

Barrera, A. y R. Satter (2019), "Hackers demand \$5 million from Mexico's Pemex in cyberattack", Reuters, Reuters, Londres, www.reuters.com/article/us-mexico-pemex/hackers-demand5-million-from-mexicos-pemex-in-cyberattack-idUSKBN1XN03A.

Bastias-Butler, E. y A. Ulrich (2019), “Transformación digital del sector salud en América Latina y el Caribe", IDB Transforming Lives, Banco Interamericano de Desarrollo, Washington, DC, https://publications.iadb.org/en/digital-transformation-health-sector-latin-america-and-caribbean.

Basto-Aguirre, N., P. Cerutti y S. Nieto-Parra (2020), "Is COVID-19 widening educational gaps in Latin America? Three lessons for urgent policy action", blog, OECD Development Matters, https://oecd-development-matters.org/2020/06/04/is-covid-19-widening-educational-gaps-inlatin-america-three-lessons-for-urgent-policy-action.

Bellon, M. et al. (2019), "Digitalization to improve tax compliance: Evidence from VAT e-invoicing in Peru", Documento de trabajo n. $.^{19} / 231$, Fondo Monetario Internacional, Washington, DC, www. imf.org/en/Publications/WP/Issues/2019/11/01/Digitalization-to-Improve-Tax-ComplianceEvidence-from-VAT-e-Invoicing-in-Peru-48672.

Benjamins, V. R. et al. (2017), "Data as a force for good", LUCA White Paper, Telefonica Data Unit, Telefónica, Madrid, https://business.blogthinkbig.com/luca-white-paper-data-as-force-for-good/.

Berger-Wolf, T. et al. (2016), “The Great Grevy's Rally: The need, methods, findings, implications and next steps", Grevy's Zebra Trust, Nairobi, https://lev.cs.rpi.edu/public/papers/parham_ggr report 2016.pdf.

BID/OEA (2020), Ciberseguridad: ¿Estamos preparados en América Latina y el Caribe?, Banco Interamericano de Desarrollo y Organización de Estados Americanos, Washington, DC.

Blyde, J. (2020), "Pandemics: The time has come for Latin America to export telemedicine services", blog, Integration and Trade, Banco Interamericano de Desarrollo, Washington, DC, https://blogs.iadb.org/integration-trade/en/pandemics-latin-america-telemedicine. 
Brito, N. (2017), "Acceso, privacidad y ética pública en la era del big data", de Manual sobre utilidades del big data para bienes públicos, publicaciones de Goberna América Latina y Entinema, Madrid, https://goberna.org/publicaciones/manual-utilidades-del-big-data-bienes-publicos/.

Buenadicha Sánchez, C. et al. (2019), La gestión ética de los datos, Banco Interamericano de Desarrollo, Washington, DC, http://dx.doi.org/10.18235/0001623.

CEPAL (2020), Observatorio Regional de Planificación para el Desarrollo de América Latina y el Caribe (base de datos), Comisión Económica para América Latina y el Caribe e Instituto Latinoamericano y del Caribe de Planificación Económica y Social, Santiago, https://observatorioplanificacion.cepal.org/en/opengov.

CEPAL (2018), Datos, algoritmos y políticas: La redefinición del mundo digital (LC/CMSI.6/4), Santiago, https://repositorio.cepal.org/bitstream/handle/11362/43477/7/S1800053_es.pdf

CEPAL (2016), The New Digital Revolution: From the Consumer Internet to the Industrial Internet, LC/L.4029/ Rev.1, Comisión Económica para América Latina y el Caribe, Santiago, https://repositorio.cepal. org/handle/11362/38767.

Cetina, C. (2020), "Tres preguntas sobre el uso de los datos para luchar contra la corrupción", Informe de políticas n. 9 , Banco de Desarrollo de América Latina, Caracas, https://scioteca.caf. com/handle/123456789/1544.

Chimhowu, A. O., D. Hulme y L. T. Munro (2019), “The 'New' national development planning and global development goals: Processes and partnerships", World Development, Vol. 120, Elsevier, pp. 76-89, https://doi.org/10.1016/j.worlddev.2019.03.013.

Comisión Europea (2020), "Configurar el futuro digital de Europa", A Europe fit for the digital age, Comisión Europea, Bruselas, https://ec.europa.eu/info/strategy/priorities-2019-2024/europefit-digital-age/shaping-europe-digital-future en.

Comisión Europea (2019a), "Adequacy decisions: How the EU determines if a non-EU country has an adequate level of data protection", International dimension of data protection, Comisión Europea, Bruselas, https://ec.europa.eu/info/law/law-topic/data-protection/international-dimensiondata-protection/adequacy-decisions en

Comisión Europea (2019b), "Ethics", Horizon 2020 Online Manual, Comisión Europea, Bruselas, https://ec.europa.eu/research/participants/docs/h2020-funding-guide/cross-cutting-issues/ ethics en.htm.

Comisión Europea (2019c), “Action plan against disinformation: Report on progress”, Comisión Europea, Bruselas, https://ec.europa.eu/commission/sites/beta-political/files/factsheet disinfo_elex_140619_final.pdf.

Comisión Europea (2018), Action Plan against Disinformation: Commission contribution to the European Council, Comisión Europea, Bruselas, https://ec.europa.eu/commission/publications/actionplan-disinformation-commission-contribution-european-council-13-14-december-2018 en.

Datta, A., M. Tschantz y A. Datta (2015), "Automated experiments on ad privacy settings", Proceedings on Privacy Enhancing Technologies, Vol. 2015, Ed. 1, Sciendo, Varsovia, pp. 92-112, https://doi. org/10.1515/popets-2015-0007.

De la Garza, A. (2020), "How social media is shaping our fears of - and response to - the coronavirus", Time, Time US LLC., Nueva York, https://time.com/5802802/social-media-coronavirus/.

Donovan, J. (2020), "Here's how social media can combat the coronavirus 'infodemic'", MIT Technology Review, Massachusetts Institute of Technology, Cambridge, www.technologyreview. $\mathrm{com} / \mathrm{s} / 615368 /$ facebook-twitter-social-media-infodemic-misinformation/.

Frias-Martinez, V. et al. (2019), "Analysis of post-migration mobility and social ties of internal migrants", www.vanessafriasmartinez.org/uploads/netmob2019Behaviors.pdf.

Gallego, J. et al. (próxima publicación), "Estudio para clasificar las ciudades colombianas bajo el concepto de Ciudades Inteligentes - Ciudades 'i'”, Universidad del Rosario, Ministerio TIC Colombia y Findeter, Bogotá.

Gallup (2019), Gallup World Poll (base de datos), Gallup Inc., Washington, DC, www.gallup.com/ analytics/232838/world-poll.aspx.

Guriev, S., N. Melnikov y E. Zhuravskaya (2019), "3G internet and confidence in government”, Discussion Paper, n. ${ }^{\circ}$ 14022, Centre for Economic Policy Research, Londres, https://cepr.org/ active/publications/discussion papers/dp.php?dpno=14022.

Hand, D. J. (2018), "Aspects of data ethics in a changing world: Where are we now?", Big Data, Vol. 6, n. ${ }^{\circ}$ 3, Mary Ann Liebert Inc., New Rochelle, pp. 176-190, http://doi.org/10.1089/big.2018.0083.

Hernández, M. A. et al. (2017), "Estimating poverty using cell phone data: Evidence from Guatemala", Documento de trabajo sobre investigaciones relativas a políticas, n. ${ }^{\circ}$ WPS 7969, Banco Mundial, Washington, DC, http://documents.worldbank.org/curated/en/122541487082260120/ Estimating-poverty-using-cell-phone-data-evidence-from-Guatemala. 
Huichalaf, P. (2017), "Big data en la Administración pública chilena: oportunidades para la gestión de políticas públicas", del Manual sobre utilidades del big data para bienes públicos, publicaciones de Goberna América Latina y Entinema, Madrid, https://goberna.org/publicaciones/manualutilidades-del-big-data-bienes-publicos/.

Isaacman, S., V. Frias-Martinez y E. Frias-Martinez (2018), "Modeling human migration patterns during drought conditions in La Guajira, Colombia", COMPASS '18: Proceedings of the 1st ACM SIGCAS Conference on Computing and Sustainable Societies (junio de 2018), Special Interest Group: Computers and Society, Association for Computing Machinery, Nueva York, pp. 1-9, https://doi. org/10.1145/3209811.3209861.

Izquierdo, A., C. Pessino y G. Vuletin (eds.) (2018), Mejor gasto para mejores vidas: Cómo América Latina y el Caribe puede hacer más con menos, Vol. 10, Banco Interamericano de Desarrollo, Washington, DC, https://flagships.iadb.org/en/DIA2018/Better-Spending-for-Better-Lives.

Katz, R. L. (2009), El papel de las TIC en el desarrollo: Propuesta de América Latina a los retos económicos actuales, Fundación Telefónica, Madrid.

Kahn, T., A. Baron y J. C. Vieyra (2018), “Tecnologías digitales para la transparencia en la inversión pública: Nuevos instrumentos para empoderar a ciudadanos y gobiernos", Documento para discusión n. ${ }^{\circ}$ IDB-DP-634, Banco Interamericano de Desarrollo, Washington, DC, http://dx.doi. org/10.18235/0001418.

Kim, M. (2020), "South Korea is watching quarantined citizens with a smartphone app", MIT Technology Review, Massachusetts Institute of Technology, Cambridge, www.technologyreview. com/s/615329/coronavirus-south-korea-smartphone-app-quarantine/.

Lafortune, G. y B. Ubaldi (2018), “OECD 2017 OURdata Index: Methodology and results”, OECD Working Papers on Public Governance, n. ${ }^{\circ}$ 30, Publicaciones de la OCDE, París, http://doi.org/10.1787/ 2807d3c8-en.

Latinobarómetro (2018), encuesta Latinobarómetro (base de datos), Latinobarómetro, Providencia, www.latinobarometro.org/lat.jsp.

Latinobarómetro (2017), encuesta Latinobarómetro (base de datos), Latinobarómetro, Providencia, www.latinobarometro.org/lat.jsp.

Lauletta, M. et al. (2019), "Monitoreando la inversión pública: El impacto de MapaRegalías en Colombia", Serie de documentos de trabajo del BID IDB-WP-1059, Banco Interamericano de Desarrollo, Washington, DC, http://dx.doi.org/10.18235/0002014.

Lazer, D. et al. (2018), "The science of fake news", Science, Vol. 359, Ed.6380, pp. 1094-1096, https://science.sciencemag.org/content/359/6380/1094.full.

Lehuedé, H. J. (2019), "Corporate governance and data protection in Latin America and the Caribbean", Serie Desarrollo Productivo, n. ${ }^{\circ} 223$, Comisión Económica para América Latina y el Caribe, Santiago, http://hdl.handle.net/11362/44629.

Local Government Association (2014), Transforming Local Public Services Using Technology and Digital Tools and Approaches, Local Government House, Londres, www.local.gov.uk/transforming-publicservices-using-technology-and-digital-tools-and-approaches.

Marwick, A. y R. Lewis (2017), Media Manipulation and Disinformation Online, Data \& Society Research Institute, Nueva York, https://datasociety.net/library/media-manipulation-and-disinfo-online.

Mattar, J. y L. M. Cuervo (2017), "Planificación para el desarrollo en América Latina y el Caribe: enfoques, experiencias y perspectivas”, Libros de la CEPAL, n. 148 (LC/PUB.2017/16-P), Comisión Económica para América Latina y el Caribe, Santiago, www.cepal.org/es/publicaciones/42139planificacion-desarrollo-america-latina-caribe-enfoques-experiencias.

Mazzucato, M. y L. MacFarlane (2018), "Patient finance for innovation-driven growth", Institute for Innovation and Public Purpose Policy Brief (junio de 2018), University College London, Londres, www.ucl.ac.uk/bartlett/public-purpose/sites/public-purpose/files/iipp-pb-01-patientfinance-13-06-18.pdf.

Metcalf, J. y K. Crawford (2016), "Where are human subjects in big data research? The emerging ethics divide”, Big Data \& Society, Primavera 2016, Vol. 3, Ed. 1, https://ssrn.com/abstract=2779647.

Ministerio de Salud de Perú (2018), “Telesalud resulta costo-efectiva para el diagnóstico y tratamiento del cáncer”, Nota de prensa, Gobierno de Perú, Lima, www.gob.pe/institucion/minsa/ noticias/20138-telesalud-resulta-costo-efectiva-para-el-diagnostico-y-tratamiento-del-cancer.

Mittelstadt, B. D. y L. Floridi (2016), "The ethics of big data: Current and foreseeable issues in biomedical contexts", Science and Engineering Ethics, Vol. 22, pp. 303-341, https://doi.org/10.1007/ s11948-015-9652-2.

Montoya, N. et al. (2020), "Using Google data to understand governments' approval in Latin America”, OECD Development Centre Working Papers, n. ${ }^{\circ} 343$, Publicaciones de la OCDE, París, https://doi.org/10.1787/89ed5e8f-en. 
Naser, A., A. Ramírez-Alujas y D. Rosales (eds.) (2017), Desde el gobierno abierto al Estado abierto en América Latina y el Caribe, Libros de la CEPAL, n. ${ }^{144}$, 2017/9-P, Comisión Económica para América Latina y el Caribe, Santiago, https://cpalsocial.org/documentos/371.pdf.

Neudert, L. M. y N. Marchal (2019), "Polarisation and the use of technology in political campaigns and communication", Estudio para el Panel sobre el Futuro de la Ciencia y la Tecnología, Parlamento Europeo, Bruselas, www.europarl.europa.eu/RegData/etudes/STUD/2019/634414/ EPRS_STU(2019)634414_EN.pdf.

Nieto-Parra, S., M. Pezzini y J. Vázquez (2019), "Social discontent in Latin America through the lens of development traps", OECD Development Matters (blog), Publicaciones de la OCDE, París, https://oecd-development-matters.org/2019/12/23/social-discontent-in-latin-america-throughthe-lens-of-development-traps/.

OCDE (próxima publicación), Digital Government in Chile: A Strategy To Improve Public Service Design and Delivery, Publicaciones de la OCDE, París.

OCDE (2020a), "Ensuring data privacy as we battle COVID-19", Key policy responses from the OECD, Publicaciones de la OCDE, París, www.oecd.org/coronavirus/policy-responses/ensuring-dataprivacy-as-we-battle-covid-19-36c2f31e/.

OCDE (2020b), “Tracking and tracing COVID: Protecting privacy and data while using apps and biometrics", Key policy responses from the OECD, Publicaciones de la OCDE, París, www.oecd.org/ coronavirus/policy-responses/tracking-and-tracing-covid-protecting-privacy-and-data-whileusing-apps-and-biometrics-8f394636/.

OCDE (2020c), “Observatorio de Políticas de Inteligencia Artificial de la OCDE”, Nota de política, enero de 2020, Publicaciones de la OCDE, París.

OCDE (2020d), OECD.AI Policy Observatory, febrero de 2020, Publicaciones de la OCDE, París, https://oecd.ai/policy-areas.

OCDE (2020e), "Combatting COVID-19 disinformation on online platforms", OECD Policy Responses to Coronavirus (COVID-19), www.oecd.org/coronavirus/policy-responses/combatting-covid-19disinformation-on-online-platforms-d854ec48/.

OCDE (2020f), Panorama de las administraciones públicas: América Latina y el Caribe 2020, Publicaciones de la OCDE, París, https://doi.org/10.1787/13130fbb-en.

OCDE (2020g), DeuCom - Red de Comunicación del Centro de Desarrollo de la OCDE, Publicaciones de la OCDE, París, www.oecd.org/dev/pgd/devcom.htm.

OCDE (2020h), Country Policy Tracker (base de datos), https://oecd.github.io/OECD-covid-action-map/.

OCDE (2020i), "COVID-19 in Latin America and the Caribbean: Regional socio-economic implications and policy priorities", Publicaciones de la OCDE, París, www.oecd.org/coronavirus/ policy-responses/covid-19-in-latin-america-and-the-caribbean-regional-socio-economicimplications-and-policy-priorities-93a64fde/.

OCDE (2019a), Tax Morale: What Drives People and Businesses to Pay Tax?, Publicaciones de la OCDE, París, https://doi.org/10.1787/f3d8ea10-en.

OCDE (2019b), The Path to Becoming a Data-Driven Public Sector, OECD Digital Government Studies, Publicaciones de la OCDE, París, https://doi.org/10.1787/059814a7-en.

OCDE (2019c), Perfilando la transformación digital en América Latina: Mayor productividad para una vida mejor, Publicaciones de la OCDE, París, https://doi.org/10.1787/8bb3c9f1-en.

OCDE (2019d), OECD Reviews of Digital Transformation: Going Digital in Colombia, Publicaciones de la OCDE, París, https://doi.org/10.1787/781185b1-en.

OCDE (2019e), Enhancing Access to and Sharing of Data: Reconciling Risks and Benefits for Data Re-use across Societies, Publicaciones de la OCDE, París, https://doi.org/10.1787/276aaca8-en.

OCDE (2019f), Artificial Intelligence in Society, Publicaciones de la OCDE, París, https://doi.org/10.1787/ eedfee77-en.

OCDE (2019g), How's Life in the Digital Age?: Opportunities and Risks of the Digital Transformation for People's Well-being, Publicaciones de la OCDE, París, https://doi.org/10.1787/9789264311800-en.

OCDE (2019h), "Strengthening digital government", Nota de política de la OCDE sobre Going Digital, Publicaciones de la OCDE, París, www.oecd.org/going-digital/strengthening-digitalgovernment.pdf.

OCDE (2019i), Cómo medir la transformación digital: Hoja de ruta para el futuro, Publicaciones de la OCDE, París, https://doi.org/10.1787/9789264311992-en.

OCDE (2019j), Digital Government Review of Panama: Enhancing the Digital Transformation of the Public Sector, OECD Digital Government Studies, Publicaciones de la OCDE, París, https://doi. org/10.1787/615a4180-en. 
OCDE (2019k), Tax Administration 2019: Comparative Information on OECD and other Advanced and Emerging Economies, Publicaciones de la OCDE, París, https://doi.org/10.1787/74d162b6-en.

OCDE (2019l), "Using digital technologies to improve the design and enforcement of public policies", OECD Digital Economy Papers, n. 274, Publicaciones de la OCDE, París, www.oecdilibrary.org/science-and-technology/using-digital-technologies-to-improve-the-design-andenforcement-of-public-policies_99b9ba70-en.

OCDE (2019m), Enhancing the Contribution of Digitalisation to the Smart Cities of the Future, Centro de Emprendimiento, pymes, regiones y ciudades de la OCDE, Publicaciones de la OCDE, París, www.oecd.org/cfe/regional-policy/Smart-Cities-FINAL.pdf.

OCDE (2019n), Digital Government in Peru: Working Closely with Citizens, OECD Digital Government Studies, Publicaciones de la OCDE, París, https://doi.org/10.1787/0c1eb85b-en.

OCDE (2019o), Going Digital: Shaping Policies, Improving Lives, Publicaciones de la OCDE, París.

OCDE (2018), Digital Government Review of Brazil: Towards the Digital Transformation of the Public Sector, OECD Digital Government Studies, Publicaciones de la OCDE, París, https://doi. org/10.1787/9789264307636-en.

OCDE (2017a), OECD Telecommunication and Broadcasting Review of Mexico 2017, Publicaciones de la OCDE, París, https://doi.org/10.1787/9789264278011-en.

OCDE (2017b), Development Co-operation Report 2017: Data for Development, Publicaciones de la OCDE, París, http://dx.doi.org/10.1787/D.C.r-2017-en.

OCDE (2017c), Creating a Citizen-Driven Environment through Good ICT Governance - The Digital Transformation of the Public Sector: Helping Governments Respond to the Needs of Networked Societies, Publicaciones de la OCDE, París.

OCDE (2017d), Innovar en el sector público: Desarrollando capacidades en Chile, Estudios de la OCDE sobre Gobernanza Pública, Publicaciones de la OCDE, París, https://doi.org/10.1787/ 9789264273283-en.

OCDE (2017e), Perspectivas de la OCDE sobre la Economía Digital 2017, Publicaciones de la OCDE, París, https://doi.org/10.1787/9789264276284-en.

OCDE (2016a), "Research ethics and new forms of data for social and economic research", OECD Science, Technology and Industry Policy Papers, n. ${ }^{\circ}$ 34, Publicaciones de la OCDE, París, https://doi. org/10.1787/5jln7vnpxs32-en.

OCDE (2016b), Panorama de las Administraciones Públicas: América Latina y el Caribe 2017, Publicaciones de la OCDE, París, http://dx.doi.org/10.1787/9789264265554-en.

OCDE (2015a), Digital Security Risk Management for Economic and Social Prosperity: OECD Recommendation and Companion Document, Publicaciones de la OCDE, París, https://doi.org/10.1787/9789264245471en.

OCDE (2015b), La educación a distancia en la educación superior en América Latina, Estudios del Centro de Desarrollo, Publicaciones de la OCDE, París, https://doi.org/10.1787/9789264209992-en.

OCDE (2014a), The Governance of Regulators, OECD Best Practice Principles for Regulatory Policy, Publicaciones de la OCDE, París, https://doi.org/10.1787/9789264209015-en.

OCDE (2014b), Estudio de la OCDE sobre políticas y regulación de telecomunicaciones en Colombia, Publicaciones de la OCDE, París, https://doi.org/10.1787/9789264208131-en.

OCDE (2014c), "Recommendation of the Council on Digital Government Strategies", Publicaciones de la OCDE, París, www.oecd.org/gov/digital-government/Recommendation-digital-governmentstrategies.pdf.

OCDE (2013a), The OECD Privacy Framework, Directrices sobre protección de la privacidad y flujos transfronterizos de datos personales, Publicaciones de la OCDE, París, www.oecd.org/sti/ ieconomy/oecd privacy framework.pdf.

OCDE (2013b), "Exploring the economics of personal data: A survey of methodologies for measuring monetary value", OECD Digital Economy Papers, n. ${ }^{\circ} 220$, Publicaciones de la OCDE, París, http://dx.doi.org/10.1787/5k486qtxldmq-en.

OCDE (2012), Estudio de la OCDE sobre políticas y regulación de telecomunicaciones en México, Publicaciones de la OCDE, París, https://doi.org/10.1787/9789264060111-en.

OCDE (2003), "Broadband driving growth: Policy responses", OECD Digital Economy Papers, n. ${ }^{\circ} 75$, Publicaciones de la OCDE, París, https://doi.org/10.1787/232838768555.

OCDE/BID (2016), Políticas de banda ancha para América Latina y el Caribe: Un manual para la economía digital, Publicaciones de la OCDE, París, https://doi.org/10.1787/9789264251823-en.

OCDE/CAF/CEPAL (2018), Perspectivas económicas de América Latina 2018: Repensando las instituciones para el desarrollo, Publicaciones de la OCDE, París, https://doi.org/10.1787/leo-2018-en. 
OCDE et al. (2019), Perspectivas Económicas de América Latina 2019: Desarrollo en transición, Publicaciones de la OCDE, París, https://doi.org/10.1787/g2g9ff18-en.

OMS (2020), Go.Data: Managing Complex Data in Outbreaks, Organización Mundial de la Salud, Ginebra, www.who.int/godata.

ONU (2020a), “308 Covid-19 - preguntas frecuentes en tiempos de cuarentena”, Radio Voces Unidas, Naciones Unidas, Colombia, https://vocesunidas.unic.org.co/producciones/programas/covid19-preguntas-frecuentes-en-tiempos-de-cuarentena/.

ONU (2020b), Verified, sitio web, Naciones Unidas, www.shareverified.com/en.

ONU (2019), UN e-Government Knowledge Database (base de datos), Departamento de Asuntos Económicos y Sociales de Naciones Unidas, Nueva York, https://publicadministration.un.org/ egovkb/en-us/Data-Center.

Ortiz, I. (2018), "GovTech: Cuando emprendedores y gobiernos se unen para mejorar la vida a los ciudadanos", BID Gobernarte (blog), Banco Interamericano de Desarrollo, Washington, DC, https://blogs.iadb.org/administracion-publica/es/govtech-cuando-emprendedores-ygobiernos-se-unen-para-mejorar-la-vida-a-los-ciudadanos/.

PNUD (2019), Informe sobre Desarrollo Humano 2019: Más allá del ingreso, más allá de los promedios, más allá del presente: Desigualdades del desarrollo humano en el siglo XXI, Programa de las Naciones Unidas para el Desarrollo, Nueva York, www.hdr.undp.org/sites/default/files/hdr2019.pdf.

Pombo, C., R. Gupta y M. Stankovic (2018), Servicios sociales para ciudadanos digitales: Oportunidades para América Latina y el Caribe, Banco Interamericano de Desarrollo, Washington, DC, http://dx.doi.org/10.18235/0001105.

Pring, C. y J. Vrushi (2019), Global Corruption Barometer, Latin America and the Caribbean 2019: Citizens' Views and Experiences of Corruption, Transparency International, Berlín, www.transparency.org/ gcb10/latin-america-and-the-caribbean?/news/feature/global_corruption_barometer_gcb_ latin_america_2019\#full-report.

Quintanilla, M. (2017), “Aspectos a tener en cuenta a nivel organizativo”, del Manual sobre utilidades del big data para bienes públicos, publicaciones de Goberna América Latina y Entinema, Madrid, https://goberna.org/publicaciones/manual-utilidades-del-big-data-bienes-publicos/.

Ramírez Álvarez, J., N. Oliva y M. Andino (2018), “Facturación electrónica en Ecuador: Evaluación de impacto en el cumplimiento tributario", Documento de debate IDB-DP-563, Banco Interamericano de Desarrollo, Washington, DC, https://publications.iadb.org/publications/spanish/document/ Facturaci\%C3\%B3n-electr\%C3\%B3nica-en-Ecuador-Evaluaci\%C3\%B3n-de-impacto-en-elcumplimiento-tributario.pdf.

República de Colombia (2019), "Política nacional para la transformación digital e inteligencia artificial”, CONPES 3975, Consejo Nacional de Política Económica y Social, Departamento Nacional de Planeación, Gobierno de la República de Colombia, Bogotá, https://colaboracion. dnp.gov.co/CDT/Conpes/Econ\%C3\%B3micos/3975.pdf.

Reuters Institute for the Study of Journalism (2019), Digital News Report 2019, Reuters Institute for the Study of Journalism, Oxford, https://reutersinstitute.politics.ox.ac.uk/sites/default/files/ inline-files/DNR 2019 FINAL.pdf.

Roseth, B., A. Reyes y C. Santiso (2018), El fin del trámite eterno: ciudadanos, burocracia y gobierno digital (Resumen ejecutivo), Banco Interamericano de Desarrollo, Washington, DC, https://publications. iadb.org/en/wait-no-more-citizens-red-tape-and-digital-government-executive-summary.

Santiso, C. (2019), “The GovTech Latin America needs”, Project Syndicate, www.project-syndicate.org/ commentary/govtech-entrepreneurship-in-latin-america-by-carlos-santiso-1-2019-02?barrier =accesspaylog.

Santiso, C. (2018), “El 'big data' al asalto de la corrupción”, BID Gobernarte (blog), Banco Interamericano de Desarrollo, Washington, DC, https://blogs.iadb.org/administracion-publica/ es/el-big-data-al-asalto-de-la-corrupcion/.

Santiso, C. (2017), "Going digital: Restoring trust in government in Latin American cities", www.oecd-forum.org/users/80160-carlos-santiso/posts/29680-going-digital-restoring-trustin-government-in-latin-american-cities.

Santiso, C. y B. Roseth (2017), "Cómo los datos pueden ayudar a destapar la corrupción", BID Gobernarte (blog), Banco Interamericano de Desarrollo, Washington, DC, https://blogs.iadb. org/administracion-publica/es/los-datos-ayudan-destapar-la-corrupcion/.

Socías, M. (2017), "La revolución del big data en el sector privado y sus implicaciones para el sector público", del Manual sobre utilidades del big data para bienes públicos, publicaciones de Goberna América Latina y Entinema, Madrid, https://goberna.org/publicaciones/manual-utilidades-delbig-data-bienes-publicos/. 
Tucker, J. et al. (2018), Social Media, Political Polarization, and Political Disinformation: A Review of the Scientific Literature, elaborado para The Hewlett Foundation, https://eprints.lse.ac.uk/87402/1/ Social-Media-Political-Polarization-and-Political-Disinformation-Literature-Review.pdf.

Twitter (2019), “Twitter transparency report: Platform manipulation”, Twitter Inc., San Francisco https://transparency.twitter.com/en/platform-manipulation.html.

UIT(2019), Índice mundial de ciberseguridad (base de datos), Unión Internacional de Telecomunicaciones, Ginebra, www.itu.int/en/ITU-D/Cybersecurity/Pages/global-cybersecurity-index.aspx.

Van Ooijen, C., B. Ubaldi y B. Welby (2019), "A data-driven public sector: Enabling the strategic use of data for productive, inclusive and trustworthy governance", Documento de trabajo de la OCDE sobre Gobernanza Pública, n. ${ }^{\circ}$ 33, Publicaciones de la OCDE, París, https://doi.org/10.1787/09ab162c-en.

Vosoughi, S., D. Roy y S. Aral (2018), “The spread of true and false news online”, Science, Vol. 359, Ed. 6380, American Association for the Advancement of Science, Washington, DC, pp. 1146-1151, https://science.sciencemag.org/content/359/6380/1146.

Wardle, C. y H. Derakhshan (2017), Information Disorder: Toward an Interdisciplinary Framework for Research and Policy Making, Council of Europe report DGI (2017)09, Consejo de Europa, Estrasburgo, https://firstdraftnews.org/wp-content/uploads/2017/11/PREMS-162317-GBR-2018-Reportde\%CC\%81sinformation-1.pdf?x29719.

Yañez-Pagans, P. y R. Sánchez (2019), “Una muestra de cómo los Big Data ayudan al transporte en nuestra región", BID Invest (blog), Banco Interamericano de Desarrollo, Washington, DC, https://blogs.iadb.org/bidinvest/en/big-data-transportation-in-latin-america-caribbean-wazeidb-invest/.

Zapata et al. (2020), The GouTech Index 2020: Unlocking the Potential of GouTech Ecosystems in Latin America, Spain and Portugal, Andean Development Corporation (CAF), Oxford Insights, Caracas, http://scioteca.caf.com/handle/123456789/1580.

Zapata, E. y N. Gerbasi (2019a), "Govtech y el futuro del gobierno: el caso de Visor Urbano en México", Informe de políticas, n. ${ }^{\circ}$ 2, Corporación Andina de Desarrollo, Caracas, http://scioteca. caf.com/handle/123456789/1485.

Zapata, E. y N. Gerbasi (2019b), "Govtech y el futuro del gobierno: el caso de MuniDigital® en Argentina”, Informe de políticas, n. 1 , Corporación Andina de Fomento, Caracas, http://scioteca. caf.com/handle/123456789/1484. 


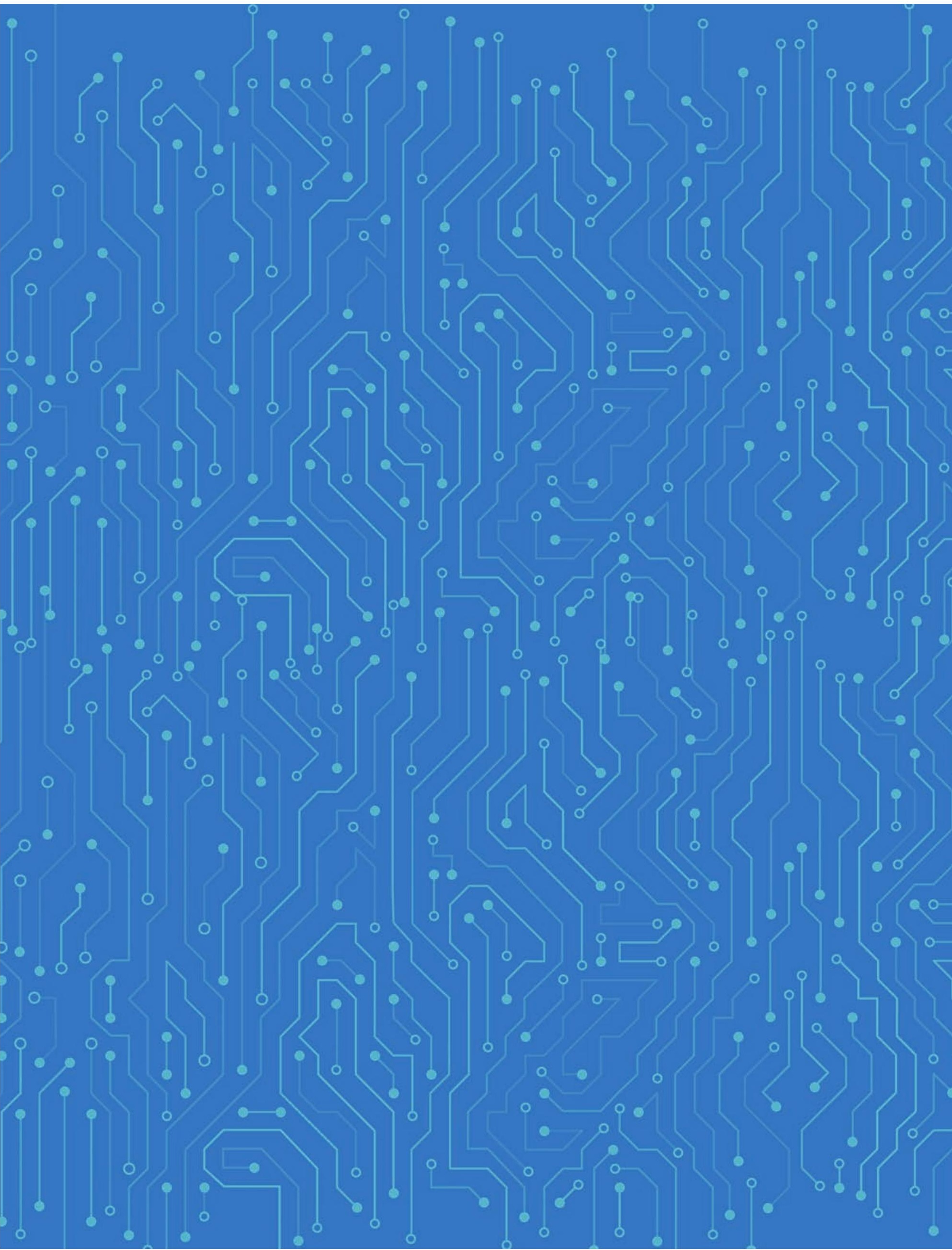




\section{Capítulo 5}

\section{El papel de la cooperación internacional en la era digital}

Dado que la digitalización genera oportunidades y desafíos que trascienden las fronteras, la cooperación internacional es una dimensión clave para aprovechar al máximo la transformación digital en el ámbito local, nacional e internacional. En este capítulo se describe cómo la adopción de un modelo renovado de cooperación internacional puede ayudar a los países de América Latina y el Caribe a aprovechar la transformación digital para promover su desarrollo sostenible. En primer lugar, se examina cómo la cooperación digital ha ayudado a los países de América Latina y el Caribe a desarrollar sus capacidades internas para superar los desafíos de las trampas del desarrollo, promoviendo así un enfoque multidimensional de desarrollo y armonizando las prioridades nacionales e internacionales. Posteriormente, se analiza cómo la creación de un mercado digital regional puede ayudar a ALC a capitalizar su potencial digital, mediante la armonización de estrategias, la articulación de todos los niveles de desarrollo digital y la participación de múltiples actores en un diálogo regional de políticas sobre temáticas digitales. Para ello, los países de la región pueden basarse en experiencias internacionales como la estrategia digital de la Unión Europea. Por último, los países latinoamericanos también pueden aprovechar su plena participación en iniciativas multilaterales para abordar los desafíos derivados de la digitalización, en particular los desafíos fiscales que surgen en torno a la digitalización de la economía. 


\section{El papel de la cooperación internacional}

\section{3 formas de facilitar la transformación digital de ALC para una mayor inclusión:}

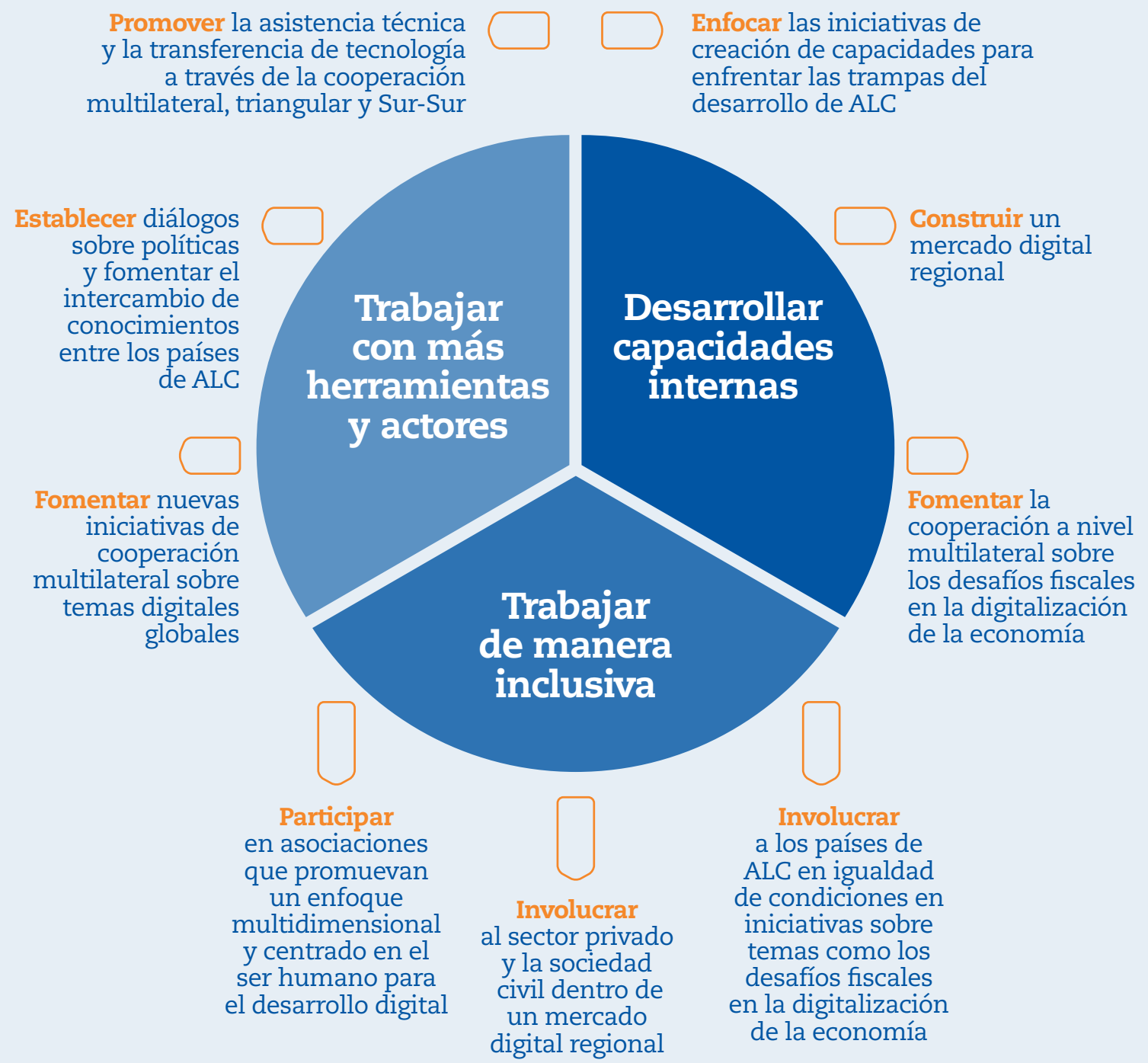




\section{Introducción}

La transformación digital, junto con la adopción de reformas estructurales, podría desempeñar un papel importante en la superación de las trampas del desarrollo que enfrenta América Latina y el Caribe. Las herramientas digitales pueden dotar a los Estados de nuevas capacidades y hacerlos más creíbles, inclusivos, eficientes e innovadores. La transformación digital puede permitir a las empresas ser más productivas, con una mayor integración y un aumento de la competitividad. Puede mejorar la calidad de vida al permitir a los ciudadanos trabajar, estudiar o recibir atención médica a través de Internet. Pero también entraña riesgos para el desarrollo inclusivo, como se ha mencionado en capítulos anteriores, como dinámicas en las que "el ganador se lo lleva todo", el aumento de disparidades entre países y dentro de ellos, la ampliación de las brechas digitales, la automatización de los trabajos y problemas de seguridad y privacidad.

La crisis del coronavirus (Covid-19) ha amplificado los beneficios y los obstáculos de la transformación digital en América Latina y el Caribe. La pandemia y las consiguientes medidas de contención han visibilizado el papel cada vez más importante de las nuevas tecnologías. Estas han permitido que parte de la población trabaje o estudie y acceda a información actualizada y servicios públicos, cumpliendo a la vez con el distanciamiento social. El Internet, las plataformas digitales y el comercio electrónico han permitido a algunos sectores socioeconómicos mantener sus actividades.

Las tecnologías digitales pueden desempeñar un papel importante en la recuperación así como en enfrentar los desafíos persistentes a los que se enfrenta la región. Pueden facilitar nuevas conexiones entre la oferta y la demanda, las operaciones comerciales y la adecuación de las competencias a los puestos de trabajo. Pueden modernizar las industrias tradicionales y crear nuevas. Las medidas de contención del coronavirus (Covid-19) han puesto de relieve la necesidad de ampliar la inclusión digital, a fin de garantizar que la transformación digital beneficie a todos. A pesar de que la conectividad ha mejorado, solo aquellos ciudadanos con una adecuada infraestructura y competencias pueden aprovechar las ventajas de las herramientas tecnológicas para trabajar, estudiar o acceder a bienes y servicios. Los Estados han tenido que balancear el uso de las herramientas digitales para preservar la salud pública con los riesgos que podrían plantear para la privacidad y la seguridad.

Para aprovechar al máximo la transformación digital en el contexto de la crisis actual, es más importante que nunca potenciar la cooperación internacional y establecer nuevas alianzas. En el informe Perspectivas Económicas de América Latina 2019: Desarrollo en Transición se instaba a la adopción de un modelo renovado en el que la cooperación internacional actuara como facilitadora del desarrollo en los países de América Latina y el Caribe, respaldando sus estrategias para superar las trampas del desarrollo (OCDE et al., 2019). Dado el impacto ampliamente transversal de las herramientas digitales, la adopción de un modelo renovado de cooperación, con una amplia red de socios que incluya al sector privado y a la sociedad civil y que se centre en la transformación digital de la región de América Latina y el Caribe, podría apoyar a los países a superar las trampas del desarrollo. En efecto, la cooperación internacional puede ayudar a los países latinoamericanos a navegar en el contexto mundial contribuyendo a la productividad, la cohesión social, la mejora de las instituciones y las economías verdes, adoptando un enfoque de diseño y aplicación de la tecnología "centrado en las personas", que dé prioridad a las necesidades y derechos de los ciudadanos.

Las alianzas digitales deberían desempeñar un papel esencial, que respalde las prioridades temáticas de la región, como la conectividad, las competencias digitales, 
la digitalización de las administraciones públicas, el emprendimiento y la creación de empleo (Comisión Europea, 2020a). Algunos países de América Latina y el Caribe y de otras regiones han aplicado buenas prácticas en materia de tecnología de la información y las comunicaciones (TIC). Los países de ALC pueden utilizar algunos de estos ejemplos de cooperación en el ámbito digital para fomentar el desarrollo.

La crisis del coronavirus (Covid-19) ha puesto de manifiesto la necesidad de aumentar la coordinación de los esfuerzos internacionales, tanto para explotar los beneficios de la era digital como para gestionar sus posibles escollos. Estos esfuerzos deberían formar parte de un papel más amplio de la cooperación internacional. Nunca se insistirá lo suficiente en la necesidad de dar una respuesta global a los efectos inmediatos y a corto y mediano plazo de la crisis del coronavirus (Covid-19). La comunidad internacional debe centrarse en tres ámbitos de cooperación: apoyo financiero, respuestas coordinadas y cooperación e integración regionales (OCDE, 2020a).

El presente capítulo comienza analizando por qué se necesita un nuevo modelo de cooperación internacional en iniciativas digitales para fomentar el desarrollo en América Latina y el Caribe. Ofrece ejemplos de cómo dicha cooperación en el sector digital puede ayudar a ALC a crear capacidades digitales nacionales para hacer frente a las cuatro trampas del desarrollo de la forma más eficiente. Se analizan los beneficios derivados de crear un mercado digital regional, lo cual incluye una integración regional más profunda, a la vista del estado de la digitalización en ALC, al tiempo que destaca qué aspectos podría aprender ALC al observar y cooperar con otras regiones en el desarrollo digital, en particular con la Unión Europea (UE). Por último, en el capítulo se analiza cómo la cooperación multilateral en materia de impuestos digitales podría ayudar a los países latinoamericanos a aprovechar mejor la transformación digital.

\section{Facilitar el desarrollo de América Latina y el Caribe mediante un modelo renovado de cooperación internacional}

Los desafíos que plantea la transformación digital exigen la coordinación de políticas innovadoras a escala internacional. La pandemia ha acelerado la necesidad de esas respuestas, sobre todo en América Latina y el Caribe, donde la cooperación internacional en materia de políticas digitales podría desempeñar un papel esencial para superar las trampas del desarrollo. Para ello, la cooperación internacional con la región debería adoptar un modelo renovado, con iniciativas digitales coordinadas a escala internacional para facilitar el desarrollo de la región.

La transformación digital de las economías y sociedades trae consigo nuevas oportunidades y desafíos que complejizan el contexto mundial y aumentan la necesidad de políticas coordinadas a nivel internacional. Por ejemplo, ha generado oportunidades comerciales transfronterizas, pero también conflictos comerciales entre países. A pesar de la actividad económica que contribuyen a crear, las empresas digitales plantean problemas tributarios que no pueden abordarse únicamente a escala nacional. La transformación digital también ha creado cuestiones en el ámbito de las políticas internacionales en relación con el acceso a las herramientas digitales, la ciberseguridad, la privacidad y la protección de los datos y la propiedad intelectual, las noticias falsas, el futuro del trabajo, la inteligencia artificial (IA) y la automatización de la producción.

En América Latina y el Caribe, la cooperación internacional en cuestiones digitales podría ayudar a resolver desafíos persistentes. En el informe Perspectivas económicas de América Latina 2019 se identificaron cuatro trampas del desarrollo en la región (baja productividad, vulnerabilidad social, debilidades institucionales y riesgos 
ambientales) (OCDE et al., 2019). La pandemia ha intensificado la necesidad de hacer frente a estos desafíos.

Muchos países de América Latina y el Caribe se adentraron en la crisis del Covid-19 con un margen fiscal reducido; se necesitarán recursos adicionales para gestionar los impactos socioeconómicos y aquellos relacionados con la salud. A medida que se dispararon las interacciones digitales durante la crisis, también se intensificaron las amenazas a la ciberseguridad, y los Estados deben cooperar para proteger a los ciudadanos frente a los riesgos externos. Si bien la pandemia ha acelerado la adopción de las tecnologías digitales en algunos países de ALC - permitiendo que algunos ciudadanos y empresas siguieran trabajando, estudiando y operando- esta situación podría también amplificar las brechas de productividad (ver el Capítulo 2) y la vulnerabilidad social, y muchos ciudadanos de la región podrían estar en riesgo de volver a caer en la pobreza (ver el Capítulo 3), erosionando aún más la confianza en las instituciones (ver el Capítulo 4). La adopción de una mayor cooperación internacional en el sector digital podría ser esencial para superar los desafíos interrelacionados de la región. Podría ayudar a las economías a ser más competitivas, diversificar la matriz productiva, asegurar que la transformación digital beneficie a todos los ciudadanos y promover Estados más fiables, eficientes, inclusivos e innovadores. También es importante que los países en la región aprovechen la cooperación internacional para cerrar las brechas digitales de ingresos, urbano-rural y de género.

La crisis del coronavirus (Covid-19) ha hecho más evidente la creciente conexión entre los desafíos nacionales y mundiales, en particular en el ámbito digital, que ha cobrado mayor importancia durante la pandemia. Dado que ya existen diversas iniciativas de cooperación cuyo objetivo es aprovechar la transformación digital para generar resultados positivos, será fundamental basarse en ellas para establecer un nuevo modelo de cooperación internacional que pueda facilitar el desarrollo de los países de ALC, tal y como se señala en el informe Perspectivas económicas de América Latina 2019 (OCDE et al., 2019).

Existen distintas iniciativas que promueven la implantación de nuevos modelos de cooperación internacional en el sector digital. La adopción de un marco renovado de cooperación internacional debería beneficiarse de los marcos regionales actuales, como la Comisión Económica para América Latina y el Caribe (CEPAL) y la Agenda Digital para América Latina y el Caribe (eLAC2020), y aprovechar una mayor cooperación y transmisión de conocimientos con otras regiones en función de sus logros (CEPAL, 2018a). Por ejemplo, la estrategia del mercado único digital de la Comisión Europea ha dado lugar a beneficios compartidos por los Estados miembros (Comisión Europea, 2019a). El Reglamento General de Protección de Datos de la UE (RGPD) se considera un paso adelante en los esfuerzos por abordar la privacidad en Internet. El desarrollo de la cooperación al tiempo que se profundiza en estos logros podría generar oportunidades para compartir las lecciones de las políticas nacionales y regionales que hayan cosechado un mayor éxito y ayudar así a los países de América Latina y el Caribe a aprovechar al máximo la transformación digital.

En el plano multilateral, la arquitectura mundial de la cooperación digital no ha aumentado necesariamente su eficacia, a pesar de ser cada vez más compleja. El Panel de Alto Nivel sobre la Cooperación Digital de las Naciones Unidas (ONU) está trabajando en nuevos modelos de cooperación digital a escala mundial, así como en aspectos como la conectividad, la inclusión digital, los bienes públicos digitales, los derechos humanos digitales y la creación de capacidades. El objetivo de la ONU es servir como plataforma para establecer un diálogo de políticas entre diversos grupos de interés en el ámbito de las tecnologías emergentes, para lo cual el secretario general de la ONU nombrará un enviado para la Tecnología en 2021 (Naciones Unidas, 2020). 
En este contexto, la adopción de tres componentes principales e interrelacionados en el marco de un nuevo modelo de cooperación internacional puede contribuir al desarrollo sostenible en América Latina y el Caribe y en los países en desarrollo en general. Dicho modelo promueve: 1) procesos de desarrollo impulsados a escala nacional mediante el fortalecimiento de las capacidades institucionales; 2 ) plataformas inclusivas de gobernanza multilateral para facilitar un intercambio en igualdad de condiciones; y 3) la inclusión de nuevas herramientas y actores en el marco de los instrumentos para coordinar las políticas a escala internacional (OCDE et al., 2019). Estas recomendaciones podrían tener aplicaciones en el sector digital.

Este modelo de cooperación internacional puede ayudar a alinear las prioridades nacionales e internacionales en el mundo digital. Con independencia de que sean bilaterales, regionales, interregionales o multilaterales, algunas iniciativas permitirán, por ejemplo, que los países de América Latina y el Caribe construyan, refuercen o redefinan los ecosistemas digitales que les ayudarán a superar las trampas del desarrollo. Dado que muchos de los problemas de desarrollo están interrelacionados, las iniciativas internacionales más eficaces contribuyen a crear capacidades en relación con varias trampas a la vez (ver la sección "Mejorar las capacidades nacionales mediante la cooperación internacional" y el Anexo 5.A1). Establecer un mercado digital regional también podría ayudar a los países de ALC a utilizar su potencial digital para su transición hacia un desarrollo más sostenible (ver la sección "Aprovechar el potencial digital de América Latina y el Caribe mediante la integración regional”). En el plano multilateral, la cooperación en cuestiones clave de política mundial, como la tributación digital internacional, podría proporcionar recursos adicionales para el desarrollo sostenible de los países de ALC (ver la sección "Afrontar los desafíos mundiales que plantea la digitalización de la economía mediante el multilateralismo"). Estas iniciativas ayudan a los países de la región a diseñar sus propias trayectorias de desarrollo y responder así a las prioridades nacionales al tiempo que avanzan en objetivos internacionales, como los Objetivos de Desarrollo Sostenible (ODS) de Naciones Unidas.

Este modelo renovado aborda la gobernanza de los marcos internacionales y la necesidad de que estos incluyan a países en todos los niveles de desarrollo en igualdad de condiciones, así como a múltiples grupos de interés, para elaborar estrategias de cooperación que aborden el carácter multidimensional del desarrollo. En el caso del sector digital de América Latina y el Caribe, esto implicar crear plataformas de cooperación multilateral en las que todos los países puedan participar en diálogos inclusivos y productivos para compartir experiencias, conocimientos e intercambios sobre políticas, así como directrices y normas internacionales. En ese sentido, será importante que los países de la región interactúen en el marco de alianzas con actores que promuevan un enfoque del desarrollo multidimensional o centrado en las personas a través de la cooperación digital (véanse las secciones "Mejorar las capacidades nacionales mediante la cooperación internacional", el Anexo 5.A1 y "Explorar el potencial de la cooperación regional y las alianzas interregionales"). Esto podría realizarse a escala regional: dentro del mercado digital de la región, los países de ALC podrían articular los diferentes niveles de desarrollo digital e incluir a diversos grupos de interés para compartir experiencias en aspectos digitales (ver la sección "Aprovechar el potencial digital de América Latina y el Caribe mediante la integración regional"). A escala multilateral, también es fundamental incluir las opiniones de los países de la región en los marcos de cooperación sobre temas digitales globales como la tributación digital (ver la sección "Afrontar los desafíos mundiales que plantea la digitalización de la economía mediante el multilateralismo"). 
Tabla 5.1. Facilitar el desarrollo de América Latina y el Caribe mediante una cooperación internacional renovada en el sector digital

\begin{tabular}{|c|c|c|}
\hline Dimensiones & Descripción & Aplicación a la cooperación digital \\
\hline $\begin{array}{l}\text { Desarrollar } \\
\text { capacidades } \\
\text { nacionales }\end{array}$ & $\begin{array}{l}\text { Fortalecer las capacidades de los países } \\
\text { para elaborar, poner en marcha y } \\
\text { evaluar sus propios planes y prioridades } \\
\text { de política en materia de desarrollo, } \\
\text { fomentar la armonización de las } \\
\text { prioridades nacionales e internacionales } \\
\text { y procurar enfoques integrados para los } \\
\text { retos más complejos e interconectados. }\end{array}$ & $\begin{array}{l}\text { - Fomentar iniciativas que desarrollen la capacidad de los países de ALC } \\
\text { para superar varias de las trampas del desarrollo. } \\
\text { - Crear un mercado digital regional para aprovechar el potencial digital de ALC. } \\
\text { - Fomentar la cooperación a escala multilateral en aspectos como la } \\
\text { tributación digital, por ejemplo, mediante el Marco Inclusivo sobre BEPS } \\
\text { de la OCDE, que actualmente cuenta con } 137 \text { miembros, entre los que se } \\
\text { encuentran la mayoría de los países de América Latina. }\end{array}$ \\
\hline $\begin{array}{l}\text { Trabajar } \\
\text { de manera } \\
\text { incluyente }\end{array}$ & $\begin{array}{l}\text { Involucrar a países de todos los niveles } \\
\text { de desarrollo en igualdad de condiciones, } \\
\text { como pares, para desarrollar y participar } \\
\text { en alianzas multilaterales y multiactores, } \\
\text { con el fin de afrontar retos de desarrollo } \\
\text { con respuestas multidimensionales. }\end{array}$ & $\begin{array}{l}\text { - Participar en alianzas que promuevan un enfoque multidimensional y } \\
\text { centrado en las personas con relación al desarrollo digital de ALC. } \\
\text { - Articular todos los niveles de desarrollo digital y potenciar la participación } \\
\text { de múltiples grupos de interés, como el sector privado y la sociedad civil, } \\
\text { en el mercado digital regional de ALC. } \\
\text { - Potenciar la participación de los países de ALC en igualdad de condiciones } \\
\text { en las iniciativas multilaterales y con múltiples grupos de interés en } \\
\text { aspectos como la tributación digital. }\end{array}$ \\
\hline $\begin{array}{l}\text { Operar } \\
\text { con más } \\
\text { herramientas } \\
\text { y actores }\end{array}$ & $\begin{array}{l}\text { Ampliar los instrumentos para una mayor } \\
\text { cooperación internacional, incluyendo } \\
\text { el intercambio de conocimientos, } \\
\text { diálogos de políticas públicas, desarrollo } \\
\text { de capacidades y transferencias de } \\
\text { tecnología, e incorporar a más actores, } \\
\text { incluso públicos, en un enfoque de } \\
\text { "gobierno completo". }\end{array}$ & $\begin{array}{l}\text { - Promover la asistencia técnica y la transferencia de tecnología mediante la } \\
\text { cooperación bilateral, multilateral, interregional, triangular y Sur-Sur para } \\
\text { el desarrollo de las capacidades digitales de ALC. } \\
\text { - Establecer diálogos sobre políticas y fomentar el intercambio de } \\
\text { conocimientos y la creación de capacidad entre los países de ALC dentro } \\
\text { de un mercado digital regional. } \\
\text { - Fomentar las nuevas iniciativas de cooperación multilateral en el ámbito de } \\
\text { las principales cuestiones digitales mundiales. }\end{array}$ \\
\hline
\end{tabular}

Fuente: OCDE et al. (2019), Perspectivas económicas de América Latina 2019: Desarrollo en transición, Publicaciones de la OCDE, París, https://doi.org/10.1787/g2g9ff1a-es.

Este modelo también aboga por incluir más herramientas y actores a la hora de elegir los instrumentos y agentes de cooperación internacional. Para ello será necesario, por ejemplo, establecer plataformas de intercambio de conocimientos, insistir en las transferencias de tecnología y en la creación de capacidad, o adoptar un enfoque de gobierno completo al incluir a actores públicos. Los países de América Latina y el Caribe pueden participar en iniciativas bilaterales, multilaterales, triangulares y de cooperación Sur-Sur que establezcan transferencias de tecnología o asistencia técnica para desarrollar sus capacidades digitales (ver las secciones "Mejorar las capacidades nacionales mediante la cooperación internacional" y el Anexo 5.A1). Un mercado digital regional también podría servir de plataforma para establecer diálogos sobre políticas, creación de capacidad e intercambio de conocimientos entre los países de ALC (ver la sección "Aprovechar el potencial digital de América Latina y el Caribe mediante la integración regional"). En el plano multilateral, esos mecanismos renovados podrían formar parte de iniciativas de cooperación basadas en cuestiones de interés internacional (ver la sección "Afrontar los desafíos mundiales que plantea la digitalización de la economía mediante el multilateralismo").

\section{Mejorar las capacidades nacionales mediante la cooperación internacional}

Existen ejemplos de cómo las iniciativas de cooperación internacional en el sector digital han generado resultados positivos para los países de América Latina y el Caribe. En particular, estas iniciativas pueden contribuir a aumentar las capacidades nacionales para abordar las trampas de desarrollo de productividad, vulnerabilidad social, institucional y ambiental (ver el Anexo 5.A1).

Sin embargo, limitar el impacto de diferentes casos a una de las cuatro trampas implicaría simplificar tanto el carácter multidimensional del desarrollo como el efecto 
de la cooperación internacional. En efecto, teniendo en cuenta que existen interacciones importantes entre las trampas al desarrollo, es importante resaltar que algunas iniciativas pueden contribuir a superar más de una de las trampas. Al mismo tiempo, puede haber efectos contradictorios. Por ejemplo, la digitalización del empleo puede mejorar la productividad (trampa de la productividad) y acentuar las desigualdades, ya que los trabajadores menos calificados podrían quedarse atrás (trampa de la vulnerabilidad social). Las transformaciones del mercado laboral también pueden representar un desafío para los servicios estatales, ya que los actuales regímenes de seguridad social podrían ser inadecuados para dar respuesta a las nuevas condiciones laborales (trampa institucional).

Cada vez resultan más pertinentes las herramientas analíticas y las respuestas coordinadas en materia de políticas que se centran en cómo las trampas del desarrollo interactúan y se refuerzan entre sí. Es fundamental comprender mejor los vínculos y las causalidades comunes que existen entre los asuntos y los objetivos de las políticas para elaborar respuestas eficaces. Igualmente, es esencial identificar políticas beneficiosas para todos que promuevan sinergias y aborden los pros y los contras. El nexo inclusiónproductividad, por ejemplo, sugiere numerosos vínculos entre esos objetivos y exige políticas que impulsen ambos simultáneamente (OCDE et al., 2019).

Al ayudar a los países de América Latina y el Caribe a hacer frente a la complejidad de sus problemas de desarrollo, las iniciativas de cooperación internacional podrían contribuir a tender los puentes necesarios entre las prioridades nacionales e internacionales de la región. Los ejemplos existentes en el sector digital podrían ayudar a plasmar las directrices en resultados concretos. Están surgiendo alianzas internacionales que abordan eficazmente la complejidad de los problemas de desarrollo de ALC: por ejemplo, el programa BELLA (Building the Europe Link with Latin America), que es una asociación digital estratégica de 12 años de duración establecida entre Brasil y la Unión Europea; el Centro de Tecnologías Ambientales (CTA) de Perú; y las oportunidades de cooperación Sur-Sur a través de la Iniciativa "Digital Belt and Road" (BRI) de la República Popular China (en adelante "China").

El programa BELLA tiene por objeto atender las necesidades de interconexión a largo plazo de las comunidades de investigación y educación de Europa y América Latina mediante la construcción de un cable submarino de fibra óptica entre las regiones. Este programa también apoya el despliegue de conexiones seguras de alta velocidad entre los países de América Latina. Esta iniciativa está cofinanciada por la Unión Europea y América Latina, con una importante contribución del sector privado. Aprovecha y refuerza la cooperación entre las comunidades de investigación y educación de las regiones (ver el Anexo 5.A1) (BELLA, 2019).

La mejora de la infraestructura de telecomunicaciones de América Latina y el Caribe, así como su conexión con otras regiones, es un ejemplo de cómo la cooperación internacional puede aportar estrategias que ayuden a la región a gestionar la transformación digital, abriendo posibilidades para su mercado digital, mejorando las perspectivas de productividad y fomentando la innovación y el crecimiento económico basado en el conocimiento. El programa BELLA también utilizará las herramientas digitales para apoyar la educación y la investigación, fortaleciendo a los ciudadanos de la región frente a la trampa de la vulnerabilidad social. Los enfoques multidimensionales con respecto a la cooperación internacional en el sector digital pueden ayudar a ALC a utilizar la transformación digital para hacer frente a varias trampas del desarrollo.

Asimismo, las iniciativas de cooperación bilateral también pueden ser eficaces. Desde 2008, Brasil y la Unión Europea han puesto en marcha una Asociación para la Cooperación Científica y Tecnológica, desarrollada a través de una serie de convocatorias para la investigación e innovación conjuntas (Comisión Europea, 2008). Gracias a las amplias consultas establecidas entre expertos y grupos de interés, esta colaboración ha 
generado 20 proyectos de investigación por un total de 50 millones de euros. Los ámbitos de cooperación, entre los que se incluyen la industria manufacturera, la ordenación de los recursos hídricos y la agricultura, así como la salud y el bienestar de las poblaciones en peligro, reflejan las prioridades de Brasil en la era digital y se mejoran constantemente reajustando sus efectos. Esta iniciativa aprovecha la transformación digital de la economía para ayudar a Brasil a crear capacidades para afrontar las trampas de la productividad, la vulnerabilidad social y el medioambiente. Al establecer un diálogo de políticas sobre temas con ramificaciones en diversas esferas - como la digitalización- las alianzas internacionales pueden poner en marcha iniciativas que aborden de forma eficaz el carácter multidimensional del desarrollo.

Esta iniciativa de cooperación ha tenido un impacto estructural más amplio al conectar las prioridades nacionales con los desafíos internacionales. Gracias a la cooperación en ámbitos como la 5G, el Internet de las cosas y la computación en la nube, a través de proyectos lanzados en 2018 en el marco del programa Horizonte 2020 de la UE, Brasil se ha unido a la Unión Europea en debates internacionales sobre el desarrollo de la 5G y el Internet de las Cosas, firmando además una declaración conjunta (Comisión Europea, 2016). Posteriormente se formalizaron acuerdos entre grupos de interés del sector industrial de la Unión Europea y Brasil, entre ellos, Telebrasil, 5GPP, la IoT Chamber y la AIOTI (Alianza para la innovación en el Internet de las Cosas). Esta fructífera cooperación sigue siendo importante para definir las prioridades digitales de Brasil, como la estrategia 5G del país o su plan en el ámbito del Internet de las Cosas: según Maximiliano Martinhão, exviceministro de Ciencia, Tecnología, Información y Comunicaciones, la cooperación con la Unión Europea desempeñó un papel clave en la remodelación del enfoque de Brasil en materia de investigación e innovación, armonizándolo con las mejores prácticas de las organizaciones internacionales, como la OCDE (Anexo 5.A1) (Ministério da Ciência, Tecnologia, Inovações e Comunicações, 2017).

Otras modalidades de cooperación internacional, como la cooperación triangular, también pueden tener un impacto positivo en las capacidades de América Latina y el Caribe. Para cumplir las nuevas regulaciones y criterios ambientales peruanos impuestos a los exportadores por los mercados internacionales, importantes ramas de la industria peruana necesitaban urgentemente expertos en tecnología ambiental, en particular en servicios de asesoramiento y de laboratorio. Entre 2012 y 2014, Brasil y Alemania cooperaron con Perú para crear el Centro de Tecnologías Ambientales (CTA) (2012-2014), que ofrecía capacitación adaptada a las necesidades del mercado. La adopción de un modelo renovado de cooperación internacional que incluya nuevas herramientas - como la cooperación triangular, el diálogo sobre lecciones aprendidas, la creación de capacidad y el intercambio de conocimientos- puede ayudar a aprovechar las TIC para desarrollar las capacidades de América Latina y el Caribe (Anexo 5.A1) (GIZ, 2014).

Aunque se trate de un marco de cooperación más reciente y con menor información disponible sobre los resultados, la iniciativa "Belt and Road" (BRI) muestra cómo la cooperación Sur-Sur puede desempeñar un papel clave en la provisión de infraestructuras a los países en desarrollo para el futuro de las TIC, al tiempo que aborda sus problemas de desarrollo. A través de la iniciativa BRI, China está liderando uno de los planes de desarrollo más ambiciosos de la historia. Aproximadamente un billón de dólares será destinado a inversiones en infraestructuras a lo largo de diez años (desde 2017) y se mejorará la conectividad en toda Eurasia, África y cerca de 100 países asociados, estableciendo así nuevas formas de cooperación a través del intercambio técnico entre países del Sur Global (OCDE, 2018a).

El componente de TIC de este marco de cooperación Sur-Sur, conocido como el "Digital Belt and Road" o la Ruta de la Seda Digital, podría promover un desarrollo sostenible 
en las economías emergentes mediante modernas infraestructuras de TIC, como redes 5G, plataformas internacionales de comercio electrónico, centros de datos y ciudades inteligentes, satélites, cables submarinos de Internet, macrodatos y redes de fibra óptica en todos los países y regiones. Hasta agosto de 2019 , las entidades chinas habían invertido más de 17.000 millones de dólares en proyectos de la Ruta de la Seda Digital completados desde 2013 (Anexo 5.A1) (Merics, 2019).

Aunque los datos sobre los resultados estimados son limitados, se espera que esta iniciativa permita a los países en desarrollo entrar en mercados internacionales y en nuevos mercados de alto valor agregado, al tiempo que se avanza hacia el logro de los ODS.

\section{Aprovechar el potencial digital de América Latina y el Caribe mediante la integración regional}

Para materializar el potencial de la transformación digital, los países de América Latina y el Caribe deben actualizar sus infraestructuras de comunicación y promover un mercado digital regional. Para superar estos obstáculos es necesario mejorar y armonizar las iniciativas de cooperación regional.

\section{Estado de la digitalización en América Latina y el Caribe y beneficios de reforzar el mercado digital regional}

América Latina y el Caribe es un mercado digital de grandes dimensiones. Sin embargo, a pesar de la mejora registrada en los últimos años, los niveles de penetración del Internet siguen siendo bajos en comparación con la OCDE y la Unión Europea (ver el Capítulo 2). América Latina y el Caribe cuenta con 600 millones de consumidores en comparación con los algo más de 500 millones de la Unión Europea. Sin embargo, el comercio electrónico representaba el 3\% del comercio minorista total en 2016, y el porcentaje de usuarios de Internet era del 56.4\% de la población total, y en 2018 ese porcentaje estaba cerca del $68 \%$ del total de la población, comparado con más del 84\% en la OCDE (ver el Capítulo 2). Aunque la red $3 \mathrm{G}$ cubre las poblaciones de ALC de manera uniforme, la cobertura de la red 4 G varía desde el $20 \%$ en Honduras hasta casi el 90\% en Chile (CEPAL, 2018b).

El mercado digital regional podría ser clave para que los países de América Latina y el Caribe cierren las brechas regionales e intrarregionales (ver los capítulos 2, 3 y 4 para los análisis de las brechas) y aprovechen todo su potencial digital (CEPAL, 2016). Podría ser especialmente relevante para los ámbitos prioritarios de la región como de desarrollo de infraestructura, la conectividad y los servicios y contenidos digitales (Cullen International SA, 2019). Un mercado digital regional podría facilitar la expansión de las infraestructuras y ayudar a América Latina y el Caribe en su transición hacia un desarrollo más sostenible e inclusivo (Cullen I., 2016; CEPAL, 2018b). El sector de las TIC podría conseguir mayores economías de escala, mayor competencia (beneficiando en última instancia a los consumidores) y mayores perspectivas de crecimiento. El aumento de la competencia es fundamental para regular los precios, promover la innovación y mejorar la capacidad de respuesta a la demanda (OCDE/BID, 2016). La mejora de la interconexión regional ayudaría a reducir los costos para los usuarios finales y a incrementar las velocidades de transmisión de datos. Asimismo, un mercado regional haría posible un mayor acceso a bienes y servicios por Internet (Cullen International SA, 2019).

La creación de un mercado digital regional también podría ayudar a América Latina y el Caribe a proporcionar un mejor acceso a los bienes y servicios a través de Internet, lo que podría contribuir a la recuperación del comercio intrarregional tras la crisis del coronavirus (Covid-19). Sin embargo, el elevado número de ciudadanos en ALC que no tienen acceso a servicios bancarios es un obstáculo importante para el desarrollo del 
comercio electrónico (Cullen International SA, 2019). Otros de los obstáculos existentes son la falta de confianza en la protección del consumidor o en la logística de entregas (CEPAL, 2018b) y, según el índice de comercio electrónico B2C de la Conferencia de las Naciones Unidas sobre Comercio y Desarrollo, la insuficiente penetración de Internet (UNCTAD, 2016). Un mercado regional podría promover la ejecución electrónica de pagos, contratos y firmas - soluciones que podrían adaptarse a la elevada penetración de la banda ancha móvil en la región y compensar la falta de métodos de pago tradicionales-para desarrollar el comercio electrónico. Para tal fin, los países de ALC deberán cooperar para fomentar directrices y herramientas comunes que aumenten la confianza y la protección. La región también carece de marcos comunes y armonizados en el ámbito de la ciberseguridad, protección de datos y privacidad, así como derechos de autor y piratería por Internet.

\section{Un mercado digital regional requiere una cooperación más integrada entre los países de ALC}

Para crear un mercado digital regional se debe mejorar la cooperación entre los países de la región aprovechando las plataformas existentes.

\section{Obstáculos para un mercado digital regional}

Los esfuerzos por aprovechar la transformación digital de la economía deberán considerar la posibilidad de establecer una regulación común. La existencia de normas comunes es un aspecto clave de las iniciativas de cooperación internacional en el sector digital, tal y como ilustran varias iniciativas de regulación digital establecidas en la UE, por ejemplo, el Reglamento General de Protección de Datos (RGPD) y el Reglamento para la libre circulación de datos no personales. Los debates internacionales en curso también demuestran la necesidad de regular la transformación digital. Las Naciones Unidas han realizado diversos esfuerzos de cooperación con miras a la regulación, la normalización o el diálogo internacional sobre unos principios comunes en materia de ciberseguridad y propiedad intelectual. ${ }^{1}$ La cooperación en términos de regulación puede contribuir a la expansión de la economía digital, como lo ilustra el impacto que los estándares de la Organización Internacional para la Estandarización (ISO) han tenido en el uso y diseminación de los medios digitales (OCDE/ISO, 2016).

Las organizaciones regionales y subregionales están estudiando la regulación del mercado digital y las formas de mejorar la conectividad, las infraestructuras y el acceso a bienes y servicios por Internet. Existen diversas asociaciones, alianzas o foros de cooperación regionales y subregionales de América Latina y el Caribe que están aplicando varios planes simultáneos para desarrollar la economía digital de la región. De hecho, hasta ahora varias iniciativas de cooperación Sur-Sur y triangular han contribuido a fortalecer las capacidades digitales de los países de ALC mediante la innovación. Estas iniciativas se implantaron en la región iberoamericana entre 2007 y 2017 (Cuadro 5.1).

\section{Recuadro 5.1. Innovación para el desarrollo en Iberoamérica mediante la cooperación Sur-Sur y triangular}

En el espacio iberoamericano se han promovido proyectos de innovación, sobre todo a través de medidas y proyectos de cooperación Sur-Sur y triangular. Según los datos recogidos en la plataforma digital de cooperación Sur-Sur y triangular, entre 2007 y 2017, los países iberoamericanos participaron en un total de 8.208 iniciativas, de las cuales más del 10\% (840) conllevaron el intercambio de conocimientos y experiencias con un claro componente de innovación (Gráfico 5.1). 


\section{Recuadro 5.1. Innovación para el desarrollo en Iberoamérica mediante la cooperación Sur-Sur y triangular (cont.)}

De las 840 iniciativas de cooperación Sur-Sur y triangular, el $30 \%$ se dedica a la innovación y el desarrollo (255), tiene un claro componente científico-tecnológico y persigue una aplicación que genera valor económico. Otro $10.8 \%$ está vinculado al sector de las comunicaciones y responde a un claro patrón de adaptación a las transformaciones impuestas por la era digital. Sin embargo, es interesante observar que casi 6 de cada 10 de estas 840 iniciativas provienen de sectores relacionados con la innovación desde un enfoque más amplio y transversal. Este ha sido un rasgo distintivo de la cooperación Sur-Sur y triangular durante más de una década en la región iberoamericana.

\section{Gráfico 5.1. Iniciativas de cooperación Sur-Sur y triangular que promueven la innovación, por sector}

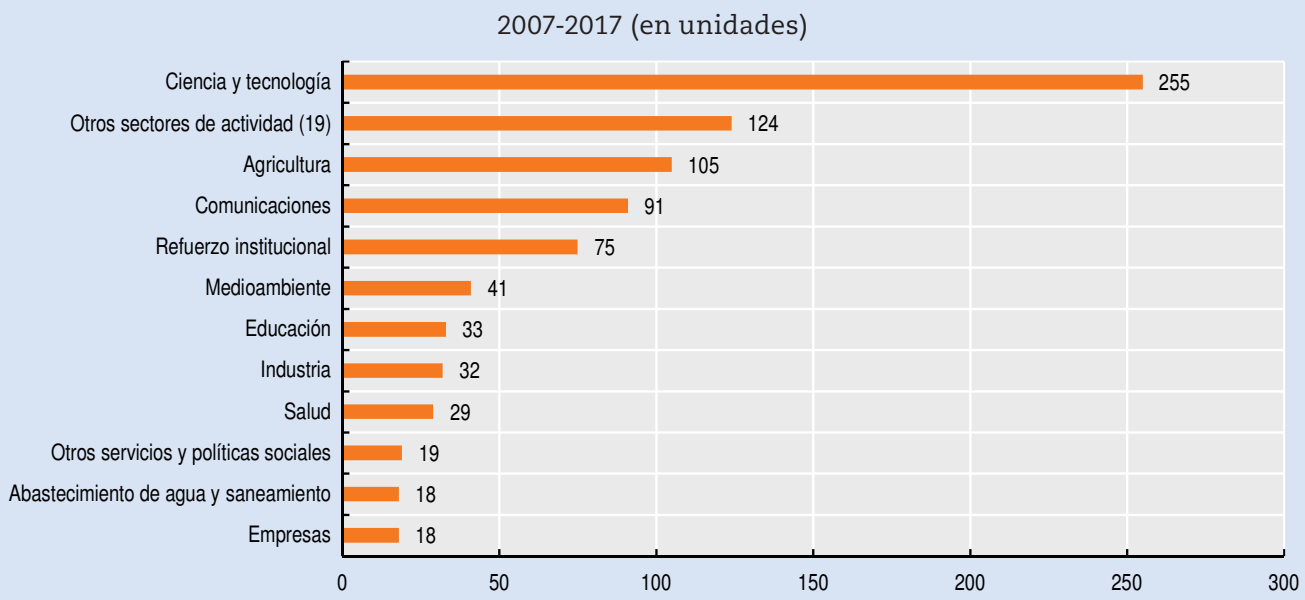

Fuente: Elaboración propia de la Secretaría General Iberoamericana (SEGIB) a partir del Sistema Integrado de Datos de Iberoamérica sobre Cooperación Sur-Sur y Triangular (SIDICSS).

StatLink ainsts https://doi.org/10.1787/888934202921

Cabe destacar, por ejemplo, que más de 100 iniciativas contribuyen al desarrollo sostenible mediante la adopción de nuevas técnicas, modelos de gestión o procesos que permiten la transformación del sector agrícola para mejorar sus niveles de productividad, pero también para adaptarlos a los desafíos que plantea el cambio climático y la mayor frecuencia de los fenómenos meteorológicos extremos. Asimismo, el 8.9\% corresponde a innovaciones que fortalecen las instituciones y las políticas públicas a través de la digitalización de la administración, gobierno electrónico y la implantación de sistemas de información y macrodatos. Otros procesos de innovación actúan sobre el medioambiente (el 5\% de las iniciativas), principalmente a partir de la adopción de tecnologías y herramientas de mitigación y adaptación al cambio climático.

Por último, cabe señalar que algunas iniciativas contribuyen a modernizar el sector industrial (5\%); otras se sitúan en el ámbito de la educación (mediante la adopción de nuevos enfoques de aprendizaje), salud (nuevos tratamientos, telemedicina y avances en biotecnología), abastecimiento de agua y saneamiento (nuevas técnicas de tratamiento de agua y su gestión). Además, algunas iniciativas están relacionadas con otros servicios y políticas sociales (transferencias de estrategias, modelos y programas que transforman la realidad social). 


\section{Recuadro 5.1. Innovación para el desarrollo en Iberoamérica mediante la cooperación Sur-Sur y triangular (cont.)}

Las evidencias sistematizadas a lo largo de los años muestran que la cooperación Sur-Sur y triangular constituyen potentes herramientas para promover la innovación a través del intercambio de conocimientos adaptados al contexto local y, por tanto, son más eficaces y eficientes, no solo dentro de la región iberoamericana sino también con otras regiones. En este marco, la SEGIB y la Unión Europea han establecido una alianza estratégica para fortalecer un modelo innovador de cooperación triangular en el marco del Desarrollo en Transición. La innovación, entendida en su concepto más amplio, es sin duda un elemento clave para el logro de la Agenda 2030 para el Desarrollo Sostenible, promovida por la Cumbre Iberoamericana de Jefes de Estado y de Gobierno, bajo el lema "Innovación para el desarrollo sostenible". En este sentido, el concepto de innovación va más allá de lo estrictamente científico y tecnológico y entiende la innovación como "todo cambio (no necesariamente tecnológico) basado en el conocimiento (no necesariamente científico) que genera valor (no solo económico)" (SEGIB, 2020).

Fuente: Secretaría General Iberoamericana (2020).

Una cooperación integrada a través de las plataformas existentes podría ayudar a América Latina y el Caribe a superar obstáculos

La idea de crear un mercado digital regional surgió en la Conferencia Ministerial de la CEPAL sobre la Sociedad de la Información de 2015, convirtiéndose en una prioridad estratégica de la Agenda Digital para América Latina y el Caribe (eLAC2020). Los países de ALC acordaron las medidas y apartados dedicados a este objetivo. Concretamente, este objetivo estratégico exige la elaboración de una estrategia regional para potenciar el comercio, ampliar la economía digital y fortalecer la competitividad mediante la coherencia regulatoria, la integración de las infraestructuras y el desarrollo de plataformas digitales, facilitar los flujos de datos transfronterizos y medidas de facilitación del comercio (CEPAL, 2018a).

La idea, inspirada en el Mercado Único Digital de la UE, ha calado a nivel subregional. La Alianza del Pacífico tiene su propia agenda digital, que incluye la implantación de una plataforma regional para el mercado digital, y que tiene como referencia los acuerdos de la eLAC2020 (Alianza del Pacífico, 2016). De manera similar, en Centroamérica, los países del Programa Mesoamérica, ${ }^{2}$ en colaboración con la Comisión Técnica Regional de Telecomunicaciones (COMTELCA) del Sistema de Integración Centroamericana (SICA), ${ }^{3}$ están iniciando actividades para establecer una agenda digital regional con aspiraciones similares a las de la Alianza del Pacífico. La Comunidad del Caribe (CARICOM) ha venido promoviendo el proyecto Espacio Único de las TIC. La estrategia constituye el brazo digital de la economía de mercado único de la CARICOM y tiene por objeto posibilitar un espacio de TIC sin fronteras que fomente la integración económica, social y cultural. Comprende políticas, legislación, regulaciones, normas técnicas, mejores prácticas, redes y servicios en el ámbito de las TIC armonizados a nivel regional.

Otros mecanismos de cooperación regional o subregional, como la Cooperación Económica Asia Pacífico (APEC), la Organización de los Estados Americanos (OEA), el Mercado Común del Sur (Mercosur) y el Acuerdo Transpacífico de Cooperación Económica (TPP), han adoptado planes y agendas de desarrollo digital o han incluido medidas que promueven el desarrollo del sector digital de América Latina y el Caribe (Cullen International SA, 2019). 
No todos los países de ALC participan en los mismos tratados u organizaciones, con la excepción de la CEPAL y la OEA, y no todas las medidas se aplican a todos los países. Como resultado de ello, a pesar de tener objetivos y áreas de trabajo comunes, existe una fragmentación de medidas y una superposición de esfuerzos (Cullen I., 2016), lo cual socava los posibles beneficios para el sector digital de la región.

Una cooperación más integrada a través de las plataformas existentes podría ayudar a América Latina y el Caribe a superar estos desafíos. Para armonizar las iniciativas existentes de cooperación digital, los países de ALC podrían basarse en plataformas de cooperación regional, como la Agenda Digital para América Latina y el Caribe (eLAC) o la Comisión Interamericana de Telecomunicaciones (CITEL) de la OEA. Una mayor integración podría promover la adopción de un modelo renovado de cooperación internacional.

Aunque América Latina y el Caribe no cuente con un marco institucional único para la adopción de normas y estándares, la eLAC es una plataforma clave para definir principios y prioridades comunes para el sector digital. Una característica importante de la eLAC es que reúne a 23 países de América Latina y el Caribe, así como a representantes del sector privado, la sociedad civil y la comunidad técnica, para cooperar en cuestiones relacionadas con la transformación digital. La eLAC2020 fue aprobada en abril de 2018 en el marco de la sexta Conferencia Ministerial sobre la Sociedad de la Información en América Latina y el Caribe. En ella se establecen 54 actividades de cooperación, que serán llevadas a cabo por 9 grupos de trabajo, dirigidas a objetivos estratégicos en diversos ámbitos: conectividad e infraestructuras de comunicación; economía digital; gobierno digital; competencias digitales y un entorno habilitador; y mercado digital regional (CEPAL, 2018a) (Gráfico 5.2).

\section{Gráfico 5.2. Áreas de acción de la Agenda Digital para América Latina y el Caribe}

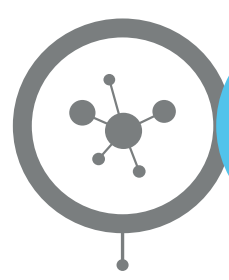

Infraestructura de Transformación telecomunicaciones

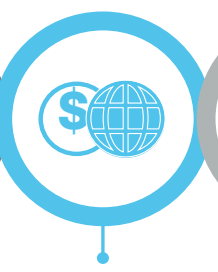

digital y economía digital

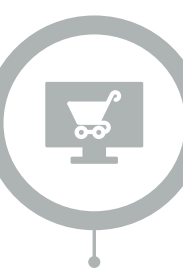

Mercado digital regional

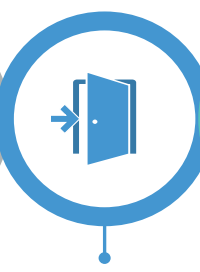

Gobierno digital

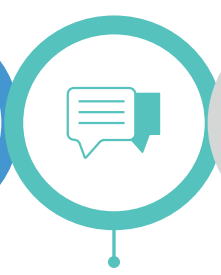

Cultura, inclusión y competencias digitales

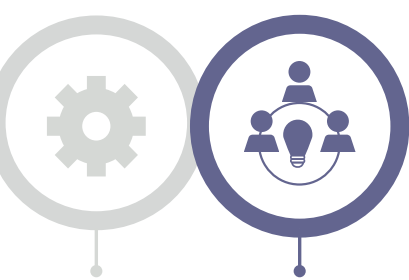
Tecnologías $\quad \begin{gathered}\text { Gobernanza } \\ \text { emergentes }\end{gathered}$ para la sociedad para de la información el desarrollo sostenible

Fuente: CEPAL (2018a), Agenda Digital para América Latina y el Caribe (eLAC2020).

En la eLAC2020 se insta a los países a que fomenten la elaboración e implantación de planes de banda ancha con objetivos mensurables para el despliegue de redes de alta capacidad. Los países también han acordado cooperar en la expansión de la penetración de Internet, especialmente a través de puntos de intercambio de Internet y el despliegue de la versión 6 del Protocolo de Internet. La eLAC2020 invita a los países y a las asociaciones del sector privado, como la Asociación Interamericana de Empresas de Telecomunicaciones y la GSMA, a participar en este diálogo y a proponer un marco regulatorio para la convergencia y políticas públicas para el desarrollo de la infraestructura de comunicación en la región (CEPAL, 2018a).

Para respaldar la economía digital, los gobiernos han acordado potenciar el uso de las tecnologías digitales en las empresas, centrándose en las pymes, y promover ecosistemas de emprendimiento y el teletrabajo. Se ha definido una lista de indicadores básicos armonizados para la industria de la información y la tecnología. Los países de América 
Latina y el Caribe también cooperarán en cuestiones relacionadas con el gobierno digital, como la adopción de normas regionales para la interoperabilidad y la gestión de servicios digitales, como la identidad digital, la provisión electrónica de firmas, apostillas e historiales médicos. En el marco de la red de gobierno electrónico de ALC, se ha propuesto un programa para elaborar y aplicar un marco para examinar y armonizar las condiciones técnicas para el reconocimiento transfronterizo de la firma electrónica (CEPAL, 2018a).

El uso de las tecnologías emergentes, la promoción del diseño de políticas públicas apoyadas en la innovación basada en evidencia y el fortalecimiento de entidades encargadas de diseñar, aplicar y supervisar las políticas digitales constituyen otro ámbito de trabajo. Los objetivos de la eLAC promueven un enfoque de gobernanza digital centrado en las personas, por ejemplo, mediante la integración de una perspectiva de igualdad de género en las políticas digitales y la salvaguardia de la información pública y la libertad de expresión. La eLAC2020 reconoce la necesidad de promover el desarrollo y la incorporación de las competencias digitales y el pensamiento computacional en la educación (CEPAL, 2018a). Dado que la eLAC abarca toda la región, podría ser la plataforma de cooperación indicada para armonizar y consolidar las iniciativas regionales y subregionales en el ámbito digital. Muchas de estas iniciativas comparten objetivos y esferas de trabajo; es fundamental establecer principios y directrices comunes para asegurar la coherencia regulatoria en toda la región.

Las instituciones subregionales, como la Alianza del Pacífico y el Programa Mesoamérica, se han basado en la eLAC para diseñar sus estrategias. La CEPAL está integrando las iniciativas en un marco regional más amplio. Por ejemplo, parte del trabajo de la eLAC de cara a promover estrategias de comercio digital se lleva a cabo en asociación con la Alianza del Pacífico (CEPAL, 2018a). El subgrupo de la agenda digital de la Alianza del Pacífico está trabajando con la CEPAL en una hoja de ruta para materializar sus compromisos y promover normas y estándares compatibles entre sus miembros en materia de interoperabilidad técnica, neutralidad tecnológica, protección de datos personales, flujo de datos transfronterizos, protección del consumidor, ciberseguridad, competencia, propiedad intelectual, facilitación del comercio e impuestos y aranceles sobre el comercio electrónico. Mercosur ha propuesto trabajos similares y la Alianza del Pacífico ya ha iniciado conversaciones para converger. En ese marco, la CEPAL proporciona plataformas adicionales, como un panel político liderado por Brasil y México, que invita a representantes de la Alianza del Pacífico y Mercosur a debatir la promoción de la actividad comercial mediante el impulso del comercio electrónico (CEPAL, 2018a).

Este marco regional más amplio podría integrar y armonizar las iniciativas existentes que atienden a las circunstancias específicas de los países y las subregiones y el desarrollo digital. Los contrastes en el ámbito del desarrollo digital en la región son tales que los países de América Latina y el Caribe pueden prestarse asistencia técnica entre sí. Por ejemplo, para reducir su brecha digital, El Salvador recibe apoyo de la Agencia Uruguaya de Gobierno Electrónico y Sociedad de la Información para promover la transformación digital de sus instituciones (Red de gobierno electrónico de América Latina y el Caribe, 2019). En el plano regional, El Salvador forma parte del Proyecto de Integración y Desarrollo de Mesoamérica, junto con Colombia, Costa Rica, Guatemala, México y otros países. La rama del proyecto relativa a la interconectividad promueve políticas públicas que reducen los costos de Internet y aumentan el acceso a las TIC, reduciendo así la brecha digital en la subregión. El proyecto puso en marcha la Autopista Mesoamericana de la Información, una red regional de fibra óptica de 1.800 kilómetros de longitud, administrada por la entidad pública-privada Red Centroamericana de Telecomunicaciones, con objeto de reducir los costos de la banda ancha y aumentar la penetración de Internet en Centroamérica (Proyecto de Integración y Desarrollo de Mesoamérica, 2020). 
Uno de los principales resultados positivos de la eLAC ha sido su influencia en el diseño de políticas nacionales. Nueve estrategias digitales nacionales articulan los objetivos con arreglo a la eLAC2020. La estrategia se está convirtiendo en una referencia regional con respecto al enfoque y el alcance de las políticas digitales en América Latina y el Caribe.

A lo largo de los años, los acuerdos políticos adoptados en el marco de la agenda han consolidado las posiciones regionales sobre cuestiones clave. En 2013, en la Declaración de Montevideo se reclamó que se evitara el registro de dominios de primer nivel con la terminación ".amazon" y ".patagonia" en varios idiomas, en defensa de los intereses nacionales y soberanos. La Declaración de Cartagena de Indias de 2018 rechazó la recopilación no autorizada y el uso indebido y/o no autorizado de datos personales por parte de cualquier entidad pública o privada, y promovió la adopción de mecanismos para asegurar el tratamiento transparente de los datos personales (CEPAL, 2018a)

La eLAC también ha generado importantes informes y análisis para ayudar en la elaboración de políticas, y ha promovido la capacitación de funcionarios públicos, la armonización de las estadísticas en el ámbito de las TIC, el intercambio de mejores prácticas y el diálogo sobre políticas. Ha demostrado ser un instrumento eficaz para catalizar los esfuerzos de cooperación a nivel regional. En los últimos años, los países han promovido una mayor armonización de las normas y estándares, sobre todo mediante la creación de una estrategia regional de mercado digital, idea que finalmente se está incorporando a los bloques comerciales y de cooperación existentes a nivel subregional. Es fundamental que se refuerce la eLAC de manera que permita un mayor diálogo entre los bloques comerciales a medida que desarrollan y aplican las estrategias de integración del siguiente nivel (CEPAL, 2018a).

Los países de ALC también podrían recurrir a la OEA, si bien esta organización se extiende a países fuera de la región. El Plan Estratégico de la CITEL para el período 2018-22 tiene como objetivo la plena integración de los Estados americanos en la sociedad mundial de la información y la economía digital, con miras a posibilitar y acelerar el desarrollo social, económico, cultural y ambientalmente sostenible de todos sus habitantes mediante el desarrollo de las TIC (OEA, 2018). Dos de las principales actividades de la CITEL son la identificación de las mejores prácticas para reducir la brecha digital entre los Estados miembros, sobre todo mediante recomendaciones de políticas públicas y entorno regulatorio, y la promoción de la igualdad de género, la diversidad y la inclusión en el sector de las TIC (OEA, 2018).

Los países de América Latina y el Caribe podrían utilizar la eLAC y la CITEL para integrar y armonizar sus esfuerzos a fin de impulsar los sectores digitales a nivel regional y subregional. Estas plataformas de cooperación regional podrían ofrecer un espacio adecuado para examinar fórmulas que beneficien a los consumidores latinoamericanos mediante la mejora de la conectividad.

La existencia de una plataforma regional más integrada permitiría a los países de ALC promover un nuevo modelo de cooperación regional en el ámbito digital. Teniendo en cuenta sus estrategias nacionales de desarrollo, podrían determinar en qué medida y en qué ámbitos profundizar la colaboración para beneficiarse aún más de sus crecientes mercados digitales. Una plataforma regional integrada podría promover la participación activa de los países en todos los niveles de desarrollo, armonizar las prioridades nacionales y mundiales y promover la participación de la región en la agenda mundial. Podría permitir debates intrarregionales sobre medidas para promover, por ejemplo, los pagos electrónicos para facilitar el comercio electrónico o una mayor interconectividad regional.

La cooperación regional para mejorar el comercio electrónico, los pagos electrónicos y la falta de confianza podría incluir asistencia técnica a países más pequeños, y el análisis, definición y estudios de impacto de planes de acción y normas comunes. Esto ayudaría 
a los países a determinar el grado de armonización de sus normas para mantener la soberanía nacional al tiempo que amplían las oportunidades del comercio electrónico en la región. Compartir ejemplos nacionales como el de la Ley General de Protección de Datos de 2018, e iniciativas de cooperación técnica como la que se realizó entre la Agencia Uruguaya de Gobierno Electrónico y Sociedad de la Información y del Conocimiento, podría permitir un enfoque más cohesionado, con una mayor cooperación técnica basada en el conocimiento, la creación de capacidad y el diálogo sobre políticas.

Para crear un mercado digital regional para América Latina y el Caribe será necesario tener un adecuado entendimiento de las correspondientes brechas regionales y subregionales así como de las vías existentes para abordarlas. También requerirá un apoyo político sólido y continuo para coordinar esfuerzos conjuntos e integrar a los distintos actores del sector digital y de los países de la región, manteniendo al mismo tiempo la soberanía nacional.

\section{Nuevas alianzas: Cómo el sector privado y la sociedad civil pueden ayudar al establecimiento der un mercado regional digital}

Las alianzas formadas por múltiples grupos de interés pueden ayudar a abordar problemas de desarrollo complejos y compartidos a través de respuestas multidimensionales. En estas alianzas, podrían participar otros grupos de interés más allá de las instituciones públicas, como el sector privado y la sociedad civil.

La creación de un mercado digital regional aumentaría considerablemente las oportunidades de negocio y apoyaría los modelos de negocio regionales. Muchas empresas digitales de la región operan en múltiples territorios nacionales, por ejemplo, a través de Mercado Libre, la mayor plataforma de comercio electrónico de la región. La creación de un mercado digital regional también podría apoyar los ecosistemas de start-ups tecnológicas que están apareciendo en los principales centros regionales, como São Paulo, Buenos Aires y México D.F.: existen un total de 123 "tecnolatinas" y entre ellas 9 "unicornios" (EMnet, 2020).

El sector privado puede contribuir a cerrar las brechas digitales. Será fundamental contar con un mayor acceso a la economía digital para asegurar que las iniciativas regionales contribuyan a cerrar esas brechas entre los países de América Latina y el Caribe y dentro de ellos. Asimismo, será clave comprender cómo se pueden aprovechar las iniciativas del sector privado orientadas a la expansión de los mercados. La iniciativa "Internet para Todos", desarrollado por Telefónica, Facebook, el Banco de Desarrollo de América Latina y el Banco Interamericano de Desarrollo, tiene como objetivo conectar a las comunidades de zonas aisladas al tiempo que se asegura un rendimiento financiero y una viabilidad comercial que pueda reproducirse para llevar el acceso a Internet a más de 100 millones de personas en ALC. Las nuevas tecnologías y los modelos de negocio han hecho que zonas anteriormente desconectadas o poco conectadas de Perú sean económicamente viables (NERA Economic Consulting, 2020).

El sector privado puede respaldar la integración de sectores de la población que no tienen acceso a servicios bancarios. Las tecnologías financieras han mejorado el acceso al financiamiento, en particular en el caso de las pymes, ayudando a reducir los gastos de cumplimiento y facilitando los pagos digitales a bajo costo y con alta seguridad, lo cual beneficia a segmentos de la sociedad que anteriormente no tenían acceso (o bien un acceso insuficiente) a servicios bancarios (OCDE et al., 2019).

Para aprovechar al máximo los avances tecnológicos, la participación del sector privado en la aplicación de una agenda digital regional debe ser multisectorial. La cooperación a diversos niveles de las administraciones públicas puede aportar un valor agregado. Por 
ejemplo, la digitalización puede crear redes eléctricas más eficientes que puedan facilitar el suministro de energías renovables a gran escala y aumentar la eficiencia energética. Mediante proyectos de valor compartido, las empresas de servicios públicos de ALC - como el Grupo Energía Bogotá de Colombia, que opera en Brasil, Colombia, Guatemala y Perúestán promoviendo el acceso a soluciones de energía sostenible para las comunidades que anteriormente no estaban conectadas a la red (EMnet, 2020), asegurando que las nuevas tecnologías contribuyan a un crecimiento inclusivo y sostenible. La creación de plataformas que trabajen con una amplia gama de grupos de interés a nivel regional y nacional será fundamental para establecer colaboraciones duraderas.

Durante la pandemia, la sociedad civil ha ayudado a superar el cierre de centros educativos y la brecha digital, impidiendo que se profundicen las desigualdades en la educación. Los sistemas escolares han aprovechado su experiencia accediendo a zonas remotas e impartiendo clases a través de medios de comunicación masiva. Los responsables educativos y el profesorado, en estrecha colaboración con las autoridades locales y el sector privado, han ampliado el acceso a Internet en zonas específicas y han proporcionado instrumentos TIC a los estudiantes. También han combinado las plataformas de aprendizaje por Internet con herramientas como WhatsApp, medios móviles o redes sociales, medios tradicionales (televisión, radio) y materiales impresos entregados a padres y alumnos sin acceso a Internet (Basto-Aguirre, Cerutti y Nieto-Parra, 2020).

La sociedad civil también puede promover el uso ético de las herramientas digitales en el espacio público mediante la cooperación internacional. La digitalización de las sociedades de América Latina y el Caribe ha tenido un fuerte impacto en los procesos políticos, los derechos de los ciudadanos y las libertades civiles. La desinformación, el uso de técnicas de microdireccionamiento digital y la acentuación de determinantes colectivos de vulnerabilidad que ya son objeto de discriminación, amenazan con erosionar la calidad de las democracias en la región (ver el capítulo 4).

Las organizaciones de la sociedad civil de América Latina y el Caribe pueden desempeñar un papel clave mediante la cooperación en diversas actividades, como la verificación de noticias en plataformas elaboradas con periodistas, la promoción de nuevas normas sociales y la desacreditación del discurso fundamentalista y "antiderechos" así como la promoción del software abierto y de soluciones digitales. Las plataformas de cooperación internacional entre gobiernos y sociedad civil podrían fortalecer los valores democráticos. Por ejemplo, un total de 15 países de América Latina y el Caribe ${ }^{4}$ han firmado la Alianza para el Gobierno Abierto, adoptando acuerdos para empoderar a los ciudadanos e incrementar su transparencia e inclusión. Cada dos años, los miembros presentan un plan de acción, elaborado en alianza con la sociedad civil, que define los compromisos para mejorar la transparencia, la rendición de cuentas y la participación pública en las administraciones públicas. Teniendo en cuenta los trastornos experimentados por los procesos de cooperación tradicionales debido a la crisis del coronavirus (Covid-19), esta asociación ha proporcionado una guía para mantener procesos de cocreación en Internet, que incluye consejos prácticos, una lista de herramientas y plataformas digitales y ejemplos de países (Alianza para el Gobierno Abierto, 2020).

\section{Explorar el potencial de la cooperación regional y las alianzas interregionales}

Al desarrollar su ecosistema digital regional, los países de América Latina y el Caribe podrían analizar qué políticas de cooperación digital funcionan en otras regiones y cómo lo consiguen, y crear alianzas interregionales para compartir dichas experiencias. La estrategia digital de la Unión Europea constituye un valioso ejemplo de cómo la cooperación regional en el sector digital puede promover un enfoque centrado en las personas. 


\section{El potencial de la cooperación regional: la estrategia digital de la Unión Europea}

La visión de la estrategia digital adoptada por la UE, que implica una transformación digital "al servicio de las personas" y que fomenta el crecimiento sostenible, ha cobrado relevancia desde la crisis del coronavirus (Covid-19). La actual estrategia digital 2019-24 se basa en la estrategia de mercado único digital adoptada por la Comisión Europea para el periodo 2014-19. El Mercado Único tiene por objeto garantizar la libre circulación de bienes, capitales, servicios y trabajadores en todos los Estados miembros de la UE para generar crecimiento económico y mejorar el bienestar de los ciudadanos. Como derivación del Mercado Único, el mercado único digital pretende abrir oportunidades digitales para las personas y las empresas y mejorar la posición de Europa como líder mundial en la economía digital, garantizando un acceso seguro por Internet en toda Europa (Comisión Europea, 2019b).

Los tres pilares de la estrategia del mercado único digital se definen como: acceso (mejora del acceso de consumidores y empresas a los bienes y servicios digitales en toda Europa); entorno (creación de las condiciones adecuadas y una oportuna igualdad de condiciones para que prosperen las redes digitales y los servicios innovadores); y economía y sociedad (aprovechar al máximo el potencial de crecimiento de la economía digital) (Comisión Europea, 2019b). La adopción de estos pilares podría mejorar la competitividad y la productividad de las empresas y el ahorro de los consumidores.

Un mercado único digital plenamente operativo podría aportar hasta 415.000 millones de euros adicionales, esto es, el $3 \%$ anual, al producto interno bruto (PIB) de la UE para el año 2020. Facilitar el comercio electrónico en toda Europa aportaría una mayor eficiencia y permitiría aprovechar las economías de escala, aportando beneficios adicionales gracias a un aumento de la competitividad y la mejora de las estrategias de abastecimiento a escala internacional. De este modo, podría conseguirse una reducción de los precios y una mayor posibilidad de elección para los consumidores. Si el comercio electrónico alcanzara el 15\% del total del sector minorista y se eliminaran las barreras al mercado único, el aumento de la intensidad en el comercio electrónico podría suponer por sí solo unas ganancias a largo plazo de 204.000 millones de euros, o el 1.6\% del PIB de la UE (Servicio de Investigación del Parlamento Europeo - Unidad Europea de Valor Añadido, 2017) (Tabla 5.2).

Tabla 5.2. Ganancias potenciales de PIB por el mercado único digital

\begin{tabular}{lc}
\hline Bloques de ganancias potenciales de PIB & Costos (miles de millones de euros al año) \\
\hline Comercio electrónico & 204 \\
Contratación pública por medios electrónicos & 100 \\
Zona Única de Pagos en Euros y pagos electrónicos & 2 \\
Facturación electrónica & 40 \\
Computación en la nube & 47 \\
Sistemas de resolución de controversias alternativas y por Internet & 22 \\
\hline Total & 415 \\
\hline
\end{tabular}

Fuente: Servicio de Investigación del Parlamento Europeo - Unidad Europea de Valor Añadido (2017), Mapping the Cost of Non-Europe 2014-19, www.europarl.europa.eu/RegData/etudes/STUD/2017/603239/EPRS STU(2017)603239 EN.pdf.

El mercado único digital también aportaría una mayor productividad gracias al aumento del flujo de información, lo cual beneficiaría a las industrias de servicios basados en el conocimiento, incrementaría la productividad en las transacciones entre empresas y los servicios públicos, y generaría ahorros en los procedimientos de contratación pública. La contratación pública electrónica se ha identificado como un vector que puede aportar a la economía europea una posible ganancia anual de 100.000 millones de euros. Si se consiguiera pasar del $5 \%$ del total de transacciones anuales realizadas entre empresas en 2010 a una adopción generalizada en 2020, la facturación electrónica podría aportar 
40.000 millones de euros anuales. Una estimación a la baja de la aplicación de la Zona Única de Pagos en Euros apunta a un superávit anual de 2.000 millones de euros para la economía europea. Al impulsar la adopción generalizada de la computación en nube tanto en el sector público como en el privado, el mercado único digital también podría aportar 47.000 millones de euros al PIB de la UE en ahorro de gastos en TIC.

Por último, el potencial ahorro para los consumidores europeos de 20.000 millones de euros (si se dispusiera de soluciones alternativas de calidad para la resolución de controversias) y de 2.500 millones de euros (si se dispusiera de soluciones de controversias por Internet para transacciones transfronterizas de comercio electrónico), aportaría 22.500 millones de euros adicionales a la economía europea.

Asimismo, es importante señalar que una iniciativa que se base en el mercado único digital de la UE podría permitir la adopción de nuevos enfoques más inclusivos con respecto al entorno laboral y promover la igualdad de género, la inclusión de género y el empoderamiento de la mujer en América Latina y el Caribe. El mercado único digital de la UE ofrece fórmulas para conseguir avances en el ODS 5 mediante iniciativas como Women in Digital (WID), que apoya la participación de la mujer en el sector digital. Si la participación de la mujer aumentara, el PIB de la UE podría conseguir un superávit anual de 16.000 millones de euros (iClaves, 2018). El cuadro de indicadores de la iniciativa WID de la Comisión Europea evalúa el desempeño de los Estados miembros en materia de igualdad de género en el sector digital. Este marcador está fuertemente correlacionado con el Índice de economía y sociedad digital de la UE, que mide el desempeño general de los Estados miembros de la UE en el sector digital. Esto significa que los Estados miembros que lideran la competitividad digital también lideran los indicadores de WID (Comisión Europea, 2019c).

La estrategia de mercado único digital de la UE para 2014-19 ha dado como resultado beneficios compartidos para los Estados miembros (Comisión Europea, 2019a). También ha conseguido avances que asegurarán una mejor coordinación en el sector digital, fomentando mejores oportunidades y protecciones (por ejemplo, el RGPD, que protege los datos personales). Asimismo, ha dado lugar a la Directiva sobre datos abiertos y el Reglamento para la libre circulación de datos no personales, que permite a las empresas y a las administraciones públicas almacenar y procesar datos no personales en toda la Unión Europea, asegurando así la libre circulación de datos no personales y el desarrollo de la economía de datos y la materialización de sus beneficios (Comisión Europea, 2019d). La estrategia del mercado único digital incluía la Ley de Ciberseguridad, que establece un marco de certificación para los productos, servicios y procesos digitales, y que ha ampliado el mandato de la Agencia de la Unión Europea para la Ciberseguridad al tiempo que ha duplicado su presupuesto (Comisión Europea, 2019e). Por último, la estrategia del mercado único digital ha dado lugar a una estrategia coordinada sobre inteligencia artificial en virtud de la cual las estrategias nacionales en este ámbito ayudarán a aumentar las inversiones regionales en inteligencia artificial, entre otros compromisos (Comisión Europea, 2018a).

La nueva estrategia digital 2019-24 profundiza en estos logros con un enfoque más resiliente y aún más centrado en las personas, al tiempo que convierte a la Unión Europea en un sólido socio de cooperación para ayudar a América Latina y el Caribe a canalizar su sector digital para conseguir una mejor recuperación tras la crisis del coronavirus (Covid-19). En las Orientaciones políticas para la próxima Comisión Europea 2019-2024 se subraya la necesidad de que Europa "lidere la transición hacia un planeta sano y un nuevo mundo digital" (Von der Leyen, 2019). Seis nuevas prioridades para 2019-24 recogen la ambición de la región de convertirse en líder mundial. Dichas prioridades incluyen una nueva estrategia para el sector digital de Europa —una Europa adaptada a la era digital— que 
tiene por objeto hacer que la transformación digital funcione en pro de las personas y las empresas, adoptando un enfoque centrado en las personas al tiempo que ayuda a Europa a alcanzar su objetivo de neutralidad climática para 2050. La Unión Europea seguirá desarrollando su modelo único de cooperación digital y lo promoverá en su cooperación con otros países y regiones.

La nueva estrategia digital cuenta con tres pilares (Comisión Europea, 2019f). El primero es asegurar que la tecnología esté al servicio de las personas. La Unión Europea invertirá en el desarrollo de las competencias digitales de los ciudadanos, protegiéndolos frente a las ciberamenazas y asegurando un desarrollo de la inteligencia artificial que respete los derechos de las personas y se gane su confianza. También incluirá el despliegue de la banda ancha de ultra alta velocidad para hogares, centros educativos y hospitales y la ampliación de la capacidad de supercomputación de Europa para desarrollar soluciones innovadoras para la medicina, el transporte y el medioambiente. El segundo pilar es seguir creando una economía digital justa y competitiva. La Unión Europea permitirá a las start-ups y a las pymes acceder al financiamiento, propondrá una Ley de Servicios Digitales para reforzar la responsabilidad de las plataformas digitales y aclarar las normas relativas a los servicios prestados por Internet, adaptar las normas de la UE a la economía digital asegurando que todas las empresas compitan en Europa en condiciones equitativas, y aumentando el acceso a los datos al tiempo que se protegen los datos personales y sensibles. El tercer pilar consiste en canalizar la transformación digital para respaldar una sociedad abierta, democrática y sostenible. La Unión Europea utilizará la tecnología para ayudar a Europa a ser climáticamente neutra de aquí a 2050, por ejemplo, reduciendo las emisiones de carbono del sector digital. La estrategia también creará un espacio europeo de datos sobre la salud para mejorar el control y la protección de los datos por parte de los ciudadanos y fomentar la investigación, el diagnóstico y los tratamientos específicos; y defenderá los valores democráticos luchando contra la desinformación en Internet y facilitando un contenido diverso y fiable de medios de comunicación.

Las tres áreas de acción establecidas para lograr estos objetivos se basan en los logros de la estrategia del mercado único digital del periodo 2014-19. La primera acción consiste en la promoción de la excelencia y la confianza en el desarrollo de la inteligencia artificial, lo cual puede ayudar a encontrar soluciones en materia de políticas, desde la salud y la agricultura hasta la seguridad y la industria manufacturera. La segunda es aprovechar los reglamentos y directivas adoptados en el marco de la última Comisión para crear un mercado único de datos. La Unión Europea aspira a convertirse en líder de una sociedad impulsada por los datos, permitiendo que los datos fluyan libremente dentro de la región y entre los sectores en beneficio de las empresas, los investigadores y las administraciones públicas. Por último, se está aplicando una estrategia industrial que se basa en las transformaciones verdes y digitales para que la industria y las pymes puedan seguir siendo competitivas a nivel mundial.

Posicionar a la Unión Europea como líder mundial de la transformación digital es un elemento clave de la nueva estrategia digital. Convertirse en un modelo mundial de la economía digital implica apoyar a las economías en desarrollo para que se digitalicen y desarrollar y promover las normas digitales internacionales. El programa BELLA y la cooperación científica y tecnológica entre la Unión Europea y Brasil muestran cómo las iniciativas de cooperación digital pueden tener un impacto multidimensional en los desafíos del desarrollo. Mediante la adopción de enfoques centrados en las personas que tengan en cuenta los aspectos sociales o ambientales, estas iniciativas harán que, en última instancia, la tecnología funcione en pro de las personas, tal y como se prevé en la estrategia digital de la Unión Europea, y ayudarán a ALC a utilizar la transformación digital para abordar varias trampas del desarrollo que a menudo están interconectadas, fortaleciendo además la capacidad de los ciudadanos de la región para luchar contra ellas. 
América Latina y el Caribe podría utilizar la estrategia digital de la Unión Europea como modelo para desarrollar un mercado digital regional y ver a la Unión Europea como un socio de cooperación que pueda ayudar a guiar la transformación digital de la región y dotarla de una mayor resiliencia frente a las trampas del desarrollo o los riesgos globales, como la pandemia del coronavirus (Covid-19).

\section{El Norte Digital: Aplicación de la estrategia digital de la Unión Europea a nivel subregional y nacional}

La región nórdica y báltica constituye un ejemplo útil de cómo los países pueden aplicar las normas regionales de digitalización de la Unión Europea a escala subregional y nacional, adaptándolas a sus niveles de digitalización al tiempo que aprovechan la cooperación internacional para cosechar los beneficios de esas políticas.

Si bien la estrategia del mercado único digital de la Unión Europea establece normas supranacionales que los Estados miembros deben cumplir en el ámbito regional, los países siguen siendo responsables de encontrar las políticas adecuadas para aplicarlas a nivel nacional: los Estados deben articular los objetivos con respecto a sus contextos, capacidades y metas nacionales. Los países nórdicos y bálticos, incluidos algunos países que no son miembros de la Unión Europea, adoptaron una visión común con respecto a la digitalización, aplicando los objetivos de la UE, acumulando experiencia y sirviendo de ejemplo para el resto de Europa. También podría servir de ejemplo para que América Latina y el Caribe articule la heterogeneidad subregional y nacional dentro de un marco regional más amplio.

El 25 de abril de 2017, durante la Conferencia Ministerial Nórdico-Báltica sobre Digitalización, los ministros responsables del desarrollo digital de Dinamarca, Estonia, Islas Feroe, Finlandia, Islandia, Letonia, Lituania, Noruega y Suecia adoptaron la declaración "La región nórdico-báltica: Una pionera digital” (La Declaración del Norte Digital). Su objetivo es aprovechar la "madurez digital" común de las sociedades de la región para estimular el desarrollo de un mercado único digital más eficiente. Concretamente, los tres objetivos, tal como se establece en la estrategia, son: "1. Fortalecer la capacidad de transformación digital de nuestros gobiernos y sociedades, sobre todo mediante la creación de un área común para los servicios digitales transfronterizos en el sector público. 2. Reforzar la competitividad de nuestras empresas a través de la digitalización. 3. Mejorar el mercado único digital en la región nórdica y báltica" (Cooperación Nórdica, 2017).

Los países de la región se basan en organismos interministeriales, como el Consejo Nórdico de Ministros para la Digitalización 2017-2020 (MR-DIGITAL) y el Consejo de Ministros del Báltico, para debatir, diseñar, adoptar y aplicar políticas digitales comunes que se adapten a sus contextos nacionales, pero que sigan canalizando las ventajas de la cooperación internacional y sirvan de base a las iniciativas regionales. En el marco del Consejo Nórdico de Ministros para la Digitalización, los proyectos son ejecutados por los distintos países, pero son coordinados y gestionados conjuntamente por todos a través de la plataforma interministerial (Cooperación Nórdica, 2018).

Algunos ejemplos de ello son el proyecto de cooperación nórdico-báltico sobre identidades digitales (NOBID) y la estrategia de adopción de la 5G. El proyecto NOBID se estructuró como un proyecto multinacional dirigido por la Agencia Noruega para la Gestión Pública y el Gobierno Electrónico. Su objetivo es asegurar el acceso a los servicios públicos de otros países basándose en el sistema nacional de identificación electrónica de cada país. El proyecto producirá conceptos técnicos, componentes elementales y normas industriales, y promoverá redes transfronterizas de conocimientos técnicos y jurídicos. De este modo, se permitirá a los países crear conceptos útiles para el intercambio transfronterizo de datos personales y la puesta en marcha de espacios regionales 
de cooperación en materia de identificación electrónica. El Ministerio de Empresa e Innovación de Suecia estableció la iniciativa 5G nórdico-báltica, que ayudará a los países a identificar los modelos de negocio más adecuados para contribuir a la expansión de las redes $5 G$ en la región. De este modo, se supervisa el estado de actualización de las redes móviles $5 G$ y se crean pequeñas redes celulares. Los países de la región cooperan desarrollando nuevas instalaciones de prueba, coordinando las bandas de frecuencia 5G y eliminando obstáculos para el despliegue de estaciones de base y antenas 5G (Cooperación Nórdica, 2018).

El Consejo Nórdico de Ministros para la Digitalización incluye otras iniciativas que podrían ser de utilidad para las economías de América Latina y el Caribe, desde la cooperación en materia de salud a través de Internet hasta la inteligencia artificial o el acceso a datos financieros para pymes en toda la región (Cooperación Nórdica, 2018). Las diversas iniciativas adoptadas muestran cómo los países con niveles de desarrollo similares pueden cooperar para aplicar las normas digitales regionales a nivel nacional. Estas iniciativas ayudarán a los países nórdicos y bálticos a desarrollar su potencial digital al tiempo que crean conocimientos que sirvan a la estrategia de mercado único digital de la UE. La cooperación digital entre los países nórdicos y bálticos podría adaptarse a los diferentes contextos y evolución de los países de América Latina y el Caribe.

\section{Afrontar los desafíos mundiales que plantea la digitalización de la economía mediante el multilateralismo: El caso de la fiscalidad internacional}

La digitalización de la economía plantea nuevos desafíos fiscales que trascienden las fronteras y afectan a todas las economías, incluidas América Latina y el Caribe. La reciente transformación digital se ha producido de manera muy rápida y expansiva, y ha generado profundas repercusiones económicas y sociales que han dado lugar a cambios significativos. Esta rápida evolución ha suscitado debates en todo el mundo en multitud de ámbitos jurídicos y regulatorios, y la fiscalidad internacional no ha quedado al margen. Las repercusiones fiscales son de gran alcance y afectan tanto a la tributación directa como a la indirecta, a cuestiones más amplias de política fiscal y a la administración tributaria.

La cooperación multilateral es esencial para superar los desafíos que trascienden las fronteras, tales como las cuestiones tributarias relacionadas con la digitalización de la economía. Sobre la base de una plena igualdad de condiciones, ALC debería beneficiarse en gran medida de una mayor cooperación dentro de la región y con otras jurisdicciones, y tiene también un importante papel que desempeñar para alcanzar soluciones de consenso mediante una cooperación multilateral eficaz.

\section{Abordar los desafíos fiscales indirectos derivados de la digitalización de la economía}

La recaudación del IVA (Impuesto sobre el Valor Agregado) en el comercio electrónico transfronterizo es uno de los principales desafíos de la economía digital (OCDE, 2015). En particular, cuando consumidores particulares adquieren bienes, servicios y productos digitales a través de Internet a vendedores digitales radicados en el extranjero. En respuesta a esos desafíos, existe un diálogo internacional permanente liderado por la OCDE sobre la elaboración de soluciones para hacer frente a estos desafíos del IVA resultantes del continuo crecimiento de los volúmenes del comercio digital. En particular, la OCDE ha presentado un completo conjunto de normas y mecanismos acordados internacionalmente para la recaudación efectiva del IVA en las actividades de comercio digital transfronterizo en las que participan mercados de comercio electrónico extraterritoriales y otros proveedores 
digitales, junto con directrices detalladas para respaldar su aplicación efectiva. Esas normas se han aplicado o se están aplicando en todo el mundo con gran éxito, incluidas economías del G20, como Arabia Saudita, Australia, China, India, Indonesia, Japón, Rusia, Sudáfrica y la Unión Europea. El impacto cada vez mayor de estas normas refleja su importancia significativa para los ingresos en concepto de IVA de los países y para reducir al mínimo las distorsiones de la competencia entre los operadores digitales y las empresas tradicionales. Esta situación ha cobrado aún más importancia a la luz del brote de Covid-19, ya que las medidas de contención y mitigación adoptadas en respuesta a la pandemia han dado lugar, en particular, a importantes repuntes en las compras por Internet y a un aumento de la demanda de productos y servicios digitales.

En América Latina y el Caribe, los desafíos transfronterizos que plantea la digitalización de la economía en la recaudación del IVA son aún más marcados. El IVA es la principal fuente de ingresos tributarios para muchas economías de ALC, y representa cerca de un tercio del total de los ingresos tributarios de la región (OCDE et al., 2020). La integridad y el desempeño de los regímenes de IVA de la región son cruciales para la movilización de los recursos internos. Los sistemas de IVA en ALC se enfrentan cada vez más a los desafíos del continuo - y en muchos casos exponencial- crecimiento del comercio electrónico. Muchas economías de América Latina y el Caribe ya han tomado medidas para salvaguardar una recaudación adecuada de los ingresos del IVA en las ventas por Internet. Los países ALC se beneficiarían enormemente de una mayor cooperación dentro de la región y con otras jurisdicciones. Esto podría permitir que ALC comparta experiencias y mejores prácticas con países que ya han implementado soluciones internacionales, como aquellas propuestas por la OCDE.

Las normas de la OCDE sobre la recaudación efectiva del IVA en el comercio digital entrañan esencialmente el requisito de que los vendedores por Internet, incluidos los mercados de comercio electrónico, se registren en la jurisdicción en que se encuentre el cliente y remitan el IVA sobre la venta digital a esa jurisdicción. Con el fin de facilitar el cumplimiento, sobre todo en el caso de los vendedores digitales no residentes, se ha elaborado un mecanismo simplificado de información que permite el registro, la presentación de informes y el pago del IVA por medios electrónicos. La respuesta a los desafíos que plantea la recaudación del IVA en los servicios prestados por Internet puede generar importantes recursos públicos que podrían contribuir a financiar las estrategias de desarrollo de la región (CEPAL, 2019).

Abordar los desafíos de los impuestos sobre las sociedades derivados de la digitalización de la economía

La digitalización de la economía ha suscitado fuertes dudas sobre si las actuales normas internacionales de los impuestos sobre los beneficios de las sociedades, elaboradas hace más de un siglo, siguen siendo adecuadas para la economía mundial moderna. Es necesario modernizar los elementos fundamentales del sistema tributario mundial que determinan dónde deben pagarse los impuestos (normas de "nexo" en función de la presencia física) y qué parte de los beneficios debe gravarse (normas de "atribución de beneficios" en función del principio de plena competencia), de manera que tengan en cuenta la globalización y la digitalización de la economía.

Por un lado, la aparición de impulsores de valor nuevos y a menudo intangibles ha revolucionado sectores enteros, creando nuevos modelos de negocio al tiempo que ha erosionado continuamente la necesidad de que exista una proximidad física a los mercados objetivo. Esta situación pone continuamente en tela de juicio la eficacia de las actuales normas de atribución de beneficios y de nexo para distribuir los derechos de imposición sobre los ingresos generados por las actividades transfronterizas de una 
manera que sea aceptable para todos los países, grandes y pequeños, desarrollados y en desarrollo (la denominada atribución de derechos de imposición).

Por otra parte, las nuevas tecnologías han facilitado la evasión fiscal mediante el desplazamiento de los beneficios de las empresas multinacionales a jurisdicciones con una baja o nula tributación. Esta es la esencia del proyecto sobre la erosión de la base imponible y el traslado de beneficios (proyecto BEPS), que llevó a la adopción del paquete BEPS en 2015. El marco inclusivo de la OCDE/G20 sobre BEPS (Marco Inclusivo), creado en junio de 2016, avanza en la aplicación del paquete BEPS y en el desarrollo de una solución a los desafíos fiscales de la digitalización de la economía. Al 1 de septiembre de 2020, un total de 137 jurisdicciones forman parte del Marco Inclusivo, incluidas 32 economías de América Latina y el Caribe. ${ }^{5}$

Asegurar la implementación de una solución multilateral y consensuada para los retos fiscales derivados de la digitalización de la economía constituye una prioridad para los 137 miembros del Marco Inclusivo de la OCDE/G20 sobre BEPS. Aunque en términos prácticos la pandemia ha afectado el ritmo de los avances conseguidos, el trabajo técnico para encontrar una solución sigue avanzando satisfactoriamente tanto en el primer pilar (establecer un nuevo nexo y una nueva atribución de derechos de imposición) como en el segundo pilar (asegurar un nivel mínimo de tributación). Desde enero de 2020 y tras la adopción de un borrador del primer pilar basado en una propuesta del Secretariado de la OCDE para un Enfoque Unificado, el Marco Inclusivo de la OCDE/G20 ha desarrollado los aspectos técnicos de 11 componentes elementales. Los trabajos relativos al segundo pilar también avanzaron, con el fin de presentar las guías de cada uno de los pilares para la reunión de los Ministros de Hacienda del G20 en octubre de 2020. Si no se alcanza un acuerdo, se corre el riesgo aumentar las tensiones, lo que socavaría aún más la economía mundial, incluida la de la región de América Latina y el Caribe. ${ }^{6}$ Las jurisdicciones de ALC, de las cuales 32 participan en igualdad de condiciones en los debates del Marco Inclusivo, tienen un importante papel que desempeñar para alcanzar dicha solución de consenso mediante una cooperación multilateral eficaz.

Por último, en el Marco Inclusivo se aprobaron recientemente nuevas normas modelo para exigir la presentación de informes por parte de los operadores de plataformas digitales con respecto a los vendedores de la economía colaborativa y de la economía bajo demanda (gig economy) (OCDE, 2020c). Las actividades facilitadas por las plataformas digitales no siempre se notifican a las administraciones tributarias, ya sea por parte de terceros o por los propios contribuyentes. Las normas modelo están concebidas para ayudar a los contribuyentes a cumplir sus obligaciones fiscales, al tiempo que aseguran una igualdad de condiciones con las empresas tradicionales en los principales sectores de la economía colaborativa y de la economía bajo demanda (por ejemplo, alojamiento y transporte). Estas normas modelo también ayudan a los operadores de plataformas digitales a evitar la excesiva carga de cumplimiento que tendrían que asumir en caso de que cada país exigiera la presentación no coordinada de informes unilaterales. Estas nuevas normas modelo constituyen un elemento importante para hacer frente a los desafíos fiscales derivados de la digitalización de la economía y demuestran los beneficios que sigue aportando la cooperación multilateral. Las jurisdicciones de América Latina y el Caribe se beneficiarían enormemente de la rápida aplicación de estas normas modelo, que constituyen un nuevo instrumento de cumplimiento fiscal y aumentarían considerablemente la transparencia en este sector de la economía digital. 


\section{Conclusiones}

La cooperación internacional y las nuevas alianzas son más importantes que nunca para aprovechar al máximo la transformación digital. Dado que esta transformación genera desafíos y oportunidades que trascienden las fronteras, es fundamental que se adopten respuestas coordinadas. La crisis del coronavirus (Covid-19 ha puesto de relieve la importancia de la cooperación internacional y las herramientas digitales. Es fundamental coordinar las políticas a escala internacional que promuevan la digitalización para todos. La cooperación internacional tradicional no ha cumplido las expectativas. Debe evolucionar hacia un modelo renovado, basado en tres pilares. En primer lugar, este modelo debe tener como objetivo apoyar las estrategias de desarrollo de los países de América Latina y el Caribe, teniendo en cuenta el carácter multidimensional de sus desafíos de desarrollo y vinculándolos a las prioridades internacionales. En segundo lugar, debe basarse en plataformas de diálogo inclusivas y productivas, en las que participen en igualdad de condiciones países de todo tipo de desarrollo. En tercer lugar, la cooperación internacional deberá incluir más instrumentos y más actores, ampliando las posibilidades y los efectos de la acción coordinada. Los ejemplos de cooperación internacional implantados en el ámbito digital muestran el camino hacia la adopción de un modelo renovado.

La crisis del coronavirus (Covid-19) amenaza con intensificar los problemas socioeconómicos de América Latina y el Caribe. Es fundamental que la región insista y multiplique los esfuerzos de cooperación internacional que puedan ayudar a los países de ALC a crear capacidades digitales propias para hacer frente a las actuales trampas del desarrollo. Las iniciativas más eficaces ayudan a hacer frente a varias trampas a la vez, siguiendo un enfoque multidimensional del desarrollo. El programa BELLA y la cooperación científica y tecnológica entre la Unión Europea y Brasil no solo generan capacidades de inclusión social o productivas en ALC a través de herramientas digitales, sino que además permiten a los países de la región cerrar la brecha entre las prioridades nacionales e internacionales. Las iniciativas de cooperación triangular, como el Centro de Tecnologías Ambientales de Perú, también podrían servir de ejemplo de cómo las nuevas herramientas pueden ayudar a crear capacidades frente a los desafíos del desarrollo (ver el Anexo 5.A1). El programa "Belt and Road Initiative" podría generar oportunidades para iniciativas de cooperación Sur-Sur, pudiendo fomentar el desarrollo sostenible mediante la cooperación digital.

La integración regional es otra forma de aprovechar el potencial digital de América Latina y el Caribe a través de este modelo renovado de cooperación internacional. La creación de un mercado digital regional podría ayudar a la región a alcanzar niveles más altos de desarrollo, ayudando a los países a mejorar la infraestructura de comunicación y a ampliar sus perspectivas comerciales, que se han visto gravemente afectadas por la pandemia. Dado que los marcos regulatorios digitales de América Latina y el Caribe y los esfuerzos de cooperación regional y subregional no suelen estar armonizados, las iniciativas de cooperación regional, como la eLAC, podrían resultar útiles para articular los marcos y niveles de desarrollo digital, intercambiar experiencias y establecer diálogos sobre políticas e intercambio de conocimientos con múltiples países y grupos de interés. Además de impulsar el desarrollo digital de ALC, la creación de un mercado digital regional podría ayudar a armonizar las estrategias nacionales con las normas internacionales y reforzar la presencia de la región en los asuntos digitales internacionales.

Es fundamental tener en cuenta los ejemplos de otras regiones y asociaciones interregionales. Europa constituye un modelo útil de cómo construir una plataforma regional integrada y crear una regulación común para las innovaciones tecnológicas, al tiempo que se posiciona como un socio clave para la cooperación, reforzando así su 
posición en el sistema multilateral. Las alianzas interregionales con la Unión Europea en cuestiones digitales basadas en el intercambio de conocimientos y las enseñanzas extraídas podrían ayudar a ALC a adaptar las estrategias regionales a su ecosistema digital e incluso a articular las diferencias subregionales en un marco regional más amplio, como hizo Europa con el Norte Digital.

Las jurisdicciones de América Latina y el Caribe tienen un importante papel que desempeñar como socios en igualdad de condiciones en los debates internacionales que se están llevando a cabo actualmente en el Marco Inclusivo de la OCDE/G20 sobre BEPS para abordar los desafíos fiscales derivados de la digitalización de la economía. Las iniciativas multilaterales existentes y futuras para abordar los asuntos digitales globales, como la tributación internacional, tienen que incluir a los países de ALC en igualdad de condiciones. La adopción de un modelo renovado de cooperación internacional en el ámbito digital —especialmente importante durante la crisis-aportará las soluciones más eficaces a los desafíos multidimensionales del desarrollo a los que se enfrenta América Latina y el Caribe. 


\section{Anexo 5.A1. Ejemplos de cooperación internacional en el ámbito de las TIC para desarrollar la capacidad de los países de América Latina y el Caribe para superar las trampas del desarrollo}

\begin{tabular}{llll}
\hline Área de trabajo & Modalidad & Socios & Políticas \\
\hline $\begin{array}{l}\text { Digitalización de } \\
\text { la industria }\end{array}$ & $\begin{array}{l}\text { Cooperación } \\
\text { multilateral }\end{array}$ & Unión Europea & Trampa de la productividad \\
& & $\begin{array}{l}\text { La nueva estrategia de la Unión Europea para la transformación digital, } \\
\text { Una Europa adaptada a la era digital, tiene tres pilares. Uno de ellos se } \\
\text { basa en una nueva estrategia industrial, que utilizará las transformaciones } \\
\text { verdes y digitales para potenciar la industria y las pequeñas y medianas } \\
\text { empresas. El capítulo digital de esta estrategia se basará principalmente en } \\
\text { los avances realizados por el mercado único digital de la UE para fomentar } \\
\text { un mayor desarrollo. La estrategia también tiene por objeto posicionar a la }\end{array}$ \\
& & $\begin{array}{l}\text { UE como líder mundial de la transformación digital, mediante la cooperación } \\
\text { internacional (Comisión Europea, 2019f). }\end{array}$ \\
$\begin{array}{lll}\text { Digitalización } \\
\text { de la industria/ }\end{array}$ & $\begin{array}{l}\text { Cooperación } \\
\text { bilateral }\end{array}$ & $\begin{array}{l}\text { Unión Europea, } \\
\text { Brasil }\end{array}$ & $\begin{array}{l}\text { Desde su adopción en 2008, la cooperación científica y tecnológica entre la } \\
\text { Unión Europea y Brasil se desarrolla mediante convocatorias de proyectos y }\end{array}$
\end{tabular}

servicios/ agricultura/5G/ Internet de las Cosas/ computación en nube

Conectividad/incomunicación

Cooperación
China con países de África, Asia, Europa, América Latina y el Pacífico.

$\begin{array}{ll}\text { Conectividad/in- } & \text { Cooperación Unión Europea } \\ \text { fraestructura de } & \text { multilateral }\end{array}$ comunicación

La cuarta convocatoria, que aborda la $5 \mathrm{G}$, el Internet de las Cosas y la computación en nube, se llevó a cabo en 2017 como parte de Horizonte 2020. Los seis proyectos financiados se pusieron en marcha a principios de 2018 y representaron una inversión de 8.5 millones de euros por parte de la Unión Europea, mientras que Brasil realizó una aportación idéntica a través de la Rede Nacional de Ensino e Pesquisa.

El proyecto del Internet de las Cosas consistió en el lanzamiento de aplicaciones piloto que ayudaron a evaluar la viabilidad, escalabilidad y sostenibilidad de los modelos de negocio asociados con los servicios del Internet de las Cosas, así como sus beneficios sociales y su aceptación.

Los ámbitos de las aplicaciones reflejaban las prioridades de Brasil: la industria manufacturera, la ordenación de los recursos hídricos y la agricultura, así como la salud y el bienestar de las poblaciones en situación de riesgo. Esta iniciativa de cooperación aprovechó la transformación digital de la economía para ayudar a Brasil a crear capacidades frente a las trampas de la productividad, la vulnerabilidad social y el medioambiente.

Al establecer un diálogo en materia de políticas sobre temas con ramificaciones en diversas áreas de la sociedad, como la digitalización, los socios internacionales podrían poner en marcha iniciativas que aborden el carácter multidimensional del desarrollo.

(Comisión Europea, 2008; 2016; Ministério da Ciência, Tecnologia, Inovações e Comunicações, 2017)

El componente de TIC de la iniciativa "Belt and Road Initiative (BRI)" de China, conocido como el BRI digital o la Ruta de la Seda Digital, podría llevar el desarrollo sostenible a los mercados emergentes mediante una moderna infraestructura de TIC, como redes $5 \mathrm{G}$, plataformas internacionales de comercio electrónico, centros de datos y ciudades inteligentes, satélites, cables submarinos de Internet, macrodatos y redes de fibra óptica en todos los países y regiones. Hasta agosto de 2019, las entidades chinas habían invertido más de 17.000 millones de dólares en proyectos de la Ruta de la Seda Digital completados desde 2013 (Merics, 2019).

El Mecanismo "Conectar Europa" (MCE) de la Comisión Europea es un programa de financiamiento que tiene por objeto respaldar la aplicación del mercado único digital mediante el financiamiento de proyectos que proporcionen infraestructuras de servicios digitales, también conocidos como componentes elementales, para mejorar la conectividad. Estos componentes elementales del MCE facilitarán la prestación de servicios públicos digitales a través de las distintas fronteras y sectores. Los componentes elementales incluyen: Infraestructura de pruebas para datos masivos, Context Broker, archivo electrónico, prestación electrónica de servicios, identificación electrónica, facturación electrónica, firma electrónica y traducción automática (Comisión Europea, 2014). 


\begin{tabular}{|c|c|c|}
\hline Área de trabajo & Modalidad & Socios \\
\hline $\begin{array}{l}\text { Inteligencia } \\
\text { Artificial (IA) }\end{array}$ & $\begin{array}{l}\text { Cooperación } \\
\text { multilateral }\end{array}$ & Unión Europea \\
\hline $\begin{array}{l}\text { Comercio } \\
\text { electrónico }\end{array}$ & $\begin{array}{l}\text { Cooperación } \\
\text { multilateral }\end{array}$ & Unión Europea \\
\hline $\begin{array}{l}\text { Tecnología } \\
\text { financiera } \\
\text { (fintech) }\end{array}$ & $\begin{array}{l}\text { Cooperación } \\
\text { multilateral }\end{array}$ & Unión Europea \\
\hline
\end{tabular}

\begin{tabular}{lll}
\hline $\begin{array}{l}\text { Impuestos/ } \\
\text { movilización }\end{array}$ & Cooperación & Centro \\
de ingresos & multilateral & Interamericano de \\
internos & Administraciones \\
& Tributarias-Secre- \\
& taría de Estado \\
& de Asuntos \\
& Económicos del \\
& Gobierno Suizo \\
& (CIAT-SECO), \\
& Bolivia, El Salvador, \\
& Guatemala, \\
& Guyana, Honduras, \\
& Nicaragua
\end{tabular}

Políticas
La nueva estrategia de la Unión Europea para la transformación digital, Una
Europa adaptada a la era digital, tiene tres pilares. Uno de estos pilares
promueve la excelencia y la confianza en la inteligencia artificial (IA), a
través de un modelo de IA centrado en las personas. Este pilar se llevará a
la práctica mediante nuevas asociaciones entre el sector público y el privado
en el ámbito de la IA y la robótica, la creación de centros de investigación
y centros digitales, y con un acceso más fácil a los fondos y procesos de
contratación. La Unión Europea promulgará nueva legislación sobre IA;
promoverá nuevos requisitos de transparencia, rastreo de productos y
conjuntos de datos imparciales; y pondrá en marcha un debate en toda la UE
sobre el reconocimiento facial (EU Monitor, 2019; Comisión Europea, 2019g).

En el marco de la estrategia de mercado único digital, la Unión Europea ha creado nuevas normas para facilitar el comercio electrónico y superar barreras en toda la región. Para aprovechar todo el potencial del comercio electrónico, la UE ha trabajado en la revisión de la Directiva sobre servicios de pago y en las nuevas normas sobre los servicios de entrega transfronteriza de paquetes que ya están en vigor; las nuevas normas para poner fin a los bloqueos geográficos injustificados; las normas revisadas de protección del consumidor que entrarán en vigor en 2020; y las nuevas normas sobre el IVA para la venta de bienes y servicios por Internet que entrarán en vigor en 2021 (Comisión Europea, 2019h).

En 2018, la Comisión Europea aprobó un plan de acción en materia de tecnología financiera para fomentar un sector financiero europeo más competitivo e innovador. En el plan de acción se establecen 19 medidas que la Comisión Europea se propone adoptar para permitir que los modelos de negocio innovadores amplíen su escala a nivel de la UE; apoyar la adopción de nuevas tecnologías, como blockchain, la inteligencia artificial y los servicios en la nube en el sector financiero; y aumentar la ciberseguridad y la integridad del sistema financiero (Comisión Europea, 2018b).

La iniciativa CIAT-SECO armoniza los intereses y recursos para identificar y apoyar asuntos prioritarios relacionados con la gestión eficaz de los ingresos fiscales en América Latina y el Caribe. Las administraciones tributarias de Bolivia, El Salvador, Guatemala, Guyana, Honduras y Nicaragua recibieron apoyo (principalmente asistencia técnica) en 2015-18. La Superintendencia de Administración Tributaria de Guatemala también recibió apoyo en el ámbito de la facturación electrónica. La arquitectura tecnológica cuenta con los estándares y requerimientos para ampliar su escala (CIAT, 2018).

\begin{tabular}{|c|c|c|c|}
\hline \multicolumn{4}{|c|}{ Trampa de la vulnerabilidad social } \\
\hline $\begin{array}{l}\text { Alfabetización } \\
\text { digital/futuro } \\
\text { del trabajo }\end{array}$ & $\begin{array}{l}\text { Cooperación } \\
\text { multilateral }\end{array}$ & $\begin{array}{l}\text { Alemania, } \\
\text { Suiza, Banco } \\
\text { Interamericano de } \\
\text { Desarrollo }\end{array}$ & $\begin{array}{l}\text { Un fondo multidonante de } 13 \text { millones de dólares acelerará la transformación } \\
\text { de la educación y la capacitación técnica y profesional en América Latina y el } \\
\text { Caribe (BID, 2019). }\end{array}$ \\
\hline $\begin{array}{l}\text { Transferencias } \\
\text { digitales de } \\
\text { dinero en } \\
\text { efectivo }\end{array}$ & $\begin{array}{l}\text { Cooperación } \\
\text { multilateral }\end{array}$ & $\begin{array}{l}\text { Fundaciones, } \\
\text { organizaciones no } \\
\text { gubernamentales, } \\
\text { organismos } \\
\text { internacionales, } \\
\text { Colombia, República } \\
\text { Dominicana, } \\
\text { México, Paraguay, } \\
\text { Perú, Uruguay, } \\
\text { otros }\end{array}$ & $\begin{array}{l}\text { La Alianza Better than Cash es una asociación de gobiernos, empresas y } \\
\text { organismos internacionales que acelera la transición desde los pagos en } \\
\text { efectivo a los sistemas de pago digital para reducir la pobreza e impulsar el } \\
\text { crecimiento inclusivo (Better Than Cash Alliance, 2019). }\end{array}$ \\
\hline $\begin{array}{l}\text { Plataforma/ } \\
\text { regulación } \\
\text { laboral de } \\
\text { la economía } \\
\text { digital }\end{array}$ & $\begin{array}{l}\text { Cooperación } \\
\text { multilateral }\end{array}$ & Unión Europea & $\begin{array}{l}\text { En 2018, el Centro Común de Investigación de la Comisión Europea publicó } \\
\text { un estudio sobre el marco jurídico europeo de las plataformas laborales } \\
\text { digitales, en el que se analizaba cómo estas influyen cada vez más en los } \\
\text { derechos de los trabajadores y cómo salvaguardar sus derechos (Centro } \\
\text { Común de Investigación de la Comisión Europea, 2018). }\end{array}$ \\
\hline
\end{tabular}




\begin{tabular}{|c|c|c|}
\hline Área de trabajo & Modalidad & Socios \\
\hline $\begin{array}{l}\text { Empleo formal/ } \\
\text { futuro del } \\
\text { trabajo }\end{array}$ & $\begin{array}{l}\text { Cooperación } \\
\text { multilateral }\end{array}$ & Unión Europea \\
\hline $\begin{array}{l}\text { Certificación } \\
\text { común de grado } \\
\text { superior/técnico }\end{array}$ & $\begin{array}{l}\text { Cooperación } \\
\text { multilateral }\end{array}$ & Unión Europea \\
\hline $\begin{array}{l}\text { Certificación } \\
\text { común de grado } \\
\text { superior/técnico }\end{array}$ & $\begin{array}{l}\text { Cooperación } \\
\text { multilateral }\end{array}$ & Unión Europea \\
\hline $\begin{array}{l}\text { Certificación } \\
\text { común de grado } \\
\text { superior/técnico }\end{array}$ & $\begin{array}{l}\text { Cooperación } \\
\text { multilateral }\end{array}$ & $\begin{array}{l}\text { Espacio Europeo de } \\
\text { Educación Superior } \\
\text { (EEES), Comisión } \\
\text { Europea }\end{array}$ \\
\hline $\begin{array}{l}\text { Inversiones en } \\
\text { infraestructuras } \\
\text { para zonas } \\
\text { fronterizas } \\
\text { rurales }\end{array}$ & $\begin{array}{l}\text { Cooperación } \\
\text { multilateral }\end{array}$ & Unión Europea \\
\hline Salud & $\begin{array}{l}\text { Cooperación } \\
\text { multilateral }\end{array}$ & Unión Europea \\
\hline $\begin{array}{l}\text { Salud/seguridad } \\
\text { alimentaria }\end{array}$ & $\begin{array}{l}\text { Cooperación } \\
\text { multilateral }\end{array}$ & $\begin{array}{l}\text { Unión Europea, UK } \\
\text { Aid, Fundación Bill y } \\
\text { Melinda Gates }\end{array}$ \\
\hline
\end{tabular}

El Grupo de Expertos de Alto Nivel sobre las repercusiones de la

transformación digital en los mercados laborales de la UE, integrado por representantes del mundo académico, la sociedad civil y la industria, proporciona análisis y asesoramiento a la Comisión Europea y estudia las opciones de políticas (Comisión Europea, 2019i).

La base de datos del Registro Europeo de la Educación Superior proporciona datos detallados sobre 2.465 instituciones de 32 países europeos a nivel de grado, maestría y doctorado. Los datos incluyen el tamaño de la institución, el número y el género del alumnado y del personal, las áreas temáticas y los niveles de titulación, así como información sobre investigación, estudiantes y personal internacional y financiamiento. Gracias a la información de las autoridades nacionales de estadística, el Registro Europeo de la Educación Superior complementa otros datos sobre el desempeño de las universidades $y$ las estadísticas de enseñanza superior a nivel de sistema (ETER, 2019). El Marco Europeo de Cualificaciones (MEC) es una herramienta de traducción que facilita la comunicación y comparación entre los sistemas de cualificaciones europeos (Unión Europea, 2019).

A través del EEES, un total de 48 países acuerdan y adoptan reformas en el ámbito de la enseñanza superior con arreglo a unos valores comunes, como la libertad de expresión y la autonomía institucional. Los países, instituciones y demás grupos de interés del EEES adaptan continuamente los sistemas de enseñanza superior para hacerlos más compatibles y reforzar sus mecanismos de garantía de la calidad. El objetivo principal es aumentar la movilidad del personal y del alumnado y facilitar la empleabilidad (EEES, 2019).

El proyecto Rural Network (RuNe) es una red de fibra de acceso abierto que abarca zonas con un promedio de 36 habitantes (y en ocasiones tan solo 3 habitantes) por kilómetro cuadrado. La red RuNe está financiada por Connecting Europe Broadband Fund, una plataforma de capital privado que promueve la inversión en banda ancha en zonas donde no hay red y no se dispone de capital inicial (Rural Network Project, 2019).

La Red de Sanidad Electrónica, creada en virtud de la Directiva 2011/24/UE relativa a los derechos de los pacientes en la atención sanitaria transfronteriza, conecta a las autoridades nacionales responsables de la sanidad electrónica. Los países de la UE pueden orientar el desarrollo de la sanidad electrónica en Europa desempeñando un papel importante en la toma de decisiones estratégicas sobre interoperabilidad y normalización en el ámbito de la prestación electrónica de servicios de salud. El plan de acción de sanidad electrónica apoya esta red a través de orientaciones técnicas y científicas para facilitar la atención sanitaria transfronteriza en toda la Unión Europea y proporciona el apoyo necesario en materia de políticas a la infraestructura del servicio digital de sanidad electrónica (Comisión Europea, 2019j).

Las Plataformas Nacionales de Información sobre Nutrición (NIPN) son una iniciativa mundial puesta en marcha por la Comisión Europea para proporcionar información sobre seguridad alimentaria y nutrición a los responsables de la formulación de políticas de diez países en desarrollo, entre los que se incluye Guatemala, con el fin de combatir la malnutrición (NIPN, 2020).

\begin{tabular}{|c|c|c|c|}
\hline \multirow[t]{3}{*}{$\begin{array}{l}\text { Educación } \\
\text { por medios } \\
\text { electrónicos }\end{array}$} & \multirow[t]{2}{*}{$\begin{array}{l}\text { Cooperación } \\
\text { multilateral }\end{array}$} & \multirow[t]{2}{*}{ Unión Europea } & $\begin{array}{l}\text { El marco estratégico para la cooperación europea en el ámbito de la } \\
\text { educación y la formación (marco ET 2020) es un foro que permite a los } \\
\text { Estados miembros desarrollar las mejores prácticas en materia de política } \\
\text { educativa, así como reunir y difundir conocimientos y avanzar en las reformas } \\
\text { de la política educativa a nivel nacional y regional. }\end{array}$ \\
\hline & & & $\begin{array}{l}\text { Este marco se basa en un modelo de aprendizaje permanente y aborda } \\
\text { los resultados, desde la primera infancia hasta la formación profesional } \\
\text { de adultos y la educación superior, abarcando el aprendizaje en todos los } \\
\text { contextos: formal, no formal e informal (Comisión Europea, 2020b). }\end{array}$ \\
\hline & $\begin{array}{l}\text { Cooperación } \\
\text { multilateral }\end{array}$ & Unión Europea & $\begin{array}{l}\text { El programa CAPITAL (para creación de capacidad colaborativa en el ámbito } \\
\text { de los sistemas de transporte inteligente), financiado por la Unión Europea, } \\
\text { es un programa dirigido a desarrollar la capacidad de colaboración y el } \\
\text { despliegue de recursos, y ofrece formación a grupos de interés públicos y } \\
\text { privados que aplican sistemas de transporte cooperativos e inteligentes al } \\
\text { tiempo que sensibiliza sobre los servicios y sus beneficios (CAPITAL, 2016). }\end{array}$ \\
\hline
\end{tabular}




\begin{tabular}{|c|c|c|c|}
\hline Área de trabajo & Modalidad & Socios & Políticas \\
\hline $\begin{array}{l}\text { Inversiones en } \\
\text { infraestruc- } \\
\text { turas para la } \\
\text { educación y la } \\
\text { investigación }\end{array}$ & $\begin{array}{l}\text { Cooperación } \\
\text { multilateral }\end{array}$ & $\begin{array}{l}\text { Unión Europea, } \\
\text { redes nacionales } \\
\text { de investigación y } \\
\text { educación (RNIE) } \\
\text { de Alemania, Brasil, } \\
\text { Chile, Colombia, } \\
\text { Ecuador, España, } \\
\text { Francia, Italia, } \\
\text { Portugal }\end{array}$ & $\begin{array}{l}\text { El programa BELLA (Building the Europe Link with Latin America) atiende } \\
\text { las necesidades de interconexión a largo plazo de las comunidades de } \\
\text { investigación y educación europeas y latinoamericanas. BELLA logrará este } \\
\text { vínculo mediante la adquisición de un derecho de uso irrevocable a largo } \\
\text { plazo sobre espectro en un cable submarino de fibra óptica entre las dos } \\
\text { regiones, reduciendo así la latencia. El programa también está desarrollando } \\
\text { y desplegando una red de investigación y educación con capacidad de } 100 \\
\text { Gbps en toda América Latina. Está financiado por tres Direcciones de la } \\
\text { Comisión Europea (DG-CONNECT, DG-DEVCO y DG-GROWTH) y por la } \\
\text { comunidad latinoamericana de RNIE (BELLA, 2019). }\end{array}$ \\
\hline \multicolumn{4}{|r|}{ Trampa institucional } \\
\hline \multirow[t]{3}{*}{ Ciberseguridad } & $\begin{array}{l}\text { Cooperación } \\
\text { bilateral }\end{array}$ & Chile, España & $\begin{array}{l}\text { Chile y España cooperan en materia de ciberseguridad para hacer frente al } \\
\text { riesgo de ataques a los sistemas informáticos de los organismos oficiales } \\
\text { y a los sistemas financieros y de seguridad. El acuerdo cita un nivel óptimo } \\
\text { de cooperación técnica y un elevado nivel de diálogo en la lucha contra el } \\
\text { terrorismo, el narcotráfico y el crimen organizado (Ministerio de Relaciones } \\
\text { Exteriores, 2018). }\end{array}$ \\
\hline & & $\begin{array}{l}\text { Unión Europea, } \\
\text { Brasil }\end{array}$ & $\begin{array}{l}\text { En } 2014 \text { se puso en marcha el diálogo de cibercooperación entre la Unión } \\
\text { Europea y Brasil, que coordina esfuerzos para lograr un comportamiento } \\
\text { estatal responsable en el ciberespacio. En la última reunión de febrero } \\
\text { de 2020, las regiones intercambiaron información sobre amenazas a la } \\
\text { ciberseguridad, la creación de capacidad y las medidas de fomento de } \\
\text { la confianza, y determinaron posibles áreas para reforzar la cooperación } \\
\text { (Servicio Europeo de Acción Exterior, 2020). }\end{array}$ \\
\hline & $\begin{array}{l}\text { Cooperación } \\
\text { multilateral }\end{array}$ & Unión Europea & $\begin{array}{l}\text { En 2017, la Comisión Europea adoptó un paquete de ciberseguridad } \\
\text { que incluye una propuesta de la Agencia de la Unión Europea para la } \\
\text { Ciberseguridad (ENISA) para ayudar a los Estados miembros a hacer frente a } \\
\text { ciberataques, y un nuevo plan de certificación europeo para asegurar que los } \\
\text { productos y servicios digitales sean seguros. La Ley de Ciberseguridad, que } \\
\text { constituye el núcleo del paquete, ya ha entrado en vigor dando lugar a dos } \\
\text { cambios: un nuevo mandato permanente y una amplia reforma de la ENISA, y } \\
\text { la creación de un marco de certificación europeo que sustentará el creciente } \\
\text { mercado de la ciberseguridad en Europa. En enero de 2020, la Unión Europea } \\
\text { publicó una comunicación sobre la ciberseguridad de las redes de } 5 \mathrm{G} \text {, que } \\
\text { incluía una serie de medidas para la mitigación de riesgos. En medio de la } \\
\text { actual pandemia de coronavirus (Covid-19), la Unión Europea elaboró un } \\
\text { modelo para el rastreo eficiente de contactos, publicando una batería de } \\
\text { herramientas para el uso de aplicaciones móviles voluntarias y conformes } \\
\text { con los requisitos de privacidad (Comisión Europea, 2019e). }\end{array}$ \\
\hline \multirow[t]{3}{*}{$\begin{array}{l}\text { Protección } \\
\text { de datos y } \\
\text { gobernanza }\end{array}$} & $\begin{array}{l}\text { Cooperación } \\
\text { multilateral }\end{array}$ & $\begin{array}{l}\text { Andorra, Argentina, } \\
\text { Chile, Colombia, } \\
\text { Costa Rica, España, } \\
\text { México, Perú, } \\
\text { Uruguay }\end{array}$ & $\begin{array}{l}\text { La Red Iberoamericana de Protección de Datos se puso en marcha en } \\
2003 \text { como un foro para el intercambio de conocimientos y el debate sobre } \\
\text { iniciativas de protección de datos. Está respaldada por el Fondo Europeo de } \\
\text { Desarrollo Regional y promueve la cooperación iberoamericana hacia marcos } \\
\text { comunes de protección de datos para permitir un flujo transfronterizo de } \\
\text { datos eficaz y facilitar la cooperación internacional entre las autoridades } \\
\text { responsables (Red Iberoamericana de Protección de Datos, 2019). }\end{array}$ \\
\hline & & $\begin{array}{l}\text { Unión Europea, } \\
\text { Brasil }\end{array}$ & $\begin{array}{l}\text { La Ley General de Protección de Datos Personales de Brasil aplica medidas } \\
\text { similares a las del Reglamento General de Protección de Datos de la Unión } \\
\text { Europea (Presidência da República, 2018). }\end{array}$ \\
\hline & & $\begin{array}{l}\text { Unión Europea, } \\
\text { Alemania, Barbados, } \\
\text { Organismo de } \\
\text { Desarrollo de las } \\
\text { Exportaciones del } \\
\text { Caribe, CARIFORUM }\end{array}$ & $\begin{array}{l}\text { La Unión Europea promueve las normas de protección de datos en los países } \\
\text { del Caribe mediante el Instrumento de Asistencia Técnica e Intercambio de } \\
\text { Información (TAIEX) de la Comisión Europea (Comisión Europea, 2020c). }\end{array}$ \\
\hline $\begin{array}{l}\text { Creación de } \\
\text { capacidad/ } \\
\text { competencias } \\
\text { digitales de } \\
\text { funcionarios } \\
\text { públicos }\end{array}$ & $\begin{array}{l}\text { Cooperación } \\
\text { bilateral }\end{array}$ & $\begin{array}{l}\text { El Salvador, } \\
\text { Uruguay }\end{array}$ & $\begin{array}{l}\text { El Salvador recibe asistencia técnica de los expertos de la Agencia Uruguaya } \\
\text { de Gobierno Electrónico y Sociedad de la Información y la Comunicación en } \\
\text { temas digitales. Los proyectos tienen por objeto capacitar a los funcionarios } \\
\text { públicos para promover la transformación digital de las administraciones } \\
\text { públicas (Red de gobierno electrónico de América Latina y el Caribe, 2019). }\end{array}$ \\
\hline
\end{tabular}




\begin{tabular}{lll}
\hline Área de trabajo & Modalidad & Socios \\
\hline $\begin{array}{l}\text { Cooperación } \\
\text { multilateral }\end{array}$ & $\begin{array}{l}\text { Red de } \\
\text { organizaciones } \\
\text { europeas de } \\
\text { formación para } \\
\text { autoridades locales } \\
\text { y regionales (Red } \\
\text { ENTO) }\end{array}$ \\
$\begin{array}{l}\text { Gobierno } \\
\text { abierto }\end{array}$ & $\begin{array}{l}\text { Cooperación } \\
\text { bilateral }\end{array}$ & $\begin{array}{l}\text { Unión Europea, } \\
\text { Colombia }\end{array}$ \\
\hline $\begin{array}{l}\text { Gobierno } \\
\text { abierto }\end{array}$ & $\begin{array}{l}\text { Cooperación } \\
\text { multilateral }\end{array}$ & Unión Europea \\
\hline
\end{tabular}

Antes de convertirse en asociación independiente, el Consejo de Europa creó

en 1995 la red europea de organizaciones de formación para autoridades

locales y regionales (ENTO) con el fin de promover una gobernanza

democrática y eficaz asegurando que el personal y los representantes elegidos de las autoridades locales y regionales estuvieran bien capacitados y cualificados para desempeñar sus responsabilidades en un mundo en constante evolución. La red ENTO permite el desarrollo de asociaciones bilaterales y multilaterales y hace posible que los organismos de formación y las autoridades locales ofrezcan a su personal cursos, estudios y visitas oficiales (ENTO, 2020).

El proyecto ACTUE Colombia, financiado por la Unión Europea, comenzó en 2014 y finalizó en 2018, y tenía como objetivo aumentar la integridad y la transparencia, y luchar contra la corrupción. Los objetivos incluían la promoción de un gobierno abierto y del control ciudadano sobre las entidades públicas (ACTUE Colombia, 2017).

En 2016, la Comisión Europea publicó dos estudios sobre gobierno abierto. Towards faster implementation and uptake of open Governmenty Analysis of the value of the new generation of eGovernment services and how can the public sector become an agent of innovation through ICT proporcionan importantes conocimientos sobre los servicios de gobierno abierto y su valor potencial, y arrojan luz sobre la forma en que las administraciones públicas y los responsables de la formulación de políticas pueden establecer prácticas de gobierno abierto y fomentar el cambio a través de las TIC (PWC, 2016; PwC, Open Evidence y the Institute of Baltic Studies, 2016).

$\begin{array}{lll}\text { Datos abiertos } & \begin{array}{l}\text { Cooperación } \\ \text { multilateral }\end{array} & \text { Unión Europea } \\ \text { Medición de la } & \begin{array}{l}\text { Cooperación } \\ \text { transformación }\end{array} & \begin{array}{l}\text { Unión Europea, 17 } \\ \text { países de América } \\ \text { digital }\end{array} \\ & \begin{array}{l}\text { Latina y el Caribe, } \\ \text { España }\end{array}\end{array}$

El Portal de datos abiertos de la UE, creado en 2012, proporciona acceso público a una gama cada vez mayor de datos de las instituciones de la UE y otros órganos europeos, que pueden impulsar el desarrollo económico y la transparencia institucional de la región (Portal de datos abiertos de la UE, 2020).

Con el apoyo del programa EUROsociAL de la Unión Europea, la Red de Transparencia y Acceso a la Información, formada por entidades públicas responsables en América Latina y el Caribe y España, desarrolló un modelo internacional para medir la transparencia y el acceso a la información en los países miembros (Red de Transparencia y Acceso a la Información, 2019).

\begin{tabular}{lll} 
Gobierno digital & $\begin{array}{l}\text { Cooperación } \\
\text { bilateral }\end{array}$ & Francia, México \\
\hline $\begin{array}{l}\text { Agenda digital/ } \\
\text { estrategias }\end{array}$ & $\begin{array}{l}\text { Cooperación } \\
\text { multilateral }\end{array}$ & $\begin{array}{l}\text { Colombia, Suecia, } \\
\text { Agencia de }\end{array}$ \\
$\begin{array}{l}\text { o planes } \\
\text { nacionales de }\end{array}$ & & $\begin{array}{l}\text { Estados Unidos } \\
\text { para el Desarrollo } \\
\text { desarrollo/ } \\
\text { transformación } \\
\text { digital }\end{array}$ \\
\hline
\end{tabular}

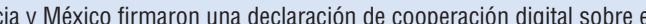
cambio cultural y tecnológico. El proyecto inicia una cooperación entre la información y la democracia con el fin de luchar contra la desinformación (noticias falsas) (Embajada de México en Francia, 2019).

A través de la cooperación internacional, el Departamento Nacional de Planeación de Colombia desarrolló la aplicación "Terridata", un portal de consulta estadística que ayuda a los responsables regionales y locales a ser más eficientes en la formulación de planes de desarrollo (Departamento Nacional de Planeación, 2018).

digital

\begin{tabular}{|c|c|c|c|}
\hline \multicolumn{4}{|r|}{ Trampa ambiental } \\
\hline $\begin{array}{l}\text { Almacenamiento } \\
\text { de datos para el } \\
\text { medio ambiente/ } \\
\text { observación de } \\
\text { la Tierra }\end{array}$ & $\begin{array}{l}\text { Cooperación } \\
\text { multilateral }\end{array}$ & Unión Europea & $\begin{array}{l}\text { El Programa de Observación de la Tierra de la UE (programa Copérnico) } \\
\text { presta servicios de información basados en la observación de la Tierra desde } \\
\text { satélites y datos in situ (no espaciales). Los servicios son gratuitos y pueden } \\
\text { utilizarse para aplicaciones en diversas esferas, como gestión de zonas } \\
\text { urbanas, desarrollo sostenible y protección de la naturaleza, planificación } \\
\text { regional y local, agricultura, silvicultura y pesca, salud, protección civil, } \\
\text { infraestructura, transporte y movilidad, y turismo. Los responsables de la } \\
\text { formulación de políticas y las autoridades públicas lo utilizan principalmente } \\
\text { para elaborar legislación y políticas ambientales o tomar decisiones en } \\
\text { casos de emergencia, como en catástrofes naturales o crisis humanitarias } \\
\text { (Copérnico, 2020). }\end{array}$ \\
\hline $\begin{array}{l}\text { Gestión de } \\
\text { desechos } \\
\text { de aparatos } \\
\text { eléctricos }\end{array}$ & $\begin{array}{l}\text { Cooperación } \\
\text { multilateral }\end{array}$ & Unión Europea & $\begin{array}{l}\text { En 2017, la Comisión Europea estableció una metodología común para } \\
\text { calcular el peso de los equipos eléctricos y electrónicos en el mercado } \\
\text { nacional de cada Estado miembro y la cantidad de residuos generados por } \\
\text { peso (Comisión Europea, 2017). }\end{array}$ \\
\hline
\end{tabular}




\begin{tabular}{|c|c|c|c|}
\hline Área de trabajo & Modalidad & Socios & Políticas \\
\hline $\begin{array}{l}\text { Modos de } \\
\text { transporte } \\
\text { inteligentes/ } \\
\text { ciudades } \\
\text { inteligentes }\end{array}$ & $\begin{array}{l}\text { Cooperación } \\
\text { subnacional } \\
\text { (ciudad a } \\
\text { ciudad) }\end{array}$ & $\begin{array}{l}\text { Unión Europea, } \\
\text { ciudades de } \\
\text { América Latina y el } \\
\text { Caribe }\end{array}$ & $\begin{array}{l}\text { El Programa de Cooperación Urbana Internacional, de tres años de } \\
\text { duración, permite a ciudades de diversas regiones del mundo entrar en } \\
\text { contacto y compartir soluciones a problemas comunes. Esta cooperación } \\
\text { de ciudad a ciudad en materia de desarrollo urbano sostenible empareja a } \\
\text { ciudades asociadas de la UE con ciudades de otras regiones y fomenta el } \\
\text { acceso a conocimientos especializados en materia de políticas, ayudando } \\
\text { a las ciudades a promover un crecimiento inteligente, verde e integrador } \\
\text { (Programa de Cooperación Urbana Internacional, 2019). }\end{array}$ \\
\hline Formación & $\begin{array}{l}\text { Cooperación } \\
\text { triangular }\end{array}$ & $\begin{array}{l}\text { Alemania, Brasil, } \\
\text { Perú }\end{array}$ & $\begin{array}{l}\text { Para cumplir con las nuevas regulaciones y criterios ambientales impuestos } \\
\text { a los exportadores por los mercados internacionales, las industrias peruanas } \\
\text { necesitaban expertos en tecnología ambiental, sobre todo en el ámbito de } \\
\text { los servicios de asesoramiento y de laboratorio. El Centro de Tecnologías } \\
\text { Ambientales de Perú (2012-14) fue creado para ofrecer capacitación adaptada } \\
\text { a las necesidades del mercado (GIZ, 2014). }\end{array}$ \\
\hline $\begin{array}{l}\text { Conservación } \\
\text { de bosques }\end{array}$ & $\begin{array}{l}\text { Cooperación } \\
\text { multilateral }\end{array}$ & $\begin{array}{l}\text { Unión Europea, } \\
\text { Asociación de } \\
\text { Comunidades } \\
\text { Forestales de } \\
\text { Petén (ACOFOP), } \\
\text { Guatemala, ICOO } \\
\text { Cooperation }\end{array}$ & $\begin{array}{l}\text { Con el apoyo de la UE, Ias ONG ACOFOP e ICOO Cooperation llevaron a cabo } \\
\text { talleres sobre el uso de drones para vigilar el trabajo comunitario en los } \\
\text { bosques e iniciar alertas tempranas de incendios (Delegación de la Unión } \\
\text { Europea en Guatemala, 2018). }\end{array}$ \\
\hline
\end{tabular}

Fuente: Elaboración propia.

\section{Notas}

1. Por ejemplo, el Grupo de Expertos Gubernamentales de las Naciones Unidas sobre los avances en la esfera de la información y las telecomunicaciones en el contexto de la seguridad internacional y el Grupo de Trabajo de composición abierta, la Unión Internacional de Telecomunicaciones y su Índice mundial de ciberseguridad, y el Simposio Mundial para Organismos Reguladores ayudan a definir nuevas normas de ciberseguridad en todo el mundo. La Organización Mundial de la Propiedad Intelectual de las Naciones Unidas realiza esfuerzos similares para proteger la propiedad intelectual.

2. Un programa de integración y cooperación para el desarrollo entre Belice, Colombia, Costa Rica, República Dominicana, El Salvador, Guatemala, Honduras, México, Nicaragua y Panamá.

3. Una institución especializada en el marco del SICA que coordina, apoya y armoniza el desarrollo de los sectores de las telecomunicaciones y las TIC.

4. Argentina, Brasil, Colombia, Costa Rica, República Dominicana, Honduras, México, Panamá y Perú.

5. Anguila, Antigua y Barbuda, Argentina, Aruba, Bahamas, Barbados, Belice, Bermudas, Brasil, Islas Vírgenes Británicas, Islas Caimán, Chile, Colombia, Costa Rica, Curazao, Dominica, República Dominicana, Granada, Haití, Honduras, Jamaica, México, Montserrat, Panamá, Paraguay, Perú, Saint Kitts y Nevis, Santa Lucía, San Vicente y las Granadinas, Trinidad y Tobago, Islas Turcas y Caicos y Uruguay.

6. Cuatro de los 24 puestos del grupo rector del Marco Inclusivo sobre BEPS están ocupados actualmente por economías de América Latina y el Caribe (Argentina, Brasil, Colombia y Jamaica).

\section{Referencias}

ACTUE Colombia (2017), "ACTUE Colombia - Proyecto Anticorrupción y Transparencia de la Unión Europea para Colombia” (página web), Fundación Internacional y para Iberoamérica de Administración y Políticas Públicas, Madrid, http://actuecolombia.net/.

Alianza del Pacífico (2016), Hoja de Ruta - Subgrupo de Agenda Digital, Alianza del Pacífico, Puerto Varas, https://alianzapacifico.net/wp-content/uploads/Hoja-de-Ruta-SGAD2016-2017.pdf.

Alianza para el Gobierno Abierto (2020), Alianza para el Gobierno Abierto (página web), Open Government Partnership, Washington, DC, www.opengovpartnership.org.

Basto-Aguirre, N., P. Cerutti y S. Nieto-Parra (2020), "COVID-19 can widen educational gaps in Latin America: Some lessons for urgent policy action" (blog), Vox Lacea, Bogotá, https://vox.lacea. org/? $=$ =blog/covid19 widen educational gaps. 
BELLA (2019), "BELLA - Building the Europe Link with Latin America” (página web), Consorcio BELLA, Cambridge, http://www.bella-programme.eu/.

Better Than Cash Alliance (2019), "Better Than Cash Alliance” (página web), Fondo de las Naciones Unidas para el Desarrollo de la Capitalización, Nueva York, www.betterthancash.org.

BID (2019), "BID, Alemania y Suiza se asocian para transformar la formación profesional en ALC" (comunicado de prensa), Banco Interamericano de Desarrollo, Washington, DC, www.iadb. org/es/noticias/bid-alemania-y-suiza-se-asocian-para-transformar-la-formacion-profesionalen-alc.

CAPITAL (2016), "Collaborative Capacity Programme on ITS Training-education and Liaison CAPITAL" (página web), CAPITAL project C/O ERTICO - ITS Europa, Bruselas, https://capitalproject.its-elearning.eu.

Centro Común de Investigación de la Comisión Europea (2018), European legal framework for "digital labour platforms", Comisión Europea, Luxemburgo, https://publications.jrc.ec.europa. eu/repository/bitstream/JRC112243/jrc112243_legal_framework_digital_labour_platforms final.pdf.

CEPAL (2019), Panorama fiscal de América Latina y el Caribe 2019: políticas tributarias para la movilización de recursos en el marco de la Agenda 2030 para el Desarrollo Sostenible, Naciones Unidas, Santiago, https://repositorio.cepal.org/bitstream/handle/11362/44517/1/S1900074 en.pdf.

CEPAL (2018a), Agenda Digital para América Latina y el Caribe (eLAC2020), Sexta Conferencia Ministerial sobre la Sociedad de la Información de América Latina y el Caribe, Comisión Económica para América Latina y el Caribe, Cartagena de Indias, https://conferenciaelac.cepal. org/6/sites/elac2020/files/cmsi.6 digital agenda-en-23 april.pdf.

CEPAL (2018b), Mercado digital regional: Aspectos estratégicos, Naciones Unidas, Santiago, https:// www.cepal.org/en/publications/43633-regional-digital-market-strategic-aspects.

CEPAL (2016), La nueva revolución digital: de la Internet del consumo a la Internet de la producción, Naciones Unidos, Santiago, https://repositorio.cepal.org/bitstream/handle/11362/38767/S1600779 en.pdf? sequence $=4 \&$ is Allowed $=\mathrm{y}$.

CIAT (2018), "Programa de Cooperación CIAT-SECO - Tres años contribuyendo al fortalecimiento de administraciones tributarias de América Latina y el Caribe (ALC)" (comunicado de prensa), Centro Interamericano de Administraciones Tributarias, Panamá, www.ciat.org/ programa-de-cooperacion-ciat-seco-tres-anos-contribuyendo-al-fortalecimiento-deadministraciones-tributarias-de-america-latina-y-el-caribe-alc/.

Comisión Europea (2020a), “Asociaciones Digitales" (página web), Cooperación Internacional y Desarrollo, Comisión Europea, Bruselas, https://ec.europa.eu/international-partnerships/ priorities/digital-partnerships en.

Comisión Europea (2020b), “Política europea de cooperación (marco ET 2020)" (página web), Comisión Europea, Bruselas, https://ec.europa.eu/education/policies/european-policycooperation/et2020-framework en.

Comisión Europea (2020c), "Servicio de Instrumentos de Política Exterior (FPI) - EU is promoting data protection standards in the Caribbean countries thanks to TAIEX-Partnership Instrument" (página web), Comisión Europea, Bruselas, https://ec.europa.eu/fpi/news/ eu-promoting-data-protection-standards-caribbean-countries-thanks-taiex-partnershipinstrument_en.

Comisión Europea (2019), "Configurar el futuro digital de Europa" (página web), Comisión Europea, Bruselas, https://ec.europa.eu/info/strategy/priorities-2019-2024/europe-fit-digitalage/shaping-europe-digital-future_en.

Comisión Europea (2019a), "Configurar el futuro digital de Europa: Ficha informativa/ Infografía - Un mercado único digital en beneficio de todos los europeos" (página web), Comisión Europea, Bruselas, https://ec.europa.eu/digital-single-market/en/news/digitalsingle-market-benefit-all-europeans.

Comisión Europea (2019b), "Mercado Único Digital" (página web), Comisión Europea, Bruselas, https://ec.europa.eu/digital-single-market/en/policies/shaping-digital-single-market, (consultada el 16 de octubre de 2019).

Comisión Europea (2019c), "Shaping Europe's digital future: Policy - Women in Digital" (página web), Comisión Europea, Bruselas, https://ec.europa.eu/digital-single-market/en/women-ict.

Comisión Europea (2019d), "Configurar el futuro digital de Europa: Política - Libre circulación de datos no personales" (página web), Comisión Europea, Bruselas, https://ec.europa.eu/digitalsingle-market/en/free-flow-non-personal-data.

Comisión Europea (2019e), “Configurar el futuro digital de Europa: Digibyte, 26 de junio de 2019 - The EU Cybersecurity Act brings a strong agency for cybersecurity and EU- 
wide rules on cybersecurity certification" (página web), Comisión Europea, Bruselas, https://ec.europa.eu/digital-single-market/en/news/eu-cybersecurity-act-brings-strongagency-cybersecurity-and-eu-wide-rules-cybersecurity.

Comisión Europea (2019f), “Shaping Europe’s digital future” (página web), Comisión Europea, Bruselas, https://ec.europa.eu/info/strategy/priorities-2019-2024/europe-fit-digital-age/ shapingeurope-digital-future en.

Comisión Europea 2019g), "Excelencia y confianza en la inteligencia artificial" (página web), Comisión Europea, Bruselas, https://ec.europa.eu/info/strategy/priorities-2019-2024/europefit-digital-age/excellence-trust-artificial-intelligence_en.

Comisión Europea (2019h), "New EU rules on e-commerce” (página web), Comisión Europea, Bruselas, https://ec.europa.eu/digital-single-market/en/new-eu-rules-e-commerce.

Comisión Europea (2019i), "High-Level Expert Group on the Impact of the Digital Transformation on EU Labour Markets" (página web), Comisión Europea, Bruselas, https://ec.europa.eu/digital-single-market/en/high-level-expert-group-impact-digitaltransformation-eu-labour-markets.

Comisión Europea (2019j), “Red de Sanidad Electrónica” (página web), Comisión Europea, Bruselas https://ec.europa.eu/health/ehealth/policy/network en.

Comisión Europea (2018a), "Los Estados miembros y la Comisión colaborarán para impulsar la inteligencia artificial 'fabricada en Europa" (comunicado de prensa), Comisión Europea, Bruselas, https://ec.europa.eu/commission/presscorner/detail/en/IP 186689.

Comisión Europea (2018b), "Plan de acción en materia de tecnología financiera: por un sector financiero europeo más competitivo e innovador" (página web), Comisión Europea, Bruselas, https://ec.europa.eu/info/publications/180308-action-plan-fintech_en.

Comisión Europea (2017), Reglamento de Ejecución (UE) 2017/699 de la Comisión de 18 de abril de 2017 que establece una metodología común para el cálculo del peso de los aparatos eléctricos y electrónicos (AEE) introducidos en el mercado de cada Estado miembro y una metodología común para el cálculo de la cantidad de residuos de aparatos eléctricos y electrónicos (RAEE) generados en cada Estado miembro, expresada en peso (Texto con relevancia para el EEE), Comisión Europea, Bruselas, https://eur-lex.europa.eu/eli/ reg_impl/2017/699/oj.

Comisión Europea (2016), "La UE y Brasil colaborarán en el campo de la tecnología móvil 5G" (comunicado de prensa), Comisión Europea, Bruselas, https://ec.europa.eu/commission/ presscorner/detail/en/IP 16382.

Comisión Europea (2014), “CEF Digital Connecting Europe” (página web), Comisión Europea, Bruselas, https://ec.europa.eu/cefdigital/wiki/display/CEFDIGITAL/CEF+Digital+Home.

Comisión Europea (2008), Plan de acción conjunto de la Asociación Estratégica UE-Brasil, 2. ${ }^{a}$ Cumbre Brasil-Unión Europea, Río de Janeiro, 22 de diciembre de 2008, Comisión Europea, Bruselas, http://eeas.europa.eu/archives/docs/brazil/docs/2008_joint_action_plan_en.pdf.

Cooperación Nórdica (2018), "Nordic co-operation on digitalisation" (página web), Nordic Cooperation, Copenhague, www.norden.org/en/information/nordic-co-operation-digitalisation (consultada el 21 de abril de 2020).

Cooperación Nórdica (2017), "The Nordic-Baltic region: A digital frontrunner", The Nordic Council and the Nordic Council of Ministers, Copenhague, www.norden.org/en/declaration/nordicbaltic-region-digital-frontrunner, consultada el 21 de abril de 2020.

Copérnico (2020), "Copernicus" (página web), Comisión Europea, Bruselas, https://www. copernicus.eu/.

Cullen, I. (2016), Building a Digital Single Market Strategy for Latin America, Banco de Desarrollo de América Latina, Buenos Aires, http://scioteca.caf.com/handle/123456789/980.

Cullen International SA (2019), Regional and Sub-Regional Approaches to the Digital Economy: Lessons from Asia Pacific and Latin America, Banco de Desarrollo de América Latina, Caracas, http:// scioteca.caf.com/handle/123456789/1381.

Delegación de la Unión Europea en Guatemala (2018), “Drones para cuidar nuestra tierra, nuestros bosques" (página web), Delegación de la Unión Europea en Guatemala, Servicio Europeo de Acción Exterior, Ciudad de Guatemala, https://eeas.europa.eu/delegations/guatemala/49989/ drones-para-cuidar-nuestra-tierra-nuestros-bosques\%C2\%A0 en.

Departamento Nacional de Planeación (2018), “Terridata facilitará elaboración de los planes de desarrollo territoriales" (comunicado de prensa), Departamento Nacional de Planeación, Gobierno de Colombia, Bogotá, www.dnp.gov.co/Paginas/Terridata-facilitar\%C3\%A1-elaboraci \%C3\%B3n-de-los-planes-de-desarrollo-territoriales.aspx.

EEES (2019), "El Espacio Europeo de Educación Superior y el Proceso de Bolonia” (página web), Secretaría del Grupo de Seguimiento de Bolonia, Roma, http://www.ehea.info/. 
Embajada de México en Francia (2019), "Concluye exitosamente encuentro sobre tecnologías digitales y cultura en París" (comunicado de prensa), Embajada de México en Francia, Secretaría de Relaciones Exteriores, Gobierno de México, París, https:// embamex.sre.gob.mx/francia/index.php/es/comunicados/740-concluye-exitosamenteencuentro-sobre-tecnologias-digitales-y-cultura-en-paris.

EMnet (2020), "Leveraging the impact of new technologies", 2020 Policy Note on Latin America, Emerging Markets Network, OCDE, París, www.oecd.org/dev/EMnet-Latin-America-PolicyNote-2020.pdf.

ENTO (2020), "European Training Organisation Network for Local and Regional Authorities ENTO" (página web), Red europea de organizaciones de formación para autoridades locales y regionales, http://ento.org/.

ETER (2019), "Registro Europeo de la Educación Superior - ETER” (página web), Registro Europeo de la Educación Superior, Bruselas, www.eter-project.com.

EU Monitor (2019), Building Trust in Human-Centric Artificial Intelligence, Comunicación de la Comisión al Parlamento Europeo, al Consejo, al Comité Económico y Social Europeo y al Comité de las Regiones, ANP y PDC Informatie Architectuur, Den Haag, www.eumonitor.eu/9353000/1/ j9vvik7m1c3gyxp/vkxhedj2bkzc\#p1.

GIZ (2014), "Cooperación triangular entre Brasil, Perú y Alemania: Creación de un Centro de Tecnologías Ambientales (CTA) en el Perú" (página web), Deutsche Gesellschaft für Internationale Zusammenarbeit (GIZ), Berlín, www.giz.de/en/worldwide/11836.html.

iClaves (2018), Women in the Digital Age, informe final, preparado para la Comisión Europea, iClaves en colaboración con la Universitat Oberta de Catalunya, Unión Europea, Bruselas, https://ec.europa.eu/digital-single-market/en/news/increase-gender-gap-digital-sectorstudy-women-digital-age.

Merics (2019), "Networking the 'Belt and Road' - The future is digital”, Mercator Institute for China Studies, Berlin, https://merics.org/en/analysis/networking-belt-and-road-future-digital.

Ministério da Ciência, Tecnologia, Inovações e Comunicações (2017), "Brasil e União Europeia se unem para desenvolver Internet das Coisas e 5G" (comunicado de prensa), Ministério da Ciência, Tecnologia, Inovações e Comunicações, Governo Federal do Brasil, Brasilia, www. mctic.gov.br/mctic/opencms/salaImprensa/noticias/arquivos/migracao/2017/03/Brasil_e_ Uniao Europeia se unem para desenvolver Internet das Coisas e 5G.html.

Ministerio de Relaciones Exteriores (2018), "Chile y España firman acuerdos sobre inversión, ciberseguridad y movilidad" (comunicado de prensa), Ministerio de Relaciones Exteriores, Gobierno de Chile, Santiago, https://minrel.gob.cl/chile-y-espana-firman-acuerdos-sobreinversion-ciberseguridad-y/minrel/2018-10-09/184701.html.

Naciones Unidas (2020), Hoja de ruta para la cooperación digital, Informe del Secretario General, Publicaciones de las Naciones Unidas, Nueva York, www.un.org/en/content/digital-cooperationroadmap/.

NERA Economic Consulting, (2020), Contribución de las inversiones en conectividad al desarrollo de las sociedades latinoamericanas, NERA Economic Consulting, Madrid, www.nera.com/content/ $\mathrm{dam} /$ nera/publications/2020/2020.05.22\%20NERA\%20report $\% 20$ for $\% 2$ Facebook $\% 20 \% 20-\% 20$ final.pdf.

NIPN (2020), "Plataformas Nacionales de Información sobre Nutrición" (página web), Capacity for Nutrition, Bruselas, www.nipn-nutrition-platforms.org.

OEA (2018), Plan Estratégico de CITEL para 2018-2022, Organización de los Estados Americanos, Washington, DC, www.citel.oas.org/en/SiteAssets/About-Citel/Strategic Plan CITEL-20182022.pdf.

OCDE (2020a), “COVID-19 en América Latina y el Caribe: Consecuencias socioeconómicas y prioridades de política. Medidas políticas clave de la OCDE ante el coronavirus (COVID-19), Publicaciones de la OCDE, París, www.oecd.org/coronavirus/policy-responses/ COVID-19-in-latin-america-and-the-caribbean-regional-socio-economic-implications-andpolicy-priorities-93a64fde/\#section-d1e847.

OCDE (2020b), OECD.Stat (base de datos), OCDE, París, https://stats.oecd.org/.

OCDE (2020c), Informe fiscal del Secretario General de la OCDE para los ministros de finanzas y los gobernadores de los bancos centrales del G20 - Julio de 2020, Publicaciones de la OCDE, París, www. oecd.org/tax/oecd-secretary-general-tax-report-g20-finance-ministers-july-2020.pdf.

OCDE (2020d), Model Rules for Reporting by Platform Operators with respect to Sellers in the Sharing and Gig Economy, Publicaciones de la OCDE, París, www.oecd.org/tax/exchange-of-tax-information/ model-rules-for-reporting-by-platform-operators-with-respect-to-sellers-in-the-sharing-andgig-economy.htm. 
OCDE (2019a), El Enfoque Unificado: La propuesta del Secretariado relativa al Primer Pilar 9 de octubre - 12 de noviembre de 2019, Documento para consulta pública, OCDE, París, www.oecd.org /tax/beps/public-consultation-document-secretariat-proposal-unified-approach-pillar-one.pdf.

OCDE (2019b), Informe fiscal del Secretario General de la OCDE para los ministros de finanzas y los gobernadores de los bancos centrales del G20 - Octubre de 2019, Publicaciones de la OCDE, París, www.oecd.org/tax/oecd-secretary-general-tax-report-g20-finance-ministers-october-2019.pdf.

OCDE(2018a), "The Belt and Road Initiative in the global trade, investment and finance landscape", in OECD Business and Finance Outlook 2018, Publicaciones de la OCDE, París, https://doi.org/10.1787/ bus fin_out-2018-6-en.

OCDE (2018b), Desafíos fiscales derivados de la Digitalización: Informe provisional 2018: Marco Inclusivo sobre BEPS, Proyecto de la OCDE y del G20 sobre la Erosión de la Base Imponible y el Traslado de Beneficios, Publicaciones de la OCDE, París, https://doi.org/10.1787/9789264293083-en.

OCDE (2017), International VAT/GST Guidelines, Publicaciones de la OCDE, París, https://doi. org/10.1787/9789264271401-en.

OCDE (2015), Cómo abordar los desafíos fiscales de la Economía Digital, Acción 1 - Informe final de 2015, Proyecto de la OCDE y del G20 sobre la Erosión de la Base Imponible y el Traslado de Beneficios, Publicaciones de la OCDE, París, http://dx.doi.org/10.1787/9789264241046-en.

OCDE/BID (2016), Políticas de banda ancha para América Latina y el Caribe: Un manual para la economía digital, Publicaciones de la OCDE, París, https://doi.org/10.1787/9789264251823-en.

OCDE et al. (2019), Perspectivas económicas de América Latina 2019: Desarrollo en transición, Publicaciones de la OCDE, París, https://doi.org/10.1787/g2g9ff1a-es.

Portal de datos abiertos de la UE (2020), "Portal de datos abiertos de la UE" (página web), Unión Europea, Luxemburgo, https://data.europa.eu/euodp/en/home.

Presidência da República (2018), Lei n. 13.709 , del 14 de agosto de 2018, Lei Geral de Proteção de Dados Pessoais, Presidência da República, Secretaria-Geral, Subchefia para Assuntos Jurídicos, Brasilia, www.planalto.gov.br/ccivil 03/ ato2015-2018/2018/lei/L13709.htm.

Programa de Cooperación Urbana Internacional (2019), "Programa Internacional de Cooperación Urbana” (página web), International Urban Cooperation Coordination Unit, Bruselas, https:// iuc.eu/lac/inicio/.

Proyecto de Integración y Desarrollo de Mesoamérica (2020), "Resultados en beneficio de los países miembros" (página web), Proyecto de Integración y Desarrollo de Mesoamérica, San Salvador, www.proyectomesoamerica.org/index.php/ejes-de-trabajo/eje-social/26-ejes-detrabajo/296-resultados-proyectos-pm.

PwC (2016), Towards Faster Implementation and Uptake of Open Government, Informe final de PwC para la Comisión Europea, Unión Europea, Bruselas, https://ec.europa.eu/futurium/en/system/ files/ged/smart_2015-0041__final_layout_-_without_executive_summaryv.1.1_0.pdf.

PwC, Open Evidence and the Institute of Baltic Studies (2016), Analysis of the Value of New Generation of eGovernment Services and How Can the Public Sector Become an Agent of Innovation through ICT, Informe final, PwC, Open Evidence y the Institute of Baltic Studies para la Comisión Europea, Unión Europea, Bruselas, https://ec.europa.eu/futurium/en/system/files/ged/final report ogs web v3.0 0.pdf.

Red de gobierno electrónico de América Latina y el Caribe (2019), "Cooperación Horizontal de Uruguay con El Salvador" (comunicado de prensa), Organización de los Estados Americanos, Washington, DC, http://www.redgealc.org/contenido-general/noticias/cooperacion-horizontalentre-uruguay-el-salvador/.

Red de Transparencia y Acceso a la Información (2019), "Modelo Indicadores RTA" (página web), Red de Transparencia y Acceso a la Información, https://redrta.org/modelo-indicadores-rta/.

Red Iberoamericana de Protección de Datos (2019), "Red Iberoamericana de Protección de Datos" (página web), Agencia Española de Protección de Datos, Madrid, www.redipd.org/.

Rural Network Project (2019), "RuNe-Rural Network Project" (página web), Rural Network Project, Sežana, www.ruralnetwork.eu.

SEGIB (2020), Camino a la XXVII Cumbre, Innovación para el Desarrollo Sostenible, Objetivo 2030 (página web), www.segib.org/cumbres-iberoamericanas/camino-a-la-xxvii-cumbre/, consultada por última vez el 27 de agosto de 2020.

Servicio de Investigación del Parlamento Europeo - Unidad Europea de Valor Añadido (2017), Mapping the Cost of Non-Europe 2014-19, 4th ed., Parlamento Europeo, Bruselas, www.europarl. europa.eu/RegData/etudes/STUD/2017/603239/EPRS STU(2017)603239_EN.pdf. 
Servicio Europeo de Acción Exterior (2020), “2nd European Union - Brazil Cyber Dialogue takes place in Brussels" (comunicado de prensa), Unión Europea, Bruselas, https://eeas. europa.eu/headquarters/headquarters-homepage/75021/2nd-european-union-brazil-cyberdialogue-takes-place-brussels_en.

UNCTAD (2016), UNCTAD B2C E-COMMERCE Index 2016, Conferencia de las Naciones Unidas sobre Comercio y Desarrollo, UNCTAD Technical Notes on ICT for Development, n. ${ }^{\circ}$, Publicaciones de las Naciones Unidas, Nueva York, https://unctad.org/en/PublicationsLibrary/tn_unctad ict4d07_en.pdf.

Unión Europea (2019), “Marco Europeo de Cualificaciones” (página web), Unión Europea, Bruselas, https://europa.eu/europass/en/european-qualifications-framework-eqf.

Von der Leyen, U. (2019), Una Unión que se esfuerza por lograr más resultados: Mi agenda para Europa. Orientaciones políticas para la próxima Comisión Europea 2019-2024, Comisión Europea, Bruselas, https://ec.europa.eu/commission/sites/beta-political/files/political-guidelines-nextcommission_en.pdf. 



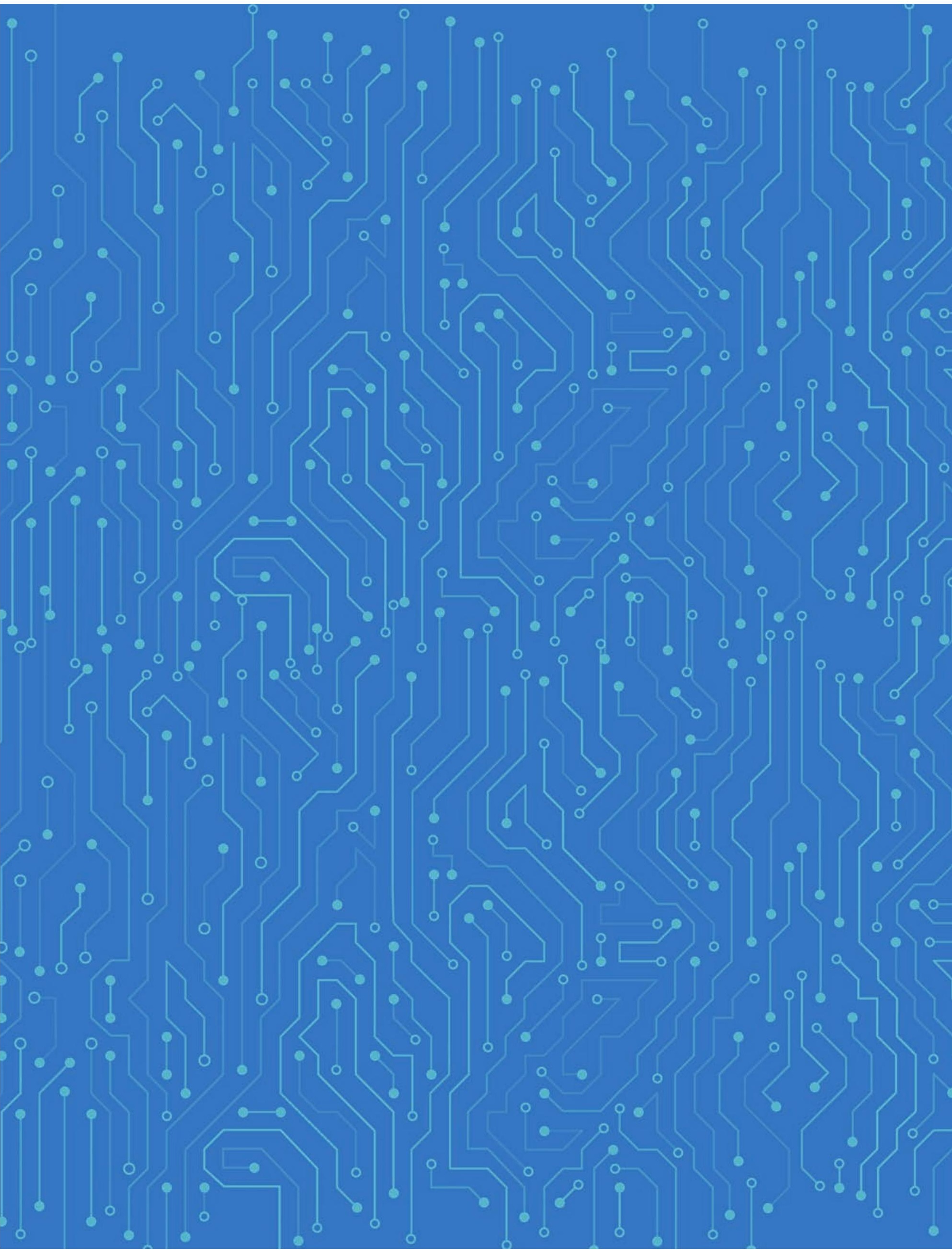




\section{Capítulo 6}

\section{Sección especial: El Caribe}

En el presente capítulo se analizan los principales desafíos a los que se enfrentan los países del Caribe para promover la transformación digital y se resume el impacto de la crisis del Covid-19 en estas economías. En particular, se analizan las estrategias digitales regionales y nacionales, centrándose en las principales dimensiones, como la infraestructura de la comunicación, el gobierno digital y la seguridad digital, al tiempo que se ponen de manifiesto las disparidades existentes entre los países y dentro de ellos. Para aprovechar al máximo la transformación digital, los países debenaplicareficazmentelasestrategias digitales nacionales y aumentar la cooperación y coordinación subregionales en materia de políticas de información y comunicaciones, infraestructuras de banda ancha, sistemas de gobierno electrónico y políticas destinadas a utilizar herramientas tecnológicas para gestionar y prevenir catástrofes naturales. 


\section{La transformación digital: Una oportunidad para que el Caribe supere diversos desafíos}

Los cierres de fronteras y otras acciones tomadas durante el brote de Covid-19 afectaron en gran medida a varias fuentes de ingresos en el Caribe
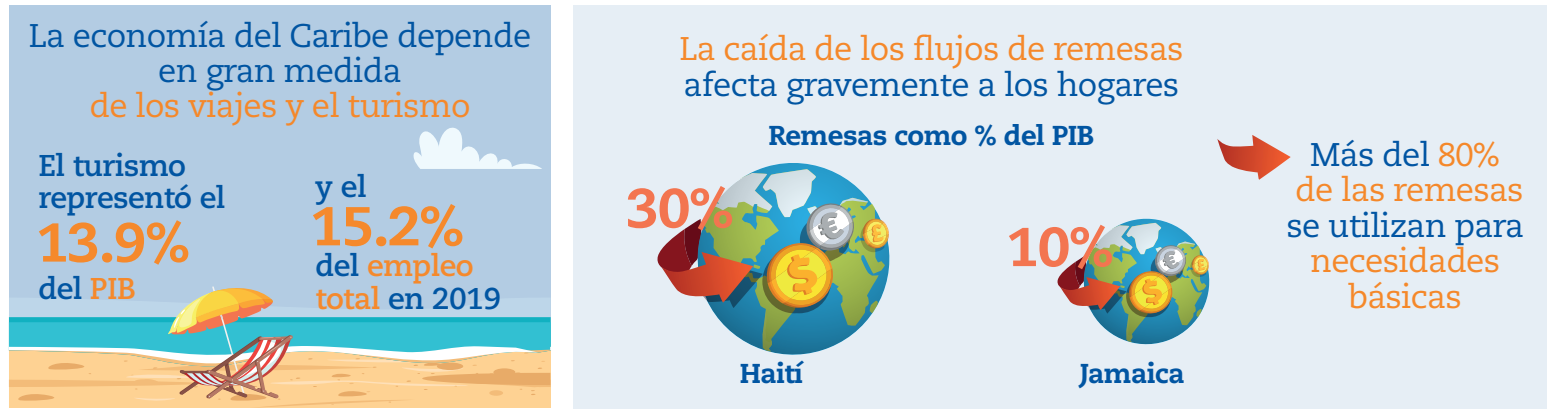

Los países del Caribe enfrentan vulnerabilidades específicas a largo plazo, que incluyen amenazas naturales y fenómenos climáticos extremos

Durante la temporada de huracanes del

Atlántico de 2020, los países del Caribe

pueden enfrentar a la vez

una crisis de salud, climáticas

y otras relacionadas

exclusivamente con los

huracanes
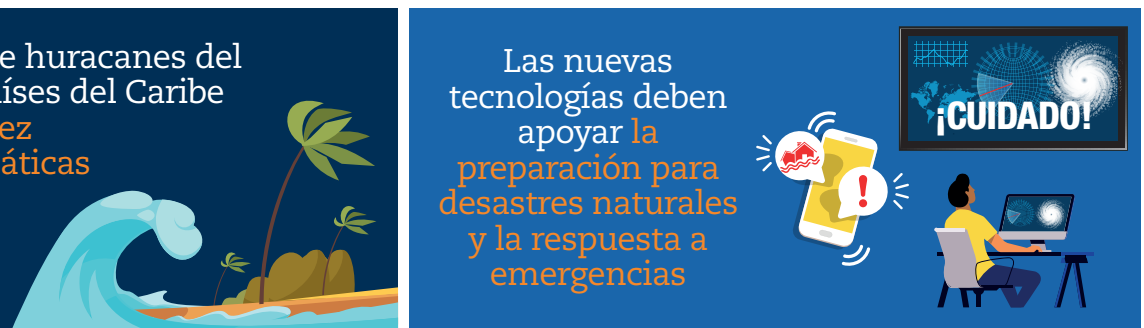

Para beneficiarse de la transformación digital, los países del Caribe deben desarrollar agendas digitales alineadas con las estrategias nacionales de desarrollo

Dadas las vulnerabilidades estructurales de la subregión, la diversificación de la estructura productiva es fundamental
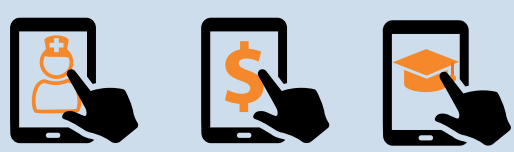

acompañada por la

digitalización de la economía en áreas como el gobierno

digital, la telemedicina

y el aprendizaje en línea

El número de usuarios de Internet en el Caribe aumentó, pero sigue siendo relativamente bajo en la mayoría de los países

$2010-2018$

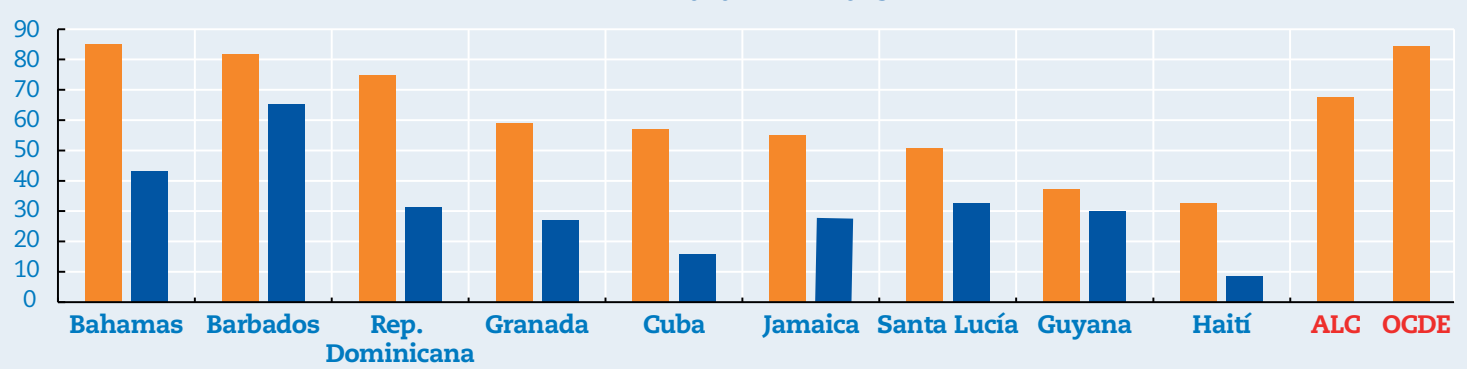




\section{Introducción}

A pesar de la gran heterogeneidad de sus efectos, la pandemia de coronavirus afecta y afectará a todos los países del Caribe. Esto se debe en parte a la elevada dependencia económica de la subregión de los viajes y el turismo, un sector que se ha visto gravemente afectado debido al cierre de las fronteras y otras medidas adoptadas para detener la propagación. Los servicios turísticos representaban el 13.9\% del producto interno bruto (PIB) y el 15.2\% del empleo total del Caribe en 2019, lo que lo convierte en la subregión con la mayor contribución económica del turismo en el mundo, seguida del Sudeste Asiático y Oceanía. La contribución del turismo al PIB y al empleo es mucho mayor en algunos países del Caribe. En el caso de los Estados del Caribe Oriental, además de las Bahamas, Belice y Jamaica, el turismo y los viajes representan más de una cuarta parte del PIB y más del 30\% del empleo (superando el $85 \%$ en el caso de Antigua y Barbuda) (CEPAL, 2020a).

El descenso de las remesas en efectivo, que podría contraerse entre el $10 \%$ y el $15 \%$ en 2020, y tardar dos o tres años en volver a los niveles de 2019, afectará gravemente a las personas y los hogares. En varios países del Caribe, la contribución de las remesas a la actividad económica es significativa: representaban más del 30\% del PIB en Haití y más del 10\% en Jamaica. Entre el $80 \%$ y el $90 \%$ de las remesas se destinan a cubrir las necesidades básicas de los hogares receptores, por lo que su contracción tendrá fuertes efectos en el consumo y la incidencia de la pobreza (CEPAL, 2020a).

Además de los efectos a corto y mediano plazo de la crisis del Covid-19, los países del Caribe se enfrentan a vulnerabilidades a más largo plazo, entre las que se incluyen los efectos adversos del cambio climático, los peligros naturales y los fenómenos meteorológicos extremos. En las últimas décadas, el Caribe ha sido la segunda región del mundo más propensa a los peligros naturales, debido a su ubicación y a la concentración de la población en zonas costeras de elevada exposición. Se prevé que la incidencia de la temporada de huracanes del Atlántico en los países del Caribe sea superior al promedio en 2020, de manera que podrían enfrentarse a múltiples crisis simultáneas relacionadas con la salud, el clima y los huracanes (Phillips et al., 2020; Taylor, 2020). Dadas las vulnerabilidades estructurales de la subregión, es fundamental la diversificación de la estructura productiva (OCDE et al., 2019), acompañada de la digitalización de la economía en ámbitos como el gobierno electrónico, la telemedicina y el aprendizaje electrónico.

Las nuevas tecnologías deberían contribuir a mejorar la preparación frente a las catástrofes naturales y la respuesta frente a las emergencias. La continuidad de los servicios digitales depende en gran medida de que exista una planificación adecuada de las infraestructuras digitales y físicas, incluidos centros de datos para evitar pérdidas de información tras las catástrofes naturales. El Caribe también debe crear un ecosistema digital adecuado y sostenible para acelerar la transformación digital, aumentar la resiliencia económica y mejorar la capacidad de respuesta frente a las catástrofes naturales (Mejía-Giraldo, 2018). En este sentido, el desarrollo de la capacidad financiera y técnica es fundamental, ya que las infraestructuras obsoletas en el ámbito de las tecnologías de la información y comunicaciones (TIC) impiden que muchos países del Caribe adopten las tecnologías digitales de forma rápida y eficiente. Las estrategias óptimas para crear ecosistemas digitales duraderos abordan múltiples vulnerabilidades.

En este capítulo se describe primeramente el ecosistema digital del Caribe, en comparación con otras subregiones. En segundo lugar, se presentan brevemente las principales estrategias digitales regionales. Posteriormente, se analizan las estrategias 
digitales nacionales. En cuarto lugar, se estudian dos componentes principales de las agendas digitales nacionales: los desafíos en materia de gobierno digital y de seguridad digital. Por último, el capítulo concluye con una serie de recomendaciones en materia de políticas.

\section{El ecosistema digital en el Caribe}

El ecosistema digital es fundamental para acelerar los beneficios de las tecnologías digitales. El Índice de Desarrollo del Ecosistema Digital se basa en ocho pilares integrados por múltiples componentes: infraestructuras, conectividad, digitalización de los hogares, digitalización de la producción, intensidad de la competencia, industrias digitales, factores de producción y marcos regulatorios (ver el capítulo 2). En 2018, este índice se situaba en el 70.4 en el caso del área OCDE, en el 49.9 el caso de América Latina y el Caribe y en el 24.3 en el caso de la subregión del Caribe (Gráfico 6.1).

\section{Gráfico 6.1. Índice de Desarrollo del Ecosistema Digital, OCDE, América Latina y el Caribe, y el Caribe, 2018}

$=\mathrm{OCDE} \quad$ ALC $\quad$ EI Caribe

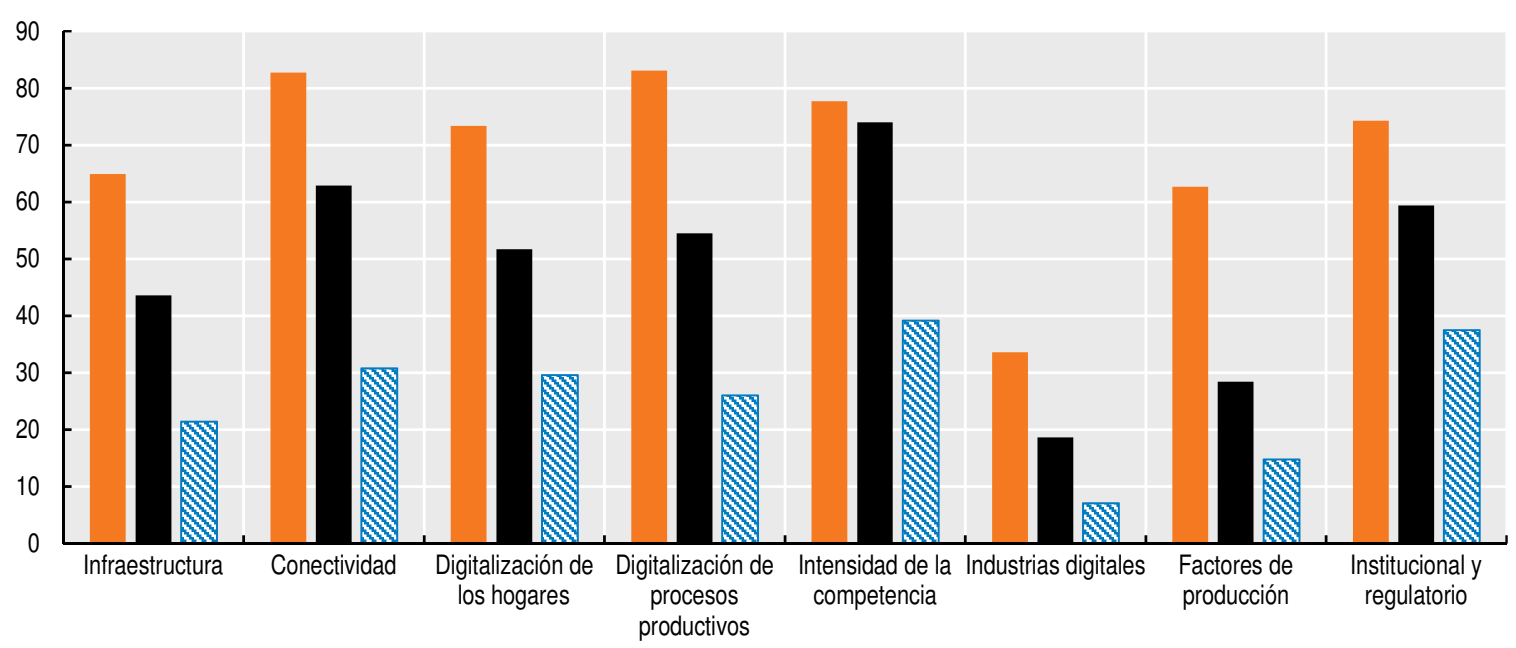

Nota: Se disponía de datos de seis países del Caribe (Barbados, Cuba, República Dominicana, Haití, Jamaica y Trinidad y Tobago), que representaban alrededor del $93 \%$ de la población de la subregión. Puntos de índice, el índice va de 0 a 100, siendo 100 la puntuación más alta.

Fuente: CAF (2020), Observatorio del Ecosistema Digital de la CAF; (CEPAL, 2020b), Observatorio Regional de Planificación para el Desarrollo de América Latina y el Caribe, https://observatorioplanificacion.cepal.org/en/opengov.

StatLink intsta https://doi.org/10.1787/888934202940

El índice general del Caribe oculta las disparidades entre países: Trinidad y Tobago mostraba una puntuación elevada (64.1), mientras que Cuba (12.7) y Haití (12.9) tenían la puntuación más baja. Dado que Cuba y Haití representan el 55\% de la población del Caribe, el promedio ponderado de la subregión es mucho más bajo. ${ }^{1}$

Como se refleja en el índice, las infraestructuras y la conectividad del Caribe son bajas en promedio, pero varían mucho de un país a otro. En la mayoría de países caribeños, la proporción de usuarios de Internet (Gráfico 6.2) sigue siendo relativamente baja en comparación con los promedios de América Latina y el Caribe y la OCDE, aunque las tasas aumentaron significativamente entre 2010 y 2018, por ejemplo, del 16\% al 57\% en Cuba 
y del $8 \%$ al 32\% en Haití. Las Bahamas, Barbados y la República Dominicana alcanzaron niveles superiores al 70\%. Los costos de conectividad y uso también varían, lo que agrava la desigualdad por país, isla y tipo de hogar. A escala nacional, los niveles de penetración y calidad de conexión a Internet son más bajos en las zonas rurales que en las urbanas, mientras que los hogares ricos tienen más probabilidades de tener acceso a Internet que el quintil más pobre de la distribución de ingresos (CEPAL, 2017). Los países han indicado además que el acceso limitado a Internet de banda ancha, y otros problemas tecnológicos, han obstaculizado el aprendizaje a distancia en el contexto de la pandemia (ver, por ejemplo, Young, 2020).

Dentro de los países, existe un servicio y acceso a las TIC desigual, ya que muchos Pequeños Estados Insulares en Desarrollo (PEID) del Caribe cuentan con multitud de islas distribuidas en grandes distancias, y cada una de ellas tiene distintos niveles de acceso y servicio en función del tamaño de la población y el sistema de gobernanza (Bleeker, 2019a). Tobago tiene unos niveles de acceso a las TIC más bajos que Trinidad, que es más grande y está más poblada. En las Islas Turcas y Caicos, solo algunas islas cuentan con servicios de banda ancha fija, y la velocidad y fiabilidad de la conexión de banda ancha varía de una isla a otra.

\section{Gráfico 6.2. Usuarios de Internet, países seleccionados del Caribe, 2010-2018 o último año disponible (porcentaje de la población total)}

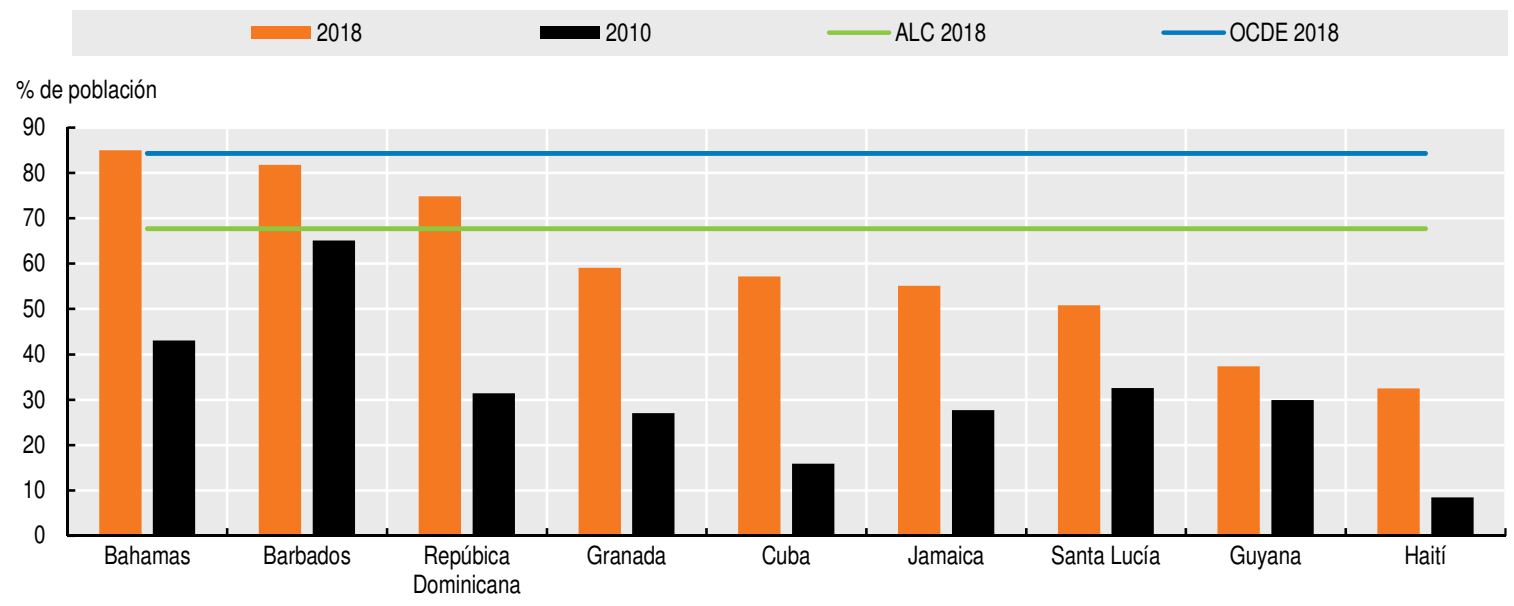

Fuente: Cálculos propios basados en datos de la UIT (2020a), Base de datos de indicadores de telecomunicaciones / TIC mundiales 2020 (base de datos), Unión Internacional de Telecomunicaciones, Ginebra, https://www.itu.int/en/ITU-D/Statistics/Pages/ publications/ wtid.aspx (consultado el 21 de agosto de 2020).

StatLink त्ञाIs https://doi.org/10.1787/888934202959

El aumento de los usuarios de Internet es resultado de la considerable evolución en la tecnología y la calidad de la conectividad en las últimas décadas. En 2018, la penetración de la banda ancha móvil fue mayor que la de la banda ancha fija (Gráfico 6.3). Sin embargo, la diferencia con el resto de la región puede observarse especialmente en la proporción de la penetración de la banda ancha móvil (Gráfico 6.4). Con la excepción de Haití, esta evolución también puede reflejar la compacidad de algunos países en relación con otros. Por ejemplo, varios países cuentan con zonas rurales o de baja población en las que la conectividad es deficiente. Un total de diez países del Caribe son Estados multiinsulares con poblaciones repartidas en masas de tierra separadas, cuyos niveles de conectividad varían (Bleeker, 2019b). 


\section{Gráfico 6.3. Penetración de banda ancha fija, países seleccionados del Caribe, 2018 o último año disponible (por cada 100 habitantes)}

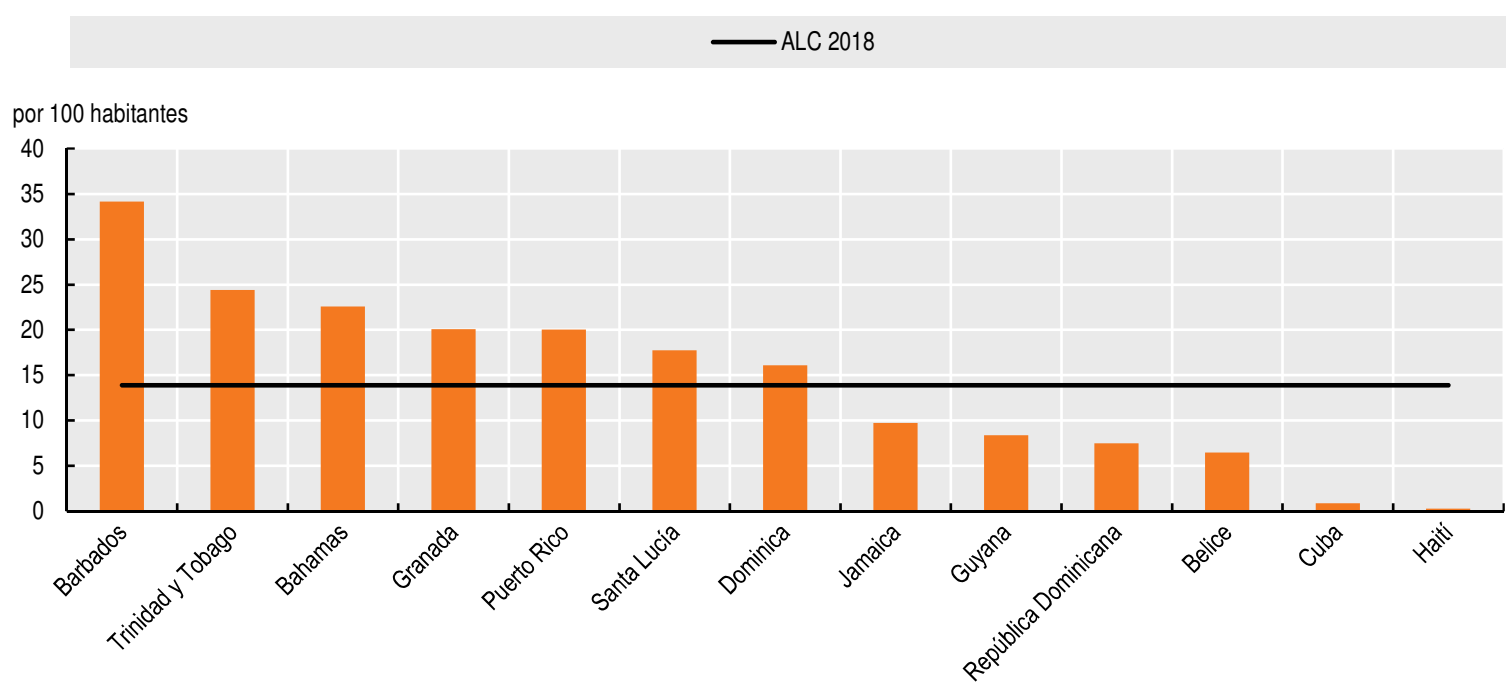

Fuente: Cálculos propios basados en datos de la UIT (2020a), Base de datos de indicadores de telecomunicaciones / TIC mundiales 2020 (base de datos), Unión Internacional de Telecomunicaciones, Ginebra, https://www.itu.int/en/ITU-D/Statistics/Pages/ publications/wtid.aspx (consultado el 21 de agosto de 2020).

StatLink तilst https://doi.org/10.1787/888934202978

\section{Gráfico 6.4. Suscripciones activas de banda ancha móvil, países seleccionados del Caribe, 2018 o último año disponible (por cada 100 habitantes)}

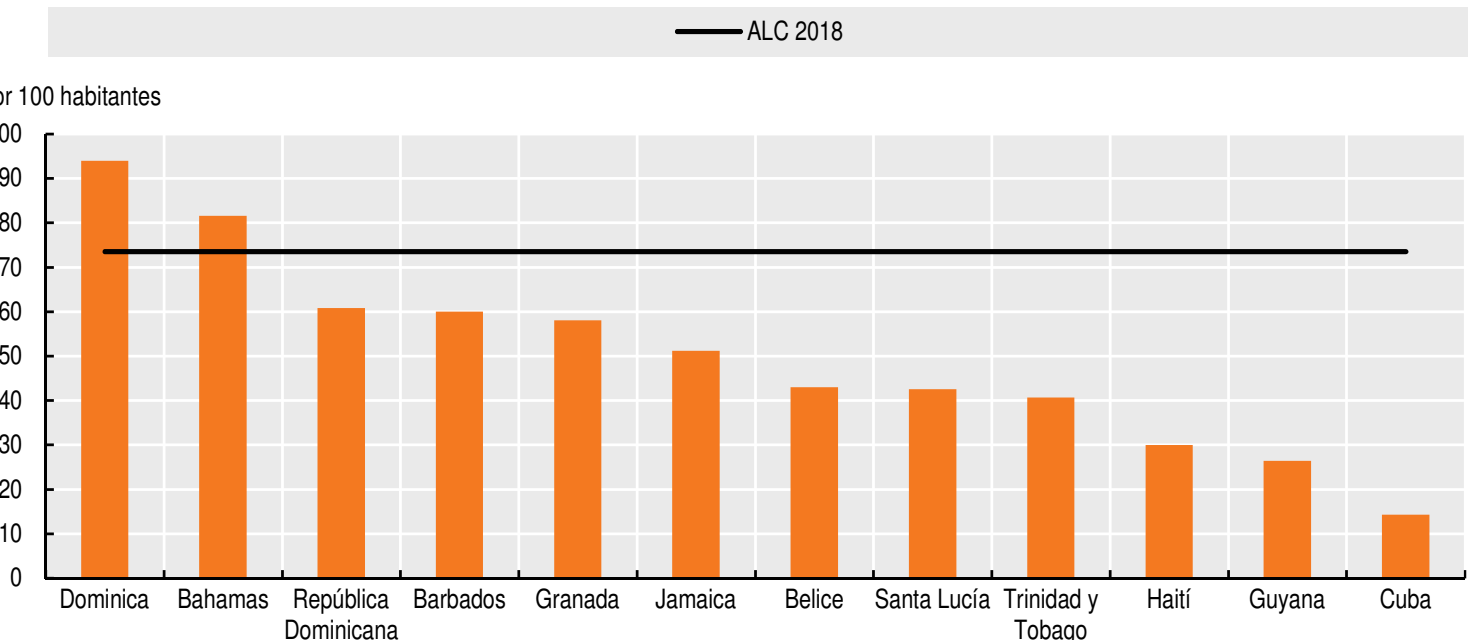

Fuente: Cálculos propios basados en datos de la UIT (2020a), Base de datos de indicadores de telecomunicaciones / TIC mundiales 2020 (base de datos), Unión Internacional de Telecomunicaciones, Ginebra, https://www.itu.int/en/ITU-D/Statistics/Pages/ publications/ wtid.aspx (consultado el 21 de agosto de 2020).

StatLink inist https://doi.org/10.1787/888934202997

La velocidad de conexión se utiliza con frecuencia para comparar la calidad de la conexión entre países. La baja velocidad de conexión imposibilita las aplicaciones simultáneas, un problema crítico durante la pandemia del Covid-19. Entre marzo y julio de 2020, las brechas con el resto del mundo han sido importantes y la variación entre los países del Caribe ha sido considerable (Gráfico 6.5). La evolución de la conexión a Internet ha sido especialmente lenta en Cuba, donde la introducción de los servicios de tercera generación no se inició hasta 2018. La velocidad de conexión también varía 
de forma considerable entre las islas de los PEID del Caribe. En las Islas Turcas y Caicos, Providenciales tiene la banda ancha móvil más rápida (15-20 MB/s) a través de cable de fibra óptica; las Islas Caicos del Norte y Caicos del Sur tienen la más lenta (6-10 MB/s) debido a las limitaciones de ancho de banda en la transmisión de microondas a estas islas (Bleeker, 2020).

\section{Gráfico 6.5. Velocidad de descarga de banda ancha fija, países seleccionados y requisitos de ancho de banda de referencia, marzo-julio de 2020}

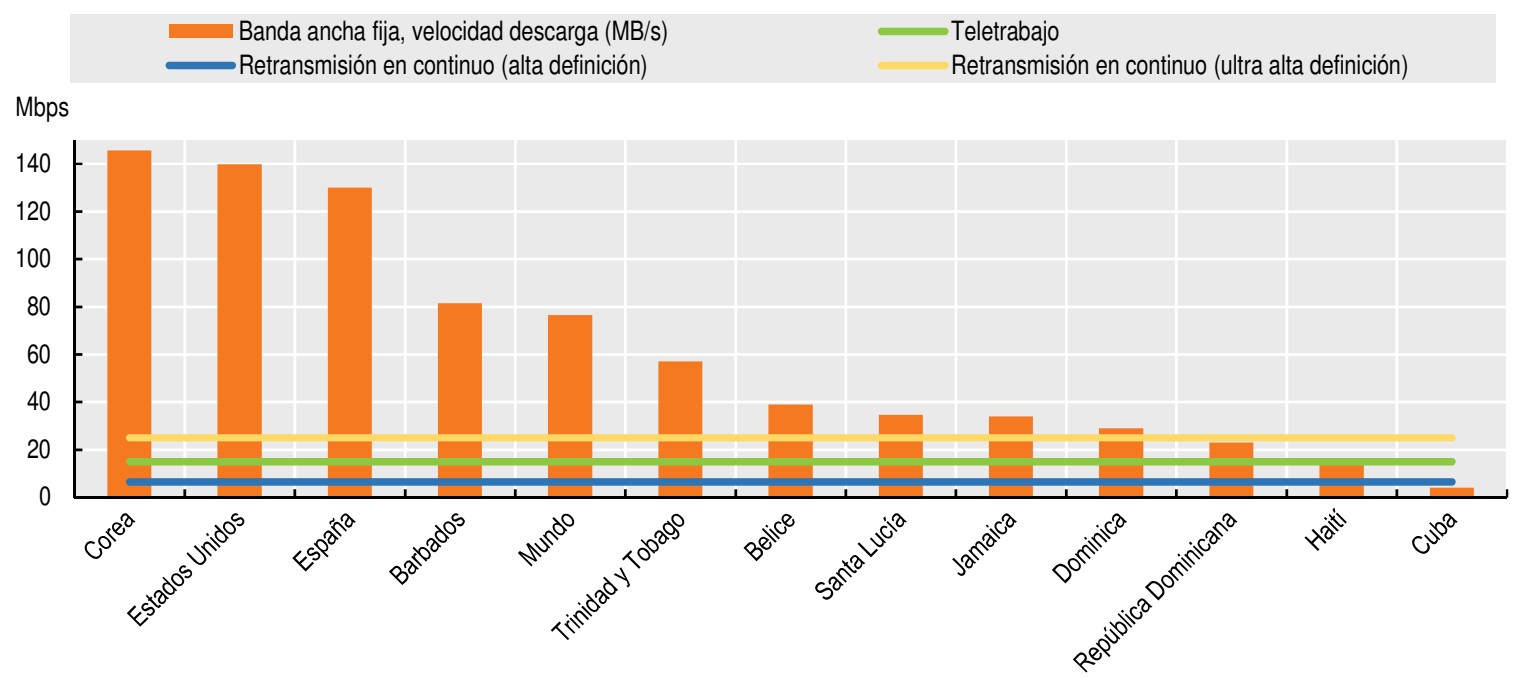

Nota: $\mathrm{HD}$ = alta definición. Mbps = Megabytes por segundo. El indicador refleja la velocidad de banda ancha cableada alcanzable "en la red". No representa completamente la experiencia general de Internet y solo proporciona una vista parcial de la velocidad de Internet. No obstante, proporciona un indicador parcial útil disponible tanto para países de la OCDE como para países que no pertenecen a la OCDE (OCDE, 2019). Los datos de velocidad de descarga de banda ancha fija son un promedio mensual de marzo a julio de 2020.

Fuente: CEPAL (2020b), Observatorio Regional de Planificación para el Desarrollo de América Latina y el Caribe, https:// observatorioplanificacion.cepal.org/en/opengov, cálculos propios basados en la Comisión Federal de Comunicaciones y el Índice de prueba de velocidad global de Ookla.

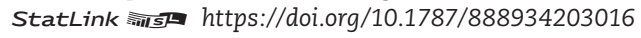

\section{Estrategias digitales regionales en el Caribe}

En 2017, los jefes de gobierno de la Comunidad del Caribe (CARICOM) aprobaron el proyecto Espacio Único de las TIC, que tiene por objeto crear un espacio sin fronteras habilitado por las TIC que fomente la integración económica, social y cultural en beneficio de los ciudadanos caribeños de los 15 Estados miembros y 5 miembros asociados de la agrupación (CTU, 2017a). Concebido como el plano digital del Mercado Único y de Economía del Caribe, el proyecto consta de cuatro pilares: 1) políticas de TIC y regímenes regulatorios y jurídicos armonizados a nivel regional; 2) una sólida infraestructura nacional y regional de banda ancha; 3) marcos comunes para gobiernos, proveedores de servicios de TIC y consumidores; y 4) sistemas tecnológicos y de gestión eficaces y seguros.

El objetivo del proyecto es la ubicuidad y la coherencia de los servicios TIC en toda la CARICOM a precios asequibles. La atención inicial se ha centrado en la creación de un entorno propicio para proyectos y sistemas de infraestructura regional mediante políticas de TIC y regímenes regulatorios y jurídicos armonizados a nivel regional, ya que se trata de un precursor necesario para establecer alianzas regionales sólidas. Según la Unión de Telecomunicaciones del Caribe (CTU por sus siglas en inglés), se necesita una nueva colaboración para cumplir muchos de los hitos de aplicación del proyecto Espacio Único de las TIC y alcanzar sus ambiciosos objetivos (Bleeker, 2019b). 
Como aspecto del proyecto, la CTU ha estado promoviendo la necesidad de que los gobiernos de la subregión se conviertan en gobiernos del siglo XXI. Para ello, deben utilizar "procesos centrados en el ciudadano, sin fisuras, abiertos, interactivos y eficientes, y harán un uso eficaz de las tecnologías de la información y la comunicación para prestar servicios a sus ciudadanos y clientes internos y externos" (CTU, 2017b). El objetivo del proyecto, que se compone de siete líneas de trabajo, es acelerar la prestación de servicios de gobierno electrónico y transformar el servicio público de los gobiernos del Caribe.

\section{Estrategias digitales nacionales en el Caribe}

Los gobiernos del Caribe han venido elaborando durante varios años estrategias nacionales para promover la adopción de las TIC (Tabla 6.1). Su eficacia ha sido desigual. Las características únicas de algunos Estados del Caribe presentan varios desafíos. Los territorios multiinsulares formados por pequeñas islas, algunas de las cuales se extienden a lo largo de grandes distancias, suelen tener unos altos costos fijos y de transporte. También tienen mercados internos pequeños y son vulnerables a los shocks externos, como la pandemia del coronavirus, y a las catástrofes naturales. Estos factores generan dificultades a la hora de aprovechar las economías de escala. No obstante, existen oportunidades considerables para que los países del Caribe promuevan la adopción de tecnologías digitales, sobre todo las destinadas a aumentar la resiliencia y a ampliar el acceso a la información y los servicios públicos de las personas que viven en islas geográficamente aisladas (Bleeker, 2020).

A la luz de las crisis del coronavirus (Covid-19), las nuevas herramientas digitales son fundamentales para proporcionar servicios de educación y salud, acceso a la seguridad social y gobierno electrónico. Los países del Caribe se han apresurado a hacer disponibles en Internet sus servicios digitales y a aumentar el acceso a las TIC durante la pandemia, aunque su capacidad para atender a todos los grupos de población se ha visto limitada por restricciones financieras y técnicas. La mejora de la prestación de servicios digitales ha surgido principalmente en las áreas de educación, salud y otros sectores públicos a través de nuevos instrumentos de aprendizaje electrónico y telemedicina, sistemas de pago por Internet y otros portales de gobierno electrónico. Sin embargo, estos servicios no han beneficiado a todos los grupos por igual: los gobiernos tienen una capacidad limitada para ofrecer programas especiales de inclusión digital para los 1.3 millones de personas con discapacidad y otros grupos marginados del Caribe, incluida la población de mayor edad. La pandemia también ha ampliado la brecha digital para aquellas personas cuyas circunstancias económicas se han deteriorado y que no han podido pagar el acceso a Internet y a dispositivos digitales.

Aunque algunos países del Caribe han adoptado algún tipo de estrategia en el ámbito de las TIC, muchos de esos planes no se han renovado más allá de su período inicial, lo que sugiere que estos países están teniendo dificultades para mantener al día dichos planes. De los siete países analizados, tres cuentan con estrategias de TIC cuyo período original sigue vigente, mientras que Jamaica optó por una estrategia a largo plazo, y San Vicente y las Granadinas y Trinidad y Tobago tienen estrategias vigentes hasta 2020. Algunos países, entre ellos las Bahamas, han incorporado los objetivos de las políticas de TIC en sus planes nacionales de desarrollo. En el caso de Barbados, a pesar de no contar con una estrategia específica de TIC actualizada, han incorporado varios objetivos relacionados con la promoción de las TIC y el desarrollo de una economía de la información como parte de su estrategia de crecimiento y desarrollo 2013-2020.

Las estrategias digitales nacionales de los países del Caribe comparten varios objetivos de políticas relativos a la utilización de las tecnologías digitales en el ámbito del desarrollo sostenible. Todos los países procuran ampliar las infraestructuras como objetivo principal 
y fomentar el despliegue de servicios de gobierno electrónico, promover la innovación y el desarrollo económico mediante el uso de tecnologías digitales, mejorar la adopción de la tecnología y la alfabetización digital en las escuelas y actualizar los marcos regulatorios. Habida cuenta de la importancia de un entorno propicio para el despliegue de proyectos de infraestructuras y servicios digitales, las estrategias suelen incluir como pilar unos marcos legislativos y regulatorios modernos y adecuados en el ámbito de la seguridad digital, protección de datos, privacidad, intercambio de información y transacciones electrónicas.

Tabla 6.1. Estrategias digitales nacionales, países del Caribe seleccionados

\begin{tabular}{|c|c|c|c|}
\hline & $\begin{array}{l}\text { Plan nacional TIC/ } \\
\text { Agenda Digital }\end{array}$ & Objetivos & Institución \\
\hline Barbados & $\begin{array}{l}\text { Plan Estratégico } \\
\text { Nacional de las } \\
\text { Tecnologías de la } \\
\text { Información y las } \\
\text { Comunicaciones de } \\
\text { Barbados 2010-2015 } \\
\text { Estrategia de } \\
\text { crecimiento y desarrollo } \\
\text { de Barbados 2013-2020 }\end{array}$ & $\begin{array}{l}6 \text { objetivos: desarrollar una sociedad alfabetizada en el ámbito de las TIC; } \\
\text { desarrollar una cultura de innovación e iniciativa empresarial; poner las TIC a } \\
\text { disposición de todos los ciudadanos; garantizar una jurisdicción competitiva; } \\
\text { transformar los sectores público y empresarial en un entorno electrónico; } \\
\text { facilitar la continuidad de la gobernanza en los desastres nacionales } \\
\text { Desarrollar una economía de la ciencia y la información y estrategias que } \\
\text { apunten a mejorar la eficiencia en la gestión del tráfico de Internet, la alerta } \\
\text { temprana y la mitigación de ataques cibernéticos, mejorar la Ley de Privacidad } \\
\text { y Protección de Datos, la Ley de Uso Indebido de Computadoras y la Ley de } \\
\text { Telecomunicaciones B282. }\end{array}$ & $\begin{array}{l}\text { Ministerio de } \\
\text { Asuntos Económicos, } \\
\text { Empoderamiento, } \\
\text { Innovación, Industria } \\
\text { y Comercio, Ministerio } \\
\text { de Finanzas, Asuntos } \\
\text { Económicos e Inversión }\end{array}$ \\
\hline Jamaica & $\begin{array}{l}\text { Visión } 2030 \text { Jamaica: } \\
\text { tecnologías de la } \\
\text { información y las } \\
\text { comunicaciones } \\
\text { (TIC): plan sectorial } \\
2009-2030\end{array}$ & $\begin{array}{l}2 \text { objetivos principales: un sector de TIC fuerte y competitivo; avance del } \\
\text { plan nacional de desarrollo de Jamaica gracias a la adopción y aplicación } \\
\text { generalizada de las TIC }\end{array}$ & Gabinete \\
\hline Santa Lucía & $\begin{array}{l}\text { Estrategia TIC nacional } \\
\text { de Santa Lucía } \\
2010-2015\end{array}$ & $\begin{array}{l}4 \text { resultados: gobernanza eficaz y amplia prestación de servicios electrónicos; } \\
\text { crecimiento económico significativo mediante la creación de nuevas } \\
\text { oportunidades de empleo; mejora de la salud y el bienestar de los ciudadanos; } \\
\text { mayor innovación y comprensión de la información por parte de los } \\
\text { ciudadanos }\end{array}$ & $\begin{array}{l}\text { Ministerio de } \\
\text { Transformación Social, } \\
\text { Servicio Público, Desarrollo } \\
\text { de Recursos Humanos, } \\
\text { Juventud y Deportes }\end{array}$ \\
\hline $\begin{array}{l}\text { San } \\
\text { Vicente } \\
\text { y las } \\
\text { Granadinas }\end{array}$ & $\begin{array}{l}\text { Plan nacional de banda } \\
\text { ancha } 2015-2020\end{array}$ & $\begin{array}{l}6 \text { objetivos: promover el desarrollo de servicios de banda ancha locales y } \\
\text { pertinentes; proporcionar al profesorado la capacitación adecuada en las } \\
\text { competencias necesarias; asegurar una conexión de banda ancha suficiente } \\
\text { para todos Ios centros educativos, centros de salud, centros comunitarios y } \\
\text { edificios públicos; promover la alfabetización digital; promover la adopción } \\
\text { de cursos pertinentes de TIC en los centros educativos; asegurar el apoyo } \\
\text { necesario a los aspirantes a emprendedores en el ámbito de las TIC }\end{array}$ & $\begin{array}{l}\text { Comisión Nacional de } \\
\text { Regulación de las Teleco- } \\
\text { municaciones }\end{array}$ \\
\hline $\begin{array}{l}\text { Trinidad } \\
\text { y Tobago }\end{array}$ & $\begin{array}{l}\text { Plan Nacional TIC } \\
\text { de Trinidad y Tobago; } \\
\text { Plan TIC } 2018 \text { - } 2022\end{array}$ & $\begin{array}{l}5 \text { ejes estratégicos: mejorar la conectividad; aumentar la capacidad humana; } \\
\text { avanzar en el gobierno digital; fomentar el desarrollo económico; avanzar en el } \\
\text { entorno digital en beneficio de la sociedad }\end{array}$ & $\begin{array}{l}\text { Ministerio de } \\
\text { Administración Pública y } \\
\text { Comunicaciones }\end{array}$ \\
\hline Granada & $\begin{array}{l}\text { Tecnologías de } \\
\text { la información y } \\
\text { comunicaciones (TIC) } \\
\text { 2006-2010: Estrategia } \\
\text { y plan de acción para } \\
\text { Granada }\end{array}$ & $\begin{array}{l}7 \text { ejes estratégicos: creación de capacidad; marco jurídico; comercio } \\
\text { electrónico; formación en materia de tecnologías de la información e Internet; } \\
\text { gobierno electrónico; infraestructuras de telecomunicaciones de alta calidad y } \\
\text { asequibles; sociedad y economía de la información }\end{array}$ & Oficina del Primer Ministro \\
\hline $\begin{array}{l}\text { San } \\
\text { Cristóbal } \\
\text { y Nieves }\end{array}$ & $\begin{array}{l}\text { Plan Estratégico } \\
\text { Nacional de Tecnologías } \\
\text { de la Información y } \\
\text { Comunicaciones (TIC) } \\
2006\end{array}$ & $\begin{array}{l}5 \text { ejes principales: construcción de la infraestructura de la información; } \\
\text { habilitación del entorno político y jurídico; desarrollo de recursos humanos } \\
\text { en el ámbito de las TIC y creación de capacidad (sociedad de la información); } \\
\text { modernización de las administraciones públicas y prestación de servicios a los } \\
\text { ciudadanos por vía electrónica; aprovechamiento de las TIC para el desarrollo } \\
\text { económico y social a través de alianzas con los sectores público y privado }\end{array}$ & No especificado \\
\hline
\end{tabular}

Fuente: Basado en fuentes públicas y en las agendas nacionales digitales de países.

Una cuestión fundamental ha sido la resiliencia de las TIC en el contexto de las catástrofes naturales, que afectan de manera desproporcionada a los países del Caribe. Estos países se enfrentan al reto de crear ecosistemas digitales que aceleren la transformación digital a fin de prevenir, mitigar y mejorar la capacidad de respuesta 
frente a estas catástrofes. Las TIC son esenciales para mejorar la eficiencia y la eficacia de la gestión del riesgo de desastres en los de los PEID del Caribe (Phillips y Williams, 2014). Después de una catástrofe natural, el hecho de contar con una infraestructura de TIC fiable y resiliente puede ser también un importante facilitador de la recuperación de las actividades públicas y de los sectores socioeconómicos, y desempeñar un papel clave en los esfuerzos de recuperación tras un desastre. Dadas las limitaciones de las inversiones de los PEID del Caribe en infraestructuras de TIC, una estrategia digital regional podría permitir la adquisición de instrumentos tecnológicos para la gestión del riesgo de desastres y fomentar el intercambio de información y la gestión del conocimiento. Un enfoque regional podría no solo salvar vidas, sino reducir el costo de los activos económicos de la subregión tras la incidencia de fenómenos meteorológicos extremos.

Las estrategias digitales de los países del Caribe muestran características institucionales comunes (Gráfico 6.6). La mayoría de ellos no han creado ministerios especializados en el ámbito de las TIC; en casi todos los casos, los ministerios encargados de dirigir la política digital tienen mandatos más amplios de prestación de servicios económicos, sociales o públicos, como en el caso de Barbados, Santa Lucía y Trinidad y Tobago. En el caso de Granada, el ente responsable es la Oficina del Primer Ministro; en el caso de Jamaica, es el Gabinete; y en San Vicente y las Granadinas, un organismo regulador. Los planes digitales del Caribe muestran un nivel adecuado de madurez en su diseño, e incluyen principios y objetivos claros. En la mayoría de los casos, las estrategias se han vinculado a un plan nacional de desarrollo más amplio.

La transformación digital, impulsada por grupos de interés del gobierno, empresariales y de otros ámbitos no gubernamentales, es un proceso que exige la participación de agentes específicos y también de la sociedad en su conjunto. Por tanto, es esencial que una amplia gama de agentes públicos, privados y de la sociedad civil participen en el diseño, la aplicación y el seguimiento de la estrategia digital. El diálogo entre los distintos grupos de interés es fundamental para identificar y superar los obstáculos y crear oportunidades de colaboración. Esto es especialmente cierto en el Caribe, donde el deficiente acceso al financiamiento para el desarrollo a bajo costo aporta una capacidad limitada para crear una infraestructura de TIC capaz de proporcionar una conectividad de alta velocidad (Bleeker, 2019b). Varios países del Caribe han establecido un sistema de participación con múltiples grupos de interés en el proceso de elaboración de sus planes digitales, si bien no se da en todos los casos. El uso de los Fondos de Servicio Universal (FSU) en la subregión para financiar infraestructuras de telecomunicaciones y proyectos de TIC es un ejemplo de participación de múltiples grupos de interés que puede apoyar la materialización de la agenda digital (Bleeker, 2019b). Si bien varios FSU tienen grandes cantidades de fondos sin desembolsar, algunos de estos se están utilizando para mejorar el acceso a los servicios digitales en el contexto de la crisis del coronavirus (Covid-19) (ver, por ejemplo, el caso del Servicio de Información de Jamaica, 2020a y 2020b).

Pocas estrategias de TIC en el Caribe tienen un diseño institucional que busque la coordinación con el sector privado y la sociedad civil para la implantación y el seguimiento de su agenda digital. No obstante, los gobiernos del Caribe han tratado de formar bloques subregionales para ejecutar proyectos de infraestructuras de TIC. Granada, Santa Lucía y San Vicente y las Granadinas se unieron recientemente con el proveedor privado de telecomunicaciones Digicel y la CTU para construir un sistema de cable de fibra submarino y redes de área gubernamentales entre estos países y también dentro de ellos. Esta asociación entre los sectores público y privado, denominado el Programa de Infraestructura Regional de Comunicaciones del Caribe (CARCIP), se financió con préstamos del Banco Mundial. El proyecto podría haber dado cabida a más países, pero la modalidad de financiamiento estaba fuera del alcance de muchos de ellos debido a sus ya elevados niveles de endeudamiento. También deben reforzarse los 
mecanismos de coordinación intergubernamental para la aplicación de las estrategias digitales nacionales a fin de apoyar la transformación digital de los países del Caribe. A este respecto, es necesario establecer una colaboración renovada que asegure que las iniciativas subregionales, como el proyecto Espacio Único de las TIC de la CARICOM y la iniciativa "21 $1^{\text {st }}$ Century Governments" de la CTU puedan cumplir sus objetivos.

Las disposiciones que detallan los presupuestos de aplicación de políticas están menos presentes en las estrategias nacionales de transformación digital del Caribe. La política de Santa Lucía sí define un presupuesto para cada uno de sus programas. La ausencia general de este tipo de disposiciones se debe en parte a que los países del Caribe suelen depender del financiamiento para el desarrollo procedente de organismos regionales e internacionales para desarrollar sus capacidades en materia de TIC y de gobierno electrónico, el cual suelen obtener tras la elaboración de una agenda digital. Dados los altos niveles de endeudamiento público en la región y el margen fiscal aún más limitado existente tras la pandemia, es posible que los países del Caribe tengan que aumentar su dependencia de los proveedores de telecomunicaciones del sector privado y del financiamiento internacional para el desarrollo para poder ejecutar sus agendas digitales.

El seguimiento de los indicadores clave de resultados es importante para evaluar los progresos y efectuar un seguimiento exhaustivo de la estrategia. Puede ser especialmente importante para ajustar los planes y comunicar los resultados previstos. Algunos países han comenzado a incluir indicadores de seguimiento para supervisar la ejecución de las agendas digitales. En la estrategia de Trinidad y Tobago se definen parámetros para medir los niveles previstos de adopción de tecnologías e impacto económico. Asimismo, se incluyen objetivos de progreso con respecto a los índices mundiales, como el índice de conectividad del Foro Económico Mundial y el índice de desarrollo de TIC de la Unión Internacional de Telecomunicaciones.

\section{Gráfico 6.6. Características institucionales de las agendas digitales nacionales, países seleccionados del Caribe}

\begin{tabular}{|l|l|l|l|l|c|c|c|}
\hline & $\begin{array}{c}\text { Ministerio } \\
\text { especializado } \\
\text { en TIC }\end{array}$ & $\begin{array}{c}\text { Objetivos } \\
\text { explícitos } \\
\text { en la AD }\end{array}$ & $\begin{array}{c}\text { Consulta pública } \\
\text { para la } \\
\text { elaboración } \\
\text { de la AD }\end{array}$ & $\begin{array}{c}\text { Comité o comisión } \\
\text { de coordinación } \\
\text { intergubernamental } \\
\text { para la AD }\end{array}$ & $\begin{array}{c}\text { Coordinación } \\
\text { de múltiples } \\
\text { grupos de interés } \\
\text { para el } \\
\text { seguimiento } \\
\text { de la AD }\end{array}$ & $\begin{array}{c}\text { Objetivos y/o } \\
\text { indicadores } \\
\text { para } \\
\text { seguimiento } \\
\text { de la AD }\end{array}$ & $\begin{array}{c}\text { Presupuesto } \\
\text { explícito } \\
\text { en la AD }\end{array}$ \\
\hline Barbados & & & & & & & \\
\hline Granada & & & & & & & \\
\hline Jamaica & & & & & & & \\
\hline San Cristóbal y Nieves & & & & & & & \\
\hline Santa Lucía & & & & & & & \\
\hline San Vicente y las Granadinas & & & & & & \\
\hline Trinidad y Tobago & & & & & & \\
\hline
\end{tabular}

Nota: La intensidad del color indica la intensidad con la que la agenda digital incluye esa característica en su diseño institucional.

Fuente: Basado en la última agenda digital nacional.

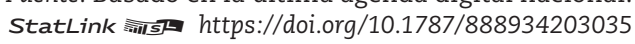

\section{Gobierno digital en el Caribe}

Los gobiernos del Caribe han comenzado a modernizar los servicios públicos, aunque su eficacia ha sido desigual. En promedio, los trámites públicos tardan en completarse cuatro horas, y más del 30\% requieren tres o más visitas a las oficinas públicas (Roseth, Reyes y Santiso, 2018). La necesidad de digitalizar estos trámites teniendo en cuenta 
la experiencia de los usuarios es evidente, pero los avances han sido lentos, en parte porque el desarrollo y el apoyo a las aplicaciones de gobierno electrónico requieren muchos recursos y suele exigir el despliegue de infraestructuras de TIC e inversiones en soluciones informáticas y capacidades humanas (Marius y Williams, 2016). Estos desafíos se ven amplificados en algunos PEID del Caribe por la elevada dispersión de pequeñas poblaciones en las islas, lo que impide aprovechar las economías de escala necesarias para justificar las inversiones.

Según el Índice de desarrollo del gobierno electrónico (EGDI) de Naciones Unidas - una de las medidas más completas para el desarrollo del gobierno electrónico en todo el mundo y referencia reconocida internacionalmente para comparar los esfuerzos de los países-, algunos países caribeños, como Haití (en el puesto 163), figuran entre los territorios con peores resultados de los 193 países estudiados (ONU, 2019). Sin embargo, la mayoría de los países del Caribe han alcanzado una clasificación "alta" o "media" y todos han mejorado sus puntuaciones en 2018 con respecto a 2016 (Bleeker, 2020). Existen disparidades entre los países de América Latina y del Caribe (ver el Capítulo 4). Los países de América del Sur tienen un mayor nivel de desarrollo, según el índice (Gráfico 6.7, Panel A). Además, solo América del Sur se sitúa por encima del promedio mundial; América Central y el Caribe están por debajo de dicho promedio y solo por encima de regiones como África y Oceanía.

Según el índice EGDI, los mayores desafíos para el Caribe, en comparación con América del Sur, se encuentran en el desarrollo de los servicios por Internet, al tiempo que las diferencias son menos evidentes en otras áreas como las infraestructuras de telecomunicaciones y el capital humano (Gráfico 6.7, Panel B). El Índice de Servicio en Línea (OSI, por sus siglas en inglés), que se elabora a partir del análisis de varios sitios web de cada país, mide la madurez de los servicios de gobierno electrónico según cuatro fases de desarrollo: servicio de información emergente, servicio de información mejorado, servicios de trámites y servicios conectados.

Uno de los principales factores que ha permitido a los países de América del Sur avanzar en la prestación de servicios por Internet ha sido el diseño y la aplicación de estrategias de gobierno electrónico (ver el Capítulo 4). Tras el éxito de la estrategia de gobierno electrónico de Uruguay, algunos países, como Barbados y Jamaica, elaboraron planes detallados y ambiciosos de gobierno electrónico. Barbados cuenta ahora con la clasificación más alta de los países del Caribe en el índice EGDI y es uno de los pocos que maneja una política específica de gobierno electrónico. Jamaica, otro de los países más avanzados del Caribe en el ámbito del gobierno electrónico, se comprometió recientemente a que el $90 \%$ de los servicios públicos estén integrados y disponibles en Internet (The Gleaner, 2020). Desde el comienzo de la crisis del coronavirus, el Gobierno de Jamaica ha venido implantando un proyecto de firma electrónica para que las personas y entidades puedan realizar de manera segura los trámites comerciales de forma digital con todos los organismos públicos (Jamaica Observer, 2020).

Aunque los países del Caribe se encuentran en diferentes fases de desarrollo del gobierno electrónico, la cuestión común más apremiante es la necesidad de un completo marco regional que abarque normas, protocolos y procesos claros para todo el sector público (Marius y Williams, 2016). Muchos países del Caribe no cuentan con marcos legislativos o regulatorios en materia de seguridad digital, protección de datos, intercambio de información y transacciones electrónicas, entre otros ámbitos. Los marcos existentes deben actualizarse a la luz de los avances tecnológicos y las capacidades de procesamiento masivo de datos de los gobiernos y las empresas. Por otra parte, algunos países no cuentan con legislación pertinente sobre protección de datos y solo unos pocos han armonizado su legislación con las mejores prácticas internacionales y regionales a fin de abordar los avances tecnológicos en materia de perfiles de datos, tratamiento 
automatizado y vigilancia pública. La ausencia de marcos modernos y adecuados de protección e intercambio de datos impide que los países del Caribe puedan asegurar la libre circulación de la información y el comercio digital dentro y fuera de la subregión.

\section{Gráfico 6.7. Gobierno electrónico en el Caribe, Índice de desarrollo del gobierno electrónico de las Naciones Unidas, 2018}
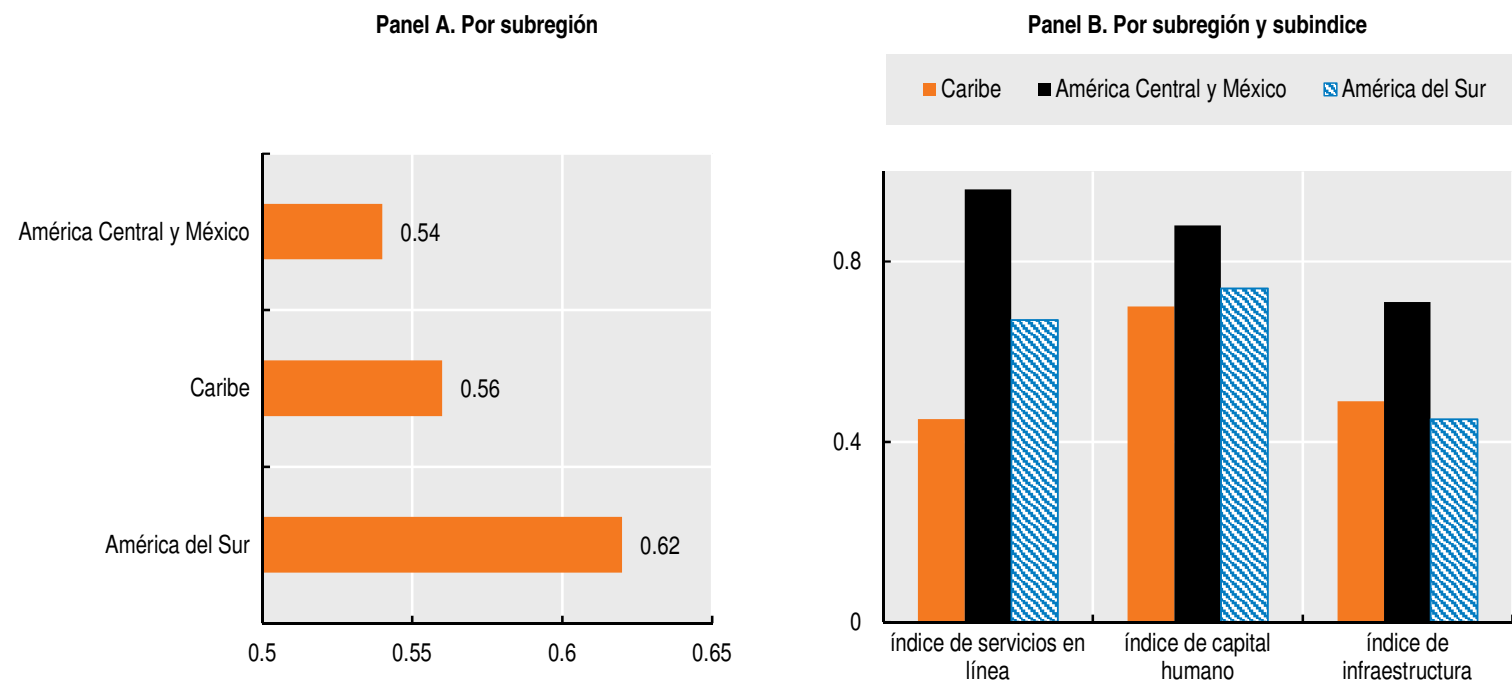

Nota: El Caribe es un promedio simple de 11 países, que no incluye a Cuba ni a la República Dominicana. América del Norte es un promedio simple de Canadá y Estados Unidos. El Índice de desarrollo del gobierno electrónico es un indicador compuesto que consta de tres índices (Índice de servicios en línea, Índice de infraestructura de telecomunicaciones e Índice de capital humano), que están igualmente ponderados. Va de 0 a 1, siendo 1 el más desarrollado.

Fuente: ONU (2019), base de datos e-Government Knowledgebase de Naciones Unidas (base de datos), https://publicadministration. un.org/egovkb/en-us/Data-Center.

StatLink तints https://doi.org/10.1787/888934203054

Si existiera un enfoque regional en el ámbito de las aplicaciones de gobierno electrónico y de la contratación de servicios, los países del Caribe se verían beneficiados ya que los enfoques incoherentes entre distintos ministerios, departamentos y organismos pueden generar duplicaciones de esfuerzos y una falta de interoperabilidad. El CARCIP es un ejemplo reciente de un proyecto conjunto de infraestructuras de TIC que ha tenido éxito. Gracias a la negociación conjunta, los países mejoraron su capacidad de negociación y adquirieron infraestructuras de banda ancha con una importante reducción de costos (Bleeker, 2019b). Otros beneficios potenciales incluyen el intercambio de conocimientos, la mejora de la calidad de las aplicaciones, la reducción de las redundancias y la estandarización de los sistemas y productos.

Si las normas nacionales se alinearan como normas regionales, podrían aprovechar las economías de escala mediante la contratación pública, la creación de capacidad y la adopción de políticas industriales. Los países del Caribe ya están adoptando proyectos de software similares, por ejemplo, el sistema automatizado de datos aduaneros, y están avanzando hacia el software de código abierto. Sin embargo, sigue habiendo redundancias en la aplicación y desajustes en la elección de las tecnologías; muchas iniciativas podrían beneficiarse de una armonización más estricta. El proyecto HIPCAR, que concluyó en 2013, fue un esfuerzo de todo el Caribe para crear políticas y legislación armonizada en el ámbito de las TIC. El proyecto BIIPAC (inventario de infraestructura de banda ancha y sensibilización pública en el Caribe) tenía por objeto "identificar un inventario de las infraestructuras de banda ancha existentes en los países participantes, así como directrices prácticas para la aplicación ubicua de las tecnologías de acceso a la banda ancha de una manera eficiente que sea compatible con las normas adoptadas a nivel 
mundial y las mejores prácticas internacionales" (Canto, 2015). El proyecto de gobierno electrónico para la integración regional de la Secretaría de la Organización de Estados del Caribe Oriental es otra iniciativa regional.

Existen enormes oportunidades para mejorar la coordinación regional, pero hay retos importantes, desde las diferentes políticas y prioridades nacionales hasta las cuestiones relativas al proceso de contratación pública, las preocupaciones sobre la gestión del cambio y las dificultades para escapar de la dependencia de los proveedores. Sin embargo, estos retos pueden resolverse, y las iniciativas regionales pueden desempeñar un papel importante en el desarrollo del gobierno electrónico en el Caribe. Los proyectos con más probabilidades de éxito son aquellos que se centran en problemas comunes, tienen un compromiso suficiente y se basan en los marcos jurídicos e institucionales existentes para la colaboración (Marius y Williams, 2016).

\section{Retos de seguridad digital en el Caribe}

Cualquier estrategia digital debe incluir un componente clave que aborde los riesgos de seguridad digital, sobre todo a medida que los ciberataques aumentan en frecuencia y sofisticación, interrumpiendo infraestructuras críticas y comprometiendo información clave. Aunque varias naciones del Caribe han comenzado a aplicar leyes y marcos de políticas que abordan la seguridad digital, pocos países cuentan con una estrategia nacional de seguridad digital o con un organismo nacional responsable de seguridad digital y de protección de infraestructuras de información crítica necesaria para hacer frente a los matices de los ciberdelitos. En los casos en que sí existen leyes, los países del Caribe todavía no cuentan con sistemas sólidos para hacer frente a la sofisticación que entrañan este tipo de delitos (McKendrick, 2020). La ineficacia de las respuestas de los gobiernos ante los ciberataques revela su falta de capacidad institucional y de gobernanza.

El Índice mundial de ciberseguridad de las Naciones Unidas (UIT, 2020b) mide el compromiso de los países con la seguridad digital en cinco dimensiones: aspectos legales, técnicos, organizativos, creación de capacidad y cooperación internacional. ${ }^{2}$ Ningún país del Caribe tiene una calificación "alta", y solo Jamaica tiene una calificación "media" (0.669-0.340). Otros países tienen una puntuación "baja” (0.339-0.000) (Tabla 6.2). En comparación con el índice anterior, 7 de cada 11 países han descendido puestos en su clasificación. Jamaica, el país caribeño de mayor puntuación, ocupa el puesto 94 de 193 países.

Con respecto a América del Sur y América del Norte, las mayores deficiencias del Caribe hacen referencia a aspectos jurídicos, como la promulgación de legislación o regulaciones sobre protección de los datos y privacidad, protocolos de respuesta a ciberdelitos y contención de correos electrónicos no deseados. Los esfuerzos también se han dirigido a los aspectos organizativos. Sigue habiendo dificultades para aplicar los aspectos técnicos, como la creación de equipos de respuesta frente a incidentes de seguridad informática, organismos que elaboren o adapten normas de seguridad digital y medidas técnicas para la contención del correo basura y la protección de menores en Internet. Es necesario que la subregión intensifique sus esfuerzos en materia de creación de capacidad en relación con campañas de sensibilización, normas de certificación profesional e inversión en investigación y cooperación internacional (Gráfico 6.8).

Al igual que con sus demás marcos de políticas y legislación en el ámbito de las TIC, los países del Caribe podrían beneficiarse de un enfoque regional armonizado en materia de leyes y procedimientos de ciberdelincuencia. Existen variaciones significativas entre las disposiciones y procedimientos jurídicos sustantivos de los países, lo cual probablemente conduce a problemas de aplicación. Dada la inexistencia de fronteras en Internet y los numerosos incidentes de seguridad digital, así como la limitada capacidad de respuesta 
ante los mismos, la adopción de un enfoque armonizado facilitaría la asistencia mutua, reduciendo la capacidad de los ciberdelincuentes para actuar sin repercusiones en el Caribe (McKendrick, 2020).

Tabla 6.2. Índice mundial de ciberseguridad de la Unión Internacional de Telecomunicaciones de las Naciones Unidas, países seleccionados del Caribe, 2018

\begin{tabular}{lcccc}
\hline & $\begin{array}{c}\text { Calificación } \\
\text { normalizada }\end{array}$ & $\begin{array}{c}\text { Clasificación } \\
\mathbf{2 0 1 8}\end{array}$ & $\begin{array}{c}\text { Variación en clasificación } \\
\mathbf{( 2 0 1 7} \text { a 2018) }\end{array}$ & $\begin{array}{c}\text { Clasificación } \\
\text { regional 2018 }\end{array}$ \\
\hline Jamaica & 0.407 & 94 & -10 & 11 \\
\hline Antigua y Barbuda & 0.247 & 113 & 3 & 17 \\
\hline Trinidad y Tobago & 0.199 & 119 & 21 & 19 \\
\hline Barbados & 0.173 & 127 & -33 & 20 \\
\hline San Vicente y las Granadinas & 0.169 & 129 & -16 & 21 \\
\hline Bahamas & 0.147 & 133 & -5 & 22 \\
\hline Granada & 0.143 & 134 & 2 & 23 \\
\hline Santa Lucía & 0.096 & 149 & 6 & 29 \\
\hline San Cristóbal y Nieves & 0.065 & 157 & -7 & 30 \\
\hline Haití & 0.046 & 164 & -4 & 31 \\
\hline Dominica & 0.019 & 172 & -10 & 33 \\
\hline
\end{tabular}

Fuente: UIT (2020b), Índice mundial de ciberseguridad (base de datos), www.itu.int/en/ITU-D/Cybersecurity/Pages/ global-cybersecurity-index.aspx.

\section{Gráfico 6.8. Cinco pilares del Índice mundial de ciberseguridad de la Unión Internacional} de Telecomunicaciones de las Naciones Unidas, 2018

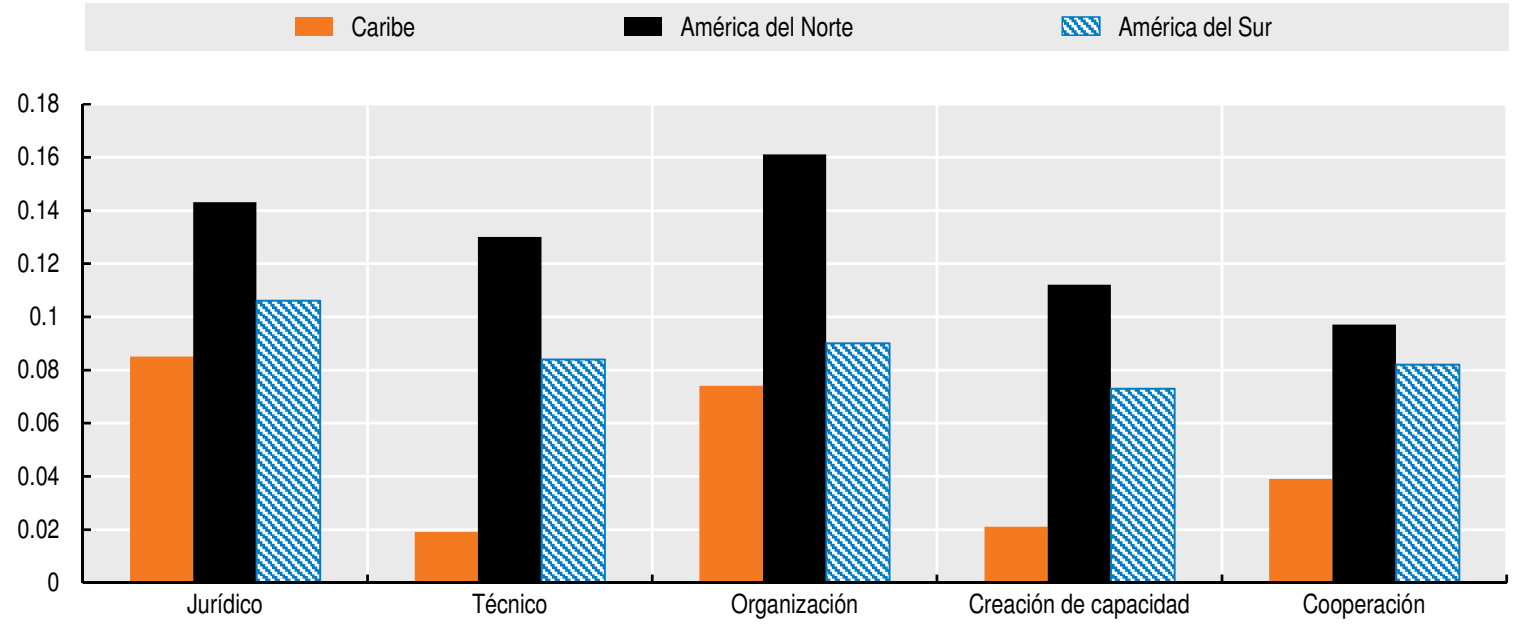

Nota: Los datos del Caribe se basan en un promedio simple de 11 países, que no incluye a Cuba ni a la República Dominicana. Norteamérica es un promedio simple de Canadá y Estados Unidos. El Índice mundial de ciberseguridad mide el compromiso de los países con la ciberseguridad a nivel mundial. Tiene cinco pilares: 1) medidas legales; 2) medidas técnicas; 3) medidas organizativas; 4) desarrollo de capacidades; y 5) cooperación. Va de 0 a 1, siendo 1 el nivel más alto de ciberseguridad.

Fuente: UIT (2020b), Índice mundial de ciberseguridad (base de datos), www.itu.int/en/ITU-D/Cybersecurity/Pages/globalcybersecurity-index.aspx.

StatLink -iाsts https://doi.org/10.1787/888934203073

\section{Conclusión}

La pandemia del coronavirus (Covid-19) impacta e impactará con fuerza a todos los países del Caribe, que dependen en gran medida de los viajes y el turismo. Además, la fuerte caída de los flujos de remesas afectará gravemente a las personas y los hogares, lo que repercutirá en el consumo y en la pobreza. 
Los países del Caribe también se enfrentan a vulnerabilidades a más largo plazo, como el cambio climático, los peligros naturales y los fenómenos meteorológicos extremos, lo que podría suponer una tormenta perfecta en la que se solapen crisis de salud, del clima y de incidencia de huracanes. Para hacer frente a los retos a corto y largo plazo, la subregión debe diversificar su estructura económica. La transformación digital puede desempeñar un papel fundamental. Dicha transformación implicaría la digitalización de la economía y los servicios públicos en ámbitos como el gobierno electrónico, la telemedicina y el aprendizaje electrónico. Las tecnologías pueden ser fundamentales para la preparación frente a las catástrofes naturales y a la respuesta frente a las emergencias.

Para beneficiarse de la transformación digital, los países del Caribe deben desarrollar agendas digitales que sean coherentes con las estrategias nacionales de desarrollo, y asignar recursos adecuados para su aplicación. El Caribe también debe crear un ecosistema digital adecuado y sostenible para acelerar la transformación digital, aumentar la resiliencia económica y mejorar la capacidad de respuesta frente a los peligros naturales. Es esencial crear capacidad financiera y técnica, ya que las infraestructuras obsoletas de TIC impiden a muchos países adoptar tecnologías digitales con rapidez y eficacia.

El diálogo entre los distintos grupos de interés es fundamental para identificar y superar los obstáculos y crear oportunidades de colaboración. Esto es especialmente evidente en el Caribe, donde el deficiente acceso al financiamiento para el desarrollo a bajo costo aporta una capacidad limitada para crear una infraestructura de TIC capaz de proporcionar una conectividad de alta velocidad.

El avance de la cooperación y la coordinación subregional es fundamental para que las economías adopten la transformación digital de manera inclusiva, eficiente y eficaz. Varios aspectos se beneficiarían de esa cooperación, entre ellos, las políticas en el ámbito de las TIC, las infraestructuras de banda ancha, los sistemas de gobierno electrónico y las políticas destinadas a utilizar instrumentos tecnológicos para gestionar y prevenir las catástrofes naturales.

\section{Notas}

1. A pesar de haber obtenido el tercer y cuarto puesto en la región por población, República Dominicana (44.3) y Jamaica (40.0) mostraban una puntuación ligeramente inferior al promedio de América Latina y el Caribe (49.9).

2. El índice combina 25 indicadores en una sola medida, que van del 0 al 1, en la que 0 indica la ausencia total de esfuerzos en materia de ciberseguridad.

\section{Referencias}

Bleeker (2020), "Strengthening ICT and Knowledge Management Capacity in Support of the Sustainable Development of Multi-island Caribbean SIDS", Serie Estudios y Perspectivas - The Caribbean, n. 81, Comisión Económica para América Latina y el Caribe, Santiago, http:// caribbean.cepal.org/content/strengthening-ict-and-knowledge-management-capacitysupport-sustainable-development.

Bleeker (2019a), "Using Universal Service Funds to Increase Access to Technology for Persons with Disabilities in the Caribbean", Serie Estudios y Perspectivas - The Caribbean, n. ${ }^{\circ} 79$, Comisión Económica para América Latina y el Caribe, Santiago, www.cepal.org/en/publications/ 44913-using-universal-service-funds-increase-access-technology-persons-disabilities.

Bleeker (2019b), "Investing in public/private and regional partnerships to improve the availability of high-speed connections in the Caribbean", Caribbean Technology Partnerships for the SDGs, FOCUS Magazine of the Caribbean Development and Cooperation Committee Series, Vol. 2019, Iss. 4, Comisión Económica para América Latina y el Caribe, Santiago, pp. 6-7, https://repositorio. cepal.org/bitstream/handle/11362/45206/1/FOCUSIssue4Oct-Dec2019.pdf.

CAF (2020), "The Observatory of the Digital Ecosystem of Latin America and the Caribbean", https://www.caf.com/app_tic/\#en/home. 
Canto (2015), "RG-T2212, Contract for Individual Consulting Services, Annex A, Tranche A, Consultant Terms of Reference", Proyecto BIIPAC (inventario de infraestructura de banda ancha $y$ sensibilización pública en el Caribe).

CEPAL (2020a), "Dimensionar los efectos del COVID-19 para pensar en la reactivación", Informe Especial COVID-19, n. ${ }^{\circ}$ 2, Comisión Económica para América Latina y el Caribe, Santiago, www.cepal.org/en/publications/45477-measuring-impact-covid-19-view-reactivation.

CEPAL (2020b), Observatorio Regional de Planificación para el Desarrollo de América Latina y el Caribe, https://observatorioplanificacion.cepal.org/en/opengov.

CEPAL (2017), The Caribbean Outlook, Comisión Económica para América Latina y el Caribe, Santiago, https://repositorio.cepal.org/bitstream/handle/11362/45206/1/FOCUSIssue4Oct-Dec2019.pdf.

CTU (2017a), Vision and Roadmap for a CARICOM Single ICT Space, Caribbean Telecommunication Union, Geneva, https://caricom.org/documents/15510-vision_and_roadmap_for_a_single_ict space - final version updated.pdf.

CTU (2017b), Towards 21st Century Government: Citizen-centric, Seamless Government, Iss. 1.4, Caribbean Telecommunication Union, Geneva, https://events.idloom.com/files/events/1307/ files/towards-21st-century-governments-issue-1-4.pdf.

Gleaner (2020), 'Williams reports progress on digital Jamaica initiative', The Gleaner, Kingston, http://jamaica-gleaner.com/article/business/20200124/williams-reports-progress-digitaljamaica-initiative.

Jamaica Observer (2020), “Gov't implements e-government infrastructure”, The Jamaica Observer, Kingston, www.jamaicaobserver.com/latestnews/Gov\%26\%238217;t_implements_e-signature infrastructure.

Marius y Williams (2016), "Regional Approaches to E-government Initiatives in the Caribbean", Serie Estudios y Perspectivas - The Caribbean, n. ${ }^{\circ} 47$, Comisión Económica para América Latina y el Caribe, Santiago, www.cepal.org/en/publications/39858-regional-approaches-governmentinitiatives-caribbean.

McKendrick (2020), "Capacity Development to Combat Cybercrime for CARIFORUM Member States", Caribbean Community (CARICOM) Implementing Agency for Crime and Security.

Mejía-Giraldo, C. (2018), "Could digital transformation help the Caribbean become more resilient to natural disasters?", Banco Interamericano de Desarrollo, Washington, DC, https://blogs.iadb. org/caribbean-dev-trends/en/could-digital-transformation-help-the-caribbean-become-moreresilient-to-natural-disasters/.

OCDE (2019), "Speed", in Measuring the Digital Transformation: A Roadmap for the Future, Publicaciones de la OCDE, París, https://doi.org/10.1787/094fe0ca-en.

OCDE et al. (2019), Perspectivas económicas de América Latina 2019: Desarrollo en transición, Publicaciones de la OCDE, París https://doi.org/10.1787/g2g9ff1a-es.

ONU (2019), base de datos e-Government Knowledge de Naciones Unidas (base de datos), Departamento de Asuntos Económicos y Sociales de Naciones Unidas, Nueva York, https://publicadministration. un.org/egovkb/en-us/Data-Center.

Phillips et al. (2020), "Compound climate risks in the COVID-19 pandemic", Nature Climate Change, $\mathrm{n}^{\circ}$ 10, Nature Climate Change, London, pp. 586-588, https://doi.org/10.1038/s41558-020-0804-2.

Phillips, A. y R.C. Williams (2014), "Information and Communication Technologies for Disaster Risk Management in the Caribbean", Serie Estudios y Perspectivas - The Caribbean, n. ${ }^{\circ} 32$, Comisión Económica para América Latina y el Caribe, Santiago, https://repositorio.cepal.org/handle/ $11362 / 36735$.

Roseth, B., A. Reyes and C. Santiso (2018), Wait No More: Citizens, Red Tape and Digital Government, Banco Interamericano de Desarrollo, Washington, DC, www.publications.iadb.org/publications/ english/document/Wait_No_More_Citizens_Red_Tape_and_Digital_Government_Caribbean Edition_en.pdf.

Servicio de Información de Jamaica (2020a), “Jamaica USF provides \$17.5 million to upgrade bandwidth of health facilities", Jamaica Information Service, Government of Jamaica, Kingston, https://jis.gov.jm/usf-provides-17-5-million-to-upgrade-bandwidth-of-health-facilities/.

Servicio de Información de Jamaica (2020b), "USF to spend $\$ 1.13$ billion on full implementation of tablets in schools project", Jamaica Information Service, Government of Jamaica, Kingston, https://jis.Gov.jm/usf-to-spend-1-13-billion-on-full-implementation-of-tablets-in-schoolsproject/.

Taylor, C. (2020), "Island nations facing a 'perfect storm' as the coronavirus intersects with hurricane season", Consumer News and Business Channel, Englewood Cliffs, NJ, www.cnbc.com/ 2020/06/12/island-nations-face-perfect-storm-as-coronavirus-meets-hurricane-season.html. 
UIT (2020a), World Telecommunication / ICT Indicators Database 2020 (base de datos), Unión Internacional de Telecomunicaciones, Ginebra, https://www.itu.int/en/ITU-D/Statistics/Pages/ publications/wtid.aspx (consultada el 21 de agosto de 2020).

UIT (2020b), Global Cybersecurity Index (database), International Telecommunication Union, Geneva, www.itu.int/en/ITU-D/Cybersecurity/Pages/global-cybersecurity-index.aspx.

Young, K. (2020), "Los desafíos tecnológicos y sociales complican el aprendizaje remoto", Cayman Compass \& Compass Media Ltd., www.caymancompass.com/2020/06/11/technological-andsocialchallenges-complicate-remote-learning. 



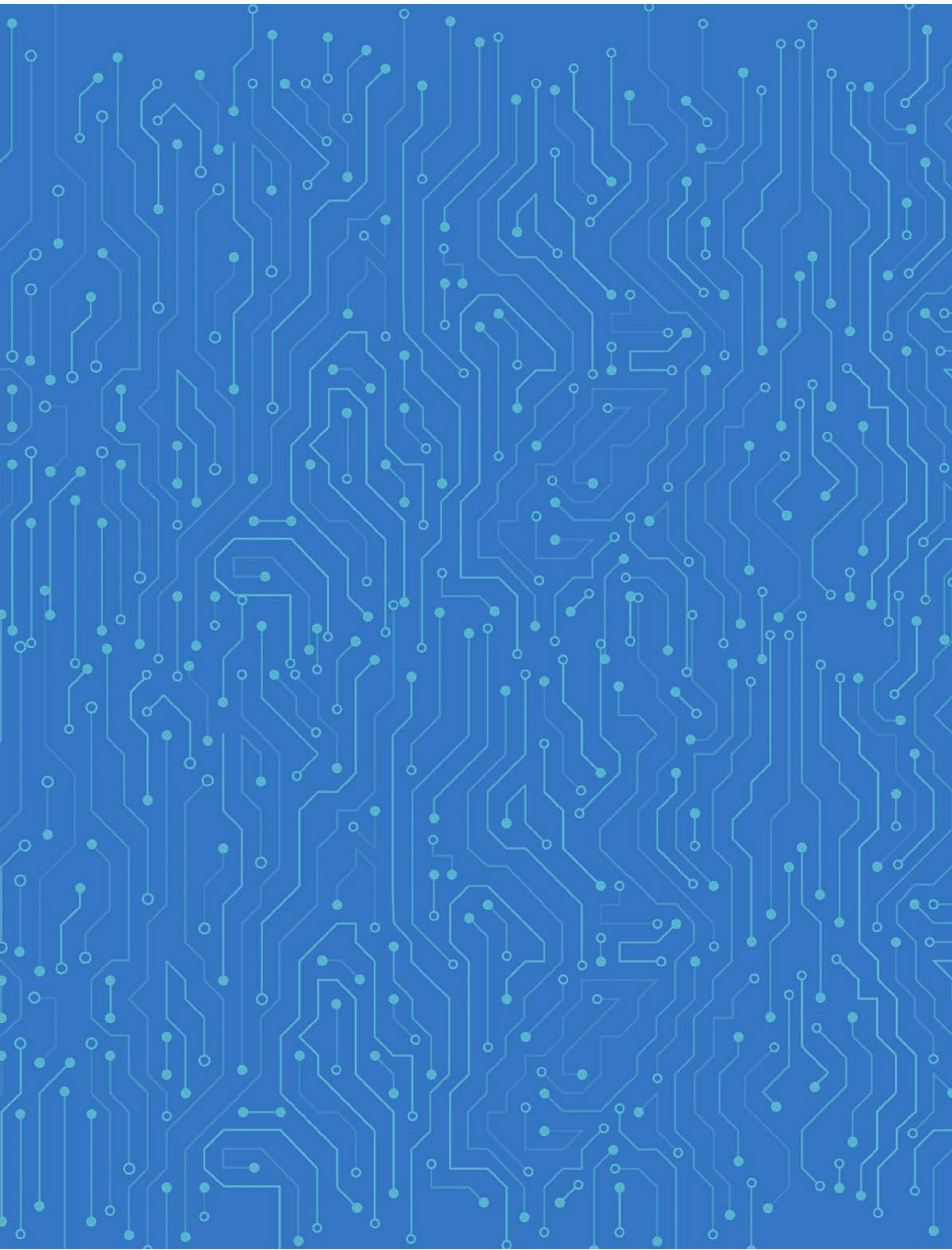




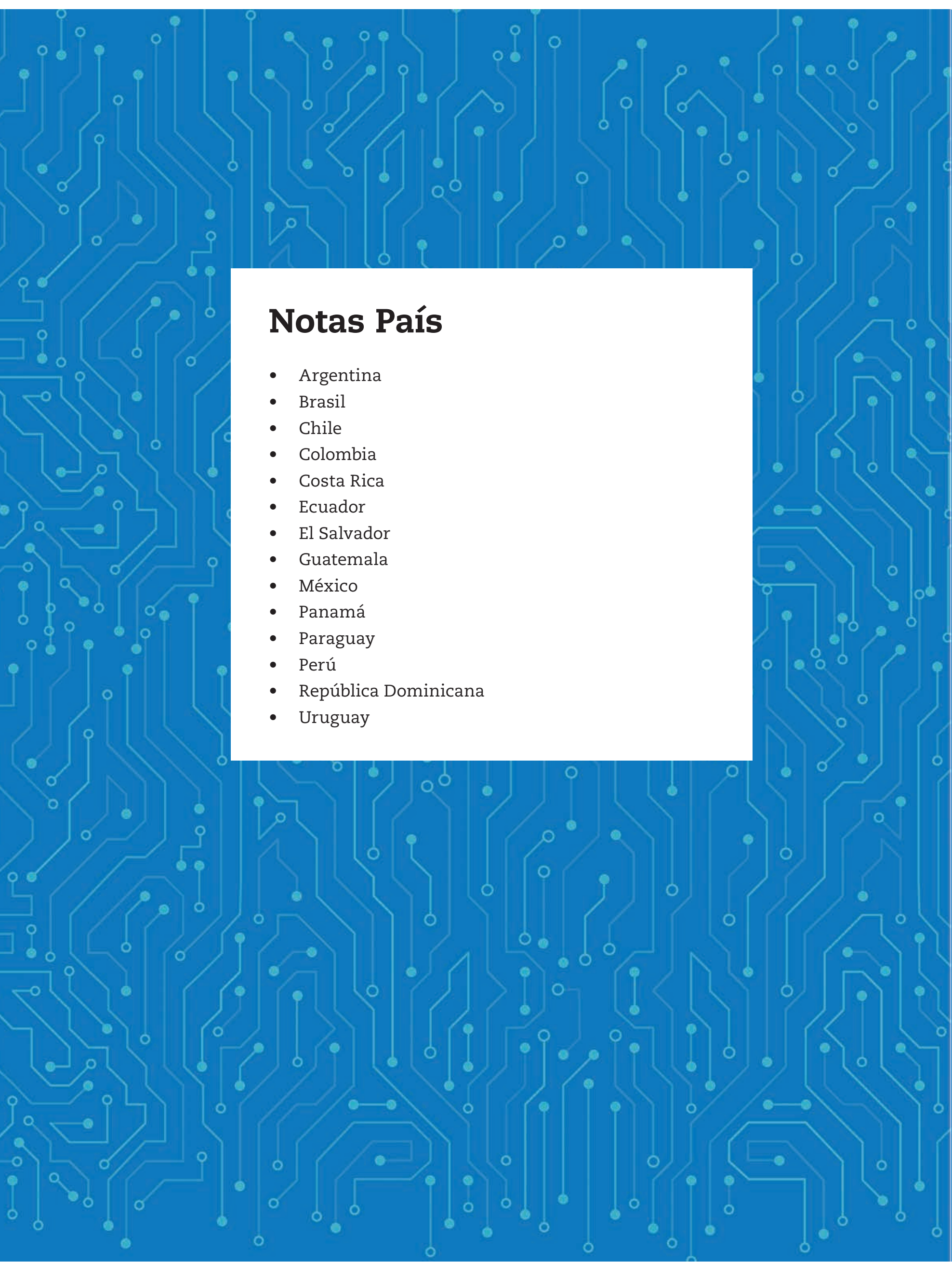




\section{ARGENTINA}

\section{Tendencias recientes}

En la última década, Argentina se ha esforzado para mejorar el acceso digital de todos sus ciudadanos. Ha aumentado el número de usuarios de Internet y de suscripciones a servicios celulares móviles y de banda ancha fija. El país ha avanzado en la transformación digital del Estado, situándose entre los países más avanzados de América Latina y el Caribe (ALC) en cuanto a políticas de datos abiertos de organismos públicos, según el índice OURdata de la OCDE.

En cuanto a la promoción de una sociedad digital inclusiva, hay retos que permanecen, incluyendo el número de estudiantes por computadora. La confianza en la privacidad en línea y la seguridad del comercio electrónico ha aumentado en la última década, pero se mantienen por debajo de los promedios de ALC. Con respecto a facilitar la innovación digital, la proporción de importaciones de servicios de tecnología de la información y las comunicaciones (TIC), al igual que las exportaciones de alta tecnología en proporción al total de las exportaciones de productos manufacturados disminuyeron entre 2008 y 2018.

\section{Estrategias nacionales y cooperación internacional para la transformación digital}

La Agenda Digital Argentina, que es coherente con la Agenda 2030 de las Naciones Unidas para el Desarrollo Sostenible, constituye la base sobre la que se rige la transformación digital del país. Dicha agenda tiene como objetivo aprovechar las tecnologías digitales para lograr la plena inclusión digital de todos los ciudadanos, mejorar la productividad y competitividad de la economía y poner el Estado al servicio de los ciudadanos. El Gobierno, que asumió el poder en diciembre de 2019, seguirá revisando dicha agenda.

Entre las iniciativas adoptadas para promover la transformación digital, el programa Aprender Conectados fomenta la innovación en la educación y la alfabetización digital, y ofrece educación digital, programación y clases de robótica en el jardín de infancia y también en la educación primaria y secundaria. El programa País Digital tiene como objetivo modernizar la administración pública, mejorar la calidad de los servicios y promover la transparencia, la inclusión digital y la innovación, en coordinación con los gobiernos municipales. Los Puntos Digitales siguen operativos en este marco, y proporcionan conectividad, capacitación y acceso a las nuevas TIC. En 2019, Argentina lanzó la Estrategia Nacional de Ciberseguridad para dotar de mayor seguridad a las personas y organizaciones públicas y privadas en el contexto del ciberespacio, y renovó el régimen que promueve la economía basada en el conocimiento. Argentina también puso en marcha el Plan Industria 4.0, en el que participan varios ministerios, para mejorar la competitividad del sector industrial mediante la adopción de tecnologías digitales, incluidos los macrodatos, la inteligencia artificial y la impresión en 3D. Para combatir el coronavirus (Covid-19), el Gobierno lanzó la app Coronavirus Argentina a fin de que los ciudadanos puedan autoevaluar sus síntomas. Además, el Ministerio de Innovación Pública, junto con el Ministerio de Salud y Facebook, lanzaron un chatbot para proporcionar información y actualizaciones oficiales (CAF, 2020).

En cuanto a la cooperación internacional, el Fondo Argentino de Cooperación Internacional (FO.AR) es responsable de las iniciativas de cooperación Sur-Sur, triangular y multilateral. A través de FO.AR, Argentina cooperó con Panamá en un proyecto para desarrollar técnicas y procesos de fotogrametría y cartografía digital.

El Ministerio de Ciencia, Tecnología e Innovación Productiva celebró la 11. ${ }^{a}$ reunión del Comité Directivo Conjunto sobre la cooperación en materia de ciencia y tecnología entre la Unión Europea (UE) y Argentina en 2019. Se acordó seguir desarrollando principios comunes y las condiciones marco necesarias para crear un entorno de igualdad que permita cooperar en materia de investigación e innovación en un clima de confianza. Argentina y la UE también cooperan en el desarrollo de la economía digital. En 2018 se celebró una primera reunión con este fin y está prevista una segunda para 2020. Argentina y la UE están colaborando en el proyecto de Cooperación Digital Internacional sobre protección de datos y flujos de datos para permitir el desarrollo de una esfera digital internacional segura y basada en los derechos. Argentina y la UE también cooperan con Colombia en un proyecto financiado por Adelante para agrupar y digitalizar datos biométricos. También hay un proyecto regional sobre digitalización y protección de datos en el marco del Instrumento de Asociación, que actualizará la legislación y el marco regulatorio, esforzándose por una mayor alineación con la UE. 


\section{Mejorar el acceso}

Suscripciones de banda ancha fija (por cada 100 habitantes) ${ }^{4}$

Suscripciones de banda ancha móvil activa (por cada 100 habitantes) ${ }^{4}$

Proporción de población cubierta por al menos una red $3 \mathrm{G}^{5}$

Velocidad de banda ancha fija (en Mbit/s) ${ }^{4}$

Aumentar el uso efectivo

Índice de desarrollo del gobierno electrónico (EGDI) ${ }^{6}$

Proporción de usuarios de Internet (\% de población) ${ }^{4}$

Índice de comercio electrónico B2C de la UNCTAD

Proporción de personas que realizan compras por Internet ${ }^{8}$

Impulsar la innovación

Exportaciones de alta tecnología (\% de exportaciones manufacturadas) ${ }^{9}$

Proporción de importaciones de servicios de TIC, como porcentaje del comercio total de servicios ${ }^{7}$

Solicitudes de patentes de TIC presentadas en virtud del Tratado de Cooperación en materia de Patentes (por millón de personas) ${ }^{10}$

Gastos en I+D, como \% del PIB ${ }^{11}$

Índice OURdata de la OCDE'12

\section{Asegurar empleos adecuados para todos}

Contribuciones a variación en empleo total, por intensidad digital de sectores, 2006-2016 ${ }^{13}$

Proporción de empleo informal en relación con empleo total ${ }^{14}$

Tasa bruta de matrícula, educación terciaria $(\%)^{9}$

Graduados de educación terciaria por campo (\%) - Educación ${ }^{11}$

Graduados de educación terciaria por campo (\%) - Salud ${ }^{11}$

Graduados de educación terciaria por campo (\%) - Ingeniería11

\section{Promocionar la prosperidad social}

Generación de desechos de aparatos eléctricos per cápita $(\mathrm{kg})^{15}$

Número de estudiantes por computadora ${ }^{16}$

Proporción de mujeres con puntuación de nivel 203 en resolución de problemas en entornos tecnológicos ${ }^{17}$

\section{Reforzar la confianza}

Índice GovTech de la $\mathrm{CAF}^{18}$

Índice de ciberseguridad global (UIT) $)^{19}$

Seguridad del comercio electrónico $(\%)^{20}$

Confianza en la privacidad en Internet $(\%)^{20}$

\section{Promocionar la apertura de mercados}

Índice de restrictividad de intercambios de servicios digitales de la OCDE ${ }^{13}$

Índice de restricción regulatoria de la IED de la $0 \mathrm{CDE}^{13}$

Las fuentes, notas a pie de página y detalles técnicos se pueden encontrar al final de las Notas País.

\begin{tabular}{cccccc}
\multicolumn{4}{c}{ Indicadores digitales - Argentina } \\
\hline \multicolumn{2}{c}{ Argentina } & \multicolumn{2}{c}{ ALC $^{2}$} & \multicolumn{2}{c}{ OCDE $^{3}$} \\
\hline $\mathbf{2 0 0 8}$ & $\mathbf{2 0 1 8}$ & $\mathbf{2 0 0 8}$ & $\mathbf{2 0 1 8}$ & $\mathbf{2 0 0 8}$ & $\mathbf{2 0 1 8}$ \\
\hline 7.8 & 19.1 & 4.1 & 13.9 & 22.2 & 32.5 \\
$\mathbf{2 0 1 0}$ & $\mathbf{2 0 1 7}$ & $\mathbf{2 0 1 0}$ & $\mathbf{2 0 1 7}$ & $\mathbf{2 0 1 0}$ & $\mathbf{2 0 1 7}$ \\
\hline 4.9 & 80.7 & 5.4 & 66.8 & 37.7 & 97.3 \\
$\mathbf{2 0 1 5}$ & $\mathbf{2 0 1 8}$ & $\mathbf{2 0 1 5}$ & $\mathbf{2 0 1 8}$ & $\mathbf{2 0 1 5}$ & $\mathbf{2 0 1 8}$ \\
\hline 90.0 & 95.0 & 86.1 & 94.6 & 98.2 & 98.8 \\
$\mathbf{2 0 0 8}$ & $\mathbf{2 0 1 7}$ & $\mathbf{2 0 0 8}$ & $\mathbf{2 0 1 7}$ & $\mathbf{2 0 0 8}$ & $\mathbf{2 0 0 7}$ \\
\hline 2.5 & 3.0 & 0.58 & 5.1 & 2.2 & 27.7
\end{tabular}

\begin{tabular}{cccccc}
\multicolumn{2}{c}{ Argentina } & \multicolumn{2}{c}{ ALC } & \multicolumn{2}{c}{ OCDE } \\
\hline $\mathbf{2 0 0 8}$ & $\mathbf{2 0 1 8}$ & $\mathbf{2 0 0 8}$ & $\mathbf{2 0 1 8}$ & $\mathbf{2 0 0 8}$ & $\mathbf{2 0 1 8}$ \\
\hline 0.58 & 0.73 & 0.52 & 0.65 & 0.72 & 0.82 \\
$\mathbf{2 0 0 8}$ & $\mathbf{2 0 1 7}$ & $\mathbf{2 0 0 8}$ & $\mathbf{2 0 1 7}$ & $\mathbf{2 0 0 8}$ & $\mathbf{2 0 1 7}$ \\
\hline 28.1 & 74.3 & 25.3 & 62.9 & 65.0 & 83.4 \\
$\mathbf{2 0 1 5}$ & $\mathbf{2 0 1 9}$ & $\mathbf{2 0 1 5}$ & $\mathbf{2 0 1 9}$ & $\mathbf{2 0 1 5}$ & $\mathbf{2 0 1 9}$ \\
\hline 51.9 & 50.0 & 46.4 & 51.5 & 73.3 & 85.0 \\
\hline \multicolumn{2}{c}{$\mathbf{2 0 1 7}$} & \multicolumn{2}{c}{$\mathbf{2 0 1 7}$} & \multicolumn{2}{c}{$\mathbf{2 0 1 7}$} \\
\hline 19.2 & \multicolumn{2}{c}{14.8} & \multicolumn{2}{c}{ N/A }
\end{tabular}

\begin{tabular}{cccccc}
\multicolumn{2}{c}{ Argentina } & \multicolumn{2}{c}{ ALC } & \multicolumn{2}{c}{ OCDE } \\
\hline $\mathbf{2 0 0 8}$ & $\mathbf{2 0 1 8}$ & $\mathbf{2 0 0 8}$ & $\mathbf{2 0 1 8}$ & $\mathbf{2 0 0 8}$ & $\mathbf{2 0 1 8}$ \\
\hline 9.4 & 5.3 & 9.3 & 8.6 & 16.3 & 15.1 \\
5.46 & 5.15 & 3.1 & 3.9 & 4.6 & 6.7 \\
$\mathbf{2 0 1 2}$ & $\mathbf{2 0 1 6}$ & $\mathbf{2 0 1 2}$ & $\mathbf{2 0 1 6}$ & $\mathbf{2 0 1 2}$ & $\mathbf{2 0 1 6}$ \\
\hline 0.19 & 0.21 & 0.14 & 0.34 & 30.9 & 38.2 \\
$\mathbf{2 0 0 6}$ & $\mathbf{2 0 1 6}$ & $\mathbf{2 0 0 6}$ & $\mathbf{2 0 1 6}$ & $\mathbf{2 0 0 6}$ & $\mathbf{2 0 1 6}$ \\
\hline 0.45 & 0.53 & 0.35 & 0.42 & 1.7 & 1.9 \\
\hline \multicolumn{2}{c}{$\mathbf{2 0 1 9}$} & \multicolumn{2019}{c}{$\mathbf{2 0 1 9}$} \\
\hline 0.53 & \multicolumn{2}{c}{0.43} & \multicolumn{2}{c}{0.61}
\end{tabular}

\begin{tabular}{|c|c|c|c|c|c|}
\hline \multicolumn{2}{|c|}{ Argentina } & \multicolumn{2}{|c|}{ ALC } & \multicolumn{2}{|c|}{ OCDE } \\
\hline \multicolumn{2}{|c|}{$2006-15$} & \multicolumn{2}{|c|}{$2006-15$} & \multicolumn{2}{|c|}{$2006-15$} \\
\hline \multicolumn{2}{|c|}{$\mathrm{N} / \mathrm{A}$} & \multicolumn{2}{|c|}{6.9} & \multicolumn{2}{|c|}{4.8} \\
\hline \multicolumn{2}{|c|}{2018} & \multicolumn{2}{|c|}{2018} & \multicolumn{2}{|c|}{2018} \\
\hline \multicolumn{2}{|c|}{48.1} & \multicolumn{2}{|c|}{54.9} & \multicolumn{2}{|c|}{$\mathrm{N} / \mathrm{A}$} \\
\hline 2007 & 2017 & 2007 & 2017 & 2007 & 2017 \\
\hline 66.4 & 90.0 & 37.5 & 60.5 & 66.6 & 73.8 \\
\hline \multicolumn{2}{|c|}{2015} & \multicolumn{2}{|c|}{2015} & \multicolumn{2}{|c|}{2015} \\
\hline \multicolumn{2}{|c|}{21.1} & \multicolumn{2}{|c|}{16.4} & \multicolumn{2}{|c|}{10.3} \\
\hline \multicolumn{2}{|c|}{20.7} & \multicolumn{2}{|c|}{14.7} & \multicolumn{2}{|c|}{14.3} \\
\hline \multicolumn{2}{|c|}{5.5} & \multicolumn{2}{|c|}{12.8} & \multicolumn{2}{|c|}{14.5} \\
\hline
\end{tabular}

\begin{tabular}{cccccc}
\multicolumn{2}{c}{ Argentina } & \multicolumn{2}{c}{ ALC } & \multicolumn{2}{c}{ OCDE } \\
\hline $\mathbf{2 0 1 5}$ & $\mathbf{2 0 1 6}$ & $\mathbf{2 0 1 5}$ & $\mathbf{2 0 1 6}$ & $\mathbf{2 0 1 5}$ & $\mathbf{2 0 1 6}$ \\
\hline 8.2 & 8.4 & 6.9 & 7.2 & 17.4 & 17.7 \\
$\mathbf{2 0 1 5}$ & $\mathbf{2 0 1 8}$ & $\mathbf{2 0 1 5}$ & $\mathbf{2 0 1 8}$ & $\mathbf{2 0 1 5}$ & $\mathbf{2 0 1 8}$ \\
\hline N/A & 2.1 & 2.4 & 1.6 & 1.8 & 1.1 \\
\multicolumn{2}{c}{$\mathbf{2 0 1 8}$} & \multicolumn{2}{c}{$\mathbf{2 0 1 8}$} & \multicolumn{2}{c}{$\mathbf{2 0 1 8}$} \\
\hline N/A & \multicolumn{2}{c}{7.7} & \multicolumn{2}{c}{27.7}
\end{tabular}

\begin{tabular}{cccccc}
\multicolumn{2}{c}{ Argentina } & \multicolumn{2}{c}{ ALC } & \multicolumn{2}{c}{ OCDE } \\
\hline \multicolumn{2}{c}{$\mathbf{2 0 2 0}$} & \multicolumn{2}{c}{$\mathbf{2 0 2 0}$} & \multicolumn{2}{c}{$\mathbf{2 0 2 0}$} \\
\hline \multicolumn{2}{c}{4.2} & \multicolumn{2}{c}{4.4} & \multicolumn{2}{c}{ N/A } \\
\hline $\mathbf{2 0 1 6}$ & $\mathbf{2 0 1 8}$ & $\mathbf{2 0 1 6}$ & $\mathbf{2 0 1 8}$ & $\mathbf{2 0 1 6}$ & $\mathbf{2 0 1 8}$ \\
\hline 0.41 & 0.41 & 0.36 & 0.43 & 0.55 & 0.78 \\
$\mathbf{2 0 1 8}$ & $\mathbf{2 0 1 9}$ & $\mathbf{2 0 1 8}$ & $\mathbf{2 0 1 9}$ & $\mathbf{2 0 1 8}$ & $\mathbf{2 0 1 9}$ \\
\hline 48.8 & 58.7 & 72.0 & 63.1 & 61.7 & 58.6 \\
\hline 40.0 & 42.0 & 52.8 & 54.9 & 41.7 & 46.0
\end{tabular}

\begin{tabular}{cccccc}
\multicolumn{2}{c}{ Argentina } & \multicolumn{2}{c}{ ALC } & \multicolumn{2}{c}{ OCDE } \\
\hline $\mathbf{2 0 1 5}$ & $\mathbf{2 0 1 9}$ & $\mathbf{2 0 1 5}$ & $\mathbf{2 0 1 9}$ & $\mathbf{2 0 1 5}$ & $\mathbf{2 0 1 9}$ \\
\hline 0.36 & 0.30 & 0.24 & 0.24 & 0.13 & 0.15 \\
\multicolumn{2}{c}{$\mathbf{2 0 1 8}$} & \multicolumn{2}{c}{$\mathbf{2 0 1 8}$} & \multicolumn{2}{c}{$\mathbf{2 0 1 8}$} \\
\hline 0.03 & \multicolumn{2}{c}{0.07} & \multicolumn{2}{c}{0.06} \\
\hline
\end{tabular}




\section{Notas técnicas}

1. La Tabla sigue lo mejor posible las siete áreas claves identificadas en el proyecto Going Digital de la OCDE: 1) mejorar el acceso a las tecnologías digitales; 2) aumentar el uso efectivo; 3) permitir la innovación digital; 4) asegurar empleos adecuados para todos; 5) promocionar la prosperidad social; 6) reforzar la confianza; y 7) promocionar la apertura de mercados (OCDE, 2019a). Los indicadores se eligen según la disponibilidad de datos para los países de ALC. Existe la posibilidad de un sesgo por la forma en que se han agregado los componentes en los indicadores de índice.

2. El promedio de ALC es un promedio simple. La composición de los países depende de la disponibilidad de datos de los países de la región. Cada promedio incluye tantos países de ALC encontrados en cada fuente como sea posible.

3. El promedio de la OCDE es un promedio simple que incluye a todos los países miembros de la OCDE en mayo de 2020.

4. Datos de la UIT (2020), Base de datos de indicadores mundiales de telecomunicaciones / TIC 2020 (base de datos). La velocidad de banda ancha fija en Mbit/s se refiere a la velocidad de descarga teórica máxima anunciada garantizada a los usuarios asociados con una suscripción mensual de Internet de banda ancha fija.

5. Datos de la División de Estadística de las Naciones Unidas, Base de datos mundial de los ODS de las Naciones Unidas (base de datos). Datos de 2015 y 2018 o los últimos disponibles.

6. Datos de la base de conocimientos sobre gobierno electrónico de las Naciones Unidas (2019), centro de datos (base de datos). El índice de desarrollo del gobierno electrónico (E-government development index) es un indicador compuesto que consta de tres índices (índice de servicios en línea, índice de infraestructura de telecomunicaciones e índice de capital humano), que están igualmente ponderados. Tiene un rango de 0 a 1, con 1 siendo un gobierno más desarrollado.

7. Datos de UNCTAD (2020), UNCTADSTAT (base de datos). El índice de comercio electrónico B2C de la UNCTAD mide la preparación de una economía para respaldar las compras en línea. Rango de 0 a 100, con 100 siendo el nivel de apoyo más alto.

8. Cálculos propios a partir de datos de Latinobarómetro (2019), Libros de Códigos por País / Año (base de datos). Datos de 2017. Datos de encuestas de opinión pública utilizando muestras representativas a nivel nacional seleccionadas al azar.

9. Datos del Banco Mundial (2020a), Banco de datos del Banco Mundial (base de datos).

10. Datos del Banco Mundial (2020b), TCdata360. Datos de 2012 y 2016 o los últimos disponibles.

11. Datos de Unesco (2019), Instituto de Estadística de la Unesco (base de datos). Gastos en I+D, como porcentaje de los datos del PIB de 2006 y 2016 o el último disponible.

12. Datos de OCDE (2020a), OECD.Stat (base de datos) y OCDE (2020b). El índice OURdata de la OCDE evalúa los esfuerzos de los gobiernos para implementar datos abiertos en tres áreas críticas: apertura, utilidad y reutilización de los datos gubernamentales. Tiene un rango de 0 a 1, con 1 siendo la puntuación más alta.

13. Datos de OCDE (2020a), OECD.Stat (base de datos). El Índice de restricción del comercio de servicios digitales de la OCDE identifica, cataloga y cuantifica las barreras que afectan el comercio de servicios habilitados digitalmente en 46 países. Tiene un rango de 0 a 1, con 1 siendo el valor más restrictivo. El Índice de Restricción Reglamentaria de la Inversión Extranjera Directa (IED RRI) mide cuatro tipos de restricciones legales a la inversión extranjera directa: 1) restricciones a la participación extranjera en el capital social; 2) requisitos de selección y aprobación previa; 3) regulaciones para personas claves; y 4) otras restricciones al funcionamiento de empresas extranjeras. El RRI de la IED es un índice compuesto, que varía de 0 a 1, con 1 siendo el valor más restrictivo.

14. Datos de ILOSTAT, datos de 2018 o último año disponible.

15. Datos de la Asociación mundial de estadísticas sobre desechos electrónicos.

16. Cálculos de la OCDE basados en OCDE (2020c), Programa de Evaluación Internacional de Estudiantes (base de datos). Datos de 2015 y 2018.

17. Datos de la OCDE (2019d), Survey of Adult Skills (2018). Los porcentajes para la resolución de problemas en entornos ricos en tecnología se calculan de modo que la suma de los porcentajes de las siguientes categorías mutuamente exhaustivas sea igual al 100\%: se excluyó de la evaluación por computadora; sin experiencia en informática; prueba de núcleo de TIC fallida; por debajo del Nivel 1, en el Nivel 1, en el Nivel 2 y en el Nivel 3.

18. Datos de CAF (2020), The GouTech Index 2020: Unlocking the Potential of GouTech Ecosystems in Latin America, Spain and Portugal. El índice GovTech 2020 mide la madurez del ecosistema GovTech. Se basa en 28 indicadores en 7 dimensiones, que, en conjunto, forman 3 pilares igualmente ponderados: industria de nueva creación, políticas gubernamentales y sistemas de adquisiciones. 
19. El Índice mundial de ciberseguridad mide el compromiso de los países con la ciberseguridad a escala global. Tiene cinco pilares: 1) medidas legales; 2) medidas técnicas; 3) medidas organizativas; 4) desarrollo de capacidades; y 5) cooperación. Va de 0 a 1, siendo 1 el nivel más alto de ciberseguridad.

20. Datos de The Economist Intelligence Unit (2019), EIU Inclusive Internet Index (base de datos). Los indicadores presentan la seguridad percibida del comercio electrónico y la confianza en la privacidad en línea entre las personas seleccionadas al azar en países seleccionados. Varía del $0 \%$ al 100\%, donde el $100 \%$ indica una confianza absoluta en la seguridad del comercio electrónico y la confianza en la privacidad en línea.

\section{Referencias}

Banco Mundial (2020a), DataBank (base de datos), Grupo del Banco Mundial, Washington, DC, https:// databank.worldbank.org/home.aspx (consultada el 11 de diciembre de 2019).

Banco Mundial (2020b), TCdata360 (base de datos), Grupo del Banco Mundial, Washington, DC, https:// tcdata360.worldbank.org/ (consultada el 4 de agosto de 2020).

Base de conocimientos sobre gobierno electrónico de la ONU (2019), Data Center (base de datos), Departamento de Asuntos Económicos y Sociales de las Naciones Unidas, Nueva York, https:// publicadministration.un.org/egovkb/en-us/Data-Center (consultada el 11 de diciembre de 2019).

CAF (2020), The GouTech Index 2020: Unlocking the Potential of GovTech Ecosystems in Latin America, Spain and Portugal, Banco de Desarrollo de America Latina, Caracas.

CEPAL (2018), Observatorio Regional de Planificación para el Desarrollo de América Latina y el Caribe, Comisión Económica para América Latina y el Caribe, Santiago, https://observatorioplanificacion.cepal.org/es.

Dispositivo de estadísticas de la ONU (2018, 2015), ODS globales de la ONU (database), Departamento de Asuntos Económicos y Sociales de las Naciones Unidas, Nueva York, https://unstats.un.org/sdgs/ indicators/database/ (consultada el 20 de mayo de 2020).

Foro Mundial Económico (2016), “The Global Information Technology Report 2016”, Foro Mundial Económico, Ginebra, https://www.weforum.org/reports/the-global-information-technology-report-2016.

Global E-waste Statistic Partnership, página de internet, Global E-waste Statistic Partnership, Bonn, https:// globalewaste.org/ (consultada el 11 de diciembre de 2019).

Latinobarómetro (2019), Libros de Códigos por País/Año (base de datos), Latinobarómetro, Providencia, www. latinobarometro.org/latCodebooks.jsp (consultada el 11 de diciembre de 2019).

OCDE (2020a), OECD.Stat (database), Publicaciones de la OCDE, París, https://stats.oecd.org/ (consultada el 11 de diciembre de 2019).

OCDE (2020b), Panorama de las Administraciones Públicas América Latina y el Caribe 2020, Publicaciones de la OCDE, París, https://doi.org/10.1787/13130fbb-en.

OCDE (2020c), Programme for International Student Assessment (base de datos), Publicaciones de la OCDE, París, www.oecd.org/pisa/data/2018database/ (consultada el 14 de febrero de 2020).

OCDE (2019a), Cómo medir la transformación digital: Hoja de ruta para el futuro, Publicaciones de la OCDE, París, https://doi.org/10.1787/9789264311992-en.

OCDE (2019b), Estudios de la OCDE sobre Transformación Digital: “Going Digital” en Colombia, Publicaciones de la OCDE, París, https://doi.org/10.1787/781185b1-en.

OCDE (2019c), Digital Government Review of Panama: Enhancing the Digital Transformation of the Public Sector, OCDE Estudios de gobierno digital, Publicaciones de la OCDE, París, https://doi.org/10.1787/615a4180-en.

OCDE (2019d), Survey of Adult Skills, Publicaciones de la OCDE, París, https://www.oecd.org/skills/piaac/data/

OIT (2019), ILO Statistics (base de datos), Organización Internacional del Trabajo, Ginebra, www.ilo.org/ global/statistics-and-databases/lang--en/index.htm (consultada el 11 de diciembre de 2019).

Open Knowledge Foundation (2019), Global Open Data Index (base de datos), Open Knowledge Foundation, Cambridge, Reino Unido, https://index.okfn.org/dataset/ (consultada el 19 de abril de 2020).

PIAAC Expert Group in Problem Solving in Technology-Rich Environments (2009), "PIAAC Problem Solving in Technology- Rich Environments: A Conceptual Framework", OCDE Documentos de trabajo educativo, n. ${ }^{\circ}$ 36, Publicaciones de la OCDE, París, https://doi.org/10.1787/220262483674.

The Economist Intelligence Unit (2019), EIU Inclusive Internet Index 2019 (base de datos), The Economist Group, Londres, https://theinclusiveinternet.eiu.com/explore/countries/performance (consultada el $11 \mathrm{de}$ diciembre 2019).

UIT (2020), base de datos de indicadores mundiales de telecomunicaciones / TIC 2020 (base de datos), Unión Internacional de Telecomunicaciones, Ginebra, https://www.itu.int/en/ITU-D/Statistics/Pages/ publications/wtid.aspx (consultada el 21 de agosto de 2020). 
UNCTAD (2020), UNCTADSTAT (base de datos), Conferencia de las Naciones Unidas sobre Comercio y Desarrollo, Ginebra, https://unctadstat.unctad.org/EN/ (consultada el 11 de diciembre de 2019).

UNESCO (2019), Instituto de Estadística de la Unesco (base de datos), Unesco, París, http://data.uis.unesco. org/Index.aspx (consultada el 20 de mayo de 2020).

World Wide Web Foundation (2017), OpenData Barometer (base de datos), World Wide Web Foundation, Ginebra, https://opendatabarometer.org/ (consultada el 19 de abril de 2020). 



\section{BRASIL}

\section{Tendencias recientes}

Brasil sigue obteniendo mejores resultados que el promedio de América Latina y el Caribe (ALC) en determinados indicadores relacionados con la configuración de una sociedad y economía digitales incluyentes. Sin embargo, a pesar de algunos avances, el país permanece por debajo de los promedios de la Organización para la Cooperación y el Desarrollo Económicos (OCDE) en algunos de estos indicadores. El país se ha esforzado para mejorar el acceso digital de todos sus ciudadanos, pero todavía persiste una brecha importante. Ha aumentado en la última década el número de usuarios de Internet y de suscripciones a servicios de banda ancha móvil activa y fija, aunque sigue por debajo del promedio de la OCDE. Brasil ascendió en el índice de desarrollo de gobierno electrónico que mide la disposición y capacidad de las administraciones nacionales para utilizar las TIC (tecnologías de la información y las comunicaciones). Pasó del 0.57 en 2008 al 0.73 en 2018, una evolución superior al promedio de ALC (0.65) pero por debajo de la OCDE (0.82). Otros indicadores de datos abiertos muestran que Brasil ocupa una buena posición tanto a nivel regional como mundial en este ámbito (Open Knowledge Foundation, 2019; World Wide Web Foundation, 2017). El índice de comercio electrónico B2C de la UNCTAD que indica el apoyo de la economía a las compras por Internet fue constante entre 2015 y 2019 y se sitúa por encima del promedio de ALC pero por debajo del de la OCDE.

El país supera a ALC en los indicadores de innovación digital, pero sigue estando por debajo del promedio de la OCDE. Las exportaciones de alta tecnología como porcentaje del total de las exportaciones de productos manufacturados aumentaron al 13\% en 2018, y se situaron por encima del promedio de ALC (8.6\%) pero por debajo de la OCDE (15.1\%). En cuanto a la promoción de una sociedad digital incluyente, el número de estudiantes por computadora aumentó de 3.7 en 2015 a 6.0 en 2018, situándolo por encima de los promedios de ALC y de la OCDE. El índice de ciberseguridad global muestra que, a pesar de haber descendido algunos puestos en 2019 con respecto a 2016, Brasil se encuentra por encima del promedio de ALC, aunque por debajo del promedio de la OCDE. En 2019, el desempeño en el índice OURdata de la OCDE, que mide las políticas de datos abiertos de organismos públicos, es superior a los promedios de ALC y de la OCDE.

\section{Estrategias nacionales y cooperación internacional para la transformación digital}

La estrategia de transformación digital E-Digital es el principal documento de política para la transformación digital del país. Esta estrategia adopta un enfoque de todos los estamentos del gobierno para una economía basada en datos y coordina las iniciativas estatales relacionadas con la transformación digital para aprovechar el potencial de las tecnologías digitales, promover un crecimiento sostenible e incluyente y aumentar la competitividad, la productividad y el empleo. La estrategia contempla tres planes de acción en el sector de las TIC: el Plan Nacional del Internet de las Cosas (IoT.Br), y los programas Ciencia en la Escuela y Brasil Conectado. En abril de este año, el país lanzó la Estrategia de Gobierno Digital que orientará las acciones de los organismos federales para transformar el gobierno digital y ofrecer mejores y más asequibles servicios a menor costo.

El plan IoT.Br se centra en promover alianzas entre organizaciones públicas y privadas y en mejorar la conectividad de todos los ciudadanos. Este plan evalúa la oferta, la demanda y la capacidad local para ayudar a formular soluciones en el ámbito del IoT y fortalecer el ecosistema de start-ups digitales. Por su parte, el programa Ciencia en la Escuela tiene por objeto reforzar la formación en ciencias centrándose en la resolución de problemas. En 2019, Brasil seleccionó 19 proyectos de universidades federales, institutos de ciencias, organizaciones culturales y otras fuentes para mejorar la enseñanza de las ciencias en 22 estados. El programa Brasil Conectado tiene como objetivo fomentar la conectividad, promover la difusión tecnológica e inclusión digital, reformar el marco institucional y dar prioridad a la cooperación entre los diferentes ministerios y las partes interesadas en educación, salud, agricultura y defensa nacional. Esto incluye una gran variedad de iniciativas para expandir la conectividad a banda ancha a nivel nacional, tales como la instalación de puntos de conexión de banda ancha satelital para ampliar la inclusión digital, sobre todo en comunidades socialmente vulnerables y en zonas remotas. Para responder a la crisis del coronavirus (Covid-19), el Ministerio de Ciencia, Tecnología, Innovación y Comunicaciones creó un comité de crisis para la supervisión y seguimiento de las comunicaciones, denominado Red Conectada. Este comité coordina las acciones de los servicios de telecomunicaciones y radiodifusión, promueve la continuidad de los servicios de telecomunicaciones, permite a los usuarios acceder a servicios de valor agregado y proporciona acceso a la información (CAF, 2020). El Ministerio de Salud también desarrolló la aplicación Coronavirus-SUS que proporciona información sobre Covid-19 y herramientas virtuales de detección. El marco jurídico de las telecomunicaciones fue objeto de una importante reforma con la Ley n. 13879 de 2019.

En materia de cooperación internacional, Brasil ha colaborado en proyectos de investigación y desarrollo 5G, por ejemplo, el Acuerdo de Cooperación Científica y Tecnológica entre la Unión Europea y Brasil, establecido en 2016 para alcanzar un consenso mundial sobre la visión, normas y requisitos del espectro 5G. Desde 2008, Brasil y la Unión Europea han trabajado en el marco de un acuerdo de cooperación científica y tecnológica: los países acordaron ampliar el diálogo y la cooperación bilateral en el ámbito de las TIC, incluyendo aspectos como la adopción de políticas, la regulación y la investigación. 


\section{Mejorar el acceso}

Suscripciones de banda ancha fija (por cada 100 habitantes) ${ }^{4}$

Suscripciones de banda ancha móvil activa (por cada 100 habitantes) ${ }^{4}$

Proporción de población cubierta por al menos una red 3G ${ }^{5}$

Velocidad de banda ancha fija (en Mbit/s) ${ }^{4}$

\section{Aumentar el uso efectivo}

Índice de desarrollo del gobierno electrónico (EGDI) ${ }^{6}$

Proporción de usuarios de Internet (\% de población $)^{4}$

Índice de comercio electrónico B2C de la UNCTAD7

Proporción de personas que realizan compras por Internet ${ }^{8}$

\section{Impulsar la innovación}

Exportaciones de alta tecnología (\% de exportaciones manufacturadas) ${ }^{9}$

Proporción de importaciones de servicios de TIC, como porcentaje del comercio total de servicios ${ }^{7}$

Solicitudes de patentes de TIC presentadas en virtud del Tratado de Cooperación en materia de Patentes (por millón de personas) ${ }^{10}$

Gastos en I+D, como \% del PIB ${ }^{11}$

Índice OURdata de la OCDE ${ }^{12}$

\section{Asegurar empleos adecuados para todos}

Contribuciones a variación en empleo total, por intensidad digital de sectores, 2006-2016 ${ }^{13}$

Proporción de empleo informal en relación con empleo total ${ }^{14}$

Tasa bruta de matrícula, educación terciaria $(\%)^{9}$

Graduados de educación terciaria por campo (\%) - Educación ${ }^{11}$

Graduados de educación terciaria por campo (\%) - Salud ${ }^{11}$

Graduados de educación terciaria por campo (\%) - Ingeniería ${ }^{11}$

\section{Promocionar la prosperidad social}

Generación de desechos de aparatos eléctricos per cápita $(\mathrm{kg})^{15}$

Número de estudiantes por computadora ${ }^{16}$

Proporción de mujeres con puntuación de nivel 203 en resolución de problemas en entornos tecnológicos ${ }^{17}$

\section{Reforzar la confianza}

Índice GovTech de la $\mathrm{CAF}^{18}$

Índice de ciberseguridad global (UIT) ${ }^{19}$

Seguridad del comercio electrónico $(\%)^{20}$ Confianza en la privacidad en Internet $(\%)^{20}$

\section{Promocionar la apertura de mercados}

Índice de restrictividad de intercambios de servicios digitales de la OCDE ${ }^{13}$

Índice de restricción regulatoria de la IED de la $0 C^{-13}$

Las fuentes, notas a pie de página y detalles técnicos se pueden encontrar al final de las Notas País.

\begin{tabular}{cccccc}
\multicolumn{6}{c}{ Indicadores digitales - Brasi I $^{1}$} \\
\hline \multicolumn{2}{c}{ Brasil } & \multicolumn{2}{c}{ ALC $^{2}$} & \multicolumn{2}{c}{ OCDE $^{3}$} \\
\hline $\mathbf{2 0 0 8}$ & $\mathbf{2 0 1 8}$ & $\mathbf{2 0 0 8}$ & $\mathbf{2 0 1 8}$ & $\mathbf{2 0 0 8}$ & $\mathbf{2 0 1 8}$ \\
\hline 5.2 & 14.9 & 4.1 & 13.9 & 22.7 & 32.9 \\
1.8 & 88.1 & 0.5 & 73.5 & 19.4 & 103.6 \\
$\mathbf{2 0 1 5}$ & $\mathbf{2 0 1 8}$ & $\mathbf{2 0 1 5}$ & $\mathbf{2 0 1 8}$ & $\mathbf{2 0 1 5}$ & $\mathbf{2 0 1 8}$ \\
\hline 93.5 & 95.5 & 86.1 & 94.6 & 98.2 & 98.8 \\
$\mathbf{2 0 0 8}$ & $\mathbf{2 0 1 7}$ & $\mathbf{2 0 0 8}$ & $\mathbf{2 0 1 7}$ & $\mathbf{2 0 0 8}$ & $\mathbf{2 0 0 7}$ \\
\hline 0.51 & 0.50 & 0.58 & 5.1 & 2.2 & 27.7
\end{tabular}

\begin{tabular}{cccccc}
\multicolumn{2}{c}{ Brasil } & \multicolumn{2}{c}{ ALC } & \multicolumn{2}{c}{ OCDE } \\
\hline $\mathbf{2 0 0 8}$ & $\mathbf{2 0 1 8}$ & $\mathbf{2 0 0 8}$ & $\mathbf{2 0 1 8}$ & $\mathbf{2 0 0 8}$ & $\mathbf{2 0 1 8}$ \\
\hline 0.57 & 0.73 & 0.52 & 0.65 & 0.72 & 0.82 \\
33.8 & 70.4 & 25.3 & 67.7 & 65.0 & 84.3 \\
$\mathbf{2 0 1 5}$ & $\mathbf{2 0 1 9}$ & $\mathbf{2 0 1 5}$ & $\mathbf{2 0 1 9}$ & $\mathbf{2 0 1 5}$ & $\mathbf{2 0 1 9}$ \\
\hline 56.2 & 56.9 & 46.4 & 51.5 & 73.9 & 85.0 \\
\multicolumn{2}{c}{$\mathbf{2 0 1 7}$} & \multicolumn{2}{c}{$\mathbf{2 0 1 7}$} & \multicolumn{2}{c}{$\mathbf{2 0 1 7}$} \\
\hline \multicolumn{2}{c}{22.3} & \multicolumn{2}{c}{14.8} & \multicolumn{2}{c}{ N/A }
\end{tabular}

\begin{tabular}{cccccc}
\multicolumn{2}{c}{ Brasil } & \multicolumn{2}{c}{ ALC } & \multicolumn{2}{c}{ OCDE } \\
\hline $\mathbf{2 0 0 8}$ & $\mathbf{2 0 1 8}$ & $\mathbf{2 0 0 8}$ & $\mathbf{2 0 1 8}$ & $\mathbf{2 0 0 8}$ & $\mathbf{2 0 1 8}$ \\
\hline 12.2 & 13.0 & 9.3 & 8.6 & 15.6 & 15.1 \\
6.36 & 6.37 & 3.1 & 3.9 & 4.6 & 6.7 \\
$\mathbf{2 0 1 2}$ & $\mathbf{2 0 1 6}$ & $\mathbf{2 0 1 2}$ & $\mathbf{2 0 1 6}$ & $\mathbf{2 0 1 2}$ & $\mathbf{2 0 1 6}$ \\
\hline 0.34 & 0.52 & 0.14 & 0.34 & 30.9 & 38.2 \\
$\mathbf{2 0 0 6}$ & $\mathbf{2 0 1 6}$ & $\mathbf{2 0 0 6}$ & $\mathbf{2 0 1 6}$ & $\mathbf{2 0 0 6}$ & $\mathbf{2 0 1 6}$ \\
\hline 0.99 & 1.3 & 0.35 & 0.42 & 1.7 & 1.9 \\
\hline \multicolumn{2}{c}{$\mathbf{2 0 1 9}$} & \multicolumn{2}{c}{$\mathbf{2 0 1 9}$} & \multicolumn{2}{c}{$\mathbf{2 0 1 9}$} \\
\hline 0.63 & \multicolumn{2}{c}{0.43} & \multicolumn{2}{c}{0.61}
\end{tabular}

\begin{tabular}{|c|c|c|c|c|c|}
\hline \multicolumn{2}{|c|}{ Brasil } & \multicolumn{2}{|c|}{ ALC } & \multicolumn{2}{|c|}{ OCDE } \\
\hline \multicolumn{2}{|c|}{$2006-15$} & \multicolumn{2}{|c|}{ 2006-15 } & \multicolumn{2}{|c|}{$2006-15$} \\
\hline \multicolumn{2}{|c|}{1.3} & \multicolumn{2}{|c|}{6.9} & \multicolumn{2}{|c|}{4.8} \\
\hline \multicolumn{2}{|c|}{2015} & \multicolumn{2}{|c|}{2018} & \multicolumn{2}{|c|}{2018} \\
\hline \multicolumn{2}{|c|}{45.0} & \multicolumn{2}{|c|}{54.9} & \multicolumn{2}{|c|}{ N/A } \\
\hline 2007 & 2017 & 2007 & 2017 & 2007 & 2017 \\
\hline 30.8 & 51.3 & 37.5 & 60.5 & 66.6 & 74.3 \\
\hline \multicolumn{2}{|c|}{2016} & \multicolumn{2}{|c|}{2016} & \multicolumn{2}{|c|}{2016} \\
\hline \multicolumn{2}{|c|}{19.7} & \multicolumn{2}{|c|}{16.0} & \multicolumn{2}{|c|}{9.8} \\
\hline \multicolumn{2}{|c|}{13.9} & \multicolumn{2}{|c|}{13.8} & \multicolumn{2}{|c|}{14.5} \\
\hline \multicolumn{2}{|c|}{11.0} & \multicolumn{2}{|c|}{12.5} & \multicolumn{2}{|c|}{14.6} \\
\hline
\end{tabular}

\begin{tabular}{cccccc}
\multicolumn{2}{c}{ Brasil } & \multicolumn{2}{c}{ ALC } & \multicolumn{2}{c}{ OCDE } \\
\hline $\mathbf{2 0 1 5}$ & $\mathbf{2 0 1 6}$ & $\mathbf{2 0 1 5}$ & $\mathbf{2 0 1 6}$ & $\mathbf{2 0 1 5}$ & $\mathbf{2 0 1 6}$ \\
\hline 7.3 & 7.4 & 6.9 & 7.2 & 17.7 & 17.7 \\
$\mathbf{2 0 1 5}$ & $\mathbf{2 0 1 8}$ & $\mathbf{2 0 1 5}$ & $\mathbf{2 0 1 8}$ & $\mathbf{2 0 1 5}$ & $\mathbf{2 0 1 8}$ \\
\hline 3.7 & 6.0 & 2.4 & 1.6 & 1.8 & 1.1 \\
\hline \multicolumn{2}{c}{$\mathbf{2 0 1 8}$} & \multicolumn{2}{c}{$\mathbf{2 0 1 8}$} & \multicolumn{2}{c}{$\mathbf{2 0 1 8}$} \\
\hline \multicolumn{2}{c}{ N/A } & \multicolumn{2}{c}{7.7} & \multicolumn{2}{c}{27.7}
\end{tabular}

\begin{tabular}{cccccc}
\multicolumn{2}{c}{ Brasil } & \multicolumn{2}{c}{ ALC } & \multicolumn{2}{c}{ OCDE } \\
\hline \multicolumn{2}{c}{$\mathbf{2 0 2 0}$} & \multicolumn{2}{c}{$\mathbf{2 0 2 0}$} & \multicolumn{2}{c}{$\mathbf{2 0 2 0}$} \\
\hline \multicolumn{2}{c}{5.3} & \multicolumn{2}{c}{4.4} & \multicolumn{2}{c}{ N/A } \\
$\mathbf{2 0 1 6}$ & $\mathbf{2 0 1 8}$ & $\mathbf{2 0 1 6}$ & $\mathbf{2 0 1 8}$ & $\mathbf{2 0 1 6}$ & $\mathbf{2 0 1 8}$ \\
\hline 0.71 & 0.56 & 0.36 & 0.43 & 0.56 & 0.79 \\
$\mathbf{2 0 1 8}$ & $\mathbf{2 0 1 9}$ & $\mathbf{2 0 1 8}$ & $\mathbf{2 0 1 9}$ & $\mathbf{2 0 1 8}$ & $\mathbf{2 0 1 9}$ \\
\hline 93.6 & 73.5 & 72.0 & 63.1 & 61.7 & 58.3 \\
60.0 & 38.0 & 52.8 & 54.9 & 41.7 & 45.6
\end{tabular}

\begin{tabular}{cccccc}
\multicolumn{2}{c}{ Brasil } & \multicolumn{2}{c}{ ALC } & \multicolumn{2}{c}{ OCDE } \\
\hline $\mathbf{2 0 1 5}$ & $\mathbf{2 0 1 9}$ & $\mathbf{2 0 1 5}$ & $\mathbf{2 0 1 9}$ & $\mathbf{2 0 1 5}$ & $\mathbf{2 0 1 9}$ \\
\hline 0.25 & 0.29 & 0.24 & 0.24 & 0.13 & 0.15 \\
2018 & \multicolumn{2}{c}{$\mathbf{2 0 1 8}$} & \multicolumn{2}{c}{$\mathbf{2 0 1 8}$} \\
\hline 0.09 & \multicolumn{2}{c}{0.07} & \multicolumn{2}{c}{0.06} \\
\hline
\end{tabular}




\section{Notas técnicas}

1. La Tabla sigue lo mejor posible las siete áreas claves identificadas en el proyecto Going Digital de la OCDE: 1) mejorar el acceso a las tecnologías digitales; 2) aumentar el uso efectivo; 3) permitir la innovación digital; 4) asegurar empleos adecuados para todos; 5) promocionar la prosperidad social; 6) reforzar la confianza; y 7) promocionar la apertura de mercados (OCDE, 2019a). Los indicadores se eligen según la disponibilidad de datos para los países de ALC. Existe la posibilidad de un sesgo por la forma en que se han agregado los componentes en los indicadores de índice.

2. El promedio de ALC es un promedio simple. La composición de los países depende de la disponibilidad de datos de los países de la región. Cada promedio incluye tantos países de ALC encontrados en cada fuente como sea posible.

3. El promedio de la OCDE es un promedio simple que incluye a todos los países miembros de la OCDE en mayo de 2020.

4. Datos de la UIT (2020), Base de datos de indicadores mundiales de telecomunicaciones / TIC 2020 (base de datos). La velocidad de banda ancha fija en Mbit/s se refiere a la velocidad de descarga teórica máxima anunciada garantizada a los usuarios asociados con una suscripción mensual de Internet de banda ancha fija.

5. Datos de la División de Estadística de las Naciones Unidas, Base de datos mundial de los ODS de las Naciones Unidas (base de datos). Datos de 2015 y 2018 o los últimos disponibles.

6. Datos de la base de conocimientos sobre gobierno electrónico de las Naciones Unidas (2019), centro de datos (base de datos). El índice de desarrollo del gobierno electrónico (E-government development index) es un indicador compuesto que consta de tres índices (índice de servicios en línea, índice de infraestructura de telecomunicaciones e índice de capital humano), que están igualmente ponderados. Tiene un rango de 0 a 1, con 1 siendo un gobierno más desarrollado.

7. Datos de UNCTAD (2020), UNCTADSTAT (base de datos). El índice de comercio electrónico B2C de la UNCTAD mide la preparación de una economía para respaldar las compras en línea. Rango de 0 a 100, con 100 siendo el nivel de apoyo más alto.

8. Cálculos propios a partir de datos de Latinobarómetro (2019), Libros de Códigos por País / Año (base de datos). Datos de 2017. Datos de encuestas de opinión pública utilizando muestras representativas a nivel nacional seleccionadas al azar.

9. Datos del Banco Mundial (2020a), Banco de datos del Banco Mundial (base de datos).

10. Datos del Banco Mundial (2020b), TCdata360. Datos de 2012 y 2016 o los últimos disponibles.

11. Datos de Unesco (2019), Instituto de Estadística de la Unesco (base de datos). Gastos en I+D, como porcentaje de los datos del PIB de 2006 y 2016 o el último disponible.

12. Datos de OCDE (2020a), OECD.Stat (base de datos) y OCDE (2020b). El índice OURdata de la OCDE evalúa los esfuerzos de los gobiernos para implementar datos abiertos en tres áreas críticas: apertura, utilidad y reutilización de los datos gubernamentales. Tiene un rango de 0 a 1, con 1 siendo la puntuación más alta.

13. Datos de OCDE (2020a), OECD.Stat (base de datos). El Índice de restricción del comercio de servicios digitales de la OCDE identifica, cataloga y cuantifica las barreras que afectan el comercio de servicios habilitados digitalmente en 46 países. Tiene un rango de 0 a 1, con 1 siendo el valor más restrictivo. El Índice de Restricción Reglamentaria de la Inversión Extranjera Directa (IED RRI) mide cuatro tipos de restricciones legales a la inversión extranjera directa: 1) restricciones a la participación extranjera en el capital social; 2) requisitos de selección y aprobación previa; 3) regulaciones para personas claves; y 4) otras restricciones al funcionamiento de empresas extranjeras. El RRI de la IED es un índice compuesto, que varía de 0 a 1, con 1 siendo el valor más restrictivo.

14. Datos de ILOSTAT, datos de 2018 o último año disponible.

15. Datos de la Asociación mundial de estadísticas sobre desechos electrónicos.

16. Cálculos de la OCDE basados en OCDE (2020c), Programa de Evaluación Internacional de Estudiantes (base de datos). Datos de 2015 y 2018.

17. Datos de la OCDE (2019d), Survey of Adult Skills (2018). Los porcentajes para la resolución de problemas en entornos ricos en tecnología se calculan de modo que la suma de los porcentajes de las siguientes categorías mutuamente exhaustivas sea igual al 100\%: se excluyó de la evaluación por computadora; sin experiencia en informática; prueba de núcleo de TIC fallida; por debajo del Nivel 1, en el Nivel 1, en el Nivel 2 y en el Nivel 3.

18. Datos de CAF (2020), The GouTech Index 2020: Unlocking the Potential of GouTech Ecosystems in Latin America, Spain and Portugal. El índice GovTech 2020 mide la madurez del ecosistema GovTech. Se basa en 28 indicadores en 7 dimensiones, que, en conjunto, forman 3 pilares igualmente ponderados: industria de nueva creación, políticas gubernamentales y sistemas de adquisiciones. 
19. El Índice mundial de ciberseguridad mide el compromiso de los países con la ciberseguridad a escala global. Tiene cinco pilares: 1) medidas legales; 2) medidas técnicas; 3) medidas organizativas; 4) desarrollo de capacidades; y 5) cooperación. Va de 0 a 1, siendo 1 el nivel más alto de ciberseguridad.

20. Datos de The Economist Intelligence Unit (2019), EIU Inclusive Internet Index (base de datos). Los indicadores presentan la seguridad percibida del comercio electrónico y la confianza en la privacidad en línea entre las personas seleccionadas al azar en países seleccionados. Varía del $0 \%$ al 100\%, donde el $100 \%$ indica una confianza absoluta en la seguridad del comercio electrónico y la confianza en la privacidad en línea.

\section{Referencias}

Banco Mundial (2020a), DataBank (base de datos), Grupo del Banco Mundial, Washington, DC, https:// databank.worldbank.org/home.aspx (consultada el 11 de diciembre de 2019).

Banco Mundial (2020b), TCdata360 (base de datos), Grupo del Banco Mundial, Washington, DC, https:// tcdata360.worldbank.org/ (consultada el 4 de agosto de 2020).

Base de conocimientos sobre gobierno electrónico de la ONU (2019), Data Center (base de datos), Departamento de Asuntos Económicos y Sociales de las Naciones Unidas, Nueva York, https:// publicadministration.un.org/egovkb/en-us/Data-Center (consultada el 11 de diciembre de 2019).

CAF (2020), The GouTech Index 2020: Unlocking the Potential of GovTech Ecosystems in Latin America, Spain and Portugal, Banco de Desarrollo de America Latina, Caracas.

CEPAL (2018), Observatorio Regional de Planificación para el Desarrollo de América Latina y el Caribe, Comisión Económica para América Latina y el Caribe, Santiago, https://observatorioplanificacion.cepal.org/es.

Dispositivo de estadísticas de la ONU (2018, 2015), ODS globales de la ONU (database), Departamento de Asuntos Económicos y Sociales de las Naciones Unidas, Nueva York, https://unstats.un.org/sdgs/ indicators/database/ (consultada el 20 de mayo de 2020).

Foro Mundial Económico (2016), “The Global Information Technology Report 2016”, Foro Mundial Económico, Ginebra, https://www.weforum.org/reports/the-global-information-technology-report-2016.

Global E-waste Statistic Partnership, página de internet, Global E-waste Statistic Partnership, Bonn, https:// globalewaste.org/ (consultada el 11 de diciembre de 2019).

Latinobarómetro (2019), Libros de Códigos por País/Año (base de datos), Latinobarómetro, Providencia, www. latinobarometro.org/latCodebooks.jsp (consultada el 11 de diciembre de 2019).

OCDE (2020a), OECD.Stat (database), Publicaciones de la OCDE, París, https://stats.oecd.org/ (consultada el 11 de diciembre de 2019).

OCDE (2020b), Panorama de las Administraciones Públicas América Latina y el Caribe 2020, Publicaciones de la OCDE, París, https://doi.org/10.1787/13130fbb-en.

OCDE (2020c), Programme for International Student Assessment (base de datos), Publicaciones de la OCDE, París, www.oecd.org/pisa/data/2018database/ (consultada el 14 de febrero de 2020).

OCDE (2019a), Cómo medir la transformación digital: Hoja de ruta para el futuro, Publicaciones de la OCDE, París, https://doi.org/10.1787/9789264311992-en.

OCDE (2019b), Estudios de la OCDE sobre Transformación Digital: “Going Digital” en Colombia, Publicaciones de la OCDE, París, https://doi.org/10.1787/781185b1-en.

OCDE (2019c), Digital Government Review of Panama: Enhancing the Digital Transformation of the Public Sector, OCDE Estudios de gobierno digital, Publicaciones de la OCDE, París, https://doi.org/10.1787/615a4180-en.

OCDE (2019d), Survey of Adult Skills, Publicaciones de la OCDE, París, https://www.oecd.org/skills/piaac/data/

OIT (2019), ILO Statistics (base de datos), Organización Internacional del Trabajo, Ginebra, www.ilo.org/ global/statistics-and-databases/lang--en/index.htm (consultada el 11 de diciembre de 2019).

Open Knowledge Foundation (2019), Global Open Data Index (base de datos), Open Knowledge Foundation, Cambridge, Reino Unido, https://index.okfn.org/dataset/ (consultada el 19 de abril de 2020).

PIAAC Expert Group in Problem Solving in Technology-Rich Environments (2009), "PIAAC Problem Solving in Technology- Rich Environments: A Conceptual Framework", OCDE Documentos de trabajo educativo, n. ${ }^{\circ}$ 36, Publicaciones de la OCDE, París, https://doi.org/10.1787/220262483674.

The Economist Intelligence Unit (2019), EIU Inclusive Internet Index 2019 (base de datos), The Economist Group, Londres, https://theinclusiveinternet.eiu.com/explore/countries/performance (consultada el $11 \mathrm{de}$ diciembre 2019).

UIT (2020), base de datos de indicadores mundiales de telecomunicaciones / TIC 2020 (base de datos), Unión Internacional de Telecomunicaciones, Ginebra, https://www.itu.int/en/ITU-D/Statistics/Pages/ publications/wtid.aspx (consultada el 21 de agosto de 2020). 
UNCTAD (2020), UNCTADSTAT (base de datos), Conferencia de las Naciones Unidas sobre Comercio y Desarrollo, Ginebra, https://unctadstat.unctad.org/EN/ (consultada el 11 de diciembre de 2019).

UNESCO (2019), Instituto de Estadística de la Unesco (base de datos), Unesco, París, http://data.uis.unesco. org/Index.aspx (consultada el 20 de mayo de 2020).

World Wide Web Foundation (2017), OpenData Barometer (base de datos), World Wide Web Foundation, Ginebra, https://opendatabarometer.org/ (consultada el 19 de abril de 2020). 



\section{CHILE}

\section{Tendencias recientes}

En la última década, Chile ha reforzado la confianza en las tecnologías digitales. En 2019, la percepción de seguridad del comercio electrónico (73.1\%) y de confianza en la privacidad en Internet (59.6\%) se encontraban por encima de los promedios de América Latina y el Caribe (ALC) (63.1\% y 54.9\% respectivamente) y de los de la OCDE (58.3\% y 45.6\%). Su posición en el índice de ciberseguridad global ha mejorado, pero sigue estando por debajo del promedio de la OCDE. El país ha conseguido avances en la inclusión digital: ha aumentado el número de usuarios de Internet y de suscripciones a servicios de banda ancha móvil activa y fija.

Chile tiene el ecosistema digital más maduro de ALC para las start-ups que dan servicio al sector público según el índice GovTech de la Corporación Andina de Fomento (CAF), índice que mide el desarrollo de la industria de las start-ups, las políticas públicas y los sistemas de contratación pública. En cuanto a la promoción de una sociedad digital incluyente, el número de estudiantes por computadora cayó de 1.7 en 2015 a 1.1 en 2018 , lo cual está acorde con el promedio de la OCDE (1.1) e inferior al promedio de ALC (1.6). Persiste una brecha en los indicadores de innovación digital: las exportaciones de alta tecnología representaron el $6.4 \%$ del total de las exportaciones de productos manufacturados en 2018, en comparación con los promedios de ALC (8.6\%) y la OCDE (15.1\%).

\section{Estrategias nacionales y cooperación internacional para la transformación digital}

La Agenda digital2020 Chile Digital para Tod@s es el principal documento de referencia para la transformación digital del país. La agenda promueve la tecnología como un medio para reducir las desigualdades, poner en marcha nuevas y mejores oportunidades de desarrollo y promover los derechos humanos. La agenda digital se basa en seis objetivos: respetar los derechos humanos relacionados con Internet y las TIC (tecnologías de la información y las comunicaciones), lograr la conectividad universal, utilizar las TIC para mejorar la calidad de vida, contribuir a la expansión de la economía digital, utilizar las tecnologías digitales para conseguir una educación de calidad y apoyar políticas de transformación digital que tengan un enfoque multisectorial.

Entre las políticas relacionadas cabe mencionar la Ley n. 21180 de 2019, que establece la transformación digital del Estado, y que tiene por objeto digitalizar y modernizar los procedimientos administrativos de las instituciones públicas. En 2012, Chile lanzó ClaveÚnica, un sistema estatal de autenticación, utilizado por más de 5 millones de chilenos en 2020, que permite acceder a los servicios públicos a través de Internet con un número de identificación único. Chile introdujo su Política de Ciberseguridad en 2018. Por otro lado, la Política Nacional de Inteligencia Artificial (IA), que se pondrá en marcha en 2020, tiene los lineamientos para empoderar a las personas en el desarrollo y uso de las herramientas de IA. La política tiene tres pilares: los factores habilitantes (esto es, capital humano, infraestructuras tecnológicas y datos); desarrollo y uso de la IA y ética, regulación y repercusiones socioeconómicas. La política está siendo ejecutada a través de un Comité de Expertos con el apoyo ejecutivo de tres grupos interministeriales junto con un proceso de participación único y más amplio que incluye la organización de mesas redondas, cursos prácticos regionales, reuniones virtuales y una consulta pública. Para responder a la crisis del coronavirus (Covid-19) en aspectos relacionados con las telecomunicaciones, el Gobierno puso en marcha el Plan Solidario de Conectividad que permite a las familias de recursos limitados conectarse a Internet de manera gratuita. El Ministerio de Educación, junto con el Ministerio de Transportes y Telecomunicaciones, está promoviendo un plan que proporcionará acceso gratuito a los sitios web de educación a 3 millones de estudiantes a través de sus dispositivos móviles. Las plataformas en Internet están dirigidas a estudiantes de prekínder hasta cuarto grado (CAF, 2020).

Entre las iniciativas del país se encuentra Tu Empresa en Un Día versión 2.0, una plataforma digital desarrollada en 2013 para fomentar el emprendimiento y facilitar la creación de empresas. Esta iniciativa permite a los emprendedores realizar los trámites del ciclo de vida de la empresa desde un solo lugar. Otra iniciativa, Estado Cero Filas, tiene como objetivo eliminar los trámites públicos innecesarios y digitalizar al menos el 80\% de los procedimientos para 2021 y el 100\% para 2023. Las instituciones públicas no podrán exigir a los ciudadanos información que ya posean, tomando las medidas necesarias para la interoperabilidad dentro de la administración pública. El programa Digitaliza tu PYME del Ministerio de Economía, Fomento y Turismo ayuda a las pequeñas y medianas empresas (pymes) a aumentar sus ventas, reducir sus costos y mejorar la relación con sus clientes y proveedores mediante las tecnologías digitales. El programa Hospital Digital consiste en la digitalización del sistema de salud, oferta de servicios de salud a través de Internet y acceso a información sobre exámenes médicos anteriores, vacunas e historia clínica de pacientes a través de un sistema de registro electrónico de salud.

Con respecto a la cooperación internacional, Chile, Nueva Zelanda y Singapur concluyeron las negociaciones del primer Acuerdo de Asociación sobre Economía Digital en enero de 2020. Su objetivo es establecer unas normas básicas sobre el comercio digital y un marco favorable a las empresas que operen en el ámbito de las TIC para potenciar el acceso de las pymes a la economía mundial.

Chile también colabora con la Unión Europea (UE) en materia de computación de alto rendimiento en el marco del programa de la Comisión Europea sobre Tecnologías Futuras y Emergentes. Las iniciativas de computación de alto rendimiento desarrollan tecnologías y soluciones para mejorar el rendimiento de las aplicaciones y servicios científicos. Este programa identificará las principales áreas de aplicación y los requisitos en cuanto a equipos y sistemas, determinará los planes de financiamiento internacional y promoverá el intercambio de mejores prácticas entre la UE y las comunidades de investigación de Chile y otros países de ALC. 


\section{Mejorar el acceso}

Suscripciones de banda ancha fija (por cada 100 habitantes) ${ }^{4}$

Suscripciones de banda ancha móvil activa (por cada 100 habitantes) ${ }^{4}$

Proporción de población cubierta por al menos una red 3G5

Velocidad de banda ancha fija (en Mbit/s) ${ }^{4}$

Aumentar el uso efectivo

Índice de desarrollo del gobierno electrónico (EGDI) ${ }^{6}$

Proporción de usuarios de Internet (\% de población) ${ }^{4}$

Índice de comercio electrónico B2C de la UNCTAD

Proporción de personas que realizan compras por Internet ${ }^{8}$

\section{Impulsar la innovación}

Exportaciones de alta tecnología (\% de exportaciones manufacturadas) ${ }^{9}$

Proporción de importaciones de servicios de TIC, como porcentaje del comercio total de servicios ${ }^{7}$

Solicitudes de patentes de TIC presentadas en virtud del Tratado de Cooperación en materia de Patentes (por millón de personas) ${ }^{10}$

Gastos en I+D, como \% del PIB ${ }^{11}$

Índice OURdata de la OCDE ${ }^{12}$

\section{Asegurar empleos adecuados para todos}

Contribuciones a variación en empleo total, por intensidad digital de sectores, 2006-2016 ${ }^{13}$

Proporción de empleo informal en relación con empleo total ${ }^{14}$

Tasa bruta de matrícula, educación terciaria $(\%)^{9}$

Graduados de educación terciaria por campo (\%) - Educación ${ }^{11}$

Graduados de educación terciaria por campo (\%) - Salud ${ }^{11}$

Graduados de educación terciaria por campo (\%) - Ingeniería ${ }^{11}$

Promocionar la prosperidad social

Generación de desechos de aparatos eléctricos per cápita $(\mathrm{kg})^{15}$

Número de estudiantes por computadora ${ }^{16}$

Proporción de mujeres con puntuación de nivel 203 en resolución de problemas en entornos tecnológicos ${ }^{17}$

\section{Reforzar la confianza}

Índice GovTech de la CAF ${ }^{18}$

Índice de ciberseguridad global (UIT) ${ }^{19}$

Seguridad del comercio electrónico $(\%)^{20}$

Confianza en la privacidad en Internet $(\%)^{20}$

\section{Promocionar la apertura de mercados}

Índice de restrictividad de intercambios de servicios digitales de la $0 \mathrm{CDE}^{13}$

Índice de restricción regulatoria de la IED de la OCDE ${ }^{13}$

Las fuentes, notas a pie de página y detalles técnicos se pueden encontrar al final de las Notas País.

\begin{tabular}{cccccc}
\multicolumn{4}{c}{ Indicadores digitales - Chile } \\
\hline \multicolumn{2}{c}{ Chile } & \multicolumn{2}{c}{ ALC $^{2}$} & \multicolumn{2}{c}{ OCDE $^{3}$} \\
\hline $\mathbf{2 0 0 8}$ & $\mathbf{2 0 1 8}$ & $\mathbf{2 0 0 8}$ & $\mathbf{2 0 1 8}$ & $\mathbf{2 0 0 8}$ & $\mathbf{2 0 1 8}$ \\
\hline 8.5 & 17.4 & 4.1 & 13.9 & 22.7 & 32.9 \\
\hline $\mathbf{2 0 0 9}$ & $\mathbf{2 0 1 8}$ & $\mathbf{2 0 0 9}$ & $\mathbf{2 0 1 8}$ & $\mathbf{2 0 0 9}$ & $\mathbf{2 0 1 8}$ \\
\hline 3.6 & 91.6 & 1.8 & 73.5 & 29.8 & 103.6 \\
$\mathbf{2 0 1 5}$ & $\mathbf{2 0 1 8}$ & $\mathbf{2 0 1 5}$ & $\mathbf{2 0 1 8}$ & $\mathbf{2 0 1 5}$ & $\mathbf{2 0 1 8}$ \\
\hline 90.0 & 95.0 & 86.1 & 94.6 & 98.2 & 98.8 \\
$\mathbf{2 0 0 8}$ & $\mathbf{2 0 1 7}$ & $\mathbf{2 0 0 8}$ & $\mathbf{2 0 1 7}$ & $\mathbf{2 0 0 8}$ & $\mathbf{2 0 0 7}$ \\
\hline 1.0 & 30.0 & 0.58 & 5.1 & 2.2 & 27.7
\end{tabular}

\begin{tabular}{cccccc}
\multicolumn{2}{c}{ Chile } & \multicolumn{2}{c}{ ALC } & \multicolumn{2}{c}{ OCDE } \\
\hline $\mathbf{2 0 0 8}$ & $\mathbf{2 0 1 8}$ & $\mathbf{2 0 0 8}$ & $\mathbf{2 0 1 8}$ & $\mathbf{2 0 0 8}$ & $\mathbf{2 0 1 8}$ \\
\hline 0.58 & 0.74 & 0.52 & 0.65 & 0.72 & 0.82 \\
$\mathbf{2 0 0 8}$ & $\mathbf{2 0 1 7}$ & $\mathbf{2 0 0 8}$ & $\mathbf{2 0 1 7}$ & $\mathbf{2 0 0 8}$ & $\mathbf{2 0 1 7}$ \\
\hline 37.3 & 82.3 & 25.3 & 62.9 & 65.0 & 83.4 \\
\hline $\mathbf{2 0 1 5}$ & $\mathbf{2 0 1 9}$ & $\mathbf{2 0 1 5}$ & $\mathbf{2 0 1 9}$ & $\mathbf{2 0 1 5}$ & $\mathbf{2 0 1 9}$ \\
\hline 60.3 & 67.0 & 46.4 & 51.5 & 73.9 & 85.0 \\
\hline \multicolumn{2}{c}{$\mathbf{2 0 1 7}$} & \multicolumn{2}{c}{$\mathbf{2 0 1 7}$} & \multicolumn{2}{c}{$\mathbf{2 0 1 7}$} \\
\hline 17.5 & \multicolumn{2}{c}{14.8} & \multicolumn{2}{c}{ N/A }
\end{tabular}

\begin{tabular}{cccccc}
\multicolumn{2}{c}{ Chile } & \multicolumn{2}{c}{ ALC } & \multicolumn{2}{c}{ OCDE } \\
\hline $\mathbf{2 0 0 8}$ & $\mathbf{2 0 1 8}$ & $\mathbf{2 0 0 8}$ & $\mathbf{2 0 1 8}$ & $\mathbf{2 0 0 8}$ & $\mathbf{2 0 1 8}$ \\
\hline 6.8 & 6.4 & 9.3 & 8.6 & 15.6 & 15.1 \\
3.64 & 4.14 & 3.1 & 3.9 & 4.6 & 6.7 \\
$\mathbf{2 0 1 2}$ & $\mathbf{2 0 1 6}$ & $\mathbf{2 0 1 2}$ & $\mathbf{2 0 1 6}$ & $\mathbf{2 0 1 2}$ & $\mathbf{2 0 1 6}$ \\
\hline 0.52 & 0.82 & 0.14 & 0.34 & 30.9 & 38.2 \\
\hline $\mathbf{2 0 0 7}$ & $\mathbf{2 0 1 6}$ & $\mathbf{2 0 0 7}$ & $\mathbf{2 0 1 6}$ & $\mathbf{2 0 0 7}$ & $\mathbf{2 0 1 6}$ \\
\hline 0.31 & 0.36 & 3.7 & 0.42 & 1.7 & 1.9 \\
\hline \multicolumn{2}{c}{$\mathbf{2 0 1 9}$} & \multicolumn{2}{c}{$\mathbf{2 0 1 9}$} & \multicolumn{2}{c}{$\mathbf{2 0 1 9}$} \\
\hline 0.41 & \multicolumn{2}{c}{0.43} & \multicolumn{2}{c}{0.61}
\end{tabular}

\begin{tabular}{ccc} 
Chile & ALC & OCDE \\
\hline $\mathbf{2 0 0 6 - 1 5}$ & $\mathbf{2 0 0 6 - 1 5}$ & $\mathbf{2 0 0 6 - 1 5}$ \\
\hline 12.1 & 6.9 & 4.8 \\
$\mathbf{2 0 1 8}$ & $\mathbf{2 0 1 8}$ & $\mathbf{2 0 1 8}$ \\
\hline
\end{tabular}

$29.3 \quad 54.9 \quad$ N/A

\begin{tabular}{llllll}
$\mathbf{2 0 0 7}$ & $\mathbf{2 0 1 7}$ & $\mathbf{2 0 0 7}$ & $\mathbf{2 0 1 7}$ & $\mathbf{2 0 0 7}$ & $\mathbf{2 0 1 7}$ \\
\hline 54.0 & 88.5 & 37.5 & 60.5 & 66.6 & 74.3
\end{tabular}

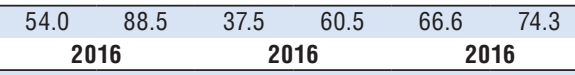

\begin{tabular}{ccc}
$\mathbf{2 0 1 6}$ & $\mathbf{2 0 1 6}$ & $\mathbf{2 0 1 6}$ \\
\hline 15.1 & 16.0 & 9.8
\end{tabular}

$\begin{array}{lll}15.1 & 9.8 \\ 21.5 & 13.8 & 14.5\end{array}$

$15.5 \quad 12.5 \quad 14.6$

\begin{tabular}{cccccc}
\multicolumn{2}{c}{ Chile } & \multicolumn{2}{c}{ ALC } & \multicolumn{2}{c}{ OCDE } \\
\hline $\mathbf{2 0 1 5}$ & $\mathbf{2 0 1 6}$ & $\mathbf{2 0 1 5}$ & $\mathbf{2 0 1 6}$ & $\mathbf{2 0 1 5}$ & $\mathbf{2 0 1 6}$ \\
\hline 8.3 & 8.7 & 6.9 & 7.2 & 17.7 & 17.7 \\
$\mathbf{2 0 1 5}$ & $\mathbf{2 0 1 8}$ & $\mathbf{2 0 1 5}$ & $\mathbf{2 0 1 8}$ & $\mathbf{2 0 1 5}$ & $\mathbf{2 0 1 8}$ \\
\hline 1.7 & 1.1 & 2.4 & 1.6 & 1.8 & 1.1 \\
\multicolumn{2}{c}{$\mathbf{2 0 1 8}$} & \multicolumn{2}{c}{$\mathbf{2 0 1 8}$} & \multicolumn{2}{c}{$\mathbf{2 0 1 8}$} \\
\hline 12.4 & \multicolumn{2}{c}{7.7} & \multicolumn{2}{c}{27.7}
\end{tabular}

\begin{tabular}{cccccc}
\multicolumn{2}{c}{ Chile } & \multicolumn{2}{c}{ ALC } & \multicolumn{2}{c}{ OCDE } \\
\hline \multicolumn{2}{c}{$\mathbf{2 0 2 0}$} & \multicolumn{2}{c}{$\mathbf{2 0 2 0}$} & \multicolumn{2}{c}{$\mathbf{2 0 2 0}$} \\
\hline \multicolumn{2}{c}{5.4} & \multicolumn{2}{c}{4.4} & \multicolumn{2}{c}{ N/A } \\
\hline $\mathbf{2 0 1 6}$ & $\mathbf{2 0 1 8}$ & $\mathbf{2 0 1 6}$ & $\mathbf{2 0 1 8}$ & $\mathbf{2 0 1 6}$ & $\mathbf{2 0 1 8}$ \\
\hline 0.38 & 0.47 & 0.36 & 0.43 & 0.56 & 0.79 \\
\hline $\mathbf{2 0 1 8}$ & $\mathbf{2 0 1 9}$ & $\mathbf{2 0 1 8}$ & $\mathbf{2 0 1 9}$ & $\mathbf{2 0 1 8}$ & $\mathbf{2 0 1 9}$ \\
\hline 70.8 & 73.1 & 72.0 & 63.1 & 61.7 & 58.3 \\
\hline 46.0 & 59.6 & 52.8 & 54.9 & 41.7 & 45.6
\end{tabular}

\begin{tabular}{|c|c|c|c|c|c|}
\hline \multicolumn{2}{|c|}{ Chile } & \multicolumn{2}{|c|}{ ALC } & \multicolumn{2}{|c|}{ OCDE } \\
\hline 2015 & 2019 & 2015 & 2019 & 2015 & 2019 \\
\hline 0.26 & 0.26 & 0.24 & 0.24 & 0.13 & 0.15 \\
\hline \multicolumn{2}{|c|}{2018} & \multicolumn{2}{|c|}{2018} & \multicolumn{2}{|c|}{2018} \\
\hline \multicolumn{2}{|c|}{0.06} & \multicolumn{2}{|c|}{0.0} & \\
\hline
\end{tabular}




\section{Notas técnicas}

1. La Tabla sigue lo mejor posible las siete áreas claves identificadas en el proyecto Going Digital de la OCDE: 1) mejorar el acceso a las tecnologías digitales; 2) aumentar el uso efectivo; 3) permitir la innovación digital; 4) asegurar empleos adecuados para todos; 5) promocionar la prosperidad social; 6) reforzar la confianza; y 7) promocionar la apertura de mercados (OCDE, 2019a). Los indicadores se eligen según la disponibilidad de datos para los países de ALC. Existe la posibilidad de un sesgo por la forma en que se han agregado los componentes en los indicadores de índice.

2. El promedio de ALC es un promedio simple. La composición de los países depende de la disponibilidad de datos de los países de la región. Cada promedio incluye tantos países de ALC encontrados en cada fuente como sea posible.

3. El promedio de la OCDE es un promedio simple que incluye a todos los países miembros de la OCDE en mayo de 2020.

4. Datos de la UIT (2020), Base de datos de indicadores mundiales de telecomunicaciones / TIC 2020 (base de datos). La velocidad de banda ancha fija en Mbit/s se refiere a la velocidad de descarga teórica máxima anunciada garantizada a los usuarios asociados con una suscripción mensual de Internet de banda ancha fija.

5. Datos de la División de Estadística de las Naciones Unidas, Base de datos mundial de los ODS de las Naciones Unidas (base de datos). Datos de 2015 y 2018 o los últimos disponibles.

6. Datos de la base de conocimientos sobre gobierno electrónico de las Naciones Unidas (2019), centro de datos (base de datos). El índice de desarrollo del gobierno electrónico (E-government development index) es un indicador compuesto que consta de tres índices (índice de servicios en línea, índice de infraestructura de telecomunicaciones e índice de capital humano), que están igualmente ponderados. Tiene un rango de 0 a 1, con 1 siendo un gobierno más desarrollado.

7. Datos de UNCTAD (2020), UNCTADSTAT (base de datos). El índice de comercio electrónico B2C de la UNCTAD mide la preparación de una economía para respaldar las compras en línea. Rango de 0 a 100, con 100 siendo el nivel de apoyo más alto.

8. Cálculos propios a partir de datos de Latinobarómetro (2019), Libros de Códigos por País / Año (base de datos). Datos de 2017. Datos de encuestas de opinión pública utilizando muestras representativas a nivel nacional seleccionadas al azar.

9. Datos del Banco Mundial (2020a), Banco de datos del Banco Mundial (base de datos).

10. Datos del Banco Mundial (2020b), TCdata360. Datos de 2012 y 2016 o los últimos disponibles.

11. Datos de Unesco (2019), Instituto de Estadística de la Unesco (base de datos). Gastos en I+D, como porcentaje de los datos del PIB de 2006 y 2016 o el último disponible.

12. Datos de OCDE (2020a), OECD.Stat (base de datos) y OCDE (2020b). El índice OURdata de la OCDE evalúa los esfuerzos de los gobiernos para implementar datos abiertos en tres áreas críticas: apertura, utilidad y reutilización de los datos gubernamentales. Tiene un rango de 0 a 1, con 1 siendo la puntuación más alta.

13. Datos de OCDE (2020a), OECD.Stat (base de datos). El Índice de restricción del comercio de servicios digitales de la OCDE identifica, cataloga y cuantifica las barreras que afectan el comercio de servicios habilitados digitalmente en 46 países. Tiene un rango de 0 a 1, con 1 siendo el valor más restrictivo. El Índice de Restricción Reglamentaria de la Inversión Extranjera Directa (IED RRI) mide cuatro tipos de restricciones legales a la inversión extranjera directa: 1) restricciones a la participación extranjera en el capital social; 2) requisitos de selección y aprobación previa; 3) regulaciones para personas claves; y 4) otras restricciones al funcionamiento de empresas extranjeras. El RRI de la IED es un índice compuesto, que varía de 0 a 1, con 1 siendo el valor más restrictivo.

14. Datos de ILOSTAT, datos de 2018 o último año disponible.

15. Datos de la Asociación mundial de estadísticas sobre desechos electrónicos.

16. Cálculos de la OCDE basados en OCDE (2020c), Programa de Evaluación Internacional de Estudiantes (base de datos). Datos de 2015 y 2018.

17. Datos de la OCDE (2019d), Survey of Adult Skills (2018). Los porcentajes para la resolución de problemas en entornos ricos en tecnología se calculan de modo que la suma de los porcentajes de las siguientes categorías mutuamente exhaustivas sea igual al 100\%: se excluyó de la evaluación por computadora; sin experiencia en informática; prueba de núcleo de TIC fallida; por debajo del Nivel 1, en el Nivel 1, en el Nivel 2 y en el Nivel 3.

18. Datos de CAF (2020), The GouTech Index 2020: Unlocking the Potential of GouTech Ecosystems in Latin America, Spain and Portugal. El índice GovTech 2020 mide la madurez del ecosistema GovTech. Se basa en 28 indicadores en 7 dimensiones, que, en conjunto, forman 3 pilares igualmente ponderados: industria de nueva creación, políticas gubernamentales y sistemas de adquisiciones. 
19. El Índice mundial de ciberseguridad mide el compromiso de los países con la ciberseguridad a escala global. Tiene cinco pilares: 1) medidas legales; 2) medidas técnicas; 3) medidas organizativas; 4) desarrollo de capacidades; y 5) cooperación. Va de 0 a 1, siendo 1 el nivel más alto de ciberseguridad.

20. Datos de The Economist Intelligence Unit (2019), EIU Inclusive Internet Index (base de datos). Los indicadores presentan la seguridad percibida del comercio electrónico y la confianza en la privacidad en línea entre las personas seleccionadas al azar en países seleccionados. Varía del $0 \%$ al 100\%, donde el $100 \%$ indica una confianza absoluta en la seguridad del comercio electrónico y la confianza en la privacidad en línea.

\section{Referencias}

Banco Mundial (2020a), DataBank (base de datos), Grupo del Banco Mundial, Washington, DC, https:// databank.worldbank.org/home.aspx (consultada el 11 de diciembre de 2019).

Banco Mundial (2020b), TCdata360 (base de datos), Grupo del Banco Mundial, Washington, DC, https:// tcdata360.worldbank.org/ (consultada el 4 de agosto de 2020).

Base de conocimientos sobre gobierno electrónico de la ONU (2019), Data Center (base de datos), Departamento de Asuntos Económicos y Sociales de las Naciones Unidas, Nueva York, https:// publicadministration.un.org/egovkb/en-us/Data-Center (consultada el 11 de diciembre de 2019).

CAF (2020), The GouTech Index 2020: Unlocking the Potential of GovTech Ecosystems in Latin America, Spain and Portugal, Banco de Desarrollo de America Latina, Caracas.

CEPAL (2018), Observatorio Regional de Planificación para el Desarrollo de América Latina y el Caribe, Comisión Económica para América Latina y el Caribe, Santiago, https://observatorioplanificacion.cepal.org/es.

Dispositivo de estadísticas de la ONU (2018, 2015), ODS globales de la ONU (database), Departamento de Asuntos Económicos y Sociales de las Naciones Unidas, Nueva York, https://unstats.un.org/sdgs/ indicators/database/ (consultada el 20 de mayo de 2020).

Foro Mundial Económico (2016), “The Global Information Technology Report 2016”, Foro Mundial Económico, Ginebra, https://www.weforum.org/reports/the-global-information-technology-report-2016.

Global E-waste Statistic Partnership, página de internet, Global E-waste Statistic Partnership, Bonn, https:// globalewaste.org/ (consultada el 11 de diciembre de 2019).

Latinobarómetro (2019), Libros de Códigos por País/Año (base de datos), Latinobarómetro, Providencia, www. latinobarometro.org/latCodebooks.jsp (consultada el 11 de diciembre de 2019).

OCDE (2020a), OECD.Stat (database), Publicaciones de la OCDE, París, https://stats.oecd.org/ (consultada el 11 de diciembre de 2019).

OCDE (2020b), Panorama de las Administraciones Públicas América Latina y el Caribe 2020, Publicaciones de la OCDE, París, https://doi.org/10.1787/13130fbb-en.

OCDE (2020c), Programme for International Student Assessment (base de datos), Publicaciones de la OCDE, París, www.oecd.org/pisa/data/2018database/ (consultada el 14 de febrero de 2020).

OCDE (2019a), Cómo medir la transformación digital: Hoja de ruta para el futuro, Publicaciones de la OCDE, París, https://doi.org/10.1787/9789264311992-en.

OCDE (2019b), Estudios de la OCDE sobre Transformación Digital: “Going Digital” en Colombia, Publicaciones de la OCDE, París, https://doi.org/10.1787/781185b1-en.

OCDE (2019c), Digital Government Review of Panama: Enhancing the Digital Transformation of the Public Sector, OCDE Estudios de gobierno digital, Publicaciones de la OCDE, París, https://doi.org/10.1787/615a4180-en.

OCDE (2019d), Survey of Adult Skills, Publicaciones de la OCDE, París, https://www.oecd.org/skills/piaac/data/

OIT (2019), ILO Statistics (base de datos), Organización Internacional del Trabajo, Ginebra, www.ilo.org/ global/statistics-and-databases/lang--en/index.htm (consultada el 11 de diciembre de 2019).

Open Knowledge Foundation (2019), Global Open Data Index (base de datos), Open Knowledge Foundation, Cambridge, Reino Unido, https://index.okfn.org/dataset/ (consultada el 19 de abril de 2020).

PIAAC Expert Group in Problem Solving in Technology-Rich Environments (2009), "PIAAC Problem Solving in Technology- Rich Environments: A Conceptual Framework", OCDE Documentos de trabajo educativo, n. ${ }^{\circ}$ 36, Publicaciones de la OCDE, París, https://doi.org/10.1787/220262483674.

The Economist Intelligence Unit (2019), EIU Inclusive Internet Index 2019 (base de datos), The Economist Group, Londres, https://theinclusiveinternet.eiu.com/explore/countries/performance (consultada el $11 \mathrm{de}$ diciembre 2019).

UIT (2020), base de datos de indicadores mundiales de telecomunicaciones / TIC 2020 (base de datos), Unión Internacional de Telecomunicaciones, Ginebra, https://www.itu.int/en/ITU-D/Statistics/Pages/ publications/wtid.aspx (consultada el 21 de agosto de 2020). 
UNCTAD (2020), UNCTADSTAT (base de datos), Conferencia de las Naciones Unidas sobre Comercio y Desarrollo, Ginebra, https://unctadstat.unctad.org/EN/ (consultada el 11 de diciembre de 2019).

UNESCO (2019), Instituto de Estadística de la Unesco (base de datos), Unesco, París, http://data.uis.unesco. org/Index.aspx (consultada el 20 de mayo de 2020).

World Wide Web Foundation (2017), OpenData Barometer (base de datos), World Wide Web Foundation, Ginebra, https://opendatabarometer.org/ (consultada el 19 de abril de 2020). 



\section{COLOMBIA}

\section{Tendencias recientes}

Colombia se ha esforzado para mejorar el acceso digital de todos sus ciudadanos. Ha aumentado el número de usuarios de Internet y de suscripciones a servicios de banda ancha móvil activa y fija en la última década. Colombia ascendió en el índice de desarrollo de gobierno electrónico de 0.53 en 2008 a 0.69 en 2018, por encima del promedio de América Latina y el Caribe (ALC) (0.65), pero por debajo del de la OCDE (0.82). En 2018, el índice de restricción regulatoria de la inversión extranjera directa (IED) de la OCDE mostraba que Colombia tenía menos restricciones a la IED que el promedio de ALC y la OCDE.

El país se sitúa por debajo del promedio de ALC en los indicadores de innovación digital. Las exportaciones de alta tecnología en proporción al total de las exportaciones de productos manufacturados aumentaron al $7.3 \%$ en 2018, si bien siguen estando por debajo del promedio de ALC (8.6\%) y la OCDE (15.1\%). En cuanto a la promoción de una sociedad digital incluyente, el número de estudiantes por computadora cayó de 1.6 en 2015 a 1.1 en 2018, lo cual está acorde con el promedio de la OCDE e inferior al promedio de ALC.

\section{Estrategias nacionales y cooperación internacional para la transformación digital}

El Plan Nacional de Desarrollo 2018-2022, Pacto por Colombia, Pacto por la Equidad y el plan TIC 2018-2022, El Futuro Digital es de Todos son los principales instrumentos de planificación de la estrategia de desarrollo y transformación digital de Colombia (CEPAL, 2018). El Plan Nacional de Desarrollo se divide en pactos estructurales y regionales. El Pacto por la Transformación Digital identifica dos líneas de trabajo principales. En primer lugar, se enfoca en el tema de la inclusión digital, con el objetivo de aumentar el acceso a las TIC y su utilización por parte de toda la población, en línea con los Objetivos de Desarrollo Sostenible de Naciones Unidas para 2030, y el empoderamiento de ciudadanos y hogares en un entorno digital. En segundo lugar, promueve temas de transparencia y eficiencia para promover el desarrollo de una sociedad y una industria digitales 4.0. Tiene además como objetivo promover la transformación digital en tres dimensiones: administración pública, sectores económicos y provincias. A través de esta línea de trabajo, el Gobierno aspira a hacer disponibles por Internet un total de 34 servicios públicos de alto impacto.

El plan TIC, estrategia digital nacional de Colombia, se basa en cuatro ejes: el entorno de las TIC, la inclusión social digital, el empoderamiento de los ciudadanos y hogares en un entorno digital y las transformaciones digitales sectoriales (OCDE, 2019b). En 2019, el Gobierno aprobó una ley para modernizar el sector de las TIC (Ley 1978 de 2019) mediante la coordinación de incentivos para agentes y autoridades, la actualización del marco institucional del sector con un único regulador y un enfoque centrado en inversiones para cerrar la brecha digital. Asimismo, implantó la política nacional 5G para facilitar su adopción en todo el país. Otras políticas pertinentes en este ámbito son la Política Nacional para la Transformación Digital e Inteligencia Artificial y la Política Nacional de Explotación de Datos. Colombia también está elaborando una política nacional sobre confianza y seguridad digital, así como una política nacional para promover la innovación en las prácticas educativas. Para responder a la crisis del coronavirus (Covid-19) con respecto a las telecomunicaciones, el Gobierno emitió un decreto para garantizar el mantenimiento y el funcionamiento de estos servicios. Dicho decreto establece las condiciones necesarias y excepcionales para asegurar que, a los usuarios, en especial los más vulnerables, no se les cancelen los servicios por falta de pago, prorrogando durante 30 días el pago de sus facturas. El decreto autoriza a dar prioridad al acceso a contenidos y aplicaciones de los servicios de salud, atención de emergencia, servicios públicos e información laboral o educativa (CAF, 2020).

En materia de cooperación internacional, Colombia cuenta con alianzas Sur-Sur con más de 90 países de África, Asia, América Latina y el Pacífico Sur. Entre los proyectos respaldados por Colombia figuran programas gubernamentales electrónicos en República Dominicana y Guatemala. La iniciativa Saber Hacer Colombia, gestionada por la Agencia Presidencial de Cooperación Internacional, recoge buenas prácticas que se pueden adoptar, incluidas en ámbitos digitales, en el marco de la cooperación internacional que ofrece Colombia.

La Unión Europea (UE) es la mayor fuente de inversión extranjera del país y apoya cuestiones que van desde las tecnologías emergentes hasta la resiliencia al clima. Recientemente, Colombia se comprometió a cooperar con la UE en materia de innovación, en el extenso acervo cultural del país y en las industrias creativas, las denominadas economías naranja (OCDE, 2019b), verde y circular. Colombia también trabaja con la UE en BELLA (Building the Europe Link with Latin América), cuyo objetivo es satisfacer las necesidades de interconectividad a largo plazo de las redes de investigación y educación entre los países europeos y de ALC. 


\section{Mejorar el acceso}

Suscripciones de banda ancha fija (por cada 100 habitantes) ${ }^{4}$

Suscripciones de banda ancha móvil activa (por cada 100 habitantes) ${ }^{4}$

Proporción de población cubierta por al menos una red 3G5

Velocidad de banda ancha fija (en Mbit/s) ${ }^{4}$

\section{Aumentar el uso efectivo}

Índice de desarrollo del gobierno electrónico (EGDI) ${ }^{6}$

Proporción de usuarios de Internet (\% de población) ${ }^{4}$

Índice de comercio electrónico B2C de la UNCTAD

Proporción de personas que realizan compras por Internet ${ }^{8}$

\section{Impulsar la innovación}

Exportaciones de alta tecnología (\% de exportaciones manufacturadas) ${ }^{9}$

Proporción de importaciones de servicios de TIC, como porcentaje del comercio total de servicios ${ }^{7}$

Solicitudes de patentes de TIC presentadas en virtud del Tratado de Cooperación en materia de Patentes (por millón de personas) ${ }^{10}$

Gastos en I+D, como \% del PIB 11

Índice OURdata de la OCDE ${ }^{12}$

\section{Asegurar empleos adecuados para todos}

Contribuciones a variación en empleo total, por intensidad digital de sectores, 2006-2016 ${ }^{13}$

Proporción de empleo informal en relación con empleo total ${ }^{14}$

Tasa bruta de matrícula, educación terciaria $(\%)^{9}$

Graduados de educación terciaria por campo (\%) - Educación ${ }^{11}$

Graduados de educación terciaria por campo (\%) - Salud ${ }^{11}$

Graduados de educación terciaria por campo (\%) - Ingeniería ${ }^{11}$

\section{Promocionar la prosperidad social}

Generación de desechos de aparatos eléctricos per cápita $(\mathrm{kg})^{15}$

Número de estudiantes por computadora ${ }^{16}$

Proporción de mujeres con puntuación de nivel 203 en resolución de problemas en entornos tecnológicos ${ }^{17}$

\section{Reforzar la confianza}

Índice GovTech de la $\mathrm{CAF}^{18}$

Índice de ciberseguridad global (UIT) $)^{19}$

Seguridad del comercio electrónico $(\%)^{20}$ Confianza en la privacidad en Internet $(\%)^{20}$

\section{Promocionar la apertura de mercados}

Índice de restrictividad de intercambios de servicios digitales de la OCDE ${ }^{13}$

Índice de restricción regulatoria de la IED de la $0 C^{-13}$

Las fuentes, notas a pie de página y detalles técnicos se pueden encontrar al final de las Notas País.

\begin{tabular}{cccccc}
\multicolumn{4}{c}{ Indicadores digitales - Colombia ${ }^{1}$} \\
\hline \multicolumn{2}{c}{ Colombia } & \multicolumn{2}{c}{ ALC $^{2}$} & \multicolumn{2}{c}{ OCDE $^{3}$} \\
\hline $\mathbf{2 0 0 8}$ & $\mathbf{2 0 1 8}$ & $\mathbf{2 0 0 8}$ & $\mathbf{2 0 1 8}$ & $\mathbf{2 0 0 8}$ & $\mathbf{2 0 1 8}$ \\
\hline 4.0 & 13.5 & 4.1 & 13.9 & 22.7 & 32.9 \\
0.35 & 52.3 & 0.53 & 73.5 & 19.4 & 103.6 \\
$\mathbf{2 0 1 5}$ & $\mathbf{2 0 1 8}$ & $\mathbf{2 0 1 5}$ & $\mathbf{2 0 1 8}$ & $\mathbf{2 0 1 5}$ & $\mathbf{2 0 1 8}$ \\
\hline 100.0 & 100.0 & 86.1 & 94.6 & 98.2 & 98.8 \\
$\mathbf{2 0 0 8}$ & $\mathbf{2 0 1 7}$ & $\mathbf{2 0 0 8}$ & $\mathbf{2 0 1 7}$ & $\mathbf{2 0 0 8}$ & $\mathbf{2 0 0 7}$ \\
\hline 0.71 & 5.0 & 0.58 & 5.1 & 2.2 & 27.7
\end{tabular}

\begin{tabular}{cccccc}
\multicolumn{2}{c}{ Colombia } & \multicolumn{2}{c}{ ALC } & \multicolumn{2}{c}{ OCDE } \\
\hline $\mathbf{2 0 0 8}$ & $\mathbf{2 0 1 8}$ & $\mathbf{2 0 0 8}$ & $\mathbf{2 0 1 8}$ & $\mathbf{2 0 0 8}$ & $\mathbf{2 0 1 8}$ \\
\hline 0.53 & 0.69 & 0.52 & 0.65 & 0.72 & 0.82 \\
25.6 & 64.1 & 25.3 & 67.7 & 65.0 & 84.3 \\
$\mathbf{2 0 1 5}$ & $\mathbf{2 0 1 9}$ & $\mathbf{2 0 1 5}$ & $\mathbf{2 0 1 9}$ & $\mathbf{2 0 1 5}$ & $\mathbf{2 0 1 9}$ \\
\hline 44.6 & 60.5 & 46.4 & 51.5 & 73.9 & 85.0 \\
\multicolumn{2}{c}{$\mathbf{2 0 1 7}$} & \multicolumn{2}{c}{$\mathbf{2 0 1 7}$} & \multicolumn{2}{c}{$\mathbf{2 0 1 7}$} \\
\hline \multicolumn{2}{c}{14.9} & \multicolumn{2}{c}{14.8} & \multicolumn{2}{c}{ N/A }
\end{tabular}

\begin{tabular}{cccccc}
\multicolumn{2}{c}{ Colombia } & \multicolumn{2}{c}{ ALC } & \multicolumn{2}{c}{ OCDE } \\
\hline $\mathbf{2 0 0 8}$ & $\mathbf{2 0 1 8}$ & $\mathbf{2 0 0 8}$ & $\mathbf{2 0 1 8}$ & $\mathbf{2 0 0 8}$ & $\mathbf{2 0 1 8}$ \\
\hline 4.0 & 7.3 & 9.3 & 8.6 & 15.6 & 15.1 \\
3.62 & 5.33 & 3.1 & 3.9 & 4.6 & 6.7 \\
$\mathbf{2 0 1 2}$ & $\mathbf{2 0 1 6}$ & $\mathbf{2 0 1 2}$ & $\mathbf{2 0 1 6}$ & $\mathbf{2 0 1 2}$ & $\mathbf{2 0 1 6}$ \\
\hline 0.13 & 0.26 & 0.14 & 0.34 & 30.9 & 38.2 \\
$\mathbf{2 0 0 6}$ & $\mathbf{2 0 1 6}$ & $\mathbf{2 0 0 6}$ & $\mathbf{2 0 1 6}$ & $\mathbf{2 0 0 6}$ & $\mathbf{2 0 1 6}$ \\
\hline 0.15 & 0.27 & 0.35 & 0.42 & 1.7 & 1.9 \\
\hline \multicolumn{2}{c}{$\mathbf{2 0 1 9}$} & \multicolumn{2}{c}{$\mathbf{2 0 1 9}$} & \multicolumn{2}{c}{$\mathbf{2 0 1 9}$} \\
\hline 0.88 & \multicolumn{2}{c}{0.43} & \multicolumn{2}{c}{0.61}
\end{tabular}

\begin{tabular}{|c|c|c|c|c|c|}
\hline \multicolumn{2}{|c|}{ Colombia } & \multicolumn{2}{|c|}{ ALC } & \multicolumn{2}{|c|}{ OCDE } \\
\hline \multicolumn{2}{|c|}{$2006-15$} & \multicolumn{2}{|c|}{$2006-15$} & \multicolumn{2}{|c|}{$2006-15$} \\
\hline \multicolumn{2}{|c|}{ N/A } & \multicolumn{2}{|c|}{6.9} & \multicolumn{2}{|c|}{4.8} \\
\hline \multicolumn{2}{|c|}{2018} & \multicolumn{2}{|c|}{2018} & \multicolumn{2}{|c|}{2018} \\
\hline \multicolumn{2}{|c|}{61.4} & \multicolumn{2}{|c|}{54.9} & \multicolumn{2}{|c|}{ N/A } \\
\hline 2007 & 2017 & 2007 & 2017 & 2007 & 2017 \\
\hline 33.7 & 56.4 & 37.5 & 60.5 & 66.6 & 74.3 \\
\hline \multicolumn{2}{|c|}{2016} & \multicolumn{2}{|c|}{2016} & \multicolumn{2}{|c|}{2016} \\
\hline \multicolumn{2}{|c|}{8.2} & \multicolumn{2}{|c|}{16.0} & \multicolumn{2}{|c|}{9.8} \\
\hline \multicolumn{2}{|c|}{6.8} & \multicolumn{2}{|c|}{13.8} & \multicolumn{2}{|c|}{14.5} \\
\hline \multicolumn{2}{|c|}{16.7} & \multicolumn{2}{|c|}{12.5} & \multicolumn{2}{|c|}{14.6} \\
\hline
\end{tabular}

\begin{tabular}{cccccc}
\multicolumn{2}{c}{ Colombia } & \multicolumn{2}{c}{ ALC } & \multicolumn{2}{c}{ OCDE } \\
\hline $\mathbf{2 0 1 5}$ & $\mathbf{2 0 1 6}$ & $\mathbf{2 0 1 5}$ & $\mathbf{2 0 1 6}$ & $\mathbf{2 0 1 5}$ & $\mathbf{2 0 1 6}$ \\
\hline 5.5 & 5.6 & 6.9 & 7.2 & 17.7 & 17.7 \\
$\mathbf{2 0 1 5}$ & $\mathbf{2 0 1 8}$ & $\mathbf{2 0 1 5}$ & $\mathbf{2 0 1 8}$ & $\mathbf{2 0 1 5}$ & $\mathbf{2 0 1 8}$ \\
\hline 1.6 & 1.1 & 2.4 & 1.6 & 1.8 & 1.1 \\
\multicolumn{2}{c}{$\mathbf{2 0 1 8}$} & \multicolumn{2}{c}{$\mathbf{2 0 1 8}$} & \multicolumn{2}{c}{$\mathbf{2 0 1 8}$} \\
\hline N/A & \multicolumn{2}{c}{7.7} & \multicolumn{2}{c}{27.7}
\end{tabular}

\begin{tabular}{cccccc}
\multicolumn{2}{c}{ Colombia } & \multicolumn{2}{c}{ ALC } & \multicolumn{2}{c}{ OCDE } \\
\hline \multicolumn{2}{c}{$\mathbf{2 0 2 0}$} & \multicolumn{2}{c}{$\mathbf{2 0 2 0}$} & \multicolumn{2}{c}{$\mathbf{2 0 2 0}$} \\
\hline \multicolumn{2}{c}{5.1} & \multicolumn{2}{c}{4.4} & \multicolumn{2}{c}{ N/A } \\
\hline $\mathbf{2 0 1 6}$ & $\mathbf{2 0 1 8}$ & $\mathbf{2 0 1 6}$ & $\mathbf{2 0 1 8}$ & $\mathbf{2 0 1 6}$ & $\mathbf{2 0 1 8}$ \\
\hline 0.59 & 0.57 & 0.36 & 0.43 & 0.56 & 0.79 \\
\hline $\mathbf{2 0 1 8}$ & $\mathbf{2 0 1 9}$ & $\mathbf{2 0 1 8}$ & $\mathbf{2 0 1 9}$ & $\mathbf{2 0 1 8}$ & $\mathbf{2 0 1 9}$ \\
\hline 80.0 & 57.8 & 72.0 & 63.1 & 61.7 & 58.3 \\
\hline 70.0 & 56.0 & 52.8 & 54.9 & 41.7 & 45.6
\end{tabular}

\begin{tabular}{cccccc}
\multicolumn{2}{c}{ Colombia } & \multicolumn{2}{c}{ ALC } & \multicolumn{2}{c}{ OCDE } \\
\hline 2015 & $\mathbf{2 0 1 9}$ & $\mathbf{2 0 1 5}$ & $\mathbf{2 0 1 9}$ & $\mathbf{2 0 1 5}$ & $\mathbf{2 0 1 9}$ \\
0.30 & 0.30 & 0.24 & 0.24 & 0.13 & 0.15 \\
2018 & \multicolumn{2}{c}{$\mathbf{2 0 1 8}$} & \multicolumn{2}{c}{$\mathbf{2 0 1 8}$} \\
\hline 0.03 & \multicolumn{2}{c}{0.07} & \multicolumn{2}{c}{0.06} \\
\hline
\end{tabular}




\section{Notas técnicas}

1. La Tabla sigue lo mejor posible las siete áreas claves identificadas en el proyecto Going Digital de la OCDE: 1) mejorar el acceso a las tecnologías digitales; 2) aumentar el uso efectivo; 3) permitir la innovación digital; 4) asegurar empleos adecuados para todos; 5) promocionar la prosperidad social; 6) reforzar la confianza; y 7) promocionar la apertura de mercados (OCDE, 2019a). Los indicadores se eligen según la disponibilidad de datos para los países de ALC. Existe la posibilidad de un sesgo por la forma en que se han agregado los componentes en los indicadores de índice.

2. El promedio de ALC es un promedio simple. La composición de los países depende de la disponibilidad de datos de los países de la región. Cada promedio incluye tantos países de ALC encontrados en cada fuente como sea posible.

3. El promedio de la OCDE es un promedio simple que incluye a todos los países miembros de la OCDE en mayo de 2020.

4. Datos de la UIT (2020), Base de datos de indicadores mundiales de telecomunicaciones / TIC 2020 (base de datos). La velocidad de banda ancha fija en Mbit/s se refiere a la velocidad de descarga teórica máxima anunciada garantizada a los usuarios asociados con una suscripción mensual de Internet de banda ancha fija.

5. Datos de la División de Estadística de las Naciones Unidas, Base de datos mundial de los ODS de las Naciones Unidas (base de datos). Datos de 2015 y 2018 o los últimos disponibles.

6. Datos de la base de conocimientos sobre gobierno electrónico de las Naciones Unidas (2019), centro de datos (base de datos). El índice de desarrollo del gobierno electrónico (E-government development index) es un indicador compuesto que consta de tres índices (índice de servicios en línea, índice de infraestructura de telecomunicaciones e índice de capital humano), que están igualmente ponderados. Tiene un rango de 0 a 1, con 1 siendo un gobierno más desarrollado.

7. Datos de UNCTAD (2020), UNCTADSTAT (base de datos). El índice de comercio electrónico B2C de la UNCTAD mide la preparación de una economía para respaldar las compras en línea. Rango de 0 a 100, con 100 siendo el nivel de apoyo más alto.

8. Cálculos propios a partir de datos de Latinobarómetro (2019), Libros de Códigos por País / Año (base de datos). Datos de 2017. Datos de encuestas de opinión pública utilizando muestras representativas a nivel nacional seleccionadas al azar.

9. Datos del Banco Mundial (2020a), Banco de datos del Banco Mundial (base de datos).

10. Datos del Banco Mundial (2020b), TCdata360. Datos de 2012 y 2016 o los últimos disponibles.

11. Datos de Unesco (2019), Instituto de Estadística de la Unesco (base de datos). Gastos en I+D, como porcentaje de los datos del PIB de 2006 y 2016 o el último disponible.

12. Datos de OCDE (2020a), OECD.Stat (base de datos) y OCDE (2020b). El índice OURdata de la OCDE evalúa los esfuerzos de los gobiernos para implementar datos abiertos en tres áreas críticas: apertura, utilidad y reutilización de los datos gubernamentales. Tiene un rango de 0 a 1, con 1 siendo la puntuación más alta.

13. Datos de OCDE (2020a), OECD.Stat (base de datos). El Índice de restricción del comercio de servicios digitales de la OCDE identifica, cataloga y cuantifica las barreras que afectan el comercio de servicios habilitados digitalmente en 46 países. Tiene un rango de 0 a 1, con 1 siendo el valor más restrictivo. El Índice de Restricción Reglamentaria de la Inversión Extranjera Directa (IED RRI) mide cuatro tipos de restricciones legales a la inversión extranjera directa: 1) restricciones a la participación extranjera en el capital social; 2) requisitos de selección y aprobación previa; 3) regulaciones para personas claves; y 4) otras restricciones al funcionamiento de empresas extranjeras. El RRI de la IED es un índice compuesto, que varía de 0 a 1, con 1 siendo el valor más restrictivo.

14. Datos de ILOSTAT, datos de 2018 o último año disponible.

15. Datos de la Asociación mundial de estadísticas sobre desechos electrónicos.

16. Cálculos de la OCDE basados en OCDE (2020c), Programa de Evaluación Internacional de Estudiantes (base de datos). Datos de 2015 y 2018.

17. Datos de la OCDE (2019d), Survey of Adult Skills (2018). Los porcentajes para la resolución de problemas en entornos ricos en tecnología se calculan de modo que la suma de los porcentajes de las siguientes categorías mutuamente exhaustivas sea igual al 100\%: se excluyó de la evaluación por computadora; sin experiencia en informática; prueba de núcleo de TIC fallida; por debajo del Nivel 1, en el Nivel 1, en el Nivel 2 y en el Nivel 3.

18. Datos de CAF (2020), The GouTech Index 2020: Unlocking the Potential of GouTech Ecosystems in Latin America, Spain and Portugal. El índice GovTech 2020 mide la madurez del ecosistema GovTech. Se basa en 28 indicadores en 7 dimensiones, que, en conjunto, forman 3 pilares igualmente ponderados: industria de nueva creación, políticas gubernamentales y sistemas de adquisiciones. 
19. El Índice mundial de ciberseguridad mide el compromiso de los países con la ciberseguridad a escala global. Tiene cinco pilares: 1) medidas legales; 2) medidas técnicas; 3) medidas organizativas; 4) desarrollo de capacidades; y 5) cooperación. Va de 0 a 1, siendo 1 el nivel más alto de ciberseguridad.

20. Datos de The Economist Intelligence Unit (2019), EIU Inclusive Internet Index (base de datos). Los indicadores presentan la seguridad percibida del comercio electrónico y la confianza en la privacidad en línea entre las personas seleccionadas al azar en países seleccionados. Varía del $0 \%$ al 100\%, donde el $100 \%$ indica una confianza absoluta en la seguridad del comercio electrónico y la confianza en la privacidad en línea.

\section{Referencias}

Banco Mundial (2020a), DataBank (base de datos), Grupo del Banco Mundial, Washington, DC, https:// databank.worldbank.org/home.aspx (consultada el 11 de diciembre de 2019).

Banco Mundial (2020b), TCdata360 (base de datos), Grupo del Banco Mundial, Washington, DC, https:// tcdata360.worldbank.org/ (consultada el 4 de agosto de 2020).

Base de conocimientos sobre gobierno electrónico de la ONU (2019), Data Center (base de datos), Departamento de Asuntos Económicos y Sociales de las Naciones Unidas, Nueva York, https:// publicadministration.un.org/egovkb/en-us/Data-Center (consultada el 11 de diciembre de 2019).

CAF (2020), The GouTech Index 2020: Unlocking the Potential of GovTech Ecosystems in Latin America, Spain and Portugal, Banco de Desarrollo de America Latina, Caracas.

CEPAL (2018), Observatorio Regional de Planificación para el Desarrollo de América Latina y el Caribe, Comisión Económica para América Latina y el Caribe, Santiago, https://observatorioplanificacion.cepal.org/es.

Dispositivo de estadísticas de la ONU (2018, 2015), ODS globales de la ONU (database), Departamento de Asuntos Económicos y Sociales de las Naciones Unidas, Nueva York, https://unstats.un.org/sdgs/ indicators/database/ (consultada el 20 de mayo de 2020).

Foro Mundial Económico (2016), “The Global Information Technology Report 2016”, Foro Mundial Económico, Ginebra, https://www.weforum.org/reports/the-global-information-technology-report-2016.

Global E-waste Statistic Partnership, página de internet, Global E-waste Statistic Partnership, Bonn, https:// globalewaste.org/ (consultada el 11 de diciembre de 2019).

Latinobarómetro (2019), Libros de Códigos por País/Año (base de datos), Latinobarómetro, Providencia, www. latinobarometro.org/latCodebooks.jsp (consultada el 11 de diciembre de 2019).

OCDE (2020a), OECD.Stat (database), Publicaciones de la OCDE, París, https://stats.oecd.org/ (consultada el 11 de diciembre de 2019).

OCDE (2020b), Panorama de las Administraciones Públicas América Latina y el Caribe 2020, Publicaciones de la OCDE, París, https://doi.org/10.1787/13130fbb-en.

OCDE (2020c), Programme for International Student Assessment (base de datos), Publicaciones de la OCDE, París, www.oecd.org/pisa/data/2018database/ (consultada el 14 de febrero de 2020).

OCDE (2019a), Cómo medir la transformación digital: Hoja de ruta para el futuro, Publicaciones de la OCDE, París, https://doi.org/10.1787/9789264311992-en.

OCDE (2019b), Estudios de la OCDE sobre Transformación Digital: “Going Digital” en Colombia, Publicaciones de la OCDE, París, https://doi.org/10.1787/781185b1-en.

OCDE (2019c), Digital Government Review of Panama: Enhancing the Digital Transformation of the Public Sector, OCDE Estudios de gobierno digital, Publicaciones de la OCDE, París, https://doi.org/10.1787/615a4180-en.

OCDE (2019d), Survey of Adult Skills, Publicaciones de la OCDE, París, https://www.oecd.org/skills/piaac/data/

OIT (2019), ILO Statistics (base de datos), Organización Internacional del Trabajo, Ginebra, www.ilo.org/ global/statistics-and-databases/lang--en/index.htm (consultada el 11 de diciembre de 2019).

Open Knowledge Foundation (2019), Global Open Data Index (base de datos), Open Knowledge Foundation, Cambridge, Reino Unido, https://index.okfn.org/dataset/ (consultada el 19 de abril de 2020).

PIAAC Expert Group in Problem Solving in Technology-Rich Environments (2009), "PIAAC Problem Solving in Technology- Rich Environments: A Conceptual Framework", OCDE Documentos de trabajo educativo, n. ${ }^{\circ}$ 36, Publicaciones de la OCDE, París, https://doi.org/10.1787/220262483674.

The Economist Intelligence Unit (2019), EIU Inclusive Internet Index 2019 (base de datos), The Economist Group, Londres, https://theinclusiveinternet.eiu.com/explore/countries/performance (consultada el $11 \mathrm{de}$ diciembre 2019).

UIT (2020), base de datos de indicadores mundiales de telecomunicaciones / TIC 2020 (base de datos), Unión Internacional de Telecomunicaciones, Ginebra, https://www.itu.int/en/ITU-D/Statistics/Pages/ publications/wtid.aspx (consultada el 21 de agosto de 2020). 
UNCTAD (2020), UNCTADSTAT (base de datos), Conferencia de las Naciones Unidas sobre Comercio y Desarrollo, Ginebra, https://unctadstat.unctad.org/EN/ (consultada el 11 de diciembre de 2019).

UNESCO (2019), Instituto de Estadística de la Unesco (base de datos), Unesco, París, http://data.uis.unesco. org/Index.aspx (consultada el 20 de mayo de 2020).

World Wide Web Foundation (2017), OpenData Barometer (base de datos), World Wide Web Foundation, Ginebra, https://opendatabarometer.org/ (consultada el 19 de abril de 2020). 



\section{COSTA RICA}

\section{Tendencias recientes}

En la última década, Costa Rica ha avanzado en la inclusión digital. Los usuarios de Internet representaban más del 74\% de la población en 2018, con más aumentos en el año anterior. Las suscripciones a servicios de banda ancha móvil activa en 2018 se situaban en 100.9 por cada 100 habitantes y las suscripciones a servicios de banda ancha fija en 16.6 por cada 100 habitantes. Estas cifras se ubicaban por encima de los promedios de América Latina y el Caribe (ALC) (73.5 y 13.9, respectivamente). También ha mejorado el desempeño en el índice de desarrollo de gobierno electrónico, que mide la disposición y capacidad de las administraciones nacionales para utilizar las TIC (tecnologías de la información y las comunicaciones). El país sigue atrazado en cuanto a las políticas de datos abiertos de organismos públicos, y sus resultados en el índice OURdata de la OCDE se sitúan por debajo de los promedios de ALC y la OCDE.

En cuanto a facilitar la innovación digital, con relación al promedio de ALC (9.6\%), las exportaciones de alta tecnología de Costa Rica en proporción al total de las exportaciones de productos manufacturados disminuyeron del 39.6\% en 2008 al 18.5\% en 2017, lo cual está acorde con el promedio de la OCDE (15.1\%). En cuanto a la promoción de una sociedad digital incluyente, el número de estudiantes por computadora cayó de 2.8 en 2015 a 1.3 en 2018, que sigue estando por encima del promedio de la OCDE, pero por debajo del promedio de ALC.

\section{Estrategias nacionales y cooperación internacional para la transformación digital}

El Plan Nacional de Desarrollo de las Telecomunicaciones 2015-2021 y la Estrategia de Transformación Digital hacia la Costa Rica del Bicentenario 4.0 2018-2022 son los principales referentes de la transformación digital del país. El plan se basa en la coordinación interinstitucional e intersectorial en tres pilares: inclusión digital, economía digital y un gobierno transparente y electrónico. La estrategia tiene como objetivo avanzar hacia un país digitalmente incluyente, mejor conectado, productivo y más innovador. Sus principios rectores son: la adopción de las tecnologías de la industria 4.0, el desarrollo de un gobierno digitalmente inteligente, servicios digitales incluyentes, integrados y seguros y el desarrollo del talento humano. El Ministerio de Ciencia, Tecnología y Telecomunicaciones (MICITT) es responsable de la implantación, la coordinación y el seguimiento de estos planes.

El eje de la estrategia de transformación 4.0 aborda el papel de las tecnologías digitales en el desarrollo de la bioeconomía para minimizar el impacto ambiental y maximizar la eficiencia. Establece que la bioeconomía, la biotecnología y la bioinformática serán vehículos para la descarbonización y la productividad. El MICITT impulsa la creación de una Estrategia Nacional de Bioeconomía con el apoyo de instituciones nacionales públicas y privadas, la Comisión Económica de las Naciones Unidas para América Latina y el Caribe y la Agencia Alemana de Cooperación Internacional. La estrategia concuerda con el Plan Nacional de Descarbonización 2018-2022, que tiene por objeto lograr una economía moderna, verde, libre de emisiones, resiliente e incluyente para 2050. Para responder a la crisis del coronavirus (Covid-19) en los aspectos relacionados con las telecomunicaciones, el Ministerio de Ciencia, Tecnología y Telecomunicaciones y el Consejo de la Superintendencia de Telecomunicaciones establecieron acuerdos con los operadores móviles del país para dar continuidad y mantenimiento a los servicios. Estos acuerdos permiten al Ministerio de Salud establecer un método sistematizado de envío de mensajes de texto con recomendaciones sanitarias. También proporciona navegación gratuita de los sitios web del Ministerio de Educación, la Caja de Seguro Social, el Ministerio de Salud, la Presidencia de la República y Pura Vida Digital (CAF, 2020).

Costa Rica ha desarrollado recientemente Bola de Cristal, una plataforma digital inteligente que pone en contacto la oferta y competencias especializadas con la demanda de empleos. Igualmente informa a los usuarios sobre las competencias necesarias en la economía del conocimiento y las carreras de mayor demanda, promueve la capacitación y certificación adaptadas a los perfiles de los usuarios, ofrece ayudas con productos financieros para acceder a la capacitación y certificación, y crea oportunidades de empleo con empresas que operan en la economía del conocimiento.

Con respecto a la cooperación internacional, Costa Rica firmó un acuerdo con Estonia en materia de gobierno digital, ciberseguridad e interoperabilidad en septiembre de 2019, con el apoyo del Banco Interamericano de Desarrollo. Entre sus proyectos se incluyen el desarrollo de la identidad digital y la promoción de la cooperación entre las empresas tecnológicas de los respectivos países.

Costa Rica también colabora con la Unión Europea (UE) en el programa Connect 2020, que se centra en fomentar la cooperación en el ámbito de las TIC entre Europa y los países de ALC. El proyecto está financiado por el Séptimo Programa Marco y forma parte del proyecto de Plataformas Tecnológicas de América Latina en Innovación en el marco del programa Horizonte 2020 de la UE. 


\section{Mejorar el acceso}

Suscripciones de banda ancha fija (por cada 100 habitantes) ${ }^{4}$

Suscripciones de banda ancha móvil activa (por cada 100 habitantes) ${ }^{4}$

Proporción de población cubierta por al menos una red $3 \mathrm{G}^{5}$

Velocidad de banda ancha fija (en Mbit/s) ${ }^{4}$

\section{Aumentar el uso efectivo}

Índice de desarrollo del gobierno electrónico (EGDI) ${ }^{6}$

Proporción de usuarios de Internet (\% de población) ${ }^{4}$

Índice de comercio electrónico B2C de la UNCTAD ${ }^{7}$

Proporción de personas que realizan compras por Internet ${ }^{8}$

\section{Impulsar la innovación}

Exportaciones de alta tecnología (\% de exportaciones manufacturadas) ${ }^{9}$

Proporción de importaciones de servicios de TIC, como porcentaje del comercio total de servicios ${ }^{7}$

Solicitudes de patentes de TIC presentadas en virtud del Tratado de Cooperación en materia de Patentes (por millón de personas) ${ }^{10}$

Gastos en I+D, como \% del PIB ${ }^{11}$

Índice OURdata de la OCDE ${ }^{12}$

\section{Asegurar empleos adecuados para todos}

Contribuciones a variación en empleo total, por intensidad digital de sectores, 2006-2016 ${ }^{13}$

Proporción de empleo informal en relación con empleo total ${ }^{14}$

Tasa bruta de matrícula, educación terciaria $(\%)^{9}$

Graduados de educación terciaria por campo (\%) - Educación ${ }^{11}$

Graduados de educación terciaria por campo (\%) - Salud ${ }^{11}$

Graduados de educación terciaria por campo (\%) - Ingeniería ${ }^{11}$

\section{Promocionar la prosperidad social}

Generación de desechos de aparatos eléctricos per cápita $(\mathrm{kg})^{15}$

Número de estudiantes por computadora ${ }^{16}$

Proporción de mujeres con puntuación de nivel 203 en resolución de problemas en entornos tecnológicos ${ }^{17}$

\section{Reforzar la confianza}

Índice GovTech de la $\mathrm{CAF}^{18}$

Índice de ciberseguridad global (UIT) $)^{19}$

Seguridad del comercio electrónico $(\%)^{20}$

Confianza en la privacidad en Internet $(\%)^{20}$

\section{Promocionar la apertura de mercados}

Índice de restrictividad de intercambios de servicios digitales de la OCDE ${ }^{13}$

Índice de restricción regulatoria de la IED de la $0 \mathrm{CDE}^{13}$

Las fuentes, notas a pie de página y detalles técnicos se pueden encontrar al final de las Notas País.

\begin{tabular}{cccccc}
\multicolumn{3}{c}{ Indicadores digitales - Costa Rica ${ }^{1}$} \\
\hline \multicolumn{2}{c}{ Costa Rica } & \multicolumn{2}{c}{ ALC $^{2}$} & \multicolumn{2}{c}{ OCDE $^{3}$} \\
\hline $\mathbf{2 0 0 8}$ & $\mathbf{2 0 1 8}$ & $\mathbf{2 0 0 8}$ & $\mathbf{2 0 1 8}$ & $\mathbf{2 0 0 8}$ & $\mathbf{2 0 1 8}$ \\
\hline 2.5 & 16.6 & 4.1 & 13.9 & 22.7 & 32.9 \\
$\mathbf{2 0 1 0}$ & $\mathbf{2 0 1 8}$ & $\mathbf{2 0 1 0}$ & $\mathbf{2 0 1 8}$ & $\mathbf{2 0 1 0}$ & $\mathbf{2 0 1 8}$ \\
\hline 7.4 & 100.9 & 5.4 & 73.5 & 37.7 & 103.6 \\
$\mathbf{2 0 1 5}$ & $\mathbf{2 0 1 8}$ & $\mathbf{2 0 1 5}$ & $\mathbf{2 0 1 8}$ & $\mathbf{2 0 1 5}$ & $\mathbf{2 0 1 8}$ \\
\hline 93.4 & 97.3 & 86.1 & 94.6 & 98.2 & 98.8 \\
$\mathbf{2 0 0 8}$ & $\mathbf{2 0 1 7}$ & $\mathbf{2 0 0 8}$ & $\mathbf{2 0 1 7}$ & $\mathbf{2 0 0 8}$ & $\mathbf{2 0 0 7}$ \\
\hline 0.26 & 1.0 & 0.58 & 5.1 & 2.2 & 27.7
\end{tabular}

\begin{tabular}{cccccc}
\multicolumn{2}{c}{ Costa Rica } & \multicolumn{2}{c}{ ALC } & \multicolumn{2}{c}{ OCDE } \\
\hline $\mathbf{2 0 0 8}$ & $\mathbf{2 0 1 8}$ & $\mathbf{2 0 0 8}$ & $\mathbf{2 0 1 8}$ & $\mathbf{2 0 0 8}$ & $\mathbf{2 0 1 8}$ \\
\hline 0.51 & 0.70 & 0.52 & 0.65 & 0.72 & 0.82 \\
32.3 & 74.1 & 25.3 & 67.7 & 65.0 & 84.3 \\
$\mathbf{2 0 1 5}$ & $\mathbf{2 0 1 9}$ & $\mathbf{2 0 1 5}$ & $\mathbf{2 0 1 9}$ & $\mathbf{2 0 1 5}$ & $\mathbf{2 0 1 9}$ \\
\hline 52.4 & 64.1 & 46.4 & 51.5 & 73.9 & 85.0 \\
\multicolumn{2}{c}{$\mathbf{2 0 1 7}$} & \multicolumn{2}{c}{$\mathbf{2 0 1 7}$} & \multicolumn{2}{c}{$\mathbf{2 0 1 7}$} \\
\hline 18.5 & \multicolumn{2}{c}{14.8} & \multicolumn{2}{c}{ N/A }
\end{tabular}

\begin{tabular}{cccccc}
\multicolumn{2}{c}{ Costa Rica } & \multicolumn{2}{c}{ ALC } & \multicolumn{2}{c}{ OCDE } \\
\hline $\mathbf{2 0 0 8}$ & $\mathbf{2 0 1 7}$ & $\mathbf{2 0 0 8}$ & $\mathbf{2 0 1 7}$ & $\mathbf{2 0 0 8}$ & $\mathbf{2 0 1 7}$ \\
\hline 39.6 & 18.5 & 9.3 & 9.6 & 15.6 & 15.1 \\
7.69 & 7.70 & 3.1 & 3.9 & 4.6 & 6.7 \\
$\mathbf{2 0 1 2}$ & $\mathbf{2 0 1 6}$ & $\mathbf{2 0 1 2}$ & $\mathbf{2 0 1 6}$ & $\mathbf{2 0 1 2}$ & $\mathbf{2 0 1 6}$ \\
\hline 0.19 & 0.50 & 0.14 & 0.34 & 30.9 & 38.2 \\
$\mathbf{2 0 0 7}$ & $\mathbf{2 0 1 6}$ & $\mathbf{2 0 0 7}$ & $\mathbf{2 0 1 6}$ & $\mathbf{2 0 0 7}$ & $\mathbf{2 0 1 6}$ \\
\hline 0.36 & 0.46 & 0.34 & 0.42 & 1.7 & 1.9 \\
\hline $\mathbf{2 0 1 9}$ & \multicolumn{2}{c}{$\mathbf{2 0 1 9}$} & \multicolumn{2}{c}{$\mathbf{2 0 1 9}$} \\
\hline 0.37 & \multicolumn{2}{c}{0.43} & \multicolumn{2}{c}{0.61}
\end{tabular}

\begin{tabular}{|c|c|c|c|c|c|}
\hline \multicolumn{2}{|c|}{ Costa Rica } & \multicolumn{2}{|c|}{ ALC } & \multicolumn{2}{|c|}{ OCDE } \\
\hline \multicolumn{2}{|c|}{$2006-15$} & \multicolumn{2}{|c|}{$2006-15$} & \multicolumn{2}{|c|}{$2006-15$} \\
\hline \multicolumn{2}{|c|}{6.8} & \multicolumn{2}{|c|}{6.9} & \multicolumn{2}{|c|}{4.8} \\
\hline \multicolumn{2}{|c|}{2018} & \multicolumn{2}{|c|}{2018} & \multicolumn{2}{|c|}{2018} \\
\hline \multicolumn{2}{|c|}{37.4} & \multicolumn{2}{|c|}{54.9} & \multicolumn{2}{|c|}{ N/A } \\
\hline 2004 & 2017 & 2004 & 2017 & 2004 & 2017 \\
\hline 26.7 & 55.7 & 34.5 & 60.5 & 63.0 & 74.3 \\
\hline \multicolumn{2}{|c|}{2016} & \multicolumn{2}{|c|}{2016} & \multicolumn{2}{|c|}{2016} \\
\hline \multicolumn{2}{|c|}{21.3} & \multicolumn{2}{|c|}{16.0} & \multicolumn{2}{|c|}{9.8} \\
\hline \multicolumn{2}{|c|}{15.1} & \multicolumn{2}{|c|}{13.8} & \multicolumn{2}{|c|}{14.5} \\
\hline \multicolumn{2}{|c|}{6.9} & \multicolumn{2}{|c|}{12.5} & \multicolumn{2}{|c|}{14.6} \\
\hline
\end{tabular}

\begin{tabular}{cccccc}
\multicolumn{2}{c}{ Costa Rica } & \multicolumn{2}{c}{ ALC } & \multicolumn{2}{c}{ OCDE } \\
\hline $\mathbf{2 0 1 5}$ & $\mathbf{2 0 1 6}$ & $\mathbf{2 0 1 5}$ & $\mathbf{2 0 1 6}$ & $\mathbf{2 0 1 5}$ & $\mathbf{2 0 1 6}$ \\
\hline 9.4 & 9.7 & 6.9 & 7.2 & 17.7 & 17.7 \\
$\mathbf{2 0 1 5}$ & $\mathbf{2 0 1 8}$ & $\mathbf{2 0 1 5}$ & $\mathbf{2 0 1 8}$ & $\mathbf{2 0 1 5}$ & $\mathbf{2 0 1 8}$ \\
\hline 2.8 & 1.3 & 2.4 & 1.6 & 1.8 & 1.1 \\
\hline \multicolumn{2}{c}{$\mathbf{2 0 1 8}$} & \multicolumn{2}{c}{$\mathbf{2 0 1 8}$} & \multicolumn{2}{c}{$\mathbf{2 0 1 8}$} \\
\hline N/A & \multicolumn{2}{c}{7.7} & \multicolumn{2}{c}{27.7}
\end{tabular}

\begin{tabular}{cccccc}
\multicolumn{2}{c}{ Costa Rica } & \multicolumn{2}{c}{ ALC } & \multicolumn{2}{c}{ OCDE } \\
\hline \multicolumn{2}{c}{$\mathbf{2 0 2 0}$} & \multicolumn{2}{c}{$\mathbf{2 0 2 0}$} & \multicolumn{2}{c}{$\mathbf{2 0 2 0}$} \\
\hline \multicolumn{2}{c}{4.0} & \multicolumn{2}{c}{4.4} & \multicolumn{2}{c}{ N/A } \\
\hline $\mathbf{2 0 1 6}$ & $\mathbf{2 0 1 8}$ & $\mathbf{2 0 1 6}$ & $\mathbf{2 0 1 8}$ & $\mathbf{2 0 1 6}$ & $\mathbf{2 0 1 8}$ \\
\hline 0.35 & 0.22 & 0.36 & 0.43 & 0.56 & 0.79 \\
\hline $\mathbf{2 0 1 8}$ & $\mathbf{2 0 1 9}$ & $\mathbf{2 0 1 8}$ & $\mathbf{2 0 1 9}$ & $\mathbf{2 0 1 8}$ & $\mathbf{2 0 1 9}$ \\
\hline N/A & 67.4 & 72.0 & 63.1 & 61.7 & 58.3 \\
N/A & 58.0 & 52.8 & 54.9 & 41.7 & 45.6
\end{tabular}

\begin{tabular}{cccccc}
\multicolumn{2}{c}{ Costa Rica } & \multicolumn{2}{c}{ ALC } & \multicolumn{2}{c}{ OCDE } \\
\hline 2015 & $\mathbf{2 0 1 9}$ & $\mathbf{2 0 1 5}$ & $\mathbf{2 0 1 9}$ & $\mathbf{2 0 1 5}$ & $\mathbf{2 0 1 9}$ \\
\hline 0.04 & 0.04 & 0.24 & 0.24 & 0.13 & 0.15 \\
2018 & \multicolumn{2}{c}{$\mathbf{2 0 1 8}$} & \multicolumn{2}{c}{$\mathbf{2 0 1 8}$} \\
\hline 0.03 & \multicolumn{2}{c}{0.07} & \multicolumn{2}{c}{0.06} \\
\hline
\end{tabular}




\section{Notas técnicas}

1. La Tabla sigue lo mejor posible las siete áreas claves identificadas en el proyecto Going Digital de la OCDE: 1) mejorar el acceso a las tecnologías digitales; 2) aumentar el uso efectivo; 3) permitir la innovación digital; 4) asegurar empleos adecuados para todos; 5) promocionar la prosperidad social; 6) reforzar la confianza; y 7) promocionar la apertura de mercados (OCDE, 2019a). Los indicadores se eligen según la disponibilidad de datos para los países de ALC. Existe la posibilidad de un sesgo por la forma en que se han agregado los componentes en los indicadores de índice.

2. El promedio de ALC es un promedio simple. La composición de los países depende de la disponibilidad de datos de los países de la región. Cada promedio incluye tantos países de ALC encontrados en cada fuente como sea posible.

3. El promedio de la OCDE es un promedio simple que incluye a todos los países miembros de la OCDE en mayo de 2020.

4. Datos de la UIT (2020), Base de datos de indicadores mundiales de telecomunicaciones / TIC 2020 (base de datos). La velocidad de banda ancha fija en Mbit/s se refiere a la velocidad de descarga teórica máxima anunciada garantizada a los usuarios asociados con una suscripción mensual de Internet de banda ancha fija.

5. Datos de la División de Estadística de las Naciones Unidas, Base de datos mundial de los ODS de las Naciones Unidas (base de datos). Datos de 2015 y 2018 o los últimos disponibles.

6. Datos de la base de conocimientos sobre gobierno electrónico de las Naciones Unidas (2019), centro de datos (base de datos). El índice de desarrollo del gobierno electrónico (E-government development index) es un indicador compuesto que consta de tres índices (índice de servicios en línea, índice de infraestructura de telecomunicaciones e índice de capital humano), que están igualmente ponderados. Tiene un rango de 0 a 1, con 1 siendo un gobierno más desarrollado.

7. Datos de UNCTAD (2020), UNCTADSTAT (base de datos). El índice de comercio electrónico B2C de la UNCTAD mide la preparación de una economía para respaldar las compras en línea. Rango de 0 a 100, con 100 siendo el nivel de apoyo más alto.

8. Cálculos propios a partir de datos de Latinobarómetro (2019), Libros de Códigos por País / Año (base de datos). Datos de 2017. Datos de encuestas de opinión pública utilizando muestras representativas a nivel nacional seleccionadas al azar.

9. Datos del Banco Mundial (2020a), Banco de datos del Banco Mundial (base de datos).

10. Datos del Banco Mundial (2020b), TCdata360. Datos de 2012 y 2016 o los últimos disponibles.

11. Datos de Unesco (2019), Instituto de Estadística de la Unesco (base de datos). Gastos en I+D, como porcentaje de los datos del PIB de 2006 y 2016 o el último disponible.

12. Datos de OCDE (2020a), OECD.Stat (base de datos) y OCDE (2020b). El índice OURdata de la OCDE evalúa los esfuerzos de los gobiernos para implementar datos abiertos en tres áreas críticas: apertura, utilidad y reutilización de los datos gubernamentales. Tiene un rango de 0 a 1, con 1 siendo la puntuación más alta.

13. Datos de OCDE (2020a), OECD.Stat (base de datos). El Índice de restricción del comercio de servicios digitales de la OCDE identifica, cataloga y cuantifica las barreras que afectan el comercio de servicios habilitados digitalmente en 46 países. Tiene un rango de 0 a 1, con 1 siendo el valor más restrictivo. El Índice de Restricción Reglamentaria de la Inversión Extranjera Directa (IED RRI) mide cuatro tipos de restricciones legales a la inversión extranjera directa: 1) restricciones a la participación extranjera en el capital social; 2) requisitos de selección y aprobación previa; 3) regulaciones para personas claves; y 4) otras restricciones al funcionamiento de empresas extranjeras. El RRI de la IED es un índice compuesto, que varía de 0 a 1, con 1 siendo el valor más restrictivo.

14. Datos de ILOSTAT, datos de 2018 o último año disponible.

15. Datos de la Asociación mundial de estadísticas sobre desechos electrónicos.

16. Cálculos de la OCDE basados en OCDE (2020c), Programa de Evaluación Internacional de Estudiantes (base de datos). Datos de 2015 y 2018.

17. Datos de la OCDE (2019d), Survey of Adult Skills (2018). Los porcentajes para la resolución de problemas en entornos ricos en tecnología se calculan de modo que la suma de los porcentajes de las siguientes categorías mutuamente exhaustivas sea igual al 100\%: se excluyó de la evaluación por computadora; sin experiencia en informática; prueba de núcleo de TIC fallida; por debajo del Nivel 1, en el Nivel 1, en el Nivel 2 y en el Nivel 3.

18. Datos de CAF (2020), The GouTech Index 2020: Unlocking the Potential of GouTech Ecosystems in Latin America, Spain and Portugal. El índice GovTech 2020 mide la madurez del ecosistema GovTech. Se basa en 28 indicadores en 7 dimensiones, que, en conjunto, forman 3 pilares igualmente ponderados: industria de nueva creación, políticas gubernamentales y sistemas de adquisiciones. 
19. El Índice mundial de ciberseguridad mide el compromiso de los países con la ciberseguridad a escala global. Tiene cinco pilares: 1) medidas legales; 2) medidas técnicas; 3) medidas organizativas; 4) desarrollo de capacidades; y 5) cooperación. Va de 0 a 1, siendo 1 el nivel más alto de ciberseguridad.

20. Datos de The Economist Intelligence Unit (2019), EIU Inclusive Internet Index (base de datos). Los indicadores presentan la seguridad percibida del comercio electrónico y la confianza en la privacidad en línea entre las personas seleccionadas al azar en países seleccionados. Varía del $0 \%$ al 100\%, donde el $100 \%$ indica una confianza absoluta en la seguridad del comercio electrónico y la confianza en la privacidad en línea.

\section{Referencias}

Banco Mundial (2020a), DataBank (base de datos), Grupo del Banco Mundial, Washington, DC, https:// databank.worldbank.org/home.aspx (consultada el 11 de diciembre de 2019).

Banco Mundial (2020b), TCdata360 (base de datos), Grupo del Banco Mundial, Washington, DC, https:// tcdata360.worldbank.org/ (consultada el 4 de agosto de 2020).

Base de conocimientos sobre gobierno electrónico de la ONU (2019), Data Center (base de datos), Departamento de Asuntos Económicos y Sociales de las Naciones Unidas, Nueva York, https:// publicadministration.un.org/egovkb/en-us/Data-Center (consultada el 11 de diciembre de 2019).

CAF (2020), The GouTech Index 2020: Unlocking the Potential of GovTech Ecosystems in Latin America, Spain and Portugal, Banco de Desarrollo de America Latina, Caracas.

CEPAL (2018), Observatorio Regional de Planificación para el Desarrollo de América Latina y el Caribe, Comisión Económica para América Latina y el Caribe, Santiago, https://observatorioplanificacion.cepal.org/es.

Dispositivo de estadísticas de la ONU (2018, 2015), ODS globales de la ONU (database), Departamento de Asuntos Económicos y Sociales de las Naciones Unidas, Nueva York, https://unstats.un.org/sdgs/ indicators/database/ (consultada el 20 de mayo de 2020).

Foro Mundial Económico (2016), “The Global Information Technology Report 2016”, Foro Mundial Económico, Ginebra, https://www.weforum.org/reports/the-global-information-technology-report-2016.

Global E-waste Statistic Partnership, página de internet, Global E-waste Statistic Partnership, Bonn, https:// globalewaste.org/ (consultada el 11 de diciembre de 2019).

Latinobarómetro (2019), Libros de Códigos por País/Año (base de datos), Latinobarómetro, Providencia, www. latinobarometro.org/latCodebooks.jsp (consultada el 11 de diciembre de 2019).

OCDE (2020a), OECD.Stat (database), Publicaciones de la OCDE, París, https://stats.oecd.org/ (consultada el 11 de diciembre de 2019).

OCDE (2020b), Panorama de las Administraciones Públicas América Latina y el Caribe 2020, Publicaciones de la OCDE, París, https://doi.org/10.1787/13130fbb-en.

OCDE (2020c), Programme for International Student Assessment (base de datos), Publicaciones de la OCDE, París, www.oecd.org/pisa/data/2018database/ (consultada el 14 de febrero de 2020).

OCDE (2019a), Cómo medir la transformación digital: Hoja de ruta para el futuro, Publicaciones de la OCDE, París, https://doi.org/10.1787/9789264311992-en.

OCDE (2019b), Estudios de la OCDE sobre Transformación Digital: “Going Digital” en Colombia, Publicaciones de la OCDE, París, https://doi.org/10.1787/781185b1-en.

OCDE (2019c), Digital Government Review of Panama: Enhancing the Digital Transformation of the Public Sector, OCDE Estudios de gobierno digital, Publicaciones de la OCDE, París, https://doi.org/10.1787/615a4180-en.

OCDE (2019d), Survey of Adult Skills, Publicaciones de la OCDE, París, https://www.oecd.org/skills/piaac/data/

OIT (2019), ILO Statistics (base de datos), Organización Internacional del Trabajo, Ginebra, www.ilo.org/ global/statistics-and-databases/lang--en/index.htm (consultada el 11 de diciembre de 2019).

Open Knowledge Foundation (2019), Global Open Data Index (base de datos), Open Knowledge Foundation, Cambridge, Reino Unido, https://index.okfn.org/dataset/ (consultada el 19 de abril de 2020).

PIAAC Expert Group in Problem Solving in Technology-Rich Environments (2009), "PIAAC Problem Solving in Technology- Rich Environments: A Conceptual Framework", OCDE Documentos de trabajo educativo, n. ${ }^{\circ}$ 36, Publicaciones de la OCDE, París, https://doi.org/10.1787/220262483674.

The Economist Intelligence Unit (2019), EIU Inclusive Internet Index 2019 (base de datos), The Economist Group, Londres, https://theinclusiveinternet.eiu.com/explore/countries/performance (consultada el $11 \mathrm{de}$ diciembre 2019).

UIT (2020), base de datos de indicadores mundiales de telecomunicaciones / TIC 2020 (base de datos), Unión Internacional de Telecomunicaciones, Ginebra, https://www.itu.int/en/ITU-D/Statistics/Pages/ publications/wtid.aspx (consultada el 21 de agosto de 2020). 
UNCTAD (2020), UNCTADSTAT (base de datos), Conferencia de las Naciones Unidas sobre Comercio y Desarrollo, Ginebra, https://unctadstat.unctad.org/EN/ (consultada el 11 de diciembre de 2019).

UNESCO (2019), Instituto de Estadística de la Unesco (base de datos), Unesco, París, http://data.uis.unesco. org/Index.aspx (consultada el 20 de mayo de 2020).

World Wide Web Foundation (2017), OpenData Barometer (base de datos), World Wide Web Foundation, Ginebra, https://opendatabarometer.org/ (consultada el 19 de abril de 2020). 



\section{ECUADOR}

\section{Tendencias recientes}

En la última década, Ecuador se ha esforzado para mejorar el acceso digital de todos sus ciudadanos. Ha aumentado el número de usuarios de Internet y de suscripciones a servicios de banda ancha móvil activa y fija. En particular, las suscripciones de banda ancha móvil activa (por cada 100 personas) aumentaron de 8.8 en 2008 a 54.7 en 2018, pero se mantuvo por debajo del promedio de América Latina y el Caribe (ALC) (73.5) y el promedio de la Organización para la Cooperación y el Desarrollo Económicos (OCDE) (103.6). La percepción de seguridad en el comercio electrónico y la confianza en la privacidad en línea están por encima de los promedios de ALC y OCDE.

El desempeño de Ecuador en términos de facilitar la innovación digital ha conseguido resultados desiguales en la última década. Las exportaciones de alta tecnología en proporción al total de las exportaciones de productos manufacturados aumentaron del 5.0\% en 2008 al 5.3\% en 2018, pero se mantienen por debajo de los promedios de ALC (8.6\%) y de la OCDE (15.1\%). Se requieren mayores esfuerzos para la transformación digital del Gobierno. Ecuador se encuentra entre los países con resultados más bajos de ALC en materia de políticas de datos abiertos de organismos públicos en el índice OURdata de la OCDE. El país también se ubica por debajo de los promedios de ALC y la OCDE en el Índice de desarrollo del gobierno electrónico (EGDI).

\section{Estrategias nacionales y cooperación internacional para la transformación digital}

El Plan Nacional de Desarrollo (PND), Toda una Vida 2017-2021 y la política Ecuador Digital son los principales referentes en materia de desarrollo y transformación digital del país. El PND se centra en tres objetivos principales: derechos universales, economía al servicio de la sociedad y mejora de las instituciones. La política Ecuador Digital se basa en tres ejes: conectividad, eficiencia y seguridad de la información e innovación y competitividad. El primer eje tiene como objetivo ampliar la cobertura de los servicios de telecomunicaciones y migrar hacia redes de mayor velocidad. El segundo aspira a asegurar la participación ciudadana, servicios públicos democráticos, simplificación de los trámites, una gestión pública eficiente, acceso y uso de datos abiertos e información y seguridad de los datos. El tercero pretende convertir a Ecuador en un modelo de innovación y competitividad en la región mediante el desarrollo de ciudades inteligentes, la transformación digital de las empresas y la creación de una Estrategia Nacional de Comercio Electrónico.

El Ministerio de Telecomunicaciones y de la Sociedad de la Información está desarrollando proyectos estratégicos en relación con estos tres ejes. La reducción de los costos de acceso a Internet aumentará la cobertura de las telecomunicaciones y beneficiará a los hogares más desfavorecidos con tarifas preferenciales. La huella digital social mejorará los servicios públicos al proporcionar información de las instituciones públicas a través de una plataforma digital integrada. Ecuador también está trabajando en una Estrategia Nacional de Ciberseguridad. Por último, un proyecto que incluirá las TIC en los currículos educativos ayudará a desarrollar el pensamiento computacional y las competencias digitales necesarias para alcanzar la innovación y competitividad. Para mitigar el impacto económico del coronavirus (Covid-19), el Gobierno acordó con el sector de las telecomunicaciones aumentar los datos proporcionados a los usuarios de servicios móviles y ampliar el ancho de banda de las líneas fijas sin costo adicional, a fin de satisfacer la creciente demanda en las redes. El Ministerio de Telecomunicaciones también creó un número de teléfono para proporcionar información actualizada sobre la pandemia, incluidos los lugares en los que se realizaban pruebas e información de telemedicina (CAF, 2020).

En cuanto a la cooperación internacional, Ecuador recibió apoyo técnico bilateral de Brasil para la implantación de la televisión digital terrestre, siguiendo el modelo japonés-brasileño. En el marco de un proyecto de cooperación triangular, Ecuador y Alemania compartieron sus experiencias en materia de gobierno electrónico con El Salvador. Asimismo, Ecuador participó en el proyecto MAGIC (2015-2017), respaldado por la Unión Europea, para racionalizar la colaboración científica y académica internacional. Entre sus principales logros figuran los programas para impulsar el intercambio de conocimientos, la capacitación y el acceso a las infraestructuras electrónicas. El país también forma parte de la Ciberresiliencia para el Desarrollo, un proyecto de la Unión Europea diseñado para promover la ciberresiliencia y la seguridad digital con el fin de proteger al público y a las empresas privadas en todo el mundo. 


\section{Mejorar el acceso}

Suscripciones de banda ancha fija (por cada 100 habitantes) ${ }^{4}$

Suscripciones de banda ancha móvil activa (por cada 100 habitantes) ${ }^{4}$

Proporción de población cubierta por al menos una red 3G5

Velocidad de banda ancha fija (en Mbit/s) ${ }^{4}$

Aumentar el uso efectivo

Índice de desarrollo del gobierno electrónico (EGDI) ${ }^{6}$

Proporción de usuarios de Internet (\% de población) ${ }^{4}$

Índice de comercio electrónico B2C de la UNCTAD

Proporción de personas que realizan compras por Internet ${ }^{8}$

\section{Impulsar la innovación}

Exportaciones de alta tecnología (\% de exportaciones manufacturadas) ${ }^{9}$

Proporción de importaciones de servicios de TIC, como porcentaje del comercio total de servicios ${ }^{7}$

Solicitudes de patentes de TIC presentadas en virtud del Tratado de Cooperación en materia de Patentes (por millón de personas) ${ }^{10}$

Gastos en I+D, como \% del PIB ${ }^{11}$

Índice OURdata de la OCDE'12

\section{Asegurar empleos adecuados para todos}

Contribuciones a variación en empleo total, por intensidad digital de sectores, 2006-2016 ${ }^{13}$

Proporción de empleo informal en relación con empleo total ${ }^{14}$

Tasa bruta de matrícula, educación terciaria $(\%)^{9}$

Graduados de educación terciaria por campo (\%) - Educación ${ }^{11}$

Graduados de educación terciaria por campo (\%) - Salud ${ }^{11}$

Graduados de educación terciaria por campo (\%) - Ingeniería ${ }^{11}$

Promocionar la prosperidad social

Generación de desechos de aparatos eléctricos per cápita $(\mathrm{kg})^{15}$

Número de estudiantes por computadora ${ }^{16}$

Proporción de mujeres con puntuación de nivel 203 en resolución de problemas en entornos tecnológicos ${ }^{17}$

\section{Reforzar la confianza}

Índice GovTech de la CAF ${ }^{18}$

Índice de ciberseguridad global (UIT) ${ }^{19}$

Seguridad del comercio electrónico $(\%)^{20}$

Confianza en la privacidad en Internet $(\%)^{20}$

\section{Promocionar la apertura de mercados}

Índice de restrictividad de intercambios de servicios digitales de la OCDE ${ }^{13}$

Índice de restricción regulatoria de la IED de la $0 C D E^{13}$

Las fuentes, notas a pie de página y detalles técnicos se pueden encontrar al final de las Notas País.

\begin{tabular}{cccccc}
\multicolumn{4}{c}{ Indicadores digitales - Ecuador ${ }^{1}$} \\
\hline \multicolumn{2}{c}{ Ecuador } & \multicolumn{2}{c}{ ALC $^{2}$} & \multicolumn{2}{c}{ OCDE $^{3}$} \\
\hline $\mathbf{2 0 0 8}$ & $\mathbf{2 0 1 8}$ & $\mathbf{2 0 0 8}$ & $\mathbf{2 0 1 8}$ & $\mathbf{2 0 0 8}$ & $\mathbf{2 0 1 8}$ \\
\hline 1.1 & 11.4 & 4.1 & 13.9 & 22.7 & 32.9 \\
$\mathbf{2 0 1 0}$ & $\mathbf{2 0 1 8}$ & $\mathbf{2 0 1 0}$ & $\mathbf{2 0 1 8}$ & $\mathbf{2 0 1 0}$ & $\mathbf{2 0 1 8}$ \\
\hline 8.8 & 54.7 & 5.4 & 73.5 & 37.7 & 103.6 \\
$\mathbf{2 0 1 5}$ & $\mathbf{2 0 1 8}$ & $\mathbf{2 0 1 5}$ & $\mathbf{2 0 1 8}$ & $\mathbf{2 0 1 5}$ & $\mathbf{2 0 1 8}$ \\
\hline 91.9 & 93.0 & 86.1 & 94.6 & 98.2 & 98.8 \\
$\mathbf{2 0 0 8}$ & $\mathbf{2 0 1 7}$ & $\mathbf{2 0 0 8}$ & $\mathbf{2 0 1 7}$ & $\mathbf{2 0 0 8}$ & $\mathbf{2 0 0 7}$ \\
\hline 0.26 & 5.0 & 0.58 & 5.1 & 2.2 & 27.7
\end{tabular}

\begin{tabular}{cccccc}
\multicolumn{2}{c}{ Ecuador } & \multicolumn{2}{c}{ ALC } & \multicolumn{2}{c}{ OCDE } \\
\hline $\mathbf{2 0 0 8}$ & $\mathbf{2 0 1 8}$ & $\mathbf{2 0 0 8}$ & $\mathbf{2 0 1 8}$ & $\mathbf{2 0 0 8}$ & $\mathbf{2 0 1 8}$ \\
\hline 0.48 & 0.61 & 0.52 & 0.65 & 0.72 & 0.82 \\
$\mathbf{2 0 0 8}$ & $\mathbf{2 0 1 7}$ & $\mathbf{2 0 0 8}$ & $\mathbf{2 0 1 7}$ & $\mathbf{2 0 0 8}$ & $\mathbf{2 0 1 7}$ \\
\hline 18.8 & 57.3 & 25.3 & 62.9 & 65.0 & 83.4 \\
2015 & 2019 & $\mathbf{2 0 1 5}$ & $\mathbf{2 0 1 9}$ & $\mathbf{2 0 1 5}$ & $\mathbf{2 0 1 9}$ \\
\hline 45.0 & 39.9 & 46.4 & 51.5 & 73.9 & 85.0 \\
\hline \multicolumn{2}{c}{2017} & \multicolumn{2}{c}{$\mathbf{2 0 1 7}$} & \multicolumn{2}{c}{$\mathbf{2 0 1 7}$} \\
\hline \multicolumn{2}{c}{14.8} & \multicolumn{3}{c}{ N/A }
\end{tabular}

\begin{tabular}{cccccc}
\multicolumn{2}{c}{ Ecuador } & \multicolumn{2}{c}{ ALC } & \multicolumn{2}{c}{ OCDE } \\
\hline $\mathbf{2 0 0 8}$ & $\mathbf{2 0 1 8}$ & $\mathbf{2 0 0 8}$ & $\mathbf{2 0 1 8}$ & $\mathbf{2 0 0 8}$ & $\mathbf{2 0 1 8}$ \\
\hline 5.0 & 5.3 & 9.3 & 8.6 & 15.6 & 15.1 \\
0.93 & 0.25 & 3.1 & 3.9 & 4.6 & 6.7 \\
$\mathbf{2 0 1 2}$ & $\mathbf{2 0 1 6}$ & $\mathbf{2 0 1 2}$ & $\mathbf{2 0 1 6}$ & $\mathbf{2 0 1 2}$ & $\mathbf{2 0 1 6}$ \\
\hline 0.01 & 0.07 & 0.14 & 0.34 & 30.9 & 38.2 \\
$\mathbf{2 0 0 6}$ & $\mathbf{2 0 1 4}$ & $\mathbf{2 0 0 6}$ & $\mathbf{2 0 1 4}$ & $\mathbf{2 0 0 6}$ & $\mathbf{2 0 1 4}$ \\
\hline 0.13 & 0.44 & 0.35 & 0.40 & 1.7 & 1.9 \\
\hline \multicolumn{2}{c}{$\mathbf{2 0 1 9}$} & \multicolumn{2}{c}{$\mathbf{2 0 1 9}$} & \multicolumn{2}{c}{$\mathbf{2 0 1 9}$} \\
\hline 0.29 & \multicolumn{2}{c}{0.43} & \multicolumn{2}{c}{0.61}
\end{tabular}

\begin{tabular}{|c|c|c|c|c|c|}
\hline \multicolumn{2}{|c|}{ Ecuador } & \multicolumn{2}{|c|}{ ALC } & \multicolumn{2}{|c|}{ OCDE } \\
\hline \multicolumn{2}{|c|}{ 2006-15 } & \multicolumn{2}{|c|}{$2006-15$} & \multicolumn{2}{|c|}{$2006-15$} \\
\hline \multicolumn{2}{|c|}{ N/A } & \multicolumn{2}{|c|}{6.9} & \multicolumn{2}{|c|}{4.8} \\
\hline \multicolumn{2}{|c|}{2018} & \multicolumn{2}{|c|}{2018} & \multicolumn{2}{|c|}{2018} \\
\hline \multicolumn{2}{|c|}{72.7} & \multicolumn{2}{|c|}{54.9} & \multicolumn{2}{|c|}{$N / A$} \\
\hline 2008 & 2015 & 2008 & 2015 & 2008 & 2015 \\
\hline 38.8 & 44.9 & 41.5 & 51.0 & 64.4 & 70.1 \\
\hline \multicolumn{2}{|c|}{2016} & \multicolumn{2}{|c|}{2016} & \multicolumn{2}{|c|}{2016} \\
\hline \multicolumn{2}{|c|}{18.8} & \multicolumn{2}{|c|}{16.0} & \multicolumn{2}{|c|}{9.8} \\
\hline \multicolumn{2}{|c|}{12.7} & \multicolumn{2}{|c|}{13.8} & \multicolumn{2}{|c|}{14.5} \\
\hline \multicolumn{2}{|c|}{9.0} & \multicolumn{2}{|c|}{12.5} & \multicolumn{2}{|c|}{14.6} \\
\hline
\end{tabular}

\begin{tabular}{cccccc}
\multicolumn{2}{c}{ Ecuador } & \multicolumn{2}{c}{ ALC } & \multicolumn{2}{c}{ OCDE } \\
\hline $\mathbf{2 0 1 5}$ & $\mathbf{2 0 1 6}$ & $\mathbf{2 0 1 5}$ & $\mathbf{2 0 1 6}$ & $\mathbf{2 0 1 5}$ & $\mathbf{2 0 1 6}$ \\
\hline 5.4 & 5.5 & 6.9 & 7.2 & 17.7 & 17.7 \\
$\mathbf{2 0 1 5}$ & $\mathbf{2 0 1 8}$ & $\mathbf{2 0 1 5}$ & $\mathbf{2 0 1 8}$ & $\mathbf{2 0 1 5}$ & $\mathbf{2 0 1 8}$ \\
\hline N/A & N/A & 2.4 & 1.6 & 1.8 & 1.1 \\
\multicolumn{2}{c}{$\mathbf{2 0 1 8}$} & \multicolumn{2}{c}{$\mathbf{2 0 1 8}$} & \multicolumn{2}{c}{$\mathbf{2 0 1 8}$} \\
\hline \multicolumn{2}{c}{4.4} & \multicolumn{2}{c}{7.7} & \multicolumn{2}{c}{27.7}
\end{tabular}

\begin{tabular}{cccccc}
\multicolumn{2}{c}{ Ecuador } & \multicolumn{2}{c}{ ALC } & \multicolumn{2}{c}{ OCDE } \\
\hline \multicolumn{2}{c}{$\mathbf{2 0 2 0}$} & \multicolumn{2}{c}{$\mathbf{2 0 2 0}$} & \multicolumn{2}{c}{$\mathbf{2 0 2 0}$} \\
\hline \multicolumn{2}{c}{3.6} & \multicolumn{2}{c}{4.4} & \multicolumn{2}{c}{ N/A } \\
\hline $\mathbf{2 0 1 6}$ & $\mathbf{2 0 1 8}$ & $\mathbf{2 0 1 6}$ & $\mathbf{2 0 1 8}$ & $\mathbf{2 0 1 6}$ & $\mathbf{2 0 1 8}$ \\
\hline 0.35 & 0.37 & 0.36 & 0.43 & 0.56 & 0.79 \\
\hline $\mathbf{2 0 1 8}$ & $\mathbf{2 0 1 9}$ & $\mathbf{2 0 1 8}$ & $\mathbf{2 0 1 9}$ & $\mathbf{2 0 1 8}$ & $\mathbf{2 0 1 9}$ \\
\hline N/A & 63.8 & 72.0 & 63.1 & 61.7 & 58.3 \\
N/A & 66.7 & 52.8 & 54.9 & 41.7 & 45.6
\end{tabular}

\begin{tabular}{cccccc}
\multicolumn{2}{c}{ Ecuador } & \multicolumn{2}{c}{ ALC } & \multicolumn{2}{c}{ OCDE } \\
\hline 2015 & 2019 & 2015 & 2019 & 2015 & $\mathbf{2 0 1 9}$ \\
\hline N/A & N/A & 0.24 & 0.24 & 0.13 & 0.15 \\
2018 & 2018 & \multicolumn{2}{c}{$\mathbf{2 0 1 8}$} \\
\hline N/A & \multicolumn{2}{c}{0.07} & \multicolumn{2}{c}{0.06} \\
\hline
\end{tabular}




\section{Notas técnicas}

1. La Tabla sigue lo mejor posible las siete áreas claves identificadas en el proyecto Going Digital de la OCDE: 1) mejorar el acceso a las tecnologías digitales; 2) aumentar el uso efectivo; 3) permitir la innovación digital; 4) asegurar empleos adecuados para todos; 5) promocionar la prosperidad social; 6) reforzar la confianza; y 7) promocionar la apertura de mercados (OCDE, 2019a). Los indicadores se eligen según la disponibilidad de datos para los países de ALC. Existe la posibilidad de un sesgo por la forma en que se han agregado los componentes en los indicadores de índice.

2. El promedio de ALC es un promedio simple. La composición de los países depende de la disponibilidad de datos de los países de la región. Cada promedio incluye tantos países de ALC encontrados en cada fuente como sea posible.

3. El promedio de la OCDE es un promedio simple que incluye a todos los países miembros de la OCDE en mayo de 2020.

4. Datos de la UIT (2020), Base de datos de indicadores mundiales de telecomunicaciones / TIC 2020 (base de datos). La velocidad de banda ancha fija en Mbit/s se refiere a la velocidad de descarga teórica máxima anunciada garantizada a los usuarios asociados con una suscripción mensual de Internet de banda ancha fija.

5. Datos de la División de Estadística de las Naciones Unidas, Base de datos mundial de los ODS de las Naciones Unidas (base de datos). Datos de 2015 y 2018 o los últimos disponibles.

6. Datos de la base de conocimientos sobre gobierno electrónico de las Naciones Unidas (2019), centro de datos (base de datos). El índice de desarrollo del gobierno electrónico (E-government development index) es un indicador compuesto que consta de tres índices (índice de servicios en línea, índice de infraestructura de telecomunicaciones e índice de capital humano), que están igualmente ponderados. Tiene un rango de 0 a 1, con 1 siendo un gobierno más desarrollado.

7. Datos de UNCTAD (2020), UNCTADSTAT (base de datos). El índice de comercio electrónico B2C de la UNCTAD mide la preparación de una economía para respaldar las compras en línea. Rango de 0 a 100, con 100 siendo el nivel de apoyo más alto.

8. Cálculos propios a partir de datos de Latinobarómetro (2019), Libros de Códigos por País / Año (base de datos). Datos de 2017. Datos de encuestas de opinión pública utilizando muestras representativas a nivel nacional seleccionadas al azar.

9. Datos del Banco Mundial (2020a), Banco de datos del Banco Mundial (base de datos).

10. Datos del Banco Mundial (2020b), TCdata360. Datos de 2012 y 2016 o los últimos disponibles.

11. Datos de Unesco (2019), Instituto de Estadística de la Unesco (base de datos). Gastos en I+D, como porcentaje de los datos del PIB de 2006 y 2016 o el último disponible.

12. Datos de OCDE (2020a), OECD.Stat (base de datos) y OCDE (2020b). El índice OURdata de la OCDE evalúa los esfuerzos de los gobiernos para implementar datos abiertos en tres áreas críticas: apertura, utilidad y reutilización de los datos gubernamentales. Tiene un rango de 0 a 1, con 1 siendo la puntuación más alta.

13. Datos de OCDE (2020a), OECD.Stat (base de datos). El Índice de restricción del comercio de servicios digitales de la OCDE identifica, cataloga y cuantifica las barreras que afectan el comercio de servicios habilitados digitalmente en 46 países. Tiene un rango de 0 a 1, con 1 siendo el valor más restrictivo. El Índice de Restricción Reglamentaria de la Inversión Extranjera Directa (IED RRI) mide cuatro tipos de restricciones legales a la inversión extranjera directa: 1) restricciones a la participación extranjera en el capital social; 2) requisitos de selección y aprobación previa; 3) regulaciones para personas claves; y 4) otras restricciones al funcionamiento de empresas extranjeras. El RRI de la IED es un índice compuesto, que varía de 0 a 1, con 1 siendo el valor más restrictivo.

14. Datos de ILOSTAT, datos de 2018 o último año disponible.

15. Datos de la Asociación mundial de estadísticas sobre desechos electrónicos.

16. Cálculos de la OCDE basados en OCDE (2020c), Programa de Evaluación Internacional de Estudiantes (base de datos). Datos de 2015 y 2018.

17. Datos de la OCDE (2019d), Survey of Adult Skills (2018). Los porcentajes para la resolución de problemas en entornos ricos en tecnología se calculan de modo que la suma de los porcentajes de las siguientes categorías mutuamente exhaustivas sea igual al 100\%: se excluyó de la evaluación por computadora; sin experiencia en informática; prueba de núcleo de TIC fallida; por debajo del Nivel 1, en el Nivel 1, en el Nivel 2 y en el Nivel 3.

18. Datos de CAF (2020), The GouTech Index 2020: Unlocking the Potential of GouTech Ecosystems in Latin America, Spain and Portugal. El índice GovTech 2020 mide la madurez del ecosistema GovTech. Se basa en 28 indicadores en 7 dimensiones, que, en conjunto, forman 3 pilares igualmente ponderados: industria de nueva creación, políticas gubernamentales y sistemas de adquisiciones. 
19. El Índice mundial de ciberseguridad mide el compromiso de los países con la ciberseguridad a escala global. Tiene cinco pilares: 1) medidas legales; 2) medidas técnicas; 3) medidas organizativas; 4) desarrollo de capacidades; y 5) cooperación. Va de 0 a 1, siendo 1 el nivel más alto de ciberseguridad.

20. Datos de The Economist Intelligence Unit (2019), EIU Inclusive Internet Index (base de datos). Los indicadores presentan la seguridad percibida del comercio electrónico y la confianza en la privacidad en línea entre las personas seleccionadas al azar en países seleccionados. Varía del $0 \%$ al 100\%, donde el $100 \%$ indica una confianza absoluta en la seguridad del comercio electrónico y la confianza en la privacidad en línea.

\section{Referencias}

Banco Mundial (2020a), DataBank (base de datos), Grupo del Banco Mundial, Washington, DC, https:// databank.worldbank.org/home.aspx (consultada el 11 de diciembre de 2019).

Banco Mundial (2020b), TCdata360 (base de datos), Grupo del Banco Mundial, Washington, DC, https:// tcdata360.worldbank.org/ (consultada el 4 de agosto de 2020).

Base de conocimientos sobre gobierno electrónico de la ONU (2019), Data Center (base de datos), Departamento de Asuntos Económicos y Sociales de las Naciones Unidas, Nueva York, https:// publicadministration.un.org/egovkb/en-us/Data-Center (consultada el 11 de diciembre de 2019).

CAF (2020), The GouTech Index 2020: Unlocking the Potential of GovTech Ecosystems in Latin America, Spain and Portugal, Banco de Desarrollo de America Latina, Caracas.

CEPAL (2018), Observatorio Regional de Planificación para el Desarrollo de América Latina y el Caribe, Comisión Económica para América Latina y el Caribe, Santiago, https://observatorioplanificacion.cepal.org/es.

Dispositivo de estadísticas de la ONU (2018, 2015), ODS globales de la ONU (database), Departamento de Asuntos Económicos y Sociales de las Naciones Unidas, Nueva York, https://unstats.un.org/sdgs/ indicators/database/ (consultada el 20 de mayo de 2020).

Foro Mundial Económico (2016), “The Global Information Technology Report 2016”, Foro Mundial Económico, Ginebra, https://www.weforum.org/reports/the-global-information-technology-report-2016.

Global E-waste Statistic Partnership, página de internet, Global E-waste Statistic Partnership, Bonn, https:// globalewaste.org/ (consultada el 11 de diciembre de 2019).

Latinobarómetro (2019), Libros de Códigos por País/Año (base de datos), Latinobarómetro, Providencia, www. latinobarometro.org/latCodebooks.jsp (consultada el 11 de diciembre de 2019).

OCDE (2020a), OECD.Stat (database), Publicaciones de la OCDE, París, https://stats.oecd.org/ (consultada el 11 de diciembre de 2019).

OCDE (2020b), Panorama de las Administraciones Públicas América Latina y el Caribe 2020, Publicaciones de la OCDE, París, https://doi.org/10.1787/13130fbb-en.

OCDE (2020c), Programme for International Student Assessment (base de datos), Publicaciones de la OCDE, París, www.oecd.org/pisa/data/2018database/ (consultada el 14 de febrero de 2020).

OCDE (2019a), Cómo medir la transformación digital: Hoja de ruta para el futuro, Publicaciones de la OCDE, París, https://doi.org/10.1787/9789264311992-en.

OCDE (2019b), Estudios de la OCDE sobre Transformación Digital: “Going Digital” en Colombia, Publicaciones de la OCDE, París, https://doi.org/10.1787/781185b1-en.

OCDE (2019c), Digital Government Review of Panama: Enhancing the Digital Transformation of the Public Sector, OCDE Estudios de gobierno digital, Publicaciones de la OCDE, París, https://doi.org/10.1787/615a4180-en.

OCDE (2019d), Survey of Adult Skills, Publicaciones de la OCDE, París, https://www.oecd.org/skills/piaac/data/

OIT (2019), ILO Statistics (base de datos), Organización Internacional del Trabajo, Ginebra, www.ilo.org/ global/statistics-and-databases/lang--en/index.htm (consultada el 11 de diciembre de 2019).

Open Knowledge Foundation (2019), Global Open Data Index (base de datos), Open Knowledge Foundation, Cambridge, Reino Unido, https://index.okfn.org/dataset/ (consultada el 19 de abril de 2020).

PIAAC Expert Group in Problem Solving in Technology-Rich Environments (2009), "PIAAC Problem Solving in Technology- Rich Environments: A Conceptual Framework", OCDE Documentos de trabajo educativo, n. ${ }^{\circ}$ 36, Publicaciones de la OCDE, París, https://doi.org/10.1787/220262483674.

The Economist Intelligence Unit (2019), EIU Inclusive Internet Index 2019 (base de datos), The Economist Group, Londres, https://theinclusiveinternet.eiu.com/explore/countries/performance (consultada el $11 \mathrm{de}$ diciembre 2019).

UIT (2020), base de datos de indicadores mundiales de telecomunicaciones / TIC 2020 (base de datos), Unión Internacional de Telecomunicaciones, Ginebra, https://www.itu.int/en/ITU-D/Statistics/Pages/ publications/wtid.aspx (consultada el 21 de agosto de 2020). 
UNCTAD (2020), UNCTADSTAT (base de datos), Conferencia de las Naciones Unidas sobre Comercio y Desarrollo, Ginebra, https://unctadstat.unctad.org/EN/ (consultada el 11 de diciembre de 2019).

UNESCO (2019), Instituto de Estadística de la Unesco (base de datos), Unesco, París, http://data.uis.unesco. org/Index.aspx (consultada el 20 de mayo de 2020).

World Wide Web Foundation (2017), OpenData Barometer (base de datos), World Wide Web Foundation, Ginebra, https://opendatabarometer.org/ (consultada el 19 de abril de 2020). 



\section{EL SALVADOR}

\section{Tendencias recientes}

El Salvador sigue avanzando en la mejora del acceso digital de todos sus ciudadanos, aunque sigue existiendo una brecha digital considerable. A pesar del progreso en los últimos años, las suscripciones a servicios de banda ancha móvil activa en 2018 fueron inferiores a los promedios de América Latina y el Caribe (ALC) y de la Organización para la Cooperación y el Desarrollo Económicos (OCDE), los usuarios de Internet representaron el $33.8 \%$ de la población, en comparación con el 62.9\% en ALC y el 83.4\% en la OCDE en 2017. Se requiere avanzar en la mejora de la confianza en el ecosistema digital. En particular, la confianza en la privacidad en línea y el Índice de ciberseguridad global están por debajo de los promedios de ALC y OCDE.

El desempeño de El Salvador en términos de facilitar la innovación digital sigue siendo moderado. A pesar del aumento del gasto en investigación y desarrollo entre 2007 y 2016, las solicitudes de patentes presentadas en virtud del PCT (tratado de cooperación en materia de patentes) siguen siendo bajas.

\section{Estrategias nacionales y cooperación internacional para la transformación digital}

La Agenda Digital 2020-2030 es el principal documento de referencia para el desarrollo y la transformación digital de El Salvador. La agenda detalla una serie de acciones para integrar a todos los actores que participan en el desarrollo del país a través de la innovación y la aplicación de las TIC. Establece un plan de diez años de duración para potenciar la transformación digital. Sus cuatro ejes de trabajo son: la identidad digital, la gobernanza digital, la modernización del Estado y la innovación, educación y competitividad. La agenda digital está armonizada con los Objetivos de Desarrollo Sostenible de Naciones Unidas y con ocho proyectos estratégicos nacionales.

La Secretaría de Innovación de la Presidencia de la República gestiona, supervisa y evalúa los avances en la implantación de la agenda digital. Entre otras responsabilidades, esta secretaría de reciente creación es responsable de desarrollar e implementar servicios de identidad digital y firma electrónica que se basan en el Número Único de Identidad. Para ello, se están normalizando los sistemas de registro de información mediante la adopción de un sistema informático único en el registro de actas de estado civil y familiares.

Otros proyectos previstos son la adopción de sistemas interoperables para facilitar el intercambio de información digital en las administraciones públicas, la integración de las tecnologías digitales en los currículos educativos a todos los niveles y la creación de un marco regulatorio en el ámbito Fintech. La Política Nacional de Datos Abiertos, introducida en 2018, y el portal de datos abiertos Datos.gob.sv forman parte de una iniciativa pública para promover la transparencia y combatir la corrupción. Para mitigar el impacto económico del coronavirus (Covid-19), el Gobierno aprobó medidas para suspender el cobro de los servicios de telecomunicaciones durante tres meses. Se presentó a la Asamblea Legislativa una iniciativa para implementar un instrumento de telemedicina que permita a los pacientes consultar al médico desde casa (CAF, 2020).

En materia de cooperación internacional, El Salvador recibe asistencia técnica experta en temas digitales de la Agencia Uruguaya de Gobierno Electrónico y Sociedad de la Información. Los proyectos tienen por objeto capacitar a los funcionarios públicos, promoviendo la transformación digital de las instituciones gubernamentales. El país también participa en el Proyecto Mesoamérica y su Agenda Digital, que buscan promover el desarrollo de las infraestructuras de las TIC y las políticas públicas para la integración de los servicios TIC.

El Salvador celebró en octubre de 2017 la VII Reunión de Altos Funcionarios en Ciencia y Tecnología de la Iniciativa Conjunta de Investigación e Innovación entre la Unión Europea (UE) y la Comunidad de Estados Latinoamericanos y Caribeños (CELAC). Los países destacaron la pertinencia estratégica de la investigación e innovación de cara a aplicar la Agenda 2030 para el Desarrollo Sostenible de las Naciones Unidas y reconocieron las aportaciones de los proyectos y programas birregionales en materia de política estratégica. 


\section{Mejorar el acceso}

Suscripciones de banda ancha fija (por cada 100 habitantes) ${ }^{4}$

Suscripciones de banda ancha móvil activa (por cada 100 habitantes) ${ }^{4}$

Proporción de población cubierta por al menos una red $3 \mathrm{G}^{5}$

Velocidad de banda ancha fija (en Mbit/s) ${ }^{4}$

\section{Aumentar el uso efectivo}

Índice de desarrollo del gobierno electrónico (EGDI) ${ }^{6}$

Proporción de usuarios de Internet (\% de población) ${ }^{4}$

Índice de comercio electrónico B2C de la UNCTAD

Proporción de personas que realizan compras por Internet ${ }^{8}$

\section{Impulsar la innovación}

Exportaciones de alta tecnología (\% de exportaciones manufacturadas) ${ }^{9}$

Proporción de importaciones de servicios de TIC, como porcentaje del comercio total de servicios ${ }^{7}$

Solicitudes de patentes de TIC presentadas en virtud del Tratado de Cooperación en materia de Patentes (por millón de personas) ${ }^{10}$

Gastos en I+D, como \% del PIB ${ }^{11}$

Índice OURdata de la OCDE ${ }^{12}$

\section{Asegurar empleos adecuados para todos}

Contribuciones a variación en empleo total, por intensidad digital de sectores, 2006-2016 ${ }^{13}$

Proporción de empleo informal en relación con empleo total ${ }^{14}$

Tasa bruta de matrícula, educación terciaria $(\%)^{9}$

Graduados de educación terciaria por campo (\%) - Educación ${ }^{11}$

Graduados de educación terciaria por campo (\%) - Salud ${ }^{11}$

Graduados de educación terciaria por campo (\%) - Ingeniería ${ }^{11}$

Promocionar la prosperidad social

Generación de desechos de aparatos eléctricos per cápita $(\mathrm{kg})^{15}$

Número de estudiantes por computadora ${ }^{16}$

Proporción de mujeres con puntuación de nivel 203 en resolución de problemas en entornos tecnológicos ${ }^{17}$

\section{Reforzar la confianza}

Índice GovTech de la CAF ${ }^{18}$

Índice de ciberseguridad global (UIT) ${ }^{19}$

Seguridad del comercio electrónico $(\%)^{20}$

Confianza en la privacidad en Internet $(\%)^{20}$

\section{Promocionar la apertura de mercados}

Índice de restrictividad de intercambios de servicios digitales de la OCDE ${ }^{13}$

Índice de restricción regulatoria de la IED de la OCDE ${ }^{13}$

Las fuentes, notas a pie de página y detalles técnicos se pueden encontrar al final de las Notas País.

\begin{tabular}{cccccc}
\multicolumn{3}{c}{ Indicadores digitales - El Salvador } \\
\hline \multicolumn{2}{c}{ El Salvador } & \multicolumn{2}{c}{ ALC $^{2}$} & \multicolumn{2}{c}{ OCDE $^{3}$} \\
\hline $\mathbf{2 0 0 8}$ & $\mathbf{2 0 1 8}$ & $\mathbf{2 0 0 8}$ & $\mathbf{2 0 1 8}$ & $\mathbf{2 0 0 8}$ & $\mathbf{2 0 1 8}$ \\
\hline 2.0 & 7.7 & 4.1 & 13.9 & 22.7 & 32.9 \\
$\mathbf{2 0 0 9}$ & $\mathbf{2 0 1 8}$ & $\mathbf{2 0 0 9}$ & $\mathbf{2 0 1 8}$ & $\mathbf{2 0 0 9}$ & $\mathbf{2 0 1 8}$ \\
\hline 1.8 & 54.5 & 1.8 & 73.5 & 29.8 & 103.6 \\
$\mathbf{2 0 1 5}$ & $\mathbf{2 0 1 8}$ & $\mathbf{2 0 1 5}$ & $\mathbf{2 0 1 8}$ & $\mathbf{2 0 1 5}$ & $\mathbf{2 0 1 8}$ \\
\hline 61.3 & 86.0 & 86.1 & 94.6 & 98.2 & 98.8 \\
$\mathbf{2 0 0 8}$ & $\mathbf{2 0 1 7}$ & $\mathbf{2 0 0 8}$ & $\mathbf{2 0 1 7}$ & $\mathbf{2 0 0 8}$ & $\mathbf{2 0 0 7}$ \\
\hline 0.26 & 3.0 & 0.58 & 5.1 & 2.2 & 27.7
\end{tabular}

\begin{tabular}{cccccc}
\multicolumn{2}{c}{ El Salvador } & \multicolumn{2}{c}{ ALC } & \multicolumn{2}{c}{ OCDE } \\
\hline $\mathbf{2 0 0 8}$ & $\mathbf{2 0 1 8}$ & $\mathbf{2 0 0 8}$ & $\mathbf{2 0 1 8}$ & $\mathbf{2 0 0 8}$ & $\mathbf{2 0 1 8}$ \\
\hline 0.50 & 0.55 & 0.52 & 0.65 & 0.72 & 0.82 \\
$\mathbf{2 0 0 8}$ & $\mathbf{2 0 1 7}$ & $\mathbf{2 0 0 8}$ & $\mathbf{2 0 1 7}$ & $\mathbf{2 0 0 8}$ & $\mathbf{2 0 1 7}$ \\
\hline 10.1 & 33.8 & 25.3 & 62.9 & 65.0 & 83.4 \\
$\mathbf{2 0 1 5}$ & $\mathbf{2 0 1 9}$ & $\mathbf{2 0 1 5}$ & $\mathbf{2 0 1 9}$ & $\mathbf{2 0 1 5}$ & $\mathbf{2 0 1 9}$ \\
\hline 31.7 & 37.2 & 46.4 & 51.5 & 73.9 & 85.0 \\
\hline \multicolumn{2}{c}{$\mathbf{2 0 1 7}$} & \multicolumn{2}{c}{$\mathbf{2 0 1 7}$} & \multicolumn{2}{c}{$\mathbf{2 0 1 7}$} \\
\hline \multicolumn{2}{c}{14.0} & \multicolumn{3}{c}{ N/A }
\end{tabular}

\begin{tabular}{cccccc}
\multicolumn{2}{c}{ El Salvador } & \multicolumn{2}{c}{ ALC } & \multicolumn{2}{c}{ OCDE } \\
\hline $\mathbf{2 0 0 8}$ & $\mathbf{2 0 1 8}$ & $\mathbf{2 0 0 8}$ & $\mathbf{2 0 1 8}$ & $\mathbf{2 0 0 8}$ & $\mathbf{2 0 1 8}$ \\
\hline 5.9 & 6.1 & 9.3 & 8.6 & 15.6 & 15.1 \\
2.92 & 2.53 & 3.1 & 3.9 & 4.6 & 6.7 \\
$\mathbf{2 0 1 2}$ & $\mathbf{2 0 1 6}$ & $\mathbf{2 0 1 2}$ & $\mathbf{2 0 1 6}$ & $\mathbf{2 0 1 2}$ & $\mathbf{2 0 1 6}$ \\
\hline 0.00 & 0.01 & 0.14 & 0.34 & 30.9 & 38.2 \\
$\mathbf{2 0 0 7}$ & $\mathbf{2 0 1 6}$ & $\mathbf{2 0 0 7}$ & $\mathbf{2 0 1 6}$ & $\mathbf{2 0 0 7}$ & $\mathbf{2 0 1 6}$ \\
\hline 0.11 & 0.15 & 0.34 & 0.42 & 1.7 & 1.9 \\
\hline \multicolumn{2}{c}{$\mathbf{2 0 1 9}$} & \multicolumn{2}{c}{$\mathbf{2 0 1 9}$} & \multicolumn{2}{c}{$\mathbf{2 0 1 9}$} \\
\hline 0.28 & \multicolumn{2}{c}{0.43} & \multicolumn{2}{c}{0.61}
\end{tabular}

\begin{tabular}{|c|c|c|c|c|c|}
\hline \multicolumn{2}{|c|}{ El Salvador } & \multicolumn{2}{|c|}{ ALC } & \multicolumn{2}{|c|}{ OCDE } \\
\hline \multicolumn{2}{|c|}{ 2006-15 } & \multicolumn{2}{|c|}{ 2006-15 } & \multicolumn{2}{|c|}{$2006-15$} \\
\hline \multicolumn{2}{|c|}{$\mathrm{N} / \mathrm{A}$} & \multicolumn{2}{|c|}{6.9} & \multicolumn{2}{|c|}{4.8} \\
\hline \multicolumn{2}{|c|}{2017} & \multicolumn{2}{|c|}{2018} & \multicolumn{2}{|c|}{2018} \\
\hline \multicolumn{2}{|c|}{70.2} & \multicolumn{2}{|c|}{54.9} & \multicolumn{2}{|c|}{$N / A$} \\
\hline 2007 & 2017 & 2007 & 2017 & 2007 & 2017 \\
\hline 24.3 & 28.6 & 37.5 & 60.5 & 66.6 & 74.3 \\
\hline \multicolumn{2}{|c|}{2016} & \multicolumn{2}{|c|}{2016} & \multicolumn{2}{|c|}{2016} \\
\hline \multicolumn{2}{|c|}{12.2} & \multicolumn{2}{|c|}{16.0} & \multicolumn{2}{|c|}{9.8} \\
\hline \multicolumn{2}{|c|}{17.8} & \multicolumn{2}{|c|}{13.8} & \multicolumn{2}{|c|}{14.5} \\
\hline \multicolumn{2}{|c|}{10.5} & \multicolumn{2}{|c|}{12.5} & \multicolumn{2}{|c|}{14.6} \\
\hline
\end{tabular}

\begin{tabular}{cccccc}
\multicolumn{2}{c}{ El Salvador } & \multicolumn{2}{c}{ ALC } & \multicolumn{2}{c}{ OCDE } \\
\hline $\mathbf{2 0 1 5}$ & $\mathbf{2 0 1 6}$ & $\mathbf{2 0 1 5}$ & $\mathbf{2 0 1 6}$ & $\mathbf{2 0 1 5}$ & $\mathbf{2 0 1 6}$ \\
\hline 5.6 & 5.8 & 6.9 & 7.2 & 17.7 & 17.7 \\
$\mathbf{2 0 1 5}$ & $\mathbf{2 0 1 8}$ & $\mathbf{2 0 1 5}$ & $\mathbf{2 0 1 8}$ & $\mathbf{2 0 1 5}$ & $\mathbf{2 0 1 8}$ \\
\hline N/A & N/A & 2.4 & 1.6 & 1.8 & 1.1 \\
\multicolumn{2}{c}{$\mathbf{2 0 1 8}$} & \multicolumn{2}{c}{$\mathbf{2 0 1 8}$} & \multicolumn{2}{c}{$\mathbf{2 0 1 8}$} \\
\hline \multicolumn{2}{c}{ N/A } & \multicolumn{2}{c}{7.7} & \multicolumn{2}{c}{27.7}
\end{tabular}

\begin{tabular}{cccccc}
\multicolumn{2}{c}{ El Salvador } & \multicolumn{2}{c}{ ALC } & \multicolumn{2}{c}{ OCDE } \\
\hline \multicolumn{2}{c}{$\mathbf{2 0 2 0}$} & \multicolumn{2}{c}{$\mathbf{2 0 2 0}$} & \multicolumn{2}{c}{$\mathbf{2 0 2 0}$} \\
\hline \multicolumn{2}{c}{ N/A } & \multicolumn{2}{c}{4.42} & \multicolumn{2}{c}{ N/A } \\
\hline $\mathbf{2 0 1 6}$ & $\mathbf{2 0 1 8}$ & $\mathbf{2 0 1 6}$ & $\mathbf{2 0 1 8}$ & $\mathbf{2 0 1 6}$ & $\mathbf{2 0 1 8}$ \\
\hline 0.21 & 0.12 & 0.36 & 0.43 & 0.56 & 0.79 \\
$\mathbf{2 0 1 8}$ & $\mathbf{2 0 1 9}$ & $\mathbf{2 0 1 8}$ & $\mathbf{2 0 1 9}$ & $\mathbf{2 0 1 8}$ & $\mathbf{2 0 1 9}$ \\
\hline 66.7 & 61.5 & 72.0 & 63.1 & 61.7 & 58.3 \\
\hline 44.0 & 39.2 & 52.8 & 54.9 & 41.7 & 45.6
\end{tabular}

\begin{tabular}{cccccc}
\multicolumn{2}{c}{ El Salvador } & \multicolumn{2}{c}{ ALC } & \multicolumn{2}{c}{ OCDE } \\
\hline 2015 & $\mathbf{2 0 1 9}$ & $\mathbf{2 0 1 5}$ & $\mathbf{2 0 1 9}$ & $\mathbf{2 0 1 5}$ & $\mathbf{2 0 1 9}$ \\
\hline N/A & N/A & 0.24 & 0.24 & 0.13 & 0.15 \\
2018 & 2018 & \multicolumn{2}{c}{2018} \\
\hline N/A & 0.07 & \multicolumn{2}{c}{0.06} \\
\hline
\end{tabular}




\section{Notas técnicas}

1. La Tabla sigue lo mejor posible las siete áreas claves identificadas en el proyecto Going Digital de la OCDE: 1) mejorar el acceso a las tecnologías digitales; 2) aumentar el uso efectivo; 3) permitir la innovación digital; 4) asegurar empleos adecuados para todos; 5) promocionar la prosperidad social; 6) reforzar la confianza; y 7) promocionar la apertura de mercados (OCDE, 2019a). Los indicadores se eligen según la disponibilidad de datos para los países de ALC. Existe la posibilidad de un sesgo por la forma en que se han agregado los componentes en los indicadores de índice.

2. El promedio de ALC es un promedio simple. La composición de los países depende de la disponibilidad de datos de los países de la región. Cada promedio incluye tantos países de ALC encontrados en cada fuente como sea posible.

3. El promedio de la OCDE es un promedio simple que incluye a todos los países miembros de la OCDE en mayo de 2020.

4. Datos de la UIT (2020), Base de datos de indicadores mundiales de telecomunicaciones / TIC 2020 (base de datos). La velocidad de banda ancha fija en Mbit/s se refiere a la velocidad de descarga teórica máxima anunciada garantizada a los usuarios asociados con una suscripción mensual de Internet de banda ancha fija.

5. Datos de la División de Estadística de las Naciones Unidas, Base de datos mundial de los ODS de las Naciones Unidas (base de datos). Datos de 2015 y 2018 o los últimos disponibles.

6. Datos de la base de conocimientos sobre gobierno electrónico de las Naciones Unidas (2019), centro de datos (base de datos). El índice de desarrollo del gobierno electrónico (E-government development index) es un indicador compuesto que consta de tres índices (índice de servicios en línea, índice de infraestructura de telecomunicaciones e índice de capital humano), que están igualmente ponderados. Tiene un rango de 0 a 1, con 1 siendo un gobierno más desarrollado.

7. Datos de UNCTAD (2020), UNCTADSTAT (base de datos). El índice de comercio electrónico B2C de la UNCTAD mide la preparación de una economía para respaldar las compras en línea. Rango de 0 a 100, con 100 siendo el nivel de apoyo más alto.

8. Cálculos propios a partir de datos de Latinobarómetro (2019), Libros de Códigos por País / Año (base de datos). Datos de 2017. Datos de encuestas de opinión pública utilizando muestras representativas a nivel nacional seleccionadas al azar.

9. Datos del Banco Mundial (2020a), Banco de datos del Banco Mundial (base de datos).

10. Datos del Banco Mundial (2020b), TCdata360. Datos de 2012 y 2016 o los últimos disponibles.

11. Datos de Unesco (2019), Instituto de Estadística de la Unesco (base de datos). Gastos en I+D, como porcentaje de los datos del PIB de 2006 y 2016 o el último disponible.

12. Datos de OCDE (2020a), OECD.Stat (base de datos) y OCDE (2020b). El índice OURdata de la OCDE evalúa los esfuerzos de los gobiernos para implementar datos abiertos en tres áreas críticas: apertura, utilidad y reutilización de los datos gubernamentales. Tiene un rango de 0 a 1, con 1 siendo la puntuación más alta.

13. Datos de OCDE (2020a), OECD.Stat (base de datos). El Índice de restricción del comercio de servicios digitales de la OCDE identifica, cataloga y cuantifica las barreras que afectan el comercio de servicios habilitados digitalmente en 46 países. Tiene un rango de 0 a 1, con 1 siendo el valor más restrictivo. El Índice de Restricción Reglamentaria de la Inversión Extranjera Directa (IED RRI) mide cuatro tipos de restricciones legales a la inversión extranjera directa: 1) restricciones a la participación extranjera en el capital social; 2) requisitos de selección y aprobación previa; 3) regulaciones para personas claves; y 4) otras restricciones al funcionamiento de empresas extranjeras. El RRI de la IED es un índice compuesto, que varía de 0 a 1, con 1 siendo el valor más restrictivo.

14. Datos de ILOSTAT, datos de 2018 o último año disponible.

15. Datos de la Asociación mundial de estadísticas sobre desechos electrónicos.

16. Cálculos de la OCDE basados en OCDE (2020c), Programa de Evaluación Internacional de Estudiantes (base de datos). Datos de 2015 y 2018.

17. Datos de la OCDE (2019d), Survey of Adult Skills (2018). Los porcentajes para la resolución de problemas en entornos ricos en tecnología se calculan de modo que la suma de los porcentajes de las siguientes categorías mutuamente exhaustivas sea igual al 100\%: se excluyó de la evaluación por computadora; sin experiencia en informática; prueba de núcleo de TIC fallida; por debajo del Nivel 1, en el Nivel 1, en el Nivel 2 y en el Nivel 3.

18. Datos de CAF (2020), The GouTech Index 2020: Unlocking the Potential of GouTech Ecosystems in Latin America, Spain and Portugal. El índice GovTech 2020 mide la madurez del ecosistema GovTech. Se basa en 28 indicadores en 7 dimensiones, que, en conjunto, forman 3 pilares igualmente ponderados: industria de nueva creación, políticas gubernamentales y sistemas de adquisiciones. 
19. El Índice mundial de ciberseguridad mide el compromiso de los países con la ciberseguridad a escala global. Tiene cinco pilares: 1) medidas legales; 2) medidas técnicas; 3) medidas organizativas; 4) desarrollo de capacidades; y 5) cooperación. Va de 0 a 1, siendo 1 el nivel más alto de ciberseguridad.

20. Datos de The Economist Intelligence Unit (2019), EIU Inclusive Internet Index (base de datos). Los indicadores presentan la seguridad percibida del comercio electrónico y la confianza en la privacidad en línea entre las personas seleccionadas al azar en países seleccionados. Varía del $0 \%$ al 100\%, donde el $100 \%$ indica una confianza absoluta en la seguridad del comercio electrónico y la confianza en la privacidad en línea.

\section{Referencias}

Banco Mundial (2020a), DataBank (base de datos), Grupo del Banco Mundial, Washington, DC, https:// databank.worldbank.org/home.aspx (consultada el 11 de diciembre de 2019).

Banco Mundial (2020b), TCdata360 (base de datos), Grupo del Banco Mundial, Washington, DC, https:// tcdata360.worldbank.org/ (consultada el 4 de agosto de 2020).

Base de conocimientos sobre gobierno electrónico de la ONU (2019), Data Center (base de datos), Departamento de Asuntos Económicos y Sociales de las Naciones Unidas, Nueva York, https:// publicadministration.un.org/egovkb/en-us/Data-Center (consultada el 11 de diciembre de 2019).

CAF (2020), The GouTech Index 2020: Unlocking the Potential of GovTech Ecosystems in Latin America, Spain and Portugal, Banco de Desarrollo de America Latina, Caracas.

CEPAL (2018), Observatorio Regional de Planificación para el Desarrollo de América Latina y el Caribe, Comisión Económica para América Latina y el Caribe, Santiago, https://observatorioplanificacion.cepal.org/es.

Dispositivo de estadísticas de la ONU (2018, 2015), ODS globales de la ONU (database), Departamento de Asuntos Económicos y Sociales de las Naciones Unidas, Nueva York, https://unstats.un.org/sdgs/ indicators/database/ (consultada el 20 de mayo de 2020).

Foro Mundial Económico (2016), “The Global Information Technology Report 2016”, Foro Mundial Económico, Ginebra, https://www.weforum.org/reports/the-global-information-technology-report-2016.

Global E-waste Statistic Partnership, página de internet, Global E-waste Statistic Partnership, Bonn, https:// globalewaste.org/ (consultada el 11 de diciembre de 2019).

Latinobarómetro (2019), Libros de Códigos por País/Año (base de datos), Latinobarómetro, Providencia, www. latinobarometro.org/latCodebooks.jsp (consultada el 11 de diciembre de 2019).

OCDE (2020a), OECD.Stat (database), Publicaciones de la OCDE, París, https://stats.oecd.org/ (consultada el 11 de diciembre de 2019).

OCDE (2020b), Panorama de las Administraciones Públicas América Latina y el Caribe 2020, Publicaciones de la OCDE, París, https://doi.org/10.1787/13130fbb-en.

OCDE (2020c), Programme for International Student Assessment (base de datos), Publicaciones de la OCDE, París, www.oecd.org/pisa/data/2018database/ (consultada el 14 de febrero de 2020).

OCDE (2019a), Cómo medir la transformación digital: Hoja de ruta para el futuro, Publicaciones de la OCDE, París, https://doi.org/10.1787/9789264311992-en.

OCDE (2019b), Estudios de la OCDE sobre Transformación Digital: “Going Digital” en Colombia, Publicaciones de la OCDE, París, https://doi.org/10.1787/781185b1-en.

OCDE (2019c), Digital Government Review of Panama: Enhancing the Digital Transformation of the Public Sector, OCDE Estudios de gobierno digital, Publicaciones de la OCDE, París, https://doi.org/10.1787/615a4180-en.

OCDE (2019d), Survey of Adult Skills, Publicaciones de la OCDE, París, https://www.oecd.org/skills/piaac/data/

OIT (2019), ILO Statistics (base de datos), Organización Internacional del Trabajo, Ginebra, www.ilo.org/ global/statistics-and-databases/lang--en/index.htm (consultada el 11 de diciembre de 2019).

Open Knowledge Foundation (2019), Global Open Data Index (base de datos), Open Knowledge Foundation, Cambridge, Reino Unido, https://index.okfn.org/dataset/ (consultada el 19 de abril de 2020).

PIAAC Expert Group in Problem Solving in Technology-Rich Environments (2009), "PIAAC Problem Solving in Technology- Rich Environments: A Conceptual Framework", OCDE Documentos de trabajo educativo, n. ${ }^{\circ}$ 36, Publicaciones de la OCDE, París, https://doi.org/10.1787/220262483674.

The Economist Intelligence Unit (2019), EIU Inclusive Internet Index 2019 (base de datos), The Economist Group, Londres, https://theinclusiveinternet.eiu.com/explore/countries/performance (consultada el $11 \mathrm{de}$ diciembre 2019).

UIT (2020), base de datos de indicadores mundiales de telecomunicaciones / TIC 2020 (base de datos), Unión Internacional de Telecomunicaciones, Ginebra, https://www.itu.int/en/ITU-D/Statistics/Pages/ publications/wtid.aspx (consultada el 21 de agosto de 2020). 
UNCTAD (2020), UNCTADSTAT (base de datos), Conferencia de las Naciones Unidas sobre Comercio y Desarrollo, Ginebra, https://unctadstat.unctad.org/EN/ (consultada el 11 de diciembre de 2019).

UNESCO (2019), Instituto de Estadística de la Unesco (base de datos), Unesco, París, http://data.uis.unesco. org/Index.aspx (consultada el 20 de mayo de 2020).

World Wide Web Foundation (2017), OpenData Barometer (base de datos), World Wide Web Foundation, Ginebra, https://opendatabarometer.org/ (consultada el 19 de abril de 2020). 



\section{GUATEMALA}

\section{Tendencias recientes}

Guatemala sigue avanzando en la mejora del acceso digital de todos sus ciudadanos. La proporción de usuarios de Internet aumentó del 8.3\% en 2008 al 65.0\% en 2018, situándose por encima del promedio actual de América Latina y el Caribe (ALC) (62.9\%). También aumentaron las suscripciones a servicios de banda ancha móvil activa, sin embargo, se mantienen por debajo del promedio de ALC y de la OCDE. El país ha avanzado en el aumento de la confianza en el ecosistema digital, como lo demuestra la mejora de la percepción de confianza en la privacidad en Internet y el índice de ciberseguridad global. En particular, este último índice aumentó de 0.21 en 2016 a 0.25 en 2018, aunque se mantiene por debajo del promedio ALC (0.43) y de la OCDE (0.79). Guatemala sigue mejorando en cuanto al desarrollo del comercio electrónico, el índice de comercio electrónico B2C aumentó entre 2015 (21.4) y 2019 (37.5).

Los resultados de Guatemala en materia de innovación digital dejan margen para la mejora. En particular, las exportaciones de alta tecnología representaron el 5.3\% del total de las exportaciones de productos manufacturados en 2017, en comparación con los promedios del 9.6\% de ALC y del 15.3\% de la OCDE. En cuanto a asegurar empleos adecuados para todos, fuentes nacionales indican que el sector de información y comunicaciones como porcentaje de la fuerza de trabajo ha permanecido constante entre el 2016 y 2019.

\section{Estrategias nacionales y cooperación internacional para la transformación digital}

El Plan Nacional de Desarrollo (PND) K'atun, Nuestra Guatemala 2032 y la Agenda Nación Digital 2016-2032 son los principales instrumentos de planificación para la transformación digital de Guatemala (CEPAL, 2018). El PND incluye un eje que se centra en el bienestar con medidas específicas para la promoción de la ciencia y la tecnología. Dicho plan cuenta con dos objetivos principales: el primero es cerrar la brecha digital en las instituciones públicas para mejorar y acelerar los procesos y transacciones y, generar conocimiento en la sociedad. El segundo es diseñar, aprobar e implementar políticas de inclusión digital. La Agenda Nación Digital pretende aprovechar las TIC (tecnologías de la información y las comunicaciones) para contribuir al desarrollo tecnológico, social y económico del país. Dicha agenda da prioridad a la educación y a la seguridad, pero también se centra en la salud, la transparencia y el desarrollo.

Entre las políticas relacionadas figura la Política Nacional de Desarrollo Científico y Tecnológico 2015-2032, que tiene por objeto generar competencias y fomentar la investigación multidisciplinaria en materia de ciencia, tecnología e innovación. También se tiene la Política Nacional de Ciberseguridad de 2018 dirigida a crear las condiciones adecuadas para potenciar la participación y desarrollo del ciberespacio. Esta política reconoce, entre otros aspectos, la cooperación internacional entre gobiernos como un pilar clave para la ciberseguridad. En 2019, Guatemala creó el Viceministerio de Asuntos Registrales para digitalizar los servicios del Ministerio de Economía. En 2020, la denominada Comisión Presidencial de Gobierno Abierto y Electrónico (GAE) se ha encargado de coordinar la aplicación de medidas, estrategias y compromisos derivados de los instrumentos internacionales y de las políticas y planes de acción nacionales en materia de gobierno abierto y firma electrónica. Esto con el fin de contribuir a la transformación de la gestión pública, la innovación de las TIC, la participación ciudadana, la rendición de cuentas y la transparencia. Para mitigar el impacto económico del coronavirus (Covid-19), el Gobierno anunció que las empresas de telecomunicaciones se considerarían un servicio esencial y seguirían operativas durante el confinamiento. Claro y Tigo, dos grandes operadores de telecomunicaciones y medios de comunicación, ofrecieron un Plan Básico de Navegación para asegurar la conexión a los usuarios que no pueden para pagar sus planes de Internet (CAF, 2020).

En materia de cooperación internacional, Guatemala participó en un proyecto de cooperación triangular con Alemania y México en 2016-2018 que tenía como objetivo crear un espacio de diálogo para identificar las mejores prácticas en la gestión de la cooperación técnica para el desarrollo entre países que enfrentan retos similares. Este proyecto incluyó la creación de una plataforma digital para registrar y organizar la cooperación técnica para el desarrollo ya existente en el país. Con la ayuda de la Unión Europea, Guatemala también puso en marcha una Plataforma de Información Nacional sobre Nutrición para ayudar a hacer un seguimiento de la malnutrición crónica. Su objetivo es fortalecer la gestión de la información, la formulación de políticas basadas en pruebas concretas y la coordinación y planificación técnicas. 


\section{Mejorar el acceso}

Suscripciones de banda ancha fija (por cada 100 habitantes) ${ }^{4}$

Suscripciones de banda ancha móvil activa (por cada 100 habitantes) ${ }^{4}$

Proporción de población cubierta por al menos una red $3 \mathrm{G}^{5}$

Velocidad de banda ancha fija (en Mbit/s) ${ }^{4}$

\section{Aumentar el uso efectivo}

Índice de desarrollo del gobierno electrónico (EGDI) ${ }^{6}$

Proporción de usuarios de Internet (\% de población) ${ }^{4}$

Índice de comercio electrónico B2C de la UNCTAD ${ }^{7}$

Proporción de personas que realizan compras por Internet ${ }^{8}$

Impulsar la innovación

Exportaciones de alta tecnología (\% de exportaciones manufacturadas) ${ }^{9}$

Proporción de importaciones de servicios de TIC, como porcentaje del comercio total de servicios ${ }^{7}$

Solicitudes de patentes de TIC presentadas en virtud del Tratado de Cooperación en materia de Patentes (por millón de personas) ${ }^{10}$

Gastos en I+D, como \% del PIB ${ }^{11}$

Índice OURdata de la OCDE ${ }^{12}$

\section{Asegurar empleos adecuados para todos}

Contribuciones a variación en empleo total, por intensidad digital de sectores, 2006-2016 ${ }^{13}$

Proporción de empleo informal en relación con empleo total ${ }^{14}$

Tasa bruta de matrícula, educación terciaria $(\%)^{9}$

Graduados de educación terciaria por campo (\%) - Educación ${ }^{11}$

Graduados de educación terciaria por campo (\%) - Salud ${ }^{11}$

Graduados de educación terciaria por campo (\%) - Ingeniería ${ }^{11}$

\section{Promocionar la prosperidad social}

Generación de desechos de aparatos eléctricos per cápita $(\mathrm{kg})^{15}$

Número de estudiantes por computadora ${ }^{16}$

Proporción de mujeres con puntuación de nivel 203 en resolución de problemas en entornos tecnológicos ${ }^{17}$

\section{Reforzar la confianza}

Índice GovTech de la $\mathrm{CAF}^{18}$

Índice de ciberseguridad global (UIT) ${ }^{19}$

Seguridad del comercio electrónico $(\%)^{20}$

Confianza en la privacidad en Internet $(\%)^{20}$

\section{Promocionar la apertura de mercados}

Índice de restrictividad de intercambios de servicios digitales de la OCDE ${ }^{13}$

Índice de restricción regulatoria de la IED de la $0 \mathrm{CDE}^{13}$

Las fuentes, notas a pie de página y detalles técnicos se pueden encontrar al final de las Notas País.

\begin{tabular}{cccccc}
\multicolumn{3}{c}{ Indicadores digitales - Guatemala } \\
\hline \multicolumn{2}{c}{ Guatemala } & \multicolumn{2}{c}{ ALC $^{2}$} & \multicolumn{2}{c}{ OCDE $^{3}$} \\
\hline $\mathbf{2 0 0 8}$ & $\mathbf{2 0 1 7}$ & $\mathbf{2 0 0 8}$ & $\mathbf{2 0 1 7}$ & $\mathbf{2 0 0 8}$ & $\mathbf{2 0 1 7}$ \\
\hline 0.67 & 3.1 & 4.1 & 12.0 & 22.7 & 32.2 \\
$\mathbf{2 0 0 9}$ & $\mathbf{2 0 1 7}$ & $\mathbf{2 0 0 9}$ & $\mathbf{2 0 1 7}$ & $\mathbf{2 0 0 9}$ & $\mathbf{2 0 1 7}$ \\
\hline 2.0 & 16.5 & 1.8 & 66.8 & 29.8 & 97.3 \\
$\mathbf{2 0 1 5}$ & $\mathbf{2 0 1 8}$ & $\mathbf{2 0 1 5}$ & $\mathbf{2 0 1 8}$ & $\mathbf{2 0 1 5}$ & $\mathbf{2 0 1 8}$ \\
\hline 92.0 & 95.0 & 86.1 & 94.6 & 98.2 & 98.8 \\
$\mathbf{2 0 0 8}$ & $\mathbf{2 0 1 7}$ & $\mathbf{2 0 0 8}$ & $\mathbf{2 0 1 7}$ & $\mathbf{2 0 0 8}$ & $\mathbf{2 0 0 7}$ \\
\hline 0.26 & 2.0 & 0.58 & 5.1 & 2.2 & 27.7
\end{tabular}

\begin{tabular}{cccccc}
\multicolumn{2}{c}{ Guatemala } & \multicolumn{2}{c}{ ALC } & \multicolumn{2}{c}{ OCDE } \\
\hline $\mathbf{2 0 0 8}$ & $\mathbf{2 0 1 8}$ & $\mathbf{2 0 0 8}$ & $\mathbf{2 0 1 8}$ & $\mathbf{2 0 0 8}$ & $\mathbf{2 0 1 8}$ \\
\hline 0.43 & 0.50 & 0.52 & 0.65 & 0.72 & 0.82 \\
$\mathbf{2 0 0 8}$ & $\mathbf{2 0 1 7}$ & $\mathbf{2 0 0 8}$ & $\mathbf{2 0 1 7}$ & $\mathbf{2 0 0 8}$ & $\mathbf{2 0 1 7}$ \\
\hline 8.3 & 65.0 & 25.3 & 62.9 & 65.0 & 83.4 \\
$\mathbf{2 0 1 5}$ & $\mathbf{2 0 1 9}$ & $\mathbf{2 0 1 5}$ & $\mathbf{2 0 1 9}$ & $\mathbf{2 0 1 5}$ & $\mathbf{2 0 1 9}$ \\
\hline 21.4 & 37.5 & 46.4 & 51.5 & 73.9 & 85.0 \\
\multicolumn{2}{c}{$\mathbf{2 0 1 7}$} & \multicolumn{2}{c}{$\mathbf{2 0 1 7}$} & \multicolumn{2}{c}{$\mathbf{2 0 1 7}$} \\
\hline 10.6 & \multicolumn{2}{c}{14.8} & \multicolumn{3}{c}{ N/A }
\end{tabular}

\begin{tabular}{cccccc}
\multicolumn{2}{c}{ Guatemala } & \multicolumn{2}{c}{ ALC } & \multicolumn{2}{c}{ OCDE } \\
\hline $\mathbf{2 0 0 8}$ & $\mathbf{2 0 1 7}$ & $\mathbf{2 0 0 8}$ & $\mathbf{2 0 1 7}$ & $\mathbf{2 0 0 8}$ & $\mathbf{2 0 1 7}$ \\
\hline 4.3 & 5.3 & 9.3 & 9.6 & 15.6 & 15.3 \\
1.72 & 4.58 & 3.1 & 3.9 & 4.6 & 6.7 \\
$\mathbf{2 0 1 2}$ & $\mathbf{2 0 1 6}$ & $\mathbf{2 0 1 2}$ & $\mathbf{2 0 1 6}$ & $\mathbf{2 0 1 2}$ & $\mathbf{2 0 1 6}$ \\
\hline 0.04 & 0.00 & 0.14 & 0.34 & 30.9 & 38.2 \\
$\mathbf{2 0 0 6}$ & $\mathbf{2 0 1 5}$ & $\mathbf{2 0 0 6}$ & $\mathbf{2 0 1 5}$ & $\mathbf{2 0 0 6}$ & $\mathbf{2 0 1 5}$ \\
\hline 0.05 & 0.03 & 0.35 & 0.40 & 1.7 & 1.9 \\
\hline \multicolumn{2}{c}{$\mathbf{2 0 1 9}$} & $\mathbf{2 0 1 9}$ & \multicolumn{2}{c}{$\mathbf{2 0 1 9}$} \\
\hline 0.54 & \multicolumn{2}{c}{0.43} & \multicolumn{2}{c}{0.61}
\end{tabular}

\begin{tabular}{|c|c|c|c|c|c|}
\hline \multicolumn{2}{|c|}{ Guatemala } & \multicolumn{2}{|c|}{ ALC } & \multicolumn{2}{|c|}{ OCDE } \\
\hline \multicolumn{2}{|c|}{ 2006-15 } & \multicolumn{2}{|c|}{$2006-15$} & \multicolumn{2}{|c|}{$2006-15$} \\
\hline \multicolumn{2}{|c|}{ N/A } & \multicolumn{2}{|c|}{6.9} & \multicolumn{2}{|c|}{4.8} \\
\hline \multicolumn{2}{|c|}{2017} & \multicolumn{2}{|c|}{2018} & \multicolumn{2}{|c|}{2018} \\
\hline \multicolumn{2}{|c|}{80.9} & \multicolumn{2}{|c|}{54.9} & \multicolumn{2}{|c|}{$\mathrm{N} / \mathrm{A}$} \\
\hline 2007 & 2015 & 2007 & 2015 & 2007 & 2015 \\
\hline 17.3 & 21.8 & 37.5 & 51.0 & 66.6 & 70.7 \\
\hline \multicolumn{2}{|c|}{2016} & \multicolumn{2}{|c|}{2016} & \multicolumn{2}{|c|}{2016} \\
\hline \multicolumn{2}{|c|}{$\mathrm{N} / \mathrm{A}$} & \multicolumn{2}{|c|}{16.0} & \multicolumn{2}{|c|}{9.8} \\
\hline \multicolumn{2}{|c|}{$\mathrm{N} / \mathrm{A}$} & \multicolumn{2}{|c|}{13.8} & \multicolumn{2}{|c|}{14.5} \\
\hline \multicolumn{2}{|c|}{$\mathrm{N} / \mathrm{A}$} & \multicolumn{2}{|c|}{12.5} & \multicolumn{2}{|c|}{14.6} \\
\hline
\end{tabular}

\begin{tabular}{cccccc}
\multicolumn{2}{c}{ Guatemala } & \multicolumn{2}{c}{ ALC } & \multicolumn{2}{c}{ OCDE } \\
\hline $\mathbf{2 0 1 5}$ & $\mathbf{2 0 1 6}$ & $\mathbf{2 0 1 5}$ & $\mathbf{2 0 1 6}$ & $\mathbf{2 0 1 5}$ & $\mathbf{2 0 1 6}$ \\
\hline 3.9 & 4.0 & 6.9 & 7.2 & 17.7 & 17.7 \\
$\mathbf{2 0 1 5}$ & $\mathbf{2 0 1 8}$ & $\mathbf{2 0 1 5}$ & $\mathbf{2 0 1 8}$ & $\mathbf{2 0 1 5}$ & $\mathbf{2 0 1 8}$ \\
\hline N/A & N/A & 2.4 & 1.6 & 1.8 & 1.1 \\
\multicolumn{2}{c}{$\mathbf{2 0 1 8}$} & \multicolumn{2}{c}{$\mathbf{2 0 1 8}$} & \multicolumn{2}{c}{$\mathbf{2 0 1 8}$} \\
\hline \multicolumn{2}{c}{ N/A } & \multicolumn{2}{c}{7.7} & \multicolumn{2}{c}{27.7}
\end{tabular}

\begin{tabular}{cccccc}
\multicolumn{2}{c}{ Guatemala } & \multicolumn{2}{c}{ ALC } & \multicolumn{2}{c}{ OCDE } \\
\hline \multicolumn{2}{c}{$\mathbf{2 0 2 0}$} & \multicolumn{2}{c}{$\mathbf{2 0 2 0}$} & \multicolumn{2}{c}{$\mathbf{2 0 2 0}$} \\
\hline \multicolumn{2}{c}{ N/A } & \multicolumn{2}{c}{4.4} & \multicolumn{2}{c}{ N/A } \\
\hline $\mathbf{2 0 1 6}$ & $\mathbf{2 0 1 8}$ & $\mathbf{2 0 1 6}$ & $\mathbf{2 0 1 8}$ & $\mathbf{2 0 1 6}$ & $\mathbf{2 0 1 8}$ \\
\hline 0.21 & 0.25 & 0.36 & 0.43 & 0.56 & 0.79 \\
\hline $\mathbf{2 0 1 8}$ & $\mathbf{2 0 1 9}$ & $\mathbf{2 0 1 8}$ & $\mathbf{2 0 1 9}$ & $\mathbf{2 0 1 8}$ & $\mathbf{2 0 1 9}$ \\
\hline 66.7 & 46.8 & 72.0 & 63.1 & 61.7 & 58.3 \\
44.0 & 56.9 & 52.8 & 54.9 & 41.7 & 45.6
\end{tabular}

\begin{tabular}{cccccc}
\multicolumn{2}{c}{ Guatemala } & \multicolumn{2}{c}{ ALC } & \multicolumn{2}{c}{ OCDE } \\
\hline $\mathbf{2 0 1 5}$ & $\mathbf{2 0 1 9}$ & $\mathbf{2 0 1 5}$ & $\mathbf{2 0 1 9}$ & $\mathbf{2 0 1 5}$ & $\mathbf{2 0 1 9}$ \\
\hline N/A & N/A & 0.24 & 0.24 & 0.13 & 0.15 \\
\multicolumn{2}{c}{2018} & \multicolumn{2}{c}{$\mathbf{2 0 1 8}$} & \multicolumn{2}{c}{$\mathbf{2 0 1 8}$} \\
\hline \multicolumn{2}{c}{ N/A } & 0.07 & \multicolumn{2}{c}{0.06} \\
\hline
\end{tabular}




\section{Notas técnicas}

1. La Tabla sigue lo mejor posible las siete áreas claves identificadas en el proyecto Going Digital de la OCDE: 1) mejorar el acceso a las tecnologías digitales; 2) aumentar el uso efectivo; 3) permitir la innovación digital; 4) asegurar empleos adecuados para todos; 5) promocionar la prosperidad social; 6) reforzar la confianza; y 7) promocionar la apertura de mercados (OCDE, 2019a). Los indicadores se eligen según la disponibilidad de datos para los países de ALC. Existe la posibilidad de un sesgo por la forma en que se han agregado los componentes en los indicadores de índice.

2. El promedio de ALC es un promedio simple. La composición de los países depende de la disponibilidad de datos de los países de la región. Cada promedio incluye tantos países de ALC encontrados en cada fuente como sea posible.

3. El promedio de la OCDE es un promedio simple que incluye a todos los países miembros de la OCDE en mayo de 2020.

4. Datos de la UIT (2020), Base de datos de indicadores mundiales de telecomunicaciones / TIC 2020 (base de datos). La velocidad de banda ancha fija en Mbit/s se refiere a la velocidad de descarga teórica máxima anunciada garantizada a los usuarios asociados con una suscripción mensual de Internet de banda ancha fija.

5. Datos de la División de Estadística de las Naciones Unidas, Base de datos mundial de los ODS de las Naciones Unidas (base de datos). Datos de 2015 y 2018 o los últimos disponibles.

6. Datos de la base de conocimientos sobre gobierno electrónico de las Naciones Unidas (2019), centro de datos (base de datos). El índice de desarrollo del gobierno electrónico (E-government development index) es un indicador compuesto que consta de tres índices (índice de servicios en línea, índice de infraestructura de telecomunicaciones e índice de capital humano), que están igualmente ponderados. Tiene un rango de 0 a 1, con 1 siendo un gobierno más desarrollado.

7. Datos de UNCTAD (2020), UNCTADSTAT (base de datos). El índice de comercio electrónico B2C de la UNCTAD mide la preparación de una economía para respaldar las compras en línea. Rango de 0 a 100, con 100 siendo el nivel de apoyo más alto.

8. Cálculos propios a partir de datos de Latinobarómetro (2019), Libros de Códigos por País / Año (base de datos). Datos de 2017. Datos de encuestas de opinión pública utilizando muestras representativas a nivel nacional seleccionadas al azar.

9. Datos del Banco Mundial (2020a), Banco de datos del Banco Mundial (base de datos).

10. Datos del Banco Mundial (2020b), TCdata360. Datos de 2012 y 2016 o los últimos disponibles.

11. Datos de Unesco (2019), Instituto de Estadística de la Unesco (base de datos). Gastos en I+D, como porcentaje de los datos del PIB de 2006 y 2016 o el último disponible.

12. Datos de OCDE (2020a), OECD.Stat (base de datos) y OCDE (2020b). El índice OURdata de la OCDE evalúa los esfuerzos de los gobiernos para implementar datos abiertos en tres áreas críticas: apertura, utilidad y reutilización de los datos gubernamentales. Tiene un rango de 0 a 1, con 1 siendo la puntuación más alta.

13. Datos de OCDE (2020a), OECD.Stat (base de datos). El Índice de restricción del comercio de servicios digitales de la OCDE identifica, cataloga y cuantifica las barreras que afectan el comercio de servicios habilitados digitalmente en 46 países. Tiene un rango de 0 a 1, con 1 siendo el valor más restrictivo. El Índice de Restricción Reglamentaria de la Inversión Extranjera Directa (IED RRI) mide cuatro tipos de restricciones legales a la inversión extranjera directa: 1) restricciones a la participación extranjera en el capital social; 2) requisitos de selección y aprobación previa; 3) regulaciones para personas claves; y 4) otras restricciones al funcionamiento de empresas extranjeras. El RRI de la IED es un índice compuesto, que varía de 0 a 1, con 1 siendo el valor más restrictivo.

14. Datos de ILOSTAT, datos de 2018 o último año disponible.

15. Datos de la Asociación mundial de estadísticas sobre desechos electrónicos.

16. Cálculos de la OCDE basados en OCDE (2020c), Programa de Evaluación Internacional de Estudiantes (base de datos). Datos de 2015 y 2018.

17. Datos de la OCDE (2019d), Survey of Adult Skills (2018). Los porcentajes para la resolución de problemas en entornos ricos en tecnología se calculan de modo que la suma de los porcentajes de las siguientes categorías mutuamente exhaustivas sea igual al 100\%: se excluyó de la evaluación por computadora; sin experiencia en informática; prueba de núcleo de TIC fallida; por debajo del Nivel 1, en el Nivel 1, en el Nivel 2 y en el Nivel 3.

18. Datos de CAF (2020), The GouTech Index 2020: Unlocking the Potential of GouTech Ecosystems in Latin America, Spain and Portugal. El índice GovTech 2020 mide la madurez del ecosistema GovTech. Se basa en 28 indicadores en 7 dimensiones, que, en conjunto, forman 3 pilares igualmente ponderados: industria de nueva creación, políticas gubernamentales y sistemas de adquisiciones. 
19. El Índice mundial de ciberseguridad mide el compromiso de los países con la ciberseguridad a escala global. Tiene cinco pilares: 1) medidas legales; 2) medidas técnicas; 3) medidas organizativas; 4) desarrollo de capacidades; y 5) cooperación. Va de 0 a 1, siendo 1 el nivel más alto de ciberseguridad.

20. Datos de The Economist Intelligence Unit (2019), EIU Inclusive Internet Index (base de datos). Los indicadores presentan la seguridad percibida del comercio electrónico y la confianza en la privacidad en línea entre las personas seleccionadas al azar en países seleccionados. Varía del $0 \%$ al 100\%, donde el $100 \%$ indica una confianza absoluta en la seguridad del comercio electrónico y la confianza en la privacidad en línea.

\section{Referencias}

Banco Mundial (2020a), DataBank (base de datos), Grupo del Banco Mundial, Washington, DC, https:// databank.worldbank.org/home.aspx (consultada el 11 de diciembre de 2019).

Banco Mundial (2020b), TCdata360 (base de datos), Grupo del Banco Mundial, Washington, DC, https:// tcdata360.worldbank.org/ (consultada el 4 de agosto de 2020).

Base de conocimientos sobre gobierno electrónico de la ONU (2019), Data Center (base de datos), Departamento de Asuntos Económicos y Sociales de las Naciones Unidas, Nueva York, https:// publicadministration.un.org/egovkb/en-us/Data-Center (consultada el 11 de diciembre de 2019).

CAF (2020), The GouTech Index 2020: Unlocking the Potential of GovTech Ecosystems in Latin America, Spain and Portugal, Banco de Desarrollo de America Latina, Caracas.

CEPAL (2018), Observatorio Regional de Planificación para el Desarrollo de América Latina y el Caribe, Comisión Económica para América Latina y el Caribe, Santiago, https://observatorioplanificacion.cepal.org/es.

Dispositivo de estadísticas de la ONU (2018, 2015), ODS globales de la ONU (database), Departamento de Asuntos Económicos y Sociales de las Naciones Unidas, Nueva York, https://unstats.un.org/sdgs/ indicators/database/ (consultada el 20 de mayo de 2020).

Foro Mundial Económico (2016), “The Global Information Technology Report 2016”, Foro Mundial Económico, Ginebra, https://www.weforum.org/reports/the-global-information-technology-report-2016.

Global E-waste Statistic Partnership, página de internet, Global E-waste Statistic Partnership, Bonn, https:// globalewaste.org/ (consultada el 11 de diciembre de 2019).

Latinobarómetro (2019), Libros de Códigos por País/Año (base de datos), Latinobarómetro, Providencia, www. latinobarometro.org/latCodebooks.jsp (consultada el 11 de diciembre de 2019).

OCDE (2020a), OECD.Stat (database), Publicaciones de la OCDE, París, https://stats.oecd.org/ (consultada el 11 de diciembre de 2019).

OCDE (2020b), Panorama de las Administraciones Públicas América Latina y el Caribe 2020, Publicaciones de la OCDE, París, https://doi.org/10.1787/13130fbb-en.

OCDE (2020c), Programme for International Student Assessment (base de datos), Publicaciones de la OCDE, París, www.oecd.org/pisa/data/2018database/ (consultada el 14 de febrero de 2020).

OCDE (2019a), Cómo medir la transformación digital: Hoja de ruta para el futuro, Publicaciones de la OCDE, París, https://doi.org/10.1787/9789264311992-en.

OCDE (2019b), Estudios de la OCDE sobre Transformación Digital: “Going Digital” en Colombia, Publicaciones de la OCDE, París, https://doi.org/10.1787/781185b1-en.

OCDE (2019c), Digital Government Review of Panama: Enhancing the Digital Transformation of the Public Sector, OCDE Estudios de gobierno digital, Publicaciones de la OCDE, París, https://doi.org/10.1787/615a4180-en.

OCDE (2019d), Survey of Adult Skills, Publicaciones de la OCDE, París, https://www.oecd.org/skills/piaac/data/

OIT (2019), ILO Statistics (base de datos), Organización Internacional del Trabajo, Ginebra, www.ilo.org/ global/statistics-and-databases/lang--en/index.htm (consultada el 11 de diciembre de 2019).

Open Knowledge Foundation (2019), Global Open Data Index (base de datos), Open Knowledge Foundation, Cambridge, Reino Unido, https://index.okfn.org/dataset/ (consultada el 19 de abril de 2020).

PIAAC Expert Group in Problem Solving in Technology-Rich Environments (2009), "PIAAC Problem Solving in Technology- Rich Environments: A Conceptual Framework", OCDE Documentos de trabajo educativo, n. ${ }^{\circ}$ 36, Publicaciones de la OCDE, París, https://doi.org/10.1787/220262483674.

The Economist Intelligence Unit (2019), EIU Inclusive Internet Index 2019 (base de datos), The Economist Group, Londres, https://theinclusiveinternet.eiu.com/explore/countries/performance (consultada el $11 \mathrm{de}$ diciembre 2019).

UIT (2020), base de datos de indicadores mundiales de telecomunicaciones / TIC 2020 (base de datos), Unión Internacional de Telecomunicaciones, Ginebra, https://www.itu.int/en/ITU-D/Statistics/Pages/ publications/wtid.aspx (consultada el 21 de agosto de 2020). 
UNCTAD (2020), UNCTADSTAT (base de datos), Conferencia de las Naciones Unidas sobre Comercio y Desarrollo, Ginebra, https://unctadstat.unctad.org/EN/ (consultada el 11 de diciembre de 2019).

UNESCO (2019), Instituto de Estadística de la Unesco (base de datos), Unesco, París, http://data.uis.unesco. org/Index.aspx (consultada el 20 de mayo de 2020).

World Wide Web Foundation (2017), OpenData Barometer (base de datos), World Wide Web Foundation, Ginebra, https://opendatabarometer.org/ (consultada el 19 de abril de 2020). 



\section{MÉXICO}

\section{Tendencias recientes}

México sigue superando a América Latina y el Caribe (ALC) con respecto a la configuración de una sociedad y economía digitales incluyentes. El país se ha esforzado para mejorar el acceso digital de todos sus ciudadanos. En la última década, ha aumentado el número de usuarios de Internet y de suscripciones a servicios de banda ancha móvil activa y fija. México ascendió en el Índice de desarrollo de gobierno electrónico del 0.59 en 2008 al 0.68 en 2018, una evolución superior al promedio de ALC, pero inferior al promedio de la OCDE.

El desempeño de México en exportaciones de alta tecnología en proporción al total de las exportaciones de productos manufacturados se ha situado por encima de los promedios de ALC y la OCDE en la última década. En cuanto a la promoción de una sociedad digital incluyente, el número de estudiantes por computadora aumentó de 2.2 en 2015 a 2.4 en 2018, por encima de los promedios de ALC (1.6) y la OCDE (1.1). El país ha mejorado su posición en el Índice mundial de ciberseguridad (0.63), con unos resultados considerablemente más altos que el promedio de ALC (0.43), aunque inferiores al promedio de la OCDE (0.79). En 2018, el índice de restricción regulatoria de la inversión extranjera directa (IED) de la OCDE mostraba que México contaba con mayores restricciones a la IED que ALC y la OCDE.

\section{Estrategias nacionales y cooperación internacional para la transformación digital}

El Plan Nacional de Desarrollo (PND) 2019-2024 es el principal instrumento de planificación de desarrollo de México (CEPAL, 2018). El PND incorpora herramientas digitales para lograr sus objetivos en determinadas áreas de políticas y se centra sobre todo en la productividad, la inclusión, la administración pública y el cambio climático. La Oficina de la Presidencia de la República desarrolló la Estrategia Digital Nacional con el objetivo de potenciar al máximo las capacidades en el ámbito de las TIC (tecnologías de la información y las comunicaciones). La Coordinación de la Estrategia Digital Nacional, que depende directamente de la Oficina de la Presidencia, es responsable de la elaboración y coordinación del plan, así como del desarrollo de las TIC para su uso en las administraciones públicas.

El Programa Nacional de Combate a la Corrupción y a la Impunidad, y de Mejora de la Gestión Pública 2019-2024 utiliza herramientas digitales para su ejecución. Su objetivo es establecer un programa para promover la eficiencia en las administraciones públicas, al tiempo que moderniza y mejora la prestación de servicios públicos. En particular, el programa pondrá en marcha un sistema de herramientas y plataformas digitales para que los ciudadanos supervisen las actividades de la administración pública federal, incluidos los procesos de contratación pública. También promoverá la adopción transversal de las TIC en todas las entidades gubernamentales y la implantación de una plataforma digital de contratación pública. Para mitigar el impacto del coronavirus (Covid-19), la Secretaría de Educación Pública puso en marcha el programa Aprende en Casa para permitir que las clases sigan desde el hogar durante el confinamiento. Se pusieron contenidos educativos a disposición del público por Internet y a través de la televisión pública. Además, el Gobierno creó un sitio web oficial de información general sobre el coronavirus (Covid-19) (CAF, 2020).

El Ministerio de Economía es responsable de la implantación del programa para el desarrollo de la industria del software y la innovación, que se centra en la innovación, adopción y desarrollo industrial. Asimismo, da prioridad a la digitalización de las empresas mexicanas a medida que abordan la industria 4.0.

En materia de cooperación internacional, México se unió a la Alianza Better than Cash a través de la cooperación multilateral con Colombia, Paraguay, Perú y otros países del mundo. Esta alianza tiene como objetivo acelerar la transición de pagos en efectivo a pagos digitales, a fin de reducir la pobreza e impulsar el crecimiento incluyente. Además, el país cooperó con Francia en un proyecto digital sobre información y democracia para luchar contra la desinformación y las noticias falsas.

México también coopera con la Unión Europea, desempeñando un papel importante en el plan para avanzar en la computación de alto rendimiento. El país recibirá apoyo para diseñar una hoja de ruta para establecer futuras colaboraciones en materia de investigación en este campo, identificar planes de financiamiento nacionales y regionales y mejorar los vínculos entre las comunidades de investigación de Europa y México y de otros países de ALC. 


\section{Mejorar el acceso}

Suscripciones de banda ancha fija (por cada 100 habitantes) ${ }^{4}$

Suscripciones de banda ancha móvil activa (por cada 100 habitantes) ${ }^{4}$

Proporción de población cubierta por al menos una red 3G5

Velocidad de banda ancha fija (en Mbit/s) ${ }^{4}$

\section{Aumentar el uso efectivo}

Índice de desarrollo del gobierno electrónico (EGDI) ${ }^{6}$

Proporción de usuarios de Internet (\% de población) ${ }^{4}$

Índice de comercio electrónico B2C de la UNCTAD

Proporción de personas que realizan compras por Internet ${ }^{8}$

\section{Impulsar la innovación}

Exportaciones de alta tecnología (\% de exportaciones manufacturadas) ${ }^{9}$

Proporción de importaciones de servicios de TIC, como porcentaje del comercio total de servicios ${ }^{7}$

Solicitudes de patentes de TIC presentadas en virtud del Tratado de Cooperación en materia de Patentes (por millón de personas) ${ }^{10}$

Gastos en I+D, como \% del PIB 11

Índice OURdata de la OCDE ${ }^{12}$

\section{Asegurar empleos adecuados para todos}

Contribuciones a variación en empleo total, por intensidad digital de sectores, 2006-2016 ${ }^{13}$

Proporción de empleo informal en relación con empleo total ${ }^{14}$

Tasa bruta de matrícula, educación terciaria $(\%)^{9}$

Graduados de educación terciaria por campo (\%) - Educación ${ }^{11}$

Graduados de educación terciaria por campo (\%) - Salud ${ }^{11}$

Graduados de educación terciaria por campo (\%) - Ingeniería ${ }^{11}$

\section{Promocionar la prosperidad social}

Generación de desechos de aparatos eléctricos per cápita $(\mathrm{kg})^{15}$

Número de estudiantes por computadora ${ }^{16}$

Proporción de mujeres con puntuación de nivel 203 en resolución de problemas en entornos tecnológicos ${ }^{17}$

\section{Reforzar la confianza}

Índice GovTech de la $\mathrm{CAF}^{18}$

Índice de ciberseguridad global (UIT) $)^{19}$

Seguridad del comercio electrónico $(\%)^{20}$ Confianza en la privacidad en Internet $(\%)^{20}$

\section{Promocionar la apertura de mercados}

Índice de restrictividad de intercambios de servicios digitales de la OCDE ${ }^{13}$

Índice de restricción regulatoria de la IED de la $0 \mathrm{CDE}^{13}$

Las fuentes, notas a pie de página y detalles técnicos se pueden encontrar al final de las Notas País.

\begin{tabular}{cccccc}
\multicolumn{4}{c}{ Indicadores digitales - México } \\
\hline \multicolumn{2}{c}{ México } & \multicolumn{2}{c}{ ALC $^{2}$} & \multicolumn{2}{c}{ OCDE $^{3}$} \\
\hline $\mathbf{2 0 0 8}$ & $\mathbf{2 0 1 8}$ & $\mathbf{2 0 0 8}$ & $\mathbf{2 0 1 8}$ & $\mathbf{2 0 0 8}$ & $\mathbf{2 0 1 8}$ \\
\hline 6.8 & 14.6 & 4.1 & 13.9 & 22.7 & 32.9 \\
0.04 & 70.0 & 0.53 & 73.5 & 19.4 & 103.6 \\
$\mathbf{2 0 1 5}$ & $\mathbf{2 0 1 8}$ & $\mathbf{2 0 1 5}$ & $\mathbf{2 0 1 8}$ & $\mathbf{2 0 1 5}$ & $\mathbf{2 0 1 8}$ \\
\hline 89.0 & 89.6 & 86.1 & 94.6 & 98.2 & 98.8 \\
$\mathbf{2 0 0 8}$ & $\mathbf{2 0 1 7}$ & $\mathbf{2 0 0 8}$ & $\mathbf{2 0 1 7}$ & $\mathbf{2 0 0 8}$ & $\mathbf{2 0 0 7}$ \\
\hline 0.51 & 10.0 & 0.58 & 5.1 & 2.2 & 27.7
\end{tabular}

\begin{tabular}{cccccc}
\multicolumn{2}{c}{ México } & \multicolumn{2}{c}{ ALC } & \multicolumn{2}{c}{ OCDE } \\
\hline $\mathbf{2 0 0 8}$ & $\mathbf{2 0 1 8}$ & $\mathbf{2 0 0 8}$ & $\mathbf{2 0 1 8}$ & $\mathbf{2 0 0 8}$ & $\mathbf{2 0 1 8}$ \\
\hline 0.59 & 0.68 & 0.52 & 0.65 & 0.72 & 0.82 \\
21.7 & 65.8 & 25.3 & 67.7 & 65.0 & 84.3 \\
$\mathbf{2 0 1 5}$ & $\mathbf{2 0 1 9}$ & $\mathbf{2 0 1 5}$ & $\mathbf{2 0 1 9}$ & $\mathbf{2 0 1 5}$ & $\mathbf{2 0 1 9}$ \\
\hline 49.1 & 47.5 & 46.4 & 51.5 & 73.9 & 85.0 \\
\multicolumn{2}{c}{$\mathbf{2 0 1 7}$} & \multicolumn{2}{c}{$\mathbf{2 0 1 7}$} & \multicolumn{2}{c}{$\mathbf{2 0 1 7}$} \\
\hline \multicolumn{2}{c}{16.8} & \multicolumn{2}{c}{14.8} & \multicolumn{2}{c}{ N/A }
\end{tabular}

\begin{tabular}{cccccc}
\multicolumn{2}{c}{ México } & \multicolumn{2}{c}{ ALC } & \multicolumn{2}{c}{ OCDE } \\
\hline $\mathbf{2 0 0 8}$ & $\mathbf{2 0 1 8}$ & $\mathbf{2 0 0 8}$ & $\mathbf{2 0 1 8}$ & $\mathbf{2 0 0 8}$ & $\mathbf{2 0 1 8}$ \\
\hline 20.6 & 21.0 & 9.3 & 8.6 & 15.6 & 15.1 \\
1.08 & 0.45 & 3.1 & 3.9 & 4.6 & 6.7 \\
$\mathbf{2 0 1 2}$ & $\mathbf{2 0 1 6}$ & $\mathbf{2 0 1 2}$ & $\mathbf{2 0 1 6}$ & $\mathbf{2 0 1 2}$ & $\mathbf{2 0 1 6}$ \\
\hline 0.21 & 0.32 & 0.14 & 0.34 & 30.9 & 38.2 \\
$\mathbf{2 0 0 6}$ & $\mathbf{2 0 1 6}$ & $\mathbf{2 0 0 6}$ & $\mathbf{2 0 1 6}$ & $\mathbf{2 0 0 6}$ & $\mathbf{2 0 1 6}$ \\
\hline 0.37 & 0.49 & 0.35 & 0.42 & 1.7 & 1.9 \\
\hline \multicolumn{2}{c}{$\mathbf{2 0 1 9}$} & \multicolumn{2}{c}{$\mathbf{2 0 1 9}$} & \multicolumn{2}{c}{$\mathbf{2 0 1 9}$} \\
\hline 0.71 & \multicolumn{2}{c}{0.43} & \multicolumn{2}{c}{0.61}
\end{tabular}

\begin{tabular}{|c|c|c|c|c|c|}
\hline \multicolumn{2}{|c|}{ México } & \multicolumn{2}{|c|}{ ALC } & \multicolumn{2}{|c|}{ OCDE } \\
\hline \multicolumn{2}{|c|}{$2006-15$} & \multicolumn{2}{|c|}{$2006-15$} & \multicolumn{2}{|c|}{$2006-15$} \\
\hline \multicolumn{2}{|c|}{7.2} & \multicolumn{2}{|c|}{6.9} & \multicolumn{2}{|c|}{4.8} \\
\hline \multicolumn{2}{|c|}{2004} & \multicolumn{2}{|c|}{2018} & \multicolumn{2}{|c|}{2018} \\
\hline \multicolumn{2}{|c|}{65.9} & \multicolumn{2}{|c|}{54.9} & \multicolumn{2}{|c|}{ N/A } \\
\hline 2007 & 2017 & 2007 & 2017 & 2007 & 2017 \\
\hline 25.4 & 40.2 & 37.5 & 60.5 & 66.6 & 74.3 \\
\hline \multicolumn{2}{|c|}{2016} & \multicolumn{2}{|c|}{2016} & \multicolumn{2}{|c|}{2016} \\
\hline \multicolumn{2}{|c|}{13.8} & \multicolumn{2}{|c|}{16.0} & \multicolumn{2}{|c|}{9.8} \\
\hline \multicolumn{2}{|c|}{9.7} & \multicolumn{2}{|c|}{13.8} & \multicolumn{2}{|c|}{14.5} \\
\hline \multicolumn{2}{|c|}{21.3} & \multicolumn{2}{|c|}{12.5} & \multicolumn{2}{|c|}{14.6} \\
\hline
\end{tabular}

\begin{tabular}{cccccc}
\multicolumn{2}{c}{ México } & \multicolumn{2}{c}{ ALC } & \multicolumn{2}{c}{ OCDE } \\
\hline $\mathbf{2 0 1 5}$ & $\mathbf{2 0 1 6}$ & $\mathbf{2 0 1 5}$ & $\mathbf{2 0 1 6}$ & $\mathbf{2 0 1 5}$ & $\mathbf{2 0 1 6}$ \\
\hline 7.9 & 8.2 & 6.9 & 7.2 & 17.7 & 17.7 \\
$\mathbf{2 0 1 5}$ & $\mathbf{2 0 1 8}$ & $\mathbf{2 0 1 5}$ & $\mathbf{2 0 1 8}$ & $\mathbf{2 0 1 5}$ & $\mathbf{2 0 1 8}$ \\
\hline 2.2 & 2.4 & 2.4 & 1.6 & 1.8 & 1.1 \\
\multicolumn{2}{c}{$\mathbf{2 0 1 8}$} & \multicolumn{2}{c}{$\mathbf{2 0 1 8}$} & \multicolumn{2}{c}{$\mathbf{2 0 1 8}$} \\
\hline 7.6 & \multicolumn{2}{c}{7.7} & \multicolumn{2}{c}{27.7}
\end{tabular}

\begin{tabular}{cccccc}
\multicolumn{2}{c}{ México } & \multicolumn{2}{c}{ ALC } & \multicolumn{2}{c}{ OCDE } \\
\hline \multicolumn{2}{c}{$\mathbf{2 0 2 0}$} & \multicolumn{2}{c}{$\mathbf{2 0 2 0}$} & \multicolumn{2}{c}{$\mathbf{2 0 2 0}$} \\
\hline \multicolumn{2}{c}{5.2} & \multicolumn{2}{c}{4.4} & \multicolumn{2}{c}{ N/A } \\
\hline $\mathbf{2 0 1 6}$ & $\mathbf{2 0 1 8}$ & $\mathbf{2 0 1 6}$ & $\mathbf{2 0 1 8}$ & $\mathbf{2 0 1 6}$ & $\mathbf{2 0 1 8}$ \\
\hline 0.32 & 0.63 & 0.36 & 0.43 & 0.56 & 0.79 \\
$\mathbf{2 0 1 8}$ & $\mathbf{2 0 1 9}$ & $\mathbf{2 0 1 8}$ & $\mathbf{2 0 1 9}$ & $\mathbf{2 0 1 8}$ & $\mathbf{2 0 1 9}$ \\
\hline 84.4 & 65.3 & 72.0 & 63.1 & 61.7 & 58.3 \\
\hline 66.0 & 51.9 & 52.8 & 54.9 & 41.7 & 45.6
\end{tabular}

\begin{tabular}{cccccc}
\multicolumn{2}{c}{} & \multicolumn{2}{c}{ ALC } & \multicolumn{2}{c}{ OCDE } \\
\hline $\mathbf{2}$ México & $\mathbf{2 0 1 5}$ & $\mathbf{2 0 1 5}$ & $\mathbf{2 0 1 9}$ & $\mathbf{2 0 1 5}$ & $\mathbf{2 0 1 9}$ \\
\hline 0.14 & 0.14 & 0.24 & 0.24 & 0.13 & 0.15 \\
2018 & \multicolumn{2}{c}{$\mathbf{2 0 1 8}$} & \multicolumn{2}{c}{$\mathbf{2 0 1 8}$} \\
\hline 0.19 & \multicolumn{2}{c}{0.07} & \multicolumn{2}{c}{0.06} \\
\hline
\end{tabular}




\section{Notas técnicas}

1. La Tabla sigue lo mejor posible las siete áreas claves identificadas en el proyecto Going Digital de la OCDE: 1) mejorar el acceso a las tecnologías digitales; 2) aumentar el uso efectivo; 3) permitir la innovación digital; 4) asegurar empleos adecuados para todos; 5) promocionar la prosperidad social; 6) reforzar la confianza; y 7) promocionar la apertura de mercados (OCDE, 2019a). Los indicadores se eligen según la disponibilidad de datos para los países de ALC. Existe la posibilidad de un sesgo por la forma en que se han agregado los componentes en los indicadores de índice.

2. El promedio de ALC es un promedio simple. La composición de los países depende de la disponibilidad de datos de los países de la región. Cada promedio incluye tantos países de ALC encontrados en cada fuente como sea posible.

3. El promedio de la OCDE es un promedio simple que incluye a todos los países miembros de la OCDE en mayo de 2020.

4. Datos de la UIT (2020), Base de datos de indicadores mundiales de telecomunicaciones / TIC 2020 (base de datos). La velocidad de banda ancha fija en Mbit/s se refiere a la velocidad de descarga teórica máxima anunciada garantizada a los usuarios asociados con una suscripción mensual de Internet de banda ancha fija.

5. Datos de la División de Estadística de las Naciones Unidas, Base de datos mundial de los ODS de las Naciones Unidas (base de datos). Datos de 2015 y 2018 o los últimos disponibles.

6. Datos de la base de conocimientos sobre gobierno electrónico de las Naciones Unidas (2019), centro de datos (base de datos). El índice de desarrollo del gobierno electrónico (E-government development index) es un indicador compuesto que consta de tres índices (índice de servicios en línea, índice de infraestructura de telecomunicaciones e índice de capital humano), que están igualmente ponderados. Tiene un rango de 0 a 1, con 1 siendo un gobierno más desarrollado.

7. Datos de UNCTAD (2020), UNCTADSTAT (base de datos). El índice de comercio electrónico B2C de la UNCTAD mide la preparación de una economía para respaldar las compras en línea. Rango de 0 a 100, con 100 siendo el nivel de apoyo más alto.

8. Cálculos propios a partir de datos de Latinobarómetro (2019), Libros de Códigos por País / Año (base de datos). Datos de 2017. Datos de encuestas de opinión pública utilizando muestras representativas a nivel nacional seleccionadas al azar.

9. Datos del Banco Mundial (2020a), Banco de datos del Banco Mundial (base de datos).

10. Datos del Banco Mundial (2020b), TCdata360. Datos de 2012 y 2016 o los últimos disponibles.

11. Datos de Unesco (2019), Instituto de Estadística de la Unesco (base de datos). Gastos en I+D, como porcentaje de los datos del PIB de 2006 y 2016 o el último disponible.

12. Datos de OCDE (2020a), OECD.Stat (base de datos) y OCDE (2020b). El índice OURdata de la OCDE evalúa los esfuerzos de los gobiernos para implementar datos abiertos en tres áreas críticas: apertura, utilidad y reutilización de los datos gubernamentales. Tiene un rango de 0 a 1, con 1 siendo la puntuación más alta.

13. Datos de OCDE (2020a), OECD.Stat (base de datos). El Índice de restricción del comercio de servicios digitales de la OCDE identifica, cataloga y cuantifica las barreras que afectan el comercio de servicios habilitados digitalmente en 46 países. Tiene un rango de 0 a 1, con 1 siendo el valor más restrictivo. El Índice de Restricción Reglamentaria de la Inversión Extranjera Directa (IED RRI) mide cuatro tipos de restricciones legales a la inversión extranjera directa: 1) restricciones a la participación extranjera en el capital social; 2) requisitos de selección y aprobación previa; 3) regulaciones para personas claves; y 4) otras restricciones al funcionamiento de empresas extranjeras. El RRI de la IED es un índice compuesto, que varía de 0 a 1, con 1 siendo el valor más restrictivo.

14. Datos de ILOSTAT, datos de 2018 o último año disponible.

15. Datos de la Asociación mundial de estadísticas sobre desechos electrónicos.

16. Cálculos de la OCDE basados en OCDE (2020c), Programa de Evaluación Internacional de Estudiantes (base de datos). Datos de 2015 y 2018.

17. Datos de la OCDE (2019d), Survey of Adult Skills (2018). Los porcentajes para la resolución de problemas en entornos ricos en tecnología se calculan de modo que la suma de los porcentajes de las siguientes categorías mutuamente exhaustivas sea igual al 100\%: se excluyó de la evaluación por computadora; sin experiencia en informática; prueba de núcleo de TIC fallida; por debajo del Nivel 1, en el Nivel 1, en el Nivel 2 y en el Nivel 3.

18. Datos de CAF (2020), The GouTech Index 2020: Unlocking the Potential of GouTech Ecosystems in Latin America, Spain and Portugal. El índice GovTech 2020 mide la madurez del ecosistema GovTech. Se basa en 28 indicadores en 7 dimensiones, que, en conjunto, forman 3 pilares igualmente ponderados: industria de nueva creación, políticas gubernamentales y sistemas de adquisiciones. 
19. El Índice mundial de ciberseguridad mide el compromiso de los países con la ciberseguridad a escala global. Tiene cinco pilares: 1) medidas legales; 2) medidas técnicas; 3) medidas organizativas; 4) desarrollo de capacidades; y 5) cooperación. Va de 0 a 1, siendo 1 el nivel más alto de ciberseguridad.

20. Datos de The Economist Intelligence Unit (2019), EIU Inclusive Internet Index (base de datos). Los indicadores presentan la seguridad percibida del comercio electrónico y la confianza en la privacidad en línea entre las personas seleccionadas al azar en países seleccionados. Varía del $0 \%$ al 100\%, donde el $100 \%$ indica una confianza absoluta en la seguridad del comercio electrónico y la confianza en la privacidad en línea.

\section{Referencias}

Banco Mundial (2020a), DataBank (base de datos), Grupo del Banco Mundial, Washington, DC, https:// databank.worldbank.org/home.aspx (consultada el 11 de diciembre de 2019).

Banco Mundial (2020b), TCdata360 (base de datos), Grupo del Banco Mundial, Washington, DC, https:// tcdata360.worldbank.org/ (consultada el 4 de agosto de 2020).

Base de conocimientos sobre gobierno electrónico de la ONU (2019), Data Center (base de datos), Departamento de Asuntos Económicos y Sociales de las Naciones Unidas, Nueva York, https:// publicadministration.un.org/egovkb/en-us/Data-Center (consultada el 11 de diciembre de 2019).

CAF (2020), The GouTech Index 2020: Unlocking the Potential of GovTech Ecosystems in Latin America, Spain and Portugal, Banco de Desarrollo de America Latina, Caracas.

CEPAL (2018), Observatorio Regional de Planificación para el Desarrollo de América Latina y el Caribe, Comisión Económica para América Latina y el Caribe, Santiago, https://observatorioplanificacion.cepal.org/es.

Dispositivo de estadísticas de la ONU (2018, 2015), ODS globales de la ONU (database), Departamento de Asuntos Económicos y Sociales de las Naciones Unidas, Nueva York, https://unstats.un.org/sdgs/ indicators/database/ (consultada el 20 de mayo de 2020).

Foro Mundial Económico (2016), “The Global Information Technology Report 2016”, Foro Mundial Económico, Ginebra, https://www.weforum.org/reports/the-global-information-technology-report-2016.

Global E-waste Statistic Partnership, página de internet, Global E-waste Statistic Partnership, Bonn, https:// globalewaste.org/ (consultada el 11 de diciembre de 2019).

Latinobarómetro (2019), Libros de Códigos por País/Año (base de datos), Latinobarómetro, Providencia, www. latinobarometro.org/latCodebooks.jsp (consultada el 11 de diciembre de 2019).

OCDE (2020a), OECD.Stat (database), Publicaciones de la OCDE, París, https://stats.oecd.org/ (consultada el 11 de diciembre de 2019).

OCDE (2020b), Panorama de las Administraciones Públicas América Latina y el Caribe 2020, Publicaciones de la OCDE, París, https://doi.org/10.1787/13130fbb-en.

OCDE (2020c), Programme for International Student Assessment (base de datos), Publicaciones de la OCDE, París, www.oecd.org/pisa/data/2018database/ (consultada el 14 de febrero de 2020).

OCDE (2019a), Cómo medir la transformación digital: Hoja de ruta para el futuro, Publicaciones de la OCDE, París, https://doi.org/10.1787/9789264311992-en.

OCDE (2019b), Estudios de la OCDE sobre Transformación Digital: “Going Digital” en Colombia, Publicaciones de la OCDE, París, https://doi.org/10.1787/781185b1-en.

OCDE (2019c), Digital Government Review of Panama: Enhancing the Digital Transformation of the Public Sector, OCDE Estudios de gobierno digital, Publicaciones de la OCDE, París, https://doi.org/10.1787/615a4180-en.

OCDE (2019d), Survey of Adult Skills, Publicaciones de la OCDE, París, https://www.oecd.org/skills/piaac/data/

OIT (2019), ILO Statistics (base de datos), Organización Internacional del Trabajo, Ginebra, www.ilo.org/ global/statistics-and-databases/lang--en/index.htm (consultada el 11 de diciembre de 2019).

Open Knowledge Foundation (2019), Global Open Data Index (base de datos), Open Knowledge Foundation, Cambridge, Reino Unido, https://index.okfn.org/dataset/ (consultada el 19 de abril de 2020).

PIAAC Expert Group in Problem Solving in Technology-Rich Environments (2009), "PIAAC Problem Solving in Technology- Rich Environments: A Conceptual Framework", OCDE Documentos de trabajo educativo, n. ${ }^{\circ}$ 36, Publicaciones de la OCDE, París, https://doi.org/10.1787/220262483674.

The Economist Intelligence Unit (2019), EIU Inclusive Internet Index 2019 (base de datos), The Economist Group, Londres, https://theinclusiveinternet.eiu.com/explore/countries/performance (consultada el $11 \mathrm{de}$ diciembre 2019).

UIT (2020), base de datos de indicadores mundiales de telecomunicaciones / TIC 2020 (base de datos), Unión Internacional de Telecomunicaciones, Ginebra, https://www.itu.int/en/ITU-D/Statistics/Pages/ publications/wtid.aspx (consultada el 21 de agosto de 2020). 
UNCTAD (2020), UNCTADSTAT (base de datos), Conferencia de las Naciones Unidas sobre Comercio y Desarrollo, Ginebra, https://unctadstat.unctad.org/EN/ (consultada el 11 de diciembre de 2019).

UNESCO (2019), Instituto de Estadística de la Unesco (base de datos), Unesco, París, http://data.uis.unesco. org/Index.aspx (consultada el 20 de mayo de 2020).

World Wide Web Foundation (2017), OpenData Barometer (base de datos), World Wide Web Foundation, Ginebra, https://opendatabarometer.org/ (consultada el 19 de abril de 2020). 



\section{PANAMÁ}

\section{Tendencias recientes}

Panamá aspira a crear una economía digital incluyente y una administración más fuerte y transparente gracias a las herramientas digitales. El país se ha esforzado por mejorar el acceso y uso de las tecnologías digitales por parte de todos sus ciudadanos. Ha aumentado el número de usuarios de Internet y de suscripciones a servicios de banda ancha móvil activa y fija en la última década, aunque las disparidades regionales, en términos de género y edad siguen siendo un reto. Panamá mejoró en el índice de desarrollo de gobierno electrónico del 0.47 en 2008 al 0.61 en 2018, por debajo del promedio de América Latina y el Caribe (ALC) $(0,65)$. Este índice mide la disposición y la capacidad de las administraciones nacionales para utilizar las TIC (tecnologías de la información y las comunicaciones) en la prestación de servicios públicos. El índice de comercio electrónico B2C de la UNCTAD indica que el apoyo de la economía a las compras por Internet, a pesar de ser un centro importante en la región, sigue estando ligeramente por debajo del promedio de ALC.

Con respecto a facilitar la innovación digital, Panamá tiene un desempeño inferior a los promedios de ALC y de la OCDE en varios indicadores, como el gasto en I+D (en proporción al PIB), solicitudes de patentes y proporción de importaciones de servicios de TIC. En cuanto a la promoción de una sociedad digital incluyente, en relación con el promedio de ALC, el país cuenta con un número similar de computadoras por estudiante.

\section{Estrategias nacionales y cooperación internacional para la transformación digital}

El Plan Estratégico del Gobierno 2019-2024 y la Agenda Digital 2020, El Camino a un Ciudadano Digital, son los principales documentos de referencia para el desarrollo y la transformación digital de Panamá. Estas estrategias ponen de manifiesto la necesidad de avanzar desde un gobierno electrónico hacia un gobierno plenamente digital, de acuerdo con la Revisión de Gobierno Digital de Panamá elaborada por la OCDE (OCDE, 2019c).

Las políticas digitales se centran principalmente en la creación de procesos digitales para las administraciones públicas. La modificación de la Ley n..$^{\circ} 83$ de 2012 mediante el Decreto n..$^{\circ} 275$ de 2018 sentó las bases para la aplicación de procedimientos electrónicos y la interoperabilidad institucional: la promoción de la firma electrónica, la protección de datos y la actualización de la información y los servicios en la plataforma Panamá Tramita y en el Portal Nacional de Pagos. Panamá Tramita cataloga los 2.700 trámites del gobierno central con los ciudadanos o empresas, así como los 1.463 trámites existentes con el gobierno local. En 2019, Panamá también aprobó una ley de protección de datos personales, que establece el marco jurídico para la interoperabilidad y el desarrollo de centros de datos para aplicaciones en la nube para empresas públicas y privadas. Otras iniciativas incluyen la modernización de la contratación pública con el objetivo de lograr una gestión más transparente y eficiente de los recursos a través de Panamá Compra, una plataforma electrónica de compras. Por último, en el marco de la Agenda Digital 2020, el país puso en marcha el Panamá Digital Hub, una iniciativa para convertir al país en un centro internacional de innovación digital. Para mitigar el impacto social del coronavirus, el Ministerio de Educación puso a disposición material educativo a través del portal Educa Panamá y lanzó la plataforma de aprendizaje electrónico Ester. La Oficina Nacional de Informática se encarga de hacer un estudio sobre el número de estudiantes que tienen acceso a dispositivos móviles y a Internet (CAF, 2020). Sin embargo, a pesar de esos esfuerzos, debido a la falta de acceso a Internet y al suministro de electricidad, existe la preocupación de que las desigualdades se puedan exacerbar con la crisis del Covid-19.

En cuanto a la cooperación internacional, Panamá colabora con otros países de América Latina y el Caribe a través del grupo eLAC. La Agenda Digital 2020 de la eLAC aborda el desarrollo de las infraestructuras digitales, fomentando la implantación de planes en áreas remotas y promoviendo tecnologías digitales que respondan a las catástrofes naturales. La agenda respalda el uso de tecnologías para el desarrollo sostenible impulsando el uso convergente de varios tipos de tecnologías emergentes en las políticas públicas y el diseño de servicios digitales. El país también forma parte de la Comisión para el Desarrollo Científico y Tecnológico de Centroamérica y Panamá, que fomenta los vínculos entre los organismos nacionales de ciencia y tecnología de los países para generar políticas científicas y elaborar un plan estratégico regional en ciencia, tecnología e innovación.

Panamá también colabora con la Unión Europea en el Programa de Sistemas de Información para la Resiliencia en Seguridad Alimentaria y Nutricional en el SICA (Sistema de la Integración Centroamericana), contribuye al proceso de integración centroamericana y se propone alcanzar los Objetivos de Desarrollo Sostenible de las Naciones Unidas relacionados con el hambre y la seguridad alimentaria. En 2019, Ciudad de Panamá organizó el taller TAIEX con el fin de fomentar la cooperación en las aplicaciones de los satélites del programa Copérnico, establecer este programa como práctica mundial y promover la asimilación de sus datos en todo el mundo a fin de maximizar su valor social en la resolución de problemas mundiales. 


\section{Mejorar el acceso}

Suscripciones de banda ancha fija (por cada 100 habitantes) ${ }^{4}$

Suscripciones de banda ancha móvil activa (por cada 100 habitantes) ${ }^{4}$

Proporción de población cubierta por al menos una red 3G5

Velocidad de banda ancha fija (en Mbit/s) ${ }^{4}$

Aumentar el uso efectivo

Índice de desarrollo del gobierno electrónico (EGDI) ${ }^{6}$

Proporción de usuarios de Internet (\% de población) ${ }^{4}$

Índice de comercio electrónico B2C de la UNCTAD

Proporción de personas que realizan compras por Internet ${ }^{8}$

\section{Impulsar la innovación}

Exportaciones de alta tecnología (\% de exportaciones manufacturadas) ${ }^{9}$

Proporción de importaciones de servicios de TIC, como porcentaje del comercio total de servicios ${ }^{7}$

Solicitudes de patentes de TIC presentadas en virtud del Tratado de Cooperación en materia de Patentes (por millón de personas) ${ }^{10}$

Gastos en I+D, como \% del PIB ${ }^{11}$

Índice OURdata de la OCDE ${ }^{12}$

\section{Asegurar empleos adecuados para todos}

Contribuciones a variación en empleo total, por intensidad digital de sectores, 2006-2016 ${ }^{13}$

Proporción de empleo informal en relación con empleo total ${ }^{14}$

Tasa bruta de matrícula, educación terciaria $(\%)^{9}$

Graduados de educación terciaria por campo (\%) - Educación ${ }^{11}$

Graduados de educación terciaria por campo (\%) - Salud ${ }^{11}$

Graduados de educación terciaria por campo (\%) - Ingeniería ${ }^{11}$

\section{Promocionar la prosperidad social}

Generación de desechos de aparatos eléctricos per cápita $(\mathrm{kg})^{15}$

Número de estudiantes por computadora ${ }^{16}$

Proporción de mujeres con puntuación de nivel 203 en resolución de problemas en entornos tecnológicos ${ }^{17}$

\section{Reforzar la confianza}

Índice GovTech de la $\mathrm{CAF}^{18}$

Índice de ciberseguridad global (UIT) ${ }^{19}$

Seguridad del comercio electrónico $(\%)^{20}$

Confianza en la privacidad en Internet $(\%)^{20}$

\section{Promocionar la apertura de mercados}

Índice de restrictividad de intercambios de servicios digitales de la $O C D E^{13}$

Índice de restricción regulatoria de la IED de la $0 \mathrm{CDE}^{13}$

Las fuentes, notas a pie de página y detalles técnicos se pueden encontrar al final de las Notas País.

\begin{tabular}{cccccc}
\multicolumn{4}{c}{ Indicadores digitales - Panamá } \\
\hline \multicolumn{2}{c}{ Panamá } & \multicolumn{2}{c}{ ALC $^{2}$} & \multicolumn{2}{c}{ OCDE $^{3}$} \\
\hline $\mathbf{2 0 0 8}$ & $\mathbf{2 0 1 8}$ & $\mathbf{2 0 0 8}$ & $\mathbf{2 0 1 8}$ & $\mathbf{2 0 0 8}$ & $\mathbf{2 0 1 8}$ \\
\hline 5.6 & 10.8 & 4.1 & 13.9 & 22.7 & 32.9 \\
$\mathbf{2 0 1 0}$ & $\mathbf{2 0 1 8}$ & $\mathbf{2 0 1 0}$ & $\mathbf{2 0 1 8}$ & $\mathbf{2 0 1 0}$ & $\mathbf{2 0 1 8}$ \\
\hline 3.2 & 79.1 & 5.4 & 73.5 & 37.7 & 103.6 \\
$\mathbf{2 0 1 5}$ & $\mathbf{2 0 1 8}$ & $\mathbf{2 0 1 5}$ & $\mathbf{2 0 1 8}$ & $\mathbf{2 0 1 5}$ & $\mathbf{2 0 1 8}$ \\
\hline 79.0 & 95.0 & 86.1 & 94.6 & 98.2 & 98.8 \\
$\mathbf{2 0 0 8}$ & $\mathbf{2 0 1 7}$ & $\mathbf{2 0 0 8}$ & $\mathbf{2 0 1 7}$ & $\mathbf{2 0 0 8}$ & $\mathbf{2 0 0 7}$ \\
\hline 0.26 & 4.0 & 0.58 & 5.1 & 2.2 & 27.7
\end{tabular}

\begin{tabular}{cccccc}
\multicolumn{2}{c}{ Panamá } & \multicolumn{2}{c}{ ALC } & \multicolumn{2}{c}{ OCDE } \\
\hline $\mathbf{2 0 0 8}$ & $\mathbf{2 0 1 8}$ & $\mathbf{2 0 0 8}$ & $\mathbf{2 0 1 8}$ & $\mathbf{2 0 0 8}$ & $\mathbf{2 0 1 8}$ \\
\hline 0.47 & 0.61 & 0.52 & 0.65 & 0.72 & 0.82 \\
$\mathbf{2 0 0 8}$ & $\mathbf{2 0 1 7}$ & $\mathbf{2 0 0 8}$ & $\mathbf{2 0 1 7}$ & $\mathbf{2 0 0 8}$ & $\mathbf{2 0 0 7}$ \\
\hline 33.8 & 57.9 & 25.3 & 62.9 & 65.0 & 83.4 \\
$\mathbf{2 0 1 5}$ & $\mathbf{2 0 1 9}$ & $\mathbf{2 0 1 5}$ & $\mathbf{2 0 1 9}$ & $\mathbf{2 0 1 5}$ & $\mathbf{2 0 1 9}$ \\
\hline 47.2 & 50.4 & 46.4 & 51.5 & 73.9 & 85.0 \\
\hline \multicolumn{2}{c}{$\mathbf{2 0 1 7}$} & \multicolumn{2}{c}{$\mathbf{2 0 1 7}$} & \multicolumn{2}{c}{$\mathbf{2 0 1 7}$} \\
\hline 14.6 & \multicolumn{2}{c}{14.8} & \multicolumn{2}{c}{ N/A }
\end{tabular}

\begin{tabular}{cccccc}
\multicolumn{2}{c}{ Panamá } & \multicolumn{2}{c}{ ALC } & \multicolumn{2}{c}{ OCDE } \\
\hline $\mathbf{2 0 0 8}$ & $\mathbf{2 0 1 6}$ & $\mathbf{2 0 0 8}$ & $\mathbf{2 0 1 6}$ & $\mathbf{2 0 0 8}$ & $\mathbf{2 0 1 6}$ \\
\hline 1.2 & 9.2 & 9.3 & 9.8 & 15.6 & 16.6 \\
$\mathbf{2 0 0 8}$ & $\mathbf{2 0 1 8}$ & $\mathbf{2 0 0 8}$ & $\mathbf{2 0 1 8}$ & $\mathbf{2 0 0 8}$ & $\mathbf{2 0 1 8}$ \\
\hline 2.9 & 1.6 & 3.1 & 3.9 & 4.6 & 6.7 \\
$\mathbf{2 0 1 2}$ & $\mathbf{2 0 1 6}$ & $\mathbf{2 0 1 2}$ & $\mathbf{2 0 1 6}$ & $\mathbf{2 0 1 2}$ & $\mathbf{2 0 1 6}$ \\
\hline 0.14 & 1.3 & 0.14 & 0.34 & 30.9 & 38.2 \\
$\mathbf{2 0 0 6}$ & $\mathbf{2 0 1 3}$ & $\mathbf{2 0 0 6}$ & $\mathbf{2 0 1 3}$ & $\mathbf{2 0 0 6}$ & $\mathbf{2 0 1 3}$ \\
\hline 0.24 & 0.06 & 0.35 & 0.32 & 1.7 & 1.9 \\
\multicolumn{2}{c}{$\mathbf{2 0 1 9}$} & \multicolumn{2}{c}{$\mathbf{2 0 1 9}$} & \multicolumn{2}{c}{$\mathbf{2 0 1 9}$} \\
\hline 0.46 & \multicolumn{2}{c}{0.43} & \multicolumn{2}{c}{0.61}
\end{tabular}

\begin{tabular}{|c|c|c|c|c|c|}
\hline \multicolumn{2}{|c|}{ Panamá } & \multicolumn{2}{|c|}{ ALC } & \multicolumn{2}{|c|}{ OCDE } \\
\hline \multicolumn{2}{|c|}{$2006-15$} & \multicolumn{2}{|c|}{$2006-15$} & \multicolumn{2}{|c|}{$2006-15$} \\
\hline \multicolumn{2}{|c|}{ N/A } & \multicolumn{2}{|c|}{6.9} & \multicolumn{2}{|c|}{4.8} \\
\hline \multicolumn{2}{|c|}{2017} & \multicolumn{2}{|c|}{2018} & \multicolumn{2}{|c|}{2018} \\
\hline \multicolumn{2}{|c|}{49.4} & \multicolumn{2}{|c|}{54.9} & \multicolumn{2}{|c|}{$\mathrm{N} / \mathrm{A}$} \\
\hline 2007 & 2016 & 2007 & 2016 & 2007 & 2016 \\
\hline 43.3 & 47.8 & 37.5 & 57.8 & 66.6 & 73.3 \\
\hline \multicolumn{2}{|c|}{2016} & \multicolumn{2}{|c|}{2016} & \multicolumn{2}{|c|}{2016} \\
\hline \multicolumn{2}{|c|}{22.8} & \multicolumn{2}{|c|}{16.0} & \multicolumn{2}{|c|}{9.8} \\
\hline \multicolumn{2}{|c|}{7.9} & \multicolumn{2}{|c|}{13.8} & \multicolumn{2}{|c|}{14.5} \\
\hline \multicolumn{2}{|c|}{9.0} & \multicolumn{2}{|c|}{12.5} & \multicolumn{2}{|c|}{14.6} \\
\hline
\end{tabular}

\begin{tabular}{cccccc}
\multicolumn{2}{c}{ Panamá } & \multicolumn{2}{c}{ ALC } & \multicolumn{2}{c}{ OCDE } \\
\hline $\mathbf{2 0 1 5}$ & $\mathbf{2 0 1 6}$ & $\mathbf{2 0 1 5}$ & $\mathbf{2 0 1 6}$ & $\mathbf{2 0 1 5}$ & $\mathbf{2 0 1 6}$ \\
\hline 7.8 & 8.0 & 6.9 & 7.2 & 17.7 & 17.7 \\
$\mathbf{2 0 1 5}$ & $\mathbf{2 0 1 8}$ & $\mathbf{2 0 1 5}$ & $\mathbf{2 0 1 8}$ & $\mathbf{2 0 1 5}$ & $\mathbf{2 0 1 8}$ \\
\hline N/A & 1.6 & 2.4 & 1.6 & 1.8 & 1.1 \\
\hline \multicolumn{2}{c}{$\mathbf{2 0 1 8}$} & \multicolumn{2}{c}{$\mathbf{2 0 1 8}$} & \multicolumn{2}{c}{$\mathbf{2 0 1 8}$} \\
\hline \multicolumn{2}{c}{ N/A } & \multicolumn{2}{c}{7.7} & \multicolumn{2}{c}{27.7}
\end{tabular}

\begin{tabular}{cccccc}
\multicolumn{2}{c}{ Panamá } & \multicolumn{2}{c}{ ALC } & \multicolumn{2}{c}{ OCDE } \\
\hline \multicolumn{2}{c}{$\mathbf{2 0 2 0}$} & \multicolumn{2}{c}{$\mathbf{2 0 2 0}$} & \multicolumn{2}{c}{$\mathbf{2 0 2 0}$} \\
\hline \multicolumn{2}{c}{4.0} & \multicolumn{2}{c}{4.4} & \multicolumn{2}{c}{ N/A } \\
\hline $\mathbf{2 0 1 6}$ & $\mathbf{2 0 1 8}$ & $\mathbf{2 0 1 6}$ & $\mathbf{2 0 1 8}$ & $\mathbf{2 0 1 6}$ & $\mathbf{2 0 1 8}$ \\
\hline 0.29 & 0.37 & 0.36 & 0.43 & 0.56 & 0.79 \\
\hline $\mathbf{2 0 1 8}$ & $\mathbf{2 0 1 9}$ & $\mathbf{2 0 1 8}$ & $\mathbf{2 0 1 9}$ & $\mathbf{2 0 1 8}$ & $\mathbf{2 0 1 9}$ \\
\hline N/A & 64.4 & 72.0 & 63.1 & 61.7 & 58.3 \\
N/A & 69.2 & 52.8 & 54.9 & 41.7 & 45.6
\end{tabular}

\begin{tabular}{cccccc}
\multicolumn{2}{c}{ Panamá } & \multicolumn{2}{c}{ ALC } & \multicolumn{2}{c}{ OCDE } \\
\hline 2015 & $\mathbf{2 0 1 9}$ & $\mathbf{2 0 1 5}$ & $\mathbf{2 0 1 9}$ & $\mathbf{2 0 1 5}$ & $\mathbf{2 0 1 9}$ \\
\hline N/A & N/A & 0.24 & 0.24 & 0.13 & 0.15 \\
2018 & \multicolumn{2}{c}{$\mathbf{2 0 1 8}$} & \multicolumn{2}{c}{$\mathbf{2 0 1 8}$} \\
\hline N/A & 0.07 & \multicolumn{2}{c}{0.06} \\
\hline
\end{tabular}




\section{Notas técnicas}

1. La Tabla sigue lo mejor posible las siete áreas claves identificadas en el proyecto Going Digital de la OCDE: 1) mejorar el acceso a las tecnologías digitales; 2) aumentar el uso efectivo; 3) permitir la innovación digital; 4) asegurar empleos adecuados para todos; 5) promocionar la prosperidad social; 6) reforzar la confianza; y 7) promocionar la apertura de mercados (OCDE, 2019a). Los indicadores se eligen según la disponibilidad de datos para los países de ALC. Existe la posibilidad de un sesgo por la forma en que se han agregado los componentes en los indicadores de índice.

2. El promedio de ALC es un promedio simple. La composición de los países depende de la disponibilidad de datos de los países de la región. Cada promedio incluye tantos países de ALC encontrados en cada fuente como sea posible.

3. El promedio de la OCDE es un promedio simple que incluye a todos los países miembros de la OCDE en mayo de 2020.

4. Datos de la UIT (2020), Base de datos de indicadores mundiales de telecomunicaciones / TIC 2020 (base de datos). La velocidad de banda ancha fija en Mbit/s se refiere a la velocidad de descarga teórica máxima anunciada garantizada a los usuarios asociados con una suscripción mensual de Internet de banda ancha fija.

5. Datos de la División de Estadística de las Naciones Unidas, Base de datos mundial de los ODS de las Naciones Unidas (base de datos). Datos de 2015 y 2018 o los últimos disponibles.

6. Datos de la base de conocimientos sobre gobierno electrónico de las Naciones Unidas (2019), centro de datos (base de datos). El índice de desarrollo del gobierno electrónico (E-government development index) es un indicador compuesto que consta de tres índices (índice de servicios en línea, índice de infraestructura de telecomunicaciones e índice de capital humano), que están igualmente ponderados. Tiene un rango de 0 a 1, con 1 siendo un gobierno más desarrollado.

7. Datos de UNCTAD (2020), UNCTADSTAT (base de datos). El índice de comercio electrónico B2C de la UNCTAD mide la preparación de una economía para respaldar las compras en línea. Rango de 0 a 100, con 100 siendo el nivel de apoyo más alto.

8. Cálculos propios a partir de datos de Latinobarómetro (2019), Libros de Códigos por País / Año (base de datos). Datos de 2017. Datos de encuestas de opinión pública utilizando muestras representativas a nivel nacional seleccionadas al azar.

9. Datos del Banco Mundial (2020a), Banco de datos del Banco Mundial (base de datos).

10. Datos del Banco Mundial (2020b), TCdata360. Datos de 2012 y 2016 o los últimos disponibles.

11. Datos de Unesco (2019), Instituto de Estadística de la Unesco (base de datos). Gastos en I+D, como porcentaje de los datos del PIB de 2006 y 2016 o el último disponible.

12. Datos de OCDE (2020a), OECD.Stat (base de datos) y OCDE (2020b). El índice OURdata de la OCDE evalúa los esfuerzos de los gobiernos para implementar datos abiertos en tres áreas críticas: apertura, utilidad y reutilización de los datos gubernamentales. Tiene un rango de 0 a 1, con 1 siendo la puntuación más alta.

13. Datos de OCDE (2020a), OECD.Stat (base de datos). El Índice de restricción del comercio de servicios digitales de la OCDE identifica, cataloga y cuantifica las barreras que afectan el comercio de servicios habilitados digitalmente en 46 países. Tiene un rango de 0 a 1, con 1 siendo el valor más restrictivo. El Índice de Restricción Reglamentaria de la Inversión Extranjera Directa (IED RRI) mide cuatro tipos de restricciones legales a la inversión extranjera directa: 1) restricciones a la participación extranjera en el capital social; 2) requisitos de selección y aprobación previa; 3) regulaciones para personas claves; y 4) otras restricciones al funcionamiento de empresas extranjeras. El RRI de la IED es un índice compuesto, que varía de 0 a 1, con 1 siendo el valor más restrictivo.

14. Datos de ILOSTAT, datos de 2018 o último año disponible.

15. Datos de la Asociación mundial de estadísticas sobre desechos electrónicos.

16. Cálculos de la OCDE basados en OCDE (2020c), Programa de Evaluación Internacional de Estudiantes (base de datos). Datos de 2015 y 2018.

17. Datos de la OCDE (2019d), Survey of Adult Skills (2018). Los porcentajes para la resolución de problemas en entornos ricos en tecnología se calculan de modo que la suma de los porcentajes de las siguientes categorías mutuamente exhaustivas sea igual al 100\%: se excluyó de la evaluación por computadora; sin experiencia en informática; prueba de núcleo de TIC fallida; por debajo del Nivel 1, en el Nivel 1, en el Nivel 2 y en el Nivel 3.

18. Datos de CAF (2020), The GouTech Index 2020: Unlocking the Potential of GouTech Ecosystems in Latin America, Spain and Portugal. El índice GovTech 2020 mide la madurez del ecosistema GovTech. Se basa en 28 indicadores en 7 dimensiones, que, en conjunto, forman 3 pilares igualmente ponderados: industria de nueva creación, políticas gubernamentales y sistemas de adquisiciones. 
19. El Índice mundial de ciberseguridad mide el compromiso de los países con la ciberseguridad a escala global. Tiene cinco pilares: 1) medidas legales; 2) medidas técnicas; 3) medidas organizativas; 4) desarrollo de capacidades; y 5) cooperación. Va de 0 a 1, siendo 1 el nivel más alto de ciberseguridad.

20. Datos de The Economist Intelligence Unit (2019), EIU Inclusive Internet Index (base de datos). Los indicadores presentan la seguridad percibida del comercio electrónico y la confianza en la privacidad en línea entre las personas seleccionadas al azar en países seleccionados. Varía del $0 \%$ al 100\%, donde el $100 \%$ indica una confianza absoluta en la seguridad del comercio electrónico y la confianza en la privacidad en línea.

\section{Referencias}

Banco Mundial (2020a), DataBank (base de datos), Grupo del Banco Mundial, Washington, DC, https:// databank.worldbank.org/home.aspx (consultada el 11 de diciembre de 2019).

Banco Mundial (2020b), TCdata360 (base de datos), Grupo del Banco Mundial, Washington, DC, https:// tcdata360.worldbank.org/ (consultada el 4 de agosto de 2020).

Base de conocimientos sobre gobierno electrónico de la ONU (2019), Data Center (base de datos), Departamento de Asuntos Económicos y Sociales de las Naciones Unidas, Nueva York, https:// publicadministration.un.org/egovkb/en-us/Data-Center (consultada el 11 de diciembre de 2019).

CAF (2020), The GouTech Index 2020: Unlocking the Potential of GovTech Ecosystems in Latin America, Spain and Portugal, Banco de Desarrollo de America Latina, Caracas.

CEPAL (2018), Observatorio Regional de Planificación para el Desarrollo de América Latina y el Caribe, Comisión Económica para América Latina y el Caribe, Santiago, https://observatorioplanificacion.cepal.org/es.

Dispositivo de estadísticas de la ONU (2018, 2015), ODS globales de la ONU (database), Departamento de Asuntos Económicos y Sociales de las Naciones Unidas, Nueva York, https://unstats.un.org/sdgs/ indicators/database/ (consultada el 20 de mayo de 2020).

Foro Mundial Económico (2016), “The Global Information Technology Report 2016”, Foro Mundial Económico, Ginebra, https://www.weforum.org/reports/the-global-information-technology-report-2016.

Global E-waste Statistic Partnership, página de internet, Global E-waste Statistic Partnership, Bonn, https:// globalewaste.org/ (consultada el 11 de diciembre de 2019).

Latinobarómetro (2019), Libros de Códigos por País/Año (base de datos), Latinobarómetro, Providencia, www. latinobarometro.org/latCodebooks.jsp (consultada el 11 de diciembre de 2019).

OCDE (2020a), OECD.Stat (database), Publicaciones de la OCDE, París, https://stats.oecd.org/ (consultada el 11 de diciembre de 2019).

OCDE (2020b), Panorama de las Administraciones Públicas América Latina y el Caribe 2020, Publicaciones de la OCDE, París, https://doi.org/10.1787/13130fbb-en.

OCDE (2020c), Programme for International Student Assessment (base de datos), Publicaciones de la OCDE, París, www.oecd.org/pisa/data/2018database/ (consultada el 14 de febrero de 2020).

OCDE (2019a), Cómo medir la transformación digital: Hoja de ruta para el futuro, Publicaciones de la OCDE, París, https://doi.org/10.1787/9789264311992-en.

OCDE (2019b), Estudios de la OCDE sobre Transformación Digital: “Going Digital” en Colombia, Publicaciones de la OCDE, París, https://doi.org/10.1787/781185b1-en.

OCDE (2019c), Digital Government Review of Panama: Enhancing the Digital Transformation of the Public Sector, OCDE Estudios de gobierno digital, Publicaciones de la OCDE, París, https://doi.org/10.1787/615a4180-en.

OCDE (2019d), Survey of Adult Skills, Publicaciones de la OCDE, París, https://www.oecd.org/skills/piaac/data/

OIT (2019), ILO Statistics (base de datos), Organización Internacional del Trabajo, Ginebra, www.ilo.org/ global/statistics-and-databases/lang--en/index.htm (consultada el 11 de diciembre de 2019).

Open Knowledge Foundation (2019), Global Open Data Index (base de datos), Open Knowledge Foundation, Cambridge, Reino Unido, https://index.okfn.org/dataset/ (consultada el 19 de abril de 2020).

PIAAC Expert Group in Problem Solving in Technology-Rich Environments (2009), "PIAAC Problem Solving in Technology- Rich Environments: A Conceptual Framework", OCDE Documentos de trabajo educativo, n. ${ }^{\circ}$ 36, Publicaciones de la OCDE, París, https://doi.org/10.1787/220262483674.

The Economist Intelligence Unit (2019), EIU Inclusive Internet Index 2019 (base de datos), The Economist Group, Londres, https://theinclusiveinternet.eiu.com/explore/countries/performance (consultada el $11 \mathrm{de}$ diciembre 2019).

UIT (2020), base de datos de indicadores mundiales de telecomunicaciones / TIC 2020 (base de datos), Unión Internacional de Telecomunicaciones, Ginebra, https://www.itu.int/en/ITU-D/Statistics/Pages/ publications/wtid.aspx (consultada el 21 de agosto de 2020). 
UNCTAD (2020), UNCTADSTAT (base de datos), Conferencia de las Naciones Unidas sobre Comercio y Desarrollo, Ginebra, https://unctadstat.unctad.org/EN/ (consultada el 11 de diciembre de 2019).

UNESCO (2019), Instituto de Estadística de la Unesco (base de datos), Unesco, París, http://data.uis.unesco. org/Index.aspx (consultada el 20 de mayo de 2020).

World Wide Web Foundation (2017), OpenData Barometer (base de datos), World Wide Web Foundation, Ginebra, https://opendatabarometer.org/ (consultada el 19 de abril de 2020). 



\section{PARAGUAY}

\section{Tendencias recientes}

Paraguay sigue mejorando con respecto al desarrollo de una sociedad y economía digital incluyente. El país se ha esforzado por mejorar el acceso digital de todos sus ciudadanos. Ha aumentado el número de usuarios de Internet y de suscripciones a servicios de banda ancha móvil activa y fija en la última década. Paraguay ascendió en el índice de desarrollo de gobierno electrónico del 0.47 en 2008 al 0.53 en 2018, una evolución inferior al promedio de América Latina y el Caribe (ALC) (0.65) y de la OCDE (0.82). Este índice mide la disposición y la capacidad de las administraciones nacionales para utilizar las TIC (tecnologías de la información y las comunicaciones) para prestar servicios públicos.

El país se encuentra por debajo del promedio de ALC en la mayoría de los indicadores de innovación digital, incluyendo el gasto en I+D y la proporción de importaciones de servicios de TIC. No obstante, las exportaciones de alta tecnología en proporción al total de las exportaciones de productos manufacturados se estancaron en torno al 9.7\% entre 2008 y 2018, por encima del promedio de ALC (8.6\%). Por último, el índice de comercio electrónico B2C de la UNCTAD aumentó entre 2015 (43.8) y 2019 (50.5) y se sitúa justo por debajo del promedio de ALC (51.5).

\section{Estrategias nacionales y cooperación internacional para la transformación digital}

El Plan Nacional de Desarrollo, Paraguay 2030, y la Agenda Digital son los principales documentos de referencia para el desarrollo y las políticas digitales del país. La Agenda Digital tiene como objetivo lograr la transformación digital a través de tres ejes: la inclusión digital y el uso de las TIC, el avance del gobierno digital y la innovación. Las políticas de transformación digital se asocian directamente con los tres objetivos generales del plan de desarrollo: la reducción de la pobreza y el desarrollo social, el crecimiento económico incluyente y una mayor inclusión en la economía internacional.

Entre las principales actividades está la Ley n. ${ }^{\circ}$ 6207/18, por la que se creó el Ministerio de Tecnologías de la Información y Comunicación (MITIC). El MITIC es la entidad técnica encargada de la formulación y ejecución de planes y proyectos de TIC del sector público. También es la autoridad administrativa responsable de los aspectos sociales y educativos de la inclusión, la innovación y la adopción de las tecnologías. Sus actuaciones se centran principalmente en la transparencia, la participación ciudadana, la protección de los derechos de los usuarios y la ciberseguridad. El MITIC destaca la importancia de la administración de la infraestructura tecnológica y el fomento de la interoperabilidad de los sistemas del sector público. Para mitigar el impacto del Covid-19, el MITIC está coordinando con los proveedores de servicios digitales para ofrecer acceso gratuito a los sitios web del Ministerio de Salud Pública y Bienestar Social y de la Organización Mundial de la Salud. Los usuarios también pueden llamar gratuitamente a la Dirección General de Vigilancia de la Salud. Este Ministerio también introdujo un instrumento de telemedicina digital para que los ciudadanos accedan a información, carguen datos y se comuniquen con los profesionales de la salud (CAF, 2020).

Con respecto a la cooperación internacional, Paraguay recibe apoyo del Banco Interamericano de Desarrollo para la aplicación de la Agenda Digital. Esta agenda proporciona un plan de implementación de seis años que promoverá la competitividad de la economía y la calidad de los servicios públicos a los ciudadanos y las empresas. Entre los objetivos del país se incluyen la reducción de los costos de los trámites de acceso a los servicios públicos y el aumento de la banda ancha mediante la ampliación de la conectividad y la mejora de la calidad de los servicios. Paraguay forma parte de la Alianza Better than Cash, junto con Colombia, México, Perú y otros países. Esta alianza de gobiernos, empresas y organizaciones internacionales tiene como objetivo acelerar la transición de pagos en efectivo a pagos digitales a fin de reducir la pobreza e impulsar el crecimiento incluyente.

Paraguay también colabora con la Unión Europea (UE) a través del Acuerdo de Asociación UE-Mercosur. En el contexto de este acuerdo, los países de Mercosur tratan de aumentar la cooperación en la economía digital y la investigación en el ámbito de la innovación. Paraguay también forma parte de la Alianza para el Gobierno Abierto junto con más de 70 países. El plan de acción 2018-2020 se centra en promover la digitalización y reducir la brecha digital. 


\section{Mejorar el acceso}

Suscripciones de banda ancha fija (por cada 100 habitantes) ${ }^{4}$

Suscripciones de banda ancha móvil activa (por cada 100 habitantes) ${ }^{4}$

Proporción de población cubierta por al menos una red $3 \mathrm{G}^{5}$

Velocidad de banda ancha fija (en Mbit/s) ${ }^{4}$

\section{Aumentar el uso efectivo}

Índice de desarrollo del gobierno electrónico (EGDI) ${ }^{6}$

Proporción de usuarios de Internet (\% de población) ${ }^{4}$

Índice de comercio electrónico B2C de la UNCTAD ${ }^{7}$

Proporción de personas que realizan compras por Internet ${ }^{8}$

\section{Impulsar la innovación}

Exportaciones de alta tecnología (\% de exportaciones manufacturadas) ${ }^{9}$

Proporción de importaciones de servicios de TIC, como porcentaje del comercio total de servicios ${ }^{7}$

Solicitudes de patentes de TIC presentadas en virtud del Tratado de Cooperación en materia de Patentes (por millón de personas) ${ }^{10}$

Gastos en I+D, como \% del PIB ${ }^{11}$

Índice OURdata de la OCDE ${ }^{12}$

\section{Asegurar empleos adecuados para todos}

Contribuciones a variación en empleo total, por intensidad digital de sectores, 2006-2016 ${ }^{13}$

Proporción de empleo informal en relación con empleo total ${ }^{14}$

Tasa bruta de matrícula, educación terciaria $(\%)^{9}$

Graduados de educación terciaria por campo (\%) - Educación ${ }^{11}$

Graduados de educación terciaria por campo (\%) - Salud ${ }^{11}$

Graduados de educación terciaria por campo (\%) - Ingeniería ${ }^{11}$

\section{Promocionar la prosperidad social}

Generación de desechos de aparatos eléctricos per cápita $(\mathrm{kg})^{15}$

Número de estudiantes por computadora ${ }^{16}$

Proporción de mujeres con puntuación de nivel 203 en resolución de problemas en entornos tecnológicos ${ }^{17}$

\section{Reforzar la confianza}

Índice GovTech de la $\mathrm{CAF}^{18}$

Índice de ciberseguridad global (UIT) $)^{19}$

Seguridad del comercio electrónico $(\%)^{20}$

Confianza en la privacidad en Internet $(\%)^{20}$

\section{Promocionar la apertura de mercados}

Índice de restrictividad de intercambios de servicios digitales de la $0 \operatorname{CDE}^{13}$

Índice de restricción regulatoria de la IED de la $0 \mathrm{CDE}^{13}$

Las fuentes, notas a pie de página y detalles técnicos se pueden encontrar al final de las Notas País.

\begin{tabular}{cccccc}
\multicolumn{4}{c}{ Indicadores digitales - Paraguay } \\
\hline \multicolumn{2}{c}{ Paraguay } & \multicolumn{2}{c}{ ALC $^{2}$} & \multicolumn{2}{c}{ OCDE $^{3}$} \\
\hline $\mathbf{2 0 0 8}$ & $\mathbf{2 0 1 8}$ & $\mathbf{2 0 0 8}$ & $\mathbf{2 0 1 8}$ & $\mathbf{2 0 0 8}$ & $\mathbf{2 0 1 8}$ \\
\hline 0.21 & 4.6 & 4.1 & 13.9 & 22.7 & 32.9 \\
$\mathbf{2 0 0 8}$ & $\mathbf{2 0 1 8}$ & $\mathbf{2 0 0 8}$ & $\mathbf{2 0 1 8}$ & $\mathbf{2 0 0 8}$ & $\mathbf{2 0 1 8}$ \\
\hline 0.93 & 57.7 & 1.8 & 73.5 & 29.8 & 103.6 \\
$\mathbf{2 0 1 5}$ & $\mathbf{2 0 1 8}$ & $\mathbf{2 0 1 5}$ & $\mathbf{2 0 1 8}$ & $\mathbf{2 0 1 5}$ & $\mathbf{2 0 1 8}$ \\
\hline 66.0 & 97.7 & 86.1 & 94.6 & 98.2 & 98.8 \\
$\mathbf{2 0 0 8}$ & $\mathbf{2 0 1 7}$ & $\mathbf{2 0 0 8}$ & $\mathbf{2 0 1 7}$ & $\mathbf{2 0 0 8}$ & $\mathbf{2 0 0 7}$ \\
\hline 0.26 & 3.0 & 0.58 & 5.1 & 2.2 & 27.7
\end{tabular}

\begin{tabular}{cccccc}
\multicolumn{2}{c}{ Paraguay } & \multicolumn{2}{c}{ ALC } & \multicolumn{2}{c}{ OCDE } \\
\hline $\mathbf{2 0 0 8}$ & $\mathbf{2 0 1 8}$ & $\mathbf{2 0 0 8}$ & $\mathbf{2 0 1 8}$ & $\mathbf{2 0 0 8}$ & $\mathbf{2 0 1 8}$ \\
\hline 0.47 & 0.53 & 0.52 & 0.65 & 0.72 & 0.82 \\
14.3 & 65.0 & 25.3 & 67.7 & 65.0 & 84.3 \\
$\mathbf{2 0 1 5}$ & $\mathbf{2 0 1 9}$ & $\mathbf{2 0 1 5}$ & $\mathbf{2 0 1 9}$ & $\mathbf{2 0 1 5}$ & $\mathbf{2 0 1 9}$ \\
\hline 43.8 & 50.5 & 46.4 & 51.5 & 73.9 & 85.0 \\
\multicolumn{2}{c}{$\mathbf{2 0 1 7}$} & \multicolumn{2}{c}{$\mathbf{2 0 1 7}$} & \multicolumn{2}{c}{$\mathbf{2 0 1 7}$} \\
\hline \multicolumn{2}{c}{13.2} & \multicolumn{2}{c}{14.8} & \multicolumn{2}{c}{ N/A }
\end{tabular}

\begin{tabular}{cccccc}
\multicolumn{2}{c}{ Paraguay } & \multicolumn{2}{c}{ ALC } & \multicolumn{2}{c}{ OCDE } \\
\hline $\mathbf{2 0 0 8}$ & $\mathbf{2 0 1 8}$ & $\mathbf{2 0 0 8}$ & $\mathbf{2 0 1 8}$ & $\mathbf{2 0 0 8}$ & $\mathbf{2 0 1 8}$ \\
\hline 9.6 & 9.7 & 9.3 & 8.6 & 15.6 & 15.1 \\
0.17 & 0.08 & 3.1 & 3.9 & 4.6 & 6.7 \\
$\mathbf{2 0 1 2}$ & $\mathbf{2 0 1 6}$ & $\mathbf{2 0 1 2}$ & $\mathbf{2 0 1 6}$ & $\mathbf{2 0 1 2}$ & $\mathbf{2 0 1 6}$ \\
\hline 0.04 & 0.00 & 0.14 & 0.34 & 30.9 & 38.2 \\
$\mathbf{2 0 0 8}$ & $\mathbf{2 0 1 6}$ & $\mathbf{2 0 0 8}$ & $\mathbf{2 0 1 6}$ & $\mathbf{2 0 0 8}$ & $\mathbf{2 0 1 6}$ \\
\hline 0.05 & 0.15 & 0.34 & 0.42 & 1.8 & 1.9 \\
\multicolumn{2}{c}{$\mathbf{2 0 1 9}$} & \multicolumn{2}{c}{$\mathbf{2 0 1 9}$} & \multicolumn{2}{c}{$\mathbf{2 0 1 9}$} \\
\hline 0.52 & \multicolumn{2}{c}{0.43} & \multicolumn{2}{c}{0.61}
\end{tabular}

\begin{tabular}{|c|c|c|c|c|c|}
\hline \multicolumn{2}{|c|}{ Paraguay } & \multicolumn{2}{|c|}{ ALC } & \multicolumn{2}{|c|}{ OCDE } \\
\hline \multicolumn{2}{|c|}{$2006-15$} & \multicolumn{2}{|c|}{$2006-15$} & \multicolumn{2}{|c|}{$2006-15$} \\
\hline \multicolumn{2}{|c|}{$\mathrm{N} / \mathrm{A}$} & \multicolumn{2}{|c|}{6.9} & \multicolumn{2}{|c|}{4.8} \\
\hline \multicolumn{2}{|c|}{2018} & \multicolumn{2}{|c|}{2018} & \multicolumn{2}{|c|}{2018} \\
\hline \multicolumn{2}{|c|}{70.3} & \multicolumn{2}{|c|}{54.9} & \multicolumn{2}{|c|}{ N/A } \\
\hline 2007 & 2010 & 2007 & 2010 & 2007 & 2010 \\
\hline 28.7 & 34.6 & 37.5 & 45.5 & 66.6 & 68.8 \\
\hline \multicolumn{2}{|c|}{2016} & \multicolumn{2}{|c|}{2016} & \multicolumn{2}{|c|}{2016} \\
\hline \multicolumn{2}{|c|}{$\mathrm{N} / \mathrm{A}$} & \multicolumn{2}{|c|}{16.0} & \multicolumn{2}{|c|}{9.8} \\
\hline \multicolumn{2}{|c|}{$\mathrm{N} / \mathrm{A}$} & \multicolumn{2}{|c|}{13.8} & \multicolumn{2}{|c|}{14.5} \\
\hline \multicolumn{2}{|c|}{$\mathrm{N} / \mathrm{A}$} & \multicolumn{2}{|c|}{12.5} & \multicolumn{2}{|c|}{14.6} \\
\hline
\end{tabular}

\begin{tabular}{cccccc}
\multicolumn{2}{c}{ Paraguay } & \multicolumn{2}{c}{ ALC } & \multicolumn{2}{c}{ OCDE } \\
\hline $\mathbf{2 0 1 5}$ & $\mathbf{2 0 1 6}$ & $\mathbf{2 0 1 5}$ & $\mathbf{2 0 1 6}$ & $\mathbf{2 0 1 5}$ & $\mathbf{2 0 1 6}$ \\
\hline 6.1 & 6.4 & 6.9 & 7.2 & 17.7 & 17.7 \\
$\mathbf{2 0 1 5}$ & $\mathbf{2 0 1 8}$ & $\mathbf{2 0 1 5}$ & $\mathbf{2 0 1 8}$ & $\mathbf{2 0 1 5}$ & $\mathbf{2 0 1 8}$ \\
\hline N/A & N/A & 2.4 & 1.6 & 1.8 & 1.1 \\
\multicolumn{2}{c}{$\mathbf{2 0 1 8}$} & \multicolumn{2}{c}{$\mathbf{2 0 1 8}$} & \multicolumn{2}{c}{$\mathbf{2 0 1 8}$} \\
\hline \multicolumn{2}{c}{ N/A } & \multicolumn{2}{c}{7.7} & \multicolumn{2}{c}{27.7}
\end{tabular}

\begin{tabular}{cccccc}
\multicolumn{2}{c}{ Paraguay } & \multicolumn{2}{c}{ ALC } & \multicolumn{2}{c}{ OCDE } \\
\hline \multicolumn{2}{c}{$\mathbf{2 0 2 0}$} & \multicolumn{2}{c}{$\mathbf{2 0 2 0}$} & \multicolumn{2}{c}{$\mathbf{2 0 2 0}$} \\
\hline \multicolumn{2}{c}{3.4} & \multicolumn{2}{c}{4.4} & \multicolumn{2}{c}{ N/A } \\
$\mathbf{2 0 1 6}$ & $\mathbf{2 0 1 8}$ & $\mathbf{2 0 1 6}$ & $\mathbf{2 0 1 8}$ & $\mathbf{2 0 1 6}$ & $\mathbf{2 0 1 8}$ \\
\hline 0.21 & 0.60 & 0.36 & 0.43 & 0.56 & 0.79 \\
\hline $\mathbf{2 0 1 8}$ & $\mathbf{2 0 1 9}$ & $\mathbf{2 0 1 8}$ & $\mathbf{2 0 1 9}$ & $\mathbf{2 0 1 8}$ & $\mathbf{2 0 1 9}$ \\
\hline N/A & N/A & 72.0 & 63.1 & 61.7 & 58.3 \\
N/A & N/A & 52.8 & 54.9 & 41.7 & 45.6
\end{tabular}

\begin{tabular}{cccccc}
\multicolumn{2}{c}{ Paraguay } & \multicolumn{2}{c}{ ALC } & \multicolumn{2}{c}{ OCDE } \\
\hline 2015 & 2019 & 2015 & 2019 & 2015 & $\mathbf{2 0 1 9}$ \\
\hline N/A & N/A & 0.24 & 0.24 & 0.13 & 0.15 \\
2018 & \multicolumn{2}{c}{2018} & \multicolumn{2}{c}{$\mathbf{2 0 1 8}$} \\
\hline N/A & 0.07 & \multicolumn{2}{c}{0.06} \\
\hline
\end{tabular}




\section{Notas técnicas}

1. La Tabla sigue lo mejor posible las siete áreas claves identificadas en el proyecto Going Digital de la OCDE: 1) mejorar el acceso a las tecnologías digitales; 2) aumentar el uso efectivo; 3) permitir la innovación digital; 4) asegurar empleos adecuados para todos; 5) promocionar la prosperidad social; 6) reforzar la confianza; y 7) promocionar la apertura de mercados (OCDE, 2019a). Los indicadores se eligen según la disponibilidad de datos para los países de ALC. Existe la posibilidad de un sesgo por la forma en que se han agregado los componentes en los indicadores de índice.

2. El promedio de ALC es un promedio simple. La composición de los países depende de la disponibilidad de datos de los países de la región. Cada promedio incluye tantos países de ALC encontrados en cada fuente como sea posible.

3. El promedio de la OCDE es un promedio simple que incluye a todos los países miembros de la OCDE en mayo de 2020.

4. Datos de la UIT (2020), Base de datos de indicadores mundiales de telecomunicaciones / TIC 2020 (base de datos). La velocidad de banda ancha fija en Mbit/s se refiere a la velocidad de descarga teórica máxima anunciada garantizada a los usuarios asociados con una suscripción mensual de Internet de banda ancha fija.

5. Datos de la División de Estadística de las Naciones Unidas, Base de datos mundial de los ODS de las Naciones Unidas (base de datos). Datos de 2015 y 2018 o los últimos disponibles.

6. Datos de la base de conocimientos sobre gobierno electrónico de las Naciones Unidas (2019), centro de datos (base de datos). El índice de desarrollo del gobierno electrónico (E-government development index) es un indicador compuesto que consta de tres índices (índice de servicios en línea, índice de infraestructura de telecomunicaciones e índice de capital humano), que están igualmente ponderados. Tiene un rango de 0 a 1, con 1 siendo un gobierno más desarrollado.

7. Datos de UNCTAD (2020), UNCTADSTAT (base de datos). El índice de comercio electrónico B2C de la UNCTAD mide la preparación de una economía para respaldar las compras en línea. Rango de 0 a 100, con 100 siendo el nivel de apoyo más alto.

8. Cálculos propios a partir de datos de Latinobarómetro (2019), Libros de Códigos por País / Año (base de datos). Datos de 2017. Datos de encuestas de opinión pública utilizando muestras representativas a nivel nacional seleccionadas al azar.

9. Datos del Banco Mundial (2020a), Banco de datos del Banco Mundial (base de datos).

10. Datos del Banco Mundial (2020b), TCdata360. Datos de 2012 y 2016 o los últimos disponibles.

11. Datos de Unesco (2019), Instituto de Estadística de la Unesco (base de datos). Gastos en I+D, como porcentaje de los datos del PIB de 2006 y 2016 o el último disponible.

12. Datos de OCDE (2020a), OECD.Stat (base de datos) y OCDE (2020b). El índice OURdata de la OCDE evalúa los esfuerzos de los gobiernos para implementar datos abiertos en tres áreas críticas: apertura, utilidad y reutilización de los datos gubernamentales. Tiene un rango de 0 a 1, con 1 siendo la puntuación más alta.

13. Datos de OCDE (2020a), OECD.Stat (base de datos). El Índice de restricción del comercio de servicios digitales de la OCDE identifica, cataloga y cuantifica las barreras que afectan el comercio de servicios habilitados digitalmente en 46 países. Tiene un rango de 0 a 1, con 1 siendo el valor más restrictivo. El Índice de Restricción Reglamentaria de la Inversión Extranjera Directa (IED RRI) mide cuatro tipos de restricciones legales a la inversión extranjera directa: 1) restricciones a la participación extranjera en el capital social; 2) requisitos de selección y aprobación previa; 3) regulaciones para personas claves; y 4) otras restricciones al funcionamiento de empresas extranjeras. El RRI de la IED es un índice compuesto, que varía de 0 a 1, con 1 siendo el valor más restrictivo.

14. Datos de ILOSTAT, datos de 2018 o último año disponible.

15. Datos de la Asociación mundial de estadísticas sobre desechos electrónicos.

16. Cálculos de la OCDE basados en OCDE (2020c), Programa de Evaluación Internacional de Estudiantes (base de datos). Datos de 2015 y 2018.

17. Datos de la OCDE (2019d), Survey of Adult Skills (2018). Los porcentajes para la resolución de problemas en entornos ricos en tecnología se calculan de modo que la suma de los porcentajes de las siguientes categorías mutuamente exhaustivas sea igual al 100\%: se excluyó de la evaluación por computadora; sin experiencia en informática; prueba de núcleo de TIC fallida; por debajo del Nivel 1, en el Nivel 1, en el Nivel 2 y en el Nivel 3.

18. Datos de CAF (2020), The GouTech Index 2020: Unlocking the Potential of GouTech Ecosystems in Latin America, Spain and Portugal. El índice GovTech 2020 mide la madurez del ecosistema GovTech. Se basa en 28 indicadores en 7 dimensiones, que, en conjunto, forman 3 pilares igualmente ponderados: industria de nueva creación, políticas gubernamentales y sistemas de adquisiciones. 
19. El Índice mundial de ciberseguridad mide el compromiso de los países con la ciberseguridad a escala global. Tiene cinco pilares: 1) medidas legales; 2) medidas técnicas; 3) medidas organizativas; 4) desarrollo de capacidades; y 5) cooperación. Va de 0 a 1, siendo 1 el nivel más alto de ciberseguridad.

20. Datos de The Economist Intelligence Unit (2019), EIU Inclusive Internet Index (base de datos). Los indicadores presentan la seguridad percibida del comercio electrónico y la confianza en la privacidad en línea entre las personas seleccionadas al azar en países seleccionados. Varía del $0 \%$ al 100\%, donde el $100 \%$ indica una confianza absoluta en la seguridad del comercio electrónico y la confianza en la privacidad en línea.

\section{Referencias}

Banco Mundial (2020a), DataBank (base de datos), Grupo del Banco Mundial, Washington, DC, https:// databank.worldbank.org/home.aspx (consultada el 11 de diciembre de 2019).

Banco Mundial (2020b), TCdata360 (base de datos), Grupo del Banco Mundial, Washington, DC, https:// tcdata360.worldbank.org/ (consultada el 4 de agosto de 2020).

Base de conocimientos sobre gobierno electrónico de la ONU (2019), Data Center (base de datos), Departamento de Asuntos Económicos y Sociales de las Naciones Unidas, Nueva York, https:// publicadministration.un.org/egovkb/en-us/Data-Center (consultada el 11 de diciembre de 2019).

CAF (2020), The GouTech Index 2020: Unlocking the Potential of GovTech Ecosystems in Latin America, Spain and Portugal, Banco de Desarrollo de America Latina, Caracas.

CEPAL (2018), Observatorio Regional de Planificación para el Desarrollo de América Latina y el Caribe, Comisión Económica para América Latina y el Caribe, Santiago, https://observatorioplanificacion.cepal.org/es.

Dispositivo de estadísticas de la ONU (2018, 2015), ODS globales de la ONU (database), Departamento de Asuntos Económicos y Sociales de las Naciones Unidas, Nueva York, https://unstats.un.org/sdgs/ indicators/database/ (consultada el 20 de mayo de 2020).

Foro Mundial Económico (2016), “The Global Information Technology Report 2016”, Foro Mundial Económico, Ginebra, https://www.weforum.org/reports/the-global-information-technology-report-2016.

Global E-waste Statistic Partnership, página de internet, Global E-waste Statistic Partnership, Bonn, https:// globalewaste.org/ (consultada el 11 de diciembre de 2019).

Latinobarómetro (2019), Libros de Códigos por País/Año (base de datos), Latinobarómetro, Providencia, www. latinobarometro.org/latCodebooks.jsp (consultada el 11 de diciembre de 2019).

OCDE (2020a), OECD.Stat (database), Publicaciones de la OCDE, París, https://stats.oecd.org/ (consultada el 11 de diciembre de 2019).

OCDE (2020b), Panorama de las Administraciones Públicas América Latina y el Caribe 2020, Publicaciones de la OCDE, París, https://doi.org/10.1787/13130fbb-en.

OCDE (2020c), Programme for International Student Assessment (base de datos), Publicaciones de la OCDE, París, www.oecd.org/pisa/data/2018database/ (consultada el 14 de febrero de 2020).

OCDE (2019a), Cómo medir la transformación digital: Hoja de ruta para el futuro, Publicaciones de la OCDE, París, https://doi.org/10.1787/9789264311992-en.

OCDE (2019b), Estudios de la OCDE sobre Transformación Digital: “Going Digital” en Colombia, Publicaciones de la OCDE, París, https://doi.org/10.1787/781185b1-en.

OCDE (2019c), Digital Government Review of Panama: Enhancing the Digital Transformation of the Public Sector, OCDE Estudios de gobierno digital, Publicaciones de la OCDE, París, https://doi.org/10.1787/615a4180-en.

OCDE (2019d), Survey of Adult Skills, Publicaciones de la OCDE, París, https://www.oecd.org/skills/piaac/data/

OIT (2019), ILO Statistics (base de datos), Organización Internacional del Trabajo, Ginebra, www.ilo.org/ global/statistics-and-databases/lang--en/index.htm (consultada el 11 de diciembre de 2019).

Open Knowledge Foundation (2019), Global Open Data Index (base de datos), Open Knowledge Foundation, Cambridge, Reino Unido, https://index.okfn.org/dataset/ (consultada el 19 de abril de 2020).

PIAAC Expert Group in Problem Solving in Technology-Rich Environments (2009), "PIAAC Problem Solving in Technology- Rich Environments: A Conceptual Framework", OCDE Documentos de trabajo educativo, n. ${ }^{\circ}$ 36, Publicaciones de la OCDE, París, https://doi.org/10.1787/220262483674.

The Economist Intelligence Unit (2019), EIU Inclusive Internet Index 2019 (base de datos), The Economist Group, Londres, https://theinclusiveinternet.eiu.com/explore/countries/performance (consultada el $11 \mathrm{de}$ diciembre 2019).

UIT (2020), base de datos de indicadores mundiales de telecomunicaciones / TIC 2020 (base de datos), Unión Internacional de Telecomunicaciones, Ginebra, https://www.itu.int/en/ITU-D/Statistics/Pages/ publications/wtid.aspx (consultada el 21 de agosto de 2020). 
UNCTAD (2020), UNCTADSTAT (base de datos), Conferencia de las Naciones Unidas sobre Comercio y Desarrollo, Ginebra, https://unctadstat.unctad.org/EN/ (consultada el 11 de diciembre de 2019).

UNESCO (2019), Instituto de Estadística de la Unesco (base de datos), Unesco, París, http://data.uis.unesco. org/Index.aspx (consultada el 20 de mayo de 2020).

World Wide Web Foundation (2017), OpenData Barometer (base de datos), World Wide Web Foundation, Ginebra, https://opendatabarometer.org/ (consultada el 19 de abril de 2020). 



\section{PERÚ}

\section{Tendencias recientes}

Perú se ha esforzado por mejorar el acceso y uso de las tecnologías digitales por parte de todos sus ciudadanos. Ha aumentado el número de usuarios de Internet y de suscripciones a servicios de banda ancha móvil activa y fija en la última década. Perú ascendió en el índice de desarrollo de gobierno electrónico del 0.53 en 2008 al 0.65 en 2018, una evolución coherente con el promedio de América Latina y el Caribe (ALC) (0.65) e inferior al promedio de la OCDE (0.82).

El desempeño de Perú en exportaciones de alta tecnología en proporción al total de las exportaciones de productos manufacturados (4.6\%) mejoró pero se mantuvo por debajo de los promedios de ALC (8.6\%) y de la OCDE (15.1\%) en 2018. Asimismo, el gasto en I+D se situó en el $0.1 \%$ del producto interno bruto (PIB), por debajo del promedio de ALC (0.4\% del PIB) en 2016. En 2018, el índice de restricción regulatoria de la inversión extranjera directa (IED) de la OCDE mostraba que Perú contaba con unas restricciones a la IED relativamente más altas que las de ALC y la OCDE. Finalmente, Perú sigue mejorando con respecto a la configuración de una sociedad digital inclusiva. En particular, el número de estudiantes por computadora cayó de 2.2 en 2015 a 1.4 en 2018, lo cual es coherente con el promedio de ALC y superior al promedio de la OCDE.

\section{Estrategias nacionales y cooperación internacional para la transformación digital}

El Plan Nacional de Competitividad y Productividad 2019-2030 y la Ley de Gobierno Digital de 2018 son los principales documentos de referencia para el desarrollo y la transformación digital de Perú. El plan nacional se centra en ocho objetivos principales para aumentar la competitividad internacional y situar a Perú en una senda de crecimiento estable para aumentar el bienestar. Casi la mitad de las medidas hacen referencia a la transformación digital, lo cual denota la importancia de la innovación digital para potenciar la competitividad y la productividad. La ley, aprobada por el Decreto legislativo n. ${ }^{\circ} .412$ de 2018, regula la transformación digital y se centra en las entidades gubernamentales. Establece el marco para la gestión de la identidad digital, los servicios digitales, los sistemas interoperables, la seguridad digital y de datos, y la aplicación transversal de las TIC en toda la administración pública.

La estrategia de transformación digital del Gobierno se compone de tres vectores. En primer lugar, aumentar la competitividad y la productividad mediante la regulación. Junto con las políticas, el Gobierno creó una Comisión de Alto Nivel para potenciar la coordinación multisectorial así como la Secretaría de Gobierno Digital de Perú, que se encarga de formular políticas y supervisar y evaluar los progresos conseguidos en el ámbito de la transformación digital del Gobierno. En segundo lugar, simplificar los procedimientos administrativos mediante la aplicación progresiva de la interoperabilidad. Las entidades de las administraciones públicas están obligadas a intercambiar sus documentos técnicos y jurídicos en formato digital. En el marco de esta estrategia, las administraciones públicas deben proporcionar a los usuarios la información sobre su estado civil, antecedentes penales, bienes registrados y títulos académicos de manera gratuita. También deben conectar sus sistemas de procesamiento de documentación a través de la Plataforma Nacional de Interoperabilidad del Estado. En tercer lugar, digitalizar los servicios públicos. La plataforma digital GOB.PE constituye un punto único de contacto para que las interacciones de los ciudadanos con el Gobierno sean claras, sencillas y seguras. Perú se ha centrado en conseguir avances en las redes nacionales de fibra óptica para reducir la brecha digital. Para mitigar el impacto del Covid-19, el Gobierno anunció que los empleadores del sector público y privado deben adaptarse al trabajo a distancia mientras esté vigente el estado de emergencia. Además, el Ministerio de Transporte y Comunicaciones donó 2.000 tabletas conectadas a Internet al Ministerio de Salud para recabar y analizar datos (CAF, 2020).

En materia de cooperación internacional, Perú se unió a la Alianza Better than Cash a través de la cooperación multilateral con Colombia, Paraguay, México y otros países del mundo. Esta alianza tiene como objetivo acelerar la adopción de los pagos digitales, en detrimento de los pagos en efectivo, a fin de reducir la pobreza e impulsar el crecimiento inclusivo. Brasil y Alemania prestaron asistencia para la creación del Centro de Tecnologías Ambientales de Perú, lo cual ha permitido al país acoger a expertos internacionales en tecnología ambiental para cumplir con la nueva legislación y los criterios impuestos a los exportadores por los mercados internacionales.

Perú también coordinó con la Unión Europea el programa para el establecimiento de un vínculo entre Europa y América Latina (programa BELLA), a fin de conseguir conectividad por cable de ultra alta velocidad, tanto submarina como terrestre, entre las regiones para el año 2021. Este programa incluye 11 redes de investigación y educación europeas y latinoamericanas y está dirigido por la RedCLARA, una organización internacional cuyo objetivo es conectar las redes informáticas de América Latina, y GEANT, una red paneuropea de investigación y educación. 


\section{Mejorar el acceso}

Suscripciones de banda ancha fija (por cada 100 habitantes) ${ }^{4}$

Suscripciones de banda ancha móvil activa (por cada 100 habitantes) ${ }^{4}$

Proporción de población cubierta por al menos una red $3 \mathrm{G}^{5}$

Velocidad de banda ancha fija (en Mbit/s) ${ }^{4}$

\section{Aumentar el uso efectivo}

Índice de desarrollo del gobierno electrónico (EGDI) ${ }^{6}$

Proporción de usuarios de Internet (\% de población) ${ }^{4}$

Índice de comercio electrónico B2C de la UNCTAD ${ }^{7}$

Proporción de personas que realizan compras por Internet ${ }^{8}$

\section{Impulsar la innovación}

Exportaciones de alta tecnología (\% de exportaciones manufacturadas) ${ }^{9}$

Proporción de importaciones de servicios de TIC, como porcentaje del comercio total de servicios ${ }^{7}$

Solicitudes de patentes de TIC presentadas en virtud del Tratado de Cooperación en materia de Patentes (por millón de personas) ${ }^{10}$

Gastos en I+D, como \% del PIB ${ }^{11}$

Índice OURdata de la OCDE'12

\section{Asegurar empleos adecuados para todos}

Contribuciones a variación en empleo total, por intensidad digital de sectores, 2006-2016 ${ }^{13}$

Proporción de empleo informal en relación con empleo total ${ }^{14}$

Tasa bruta de matrícula, educación terciaria $(\%)^{9}$

Graduados de educación terciaria por campo (\%) - Educación ${ }^{11}$

Graduados de educación terciaria por campo (\%) - Salud ${ }^{11}$

Graduados de educación terciaria por campo (\%) - Ingeniería ${ }^{11}$

Promocionar la prosperidad social

Generación de desechos de aparatos eléctricos per cápita $(\mathrm{kg})^{15}$

Número de estudiantes por computadora ${ }^{16}$

Proporción de mujeres con puntuación de nivel 203 en resolución de problemas en entornos tecnológicos ${ }^{17}$

\section{Reforzar la confianza}

Índice GovTech de la CAF ${ }^{18}$

Índice de ciberseguridad global (UIT) ${ }^{19}$

Seguridad del comercio electrónico $(\%)^{20}$

Confianza en la privacidad en Internet $(\%)^{20}$

\section{Promocionar la apertura de mercados}

Índice de restrictividad de intercambios de servicios digitales de la $0 \mathrm{CDE}^{13}$

Índice de restricción regulatoria de la IED de la OCDE ${ }^{13}$

Las fuentes, notas a pie de página y detalles técnicos se pueden encontrar al final de las Notas País.

\begin{tabular}{cccccc}
\multicolumn{4}{c}{ Indicadores digitales - Perú } \\
\hline \multicolumn{2}{c}{ Perú } & \multicolumn{3}{c}{ ALC $^{2}$} & \multicolumn{2}{c}{ OCDE $^{3}$} \\
\hline $\mathbf{2 0 0 8}$ & $\mathbf{2 0 1 7}$ & $\mathbf{2 0 0 8}$ & $\mathbf{2 0 1 7}$ & $\mathbf{2 0 0 8}$ & $\mathbf{2 0 1 7}$ \\
\hline 2.5 & 7.3 & 4.1 & 12.0 & 22.7 & 32.2 \\
$\mathbf{2 0 0 9}$ & $\mathbf{2 0 1 7}$ & $\mathbf{2 0 0 9}$ & $\mathbf{2 0 1 7}$ & $\mathbf{2 0 0 9}$ & $\mathbf{2 0 1 7}$ \\
\hline 0.29 & 65.7 & 1.8 & 66.8 & 29.8 & 97.3 \\
$\mathbf{2 0 1 5}$ & $\mathbf{2 0 1 7}$ & $\mathbf{2 0 1 5}$ & $\mathbf{2 0 1 7}$ & $\mathbf{2 0 1 5}$ & $\mathbf{2 0 1 7}$ \\
\hline 70.8 & 73.9 & 86.1 & 93.2 & 98.2 & 99.0 \\
\hline $\mathbf{2 0 0 8}$ & $\mathbf{2 0 1 7}$ & $\mathbf{2 0 0 8}$ & $\mathbf{2 0 1 7}$ & $\mathbf{2 0 0 8}$ & $\mathbf{2 0 0 7}$ \\
\hline 0.40 & 2.0 & 0.58 & 5.1 & 2.2 & 27.7
\end{tabular}

\begin{tabular}{cccccc}
\multicolumn{2}{c}{ Perú } & \multicolumn{2}{c}{ ALC } & \multicolumn{2}{c}{ OCDE } \\
\hline $\mathbf{2 0 0 8}$ & $\mathbf{2 0 1 8}$ & $\mathbf{2 0 0 8}$ & $\mathbf{2 0 1 8}$ & $\mathbf{2 0 0 8}$ & $\mathbf{2 0 1 8}$ \\
\hline 0.53 & 0.65 & 0.52 & 0.65 & 0.72 & 0.82 \\
30.6 & 52.5 & 25.3 & 67.7 & 65.0 & 84.3 \\
$\mathbf{2 0 1 5}$ & $\mathbf{2 0 1 9}$ & $\mathbf{2 0 1 5}$ & $\mathbf{2 0 1 9}$ & $\mathbf{2 0 1 5}$ & $\mathbf{2 0 1 9}$ \\
\hline 43.1 & 47.8 & 46.4 & 51.5 & 73.9 & 85.0 \\
\multicolumn{2}{c}{$\mathbf{2 0 1 7}$} & \multicolumn{2}{c}{$\mathbf{2 0 1 7}$} & \multicolumn{2}{c}{$\mathbf{2 0 1 7}$} \\
\hline \multicolumn{2}{c}{13.2} & \multicolumn{2}{c}{14.8} & \multicolumn{2}{c}{ N/A }
\end{tabular}

\begin{tabular}{cccccc}
\multicolumn{2}{c}{ Perú } & \multicolumn{2}{c}{ ALC } & \multicolumn{2}{c}{ OCDE } \\
\hline $\mathbf{2 0 0 8}$ & $\mathbf{2 0 1 8}$ & $\mathbf{2 0 0 8}$ & $\mathbf{2 0 1 8}$ & $\mathbf{2 0 0 8}$ & $\mathbf{2 0 1 8}$ \\
\hline 2.9 & 4.6 & 9.3 & 8.6 & 15.6 & 15.1 \\
$\mathbf{2 0 0 8}$ & $\mathbf{2 0 1 7}$ & $\mathbf{2 0 0 8}$ & $\mathbf{2 0 1 7}$ & $\mathbf{2 0 0 8}$ & $\mathbf{2 0 1 7}$ \\
\hline 2.3 & 3.7 & 3.1 & 3.8 & 4.6 & 6.6 \\
$\mathbf{2 0 1 2}$ & $\mathbf{2 0 1 6}$ & $\mathbf{2 0 1 2}$ & $\mathbf{2 0 1 6}$ & $\mathbf{2 0 1 2}$ & $\mathbf{2 0 1 6}$ \\
\hline 0.00 & 0.09 & 0.14 & 0.34 & 30.9 & 38.2 \\
$\mathbf{2 0 1 1}$ & $\mathbf{2 0 1 6}$ & $\mathbf{2 0 1 1}$ & $\mathbf{2 0 1 6}$ & $\mathbf{2 0 1 1}$ & $\mathbf{2 0 1 6}$ \\
\hline 0.08 & 0.12 & 0.33 & 0.42 & 1.9 & 1.9 \\
\hline $\mathbf{2 0 1 9}$ & \multicolumn{2}{c}{$\mathbf{2 0 1 9}$} & \multicolumn{2}{c}{$\mathbf{2 0 1 9}$} \\
\hline N/A & \multicolumn{2}{c}{0.43} & \multicolumn{3}{c}{0.61}
\end{tabular}

\begin{tabular}{ccc} 
Perú & ALC & OCDE \\
\hline $\mathbf{2 0 0 6 - 1 5}$ & $\mathbf{2 0 0 6 - 1 5}$ & $\mathbf{2 0 0 6 - 1 5}$ \\
\hline N/A & 6.9 & 4.8 \\
$\mathbf{2 0 1 7}$ & $\mathbf{2 0 1 8}$ & $\mathbf{2 0 1 8}$ \\
\hline
\end{tabular}

\begin{tabular}{cccccc}
\hline \multicolumn{2}{c}{68.9} & \multicolumn{2}{c}{54.9} & \multicolumn{2}{c}{ N/A } \\
$\mathbf{2 0 0 6}$ & $\mathbf{2 0 1 7}$ & $\mathbf{2 0 0 6}$ & $\mathbf{2 0 1 7}$ & $\mathbf{2 0 0 6}$ & $\mathbf{2 0 1 7}$ \\
\hline 34.2 & 70.7 & 39.9 & 60.5 & 64.3 & 74.3
\end{tabular}

$2016 \quad 2016 \quad 2016$

\begin{tabular}{ccc}
$\mathbf{2 0 1 6}$ & $\mathbf{2 0 1 6}$ & $\mathbf{2 0 1 6}$ \\
\hline 9.1 & 16.0 & 9.8
\end{tabular}

$\begin{array}{lll}16.3 & 13.8 & 14.5\end{array}$

$\begin{array}{lll}16.0 & 12.5 & 14.6\end{array}$

\begin{tabular}{cccccc}
\multicolumn{2}{c}{ Perú } & \multicolumn{2}{c}{ ALC } & \multicolumn{2}{c}{ OCDE } \\
\hline $\mathbf{2 0 1 5}$ & $\mathbf{2 0 1 6}$ & $\mathbf{2 0 1 5}$ & $\mathbf{2 0 1 6}$ & $\mathbf{2 0 1 5}$ & $\mathbf{2 0 1 6}$ \\
\hline 5.6 & 5.8 & 6.9 & 7.2 & 17.7 & 17.7 \\
$\mathbf{2 0 1 5}$ & $\mathbf{2 0 1 8}$ & $\mathbf{2 0 1 5}$ & $\mathbf{2 0 1 8}$ & $\mathbf{2 0 1 5}$ & $\mathbf{2 0 1 8}$ \\
\hline 2.2 & 1.4 & 2.4 & 1.6 & 1.8 & 1.1 \\
\multicolumn{2}{c}{$\mathbf{2 0 1 8}$} & \multicolumn{2}{c}{$\mathbf{2 0 1 8}$} & \multicolumn{2}{c}{$\mathbf{2 0 1 8}$} \\
\hline 6.3 & \multicolumn{2}{c}{7.7} & \multicolumn{2}{c}{27.7}
\end{tabular}

\begin{tabular}{cccccc}
\multicolumn{2}{c}{ Perú } & \multicolumn{2}{c}{ ALC } & \multicolumn{2}{c}{ OCDE } \\
\hline \multicolumn{2}{c}{$\mathbf{2 0 2 0}$} & \multicolumn{2}{c}{$\mathbf{2 0 2 0}$} & \multicolumn{2}{c}{$\mathbf{2 0 2 0}$} \\
\hline \multicolumn{2}{c}{4.0} & \multicolumn{2}{c}{4.4} & \multicolumn{2}{c}{ N/A } \\
\hline $\mathbf{2 0 1 6}$ & $\mathbf{2 0 1 8}$ & $\mathbf{2 0 1 6}$ & $\mathbf{2 0 1 8}$ & $\mathbf{2 0 1 6}$ & $\mathbf{2 0 1 8}$ \\
\hline 0.32 & 0.40 & 0.36 & 0.43 & 0.56 & 0.79 \\
\hline $\mathbf{2 0 1 8}$ & $\mathbf{2 0 1 9}$ & $\mathbf{2 0 1 8}$ & $\mathbf{2 0 1 9}$ & $\mathbf{2 0 1 8}$ & $\mathbf{2 0 1 9}$ \\
\hline 64.6 & 72.5 & 72.0 & 63.1 & 61.7 & 58.3 \\
\hline 52.0 & 75.5 & 52.8 & 54.9 & 41.7 & 45.6
\end{tabular}

\begin{tabular}{cccccc}
\multicolumn{2}{c}{ Perú } & \multicolumn{2}{c}{ ALC } & \multicolumn{2}{c}{ OCDE } \\
\hline $\mathbf{2 0 1 5}$ & $\mathbf{2 0 1 9}$ & $\mathbf{2 0 1 5}$ & $\mathbf{2 0 1 9}$ & $\mathbf{2 0 1 5}$ & $\mathbf{2 0 1 9}$ \\
\hline N/A & N/A & 0.24 & 0.24 & 0.13 & 0.15 \\
2018 & 2018 & \multicolumn{2}{c}{$\mathbf{2 0 1 8}$} \\
\hline 0.08 & 0.07 & \multicolumn{2}{c}{0.06}
\end{tabular}




\section{Notas técnicas}

1. La Tabla sigue lo mejor posible las siete áreas claves identificadas en el proyecto Going Digital de la OCDE: 1) mejorar el acceso a las tecnologías digitales; 2) aumentar el uso efectivo; 3) permitir la innovación digital; 4) asegurar empleos adecuados para todos; 5) promocionar la prosperidad social; 6) reforzar la confianza; y 7) promocionar la apertura de mercados (OCDE, 2019a). Los indicadores se eligen según la disponibilidad de datos para los países de ALC. Existe la posibilidad de un sesgo por la forma en que se han agregado los componentes en los indicadores de índice.

2. El promedio de ALC es un promedio simple. La composición de los países depende de la disponibilidad de datos de los países de la región. Cada promedio incluye tantos países de ALC encontrados en cada fuente como sea posible.

3. El promedio de la OCDE es un promedio simple que incluye a todos los países miembros de la OCDE en mayo de 2020.

4. Datos de la UIT (2020), Base de datos de indicadores mundiales de telecomunicaciones / TIC 2020 (base de datos). La velocidad de banda ancha fija en Mbit/s se refiere a la velocidad de descarga teórica máxima anunciada garantizada a los usuarios asociados con una suscripción mensual de Internet de banda ancha fija.

5. Datos de la División de Estadística de las Naciones Unidas, Base de datos mundial de los ODS de las Naciones Unidas (base de datos). Datos de 2015 y 2018 o los últimos disponibles.

6. Datos de la base de conocimientos sobre gobierno electrónico de las Naciones Unidas (2019), centro de datos (base de datos). El índice de desarrollo del gobierno electrónico (E-government development index) es un indicador compuesto que consta de tres índices (índice de servicios en línea, índice de infraestructura de telecomunicaciones e índice de capital humano), que están igualmente ponderados. Tiene un rango de 0 a 1, con 1 siendo un gobierno más desarrollado.

7. Datos de UNCTAD (2020), UNCTADSTAT (base de datos). El índice de comercio electrónico B2C de la UNCTAD mide la preparación de una economía para respaldar las compras en línea. Rango de 0 a 100, con 100 siendo el nivel de apoyo más alto.

8. Cálculos propios a partir de datos de Latinobarómetro (2019), Libros de Códigos por País / Año (base de datos). Datos de 2017. Datos de encuestas de opinión pública utilizando muestras representativas a nivel nacional seleccionadas al azar.

9. Datos del Banco Mundial (2020a), Banco de datos del Banco Mundial (base de datos).

10. Datos del Banco Mundial (2020b), TCdata360. Datos de 2012 y 2016 o los últimos disponibles.

11. Datos de Unesco (2019), Instituto de Estadística de la Unesco (base de datos). Gastos en I+D, como porcentaje de los datos del PIB de 2006 y 2016 o el último disponible.

12. Datos de OCDE (2020a), OECD.Stat (base de datos) y OCDE (2020b). El índice OURdata de la OCDE evalúa los esfuerzos de los gobiernos para implementar datos abiertos en tres áreas críticas: apertura, utilidad y reutilización de los datos gubernamentales. Tiene un rango de 0 a 1, con 1 siendo la puntuación más alta.

13. Datos de OCDE (2020a), OECD.Stat (base de datos). El Índice de restricción del comercio de servicios digitales de la OCDE identifica, cataloga y cuantifica las barreras que afectan el comercio de servicios habilitados digitalmente en 46 países. Tiene un rango de 0 a 1, con 1 siendo el valor más restrictivo. El Índice de Restricción Reglamentaria de la Inversión Extranjera Directa (IED RRI) mide cuatro tipos de restricciones legales a la inversión extranjera directa: 1) restricciones a la participación extranjera en el capital social; 2) requisitos de selección y aprobación previa; 3) regulaciones para personas claves; y 4) otras restricciones al funcionamiento de empresas extranjeras. El RRI de la IED es un índice compuesto, que varía de 0 a 1, con 1 siendo el valor más restrictivo.

14. Datos de ILOSTAT, datos de 2018 o último año disponible.

15. Datos de la Asociación mundial de estadísticas sobre desechos electrónicos.

16. Cálculos de la OCDE basados en OCDE (2020c), Programa de Evaluación Internacional de Estudiantes (base de datos). Datos de 2015 y 2018.

17. Datos de la OCDE (2019d), Survey of Adult Skills (2018). Los porcentajes para la resolución de problemas en entornos ricos en tecnología se calculan de modo que la suma de los porcentajes de las siguientes categorías mutuamente exhaustivas sea igual al 100\%: se excluyó de la evaluación por computadora; sin experiencia en informática; prueba de núcleo de TIC fallida; por debajo del Nivel 1, en el Nivel 1, en el Nivel 2 y en el Nivel 3.

18. Datos de CAF (2020), The GouTech Index 2020: Unlocking the Potential of GouTech Ecosystems in Latin America, Spain and Portugal. El índice GovTech 2020 mide la madurez del ecosistema GovTech. Se basa en 28 indicadores en 7 dimensiones, que, en conjunto, forman 3 pilares igualmente ponderados: industria de nueva creación, políticas gubernamentales y sistemas de adquisiciones. 
19. El Índice mundial de ciberseguridad mide el compromiso de los países con la ciberseguridad a escala global. Tiene cinco pilares: 1) medidas legales; 2) medidas técnicas; 3) medidas organizativas; 4) desarrollo de capacidades; y 5) cooperación. Va de 0 a 1, siendo 1 el nivel más alto de ciberseguridad.

20. Datos de The Economist Intelligence Unit (2019), EIU Inclusive Internet Index (base de datos). Los indicadores presentan la seguridad percibida del comercio electrónico y la confianza en la privacidad en línea entre las personas seleccionadas al azar en países seleccionados. Varía del $0 \%$ al 100\%, donde el $100 \%$ indica una confianza absoluta en la seguridad del comercio electrónico y la confianza en la privacidad en línea.

\section{Referencias}

Banco Mundial (2020a), DataBank (base de datos), Grupo del Banco Mundial, Washington, DC, https:// databank.worldbank.org/home.aspx (consultada el 11 de diciembre de 2019).

Banco Mundial (2020b), TCdata360 (base de datos), Grupo del Banco Mundial, Washington, DC, https:// tcdata360.worldbank.org/ (consultada el 4 de agosto de 2020).

Base de conocimientos sobre gobierno electrónico de la ONU (2019), Data Center (base de datos), Departamento de Asuntos Económicos y Sociales de las Naciones Unidas, Nueva York, https:// publicadministration.un.org/egovkb/en-us/Data-Center (consultada el 11 de diciembre de 2019).

CAF (2020), The GouTech Index 2020: Unlocking the Potential of GovTech Ecosystems in Latin America, Spain and Portugal, Banco de Desarrollo de America Latina, Caracas.

CEPAL (2018), Observatorio Regional de Planificación para el Desarrollo de América Latina y el Caribe, Comisión Económica para América Latina y el Caribe, Santiago, https://observatorioplanificacion.cepal.org/es.

Dispositivo de estadísticas de la ONU (2018, 2015), ODS globales de la ONU (database), Departamento de Asuntos Económicos y Sociales de las Naciones Unidas, Nueva York, https://unstats.un.org/sdgs/ indicators/database/ (consultada el 20 de mayo de 2020).

Foro Mundial Económico (2016), “The Global Information Technology Report 2016”, Foro Mundial Económico, Ginebra, https://www.weforum.org/reports/the-global-information-technology-report-2016.

Global E-waste Statistic Partnership, página de internet, Global E-waste Statistic Partnership, Bonn, https:// globalewaste.org/ (consultada el 11 de diciembre de 2019).

Latinobarómetro (2019), Libros de Códigos por País/Año (base de datos), Latinobarómetro, Providencia, www. latinobarometro.org/latCodebooks.jsp (consultada el 11 de diciembre de 2019).

OCDE (2020a), OECD.Stat (database), Publicaciones de la OCDE, París, https://stats.oecd.org/ (consultada el 11 de diciembre de 2019).

OCDE (2020b), Panorama de las Administraciones Públicas América Latina y el Caribe 2020, Publicaciones de la OCDE, París, https://doi.org/10.1787/13130fbb-en.

OCDE (2020c), Programme for International Student Assessment (base de datos), Publicaciones de la OCDE, París, www.oecd.org/pisa/data/2018database/ (consultada el 14 de febrero de 2020).

OCDE (2019a), Cómo medir la transformación digital: Hoja de ruta para el futuro, Publicaciones de la OCDE, París, https://doi.org/10.1787/9789264311992-en.

OCDE (2019b), Estudios de la OCDE sobre Transformación Digital: “Going Digital” en Colombia, Publicaciones de la OCDE, París, https://doi.org/10.1787/781185b1-en.

OCDE (2019c), Digital Government Review of Panama: Enhancing the Digital Transformation of the Public Sector, OCDE Estudios de gobierno digital, Publicaciones de la OCDE, París, https://doi.org/10.1787/615a4180-en.

OCDE (2019d), Survey of Adult Skills, Publicaciones de la OCDE, París, https://www.oecd.org/skills/piaac/data/

OIT (2019), ILO Statistics (base de datos), Organización Internacional del Trabajo, Ginebra, www.ilo.org/ global/statistics-and-databases/lang--en/index.htm (consultada el 11 de diciembre de 2019).

Open Knowledge Foundation (2019), Global Open Data Index (base de datos), Open Knowledge Foundation, Cambridge, Reino Unido, https://index.okfn.org/dataset/ (consultada el 19 de abril de 2020).

PIAAC Expert Group in Problem Solving in Technology-Rich Environments (2009), "PIAAC Problem Solving in Technology- Rich Environments: A Conceptual Framework", OCDE Documentos de trabajo educativo, n. ${ }^{\circ}$ 36, Publicaciones de la OCDE, París, https://doi.org/10.1787/220262483674.

The Economist Intelligence Unit (2019), EIU Inclusive Internet Index 2019 (base de datos), The Economist Group, Londres, https://theinclusiveinternet.eiu.com/explore/countries/performance (consultada el $11 \mathrm{de}$ diciembre 2019).

UIT (2020), base de datos de indicadores mundiales de telecomunicaciones / TIC 2020 (base de datos), Unión Internacional de Telecomunicaciones, Ginebra, https://www.itu.int/en/ITU-D/Statistics/Pages/ publications/wtid.aspx (consultada el 21 de agosto de 2020). 
UNCTAD (2020), UNCTADSTAT (base de datos), Conferencia de las Naciones Unidas sobre Comercio y Desarrollo, Ginebra, https://unctadstat.unctad.org/EN/ (consultada el 11 de diciembre de 2019).

UNESCO (2019), Instituto de Estadística de la Unesco (base de datos), Unesco, París, http://data.uis.unesco. org/Index.aspx (consultada el 20 de mayo de 2020).

World Wide Web Foundation (2017), OpenData Barometer (base de datos), World Wide Web Foundation, Ginebra, https://opendatabarometer.org/ (consultada el 19 de abril de 2020). 



\section{REPÚBLICA DOMINICANA}

\section{Tendencias recientes}

En la última década, la República Dominicana se ha esforzado para mejorar el acceso digital de todos sus ciudadanos. Ha aumentado el número de usuarios de Internet y de suscripciones a servicios de banda ancha móvil activa y fija. El país también está avanzando en el aumento de la confianza en el ecosistema digital. Su posición en el Índice mundial de ciberseguridad está acorde con el promedio de América Latina y el Caribe (ALC) (0.43), pero se sitúa por debajo del promedio de la OCDE (0.79).

La clasificación de la República Dominicana en materia de gobierno electrónico también ha mejorado, pero puede aún seguir ampliando las políticas de datos abiertos de organismos públicos, según el índice OURdata de la OCDE. En cuanto a la promoción de una sociedad digital incluyente, el número de computadoras por estudiante aumentó entre 2015 y 2018 y superó el promedio de ALC, cerrando la brecha con la OCDE. No obstante, el $40 \%$ de los estudiantes dispone de una computadora en buen estado, el 30\% tiene una que necesita una reparación y el 10\% tiene una en mal estado.

\section{Estrategias nacionales y cooperación internacional para la transformación digital}

La Agenda digital de la República Dominicana 2016-2020 es el principal documento que rige la transformación digital del país y concuerda con la Estrategia Nacional de Desarrollo 2030. Dicha agenda se basa en cinco ejes estratégicos: infraestructuras y acceso, gobierno electrónico y servicios digitales, desarrollo de competencias, desarrollo productivo e innovación y entorno favorable. La Comisión Nacional para la Sociedad de la Información y el Conocimiento (CNSIC) se encarga de formular, coordinar y realizar un seguimiento de la aplicación de esta agenda. La CNSIC está integrada por entidades nacionales del Gobierno, el sector privado, el mundo académico y la sociedad civil. Su objetivo es fomentar el uso sostenible de las TIC (tecnologías de la información y las comunicaciones) para el desarrollo a través de la colaboración entre esos grupos.

Como una de las actividades relacionadas, el proyecto República Digital tiene por objeto reducir la brecha digital y ofrecer mejores servicios a los ciudadanos. Este proyecto se basa en cuatro ejes: educación, acceso a las TIC, productividad y empleo, y gobierno digital. Hasta la fecha, el país ha puesto a disposición del público a través de Internet más de 1.000 servicios, ha promovido clases de robótica y ciencias en 742 servicios educativos y ha elaborado una Estrategia Nacional de Ciberseguridad 2018-2021 para promover la confianza en el ecosistema digital. Para mitigar el impacto económico del coronavirus (Covid-19), el Instituto de Telecomunicaciones prohibió la suspensión o cancelación de los servicios de telecomunicaciones durante el estado de emergencia y eximió a los usuarios de la morosidad en los cinco días siguientes a la finalización del estado de emergencia (CAF, 2020).

La República Dominicana es miembro de la Alianza Better than Cash, una asociación de gobiernos, empresas y organizaciones internacionales que acelera la adopción de los pagos digitales, en vez de los pagos en efectivo, para avanzar en los Objetivos de Desarrollo Sostenible de Naciones Unidas. Entre otros proyectos, la alianza respalda la distribución de beneficios en una tarjeta Visa recargable como parte del programa Solidaridad por parte de la Administradora de Subsidios Sociales, en asociación con Visa e instituciones financieras locales. El país es miembro de la Alianza para el Gobierno Abierto, un proyecto de colaboración entre gobiernos y organizaciones de la sociedad civil para promover una gobernanza responsable, receptiva e incluyente. Como parte de sus compromisos, actualmente la República Dominicana lleva a cabo el Cuarto Plan de Acción de Gobierno Abierto 2018-2020. Como parte del plan, el país ha introducido el concepto de Estado de derecho social y democrático en la contratación pública. Del mismo modo, el país también participa en debates sobre políticas en la Cumbre Mundial sobre la Sociedad de la Información y presidirá la edición centrada en el uso de tecnologías digitales en la respuesta y mitigación de Covid-19.

La República Dominicana formó parte de la Red de América Latina, el Caribe y la Unión Europea sobre investigación e innovación (2012-2017). El país también colaboró con la Unión Europea (UE) mediante cursos prácticos sobre cooperación digital encaminados a armonizar las regulaciones y políticas digitales de la UE y ALC. Los principales temas fueron la ciberseguridad, la regulación de las telecomunicaciones, las plataformas de comercio electrónico y los medios de comunicación. Los cursos prácticos han permitido definir posibles mecanismos para estructurar la colaboración a medio y largo plazo. Desde 2019, en línea con los desafíos de las sociedades de la información y el conocimiento, la República Dominicana se ha involucrado en la creación de un marco para la regulación de la protección de datos personales, basado en experiencias del marco legal de la UE. 


\section{Mejorar el acceso}

Suscripciones de banda ancha fija (por cada 100 habitantes) ${ }^{4}$

Suscripciones de banda ancha móvil activa (por cada 100 habitantes) ${ }^{4}$

Proporción de población cubierta por al menos una red 3G5

Velocidad de banda ancha fija (en Mbit/s) ${ }^{4}$

\section{Aumentar el uso efectivo}

Índice de desarrollo del gobierno electrónico (EGDI) ${ }^{6}$

Proporción de usuarios de Internet (\% de población $)^{4}$

Índice de comercio electrónico B2C de la UNCTAD7

Proporción de personas que realizan compras por Internet ${ }^{8}$

\section{Impulsar la innovación}

Exportaciones de alta tecnología (\% de exportaciones manufacturadas) ${ }^{9}$

Proporción de importaciones de servicios de TIC, como porcentaje del comercio total de servicios ${ }^{7}$

Solicitudes de patentes de TIC presentadas en virtud del Tratado de Cooperación en materia de Patentes (por millón de personas) ${ }^{10}$

Gastos en I+D, como \% del PIB ${ }^{11}$

Índice OURdata de la OCDE ${ }^{12}$

\section{Asegurar empleos adecuados para todos}

Contribuciones a variación en empleo total, por intensidad digital de sectores, 2006-2016 ${ }^{13}$

Proporción de empleo informal en relación con empleo total ${ }^{14}$

Tasa bruta de matrícula, educación terciaria $(\%)^{9}$

Graduados de educación terciaria por campo (\%) - Educación ${ }^{11}$

Graduados de educación terciaria por campo (\%) - Salud ${ }^{11}$

Graduados de educación terciaria por campo (\%) - Ingeniería ${ }^{11}$

\section{Promocionar la prosperidad socia}

Generación de desechos de aparatos eléctricos per cápita $(\mathrm{kg})^{15}$

Número de estudiantes por computadora ${ }^{16}$

Proporción de mujeres con puntuación de nivel 203 en resolución de problemas en entornos tecnológicos ${ }^{17}$

\section{Reforzar la confianza}

Índice GovTech de la $\mathrm{CAF}^{18}$

Índice de ciberseguridad global (UIT) $)^{19}$

Seguridad del comercio electrónico $(\%)^{20}$

Confianza en la privacidad en Internet $(\%)^{20}$

\section{Promocionar la apertura de mercados}

Índice de restrictividad de intercambios de servicios digitales de la OCDE ${ }^{13}$

Índice de restricción regulatoria de la IED de la $0 \mathrm{CDE}^{13}$

Las fuentes, notas a pie de página y detalles técnicos se pueden encontrar al final de las Notas País.

\begin{tabular}{cccccc}
\multicolumn{3}{c}{ Indicadores digitales - República Dominicana ${ }^{1}$} \\
\hline República Dominicana & \multicolumn{2}{c}{ ALC $^{2}$} & \multicolumn{3}{c}{ OCDE $^{3}$} \\
\hline $\mathbf{2 0 0 8}$ & $\mathbf{2 0 1 8}$ & $\mathbf{2 0 0 8}$ & $\mathbf{2 0 1 8}$ & $\mathbf{2 0 0 8}$ & $\mathbf{2 0 1 8}$ \\
\hline 2.5 & 7.5 & 4.1 & 13.9 & 22.7 & 32.9 \\
0.44 & 60.8 & 0.53 & 73.5 & 19.4 & 103.6 \\
$\mathbf{2 0 1 5}$ & $\mathbf{2 0 1 8}$ & $\mathbf{2 0 1 5}$ & $\mathbf{2 0 1 8}$ & $\mathbf{2 0 1 5}$ & $\mathbf{2 0 1 8}$ \\
\hline 98.8 & 99.2 & 86.1 & 94.6 & 98.2 & 98.8 \\
$\mathbf{2 0 0 8}$ & $\mathbf{2 0 1 7}$ & $\mathbf{2 0 0 8}$ & $\mathbf{2 0 1 7}$ & $\mathbf{2 0 0 8}$ & $\mathbf{2 0 0 7}$ \\
\hline 0.40 & 2.0 & 0.58 & 5.1 & 2.2 & 27.7
\end{tabular}

\section{República Dominicana ALC OCDE}

\begin{tabular}{cccccc}
\hline $\mathbf{2 0 0 8}$ & $\mathbf{2 0 1 8}$ & $\mathbf{2 0 0 8}$ & $\mathbf{2 0 1 8}$ & $\mathbf{2 0 0 8}$ & $\mathbf{2 0 1 8}$ \\
\hline 0.49 & 0.57 & 0.52 & 0.65 & 0.72 & 0.82 \\
20.8 & 74.8 & 25.3 & 67.7 & 65.0 & 84.3 \\
$\mathbf{2 0 1 5}$ & $\mathbf{2 0 1 9}$ & $\mathbf{2 0 1 5}$ & $\mathbf{2 0 1 9}$ & $\mathbf{2 0 1 5}$ & $\mathbf{2 0 1 9}$ \\
\hline 39.9 & 60.4 & 46.4 & 51.5 & 73.9 & 85.0 \\
\multicolumn{2}{c}{$\mathbf{2 0 1 7}$} & \multicolumn{2}{c}{$\mathbf{2 0 1 7}$} & \multicolumn{2}{c}{$\mathbf{2 0 1 7}$}
\end{tabular}

\begin{tabular}{ccc}
2017 & $\mathbf{2 0 1 7}$ & $\mathbf{2 0 1 7}$ \\
\hline 13.2 & 14.8 & N/A
\end{tabular}

República Dominicana $\quad$ ALC OCDE

\begin{tabular}{|c|c|c|c|c|c|}
\hline 2008 & 2017 & 2008 & 2017 & 2008 & 2017 \\
\hline 3.7 & 8.6 & 9.3 & 9.6 & 15.6 & 15.3 \\
\hline 2.70 & 2.70 & 3.1 & 3.9 & 4.6 & 6.7 \\
\hline 2012 & 2016 & 2012 & 2016 & 2012 & 2016 \\
\hline 0.14 & 0.05 & 0.14 & 0.34 & 30.9 & 38.2 \\
\hline 2006 & 2016 & 2006 & 2016 & 2006 & 2016 \\
\hline $\mathrm{N} / \mathrm{A}$ & $\mathrm{N} / \mathrm{A}$ & 0.35 & 0.42 & 1.7 & 1.9 \\
\hline \multicolumn{2}{|c|}{2019} & \multicolumn{2}{|c|}{2019} & \multicolumn{2}{|c|}{2019} \\
\hline \multicolumn{2}{|c|}{0.46} & \multicolumn{2}{|c|}{0.43} & \multicolumn{2}{|c|}{0.61} \\
\hline
\end{tabular}

\begin{tabular}{|c|c|c|c|c|c|}
\hline \multicolumn{2}{|c|}{ República Dominicana } & \multicolumn{2}{|c|}{ ALC } & \multicolumn{2}{|c|}{ OCDE } \\
\hline \multicolumn{2}{|c|}{$2006-15$} & \multicolumn{2}{|c|}{$2006-15$} & \multicolumn{2}{|c|}{$2006-15$} \\
\hline \multicolumn{2}{|c|}{$\mathrm{N} / \mathrm{A}$} & \multicolumn{2}{|c|}{6.9} & \multicolumn{2}{|c|}{4.8} \\
\hline \multicolumn{2}{|c|}{2017} & \multicolumn{2}{|c|}{2018} & \multicolumn{2}{|c|}{2018} \\
\hline \multicolumn{2}{|c|}{57.2} & \multicolumn{2}{|c|}{54.9} & \multicolumn{2}{|c|}{ N/A } \\
\hline 2003 & 2017 & 2003 & 2017 & 2003 & 2017 \\
\hline 34.1 & 59.9 & 35.3 & 60.5 & 59.9 & 74.3 \\
\hline \multicolumn{2}{|c|}{2016} & \multicolumn{2}{|c|}{2016} & \multicolumn{2}{|c|}{2016} \\
\hline \multicolumn{2}{|c|}{19.6} & \multicolumn{2}{|c|}{16.0} & \multicolumn{2}{|c|}{9.8} \\
\hline \multicolumn{2}{|c|}{16.5} & \multicolumn{2}{|c|}{13.8} & \multicolumn{2}{|c|}{14.5} \\
\hline \multicolumn{2}{|c|}{8.7} & \multicolumn{2}{|c|}{12.5} & \multicolumn{2}{|c|}{14.6} \\
\hline
\end{tabular}

\begin{tabular}{|c|c|c|c|c|c|}
\hline \multicolumn{2}{|c|}{ República Dominicana } & \multicolumn{2}{|c|}{ ALC } & \multicolumn{2}{|c|}{ OCDE } \\
\hline 2015 & 2016 & 2015 & 2016 & 2015 & 2016 \\
\hline 5.6 & 5.8 & 6.9 & 7.2 & 17.7 & 17.7 \\
\hline 2015 & 2018 & 2015 & 2018 & 2015 & 2018 \\
\hline 3.2 & 1.4 & 2.4 & 1.6 & 1.8 & 1.1 \\
\hline \multicolumn{2}{|c|}{2018} & \multicolumn{2}{|c|}{2018} & \multicolumn{2}{|c|}{2018} \\
\hline \multicolumn{2}{|c|}{$\mathrm{N} / \mathrm{A}$} & \multicolumn{2}{|c|}{7.7} & \multicolumn{2}{|c|}{27.7} \\
\hline
\end{tabular}

\begin{tabular}{cccccc}
\cline { 1 - 4 } República Dominicana & \multicolumn{2}{c}{ ALC } & \multicolumn{2}{c}{ OCDE } \\
\cline { 1 - 5 } \multicolumn{2}{c}{$\mathbf{2 0 2 0}$} & \multicolumn{2}{c}{$\mathbf{2 0 2 0}$} & \multicolumn{2}{c}{$\mathbf{2 0 2 0}$} \\
\hline \multicolumn{2}{c}{3.7} & \multicolumn{2}{c}{4.4} & \multicolumn{2}{c}{ N/A } \\
\hline $\mathbf{2 0 1 6}$ & $\mathbf{2 0 1 8}$ & $\mathbf{2 0 1 6}$ & $\mathbf{2 0 1 8}$ & $\mathbf{2 0 1 6}$ & $\mathbf{2 0 1 8}$ \\
\hline 0.12 & 0.43 & 0.36 & 0.43 & 0.56 & 0.79 \\
$\mathbf{2 0 1 8}$ & $\mathbf{2 0 1 9}$ & $\mathbf{2 0 1 8}$ & $\mathbf{2 0 1 9}$ & $\mathbf{2 0 1 8}$ & $\mathbf{2 0 1 9}$ \\
\hline N/A & 56.1 & 72.0 & 63.1 & 61.7 & 58.3 \\
N/A & 56.0 & 52.8 & 54.9 & 41.7 & 45.6
\end{tabular}

República Dominicana ALC OCDE

\begin{tabular}{cccccc}
\hline 2015 & $\mathbf{2 0 1 9}$ & $\mathbf{2 0 1 5}$ & $\mathbf{2 0 1 9}$ & $\mathbf{2 0 1 5}$ & $\mathbf{2 0 1 9}$ \\
\hline N/A & N/A & 0.24 & 0.24 & 0.13 & 0.15 \\
2018 & 2018 & $\mathbf{2 0 1 8}$ \\
\hline N/A & 0.07 & 0.06 \\
\hline
\end{tabular}




\section{Notas técnicas}

1. La Tabla sigue lo mejor posible las siete áreas claves identificadas en el proyecto Going Digital de la OCDE: 1) mejorar el acceso a las tecnologías digitales; 2) aumentar el uso efectivo; 3) permitir la innovación digital; 4) asegurar empleos adecuados para todos; 5) promocionar la prosperidad social; 6) reforzar la confianza; y 7) promocionar la apertura de mercados (OCDE, 2019a). Los indicadores se eligen según la disponibilidad de datos para los países de ALC. Existe la posibilidad de un sesgo por la forma en que se han agregado los componentes en los indicadores de índice.

2. El promedio de ALC es un promedio simple. La composición de los países depende de la disponibilidad de datos de los países de la región. Cada promedio incluye tantos países de ALC encontrados en cada fuente como sea posible.

3. El promedio de la OCDE es un promedio simple que incluye a todos los países miembros de la OCDE en mayo de 2020.

4. Datos de la UIT (2020), Base de datos de indicadores mundiales de telecomunicaciones / TIC 2020 (base de datos). La velocidad de banda ancha fija en Mbit/s se refiere a la velocidad de descarga teórica máxima anunciada garantizada a los usuarios asociados con una suscripción mensual de Internet de banda ancha fija.

5. Datos de la División de Estadística de las Naciones Unidas, Base de datos mundial de los ODS de las Naciones Unidas (base de datos). Datos de 2015 y 2018 o los últimos disponibles.

6. Datos de la base de conocimientos sobre gobierno electrónico de las Naciones Unidas (2019), centro de datos (base de datos). El índice de desarrollo del gobierno electrónico (E-government development index) es un indicador compuesto que consta de tres índices (índice de servicios en línea, índice de infraestructura de telecomunicaciones e índice de capital humano), que están igualmente ponderados. Tiene un rango de 0 a 1, con 1 siendo un gobierno más desarrollado.

7. Datos de UNCTAD (2020), UNCTADSTAT (base de datos). El índice de comercio electrónico B2C de la UNCTAD mide la preparación de una economía para respaldar las compras en línea. Rango de 0 a 100, con 100 siendo el nivel de apoyo más alto.

8. Cálculos propios a partir de datos de Latinobarómetro (2019), Libros de Códigos por País / Año (base de datos). Datos de 2017. Datos de encuestas de opinión pública utilizando muestras representativas a nivel nacional seleccionadas al azar.

9. Datos del Banco Mundial (2020a), Banco de datos del Banco Mundial (base de datos).

10. Datos del Banco Mundial (2020b), TCdata360. Datos de 2012 y 2016 o los últimos disponibles.

11. Datos de Unesco (2019), Instituto de Estadística de la Unesco (base de datos). Gastos en I+D, como porcentaje de los datos del PIB de 2006 y 2016 o el último disponible.

12. Datos de OCDE (2020a), OECD.Stat (base de datos) y OCDE (2020b). El índice OURdata de la OCDE evalúa los esfuerzos de los gobiernos para implementar datos abiertos en tres áreas críticas: apertura, utilidad y reutilización de los datos gubernamentales. Tiene un rango de 0 a 1, con 1 siendo la puntuación más alta.

13. Datos de OCDE (2020a), OECD.Stat (base de datos). El Índice de restricción del comercio de servicios digitales de la OCDE identifica, cataloga y cuantifica las barreras que afectan el comercio de servicios habilitados digitalmente en 46 países. Tiene un rango de 0 a 1, con 1 siendo el valor más restrictivo. El Índice de Restricción Reglamentaria de la Inversión Extranjera Directa (IED RRI) mide cuatro tipos de restricciones legales a la inversión extranjera directa: 1) restricciones a la participación extranjera en el capital social; 2) requisitos de selección y aprobación previa; 3) regulaciones para personas claves; y 4) otras restricciones al funcionamiento de empresas extranjeras. El RRI de la IED es un índice compuesto, que varía de 0 a 1, con 1 siendo el valor más restrictivo.

14. Datos de ILOSTAT, datos de 2018 o último año disponible.

15. Datos de la Asociación mundial de estadísticas sobre desechos electrónicos.

16. Cálculos de la OCDE basados en OCDE (2020c), Programa de Evaluación Internacional de Estudiantes (base de datos). Datos de 2015 y 2018.

17. Datos de la OCDE (2019d), Survey of Adult Skills (2018). Los porcentajes para la resolución de problemas en entornos ricos en tecnología se calculan de modo que la suma de los porcentajes de las siguientes categorías mutuamente exhaustivas sea igual al 100\%: se excluyó de la evaluación por computadora; sin experiencia en informática; prueba de núcleo de TIC fallida; por debajo del Nivel 1, en el Nivel 1, en el Nivel 2 y en el Nivel 3.

18. Datos de CAF (2020), The GouTech Index 2020: Unlocking the Potential of GouTech Ecosystems in Latin America, Spain and Portugal. El índice GovTech 2020 mide la madurez del ecosistema GovTech. Se basa en 28 indicadores en 7 dimensiones, que, en conjunto, forman 3 pilares igualmente ponderados: industria de nueva creación, políticas gubernamentales y sistemas de adquisiciones. 
19. El Índice mundial de ciberseguridad mide el compromiso de los países con la ciberseguridad a escala global. Tiene cinco pilares: 1) medidas legales; 2) medidas técnicas; 3) medidas organizativas; 4) desarrollo de capacidades; y 5) cooperación. Va de 0 a 1, siendo 1 el nivel más alto de ciberseguridad.

20. Datos de The Economist Intelligence Unit (2019), EIU Inclusive Internet Index (base de datos). Los indicadores presentan la seguridad percibida del comercio electrónico y la confianza en la privacidad en línea entre las personas seleccionadas al azar en países seleccionados. Varía del $0 \%$ al 100\%, donde el $100 \%$ indica una confianza absoluta en la seguridad del comercio electrónico y la confianza en la privacidad en línea.

\section{Referencias}

Banco Mundial (2020a), DataBank (base de datos), Grupo del Banco Mundial, Washington, DC, https:// databank.worldbank.org/home.aspx (consultada el 11 de diciembre de 2019).

Banco Mundial (2020b), TCdata360 (base de datos), Grupo del Banco Mundial, Washington, DC, https:// tcdata360.worldbank.org/ (consultada el 4 de agosto de 2020).

Base de conocimientos sobre gobierno electrónico de la ONU (2019), Data Center (base de datos), Departamento de Asuntos Económicos y Sociales de las Naciones Unidas, Nueva York, https:// publicadministration.un.org/egovkb/en-us/Data-Center (consultada el 11 de diciembre de 2019).

CAF (2020), The GouTech Index 2020: Unlocking the Potential of GovTech Ecosystems in Latin America, Spain and Portugal, Banco de Desarrollo de America Latina, Caracas.

CEPAL (2018), Observatorio Regional de Planificación para el Desarrollo de América Latina y el Caribe, Comisión Económica para América Latina y el Caribe, Santiago, https://observatorioplanificacion.cepal.org/es.

Dispositivo de estadísticas de la ONU (2018, 2015), ODS globales de la ONU (database), Departamento de Asuntos Económicos y Sociales de las Naciones Unidas, Nueva York, https://unstats.un.org/sdgs/ indicators/database/ (consultada el 20 de mayo de 2020).

Foro Mundial Económico (2016), “The Global Information Technology Report 2016”, Foro Mundial Económico, Ginebra, https://www.weforum.org/reports/the-global-information-technology-report-2016.

Global E-waste Statistic Partnership, página de internet, Global E-waste Statistic Partnership, Bonn, https:// globalewaste.org/ (consultada el 11 de diciembre de 2019).

Latinobarómetro (2019), Libros de Códigos por País/Año (base de datos), Latinobarómetro, Providencia, www. latinobarometro.org/latCodebooks.jsp (consultada el 11 de diciembre de 2019).

OCDE (2020a), OECD.Stat (database), Publicaciones de la OCDE, París, https://stats.oecd.org/ (consultada el 11 de diciembre de 2019).

OCDE (2020b), Panorama de las Administraciones Públicas América Latina y el Caribe 2020, Publicaciones de la OCDE, París, https://doi.org/10.1787/13130fbb-en.

OCDE (2020c), Programme for International Student Assessment (base de datos), Publicaciones de la OCDE, París, www.oecd.org/pisa/data/2018database/ (consultada el 14 de febrero de 2020).

OCDE (2019a), Cómo medir la transformación digital: Hoja de ruta para el futuro, Publicaciones de la OCDE, París, https://doi.org/10.1787/9789264311992-en.

OCDE (2019b), Estudios de la OCDE sobre Transformación Digital: “Going Digital” en Colombia, Publicaciones de la OCDE, París, https://doi.org/10.1787/781185b1-en.

OCDE (2019c), Digital Government Review of Panama: Enhancing the Digital Transformation of the Public Sector, OCDE Estudios de gobierno digital, Publicaciones de la OCDE, París, https://doi.org/10.1787/615a4180-en.

OCDE (2019d), Survey of Adult Skills, Publicaciones de la OCDE, París, https://www.oecd.org/skills/piaac/data/

OIT (2019), ILO Statistics (base de datos), Organización Internacional del Trabajo, Ginebra, www.ilo.org/ global/statistics-and-databases/lang--en/index.htm (consultada el 11 de diciembre de 2019).

Open Knowledge Foundation (2019), Global Open Data Index (base de datos), Open Knowledge Foundation, Cambridge, Reino Unido, https://index.okfn.org/dataset/ (consultada el 19 de abril de 2020).

PIAAC Expert Group in Problem Solving in Technology-Rich Environments (2009), "PIAAC Problem Solving in Technology- Rich Environments: A Conceptual Framework", OCDE Documentos de trabajo educativo, n. ${ }^{\circ}$ 36, Publicaciones de la OCDE, París, https://doi.org/10.1787/220262483674.

The Economist Intelligence Unit (2019), EIU Inclusive Internet Index 2019 (base de datos), The Economist Group, Londres, https://theinclusiveinternet.eiu.com/explore/countries/performance (consultada el $11 \mathrm{de}$ diciembre 2019).

UIT (2020), base de datos de indicadores mundiales de telecomunicaciones / TIC 2020 (base de datos), Unión Internacional de Telecomunicaciones, Ginebra, https://www.itu.int/en/ITU-D/Statistics/Pages/ publications/wtid.aspx (consultada el 21 de agosto de 2020). 
UNCTAD (2020), UNCTADSTAT (base de datos), Conferencia de las Naciones Unidas sobre Comercio y Desarrollo, Ginebra, https://unctadstat.unctad.org/EN/ (consultada el 11 de diciembre de 2019).

UNESCO (2019), Instituto de Estadística de la Unesco (base de datos), Unesco, París, http://data.uis.unesco. org/Index.aspx (consultada el 20 de mayo de 2020).

World Wide Web Foundation (2017), OpenData Barometer (base de datos), World Wide Web Foundation, Ginebra, https://opendatabarometer.org/ (consultada el 19 de abril de 2020). 



\section{URUGUAY}

\section{Tendencias recientes}

Uruguay sigue destacándose en América Latina y el Caribe (ALC) con respecto al desarrollo de una sociedad y economía digitales inclusivas. El país ha hecho esfuerzos significativos para mejorar el acceso digital de todos sus ciudadanos. Ha aumentado el número de usuarios de Internet y de suscripciones activos a servicios de banda ancha móvil y fija en la última década. Uruguay mejoró en el índice de desarrollo de gobierno electrónico del 0.56 en 2008 al 0.79 en 2018, una evolución superior al promedio de ALC (0.65) pero inferior al promedio de la OCDE (0.82). El índice de comercio electrónico B2C de la UNCTAD indica que el apoyo de la economía a las compras por Internet sigue estando por encima del promedio de ALC. Este resultado positivo se atribuye en parte al desarrollo de la banca digital en el país.

Uruguay se sitúa por debajo del promedio de ALC en los indicadores de innovación digital. Las exportaciones de alta tecnología en proporción al total de las exportaciones de productos manufacturados aumentaron al $7.2 \%$ en 2018, si bien siguen estando por debajo del promedio de ALC (8.6\%). El gasto en I+D en proporción al producto interno bruto aumentó en la última década y está en consonancia con el promedio ALC. En cuanto a la promoción de una sociedad digital inclusiva, el número de estudiantes por computadora descendió de 2.7 en 2015 a 2.3 en 2018, pero sigue estando por encima de los promedios de ALC y la OCDE.

\section{Estrategias nacionales y cooperación internacional para la transformación digital}

La Agenda Uruguay Digital 2020 va más allá de las infraestructuras y herramientas tecnológicas para mejorar y apoyar los procesos tradicionales. La agenda es coherente con los objetivos de desarrollo estratégico del país y con la Agenda 2030 para el Desarrollo Sostenible de las Naciones Unidas. La agenda digital se centra en actividades claves para la transformación digital del país, como el refuerzo de las competencias, la incorporación de la tecnología a los sectores productivos, el desarrollo de vínculos entre el Estado y los ciudadanos, y el establecimiento de un marco propicio para potenciar la agenda digital.

En el marco de dicha agenda, Uruguay estableció el Plan de Gobierno Digital 2020, que propone una visión global del gobierno digital y seis áreas de acción: gobierno inteligente, gobierno abierto, gobierno eficiente, gobierno cercano, gobierno integrado y gobierno digital confiable. La Agencia de Gobierno Electrónico y Sociedad de la Información y el Conocimiento (Agesic) actuará como promotora e incubadora de las iniciativas propuestas. Para mitigar el impacto del Covid-19, Antel, una empresa pública de telecomunicaciones, ofrece recargas gratuitas de 50 GB. Además, el gobierno creó la aplicación coronavirus.uy para que los ciudadanos con posibles síntomas se puedan poner en contacto con los proveedores de servicios de salud y reducir así los tiempos de espera (CAF, 2020).

Agesic es la entidad coordinadora de la agenda digital de Uruguay y es responsable del desarrollo del ecosistema digital, facilitando el diálogo entre los actores de la transformación digital y promoviendo el desarrollo de las competencias de los ciudadanos y la digitalización de las pymes. Promueve la investigación y la innovación en coordinación con universidades y otros organismos. El Plan Ibirapitá, por ejemplo, proporciona tabletas y conectividad a jubilados con bajos ingresos para mejorar la inclusión social, la participación y la equidad. Por su parte, el Plan Ceibal garantiza que todos los niños de la educación pública tengan una computadora portátil conectada a Internet.

En cuanto a la cooperación internacional, Uruguay se propone desarrollar la conectividad, el gobierno abierto y los estándares abiertos en el marco del grupo Digital Nations (junto con Canadá, Dinamarca, Estonia, Israel, Corea, México, Nueva Zelanda, Portugal y Reino Unido). A través de esta cooperación, Uruguay ha permitido que toda su población pueda acceder a su historia médica de forma electrónica y adoptar la firma digital. Digital Nations también se esfuerza por asegurar los derechos digitales y el apoyo a todos los ciudadanos para acceder a los servicios digitales.

Uruguay también colabora con la Unión Europea en el proyecto MAGIC, que agiliza la cooperación científica y académica a escala mundial. Se centra en abordar las cuestiones técnicas relativas a la incompatibilidad de los sistemas, el acceso y la seguridad. A través de MAGIC se han creado programas para mejorar el intercambio de conocimientos, la capacitación y el acceso a la infraestructura electrónica. 


\section{Mejorar el acceso}

Suscripciones de banda ancha fija (por cada 100 habitantes) ${ }^{4}$

Suscripciones de banda ancha móvil activa (por cada 100 habitantes) ${ }^{4}$

Proporción de población cubierta por al menos una red $3 \mathrm{G}^{5}$

Velocidad de banda ancha fija (en Mbit/s) ${ }^{4}$

\section{Aumentar el uso efectivo}

Índice de desarrollo del gobierno electrónico (EGDI) ${ }^{6}$

Proporción de usuarios de Internet (\% de población) ${ }^{4}$

Índice de comercio electrónico B2C de la UNCTAD ${ }^{7}$

Proporción de personas que realizan compras por Internet ${ }^{8}$

\section{Impulsar la innovación}

Exportaciones de alta tecnología (\% de exportaciones manufacturadas) ${ }^{9}$

Proporción de importaciones de servicios de TIC, como porcentaje del comercio total de servicios ${ }^{7}$

Solicitudes de patentes de TIC presentadas en virtud del Tratado de Cooperación en materia de Patentes (por millón de personas) ${ }^{10}$

Gastos en I+D, como \% del PIB ${ }^{11}$

Índice OURdata de la OCDE ${ }^{12}$

\section{Asegurar empleos adecuados para todos}

Contribuciones a variación en empleo total, por intensidad digital de sectores, 2006-2016 ${ }^{13}$

Proporción de empleo informal en relación con empleo total ${ }^{14}$

Tasa bruta de matrícula, educación terciaria $(\%)^{9}$

Graduados de educación terciaria por campo (\%) - Educación ${ }^{11}$

Graduados de educación terciaria por campo (\%) - Salud ${ }^{11}$

Graduados de educación terciaria por campo (\%) - Ingeniería11

\section{Promocionar la prosperidad social}

Generación de desechos de aparatos eléctricos per cápita $(\mathrm{kg})^{15}$

Número de estudiantes por computadora ${ }^{16}$

Proporción de mujeres con puntuación de nivel 203 en resolución de problemas en entornos tecnológicos ${ }^{17}$

\section{Reforzar la confianza}

Índice GovTech de la $\mathrm{CAF}^{18}$

Índice de ciberseguridad global (UIT) $)^{19}$

Seguridad del comercio electrónico $(\%)^{20}$

Confianza en la privacidad en Internet $(\%)^{20}$

\section{Promocionar la apertura de mercados}

Índice de restrictividad de intercambios de servicios digitales de la OCDE ${ }^{13}$

Índice de restricción regulatoria de la IED de la $0 \mathrm{CDE}^{13}$

Las fuentes, notas a pie de página y detalles técnicos se pueden encontrar al final de las Notas País.

\begin{tabular}{|c|c|c|c|c|c|}
\hline \multicolumn{6}{|c|}{ Indicadores digitales - Uruguay ${ }^{1}$} \\
\hline \multicolumn{2}{|c|}{ Uruguay } & \multicolumn{2}{|c|}{$\mathrm{ALC}^{2}$} & \multicolumn{2}{|c|}{$\mathrm{OCDE}^{3}$} \\
\hline 2008 & 2018 & 2008 & 2018 & 2008 & 2018 \\
\hline 7.3 & 28.3 & 4.1 & 13.9 & 22.7 & 32.9 \\
\hline 2009 & 2018 & 2009 & 2018 & 2009 & 2018 \\
\hline 3.3 & 99.0 & 1.8 & 73.5 & 29.8 & 103.6 \\
\hline 2015 & 2018 & 2015 & 2018 & 2015 & 2018 \\
\hline 90.0 & 91.0 & 86.1 & 94.6 & 98.2 & 98.8 \\
\hline 2008 & 2017 & 2008 & 2017 & 2008 & 2007 \\
\hline 0.51 & 0.50 & 0.58 & 5.1 & 2.2 & 27.7 \\
\hline \multicolumn{2}{|c|}{ Uruguay } & \multicolumn{2}{|c|}{ ALC } & \multicolumn{2}{|c|}{ OCDE } \\
\hline 2008 & 2018 & 2008 & 2018 & 2008 & 2018 \\
\hline 0.56 & 0.79 & 0.52 & 0.65 & 0.72 & 0.82 \\
\hline 39.3 & 74.8 & 25.3 & 67.7 & 65.0 & 84.3 \\
\hline 2015 & 2019 & 2015 & 2019 & 2015 & 2019 \\
\hline 62.6 & 51.4 & 46.4 & 51.5 & 73.9 & 85.0 \\
\hline \multicolumn{2}{|c|}{2017} & \multicolumn{2}{|c|}{2017} & \multicolumn{2}{|c|}{2017} \\
\hline \multicolumn{2}{|c|}{23.5} & \multicolumn{2}{|c|}{14.8} & \multicolumn{2}{|c|}{$N / A$} \\
\hline
\end{tabular}

\begin{tabular}{cccccc}
\multicolumn{2}{c}{ Uruguay } & \multicolumn{2}{c}{ ALC } & \multicolumn{2}{c}{ OCDE } \\
\hline $\mathbf{2 0 0 8}$ & $\mathbf{2 0 1 8}$ & $\mathbf{2 0 0 8}$ & $\mathbf{2 0 1 8}$ & $\mathbf{2 0 0 8}$ & $\mathbf{2 0 1 8}$ \\
\hline 4.8 & 7.2 & 9.3 & 8.6 & 15.6 & 15.1 \\
2.0 & 9.6 & 3.1 & 3.9 & 4.6 & 6.7 \\
$\mathbf{2 0 1 4}$ & $\mathbf{2 0 1 6}$ & $\mathbf{2 0 1 4}$ & $\mathbf{2 0 1 6}$ & $\mathbf{2 0 1 4}$ & $\mathbf{2 0 1 6}$ \\
\hline 0.42 & 0.58 & 0.24 & 0.34 & 29.9 & 38.2 \\
$\mathbf{2 0 0 6}$ & $\mathbf{2 0 1 6}$ & $\mathbf{2 0 0 6}$ & $\mathbf{2 0 1 6}$ & $\mathbf{2 0 0 6}$ & $\mathbf{2 0 1 6}$ \\
\hline 0.37 & 0.41 & 0.35 & 0.42 & 1.7 & 1.9 \\
\hline $\mathbf{2 0 1 9}$ & \multicolumn{2}{c}{$\mathbf{2 0 1 9}$} & \multicolumn{2}{c}{$\mathbf{2 0 1 9}$} \\
\hline 0.62 & \multicolumn{2}{c}{0.43} & \multicolumn{2}{c}{0.61}
\end{tabular}

\begin{tabular}{|c|c|c|c|c|c|}
\hline \multicolumn{2}{|c|}{ Uruguay } & \multicolumn{2}{|c|}{ ALC } & \multicolumn{2}{|c|}{ OCDE } \\
\hline \multicolumn{2}{|c|}{$2006-15$} & \multicolumn{2}{|c|}{ 2006-15 } & \multicolumn{2}{|c|}{ 2006-15 } \\
\hline \multicolumn{2}{|c|}{ N/A } & \multicolumn{2}{|c|}{6.9} & \multicolumn{2}{|c|}{4.8} \\
\hline \multicolumn{2}{|c|}{2018} & \multicolumn{2}{|c|}{2018} & \multicolumn{2}{|c|}{2018} \\
\hline \multicolumn{2}{|c|}{24.0} & \multicolumn{2}{|c|}{54.9} & \multicolumn{2}{|c|}{ N/A } \\
\hline 2007 & 2017 & 2007 & 2017 & 2007 & 2017 \\
\hline 50.7 & 63.1 & 37.5 & 60.5 & 66.6 & 74.3 \\
\hline \multicolumn{2}{|c|}{2016} & \multicolumn{2}{|c|}{2016} & \multicolumn{2}{|c|}{2016} \\
\hline \multicolumn{2}{|c|}{$\mathrm{N} / \mathrm{A}$} & \multicolumn{2}{|c|}{16.0} & \multicolumn{2}{|c|}{9.8} \\
\hline \multicolumn{2}{|c|}{$\mathrm{N} / \mathrm{A}$} & \multicolumn{2}{|c|}{13.8} & \multicolumn{2}{|c|}{14.5} \\
\hline \multicolumn{2}{|c|}{$\mathrm{N} / \mathrm{A}$} & \multicolumn{2}{|c|}{12.5} & \multicolumn{2}{|c|}{14.6} \\
\hline
\end{tabular}

\begin{tabular}{cccccc}
\multicolumn{2}{c}{ Uruguay } & \multicolumn{2}{c}{ ALC } & \multicolumn{2}{c}{ OCDE } \\
\hline $\mathbf{2 0 1 5}$ & $\mathbf{2 0 1 6}$ & $\mathbf{2 0 1 5}$ & $\mathbf{2 0 1 6}$ & $\mathbf{2 0 1 5}$ & $\mathbf{2 0 1 6}$ \\
\hline 10.5 & 10.8 & 6.9 & 7.2 & 17.7 & 17.7 \\
$\mathbf{2 0 1 5}$ & $\mathbf{2 0 1 8}$ & $\mathbf{2 0 1 5}$ & $\mathbf{2 0 1 8}$ & $\mathbf{2 0 1 5}$ & $\mathbf{2 0 1 8}$ \\
\hline 2.7 & 2.3 & 2.4 & 1.6 & 1.8 & 1.1 \\
\hline \multicolumn{2}{c}{$\mathbf{2 0 1 8}$} & \multicolumn{2}{c}{$\mathbf{2 0 1 8}$} & \multicolumn{2}{c}{$\mathbf{2 0 1 8}$} \\
\hline \multicolumn{2}{c}{ N/A } & \multicolumn{2}{c}{7.7} & \multicolumn{2}{c}{27.7}
\end{tabular}

\begin{tabular}{cccccc}
\multicolumn{2}{c}{ Uruguay } & \multicolumn{2}{c}{ ALC } & \multicolumn{2}{c}{ OCDE } \\
\hline \multicolumn{2}{c}{$\mathbf{2 0 2 0}$} & \multicolumn{2}{c}{$\mathbf{2 0 2 0}$} & \multicolumn{2}{c}{$\mathbf{2 0 2 0}$} \\
\hline \multicolumn{2}{c}{5.1} & \multicolumn{2}{c}{4.4} & \multicolumn{2}{c}{ N/A } \\
\hline $\mathbf{2 0 1 6}$ & $\mathbf{2 0 1 8}$ & $\mathbf{2 0 1 6}$ & $\mathbf{2 0 1 8}$ & $\mathbf{2 0 1 6}$ & $\mathbf{2 0 1 8}$ \\
\hline 0.62 & 0.68 & 0.36 & 0.43 & 0.56 & 0.79 \\
\hline $\mathbf{2 0 1 8}$ & $\mathbf{2 0 1 9}$ & $\mathbf{2 0 1 8}$ & $\mathbf{2 0 1 9}$ & $\mathbf{2 0 1 8}$ & $\mathbf{2 0 1 9}$ \\
\hline N/A & 58.7 & 72.0 & 63.1 & 61.7 & 58.3 \\
N/A & 45.1 & 52.8 & 54.9 & 41.7 & 45.6
\end{tabular}

\begin{tabular}{cccccc}
\multicolumn{2}{c}{ Uruguay } & \multicolumn{2}{c}{ ALC } & \multicolumn{2}{c}{ OCDE } \\
\hline 2015 & 2019 & 2015 & $\mathbf{2 0 1 9}$ & $\mathbf{2 0 1 5}$ & $\mathbf{2 0 1 9}$ \\
\hline N/A & N/A & 0.24 & 0.24 & 0.13 & 0.15 \\
2018 & \multicolumn{2}{c}{2018} & \multicolumn{2}{c}{$\mathbf{2 0 1 8}$} \\
\hline N/A & \multicolumn{2}{c}{0.07} & \multicolumn{2}{c}{0.06} \\
\hline
\end{tabular}




\section{Notas técnicas}

1. La Tabla sigue lo mejor posible las siete áreas claves identificadas en el proyecto Going Digital de la OCDE: 1) mejorar el acceso a las tecnologías digitales; 2) aumentar el uso efectivo; 3) permitir la innovación digital; 4) asegurar empleos adecuados para todos; 5) promocionar la prosperidad social; 6) reforzar la confianza; y 7) promocionar la apertura de mercados (OCDE, 2019a). Los indicadores se eligen según la disponibilidad de datos para los países de ALC. Existe la posibilidad de un sesgo por la forma en que se han agregado los componentes en los indicadores de índice.

2. El promedio de ALC es un promedio simple. La composición de los países depende de la disponibilidad de datos de los países de la región. Cada promedio incluye tantos países de ALC encontrados en cada fuente como sea posible.

3. El promedio de la OCDE es un promedio simple que incluye a todos los países miembros de la OCDE en mayo de 2020.

4. Datos de la UIT (2020), Base de datos de indicadores mundiales de telecomunicaciones / TIC 2020 (base de datos). La velocidad de banda ancha fija en Mbit/s se refiere a la velocidad de descarga teórica máxima anunciada garantizada a los usuarios asociados con una suscripción mensual de Internet de banda ancha fija.

5. Datos de la División de Estadística de las Naciones Unidas, Base de datos mundial de los ODS de las Naciones Unidas (base de datos). Datos de 2015 y 2018 o los últimos disponibles.

6. Datos de la base de conocimientos sobre gobierno electrónico de las Naciones Unidas (2019), centro de datos (base de datos). El índice de desarrollo del gobierno electrónico (E-government development index) es un indicador compuesto que consta de tres índices (índice de servicios en línea, índice de infraestructura de telecomunicaciones e índice de capital humano), que están igualmente ponderados. Tiene un rango de 0 a 1, con 1 siendo un gobierno más desarrollado.

7. Datos de UNCTAD (2020), UNCTADSTAT (base de datos). El índice de comercio electrónico B2C de la UNCTAD mide la preparación de una economía para respaldar las compras en línea. Rango de 0 a 100, con 100 siendo el nivel de apoyo más alto.

8. Cálculos propios a partir de datos de Latinobarómetro (2019), Libros de Códigos por País / Año (base de datos). Datos de 2017. Datos de encuestas de opinión pública utilizando muestras representativas a nivel nacional seleccionadas al azar.

9. Datos del Banco Mundial (2020a), Banco de datos del Banco Mundial (base de datos).

10. Datos del Banco Mundial (2020b), TCdata360. Datos de 2012 y 2016 o los últimos disponibles.

11. Datos de Unesco (2019), Instituto de Estadística de la Unesco (base de datos). Gastos en I+D, como porcentaje de los datos del PIB de 2006 y 2016 o el último disponible.

12. Datos de OCDE (2020a), OECD.Stat (base de datos) y OCDE (2020b). El índice OURdata de la OCDE evalúa los esfuerzos de los gobiernos para implementar datos abiertos en tres áreas críticas: apertura, utilidad y reutilización de los datos gubernamentales. Tiene un rango de 0 a 1, con 1 siendo la puntuación más alta.

13. Datos de OCDE (2020a), OECD.Stat (base de datos). El Índice de restricción del comercio de servicios digitales de la OCDE identifica, cataloga y cuantifica las barreras que afectan el comercio de servicios habilitados digitalmente en 46 países. Tiene un rango de 0 a 1, con 1 siendo el valor más restrictivo. El Índice de Restricción Reglamentaria de la Inversión Extranjera Directa (IED RRI) mide cuatro tipos de restricciones legales a la inversión extranjera directa: 1) restricciones a la participación extranjera en el capital social; 2) requisitos de selección y aprobación previa; 3) regulaciones para personas claves; y 4) otras restricciones al funcionamiento de empresas extranjeras. El RRI de la IED es un índice compuesto, que varía de 0 a 1, con 1 siendo el valor más restrictivo.

14. Datos de ILOSTAT, datos de 2018 o último año disponible.

15. Datos de la Asociación mundial de estadísticas sobre desechos electrónicos.

16. Cálculos de la OCDE basados en OCDE (2020c), Programa de Evaluación Internacional de Estudiantes (base de datos). Datos de 2015 y 2018.

17. Datos de la OCDE (2019d), Survey of Adult Skills (2018). Los porcentajes para la resolución de problemas en entornos ricos en tecnología se calculan de modo que la suma de los porcentajes de las siguientes categorías mutuamente exhaustivas sea igual al 100\%: se excluyó de la evaluación por computadora; sin experiencia en informática; prueba de núcleo de TIC fallida; por debajo del Nivel 1, en el Nivel 1, en el Nivel 2 y en el Nivel 3.

18. Datos de CAF (2020), The GouTech Index 2020: Unlocking the Potential of GouTech Ecosystems in Latin America, Spain and Portugal. El índice GovTech 2020 mide la madurez del ecosistema GovTech. Se basa en 28 indicadores en 7 dimensiones, que, en conjunto, forman 3 pilares igualmente ponderados: industria de nueva creación, políticas gubernamentales y sistemas de adquisiciones. 
19. El Índice mundial de ciberseguridad mide el compromiso de los países con la ciberseguridad a escala global. Tiene cinco pilares: 1) medidas legales; 2) medidas técnicas; 3) medidas organizativas; 4) desarrollo de capacidades; y 5) cooperación. Va de 0 a 1, siendo 1 el nivel más alto de ciberseguridad.

20. Datos de The Economist Intelligence Unit (2019), EIU Inclusive Internet Index (base de datos). Los indicadores presentan la seguridad percibida del comercio electrónico y la confianza en la privacidad en línea entre las personas seleccionadas al azar en países seleccionados. Varía del $0 \%$ al 100\%, donde el $100 \%$ indica una confianza absoluta en la seguridad del comercio electrónico y la confianza en la privacidad en línea.

\section{Referencias}

Banco Mundial (2020a), DataBank (base de datos), Grupo del Banco Mundial, Washington, DC, https:// databank.worldbank.org/home.aspx (consultada el 11 de diciembre de 2019).

Banco Mundial (2020b), TCdata360 (base de datos), Grupo del Banco Mundial, Washington, DC, https:// tcdata360.worldbank.org/ (consultada el 4 de agosto de 2020).

Base de conocimientos sobre gobierno electrónico de la ONU (2019), Data Center (base de datos), Departamento de Asuntos Económicos y Sociales de las Naciones Unidas, Nueva York, https:// publicadministration.un.org/egovkb/en-us/Data-Center (consultada el 11 de diciembre de 2019).

CAF (2020), The GouTech Index 2020: Unlocking the Potential of GovTech Ecosystems in Latin America, Spain and Portugal, Banco de Desarrollo de America Latina, Caracas.

CEPAL (2018), Observatorio Regional de Planificación para el Desarrollo de América Latina y el Caribe, Comisión Económica para América Latina y el Caribe, Santiago, https://observatorioplanificacion.cepal.org/es.

Dispositivo de estadísticas de la ONU (2018, 2015), ODS globales de la ONU (database), Departamento de Asuntos Económicos y Sociales de las Naciones Unidas, Nueva York, https://unstats.un.org/sdgs/ indicators/database/ (consultada el 20 de mayo de 2020).

Foro Mundial Económico (2016), “The Global Information Technology Report 2016”, Foro Mundial Económico, Ginebra, https://www.weforum.org/reports/the-global-information-technology-report-2016.

Global E-waste Statistic Partnership, página de internet, Global E-waste Statistic Partnership, Bonn, https:// globalewaste.org/ (consultada el 11 de diciembre de 2019).

Latinobarómetro (2019), Libros de Códigos por País/Año (base de datos), Latinobarómetro, Providencia, www. latinobarometro.org/latCodebooks.jsp (consultada el 11 de diciembre de 2019).

OCDE (2020a), OECD.Stat (database), Publicaciones de la OCDE, París, https://stats.oecd.org/ (consultada el 11 de diciembre de 2019).

OCDE (2020b), Panorama de las Administraciones Públicas América Latina y el Caribe 2020, Publicaciones de la OCDE, París, https://doi.org/10.1787/13130fbb-en.

OCDE (2020c), Programme for International Student Assessment (base de datos), Publicaciones de la OCDE, París, www.oecd.org/pisa/data/2018database/ (consultada el 14 de febrero de 2020).

OCDE (2019a), Cómo medir la transformación digital: Hoja de ruta para el futuro, Publicaciones de la OCDE, París, https://doi.org/10.1787/9789264311992-en.

OCDE (2019b), Estudios de la OCDE sobre Transformación Digital: “Going Digital” en Colombia, Publicaciones de la OCDE, París, https://doi.org/10.1787/781185b1-en.

OCDE (2019c), Digital Government Review of Panama: Enhancing the Digital Transformation of the Public Sector, OCDE Estudios de gobierno digital, Publicaciones de la OCDE, París, https://doi.org/10.1787/615a4180-en.

OCDE (2019d), Survey of Adult Skills, Publicaciones de la OCDE, París, https://www.oecd.org/skills/piaac/data/

OIT (2019), ILO Statistics (base de datos), Organización Internacional del Trabajo, Ginebra, www.ilo.org/ global/statistics-and-databases/lang--en/index.htm (consultada el 11 de diciembre de 2019).

Open Knowledge Foundation (2019), Global Open Data Index (base de datos), Open Knowledge Foundation, Cambridge, Reino Unido, https://index.okfn.org/dataset/ (consultada el 19 de abril de 2020).

PIAAC Expert Group in Problem Solving in Technology-Rich Environments (2009), "PIAAC Problem Solving in Technology- Rich Environments: A Conceptual Framework", OCDE Documentos de trabajo educativo, n. ${ }^{\circ}$ 36, Publicaciones de la OCDE, París, https://doi.org/10.1787/220262483674.

The Economist Intelligence Unit (2019), EIU Inclusive Internet Index 2019 (base de datos), The Economist Group, Londres, https://theinclusiveinternet.eiu.com/explore/countries/performance (consultada el $11 \mathrm{de}$ diciembre 2019).

UIT (2020), base de datos de indicadores mundiales de telecomunicaciones / TIC 2020 (base de datos), Unión Internacional de Telecomunicaciones, Ginebra, https://www.itu.int/en/ITU-D/Statistics/Pages/ publications/wtid.aspx (consultada el 21 de agosto de 2020). 
UNCTAD (2020), UNCTADSTAT (base de datos), Conferencia de las Naciones Unidas sobre Comercio y Desarrollo, Ginebra, https://unctadstat.unctad.org/EN/ (consultada el 11 de diciembre de 2019).

UNESCO (2019), Instituto de Estadística de la Unesco (base de datos), Unesco, París, http://data.uis.unesco. org/Index.aspx (consultada el 20 de mayo de 2020).

World Wide Web Foundation (2017), OpenData Barometer (base de datos), World Wide Web Foundation, Ginebra, https://opendatabarometer.org/ (consultada el 19 de abril de 2020). 


\section{Perspectivas económicas de América Latina 2020}

\section{TRANSFORMACIÓN DIGITAL PARA UNA MEJOR RECONSTRUCCIÓN}

El informe Perspectivas económicas de América Latina 2020 (LEO 2020 por sus siglas en inglés) analiza cómo la transformación digital puede ayudar a la región a enfrentar estos tiempos difíciles. La pandemia del Covid-19 está teniendo un profundo impacto en las condiciones socioeconómicas de América Latina y el Caribe, acentuando un escenario ya muy complejo debido a las debilidades estructurales existentes en la región. Esta crisis sin precedentes llega en un momento de altas aspiraciones de la sociedad y refuerza la necesidad de transformar el modelo de desarrollo de la región. El informe explora cómo la transformación digital puede ayudar a hacer frente a la situación socioeconómica actual, impulsar la productividad, fortalecer las instituciones y lograr niveles más altos de inclusión y bienestar. El LEO 2020 también destaca el papel clave que las alianzas internacionales tienen para aprovechar los beneficios de la transformación digital.

El informe LEO es una publicación anual conjunta producida por el Centro de Desarrollo de la OCDE, la Comisión Económica para América Latina y el Caribe (CEPAL) de las Naciones Unidas, el Banco de Desarrollo de América Latina (CAF) y la Unión Europea (UE). Este informe es el Pilar 1 de la Facilidad Regional de la UE para el Desarrollo en Transición en América Latina y el Caribe.
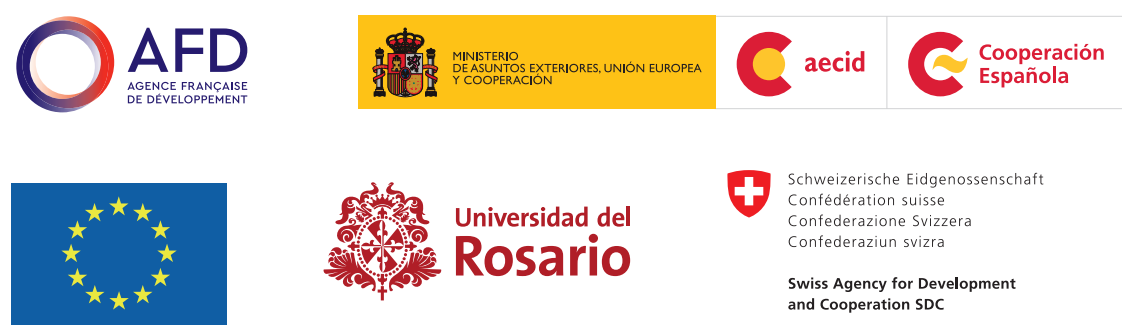
Española

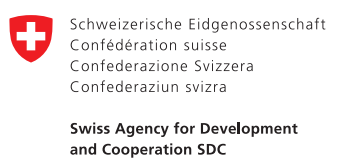

Cofinanciado por la Unión Europea Swiss Agency for Dev
and Cooperation SDC

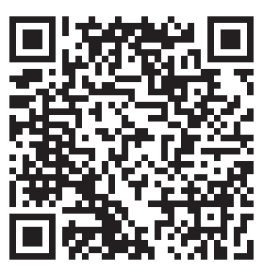

PRINT ISBN 978-92-64-79884-7 PDF ISBN 978-92-64-63131-1

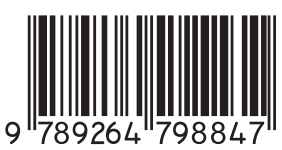

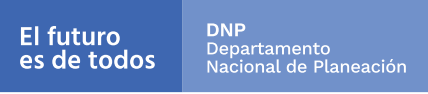

Telefonica 